\title{
SOIL FERTILITY \\ AND PERMANENT AGRICULTURE
}

\section{ty}

Southern Re

Library $\mathrm{Fal}$

\section{CYRIL G.HOPKINS}



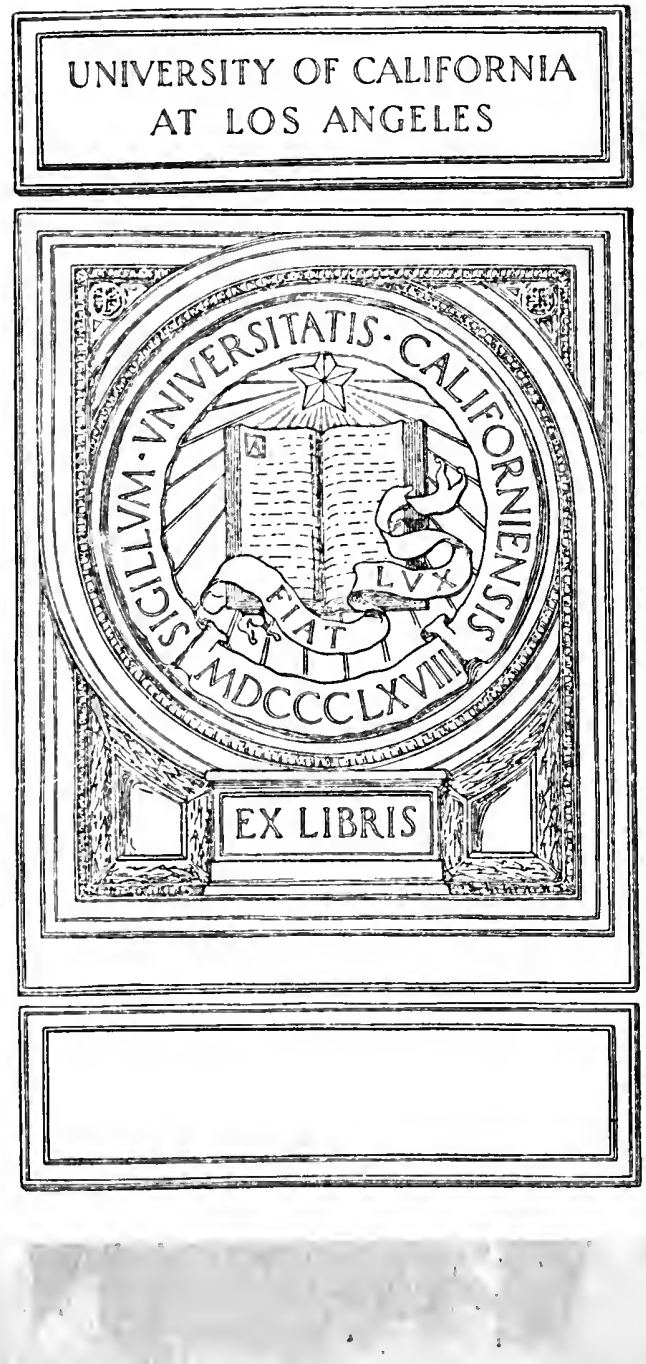


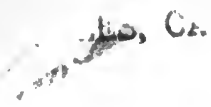

$$
\begin{aligned}
& \text { SCHOOL } \\
& \text { STATE HORIS CALIFORNIA }
\end{aligned}
$$





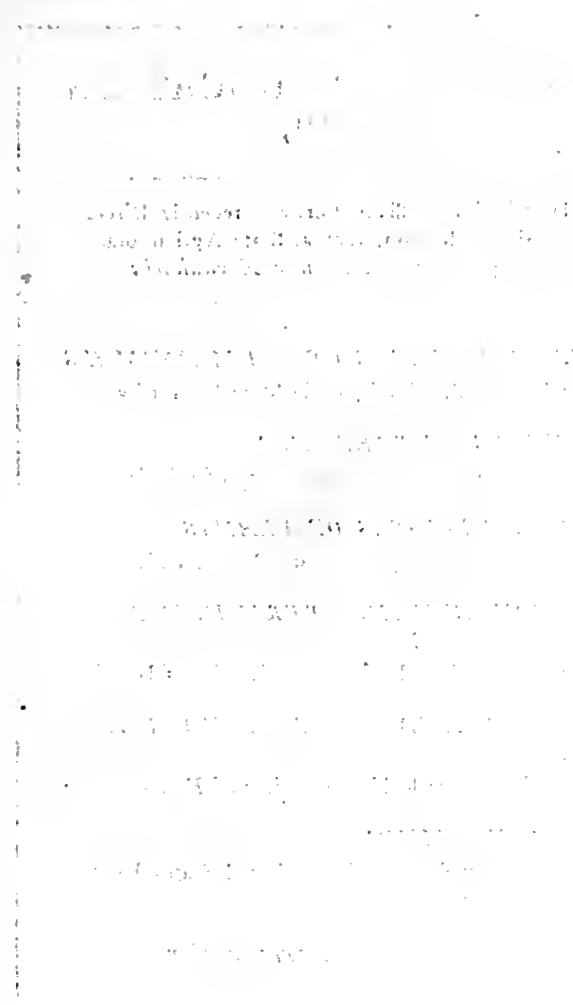




\section{COUNTRY LIFE EDUCATION SERIES}

Edited by Charles William Burkett, recently Director of Experiment Station, Kansas State Agricultural

College; Editor of American Agriculturist

TYPES AND BREEDS OF FARM ANIMALS

By Charles S. Plumb, Ohio State University

PRINCIPLES OF BREEDING

By Eugene Davenport, University of 'Illinois

FUNGOUS DISEASES OF PLANTS

By Benjamin Minge Duggar, Cornell University

SOIL FERTILITY AND PERMANENT AGRICULTURE

By Cyril George Hopkins, University of Illinois

PRINCIPLES AND PRACTICE OF POULTR $\gamma^{\circ}$ CULTURE

By John Henry Robinson, Editor of Farm-Poultry

GARDEN FARMING

By Lee Cleveland Corbett, United States Department of Agriculture

Other volumes in preparation 


\section{SOIL FERTILITY AND \\ PERMANENT AGRICULTURE}

BY

CYRIL G. HOPKINS, PH.D.

PROFESSOR OF AGRONOMV IN THE UNIVERSITY OF ILLINOIS, CHIEF IN AGRONOMY AND CHEMISTRY AND VICE DIRECTOR OF THE

ILLINOIS AGRICULTURAL EXPERIMENT STATION

25983 
Digitized by the Internet Archive in 2007 with funding from

Microsoft Corporation 


\section{PREFACE}

Liebig said, "Agriculture is, of all industrial pursuits, the richest in facts and the poorest in their comprehension." To a large degree this statement is still true, and the chief purpose of this volume is to bring together in convenient form the world's most essential facts gathered from the field and laboratory, and to develop from them some foundation principles of permanent agriculture; for, as Liebig also truly said, "Facts are like grains of sand which are moved by the wind, but principles are these same grains cemented into rocks."

While one dare not believe that error has been completely avoided, the facts presented have been checked with all reasonable care, and they may be accepted with the confidence that they are accurately reproduced from the original data.

Unsolved problems still remain, and some conclusions which seem to be indicated by the data thus far reported may be modified later when more complete information is afforded. The author will always receive with deep appreciation suggested additions, modifications, or corrections.

It is, perhaps, unnecessary to say to the reader that his general knowledge of farm practice is presupposed, and no attempt has been made to include herein a thousand details with which every man experienced in the art of agriculture already is familiar.

For the sake of himself and children it must be said to the practical farmer that he should encourage the teaching of the science of agriculture in the school, even though he may know much more than the teacher concerning the art of agriculture. 
To encourage the teacher, let me say that much of the science of agriculture can be successfully taught without a field or a garden, and even without complete knowledge of the art. Thus, you may teach why clover should be grown and when it contains the most nitrogen, but leave the farmer to determine for himself when to plow it under, if he is the better judge of seasonal conditions and of their probable influence upon his own soil and crop.

\section{UNIVERSITY OF ILLINOIS}

CYRIL G. HOPKINS

\section{URBANA}

NotE. Opportunity has been taken to insert in this edition the later data from some of the most important long-continued field investigations. In addition, a list of questions relating to the most important facts in every chapter has been prepared for the convenience of the teacher in helping the student to acquire a thorough knowledge of the most essential facts and principles of soil fertility, with economy of time and with conservation of mental energy. These questions are supplied in pamphlet form by the publishers. - C. G. H. 


\section{CONTENTS}

INTRODUCTION .

PAGE

xvii

CHAPTER

PART I. SCIENCE AND SOIL

I. Foundation Facts and Principles . . . . . . I

II. The More Important Elements and Compounds • • . 12

III. Plant Food and Plant Growth • • • • . 26

IV. The Eakth's Crust . . . . . . . . . 46

V. Soll Formations and Classifications, . . . . $\quad . \quad 54$

VI. Soll Composition . . . . . . . . . .

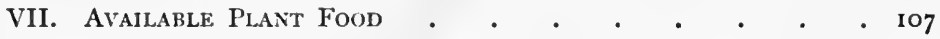

ViII. Soll Surveys by the United States Bureau of Solls. - II4

IX. Soll Analyses by the United States Bureau of Solls - I36

- X. Crop Requirements for Nitrogen, Phosphorus, and Po-

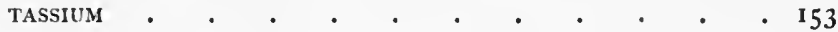

XI. Sources of Plant Food . . . . . . . . . ${ }^{1} 56$

PART II. SYSTEMS OF PERMANENT AGRICULTURE

XII. LIMESTONE • • . . . • . . • • . 160

XIII. PhOSPhorvs. . . . . . . . . . . . 183

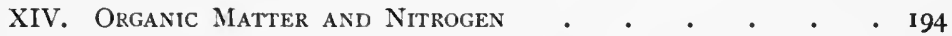

- XV. Rotation Systems for Grain Farming . • • . . 226

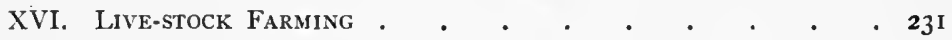

XViI. The Use of Phosphorus in Different Forms . . . ${ }_{23} 236$

XVIII. Theories CONCERning SOIL Fertility . . . . . 300

PART III. SOIL INVESTIGATIONS BY CULTURE EXPERIMENTS

XIX. The Rothansted Experiments . . . . . . 344

XX. Pennsyluania Fieid Experiments . . . . . . 420

XXI. Ohio Field Experiments . . . . . . . . 44I

XXII. Illinois Field Experiments • . • • • • 4433

XXIII. Field Experiments in the South, including Southern

IlLiNoIS • • • • • • • • . • 476 
CHAPTER $\quad$ PAGE

XXIV. Minnesota Soll Investigations . • , . . . 499

XXV. Canadian Field Experiments . . . . . . . . . 505

XXVI. Short-time Pot-culture and Water-culture Experiments in Comparison with Field Results . • . . $\quad 5$ I 3

\section{PART IV. VARIOUS FERTILITY FACTORS}

XXVil. Manufactured Commercial Fertilizers . • . . . 517

XXViII. Crop Stimulants and Protective Agents . . . . 533

XXiX. Critical Periods in Plant life.$\quad \cdot \quad \cdot \quad \cdot \quad \cdot \quad{ }^{\circ} 538$

XXX. Farm Manure . . . . . . . . . . . . 54 I

XXXi. Losses of Plant Food from Plants . . . . $\quad$. 549

XXXil. Losses of Plant Food from Solls . . . . . . 556

XXXIII. Fixation of Plant Food bV Solls . • • . • . 562

XXXIV. Analyzing and Testing Solls • • • • • • $\quad{ }^{6}{ }_{5}$

XXXV. Reifation of Fertility to Appeakance of Solls or Crops 572

XXXVI. Factoks in Crop Pronuction . • . . . . . 575

XXXVil. Essential Factors of Success in Farming • • • • $\quad 584$

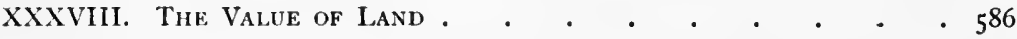

XXXiX. Two Perions in Agricultural History • . . . . . 590

SECTION

\section{APPENDIX}

I. The Production of Phosphate Rock . . . . • . 595

II. Model Fertillzer Law . • • • • • • • • • 599

III. Composition of Animal and Plant Products . . . . . . 602

IV. Statistics of Agricultural Products . . . . . . . . . . 605

V. Methods of Soll Analysis . . . . . . . . . . . 626

VI. Composition of Some European Solis . . . . . . . . . 634

VII. Agricultural Colifges and Experiment Stations in the United

States AND CaNADA $\quad . \quad$. . . . . . . . . 643

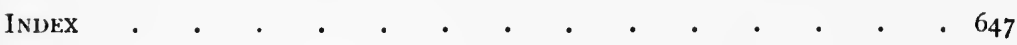




\section{LIST OF TABLES}

TABLE PAGE

1. Elements, Symbols, and Atomic Weights . . . . . 10

2. The More Important Elements : Occurrence . . . . . 13

3. Composition of Silicates . . . . . . . . . 48

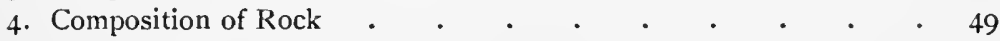

5. Composition of Fresh Limestone and Residual Clay . . . 5 I

6. Soils : General Groups . . . . . . . . 55

7. Recognized Soil Types . . . . . . . . . $\quad{ }_{56}$

8. Relative "Supply and Demand" of Seven Elements . . . 59

9. Composition of Productive and Nonproductive Soils . . . $\quad 63$

1 . Composition of Adobe and Coral Limestone Soils . . . . . 65

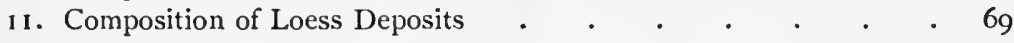

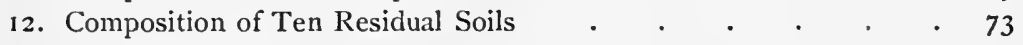

13. Mineral Plant Food in Wheat, Corn, Oats, and Clover . . $\quad 75$

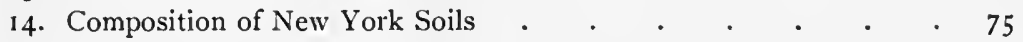

15. Fertility in Illinois Soils : Surface . $+. \quad+\quad . \quad$. $\quad$. 82

16. Fertility in Illinois Soils : Subsurface . . . . . . . 84

17. Fertility in Illinois Soils : Subsoil . . . . . . . 86

I8. Composition of Southern Indiana Surface Soils . . . . 88

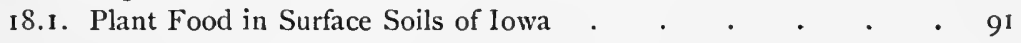

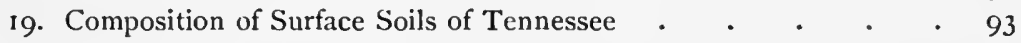

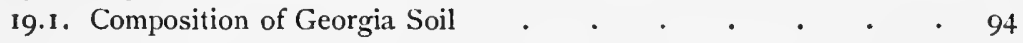

19.2. Average Composition of Some Texas Soils . . . . . 95

19.3. Composition of Some Louisiana Soils . • • • • • • . 96

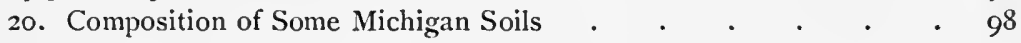

20.1. Composition of Canadian Soils . . . . . . . . 103

20.2. Certain Plant-food Elements in Illinois Surface Soils . . 105

21. Annually Available Fertility in Illinois Soils . . . . . 110

22. Composition of Various Extensive Soil Types of the United States $\quad 13^{8}$

23. Fertility in Farm Produce . . . . . . . . . $\quad$. 154

24. Fertility in Manure, Rough Feeds, and Fertilizers . • . 157

25. Pennsylvania Experiments with Lime . . . . . . . 165

25.1. Maryland Experiments with Lime . . . . . . . $\quad$. 167

26. Experiments with Magnesium Carbonate + . • • • • 171

27. Losses of Calcium Carbonate from Broadbalk Field . . $\quad$ - 174

28. Losses of Calcium Carbonate from Hoos Field . . . $\quad$ - 175

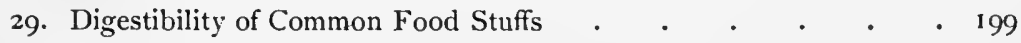


TABLE

30. Plant Food recovered from Food Consumed (Illinois) . . . 201

31. Plant Food recovered from Food Consumed (Pennsylvania) . . 202

32. Plant Food recovered from Six Months' Feeding (Ohio) . . 204

33. Fixation of Nitrogen by Alfalfa . . . . . . . 214

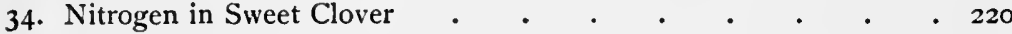

35. Composition of Crimson Clover . . . . . . 221

36. Composition of Legumes and Other Plants . . . . . 222

37, 38, 39, and 39b. Comparison of Raw Phosphate and Acid Phosphate

247-253

40. Ohio Experiments with Manure, Phosphate, Kainit, Gypsum, and Complete Fertilizers . . . . . . . • . 256

41. Balance Sheet for Nitrogen and Phosphorus in Manure-phosphate

Experiments . . . . . . . • . . 257

42. Maryland Experiments with Different Phosphates . . . . 262

43. Pennsylvania Experiments with Different Phosphates . . . 264

$44,45,44 c$, and $45 c$. Rhode Island Experiments with Nine Phosphates

268-274

46 and 47. Maine Experiments with Different Phosphates . . 276, 277

48 and 49. Massachusetts Experiments with Different Phosphates 279, 282

50. Illinois Experiments with Raw Rock Phosphate . . . . 285

51. Steamed Bone Meal and Raw Rock Phosphate . . . . 287

52-58. Rotation Crops on Agdell Field . . . . . 346-352

59. Summary of Crop Yields and Values, Agdell Field . . . . 360

60 and $6 r$. Wheat Yields, Broadbalk Field, Averages . . . . 364, 365

62. Wheat Yields at Rothamsted, Comparisons . . • • 372, 373

63. Wheat Yields, Broadbalk Field, Nitrogen Increments . . $\quad 374$

64. Wheat Yields at Rothamsted, Summaries . . . . 375

65. Rothamsted Records, Rainfall and Drainage . . . . . 377

66 and 67. Barley Yields on Hoos Field . . . . . 380,381

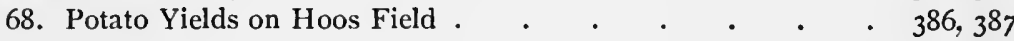

69. Residual Effect of Fertilizers on Hoos Field . . . . . 390

70. Hay Yields on The Park at Rothamsted . . . . 393

71. Root Crops on Barn Field . . . . . . . . $\quad .399,400$

72. Rothamsted Fields abandoned to Nature . . . . . 404

73. Plant Food in Soil of Broadbalk Plots . . . . . . 4 $4 \mathrm{II}$

74. Composition of Drainage Waters from Broadbalk Field . . . 4 413

75. Nitrogen in Soil of Agdell Plots . . . . . . . 416

76. Composition of Crops grown on Agdell Field . . . . . 417

77. Composition of Hay from The Park, Rothamsted . . . . 418

78. Pennsylvania Crop Yields in Field Experiments . $\quad$ • $\quad \cdot \quad 4423$

79 and 8o. Pennsylvania Experiments by Twelve-year Periods . 428, 429

81. Pennsylvania Experiments : Financial Summary . . . . 431

8IP. Pennsylvania Experiments: Twenty-five-year Average . . . 434 
82. Ohio Experiments : Five-year Rotation

83. Ohio Experiments : Potatoes, Wheat, Clover

84. Experiments at Strongsville, Ohio

85. Illinois Experiment Plots, Urbana . . . . . . 457

86. Comparable Corn Yields, Illinois Experiments . • • • • . 459

87. Crop Yields on Sibley Field, lllinois . • • • • • • . 462

88. Crop Yields on Bloomington Field, Illinois . • • • . $\quad$ • 464

89. Crop Yields on Antioch Field, Illinois . . . . . . . 467

9o. Crop Yields on Sand Land, Illinois . . . . . . . 468

91. Corn Yields on Deep Peat Soil, Illinois . . . . . $47 \mathrm{I}$

92 and 93. Corn Yields on Peaty Alkali Soil, Illinois . • • 473, 475

94. Crop Yields in Southern Illinois, Odin Field . • . $\quad .478$

95. Crop Yields in Southern Illinois, Du Bois Field . • . . $48 \mathrm{I}$

96 and 97. Crop Yields on Worn Hill Land, Vienna, Illinois • 483, 485

98 and 98.I. Pot-culture Experiments with Worn Hill Soil . . 486, 487

99. Southern Iowa Field Experiments . • • • • • • 488

100. Georgia Fertilizer Experiments with Corn . . . . . 490

10I. Rainfall Records at Experiment, Georgia . • . . . 491

102 and 103. Georgia Fertilizer Experiments with Cotton . • 492, 493

104. Alabama Field Experiments with Cotton . . . . . 495

104.1. Louisiana Field Experiments . . . . . . . 496

105. Minnesota Soil Investigations . . . . . . . 499

106 and 107. Canadian Field Experiments . . . . . 508, 511

108 and 109. Comparison of Pot Cultures and Field Experiments . 513, $5^{14}$

I IO. Composition of Farm Manures . . . . . . $\quad$. 543

11 I. Composition of Pulverized Dried Manures . . . . 545

112. Composition of Manure before and after Exposure . . . 547

113. Composition of Bean Crop at Different Periods of Growth • $55^{\circ}$

114. Composition of Barley at Different Periods of Growth . • . 552

115. Plant Food removed from Plants by Leaching . . . . 555

116. Nitrogen in Rothamsted Drainage Waters . . . . 557

117. Soluble Nitrogen in Cropped Soils, Rothamsted . . . . 558

118. Ammonia Fixation and Nitrification . . . . . . 563

I 19. Effect of Soil Preparation, Cultivation, Irrigation, and Fertilization

on the Yield of Corn . $\quad$ • . . . . . . 578

120. Value of Land, measured by Crop Yields . . . . . 587

121. Composition of Animal and Plant Products . . . . . 602 


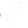

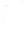




\section{ILLUSTRATIONS}

PAGE

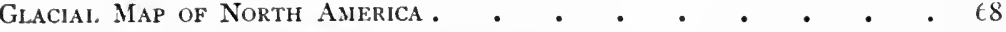

General Survey Soll Map of Illinois • • • • • • • $\quad$. 76

A Man of Science: Eugene Woldemar Hilgard . . . . . . 102

Map of United States Soll Provinces • • • • • • • $~ 116$

Nitrogen Fixation by Clover • • • • • • • • • • $\quad$ • 218

Topographic Map of Ohio Experiment Field • • • • • . $\quad 252$

Director Charles E. Thorne • • • • • • • • • • 254

Sir John Bennet Lawes . • • • • • • • • • 342

Sir Joseph Henry Gilbert • • • • • • • • • • 344

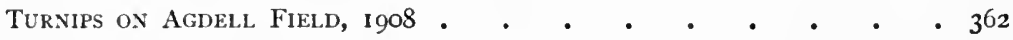

Director A. D. Hall . . . . . • • • • • • 408

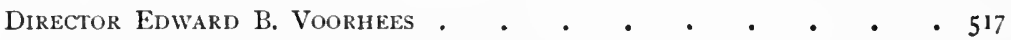

Rajnfall Chart of North Platte, Nebraska . • • • • • 580

Rainfall Map of the United States. • • • • • • • $\quad 58 z$ 



\section{INTRODUCTION}

IT is the first business of every farmer to reduce the fertility of the soil, by removing the largest crops of which the soil is capable; but ultimate failure results for the landowner unless provision is made for restoring and maintaining productiveness. Every landowner should adopt for his land a system of farming that is permanent,- a system under which the land becomes better rather than poorer.

If the independent farmer is to adopt and maintain permanent systems of profitable agriculture, he cannot accept "parrot" instruction; he must know the why and wherefore, the reason for doing things, and the ultimate effect of his agricultural practice upon the productive power of the land. Every farm is an independent enterprise in which the farmcr himself is the superintendent and general manager, and he must be able to direct the business, even though he may be the only man to execute his own plans. The agriculture of a state cannot be managed from a central office. The landowner must think for the land.

The author is familiar with the often expressed idea that what the farmer wants is a simple statement of facts, but he is even more familiar with the absolute truth that what the farmer demands is the most positive proof of the correctness of such statement before he is willing to make any change from a practice based upon long experience.

In the preparation of this book free use has been made of such technical terms as are necessary to the discussion of fundamental principles with scientific correctness. No apology is offered for this. Farmers and agricultural students have at least as good intellects as other classes of people; and if when they leave the farm they can learn to understand and manage successfully such lines of business as banking, contracting, building, operating railroads, factories, and other commercial establishments, xvii 
which they are doing everywhere, - they can also understand their own business, if they will, when they remain on the farm or in control of land.

Technical books are to be studied; they are not written for entertainment. They furnish definite facts, accurate data, and necessary information, relating to underlying principles upon which permanent successful practice must be based.

The most important material problem of the United States is to maintain the fertility of the soil, and no extensive agricultural country has ever solved this problem. The frequent periods of famine and starvation in the great agricultural countries of China, India, and Russia, and the depleted lands and abandoned farms of our own eastern United States are facts that serve as a constant proof that the common practice of agriculture reduces the productive power of land.

The rule is almost universal that old land is less productive than new land. This simple and well-recognized fact points inevitably toward future poverty, not only for the individual or the family, but likewise for the commonwealth and for the nation. We may ignore this if we choose in America for a few more years, but with the decreasing productive power of our lands and with a rapidly increasing population the truth must strike us in the face in the near future.

We cannot afford to let ignorance, prejudice, or bigotry blind us in this matter, neither in ourselves nor in others. Even the confident assurance, by those who live in continued plenty, that the people of earth are not destined to suffer hunger, does not remove the positive fact that thousands, and sometimes millions, of people actually die of starvation within a single year in some of the old agricultural countries.

An early recognition of these world-wide conditions and tendencies is of paramount importance to the people controlling the more productive lands of the United States, not only for their own sake, but also for the sake of others who are dependent upon those lands for their present and future support, whether engaged directly in agricultural pursuits or in other industrial or professional lines, which cannot exist and prosper without agriculture.

If the art of agriculture has ruined land, the science of agricul- 
ture must restore it; and the restoration must begin while some farmers are still prosperous, for poverty-stricken people are at once helpless and soon ignorant. Outside help will always be required to redeem impoverished soils, for poverty makes no investments, and some initial investment is always required for soil improvement.

It is the purpose of this book to teach the science of soil fertility and permanent agriculture, chiefly by reporting facts rather than by offering theories; and any one of common sense who reads the English language, and who can understand the common school arithmetic, can understand this book if he will study it. (The fact may well be recognized that some who have ample time for study, though physically industrious, are mentally lazy. ${ }^{1}$ )

The author suggests, however, that the busy farmer, who wishes to familiarize himself as quickly as possible with the most essential practical facts pertaining to the economical and permanent improvement of common or normal soils, and who is willing to pass over temporarily the discussion of foundation principles, may well begin the study of this book with "Systems of Permanent Agriculture," Part II, after first making the following facts a part of his ever ready knowledge:

(I) Phosphorus and decaying organic matter are the two substances which constitute the key to profitable systems of permanent agriculture on most of the normal soils of America; although, when soils become sour, or acid, ground natural limestone should also be regularly applied, at the rate of about two tons per acre every four to six years.

(2) There are six essential positive factors in crop production: the seed, a home for the plant, the food of which the plant is made (and this factor is just as important for plants as it is for animals), moisture, heat, and light. Of these six factors, the least appreciated and the most neglected is that of plant food, and yet this is a factor which the farmer can very largely control, whereas the others (except the seed) are largely beyond his control. (An important negative factor is protection from weeds, insects, and disease.)

1 "Many poor farmers have a lazy faith in the Lord; they think or hope that He will somehow make up for whatever they fail to do." - HOARD. 
(3) Of the ten different chemical elements absolutely required for the growth of every agricultural plant, three come directly from air and water in practically unlimited amounts, and these three (carbon and oxygen from air and hydrogen from water) constitute about 95 per cent of the common mature crops. Nevertheless, each one of the seven elements obtained from the soil, though aggregating only 5 per cent, is absolutely necessary to the life and full development of the plant. Indeed, if any one of these elements be entirely lacking, the soil would be infertile and barren. So important are these plant-food elements, that soils are found so deficient in some essential plant food that the addition of a single element will more than double the crop yield.

(4) The five elements, potassium, magnesium, calcium, iron, and sulfur, are contained in most normal soils in such large amounts, compared to the requirements of crops, that the supply rarely becomes depleted. Thus, in most cases, the problem is narrowed to the two elements, nitrogen and phosphorus, although, for various reasons, potassium also has come to have a recognized money value in commercial fertilizers.

(5) Nitrogen is contained in the air in inexhaustible amount, but the legumes (clover, alfalfa, peas, beans, etc.) are the only agricultural plants which have power to utilize the free nitrogen of the air. Nitrogen in limited amount is contained in the soil in the organic matter, the principal material which gives a good soil its dark color. If the supply of organic matter is maintained, by plowing under farm manure, clover, cowpeas, or other green manures, then the supply of nitrogen will also be maintained.

(6) The plowed soil of an acre (2 million pounds, for a depth of $6 \frac{2}{3}$ inches) of rich, well-balanced normal land in the Corn Belt contains about 8000 pounds of nitrogen, 2000 pounds of phosphorus, 35,000 pounds of potassium, and $I_{5}$ tons of calcium carbonate (limestone).

(7) The surface soils of the United States vary in composition: (a) in nitrogen content, from I000 pounds to 35,000 pounds; (b) in phosphorus content, from 160 pounds to 15,000 pounds; (c) in potassium content from 3000 pounds to 60,000 pounds, per acre; and many soils not only contain no lime, but are markedly acid and thus require heavy applications of lime, while some pro- 
ductive soils contain as much as 20 per cent of calcium carbonate, corresponding to 200 tons of limestone per acre.

(8) A roo-bushel crop of corn takes from the soil about roo pounds of nitrogen, 17 pounds of phosphorus, and 19 pounds of potassium, in the grain, and about 48,6 , and 52 pounds of these respective elements in the stalks or stover.

(9) One ton of average fresh farm manurc contains about ro pounds of nitrogen, 2 pounds of phosphorus, and 8 pounds of potassium; and Ioo pounds of the most common "complete" commercial fertilizer contains about 2 pounds of nitrogen, 4 pounds of phosphorus, and 2 pounds of potassium.

(Io) One ton of clover hay contains about 40 pounds of nitrogen, 5 pounds of phosphorus, and 30 pounds of potassium. When grown on soil of fair productive capacity, the roots and stubble of the clover plant contain no more nitrogen than the soil has furnished to the plant; but for each ton of clover plowed under, the soil is enriched by about 40 pounds of nitrogen.

(II) Roughly estimated, the plant food liberated from an average soil during an average season with average farming is equivalent to about 2 per cent of the nitrogen, I per cent of the phosphorus, and $\frac{1}{4}$ of I per cent of the potassium, contained in the surface stratum (about $6 \frac{2}{3}$ acre inches, or 2 million pounds of average soil).

(I2) As an average in live-stock farming, the animals retain about onc fourth of the nitrogen and phosphorus and destroy two thirds of the organic matter of the food consumed, and large loss is likely to occur in the manure produced, especially in nitrogen and organic matter, a loss of one half of these constituents being easily possible during three or four months, in part from fermentation, which may occur even under cover, and in part from leaching where the manure is exposed to the weather or where too little absorbent bedding is used.

(I3) It is less difficult to maintain or increase the organic matter of the soil by means of legume crops and crop residucs in a good rotation for grain farming than in any system of live-stock farming which does not include the purchase of feed.

(I4) Some satisfactory rotation plans for grain farmers are wheat, corn, oats, and clover ; or wheat, corn, and cowpeas ; or 
cotton, corn, and oats and cowpeas. The first of these is a fouryear rotation which should include a catch crop of clover seeded the first year and plowed under for corn as late as practicable in the spring of the second year. The other two are three-year rotations, and they should also include legume catch crops wherever practicable. In each rotation for grain farming, all products are to be returned to the soil excepting the grain, or seed, and the cotton lint. Either the whole cotton seed or the hulls and meal should also be returned for fertilizer.

(I5) In live-stock farming the feeding should be done on the fields so far as practicable, and manure produced in the barn should be hauled and spread in the fresh condition so far as possible. Sufficient bedding should be used to absorb all of the liquid excrement, which is as valuable, ton for ton, as the solid excrement.

(I6) To insure the maintenance of the phosphorus content of the soil where large crops are produced, about 20 pounds of phosphorus per acre for each year in the rotation should be applied in grain farming and about to pounds per acre in live-stock farming (aside from that returned in the manure). To enrich the soil in phosphorus, heavier applications should be made for a time.

(I7) The average investment required for 25 pounds of phosphorus is about 75 cents in 200 pounds of fine-ground natural rock phosphate of good grade, about $\$ 2.50$ in 200 pounds of good steamed bone meal, about $\$ 3.00$ in 400 pounds of good acid phosphate, about $\$ 6.00$ in 600 pounds of the average "complete" commercial fertilizer, and about $\$ 80$ in manure made from corn costing 40 cents a bushel. The natural phosphate, if ground to pass through a sieve with 10,000 meshes to the square inch, gives satisfactory results when applied in liberal amounts (as rooo pounds per acre every three or four years), if used in connection with decaying organic matter in sufficient amount to maintain the nitrogen.

(18) Potassium salts are used with very great profit on soils positively deficient in that element, as on most well-drained extensive peaty swamp lands; and soluble salts, such as kainit, may produce some profit for a time if used in connection with phosphorus on soils deficient in decaying organic matter, even where the total supply of potassium in the soil is very large. 
(I9) Commercial nitrogen can usually be used with profit in market gardening, in cotton growing, and sometimes in the production of timothy hay near large cities; or, as a rule, wherever the gross returns from an acre of produce exceeds $\$ 50$ or $\$ 75$.

(20) As a rule, commercial nitrogen cannot be used with profit for the production of the staple grain crops, such as corn and wheat, although under some conditions small applications of nitrogen alone or with other elements, as in the ordinary so-called " complete" fertilizer, may stimulate the plants sufficiently to enable them to draw more heavily upon the soil, and thus return apparent temporary profit in a system of ultimate land ruin.

And other seed fell on good ground, and sprang up, and bare fruit an hundred fold. - Jesus.

I applied mine heart to know, and to search, and to seek out wisdom, and the reason of things. - SOLOMON.

Every man shall receive his own reward according to his own labor; for we are laborers together with God. - PAUL. 


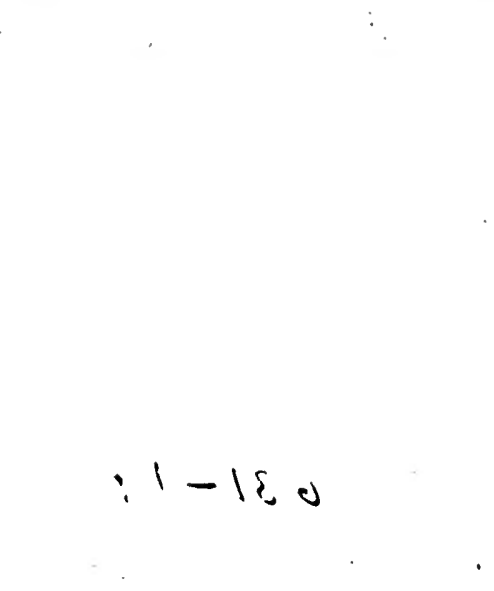




\section{SOIL FERTILITY AND \\ PERMANENT AGRICULTURE}

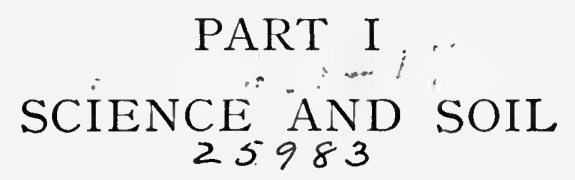

\section{CHAPTER I}

\section{FOUNDATION FACTS AND PRINCIPLES}

Science. Science means knowledge, nothing more and nothing less. It does not mean theory unsupported by fact. To plow the land and plant the seed and cultivate the crop is art, or practice. To know what the soil and air contain and what the crop requires is science. If ro cents are taken from 70 cents, only 60 cents remain. This is science, knowledge, fact, and not mere opinion. In the study of soil fertility we must make large use of two well-established exact sciences, mathematics and chemistry. Several other sciences furnish much exact data, but in some branches the data thus far secured are not sufficient to fully reveal the controlling facts and principles.

Chemistry. Chemistry is the science which deals with the composition of matter. All material things are composed of about eighty primary substances, ealled elements, which may exist separately or in various combinations, called compounds. About forty of the elements are more or less common, the others being rare elements. Air and soil and plants and animals contain less than twenty elements that are of interest to agriculture; while only ten different elements are known to be essential for the making of agricultural plants. (One other element, chlorin, may be essential, but, if so, only in minute quantity.) 
Chemical elements. An element is a substance which cannot be divided into two or more different substances. Sulfur (S) is a solid, nonmetallic element, easily melted to the liquid form. A piece of sulfur may be divided into two parts, but each part is sulfur, and if nothing else is added to sulfur, nothing but sulfur can be obtained from it. Carbon (C) is the principal element contained in coal. Iron is a well-known metallic element. Oxygen $(\mathrm{O})$ is an element contained in the air in the gas form.

Chemical compounds. A ! compound is a substance which contains two or more different elements and which possesses some properties or characteristics not possessed by either element alone. Thus, if carbon and sulfur be mixed together at the ordinary temperature, the product is only a mixture in which each element retains its own properties; but, at a higher temperature and under proper conditions, one combining weight of black carbon will unite with two combining weights of yellow sulfur and form the compound called carbon disulfid $\left(\mathrm{CS}_{2}\right)$, which is neither black nor yellow nor solid, but a colorless liquid somewhat resembling water, but which, when pure, contains absolutely nothing but the two elements, carbon and sulfur.

Carbon, in charcoal for example, may be eaten in considerable quantity without harm, and sulfur is not dangerous in large doses; but the compound, carbon disulfid, is a deadly poison, and is frequently used as an insecticide and for the extermination of gophers and other burrowing animals. Thus the properties of the compound may differ in many respects from those of either element contained in it.

On the other hand, when carbon is burned, by uniting with the oxygen of the air, the compound, carbon dioxid $\left(\mathrm{CO}_{2}\right)$, is formed, and when sulfur is likewise burned, the compound, sulfur dioxid $\left(\mathrm{SO}_{2}\right)$, is formed; while if carbon disulfid is burned, by uniting with the oxygen of the air, the products of combustion are exactly the same as though the carbon and sulfur were burned separately with oxygen, carbon dioxid and sulfur dioxid being formed.

Sodium (Na, natrium in Latin) is a soft metallic element which takes fire when thrown into water, and the element chlorin $(\mathrm{Cl})$ is a greenish colored poisonous gas, but when united these two elements form the compound called sodium chlorid $(\mathrm{NaCl})$, salt. 
Chemical action. Chemical reaction is the union of two or more elements into a compound, or the separation of a compound into its elements, or the formation of new compounds from other compounds. In the most common chemical reactions heat is evolved.

Place some coal in the stove, raise the temperature to the kindling point, and 32 pounds of the element oxygen entering the vent of the stove in gas form will unite with I 2 pounds of the element carbon in the coal and 44 pounds of the compound carbon dioxid $\left(\mathrm{CO}_{2}\right)$ will form and pass off as a gas througn the chimney. After this chemical reaction is completed, the stove is found to contain only a few ounces of ashes, which represent the impurities in the coal.

From this compound, carbon dioxid $\left(\mathrm{CO}_{2}\right)$, which is always present in the air in small amount, all agricultural plants obtain their supply of carbon and oxygen, which together constitute about 90 per cent of the total dry matter contained in plants.

Combining weights. Combining weights of elements are the relative proportions in which those elements combine to form compounds. The combining weight of the element hydrogen is smaller than that of any other element, and for this reason all other combining weights are referred to that of hydrogen as the standard, or unit, of weight. The combining weight of hydrogen is $I$. One part of hydrogen will unite with 35.5 parts of chlorin to form the compound hydrogen chlorid $(\mathrm{HCl})$, which is also properly called hydrochloric acid, and sometimes incorrectly called " muriatic" acid. Thus, the combining weight of chlorin is $35 \cdot 5$.

We may take I pound of hydrogen and let it unite with 35.5 pounds of chlorin to form 36.5 pounds of the compound $\mathrm{HCl}$; or we may use I ounce of hydrogen and 35.5 ounces of chlorin, or I gram of hydrogen and 35.5 grams of chlorin, or I milligram of hydrogen and 35.5 milligrams of chlorin. All that is necessary is, that we maintain these proportions. This is one of the absolute mathematical laws of chemistry and is fundamental to the principles of soil fertility and plant growth. If we try to combine 3 parts of hydrogen with 35.5 parts of chlorin, 36.5 parts of the compound $\mathrm{HCl}$ would be formed and 2 parts of hydrogen would be left in its original form.

Atoms. An atom is the smallest particle of an element. It is not known how small the atom is, but it is known that the weight of 
an atom of carbon is 12 times, of oxygen is 16 times, of sulfur is 32 times, and of chlorin is 35.5 times, as great as the weight of an atom of hydrogen. Thus the atomic weights of all other elements are referred to the weight of the hydrogen atom as the chemical unit.

Molecules. A molecule is the smallest enduring particle of an element or compound. The atom, if set free, instantly unites with another atom (either of the same element or of a different element) to form a molecule, and the molecule may endure permanently. One atom of hydrogen and one atom of chlorin unite to form one molecule of hydrochloric acid, $\mathrm{HCl}$. The molecular weight of this compound is 36.5 , which is the sum of the atomic weights, the weight of the hydrogen atom always being $I$. It is true that this is an arbitrary standard, but so is every common standard of weight or measure, such as the ounce or the inch or the dollar. The inch is an arbitrary standard of length to which we may refer other lengths or distances, and likewise the weight of the hydrogen atom is an arbitrary standard to which we may with equal accuracy refer the weights of the atoms of all other elements, and also the weights of all molecules of either compounds or elements.

Atomic bonds. Atomic bonds are the links of union between atoms. This bond between atoms may be likened to the hand clasp between persons, except that under normal conditions the hand of one atom always grasps the hand of another atom. If the bond is broken, the freed hands immediately grasp other hands, breaking the bonds between other atoms if necessary to secure union. At the instant a bond is broken, when free hands exist, the atoms are called nascent, and in that condition they have unusual power to attack the molecules of other elements or compounds. Free hydrogen means hydrogen not combined with some other element. Thus we have nascent hydrogen $(\mathrm{H})$, ordinary free hydrogen $\left(\mathrm{H}_{2}\right)$, and combined hydrogen, as in water $\left(\mathrm{H}_{2} \mathrm{O}\right)$. Of course, nascent hydrogen is also free hydrogen, but in an extraordinary form; namely, as a free atom, which as such can exist but an instant until it unites with another atom of hydrogen (or of some other element) to form a molecule.

Valence. Valence refers to the number of bonds, or hands, possessed by an atom. The hydrogen atom has but one hand $(\mathrm{H}-)$, while the oxygen atom has two hands (-O-), and the carbon 
atom has four hands $(=\mathrm{C}=)$. In hydrogen molecules the atoms are always in pairs $\left(\mathrm{H}-\mathrm{H}\right.$ or $\left.\mathrm{H}_{2}\right)$. Thus the weight of the hydrogen molecule is two, because it contains two of the unit atoms. The atom of oxygen weighs sixteen times as much as the hydrogen atom, consequently 16 is the atomic weight, or the combining weight, of the element oxygen. The molecule of ordinary oxygen contains two atoms $\left(\mathrm{O}=\mathrm{O}\right.$ or $\left.\mathrm{O}_{2}\right)$, but there is a form of oxygen,

called ozone, which contains three atoms in the molecule (O-O or $\mathrm{O}_{3}$ ). The molecular weight of ordinary oxygen is 32 , while the molecule of ozone weighs 48 times as much as one hydrogen atom. One oxygen atom has power to hold two hydrogen atoms $\left(\mathrm{H}-\mathrm{O}-\mathrm{H}\right.$ or $\left.\mathrm{H}_{2} \mathrm{O}\right)$. This is a compound which might be called dihydrogen oxid, but which is commonly called water. The molecular weight of water is $\mathrm{I} 8$, the sum of the atomic weights. Separately, hydrogen and oxygen are both gases under ordinary conditions, but the compound $\mathrm{H}_{2} \mathrm{O}$ possesses different properties, being a liquid at ordinary temperatures, although water becomes a gas at high temperature and a solid at low temperature.

While it is common knowledge that this compound exists in three forms, solid, liquid, and vapor, and that it is easily changed from solid ice to liquid water and from liquid to vapor (steam), it is not so generally known that most elements and most compounds may exist in each of these three forms under proper conditions of temperature and pressure.

One atom of carbon may combine with four atoms of hydrogen, forming the gas compound $\left({ }_{\mathrm{H}}^{\mathrm{H}} \searrow^{\mathrm{C}} \searrow_{\mathrm{H}}^{\mathrm{H}}\right.$ or $\left.\mathrm{CH}_{4}\right)$ called methane or marsh gas, a constituent of illuminating gas, and sometimes formed in stagnant marshes. This hydrocarbon has a molecular weight of 16 and is the lowest in a very large series of compounds containing only hydrogen and carbon. One atom of carbon with its four bonds may unite with two atoms of oxygen, forming carbon dioxid $\left(\mathrm{O}=\mathrm{C}=\mathrm{O}\right.$ or $\left.\mathrm{CO}_{2}\right)$, a chemical reaction which occurs in the combustion of coal or other substances containing carbon, as already explained.

Monovalent atoms have one bond, or one hand (mono means 
one, as in monotone); bivalent atoms have two bonds ( $b i$ or $d i$ means two); trivalent atoms have three bonds; tetravalent, four bonds; pentavalent, five bonds; hexavalent, six bonds; heptavalent atoms have seven bonds; and octovalent atoms have eight bonds, with power to hold four of the bivalent atoms of oxygen.

There are a few cases in which the atom does not make common use of all the bonds it possesses. Thus the nitrogen atom has five bonds, or hands, but in some compounds only three bonds are used to hold other atoms. It might be conceived in this case that the other two hands are clasped together, and this conception might cven be extended to cover a molecule composed of a single bivalent atom (such as mercury and, possibly, argon). One atom of nitrogen and three atoms of hydrogen form the compound called ammonia $\left(\mathrm{NH}_{3}\right)$. This compound is frequently sold in fertilizers, but the hydrogen has no money value because water $\left(\mathrm{H}_{2} \mathrm{O}\right)$ contains hydrogen. The molecular weight of ammonia is $\mathrm{I} 7$, of which the nitrogen atom is 14 and the hydrogen atoms are 3 . If a fertilizer is guaranteed to contain 17 per cent of ammonia, it should contain I 4 per cent of the element nitrogen; while $8 \frac{1}{2}$ per cent of ammonia is equivalent to only 7 per cent of nitrogen. Ammonia itself contains $\frac{14}{17}$, or 82 per cent, of the element nitrogen.

In the compound called ammonium chlorid $\left(\mathrm{NH}_{4} \mathrm{Cl}\right)$, the atom of nitrogen is pentavalent; that is, it has and uses five bonds: $\mathrm{N}_{\mathrm{H}}^{\mathrm{H}} \leq \stackrel{\mathrm{Cl}}{\mathrm{H}}$

The molecular weight of this compound is

$53 \cdot 5$

$(\mathrm{I} 4+4+35 \cdot 5)$, and it contains $\frac{\mathrm{I} 4.0}{53.5}$, or 26 per cent, of nitrogen.

Phosphorus is another element which sometimes uses only three bonds, as in hydrogen phosphid, $\mathrm{P}-_{\mathrm{H}}^{\mathrm{H}}$, and in phosphorus trichlorid, $\mathrm{P} / \mathrm{Cl}$, and sometimes five bonds, as in phosphorus pentachlorid,<smiles>ClP(Cl)(Cl)(Cl)Cl</smiles>
Thus, the hydrogen phosphid contains $\frac{31}{3}$, or 9 I per 
cent, of phosphorus (the atomic weight of phosphorus being $3 \mathrm{I}$ ), while the phosphorus pentachlorid contains less than ${ }_{5} 5$ per cent of phosphorus.

Nitrogen and phosphorus are in some respects very much alike, and in other respects they are very unlike. They are the two most precious elements of plant food, and they deserve from the author and from the reader all of the consideration they are to receive in this book.

The gas law. This law is that equal volumes of gases under like conditions of temperature and pressure contain the same number of molecules. In other words, in the gas form, every molecule occupies, or controls, the same amount of space. Thus, the hydrogen molecule, with a weight of 2 , occupies as much space as the oxygen molecule, which weighs 32 , or the molecule of carbon dioxid, weighing 44, or of sulfur dioxid with a molecular weight of 64 . (The atomic weight of sulfur is 32 .)

If a 6-gallon bottle holds 2 grams of hydrogen $\left(\mathrm{H}_{2}\right)$, it will hold 32 grams of oxygen $\left(\mathrm{O}_{2}\right), 28$ grams of nitrogen $\left(\mathrm{N}_{2}\right)$, I6 grams of methane $\left(\mathrm{CH}_{4}\right)$, I 7 grams of ammonia gas $\left(\mathrm{NH}_{3}\right), 44$ grams of carbon dioxid $\left(\mathrm{CO}_{2}\right), 64$ grams of sulfur dioxid $\left(\mathrm{SO}_{2}\right)$, and a grammolecule (the molecular weight in grams) of any other gas. This law does not apply to liquids or solids, but only to gases.

Chemical symbols. A symbol is used to represent one atom of an element. $\mathrm{H}$ stands not only for the element hydrogen, but also for one atom of hydrogen with a combining weight of I. Likewise $\mathrm{S}$ stands for sulfur and for one atom of sulfur, and represents a weight of 32 .

Chemical formulas. A formula is used to represent a molecule and shows the kind and the number of atoms contained in the molecule. The formula $\mathrm{H}_{2} \mathrm{O}$ represents one molecule of water, containing two atoms of hydrogen, each having a combining weight of $\mathrm{I}$, and one atom of oxygen, with a weight of $\mathrm{I} 6$. Thus, the molecular weight of water is $\mathrm{I} 8$. The formula $\mathrm{Ca}_{3}\left(\mathrm{PO}_{4}\right)_{2}$ (read: $\mathrm{Ca}$ three, PO four, twice) represents one molecule of tricalcium phosphate, the valuable phosphorus compound contained in bones and in natural phosphate rock. The metallic element calcium (Ca) is also contained in limestone, which is calcium carbonate $\left(\mathrm{CaCO}_{3}\right)$, and in quicklime, or burned lime, which is calcium 
oxid $(\mathrm{CaO})$. The atomic weight of calcium is 40 . The subscript figures used in a chemical formula always refer to the preceding element, or to the inclosed group of elements if parentheses are used. In the calcium phosphate, $\mathrm{Ca}_{3}\left(\mathrm{PO}_{4}\right)_{2}$, the subscript 3 shows that three atoms of calcium are contained in the molecule. The parentheses are used to inclose a group of atoms (one atom of phosphorus and four atoms of oxygen) which occurs in many other compounds, as in $\mathrm{H}_{3} \mathrm{PO}_{4}$ (phosphoric acid), $\mathrm{FePO}_{4}$ (iron phosphate), etc. (Fe is from ferrum, the Latin word for iron, and I is the symbol used for the element iodin.) The subscript 2 following the parenthesis in $\mathrm{Ca}_{3}\left(\mathrm{PO}_{4}\right)_{2}$ means that the molecule contains the $\mathrm{PO}_{4}$ group twice, and for this reason $\mathrm{Ca}_{3}\left(\mathrm{PO}_{4}\right)_{2}$ is a better formula than $\mathrm{Ca}_{3} \mathrm{P}_{2} \mathrm{O}_{8}$, which may also be correctly used. A molecule of tricalcium phosphate contains three atoms of calcium $(3 \times 40=120)$, two atoms of phosphorus $(2 \times 3 \mathrm{I}=62)$, and eight atoms of oxygen $(2 \times 4 \times 16=128)$, and the molecular weight is 310 ( $20+62+128)$, of which the phosphorus represents only 62 . Thus, tricalcium phosphate contains $\frac{62}{310}$, or 20 per cent, of the element phosphorus. In other words, one fifth of pure tricalcium phosphate is phosphorus, while the remaining four fifths consist of calcium and oxygen in nearly equal parts.

The law of constant proportions. This law is that in every chemical combination the constituents occur in definite and constant proportions by weight. The percentage of phosphorus in pure tricalcium phosphate is absolutely constant. It matters not whether the compound is made in the United States, in Germany, or in Japan, nor whether it is obtained from bones or from phosphate rock, the percentage of phosphorus it contains is always the same, if the compound is pure. This percentage is exactly 20 , according to the most accurate accepted determinations. The atomic weights are determined by several different methods, but, even with the finest and most accurate balances and other instruments and means, absolute exactness may not be achieved, because of the human error. No man can measure a mile with absolute exactness, because two different measurements made by one man may vary by an inch, a tenth of an inch, or, at least, by a hundredth or a thousandth of an inch.

According to the chemical law, the proportion of the different 
elements in any pure compound is absolutely definite and constant, in strict accordance with the chemical law, and the proportion can be determined with ten times the degree of accuracy required for all practical purposes; nevertheless, the determination may not be absolutely exact.

While all atomic weights are essentially referred to hydrogen as unity, the mathematical basis is exactly 16 for the atomic weight of oxygen, because the element oxygen constitutes in quantity one half of the earth's crust (including the air, the ocean, and the solid crust to a depth of ten miles), and forms compounds with nearly all other elements, thus affording closer comparisons than hydrogen.

The known chemical elements. In the accompanying table is the complete list of 80 known elements. For convenience the more common elements, that every one should know, are given in one group, and the rare elements, that few people have ever seen, are grouped by themselves.

The symbols used for the chemical elements are essentially the same in all languages. In a few cases where the modern name varies in different languages, the nations have agreed upon a symbol derived from the Latin name of the element; as, for example, $\mathrm{Fe}$ for iron (ferrum in Latin), $\mathrm{K}$ for potassium (kalium), and $\mathrm{Na}$ for sodium (natrium).

Some of the atomic weights of the rare elements have not yet been determined with a sufficient degree of accuracy to justify assigning a more specific value than the nearest whole number. Further investigation must determine whether such whole numbers are correct. It is a noteworthy fact that the chemists of the world are agreed that, of these forty more common elements, sixteen have atomic weights that differ from whole numbers by less than .05 , and twelve others differ only by about.I, thus showing twenty-eight of the best-established atomic weights apparently grouped with relation to the unit, with only twelve scattering; and some of these (as nickel) are doubtful, while others are high atomic weights with consequent possibilities of error, the accepted atomic weights of gold and platinum both having been changed by .5 within recent years. These data and the recognized periodic law, that the properties of the elements are periodic functions of their 
Table i. Elements, Symbols, and International Atomic Weights FOR 1909. (Decimals, including ciphers, indicate supposed accuracy.)

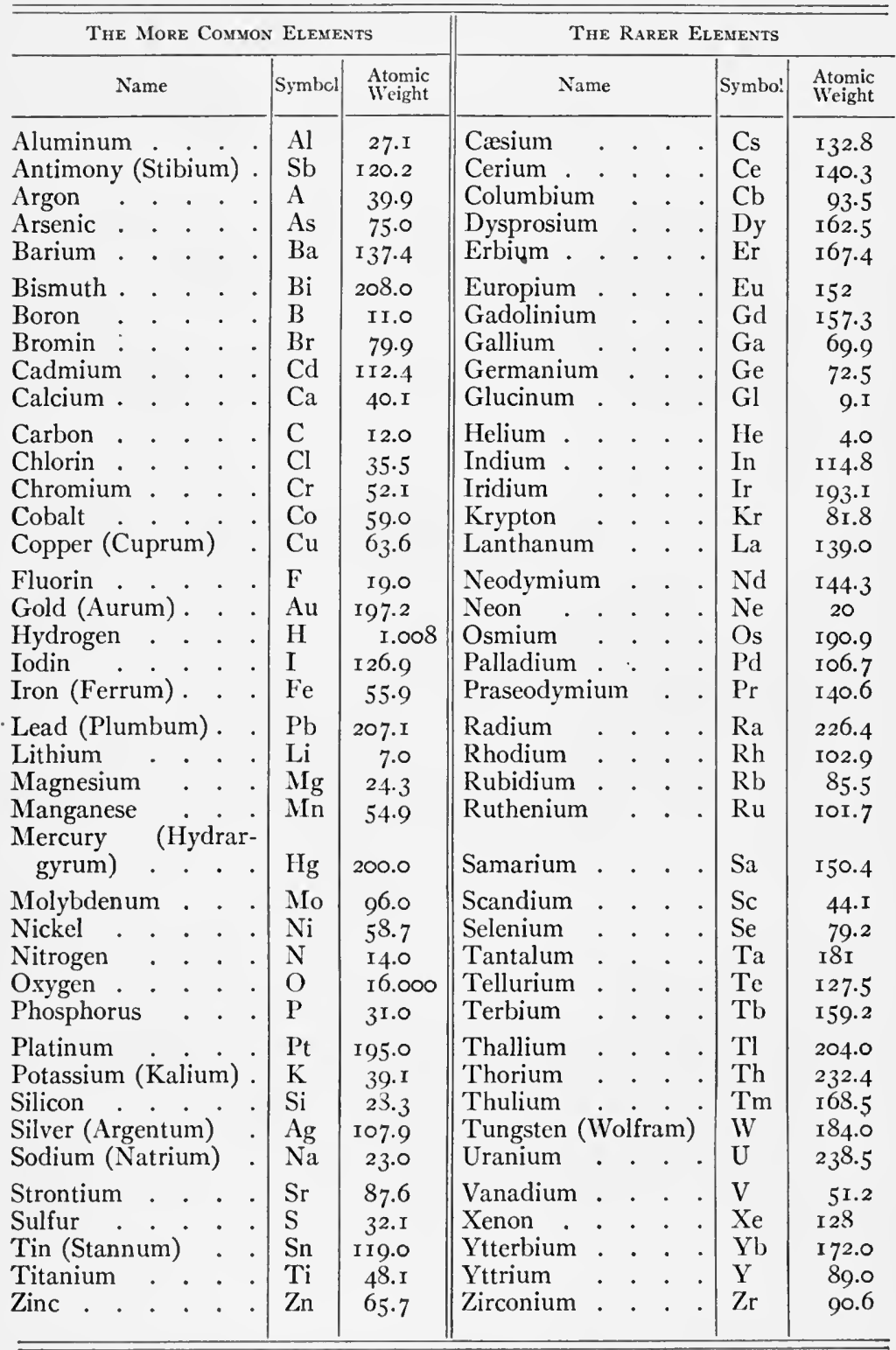


atomic weights, ${ }^{1}$ together with the recently discovered radium and radio activity, and the evidences ${ }^{2}$ of accomplished transformation of one element into another, strongly indicate a common origin for different elements, and lend to the subject a present-day interest as intense as ever moved the alchemist to try to turn the baser metals into gold.

${ }^{1}$ It is worth while to note some relations that exist between the monovalent elements fluorin, chlorin, bromin, iodin; between the bivalent elements oxygen, sulfur, selenium, molybdenum; between the trivalent (or pentavalent) nitrogen, phosphorus, arsenic, antimony; and also between the tetravalent carbon, silicon, titanium, and germanium:

\begin{tabular}{|c|c|c|c|}
\hline $\begin{array}{l}\text { Fluorin } \\
F=\text { I9 } \\
\text { HF }\end{array}$ & $\begin{array}{c}\text { Chlorin } \\
\mathrm{Cl}=35 \cdot 5 \\
\mathrm{HCl}\end{array}$ & $\begin{array}{c}\text { Bromin } \\
\mathrm{Br}=80 \\
\mathrm{HBr}\end{array}$ & $\begin{array}{c}\text { Iodin } \\
\mathrm{I}=\mathrm{12} 27 \\
\mathrm{HI}\end{array}$ \\
\hline $\begin{array}{c}\text { Oxygen } \\
\mathrm{O}=\mathrm{r} 6 \\
\mathrm{H}_{2} \mathrm{O}\end{array}$ & $\begin{array}{c}\text { Sulfur } \\
\mathrm{S}=32 . \mathrm{I} \\
\mathrm{H}_{2} \mathrm{~S} \\
\mathrm{H}_{2} \mathrm{SO}_{4}\end{array}$ & $\begin{array}{c}\text { Selenium } \\
\mathrm{Se}=79.2 \\
\mathrm{H}_{2} \mathrm{Se} \\
\mathrm{H}_{2} \mathrm{SeO}_{4}\end{array}$ & $\begin{array}{c}\text { Molybdenum } \\
\mathrm{Mo}=96_{\mathrm{H}_{2} \mathrm{MoO}_{4}}\end{array}$ \\
\hline $\begin{array}{c}\text { Nitrogen } \\
\mathrm{N}=\mathrm{I} 4 \\
\mathrm{NH}_{3} \\
\mathrm{~N}_{2} \mathrm{O}_{5}\end{array}$ & $\begin{array}{c}\text { Phosphorus } \\
\mathrm{P}=3^{\mathrm{I}} \\
\mathrm{PH}_{3} \\
\mathrm{P}_{2} \mathrm{O}_{5}\end{array}$ & $\begin{array}{c}\text { Arsenic } \\
\mathrm{As}=75 \\
\mathrm{AsH}_{3} \\
\mathrm{As}_{2} \mathrm{O}_{5}\end{array}$ & $\begin{array}{c}\text { Antimony } \\
\mathrm{Sb}=\mathrm{I}_{20.2} \\
\mathrm{SbH}_{3} \\
\mathrm{Sb}_{2} \mathrm{O}_{5}\end{array}$ \\
\hline $\begin{array}{c}\text { Carbon } \\
\mathrm{C}=\mathrm{I}^{2} \\
\mathrm{CH}_{4} \\
\mathrm{CO}_{2}\end{array}$ & $\begin{array}{c}\text { Silicon } \\
\mathrm{Si}=28.4 \\
\mathrm{SiH}_{4} \\
\mathrm{SiO}_{2}\end{array}$ & $\begin{array}{l}\begin{array}{c}\text { Titanium } \\
\mathrm{Ti}={ }_{4} 8\end{array} \\
\mathrm{TiO}_{2}\end{array}$ & $\begin{array}{c}\text { Germanium } \\
\text { Ge }=72.5 \\
\mathrm{GeO}_{2}\end{array}$ \\
\hline
\end{tabular}

Aside from the similarity of valence and other properties and of compounds formed, there is interest in the relation of atomic weights, especially in the second and fourth groups, and, even in the fact that the atomic weight of antimony is so nearly the sum of the other three in the group.

${ }^{2}$ In 1907 Ramsay and Cameron, of England, reported that they had reduced copper, in the presence of radium emanation, into other elements of the same series: potassium, sodium, lithium. (See Nature, July, 1907, and Journal of the Chemical Society, September, I907.) The correctness of Ramsay and Cameron's experiments has been called in question by Mme. Curie and Mlle. Gleditsch; Comptes rendus, 147, 345 (1908); Science, December 4, 1908. 


\section{CHAPTER II}

\section{THE MORE COMMON ELEMENTS AND COMPOUNDS}

Important elements. Fifteen elements are of special interest and importance in the study of soil fertility, because they are commonly found in plants and animals and because they so largely constitute the soil and air and ocean and the common things of earth. Of these fifteen elements, ten are known to be essential to plant growth; eight of them constitute 98 per cent of the solid crust of the earth; four of them constitute 99.6 per cent of the ocean, about 96.4 per cent being water $\left(\mathrm{H}_{2} \mathrm{O}\right)$ and 3.2 per cent common salt $(\mathrm{NaCl})$; and two of them (nitrogen and oxygen) constitute 98.5 per cent by weight of the dry atmosphere, about 1.5 per cent of the air consisting of the recently discovered element, argon.

The ten essential elements of plant food may be grouped as follows:

$\mathrm{C}, \mathrm{H}, \mathrm{O}$, obtained by plants from air and water.

$\mathrm{P}, \mathrm{K}, \mathrm{N}$, sometimes deficient in soils, and of money value as plant food.

$\mathrm{S}, \mathrm{Ca}, \mathrm{Fe}, \mathrm{Mg}$, required in small amounts and not likely to be deficient in soils.

The five other elements commonly present in plants are silicon, aluminum, sodium, chlorin, and manganese.

The reader is earnestly advised to learn by groups ${ }^{1}$ the name and atomic weight and the valence of each of these important elements, and the following table is constructed for this purpose.

Aside from the name, symbol, atomic weight, and valence, Table 2 furnishes some extremely valuable and useful information concerning the occurrence and relative abundance of the elements which essentially constitute the crust of the earth, the ocean, the air, and the agricultural plants and animals. These data are based

${ }^{1}$ The author consents to the students' menory key: "C. HOPK'NS' CaFe,-Mg," if $\mathrm{Mg}$ stands for "Mighty good" and the omission of I, for modesty. 
upon the recent computations of. Professor F. W. Clarke of the United States Geological Survey for the average composition of the ocean and of the earth's crust ${ }^{1}$ to a depth of ten miles, essentially upon Sir William Ramsay's recent estimate for the average composition of air, and upon the author's compilations and computations for the average composition of shelled corn (maize).

\section{Table 2. The More Important Elements}

\begin{tabular}{|c|c|c|c|c|c|c|c|}
\hline \multirow[b]{2}{*}{ Name } & \multirow[b]{2}{*}{ Symbol } & \multirow[b]{2}{*}{$\begin{array}{l}\text { Atomic } \\
\text { WeIGHT } \\
(\mathrm{O}=16)\end{array}$} & \multirow[b]{2}{*}{$\begin{array}{l}\text { VALENCE, OR } \\
\text { NUMBER OF } \\
\text { BONDS }\end{array}$} & \multicolumn{4}{|c|}{ OCCURRENCE } \\
\hline & & & & $\begin{array}{c}\text { In Earth's } \\
\text { Crust } \\
\text { (Per Cent) }\end{array}$ & $\begin{array}{c}\text { In the } \\
\text { Ocean } \\
\text { (Per Cent) }\end{array}$ & $\begin{array}{c}\text { In the } \\
\text { Air } \\
\text { (Per Cent) }\end{array}$ & $\begin{array}{l}\text { In the } \\
\text { Corn Ker- } \\
\text { nel } \\
\text { (Per Cent) }\end{array}$ \\
\hline $\begin{array}{l}\text { Oxygen . } \\
\text { Carbon . } \\
\text { Hydrogen }\end{array}$ & $\begin{array}{l}\mathrm{O} \\
\mathrm{C} \\
\mathrm{H}\end{array}$ & $\begin{array}{r}16 \\
\text { I } 2 \\
\text { I }\end{array}$ & $\begin{array}{l}2 \\
4 \\
I\end{array}$ & $\begin{array}{r}47.07 \\
.20 \\
.22\end{array}$ & $\frac{85 \cdot 79}{10.67}$ & $\begin{array}{r}23.00 \\
.01 \\
\end{array}$ & $\begin{array}{r}46.000 \\
45.000 \\
6.400\end{array}$ \\
\hline $\begin{array}{l}\text { Nitrogen } \\
\text { Phosphorus } \\
\text { Potassium . }\end{array}$ & $\begin{array}{l}\mathrm{N} \\
\mathrm{P} \\
\mathrm{K}\end{array}$ & $\begin{array}{l}\text { I4 } \\
3^{I} \\
39\end{array}$ & $\begin{array}{c}3 \text { or } 5 \\
3 \text { or } 5 \\
\text { I }\end{array}$ & $\begin{array}{l}\text { trace } \\
. \text { II } \\
2.46\end{array}$ & $\bar{\square}$ & $75 \cdot 5^{\circ}$ & $\begin{array}{r}1.760 \\
.300 \\
.340\end{array}$ \\
\hline $\begin{array}{l}\text { Magnesium } \\
\text { Calcium . } \\
\text { Iron . } \\
\text { Sulfur . }\end{array}$ & $\begin{array}{l}\mathrm{Mg} \\
\mathrm{Ca} \\
\mathrm{Fe} \\
\mathrm{S}\end{array}$ & $\begin{array}{l}24 \cdot 3 \\
40 \\
56 \\
32\end{array}$ & $\begin{array}{c}2 \\
2 \\
2,3,6, \text { or } 7 \\
2,4, \text { or } 6\end{array}$ & $\begin{array}{r}2.40 \\
3.44 \\
4.43 \\
. \text { I I }\end{array}$ & $\begin{array}{l}.14 \\
.05 \\
\end{array}$ & & $\begin{array}{l}.125 \\
.022 \\
.008 \\
.004\end{array}$ \\
\hline $\begin{array}{l}\text { Silicon . } \\
\text { Aluminum . } \\
\text { Sodium . } \\
\text { Chlorin . } \\
\text { Manganese }\end{array}$ & $\begin{array}{l}\mathrm{Si} \\
\mathrm{Al} \\
\mathrm{Na} \\
\mathrm{Cl} \\
\mathrm{Mn}\end{array}$ & $\begin{array}{l}28 \cdot 3 \\
27 \\
23 \\
35 \cdot 5 \\
55\end{array}$ & $\begin{array}{c}4 \\
3 \\
I \\
I, 3,5 \text {, or } 7 \\
2,3,6 \text {, or } 7\end{array}$ & $\begin{array}{r}28.06 \\
7.90 \\
2.43 \\
.07 \\
.07\end{array}$ & $\begin{array}{l}\overline{I .14} \\
2.07\end{array}$ & & $\begin{array}{l}.014 \\
.013 \\
.013\end{array}$ \\
\hline $\begin{array}{l}\text { Titanium . } \\
\text { Argon . }\end{array}$ & $\underset{\mathrm{A}}{\mathrm{Ti}}$ & $\begin{array}{l}48 \\
40\end{array}$ & $\begin{array}{c}4 \\
(?)\end{array}$ & .40 & & $1.4^{8}$ & \\
\hline \multicolumn{4}{|c|}{ Totals } & $99 \cdot 3^{2}$ & 99.99 & $99.99^{3}$ & 99.99 \\
\hline
\end{tabular}

${ }^{1}$ United States Geological Survey Bulletin 330 (I908). The data for phosphorus and potassium include analyses of $167 \mathrm{I}$ and 2110 different samples, respectively, of representative rocks, some of which were kindly furnished to the author by Doctor Clarke since Bulletin 330 was published.

${ }^{2}$ About sixty other elements (most of them very rare) must account for this deficiency.

${ }^{3}$ Constant traces of helium, neon, krypton, and xenon are also found in the air, of which they may constitute five parts per million. Varying amounts of moisture, compounds of nitrogen, sulfur, chlorin, and more or less dust, also exist in the air. 
It may well be stated here that plants secure their supply of both carbon and oxygen from the carbon dioxid of the air. The .or per cent of carbon $(\mathrm{C}=12)$ shown in the table is equivalent to nearly .04 per cent of carbon dioxid $\left(\mathrm{CO}_{2}=44\right)$. The hydrogen of plants is taken from the water absorbed by the roots. The corn plant secures its supply of nitrogen from the "trace" contained in the earth's crust, which, however, amounts to about .25 per cent, in the tilled stratum of a good soil. Under proper conditions legume plants secure more or less of their nitrogen from the air. The remaining six essential elements are secured only from the soil by all plants.

Of the atmosphere, ocean, and solid crust (ten miles deep), the solid crust constitutes about 93 per cent of the whole; while the entire atmosphere amounts to only .03 per cent. These additional facts make possible a mathematical comparison between the supply and crop requirements of carbon and oxygen (in $\mathrm{CO}_{2}$ ) and nitrogen in the air, and emphasize the importance of the carbon cycle and of the circulation of some other elements, all of which is more fully discussed and explained in the following pages.

A ready working knowledge, sufficient for everyday use, lies at the basis of success in every industry and profession. It is worth while to have in mind a few fundamental facts relating to the seventeen elements named in Table 2, which constitute more than 99 per cent of earth, sea, and air, and of all plants and animals. Nothing can be made of nothing.

Compounds consist of two or more elements, and the molecule of a compound must contain two or more atoms. If one knows the valence of the elements, he is then in control of much information of very great value in relation to compounds. Valence is the key to the understanding of compounds and chemical reactions. Table 2 gives this information for the very important elements.

Three of these elements - hydrogen, potassium, and sodium have only one bond, or hand, for each atom $(\mathrm{H}-, \mathrm{Na}-$, and $\mathrm{K}-$ ); while chlorin ( $\mathrm{Cl}$ ) may use $\mathrm{I}, 3,5$, or 7 bonds.

Three other elements have only two bonds for each atom $(\mathrm{O}=, \mathrm{Mg}=$, and $\mathrm{Ca}=)$, these clements being strictly bivalent. Sulfur sometimes uses only two bonds (in $\mathrm{H}_{2} \mathrm{~S}$ and $\mathrm{CS}_{2}$ ), but may use four or six. 
Iron and manganese are alike peculiar, with a valence of $2,3,6$, or 7 .

Aluminum is a trivalent element with three-handed atoms, while nitrogen and phosphorus may use either three or five bonds.

This leaves only the strictly tetravalent family, carbon $(=\mathrm{C}=)$, silicon $(=\mathrm{Si}=)$, and titanium $(=\mathrm{Ti}=) .{ }^{1}$

When an iron atom uses three hands, it is called $-i c$ iron, but if it uses only two hands it is called -ous iron. Thus we have the ferrous chlorid $\left(\mathrm{FeCl}_{2}\right)$ and ferric chlorid $\left(\mathrm{FeCl}_{3}\right)$; also ferrous oxid $(\mathrm{FeO})$ and ferric oxid $\left(\mathrm{Fe}_{2} \mathrm{O}_{3}\right)$. Likewise, when phosphorus uses only three bonds, it is called -ous phosphorus, but with the five bonds in use it is $-i c$ phosphorus, as in phosphorous chlorid $\left(\mathrm{PCl}_{3}\right)$ and phosphoric chlorid $\left(\mathrm{PCl}_{5}\right)$, which are also called phosphorus trichlorid and phosphorus pentachlorid, the endings, -ous and -ic, being unnecessary when the valence is specified in the number of chlorin atoms held.

Matter may exist in three distinctly different forms or classes which might be called "monary" (single), "binary" (double), and "trinary," or ternary (triple).

First, matter may exist in the form of free or uncombined elements; as solid metallic iron, aluminum, magnesium, calcium, sodium, or potassium; as solid nonmetallic carbon, phosphorus, sulfur, or silicon; as liquid mercury or bromin; or as gaseous oxygen, nitrogen, hydrogen, or chlorin. This might be termed the "monary" form, all atoms in the molecule being of the one element.

Second, matter may exist in binary compounds; that is, with

${ }^{1}$ Argon is of interest chiefly because it is so very common and yet so recently discovered. Argon is everywhere present in the air and we respire more than an ounce a day of that element. It is an invisible gas, and because it is mixed with so much nitrogen (which it resembles somewhat) and oxygen, and cannot be seen, it would be less easily discovered than many other elements; but the chief difficulty in detecting it by chemical methods was due to its chemical inaction. Because of this inaction, it has been named argon, which means without action. When the element was discovered and very thoroughly investigated, the discoverers (Rayleigh and Ramsay, in 1894) concluded that the argon atom has no valence, - no hand with which to clasp the hand of another atom, either of argon or of any other element. In other words, they discovered that argon forms no compounds, and that the molecule of argon is monatomic (mon or mono means one, as in monotone = one tone). Later investigations indicate, however, that argon has some weak affinities. 
two elements represented in the molecule. In the name of such a compound both elements are expressed, and sometimes the name also includes the number of atoms of each of the elements in the molecule, as phosphorus pentachlorid $\left(\mathrm{PCl}_{5}\right)$. As a rule, the name of one element is modified slightly so as to end in -id, a termination that means that the compound is binary, containing but two elements. (Any exception to this rule will be self-explanatory.) Thus sodium chlorid must contain only two elements, sodium and chlorin, because of the names and the ending - $i d$; and, since sodium must be monovalent and chlorin may be, the formula for the molecule is probably $\mathrm{Na}-\mathrm{Cl}$, which is correct for common salt.

As a matter of fact, chlorin is always monovalent in binary compounds with metals. Calcium oxid (quicklime) must be a binary compound of the two strictly bivalent elements, calcium and oxygen, and the molecular formula may be $\mathrm{Ca}=\mathrm{O}$, which is also correct. Calcium chlorid should be $\mathrm{Ca}=\mathrm{Cl}_{2}$; and magnesium chlorid, $\mathrm{Mg}=\mathrm{Cl}_{2}$; and potassium oxid, $\mathrm{K}_{2}=\mathrm{O}$; hydrogen sulfid, $\mathrm{H}_{2}=\mathrm{S}$; sulfur dioxid, $\mathrm{SO}_{2}(\mathrm{O}=\mathrm{S}=\mathrm{O})$; and sulfur trioxid, $\mathrm{SO}_{3}$ (in which the sulfur atom must use six bonds), all of which are correct. More complex molecules, which, however, are easily understood, are aluminum oxid $\left(\mathrm{Al}_{2} \mathrm{O}_{3}\right)$ and phosphorus pentoxid $\left(\mathrm{P}_{2} \mathrm{O}_{5}\right)$. The aluminum atom has three bonds (or hands), and the phosphorus uses five bonds in this oxid, while the oxygen atom is always bivalent, having but two hands. There are six bonds of union in aluminum oxid and ten bonds in phosphorus pentoxid, thus: $\stackrel{\mathrm{Al}}{\mathrm{Al}} \mathrm{O} \mathrm{O}, \stackrel{\mathrm{O}=\mathrm{O}}{\mathrm{P}=\mathrm{O}}$

Thus, if one knows the name, the atomic

weight, and the valence of the fifteen most important elements, he has the key to the formula and percentage composition of their binary compounds.

Third, matter may exist in ternary (triple) compounds, with three elements represented in the molecule. Most ternary compounds contain oxygen, and, in naming such compounds, the most common rule is to express the names of only two of the elements 
and then to employ a short ending to designate the oxygen. Thus, the ending -ate commonly means oxygen. Ternary compounds may best be studied in groups, in which the relation of oxygen to one of the other elements is constant. Thus, the carbonates constitute a large class of compounds in which the group, or radicle $\left(=\mathrm{CO}_{3}\right)$, is always present. The structural formula for

this radicle is as follows:

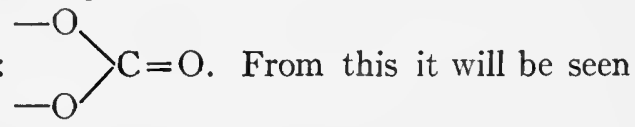

that the carbonate radicle has two free hands, or bonds, capable of holding two monovalent atoms or one bivalent atom. Now, the fact is, that almost any metallic element can join hands with this radicle. Thus we have calcium carbonate $\left(\mathrm{CaCO}_{3}\right)$, magnesium carbonate $\left(\mathrm{MgCO}_{3}\right)$, ferrous carbonate $\left(\mathrm{FeCO}_{3}\right)$, sodium carbonate $\left(\mathrm{Na}_{2} \mathrm{CO}_{3}\right)$, etc.

The nitrate radicle is $-\mathrm{NO}_{3}$, as in sodium nitrate $\left(\mathrm{NaNO}_{3}\right)$.

The chlorate radicle is $-\mathrm{ClO}_{3}$, as in potassium chlorate $\left(\mathrm{KClO}_{3}\right)$.

The silicate radicle is $=\mathrm{SiO}_{3}$ (like the carbonate radicle $=\mathrm{CO}_{3}$ ).

The sulfate radicle is $=\mathrm{SO}_{4}$, as in calcium sulfate $\left(\mathrm{CaSO}_{4}\right)$.

The phosphate radicle is $\equiv \mathrm{PO}_{4}$, as in ferric phosphate $\left(\mathrm{FePO}_{4}\right)$.

If we can remember these six radicles, we have the key to the constitution and composition of a large number of ternary compounds, some of which are of the greatest importance in soil fertility; as, for example, limestone, which is calcium carbonate $\left(\mathrm{CaCO}_{3}\right)$; land plaster, which is calcium sulfate $\left(\mathrm{CaSO}_{4}\right)$; and the important compound in phosphate rock and in bones, called "bone phosphate," which is calcium phosphate, $\mathrm{Ca}_{3}\left(\mathrm{PO}_{4}\right)_{2}$, also properly called tricalcium phosphate.

When the element chlorin, or the element sulfur, or any of these radicles join hands with metallic elements, the resulting compound is called a salt; as $\mathrm{NaCl}$ (common salt), $\mathrm{Na}_{2} \mathrm{SO}_{4}$ (Glauber's salt), $\mathrm{MgSO}_{4}$ (Epsom salt); and even limestone $\left(\mathrm{CaCO}_{3}\right)$ may properly be called a salt of calcium, and ferrous sulfate (copperas, which, however, contains no copper) is a salt of iron $\left(\mathrm{FeSO}_{4}\right)$.

Oxids and hydroxids. As already explained, matter may exist in the form of free elements, as nitrogen $\left(\mathrm{N}_{2}\right)$, sulfur $\left(\mathrm{S}_{2}\right)$, or phosphorus $\left(\mathrm{P}_{4}\right)$. 
Oxygen and hydrogen are not only very abundant elements (water, the " universal solvent," being $\mathrm{H}_{2} \mathrm{O}$ ), but they are also very active, chemically, and one or both have some part in nearly all important groups of compounds.

Oxids are binary compounds of oxygen with other elements, and they constitute a very large class, because almost all other elements form compounds with oxygen. Important examples are common quartz sand, which is silicon dioxid $\left(\mathrm{SiO}_{2}\right)$; water itself, which is hydrogen oxid $\left(\mathrm{H}_{2} \mathrm{O}\right)$; and carbon dioxid $\left(\mathrm{CO}_{2}\right)$.

Hydroxids are compounds which always contain the radicle $-\mathrm{OH}$, which is known as hydroxyl, or the hydroxid group, or the hydroxid radicle. This group, consisting of one atom of oxygen holding one atom of hydrogen with one hand and with the other hand free, or clasping some other atom, is the most important group of atoms in all chemistry. As a group it is monovalent, having one free bond, and it unites with almost all elements. Thus, we may consider:

Hydrogen hydroxid, $\mathrm{HOH}$, or water.

Potassium hydroxid, $\mathrm{KOH}$.

Calcium hydroxid, $\mathrm{Ca}(\mathrm{OH})_{2}$.

Iron hydroxid, $\mathrm{Fe}(\mathrm{OH})_{3}$.

Silicon hydroxid, $\mathrm{Si}(\mathrm{OH})_{4}$.

Phosphorus hydroxid, $\mathrm{P}(\mathrm{OH})_{5}$.

Sulfur hydroxid, $\mathrm{S}(\mathrm{OH})_{6}$.

Ethyl hydroxid, $\mathrm{C}_{2} \mathrm{H}_{5} \mathrm{OH}$, or alcohol.

In these compounds, the valence of the different elements varies from $\mathrm{I}$ to 6 , and a corresponding number of hydroxyl groups (-OH) may be held. While these various hydroxids, as $\mathrm{KOH}$, are not strictly binary compounds, the unbroken $-\mathrm{OH}$ group acts much like an element and the ending - $i d$ is used for these compounds. This cannot be misunderstood, because potassium hydroxid (for example) plainly indicates the three elements, potassium, hydrogen, and oxygen.

Nore. The meanings of a few word endings and prefixes are noted here for reference: 
The ending -ic means common, as in ferric chlorid $\left(\mathrm{FeCl}_{3}\right)$, and sulfuric acid $\left(\mathrm{H}_{2} \mathrm{SO}_{4}\right)$.

The ending -ous means less, as less chlorin, in ferrous chlorid $\left(\mathrm{FeCl}_{2}\right)$, and less oxygen, in sulfurous acid $\left(\mathrm{H}_{2} \mathrm{SO}_{3}\right)$.

The ending ate means common; usually suggests oxygen, as in sodium nitrate $\left(\mathrm{NaNO}_{3}\right)$.

The ending -ite means less, as in sodium nitrite $\left(\mathrm{NaNO}_{2}\right)$.

The prefix hypo- means still less, as in hyposulfurous acid $\left(\mathrm{H}_{2} \mathrm{SO}_{2}\right)$, or in sodium hyposulfite $\left(\mathrm{Na}_{2} \mathrm{SO}_{2}\right)$.

The prefix per-means more, as in persulfuric acid $\left(\mathrm{H}_{2} \mathrm{~S}_{2} \mathrm{O}_{8}\right)$.

The prefix hydro-means hydrogen and no oxygen, as in hydrochloric acid $(\mathrm{HCl})$.

The ending $-i c$ in the names of acids without the prefix hydro- suggests oxygen, as in sulfuric acid $\left(\mathrm{H}_{2} \mathrm{SO}_{4}\right)$.

The ending $-i d$ is used for binary compounds.

$H y d r o-i c$ acids yield -id salts; other -ic acids yield -ate salts; and -ous acids yield -ite salts.

Hydroxid oxids. We have, not only oxids and hydroxids, but also compounds that are part oxid and part hydroxid, as shown by the structure formulas given in the first column in the following classified list:

$\mathrm{ClOH}$. . . Hypochlorous acid, $\mathrm{HClO}$.

$\mathrm{OClOH}$. $\quad$ Chlorous acid, $\mathrm{HClO}_{2}$.

$\mathrm{O}_{2} \mathrm{ClOH}$. . Chloric acid, $\mathrm{HClO}_{3}$.

$\mathrm{O}_{3} \mathrm{ClOH}$. . Perchloric acid, $\mathrm{HClO}_{4}$.

$\mathrm{S}(\mathrm{OH})_{2}$. . Hyposulfurous acid, $\mathrm{H}_{2} \mathrm{SO}_{2}$.

$\mathrm{OS}(\mathrm{OH})_{2}$ - . Sulfurous acid, $\mathrm{H}_{2} \mathrm{SO}_{3}$.

$\mathrm{O}_{2} \mathrm{~S}(\mathrm{OH})_{2}$. Sulfuric acid, $\mathrm{H}_{2} \mathrm{SO}_{4}$.

$\mathrm{ONOH}$. . Nitrous acid, $\mathrm{HNO}_{2}$.

$\mathrm{O}_{2} \mathrm{NOH}$. . Nitric acid, $\mathrm{HNO}_{3}$.

Here we have an atom of chlorin, sulfur, or nitrogen, one or more oxygen atoms, and also one or more hydroxyl groups, in the same molecule, and the increasing valence of certain elements is illustrated, - that of chlorin from I (in $\mathrm{HCl}$ ) to 3,5 , and 7 , in the compounds shown; that of sulfur from 2 (in $\mathrm{H}_{2} \mathrm{~S}$ and $\mathrm{CS}_{2}$ ) to 4 and 6 , in the compounds here shown; and nitrogen with three and with five bonds.

The formulas, showing both oxid and hydroxid characters, can 
all be derived from the corresponding hydroxids by subtracting water $\left(\mathrm{H}_{2} \mathrm{O}\right)$, thus:

$\mathrm{Cl}(\mathrm{OH})_{3}$ yields $\mathrm{OClOH}$ and $\mathrm{H}_{2} \mathrm{O}$.

$\mathrm{Cl}(\mathrm{OH})_{5}$ yields $\mathrm{O}_{2} \mathrm{ClOH}$ and $2 \mathrm{H}_{2} \mathrm{O}$.

$\mathrm{Cl}(\mathrm{OH})_{7}$ yields $\mathrm{O}_{3} \mathrm{ClOH}$ and $3 \mathrm{H}_{2} \mathrm{O}$.

$\mathrm{S}(\mathrm{OH})_{4}$ yields $\mathrm{OS}(\mathrm{OH})_{2}$ and $\mathrm{H}_{2} \mathrm{O}$.

$\mathrm{S}(\mathrm{OH})_{6}$ yields $\mathrm{O}_{2} \mathrm{~S}(\mathrm{OH})_{2}$ and $2 \mathrm{H}_{2} \mathrm{O}$.

(Sulfur hexahydroxid)

(Sulfuric acid)

(Water)

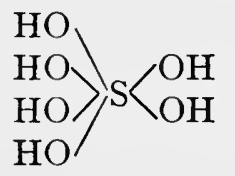

yields $\quad \geqslant \mathrm{O}<\mathrm{OH}$

and

$2 \mathrm{H}_{2} \mathrm{O}$.

Acids, alkalis (bases), and salts. The most important chemical elements may be divided into three great groups:

First, the six metals (iron, aluminum, calcium, magnesium, potassium, sodium); second, the six nonmetals (nitrogen, phosphorus, sulfur, carbon, silicon, chlorin); and, third, the two special elements, oxygen and hydrogen. When combined with oxygen and hydrogen, the six metals form alkaline, or basic, compounds, while the six nonmetals form acid compounds, as shown above.

Alkali and acid are exactly opposite terms. An acid is sour, while an alkali is sweet (chemically speaking). A better expression than sweet is basic, which means the chemical opposite of sour. Thus, if the land becomes sour because of the development of acids in the soil, we may make it sweet by adding a basic substance like calcium hydroxid, $\mathrm{Ca}(\mathrm{OH})_{2}$. This compound is slacked lime. The use of limestone and other forms of lime for correcting soil acidity is fully explained in the following pages.

$\mathrm{Ca}(\mathrm{OH})_{2}$ and $\mathrm{S}(\mathrm{OH})_{6}$ are both hydroxids, but the first is a strong base (or alkali) and the other is a strong acid. When they are brought together, a chemical reaction occurs and the products are neither acid nor basic, but neutral. The sulfur hydroxid $\mathrm{S}(\mathrm{OH})_{6}$ may also be called hexahydroxyl sulfuric acid. It is often written $\mathrm{H}_{6} \mathrm{SO}_{6}$ but it should be borne in mind that, in the structure of the molecule, oxygen is the middle link. If this is heated, or 
made to react with a base, it first loses two molecules of water, as already shown:

$$
\mathrm{H}_{6} \mathrm{SO}_{6}=\mathrm{H}_{2} \mathrm{SO}_{4}+2 \mathrm{H}_{2} \mathrm{O} \text {. }
$$

The compound $\mathrm{H}_{2} \mathrm{SO}_{4}$ is common sulfuric acid, and it reacts with calcium hydroxid in accordance with the following equation:

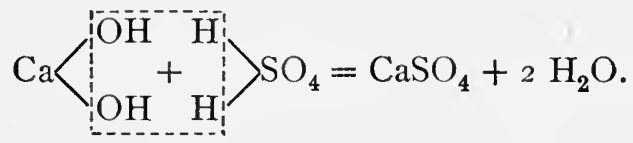

The dotted line shows how the two compounds are broken. The two hydrogen atoms are broken off from the sulfuric acid and the two hydroxyl groups are broken off from the calcium hydroxid, and each hydrogen atom $(\mathrm{H}-)$ immediately joins hands with a hydroxyl group $(-\mathrm{OH})$ and thus are formed two molecules of water, $2(\mathrm{H}-\mathrm{O}-\mathrm{H})$. The bivalent calcium atom $(\mathrm{Ca}=)$ also grasps the two free hands of the radicle $=\mathrm{SO}_{4}$, and forms the compound $\mathrm{CaSO}_{4}$, which is calcium sulfate. Thus, from a base (alkali) and an acid, we have formed water and a neutral salt, neither acid nor alkaline.

This is a typical reaction between a hydroxid acid and a hydroxid base, resulting in the formation of a salt. Many other salts may be formed by similar reactions between basic hydroxids, oxids, or free metals, on the one hand, and different kinds of acids, on the other hand, which may contain oxygen in the form of hydroxid only, or in both hydroxid and oxid form, or the acid may contain no oxygen, but only hydrogen joined directly to some nonmetallic element, as in hydrochloric acid $(\mathrm{HCl})$ or hydrosulfuric acid $\left(\mathrm{H}_{2} \mathrm{~S}\right)$.

Salts are the most abundant and important compounds. The earth's crust consists largely of insoluble mineral salts, called silicates. These are, as a rule, very complex salts, one of the simplest being common felspar, potassium aluminum silicate, $\mathrm{KAlSi}_{3} \mathrm{O}_{8}$. This double salt is the principal source of potassium, one of the essential elements of plant food. Common salt is sodium chlorid, $\mathrm{NaCl}$. Epsom salt is magnesium. sulfate, $\mathrm{MgSO}_{4}$. Glauber salt is sodium sulfate, $\mathrm{Na}_{2} \mathrm{SO}_{4}$. Even limestone is a kind of salt, calcium carbonate, $\mathrm{CaCO}_{3}$.

For convenience, the formulas of salts containing oxygen are 
written with the oxygen in one group, as $\mathrm{Na}_{2} \mathrm{SO}_{4}$, but it may well be remembered that oxygen is regularly the linking element between the metal and the nonmetal, and the structure of the molecule is better shown if written thus:

$$
\begin{aligned}
& \mathrm{Na}-\mathrm{O} \\
& \mathrm{Na}-\mathrm{O}
\end{aligned}>\mathrm{S} \leqslant \mathrm{O} \text { or } \mathrm{Na}_{2} \mathrm{O}_{2} \mathrm{SO}_{2} \text {. }
$$

A few more equations for typical reactions will show the various ways by which salts may be formed. Other similar acids and bases give similar products:

$$
\begin{aligned}
& \mathrm{Ca}(\mathrm{OH})_{2}+\mathrm{H}_{2} \mathrm{SO}_{4}=\mathrm{CaSO}_{4}+2 \mathrm{H}_{2} \mathrm{O} . \\
& \mathrm{KOH}+\mathrm{HNO}_{3}=\mathrm{KNO}_{3}+\mathrm{H}_{2} \mathrm{O} .
\end{aligned}
$$

These equations represent, first, the reaction between the calcium hydroxid and sulfuric acid with the formation of calcium sulfate (gypsum, or land plaster), and, second, the reaction between potassium hydroxid and nitric acid with the formation of potassium nitrate (saltpeter). thus:

In place of a hydroxid base, we may use an oxid of some metal,

$$
\begin{aligned}
& \mathrm{CaO}+\mathrm{H}_{2} \mathrm{SO}_{4}=\mathrm{CaSO}_{4}+\mathrm{H}_{2} \mathrm{O} . \\
& \mathrm{CaO}+2 \mathrm{HNO}_{3}=\mathrm{Ca}\left(\mathrm{NO}_{3}\right)_{2}+\mathrm{H}_{2} \mathrm{O} . \\
& \mathrm{K}_{2} \mathrm{O}+\mathrm{H}_{2} \mathrm{SO}_{4}=\mathrm{K}_{2} \mathrm{SO}_{4}+\mathrm{H}_{2} \mathrm{O} .
\end{aligned}
$$

The salts formed are calcium sulfate, calcium nitrate, and potassium sulfate, and in each reaction only one molecule of water is formed, when the oxid base is used, in place of two molecules of water from the use of a bivalent hydroxid base.

The base may be not only in the form of an oxid or hydroxid of the metal, but we may use the free metal itself as a base, thus:

$$
\begin{aligned}
& \mathrm{Fe}+\mathrm{H}_{2} \mathrm{SO}_{4}=\mathrm{FeSO}_{4}+\mathrm{H}_{2} . \\
& \mathrm{Mg}+\mathrm{HNO}_{3}=\mathrm{Mg}\left(\mathrm{NO}_{3}\right)_{2}+\mathrm{H}_{2} .
\end{aligned}
$$

In these reactions the hydrogen atoms are displaced by the metal and liberated as a gas.

While most acids contain oxygen either as a hydroxid $(\mathrm{ClOH})$ or a hydroxid oxid ( $\mathrm{OClOH}$ or $\left.\mathrm{O}_{2} \mathrm{ClOH}\right)$, a few acids, with the prefix hydro-, contain no oxygen; as, for example, hydrochloric acid 
$(\mathrm{HCl})$; but these acids also react with bases (metals, metallic oxids, or metallic hydroxids), as shown above for the oxygen acids, thus:

$$
\begin{aligned}
& \mathrm{Fe}+2 \mathrm{HCl}=\mathrm{FeCl}_{2}+\mathrm{H}_{2} . \\
& \mathrm{CaO}+2 \mathrm{HCl}=\mathrm{CaCl}_{2}+\mathrm{H}_{2} \mathrm{O} . \\
& \mathrm{NaOH}+\mathrm{HCl}=\mathrm{NaCl}+\mathrm{H}_{2} \mathrm{O} .
\end{aligned}
$$

In these reactions the salts formed are chlorids. The last equation shows the reaction between sodium hydroxid, which is ordinary concentrated lye, a poisonous substance, and hydrochloric acid, which is also a poisonous substance; and the salt formed is sodium chlorid $(\mathrm{NaCl})$, the common table salt, and the most abundant salt of the ocean.

Hydrosulfuric acid $\left(\mathrm{H}_{2} \mathrm{~S}\right)$ also forms many salts, called sulfids, as iron sulfid (FeS), calcium sulfid $(\mathrm{CaS})$, etc.

In all of these reactions the number of pounds of any base required to react with a given amount of any acid is easily and accurately computed, and the amount of the salt to be formed and of the water or hydrogen to be liberated can also be told in advance, if one knows the atomic weights and the equation for the reaction. Thus, 40 pounds of sodium hydroxid will react with 36.5 pounds of hydrochloric acid, and form 58.5 pounds of common salt and I8 pounds of water. It will be seen that 76.5 pounds of materials are used, and that 76.5 pounds of products are formed. In like manner, all such equations must balance. In other words, the number and kind of atoms and the total quantity of materials put into the reaction on one side of the equation must be exactly the same as appear in the products on the other side of the equation.

Acid salts are salts which still contain some of the hydrogen of the acid from which they were made. Thus, if we supply only one half as much potassium as would be required to react with a certain amount of sulfuric acid, if an acid salt is possible, it will be formed:

$$
\mathrm{KOH}+\mathrm{H}_{2} \mathrm{SO}_{4}=\mathrm{KHSO}_{4}+\mathrm{H}_{2} \mathrm{O} \text {. }
$$

The sulfuric acid molecule has two hydrogen atoms, and, to make neutral potassium sulfate, both hydrogen atoms must be replaced with potassium atoms; but in the equation here shown, only one potassium atom is provided. Consequently, only one 
hydrogen atom is replaced by potassium, and the compound formed is acid potassium sulfate $\left(\mathrm{HKSO}_{4}\right.$ or $\left.\mathrm{KHSO}_{4}\right)$. The character of this compound is one half acid and one half salt. If applied to the soil, it would tend to make the soil sour, or acid, which is also true of the common acid phosphate of the fertilizer trade, which is further discussed under phosphorus.

Common acids are so few in number that it is well worth while to memorize the formulas. The following are important in the study of soil fertility:

\begin{tabular}{|c|c|}
\hline $\mathrm{HCl}$. & Hydrochloric acid (no oxygen). \\
\hline $\mathrm{HNO}_{3}$ & Nitric acid. \\
\hline $\mathrm{HNO}_{2}$ & . Nitrous acid (less oxygen). \\
\hline $\mathrm{H}_{2} \mathrm{SO}_{4}$ & . Sulfuric acid. \\
\hline $\mathrm{H}_{3} \mathrm{PO}_{4}$ & - Phosphoric acid. \\
\hline $\mathrm{H}_{2} \mathrm{CO}_{3}$ & Carbonic acid. \\
\hline $\begin{array}{l}\mathrm{H}_{2} \mathrm{SiO}_{3} \\
\mathrm{H}_{2} \mathrm{~S}\end{array}$ & $\begin{array}{l}\text { - Silicic acid. } \\
\text {. Hydrosulfuric acid (no oxygen). }\end{array}$ \\
\hline
\end{tabular}

The salts made from these acids, and their derivatives, by reaction with the bases represented by the six metals (iron, aluminum, calcium, magnesium, potassium, and sodium) constitute, in large part, the solid crust of the earth and the salts of the sea. One nonmetallic oxid $\left(\mathrm{SiO}_{2}\right)$ and two oxids of metallic elements $\left(\mathrm{Fe}_{2} \mathrm{O}_{3}\right.$ and $\mathrm{Al}_{2} \mathrm{O}_{3}$ ) are also found native in very considerable amounts.

Some acids are strong and some are weak. The weakest acid is carbonic $\left(\mathrm{H}_{2} \mathrm{CO}_{3}\right)$, but siliçic $\left(\mathrm{H}_{2} \mathrm{SiO}_{3}\right)$ and hydrosulfuric $\left(\mathrm{H}_{2} \mathrm{~S}\right)$ are also weak acids; while hydrochloric $(\mathrm{HCl})$, nitric $\left(\mathrm{HNO}_{3}\right)$, sulfuric $\left(\mathrm{H}_{2} \mathrm{SO}_{4}\right)$, and phosphoric $\left(\mathrm{H}_{3} \mathrm{PO}_{4}\right)$ are all very strong acids. A strong acid may take a base away from a weak acid, thus:

$$
\mathrm{CaCO}_{3}+\mathrm{H}_{2} \mathrm{SO}_{4}=\mathrm{CaSO}_{4}+\mathrm{H}_{2} \mathrm{CO}_{3} \text {. }
$$

Here we have the strong sulfuric acid reacting with calcium carbonate (limestone) to form a neutral salt, calcium sulfate, and the weak carbonic acid. The carbonic acid is so weak that it may break in two, forming water and carbon dioxid:

$$
\mathrm{H}_{2} \mathrm{CO}_{3}=\mathrm{H}_{2} \mathrm{O}+\mathrm{CO}_{2} \text {. }
$$


Thus we may apply limestone $\left(\mathrm{CaCO}_{3}\right)$ to an acid soil (containing organic acids, silicic acid, or acid silicates), and the soil acids will take the base (calcium), and the liberated carbonic acid will break in two, the gas carbon dioxid $\left(\mathrm{CO}_{2}\right)$ passing out of the soil into the air and thus leaving the soil with no acid in it. 


\section{CHAPTER III}

\section{PLANT FOOD AND PLANT GROWTH}

Oxygen. Oxygen is the most abundant element. It constitutes about one half the sum of all known matter. It forms chemical compounds with nearly all other elements, ${ }^{1}$ and is, in consequence, termed a chemically active element. In the free state $\left(\mathrm{O}_{2}\right)$, it is a gas. In this form it constitutes about 23 per cent of the air. It is thus present everywhere and ready to form compounds with other elements, or to attack other compounds under favorable conditions. The compounds formed with oxygen may at ordinary temperatures be gases, such as carbon dioxid $\left(\mathrm{CO}_{2}\right)$, liquids, such as water $\left(\mathrm{H}_{2} \mathrm{O}\right)$, solids, such as iron oxid $\left(\mathrm{Fe}_{2} \mathrm{O}_{3}\right)$.

All ordinary combustion consists of chemical reaction with oxygen, and the principal products formed are carbon dioxid and water.

Water is eight ninths oxygen, and carbon dioxid is eight elevenths oxygen, as any one can determine for himself if he knows the atomic weights given in Table 2. The grain of corn is nearly one half oxygen ( 46 per cent).

Carbon. This is a very common element, but not very abundant as compared with nine other elements. Even titanium, a tetravalent element belonging to the same periodic group as carbon and silicon, is one half more abundant than carbon in the earth's crust. But titanium has no agricultural value, while carbon is one of the most important elements in the structure of plants and animals. About 45 per cent of the corn kernel is carbon.

Carbon in the free state is the principal element in coal and charcoal. Soft coal (bituminous) contains about 90 per cent of carbon, and hard coal (anthracite) contains about 97 per cent of carbon.

Graphite, the "lead" used in lead pencils, is not lead, but car-

1 No oxygen compounds are known with fluorin, argon, or helium. 
bon. It differs in some manner from the carbon in coal or charcoal, probably because of a different number, or a different arrangement, of the atoms in the molecule.

The diamond is very pure carbon in crystallized form. Both the diamond and ordinary carbon may be converted into graphite, and small diamonds have been made artificially from ordinary carbon.

Free carbon in any form burns with oxygen to form carbon dioxid $\left(\mathrm{CO}_{2}\right)$, but with graphite and the diamond the reaction occurs only at higher temperatures than are necessary with ordinary carbon.

Carbon in the free state has never been liquefied, but it has been volatilized at the temperature of $3500^{\circ}$ Centigrade $\left(633^{\circ}\right.$ Fahrenheit). On the other hand, many of the compounds with carbon are liquids or gases at ordinary temperatures. Examples of liquid compounds are carbon disulfid $\left(\mathrm{CS}_{2}\right)$, benzene $\left(\mathrm{C}_{6} \mathrm{H}_{6}\right)$, and many other hydrocarbons contained in petroleum; while carbon dioxid $\left(\mathrm{CO}_{2}\right)$, methane $\left(\mathrm{CH}_{4}\right)$, and acetylene $\left(\mathrm{C}_{2} \mathrm{H}_{2}\right)$ are well-known gases containing carbon.

In the solid form, carbon occurs not only in the free state, but also in compounds, of which two very important groups are the carbonates and the carbohydrates. Marble, limestone, chalk, and marl are different forms of calcium carbonate $\left(\mathrm{CaCO}_{3}\right)$, one of the few compounds with a molecular weight of Ioo, and thus containing $\mathrm{I} 2$ per cent of carbon, 40 per cent of calcium, and 48 per cent of oxygen. Of these four materials marble is nearly pure calcium carbonate, while the others may be nearly pure or very impure. When calcium carbonate is heated, two bonds are broken and then joined in another way, so that the one compound $\left(\mathrm{CaCO}_{3}\right)$ is broken into two $(\mathrm{CaO})$ and $\left(\mathrm{CO}_{2}\right)$, thus:

$$
\begin{gathered}
\mathrm{Ca}\left\langle{ }_{\mathrm{O}}^{\mathrm{O}}\right\rangle \mathrm{C}=\mathrm{O} \text { becomes } \mathrm{Ca} \gg \mathrm{O}{ }^{\Downarrow} \mathrm{C}=\mathrm{O} \text {, or } \\
\mathrm{CaCO}_{3}=\mathrm{CaO}+\mathrm{CO}_{2},
\end{gathered}
$$

The calcium oxid $(\mathrm{CaO})$ is burned lime, or quicklime, which remains in the kiln; while carbon dioxid $\left(\mathrm{CO}_{2}\right)$ is a gas which passes off into the air. It is easy to see that only $5^{6}$ pounds of quicklime could be made from roo pounds of pure limestone. 
Limestone is a constituent of good soils, and if limestone is not present in a soil, then it should be applied; for, as already explained, carbonic acid is the weakest of all acids, and, consequently, if the soil contains limestone, it cannot be an acid soil, because the soil acids will take the base away from calcium carbonate (and also from any other carbonate), and the liberated carbonic acid is broken up into water and carbon dioxid.

Magnesium carbonate and iron carbonate are found in rock deposits; while potassium carbonate $\left(\mathrm{K}_{2} \mathrm{CO}_{3}\right)$ is the lye (alkali) obtained from wood ashes, and sodium carbonate $\left(\mathrm{Na}_{2} \mathrm{CO}_{3}\right)$ is the most harmful alkali in alkali soils. The carbonic acid is so weak that the carbonates of the strongest bases (potassium and sodium) are almost as basic (alkaline) as the hydroxids of the same elements $(\mathrm{KOH}$ and $\mathrm{NaOH})$.

The term hydrate used in the name of a chemical compound means that it contains water combined with some other constituent, or that hydrogen and oxygen are present in the same proportion as in water $\left(\mathrm{H}_{2} \mathrm{O}\right)$. Thus, carbohydrates contain carbon and water. This very important group of carbon compounds, including sugar, starch, and cellulose (wood fiber) will be explained after hydrogen has been discussed.

Hydrogen. Hydrogen is the third most important element in plants, constituting about 6.4 per cent of the corn kernel. Water is the only abundant source of hydrogen, although the element is found in the earth's crust in appreciable amount, chiefly in hydrated mineral compounds containing, as the name indicates, water in combination with salts. In some cases the combined water corresponds to the amount that might be held in hydroxid form; as, for example, in the abundant mineral called gypsum, or land plaster, which is calcium sulfate crystallized with two molecules of water, $\mathrm{CaSO}_{4}: 2 \mathrm{H}_{2} \mathrm{O}$, or $\mathrm{CaO}_{2} \mathrm{~S}(\mathrm{OH})_{4}$.

Hydrogen in the free state $\left(\mathrm{H}_{2}\right)$ is a gas. From Table I it will be seen that the molecule of hydrogen $\left(\mathrm{H}_{2}\right)$ is lighter than the atom of any other element; and, according to the gas law, a given volume will be filled by the same number of molecules of hydrogen as of any other gas. Consequently, hydrogen gas is the lightest of all known gases, so that a balloon filled with hydrogen easily floats in the atmosphere of nitrogen $\left(\mathrm{N}_{2}\right)$ and oxygen $\left(\mathrm{O}_{2}\right)$, one of which 
is fourteen times, and the other sixteen times, heavier than hydrogen.

At the ordinary temperature, hydrogen and oxygen gases can be mixed together and remain a mixture; but, if heated or ignited, the bonds which hold the atoms in molecules $\left(\mathrm{H}_{2}\right.$ and $\left.\mathrm{O}_{2}\right)$ are broken, and the mixture explodes with terrific force and loud report. The only product of the explosion, or at least of the reaction, is water, $\mathrm{H}_{2} \mathrm{O}$; and, if either gas was present in the mixture in excess of these proportions, the excess remains unchanged. The corn kernel contains 6.4 per cent of hydrogen, or about $97 \frac{1}{2}$ per cent of the three elements, oxygen, carbon, and hydrogen.

Life. The fixation of carbon is the most important process in the growth of plants. By the term fixation is meant the changing of a gas or soluble substance to a solid or insoluble form by means that involve chemical reaction. (The fixation of atmospheric nitrogen, the fixation of soluble phosphorus in soils, and the fixation of potassium and other bases will be explained in the following pages.)

The process known as the fixation of carbon is the more important, because it involves, not only the fixation of carbon itself, but likewise the fixation of both oxygen and hydrogen. Its importance is better appreciated by recalling that these three ele- ments compose about 95 per cent of the entire weight of most agricultural plants or crops. Both the carbon and oxygen utilized in plant growth are derived from the carbon dioxid contained in the air. It is truly remarkable that 90 per cent ( 90 pounds in 100 ) of our common crops must be secured from .04 per cent (4 parts in ro,ooo) of the air.

The fixation of carbon, oxygen, and hydrogen takes place in the green parts of plants. The carbon dioxid enters through the breathing pores ${ }^{1}$ on the under side of the leaf; and the water, composed

${ }^{1} \mathrm{~A}$ breathing pore consists of two guard cells with a slit between them, passing through the outer coat of the leaf. These slits or openings are greatly influenced by the moisture and temperature of the air. In the absence of light they remain closed. When the breathing pores are open, the outside air has free access to the intercellular spaces and passages within the leaf.

The number of breathing pores varies with different plants. About $\mathrm{I} 7,000$ per square inch have been found on oat leaves, 102,000 on corn leaves, and 216,000 per square inch on the leaves of red clover. They are found chiefly on the under side of leaves and on green stems, but sometimes in small numbers on the upper leaf surface and even on underground stems. 
of hydrogen and oxygen, enters the leaf through the stem, having passed from the soil into the plant through the roots.

As the carbon dioxid and water come together within the leaf, a chemical reaction occurs which may be illustrated by the following equation:

$$
\mathrm{H}_{2} \underset{\vdots}{\stackrel{1}{=} \mathrm{O}+\mathrm{O}=} \mathrm{C}=\mathrm{O}=\mathrm{H}_{2} \mathrm{CO}+\mathrm{O}_{2} .
$$

The dotted line shows how the bonds are broken. The two atoms of oxygen that are set free immediately join hands to form a molecule of oxygen $\left(\mathrm{O}_{2}\right)$, which passes from the leaf into the outer air. The two hydrogen atoms $\left(\mathrm{H}_{2}=\right)$ attach themselves to the group, $=\mathrm{CO}$, forming the compound, $\mathrm{H}_{2} \mathrm{CO}$, which may also be written $\mathrm{CH}_{2} \mathrm{O}$, to show its hydrate character, and which might be called monose, but is commonly known as formic aldehyde. This reaction occurs only in the light and only in the presence of active living chlorophyll (the green coloring matter of leaves). In other words, this compound is formed under the influence of life, and by it we enter a new field known as organic chemistry.

Organic matter. Organic matter consists of compounds formed by life processes, - compounds that are, or have been, living matter; whereas, inorganic matter consists of rocks, minerals, and metals, of salts, liquids, and gases, whose origin has no necessary connection with any living substance. Organic matter consists of carbon compounds, ${ }^{1}$ such as hydrocarbons (containing only hydrogen and carbon), fats (containing much carbon and hydrogen with little oxygen), carbohydrates (containing carbon with hydrogen and oxygen in proportion to form water - as the name indicates), and proteids, which contain not only carbon, hydrogen, and oxygen, but also nitrogen, and sometimes phosphorus and sulfur. These are the great groups of organic compounds composing plants and animals. The carbohydrates are the most abundant in plants, while the proteids, although a necessary part of plants, are the most abundant compounds in animals.

Aldehydes and carbohydrates. Formic aldehyde is only one of many aldehydes, which constitute a large class or series of organic compounds. The aldehydes are extremely active substances and

${ }^{1}$ Many of the simpler carbon compounds can be made artificially. 
have power to attack and decompose other substance. Formic aldehyde is often used as a disinfectant, and a 40 per cent solution, known as "formalin," is employed (at the rate of one pound of formalin in $5^{\circ}$ gallons of water) to destroy smut in seed oats, for example.

A remarkable property of the aldehydes is the power of condensation, by which two or more molecules are condensed into one. Thus, two molecules of formic aldehyde, or monose, ${ }_{2} \mathrm{CH}_{2} \mathrm{O}$, may become one molecule of diose, $\mathrm{C}_{2} \mathrm{H}_{4} \mathrm{O}_{2}$; while three molecules may form one of triose, $\mathrm{C}_{3} \mathrm{H}_{6} \mathrm{O}_{3}$; and four may form tetrose, $\mathrm{C}_{4} \mathrm{H}_{8} \mathrm{O}_{4}$; and five, pentose, $\mathrm{C}_{5} \mathrm{H}_{10} \mathrm{O}_{5}$; etc.

The condensation process is so rapid that formic aldehyde itself is found in plants only in very small amount, while the condensation products constitute commonly 80 to 90 per cent of the entire plant. The ending -ose means sugar, and the prefix mon-, di-, tri-, etc., designate the number of carbon atoms in the molecule. The following may illustrate this series of carbohydrates: ${ }^{1}$
$\mathrm{CH}_{2} \mathrm{O}$, monose (formic aldehyde).
$\mathrm{C}_{2} \mathrm{H}_{4} \mathrm{O}_{2}$, diose (unknown).
$\mathrm{C}_{3} \mathrm{H}_{6} \mathrm{O}_{3}$, triose (glycerose).
$\mathrm{C}_{4} \mathrm{H}_{8} \mathrm{O}_{4}$, tetrose (erythrose).
$\mathrm{C}_{5} \mathrm{H}_{10} \mathrm{O}_{5}$, pentose (xylose).
$\mathrm{C}_{6} \mathrm{H}_{12} \mathrm{O}_{6}$, hexose (glucose).
$\mathrm{C}_{12} \mathrm{H}_{24} \mathrm{O}_{12}$, lactose (milk sugar).
$\mathrm{C}_{12} \mathrm{H}_{22} \mathrm{O}_{11}^{\circ}$, sucrose (common sugar).

Here we may see the possible development of the well-known glucose, milk sugar, and common sugar (obtained from sugar cane and sugar beets), as condensation products from monose, or formic aldehyde, formed in the living plant from carbon dioxid and water.

${ }^{1}$ It cannot be considered as absolutely proven that formic aldehyde is always the first product of this fixation process; and, if it is, it seems that the first condensation product results from the union of three molecules, because the compound that might be called diose is not found in plants and is not known to exist.

The known facts are that carbon dioxid is condensed in the leaves of plants and that oxygen is given off in the proportions required for this reaction (aside from the oxygen normally exhaled), also that formic aldehyde is found in plant leaves, that aldehydes have the power of condensation, and that multiples of the formic aldehyde molecule are actually present in plants (as hexose) or represented (as in starch, cellulose, pentosans, etc.). 
It may be noted that cane sugar differs from milk sugar by one molecule of water $\left(\mathrm{H}_{2} \mathrm{O}\right)$. The sugars are a very important group of compounds, but perhaps the starches are a still more important group. Starch $\left(\mathrm{C}_{6} \mathrm{H}_{10} \mathrm{O}_{5}\right)$ appears to differ from glucose $\left(\mathrm{C}_{6} \mathrm{H}_{12} \mathrm{O}_{6}\right)$ by one molecule of water $\left(\mathrm{H}_{2} \mathrm{O}\right)$, but it is known that the starch molecule is not simply $\mathrm{C}_{6} \mathrm{H}_{10} \mathrm{O}_{5}$, but some multiple of this formula, which is best written $\left(\mathrm{C}_{6} \mathrm{H}_{10} \mathrm{O}_{5}\right)_{x}$, in which $x$ stands for the number by which this formula should be multiplied, for as yet $x$ is unknown, although the proportion or percentage of each element in starch is known.

The formula for cellulose (plant fiber) must also be recorded as $\left(\mathrm{C}_{6} \mathrm{H}_{10} \mathrm{O}_{5}\right)_{x}$, but this $x$ may be a different number than the $x$ of the starch molecule.

Growth. Rapidity of growth is related to leaf surface. Sugar, starch, and fiber constitute the great carbohydrate group of plant structure, and their formation is dependent primarily upon the fixation of carbon, with oxygen and hydrogen, in the leaf; and, with all necessary things provided in proportionate amounts, this process goes on in direct proportion to leaf surface. In other words, under perfect conditions, a leaf four inches long will grow four times as much during the day as a leaf only one inch long; and, with sufficient moisture and with plant food provided in abundance, a pasture with the grass kept six inches long will furnish twice as much feed as one with the grass kept down to three inches.

If the foundation principles and the controlling factors in plant growth can be known, then the ideal conditions for crop production may be provided much more nearly than is common. The ideal condition is to provide all controllable factors in such abundance or perfection that the crop yields will be limited only by the sunshine and rainfall. With all other limiting factors removed, the a verage yield of corn in the corn belt would undoubtedly exceed Ioo bushels per acre. (See the records of actual yields, in the following pages.)

Carbon cycle. The carbon cycle includes both the fixation and the liberation of carbon. Animals feed upon plants and plant products rich in carbon compounds, which in part are digested and carried into the blood to meet the oxygen inhaled through the lungs. The carbon is burned, or oxidized, to carbon dioxid, furnishing 
to the animal the energy or heat equivalent to that of ordinary combustion in the furnace, of the same materials; and the carbon dioxid is then thrown off through the lungs into the air, again to become the source of carbon and oxygen for plants. Thus, the fixation of carbon by the plants on the one side, and, on the other, all forms of combustion, including the visible flame, the consumption and oxidation of food by animals, or the oxidation of organic matter in the soil, completes the endless carbon cycle.

But for this carbon cycle, plant growth and crop production would soon cease. A simple computation reveals facts not commonly appreciated:

A column of air one inch square and the height of the atmosphere weighs 15 pounds, which is equivalent to $2 \mathrm{I} 60$ pounds per square foot, or less than 95 million pounds per acre. In ten thousand pounds of average air there is less than four pounds of carbon dioxid $\left(\mathrm{CO}_{2}\right)$ or about one pound of carbon. Consequently, there is less than I0,000 pounds of carbon in the air above one acre of land. In 100 bushels of corn ( 5600 pounds), there are 2500 pounds of carbon. (See Table 2, or compute from the per cent of carbon in starch and fiber, $\mathrm{C}_{6} \mathrm{H}_{10} \mathrm{O}_{5}$.) Thus, the total supply of carbon over an acre of land is only equal to the needs of four such corn crops as are commonly produced on the best-treated corn-belt land in the best seasons, the grain only being considered, or to only two crops, considering both grain and stalks. If, however, only one fourth of the earth's surface is land, if only one fourth of the land is cropped, and if only one fourth of roo bushels is the average crop, then the supply of carbon is sufficient, not for two years only, but for I28 years, which, however, still emphasizes the fact that the carbon cycle makes possible the continuation of plant life on the earth.

A maintenance ration for animals is a supply of food sufficient only to support the animal body in health, to provide food materials for repairing the daily waste, and to furnish energy sufficient to keep the body warm and to maintain the circulation of the blood and other necessary activities. Plants also have some vital processes to provide for, and, to a limited extent, plants are consumers of energy day and night. Food materials are stored by the plant, chiefly to be utilized in subsequent plant development. Thus 
sugars are converted into starch and stored away in roots, tubers, or seeds, to supply the future needs of the same plant or of new plants. At the proper time the plant reconverts the insoluble starch into soluble sugar ${ }^{1}$ and carries it through the circulation to the point of consumption as food by the plant, either for energy, repair, or growth. Food materials are thus consumed or oxidized within the plant, and carbon dioxid is constantly given off from all its living parts, including the roots. During the day the fixation of carbon is commonly so great as to completely mask the liberation of carbon dioxid in the green parts of the plant.

Vegetable fats. Before leaving the subject of the fixation of carbon, oxygen, and hydrogen, some further mention should be made of the group of compounds called fats, whose importance is exceeded only by that of carbohydrates and protein.

The vegetable fats and oils show distinct relationship to a condensation process similar to the formation of sugars and other carbohydrates from formic aldehyde, the photosynthetic product of the reaction between carbon dioxid and water in the leaves of plants. The following series of compounds will show this relationship:

HYDROCARBONS

Fatry acids

$\mathrm{HCH}_{3}$ - Methane

$\mathrm{CH}_{3} \mathrm{CH}_{3}$ - Ethane

$\mathrm{C}_{2} \mathrm{H}_{5} \mathrm{CH}_{3}$ - Propane

$\mathrm{C}_{3} \mathrm{H}_{7} \mathrm{CH}_{3}$ - Butane .

$\mathrm{C}_{4} \mathrm{H}_{9} \mathrm{CH}_{3}$ - Pentane .

$\mathrm{C}_{5} \mathrm{H}_{11} \mathrm{CH}_{3}$ - Hexane

$\mathrm{C}_{6} \mathrm{H}_{13} \mathrm{CH}_{3}$ - Heptane

$\mathrm{C}_{7} \mathrm{H}_{15} \mathrm{CH}_{3}$ - Octane .

$\mathrm{C}_{11} \mathrm{H}_{23} \mathrm{CH}_{3}$ - Dodecane.

$\mathrm{C}_{15} \mathrm{H}_{31} \mathrm{CH}_{3}$ - Hecdecane

Unsaturated .

$\mathrm{HCOOH}-$ Fornic acid.
$\mathrm{CH}_{3} \mathrm{COOH}$ - Acetic acid.

$\mathrm{C}_{2} \mathrm{H}_{5} \mathrm{COOH}-$ Propionic acid.

$\mathrm{C}_{3} \mathrm{H}_{7} \mathrm{COOH}-$ Butyric acid.

$\mathrm{C}_{4} \mathrm{H}_{9} \mathrm{COOH}$ - Valeric acid.

$\mathrm{C}_{5} \mathrm{H}_{11} \mathrm{COOH}-\mathrm{Hexoic}$ acid.

$\mathrm{C}_{6} \mathrm{H}_{13} \mathrm{COOH}-$ Heptoic acid.

$\mathrm{C}_{7} \mathrm{H}_{15} \mathrm{COOH}$ - Octoic acid.

$\mathrm{C}_{11} \mathrm{H}_{23} \mathrm{COOH}$ - Lauric acid.

$\mathrm{C}_{15} \mathrm{H}_{31} \mathrm{COOH}-$ Palmitic acid.

$\mathrm{C}_{17} \mathrm{H}_{35} \mathrm{COOH}$ - Stearic acid.

$\mathrm{C}_{17} \mathrm{H}_{33} \mathrm{COOH}$ - Oleic acid.

$\left\{\mathrm{C}_{17} \mathrm{H}_{31} \mathrm{COOH}-\right.$ Linolic acid.

$\mathrm{C}_{17} \mathrm{H}_{29} \mathrm{COOH}$ - Linolenic acid.

The hydrocarbons, which constitute the simplest series of carbon compounds, are shown for direct comparison with the fatty acid

1 Glucose sugars and sirups are manufactured in large quantities by use of strong acids for converting the starch into glucose. 
series. All of the compounds here illustrated are known. The two series differ only by the - $\mathrm{COOH}$ group in the fatty acid series in place of the $-\mathrm{CH}_{3}$ group in the hydrocarbon series. The $-\mathrm{CH}_{3}$ group is methane from which one hydrogen atom is removed, leaving the radicle $-\mathrm{CH}_{3}$, which is called methyl (one of the alkyl radicles), and acts as a monovalent radicle, replacing one hydrogen atom. It finds a place in many organic compounds, as in ethane $\left(\mathrm{CH}_{3}-\mathrm{CH}_{3}\right)$, butane $\left(\mathrm{CH}_{3}-\mathrm{CH}_{2}-\mathrm{CH}_{2}-\mathrm{CH}_{3}\right)$, etc.

The group, $-\mathrm{COOH}$, is called carboxyl, or the acid group. It may be represented:

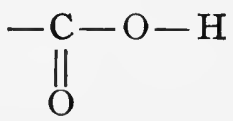

This group also has one free bond and acts as a monovalent radicle. Whenever this group is contained in an organic compound, the compound is an acid. The hydrogen in the hydroxyl part of this group may be replaced by metals, thus forming salts. If the free hand in this carboxyl group is grasped by a hydrogen atom, the compound formed is formic acid, but if methyl $\left(-\mathrm{CH}_{3}\right)$ joins hands with carboxyl $(-\mathrm{COOH})$, the compound formed is acetic acid $\left(\mathrm{CH}_{3} \mathrm{COOH}\right)$, the acid which gives to vinegar its sour taste. When lead $(\mathrm{Pb})$ is used as a base to form a salt with acetic acid by replacing the acid hydrogen of the hydroxyl group, the sourness is destroyed and the salt is known as sugar of lead, or lead acetate, $\left(\mathrm{CH}_{3} \mathrm{COO}\right)_{2} \mathrm{~Pb}$. When the hydroxyl group joins alkyl radicles $\left(-\mathrm{CH}_{3},-\mathrm{C}_{2} \mathrm{H}_{5}\right.$, etc.), alcohols are formed, as methyl alcohol $\left(\mathrm{CH}_{3} \mathrm{OH}\right)$, called wood alcohol, and ethyl alcohol $\left(\mathrm{C}_{2} \mathrm{H}_{5} \mathrm{OH}\right)$, which is common alcohol.

Common glycerin, which is also called glycerol (because it is an alcohol), is an organic compound consisting of a trivalent radicle, called glyceryl, united with three hydroxyl groups, $\mathrm{C}_{3} \mathrm{H}_{5}(\mathrm{OH})_{3}$.

Common animal fats consist chiefly of palmitic, stearic, and oleic acids combined with this radicle, $\equiv \mathrm{C}_{3} \mathrm{H}_{5}$, and the fats themselves are called palmitin, stearin, and olein. The harder fats, like tallow, contain more stearin $\left(\mathrm{C}_{17} \mathrm{H}_{35} \mathrm{COO}\right)_{3} \mathrm{C}_{3} \mathrm{H}_{5}$, while the softer fats, like lard and butter, contain considerable olein, which differs from 
stearin by having two less hydrogen atoms in each acid radicle. By itself, olein is a liquid or oil.

The oil of corn contains about 4 per cent of stearin, 45 per cent of olein, and 48 per cent of linolin, which differs from olein by two hydrogen atoms, and from stearin by four hydrogen atoms, in each acid radicle.

When these fats and oils are heated with a strong base (alkali) such as potassium hydroxid, three potassium atoms displace the glyceryl radicle $\left(\equiv \mathrm{C}_{3} \mathrm{H}_{5}\right)$ and form potassium stearate $\left(\mathrm{C}_{17} \mathrm{H}_{35} \mathrm{COOK}\right)$, potassium oleate $\left(\mathrm{C}_{17} \mathrm{H}_{33} \mathrm{COOK}\right)$, etc.; while the three hydroxyl groups unite with glyceryl to form glycerin, $\mathrm{C}_{3} \mathrm{H}_{5}(\mathrm{OH})_{3}$. The salts formed by potassium or sodium with these fatty acids are what we call soap, the potassium compounds being soft soap, and the sodium, hard soap.

While the fixation of carbon, oxygen, and hydrogen, resulting ultimately in the formation of carbohydrates and fats, is properly considered the most important process in plant growth, we may well remember that no fixation and no growth occur in the absence of the other seven essential elements of plant food. Indeed, from the standpoint of possible control of crop production, another tripod is more important than these three; namely, nitrogen, phosphorus, and limestone.

Nitrogen. This element has received more consideration as plant food than any other essential element. In the free state $\left(\mathrm{N}_{2}\right)$ it is a gas, and in this form it constitutes three fourths of the air. The total supply of nitrogen over each acre of the earth's surface, if available, would meet the needs of a hundred-bushel crop of corn every year for 500,000 years; whereas the supply of carbon is sufficient for such crops for only two years. Nevertheless, carbon has no commercial value as plant food, while nitrogen in available form is worth 15 to 20 cents a pound in the markets. These facts only emphasize the need of science in agriculture.

Nitrogen is not contained in the mineral matter of the earth, but it is a constituent of common organic matter. It is an essential part of the structure of every plant and animal, and is present in all crops and crop residues and, consequently, in the organic matter, vegetable matter, or humus, of the top soil; and it is from the decomposition products of this organic matter that nitrogen is 
furnished to most growing crops, by a process (nitrification) that is more fully explained in the following pages.

Protein. Protein is the general name for organic nitrogen compounds, including the proteids, or final products, and the amids, or intermediate products. The amids and proteids of the protein group might be compared with the sugars and starches (and fibers) of the carbohydrate group in which the sugars are the intermediate form and the starches (and fibers) the more permanent form. Protein always contains nitrogen in addition to oxygen, carbon, and hydrogen.

The chemical reactions involved in the formation of proteids are not yet well understood, although many of the intermediate products (amids) are well known, and some can be made artificially. The amids are especially abundant in young or immature plants, and they are also liberated as intermediate decomposition products. Thus, carbamid, $\mathrm{O}=\mathrm{C}=\left(\mathrm{NH}_{2}\right)_{2}$, which is also called urea, is a common nitrogen compound in urine, the medium by which most of the nitrogen waste is thrown off from the animal body. This compound might be considered as formic aldehyde, or monose $\left(\mathrm{O}=\mathrm{C}=\mathrm{H}_{2}\right)$, in which the two hydrogen atoms are replaced by two amido groups, and the amido group $\left(-\mathrm{NH}_{2}\right)$ may be considered as ammonia in which only two monovalent hydrogen atoms are joined to the trivalent nitrogen atom, thus leaving one free hand by which this group may be attached to other groups or atoms in the building of molecules. The hydroxyl group (-OH) and water $\left(\mathrm{OH}_{2}\right)$, in relation to oxygen, correspond to the amido group $\left(-\mathrm{NH}_{2}\right)$ and ammonia $\left(\mathrm{NH}_{3}\right)$, in relation to nitrogen, and also to the methyl group $\left(-\mathrm{CH}_{3}\right)$ and methane $\left(\mathrm{CH}_{4}\right)$, in relation to carbon. The amido group $\left(-\mathrm{NH}_{2}\right)$ acts as a monovalent radicle, and by replacing hydrogen atoms in various compounds forms new compounds called amids, or amido compounds, and these by condensation or combination with other groups may form the final nitrogenous organic compounds called proteids, which constitute chiefly the flesh (not fat) and vital organs of animals, and the protein of mature plants.

It has been suggested that amido formic aldehyde, $\mathrm{H}_{2} \mathrm{NCHO}$, or amido acetic aldehyde, $\mathrm{CH}_{2}\left(\mathrm{NH}_{2}\right) \mathrm{CHO}$, or aspartic aldehyde (see aspartic acid and asparagin in the following list) may furnish the 
initial molecules whose condensation produces proteids, but this is largely speculative.

The following list illustrates some instructive relationships of important and well-known compounds:

$\mathrm{HCOOH}$, or $\mathrm{H}-\underset{\mathrm{O}}{\mathrm{C}-\mathrm{OH}} \cdot$. . . Formic acid.

$\mathrm{CH}_{3} \mathrm{COOH}$, or $\mathrm{H}_{3}=\mathrm{C}-\mathrm{C}-\mathrm{OH}$. . Acetic acid (the acid in vinegar).

$\mathrm{CH}_{2}\left(\mathrm{NH}_{2}\right) \mathrm{COOH}$. . . . . . Amido acetic acid.

$\mathrm{COOH}$

COOH, or $(\mathrm{COOH})_{2}$. . . . Oxalic acid.

$\mathrm{CH}_{2} \mathrm{COOH}$

।

$\mathrm{CH}_{2} \mathrm{COOH}$. . . . . . . Succinic acid.

$\mathrm{CH}_{2} \mathrm{COOH}$

$\stackrel{\mathrm{CH}}{\mathrm{C}}\left(\mathrm{NH}_{2}\right) \mathrm{COO} \mathrm{H}$

$\mathrm{CH}_{2} \mathrm{CONH}_{2}$

$\stackrel{\mathrm{CH}}{\mathrm{C}\left(\mathrm{NH}_{2}\right) \mathrm{COOH}}$

Amido succinamic acid (the asparagin found in asparagus, in beans and peas, and in many seeds when ger-<smiles>C=CCCCCCCCCCCCCCCCCCCCCCCC</smiles>

Amido succinic acid (the aspartic acid in pumpkin seed, beets, etc.). minating).

$\mathrm{C}_{6} \mathrm{H}_{5}-\mathrm{OH}$

Hydroxy benzene, or phenol (carbolic acid).

$\mathrm{C}_{6} \mathrm{H}_{5}-\mathrm{NH}_{2}$. . . . . . . Amido benzene, or anilin.

$\mathrm{C}_{6} \mathrm{H}_{3}(\mathrm{OH})_{3}$. . . . . . . Trihydroxy benzene, or pyrogallol (pyrogallic acid).

$\mathrm{C}_{6} \mathrm{H}_{3}\left(\mathrm{NH}_{2}\right)_{3}$. . . . . . . . Triamido benzene.

$\mathrm{C}_{10} \mathrm{H}_{14} \mathrm{~N}_{2}$. . . . . . Dipyridyl hexahydrid, or nicotin (the alkaloid of tobacco).

$\mathrm{C}_{17} \mathrm{H}_{21} \mathrm{NO}_{4}$. . . . . . . Morphin (the alkaloid of opium, from the poppy).

$\mathrm{C}_{21} \mathrm{H}_{22} \mathrm{~N}_{2} \mathrm{O}_{2}$. . . . . . . . Strychnin (the alkaloid of nux vomica).

$\mathrm{C}_{240} \mathrm{H}_{892} \mathrm{~N}_{65} \mathrm{O}_{75} \mathrm{~S}_{3}$. . . . . . . Albumen, or the white of egg. (Formula suggested by Schutzenberger ) 
Zein, the most abundant proteid in corn (Zea mays), has the following composition:

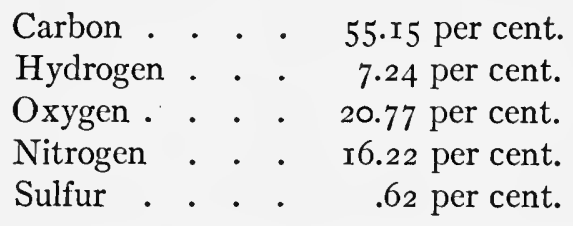

According to this analysis, the molecule of zein might be represented by the following formula:

$$
\mathrm{C}_{230} \mathrm{H}_{362} \mathrm{O}_{65} \mathrm{~N}_{58} \mathrm{~S} \text {. }
$$

Ordinary corn contains I I per cent of protein, of which about one half consists of the proteid zein. This nitrogenous substance has been separated, purified, and investigated with very great care, especially by Chittenden and Osborne (American Chemical Journal (I89I), I 3, 453, 529; (I892), I 4, 20). The percentage composition represents the average of several closely agreeing analyses of what was believed to be very pure zein. Based on the percentage of sulfur, the molecular weight cannot be less than about 5000, and the formula given above or some multiple of it must be approximately correct.

Certainly the proteid molecule is exceedingly complex, and the number of different proteids is very large. They all contain nitrogen, usually about r6 per cent, and some of them contain also sulfur and phosphorus.

Sulfur. This is an essential element for all plants, but the amount required for normal growth and full development is relatively very small, even when compared with the small percentage present in the earth's crust: Most proteids (as zein, for example) contain sulfur, but the percentage is usually very low. It is present, however, in organic combination, and does not give the ordinary tests for sulfates, the form in which it is usually taken from the soil.

Many of the simpler organic compounds of sulfur are well known, and some can be made artificially. The oil of onions and garlic, which gives to those plants their peculiar odor and taste, consists 
chiefly of allyl ${ }^{1}$ sulfid $\left(\mathrm{C}_{3} \mathrm{H}_{5}\right)_{2} \mathrm{~S}$; and mustard oil is also composed of organic sulfur compounds.

Phosphorus. Phosphorus is the Greek word for the morning star, and signifies light. The element phosphorus is closely associated with the beginning of all forms of mortal life. The nucleus of every living cell in plants and animals is rich in phosphorus. Nuclein, the phosphorized nitrogenous constituent of the cellnucleus, contains as high as ro per cent of the element phosphorus, although it may contain no sulfur. The following formula has been suggested by Miescher for nuclein derived from animal cells:

$$
\mathrm{C}_{29} \mathrm{H}_{49} \mathrm{O}_{22} \mathrm{~N}_{9} \mathrm{P}_{3} \text {. }
$$

Lecithin, $\dot{\mathrm{C}}_{44} \mathrm{H}_{90} \mathrm{O}_{9} \mathrm{NP}$, is a well-known organic phosphorus compound, which it is thought may have some controlling influence in the formation of fats and oils. Ordinary corn contains about 5 per cent of oil, of which I.5 per cent consists of lecithin; that is, $I \frac{1}{2}$ pounds of lecithin are found in roo pounds of the oil.

It should be remembered that, while sulfur is contained in many proteids, phosphorus is present in every cell of every plant. The grain or seed of plants contains, as a rule, more than fifty times as much phosphorus as sulfur. The phosphorus of the corn kernel is found largely in the germ. In Iooo pounds of corn there are about Io pounds of germs containing more than two pounds of the element phosphorus. About 95 per cent of the ash obtained from the burning of corn consists of the phosphates of potassium and magnesium. Hay, straw, and other coarse products usually contain more sulfur than the grain, but these coarser parts commonly remain on the farm, while the grain is more likely to be sold.

${ }_{1}^{1}$ The monovalent allyl group $\left(-\mathrm{C}_{3} \mathrm{H}_{6}\right)$ differs from the trivalent glyceryl $\left(\equiv \mathrm{C}_{3} \mathrm{H}_{6}\right)$ only in having a double bond, as shown in allyl alcohol and glycerin (which might also be called glyceryl alcohol):

Allyl alcohol

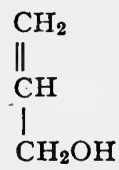

Glycerin

$\mathrm{CH}_{2} \mathrm{OH}$

1

$\mathrm{CHOH}$

1

$\mathrm{CH}_{2} \mathrm{OH}$ 
The proteid of milk, called casein, has the following composition:

\begin{tabular}{|c|c|c|}
\hline arbon . & & \\
\hline Hydrogen & & \\
\hline & & 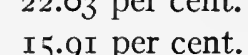 \\
\hline & & .82 per \\
\hline Pho & & .87 per \\
\hline
\end{tabular}

A ton of wheat bran contains about 24 pounds of phosphorus, or 1.22 per cent. About 86 per cent of the total phosphorus in bran is soluble in water, and, according to Patten and Hart (New York State Agricultural Experiment Station Bulletin 250), this water-soluble phosphorus is contained in the salt of an organic acid, which is probably identical with a compound investigated by Posternak, and called by him anhydro-oxymethylene diphosphoric acid, the formula being $\mathrm{C}_{2} \mathrm{H}_{8} \mathrm{P}_{2} \mathrm{O}_{9}$. As determined by Patten and Hart, the complex salt of this acid which constitutes the principal phosphorus compound in wheat bran, has the following composition, as found by the ultimate analysis of the isolated compound:

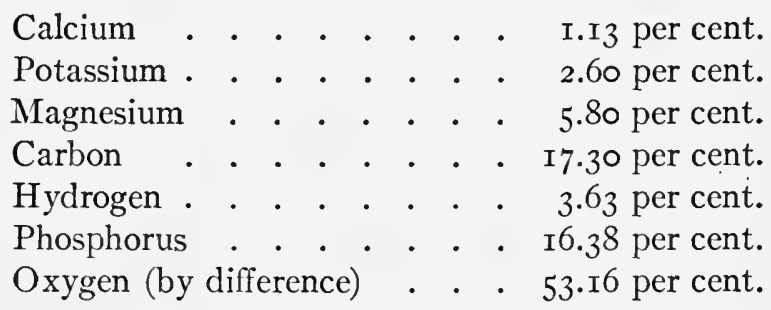

The free acid was found to contain Io.63 per cent of carbon, 3.38 per cent of hydrogen, and 25.98 per cent of phosphorus, which corresponds fairly closely, especially in phosphorus, with the theoretical percentages, which any one can compute for the formula $\mathrm{C}_{2} \mathrm{H}_{8} \mathrm{P}_{2} \mathrm{O}_{9}$.

The mineral part of animal bone consists largely of tricalcium phosphate, $\mathrm{Ca}_{3}\left(\mathrm{PO}_{4}\right)_{2}$, which, when pure, contains 20 per cent of the element phosphorus, as can be easily computed by any one who knows the atomic weights. In Ioo pounds of raw bone are about 
10 pounds of phosphorus. The phosphorus required by animals is, as a rule, supplied in the plants that serve as animal foods.

The percentage of phosphorus in the earth's crust is small when compared with the requirements of plants, especially when we also consider that the phosphorus accumulates in the more concentrated and more salable products, as in the seed or grain, and also in the flesh, bone, and milk, of animals.

Phosphorus is usually taken up by plants in the form of phosphates, but within the plant it enters into organic combination as shown above.

The six elements thus far discussed in some detail - carbon, oxygen, hydrogen, nitrogen, phosphorus, and sulfur - are all nonmetallic. Three of them - oxygen, hydrogen, and nitrogen - are gases in the free state, and the other three - carbon, phosphorus, and sulfur-are nonmetallic solids. Four other elements are also absolutely essential to the growth of all agricultural plants.

Potassium and magnesium. These are metallic elements which have very important functions in plant growth and which are required in considerable amounts. Both are stored in the seed in relative abundance, and are found in the ash of grains in the form of phosphates, although still larger amounts of potassium are stored in the coarser parts of plants (as in straw, cornstalks, etc.).

It is not known that potassium and magnesium are essential constituents of protoplasm, but, like nitrogen and phosphorus, they are found in largest proportions in the embryo tissues. It is suggested that one of their essential functions may be as carriers of nitrogen and phosphorus in the form of definite salts (as nitrates and phosphates) capable of reaction with certain products resulting from the fixation of carbon, oxygen, and hydrogen. Certainly it is not sufficient that phosphorus, for example, shall merely be carried in the form of some soluble phosphate into the laboratory (the leaf) of the plant, but the compound must be such that the metallic base will release the phosphorus at the proper time, in order that it may enter the organic combination and thus become a part of the living organism.

It is known that organic acids are developed by the plant with which potassium and other bases carried into the plant in the form of nitrates, phosphates, etc., may unite, and do unite, at some time 
during the life of the plant; for some of the potassium that enters the plant roots as nitrates, phosphate, or sulfate is afterward found in the plant in organic salts, as tartrate (in grapes), oxalate (in sorrel), etc. There appears to be little or no evidence that any living organic compounds of potassium or magnesium exist.

It is the common belief that potassium has large influence over the formation of carbohydrates; but the information is not sufficient to determine whether this influence is direct or very indirect, as in maintaining the general health of the plant by having some absolutely necessary part in reactions involving the transference of nitrogen or phosphorus from inorganic compounds to the living organic combination.

The potassium contained in plants is in large part very easily removed by leaching with water, and hence peaty swamp soils consisting largely of organic matter are frequently very deficient in potassium. While potassium and magnesium are required by plants in very considerable amounts, as stated, and as shown in Table 2, yet, when measured by the average composition of the earth's crust and by average crop requirements, the supply of these two elements is very great.

Calcium and iron. These elements are absolutely essential to the normal growth and development of all agricultural plants, but for the grain crops the amounts positively necessary are so extremely small and the quantities present in the earth's crust are so extremely large that it is rarely that either calcium or iron is furnished to such plants in amounts insufficient to perform their essential functions, except, of course, when they are artificially withheld, as in investigational work. Legume plants are a very marked exception, however, so far as calcium is concerned.

Iron evidently has some important connection, direct or indirect, with the formation of chlorophyll (the green coloring matter of leaves); for, if iron is withheld from the plant, the leaves do not become green, and if later iron is supplied, the chlorophyll soon begins to develop. On the other hand, analysis has shown that the chlorophyll itself does not contain iron, and the somewhat common assumption that the green color of plants is due to the presence of iron compounds of that color is incorrect.

The iron held in nuclein compounds is not dissolved out by dilute 
hydrochloric acid, - a fact which indicates that the iron is a constituent of the living matter of plants. Animals also have a small but absolute requirement for iron.

Aside from oxygen, iron is the most abundant essential plantfood element, constituting about $4 \frac{1}{2}$ per cent of the solid crust of the earth, although the amount required by plants is very insignificant. Thus, the earth contains more than 40 times as nuch iron as phosphorus, while the corn kernel contains nearly 40 times as much phosphorus as iron, so that the supply of phosphorus would be depleted as much by the removal of roo crops as the supply of iron would be by 160,000 crops.

While a very small supply of calcium is of vital importance, considerable amounts of that element are commonly taken up and deposited in the coarser parts of plants, as in straw, cornstalks, and hay, and large supplies of calcium are required for legumes, especially for clover and alfalfa. This larger use of calcium appears to be due, especially in grain crops, to its power as a base to unite with organic acids that might otherwise injure the plant; and the salts formed are commonly deposited, not in the seed or with stored food materials, but in the older tissues as inert matter.

The common use of certain calcium compounds, such as burned lime and ground limestone, for correcting soil acidity should not be confused with the essential need of the element calcium as plant food. Even strongly acid soils often contain abundance of the elcment calcium for plant food, not in the form of carbonates, but in silicates, which, however, have no power to correct soil acidity.

Aluminum, silicon, sodium, chlorin, and manganese. These elements are not known to be essential to plant growth, but they are commonly found in plants, although the amount of manganese is very small and that of aluminum still smaller.

The opinion that silicon was essential and gave stiffness to the straw of cereals is not correct, and the report that manganese exerts a marked stimulating action on plant growth has not been verified upon more thorough investigation. Sodium is now known to be a nonessential, but there is still a possible question regarding chlorin. According to Pfeffer, "it remains for precise researches to determine whether a minimal amount is essential, or whether chlorin simply favors growth under special cultural çonditions." 
Common functions. Some common functions may be performed by several elements. Thus, if there is need for a base to correct an excess of acid that has developed in the plant, sodium may serve as well as potassium, although with enough potassium provided, no sodium is needed. As already stated, the largest use of calcium appears to be in this line, in which, perhaps, manganese, magnesium, or iron might serve equally well if they were present in the plant in sufficient amount. Likewise, in solvent compounds, chlorin may serve as well as nitrogen or phosphorus, but cannot take their place in living tissue.

We shall also consider in the following pages the value to plants of certain materials when applied to certain soils, which serve not as plant food, but rather as soil stimulants, having power to liberate from the soil some essential plant-food element more rapidly than it would otherwise become available - an action that may result in temporary profit and ultimate land ruin. Caustic lime, salt, gypsum (land-plaster), and, under certain conditions, commercial fertilizers, and even farm manure, clover, and green manures, may act in part, at least, as soil stimulants; and, to guard against such injurious action, practice must be controlled by science (knowledge). 


\section{CHAPTER IV}

\section{THE EARTH'S CRUST}

NEARLy 98 per cent of the solid crust of the earth consists of silicates of the six metals, aluminum, iron, calcium, potassium, sodium, and magnesium (in this order of relative abundance); and the remainder is largely composed of the closely related titanates.

Silicon. Silicon in the mineral matter constituting the earth's crust corresponds to carbon in the organic matter of the vegetable and animal kingdoms. In all of the great groups of organic compounds the molecule is built up by the linking power of the fourhanded carbon atom, as, for example, in the hydrocarbon, hexane $\left(\mathrm{C}_{6} \mathrm{H}_{14}\right)$ :

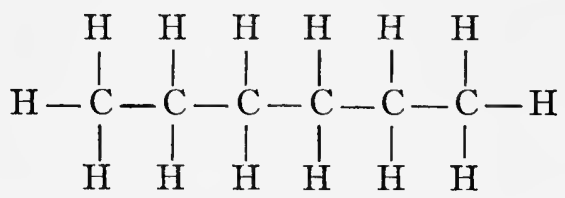

Silicon is the second member of the carbon group ${ }^{1}$ in the periodic system, as shown on page $\mathrm{II}$, and its linking power is also very great, although alternating with oxygen and metals and restricted mainly to silicates. Thus, instead of the almost unlimited number of hydrocarbons, carbohydrates, and other numerous compounds of carbon, hydrogen, and oxygen (alcohols, fats, organic acids, etc.), there are but four such silicon compounds known: $\mathrm{SiH}_{4}, \mathrm{SiO}_{2}$, $\mathrm{OSi}(\mathrm{OH})_{2}$ or $\mathrm{H}_{2} \mathrm{SiO}_{3}$, and $\mathrm{Si}(\mathrm{OH})_{4}$ or $\mathrm{H}_{4} \mathrm{SiO}_{4}$, which differs from silicon dioxid by two molecules of water.

${ }^{1}$ A most interesting compound is $\mathrm{SiC}$, silicon carbid, so-called carborundum, formed by the union of the two tetravalent elements and, next to the diamond, one of the hardest known substances. 
The numerous natural polysilicates (poly-means many) composing granite and most other rocks of the earth's crust are salts of polysilicic acids, although the acids themselves are not known to exist free from the basic elements or radicles. The following may illustrate a few of the possible combinations, the last three being known only in salts in which bases appear in place of the acid hydrogen:

Silicon dioxid, $\mathrm{SiO}_{2}$. . . $\mathrm{O}=\mathrm{Si}=\mathrm{O}$.

Metasilicic acid, $\mathrm{H}_{2} \mathrm{SiO}_{3}$. $\mathrm{O}=\mathrm{Si}=(\mathrm{OH})_{2}$.

Orthosilicic acid, $\mathrm{H}_{4} \mathrm{SiO}_{4} \cdot \quad \cdot(\mathrm{HO})_{2}=\mathrm{Si}=(\mathrm{OH})_{2}$.

Disilicic acid, $\mathrm{H}_{2} \mathrm{Si}_{2} \mathrm{O}_{5}$. . . $\mathrm{HO}-\mathrm{Si} \equiv \mathrm{O}_{3} \equiv \mathrm{Si}-\mathrm{OH}$.

Polysilicic acid, $\mathrm{H}_{4} \mathrm{Si}_{3} \mathrm{O}_{8}$. $(\mathrm{HO})_{2}=\mathrm{Si}=\mathrm{O}_{2}=\mathrm{Si}=\mathrm{O}_{2}=\mathrm{Si}=(\mathrm{OH})_{2}$.

$\left.\begin{array}{c}\text { Polysilicic } \\ \text { acid, } \mathrm{H}_{4} \mathrm{Si}_{4} \mathrm{O}_{10}\end{array}\right\}(\mathrm{HO})_{2}=\mathrm{Si}=\mathrm{O}_{2}=\mathrm{Si}=\mathrm{O}_{2}=\mathrm{Si}=\mathrm{O}_{2}=\mathrm{Si}=(\mathrm{OH})_{2}$.

Among the most common mineral compounds found in granite is ordinary felspar, or orthoclase, or potassium aluminum polysilicate, $\mathrm{KAlSi}_{3} \mathrm{O}_{8}$, or $\left(\mathrm{KAlSi}_{3} \mathrm{O}_{8}\right)_{2}$, whose structural formula may be represented thus:

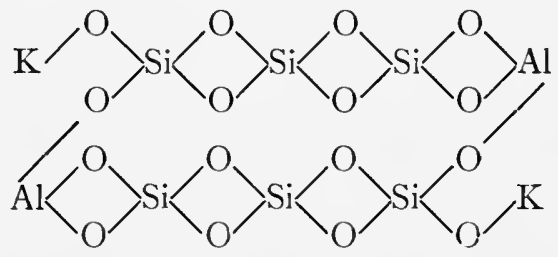

This is sufficient to illustrate what is meant by polysilicates. Other silicates differ from the common felspar by the substitution of other elements for potassium or aluminum or both, and also by different proportions of the various constituents, as:

Orthoclase (potassium felspar) . . . $\mathrm{KAlSi}_{3} \mathrm{O}_{8}$. Albite (sodium felspar) . . . . . $\mathrm{NaAlSi}_{3} \mathrm{O}_{8}$.

Anorthite (calcium felspar) . . . . . . $\mathrm{CaAl}_{2} \mathrm{Si}_{2} \mathrm{O}_{8}$.

Crysolite (magnesium iron silicate) . . $\mathrm{MgFeSiO}_{4}$.

In some cases hydroxyl groups are included, and when such compounds are heated, two hydroxyl groups are broken, leaving one oxygen atom in their place, thus yielding water and anhydrous 
silicate. Silicates from which water can be separated are called hydrated silicates or, sometimes, acid silicates:

Steatite (soapstone) . . . . . . . $\mathrm{Mg}_{6} \mathrm{Si}_{4} \mathrm{O}_{13}(\mathrm{OH})_{2}$.

Kaolin (clay) . . . . . . . . $\mathrm{Al}_{2} \mathrm{Si}_{2} \mathrm{O}_{5}(\mathrm{OH})_{4}$.

Commonly, the silicates of the earth's crust are more or less mixed, so that samples of pure compounds are rarely, if ever, found in native state. Following are the results of analysis of specimens of orthoclase, kaolin, and steatite as found in nature:

\section{Table 3. Percentage Composition of Silicates}

\begin{tabular}{|c|c|c|c|c|c|c|c|c|c|c|}
\hline \multicolumn{8}{|c|}{ Constituents } & \multirow{2}{*}{$\begin{array}{c}\text { ORTHOCLASE } \\
\text { (PotASSIUM } \\
\text { FELSPAR) }\end{array}$} & \multirow{2}{*}{$\frac{\left.\text { KaOLIN }_{\text {(C,AY }}\right)}{.34}$} & \multirow{2}{*}{$\begin{array}{c}\begin{array}{c}\text { STEATITE } \\
\text { (SOAPSTONE) }\end{array} \\
.27\end{array}$} \\
\hline Potassium & . & . & . & . & & & . & & & \\
\hline Magnesium & & . . & - & - & & & - & .04 & .07 & I 5.43 \\
\hline Calcium & . & . . & . & & & & . & .24 & .II & $2.3^{2}$ \\
\hline Iron . & - & - & • & - & & & • & trace & .55 & 9.15 \\
\hline Silicon . & - & - & & - & & & • & 30.89 & 22.87 & I9.9I \\
\hline Aluminum & & & & & & & & 9.84 & I9.59 & 3.22 \\
\hline Sodium . & & & & & & & - & .93 & .03 & .12 \\
\hline Water of $h$ & $\mathrm{ydr}$ & ation & • & • & & & . & & I 2.83 & 8.45 \\
\hline Oxygen, et & & .. & - & . & & & . & 46.42 & 43.61 & 4I.I3 \\
\hline
\end{tabular}

While the samples of orthoclase and kaolin were fairly pure, the steatite contained other metals aggregating almost as much as the magnesium.

Granite and gneiss. These are among the most common rocks, the former being of igneous or eruptive origin, while gneiss is essentially the same material in sedimentary stratified form. In other words, when granite has been disintegrated by the action of heat and cold, rain and frost, has been transported by wind and flowing water, has been redeposited in strata over river bottoms, or ocean beds, and has become reformed into compact masses by the cementing action of acids, alkalies, or salts, it is then called gneiss. Gneiss is one of the oldest stratified rocks, and was formed chiefly previous to the beginning of plant or animal life on the earth.

Granite and gneiss consist principally of the four mineral groups, felspar, hornblende, mica, and quartz. Of these the felspar group 
has already been discussed. The hornblendes (or amphiboles) include certain white or light-colored silicates of calcium and magnesium, often with fibrous structure, of which common asbestos is a good example; also silicates of aluminum, magnesium, and iron, of darker colors, green or black. The micas include light-colored or transparent potassium aluminum silicates and black silicates of aluminum, magnesium, and iron. While the hornblendes are often fibrous, the micas, as a rule, are easily split in to the well-known mica sheets.

Quartz. Quartz, when pure, is crystallized silicon dioxid $\left(\mathrm{SiO}_{2}\right)$, but it is often colored by small amounts of metallic compounds. Aside from being a common constituent of granite and gneiss and of many other less abundant silicate rocks, quartz is often found in rock masses or seams in a nearly pure state. Quartz sand is not uncommon, but the opinion that sand and quartz are synonymous terms is very incorrect, for sand usually includes very considerable amounts of granite or gneiss and other mineral particles.

The following statement shows the composition of common samples of original granite, fresh gneiss, and decomposed gneiss; also the percentage of each constituent saved from the fresh gneiss and found in the decomposed gneiss, as computed by Merrill, ${ }^{1}$ assuming no loss of aluminum, which indicates a total loss of 44.67 per cent of the original rock. They serve only as illustrations, and other samples may vary greatly from these.

Table 4. Percentage Composition of Rock

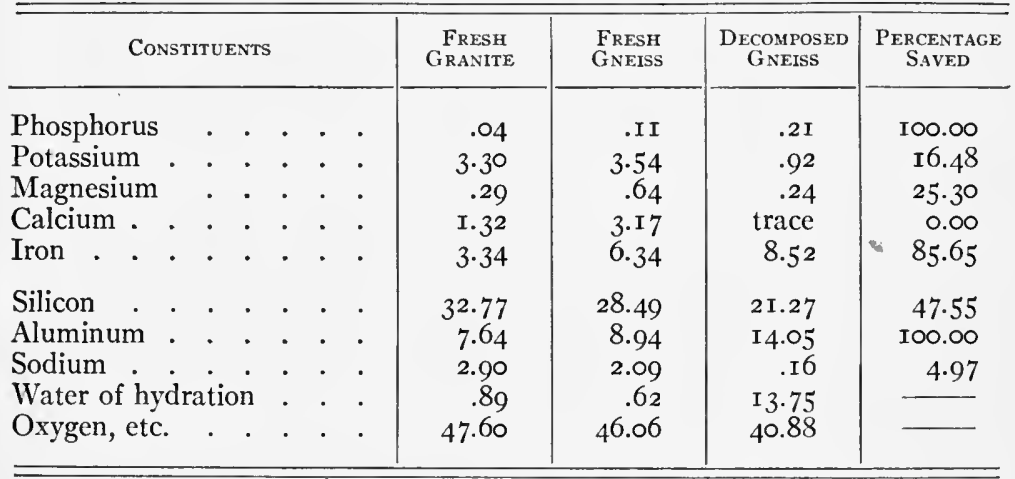

1 “ Rocks, Rock Weathering, and Soils," IS97, p. 2 I5. 
Gneiss may contain constituents not always present in granite, because of admixture of other materials in transportation; also certain constituents are likely to be lost to some extent in the original disintegration and transportation, and to a great extent in the subsequent more complete decomposition, so that often certain constituents may show higher percentages in the final residue.

Zeolites. Zeolites are formed from partially decomposed minerals, like granite and gneiss. They are hydrated double silicates of aluminum with calcium or sodium, and may contain other bases, especially potassium. They are credited with important functions in soils to which further reference will be made.

Shale, kaolin, and clay. These materials consist chiefly of hydrated aluminum silicate related to the mineral kaolinite, $\mathrm{Al}_{2} \mathrm{Si}_{2} \mathrm{O}_{5}(\mathrm{OH})_{4}$, and representing in part the final residue from the decomposition of felspar, hornblendes, micas, etc., from granite, gneiss, and other silicate rocks. They may be grouped under the general term argillites (from argil, meaning potter's clay). Slate is the wellknown roofing material. Shale is the term applied to the more thinly stratified formations which disintegrate more or less readily when exposed to the weather. Kaolin is common fire clay. Ordinary brick clay belongs in the same group, and, in fact, shale itself is often ground and used for making brick or tile.

Aluminum silicate is the final residue from the disintegration of many different rocks, and consequently is itself one of the most permanent substances. The oldest records of man have been preserved in burnt clay, both in tablets and in pottery.

Carbonates. The carbonates include a very important group of rocks, although they constitute a small portion of the earth's crust when compared with the silicates. Of the carbonates, the common limestone, calcium carbonate, $\mathrm{CaCO}_{3}$, is by far the most abundant. It is frequently quite impure. Marble is calcium carbonate, mottled or colored with impurities and of sufficiently close texture to admit of polishing. The mineral calcite is very pure crystallized calcium carbonate, $\mathrm{CaCO}_{3}$. Magnesian limestone (dolomite) is a double carbonate of calcium and magnesium, $\mathrm{CaMg}\left(\mathrm{CO}_{3}\right)_{2}$, but this compound is frequently mixed with calcium carbonate, $\mathrm{CaCO}_{3}$, so that varying percentages of calcium and magnesium are found in dolomitic limestone. 
Most limestone deposits are marine formations, and frequently consist largely of shells, but this is not always the case. Small amounts of calcium carbonate are found in many other stratified rocks.

Impure limestones containing silicate minerals may lose, by weathering and leaching, practically all of the calcium carbonate or magnesium carbonate which they originally contained and leave a residue free from carbonates, as shown by the following analyses:

Table 5. Composition of Fresh limestone and its Resideal Clay

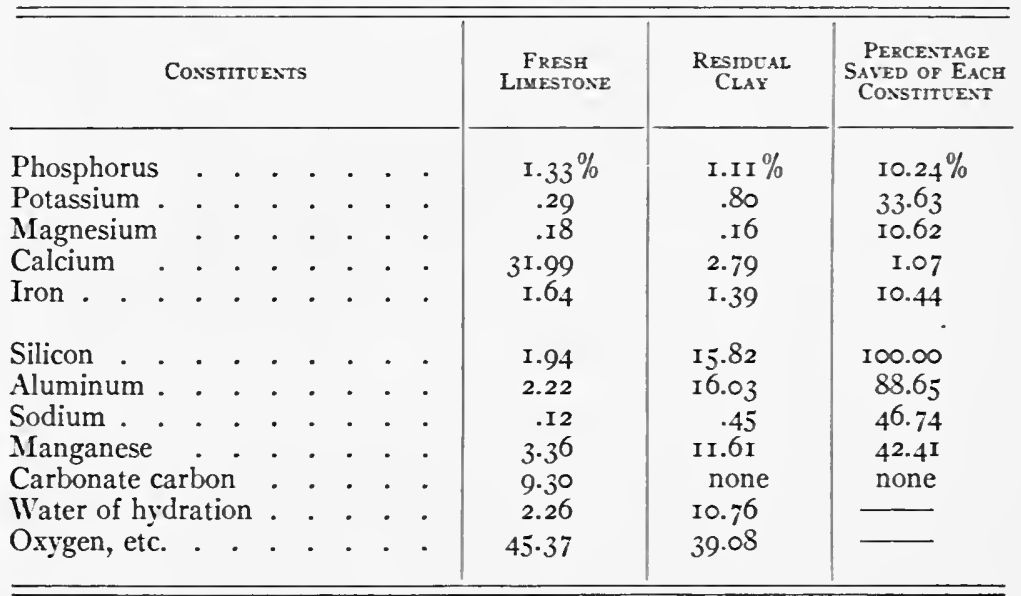

Penrose ${ }^{1}$ presents convincing eridence that this peculiar manganese clay was derived from impure limestone, and Merrill ("Rocks, Rock Weathering, and Soils," I897, pp. 232, 233) computes that more than 93.6 per cent of the original rock was lost during the processes of decomposition, weathering, and leaching, assuming no loss of silicon. While these analyses represent very satisfactorily the general results of rock weathering, it must not be assumed that the representation is exact in all details. In minor constituents the sample of rock taken for analysis may vary greatly from the particular rock stratum of which the sample of clay was the residue, and the loss by leaching of the same constituent may also vary greatly in different rocks. Thus, in the decomposition of the

${ }^{1}$ Arkansas Geological Survey, Annual Report for I890, p. I79. 
more common rocks (see Table 4 ) the loss of potassium and sodium is very great, while most of the iron and phosphorus is likely to be found in the residue.

Sulfates. Natural sulfates are confined chiefly to hydrated calcium sulfate, $\mathrm{CaSO}_{4}\left(\mathrm{H}_{2} \mathrm{O}\right)_{2}$ or $\mathrm{CaO}_{2} \mathrm{~S}(\mathrm{OH})_{4}$, containing about I8.6 per cent of sulfur and more than 20 per cent of water of hydration. This is the mineral called gypsum. It occurs in numerous deposits, at various depths, and sometimes extends over hundreds of square miles, as in northern Ohio. Under the name of land-plaster this mineral has been used very extensively in places as a soil stimulant. Traces of calcium sulfate are found in most limestones and in some other rocks.

Sulfids. The sulfids of iron are widely distributed in nature. Iron disulfid, $\mathrm{FeS}_{2}$, is commonly known as pyrite, also called " fool's gold," because of its glitter and yellow color. One form of iron disulfid decomposes quite readily when exposed to air and moisture, and yields ferrous sulfate, $\mathrm{FeSO}_{4}$, as one of the products.

Phosphates. These occur in small amount in connection with many other rocks and minerals, principally in the form of calcium phosphate, $\mathrm{Ca}_{3}\left(\mathrm{PO}_{4}\right)_{2}$, specifically called tricalcium phosphate, when mentioned in connection with the artificial dicalcium phosphate, $\mathrm{Ca}_{2} \mathrm{H}_{2}\left(\mathrm{PO}_{4}\right)_{2}$, or monocalcium phosphate, $\mathrm{CaH}_{4}\left(\mathrm{PO}_{4}\right)_{2}$.

Granite commonly contains a trace of phosphorus, and in gneiss about . I per cent of phosphorus is found as an a verage, corresponding to ro pounds of calcium phosphate ( 2 pounds of phosphorus) in one ton of gneiss. Limestones also contain calcium phosphate, as a rule. While the amount is usually less than $\mathrm{r}$ per cent, some quite extensive deposits of phosphatic limestone exist which contain from ro to 30 per cent of tricalcium phosphate. In places where such rocks have been long exposed near the surface, the calcium carbonate has been largely removed by leaching, so that the remaining porous rock may contain as high as 75 per cent of the phosphates of calcium, iron, and aluminum, in which the calcium compound, $\mathrm{Ca}_{3}\left(\mathrm{PO}_{4}\right)_{2}$, greatly predominates (as in the Tennessee brown rock phosphate).

There are also some natural deposits of compact calcium phosphate rock, varying in purity from about 40 to 80 per cent (as the Tennessee blue rock phosphate). These deposits of phosphate 
and of phosphatic limestone show evidence of living organisms having been connected with their origin, as in limestone shells and bony skeletons.

Apatite is crystallized calcium phosphate, containing small amounts of calcium chlorid or calcium fluorid. This mineral is largely found in masses, but traces of it are found in nearly all other rocks, whether of igneous or aqueous formation.

Oxids. Oxids of silicon, iron, and aluminum are more or less abundant and distributed almost universally, in quartz $\left(\mathrm{SiO}_{2}\right)$ and quartz sand, in the iron ore, hematite $\left(\mathrm{Fe}_{2} \mathrm{O}_{3}\right)$, and in the aluminum ore, bauxite $\left(\mathrm{Al}_{2} \mathrm{O}_{3}\right)$ and $\left(\mathrm{Fe}_{2} \mathrm{O}_{3}\right)$.

Other deposits. Various other deposits found naturally in the earth, but constituting extremely small percentages of the earth's crust, include common rock salt $(\mathrm{NaCl})$; potassium salts, as carnallite $\left(\mathrm{KClMgCl}_{2} 6 \mathrm{H}_{2} \mathrm{O}\right)$; and kainit $\left(\mathrm{K}_{2} \mathrm{SO}_{4} \mathrm{MgSO}_{4} \mathrm{MgCl}_{2} 6 \mathrm{H}_{2} \mathrm{O}\right)$, from which potassium chlorid $(\mathrm{KCl})$ and potassium sulfate $\left(\mathrm{K}_{2} \mathrm{SO}_{4}\right)$, respectively, are separated; saltpeter $\left(\mathrm{KNO}_{3}\right)$, and Chile saltpeter or sodium nitrate $\left(\mathrm{NaNO}_{3}\right)$; also the extensive deposits of anthracite and bituminous coal, the former consisting of nearly pure carbon, while the latter contains considerable amounts of hydrocarbon compounds in addition to the free carbon. 


\section{CHAPTER V}

\section{SOIL FORMATIONS AND CLASSIFICATIONS}

Residual soils. Residual soils are those that are formed in place from the disintegration of rocks. They consist of the least soluble decomposition products, which often constitute but a small proportion of the original rock. Thus a limestone containing 80 per cent of calcium carbonate and 20 per cent of impurities (as polysilicates, etc.) may weather to a soil composed entirely of the impurities from which the calcium carbonate has been completely removed by leaching, and the polysilicates may have partially broken down into acid silicates, zeolites, clay, oxids of silicon and iron, etc.

Transported soils. These are also formed from disintegrated and partially decomposed rock, but instead of remaining in the place previously occupied by the rock, they have been transported, and often retransported, by various agencies (materials from many sources sometimes being mixed together), and finally deposited in the places which they now occupy. Wind, water, and glaciers are the chief carrying agencies.

Glacial material (bowlder clay) is characterized by the presence of worn or rounded stones, varying in size from sand grains to bowlders, embedded in silty clay. While glacial drift covers extensive areas in northern United States, sometimes to a depth of 100 feet or more, the glacial material is covered in many areas by a deposit of loess, ${ }^{1}$ varying in depth from a few inches to several feet.

Loess is characterized in part by the absence of pebbles. It consists largely of silt, with some very fine sand and but little clay. It has been transported by wind, as a rule, and in places is found in high elevations and even overlying residual soiłs, but in deep loess deposits, as in the bluffs along the Mississippi and other large streams, evidences are found of some transportation by water.

1 This word is taken directly from the German (like sauerkraut) and pronounced like less, with the lips protruded as in whistling. Similarly, the English word beefsteak has been adopted into the German language. 
Alluvial soils are the common formation in river valleys and other lowlands that receive deposits of material washed from the higher lands.

Soil materials. Soil materials consist of stones, gravel, sand, silt, clay, and organic matter. The term clay, as correctly used, is applied to the material that gives to certain soils their sticky, plastic property, including hydrated aluminum silicate and other plastic substances, in part reduced probably to the molecular state of division and without granular character, although most so-called "clay" contains more or less undecomposed, or but partially decomposed, mineral particles. Silt includes a grade of particles that are smaller than sand, impalpable in fact, but still granular as seen through the microscope, and not plastic when free from clay.

Soil types. Soil types are based largely upon the relative proportion of these several soil materials, as may be noted by inspection or determined by mechanical analysis. The following general groups are recognized:

Table 6. Solls: General Groups

\begin{tabular}{|c|c|c|}
\hline $\begin{array}{l}\text { NUMBER } \\
\text { LIMITS }\end{array}$ & Group Names & DESCRIPTION \\
\hline o to 9 & Peat soil . . & With 25 to 75 per cent or more of organic matter. \\
\hline Io to 12 & Peaty loam . & Io to 25 per cent of organic matter with loam. \\
\hline I 3 to 14 & Muck . . . & Io to 25 per cent of organic matter with much clay. \\
\hline I 5 to I9 & Clay . . . & Plastic clay predominating. \\
\hline 20 to 24 & Clay loam . & Much clay with loam. \\
\hline 25 to 49 & Silt loam . . & Much silt with loam. \\
\hline 50 to 59 & Loam . . . & $\begin{array}{l}\text { Sand, silt, clay, and organic matter with neither } \\
\text { markedly predominating. }\end{array}$ \\
\hline 60 to 79 & Sandy loam . & Much sand with loam. \\
\hline 80 to 89 & Sand $\cdot \cdot$. & Sand without much silt or clay. \\
\hline 90 to 94 & Gravelly loam & Gravel with loam. \\
\hline 95 to 97 & Gravel . & Gravel without much silt or clay. \\
\hline $98-\cdots$ & Stony loam . & Stones with loam. \\
\hline $99-$ & Rock outcrop & Disintegrating rock. \\
\hline
\end{tabular}


Table 7. Some Recognized Soll Types

\begin{tabular}{|c|c|c|c|}
\hline No. & Name & No. & Name \\
\hline I & Deep peat. & 32 & Light gray silt loam on tight \\
\hline 2 & Medium peat on clay. & & clay. \\
\hline 2.r & Medium peat on clayey sand. & 32.1 & White silt loam on tight clay. \\
\hline 2.2 & Medium peat on sand. & 33 & Gray-red silt loam on tight \\
\hline 2.3 & Medium peat on rock. & & clay. \\
\hline 3 & Shallow peat on clay. & 34 & Yellow-gray silt loam. \\
\hline 3.1 & Shallow peat on clayey sand. & $34 . I$ & Yellow-gray silt loam on \\
\hline 3.2 & Shallow peat on sand. & & tight clay. \\
\hline $3 \cdot 3$ & Shallow peat on rock. & 35 & Yellow silt loam. \\
\hline IO & Peaty loam on clay. & 35.1 & Yellow silt loam on tight clay. \\
\hline IO.I & Peaty loam on clayey sand. & 35.2 & Yellow silt loam on clay. \\
\hline ro.2 & Peaty loam on sand. & $35 \cdot 3$ & Yellow silt loam on sand. \\
\hline 10.3 & Peaty loam on rock. & $35 \cdot 4$ & Yellow silt loam on gravel. \\
\hline I3 & Muck on clay. & $35 \cdot 5$ & Yellow silt loam on rock. \\
\hline I3.I & Muck on clayey sand. & 50 & Black loam. \\
\hline $\mathrm{r} 3.2$ & Muck on sand. & 50.I & Black loam on clay. \\
\hline I $3 \cdot 3$ & Muck on rock. & $5 \mathrm{I}$ & Brown loam. \\
\hline 15 & Drab clay. & $5 \mathrm{r} . \mathrm{I}$ & Brown loam on clay. \\
\hline I 5.1 & Sandy drab clay. & $5 \mathrm{I} .2$ & Brown loam on silt. \\
\hline $\mathrm{I} 5.2$ & Gravelly drab clay. & 51.3 & Brown loam on sand. \\
\hline r6 & Gray clay. & $5 \mathrm{I} .4$ & Brown loam on gravel. \\
\hline 20 & Black clay loam. & 51.5 & Brown loam on rock. \\
\hline 20.I & Sandy black clay loam. & 52 & Gray loam. \\
\hline 20.2 & Gravelly black clay loam. & 53 & Yellow loam. \\
\hline $2 \mathrm{I}$ & Drab clay loam. & 54 & Mixed loam. \\
\hline $2 \mathrm{I} . \mathrm{I}$ & Drab clay loam on sand. & 60 & Brown sandy loam. \\
\hline 22 & Gray clay loam. & 60.1 & Brown sandy loam on silt. \\
\hline 25 & Black silt loam. & 60.2 & Brown sandy loam on sand. \\
\hline 25.1 & Black silt loam on clay. & 60.4 & Brown sandy loam on gravel. \\
\hline 26 & Brown silt loam. & 60.5 & Brown sandy loam on rock. \\
\hline 26. I & Brown silt loam on clay. & $6 I$ & Mixed sandy loam. \\
\hline 26.2 & Brown silt loam on sand. & 62 & Brown fine sandy loam. \\
\hline 26.3 & Brown silt loam on till. & 63 & Light brown fine sandy loam. \\
\hline 26.4 & Brown silt loam on gravel. & 64 & Yellow fine sandy loam. \\
\hline 26.5 & Brown silt loam on rock. & 65 & Gray fine sandy loam. \\
\hline 27 & Brown silt loam over gravel. & 80 & River sand. \\
\hline 28 & Brown-gray silt loam on & $8 I$ & Dune sand. \\
\hline & tight clay. & 82 & Beach sand. \\
\hline 29 & Drab silt loam. & 90 & Gravelly loam. \\
\hline 29.1 & Drab silt loam on clay. & 95 & Gravel. \\
\hline 30 & Gray silt loam on tight clay. & 98 & Stony loam. \\
\hline $3^{\mathrm{r}}$ & Deep gray silt loam. & 99 & Rock outcrop. \\
\hline
\end{tabular}


The soil strata are commonly classed as top soil and subsoil, and in the name of a soil type the character of the top soil is indicated, and also that of the subsoil if it is peculiar or markedly different from the top soil. In the detail soil survey of Illinois conducted by the State Experiment Station, which now covers about thirty counties, or one third of the state, the preceding soil types have been recognized and mapped, and records are kept under the numbers and names given.

The system of numbering (similar to the Dewey library system) is flexible, and permits additions of main types or related types (by decimals), and the name is designed to carry with it a definite suggestion of the character of the soil.

Note to Chapter VI. - In considering the subject of sulfur, as discussed in the following pages, the reader's attention is called to the fact that recent investigations show soils and plants to contain considerably more sulfur than was indicated by most of the analyses formerly reported, part of the sulfur having been lost in the older methods of analysis (as suggested on page 64). On the other hand, where this larger amount of sulfur is found in plants, it is not known to be required, but more probably is merely tolerated by the plant. It is safe to conclude that a plant requires all the sulfur it contains only when it is grown on a soil in which sulfur is the element which limits the growth, so that the addition of more sulfur would increase the yield.

In the author's opinion, the fact that sodium nitrate is usually more valuable than ammonium sulfate, and that bone meal in continued use gives as good or better results than acid phosphate (containing calcium sulfate), justifies the conclusion that sulfur deserves no more consideration than is hereinafter given to it. (Note the results from plots $\mathrm{A} \mathrm{r}$ and $\mathrm{N} \mathrm{r}$ in Table 66, plots 5 and 6 in Table 68, plots 5 and $\mathrm{I}_{7}$ in Table 70 , and plots $\mathrm{N}_{\mathrm{I}}$ and $\mathrm{A} \mathrm{I}_{1} \mathrm{~N}_{3}$ and $\mathrm{A}_{3}$, and $\mathrm{N} 8$ and A 8 , in Table $7 \mathrm{I}$ B. Also compare plots $6,9,10,17$, and 19 with plots 12 and 35, in Table 80.)

It may be stated that, in addition to the sulfur contained in the soil and in addition to the known amount brought to the soil in rain, there is an unknown amount absorbed by the soil directly from the atmosphere, owing to the presence of sulfur oxids and sulfur acids in the air (as products of the combustion of wood, grass, coal, etc.) and to the movement of the air into and out of the pores of the soil with the changes in barometric pressure and wind velocity. 


\section{CHAPTER VI}

\section{SOIL COMPOSITION}

\section{Soils in General}

Aside from the organic matter, any soil material (excepting quartz sand, but including granitic sand) will commonly contain all of the elements found in ordinary silicate rocks, but, of course, in very varying proportions. Soils contain large amounts of silicon and much aluminum and sodium, none of which are essential to plant growth, also very large amounts of oxygen, an element which as plant food is supplied in the carbon dioxid taken into the plant through the leaves. This means that about 85 per cent of the solid crust of the earth has no value as plant food. This includes not only silicon dioxid (as quartz sand), aluminum silicate (as pure clay), and aluminum sodium polysilicates, but also these elements when present in other combinations.

The remaining abundant elements, iron, calcium, magnesium, and potassium, are all essential as plant food. Of these four, iron is the most abundant in the earth and the least abundant in plants, and, so far as the writer is aware, soil has never been known to become deficient in iron as measured by crop requirements.

Calcium and magnesium are somewhat less abundant than iron, and are required by crops in very much larger amounts, and on some soils crop yields are appreciably increased by the application of one or both of those elements in suitable compounds, but in many or most such cases the increase in crop yields is not due to the direct effect of the calcium or magnesium as plant food, but rather to the indirect effect their compounds may produce in increasing the availability of other less abundant plant-food elements.

In the average crust of the earth, potassium is slightly more abundant than magnesium but less abundant than iron or calcium. Of these four elements, potassium is required by plants in greatest 
amount, but nevertheless the total supply of potassium in nearly all soils is exceedingly large compared with crop requirements; and, while it has a money value in commercial fertilizers and is quite extensively used, there is much evidence to show that on many soils the influence which it produces is due in part at least to indirect effects, as in the liberation of other more deficient plantfood elements.

Sulfur and phosphorus are not in the same class with the eight abundant elements composing the silicates; and between these two elements there are also marked differences, since sulfur is brought to the earth in rain in considerable amounts and is also about as abundant as phosphorus in the earth's crust, while crops require from three to ten times as much phosphorus as sulfur.

If we disregard the three elements which agricultural plants obtain from the air and water (in $\mathrm{CO}_{2}$ and $\mathrm{H}_{2} \mathrm{O}$ ), as being in large measure beyond our control, we may secure a clear conception of the relative abundance of the remaining essential plant-food elements, based both upon the most original natural supplies and upon crop requirements, by a study of Table 8 .

Table 8., Relative "Supply and Demand" of Seven Elements

\begin{tabular}{|c|c|c|c|c|c|c|c|}
\hline Essential & Plan & T-FOOD & Elements & & $\begin{array}{l}\text { POUNDS IN } 2 \text { MIL- } \\
\text { LION OF THE } \\
\text { AVERAGE CRUST } \\
\text { OF THE EARTH }\end{array}$ & $\begin{array}{l}\text { POUNDS IN } \\
\text { I0O BUSHELS } \\
\text { OF CoRN } \\
\text { (Grain only) }\end{array}$ & $\begin{array}{c}\text { NUMBER OF } \\
\text { YEARS' SUPPLY } \\
\text { INDICATED } \\
\text { (See Table 2) }\end{array}$ \\
\hline $\begin{array}{l}\text { Phosphorus } \\
\text { Potassium } \\
\text { Magnesium } \\
\text { Calcium } \\
\text { Iron . } \\
\text { Sulfur . }\end{array}$ & $\begin{array}{l}\cdot \\
\cdot \\
\cdot \\
\cdot \\
\cdot\end{array}$ & $\begin{array}{ll}\cdot & \cdot \\
\cdot & \cdot \\
\cdot & \cdot \\
\cdot & \cdot \\
\cdot & \cdot \\
\cdot & \cdot\end{array}$ & $\begin{array}{lll}\cdot & \cdot & \cdot \\
\cdot & \cdot & \cdot \\
\cdot & \cdot & \cdot \\
\cdot & \cdot & \cdot \\
\cdot & \cdot & \cdot \\
\cdot & \cdot & \cdot\end{array}$ & - & $\begin{array}{r}2200 \\
49200 \\
48000 \\
68800 \\
88600 \\
2200\end{array}$ & $\begin{array}{l}\text { I } 7 \\
\text { I } 9 \\
7 \\
\text { I } \frac{1}{4} \\
\frac{1}{2} \\
\frac{1}{4}\end{array}$ & $\begin{array}{r}130 \\
2600 \\
7000 \\
55000 \\
200000 \\
10000\end{array}$ \\
\hline Nitrogen in & air & . . & . . . & & $\begin{array}{l}70 \text { million } \mathrm{lb} \text {. } \\
\text { over one acre }\end{array}$ & 100 & 700000 \\
\hline
\end{tabular}

Two million pounds correspond to the weight of the plowed soil of an acre of average land to a depth of $6 \frac{2}{3}$ inches (counting 300,000 pounds per acre inch), so that the supply of the plant-food elements given in Table 8 is simply what would be contained in an acre of 
plowed soil if it represented the average composition of the solid crust of the earth. Corn is the most important American crop, and the common farm practice is to retain on the farm the cornstalks (stover), so that the plant food removed in the grain is of the greatest consideration.

While there is probably no cultivated soil whose composition is exactly the same as the average of the earth's crust, and while roo bushels of corn per acre is about four times the average yield for the United States, nevertheless the data given in Table 8 present the broadest possible conception of the great problem of soil fertility in relation to permanent agriculture; because all soils are made essentially from the earth's crust, and, if some are richer, others are certainly poorer, than this general average. Likewise the roo-bushel yield of corn is of immediate interest, for it has been produced, - and can be produced throughout the corn belt in normal seasons with good farming on the richest and best-treated soils; and the production of large yields is an essential consideration, both from the standpoint of profitable farming and for the future support of a rapidly increasing population.

There are natural agencies which may operate under different conditions to enrich, deplete, or maintain the fertility of the soil.

In the formation of residual soils from the leaching of disintegrating and decomposing rock materials, as illustrated in Tables 4 and 5, the percentage of a given plant-food element may increase or decrease or remain constant, depending upon whether the compound in which that element occurs is proportionately less or more soluble than the bulk of the material. Thus in the decomposition of gneiss (Table 4), it is evident that the alkali bases, as potassium, magnesium, calcium, and sodium, were leached out much more rapidly than the iron, aluminum, silicon, and phosphorus; and consequently the per cent of phosphorus doubled and the per cent of potassium and magnesium markedly decreased, while the calcium practically disappeared. On the other hand, in the formation of residual clay from limestone (Table 5), the per cent of phosphorus decreased distinctly and the per cent of calcium very greatly, while most of the elements in the silicate minerals, including potassium and sodium, very markedly increased in percentage. 
In level upland areas, such as the loess-covered prairies of the Central West, which neither receive deposits from overflow nor lose partially depleted soil by erosion (especially while covered by prairie grasses), the operation of the natural laws tends steadily toward soil depletion, with respect to the valuable mineral elements; and this law has been in operation since the glacial age, or since the loess was deposited, wherever the climatic conditions have been similar to those prevailing in historic time. Thus we find (as hereinafter shown) that the oldest glacial or loessial soils (as in the lower Illinoisan glaciation) are markedly poorer in total phosphorus, potassium, magnesium, and calcium than are the similarly formed soils of more recent formation (as in the late Wisconsin glaciation). With some elements the difference is most marked in the surface soil, and with others in the subsoil.

The accumulation of organic matter in the glacial or loessial soil begins sometime after its deposition and continues until a maximum is reached, after which the organic matter, as well as the valuable mineral elements, tends to decrease, the latter because of leaching, as from the beginning, and the former because the rate of decay finally exceeds the rate of growth or accumulation. Ultimately, under these natural processes, the level lands would become practically barren. All of the level upland soils of southern Illinois were far past the maximum in productive power when this country was first settled. Indeed, much of the land of central and northern Illinois was past the maximum and tending toward depletion. Probably the black clay loam soil of the flat prairie lands in the Wisconsin glaciation was almost at its maximum condition of productiveness when the White Man took possession, but even the soil of this topography (drab silt loam)was far past its prime in the lower Illinoisan glaciation.

In some of the Southern states there are still to be found level upland virgin soils that are known, as a class, to be too unproductive to justify cultivation. The author has collected representative samples of this class of virgin gray silt loam soils that were found upon analysis to contain less than 400 pounds of total phosphorus in 2 million pounds of surface soil, while the subsoil of adjoining moderately productive slopes contained I500 pounds of phosphorus. The carbonates of calcium and magnesium have entirely 
disappeared from these level upland soils, and in their place marked acidity has developed. Under these conditions the growth of vegetation and the fixation of nitrogen by legumes become very limited, and level virgin soil, not subject to erosion, was found to contain less than one fifth as much as the average nitrogen content of the black clay loam of the late Wisconsin glaciation in northern Illinois.

In the progress of geologic time, surface drainage courses are developed, and all level uplands become eroded hills and valleys, thus exposing the lower subsoils with their larger supplies of unleached mineral plant food, more or less of which is spread out over the lower lying slopes or level bottom lands, which sometimes again become depleted, as broad terraces above the deepened channel.

Thus, moderate soil erosion is not an unmixed evil; and, with no adequate return of mineral plant food, the bottom lands and the sloping hill lands are more permanently productive (with legumes made prominent in the crop rotations) than are the level upland soils. It is doubtful if there has ever been a land on the face of the earth, where the same soil particles have been turned with the plow year after year, that has remained productive for two centuries, with no return of mineral plant food. Even in populous China there are many level upland areas, sometimes of a hundred square miles in extent, where no one lives; and the restoration of these areas has been called the "Problem of China."

"In nature all things are in equilibrium" is often stated as though it were a self-evident fact. So far as the soil is concerned, the opposite is essentially true, - that, in nature, there is no equilibrium. Thus an ancient forest land now lies from to to 300 feet beneath the Illinois black prairie, which covers the unweathered glacial drift of the most southern lobe of the Wisconsin glaciation.

It is of first importance that the man who controls land, and who is thus responsible for its future productive power, should have sufficient fundamental knowledge concerning the composition of common soils and the plant-food requirements of common staple crops to furnish him a foundation of absolute facts on which to build possible systems of permanent agriculture. Because of this need, considerable space is devoted to the ultimate composition of soils as they exist on the earth to-day. 
First, in comparison with the average composition of the earth's crust, and as a good basis of comparison for all other soils, let us consider the total nitrogen, phosphorus, and potassium in the unmanured land on the Rothamsted Experiment Station at Harpenden, England. In 2 million pounds ( $6 \frac{2}{3}$ inches per acre) of the surface soil where a four-year crop rotation of wheat, turnips, barley, and clover (or beans) has been followed for 60 years, there are found, in round numbers, 2500 pounds of nitrogen, rooo pounds of phosphorus, and 35,000 pounds of potassium. These are numbers worth keeping in mind.

In Table 9 is given the composition of four different soils, of which two (from Holland and Scotland) are extremely productive, and the other two (from Germany and Maryland) are nonproductive soils from barren lands.

The first is an analysis by Baumhauer of a fertile alluvial soil near the Zuider Zee, and the second is Anderson's analysis of rich wheat soil of Midlothian.

The third analysis, by Johnson, is said to represent "the most sterile soil in Bavaria," and the last, by Veitch, represents the "barrens" of southern Maryland.

Table 9. Composition of Solls

Pounds in 2 Million (per Acre about $6 \frac{2}{3}$ Inches Deep)

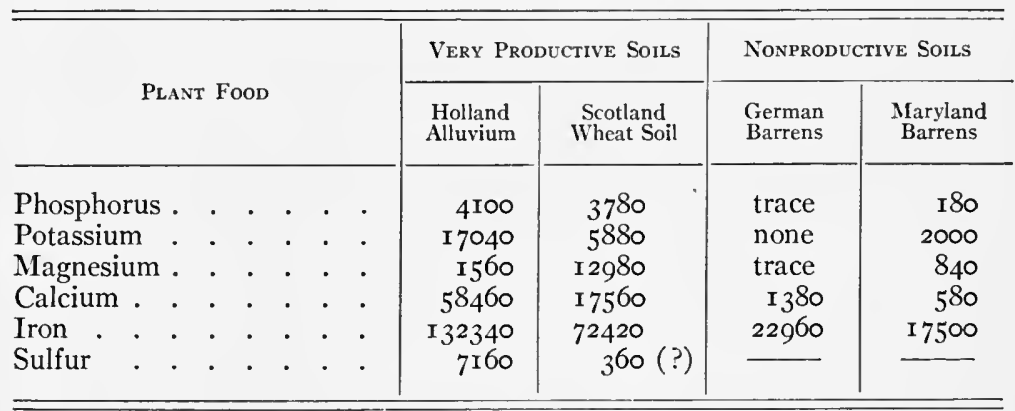

These analyses are given to show that the supply of plant food in the soil is sometimes the great factor of difference between productive and nonproductive land; but the fact should not be overlooked that in other cases other factors may also be important (as excess or deficiency of moisture, poor physical condition, 
absence or inactivity of soil organisms, or the presence of injurious substances).

Compared with the average crust of the earth (Table 8), these two fertile soils are both characterized by their high phosphorus content. The Holland soil is low in magnesium, and the Scotland soil is low in potassium, when compared with the earth's crust, although when compared with the phosphorus supply and with crop requirements, a somewhat different view is presented. It is fair to raise the question whether the sulfur reported for the Scotland soil represents the total or only the nonvolatile,-because this soil contained more than ro per cent of organic matter, and it is now known that most of the sulfur may be lost in the ignition of such a soil.

The analysis of the German soil reports "insoluble silicates," and probably the amounts given are for plant food soluble in strong acid, but Veitch's analysis of the Maryland soil represents total amounts, determined by the fusion process. It will be seen that the Holland soil contains eight times as much potassium, twentythree times as much phosphorus, and a hundred times as much calcium as the Maryland soil.

The first requisite for a good soil is that it shall be rich in plant food, but it should always be remembered that that provision alone does not insure large crops, nor does a large stock of goods in the merchant's store to-day insure a good business for him to-morrow.

In this connection, we may refer to the analysis of residual clay from slightly phosphatic limestone, shown in Table 5 , with I. I per cent of phosphorus, which amounts to 22,200 pounds, or more than I I tons, of phosphorus per acre in a $6 \frac{2}{3}$-inch stratum of 2 million pounds' weight. Other soils abnormally high in phosphorus are found in the phosphate regions of Tennessee and Central Kentucky. Thus, Mooers (Tennessee Bulletin 78 ) reports the analysis of an upland soil and a bottom-land soil, from near Pulaski, Giles County, Tennessee, showing $\mathrm{I}_{3}, 200$ and $\mathrm{I}_{4}, 800$ pounds, respectively, of phosphorus per acre in a $6 \frac{2}{3}$-inch stratum ( 2 million pounds); and analyses by Peter and A veritt (Kentucky Bulletin I 26) show I 2,100 pounds and 12,400 pounds of phosphorus in 2 million pounds of the surface and subsurface, respectively, of soil from 
near Midway, Woodford County, Kentucky, and I 5,330 pounds and 14,800 pounds of phosphorus in 2 million pounds of surface soil from two fields near Tebb's Station, Clark County, Kentucky.

On the farm of the Kentucky Agricultural Experiment Station at Lexington, Fayette County, the surface soil contains I $5, \infty 00$ pounds of phosphorus per acre in a $6 \frac{2}{3}$-inch stratum, and the lower subsoil contains 100,000 pounds of phosphorus in 2 million of earth. In other words, the lower subsoil between 40 and 80 inches contains, as an a verage, about 5 per cent of the element phosphorus, equivalent to 25 per cent of tricalcium phosphate. Notwithstanding the occasional existence of such abnormal soils, the more common soils even of Kentucky and Tennessee, outside of the limestone or phosphate regions, are very deficient in phosphorus.

Four samples of residual limestone soils from tobacco plantations about 35 miles southwest of Havana, Cuba, were found to contain as an average 4790 pounds of acid-soluble phosphorus in 2 million pounds of soil. (Frear, Penn. Report, I90I.)

In Table 10 is shown the composition of adobe soil from New Mexico and " the characteristic red earth from the decomposition of coralline limestone on the Islands of Bermuda" (Merrill).

Table io. Composition of Adobe and Coral limestone Solls

Pounds in 2 Million of Soil (per Acre about $6 \frac{2}{3}$ Inches Deep)

\begin{tabular}{|c|c|c|c|c|c|c|c|c|c|c|}
\hline \multicolumn{9}{|c|}{ Constituents } & \multirow{2}{*}{$\begin{array}{c}\text { Adobe Sorl, } \\
\text { New Mexico } \\
\begin{array}{r}8200 \\
28600\end{array}\end{array}$} & \multirow{2}{*}{$\begin{array}{c}\begin{array}{c}\text { Coral Limestone SoIL } \\
\text { Bermud IsLandS }\end{array} \\
\begin{array}{c}5400 \\
2000\end{array}\end{array}$} \\
\hline $\begin{array}{l}\text { Phosphorus } \\
\text { Potassium }\end{array}$ & $\begin{array}{l}\cdot \\
\cdot\end{array}$ & & . & . & . & $\dot{.}$ & $\begin{array}{l}\cdot \\
\cdot\end{array}$ & . & & \\
\hline $\begin{array}{l}\text { Magnesium } \\
\text { Calcium . } \\
\text { Iron . . } \\
\text { Sulfur . } .\end{array}$ & $\begin{array}{ll}\cdot & \cdot \\
\cdot & \cdot \\
\cdot & \cdot \\
\cdot & \cdot\end{array}$ & $\begin{array}{l}\dot{ } \\
\dot{.}\end{array}$ & $\begin{array}{l}\dot{ } \\
\dot{.}\end{array}$ & $\begin{array}{l}\dot{.} \\
\dot{.}\end{array}$ & . & i. & $\begin{array}{l}\dot{.} \\
\dot{.}\end{array}$ & $\dot{.}$ & $\begin{array}{r}35600 \\
198800 \\
71600 \\
5200\end{array}$ & $\begin{array}{r}5800 \\
50200 \\
172400 \\
\end{array}$ \\
\hline $\begin{array}{l}\text { Silicon . } \\
\text { Aluminum } \\
\text { Sodium } \\
\text { Chlorin } \\
\text { Manganese }\end{array}$ & $\begin{array}{ll}\cdot & \cdot \\
\cdot & \cdot \\
\cdot & \cdot \\
\cdot & \cdot \\
\cdot & \cdot\end{array}$ & $\begin{array}{l}\dot{.} \\
\dot{.} \\
\dot{.}\end{array}$ & $\begin{array}{l}\dot{ } \\
\dot{.} \\
.\end{array}$ & $\begin{array}{l}\dot{ } \\
\dot{.} \\
\dot{ } \\
\dot{ }\end{array}$ & $\begin{array}{l}\dot{ } \\
\dot{ } \\
\dot{ } \\
\dot{ } \\
\dot{ }\end{array}$ & $\begin{array}{l}\dot{ } \\
\dot{ } \\
\dot{ } \\
\dot{ }\end{array}$ & $\begin{array}{l}\dot{.} \\
\dot{.} \\
\dot{.} \\
\dot{ }\end{array}$ & $\begin{array}{l}\dot{ } \\
\dot{.} \\
\dot{.} \\
\dot{.}\end{array}$ & $\begin{array}{r}419200 \\
\text { I } 39600 \\
8800 \\
2800 \\
2000\end{array}$ & $\begin{array}{r}376800 \\
145600 \\
80 \\
\end{array}$ \\
\hline $\begin{array}{l}\text { Carbonate ca } \\
\text { Water of hyd } \\
\text { Volatile } \\
\text { Oxygen, etc. }\end{array}$ & $\begin{array}{l}\text { arbon } \\
\text { dration } \\
. \quad \cdot \\
. \quad\end{array}$ & . & $\dot{.}$ & $\begin{array}{l}\dot{.} \\
\dot{.}\end{array}$ & $\begin{array}{l}\dot{ } \\
\dot{.} \\
\dot{.}\end{array}$ & $\begin{array}{l}\dot{ } \\
\dot{.} \\
\dot{.}\end{array}$ & $\begin{array}{l}\dot{ } \\
\dot{.} \\
\dot{.}\end{array}$ & $\dot{.}$ & $\begin{array}{r}46600 \\
76800 \\
68600 \\
887600\end{array}$ & $\begin{array}{r}12300 \\
324600 \\
224200 \\
680780\end{array}$ \\
\hline
\end{tabular}


These abnormal soils are likewise characterized by a high phosphorus content. The coral soil is also abnormal in its extremely low potassium content, when compared with ordinary soils.

Leather reports the average acid-soluble phosphorus of the "black cotton soils" of India as 520 pounds in 2 million of soil, and the analyses of eighteen other types of Indian soils show the phosphorus as varying from a "trace" to 790 pounds; while among the other four types described by him, one abnormal soil (essentially an iron ore) contained 34 . Io per cent of iron and .28 per cent of phosphorus, corresponding to 5600 pounds of phosphorus per acre in a $6 \frac{2}{3}$-inch stratum.

Von Ugrimor's analyses ${ }^{1}$ of the cultivated " black earth " soil of southwest Russia shows only 260 pounds of acid-soluble phosphorus in 2 million of soil; while Hilgard ${ }^{2}$ gives . 3 per cent of $\mathrm{P}_{2} \mathrm{O}_{5}$, corresponding to I 30 pounds of phosphorus in 2 million of cultivated soil, and .I4 per cent of $\mathrm{P}_{2} \mathrm{O}_{5}$, or $\mathrm{I}_{2} 20$ pounds of phosphorus, in 2 million of virgin soil. The fact that the samples secured upon his request and analyzed by Hilgard showed 5.54 per cent of humus in the cultivated soil and only 5.I I per cent in the virgin soil, leads one to question whether the sample referred to as cultivated soil, containing 4800 pounds of nitrogen, and acidsoluble minerals amounting to II 30 pounds of phosphorus, 8600 of potassium, 9000 pounds of magnesium, and i 8,300 of calcium (in 2 million of soil), can fairly represent the black earth soil of Russia whose average yield of wheat for 20-year periods is less than ro bushels per acre in a three-year rotation, including one year of green fallow. (See Bulletin 42, Bureau of Statistics, United States Department of Agriculture.)

The report of Von Ugrimov's in vestigations states that "pot and field experiments with wheat, and analyses of the crop produced, bear out the chemical analysis in indicating that phosphorus is the element of plant food especially needed in this soil."

Analysis of "typical soils" of British East Africa shows that they are fairly well supplied with nitrogen and potassium, but deficient in phosphorus, - " a deficiency which is stated to be common throughout East Africa." 3

${ }^{1}$ Experiment Station Record, 19, Ior 5. 2 "Soils," page $36_{4}$.

${ }^{3}$ Experiment Station Record (I908), I9, IOI5. 
Investigations by Ingle ${ }^{1}$ (as chief chemist for the Transvaal Department of Agriculture) showed that " analyses of Transvaal soils indicate that they are, as compared with English soils, very poor in phosphorus, nitrogen, and lime, but usually rich in potassium."

The Massachusetts Experiment Station (Bulletin II $)$ ) reports the following analysis of soil from Turkey, Asia, the amounts per acre being computed for 2 million pounds of surface soil (about $6 \frac{2}{3}$ inches deep).

Nitrogen . . . . . . 06 per cent, or I 200 pounds per acre.

Phosphorus . . . "none"

Potassium . . . . .5I per cent, or I0,200 pounds per acre. Calcium . . . . . .72 per cent, or I 4,400 pounds per acre.

The I0,200 pounds of acid-soluble potassium is probably much below the total potassium present.

Professor J. B. Harrison has recently reported ${ }^{2}$ that the soil of the Experiment Station Farm in British Guiana, South America, contains 43,600 pounds of total potassium in 2 million of soil. The amount of phosphorus is not reported.

In the volcanic ash ejected from Vesurius during the eruption of April 4 and 5 , I906, Comanducci found .33 per cent of phosphorus and 3.87 per cent of potassium, - amounts which correspond to 6600 pounds of phosphorus and 77,400 pounds of potassium in 2 million pounds of the rolcanic material.

The surface of the United States may be divided into two areas, the glaciated and the unglaciated, as shown on the accompanying map. In general, the great ice sheets moved from north to south, and as they flowed slowly over the face of the earth, they caused enormous erosion of the surface. The eroded material was carried forward in the ice, and much of it was ground to powdered form, while some was reduced only to the form of rounded bowlders, pebbles, and sand grains. This mixture embedded in silt and clay is called glacial drift, or till, or bowlder clay. As the ice melted, the drift material was deposited, sometimes in moraines, or ridges, where for a long period of time the forward movement of the gla-

1 Journal of Agricultural Science, December, rgos.

2 West Indian Bulletin (1908), 9, 9. 
cier was practically equaled by the rapidity with which the ice melted at the terminus, and sometimes over broad inter-morainal tracts, where the melting proceeded more rapidly. Many preglacial valleys were filled with the drift (in places 300 feet deep), and commonly glacial drift was deposited over the general level of the glaciated area to a depth of Io to roo feet.

We are especially interested in four of the important ice sheets that occurred during the glacial epoch. Where the drift from the first of these was not covered by a subsequent glacier, the area is termed the Kansan glaciation; where the drift from the second glacier was not covered by a subsequent glacier, the area is termed the Illinoisan glaciation; where the drift from the third glacier was not covered by a subsequent glacier, the area is called the Iowan glaciation; and the area covered by the drift from the fourth glacier is termed the Wisconsin glaciation, where not covered by a subsequent glacier. As will be seen from the glacial map, these respective areas are not confined to the states named.

It should be understood that, notwithstanding the extensive glaciated regions, glacial soils are not common in the older glaciated areas. The most common soil material between the Alleghanies and the Rocky Mountains; and between the Great Lakes and the Gulf, is loess.

Loess is a very fine material ${ }^{1}$ consisting of grains of quartz, felspar, mica, hornblende, and other granitic or silicate minerals, with more or less limestone, dolomite, magnetite, pyrite, etc., and some clay. Loess has been derived in large part from glacial drift, having been transported by the action of wind and flowing water, probably from deposits of exposed till before it was protected by vegetation (and to some extent from the melting or evaporating glaciers), and deposited over all other soil formations and over older glaciated areas. Many of the residual soils in the driftless, or unglaciated, areas in the Mississippi Basin are now covered with loess. Even the tops of the Ozark Hills of southern Illinois, beyond the most southern point of the glacial lobe, and high above

${ }^{1}$ In 'some places the loess is more or less mixed with the underlying residual or glacial materials, through the action of crawfish, burrowing animals, etc., and occasionally loess deposits are subsequently covered by mixed alluvial materials, which may include sand and gravel with silt, clay, and organic matter. 


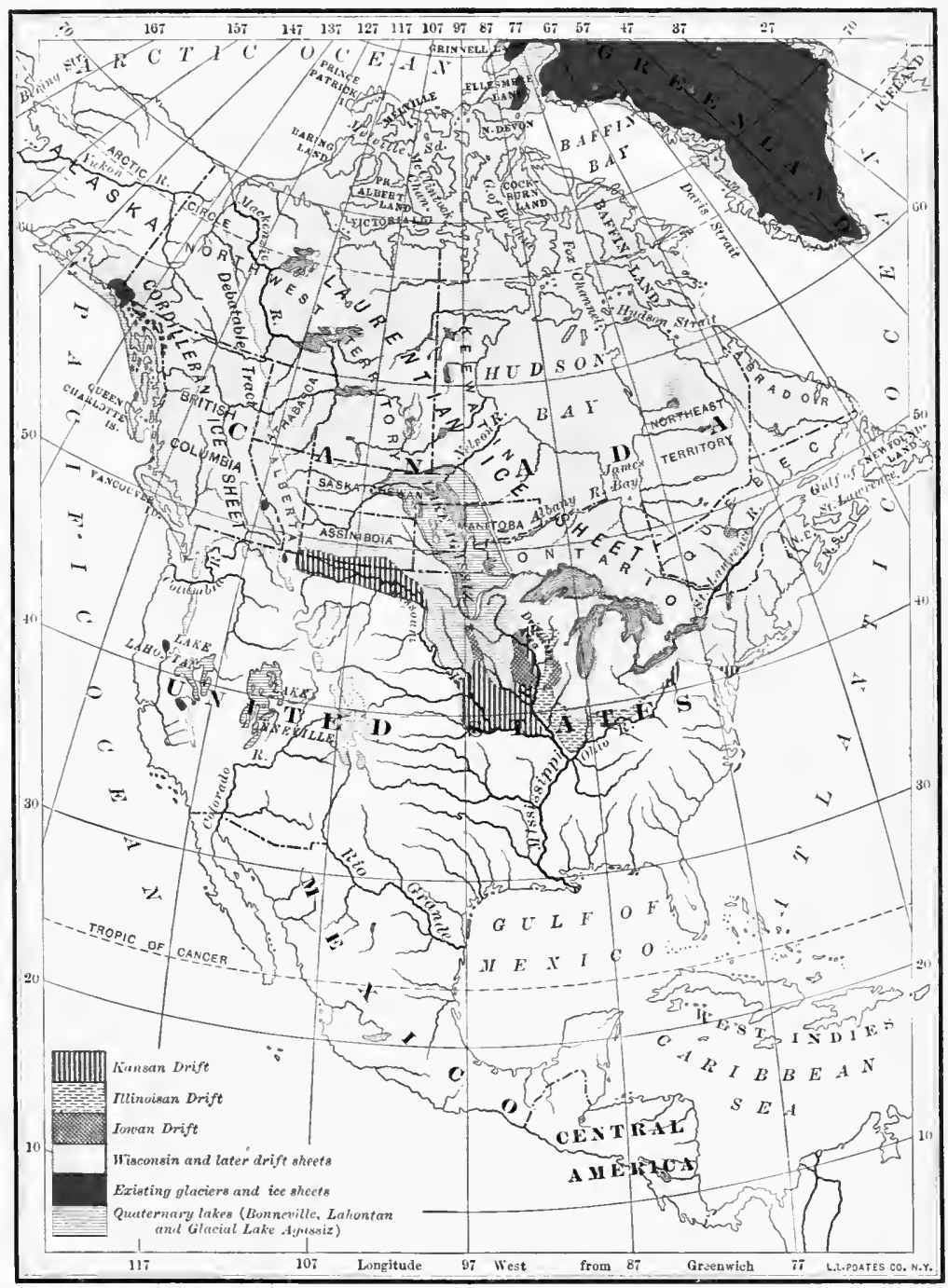

Map of the Glaciaten Arei of North America

From L'pham's map as modified by Leverett, L'nited States Geological Survey 

the nearest glacial ridges, are covered with several feet of loess. The older glacial drift is usually loess-covered. 'The depth of loess varies from three feet or less in the somewhat recent glaciations, and in driftless areas, remote alike from the glacial borders and from large stream courses, to eight or ten feet in areas ncar the borders of the greatest glacial action; while in the "deep loess" areas covering the bluff lands along some of the large streams the depth of loessial material may be from ten to fifty feet or more.

Some very complete analyses have been made of samples of loess from widely separated areas. The results given in Table I I are reported by the United States Geological Survey. The first three represent loess deposits covering the bluffs at Galena, Illinois; Vicksburg, Mississippi; and Kansas City, Missouri; while the fourth "was taken from the summit of a ridge in the suburbs of Dubuque, Iowa, at a point about 300 feet above the Mississippi River."

Table iI. Composition of Loess Deposits

Pounds in 2 Million of Loess

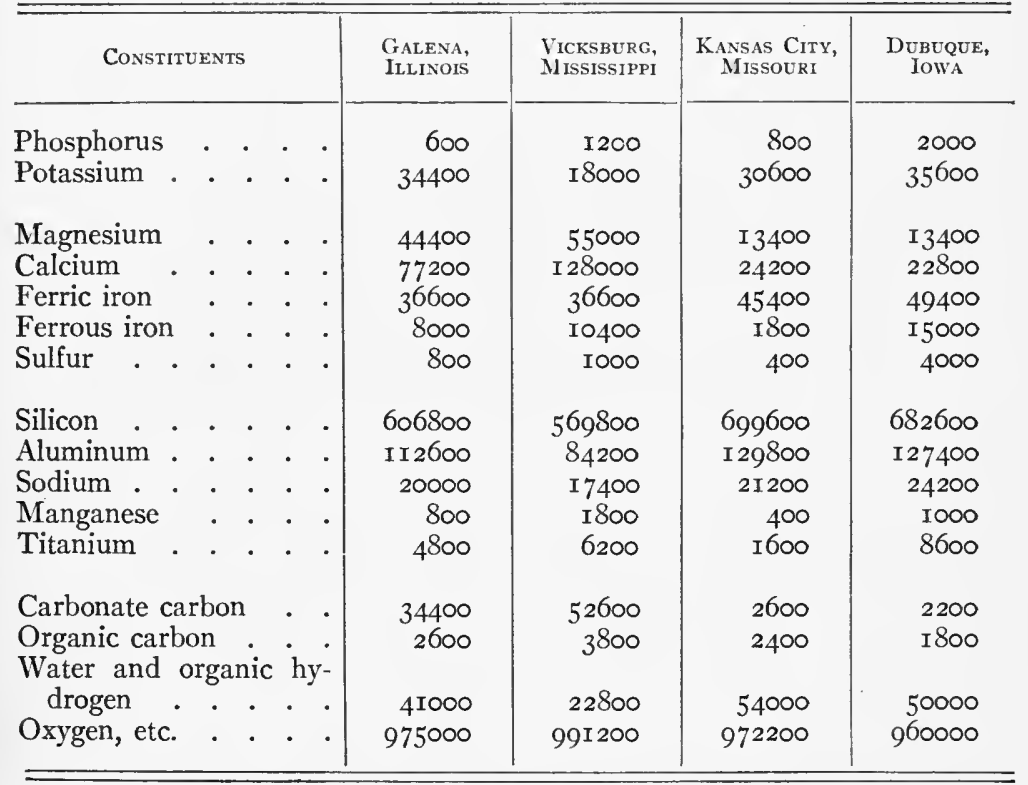


These analyses show the general range in composition of the mineral material constituting the bulk of our most common, most extensive, and most valuable soils, in the central part of the United States, both north and south (along the Mississippi Valley), where, as a very general rule, the surface is covered by a blanket of loess two feet or more in depth.

In the fresh condition, as in the deeper strata, loess usually contains considerable amounts of calcium carbonate and more or less magnesium carbonate, as is the case with the samples from Galena and Vicksburg, both of which are known to represent strata of considerable depth. The Dubuque sample was evidently taken from the surface, and this may be the case with the Kansas City sample, in both of which the carbonates have evidently been greatly reduced by leaching.

As an average, the phosphorus content amounts to I I 50 pounds per acre for a stratum of $6 \frac{2}{3}$ inches ( 2 million pounds), including the Galena sample, which is decidedly low, and the Dubuque sample, which is abnormally high. The a verage of nine different composite samples of subsoils from different places in the deep loess areas in Illinois shows I I I pounds of total phosphorus in 2 million pounds of loess, the extreme variation being from 740 to 1540 pounds. (See Illinois Experiment Station Bulletin I23, pages 288-289.)

While phosphorus is, in a sense, an incidental substance in loess deposits, the element potassium is an important constituent of the most common original minerals, and any marked variation in potassium content must be accounted for largely by decomposition and loss by weathering of the particles, the chief losses having occurred probably before the accumulation into the present loessial deposits.

The a verage of the two northern samples (Galena and Dubuque) shows 35,000 pounds of potassium, while the sample from the southwest (Kansas City) shows 30,600 pounds, and the southern loess contains only i 8,000 pounds of potassium in 2 million. If loess is derived chiefly from glacial drift, as viewed by the United States Geological Survey (38th Monograph, page I59), then it would be expected that the southern loess, transported far from glacial deposits, would be lower in potassium than the northern loess, which has been less exposed to weathering. As an average of the nine 
composite samples of subsoil from different places in the deep loess areas of Illinois, 35,070 pounds of potassium were found in 2 million of loess.

In the loess which was not mixed with carbonates, or from which most of the carbonates have been removed, presumably by leaching (Dubuque and Kansas City samples), the total supply of magnesium and calcium is markedly smaller than the supply of potassium; but when compared with the average requirements of a general crop rotation (see Table $\mathrm{I}_{3}$ ) the supply of magnesium and calcium is still somewhat more-ample than that of potassium.

While the average supplies of sulfur and phosphorus are about equal, the requirement for phosphorus is five times as great as for sulfur in the total produce of the average crop rotation, and forty times as great if the grain only is removed and not returned.

A partial analysis of loess from Cheyenne, Wyoming, reported by Eakin, shows, in 2 million pounds of loess, 960 pounds of phosphorus, 44,500 of potassium, 14,880 of magnesium, 69,700 of calcium, and 20,000 pounds of carbonate carbon.

It is suggested that most of the carbonates contained in deep loess deposits may have a different origin than the silicates, which constitute the bulk of the material. In many deep loess deposits, pieces of limestone shells (usually of light weight) are a characteristic, indicating that a part of the locssial material may have come from areas which were at times covered with water and at other times dried on the surface and exposed to wind action. Thus, while such loess may have been derived from glacial drift, more or less of it has had some intermediate resting place where carbonates tend to accumulate, as in ponds, shallow lakes, swamp areas, bottom lands, or on seepy slopes; and from the dried surfaces of such areas much of it has been transported by wind action over bluffs and upland plains. It is noteworthy that the broadest deep loess deposits along the river bluffs are found where the valley is correspondingly wide (Illinois Bulletin I23, page 238).

The most definite lesson to be drawn from these analyses of this most important soil material is, that phosphorus is clearly the most limited element of plant food; whereas among the four elements, potassium, magnesium, calcium, and sulfur, it is difficult to determine which is likely to be the most limited. 


\section{SOME EASTERN RESIDUAL SOILS}

In Table $\mathrm{I} 2$ is given the ultimate chemical composition of residual soils derived from ten different geological formations, and as a rule the results are the average from several samples of the same type of soil. The soils were collected in Maryland, but in most cases the same soil types extend into other states and may be considered as more widely representative of these soil formations.

The soil analyses ${ }^{1}$ were made by Mr. F. P. Veitch of the United States Department of Agriculture, under the direction of Professor Milton Whitney, Chief of the Bureau of Soils, and with the indorsement of Doctor H. W. Wiley, Chief Chemist of the Department of Agriculture.

In all cases the samples analyzed were taken "immediately under the top soil," and thus represent the upper stratum of the subsoil. The results are given in Table $\mathrm{I} 2$ on the basis of pounds of the different elements present in 2 million pounds of the soil, corresponding approximately to the amounts per acre in a $6 \frac{2}{3}$-inch stratum. "Volatile" means loss on ignition, and includes organic matter, combined water, probably some sulfur, which may be oxidized from organic matter or from pyrites, and possibly some carbon dioxid (not completely replaceable if derived from magnesium carbonate). Oxygen may be lost or gained during ignition, depending upon the compounds of iron, sulfur, etc., the amount of organic matter, and the stage to which the ignition is carried. The oxygen is estimated by. difference, which really includes errors and all undetermined elements not otherwise reported.

It should be kept in mind that sandstone does not mean quartz. It means a stone with sand grains cemented together. The sand grains may consist of quartz (silicon dioxid), but more commonly they are grains of silicate minerals, including much aluminum and iron and more or less of the other abundant mineral elements. Residual soils resulting from the disintegration, decomposition, and leaching of the previous geological formations vary with the character of the original rock, and with the loss by leaching. In the case of the limestone formations, it is apparent that the residual soil consists of impurities contained in the original limestone, the 


\begin{tabular}{|c|c|c|c|c|}
\hline & 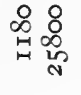 & 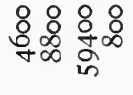 & 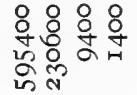 & 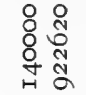 \\
\hline
\end{tabular}

\begin{tabular}{|c|c|c|c|c|}
\hline 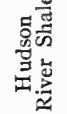 & $\begin{array}{l}88 \\
\infty 8 \\
8 \\
q\end{array}$ & 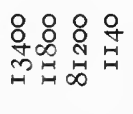 & 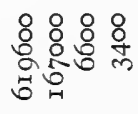 & 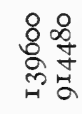 \\
\hline
\end{tabular}

\section{战总}

$888 \% 80.808$

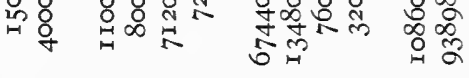

穿导

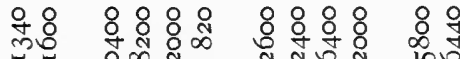
ॠ出

\begin{tabular}{|c|c|c|c|}
\hline 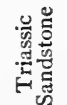 & \begin{tabular}{l}
0.8 \\
0 \\
0 \\
\hdashline \\
\end{tabular} & 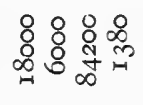 & 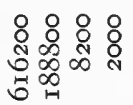 \\
\hline
\end{tabular}

\begin{tabular}{|c|c|c|c|c|}
\hline 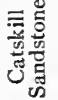 & 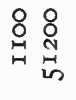 & 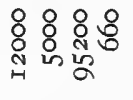 & 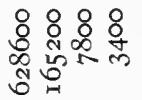 & 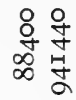 \\
\hline
\end{tabular}

\begin{tabular}{|c|c|c|c|c|}
\hline 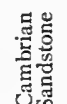 & 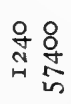 & 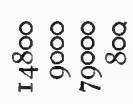 & 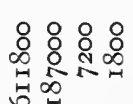 & $\begin{array}{ll}\circ & 0 \\
0 & 0 \\
0 & 0 \\
0 & 0 \\
0 & 1\end{array}$ \\
\hline
\end{tabular}

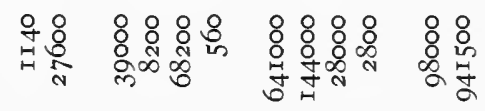

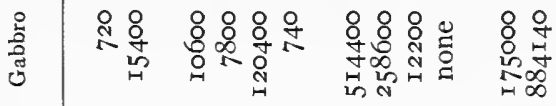

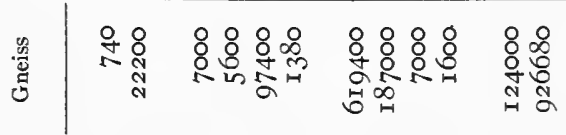

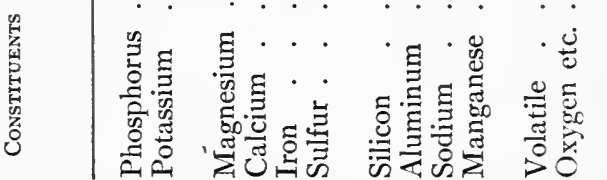


carbonates of calcium and magnesium, which may have constituted 75 to 90 per cent or more of the original rock, having been nearly or completely dissolved out (see Table 5).

Two striking facts are revealed by the analyses of these ten soils from ten different geological formations:

I. The amount of phosphorus is very small compared with the requirements of large crops for many years, the amount varying from 720 pounds in the Gabbro soil to I 500 pounds in the Helderberg limestone soil. Counting I 7 pounds of phosphorus for 100 bushels of corn, the 720 pounds would be sufficient for only 43 such crops; or, if both grain and stalks are removed from the land and if one pound of phosphorus per acre is the yearly loss in drainage water, the 720 pounds is sufficient for only 30 such crops; while the best soil contains sufficient total phosphorus in a $6 \frac{2}{3}$ inch stratum for only 63 such crops. The average of the ten soils shows I too pounds of phosphorus in two million pounds of soil, or about one half as much as in the average crust of the earth.

2. The amount of potassium is very large, varying from 20 to 50 times as much as the phosphorus. The 15,400 pounds of potassium in $6 \frac{2}{3}$ acre inches of the poorest soil would be sufficient for Ioo bushels of corn every year for 800 years, while the 57,400 pounds in the best soil would suffice for 3000 years, if it could be made available as needed and if only the grain were removed. If both grain and stalks were removed, these supplies are sufficient for 200 and 800 crops, respectively, counting I9 pounds of potassium for roo bushels of corn and 52 pounds for the stalks for such a crop, not including the loss in drainage, which, however, would be somewhat greater than for phosphorus. Six of these soils average nearly as rich in potassium as the earth's crust, while the poorest soil is about one third as rich.

Several of these soils are less abundantly supplied with magnesium and calcium than with potassium, not only in total amounts, but also in comparison with the requirements of some general farm crops. In some cases the soils contain less than one third as much magnesium, and less than one fifth as much calcium, as potassium; while corn contains more than one third as much magnesium as potassium, and clover hay contains almost as much calcium as potassium, and one fourth as much magnesium (see Table I3). 
Table i3. Mineral Plant food in Wheat, Corn, Oats, and Clover

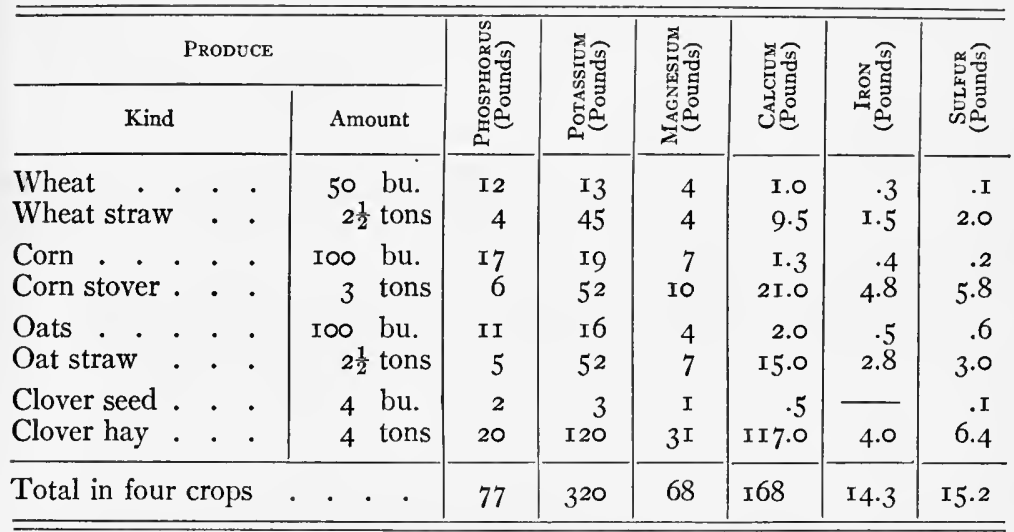

Note the accumulation of phosphorus in the grain and straw and compare with potassium and with sulfur; also compare magnesium and calcium in this respect.

\section{OTHER EASTERN SOILS}

By the action of the different agencies of transportation, soil particles are often sorted into grades, as clay, silt, sand, and gravel, and in addition there are stony loams and other residual soils, and the cumulose soils (as peaty soils), which accumulate in swamps and bogs and consist largely of plant residues.

In Table 14 is recorded a valuable series of analyses from the Cornell Experiment Station (Roberts' "Fertility of the Land," I900, page I3), representing "the amounts of plant food in surface soils in New York State."

Table i4. Composition of Surface Solls in New York State

Pounds in 2 Million (per Acre about $6 \frac{2}{3}$ Inches Deep)

\begin{tabular}{|c|c|c|c|c|c|c|c|c|c|}
\hline \multicolumn{6}{|c|}{ SoIL TypE } & $\begin{array}{c}\text { No. OF } \\
\text { ANALYSES }\end{array}$ & $\begin{array}{l}\text { TOTAL } \\
\text { NITROGEN } \\
\text { POUNDS }\end{array}$ & $\begin{array}{c}\text { TOTAL } \\
\text { PHOSPHORUS } \\
\text { POUNDS }\end{array}$ & $\begin{array}{c}\text { TotaL } \\
\text { POTASSIUM } \\
\text { POUNDS }\end{array}$ \\
\hline Clay loam & - & & . & - & . & I I & 2960 & I 360 & 23490 \\
\hline Loam . & . & • & $\cdot$ & . & - & 8 & 5480 & 1480 & 30210 \\
\hline Sandy loam & . & & • & . & . & 8 & 2500 & I 440 & 32620 \\
\hline Gravelly loam & . & & 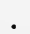 & . & . & IO & 5480 & 2170 & 26640 \\
\hline Slaty loam. & . & 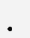 & . & . & . & I & 3000 & I570 & 29050 \\
\hline Peaty soil & . & & 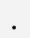 & . & . & 2 & $2295^{1}$ & $1800^{1}$ & $3280^{1}$ \\
\hline
\end{tabular}

${ }^{1}$ Amounts in I million pounds. 
These New York soils are somewhat richer in phosphorus than most of the older residual soils, and noticeably richer than the average loessial soils of the older formations.

The ten samples of gravelly loam show an average phosphorus content of 2170 pounds in 2 million of soil, which is about the same as the average of the earth's crust.

With one notable exception these soils are very rich in potassium, although not quite equal to the average loessial soils of the corn belt.

Two of the common New York soils (loam and gravelly loam) exceed 5000 pounds per acre in the nitrogen content of the surface $6 \frac{2}{3}$ inches, an amount which represents approximately the average of the most abundant prairie soils of the corn belt, while the three soils, clay loam, sandy loam, and slaty loam, contain about one half as much.

In the peaty soil we find another very abnormal soil type, which it is instructive to compare with the barren soils of Germany and Maryland, with the depleted long-cultivated soils of India, Turkey, Russia, and Africa, with the coral limestone soil of the Bermuda Islands and the limestone soils of Cuba, and with the phosphatic soils of Tennessee and Kentucky. The peaty soil contains in a $6 \frac{2}{3}$-inch stratum nearly ten times as much nitrogen, nearly twice as much phosphorus, and only one tenth as much potassium as the general average of the most common American soils.

The soil on the Experiment Station farm at the State College, Pennsylvania, contains 2320 pounds of total nitrogen, ro8o pounds of acid-soluble phosphorus, and 5600 pounds of acid-soluble potassium, in 2 million pounds of the surface soil (Frear, Penn. Dept. Agr. Report, 1906). While most of the phosphorus is usually soluble in the acid used ( $\mathrm{HCl}$ of I.II5 sp. gr.), only about one sixth of the total potassium contained in old soils is thus dissolved, as a general average, although the proportion varies greatly with different types of soil. Doctor Frear has subsequently furnished data showing that 2 million pounds of the fine earth in the surface soil on the Pennsylvania State College farm contain 50,700 pounds of total potassium. 
$-\cdot$ 


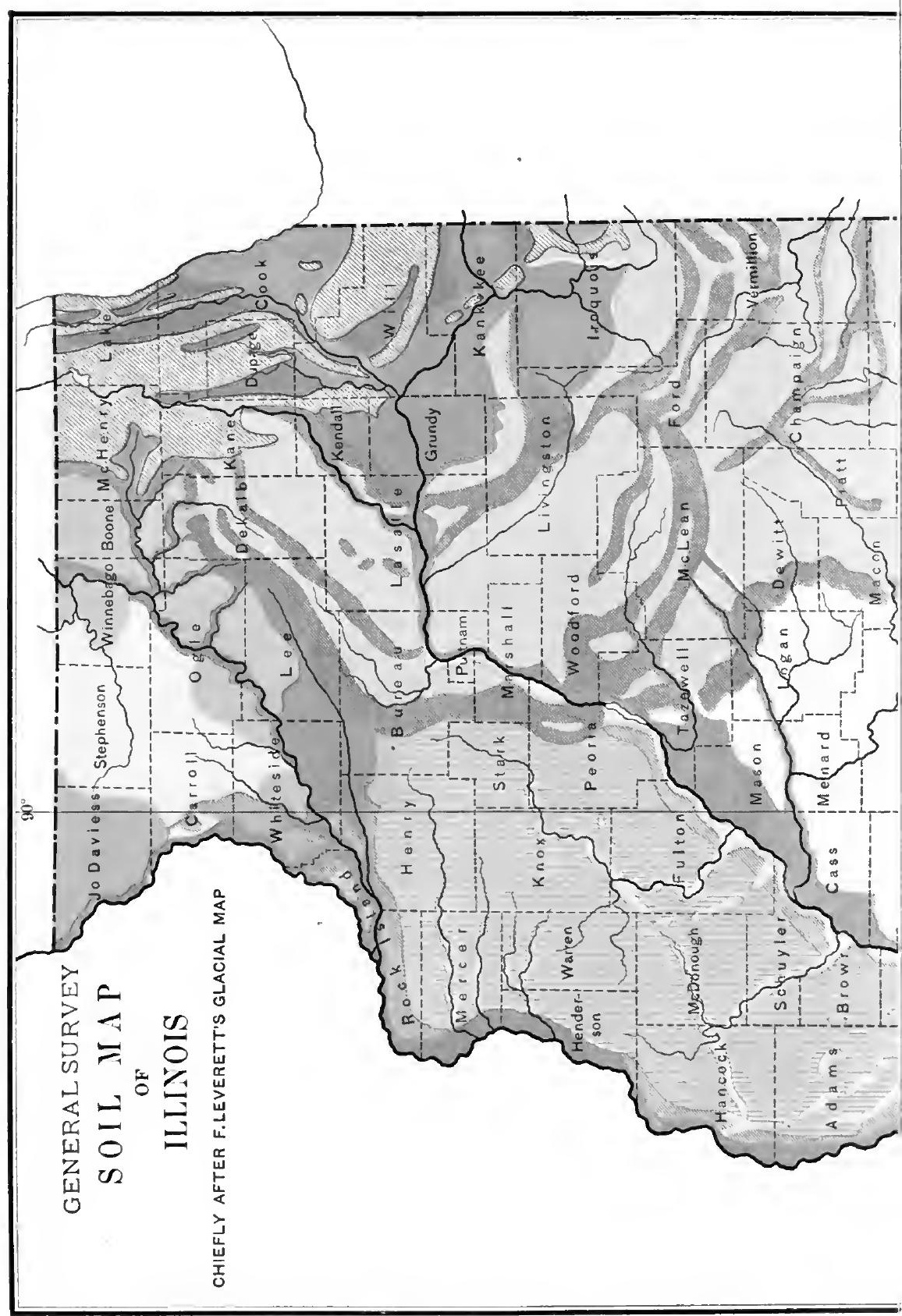




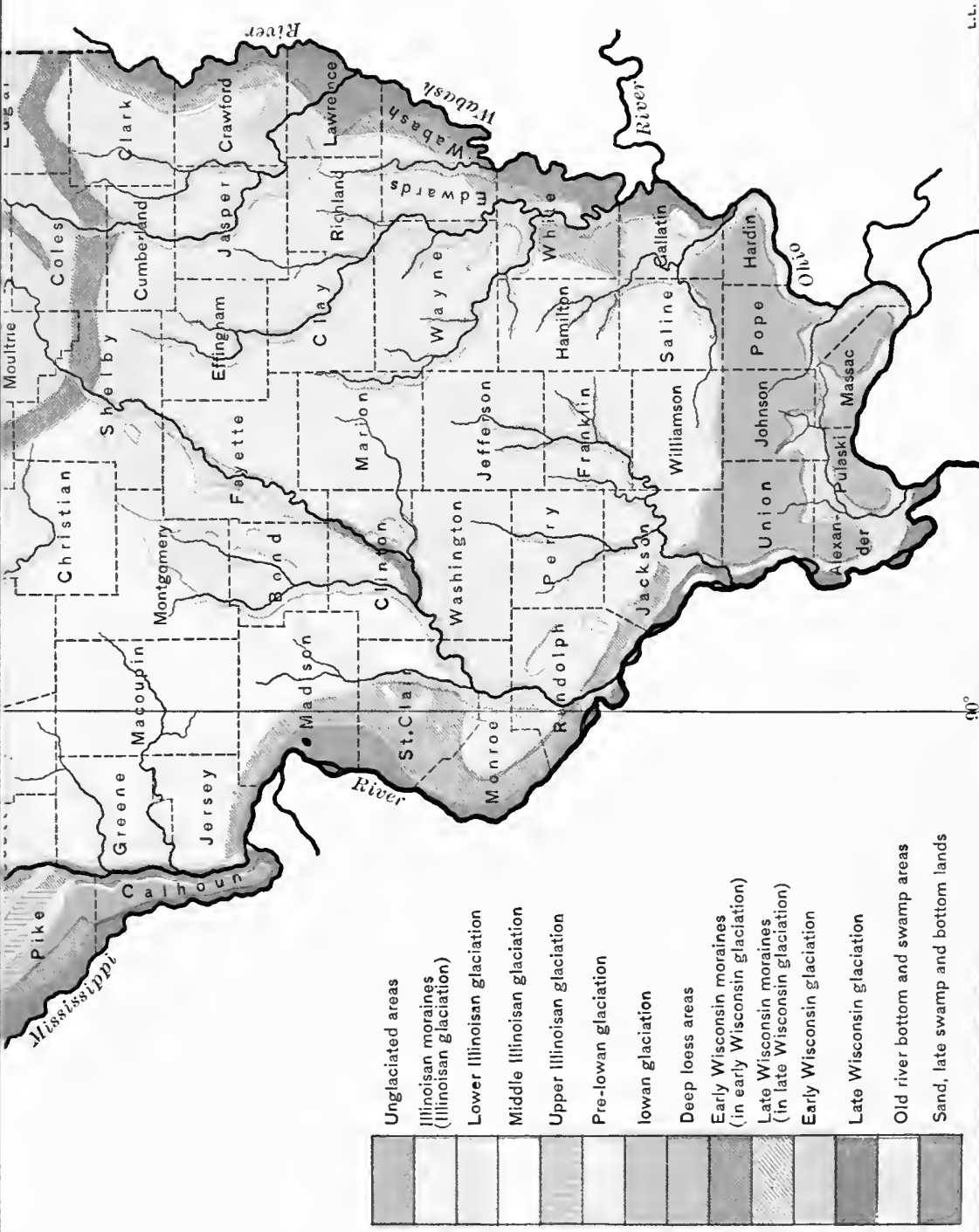




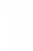




\section{SOILS OF THE CENTRAL STATES}

The accompanying soil map of Illinois and Tables I5, I6, and I 7 serve to illustrate in a very trustworthy manner both the uniformity and variation that may be expected among the most important soil types in the North Central States. This detailed information from Illinois applies with almost equal value to similar soils in many other states. With a north and south extension of nearly 400 miles in the center of the greatest agricultural region of the United States, Illinois occupies a unique position. In latitude it reaches almost from Vermont to North Carolina, Cairo being farther south than Richmond, and Beloit farther north than Boston. Cairo is within 35 miles of the Tennessee line, and 150 miles south of Covington, Kentucky. From Cairo to Mobile on the Gulf is no farther than from Beloit to the 49th parallel, which marks the northern boundary of the United States. The soils of Illinois are in large measure representative of the soils of the wheat belt, of the corn belt, and, in part, of the cotton belt. Cotton growing has been a commercial success in southern Illinois, and much spring wheat has been produced in the north end of the state, while central Illinois is the heart of the corn belt.

Fourteen great soil areas are recognized in Illinois, including the extensive unglaciated regions in the southern and northwestern parts of the state, the lower, middle, and upper Illinoisan glaciations, the pre-Iowan and Iowan glaciations, the early and late Wisconsin glaciations, with numerous moraines and intermorainal tracts, the deep loess deposits, and the early and late swamp and sand areas, and extensive and widely distributed bottom lands and terraces.

As already explained, the material called loess constitutes the chief basis for nearly all of the upland soils of central United States. The principal differences among these soils of loessial origin are due to difference in age, topography, and climatic conditions. Some additional or subsequent differences have been brought about by variation in native vegetation and in systems of farming.

Prairie and timber soils. The upland soils may be divided into prairie soils and timber soils, according to the character of the original vegetation; and with similar topography the difference in 
vegetation is not due to original differences in the soil materials; but rather the difference between prairie land and timber land is due to the influence of the vegetation upon the soil. The existence of prairies over areas naturally well surface-drained is due very largely, if not entirely, to the prairie fires, which were, as a rule, of annual occurrence and often a source of danger to the early settlers in prairie regions.

The annual destruction of any seedlings that may have started effectually prevented the growth of forests on the prairie lands, and it is noteworthy that level areas or valleys on the northeast side of streams were usually timbered, while corresponding areas on the southwest were usually prairie, because of the prevailing southwest winds during summer and autumn. (See "Soils of Clay County, Illinois.") Prairie fires have no tendency to run down hill, and they make but little progress against the wind.

The wild prairie grasses and weeds, including native legumes, developed an abundant root system to an average depth of 16 to 20 inches, varying somewhat with the latitude or length of season, the depth being greater in the latitude of central Illinois than in northern Illinois; and, with the partial decay of these roots, followed the marked accumulation of humus which characterizes the "black soil " of the prairie; while the smaller amount of humus is the chief characteristic of the timber soils. Rotting tree roots are subject to very complete decay, because of the large cavities and ready admission of air. Boring insects and burrowing animals also hasten the destruction, so that the small amount of leaf mold that remains constitutes the main source of humus for timber soils, and even this is exposed to rapid decay. Being poorer in organic matter, the upland timber soils are correspondingly poorer in nitrogen than the prairie soils.

The prairie lands may be classified according to topography, as undulating prairies and flat prairies.

The undulating prairie soil covers the nearly level or gently rolling prairie lands that were naturally fairly well surface-drained. It is usually markedly uniform in a given formation, and constitutes the most important soil of the corn belt. More or less of the clay and finer silt has been carried downward from the surface and accumulated in the subsoil, and some has been carried away by 
surface washing during many centuries and collected in lower lying flat areas. The exposure of the surface after the annual prairie fires permitted some slight surface washing which otherwise would not have occurred.

The flat prairie soils occupy the lower lying level areas that were naturally poorly surface-drained and inclined to be swampy, especially during the wet season of the year. This soil has been formed in part from deposits of fine earth and vegetable matter washed in from the surrounding higher land. The rank growing swamp grasses have, from the partial decay of their roots (and of more or less of their tops), added much organic matter to this soil.

The undulating prairie soils vary from a gray silt loam on tight clay in the older areas, to a dark brown silt loam, in the later formations, and the common flat prairie soils vary with age from drab silt loam to black clay loam.

Many other less extensive soil types occur here and there on the prairies, including, as extremes, sand dunes formed of wind-blown material from old shallow lake beds, gravel points, or exposed glacial till, bogs of peat or muck, and sometimes adjoining strips of plastic clay. Some intermediate types include deep silt loam, sandy loam, silt on clay, etc. These are of small importance compared with the very extensive and most common prairie soils reported in Tables $\mathrm{r}_{5}, \mathrm{I} 6$, and $\mathrm{r}_{7}$.

There are three principal types of upland timber soils in most of the great loess-covered areas. One, a light gray silt loam, occupies the flat areas; a second type, yellow-gray silt loam, covers the undulating or gently sloping lands; and the third (yellow silt loam) is hilly or steeply sloping and consequently subject to serious erosion, or surface washing, especially when under cultivation. In addition, there are the areas of deep loess (yellow fine sandy loam) covering the bluffs in many places along the larger river valleys; and other less extensive types are sometimes found. In northern Illinois and southern Wisconsin, in what is termed the Iowan glaciation, considerable areas are found of a brown sandy loam, occupying in the main the undulating uplands. The top soil consists of brown sandy loam, containing some gravel in places and occasionally pieces of stone. The subsoil at a depth of three feet or more frequently contains much stone, the proportion increasing 
with the depth, the disintegrating bed rock being found at 4 to ro feet beneath the surface. The bed rock and some of the pieces found in the soil and subsoil consist of impure limestone. The soil is commonly recognized as drift, but it is certainly much modified by the residual material, and in places there is but little evidence of glacial or loessial deposit.

Sand, swamp, and bottom lands. In the older formations, as in the Illinoisan glaciations and still farther south, the soil of the smaller river bottoms is chiefly a deep gray silt loam; while, in the more recently formed great soil areas, the principal bottom land soil is a brown loam. In both cases the bottom land resembles somewhat the top soil of the adjoining upland (which has contributed much to its formation), modified by additions of humus and alluvium from other sources. Many other types of bottom land are also found, but usually they are less abundant.

Extensive swamp regions are found in most of the Northern States, especially in Michigan, Wisconsin, and Minnesota, and in the northern parts of Ohio, Indiana, Illinois, and Iowa. These swamp soils vary almost from pure sand to pure clay, and almost from Ioo per cent mineral matter to Ioo per cent organic matter; and they also vary from moderately acid soils to marls containing more than 50 per cent of calcium carbonate, and not infrequently magnesium carbonate is present in sufficient amount to render the soil non-productive and place it in the alkali class. These different constituents vary quite independently, sand, peat, clay, peaty sand, sandy peat, peaty clay or clayey peat (muck), sandy clay, clayey sand, loam, sandy loam, clay loam, and peaty loam being among the possible soil types; and any of these may be acid or may contain "alkali." In addition we find such variations as deep peat, medium peat, and shallow peat, with sand or clay or sandy clay subsoil. In places there are broad, level, and very uniform areas of deep peat, of peat on sand, or of nearly pure sand; and in other places peat bogs and sand ridges alternate every few rods. Not infrequently sand dunes (still subject to more or less wind action) are found in or adjoining these swamp regions; and in some sections there are more extensive sand regions, including considerable parts of counties in Ohio, Indiana, Illinois, and Wisconsin, and an area of several counties in the north central part of the lower peninsula of Michigan. 
In case of the most important soil types the averages reported in Tables I 5,16 , and 17 are based upon analyses of a large number of composite soil samples. The two most extensive soil types in Illinois are the gray silt loam prairie (330) of the lower Illinoisan glaciation (the so-called hard-pan soil of "Egypt"), and the brown silt loam prairie (II 26) of the early Wisconsin glaciation.

The averages reported for the gray silt loam on tight clay of the lower Illinoisan glaciation represent 57 different soil samples. In 2 million pounds of the surface soil the potassium (the most constant constituent) varied from $23, \mathrm{I} 20$ to 26,440 pounds, the phosphorus varied from 700 to I000 pounds, and the nitrogen varied from 2140 to 3500 pounds; and in every case the surface, subsurface, and subsoil were found to be acid.

The data reported for the brown silt loam of the early Wisconsin glaciation are a verages obtained by analyzing 90 different samples of soil collected in ten different counties, and representing more than 500 different borings. In 2 million pounds of the surface soil of this type the potassium varied from 3 I, 980 to 43 , Ioo pounds, the phosphorus varied from 980 to 1620 pounds (or, if we disregard four samples, from IO2O to 1340 pounds), and the nitrogen varied from 3980 to 7520 pounds (or from 3980 to 6340 , if we disregard two samples).

The limestone has not been leached out of the early Wisconsin brown silt loam to such a depth as in the older gray silt loam. In one case limestone was present in the surface of the brown silt loam, and in three cases it was found in the subsurface, while it was more often present in the subsoil, although in many cases even the subsoil was found to be acid, but never to such a degree as is common for the subsoils of the older brown silt loams (middle and upper Illinoisan, pre-Iowan, and Iowan).

With unimportant exceptions, all samples of surface, subsurface, and subsoil of the yellow silt loams (and the yellow fine sandy loam) of the hill lands were distinctly acid, the degree varying with the age of the soil.

In the late Wisconsin glaciation both the brown silt loam and the yellow-gray silt loam samples were almost invariably slightly acid in the surface and subsurface, but exceedingly well supplied with carbonates in the subsoil. 
TABle I5. Fertility in IllinoIs Solls

Average Pounds per Acre in 2 Million Pounds of Surface Soil (o-6 $\frac{2}{3}$ Inches) ${ }^{1}$

\begin{tabular}{|c|c|c|c|c|c|c|c|}
\hline $\begin{array}{l}\text { SoIL } \\
\text { TYPE } \\
\text { No. }\end{array}$ & $\begin{array}{l}\text { Soll AREA oR } \\
\text { GLACIATION }\end{array}$ & SoIL TrPe & $\begin{array}{l}\text { Total } \\
\text { NITRO- } \\
\text { GEN }\end{array}$ & $\begin{array}{l}\text { Total } \\
\text { PHOS- } \\
\text { PHOR- } \\
\text { US }\end{array}$ & $\begin{array}{l}\text { Total } \\
\text { PotAS- } \\
\text { SIUM }\end{array}$ & $\begin{array}{c}\text { Lime. } \\
\text { StONe } \\
\text { PRESENT }\end{array}$ & $\begin{array}{c}\text { LIME- } \\
\text { STONE } \\
\text { RE- } \\
\text { QUIRED }\end{array}$ \\
\hline
\end{tabular}

Pratrie Lands, Undulating

\begin{tabular}{|c|c|c|c|c|c|c|}
\hline $33^{\circ}$ & Lower Illinoisan & $\begin{array}{l}\text { Gray silt loam on } \\
\text { tight clay }\end{array}$ & 2880 & 840 & 24940 & II6o \\
\hline 426 & Middle Illinoisan & Brown silt loam & 4370 & I I 70 & 32240 & 70 \\
\hline $5^{26}$ & Upper Illinoisan & Brown silt loam & 4840 & 1200 & 32940 & 70 \\
\hline 626 & Pre-Iowan . . & Brown silt loam & 4290 & 1190 & 35340 & IIO \\
\hline 726 & Iowan . . . & Brown silt loam & 4910 & 1220 & 32960 & 90 \\
\hline 1126 & Early Wisconsin & Brown silt loam & 5050 & 1190 & 36250 & 60 \\
\hline 1026 & Late Wisconsin & Brown silt loam & 6750 & 1410 & 45020 & 60 \\
\hline
\end{tabular}

Prairie Lands, Flat

\begin{tabular}{|c|c|c|c|c|c|c|c|}
\hline 329 & Lower Illinoisan & Drab silt loam & 2800 & 710 & 26260 & & 1300 \\
\hline 420 & Middle Illinoisan & Black clay loam & 5410 & $143^{\circ}$ & 31860 & 830 & \\
\hline 520 & Upper Illinoisan & Black clay loam & 6760 & 1690 & 29770 & 30 & \\
\hline I 20 & Early Wisconsin & Black clay loam & 7840 & 2030 & 35140 & 32530 & \\
\hline 1220 & Late Wisconsin & Black clay loam & 8900 & 1870 & 37370 & 980 & \\
\hline
\end{tabular}

Timber Uplands, Rolling or Hilly

\begin{tabular}{|c|c|c|c|c|c|c|}
\hline I 35 & Unglaciated & Yellow silt loam & 1890 & $95^{\circ}$ & $3 \mathrm{I} 450$ & 80 \\
\hline 335 & Lower Illinoisan & Yellow silt loam & 2150 & $95^{\circ}$ & 31850 & 310 \\
\hline 435 & Middle Illinoisan & Yellow silt loam & 1870 & 820 & 33470 & 40 \\
\hline 535 & Upper Illinoisan & Yellow silt loam & 2010 & 840 & 34860 & I3O \\
\hline 635 & Pre-Iowan . . & Yellow silt loam & 2390 & 850 & 37180 & 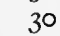 \\
\hline 735 & Iowan $\cdot \cdot$ & Yellow silt loam & I910 & 910 & 35780 & 30 \\
\hline I I 35 & Early Wisconsin & Yellow silt loam & 1890 & 870 & 32720 & 60 \\
\hline 864 & Deep loess & $\begin{array}{l}\text { Yellow fine sandy } \\
\text { loam } .\end{array}$ & 2170 & 960 & 35640 & $7^{\circ}$ \\
\hline
\end{tabular}

I The numbers given in Table 15 represent the total amount contained in 2 million pounds of the surface soil on the dry basis, with the exception of deep peat swamp soil, for which the amounts in $\mathrm{I}$ million pounds are used, because its specific gravity is only one half that of ordinary soil, and of sand soil for which $2 \frac{1}{2}$ million pounds are used, because it is about one fourth heavier than ordinary soil. 
TABLE 15. Fertility in Illinois Solls - Continued

\begin{tabular}{|c|c|c|c|c|c|c|c|}
\hline $\begin{array}{c}\text { SoIL } \\
\text { TYPE } \\
\text { No. }\end{array}$ & $\begin{array}{l}\text { SoIL AREA OR } \\
\text { GLACLATION }\end{array}$ & SOIL TypE & $\begin{array}{l}\text { Total } \\
\text { NItRo- } \\
\text { GEN }\end{array}$ & $\begin{array}{c}\text { Total } \\
\text { PHOS- } \\
\text { PHOR- } \\
\text { US }\end{array}$ & $\begin{array}{c}\text { Total } \\
\text { Potas- } \\
\text { SIUM }\end{array}$ & $\begin{array}{c}\text { Lime- } \\
\text { STONE } \\
\text { PRESENT }\end{array}$ & $\begin{array}{l}\text { LIME- } \\
\text { STONE } \\
\text { RE- } \\
\text { QUIRED }\end{array}$ \\
\hline
\end{tabular}

Timber Uplands, Undulating

\begin{tabular}{|c|c|c|c|c|c|c|}
\hline & Late Wisconsin & $\begin{array}{l}\text { Yellow-gray silt } \\
\text { loam } . .\end{array}$ & 2890 & 810 & 47600 & \\
\hline 760 & Iowan & Brown sandy loam & 3070 & $85^{\circ}$ & 26700 & 100 \\
\hline
\end{tabular}

Timber Uplands, Flat

\begin{tabular}{|c|c|c|c|c|c|c|}
\hline $33^{2}$ & Lower Illinoisan & $\begin{array}{l}\text { Light gray silt } \\
\text { loam on tight } \\
\text { clay }\end{array}$ & 1890 & 810 & 27280 & $45^{\circ}$ \\
\hline
\end{tabular}

SAND, Swamp, and Botrom Lands

\begin{tabular}{|c|c|c|c|c|c|c|c|}
\hline I33I & Old bottom lands & $\begin{array}{c}\text { Deep gray si } \\
\text { loam } .\end{array}$ & 3620 & 1420 & 36360 & & 440 \\
\hline I $45 \mathrm{I}$ & Late bottom lands & Brown loam . & 4720 & 1620 & 39970 & 2090 & \\
\hline I $48 \mathrm{I}$ & $\begin{array}{l}\text { Sand plains and } \\
\text { dunes . . }\end{array}$ & Sand soil . & I 440 & 820 & 30880 & & 200 \\
\hline I 40I & Late swamp . & Deep peat & 34880 & I960 & 2930 & & I 30 \\
\hline I 4 I 5 & Late swamp & Drab clay. & 5760 & I900 & 48080 & 36300 & \\
\hline 1400 & Late swamp & Marly peat. & 20900 & 1520 & 920 & I 278000 & \\
\hline
\end{tabular}

A careful study of the mass of evidence recorded in Tables $\mathrm{I}_{5}$, I6, and I 7 clearly reveals the fact that the most important and most extensive areas of Illinois soils are poor in phosphorus. The only soils well supplied with phosphorus are the black clay loams, the bottom lands, and the clay and peaty swamp soils. On the other hand, the supply of total potassium is very great in all of the soils reported upon, with the exception of the deep peat and the abnormal marly peat, which are markedly deficient in that element.

It should be kept in mind that small bodies of peat soil surrounded by normal upland soils rich in potassium are likely to have received deposits of silt or clay by overflow from time to time, and as a rule they are not deficient in potassium, and shallow peat bogs with clay 


\section{Table i6. Fertility in Illinois SoILS}

Average Pounds per Acre in 4 Million Pounds of Subsurface Soil ( $6_{3}^{2}-20$ inches)

\begin{tabular}{|c|c|c|c|c|c|c|c|}
\hline $\begin{array}{l}\text { SorL } \\
\text { TyPE } \\
\text { No. }\end{array}$ & $\begin{array}{l}\text { Soll AREA OR } \\
\text { GLACIATION }\end{array}$ & SoIL Type & $\begin{array}{c}\text { Total } \\
\text { Nitro- } \\
\text { GEN }\end{array}$ & $\begin{array}{l}\text { TOTAL } \\
\text { PHOS- } \\
\text { PHOR- } \\
\text { US }\end{array}$ & $\begin{array}{c}\text { Total } \\
\text { Potas- } \\
\text { SIUM }\end{array}$ & 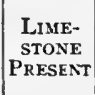 & $\begin{array}{l}\text { LME- } \\
\text { STONE } \\
\text { RE- } \\
\text { QUIRED }\end{array}$ \\
\hline
\end{tabular}

Prairie Lands, Undulating

\begin{tabular}{|c|c|c|c|c|c|c|}
\hline 330 & Lower Illinoisan & $\begin{array}{l}\text { Gray silt loam on } \\
\text { tight clay }\end{array}$ & 3210 & I 500 & $5357^{\circ}$ & $635^{\circ}$ \\
\hline 426 & Middle Illinoisan & Brown silt loam & 5800 & 1920 & 62590 & IIO \\
\hline 526 & Upper Illinoisan & Brown silt loam & 6480 & 2090 & 64820 & I 20 \\
\hline 626 & Pre-Iowan . & Brown silt loam & 4650 & 2060 & 72370 & 570 \\
\hline 726 & Iowan . & Brown silt loam & 5140 & I 940 & 66220 & 360 \\
\hline I 126 & Early Wisconsin & Brown silt loam & 6560 & 2000 & 72780 & \\
\hline 1026 & Late Wisconsin & Brown silt loam & 6870 & 1960 & 96420 & I 50 \\
\hline
\end{tabular}

Prairie Lands, Flat

\begin{tabular}{|c|c|c|c|c|c|c|c|}
\hline 329 & Lower Illinoisan & Drab silt loam & 3160 & 1230 & 54420 & & 3980 \\
\hline 420 & Middle Illinoisan & Black clay loam & 6180 & 2260 & 64070 & 2940 & \\
\hline 520 & Upper Illinoisan & Black clay loam & 7380 & 2690 & 60760 & 70 & \\
\hline II 20 & Early Wisconsin & Black clay loam & 7200 & 3090 & 71670 & 49300 & \\
\hline 1220 & Late Wisconsin . & Black clay loam & 9100 & 2860 & 78840 & I 310 & \\
\hline
\end{tabular}

Timber Uplands, Rolling or Hilly

\begin{tabular}{|c|c|c|c|c|c|c|}
\hline I35 & Unglaciated . & Yellow silt loam & 2030 & 2120 & 67320 & 4850 \\
\hline 335 & Lower Illinoisan & Yellow silt loam & 2170 & 2000 & $673^{80}$ & 6630 \\
\hline 435 & Middle Illinoisan & Yellow silt loam & I980 & I5 10 & 65370 & 370 \\
\hline 535 & Upper Illinoisan & Yellow silt loam & 1900 & 1610 & 72570 & 2220 \\
\hline 635 & Pre-Iowan . . & Yellow silt loam & 2290 & I 750 & 76150 & 650 \\
\hline 735 & Iowan $\cdot \cdot \cdot$ & Yellow silt loam & 2120 & 1960 & $7 \mathrm{II} 80$ & 150 \\
\hline I 135 & Early Wisconsin & Yellow silt loam & 1870 & 1590 & 68690 & 3910 \\
\hline 864 & Deep loess & $\begin{array}{c}\text { Yellow fine sandy } \\
\text { loam }\end{array}$ & 2610 & 1600 & 71760 & 8 \\
\hline
\end{tabular}

Timber Lands, Undulating

\begin{tabular}{|c|c|c|c|c|c|}
\hline $\begin{array}{r}1034 \\
760\end{array}$ & $\begin{array}{l}\text { Late Wisconsin . } \\
\text { Iowan . . . . }\end{array}$ & $\begin{array}{l}\text { Yellow-gray silt } \\
\text { loam } \cdot \dot{ } \\
\text { Brown sandy } \\
\text { loam } \cdot\end{array}$ & $\begin{array}{l}2710 \\
3920\end{array}$ & $\begin{array}{l}\text { I } 390 \\
\text { I } 590\end{array}$ & $\begin{array}{r}\text { I } 11100 \\
54300\end{array}$ \\
\hline
\end{tabular}


Table i6. Ferthity in Illinois SoIls - Continued

\begin{tabular}{|c|c|c|c|c|c|c|c|}
\hline $\begin{array}{l}\text { SolL } \\
\text { TYPE } \\
\text { No. }\end{array}$ & $\begin{array}{l}\text { SOIL AREa OR } \\
\text { GLACIATION }\end{array}$ & SOIL Type & $\begin{array}{c}\text { Total } \\
\text { NITRO- } \\
\text { GEN }\end{array}$ & $\begin{array}{c}\text { TotaL } \\
\text { PHOS- } \\
\text { PHOR- } \\
\text { US }\end{array}$ & $\begin{array}{c}\text { Total } \\
\text { Potas- } \\
\text { SIUM }\end{array}$ & $\begin{array}{c}\text { LIME- } \\
\text { STONE } \\
\text { PRESENT }\end{array}$ & $\begin{array}{l}\text { LIME- } \\
\text { STONE } \\
\text { RE- } \\
\text { QUIRED }\end{array}$ \\
\hline
\end{tabular}

Timber Uplands, Flat

\begin{tabular}{|c|c|c|c|c|c|c|}
\hline 332 & Lower Illinoisan & $\begin{array}{l}\text { Light gray silt } \\
\text { loam on tight } \\
\text { clay. }\end{array}$ & I920 & 1240 & $5^{8} 480$ & 7200 \\
\hline
\end{tabular}

Sand, Swamp, and Bottom Lands

\begin{tabular}{|c|c|c|c|c|c|c|c|}
\hline I $33^{I}$ & Old bottom lands & $\begin{array}{c}\text { Deep gray silt } \\
\text { loam } .\end{array}$ & $225^{\circ}$ & I83O & 68090 & & $4499^{\circ}$ \\
\hline $145^{\mathrm{I}}$ & Late bottom lands & Brown loam . . & 6660 & 2160 & 77540 & 980 & \\
\hline I $48 \mathrm{I}$ & $\begin{array}{c}\text { Sand plains and } \\
\text { dunes }\end{array}$ & & 2070 & I 480 & & & 5 \\
\hline I 401 & Late swamp. . & Deep peat & 64980 & 2940 & 7010 & & 210 \\
\hline
\end{tabular}

subsoils are also well supplied with potassium, or may be by deep plowing; whereas broad areas of deep peat or of shallow or medium peat on sand are as a rule deficient in potassium.

Most of the older soils (chiefly in southern and western Illinois) are markedly acid in the surface and subsurface, and exceedingly acid in the subsoil. The rolling or hilly timber uplands and the sand soil are very deficient in nitrogen, while the undulating prairie lands (except in the late Wisconsin glaciation), the undulating timber lands, and even the flat prairie lands in the oldest formation, are only moderately well supplied with nitrogen. The black clay loams (especially in the more recent formations) are rich, and the peaty soils exceedingly rich, in humus and nitrogen.

In the main the soils of central and northern Illinois are comparable with similar soil types in Indiana and Ohio on the east, and with Iowa and eastern Nebraska soils on the west; and the soils of southern Illinois are comparable with similar types in Missouri and eastern Kansas on the west, and also with the loesscovered areas in southern Indiana, Kentucky, Tennessee, and northwest Mississippi; while some of the same soil types that are 


\section{Table i 7. Fertility in Illinois Solls}

Average Pounds per Acre in 6 Million Pounds of Subsoil (20-40 Inches)

\begin{tabular}{|c|c|c|c|c|c|c|c|}
\hline $\begin{array}{l}\text { SoIL } \\
\text { TyPE } \\
\text { No. }\end{array}$ & $\begin{array}{l}\text { SOIL AREA OR } \\
\text { GLACIATION }\end{array}$ & Sort Type & $\begin{array}{c}\text { Total } \\
\text { Nitro- } \\
\text { GEN }\end{array}$ & $\begin{array}{c}\text { TOTAL } \\
\text { PHOS- } \\
\text { PHOR- } \\
\text { US }\end{array}$ & $\begin{array}{l}\text { Total } \\
\text { Potas- } \\
\text { SIUM }\end{array}$ & $\begin{array}{c}\text { LIME- } \\
\text { STONE } \\
\text { PrESENT }\end{array}$ & $\begin{array}{c}\text { LIME- } \\
\text { STONE } \\
\text { RE- } \\
\text { QUIRED }\end{array}$ \\
\hline
\end{tabular}

Prairie Lands, Undulating

\begin{tabular}{|c|c|c|c|c|c|c|c|}
\hline $33^{\circ}$ & Lower Illinoisan & $\begin{array}{l}\text { Gray silt loam on } \\
\text { tight clay }\end{array}$ & $3^{240}$ & 2400 & 84300 & & 21580 \\
\hline 426 & Middle Illinoisan & Brown silt loam & 3440 & 2680 & 90040 & & \\
\hline 526 & Upper Illinoisan & Brown silt loam & 3440 & 2790 & 98580 & & \\
\hline 626 & Pre-Iowan . & Brown silt loam & 3940 & 3380 & 102620 & & 1650 \\
\hline 726 & Iowan . . & Brown silt loam & 3540 & 2780 & 99780 & & $x 940$ \\
\hline II 26 & Early Wisconsin & Brown silt loam & 3420 & 2620 & I 7880 & 66600 & \\
\hline 1026 & Late Wisconsin & Brown silt loam & $3^{6} 30$ & $263 c$ & 160140 & 728000 & \\
\hline
\end{tabular}

Prairie Lands, Flat

\begin{tabular}{|c|c|c|c|c|c|c|c|}
\hline 329 & Lower Illinoisan & Drab silt loam & 3400 & I69o & 80830 & & I5 5770 \\
\hline 420 & Middle Illinoisan & Black clay loam & 3020 & $3 \circ 30$ & 94900 & I 49200 & \\
\hline 520 & Upper Illinoisan & Black clay loam & 3140 & 3640 & 96220 & 1210 & \\
\hline I 20 & Early Wisconsin & Black clay loam & 3490 & 3630 & I I I 280 & I X 7500 & \\
\hline 1220 & Late Wisconsin & Black clay loam & 3180 & 3930 & I 25370 & 5470 & \\
\hline
\end{tabular}

Timber Lands, Rolling or Hilly

\begin{tabular}{|c|c|c|c|c|c|c|}
\hline r 35 & Unglaciated . . & Yellow silt loam & r970 & 3280 & 105430 & 20660 \\
\hline 335 & Lower Illinoisan & Yellow silt loam & 2480 & 3170 & 99670 & 21500 \\
\hline 435 & Middle Illinoisan & Yellow silt loam & 2820 & 2810 & 99000 & 3700 \\
\hline 535 & Upper Illinoisan & Yellow silt loam & 2280 & 3270 & I00950 & 6210 \\
\hline 635 & Pre-Iowan . . & Yellow silt loam & 2380 & 3400 & 102100 & 5480 \\
\hline 735 & Iowan . . . . & Yellow silt loam & 2490 & 3900 & 105030 & $375^{\circ}$ \\
\hline I 35 & Early Wisconsin & Yellow silt Ioam & $245 \circ$ & 2660 & 103830 & 4400 \\
\hline 864 & Deep loess & $\begin{array}{l}\text { Yellow fine sandy } \\
\text { loam }\end{array}$ & $273^{\circ}$ & 3320 & $105^{210}$ & 3620 \\
\hline
\end{tabular}

Timber Uplands, Undulating

\begin{tabular}{|c|c|c|c|c|c|c|}
\hline $\begin{array}{r}1034 \\
760\end{array}$ & $\begin{array}{l}\text { Late Wisconsin } \\
\text { Iowan . . . . }\end{array}$ & $\begin{array}{c}\text { Yellow gray silt } \\
\text { loam } \cdot \cdot \cdot \cdot \\
\text { Brown } \\
\text { loam } \\
\text { sandy }\end{array}$ & $\begin{array}{l}3240 \\
4160\end{array}$ & 2400 & $\begin{array}{r}156740 \\
81180\end{array}$ & $\begin{array}{r}1034000 \\
49700\end{array}$ \\
\hline
\end{tabular}


Table i 7. Fertulity in Illinors Solls-Continued

\begin{tabular}{|c|c|c|c|c|c|c|c|}
\hline $\begin{array}{l}\text { Soll, } \\
\text { TyPE } \\
\text { No. }\end{array}$ & $\begin{array}{l}\text { SOIL. AREA or } \\
\text { GLACIATION }\end{array}$ & SoIL, Txpe & $\begin{array}{l}\text { Total } \\
\text { NITRO- } \\
\text { GEN }\end{array}$ & $\begin{array}{c}\text { TOTAL } \\
\text { PHOS- } \\
\text { PHOR- } \\
\text { US }\end{array}$ & $\begin{array}{l}\text { Total. } \\
\text { Potas- } \\
\text { SIUMI }\end{array}$ & $\begin{array}{c}\text { LiMe- } \\
\text { STONE } \\
\text { PrESENT }\end{array}$ & $\begin{array}{l}\text { LIME- } \\
\text { STONE } \\
\text { RE- } \\
\text { QUIRED }\end{array}$ \\
\hline
\end{tabular}

Timber Uplands, Flat

\begin{tabular}{|c|c|c|c|c|c|c|}
\hline $33^{2}$ & Lower Illinoisan & $\begin{array}{l}\text { Light gray silt loam } \\
\text { on tight clay. }\end{array}$ & 2100 & 2230 & $9055^{\circ}$ & I $975^{\circ}$ \\
\hline
\end{tabular}

Sand, Swamp, and Bottom Lands

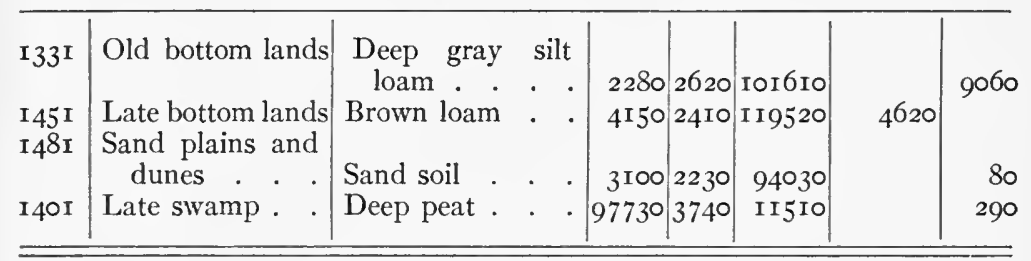

found in the "Great American Bottoms" in southwestern Illinois, are found in the Mississippi Delta farther south.

The terminal moraine of the Wisconsin glaciation extends from southern Edgar County, Illinois, to the center of Parke County, Indiana, thence in a southeast direction to the north line of Jennings County, thence northeast to the south line of FayetteCounty, and thence to the southeast corner of Franklin County.

About two thirds of the state lies north of this line and resembles the timber uplands of northeastern Illinois, with a smaller proportion of prairie lands and considerable areas of swamp, especiallyl in the Kankakee river basin.

South of the terminal moraine the state is largely loess covered, and resembles the timber lands of southern Illinois, except for a central area of residual soils in Monroe, Lawrence, Martin, Orange, Washington, Warrick, DuBois, Crawford, and parts of most adjoining counties.

In the I907 Report of the Indiana Geological Survey, Mr. Robert E. Lyons gives data from which the following table is derived: 
Table i8. Composition of Southern Indiana Surface Soils Pounds per Acre in 2 Million of Soil (About $6 \frac{2}{3}$ Inches Deep)

\begin{tabular}{|c|c|c|c|}
\hline Sorts & $\begin{array}{l}\text { NuMber of } \\
\text { ANALYSES }\end{array}$ & $\begin{array}{c}\text { Total } \\
\text { NitROGEN }\end{array}$ & $\begin{array}{l}\text { Acid-soluble } \\
\text { Phosphords }\end{array}$ \\
\hline Limestone soil (Residual rolling) . . . & 5 & 3080 & I330 \\
\hline Limestone and shale soil (Residual rolling) & I & 3660 & 4990 \\
\hline Volusia silt loam (Residual shale, rolling) & I & 2300 & 1160 \\
\hline Miami silt loam (Loessial, level) . . . & I & I 160 & I 340 \\
\hline Waverly silt loam (Stream valleys). & 2 & $445^{\circ}$ & 2162 \\
\hline Ohio river bottom land . . . & I & 1840 & $243^{\circ}$ \\
\hline
\end{tabular}

Aside from the bottom lands, these soils are as a rule markedly acid. The residual soil derived from limestone and shale is rich in phosphorus, and the bottom lands are also well supplied with that element. On the other soils much commercial fertilizer, chiefly bone meal and acid phosphate, is already being used. The upland silt loams are becoming very deficient in nitrogen and organic matter. Two analyses of the shale underlying some of the residual soils show an average potassium content of 64,500 pounds and only 3000 pounds of total calcium, in 2 million of shale.

The rolling residual soil derived from shale (Volusia silt loam) and the level or gently undulating loessial soil (Miami silt loam) are very acid.

A residual soil of sandstone origin is found in Martin, Lawrence, and some adjoining counties. In his discussion of Indiana soil types, Mr. Charles W. Shannon makes the following suggestive statement:

"Large amounts of planer dust from the stone mills are being used as a lime application on the various soils with good results. The most noted of these experiments are in cases where from 1000 to 2000 pounds per acre of the dust was applied to fields of alfalfa and clover, and as a result much better stands were secured than in parts without the lime. This is a cheap source of lime for those who have access to the mills."

As an average of $2 \mathrm{I}$ analyses the Ohio Experiment Station (Bulletin ${ }_{15}{ }^{\circ}$ ) finds, in 2 million pounds of the surface soil on the Station farm at Wooster, I880 pounds of total nitrogen and 920 pounds of acid-soluble phosphorus; and Ohio Circular No. 79 re- 
ports data showing 31,000 pounds of total potassium in the same stratum. The average of $\mathrm{r} 6 \mathrm{r}$ soils from various parts of Ohio shows 960 pounds of acid-soluble phosphorus in 2 million of soil. As a general average about 85 per cent of the phosphorus in such soils is soluble in the acid used, so that the total phosphorus probably amounts to about II00 pounds.

The average composition of three samples of surface soil from the loess-covered uplands at the Missouri Experiment Station at Columbia, in central Missouri, shows 27 ro pounds of total nitrogen, 690 pounds of total phosphorus, and 28,500 pounds of total potassium, in 2 million pounds of soil (Schweitzer, Missouri Bulletin No. 5). These amounts correspond closely with the average composition of the most common upland soils of southern Illinois; and the more highly productive corn belt soils of north central and northwest Missouri are more nearly comparable with the brown silt loams and black clay loams of the middle Illinoisan glaciation.

An analysis ${ }^{1}$ of the worn upland soil near St. Louis, Missouri, shows Ir60 pounds of nitrogen, 700 pounds of total phosphorus, and 35,200 pounds of potassium in 2 million of soil. This is about the average composition of the subsurface soil of the deep loess area in Illinois, and indicates previous loss of surface soil by washing.

Professor Keyser has kindly furnished the author with some unpublished data concerning the soils of Nebraska, showing that the glacial silt loam of eastern Nebraska, which has been formed evidently from the weathering of the till of the Kansan glaciation, contains, in 2 million pounds of the surface, 3940 pounds of nitrogen, 660 pounds of total phosphorus, and 23,000 pounds of potassium; while the ordinary loessial soil representing the most common corn belt type in the southeast part of the state (and probably of northeast Kansas as well) contains $5 \mathrm{I} 60$ pounds of nitrogen, I060 of total phosphorus, and 29,000 pounds of potassium, corresponding very closely to the brown silt loams in the loess-covered middle and upper Illinoisan glaciation. The common silt loam of the less humid region of central Nebraska contains 3680 pounds of nitrogen, I520 of phosphorus, and 48,000 of potassium.

A preliminary general soil survey of Iowa (Stevenson, Iowa

${ }^{1}$ Reported by Doctor R. O. Graham, Bloomington, Illinois, as a commercial analysis. 
Bulletin 82) shows five important soil areas in Iowa, which closely resemble similar areas in Illinois.

(I) About one tier of counties bordering the Mississippi (with a western projection which includes most of Cedar, Johnson, Iowa, Poweshiek, and Jasper counties) is termed the Mississippi loess area, and resembles the loessial soil on the Illinois side.

(2) Similarly, along the Missouri and Big Sioux rivers the two western tiers of counties are chiefly in the Missouri loess area.

(3) The Kansan glaciation (overlaid with shallow loess on the less rolling lands) covers the southern third of the remainder of Iowa, and this resembles closely the lower Illinoisan, except that the older Kansan is more broken and has much more exposed till on the eroded hillsides.

(4) The eastern part of the remainder of the state is covered by the Iowan glaciation, and (5) the somewhat larger western part by the Wisconsin glaciation, both of which are also found in Illinois. In both states the Iowan glaciation is characterized by its rolling topography and perfect surface drainage, and the Wisconsin by its level prairies which require much artificial drainage by tile and open ditches.

Eight analyses of Iowan soils, reported to the author by Doctor J. B. Weems while professor of agricultural chemistry in the Iowa State College, showed goo pounds of acid-soluble phosphorus in 2 million of soil, as a general average. The several soil types represented varied considerably, however, as would be expected from comparison with similar Illinois soils, the highest amount reported being 1600 pounds of acid-soluble phosphorus per acre in a $6 \frac{2}{3}$-inch stratum, corresponding to 1880 pounds of total phosphorus, if 85 per cent were acid-soluble. (This method of estimating total phosphorus from the acid-soluble phosphorus is never safe for application to individual soil samples, but it is approximately correct for large averages of most common soils of central United States.) The acid-soluble potassium (which varies from less than one sixth of the total in old soils to more than one third of the total in more recent, less weathered soils) amounted to 4670 pounds as an average of the eight soils (the highest being 7800 pounds) in 2 million of surface soil, corresponding probably to 30,000 to 40,000 pounds of total potassium. The analysis of loess from Dubuque, 
Iowa, shows 35,600 pounds of total potassium in 2 million (see Table II).

Since the above was written the author has secured, through the kindness of Professor Stevenson, the unpublished data shown in Table I8. I which present the average results of from one to six analyses of the most important soil types in the great soil areas of the state. Professor Stevenson writes: "The samples are believed to represent the most widely distributed type of the respective areas. We did not determine total potassium." (Two types, the uncovered glacial till, and the shallow loess, are included for the Kansan area.)

Table I8.I. Plant Food in Surface Soils of Iowa Pounds per Acre in 2 Million (about $6 \frac{2}{3}$-inch Stratum)

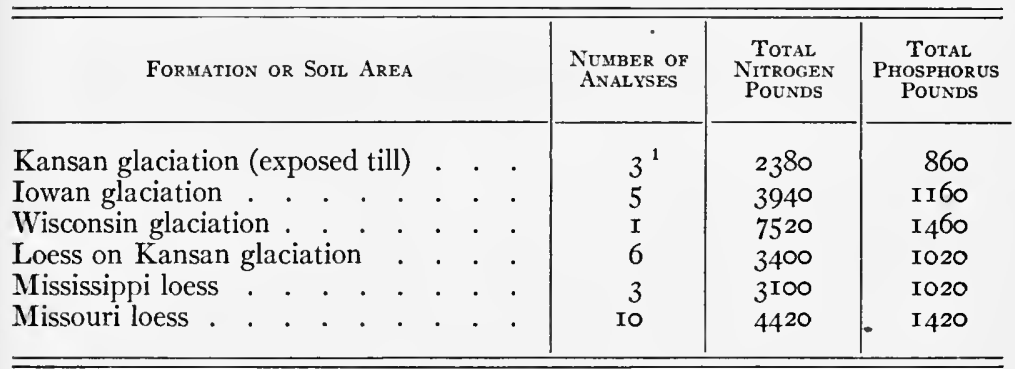

${ }^{1}$ Only two analyses for phosphorus in the Kansan till

The Kansan drift is the oldest and the poorest in both nitrogen and phosphorus, while the Wisconsin is the newest and the richest, with the Iowan intermediate in both respects. The Mississippi loess and the shallow loess on the less rolling parts of the Kansan glaciation are similar in composition and probably of similar origin (of the Iowan age), but the Mississippi loess is much deeper and of a more rolling topography, which insures a much better subsoil, physically, and may also account for the somewhat lower nitrogen content of the surface, through loss of organic matter by washing. The higher phosphorus content of the Missouri loess suggests that it owes its origin in part to deposits from the semi-arid plains of the northwest, the richer mineral soil having encouraged the more recent accumulation of nitrogen. 


\section{SOILS OF THE SOUTHERN STATES}

The average composition of twelve samples of soil from seven different counties in Kentucky outside of the Blue Grass Region shows $55^{\circ}$ pounds of acid-soluble phosphorus in 2 million pounds of surface soil; and within the famous Blue Grass Region the supply of acid-soluble phosphorus amounts to 5200 pounds (nearly ten times as much) in 2 million of soil, as the average of 30 soil analyses, collected from five counties, these residual soils having been formed in part at least from the weathering of phosphatic limestone.

The state of Tennessee may be divided geologically into five principal sections:

(I) The great loess-covered undulating upland area of west Tennessee, lying chiefly between the Mississippi and Tennessee rivers.

(2) The Central Basin, including most of ten counties (Davidson, Trousdale, Jackson, Smith, Wilson, Williamson, Rutherford, Bedford, Marshall, and Maury) and parts of several adjoining counties. The Central Basin includes much of the great phosphate beds of Tennessee. It resembles in some respects the Blue Grass region of Kentucky, and by some the Central Basin of Tennessee is claimed to be the original home of Kentucky blue grass.

(3) The Highland Rim, surrounding the Central Basin.

(4) The Cumberland Plateau, farther east.

(5) The East Tennessee Valley, lying between the Cumberland Plateau and the Unaka Mountains on the eastern border of the state.

Table I9 shows the plant food in representative soils of each of these great sections, the averages of several soil analyses being reported for the more important areas (Mooers, Tennessee Bulletin 78).

The a verage composition of the yellow silt loam soil on the loesscovered Ozark Hills of southern Illinois shows 1890 pounds of nitrogen, $95^{\circ}$ pounds of phosphorus, and $31,45^{\circ}$ pounds of potassium per acre in 2 million pounds of surface soil, which is practically the same as for the west Tennessee soil. It may be kept in mind, too, that the north line of west Tennessee is only 35 miles 
Table i9. Composition of Surface Solls of Tennessee Average Pounds per Acre in 2 Million of Soil (about $6 \frac{2}{3}$-inch Stratum)

\begin{tabular}{|c|c|c|c|c|}
\hline SECTION OR AREA & ORIGIN OF SoIL & $\begin{array}{c}\text { Nrrrogen } \\
\text { (Total) }\end{array}$ & $\begin{array}{l}\text { PhosphoRUS } \\
\text { (Total) }\end{array}$ & $\begin{array}{l}\text { Potassium } \\
\text { ('Total) }\end{array}$ \\
\hline $\begin{array}{l}\text { West Tennessee } \\
\text { Highland Rim . } \\
\text { Central Basin . } \\
\text { Cumberland Plateau . } \\
\text { East Tennessee Valley } \\
\text { Bottom land . . . }\end{array}$ & $\begin{array}{l}\text { Loess deposit } \\
\text { Limestone } \\
\text { Limestone and phos- } \\
\text { phate } \cdot . \\
\text { Sandstone } \cdot . \\
\text { Limestone and dolomite } \\
\text { Alluvial . . . . }\end{array}$ & $\begin{array}{l}1890 \\
2100 \\
2350 \\
1700 \\
2080 \\
2620\end{array}$ & $\begin{array}{r}890 \\
660 \\
2030 \\
380 \\
980 \\
1840\end{array}$ & $\begin{array}{r}31020 \\
24600 \\
18160 \\
7840 \\
12130 \\
34160\end{array}$ \\
\hline
\end{tabular}

from the southern point of Illinois, and that much of the upland soil of northwest Mississippi is essentially of the same character.

It will be noted that the average soil of the Central Basin is comparatively rich in phosphorus, while the soils of the Highland Rim, and more especially the sandstone soils of the Cumberland Plateau, are extremely deficient in phosphorus, and the latter is also very poor in potassium, as might be expected from its origin.

The number of soil analyses entering the averages in Table ig is not sufficient for final data, but in the main they are supported by larger numbers of analyses for acid-soluble plant food. Thus, the averages of 25 analyses of soils from eight counties in the Central Basin show 2020 pounds of acid-soluble phosphorus in 2 million of soil, while 700 pounds of phosphorus is the corresponding average for 16 analyses of loessial soil from eleven counties in west Tennessee. The acid-soluble phosphorus in the samples whose total phosphorus content was determined (and thus afforded for use in Table I9) was I7 ro pounds for the Central Basin and $75^{\circ}$ pounds for the,west Tennessee soil, 84 per cent of the total having been dissolved by strong hydrochloric acid, in either case. On this basis, the general average of all samples would show 830 pounds of total phosphorus for west Tennessee and 2400 pounds for the Central Basin, in 2 million pounds of surface soil.

Hilgard reports the average of 97 analyses of Mississippi soils showing 790 pounds of acid-soluble phosphorus in 2 million pounds of surface soil, but the more abundant upland soils average about 
700 pounds, while 4100 pounds of phosphorus per acre (in a $6 \frac{2}{3}$-inch stratum) have been found in an upland soil of limestone origin. The "black prairie" limestone soils found in limited area in northeastern Mississippi and in northwestern Alabama are as a rule well supplied with phosphorus. This formation is apparently an extension of that found so commonly in the broad Central Basin of Tennessee, which also extends into Kentucky, where it again expands into the great Blue Grass Region.

An analysis made by Doctor H. C. White of a sample of soil representing the University farm of Georgia, collected in March, I884, from land that " had been cleared in December ( $188_{3}$ ) of a second growth of oak and hickory," gave the following amounts per acre based upon the surface foot, which was assumed to weigh $3,528,000$ pounds.

Table ig.i. Composition of Georgia Soll (University Farm)

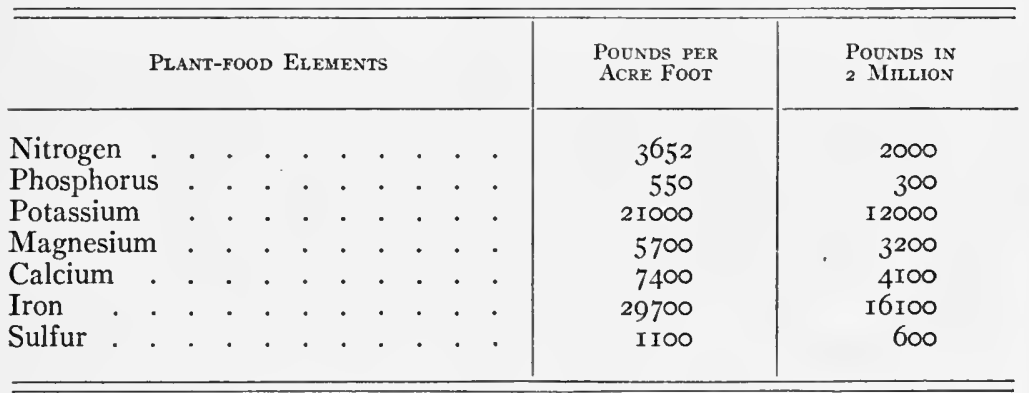

The original statement reports "sand and clay," and it must be assumed that the mineral elements as given above represent the amounts soluble in strong acid.

The Texas Experiment Station has analyzed a considerable number of soil samples collected to represent six general groups or "series," as mapped and named by the United States Bureau of Soils. The following descriptions are taken from Texas Bulletin 99 (1907):

"Norfolk soils. These are light-colored upland sandy soils, with a yellow clay or sandy clay subsoil, usually with good drainage.

"Of the areas under study, the Norfolk soils are found in Anderson, Houston, and Bexar counties. They are widely distributed in the eastern part of the state. 
"Orangeburg soils. The Orangeburg soils are gray to brown upland soils, with a red or yellowish clay sandy subsoil. The red color of the subsoil distinguishes the Orangeburg soils from the Norfolk soils. The red soils appear to be more productive, and are generally stronger than the corresponding soils of the Norfolk series. The Orangeburg soils are widely distributed, especially in East Texas.

"Lufkin soils. The Lufkin soils are gray, with heavy, very impervious plastic gray and mottled subsoils. These soils are generally lower in agricultural value than the Norfolk and Orangeburg soils, perhaps on account of the nature of the subsoils. These soils are found in Houston, Lamar, and Travis counties, of the areas studied.

"Susquehanna series. These are gray and brown surface soils with heavy plastic mottled subsoils. They differ from the Lufkin series in the color of subsoil. They are generally of low productiveness.

"Houston series. These are black calcareous prairie soils, very productive and durable. They are among the best soils of the state. Some of them have been in cultivation forty or fifty years without fertilizer, and though some of them have decreased somewhat in fertility, they are still productive. They are found, in areas surveyed, in Lamar, Hays, Travis, and Bexar counties. They are of general occurrence in the east-central portion of the state.

"These soils appear to owe their productiveness to their content of lime and organic matter, and nitrogen. Some of these soils will become deficient in phosphoric acid.

"Yazoo soils. These soils are bottom land, generally subject to overflow and very productive. The soils are mapped in only two areas, Anderson and Travis counties."

The following tabular statement gives the average amounts of total nitrogen, acid-soluble phosphorus, and acid-soluble potassium in 2 million pounds of the surface soil of these different soil types, based upon the analyses reported by Doctor Fraps.

\section{Table ig.2. Average Composition of Some Texas Solls Pounds in 2 Million of Soil}

\begin{tabular}{|c|c|c|c|c|}
\hline Conventional Name & SoIL Type & $\begin{array}{c}\text { TotaL } \\
\text { Nitro- } \\
\text { GEN }\end{array}$ & $\begin{array}{l}\text { ACID- } \\
\text { SOLUBLE } \\
\text { PHOS- } \\
\text { PHORUS }\end{array}$ & $\begin{array}{l}\text { ACID- } \\
\text { Soluble } \\
\text { Potas- } \\
\text { SIUM }\end{array}$ \\
\hline Norfolk soils . & Light sandy upland . . & 1000 & I80 & 2000 \\
\hline Orangeburg soils & Gray-brown sandy upland . & I 200 & 440 & 6200 \\
\hline Lufkin soils . . & Gray silt loam on tight clay . & 1000 & 180 & I800 \\
\hline Susquehanna series & Gray-brown silt loam on tight clay & I 400 & 260 & 3700 \\
\hline Houston series & Black prairie . . . . . . & 2800 & 530 & 5600 \\
\hline Yazoo soils . . . & Bottom land . . . . . . . . . & I600 & 960 & 6700 \\
\hline
\end{tabular}


With the exception of the bottom land, these soils are extremely poor in phosphorus; and, aside from the black prairie, they are also very poor in nitrogen.

Hilgard reports 940 pounds of acid-soluble phosphorus in 2 million pounds of Louisiana soil, as an average of 35 analyses. The Geological Survey of Louisiana has furnished the data for the following statement, showing the total nitrogen, acid-soluble phosphorus, and acid-soluble potassium in 8 surface soils and 2 subsoils in Madison Parish, opposite Vicksburg. These are all alluvial soils deposited from the overflow of the Mississippi River.

Table 19.3. Composition of Louisiana Soils in Madison Parish

Pounds in 2 Million of Soil

\begin{tabular}{|c|c|c|c|}
\hline \multirow{2}{*}{ Description of SoIL } & \multirow{2}{*}{$\begin{array}{c}\text { Total } \\
\text { NITROGEN }\end{array}$} & \multicolumn{2}{|c|}{ ACID-SOLUBLE } \\
\hline & & Phosphorus & Potassium \\
\hline 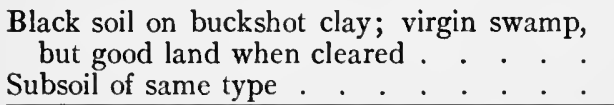 & $\begin{array}{l}3986 \\
\text { I } 286\end{array}$ & $\begin{array}{l}\text { I } 450 \\
1044\end{array}$ & $\begin{array}{l}6562 \\
4976\end{array}$ \\
\hline $\begin{array}{l}\text { Dark gray soil on buckshot clay; once swamp; } \\
\text { cultivated } 9 \text { years } \\
\text { Subsoil of same }\end{array}$ & $\begin{array}{r}3334 \\
95^{\circ}\end{array}$ & $\begin{array}{r}\text { I } 74 \\
928\end{array}$ & $\begin{array}{l}5466 \\
3570\end{array}$ \\
\hline 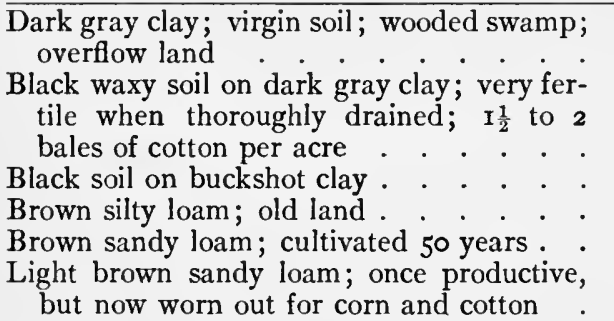 & $\begin{array}{l}2456 \\
2662 \\
1562 \\
1244 \\
1306\end{array}$ & $\begin{array}{r}2024 \\
1760 \\
1234 \\
1474 \\
1206\end{array}$ & $\begin{array}{l}5 \text { I } 34 \\
4748 \\
5084 \\
4100 \\
3806\end{array}$ \\
\hline
\end{tabular}

In phosphorus content these soils resemble the late bottom lands of Illinois, but the nitrogen content is, as a rule, much lower in the Louisiana soils, and extremely low in the old, worn soils.

It may be mentioned here that the Mississippi Experiment Station has conducted some field experiments on delta lands, concerning which the following is reported in Mississippi Bulletin I I9: 
"The land on which the tests were made had been cropped in cotton for many years. A part of it is loam soil and is well drained. A test was also made on stiff buckshot land."

"The average increase from 300 pounds of high grade cotton seed meal per acre for the three years (1906-8) has been 106 pounds of lint cotton. We have not been able to increase the size of the crop nor its earliness by the use of either phosphorus or potash."

"The increase from the application of 300 pounds of cotton seed meal to the stiff buckshot land was 36 pounds of lint cotton per acre. This is not sufficient to make the use of the meal profitable on this character of land."

As an average of $3^{8}$ analyses of Arkansas soils, Hilgard gives I 400 pounds of acid-soluble phosphorus in 2 million of soil, suggesting bottom-land soils or some connection with the phosphate deposits of that state.

\section{SOILS OF THE NORTHERN STATES}

In the northern tier of states, where the soils are of more recent origin and where the climate of winter offers less exposure to weathering and leaching, the normal soils are, as a rule, richer in mineral plant food, as is indicated, for example, by comparing the soils of the late Wisconsin glaciation in northern Illinois with similar types in the older middle Illinoisan glaciation. Of course, the upland timber soils are not comparable in nitrogen content with the black prairie soils.

The late Doctor Robert C. Kedsie, one of the few great scientists who, with Doctor E. W. Hilgard and Doctor S. W. Johnson, helped to lay firm foundations for the American Agricultural Experiment Stations, reported analyses of $28 \mathrm{Michigan}$ soils grouped in accordance with a general survey or classification of the soils of that state (Michigan Bulletin 99):

I. The four southern tiers of counties are classed as theMichigan "wheat belt."

2. The area along the eastern shore of Lake Michigan, including especially the light porous soils upon which peaches of the finest quality are extensively produced, is termed the "peach belt."

3. Several counties in the Traverse Bay region, including much soil of the sandy-loam type, constitute the " potato district." 
4. The large tract of light, sandy lands in the north-central part of the Lower Peninsula is called the " Jack Pine Plains."

5. The peaty swamp soils, used especially for the growing of celery, peppermint, etc., are so designated.

In Table 20 is given the average composition of the soils from each of these sections. The nitrogen reported is total, but the data for phosphorus and potassium represent only the amount soluble in acids, probably much stronger, however, than now commonly used. The amount closely approaches the total in case of phosphorus, but probably represents less than one half of the total potassium actually present in the soil. (A larger proportion of the total potassium present in the newer, less-weathered soils is soluble in acid than of the total potassium in the older leached soils found in the states farther south.)

Table 20. Average Composition of Some Michigan Solls

Pounds per Acre in 2 Million of Soil (about $6 \frac{2}{3}$ Inches)

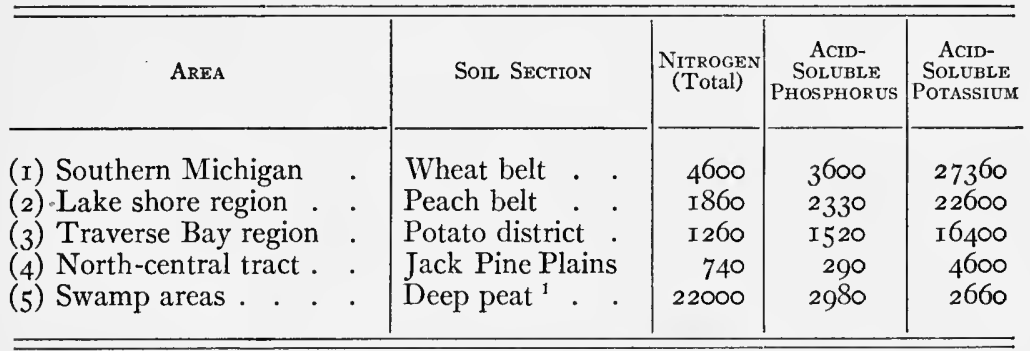

${ }^{1}$ The amounts given for deep peat represent the plant food in 1 million pounds of the material, the specific gravity of which is about one half that of ordinary soils.

These striking and valuable results obtained in a very preliminary general survey of Michigan soils clearly indicate the much greater possible value of an extended and detailed investigation of the soils of the state. The high phosphorus content of theMichigan soils, especially of the great area of the wheat belt (3600 pounds), is in marked contrast, not only with the extremely low phosphorus content of the Jack Pine Plains (290 pounds, - less than one tenth as much), but also with the small supply of phosphorus in the common upland soils of southern Illinois, central Missouri, and the western parts of Kentucky, Tennessee, and other southern states. 
In commenting on his study of Michigan soils, Doctor Kedsie said:

"Chemical analysis of the soil is of value in determining whether the soil is capable of fertility or the contrary; also in determining the measure of its possible fertility. ${ }^{1} \quad$ There are certain ash elements which are absolutely necessary for plant growth, in the absence of any one of which vegetable growth is impossible; if the supply is relatively limited, plant growth will be limited correspondingly. Hence, chemical analysis of a soil is of importance in determining possibility of fertility and of the relative fertility which may be secured under favorable conditions. . . . Chemical analysis will not always distinguish between a fruitful and an unfruitful soil. A soil may be unproductive for physical reasons, though it may still contain all the chemical elements of fertility."

The Michigan wheat-belt soils include several different soil types, but among the nine soil samples analyzed from that area, the poorest contained 2600 pounds of acid-soluble phosphorus, or 500 pounds more than the average of the best Illinois soil. More than four times as much phosphorus is contained in the average Michigan wheat-belt soil (when these samples were taken) as is now contained in the common soils of southern Illinois.

A preliminary general survey of Wisconsin soils (Whitson, Wisconsin Agricultural Experiment Station, Annual Report for I905, pages 262-270) outlines seven different great soil areas in that state:

(I) The unglaciated area of the southwest quarter (extending into northwestern Illinois) with three subdi visions in which residual sands, sandy loams, and clay loams, respectively, predominate; (2) the early, and (3) the late glaciations (each in two divisions based upon the underlying rocks), occupying largely the remaining three fourths of the state, and covered with glacial till, with little or no loess deposit; (4) separated sand areas of glacial origin, as in the south-central, extreme northern, and northwest parts of the state; (5) a loessial area covering a strip of upland along the Mississippi; (6) "red clay" areas of lacustrine origin between Green Bay and Lake Winnebago and on the Lake Superior shore; and (7) the scattered swamps of muck and peat.

But few analyses of Wisconsin soils have been reported. An

1 Italics by C. G. H. 
ultimate analysis of virgin soil from the Wisconsin Experiment Station Farm at Madison, in the late glaciation, shows 3600 pounds of nitrogen, 1500 pounds of phosphorus, and 36,300 pounds of potassium, in 2 million pounds of surface soil. Where the same soil had been heavily cropped in pot cultures (I9 crops having been removed) the nitrogen was reduced to 2200 pounds and the phosphorus to II40 pounds, with no determinable change in total potassium content. The analysis of another soil from the late glaciation from northern Outagamie County showed I 400 pounds of nitrogen and 2380 pounds of acid-soluble phosphorus. This glaciation Professor Whitson regards as the best soil area in the state.

Residual sand from Jackson County contained rooo pounds of nitrogen, 870 of phosphorus, and 5100 of total potassium in 2 million of surface soil, and the glacial sand from Vilas County contained 1000 pounds of nitrogen, 1580 pounds of phosphorus, and 30,000 pounds of potassium, indicating that the residual sand is more largely quartz, while the glacial sand consists chiefly of silicate minerals. (Compare with Tennessee soils.)

Red clay from Ashland County contained 1400 pounds of acidsoluble phosphorus in 2 million of soil; and peaty swamp soil from Sauk County contained 32,000 of nitrogen, 1230 pounds of acidsoluble phosphorus, and only 9 ro pounds of acid-soluble potassium, in I million pounds of the surface soil.

The acid-soluble plant food hás been determined in many Minnesota soils (Snyder, Minnesota Bulletin 4I), and a few analyses are reported showing the total plant food in representative soils.

The average prairie soil of the Red River Valley in northwestern Minnesota contains 8200 pounds of nitrogen, 3340 pounds of phosphorus, and 45,100 pounds of potassium in the surface 2 million pounds; and the average prairie soil in west-central Minnesota contains 5300 pounds of nitrogen, I 760 pounds of phosphorus, and 63,300 pounds of potassium. A general average for the soils of the east-central part of the state is 5600 pounds of nitrogen, 2460 pounds of phosphorus, and 29,000 pounds of total potassium; while the average southeastern Minnesota soils contain 4400 pounds of nitrogen, I910 pounds of phosphorus, and 30,200 pounds of potassium, in 2 million pounds of surface. 
From the general glacial map of the United States it will be seen that southeastern Minnesota lies in the older Iowan glaciation, while most of the remainder of the state is covered by the late Wisconsin glaciation. This may account for the marked difference in potassium content between the soils of eastern and western Minnesota. (See also Tables 15,16 , and 17 for a comparison of these areas in Illinois.) It will be noted that the Red River basin lies within the boundaries of the old glacial lake, "Agassiz." (See also Canadian soils.)

The analysis of a sample composed of equal parts of two hundred representative soils from various parts of Minnesota showed 2360 pounds of acid-soluble phosphorus in 2 million of soil.

\section{SOILS OF THE WESTERN STATES}

The soils of the arid plains are, as a rule, rich in mineral plant food and poor in nitrogen, doubtless due to the fact that with but little rainfall there has been practically no loss of minerals by leaching, and but small accumulation of vegetable matter, in which the supply of nitrogen is contained. Headden (Colorado Bulletin 65) reports ultimate analyses of four Colorado soils, showing as an average 2900 pounds of phosphorus and 39,500 pounds of potassium; but the average of six soils shows only 2000 pounds of nitrogen, in 2 million of surface soil. Widtsoe (Utah Bulletin 52) shows 37 analyses of Utah soils a veraging $185^{\circ}$ pounds of acid-soluble phosphorus and $245^{\circ}$ pounds of total nitrogen, in 2 million of soil, in the most fertile valleys. On the arid plains the supply of nitrogen is usually very much less. Doctor Widtsoe states that he, "in common with those who have traversed the wastes of western America, has traveled for days without seeing a trace of vegetation, and such soils are almost devoid of organic matter and humus, and contain but small quantities of nitrogen." Hilgard gives 600 pounds of total nitrogen and 2000 pounds of acid-soluble phosphorus in 2 million of soil, as the average of 16 analyses of the arid soils of Colorado. As a rule, the soils of the arid region contain about 3 per cent of lime $\left(\mathrm{CaCO}_{3}\right)$, or 30 tons of calcium carbonate in 2 million pounds of soil; and the Utah Station reports 18 soil analyses from one county, containing as an average more than 20 percent 
of calcium carbonate corresponding to 200 tons per acre to a depth of $6 \frac{2}{3}$ inches.

For 2 million pounds of surface soil, Hilgard's "Soils" gives the following amounts of acid-soluble phosphorus as the average of many analyses: Nevada, 2800; Wyoming, 1570 ; Montana, I920; Idaho, I400. Mr. E. E. Hoskins, while a student in the University of Illinois, analyzed a sample said to represent good "bench" land near Boise City, Idaho, finding 2350 pounds of nitrogen, I320 of total phosphorus, and 4I,400 pounds of potassium, in 2 million of soil.

In the Pacific coast states, Hilgard reports (as acid-soluble) I830 pounds of phosphorus and 10,790 of potassium for Washington, 960 of phosphorus and 8960 of potassium for Oregon, in 2 million pounds of surface soil; also 2800 pounds of total nitrogen, 875 of acid-soluble phosphorus, and 10,100 pounds of acid-soluble potassium, in 2 million pounds of the surface soils of California, as an average of 262 analyses.

\section{THE SOILS OF CANADA}

It will be kept in mind, of course, that Canada comprises an immense territory $(3,300,000$ square miles, compared with $3,600,000$ square miles in the United States, including nearly 600,000 square miles in Alaska) and includes vast areas that are uninhabited, and in part uninhabitable, although the more favored regions are sufficiently extensive ultimately to support a mighty nation.

The Canadian Agricultural Experiment Station (known officially as the Dominion Experimental Farms, with headquarters at Ottawa) has made analyses of Canadian soils collected from Vancouver Island on the west to Nova Scotia on the east. Perhaps the most complete investigation has been made of the valley lands and Piedmont soils of British Columbia. In general, these soil investigations have been conducted with reference to uncultivated lands or lands put under cultivation in recent ycars. They do not represent the comparatively small areas of Canadian soil that have been long cultivated, some of which has already been much depleted or much fertilized. The samples have been collected with 


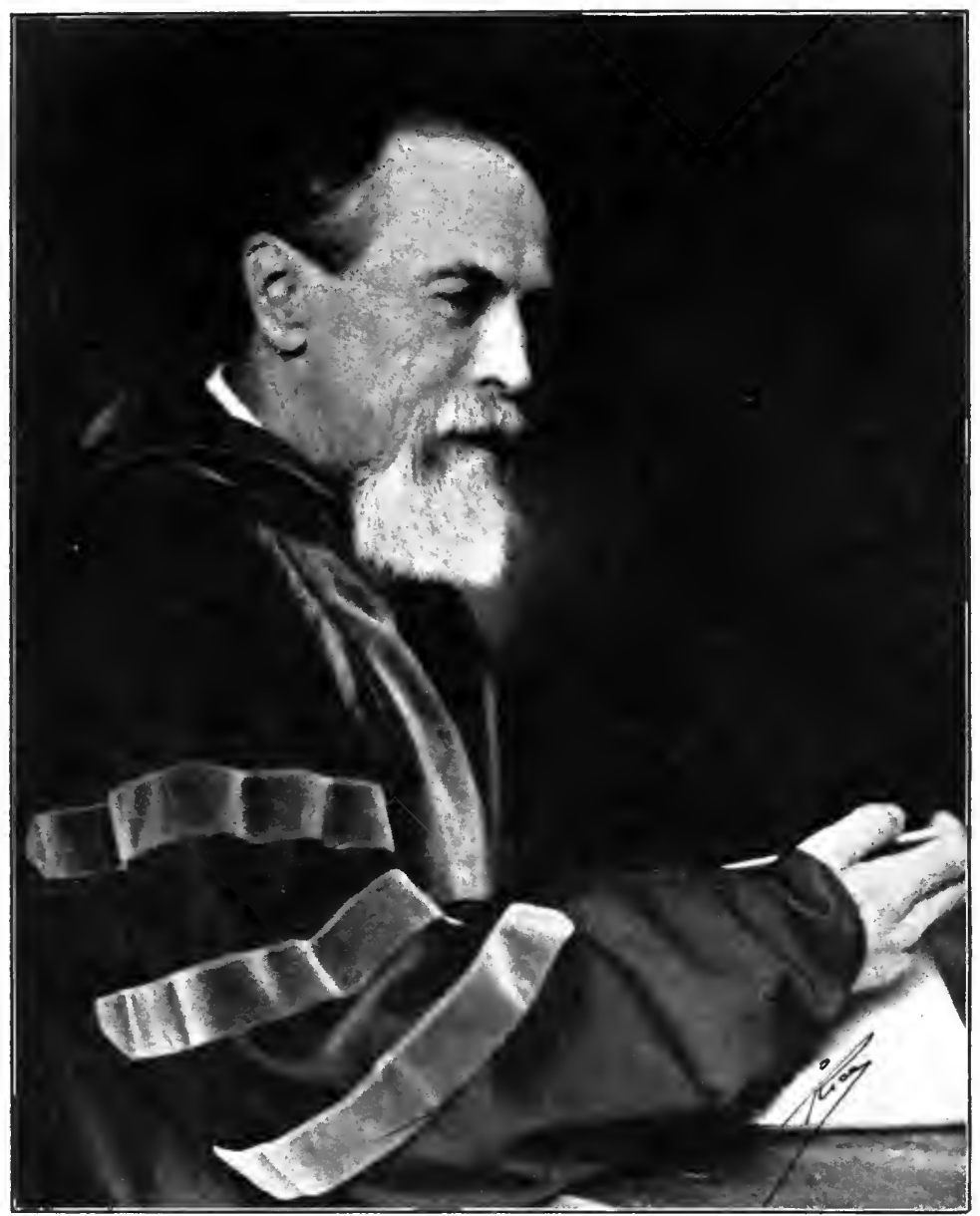

Eugexe Wuldemar Hilgard, a Max of SClexce

Born at Zweibriicken, Bavaria, January 5, $18_{33}$ : educated at Belleville, Illinois, and Heidelberg, ( Fermany : state geologist and professor of chemistry of the Lniversity of Mississippi, I $855-1873$ : professor of geology and natural history of the University of Michigan, $1873^{-}$ 1875 : professor of agriculture and director and chemist of the agricultural experiment station, Lniversity of California, $1 \$_{75}-1906$; chemist since 1906; author of "Soils" (1906) 
sufficient purpose, method, and discrimination to give much importance to the results, which are summarized as follows:

Table 20.I. Composition of Canadian Surface Solls Pounds per Acre in 2 Million of Soil (about $6 \frac{2}{3}$ Inches)

\begin{tabular}{|c|c|c|c|c|c|c|}
\hline \multirow{2}{*}{$\begin{array}{l}\text { NUMBER OF } \\
\text { SAMPLES } \\
\text { ANALYZED }\end{array}$} & \multirow{2}{*}{ Canadian Province } & & \multirow{2}{*}{$\begin{array}{c}\text { Total } \\
\text { NITROGEN }\end{array}$} & \multicolumn{3}{|c|}{ Acid-Soluble } \\
\hline & & & & Phosphorus & Potassium & Calcium \\
\hline $2 I$ & British Columbia . & & 5240 & 2360 & 6970 & 16700 \\
\hline 6 & Northwest Territory . & & 9180 & I520 & 5670 & 4130 \\
\hline $\mathrm{I}$ & Manitoba . . & & 20100 & 2530 & I 7100 & 27000 \\
\hline 6 & Quebec . . . . . & - & 4520 & I $75^{\circ}$ & 7300 & 7400 \\
\hline 6 & Ontario (Muscoka only) & - & 2700 & $125^{\circ}$ & 3650 & 6300 \\
\hline 5 & Maritime Provinces & - & 2600 & 960 & 7300 & I570 \\
\hline
\end{tabular}

In referring to the averages represented in this tabular statement, Professor Frank T. Shutt (Chief Chemist for the Dominion Experimental Farms since r887) says:

"They are not provincial averages; they are rather averages from large untilled areas in the several provinces, and may therefore serve to indicate the general character of much of the yet unoccupied lands of Canada." (Dominion Experimental Farms Reports, I897, page I69.)

A study of the details shows much variation, but in the main these are counterbalanced so that the averages have much meaning. Professor Shutt states that the one sample from Manitoba " represents the unfertilized and uncropped prairie soil of the Red River Valley, Manitoba," and adds:

"It was taken from section 3 I, township 4, range $\mathbf{I}$ west. The uniformity in character of the soil over a very large area in Manitoba makes the data here presented of more than ordinary importance."

"We may safely conclude that there is here ample scientific proof of the wellnigh inexhaustible stores of plant food, and that this prairie land, as regards the elements of fertility, ranks with the richest of known soils."

Doctor George M. Dawson, Director of the Geological Survey of Canada, is quoted as follows:

"Of the alluvial prairie of the Red River much has already been said, and the uniform fertility of its soil cannot be exaggerated. . . . The area of this lowest prairie has been approximately stated as 6900 square miles." 
Of course, these averages from the various Canadian provinces must be considered as tentative and very preliminary, but they must also be accepted as giving a reasonably correct general view of the invoice of soil fertility in the most extensive types of soil in those sections. Some other analyses made in part in connection with special investigations are discussed in another place.

\section{Review of Soll CoMposition}

A general summary of the mass of evidence contained in the preceding pages concerning the composition of soils clearly sets forth a number of definite and assured facts bearing significant relations to systems of permanent agriculture. One of these most clearly established facts is that potassium as an element of plant food belongs in the class with calcium and magnesium rather than with phosphorus and nitrogen. In all normal soils the supply of potassium is enormous. Thus, as an average of the Maryland soils reported in Table $\mathrm{x} 2$, representing ten different geological formations, more or less abundant in most of the Atlantic states, we find 37,860 pounds of potassium and only 14,080 pounds of magnesium, 7840 pounds of calcium, and I 100 pounds of phosphorus, in 2 million pounds of soil.

Measured by the total requirements of approximately maximum crops in a rotation of wheat, corn, oats, and clover (Table 13 ), the potassium is sufficient for 473 years, the magnesium for 828 years, and the calcium for 187 years; while the total phosphorus is sufficient for the same crops for only 57 years. If we consider the plant food removed in the grain alone, assuming that the coarse products will remain on the farm, and also disregard the one abnormal magnesium soil (from serpentine), the relative plant-food supply is represented by 105 years for phosphorus, 3060 years for potassium, 2828 years for magnesium, and 6970 years for calcium.

The complete analyses of the loess deposits at Dubuque, Iowa, and Kansas City, Missouri, which contain only moderate amounts of carbonates, show, as an average, 33,100 pounds of potassium, I3,400 pounds of magnesium, 23,500 pounds of calcium, and I 400 pounds of phosphorus, in 2 million of loess.

In the following summary are reported the total phosphorus, 
total potassium, total magnesium, and total calcium in the surface soil of the five most cxtensive soil types of Illinois.

Table 20.2. Certain Plant-food Elements in Illinois Surface Soils Pounds per Acre in 2 Million of Soil (about $6 \frac{2}{3}$ Inches)

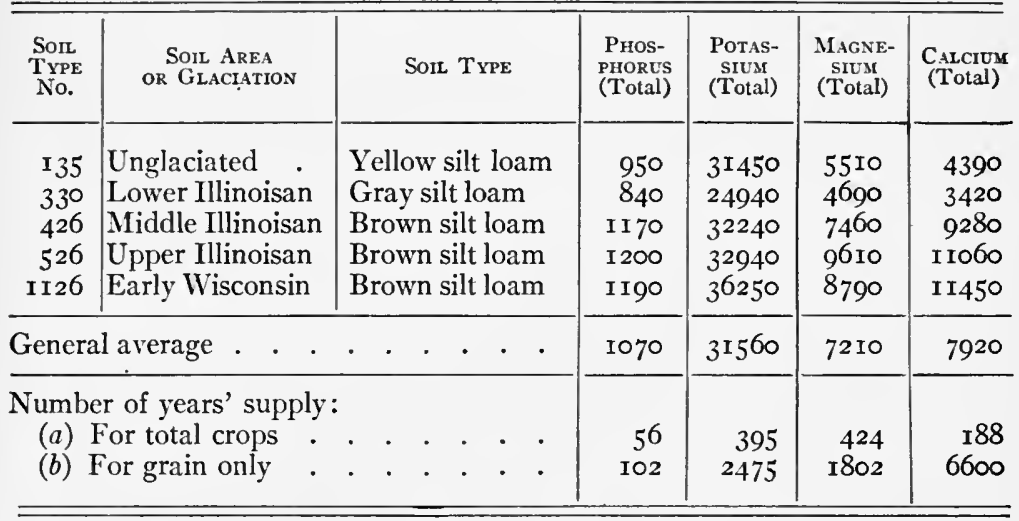

It should be kept in mind that these data are based upon the average composition of many soil samples from every type, and that these are widely representative of the most extensive and important soil types in the Central states. They signify determined facts. As a general average of these soils, potassium is better supplied than magnesium for grain farming (in which all coarse products are returned to the land), and potassium is better supplied than calcium for a system in which all of the produce is removed. In normal soil types the relations existing among these four elements in the subsoil are not essentially different from those in the surface, except in subsoils that are rich in calcium and magnesium carbonates. Even in the almost unweathered glacial subsoils of the principal types of the late Wisconsin glaciation (brown silt loam and yellow-gray silt loam; see Table I 7), 2500 pounds of phosphorus and $5_{5} 8,000$ pounds of potassium are the relative and total amounts of those two elements per acre in a 20 -inch stratum. Measured by the a verage losses from the farm by selling maximum crops of corn and wheat, our two principal grains, the phosphorus in 6 million pounds of this subsoil is sufficient for I73 years, or one half as long as from ${ }_{15} 5_{5}$ to I9I $\mathrm{I}$, and the potassium is sufficient 
for 9900 years, or as long as from 8000 years before Christ to 1900 years after Christ. In other words, on the absolute mathematical basis there is less of reason for applying potassium to normal soils as plant food than there is for applying magnesium and calcium for the sake of adding them also as plant food (see page $5^{6} \mathrm{r}$ ).

The use of potassium on soils actually deficient in that element (as peaty swamp soils), and on some other soils as a soil stimulant, is discussed in the following pages.

In brief, it may be said, of the plant-food elements supplied by the soil, that nitrogen and phosphorus are in one class; that potassium, magnesium, and calcium are far removed in a second class; and that iron is distinctly in a third class; while the nitrogen of the air, so far as concerns the supply for permanent agriculture, should be classed with carbon, hydrogen, and oxygen. The place of sulfur is not so easily determined. Measured by the soil's supply, sulfur would be classed with phosphorus and nitrogen; or measured by the crop demands, it would be classed with iron; but, if both supply and demand are considered, it must be classed with potassium, magnesium, and calcium. It is, however, known with certainty that more or less sulfur is carried into the air with the products of combustion and of decay, and some sulfates are also carried into the atmosphere in the dust from evaporated occan spray. Longcontinued investigations at Rothamsted and elsewhere have shown that as an average rainfall brings to the soil, chiefly in the form of sulfates, about 7 pounds of sulfur per acre per annum, or I pound more than would be required for a roo-bushel crop of corn (p. 57).

Note. In New Hampshire Agricultural Experiment Station Bulletin $\mathrm{I}_{42}$ (December, 1909), Morse and Curry report 37,400 pounds of total potassium in two million pounds of surface soil of the uplands, and 50,000 pounds in two million of surface soil of the lowlands, in the vicinity of Durham, these amounts representing averages of ten and fifteen respective soil analyses of clays and clay loams. The summary of this bulletin contains the conclusions that the potassium in these soils is soluble enough to supply potassium for heavy crops of grass without artificial reënforcement, and that additional potassium when supplied in commercial fertilizers does not affect the yield or the composition of the grasses. 


\section{CHAPTER VII}

\section{AVAILABLE PLANT FOOD}

"Avallable plant food" is an expression much used in connection with commercial fertilizers, and the argument is commonly made that because the soil does nct contain a vailable plant food, we should therefore apply available plant food in commercial fertilizers. Instead of following this advice, however, the farmer should, as a very general rule, adopt a system of farming that will make available the plant food in the soil so far as practicable, and, if any element is actually deficient in the soil, apply that element in cheap form and in positively larger quantities than will be removed in large crops; and then make it, too, available by his method of farming.

There are three methods of determining with some degree of satisfaction which elements, if any, are deficient in the soil:

First, we may compute from the composition of the soil and the requirements of crops the probable durability of a soil with reference to any element of plant food. Thus, we may determine that the unglaciated yellow silt loam surface soil of Illinois, Kentucky, Tennessee, and other adjoining states contains sufficient nitrogen for less than 20 large corn crops if only the grain were removed; while the potassium in the late Wisconsin brown silt loam is sufficient for more than 2300 such crops.

Second, we can assume for a rough estimation that the equivalent of 2 per cent of the nitrogen, I per cent of the phosphorus, and $\frac{1}{4}$ of I per cent of the total potassium contained in the surface soil can be made available during one season by practical methods of farming. Of course, the percentage that can be made available will vary very much with different seasons, with different soils, and for different crops; and yet with normal soils and seasons and for ordinary crops the above percentages represent roughly about the 
proportion that is liberated from our common soils of the element that limits the yield of the crop.

In Table 2I are given the amounts of annually available plant food in Illinois soils as roughly estimated by this method of computation.

Of course, these amounts would be smaller and smaller year by year in proportion as the total supply is decreased, and accordingly complete exhaustion is not only impracticable and unprofitable because of the continual reduction in crop yields, but it is mathematically impossible, just as it would be impossible to exhaust a bank account if only one per cent of the remaining deposit could be withdrawn each week.

A peaty swamp soil containing 2930 pounds of total potassium per acre in the first $6 \frac{2}{3}$ inches would liberate during the season, according to this estimate, about 7 pounds of potassium, which would be equivalent to a crop of Io bushels of corn, which represents roughly about the average yield from such land when not treated with potassium, as is shown in the following pages. The common brown silt loam prairie soil, when well farmed, will average about 50 bushels of corn per acre, which would require $11 \frac{1}{2}$ pounds of phosphorus and 74 pounds of nitrogen, while 12 and 96 pounds represent I per cent of the phosphorus and 2 per cent of the nitrogen, respectively, in the surface soil, where phosphorus is the first limiting element and nitrogen the second.

These illustrations are given not to prove that this rough estimate is applicable, but rather to show the basis which suggests such a computation. It has some value, chiefly, perhaps, in that it helps one to understand why it is that with phosphorus enough in the surface soil for 50 crops, we obtain only half a crop as an a verage.

On this basis we should try to keep sufficient phosphorus in the surface soil for 100 large crops, of which one per cent would then be sufficient for one large crop. This would require about 2300 pounds of phosphorus per acre, or but little more than is actually contained in the most productive Illinois corn-belt soil, as the early Wisconsin black clay loam in such counties as McLean, Champaign, Edgar, et al.

While there are several agencies that tend to convert insoluble 
plant food into available forms, such as the products of decaying organic matter, including carbonic, nitric, and various organic acids, the different forms of lime, and most soluble salts, each of which is more fully discussed in its proper place, it is also known that the plant roots themselves influence the a vailability of plant food, probably by means of the carbonic acid or other substances which they excrete.

The juices of plants are commonly distinctly acid, and the roots have some power to exude moisture, which certainly contains carbonic acid and very possibly contains no other solvents, although this question is not fully settled. Where growing plant roots lie in contact with the polished surface of marble (calcium carbonate) and some other materials (as prepared slabs of calcium phosphate), distinct etching occurs, as was early shown by Sachs and Czapek.

Kossowitsch conducted an experiment in which he grew plants (peas, flax, and mustard) in two pots of sand which differed only by the addition of fine-ground rock phosphate to one. The plants were watered with the slow and constant application of like amounts of a dilute solution containing all essential plant-food elements, except phosphorus. For the pot which contained no phosphate this solution was, in this continuous process of watering, passed through a third pot of sand to which the fine-ground rock phosphate had also been added.

Kossowitsch found that the plants made a much better growth in the pot where the roots were in direct contact with the phosphate, thus showing that they exert a solvent action in addition to any that may be exerted by the nutrient solution.

If, for example, the plant roots come in contact with, or exert an influence upon, the equivalent of only one per cent of the surface of the soil particles within the root range, this would offer an explanation of the relationship (which is very irregular in different soils and seasons) that exists between the total amount of any plant-food element in a given soil stratum and the amount secured by a given crop during the growing season.

It is well known that soluble phosphates and soluble potassium salts, when applied to normal soils, are almost immediately converted into insoluble forms; and the higher availability of such soluble fertilizers is now believed to be largely due to the fact that 
Table 21. Annually Available Fertility in Illinois Solls, Roughly Estimated

Pounds per Acre

\begin{tabular}{|c|c|c|c|c|c|}
\hline $\begin{array}{l}\text { SoIL } \\
\text { TyPE: } \\
\text { No. }\end{array}$ & Soil AREA or Glaciation & SoIL TyPe & $\begin{array}{l}\text { AvaIL- } \\
\text { ABLE } \\
\text { NItro- } \\
\text { GEN }\end{array}$ & $\begin{array}{l}\text { AvAIL- } \\
\text { ABLE } \\
\text { PHOS- } \\
\text { PHORUS }\end{array}$ & $\begin{array}{l}\text { AVAIL- } \\
\text { ABLE } \\
\text { POTAS- } \\
\text { SIUM }\end{array}$ \\
\hline
\end{tabular}

Prairie Lands, Undulating

\begin{tabular}{|c|c|c|c|c|c|c|}
\hline $33^{\circ}$ & Lower Illinoisan & . & Gray silt loam on tight clay & $5^{8}$ & 8 & 62 \\
\hline 426 & Middle Illinoisan & & Brown silt loam & 87 & I 2 & $8 \mathrm{I}$ \\
\hline 526 & Upper Illinoisan & & Brown silt loam & 97 & 12 & 82 \\
\hline 626 & Pre-Iowan . . & . & Brown silt loam . & 86 & 12 & 88 \\
\hline 726 & Iowan . & . & Brown silt loam . & 98 & 12 & 82 \\
\hline II 26 & Early Wisconsin & . & Brown silt loam & IOI & I 2 & $9 \mathrm{I}$ \\
\hline 1026 & Late Wisconsin & . & Brown silt loam & I 35 & 14 & II 3 \\
\hline
\end{tabular}

Prairie Lands, Flat

\begin{tabular}{|c|c|c|c|c|c|c|c|}
\hline 329 & Lower Illinoisan & . & Drab silt loam & . & 56 & 7 & 66 \\
\hline 420 & & & & & & & 80 \\
\hline 520 & & & & . & I 35 & 17 & 74 \\
\hline II $2 C$ & & . & & & I5 & 20 & 88 \\
\hline I 220 & Late Wisconsin & . & Black clay loam & . & I 78 & I9 & 93 \\
\hline
\end{tabular}

Timber Uplands, Rolling or Hilly

\begin{tabular}{|c|c|c|c|c|c|c|c|}
\hline I 35 & Unglaciated . & . & Yellow silt loam & & $3^{8}$ & IO & 79 \\
\hline 335 & oisan & & llow silt loam & & 43 & Io & 80 \\
\hline 34 & Middle I & & loam & & & 8 & 82 \\
\hline 53 & Upper Illinoisan & & ellow silt loam & & 40 & 8 & 87 \\
\hline 635 & Pre-Iowan . . & & loam & & 48 & 9 & 93 \\
\hline 735 & Iow: & & Yellow: & & $3^{8}$ & $y$ & \\
\hline & Early Wisconsin & & Yellow silt loam & & 38 & 9 & 82 \\
\hline 864 & Deep loess . & & Yellow fine sandy loan & & 43 & IO & 89 \\
\hline
\end{tabular}

Timber Uplands, Undulating

\begin{tabular}{r|ll|l|l|l|l}
\hline I034 & Late Wisconsin . . &. & Yellow-gray silt loam & $5^{8}$ & 8 & I I9 \\
760 & Iowan... &. & Brown sandy loam . & 6r & 9 & 67 \\
\hline
\end{tabular}

Timber Uplands, Flat

\begin{tabular}{l|l|l|l|l|l}
\hline 332 & Lower Illinoisan . & \begin{tabular}{|} 
Light gray silt loam on \\
tight clay $\cdot . \cdot$
\end{tabular} & 38 & 8 & 68 \\
\hline
\end{tabular}


Table 21. Annually Available Fertility in Illinois Solls, roughly Estrmated - Continued

\begin{tabular}{|c|c|c|c|c|c|}
\hline $\begin{array}{l}\text { SoIL } \\
\text { TYPE } \\
\text { No. }\end{array}$ & Soll Area or Glaciation & SOIL TyPE & $\begin{array}{l}\text { AvaIL- } \\
\text { ABLE } \\
\text { NITRO- } \\
\text { GEN }\end{array}$ & $\begin{array}{l}\text { AVAIL- } \\
\text { ABLE } \\
\text { PhOS- } \\
\text { PHORUS }\end{array}$ & $\begin{array}{l}\text { AVAIL- } \\
\text { ABLE } \\
\text { POTAS- } \\
\text { SIUM }\end{array}$ \\
\hline
\end{tabular}

Sand, Swamp, and Bottom Lands

\begin{tabular}{|c|c|c|c|c|c|c|c|}
\hline I 33 I & Old bottom lands & & Deep gray silt loam & & 72 & I 4 & 9I \\
\hline I $45^{\mathrm{I}}$ & Late bottom lands & & Brown loam . & - & 94 & 16 & 100 \\
\hline I $48 \mathrm{I}$ & Sand plains and dune & & Sand soil . & & 29 & 8 & 77 \\
\hline $140 I$ & Late swamp & - & Deep peat . & - & (?) ${ }^{1}$ & 20 & 7 \\
\hline I4I5 & Late swamp & . & Drab clay. & - & II 5 & I9 & I 20 \\
\hline
\end{tabular}

I The nitrogen in peat is so very slowly available that not even a rough estimate can be made here.

they first dissolve in the soil water and spread over the surface of the soil particles before becoming insoluble, and thus they offer a much more extensive surface for contact with plant roots than would plant-food particles applied in insoluble form, unless very finely ground.

Third, we may apply different elements of plant food to the soil and note the effect, if any, in increasing the yield of crops, and thus sometimes discover what element is most deficient in the soil. One might suppose that this would be the best method, but such is not the case. This method frequently gives erroneous results which, if followed, may lead to land ruin, because the substance applied may produce little or no benefit on account of the special plant-food element it contains, but it may act as a powerful soil stimulant and thus liberate from the soil some other entirely different element in which the soil is already becoming deficient. Thus have many lands been practically ruined by the use of land-plaster and salt, by the improper use of lime, and even by the use of clover merely as a soil stimulant. Some good illustrations of this action of soluble salts are shown in the following pages.

"In considering the general subject of culture experiments for determining fertilizer needs, emphasis must be laid on the fact that such experiments should never be accepted as the sole guide in determining future agricultural practice. 
If the culture experiments and the ultimate chemical analysis of the soil agree in the deficiency of any plant-food element, then the information is conclusive and final; but if these two sources of information disagree, then the culture experiments should be considered as tentative and likely to give way with increasing knowledge and improved methods to the information based on chemical analysis, which is absolute." 1

The plant food in the subsurface and subsoil is unquestionably of some value, but even the total supplies of nitrogen and phosphorus that are held within the feeding range of ordinary plant roots are not unlimited when measured by crop requirements in permanent agriculture. However, the thing of first importance is to maintain a rich surface soil, for no subsoil is of much practical value if it lies beneath a worn-out surface. On the other hand, if the subsoil will act as a reservoir for moisture, then a rich top soil will produce large crops. Manures and fertilizers are applied to, and incorporated with, the plowed stratum only. On the Rothamsted fields where chalk exceeding Ioo tons per acre was applied to the land a hundred years ago, practically no calcium carbonate is found below the plowed soil even after a century of cultivation, although 50 tons of the chalk applied still remain in the surface soil; and the land fertilized with nitrogen, phosphorus, and potassium, which has yielded more than 30 bushels of wheat per acre as an average of fifty years, contains, as an average, no more plant food in the strata below the surface 9 inches than is found in the same strata where the land has been unfertilized and has produced an average yield of only ${ }^{3} 3$ bushels of wheat for the same fifty years.

The supply of nitrogen in soils is contained only in the organic matter; and thus the amount of nitrogen in the subsoil of normal soil types is relatively small, as will be scen from a study of Tables I5, I6, and 17 , six million pounds of subsoil containing, as a rule, less nitrogen than two million pounds of surface, except where the surface is much worn. The small amount of humus in the subsoil is also quite inactive, and the liberation of nitrogen from its decomposition is very slight. Furthermore, in all humid regions there is large loss of nitrogen in drainage waters; so that in practice the addition of nitrogen to the surface soil must be somewhat greater

1 "Cyclopedia of American Agriculture," Vol. I, page 475. 
than that removed in crops, if the productive power of the soil is maintained.

The phosphorus of the soil exists in both organic and mineral forms. While the supply of mineral phosphorus is likely to be smaller in the surface and subsurface than in the subsoil, the organic phosphorus, like nitrogen, varies with the organic matter, which, as a rule, decreases rapidly below the plowed soil. As a consequence, there is usually less phosphorus in the subsurface than in the surface, unless the surface is very poor in organic matter; and also there is less phosphorus in the subsurface than in the subsoil, unless the subsurface is much richer in organic matter. A larger supply of phosphorus in the surface than in the subsurface is sufficient to prove that plants secure some phosphorus from below the surface soil, because the excess of phosphorus in the surface is contained in the decomposition products of plant residues from the centuries gone by. Where the subsoil is richer in phosphorus than the subsurface, it indicates either that phosphorus has been lost from the subsurface by leaching or that the plant roots have withdrawn phosphorus from the subsurface to a greater extent than from the subsoil.

With the brown silt loams and black clay loams of the corn belt, the surface stratum rich in organic matter is always richer in phosphorus than the subsurface; and, with one exception, the subsurface, which is also quite well supplied with organic matter, is richer in phosphorus than the subsoil, but the other upland soils contain less organic matter in the surface and much less in the subsurface, and the subsoil, with a single exception, is richer in phosphorus than the subsurface, equal weights of soil always being considered.

The potassium is contained almost solely in the mineral part of the soil, and the supply regularly increases with depth, the subsurface being richer than the surface and the subsoil still richer. 


\section{CHAPTER VIII}

\section{SOIL SURVEYS BY THE UNITED STATES BUREAU OF SOILS}

The Bureau of Soils of the United States Department of Agriculture was organized in I895, with Professor Milton Whitncy as Chief. The energies of this Bureau have been devoted largely to making surveys of the soils in certain localities in most of the different states; and, second, to laboratory investigations in support of a theory early announced by Whitney and Cameron, to the effect that practically all soils contain sufficient plant food for good crop yields, and that this supply will be indefinitely maintained.

The soil surveys are of general interest but of doubtful value to the local farmers and landowners, because they are reported with practically no information concerning valuable methods of soil improvement other than that based upon the actual practice already in vogue, the Bureau having conducted no systematic field experiments and having reported practically no chemical analyses of the various soil types identified. The mechanical analyses which are almost invariably reported give little information of value further than to support the soil surveyor's classification of the soils into sandy soils, silty soils, clay soils, etc. Even the soil survey, as conducted by the Bureau, is of ten too general or superficial in character to be of local use, differences in soils which are clearly recognized by the farmers being often ignored or overlooked. This will be better understood by examination of concrete illustrations; such, for example, as a comparison of the Bureau's map of Tazewell County, Illinois, published in the Report of Field Operations for 1902, with that of McLean County, which joins Tazewell on the east, and which accompanies the Report for I903; or by a comparison of the Bureau's map of Clay County, Illinois 
(Igo2), showing all of the upland, comprising 85 per cent of the county, as one soil type (Marion silt loam), with the detail soil map published by the University of Illinois Agricultural Experiment Station (I9II), showing eleven different types of upland soil, most of which are commonly recognized by the local farmers, the most extensive type (gray silt loam on tight clay, or " typical " Marion silt loam) comprising only 37 per cent of the county. These upland soil types vary in agricultural value from $\$_{15}$ to $\$ 60$ an acre. They vary in average composition from I Ioo pounds of nitrogen and 400 pounds of phosphorus to 3890 pounds of nitrogen and 820 pounds of phosphorus in 2 million pounds of the surface soil. On more than 15,000 acres of the level upland prairie soil, surface drainage can be provided only with much difficulty, while 40,000 acres of eroded timberlands are so rough that the soil ought not to be kept under cultivation. About 30 per cent of the upland is not underlain with tight clay, while the remainder has the subsoil sometimes called "hardpan" by the resident farmers.

These facts are mentioned in order that the student may understand that the soil survey as made by the Bureau of Soils is not intended to be in sufficient detail for local, specific use. To quote Professor Whitney's language from a letter to the author under date of March 26, I903:

"In the work on the scale in which the Bureau is engaged, we cannot recognize differences that might and should be recognized in a more detailed survey of a limited area. It is necessary for us to show only important differences in the soils which will be of value to the people of large areas."

Nevertheless, the soil surveys of the Bureau have large value as a source of general information concerning the soils of the United States. The author has very great respect for the art of surveying soils, whether for general information over broad areas or for specific use where the details are mapped.

The accompanying map of the United States, showing "Soil Provinces," as published by the Bureau of Soils, is based in part upon the work of the United States Geological Survey. Within these I4 great soil provinces, the Bureau of Soils had recognized (previous to January I, I908) different soil types to the number of 
7 I5, most of which have been grouped into 86 soil series; and the following extracts from Bureau of Soils Bulletin 55 (I909), descriptive of these soils, cannot fail to be of interest and value to the student of American soils.

\section{Classification of Soils}

"The texture of the soil is expressed in the mechanical analysis by a separation into seven grades, the sizes of which are arbitrarily fixed. The results of the analysis show the percentages of sand, silt, and clay."

"When, aside from texture, the physical and chemical properties of the soil and its method of formation are alike, we have what we call a soil series, extending from the coarse gravelly or sandy soils on the one side to the finer silt and clay soils on the other, and in such a series the texture of the soil determines the distribution of crops.

"It would be a comparatively simple matter to compare and classify soils according to the mechanical analysis or texture, but this standard alone is not sufficient, and the problem is in reality a very difficult thing, for in working out the relation of the soils to crops, other factors enter which must be recognized in the correlation. One of the most important of these is the structure or the arrangement of the mineral matter. In some soils the mineral particles have a granular arrangement of flocculated masses, making the soil loose and porous. In others the grains appear to have no such coherency, but exist in a compact form, making the soil hard and compact. We also have the gumbo and adobe soils and others that are exceedingly plastic. Then, again, the amount and character of the organic matter influences not only the productive capacity of the soil, but its adaptation to crops, while the color of the soil has to be considered as indicative of certain obsure chemical or physical relations that influence the adaptation and productivity. The drainage features also come in, often with material influence on the organic constituents, on the aëration, and on oxidation processes."

"The experienced soil-survey man can judge very accurately of the texture of the soil matcrial, but even his judgment, before being accepted, is always confirmed by mechanical analysis.

"Where soils have a common origin and differ only in texture and are alike in color and in physical properties other than those affected by texture, they are arranged in what we call a series having the soil generic name with qualifying textural terms. We have, for example, the Miami gravelly loam, the Miami fine sand, the Miami sandy loam, the Miami silt loam, and the Miami clay loam as prominent types in the Miami series. In this particular series we have fourteen types, and possibly two or three other types will be encountered. In the Norfolk series we have twelve types."

"If the texture and structure of two soils is the same, and one differs in a marked degree from the series color, and that departure is fairly constant and 
$\ldots \ldots . \quad \therefore \quad+\cdots$ 


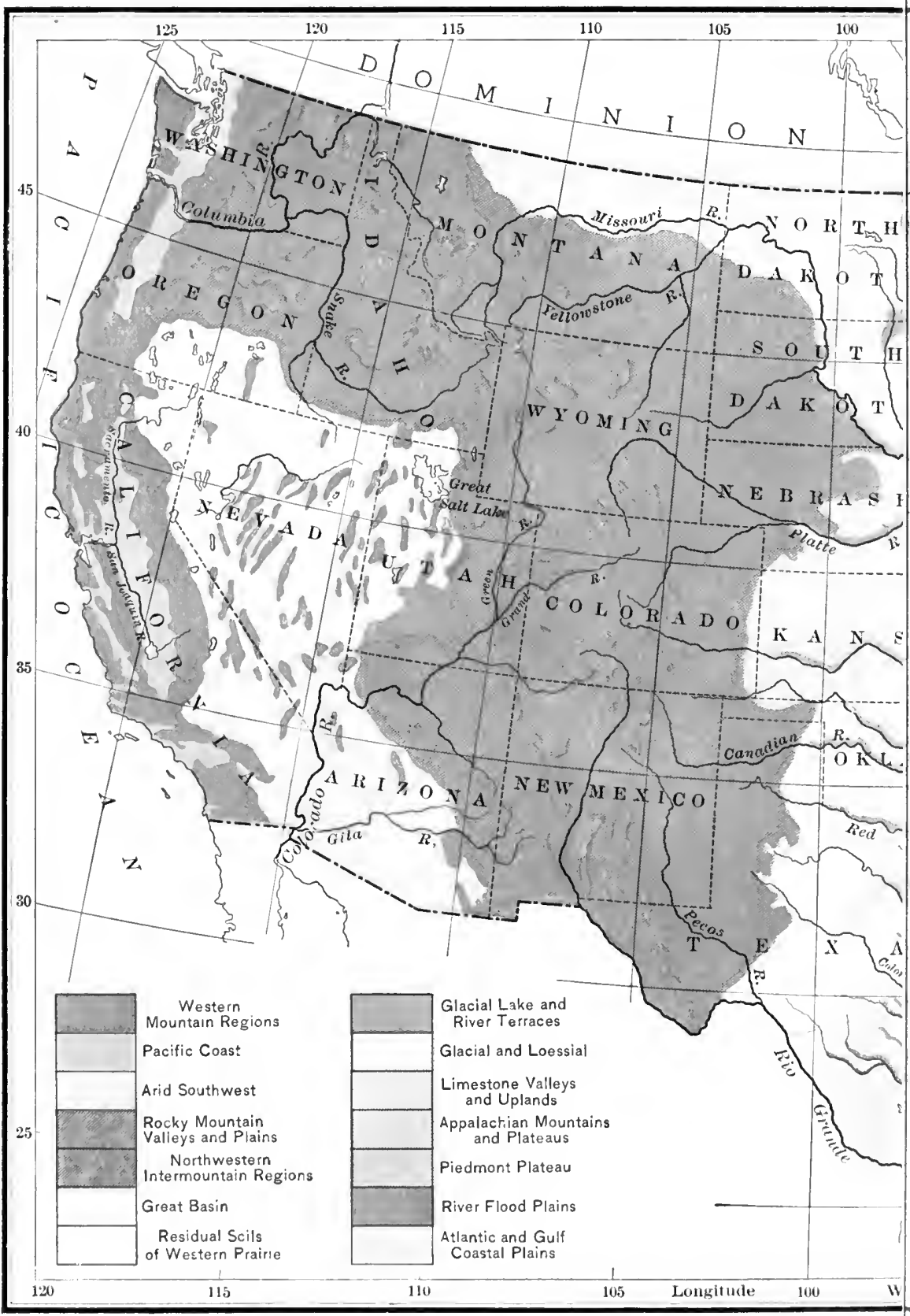




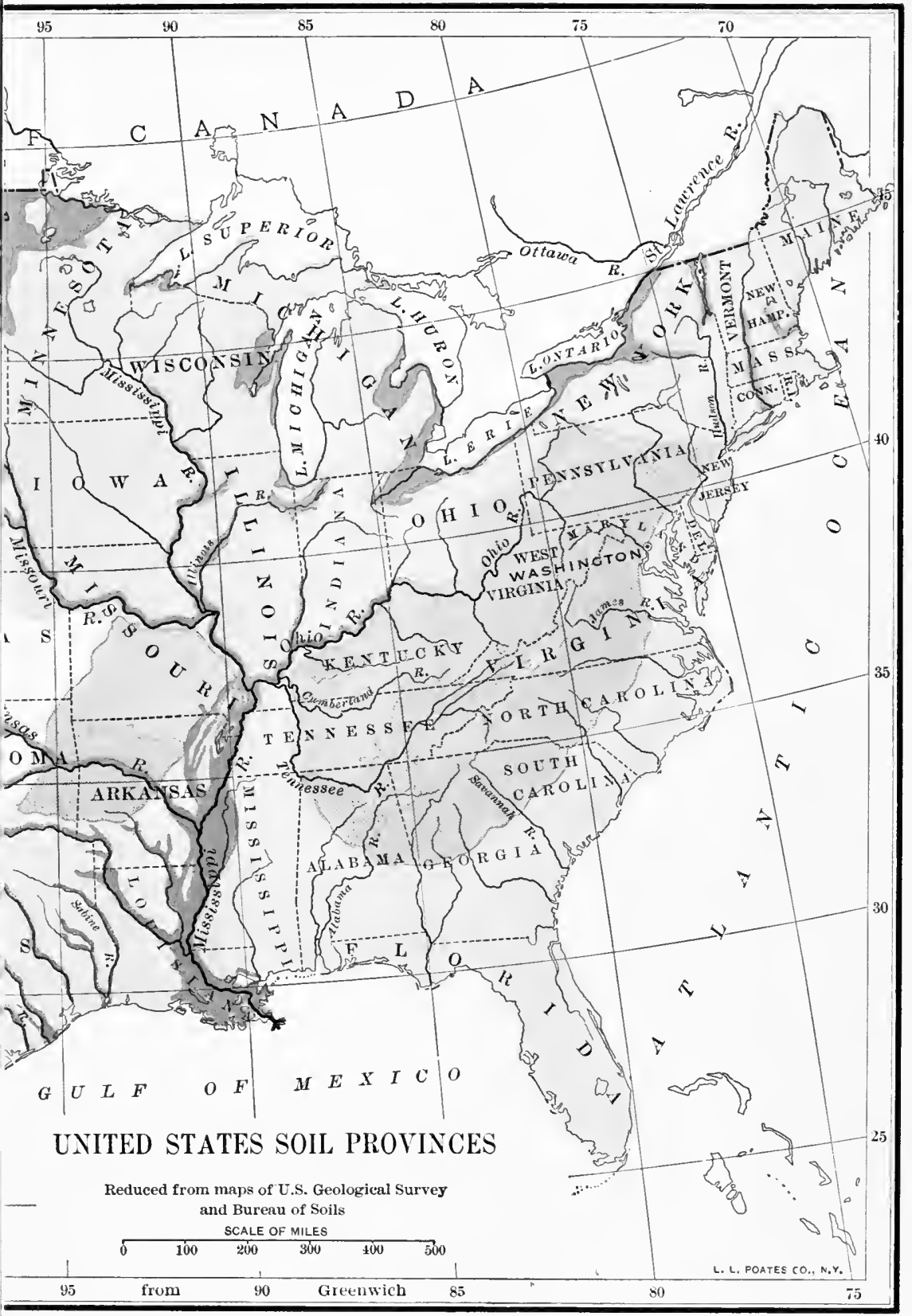


typical of the area covered by the soil, this soil likewise is thrown out of the series, because we have reason to know, by observation of the growing crops, that this color difference stands for a difference in the chemical changes which go on in the soil and which are necessary for the welfare of certain crops.

"In the classification of soils, therefore, the texture is used to determine the place in the series; the structure and color to determine what series the soil can be correlated with."

The following table gives the name and area of the soil provinces and the proportion of each that has been covered by the soil survey. It is not unlikely that as the work progresses and as our knowledge of the soils increases it will seem advisable to divide some of these provinces into two or more parts.

Soll Provinces of the United States

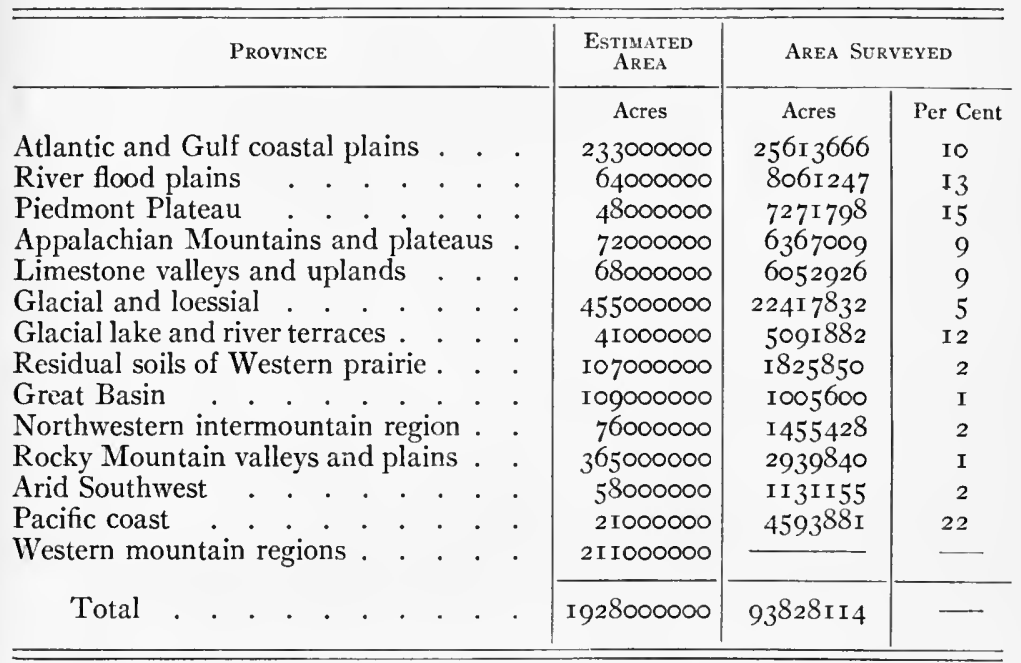

\section{Atlantic and Gulf Coastal Plains}

The Atlantic and Coastal plains together constitute one of the most important physiographic divisions of the United States. The Atlantic Coastal Plain extends from the New England states southward to the Florida Peninsula, where the Gulf Coastal Plain begins, and extends thence westward to the Mexican boundary line. It is, however, discontinuous, being interrupted by the alluvial bottoms of the Mississippi River. From the coast the Atlantic Plain extends inland to the margin of the Piedmont Plateau; that is, to a line passing through Trenton, Baltimore, Washington, Richmond, Raleigh, Columbia, Augusta, and Macon. In its northern extension it is represented by a narrow belt, but widens in New Jersey, and attains its maximum breadth 
of about 200 miles in North Carolina. The Gulf Plain extends up the Mississippi to the mouth of the Ohio, its inner boundary line passing through or near Montgomery, Iuka, Cairo, Little Rock, Texarkana, Austin, and San Antonio.

The surface is that of a more or less deserted plain marked by few hills, slightly terraced with bluffs along streams. The inner margin of the Coastal Plain is usually from 200 to 300 feet above tide water, but sometimes rises to 500 feet. The drainage here is usually well established, and the surface is rolling to hilly, and consequently carved and eroded. There is a wide belt bordering the coast where the elevations are mostly under roo feet. North of the James River, where the Coastal Plain is narrow and deeply indented with tidal estuaries, drainage is usually well established and the surface is rolling, but in the broad southern extension, where the seaward slope is hardly more than I foot to the mile, drainage is apt to be deficient. Here rain water often remains upon the surface for a considerable time, although the conditions are not comparable with those of a true swamp. The soils in this level section, while composed largely of sand, are compact, usually deficient in organic matter, and not very productive. Many of the flat interstream areas possess such poor drainage that true swamps, such as the Dismal and Okefenokee, have been formed. Near the coast and along the tidal estuaries, extensive marshes, separated from the ocean by sand barriers, are found.

The Coastal Plain is made up of unconsolidated gravels, sands, and sandy clays, with less frequent beds of silts and heavy clays. The desposits on the Atlantic coast have been derived mainly from the erosion of the Piedmont Plateau and other inland areas, while the deposits on the Gulf coast have been derived mainly from transported glacial material and from western plains. The materials have been transported and deposited beneath the sea and subsequently exposed by the uplift of the ocean floor. In the more northern parts of the Coastal Plain, and even as far south as Virginia, the character of the deposits has been modified by glacial action and the flooded condition of the streams resulting from the melting of the ice.

The Coastal Plain deposits range in age from Cretaceous to Recent. Although extensive areas of the older sediment are exposed at the surface to form soils, still by far the greater part of the materials is Quarternary or Recent in age.

The soils are for the most part composed of sands and light sandy loams, with occasional deposits of silts and heavy clays. The heavy clays are found principally near the inner margin of the Coastal Plain. The silts, silty clays, and black calcareous soils, upon which the rice and sugar-cane industries of southern Louisiana and Texas are being so extensively developed, have no equivalents in the Atlantic division.

Bastrop series. Brown soils with reddish brown to red subsoils occurring as nonoverflow terraces. Cotton, corn, sorghum, alfalfa, melons, and potatoes are successfully produced.

Crockett series. Dark gray prairie soils underlain by mottled red subsoils. Derived from slightly calcareous material, the soils of this series are 
productive. Cotton and the general farm crops are the leading products. The gravelly soil is early and adapted to early truck.

Elkton series. Light gray to white surface soils, with mottled whitish gray and yellow subsoils, overlying gravel and coarse sands.

Gadsden series. Gray soils, with subsoils of similar texture occupying gentle slopes and depressions and formed by wash or creep from higher areas. This series occurs in rather local development, particularly in Florida, southern Georgia, and Alabama. They are very productive soils and well adapted to tobacco. No heavy members of the series have been encountered, and it is doubtful if any exist.

Guin series. Gray soils with brown to yellowish red subsoils, occurring as rolling and hilly lands. Intermediate series between the Norfolk and Orangeburg series. Owing to the rather rough topography, these soils have not been developed as much as either of the other series, although they seem capable of producing better crops than they do now.

Houston series. Dark gray or black calcareous prairies. One of the most productive series for Upland cotton and well adapted to alfalfa and other forage crops.

Laredo series. Gray to light brown calcareous soils with gray subsoils. Good cotton, corn, and sugar-cane soils, and especially adapted to the early production of vegetables - cabbage and onions in particular.

Lufkin series. Light-colored soils with heavy mottled gray and yellow subsoils. The soils of this series have only a moderate degree of productivity.

Montrose series. Gray soils with heavy plastic mottled yellow subsoils. These soils are in part poorly drained, but where cultivated they produce moderate yields of cotton and corn.

Myatt series. Gray soils with mottled yellow, gray, and whitish subsoils occurring in poorly drained areas around heads of streams and intermediate between uplands and bottom lands. The series seems to be of local extent and but little developed.

Norfolk series. Light-colored soils with yellow sand or sandy clay subsoils. This series contains some of the most valuable truck soils of the Atlantic and Gulf Coast states, and certain members of the series are adapted under certain climatic conditions to wheat, grass, tobacco, and fruit.

Oktibbeha series. Gray soils with brown to yellowish brown heavy subsoils related to Houston series in origin. The soils of this series are distinctly inferior to the soils of the Houston series and, as they appear to cover large areas in Mississippi and Alabama, present a difficult problem in soil improvement.

Orangeburg series. Light-colored soils with red sandy clay subsoils. This series constitutes some of the best cotton soils of the South, and certain members of the series are particularly adapted to tobacco.

Portsmouth series. Dark-colored soils with yellow or mottled gray sand or sandy clay subsoils. Where drainage is adequate, this series is adapted to some of the heavier truck crops, to small fruits, and to Indian corn. 
Sassafras series. Yellowish brown surface soils with reddish yellow to light orange subsoils overlying gravel beds.

Susquehanna series. Gray soils with heavy red clay subsoils which become mottled and variegated in color in the deep subsoil. Only one member of this series, the sandy loam, has been developed to any considerable extent. This one is used for fruit and general farm purposes, but the other members are particularly refractory and difficult to bring into a productive state.

$W e b b$ series. Brown to reddish brown soils with reddish brown to red sub. soils, a semiarid prototype of the Orangeburg series. The soils of this series have not been used to any great extent, owing to lack of irrigation facilities.

Wickham series. Reddish or reddish brown terrace soils overlying reddish, micaceous heavy sandy loam or loam subsoils. The soils of this series have a relatively high productivity for general farm crops.

Wilson series. Dark gray prairie soils with mottled gray subsoils. The clay member of this series is a strong soil devoted to general farming, with cotton as the leading crop. The other members are used for cotton, but are inclined to be droughty.

\section{River Flood Plains}

An extensive and characteristic group of soils, usually known as "bottom lands," is found in the flood plains of numerous rivers and streams of the United States. The largest development of this group occurs along the Mississippi River, where the bottoms are often many miles in width.

The soils have been formed by deposition from stream waters during periods of overflow. The texture of the material depends upon the velocity of the current at the time of the deposition. Where the current is very rapid, large stones and bowlders are borne along, and beds of gravel and sand are formed. Along the swift-flowing streams the texture of the soil changes often within short distances, but in wide bottoms large areas of very uniform soils are often formed. The soil material has usually been derived from various kinds of rocks, but in some instances is closely related to the surrounding geological formation. The red soils along the Red and other rivers in the Southwest have been formed by the reworking of the Permian Red Beds. In general, the soils along the streams which flow through the prairie region have a darker color than those along the streams which run only through the timbered sections of the country.

The difference in the origin, drainage, color, and organic-matter content has given rise to several series of alluvial soils in the humid portion of the United States.

Congaree series. Brown or reddish brown soils found along Piedmont streams and representing wash from Cecil soils. Valuable and dependable corn soils, but too low and moist for cotton.

Huntington series. Dark brown to yellowish brown soils occurring along streams in the Alleghany plateaus. Both the general farm crops and truck crops thrive on these soils. 
Miller series. Brown to red alluvial soils formed from the reworking of materials derived from the Permian Red Beds. Very productive soils suitable for cotton, corn, sugar cane, alfalfa, and vegetables; especially adapted to peaches.

Ocklocknee series. Gray to yellowish brown soils found along streams in Coastal Plain Georgia, Alabama, and Mississippi. Cotton, corn, and pasturage are the leading products.

Wabash series. Dark brown or black soils subject to overflow. Very productive soils used for cotton, sugar cane, corn, wheat, oats, grass, alfalfa, sugar beets, and potatoes and other vegetables.

Waverly series. Light-colored, alluvial soils subject to overflow. Less productive than the Wabash soils, but adapted to the same wide range of crops.

Wheeling series. Brown to yellowish brown soils occurring on gravel terraces along streams issuing from glaciated regions. Excellent soils for general farming, and fruit and truck growing.

\section{Piedmont Plateau}

Lying between the Atlantic Coastal Plain and the Appalachian Mountains and extending from the Hudson River to east-central Alabama is an area of gently rolling to hilly country known as the Piedmont Plateau. On the Atlantic side it is closely defined by the "fall line," which separates it from the Coastal Plain, but on the northwestern side the boundary is not sharp, although in the main distinct. In its northern extension the Piedmont Plateau is quite narrow, but broadens toward the south, attaining its greatest width in North Carolina.

The surface features are those of a broad rolling plain that has been deeply cut by an intricate system of small streams, whose valley walls are rounded and covered with soil, although many small gorges and rocky areas occur. The altitude varies from about 300 feet to more than rooo feet above sea level.

The extreme northern part of the Piedmont region, in New Jersey, has been glaciated, but elscwhere the soils are purely residual in origin and have been derived almost exclusively from the weathering of igneous and metamorphic rocks. The chief exception is the detached areas of sandstones and shales of Triassic age. Marked differences in the character of the rock and the method of formation has given rise to a number of soil types, those derived from crystalline rocks being the most numerous and widely distributed. Among these the soils of the Cecil and Chester series predominate. The principal types formed from the sandstones and shales are included in the Penn series.

Cecil series. Gray to red soils with bright red clay subsoils, derived from igncous and metamorphic rocks. Constituting by far the larger portion of the province, these soils are well adapted to, and used for, cotton, export tobacco, and fruit, and the lighter members for truck crops. As a rule, they are not highly developed, but where properly handled the heavier members produce excellent crops of corn and grazing and hay grasses. 
Chester series. Gray to brown surface soils with yellow subsoils, derived principally from schists and gneisses. The most valuable soils of the province for wheat and corn, and good for certain fruits. The most highly developed soils of the Piedmont Plateau.

Penn series. Dark Indian red soils with red subsoils, derived from red sandstones and shales of Triassic age. Excellent soils for general farm crops, particularly wheat, corn, and hay.

\section{Appalachian Mountains and Plateau}

The Appalachian Mountains are made up of a number of parallel ranges and intervening valleys, which extend in a general northeast and southwest direction from southern New York to northern Alabama. The elevation ranges from about 1500 to nearly 7000 feet above sea level, the highest point being attained in western North Carolina.

Immediately east of the Appalachian Mountains, and usually separated from them by a valley, is a wide stretch of country known as the Alleghany Plateau. In a broad way this plateau is carved out of a great block of sedimentary rocks tilted to the northwest from the mountains. It is crossed by numerous streams. As they run in deep channels (all the larger ones being from 200 to rooo feet in depth), the dissection of the plateau block is often minute.

The rocks of the eastern ranges of the Appalachian Mountains are igneous or metamorphic in origin, while the western ranges, as well as the Alleghany Plateau, are made up of sedimentary rocks. Different series of soils have, therefore, been formed in different parts of these mountains and plateau. The igneous and metamorphic rocks give rise to the soils of the Porter series, while the Dekalb and Upshur series are formed from the weathering of the sandstones and shales of sedimentary origin.

The character of the topography in the mountain and much of the plateau region is such that general farming is not practicable. These areas are, however, well suited to grazing and fruit growing, and these are very important industries.

Dekalb series. Brown to yellow soils with yellow subsoils, derived from sand stones and shales. Soils of this series are used, according to texture, elevation, exposure, and character of surface, either for the production of hay, for pasture, or for orchard and small fruits.

Fayetteville series. Grayish brown to brown soils with yellowish or reddish brown subsoils. Adapted to apples, grapes, and small fruits, and give moderate yields of general farm crops.

Porter series. Gray to red soils with red clay subsoils, derived from igneous and metamorphic rocks. This is the greatest mountain fruit series of the eastern United States. It is also used for general farming.

Upshur series. Brown to red soils with red subsoils, derived from sandstones and shales. Somewhat more productive than the Dekalb soils. Used for cotton, corn, wheat, and forage crops. 


\section{Limestone Valleys and Uplands}

The limestone soils are among the most extensively developed of any in the United States and occur in both broad upland and inclosed narrow valley areas. The greatest upland development is seen upon the Cumberland Plateau in eastern Tennessee and Kentucky and upon the Carboniferous formation in central Tennessee and Kentucky, northern Alabama and Georgia, and in Missouri. The valley soils are found principally in Pennsylvania, Maryland, and Virginia, and in the mountain section of eastern Tennessee and Kentucky and northern Alabama and Georgia. The topography of the plateau soils varies considerably. In the Cumberland Plateau and Highland Rim the surface is undulating; in the region of the Ozark uplift in Missouri and Arkansas it is quite rough and hilly, and where there is an elevation of the surface, or where the plateau is deeply dissected by erosion, it presents a quite mountainous topography. The valley soils of the Appalachian region also show considerable topographic relief, sometimes exhibiting mountainous surface features.

The limestone soils are residual in origin, being derived from the weathering in place of limestone of differing age and composition. This is accomplished by the removal through solution of the calcium carbonate of the limestone, leaving behind the more resistant siliceous minerals. These soils are remarkable for the fact that they contain but a very small percentage of the original limestone rock, the larger part having gone into solution. It has thus required the solution of many feet of rock to form a single foot of soil. Thus far the limestone soils east of Kansas and Texas and north of central Alabama and Georgia have been grouped in two important series, known as the Hagerstown and Clarksville.

Clarksville series. Light gray to brown soils with yellow to red subsoils, derived mainly from the St. Louis limestone. While not as strong as the Hagerstown soils, this is a valuable series. Apples and peaches are commercially important. Tobacco is a leading product. General farming is firmly established in many extensive regions.

Cumberland series. Brown surface soils, derived from thin deposit of sedimentary material overlying residual limestone subsoils. Used for cotton and other general farm crops, truck and fruit.

Decatur series. Reddish brown to red soils with intensely red subsoils. Intermediate in value between the two series just described. Cotton, corn, wheat, oats, forage crops, blue grass, and peaches are the leading crops.

Hagerstown series. Brown to yellowish soils with yellow to reddish subsoils, derived from massive limestone. Among the most productive soils of the eastern United States. Fine wheat and general farming soils, and the seat of important apple orcharding interests. Blue grass is indigenous.

\section{Glactal and Loessial Regions}

The soils of the glaciated part of the country constitute one of the most important groups in the United States. The group includes all soils derived 
directly from till or loess. The soils formed from the till are confined to that part of the country lying north of the southern limit of glacial action, but the loess soils occur also south of this line, especially along the Mississippi and Ohio rivers and in Kansas and Nebraska. The line of the southern extension of the ice sheet touches the Atlantic coast about New York City, passes through northern New Jersey, southern New York, and northwestern Pennsylvania, swings southward through Ohio to Cincinnati, crosses the Mississippi River at St. Louis, and follows the south side of the Missouri River into Montana, where it crosses the Canadian boundary line, then dips southward into Idaho as a long lobe in the mountainous nonagricultural region, and crosses the northwestern part of Washington, including the Puget Sound region.

Practically all of the United States north of this line was covered in recent geological time by a great continental glacier, many hundreds, and even thou* sands, of feet in thickness. This great ice sheet, moving in a southern direction, filled up valleys, planed off the tops of hills and mountains, ground up the underlying rocks, carried the derived material both within and upon the ice, and finally deposited the gravel, sand, silt, and clay, as a mantle, varying in thickness from a few feet to more than 300 feet. Often this material has been transported hundreds of miles, and is wholly unrelated to the underlying rocks, but in some places the movement has been slight, and the drift consists very largely of the ground-up underlying rock. Over a large porportion of the area covered by the drift and also along the Ohio and Mississippi rivers and in Kansas and Nebraska, the surface material consists of a fine silty deposit, known geologically as "loess" and "Plains marl." In the classification of the glacial soils, three important series - Miami, Marshall, and Volusia - having distinct characteristics have been recognized and, in addition, quite a number of miscellaneous soils which cannot be put in any series.

Marshall series. Dark-colored upland prairie soils. The principal soils of the great corn belt belong to this series, while in the Northwest the finest wheat soils are found in this group. They are among the best general farming soils of the entire country.

Miami series. Light-colored upland timbered soils. The different members of this series are considered good general farming soils and have in addition special adaptations for truck, fruit, small fruit, and alfalfa.

Volusia series. Light-colored soils with yellowish sulsoils, derived by feeble glacial action from sandstones and shales. The soils of this series are adapted to the production of potatoes, grass, oats, buckwheat, and, in the less elevated positions, to corn.

\section{Glactal Lake and River Terraces}

Another important group of soils occurs in the glacial region, principally as terraces around lakes, or along streams, or as deposits in areas which were formerly covered by water. At the close of the glacial epoch the lakes in this part of the United States were not only more numerous, but the waters of those which remain reached a higher level and covered areas that are now far above 
their present shore lines. In some cases several distinct terraces, each one marked by an old shore line, are easily discernible, and represent successive stages in the lowering of the water level. The elevation above the lake varies from a few feet to more than 200 feet. The surface of each terrace is usually rolling to level, with a gradual slope toward the lake, but sometimes areas of a rough and broken character occur. The streams which cross these terraces have frequently, by their cutting, produced deep, steep-sided valleys, especially near the lakes.

The soils of this group vary from typical beach gravels to offshore deposits of heavy clays. The material from which they are derived consists of glacial débris reworked and redeposited in the lakes or along streams. While this glacial material is made up of rocks of widely varying origin, a large proportion of it often consists of the country rock. In the eastern part of the Great Lake region the percentage of sandstone and shale fragments is usually very high, while in the western part more of the igneous rocks are present. This fact, together with differences in drainage conditions, has given rise to several series of soils.

Clyde series. Dark-colored swamp soils formed from reworked glacial material deposited in glacial lakes. A special use for these soils is the production of sugar beets, while general farm crops, truck and canning crops, are grown extensively.

Dunkirk series. Light-colored reworked glacial material occurring as terraces around lakes and along streams. Good general farming soils and especially adapted to grapes and other fruits.

Fargo series. Black calcareous soils rich in organic matter formed by deposition of material in glacial lakes. This is the most important group of soils in the Red River Valiey, and includes exceptional soils for the production of wheat, barley, and flax. While these are the chief crops at present, the soil adaptations are by no means limited to small grain production. Timothy and vegetables may become more important products with the development of markets.

Hudson series. Light brown to yellowish brown soils, with drab to yellowish subsoils.

Merrimac series. Brown terrace soils underlain by gravel, formed principally of reworked glaciated crystalline rocks. Leachy soils of low general farming value, but especially adapted to trucking and apple orcharding in some sections.

Sioux series. Dark-colored soils resting on dark or light-colored subsoils, with gravel beds usually within 3 feet of the surface. The crops produced on soils of this series range from early short-seasoned truck crops through special crops like alfalfa and sugar beets to the wide variety of general farm crops produced in the Central West.

Superior series. Gray and red soils with red subsoils, formed from reworked glacial material deposited in glacial lakes. Not extensively developed, but known to include fine types for clover, timothy, and small fruits. 
Vergennes series. Light-colored soils, with gray or whitish subsoils, derived from Champlain clay, or lighter deposits over these clays. This series includes the best hay and apple soils of the Champlain Valley. A wide variety of tillage crops is grown, but cultivation of the heavier members of the series is very difficult.

\section{Residual Solls of the Western Prairie Region}

This region consists of the nonglacial part of the prairie plains bounded on the north by the Missouri River, the southern limit of glaciers, and extending southward through Texas to the Rio Grande. On the west it merges into the Plateau region at very near the 2000 -foot contour, and on the east is limited by the Gulf Coastal Plain and the Ozark Plateau. Its surface is gently rolling, with occasional low hills, and is cut by numerous stream channels. The rocks are of Carboniferous age, and consist of sandstones, shales, and limestones more or less interbedded. These rocks give rise to three series of soils, viz. Oswego, Crawford, and Vernon, together with a number of miscellaneous soils. In Kansas and Texas these soils are in some instances more or less modified by the admixture of gravel and sand from Tertiary deposits brought down from the higher areas farther west occupied by crystalline rocks.

Crawford series. Brown soils with reddish subsoils, derived from limestones. The soils of this series range from rough areas suited mainly for pastures to fertile general farming, fruit growing, and trucking soils.

Oswego series. Gray or brown soils, derived from sandstones and shales. The lighter members of this series are adapted to corn, oats, potatoes, truck, and fruit; the heavier to these crops and wheat.

Vernon series. Brown to red soils typical of the Permian formation. Soils of this series show a wide adaptation according to texture. General farm crops, including cotton, corn, wheat, Kafir corn, and sorghum are the leading products. Small fruit, peaches, and truck are grown to some extent and are capable of marked extension.

\section{GREAT BASIN}

With the exception of one soil type recognized in the Laramie area, Wyoming, the soils in this group, so far as mapped, are confined to the Great Interior Basin region. They are derived from a great variety of rocks, and consist of colluvial soil of the mountain slopes, deep lacustrine and shore deposits of the Bonneville period, and of recent stream-valley sediments and river-delta deposits.

When not situated above or outside the limits of irrigation, or rendered unfit for cultivation by accumulation of alkali or seepage waters, they are of great agricultural importance, and are devoted mainly to the production of grains, sugar beets, alfalfa, stone or other tree fruits, and vegetables.

Bingham series. Porous dark or drab colluvial and alluvial soils underlain by gravel or rock, occupying lower mountain slopes. The lighter types 
when irrigable are devoted to orchard fruits, the heavier types to alfalfa and sugar beets.

Jordan series. Light to dark-colored lacustrine desposits. These soils are utilized principally in the production of alfalfa, sugar beets, truck crops, and grains under favorable conditions for irrigation and drainage, but considerable areas covered by some of the members of this series are not utilized on account of the accumulation of alkali, poor drainage, or because of their drifting character.

Malade series. Dark-colored alluvial soils underlain by light-colored sands, sandy loams, or heavy reddish material. These soils are devoted chiefly to sugar beets, alfalfa, grain, and some orchard fruits.

Redfield series. Red soils consisting of colluvial and alluvial materials derived from red sandstones and other rocks. The lighter members are adapted to the production of alfalfa, grain, and general farm crops when irrigable and well drained. The heavier members, as far as encountered, are poorly drained and have not been developed.

Salt Lake series. Dark-colored soils underlain by stratified sediments of lacustrine origin. These soils, as far as encountered, occupy very low, flat positions around the lake, and have not been developed to any extent.

\section{NorthWEStern Intermountain Region}

The most extensive and uniform soil types of this region consist of residual materials overlying and derived from extensive basaltic lava plains and in some cases from granite rocks or of ancient lacustrine sediments or extensive lake beds now more or less modified by erosion or æolian agencies. Owing to erosion by streams and to movements of the earth's crust, these soils now generally occupy more or less elevated sloping or rolling plains. About the margins of the lacustrine or residual deposits they are covered by sloping plains and fans of colluvial wash from the adjacent mountain borders, while in the vicinity of the larger streams, which have carved and terraced the lacustrine beds and residual soils, occur other series of recent alluvial stream sediments derived from reworked materials of the lake beds or from the weathered products of the mountains. It is the soils of this region that constitute a large portion of the great grain-producing lands of the Northwest.

Bridger series. Dark-colored soils with sticky yellow subsoils, of colluvial and alluvial origin. These soils generally occupy elevated foot slopes or sloping valley plains and have not been developed to a great extent. They are most extensively used for the production of grain, and, when irrigated, are utilized in the production of alfalfa and other hay crops and, under favorable climatic conditions, are adapted to fruits.

Gallatin series. Light to dark-colored soils with yellowish to dark compact subsoils, of recent alluvial origin from basaltic and volcanic rocks. These soils generally occupy low positions, very frequently poorly drained, often subject to overflow, and have not been extensively developed for agricultural 
purposes. They are used chiefly for grazing and, to some extent, in the production of hay, grains, and in some sections for vegetables.

Yakima series. Ash-gray to light brown soils derived principally from ancient lake sediments consisting of an admixture of volcanic dust and basaltic, andesitic, and granitic materials. Certain members of this series have been very successfully developed for hop culture, alfalfa, grass, grain, and fruit, while other members of the series, owing to their elevated position and general rough character, have not been developed at all.

\section{Rocky Mountain Valleys, Plateaus, and Plains}

The soils of the Rocky Mountain valleys, plateaus, and plains are derived from a wide range of igneous, eruptive, metamorphic, and sedimentary rocks. The plateau and plain types occupy a more or less elevated position, and have sloping, undulating, or irregular surface features. They are derived from underlying sedimentary rocks or consist of the remains of the ancient extensive mountain foot-slope material or of alluvial deposits along streams trenching and terracing the sedimentary rocks of the plateaus and plains. The mountain slope and intermountain types consist of residual and colluvial deposits or of ancient lacustrine or later stream sediments, occupying mountain foot slopes and narrow valleys.

The soils of the mountain slopes are usually of little agricultural value, owing to their rough surface, elevated position, and the consequent impracticability of irrigation. Those of the plateaus, valleys, and plains vary widely in economic importance, depending largely upon climatic features, topography, position, and water supply for irrigation. They range from grazing lands of nominal value to soils adapted to the most important and intensively cultivated fruit, melon, sugar beet, and other special crops.

Billings series. Compact adobe-like gray to dark or brown soils and subsoils, formed mainly by reworking of sandstones and shales, and occupying old elevated stream terraces. This is an important series adapted to alfalfa and general farm crops and stock raising; also used to a considerable extent in the production of sugar beets.

Colorado series. Light gray to reddish brown soils and subsoils, derived from colluvial wash. Where irrigable, these soils are important soils in the production of alfalfa, sugar beets, melons, and, to a limited extent, fruits. A number of the soils of the series, however, are so situated as not to be susceptible to irrigation, and have not been developed for agricultural purposes.

Finney series. Brown to nearly black soils derived from glacial material underlain by lighter-colored subsoils. The heavier soils may be dry farmed to advantage, and would become very productive with irrigation. The lighter soils have a broken surface, are porous, and easily drifted by the wind. They are best adapted to grazing.

Fruita series. Reddish brown soils, formed by reworking of sandstones and shales, occurring as stream terraces. When well drained and free from 
alkali, the members of this series are admirably adapted to the production of choice fruits, alfalfa, sugar beets, grains, and truck crops.

Laramie series. Dark-colored soils, with light-colored gravelly subsoils, derived from colluvial mountain wash. These soils have not been extensively developed, owing to their elevation, and are used principally for grazing purposes.

Laurel series. Light gray to black soils, underlain by river sands or gravels, occurring in flood plains along streams. Under favorable moisture conditions, these are fertile soils, adapted according to locality to corn, alfalfa, sugar beets, and truck crops, but the areas are often subject to overflow, and in some cases cannot be drained.

Mesa series. Light gray to brown soils derived from old flood-plain deposits, now elevated to form mesa lands. Where these soils have been developed and are susceptible of irrigation, they are used mainly for alfalfa and sugar beets. One member of the series has been quite extensively and very successfully used for the production of apples and peaches.

Morton series. Brown residual soils, derived from sandstones and shales. The soils lie in the semiarid region, and give good yields of wheat, flax, oats, and potatoes, when rainfall is sufficient.

San Luis series. Reddish brown gravelly soils, formed from lacustrine sediments of volcanic rock materials. On account of the position and the danger from alkali, these soils have not been successfully developed, but have been used mainly for pasturage and forage crops.

Wade series. Brown to dark brown alluvial soils, formed by reworking of sandstones and shales. Used for oats, flax, millet, and wheat.

\section{ARID Southwest}

The soils of the arid Southwest are mainly of colluvial, alluvial, and lacustrine origin. They occupy mountain foot slopes, alluvial fans, débris aprons, or sloping plains of filled valleys, sloping or nearly level plains, and bottoms of stream valleys or sinks and drainage basins. The principal colluvial soils of this region are also common to the Pacific coast. The climate of the arid Southwest is characterized by semitropical desert conditions, and where the soils are not capable of irrigation, they have little or no present agricultural value.

Gila series. Light to dark brown soils of flood-plain alluvium, underlain at varying depths by coarse sands and gravels. Under favorable irrigation and drainage conditions, the members of the Gila series are adapted chiefly to the production of alfalfa, potatoes, truck, and root crops.

Imperial series. Light-colored or reddish soils formed from old marine or lacustrine sediments modified by more recent deposits, and underlain to great depths by heavy material. These soils are particularly adapted to alfalfa, sorghum, and other forage crops.

Indio series. Light-colored soils usually underlain by coarser sands and 
gravels, formed by colluvial and alluvial wash from granitic rock, mingled with some shale and sandstone. These soils are adapted to fruit, truck crops, sweet potatoes, melons, and alfalfa, under favorable conditions of irrigation and drainage.

\section{Pacific CoAst}

The soils of the Pacific coast, including those of the coastal and interior mountain ranges, foothills, and valleys, have been classified into a number of series, varying in field characteristics, topography, origin and mode of formation, and agricultural importance. They range from residual and colluvial soils of the mountain sides, foot slopes, and foothills, to deep and extensive river flood plains and delta sediments, and ancient and modern shore and marine lacustrine deposits. While some of these series are confined to a single coastal or interior mountain range or valley, others are of wider range and extend over several different physiographic regions. The value of these soils and their adaptation to crops is dependent largely upon the possibilities of irrigation and upon local conditions of rainfall and temperature, all of which are to great extent dependent upon topography. They range in agricultural importance from those devoted only to extensive grain farming to the most valuable and intensively cultivated lands devoted to citrus and deciduous fruits, vines, small fruits, and other special crops.

Anderson series. Reddish gray or light red alluvial soils occupying principal valley plains and the bottoms of intermittent streams. Generally gravelly. The soils of this series, when not too gravelly, are adapted to the production of peaches, pears, prunes, and small fruits, but are, in so far as mapped at present, inextensive types of secondary agricultural importance.

Fresno series. Light-colored soils with light gray, ashy subsoils, and alkali-carbonate hardpan, derived from old alluvial wash. Where protected from alkali accumulations, these soils have been very successfully used for vineyards and raisin grapes, and are particularly adapted to almonds, peaches, and apricots.

Hanford series. Recent alluvium of flood or delta plains derived from a variety of rocks. The light-textured soils are light in color, and the heavy textured soils are dark in color. The lighter members of the series are adapted to the same class of fruits and raisin grapes as the Fresno series. The heavier members of this series, however, are better adapted to alfalfa, sugar beets, celery, asparagus, and other truck crops.

Maricopa series. Loose, dark-colored soils derived from unassorted colluvial or partially assorted alluvial materials, generally derived from granitic or volcanic rocks. There are two heavy members of this series upon which alfalfa, grain, and sugar beets are important crops. The lighter members, when occupying positions so that they can be irrigated, are adapted to citrus and deciduous fruits; also vines.

Oxnard series. Dark-colored alluvial or colluvial soils derived from higher lying areas of sandstones and shales. Members of this series are used to a very 
large extent for sugar beets and lima beans, and, where irrigation is not practicable, extensively used for grain.

Placentia series. Reddish soils derived largely from the weathering of alluvial and colluvial deposits, generally underlain by heavy compact red material with an impervious adobe structure. Large areas of these soils are devoted to dry farming of grain, and occur throughout southern California and in some of the coastal valleys, viz., Bakersfield, Salinas, and San José. These are extensive areas under irrigation, which are valuable for producing both deciduous and citrus fruits. The heavier members of this series have been more successfully used for grain production in southern California. They seem particularly well adapted to English walnuts and olives. The soils are usually well drained. The English walnut does not thrive on poorly drained soils.

Redding series. Ancient alluvial valley deposits of red and deep red color, generally gravelly. Heavy red subsoils with hardpan. The soils of this series, when not carrying an excess of cobbles or underlain at shallow depths by hardpan, are excellently adapted to the production of choice peaches and small fruits.

Sacramento series. Gray alluvial soils consisting of recent stream sediments. The lighter members of this series are used mainly for the production of prunes, pears, and peaches. The members of the series having a medium texture are adapted to sugar beets, alfalfa, and prunes. The heavier members are at present poorly drained, and have not been highly developed, being used mostly for grain and grazing.

Salem series. Residual, alluvial, or colluvial soils, either red or dark in color, derived from rocks of basaltic, schistose, crystalline, or arenaceous character. These soils, so far as they have been encountered, seem particularly adapted to hops, potatoes, and have been used to some extent for apples, peaches, and grain. They have not been very highly developed in the areas in which they have been encountered.

San Joaquin series. Compact red soils and subsoils derived from old marine sediments, usually underlain by red hardpan. These soils have been used almost exclusively for dry farming to grain on account of the general occurrence of hardpan and very stiff and impervious subsoils. Recently, in the Sacramento area, some members of this series have been very successfully used for the production of the Tokay grape and strawberries.

Sierra series. Light gray to red and frequently gravelly soils, often underlain by red adobe. Members of this series constitute some of the most valuable deciduous fruit soils of the foothills in northern California.

Sites series. Residual and colluvial soils of reddish gray or dark brown color, derived from sandstones, shales, conglomerates, and volcanic or altered material occupying low, rolling foothills and their valley slopes, usually underlain at shallow depths by sandstones, conglomerates, or heavy subsoils. The Sites loam and clay loam adobe are the important soils of this series and are productive, but, owing to their positions, are generally unirrigable and adapted to dry farming to grains. 
Stockton series. Brown to black soils with heavy yellow subsoils, derived from old alluvial sediments. These soils have been used principally for the production of grain. The lighter members of this series have been adapted to fruit.

Willow series. Brown soils consisting of wash deposited by intermittent foothill streams. These soils have been used almost exclusively for dry farming grain crops. Large ranches are being broken up and brought under irrigation, and alfalfa and sugar beets are likely to prove the most important crops.

\section{The following additional quotations from Bureau of Soils Bulle-} tin 55 will serve to acquaint the student with the general character of the more detailed descriptions which are given of the soil types singly and in series:

\section{Leonardtown loam ${ }^{1}$ (Maryland, Virginia, Kentucky, - I96,834 acres).} "The Leonardtown loam is a valuable upland soil of Maryland and Virginia. The surface is slightly rolling, the drainage in most areas is good, and altogether the land is well suited to general farming. The soil has a special value in the production of wheat and grass."

Marion silt loam (Illinois, Missouri, - 695,040 acres). "A large proportion of southern Illinois is occupied by Marion silt loam. The type occupies level prairie land and is characterized by hard silty clay subsoil locally known as ' hardpan.' It is low in organic matter, and this, combined with the impervious nature of the subsoil, causes crops to suffer in wet as well as dry seasons. Wheat, corn, and grasses are the principal crops, but the average yields are considerably lower than upon the black prairie soils. It seems especially well adapted to apples, and many large orchards have been planted. Strawberries also do well."

Marshall series (glacial and loessial regions). "The Marshall series includes the dark-colored upland glacial and loessial soils, which cover almost all of the great prairie region of the Central West. The soils of this series are characterized and distinguished from those of the Miami series by the relatively large quantity of organic matter in the surface soils, which gives them a dark brown to black color. The topography is level to rolling, and artificial drainage is necessary on many level and low-lying areas to secure the best results. The soils of this series are very productive and constitute the great corn soils of the country.

"The Marshall silt loam, loam, and clay loam constitute the principal soil types throughout the great corn belt, and rank among the most productive of our general farming soils. In Iowa, Illinois, and Nebraska, corn, oats, clover, and timothy are the leading crops, while in Minnesota and the Dakotas wheat becomes of primary importance. The Miami (Marshall) black clay loam, when drained, is also an exceedingly fertile soil, being particularly well adapted

${ }^{1}$ The Leonardtown loam and Leonardtown gravelly boam in the Norfolk, Virginia, report are the Portsmouth silt loam. 
to corn. The sandy loam and fine sandy loam, while not so well adapted to general farming as the heavier soils, are quite productive and have a wide crop adaptation. The sand and fine sand are well suited to truck crops, but give rather uncertain yields of general farm crops.

"The acreage of the types so far encountered is as follows:

Area and Distribution of the Solls of the Marshall Series

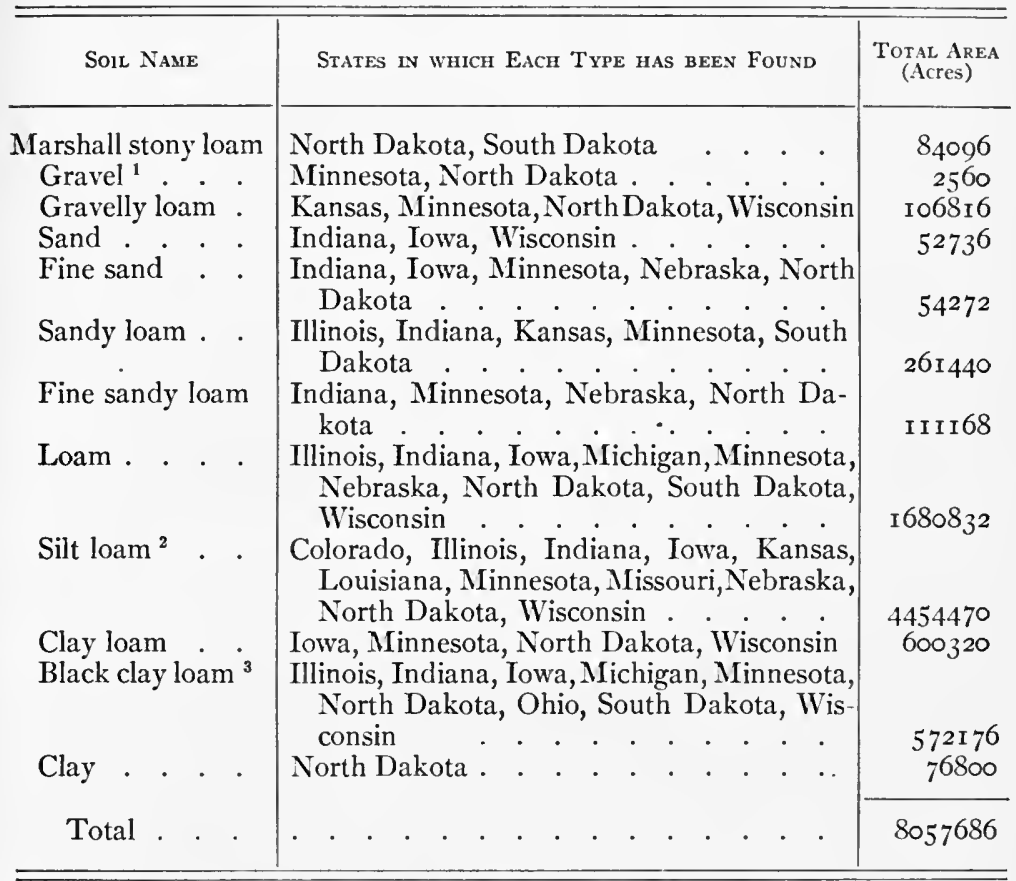

I The soil mapped as Marshall gravel in Pontiac area, Michigan, is Miami gravelly sand.

${ }^{2}$ Mapped as Miami silt loam in Clinton and St. Clair counties, Illinois, and as Fresno fine sandy loam in Lower Arkansas Valley area, Colorado.

${ }^{3}$ The soil mapped as Miami (now Marshall) black clay loam in the Toledo area, Ohio, is Clyde clay.

Miami series (glacial and loessial regions). "The Miami series is one of the most important, widely distributed, and complete soil series that has been established. The series is characterized by the light color of the surface soils, by derivation from glacial material, and by being timbered either now or originally. The heavier members of the series are better adapted to wheat 
Area and Distribution of the Solls of the Miami Series

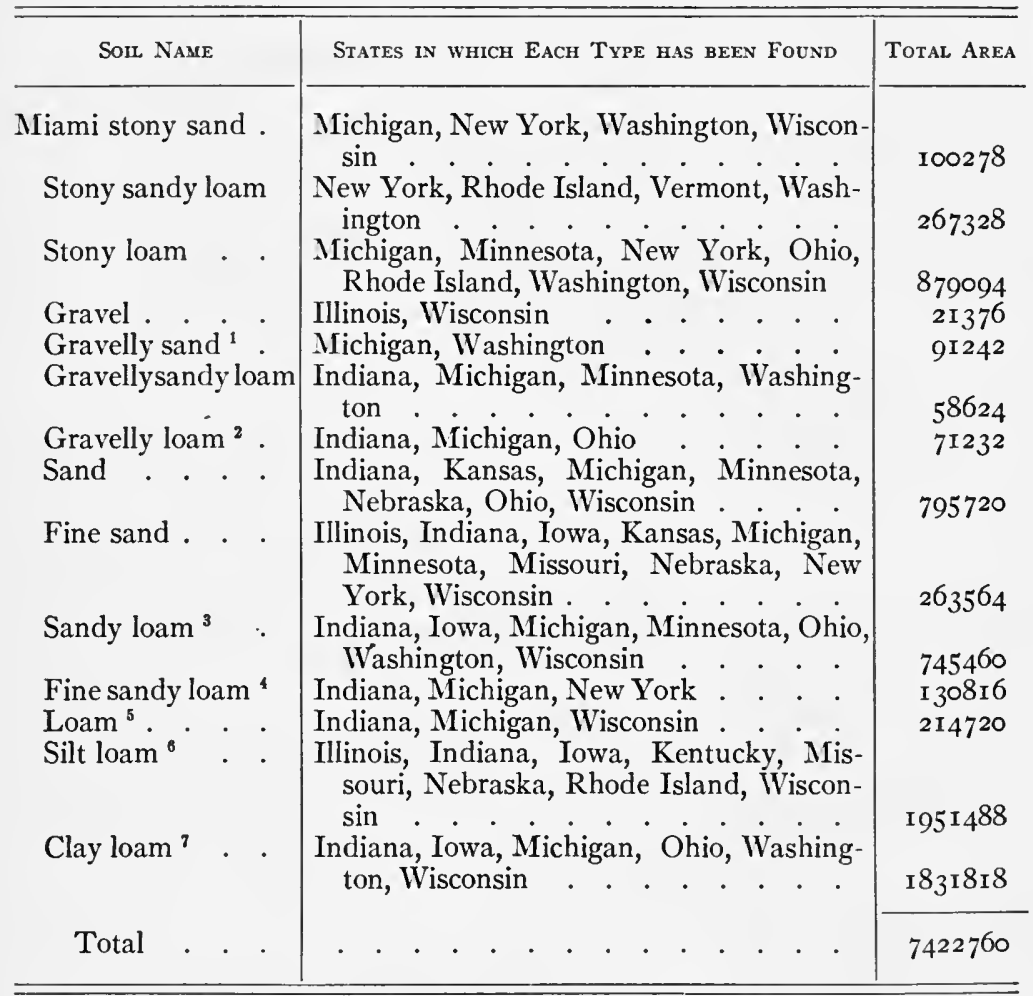

${ }^{1}$ Mapped as Marshall gravel in Pontiac area, Michigan.

2 The soil mapped as Miami gravelly loam in the Big Flats area and Syracuse area, New York, is the Dunkirk gravelly loam.

${ }^{3}$ The soil mapped as Miami sandy loam in the Grand Forks area, North Dakota, is the Clyde fine sandy loam; in the Montgomery County area, Ohio, is Wabash sandy loam; and in Posey County area, Indiana, is Wabash fine sandy loam.

4 'The soil mapped as Miami fine sandy loam in Posey County, Indiana, and Union County, Kentucky, is Waverly fine sandy loam; in the Boonville area, Indiana, is the Norfolk fine sandy loam; in the Lyons and Syracuse areas, New York, is Dunkirk fine sandy loam; and in St. Claire County, Illinois, is Memphis silt loam.

5 The Miami loam in the Auburn, Lyons, and Syracuse areas, New York; the Columbus, Coshocton, Montgomery, Toledo, and Westerville areas, Ohio; the Fargo and Grand Forks areas, North Dakota; the Marshall, Minnesota, and Pontiac areas, Michigan; and the Viroqua area, Wisconsin, is Wabash loam. The soil mapped as Miami loam in Tazewell County, Illinois, is Sioux loam, and that mapped as Miami loam in the Janesville area, Wisconsin, is the Sioux sandy loam.

- The soil mapped as Miami silt loam in the Syracuse area, New York, is Dunkirk 
than the corresponding members of the Marshall series, but they do not produce as large yields of corn.

"The clay loam is the most important for general farming, and forms the principal type of soil in western Ohio and central and eastern Indiana. It is especially well adapted to small grain and grass crops. The silt loam is more rolling and hilly than the clay loam and is not so well suited to general farming. Wheat does better upon it than upon the Marshall silt loam, with which it is closely associated, but the yields of corn are considerably less. It is also well adapted to fruit, especially apples. The sandy loam and fine sandy loam are used for general agriculture, but are especially adapted to medium and late truck crops and fruit. The loam is suited to corn and potatoes, while small grain and grass are grown, but with less success than upon the clay loam. Strawberries and raspberries, as well as other small fruits, do well on this type. The stony sand, gravelly sand, and gravel are not of much agricultural value under present conditions. The stony loam is a good general farming soil, is also well adapted to apples, and furnishes excellent pasture, while in New York alfalfa is grown upon it very successfully. The stony sandy loam and gravelly sandy loam are not strong soils, but are fairly well suited to light farming, fruit, and truck. The sand and fine sand are not adapted to general farming, but are the best early truck soils of this section.

"The acreage of the different types so far encountered is shown in the preceding table."

silt loam, and that mapped as Miami silt loam in Clinton and St. Claire counties, Illinois, is Marshall silt loam.

${ }^{7}$ The soil mapped as Miami clay loam in Toledo area, Ohio, is Dunkirk clay loam, and that mapped as Miami clay loam in the Stuttgart area, Arkansas, is Crowley silt loam. 


\section{CHAPTER IX}

\section{SOIL ANALYSIS BY THE UNITED STATES BUREAU OF SOILS}

ThE United States Bureau of Soils Bulletin 54 (December, I908), on "The Mineral Composition of Soil Particles," contains data from which can be computed ${ }^{1}$ accurately the total amounts of phosphorus, potassium, magnesium, and calcium, in the ignited surface soil of twenty-seven important soil types of the United States. The loss on ignition of ordinary soils usually approaches Io per cent, and includes chiefly the combined water, organic matter, and more or less carbon dioxid, if carbonates are present; consequently, the results given on the basis of ignited soil are, as a rule, about one tenth higher than if given on the usual basis of dry soil.

The following general statements regarding these soil samples are made by the Bureau of Soils (Bulletin 54, page I $_{5}$ ):

"Our extensive collection of soils from important and well-marked soil types enables us to select samples fully representative of the soils of the country. Accordingly, agricultural soils of known character were selected so as to include those from various geographical sections and from a number of soil provinces. Thus we have taken soils from the Coastal Plains, the Piedmont region, glacial soils, nonglacial soils of the interior, and those of the arid region, the list comprising 27 soil types."

"We have but two soils of the arid region to compare with the twenty-five of the humid region. The latter were collected to represent soils of all classes - those of low, of medium, and of high productivity; sandy soils, clay soils, calcareous soils, and those intermediate between these extremes. They may be taken as fairly well representing the humid soils. The two arid soils cannot be considered to represent so well those of the region because of their limited number and similarity of texture, both being fine sandy loams."

"The Coastal Plains soils have resulted, to a large extent, from material washed from the Piedmont Plateau and deposited in water at lower levels.

1 The Bureau of Soils Report shows, for example (Bulletin 54, page 19), that Leonardtown loam contains 29.5 per cent of sand, 55 per cent of silt, and 15 per cent of clay, and that the total $\mathrm{P}_{2} \mathrm{O}_{5}$ which these particles contain is or per cent in the sand, .02 per cent in the silt, and .03 per cent in the clay. 
They have suffered from decomposition and solution more than have the Piedmont and Appalachian soils, and there has often been a greater separation of the finer from the coarser particles."

"The tables show that the residual soils, Chester mica loam, Porter's black loam, and Cecil clay, contain more plant-food constituents than do the Coastal Plains soils. This is especially true of the phosphorus, the potassium, and the magnesium."

"The sandy and the silty glacial soils are somewhat similar in percentage composition. Owing to the latter consisting to so large an extent of such fine particles, it might have been supposed that decomposition and leaching would have affected them more . . but the silty soils are loessial for the most part, and were formed from material blown by winds from glaciated areas and deposited where now found, or of material that has since been reworked by water. Minerals rich in alkalis and alkaline earths, being relatively easily crushed, would form a larger percentage of these silty soils than they do of the original glacial soils; so that even if there has been a tendency to impoverish them by leaching, their originally greater richness enables the loessial soils to compare well with those strictly glacial."

In Table 22 are reported the total amounts of phosphorus, potassium, magnesium, and calcium found by the Bureau of Soils in 2 million pounds of ignited soil for the surface soil of each of the 27 type soils, and also the amounts in the acid-soluble portion of one subsoil, or underlying greensand marl.

While these soils " were selected to represent all classes - those of low, of medium, and of high productivity," Bulletin 54 gives no information as to the agricultural value of the different soils. Fortunately, the Annual Reports of the Bureau of Soils contain the descriptions made by the soil survey men concerning the common crops and normal crop yields produced on each of these soils, and thus a correlation is made possible between chemical composition (as recently determined by actual ultimate analysis) and productive capacity, of these important and extensive types of soil (as reported in previous years from field investigations). Even here the student is advised not to accept opinions expressed, predictions made, or conclusions drawn, unless clearly supported by chemical facts or by long-continued agricultural experience.

In each of the following descriptions the first paragraph is quoted from Bureau of Soils Bulletin 54 (December, Igo8), and the second paragraph is quoted from the Annual Report of the "Field 


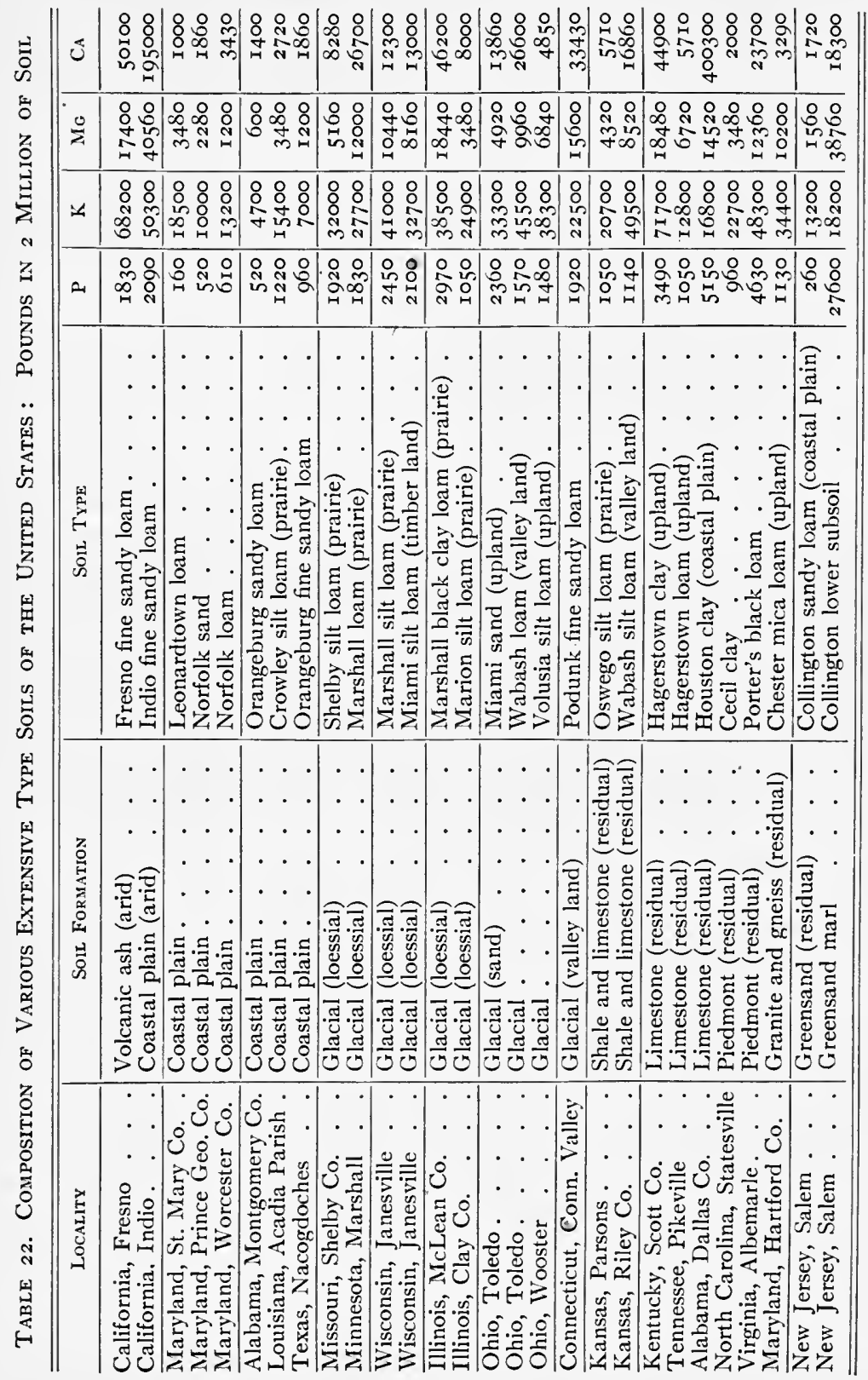


Operations of the Bureau of Soils" for the year designated. For convenient reference, the number of pounds of phosphorus shown in Table 22 is given at the beginning of the second paragraph in each description, not that the supply of the one element always correlates with productive power, but because it does so more frequently than any other.

\section{SOILS OF THE ARID Region}

Fresno fine sandy loam (California) "is composed largely of silt to fine sand. It is locally known as 'white-ash land,' from its color and its physical character. The soil has probably been derived from volanic ash, but lightcolored loams and sands have also contributed to it. The soil lies flat and works well, unless it be puddled, when water penetrates it slowly and hard clods or lumps form on drying. The lower subsoil is heavier, a blue clay being encountered at the depth of a few feet. Because of the poor drainage or light rainfall, this soil generally contains alkali."

(I830 lb. P.) "Was originally considered extremely productive, and is now, where the drainage is good. Some of the first colonists settled on this land through choice." (Report for I900, page 46.)

Indio fine sandy loam (California) "is made up of clay, silt, and the fine grades of sand. The clay is so flocculated that the soil in its field condition is lighter than the mechanical composition would indicate. The soil was mainly formed by erosion from adjacent mountains, the material being deposited in a bay or arm of the sea, but it has been greatly modified by wind action. It contains micaceous grains and minute shells. The soil ranges in depth from $2 \frac{1}{2}$ to 5 feet and is underlain with sandy loam or sand. The surface usually has a uniform slope and is generally well drained, but its high capillary power draws much water to the surface, causing an accumulation of alkali by its evaporation. In the lower levels the alkali is present in injurious amounts. Owing to insufficient rainfall, the salts are not washed out of this soil so well as might be expected from its physical character."

$(2090 \mathrm{lb}$. P.) "Where not too strongly alkaline, it will produce in abundance any of the crops suited to the climate." (Report for I903, page I255.)

\section{Coastal Plains Solls}

Leonardtown loam (Maryland) "consists of a yellow silty loam, fine and powdery when dry, but puddling to a plastic mass when thoroughly wet. The subsoil consists of a brittle mass of interlocking clay lenses, lumps, and fragments, separated by seams and pockets of medium to fine sand. This subsoil is as impervious as clay, owing to its peculiar shingle-like structure. It is an upland soil, and is generally slightly rolling."

(I60 lb. P.) "Covers about 4I per cent of St. Mary County. . . . This 
soil has been cultivated for upward of two hundred years, but it is now little valued and is covered with oak and pine over much of its area. It is worth from $\$_{1}$ to $\$_{3}$ an acre. The cultivated areas produce small crops of corn, wheat, and an inferior grade of tobacco."

To this statement of facts is added the opinion that " the generally low estimation in which land is held is probably wholly unjustified. ... In texture, in chemical composition, ${ }^{1}$ and in general agricultural value (when carefully and intelligently farmed) these lands compare favorably with the Hagerstown loam of western Maryland and Lancaster County, Pa., which are considered the most valuable soils of the Atlantic States for general farm crops." (Report for I900, page 33.)

The Bureau of Soils also reports that 45,770 acres of this type of soil are found in Prince George County, which borders the District of Columbia on the east and south, concerning which the Bureau's Report for I90 contains the following statements:

"The soil is not adapted to tobacco, and has consequently been allowed to grow up to scrub forests, so that large portions of it are at present uncleared. Such unimproved lands can be bought for $\$ \mathbf{r} .50$ to $\$ 5.00$ an acre, even within a few miles of the District line. The soil has been badly neglected, and, when cultivated, the methods have not been such as to promote fertility. It is frequently acid, and needs lime and manure, or green crops turned under. When properly handled, as it is in a few places, good yields of wheat, corn, and grass are obtained."

And to this statement of facts is also added the opinion that " upon the whole it is one of the most promising soils ${ }^{2}$ of the local-

${ }^{1}$ See Table 22 for chemical composition of the Leonardtown loam and the loam and clay of the Hagerstown series. - C. G. H.

2 Determinations of the water-soluble constituents in 36 samples of Leonardtown loam are included in the data which led Whitney and Cameron to draw the very erroneous conclusions that "practically all soils contain sufficient plant food for good crop yields, that this supply will be indefinitely maintained, and that the actual yield of plants adapted to the soil depends mainly, under favorable climatic conditions, upon the cultural methods and suitable crop rotations." (Bureau of Soils Bulletin 22, page 64.)

The following quotations are taken from page 34 of Bureau of Soils Bulletin 22 (1903). They furnish some information as to what is done when this soil is "properly handled":

"There is no apparent relation between the yield of crops and the soluble salt content of soils, even where the yields per acre differ as much as from 4 bushels to 25 or 30 bushels. 
ity, although it is not so considered by the resident farmers." (Report for I901, page 45.)

Norfolk sand (Maryland) "is a coarse to medium orange or yellow sand, having a depth of about ro inches. The subsoil is coarse to medium, becom-

"As bearing upon this point of the association or ronassociation of high analytical figures with large crop yields, no more striking evidence occurs to us than the following letter written by Mr. Taylor, May 26, while in the field in St. Mary County, Md., and forming a part of his regular reports to the Bureau at Washington:

"At Park Hall, upon the farm of Mr. S-, who is recognized as one of the best farmers of the community, I secured some samples of the Leonardtown loam from a wheat field which will produce from 30 to 35 bushels per acre this season. The land was in tobacco last season, upon which barnyard manure and 400 pounds of fertilizer had been used. Nothing was added when the wheat was sown. The land was plowed about 8 inches deep. The soil lacked the usual grayish, ashy appearance of the Leonardtown loam, and, owing to cultivation, was loose and mellow to a depth of over two feet. One of these samples was compared with one taken from another wheat field upon the same type, where the yield would not be over 6 or 8 bushels. This latter land was farmed by negroes, was in wheat last year, and produced a fair crop, so it is said. No manure but a little guano was used last fall. The ground was uneven on the surface, and below the first 4 or 5 inches the soil was hard and compact. A comparison of the analyses is given below:

Parts per Million of Oven-dried Soll

\begin{tabular}{|c|c|c|c|c|c|c|c|c|c|}
\hline \multicolumn{5}{|c|}{ Condition } & $\begin{array}{l}\text { Per Cent } \\
\text { of } \\
\text { Moisture }\end{array}$ & $\begin{array}{l}\text { PHOSPHORIC } \\
\text { ACTD } \\
\left(\mathrm{PO}_{4}\right)\end{array}$ & $\begin{array}{l}\text { NITRIC } \\
\text { AcID } \\
\left(\mathrm{NO}_{3}\right)\end{array}$ & $\begin{array}{c}\text { Calcium } \\
\text { (Ca) }\end{array}$ & $\begin{array}{l}\text { Potas- } \\
\text { SIUM } \\
(\boldsymbol{K})\end{array}$ \\
\hline \multicolumn{10}{|l|}{ Good wheat: } \\
\hline First foot & & & & & I 4.2 & 2.90 & I 3.22 & I 4.33 & $24 \cdot 3^{6}$ \\
\hline $\begin{array}{l}\text { Second foot } \\
\text { Poor wheat: }\end{array}$ & ${ }^{\circ}$ & $\cdot$ & • & - & I 9.9 & $3 \cdot 72$ & I0.9I & 12.52 & 24.80 \\
\hline First foot & 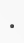 & - & - & - & I $4 \cdot 7$ & $4 \cdot 72$ & I $5 \cdot 34$ & 7.91 & 35.40 \\
\hline Second foot . & . & . & . & . & I9.9 & $4 \cdot 34$ & II. 16 & 4.I 5 & $30.3^{8}$ \\
\hline
\end{tabular}

It will be noted that the poor soil shows more water-soluble plant food with all elements except calcium. Other data reported show that the pounds of watersoluble calcium per million pounds of oven-dried soil of the Leonardtown loam varied from 2.66 to 29.52 in the first two feet where the soil was in "good condition," and from 3.95 to 24.99 where the soil was in "poor condition."

It appears, however, that the conclusions of Whitney and Cameron even concerning the nonrelationship between crop yields and water-soluble plant food are wrong. Professor F. H. King, a most careful investigator of the highest integrity, as the result of two years' experiments, including many determinations made during the crop season, before severing his connection with the Bureau of Soils, was led to the following conclusions: 
ing loamy at about 3 feet. It is a common type of soil in the Atlantic and Gulf Coastal plains. The surface is level to rolling, and the soil is well drained."

"Our own observations, published by the Bureau of Soils (Bulletin No. 26), have demonstrated that four good soils, observed to produce two and a half times the yield per acre of corn and potatoes that four poorer soils did under identical treatment, also gave up, when washed three minutes in five times their weight of pure water, $2.5^{8}$ times as much plant food. Not only was there this difference in the a mount of plant food carried in water-soluble form in the best and in the poorer soils, but the amounts of this same plant food taken out of like areas of field by like numbers and like kinds of plants during the same time was 3.2 times as great in the sap of the plants which gave the highest yields." (Proceedings Jamestown Congress of Horticulture, 1907, page Ir.)

The following tabular statement is a summary of Professor King's data secured under known conditions from the eight soils mentioned. (See Bureau of Soils Bulletin 26, page 120.) It should be stated that each value recorded for plant food determined is the average of 28 different determinations. These data are certainly far more trustworthy than the selected results from such miscellaneous samples as are referred to by Professor Whitney in Bulletin 22 (see above quotation).

Average Crop Yields and Mean Amount of Water-soluble Plant Food in Four Poor Solls and Four Good Solls for the SEASON OF 1903.-By F. H. King

\begin{tabular}{|c|c|c|c|c|c|c|c|c|c|c|}
\hline \multicolumn{6}{|c|}{ Poor Soils } & \multicolumn{5}{|c|}{ Goop Solls } \\
\hline State . . & $\begin{array}{l}\mathrm{No} \\
\mathrm{Car}\end{array}$ & $\begin{array}{l}\text { rth } \\
\text { lina }\end{array}$ & & land & & & Penn & lvania & Wis & $n \sin$ \\
\hline SoIt Type. . & 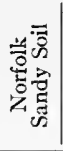 & 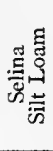 & 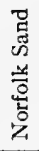 & 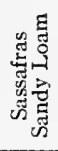 & 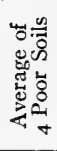 & 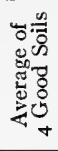 & 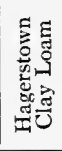 & 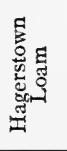 & 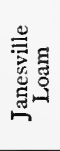 & 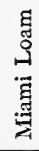 \\
\hline
\end{tabular}

Crop Yields per Acre: Average of Five Plots for Each Soll \begin{tabular}{|l|l|l|l|l|l|l|l|l|l|l}
\hline Corn, bu. . . . & 36.3 & 38.9 & 29.6 & 29.5 & 33.6 & 64.3 & 52.9 & 54.7 & 80.4 & 69.3 \\
\hline
\end{tabular}

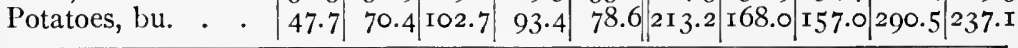

Pounds of Water-soluble Plant-food Elements in 4 Million Pounds of Soll: Average of 28 Determinations for Each Soll

\begin{tabular}{|c|c|c|c|c|c|c|c|c|c|c|c|}
\hline Nitrogen & 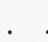 & 8.3 & 6.0 & 8.I & $7 \cdot 7$ & $7 \cdot 5$ & $2 \mathrm{I} \cdot 3$ & 15.0 & 23.7 & 34.6 & II. 9 \\
\hline Phosphorus & . & 10.4 & I0.8 & I 5.2 & I I. 9 & I 2.I & 22.2 & 18.3 & I 5.6 & 30.0 & 24.7 \\
\hline Potassium & & 47.5 & 42.7 & $4^{6.5}$ & $47 . \mathrm{I}$ & 46.0 & $69 \cdot 3$ & 48.9 & 60.4 & 99.9 & 68.0 \\
\hline Magnesium & . & 44.7 & 45.I & 42.2 & 47.5 & 44.9 & 9I.I & 78.0 & 69.I & I I $5.2 \mid$ I & 102.I \\
\hline Calcium . & . & 9 1. 6 & II 4.9 & 94.5 & 100.8 & 100.5 & 264.8 & 264.4 & 223.4 & 293.6 & 277.7 \\
\hline Sulfur & . & 62.3 & 71.9 & 50.2 & 83.1 & 66.9 & I 56.9 & І 2 工 . 6 & I04.9 & 217.9 & I83. I \\
\hline
\end{tabular}


(520 lb. P.) "Very poorly adapted to general farm crops, and little success is attained with either corn or wheat, and none of the grasses do well." (Report for I90I, page 46. )

Norfolk loam (Maryland) "is a mellow brown sandy loam to a depth of about 9 inches. The subsoil to 36 inches is a medium to heavy loam, which is often underlain by fine yellow sand. In the area from which the samples were taken it has a slight elevation and is gently rolling. It is usually well drained."

(610 lb. P.) "The principal crop grown is wheat, which yields 20 to 30 bushels per acre on the heaviest phase of the type in fair seasons and from 15 to 20 bushels on the lighter areas, these yields depending largely on the amount of fertilizer used. ... It responds readily to applications of fertilizer and lime." (Report for 1903, page I 72.)

Orangeburg sandy loam (Alabama), "locally called 'red lands,' is a brown to a reddish brown light sandy loam, 4 to 15 inches deep, resting on a friable brick-red sandy clay subsoil. The surface is rolling. It is generally well drained, although there is a tendency to form a 'plow sole' or 'hardpan."'

$(520 \mathrm{lb}$. P.) "Practically all of this type is under cultivation, and is highly prized for the production of cotton. The yields are not so high in some instances as on the Houston clay and other prairie types, but it is considered a safer soil from year to year than the prairie type. Cotton yields from one half to I bale per acre. As much as $I_{2}^{\frac{1}{2}}$ bales per acre has been produced where the land has been heavily fertilized. Very little corn is grown, as it is claimed that the yields are generally light. The difficulty here, as with the Orangeburg fine sandy loam, is that the soil proper is shallow." (Report for I905, page 436.)

In the same report (page 438) the Orangeburg fine sandy loam, mentioned above, is described as follows:

"Cotton is the principal crop grown on the Orangeburg fine sandy loam. The yields range from one fourth to $\mathrm{I}$ bale per acre, depending upon the amount of fertilizers used and the methods of cultivation. It is not considered a good corn soil, and, as a result, not much corn is planted. Corn yields range from 10 to 20 bushels per acre."

Crowley silt loam (Louisiana) "usually has a surface of about 16 inches. It is of a brown color when wet, but ash gray when dry. It is composed of fine sand and silt, with sufficient clay to render it rather impervious. If stirred when wet, it puddles somewhat. This soil is underlain by a clay of mottled brown and yellow color, with brick-red streaks and blotches. The subsoil is highly impervious and the surface level, so that the soil has very poor drainage. The samples analyzed are from level prairies in southern Louisiana."

(I220 lb. P.) "From the time that the Crowley silt loam was first cultivated, rice has been the only crop to receive attention. Nothwithstanding this continued annual cropping with the same crop, without attempting in any way to maintain the productiveness of the soil, there has as yet been no decrease in yields." (Report for 1903 , page 470 .) 
Orangeburg fine sandy loam (Texas). "Varies in color, being red, brown, or gray. It is a light sandy loam, generally carrying iron concretions. The subsoil is red, friable, sandy clay. The type occupies the upland and has good natural drainage."

( $960 \mathrm{lb}$. P.) "Cotton is the principal crop raised upon this soil. Yields from one half to three fourths of a bale per acre are secured. Corn does fairly well." (Report for 1903, page 495.)

\section{Glacial or Loessial SoILs}

Shelby silt loam (Missouri) " is a silty soil of medium depth and of a light gray color when dry; dark gray when wet. It grades into a stiff, impervious silty clay, plastic and waxy when wet, friable and loamy when dry. The subsoil is a dark mottled clay. It is level or gently rolling. The original growth on this type of soil was the prairie grasses."

(I920 lb. P.) "The following yields are secured on this soil in good seasons: Hay, from 2 to 3 tons; corn, from 35 to 40 bushels; oats, 30 to 60 bushels; wheat, I 5 to 20 bushels, but uncertain; Kafir corn, 20 to 40 bushels; millet, 30 to 40 bushels of seed per acre. The Shelby silt loam is a typical grass soil." (Report for I903, page 884.)

Marshall loam (Minnesota) "is a somewhat heavy loam from to to 12 inches in depth and of a dark brown color. Under this is a stiff, sticky yellow subsoil to a depth of about 3 feet. Below this is a stiff bowlder clay, mottled yellow and gray. The type is generally rolling and well drained. Bowlders and glacial gravel occur to some extent over this soil."

(I830 lb. P.) "The Marshall loam is the safest soil in the area, as it is the surest to produce at least an average crop. ... The Marshall loam, taken as a whole, excels all other soil types of the area in the production of wheat, on account of the superior quality of the grain produced." (Report for 1903, page 820 .)

Marshall silt loam (Wisconsin) "is a mealy, chocolate-colored silt loam with a dark brown tint when moist. It contains a large amount of silt, and becomes somewhat sticky when wet. It is about ro inches deep. The subsoil is a sticky, reddish-yellowish silty clay, about 3 feet deep, and rests upon a glacial gravel or the disintegrating limestone of the region. The soil probably owes some of its distinguishing characteristics to the influence of this limestone. The type is rolling and well drained. It was originally covered with the prairie grasses of the region."

(2450 lb. P.) "It is one of the strongest and most fertile soil types of the region, forming the larger portion of the original rolling prairie of southern Wisconsin. It produces, under average seasonal conditions, from 50 to 60 bushels of corn, from 40 to 50 bushels of oats, about $I \frac{1}{2}$ tons of hay, and 1200 pounds of tobacco." (Report for I902, page 557.)

Miami silt loam (Wisconsin) "is a very silty loam, light brown when wet, and light gray when dry. Its depth is about 8 inches. It is underlain by several 
feet of stiff, yellow, silty clay that is always mottled with gray, showing poor drainage and aëration. This type originally consisted mainly of timber lands and oak openings."

(2100 lb. P.) "The crop yields on the Edgerton (Miami) silt loam average from 45 to 50 bushels of corn per acre, about 40 bushels of oats, from I to $I \frac{1}{2}$ tons of hay, and from IIO0 to I 200 pounds of tobacco." (Report for I902, page 557.)

Marshall black clay loam (Illinois) "is a heavy, somewhat sticky, granular clay loam, containing a large percentage of silt and organic matter. It has a depth of about 18 inches. The subsoil is a mottled yellow or drab-colored sticky, silty clay. This soil type has formed where the natural drainage was poor. The surface is level. In its original condition it was wet and swampy and required thorough drainage."

(2970 lb. P.) "There are few soils more productive than the Miami (Marshall) black clay loam. Some areas have been cropped almost continuously in corn for nearly fifty years without much diminution in the yields, but the effect will undoubtedly be seen if the practice is continued much longer." (Report for 1903, page 787.)

Marion silt loam (Illinois, gray silt loam on tight clay) "consists of a light brown to whitish very silty loam, containing very little organic matter. Its depth averages $\mathrm{I} 2$ inches. The soil cakes on drying, but breaks down into flourlike dust when pulverized. The subsoil is heavier, and contains more clay. It is so impervious to water as to be locally called hardpan. The lower subsoil is a hard, silty, mottled yellow clay, often containing iron concretions. Below 4 or 5 feet, more or less gravel is found. The type is level or slightly rolling. The soil has very poor natural drainage, owing to the rather impervious subsoil and the level surface. While of loessial origin, this soil has been largely formed from sandstones and shales ground up by glaciers."

(1050 lb. P.) "The average yield of corn is not much more than 15 bushels per acre. . . . The Marion silt loam is not a strong soil, and is not well adapted to general farming purposes. The small yield of corn indicates that it is not a good soil for that crop, although the profit from corn, according to many farmers, is as much as from other crops." (Report for I902, page 542.)

Miami sand (Ohio) "is a coarse to medium loose and deep yellowish sand. It is underlain by a yellow sand of about the same texture. It is level to rolling, and consists of glacial material somewhat modified by wind action. It occupies elevated positions, and is well drained."

$(2360 \mathrm{lb}$. P.) "Grass, corn, wheat, truck, and fruit are grown on this soil. The quality of these is good, and in some cases better than the produce grown on the other soils in the area, but the yield is usually 15 to 3 o per cent less, and crops sometimes are cut short or fail because of susceptibility to drought. The yield of wheat ranges from to to 20 bushels per acre, and of corn from 20 to 45 bushels per acre. . . . This soil yields from 75 to I 20 bushels per acre of an excellent quality of potatoes." (Report for 1902, page 394.)

Wabash loam (Ohio) "is a dark brown to black soil of good depth, and con- 
taining a small proportion of the coarser grades of sand. The subsoil is a heavy brownish yellow loam overlying a fine gravelly loam. It is a bottom land, frequently occurring as terraces. It is generally well drained. It consists of glacial drift redeposited by stream action."

(I570 lb. P.) "One of the more fertile soils of the area. Some of the fields, tilled for more than half a century and only moderately manured, still produce abundantly. . . . Corn yields from 40 to 100 bushels per acre, with the average production probably about 75 bushels, and wheat from 20 to 35 bushels per acre." (Report for 1902, page 395.)

Volusia silt loam (Ohio) "is a gray to brown silty loam with an average depth of 8 inches. The subsoil is a light yellow silty loam, mottled with gray in its lower portions. It has resulted in most part from the glaciation of shales. Its mechanical constituents closely resemble in size those of the soils derived from the loess, being composed largely of silt. This is doubtless due to the silt in the shales from which this soil type comes in large part."

( $1480 \mathrm{lb}$. P.) "The average yield of wheat is about 20 bushels per acre, and yields as high as 30 bushels are not uncommon. Corn, under the best cultural methods, will average 40 to 45 bushels per acre. Oats will yield an average of 50 bushels per acre, although larger yields are often reported. From 100 to 150 bushels of marketable potatoes per acre is the average production of this crop." (Report for 1904, page 559.)

Podunk fine sandy loam (Connecticut) "is an alluvial soil, formed by the reworking by running water of glaciated granites, gneisses, and schists. It contains an abundance of micaceous mineral particles visible to the eye. It is underlain by fine sand. The soil is of a dark brown color and is well drained. The tobacco field from which the sample came had been heavily fertilized for years."

(I920 lb. P.) "The type is entirely under cultivation and produces good crops of corn, late truck, cucumbers for pickling, and tobacco. The area in the latter crop is large, and the yields range from I 700 to I 900 pounds in the open field." (Report for 1903, page 54.)

\section{Residual SoILS}

Oswego silt loam (Kansas) "consists of a dark gray silty loam, varying from very shallow to ro inches deep, which grades into a stiff clay, becoming more impervious with depth. It becomes hard and compact on drying, but it is easily broken up into a mellow loam if plowed when in proper condition of moisture. This is an upland type, and occupies gently rolling prairies. Owing to the topography of the country, the type has good surface drainage. The Oswego silt loam is derived from the weathering of the underlying rock, this usually being shales, with occasional interbedded layers of sandstone and limestone.

(I050 lb. P.) "The Oswego silt loam is not a strong soil. . . . . It is better adapted to wheat than to any of the other crops grown in the area, but, even with wheat, commercial fertilizer costing about $\$ \mathbf{1 . 2 5}$ an acre is used on 
this soil, while none is deemed necessary on the other soils." (Report for r903, page 897.)

Wabash silt loam (Kansas) "varies from $\mathrm{I} 2$ to 24 inches in depth and consists of a dark brown to black heavy silt loam. It is easily cultivated and readily kept in good tilth. The subsoil consists of a compact and rather heavy brown or yellowish silt loam. It occurs as long, narrow, tracts in the creek valleys and along the outer edges of the river valleys. The type occupies a rather low position in.stream valleys and on gentle slopes. Its surface is nearly level or gently sloping. It forms first bottoms of smaller streams and second bottoms of larger ones. It is well drained naturally. The type has been deposited by water, the surface consisting largely of material washed from the surrounding hills, which are made up of shales and limestones. This wash from the hills is continually adding to the type."

(II $40 \mathrm{lb}$. P.) "Corn is the most important crop, and yields from 30 to 75 bushels per acre, 40 to 45 bushels being an average yield in ordinary seasons. Alfalfa, a very important crop on this type, yields 3 to 5 cuttings a year, and averages about $I$ ton per acre for each cutting. The average annual yield is probably 3 or 4 tons of cured hay per acre. Wheat yields from 20 to 35 bushels per acre. . . . The land is cropped constantly, but as yet the yields have not diminished greatly, although no fertilizer and very little manure is used. The soil is naturally rich in organic matter, which may account for its continued productiveness. Corn is often cropped year after year on this type, and no system of rotation is used." (Report for 1906, page 932.)

Hagerstown clay (Kentucky) "has a heavy texture, and varies from 3 to $\mathbf{1 2}$ inches in depth. It is yellow or brown in color. The subsoil is a heavy yellow clay, extending to a depth of 3 or more feet. This soil type is derived from limestones and shales. These rocks offer considerable resistance to disintegration, and the soil may therefore be more thoroughly leached than would be the case were the rocks more readily decomposed. The surface is rather rough, rounded hills being dominant features. Surface washing has been great, and the soil is generally shallow, the depth depending on its position. This is a residual soil, being formed from the breaking down in place of the underlying limestones and shales."

( 3490 lb. P.) "Tobacco yields from 800 to 1200 pounds; wheat from 25 to 35 bushels; corn from 25 to 40 bushels; and hay from $1 \frac{1}{2}$ to 2 tons to the acre. ... On the stony phase of this soil the same crops are produced, but the yields are lower - tobacco, 500 pounds; corn, about 25 bushels; wheat, less than 12 bushels. . . The Hagerstown clay is a good grain and grass land, but it is rapidly deteriorating from continuous surface washing. . . . Unless better methods are speedily adopted, this soil type will soon reach the condition of its stony phase, locally known as the 'barren limestone' land." (Report for 1903, page 626.)

Hagerstown loam (Tennessee) " consists of brown or yellowish brown mellow loam from 9 to 12 inches deep. It is underlain by a yellow to reddish yellow 
stiff loam or light clay loam, which becomes a more pronounced red in depth. Traces of chert are found in both soil and subsoil. This type was formed by the slow weathering of limestones. In this soil the weathering has been so complete and the leaching so excessive that the lime of the disintegrated stone has been largely washed from the soil. The type has a moderately rolling surface, and has good surface drainage, but the subsoil is rather impervious. The underlying limestone comes near the surface in some places, owing to erosion."

(ro5o lb. P.) "The Hagerstown loam is all used in the extensive system of general farming which is practiced throughout the area. Corn yields from 15 to 30 bushels, with a probable average of 22 bushels per acre. Wheat yields from 5 to 20 bushels, with an average of Io bushels, and the comparatively small amount of hay which is grown yields an average crop of 1 ton per acre." (Report for I903, page 584.)

Houston clay (Alabama) "has resulted from the weathering of rotten limestones or chalks of Cretaceous time. Owing to its proximity to the soft and easily broken down lime rock, this soil is highly calcareous, and often contains lime concretions, especially in the subsoil. It may be considered to be of comparatively recent origin and as a residual Coastal Plains soil. The soil is a gray, brown, or black loamy clay, 6 inches deep. This is underlain with 3 feet or more of heavy gray or mottled yellow clay. The surface is gently rolling and the drainage very good. Agriculturally, the soil is lighter than would be expected, from its high clay content. This may be due to flocculation by the high percentage of lime present."

(5I50 lb. P.) "The Houston clay, while clodding badly when plowed too wet, and requiring care in its management, is a very strong and productive soil." (Report for 1905, page 464.)

Cecil clay (North Carolina) "is found on uplands, gentle slopes, and rolling lands of the Piedmont Plateau. The Cecil clay is a residual soil, resulting from the disintegration of a number of rocks, differing in mineralogical characters. Granites, gneisses, schists, and other somewhat similar rocks have contributed to the formation of this type, and so thorough have been the disintegration and decomposition that the same red clay results from all. There is such a gradual change from soil to the parent rock that there is generally no sharp line between the two. The soil consists of a heavy red loam, containing many sand grains of the original minerals forming the rocks from which the soil is derived. It is shallow, averaging about 5 inches. The subsoil is a stiff, tenacious red clay to a depth of 3 or more feet. It becomes heavier at greater depths. Natural drainage is fairly good, probably due to the sand and rock fragments contained in soil and subsoil."

( 960 lb. P.) "The soil is generally thin, but can be deepened by proper methods of cultivation and by green manuring. When so deepened, it assumes the properties of a heavy clay loam, and is very productive. It requires, however, considerable care and labor to maintain its fertility." (Report for. 1901, page 55.) 
The average yields of corn, wheat, and oats are reported as 18 , I2, and 20 bushels, respectively, per acre. In the description of this same type of soil for the Leesburg area of Virginia, the following statements were recorded by the field men of the Bureau of Soils:

"The soil responds readily to applications of lime, and is much benefited by its use. Much commercial fertilizer, as well as lime and barn-yard manure, is used on this soil. In fact, so much acid phosphate has been added of late years that the land has become quite sour, and it is hardly possible to obtain a stand of grass or clover without the use of lime." (Report for I903, page 221.)

Porter's black loam (Virginia) "is a loose, mellow black loam, averaging about $\mathrm{I} 2$ inches deep. The subsoil is slightly heavier and of a light brown to yellowish color. In depressions and coves, where wash from the higher ground has accumulated, there is no sharp distinction between soil and subsoil, the loose black loam being several feet deep. Both soil and subsoil contain fragments of the rocks whose decomposition has formed the soil - granites, gneisses, and schists. This type occurs principally in the coves of the Blue Ridge Mountains, but is also found upon the tops and upper slopes."

(4630 lb. P.) "Locally the Porter's black loam is called 'black land' and 'pippin land,' the latter term being applied because, of all the soils in the area, it is preëminently adapted to the production of the Newtown or Albemarle Pippin. This black land has long been recognized as the most fertile of the mountain soils. It can be worked year after year without apparent im pairment of its fertility." (Report for 1902, page 210.)

Chester mica loam (Maryland) "as its name indicates, is characterized oy a great quantity of micaceous particles. It is derived from granites, gneisses, and other micaceous rocks over which the type lies. It is strictly a residual soil and consists of a brownish loam ro to I 5 inches deep, underlain by a lighter colored, heavier loam, also containing mica. The surface varies from gently rolling to somewhat hilly."

(II30 lb. P.) "It is not naturally a strong soil, but is susceptible of being made quite fertile and productive through intelligent tilling and manuring." (Report for rgor, page 222.)

Collington sandy loam (New Jersey) "has resulted from the weathering of the greensand, or glauconite, of New Jersey. The subsoil, which comes within 6 or 8 inches of the surface, is a sticky, tenacious, claylike material, yellowish or greenish in color. Owing to its relations to the greensand deposits, this type differs from the other Coastal Plains soils."

(From $260 \mathrm{lb}$. P. in surface to $27,600 \mathrm{lb}$. P. in lower subsoil.) "Since millions of tons of this greensand marl have been employed as fertilizers, it is at once evident that any soil possessing a subsoil of this material will contain more than the ordinary amounts of potash and lime. When, in addition to this, its physical structure is also well adapted to crop production, it would seem that a particularly valuable soil was formed. ... The marl specimen was collected 
as a sample to show the amounts of plant foods in the material actually used as a fertilizer. The potash content is not high for a greensand marl, but the phosphoric-acid content is unusually high. The subsoil analysis (by acid digestion) reveals the fact that the lime, potash, and phosphoric acid of the original material have been extensively dissolved and removed, though fair amounts still remain." (Report for I901, page I39.)

Unless otherwise stated, the above quotations from the soil survey field men and from Bureau of Soils Bulletin 54 refer specifically to the areas in which the samples analyzed (Table 22) were collected.

In general, there is very distinct correlation between the composition of these extensive soil types and their natural productiveness as recorded by the soil surveyors themselves some years before the chemical analyses were made. It should be kept in mind that the data reported in Table 22 are for amounts in 2 million pounds of ignited soil, and are thus somewhat higher than, and not strictly comparable with, the results of analyses of the ordinary dry soil. It is important, also, to know that most of the 27 type soils described are found not only in the state and area in which these analyzed samples were taken, but are widely distributed throughout the respective formations, as the Coastal Plains, glacial areas, Piedmont, or other regions. Thus the I903 Report of Field Operations of the Bureau of Soils mentions that Norfolk sand was found that year in New York, Delaware, Maryland, Virginia, North Carolina, Georgia, Florida, and Alabama; and Marshall black clay loam has been reported for Ohio, Indiana, Michigan, Wisconsin, Illinois, Iowa, Minnesota, South Dakota, and North Dakota.

The Bureau of Soils includes in the one soil type (Marshall silt loam) the common brown silt loams of the Middle and Upper Illinoisan glaciations, of the Pre-Iowan, Iowan, and Early Wisconsin glaciations, in Illinois, as well as soil in the Janesville and Viroqua areas of Wisconsin, in the Grand Island and Staunton areas of Nebraska, and in the Jamestown area of North Dakota, with other areas in Colorado, Minnesota, Kansas, Missouri, Iowa, Indiana, and Louisiana; but it is apparent that the ultimate chemical composition of the soil is not considered among the characteristics required by the Bureau for a soil type. Thus the Marshall silt loam (brown silt loam) of the Middle Illinoisan glacia- 
tion contains I 70 pounds of total phosphorus in 2 million of dry soil (see Table I $_{5}$ ), while $245^{\circ}$ pounds are reported in 2 million pounds of ignited soil of the Wisconsin area (see Table 22). Doctor Fraps finds 480 pounds of acid-soluble phosphorus in 2 million pounds of the Houston clay of Texas from samples furnished him by the Bureau of Soils, while Table 22 shows $5^{\text {I }} 50$ pounds of total phosphorus in 2 million pounds of ignited Houston clay of Alabama. The Texas soil is evidently very deficient in phosphorus, but this is certainly not the case with the Alabama soil, which, it will be seen, outranks in phosphorus content every other soil reported in Table 22. The Bureau of Soils has not reported the ultimate chemical analyses of different samples of the same type soil from different areas, so that it is impossible to make any such comparative study from the Bureau's data alone.

In the author's opinion, the exact chemical data from which Table 22 is derived, and the careful descriptions given of the type soils analyzed, constitute the most valuable contribution of the United States Bureau of Soils to American agriculture. This absolute invoice of plant food, together with the description of physical properties, crop adaptations, and topographic features, furnishes a basis for the intelligent consideration of possible permanent and profitable systems of agriculture. Actual field experiments, to determine the rate at which the plant food can be made available, are lacking, and no report is made of the nitrogen content of the soils or of the limestone present or required. The percentages of "lime" $(\mathrm{CaO})$ and magnesia $(\mathrm{MgO})$ are given in Bulletin 54, but these signify little or nothing in relation to lime. Even the very acid Marion silt loam of Clay County, Illinois (gray silt loam on tight clay), is reported by the Bureau to contain ${ }_{5} 6$ per cent of $\mathrm{CaO}$ ( 5.6 tons in 2 million pounds of soil), whereas it contains neither calcium oxid nor calcium carbonate, the calcium present existing usually in acid silicates.

In general, the work of the Bureau of Soils has been directed toward a study of crop adaptation, in accordance with a somewhat prevalent notion that every soil is intended to grow some definite crop or crops, and that success will be attained if the proper crop is found for the special soil. While all must recognize that the natural adaptation of soil and crop is an important factor in many 
cases, in the author's opinion it is a matter which has been given undue consideration in comparison with other extremely important factors.

Even in the common practice of agriculture, soils at first well adapted to the growing of a certain crop do not remain so adapted. The fact is too well known to need illustration that specific crops are often grown with success for years finally to fail and be abandoned for some other successful crops, which in turn finally give way to others. Thus good wheat land finally becomes poor wheat land, but still remains good for timothy hay, which in turn gives way to red top, and this may be followed by partial abandonment of the land for crop production.

At any stage in this process of soil depletion, the land may be restored to its original power to produce wheat, by adopting the proper systems of soil enrichment.

When land refuses longer to grow any crop which it has formerly produced with satisfaction and profit, the landowner should, as a very general rule, find out what the trouble is, and then proceed to remedy it; but, instead of meeting and overcoming such difficulties, the American farmer has literally run away from them; either by seeking newer lands or by adopting any other crop which the land would still produce.

The most common staple crops can be grown on almost any soil if it is well drained, well watered, and sufficiently rich. Of course, the matter of crop adaptation must not be ignored, but if we would grow either plants or animals, we must not neglect the food supply. 


\section{CHAPTER X}

\section{CROP REQUIREMENTS FOR NITROGEN, PHOSPHORUS, AND POTASSIUM}

A STUDy of Table 23 is sufficient to make one familiar with the requirements of the more important crops of the United States for the three plant-food elements that are now recognized as having money values in commercial fertilizers. Information is also given regarding the amounts of these three elements in different parts of the crop, as in grain, straw, corn stover, and cotton stalks and lint, in order that it may be known with some degree of accuracy how much of each element is removed from the soil in crops and how much is sold from the farm in different kinds of farm produce. The ideal practice is to return to the soil, either directly or in farm manure, all plant food not sold from the farm.

The data given in Table 23 are on the basis of pounds per acre for crop yields which are large, but which, when the best conditions are provided, have been and may be produced with very great profit, - yields that may well stand as ideals, desirable and possible to be attained. Approximately proportionate amounts of plant food would be required for any other yields. Thus, if it is preferred to plan to make possible yields only one half as large, then the amounts given in Table 23 may be divided by two. (In Section 3 of the Appendix, data are reported showing the more complete composition of a much larger number of crops, but the results there given are derived from a smaller number of analyses than are represented for the crops reported in Table 23; and, consequently, some differences are to be expected.)

The value of the elements is computed on the basis of the present market prices for plant food from the most abundant natural deposits, delivered in car-load lots to central Illinois, and in suitable condition for direct application to the land.

Nitrogen in sodium nitrate . . . . . . I5 cents a pound. Phosphorus in ground raw phosphate . . . 3 cents a pound. Potassium in kainit . . . . . . 6 cents a pound. 
Table 23. Fertility in Farm Produce Approximate maximum amounts removable per acre annually

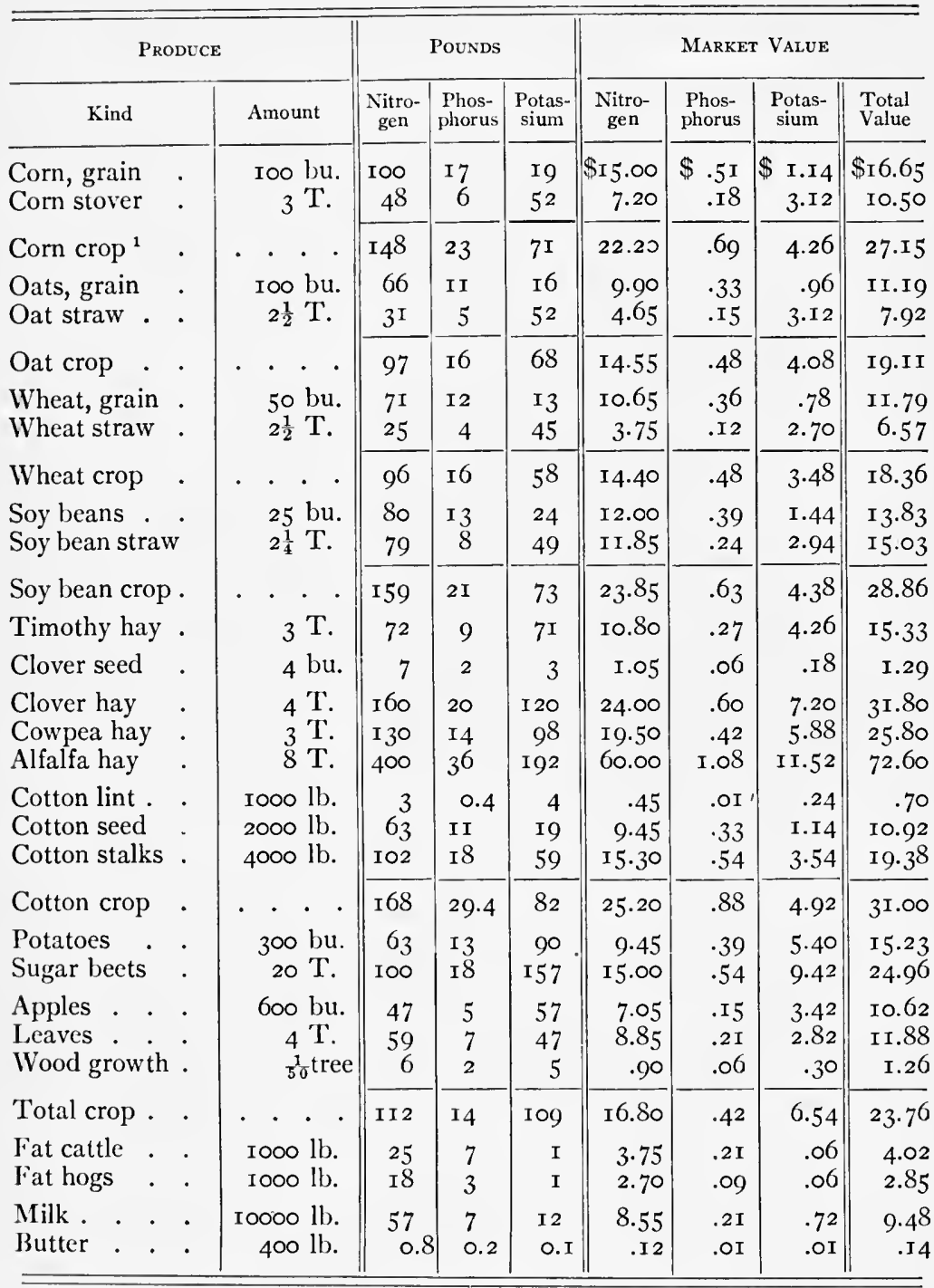

${ }^{1}$ To this might also be added rooo pounds of corncobs, containing 2 pounds of nitrogen, less than $\frac{1}{2}$ pound of phosphorus, and 2 pounds of potassium. 
The figures given in Table 23 are based upon averages of large numbers of analyses of normal products, of which some have been made by the author and his associates, and many others by various chemists in America and Europe. These averages are trustworthy for large crops of good quality. Abnormal or special crops may vary considerably from these a verages. Thus, we have high-protein corn and low-protein corn, one strain requiring $5^{\circ}$ per cent more nitrogen, and somewhat more phosphorus, than the other (Illinois Bulletins 87 and I28); and it has been shown, for example, that alfalfa and cowpeas are not only much more productive, but also much richer in nitrogen, when grown on normal soils with the proper root-tubercle bacteria than without bacteria. On the whole, however, it is as nearly correct to say that a fifty-bushel crop of wheat requires 96 pounds of nitrogen and 16 pounds of phosphorus as it is to say that a measured bushel of wheat weighs 60 pounds.

It may be said that other similar crops resemble somewhat closely those given in Table 23 as to plant-food requirements. Thus rye and barley are not markedly different in requirements from wheat and oats, considering equal yields in pounds of grain and straw. Other root crops may be compared with sugar beets, other grasses with timothy, hay from other annual legumes with cowpea hay, and other biennial and perennial legumes may be compared in a general way with red clover and alfalfa.

How many years would be required to sell as much phosphorus from the farm in cotton lint yielding 2 bales (of 5 co pounds each) per acre as in 4 tons of clover hay, which may be produced in the two cuttings in one season? Compare the nitrogen and potassium contained in 100 bushels of corn and in 20 tons of sugar beets. Compare wheat and clover in plant-food requirements.

Assuming that two thirds of the nitrogen used by the clover plant is deposited in the tops and only one third in the roots, and that a given soil will furnish as much nitrogen to a growing clover crop as to a growing wheat crop, what is the effect upon the total nitrogen content of the soil of growing clover if all of the tops are removed? Compute the cost of commercial nitrogen for a 50-bushel crop of corn, assuming that 40 per cent of the nitrogen applied will be lost in drainage waters. 


\section{CHAPTER XI \\ SOURCES OF PLANT FOOD}

IF the productive capacity of American soils is to be maintained, elements of plant food which are present in such small amounts as to limit the crop yields even under good systems of farming must be returned to the soil as needed, and information is given in Table 24 to show the average quantities in pounds of the different valuable elements of plant food contained in one ton of average fresh farm manure, rough feeds and bedding, and other fertilizer materials.

In computing the value of plant food in these materials, nitrogen is counted at 15 cents a pound and potassium at 6 cents a pound; while phosphorus is counted at 3 cents a pound in raw rock phosphate, at ro cents a pound in bone meal, and at 12 cents a pound in acid phosphate, these prices being based upon the usual average market values for the standard fertilizing materials in such quantities as ought to be purchased by farmers, either singly or by two or more uniting.

From the data given in Tables 23 and 24 it is a simple matter to compute the amounts of a verage manure or other fertilizers necessary to be applied to the land to replace the plant food removed in any rotation of crops. Observe, for example, that a four-year rotation, including corn for two years, oats with clover seeding the third year, and clover for hay and seed crops the fourth year, would require 39 tons of manure to supply the nitrogen, $4 \mathrm{I}$ tons to supply the phosphorus, 40 tons to supply the potassium, assuming the yields given in Table 23 , and counting that the clover secures from the air as much nitrogen as is removed in the hay and seed crops. Observe that one ton of raw rock phosphate or one ton of steamed bone meal contains more phosphorus than roo tons of a verage manure. Observe that 250 pounds of phosphorus can be purchased for $\$ 7.50$ in ground natural rock phosphate, for $\$ 25.00$ 
in steamed bone meal, for $\$ 30.00$ in acid phosphate, and for $\$ 65.00$ in "complete" fertilizer.

Table 24. Fertility in Manure, Rovgh Feeds, and Fertilizers

\begin{tabular}{|c|c|c|c|c|c|c|c|c|}
\hline \multirow{2}{*}{ Name of Material } & & \multicolumn{3}{|c|}{ POUNDS PER TON } & \multicolumn{4}{|c|}{ Market Value per Ton } \\
\hline & & $\begin{array}{l}\mathrm{Ni}- \\
\text { tro- } \\
\text { gen }\end{array}$ & $\begin{array}{c}\text { Phos- } \\
\text { phor- } \\
\text { us }\end{array}$ & $\begin{array}{c}\text { Po- } \\
\text { tas- } \\
\text { sium }\end{array}$ & Nitrogen & $\begin{array}{l}\text { Phos- } \\
\text { phorus }\end{array}$ & Potassium & Total Value \\
\hline Fresh farm manure. & & IO & 2 & 8 & $\$ 1.50$ & .24 & $\$ .48$ & $\$ 2.22$ \\
\hline Barnyard manure $^{1}$ & & IO & 3 & 8 & 1.50 & $\cdot 3^{6}$ & .48 & 2.34 \\
\hline Corn stover . & & I6 & 2 & I 7 & 2.40 & .24 & I.O2 & 3.66 \\
\hline Oat straw . . . . & & I 2 & 2 & $2 \mathrm{I}$ & I.80 & .24 & I.26 & $3 \cdot 30$ \\
\hline Wheat straw . & & Io & 2 & I8 & 1.50 & .24 & 1.08 & 2.82 \\
\hline Clover hay & & 40 & 5 & 30 & 6.00 & .60 & I.80 & 8.40 \\
\hline Cowpea hay . . . & & 43 & 5 & 33 & 6.45 & .60 & I.98 & 9.03 \\
\hline Alfalfa hay . . . & & 50 & 4 & 24 & $7 \cdot 50$ & $\cdot 4^{8}$ & I. 44 & $9 \cdot 4^{2}$ \\
\hline Dried blood . & & 280 & & & 42.00 & & & 42.00 \\
\hline Sodium nitrate . & & 310 & & & 46.50 & & & 46.50 \\
\hline Ammonium sulfate & & 400 & & & 60.00 & & & 60.00 \\
\hline Raw bone meal . & & 80 & I80 & & I 2.00 & 18.00 & & 30.00 \\
\hline Steamed bone meal & & 20 & 250 & & 3.00 & 25.00 & & 28.00 \\
\hline Acidulated bone meal & & 40 & $\mathrm{r} 40$ & & 6.00 & I6.80 & & 22.80 \\
\hline Raw rock phosphate & & & 250 & & & $7 \cdot 50$ & & $7 \cdot 50$ \\
\hline Acid phosphate . . & & & I 25 & & & 15.00 & & I5.00 \\
\hline Double superphosphat & & & 400 & & & 48.00 & & 48.00 \\
\hline Basic slag phosphate & & & I60 & & & I6.00 & & I6.00 \\
\hline Potassium chlorid & & & & 850 & & & 51.00 & $5 \mathrm{I} .00$ \\
\hline Potassium sulfate & & & & 850 & & & 51.00 & 51.00 \\
\hline Kainit : • . . . & & & & 200 & & & I 2.00 & 12.00 \\
\hline Wood ashes $^{2}$. . . & & & Io & 100 & & 1.20 & 6.00 & 7.20 \\
\hline "Complete" fertilizer & & 33 & 88 & 33 & (?) & (?) & (?) & $23.00(?)$ \\
\hline
\end{tabular}

1 About two tons of fresh farm manure are required to produce one ton of common barnyard manure six months old, with losses about as indicated.

${ }^{2}$ Wood ashes also contain about rooo pounds of lime (calcium carbonate) per ton.

${ }^{3}$ This is the average composition and the average selling price of twelve brands of so-called "complete" fertilizer offered for sale in Illinois. Only 70 pounds of the phosphorus is guaranteed available, 18 pounds being insoluble. The cost of 88 pounds of phosphorus in raw rock phosphate would be $\$ 2.64$. 
If the element calcium becomes deficient in the soil (and it does in some cases), the most economic source is ordinary limestone; and, if magnesian limestone is applied, both calcium and magnesium are thus added to the soil. Kainit also supplies magnesium.

Sulfur would be furnished in applications of acid phosphate, land-plaster, potassium sulfate, or kainit, as well as in magnesium sulfate and sodium sulfate, both of which are sometimes to be had as waste products or by-products.

Iron sulfate $\left(\mathrm{FeSO}_{4}\right)$ is a common by-product in certain manufacturing processes, and strenuous efforts have been made from time to time to encourage its use as a fertilizer. Since numerous investigations have been conducted both in Europe and America to ascertain its fertilizing value, it is easily possible to select, from the many results thus secured, some few which indicate appreciable or even marked benefit. These results, however, have failed of verification. As a general average, iron sulfate produces less benefit than land-plaster, and sometimes detrimental effects are shown. A fair consideration of all results of carefully conducted experiments certainly leads to the conclusion that the use of iron sulfate as a fertilizer cannot be recommended in systems of soil improvement; although, like common salt $(\mathrm{NaCl})$, it may sometimes produce a stimulating action sufficient to cover the cost where it can be secured at less expense than land-plaster, common salt, or other soluble salts. 


\section{PART II}

\section{SYSTEMS OF PERMANENT AGRICULTURE}

For practically all of the normal soils of the United States, and especially for those of the Central statés, there are only three constituents that must be supplied in order to adopt systems of farming that, if continued, will increase, or at least permanently maintain, the productive power of the soil. These are limestone, phosphorus, and organic matter. The limestone must be used to correct acidity and sometimes to supply the element calcium. The phosphorus is needed solely for its plant-food value. The supply of organic matter must be renewed to provide nitrogen from its decomposition and to make available the potassium and other essential elements contained in the soil in abundance, as well as to liberate phosphorus from the raw mineral phosphate naturally contained in or applied to the soil.

Other fertilizer materials have some value, and sometimes great value, on uncommon or abnormal soils, and certain other substances are powerful soil stimulants, especially on soils deficient in organic matter; and, if applied with intelligence, they may sometimes be used temporarily with advantage and justification, but they are unnecessary and, as a very general rule, they are unprofitable, in good systems of soil improvement.

There are, of course, numerous and more or less extensive areas of abnormal soils, such as the residual sands and the peaty swamp lands (both of which are very deficient in potassium), and also soils exceedingly rich in phosphorus, as in the geologic neighborhood of the natural phosphate deposits in the Central Basin of Tennessee and the Blue Grass Region of Kentucky. 


\section{CHAPTER XII}

\section{LIMESTONE}

CALcium carbonate, in the form of chalk or marl, has been used for soil improvement since the beginning of agricultural history. Large use has been made of these natural materials in England and France, especially. An English record of 1795 mentions the " prevailing practice of sinking pits for the purpose of chalking the surrounding land therefrom," and states that "the most experienced Hertfordshire farmers agree that chalking of lands so circumstanced is the best mode of culture they are capable of receiving."

On the famous Rothamsted Experiment Station it has been found that the fields that had received liberal applications of this natural limestone a century ago are still moderately productive, while certain fields remote from the chalk pits which show no evidence of such applications are extremely unproductive. Director Hall of the Rothamsted Expcriment Station states that many of the farmers in that vicinity are still reaping profitable crops from lands enriched by the heavy applications of chalk made by their ancestors many years ago.

There appears to be no record that these easily pulverized limestone materials have ever been burned in order to increase their agricultural value. The productive power and durability of the natural limestone soils is indicated by the time-honored truth, "A limestone country is a rich country."

Where such natural materials as chalk and marl have not been accessible, more or less use has been made of water-slacked or airslacked lime; because, by burning and slacking, limestone rock may be reduced to powdered form and thus distributed over the land.

With the development of rock-crushing and rock-grinding machinery, pulverized natural unburned limestone can be had, and where this material can be gotten at reasonable cost, it replaces all other forms of lime used for the improvement of normal soils. 
In the "Georgical Essays" ( 777 edition), we find an article by T. Henry, F.R.S., on the "Action of Lime and Marl as Manures," in which the following statements occur:

"The lime, that we may come nearer to nature in our imitation, should not only be slacked, but be exposed to the open air, and often turned for several months, that it may recover its air; for it requires a long series of time before it recovers the whole of which it has been deprived in calcination. . . .

"I find that Doctor Home thinks that lime produces little effect on vegetation till it is become effete. It may be known to have recovered its air by its no longer forming lime water, and by effervescing violently with acids without growing hot. If, however, the method described in the last note be used, it will be sufficient, if the lime be fallen, without waiting for the recovery of its air, as this point will be acquired during the long time which the mixture is to be exposed to the action of the atmosphere. . . .

"Upon the whole, may we not conclude that lime, in most cases, is a stronger manure, when it has recovered the air of which it has been deprived in calcination, than it is when brought fresh from the kiln; and that when procured for the purposes of agriculture, its efficacy and permanency will in general be increased, by mixing it, in its effete state, with the other ingredients which enter into the composition of marl?"

When limestone is burned, the calcium carbonate $\left(\mathrm{CaCO}_{3}\right)$ is decomposed, the carbon dioxid $\left(\mathrm{CO}_{2}\right)$ passes off as a gas, leaving the product calcium oxid $(\mathrm{CaO})$, which constitutes 56 per cent by weight of the limestone used.

When exposed to the moisture of the air or soil, the quicklime $(\mathrm{CaO})$ quickly takes up water and forms calcium hydroxid, $\mathrm{Ca}(\mathrm{OH})_{2}$, sometimes called hydrated lime, which means merely water-slacked lime. The product is the same whether the slacking (hydrating) is performed by the manufacturer at large expense, or by the farmer at little or no expense.

When slacked lime is exposed in the air or soil, carbon dioxid is gradually absorbed, and the calcium carbonate is thus reformed. Thoroughly air-slacked lime is exactly the same material as fineground limestone. In other words, no matter what form of lime we apply to the soil, the benefit derived during the subsequent months or years is due to one and the same compound, calcium carbonate.

These facts alone would be sufficient, perhaps, to lead one to use ground natural limestone in preference to the disagreeable caustic 
lime, but there are other facts worthy of the most careful consideration.

Burned lime, whether fresh or hydrated, is known always as caustic lime. According to Webster's Dictionary, the word caustic means "capable of destroying the texture of anything or eating away its substance by chemical action." This definition well describes the action of caustic lime upon the organic matter of the soil. The lime breaks down the organic compounds and unites with the liberated carbon dioxid or other acid products. Not all of the reactions involved are understood, but the general effect is well known, and its long recognition in European countries has given rise to the proverbial expressions,

"Lime, and lime without manure,

Will make both farm and farmer poor,"

and "Kalk macht die Väter reich, aber die Söhne arm." (Lime makes the fathers rich, but the sons poor.)

Caustic lime is not only a powerful agent in hastening the destruction of organic matter, but it also has some power to increase the solubility of phosphorus and potassium, all of which may be of special help to legume crops; and if such crops are grown and removed from the land and the decaying roots and residues used as a further stimulant for the production of wheat, corn, or other crops, more rapid progress can be made toward land ruin than where no lime is used.

On the other hand, even caustic lime can be used with profit if ample provision is made to replace the organic matter destroyed and also to restore the phosphorus (and potassium if necessary) removed in the crops.

The caustic action of slacked lime on the skin or flesh is familiar to all, but a child can play in ground limestone as safely as in the soil of the garden.

The chief reason, and usually the only justifiable reason, for applying lime to soils is to correct, or neutralize, soil acidity. The fermentation and decay of nearly all forms of organic matter is accompanied by the formation of acids, including carbonic acid, nitric acid, and various organic acids, such as the well-known lactic acid of sour milk, acetic acid of vinegar from apple juice, various 
acids in ensilage and sauerkraut, etc. Souring is usually the first stage in the process of decay of organic matter.

Thus, there are two principal effects produced by applying lime to soils: one of these is to furnish a base for neutralizing the acids that may exist in the soil or that may form in such necessary processes as nitrification, and the other is a more active decomposition or destruction of the soil itself, especially of its organic matter or humus content.

To correct the acidity of sour soils is certainly a very desirable and profitable use of lime. Clover, alfalfa, alsike, cowpeas, soybeans, and most other valuable legumes will not thrive on soils that are strongly acid. To be sure, such crops can be made to grow on acid soils by liberal applications of farm manure or other fertilizers, but the nitrogen-gathering bacteria of such legume plants do not properly develop and multiply in acid soils, and consequently the legumes do not have the power which they should have to accumulate large quantities of atmospheric nitrogen by means of the root-tubercle bacteria. Furthermore, the process termed nitrification by which the nitrifying bacteria transform the insoluble organic nitrogen, in farm manure and plant residues, into soluble nitrate nitrogen, the form in which it becomes available as plant food, is greatly promoted by the presence of limestone and retarded by acid conditions.

The use of some form of lime for correcting the acidity of soils, and thus encouraging nitrification and the growth of clover and other legumes with their wonderful power to enrich the soil in nitrogen, is certainly good farm practice. Any form of lime which is finely divided and can be thoroughly mixed with the soil will serve this purpose, whether it be ground limestone, marl, or chalk, or fresh-burned lime, water-slacked lime, or air-slacked lime.

The one effect of lime, due to its basic property, results in a building-up process, through the increased growth of legumes and nitrogen-gathering bacteria; while the other effect, the decomposition of the soil, produced by its caustic property, is in all respects a destructive process, serving only to destroy humus and to liberate and reduce the stock of plant food stored in the soil. Whether this second effect is desirable, will depend upon the soil itself. On soils which are exceedingly rich in organic matter, such as peaty 
soils and other swamp soils, it would seem altogether rational to make temporary use of caustic lime to hasten the decomposition of the soil and consequent liberation of nitrogen, if such treatment is necessary, which is not usually the case.

There may possibly be conditions under which soils contain large amounts of phosphorus and potassium which are too slowly a vailable for profitable crop production, and in such cases it might be good farm practice for a time to make use of lime to hasten the liberation of these mineral elements of plant food. We should bear in mind, however, that this use of lime on a soil which is already deficient in nitrogen, or other plant food, only serves to still further exhaust the soil of its meager supply of these elements. Without a doubt, this is the most common condition and the most common effect of the continued use of caustic lime. It is true that the immediate effect is usually somewhat increased crops, but it should be borne in mind that when a farmer pays out money for lime to be used for this purpose, he is purchasing a stimulant which will ultimately leave his land in worse condition than before, especially in the loss of nitrogen and organic matter.

Of course, the landowner must be governed somewhat by the cost of the material. As a rule, pulverized limestone will be both the best and the most economical form of lime to use, wherever it can easily be obtained. If caustic lime be used, we should make special provision to maintain the humus in the soil by making even larger use of farm manure, legume crops, and green manures.

It might be expected that burned lime would produce a greater increase in the crops for the first year or two than would be produced by the ground limestone, more especially where the mineral elements, phosphorus and potassium, are not applied; for the reason stated, that ground limestone produces only the milder action, chiefly of correcting the acidity of the soil and thus encouraging the multiplication and activity of the nitrogen-gathering and nitrifying bacteria; whereas, the burned lime not only produces this same effect, but it also acts as a powerful soil stimulant, or soil destroyer, attacking and destroying the organic matter and thus liberating plant food from the soil, usually resulting in more or less waste of valuable nitrogen and humus.

The most extended investigation ever conducted relating to the 
use of burned lime and ground limestone in comparative tests is reported by the Pennsylvania Experiment Station (Report I902). Four plots were treated with burned lime (slacked before being spread) at the rate of two tons per acre once in four years. Four other plots were treated with ground limestone at the rate of two tons per acre every two years. A four-year rotation was practiced, consisting of corn, oats, wheat, and hay, the hay being mixed timothy and clover, seeded on the wheat land in the spring. By having four sets of plots, each crop was grown every year. Seven products were obtained and weighed each year; namely, corn, corn stover, oats, oat straw, wheat, wheat straw, and hay.

Table 25. Pennsylvania Experinents with Burned Lime and Ground LiMESTONE

Twenty Years' Produce per Acre

\begin{tabular}{|c|c|c|c|c|c|c|c|c|}
\hline \multirow{2}{*}{\multicolumn{2}{|c|}{ Soll Treatment }} & \multicolumn{2}{|c|}{ CoRN } & \multicolumn{2}{|c|}{ OATS } & \multicolumn{2}{|c|}{ WheAt } & \multirow{2}{*}{$\begin{array}{c}\text { Hay, } \\
\text { ToNS } \\
\text { (19 yr.) }\end{array}$} \\
\hline & & $\mid \begin{array}{c}\text { Grain } \\
\text { (Bushels) }\end{array}$ & $\begin{array}{l}\text { Stover } \\
\text { (Tons) }\end{array}$ & $\underset{\text { (Bushels) }}{\text { Grain }}$ & $\begin{array}{l}\text { Straw, } \\
\text { (Tons) }\end{array}$ & $\mid \begin{array}{c}\text { Grain } \\
\text { (Bushels) }\end{array}$ & $\begin{array}{l}\text { Straw } \\
\text { (Tons) }\end{array}$ & \\
\hline $\begin{array}{l}\text { None } . \cdot . \\
\text { Burned lime } \\
\text { Ground limestone }\end{array}$ & $\begin{array}{ll}\cdot & \cdot \\
\cdot & \cdot \\
\cdot & \cdot\end{array}$ & $\begin{array}{l}8 \mathrm{rg} \\
699 \\
798\end{array}$ & $\begin{array}{l}\text { I8.8 } \\
\text { I6.5 } \\
\text { I8.6 }\end{array}$ & $\begin{array}{l}678 \\
6 \text { I } 7 \\
733\end{array}$ & $\begin{array}{l}\text { I } 4.3 \\
\text { I } 7.8 \\
20.4\end{array}$ & $\begin{array}{l}279 \\
318 \\
33^{r}\end{array}$ & $\begin{array}{l}13.2 \\
14.6 \\
16.6\end{array}$ & $\begin{array}{l}24.9 \\
23.6 \\
29.2\end{array}$ \\
\hline
\end{tabular}

Thus, after twenty years' results had been obtained (I882 to I90I), the Pennsylvania Station reports data showing that with every product a greater total yield had been obtained from the plots treated with limestone than from those treated with caustic lime. Furthermore, with every product whose total yield for the last eight years was greater than the total yield of the first eight years, the limestone produced a greater increase than the caustic lime; and with every product whose total yield for the last eight years was less than the total yield of the first eight years, the decrease was less where limestone was used than where caustic lime was applied (oat straw alone excepted). This is significant, in that it demonstrates the tendency of caustic lime with continued use to exhaust or destroy the fertility of the soil. In discussing these investigations, Doctor Frear of the Pennsylvania Station says: 
"In each case the yields with the carbonate of lime showed superiority under the conditions of this experiment over those following an equivalent application of caustic lime."

After these experiments had been in progress for sixteen years, the soil of each of the four plots in each test was sampled for analysis. The average nitrogen content for the four plots recciving ground limestone was found to be 2979 pounds per acre to a depth of 9 inches, while only 2604 pounds were found in the soil treated with caustic lime. This difference of 375 pounds of nitrogen is equal to the nitrogen contained in $37 \frac{1}{2}$ tons of farm manure. In other words, the data indicate that the effect of caustic lime as compared with ground limestone was equivalent to the destruction of $37 \frac{1}{2}$ tons of farm manure in 16 years, or more than two tons a year to the acre. Or, if we count the soil nitrogen worth ${ }_{5} 5$ cents a pound (a fair market price), there is a liberation of more than $\$ 7.00$ worth of nitrogen for every ton of burned lime used during the 16 years.

The estimation of humus in these soils, based upon the determination of organic carbon (multiplied by Wolff's factor, I.724), showed the soil receiving limestone to contain 38.9 tons of humus per acre to a depth of 9 inches (counting 300,000 pounds of soil to the acre-inch), while only 34.2 tons of humus remained in the soil treated with caustic lime. If 4 tons of farm manure contain only I ton of dry matter (average fresh farm manure contains about 75 per cent of water), and if 2 tons of dry matter would be required to make I ton of humus (when exposed to the weather, manure usually loses half of its dry-matter content within one year or less), then this difference of 4.7 tons of humus would be equal to 37.6 tons of fresh farm manure, which represents the loss from the destructive action of caustic lime as compared with ground limestone.

During the 20 years, the land treated with ground limestone produced per acre 99 bushels more corn, I 6 bushels more oats, $r_{3}$ bushels more wheat, and 5.6 tons more hay, than the land treated with caustic lime. Counting 35 cents a bushel for corn, 30 cents for oats, 70 cents for wheat, and $\$ 6.00$ a ton for hay, the value of the produce from the limestone treatment was \$I I 2.I 5 more than that from the land treated with caustic lime. The total ultimate 
effect of the caustic lime for the 20 years was an actual decrease in the yields of all crops except wheat; while the ground limestone produced an increase in all crops except corn, on which the decrease was only one sixth as much as with caustic lime.

If it is true, as indicated by the Pennsylvania experiments, that 8 tons of burned lime, applied during 16 years, released 375 pounds of nitrogen and destroyed organic matter equivalent to 37 tons of farm manure, or more than $\$ 7.00$ worth of nitrogen and $4 \frac{1}{2}$ tons of manure destroyed for each ton of burned lime used, as compared with ground limestone; and if larger crops were obtained where limestone was used, especially where the practice is extended over several years, and if the ground limestone is sustaining the productive capacity of the soil much better than the burned lime; then, as a very general rule, we should avoid applying caustic lime to the land, but make liberal use of ground limestone where needed to correct the acidity of the soil and to furnish a natural base, although, as used in these Pennsylvania experiments, without manure and with no return of plant food, the increase in crop yields produced by ground limestone has not been sufficient to pay for the heavy applications.

The Maryland Experiment Station has recently reported experiments with different kinds of lime, covering eleven years, with a rotation of corn, wheat, and hay (timothy and clover), r 400 pounds of calcium oxid (burned lime) and equivalent amounts of calcium carbonate (ground oyster shells and shell marl) having been applied per acre at the beginning. Four crops of corn, three of wheat, and four of hay were harvested during the eleven years, with the following total results per acre:

Table 25.I. Maryland Experiments with Lime

\begin{tabular}{|c|c|c|c|}
\hline \multirow[b]{2}{*}{ Kinds of Lime Used } & \multicolumn{3}{|c|}{ Produce in Eleven Years } \\
\hline & $\begin{array}{c}\text { Corn (Bushels) } \\
4 \text { Crops }\end{array}$ & $\begin{array}{c}\text { Wheat (Bushels) } \\
3 \text { Crops }\end{array}$ & $\begin{array}{c}\text { Hay (Tons) } \\
4 \text { Crops }\end{array}$ \\
\hline None . . . . . . . . . . . . & $9^{8}$ & $3^{2}$ & 2.60 \\
\hline Caustic lime burned from stone ${ }^{1}$. & I 28 & $3^{2}$ & 3.09 \\
\hline Caustic lime burned from shells ${ }^{1}$. & 129 & 34 & 3.82 \\
\hline Calcium carbonate in ground shells & I 48 & 42 & 3.97 \\
\hline Calcium carbonate in shell marl . . & I 45 & 43 & $4 \cdot 29$ \\
\hline
\end{tabular}

${ }^{1}$ Average of two plots. 
In commenting on these results, Director Patterson of the Mary land Experiment Station says: "It will be noted that the carbonate of lime gave decidedly better results than the caustic lime."

Neuffer, of Heilbronn, Germany, has published a book entitled, "Das Kalksteinmehl im Dienste der Landwirtschaft" (The Use of Ground Limestone in Agriculture), in which he advises that ground limestone, and " not burned lime," should be used in the improvement of soils deficient in lime.

Porter and Grant, in a recent Farmers' Bulletin issued by the Agricultural Department of the County Council of Lancaster, England, report experiments on manured and unmanured meadow lands, showing that ground limestone is more profitable as an application to grass lands than burned lime, and that it can be economically used on grass lands which are in need of lime.

No trustworthy investigations support the use of burned lime in preference to ground limestone; although we have ample information showing that on many soils a moderate use of burned lime in connection with a liberal use of farm manure and green manures yields profitable returns, which would, no doubt, be still more profitable if the burned lime were replaced with ground limestone.

The most abundant impurity of limestone is magnesium carbonate, which sometimes occurs in equal molecular proportion with calcium carbonate, in what is called dolomite $\left(\mathrm{CaCO}_{3} \mathrm{MgCO}_{3}\right)$. Limestones containing considerable amounts of magnesium carbonate are also called magnesian limestones, even though the proportion of magnesium may be less than in dolomite.

Dolomitic limestone is usually slightly heavier than ordinary limestone, and it is scarcely attacked by cold hydrochloric or acetic acid, while pure calcium carbonate is rapidly decomposed, the carbon dioxid being liberated as a gas.

The molecular weights are 100 for calcium carbonate and 84 for magnesium carbonate, and consequently 84 pounds of the latter has the same power to correct soil acidity as roo pounds of the former; or 92 pounds of dolomite will correct as much soil acidity as roo pounds of pure ordinary limestone.

To determine the amount of limestone present in the soil, or to determine the value of a sample of limestone for use on acid soils, 
it is usually sufficient to determine the content of carbonate carbon (or carbon dioxid) and compute from this the equivalent amount of calcium carbonate. Of course, this computation would show that roo pounds of pure dolomite would be equivalent to about rog pounds of pure limestone.

Agricultural writers have placed upon record the general opinion that magnesian lime is very likely to produce injurious effects when used upon the soil.

In his comprehensive and very valuable treatise upon "The Agricultural Use of Lime," Doctor William Frear includes the following comments (Report Pennsylvania State College, r899-1900, pages 14 to 176$)$ :

"Lloyd states that lime $(\mathrm{CaO})$ is the only material of value in burnt lime and applies the adjective 'bad' to a lime containing 60 per cent of lime $(\mathrm{CaO})$ and 30 per cent of magnesia $(\mathrm{MgO})$. Low says of the magnesian limestone of England: 'If applied after being calcined, in the same quantity as other limes, it produces a temporary sterility, burning, as it were, the soil; hence, it is termed hot lime and is applied in much smaller quantity than other kinds of lime.' This action he attributes, after Sir Humphry Davy, to the longer period of causticity commonly supposed to occur with magnesia. In the form of carbonate, he says, 'magnesia seems to exercise a highly favorable action; and magnesian limestone may perhaps be regarded as the most valuable of any, since a smaller quantity of it suffices for the ends proposed.'

"The subject is quite fully discussed by Storer (Agriculture, I897, Vol. 2, page I35), who notes that it was early observed by English chemists that certain limestones which had sometimes been found in practice to injure crops, contained magnesia, and that Tennant, on applying calcined magnesia to various soils with different crops, found that his plants either died, were unhealthy, or vegetated very imperfectly; also, that Knop found, in growing plants by water culture (i.e., in very dilute solutions of plant foods), that magnesium salts are distinctly harmful unless accompanied by abundance of lime, potash, or ammonia salts; by themselves, the magnesium salts caused peculiar malformations of the plant roots, followed shortly by the death of the plants.

"Storer notes, on the other hand, that Sir Humphry Davy found that the very magnesian limestones to which objection was made, gave very beneficial results on certain soils, and that magnesia, though injurious when present in caustic condition in considerable quantity in ordinary soils, may be beneficial when mixed with peat or where present as carbonate."

In a recent investigation at Rothamsted, Ashby reports a larger fixation of nitrogen by Azotobacter when magnesium carbonate was present than when calcium carbonate was used. For each 
gram of carbohydrate (mannite) consumed, 8.92 milligrams of nitrogen were fixed in 6.6 days with magnesium carbonate, and 5.80 milligrams in 4.6 days with calcium carbonate. Ashby says (Journal of Agricultural Science, January, I907, pages 46, 47):

"With magnesium carbonate there was 50 per cent more nitrogen fixed, and a delay of two days in development. . . . One must conclude, therefore, the magnesium carbonate not only neutralizes more effectually than calcium carbonate any trace of acidity due to foreign organisms in the early stages of culture, but also prevents butyric fermentation; but at first it inhibits the growth of Azotobacter itself."

'Table 26 gives the results of an investigation concerning magnesium carbonate conducted with the assistance of the author's students and associates at the University of Illinois. The experiment bears upon two lines of inquiry - (I) the value of magnesium carbonate for soil improvement, and (2)methods of correcting this "alkali" when present in injurious amounts.

Several series of 4 -gallon pots were filled with the common brown silt loam prairie soil from the University farm, and to five of the six pots in each series was added magnesium carbonate in amounts varying from .4 per cent to 2 per cent of the dry soil. In addition, Series $\mathrm{C}$ and $\mathrm{F}$ received calcium sulfate in such an amount as to maintain the ratio of $\mathrm{MgO}$ to $\mathrm{CaO}=4$ to 7 , in accordance to Loew's advocated optimum ratio.

After the crop of I904 was harvested, the pots in Series F were thoroughly leached in order to remove magnesium, more or less of which was expected to react with the calcium sulfate, leaving the harmless calcium carbonate.

The data recorded in Table 26 show a distinct and persistent benefit from the use of magnesium carbonate up to .8 per cent of the soil, while with 1.2 per cent the plants are very seriously injured and with I.6 per cent they are usually so nearly killed as to produce no grain, and they are practically all killed with 2 per cent of magnesium carbonate.

The application of I per cent of magnesium carbonate would require Io tons per acre for the surface $6 \frac{2}{3}$ inches, but if the material were applied and mixed with only the surface inch by a light harrowing, it would require only $\mathbf{I}_{2}^{\frac{1}{2}}$ tons per acre for $\mathrm{I}$ per cent. Since pure dolomite would contain only 46 per cent of magnesium 
Table 26. Illinois Pot-culture Experiments

Magnesium Carbonate in Brown Silt Loam Prairie Soil

\begin{tabular}{|c|c|c|c|c|c|c|c|c|c|}
\hline \multirow{2}{*}{$\begin{array}{l}\text { Pot } \\
\text { No. }\end{array}$} & \multicolumn{2}{|c|}{ "Alkali" ApPlifd } & \multirow{2}{*}{$\begin{array}{l}\text { AMEND- } \\
\text { MENT } \\
\text { APPLIED }\end{array}$} & \multirow{2}{*}{$\begin{array}{c}\text { ADDITIONAL } \\
\text { TrEATMENT } \\
\text { GIVEN }\end{array}$} & \multicolumn{5}{|c|}{$\begin{array}{c}\text { YiELDS of WhEAT GRAIN, } \\
\text { GRAMS PER POT }\end{array}$} \\
\hline & Kind & $\begin{array}{l}\text { Per } \\
\text { Cent }\end{array}$ & & & 1904 & 1905 & 1906 & 1907 & 1908 O. $1908 \mathrm{R}$. \\
\hline
\end{tabular}

Series A: Magnesium Carbonate

\begin{tabular}{|c|c|c|c|c|c|c|c|c|c|c|}
\hline I & None & .0 & None & None & I5.23 & 10.93 & II. 50 & 6.30 & 8.60 & 9.6 I \\
\hline 2 & $\mathrm{MgCO}_{3}$ & .4 & None & None & 21.02 & 10.97 & I 3.20 & $9 \cdot 35$ & I 7.I 8 & I9.I8 \\
\hline 3 & $\mathrm{MgCO}_{3}$ & .8 & None & None & 24.88 & I 2.57 & 12.60 & 10. 35 & 8.16 & 21.09 \\
\hline 4 & $\mathrm{MgCO}_{3}$ & 1.2 & None & None & 4.I5 & 9.02 & 9.40 & 14.00 &.$\infty$ & 10.63 \\
\hline 5 & $\mathrm{MgCO}_{3}$ & I. 6 & None & None & .00 & .00 & . IO & 2.10 & 3.00 & I 2.86 \\
\hline 6 & $\mathrm{MgCO}_{3}$ & 2.0 & None & None &.$\infty 0$ &.$\infty$ & .00 & 2.50 & .70 & 2.72 \\
\hline
\end{tabular}

Series C: Magnesium Carbonate and Calcium Sulfate

\begin{tabular}{|c|c|c|c|c|c|c|c|c|c|c|}
\hline I & None & .0 & None & None & I I. 22 & 8.94 & I 2.20 & I $2.9 \mathrm{I}$ & 8.00 & 6.18 \\
\hline 2 & $\mathrm{MgCO}_{3}$ & .4 & $\mathrm{CaSO}_{4}$ & None & 27.00 & 12.02 & 10.00 & 8.79 & I5.00 & I6.32 \\
\hline 3 & $\mathrm{MgCO}_{3}$ & .8 & $\mathrm{CaSO}_{4}$ & None & 24.85 & I 3.47 & I 5.70 & 8.42 & I 4.86 & $2 \mathrm{I} . \mathrm{I} 5$ \\
\hline 4 & $\mathrm{MgCO}_{3}$ & I. 2 & $\mathrm{CaSO}_{4}$ & None & 5.59 & II. 25 & I 7.80 & I0. 18 & $6.5^{2}$ & $22.5^{\circ}$ \\
\hline 5 & $\mathrm{MgCO}_{3}$ & I. 6 & $\mathrm{CaSO}_{4}$ & None & .00 & 2.03 & I. I6 & 8.58 & 1.42 & I1. 98 \\
\hline 6 & $\mathrm{MgCO}_{3}$ & 2.0 & $\mathrm{CaSO}_{4}$ & None & .00 & .00 & .50 & 6.68 & .62 & $3 \cdot 3^{2}$ \\
\hline
\end{tabular}

Series F: Magnesium Carbonate and Calcium Sulfate - Leached

\begin{tabular}{|c|c|c|c|c|c|c|c|c|c|c|}
\hline I & None & .0 & None & None & 13.00 & $8.5^{I}$ & 14.20 & 6.67 & I5.I 2 & 17.40 \\
\hline 2 & $\mathrm{MgCO}_{3}$ & .4 & $\mathrm{CaSO}_{4}$ & Leached ${ }^{1}$ & I 7.12 & I $3.3^{8}$ & I I. 40 & I 2.39 & I 2.72 & I 2.64 \\
\hline 3 & $\mathrm{MgCO}_{3}$ & .8 & $\mathrm{CaSO}_{4}$ & Leached ${ }^{1}$ & 22.35 & $14.3^{2}$ & 8.30 & 12.60 & I 3.50 & I 5.80 \\
\hline 4 & $\mathrm{MgCO}_{3}$ & I. 2 & $\mathrm{CaSO}_{4}$ & Leached ${ }^{1}$ & 6.72 & I 4.18 & 10.20 & I6.66 & I 2.78 & I 4.57 \\
\hline 5 & $\mathrm{MgCO}_{3}$ & I. 6 & $\mathrm{CaSO}_{4}$ & Leached ${ }^{1}$ & 3.73 & I I. 54 & I I.IO & Io. 75 & I0.24 & I 3.24 \\
\hline 6 & $\mathrm{MgCO}_{3}$ & 2.0 & $\mathrm{CaSO}_{4}$ & Leached $^{1}$ & .00 & I 4.15 & 10.70 & $9 \cdot 52$ & I0.22 & $\mathrm{I} 3.20$ \\
\hline
\end{tabular}

${ }^{I}$ Leached after I904.

carbonate, while most magnesian limestones contain a lower percentage, and since thorough harrowing or disking will mix the material with at least 2 or 3 inches of soil, there is no likelihood of any but beneficial effects from initial applications of 5 or 6 tons to the acre, and subsequent applications of 2 tons per acre every four or five years would probably never produce injury. On the other hand, it is highly probable that the element magnesium 
applied in dolomitic limestone may produce quite as much benefit for its own sake as will the element potassium on most soils where it proves more or less beneficial. (The limestones in Pennsylvania and in the northern parts of Ohio, Indiana, and Illinois are, as a rule, more or less magnesian, containing, as an average, perhaps 30 per cent of magnesium carbonate and 60 per cent of calcium carbonate, with Io per cent of impurities, which would be equivalent to a purity of 95 per cent for the common limestone.)

As an experiment, the double decomposition and leaching proved a success, as is clearly shown in Series F, pot 6 being changed from a sterile condition to as productive soil as any. It should be remembered that high temperatures may occur at a critical period, and consequently seasonal variations are marked even in glasshouse cultures. Loew's ratio finds little support from these data.

Incidentally, it may be stated that during the progress of these experiments, several resistant plants have developed, which explains some apparent discrepancies in the yields of wheat from pots near the border line of injury; and consequently the seeds of these resistant plants have been used in part throughout one or more series. In 1908, one half of each pot was planted with ordinary (O.) wheat, and the other half with the resistant (R.) strain, and, consequently, double the weights harvested are recorded for the Igo8 yields.

\section{Amount of Limestone to Apply}

From the information thus far secured, no fixed limits can be placed upon the amounts of limestone to use as an initial application to acid soils. One ton to the acre is more than enough to destroy the acid commonly contained in the plowed soil, provided the limestone is sufficiently fine and thoroughly mixed with the soil; but, as a rule, it is less expensive to apply more limestone and then to allow the mixing to go on more slowly by the necessary processes of plowing, disking, harrowing, etc., in the regular farm operations, keeping in mind also that the heavier the application, the longer it will last.

About one half of the water that falls in rain and soaks into the soil is brought back to the surface from lower depths by capillary 
action and evaporated. More or less acidity is thus brought up from the acid subsoil, especially in time of drouth, and there should be sufficient limestone in the surface to destroy this acidity as it rises. Quantitative determinations have shown that to correct the total acidity contained in much of the upland soil of southern Illinois to a depth of 40 inches would require more than to tons of limestone per acre.

It is not necessary to apply such amounts, because the limestone does not descend very much below the plowed soil, and the rise of acidity from below is only occasional and not rapid.

It may be said, however, that ro tons of ground limestone per acre would not only do no harm, but would probably produce somewhat larger crops than any lighter application. As much as ro tons per acre has been applied on an experiment field in southern Illinois, and the crop yields on that field have been larger during the last three years than on any other experiment field in that area. Two to four tons per acre, however, have usually produced much benefit.

The author has used 2 to 3 tons per acre of magnesium limestone on his own southern Illinois farm (gray silt loam on tight clay), and as much as ro tons per acre of the same material has been used on another farm with evident benefit. He advises an application of at least 2 tons of ground limestone per acre, where the addition of limestone is necessary, believing that less than this will not give satisfactory results in practice. Heavier applications will give greater profits per acre, but probably less profit per ton of limestone used.

These two factors, it may be noted, are commonly opposed to exch other in many farm operations. Thus, farm manure gives the greatest profit per acre in heavy applications, but the greatest profit per ton in light applications. With little manure and much land we apply the manure lightly, but, with a small area of land and large supplies of manure, we apply it heavily. So, with ground limestone: If one must cultivate much land and can use but little limestone, apply 2 tons per acre, and plan to apply more in later years; but, if one cultivates less land and wishes to improve it more rapidly, apply 4 to to tons of limestone per acre, and it will give more marked results and will last much longer. 
The amount and frequency of subsequent applications will depend upon the rate of loss by leaching and by removal in crops.

The soil of the Rothamsted Experiment Station, England, is underlain with a bed of calcium carbonate, in the form of chalk, at a depth of 8 feet or more; but, nevertheless, the overlying residual soil material is normally deficient in limestone to a depth of several feet. A century or more ago certain fields were given heavy applications of chalk, dug out of pits excavated for the purpose, and the fact that some of these fields still contain 50 tons of calcium carbonate per acre in the plowed soil and continue to produce good crops, with fair treatment, is proof sufficient that there is no danger of applying too much ground limestone.

During a period of 40 years, from 1865 to I 905 , large numbers of analyses have been made of the Rothamsted soils. During that time, according to Director Hall and Doctor Miller (Proceedings of the Royal Society, I905, Vol. 77), there have been the following losses of calcium carbonate from nine different plots on Broadbalk Field, where wheat is grown every year:

Table 27. Losses of Calcium Carbonate from Broadbalk Field, ROTHAMSTED, FROM I865 TO I905

\begin{tabular}{|c|c|c|c|}
\hline $\begin{array}{l}\text { Plot } \\
\text { No. }\end{array}$ & Soll Treatment & $\begin{array}{l}\text { TONS PER ACRE } \\
\text { IN } 40 \text { YEARS }\end{array}$ & $\begin{array}{l}\text { POUNDS PER ACRE } \\
\text { PER ANNUM }\end{array}$ \\
\hline \multirow{10}{*}{$\begin{array}{c}2 b \\
3 \\
5 \\
6 \\
7 \\
8 \\
9 \\
10 \\
11\end{array}$} & Farm manure. . & I I. 8 & 590 \\
\hline & Unmanured . . . . . . . . . . & I6.0 & 800 \\
\hline & Minerals . . • . . . . . . . & I 7.6 & 878 \\
\hline & Minerals and single ammonium salts . & $23 \cdot 5$ & I I 74 \\
\hline & Minerals and double ammonium salts & 20.2 & IOIO \\
\hline & Minerals and treble ammonium salts & $23 \cdot 5$ & I I 74 \\
\hline & Minerals and single nitrate . . . & II. 3 & 564 \\
\hline & Double ammonium salts . . . . & 20.9 & 1045 \\
\hline & Double ammonium salts and acid & & \\
\hline & 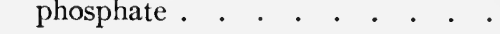 & 28.6 & I 429 \\
\hline
\end{tabular}

The loss of calcium carbonate during the period of 40 years ranges from II. 3 to 28.6 tons per acre. The average annual loss where ammonium salts have been applied is I 70 pounds, but with no ammonium salts the average loss is only 7 io pounds a year, or about one ton per acre in three ycars. 
From eight plots on Hoos Field, where barley is grown every year, the following losses of calcium carbonate have occurred:

Table 28. Losses of Calcium Carbonate from Hoos Field, Rothamsted, FROM I865 TO I9O5

\begin{tabular}{|c|c|c|c|c|c|c|c|c|c|c|c|c|c|c|}
\hline $\begin{array}{l}\text { PLot } \\
\text { No. }\end{array}$ & \multicolumn{12}{|c|}{ Soll Treatment } & $\begin{array}{c}\text { ToNS PER } \\
\text { ACRE IN } \\
40 \text { YEARS }\end{array}$ & $\begin{array}{l}\text { POUNDS PER } \\
\text { ACRE PER } \\
\text { ANNUM }\end{array}$ \\
\hline $\mathrm{O}_{\mathbf{I}}$ & Unmanured & & - & . & & & & & - & - & - & - & 23.7 & I I 85 \\
\hline $\mathrm{O}_{4}$ & Minerals . & & . & . & . & & & & . & . & . & . & I 4.5 & 723 \\
\hline AI & Ammonium sa & & & & . & & & . & . & . & . & . & I5.9 & 793 \\
\hline $\mathrm{A}_{4}$ & Minerals and & am & mol & niu & $\mathrm{m}$ & sal & & • & - & - & & - & I 5.0 & $75^{\circ}$ \\
\hline Ni & Sodium nitrate & & . & . & & & & . & . & . & . & . & I 5.4 & 772 \\
\hline $\mathrm{N}_{4}$ & Minerals and $s$ & sod & ium & $\mathrm{ni}$ & tra & & & & & & - & . & II.I & 554 \\
\hline $\mathrm{CI}_{\mathrm{I}}$ & Rape cake . & . & . & . & 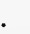 & & • & • & - & . & - & . & I5.0 & 750 \\
\hline $7^{-2}$ & Farm manure & . & . & . & . & • & • & - & . & . & . & - & I 7.0 & 848 \\
\hline
\end{tabular}

The average of the eight plots on Hoos Field shows for 40 years an average annual loss of 800 of calcium carbonate per acre. The ammonium salts have not markedly increased the average loss on this field above that from the nitrate plots or the untreated land.

The investigations reported also include Agdell Field and Little Hoos Field, both of which have lost calcium carbonate in about the same amount as Broadbalk and Hoos.

Practice based upon these results would require an application of two tons per acre of ground limestone about every five or six years, in order to replace the regular losses.

The loss of calcium carbonate from soils is largely due to leaching. The soil waters contain carbonic acid $\left(\mathrm{H}_{2} \mathrm{CO}_{3}\right)$ formed by the absorption of carbon dioxid $\left(\mathrm{CO}_{2}\right)$ from the atmospheric air and from the soil air. This carbonic acid has power to react with calcium carbonate and form calcium bicarbonate, $\mathrm{CaH}_{2}\left(\mathrm{CO}_{3}\right)_{2}$, which is soluble in water, thus:

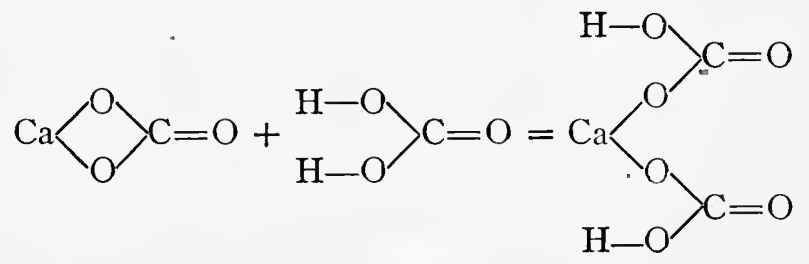


In all humid regions where water passes through the soil, there is loss of calcium carbonate, leached out in the form of soluble bicarbonate. The "lime" carried in solution in "hard" waters from surface wells appears as a crust or scale in the teakettle, the soluble bicarbonate being decomposed by heat and the insoluble normal carbonate thus precipitated. Even virgin soils in old soil formations are often not only deficient in limestone, but they are sometimes found to be exceedingly acid, and thus require heavy applications of limestone to correct or neutralize the acids in the soil.

Usually these soil acids exist in part, at least, as organic acids (humic acid etc.), but it is very evident that they are not always entirely organic, because the acidity often markedly increases while the organic matter decreases, with depth of soil, as will be seen from Tables I5, I6, and I7 (see soil types 330, I35, and 335), in which the measure of acidity is shown by the "limestone required," and the organic matter is indicated roughly by the nitrogen. Thus, in the lower Illinoisan yellow silt loam, limestone required to correct the acidity increases from 3 ro pounds in the surface to $33^{\text {I } 5}$ pounds in the subsurface, and to 7200 pounds in the subsoil, considering 2 million pounds of each; while the nitrogen decreases from 2150 pounds in the surface to 1085 pounds in the subsurface, and to 827 pounds in the subsoil; and, as a matter of fact, the organic carbon decreases from 23,400 pounds in the surface, to 97 ro pounds in the subsurface, and to 6190 pounds in the subsoil, 2 million pounds of each being considered.

Detmer assigns to humic and ulmic acids the molecular formula $\mathrm{C}_{60} \mathrm{H}_{54} \mathrm{O}_{27}$, and to their salts such formulas as $\mathrm{Ag}_{8} \mathrm{C}_{60} \mathrm{H}_{46} \mathrm{O}_{27}$, and $\mathrm{Ca}_{3}\left(\mathrm{NH}_{4}\right)_{2} \mathrm{C}_{60} \mathrm{H}_{46} \mathrm{O}_{27}$. These would correspond to $\mathrm{Ca}_{4} \mathrm{C}_{60} \mathrm{H}_{46} \mathrm{O}_{27}$. On this basis, if all of the organic carbon in the subsoil were in the form of humic acid, it would be equal to less than one half of the acidity found. These computations are based upon the average of many analyses of soil samples from this type. Individual samples show as high as six times as much acidity as could be accounted for from the total organic carbon if in the form of humic acid.

Acid silicates.(see acid salts), former from polysilicates (see under silicon), from which some basic elements may have been removed and replaced with acid hydrogen, by reaction with soluble 
organic acids, or possibly by the long-continued weak action of drainage waters charged with carbonic acid, do exist in the soil, and the evidence thus far secured indicates that they account for most of the acidity of soils that are at the same time strongly acid and very deficient in humus.

Calcium bicarbonate may be formed by the action of carbonic acid on silicates containing calcium, even though no limestone is present. It is well known that plants have power to secure calcium, as plant food, from acid soils containing calcium in silicates but not containing limestone.

Of course, it is not necessary to apply limestone to soils that already contain abundance of calcium carbonate, but it should be applied to soils that show acidity in the top soil and subsoil. Not infrequently slight acidity exists in the surface, and sometimes in the subsurface also, where the subsoil contains very large amounts of limestone. From present information we cannot strongly advise the application of limestone to such soils, although it would certainly do no harm, and for some crops might be beneficial. But where the subsoil also is strongly acid, liberal applications of limestone should be made. While a small amount of acidity in the surface may not be a scrious injury when the rainfall is abundant, there is apparently in humid regions some rise of acidity from strongly acid subsoils in times of partial drouth, corresponding somewhat to the "rise of alkali" in arid regions, where the water leaves the soil only by evaporation from the surface. If, however, the subsoil contains abundance of limestone, some calcium bicarbonate will be brought upward into the subsurface or surface soil with the capillary rise of the soil moisture, and this will be left as normal carbonate when the water evaporates, and may serve to reduce the acidity of the subsurface or surface soil, at critical times, as in time of drouth.

Clover and alfalfa are plants that are very sensitive to acid conditions when dependent for most of their nitrogen upon the bacteria, Pseudomonas radicicola, but these crops are grown very successfully upon such soils as the brown silt loam of the early Wisconsin glaciation and the brown silt loam, yellow-gray silt loam, and yellow silt loam, of the late Wisconsin; whereas they are complete failures on the lower Illinoisan gray silt loam prairie, 
and very unsatisfactory crops for all soils with strongly acid subsoils, although, as already stated, such crops can be grown for a time on such soils if liberally fed with farm manure or other fertilizers. The legume plants, themselves, are not so sensitive to acid conditions, but, rather, the bacteria depended upon to furnish nitrogen; and while these will sometimes live and even form tubercles, they seem to develop but little power to fix nitrogen under such unfavorable conditions.

\section{The Time to Apply Limestone}

The answer to this question can be no more definite than to a similar question concerning farm manure. We should consider the matter of hauling and spreading limestone in relation to the other necessary farm work, keeping in mind conditions of weather, roads, and land. It is applied but once during the crop rotation and for the benefit of all crops, although its most direct benefit is for the legumes, the other crops receiving large indirect benefit if the legume crops are returned to the soil.

It is sometimes applied in winter or spring, but, as a rule, it is more satisfactory to apply it during the summer or early fall, when the land is dry, the roads are good, and the days are long. It is not best to apply it in intimate connection with phosphate, because the limestone will retard the a vailability of the phosphorus, although this effect is temporary, and in any case the two materials must ultimately become mixed if applied to the same land. The phosphate may well be applied with organic matter (manure or clover), mixed with the surface soil by disking, and then plowed under, and the limestone may then be applied after plowing and well mixed with the surface soil in the preparation of the seed bed, where wheat and clover are to be seeded, or where corn is to be followed by oats and clover, the oats being disked in without replowing. Thus the limestone is well distributed in the first 3 or 4 inches of the soil where the atmospheric nitrogen enters and where the nitrogen-fixing bacteria do much of their work, while the phosphate is mixed with the decaying organic matter in the next 3 or 4 inches of soil where the plant roots feed in large degree. Another good way is to apply the phosphate for corn and the limestone for wheat about three years later. 


\section{Methods of Applying Limestone}

No single method need be followed in applying limestone to the land, but it should be spread as evenly as practicable. This may be done by hand with a light shovel, either from the wagon or from small equal-sized piles placed at regular intervals. Thus, a pile of roo pounds every 33 feet each way makes two tons to the acre. It can easily be thrown 16 or I 8 feet with a shovel.

A spreader made for the purpose of applying ground limestone or rock phosphate is very useful: There are some fairly satisfactory machines on the market at the present time. Several spreaders are manufactured that serve well for applying ashes, slacked lime, or other light materials, but most of them are not suited for handling such heavy materials as limestone and rock phosphate.

The directions given below are similar to those published by the Ohio Experiment Station for a "home-made" spreader which any farmer can have made, and which is more satisfactory for spreading these heavy materials than some of the machines on the market.

Make a hopper similar to that of an ordinary grain drill, measuring inside $8 \frac{1}{4}$ feet or II feet long with sides about $2 \mathrm{I}$ inches wide and about 20 inches apart at the top. The sides may be trussed with $\frac{3}{8}$-inch iron rods running from the bottom at the middle to the top at the ends of the hopper. Let the bottom be 5 inches wide in the clear, and cut in it crosswise a row of diamond-shaped holes, 2 inches wide, $2 \frac{1}{2}$ inches long, and 4 inches apart ( 6 inches between centers). Make a second bottom with holes in it of the same size and shape as those of the main bottom, and so shaped that they will register. Let this second bottom slide loosely under the first, moving upon supports made by leaving a space for it above bands of strap iron 12 inches apart, which should be carried from one side to the other under the hopper to strengthen it. The upper bottom piece may be of about 8-inch sheet steel, and the lower one may be of smooth, seasoned hard wood, about I inch thick and 7 inches wide, reënforced with strap iron if necessary, and well oiled or painted. To this under strip, attach a V-shaped arm, extending an inch in front of the hopper, with a half-inch hole in the point of the $V$, in which drop the end of a strong lever, bolting 
the lever loosely but securely to the side of the hopper, and fasten to the top of the hopper a guide of strap iron, in which the lever may move freely back and forth. The object of this lever is to regulate the size of the openings by moving the bottom board. Make a frame for the hopper, with a tongue to it, similar to the frame of an ordinary grain drill.

Get a pair of old mowing-machine wheels with strong ratchets in the hubs, and with pieces of round axle of sufficient length to pass through the frame and into the ends of the hopper, which are to be welded to a square bar of iron about $\mathrm{I} \frac{3}{8}$ inches in diameter and the length of the inside of the hopper. The axles should be fitted with journals, bolted to the under side of the frame.

Make a reel to work inside of the hopper by securing to the axle, I 2 inches apart, short arms of $\frac{3}{8}$-inch by $\mathrm{I}$-inch iron, and fastening to these arms four beaters of $\frac{5}{8}$-inch square iron, about an inch shorter than the inside of the hopper, the reel being so adjusted that the beaters will almost scrape the bottom of the hopper, but will revolve freely between the sides. The arms may be made of two pairs of pieces, bent so as to fit around the axle on opposite sides, and secured by small bolts passing through the ends and through the beater, which is held between them. The diameter of the completed reel is about 5 inches, and it serves as a force feed.

Two pieces of oilcloth may be tacked to the bottom of the hopper, one in front and one behind, of sufficient width to reach nearly to the ground, in order to reduce the annoyance of the flying dust to man and team. Another piece may be buttoned across the top of the hopper in windy weather, if desired; but the dust of limestone or of natural phosphate is certainly no worse than the dust of the field.

A sort of second force feed has been evolved from the extensive experience of Illinois farmers in building home-made machines: Two pieces of sheet steel, each about 6 inches wide and the length of the machine, are used as a V-shape bottom for the hopper, forming nearly a right angle at the lowest point. One piece is stationary and the other is given an endwise motion back and forth by means of a small wheel with a heavy rim waving in and out horizontally and running through a slotted piece firmly attached to the movable sheet steel. Two very small wheels 
forming the sides of the slot serve to reduce the friction, and a lever is arranged to throw this mechanism out of gear. One of the pieces of sheet steel is provided with an adjustment by means of which a crack is opened of any desired width, the entire length of the bottom. Thus the stone falls, not through holes or in streaks, but in a perfect broadcast. Several of these home-made machines are in use. The draft is more than with the reel alone, but they are undoubtedly more satisfactory than anything on the market.

The cash expense for such a machine, aside from the mower wheels with axle and ratchets, has varied from less than \$IO to more than $\$ 20$, depending on cost of material and labor. Farmers with some mechanical skill hire only the necessary blacksmithing.

\section{Hints on spreading Limestone (and Phosphate)}

In hauling and spreading limestone it is of first importance to save time and labor. As a rule, it is more economical to purchase both limestone and raw phosphate in bulk, and have it shipped in paper-lined box cars. Wetting will do no harm except to give trouble in spreading. Bags are expensive and easily damaged, and with tight wagon boxes the use of bags is wholly unnecessary. As a rule, the plan should be to haul the limestone direct from the car to the field, and spread it at once. Only two days are allowed to unload a car, although an extra day's car service costs only one dollar.

With a haul of two miles or less, and with two men, one boy, and two teams, with three wagons and one spreader, 30 tons of ground limestone can be taken from the car and spread over Io to 15 acres of land in two or three days, provided the roads and other conditions are favorable.

One man is kept in the car loading the limestone into a wagon. The boy with one team hauls the loaded wagon to the field, leaves it there, and takes an empty wagon back to the car, hitching at once to the loaded wagon and leaving the empty wagon to be loaded. The other man and team remain in the field with the spreader, spreading one load while the boy is gone for the next. If an extra team is at hand, the man at the car may drive to meet the empty wagon and thus save some time. 
When spreading across a forty-acre field, the loaded wagon should either be hauled to the middle line of the field, or half of the loads should be hauled to one side and the other half to the opposite side of the field, using an extra wagon. The spreader hopper should hold at least Ioo pounds on the half-rod machines, or I333 pounds on the II-foot machines, so that by driving 80 rods, the load will amount to at least two tons per acre. Starting from the middle of the field, one hopperful will spread to the side (40 rods) and back, when the spreader must be backed up to the wagon and refilled. Four such drives ( 320 rods) with the half-rod machine, or three drives (240 rods) with the II-foot machine, will spread a two-ton load over an acre.

If the roads are good, two tons can be hauled at a load with a good team and wagon. If necessary to draw the loaded wagon to the middle line of the field, a four-horse team is provided by adding the spreader team.

For making applications from one half ton to two or three tons per acre of limestone or rock phosphate, an arrangement of this sort is very satisfactory. For heavier applications one can go over the ground twice, or it can be spread by hand. For longer distances, one or more additional teams are needed on the road.

Where manure is to be spread, rock phosphate may well be spread with it. The phosphate may be sprinkled over the manure from day to day as it is being made in the stall or covered feeding shed, or the manure spreader may be partly filled with manure, phosphate then being sprinkled on sufficient for the load, the load completed, and then spread on the land. It should be kept in mind, however, that, if any leaching occurs after the phosphate is mixed with the manure and before the manure is spread on the land, some loss may ensue of the added phosphate; while if the phosphate is taken directly from the car and spread on the land where manure has been or is to be applied, it can later be plowed under with the manure with no danger of loss of phosphate.

NотЕ. Limestone is soluble in soil water containing carbonic acid, and if ground to pass a sieve with about ro meshes to the linear inch, it is sufficiently fine, provided the product contains all of the finer material. Fineness correlates with loss by lcaching as well as with "availability," while the coarser particles are more durable and serve as centers of alkalinity. (See pages $174,198,561$.) 


\section{CHAPTER XIII}

\section{PHOSPHORUS}

PHOSPHORUS is the only element that must be purchased and returned to the most common soils of the United States. Phosphorus is the key to permanent agriculture on these lands. To maintain or increase the amount of phosphorus in the soil makes possible the growth of clover (or other legumes) and the consequent addition of nitrogen from the inexhaustible supply in the air; and, with the addition of decaying organic matter in the residues of clover and other crops and in manure made in large part from clover hay and pasture and from the larger crops of corn and other grains which clover helps to produce, comes the possibility of liberating from the immense supplies in the soil sufficient potassium, magnesium, and other essential abundant elements, supplemented by the amounts returned in manure and crop residues, for the production of large crops at least for thousands of years; whereas, if the supply of phosphorus in the soil is steadily decreased in the future, in accordance with the past and present most common farm practice, then poverty is the only future for the people who till the common agricultural lands of the United States.

And this does not refer to the far-distant future only, for the turning point is already past on most farms in our older states and on many farms in the corn belt; and lands that have passed their prime with sixty years of cultivation will decrease rapidly in productive power and value during another sixty years of similar exhaustive farm practice.

The world's supply of phosphorus exists in three principal sources: First are the supplies in the various soils, concerning which the reader of the preceding pages will have sufficient positive knowledge for intelligent thought.

Second are the natural beds of calcium phosphate, varying in purity from a ferw per cent, to as high as 80 per cent, of tricalcium phosphate, $\mathrm{Ca}_{3}\left(\mathrm{PO}_{4}\right)_{2}$. 
Third are the extensive deposits of phosphatic iron ores containing more or less ferric phosphate, $\mathrm{FePO}_{4}$, the phosphorus being recovered in the slag produced in the conversion of pig iron into steel.

About three fourths of the phosphorus taken from the soil by crops of corn, wheat, or other cereals, is deposited in the grain or seed, about one fourth remaining in the straw or stalks. If the grain is sold, three fourths of the phosphorus required for the crop is sold with it; and, likewise, when grain is bought and brought to the farm, a like proportion of phosphorus is brought with it.

When crops are fed to animals, as a general average about three fourths of the phosphorus, three fourths of the nitrogen, and practically all of the potassium are returned in the manurial excrements. Thus, if sufficient grain is bought and fed, and if the manure is saved and applied to the land, the soil can be made richer in phosphorus year by year, and in most sections some instances can be found of farmers who succeed in maintaining or increasing the fertility of their soil by this practice. If they have the necessary knowledge and skill and material equipment and sufficient capital, they may feed stock for the open market, or if this is not profitable, they may produce pure-bred stock to sell at higher prices for breeding purposes. In any case, live-stock farming can never be permanently profitable to a large proportion of the farmers in a great agricultural country, because the world cannot live on meat and dairy products only, and the relative supply and demand always compels the sale of much grain from most farms. Consequently, this system of adding phosphorus to one farm by taking it from other farms must be of limited application; and live-stock farmers who feed only the produce from their own land gradually reduce the phosphorus of the soil at least by the amount sold in the animal products.

A still more limited supply of phosphorus is secured for use in soil improvement by utilizing the bone meal prepared by the packing houses. 'This, of course, also comes from the soil originally. It is made chiefly from bone scraps which have no value for other uses. The best bone is worth several times as much for the manufacture of buttons, cutlery, toilet articles, etc., as for fertilizer purposes. Probably not more than one tenth of all the phos- 
phorus shipped off from American farms in animal products is returned to the soil in bone fertilizers. The mineral matter in bone consists chiefly of tricalcium phosphate, with a small amount of calcium carbonate. There is practiced more or less adulteration of bone fertilizers by admixture of raw rock phosphate or acid phosphate.

There are three principal forms of bone meal 'offered for sale(I) raw bone, (2) steamed bone, and (3) acidulated bone.

Raw bone meal. Raw bone meal contains about 9 per cent of phosphorus, 4 per cent of nitrogen, and much organic matter, including more or less fat, which tends to retard decomposition. The most common application of bone or other ordinary commercial fertilizer is 200 pounds per acre. Since 9 per cent means 9 pounds per hundred, this application would amount to I8 pounds of phosphorus per acre, or one pound more than is contained in Ioo bushels of corn. Since 200 pounds is one tenth of a ton, raw bone meal contains about I8o pounds of phosphorus per ton.

Hence, the rule: To convert per cent into pounds per ton, double the per cent and add one cipher. It is always advisable to memorize pounds per ton and to think in those amounts, rather than in per cent. At ro cents a pound for phosphorus and I5 cents for nitrogen, a ton of raw bone meal costs about $\$ 30$, which is \$I8 for the phosphorus and \$I 2 for the nitrogen.

Nearly $I_{2}^{1}$ tons of raw bones are required to make one ton of steamed bones, the loss in weight consisting of fat, flesh, glue, and other organic matters rich in nitrogen.

Steamed bone meal. Steamed bone meal contains from I2 to 14 per cent of phosphorus, and it should average at least I $2 \frac{1}{2}$ per cent, or 250 pounds of phosphorus per ton, costing $\$ 25$ at ro cents a pound for the element phosphorus. Thus, 200 pounds of steamed bone per acre supplies 25 pounds of phosphorus, or two pounds more than is required for a hundred-bushel crop of corn (grain and stalks). By steaming bones the nitrogen is largely removed in the organic matter, only about .8 per cent, or I 6 pounds per ton, being found in good steamed bone, an amount within the legal limits of error in some fertilizer laws, and too small to justify consideration in the purchase price, especially when nitrogen can be secured from the inexhaustible supply in the air by using leg- 
umes in crop rotations. To supply sufficient nitrogen for a hundred-bushel crop of corn would require 9 tons of steamed bone meal, costing about $\$ 225$.

The phosphorus in raw bone and steamed bone exists in the form of the insoluble tricalcium phosphate, but because of the porosity and fine division of the bone particles and the presence of decomposing organic matter in intimate contact with the extensive surface within the pores, phosphorus is liberated quite readily from bone meal, steamed bone being more active because of the removal of the fat and because it is usually more finely ground than raw bone.

Acidulated bone meal. Acidulated bone meal ("acid bone") is made by adding to a ton of bone meal sufficient sulfuric acid to convert a part of the insoluble tricalcium phosphate into the soluble monocalcium phosphate, or at least into the more readily available dicalcium phosphate. The bone meal thus treated is said to be mildly acidulated. As an average, it contains about 140 pounds of phosphorus and 40 pounds of nitrogen per ton. Much of the so-called "dissolved bone" sold in the fertilizer trade is made from phosphate rock, and this is no detriment to the product so far as the soluble portion is concerned, but the insoluble portion is more rapidly available if derived from bone than from rock. In the acidulated and most readily available form, phosphorus sells at about $\mathrm{I} 2$ cents a pound.

Other bone products include bone black, dissolved bone black, and bone ash. Tankage from the packing houses varies from nearly pure bone to a high percentage of nitrogenous organic matter, including dried blood, meat, and mixed offal. Some further data will be found under nitrogen fertilizers.

Three principal kinds of phosphorus fertilizer are derived from phosphate rock. These are (I) the fine-ground natural rock, (2) acid phosphate, and (3) double superphosphate.

Natural phosphates. Natural phosphate beds are widely distributed over the earth, some of the most important deposits being in Tennessec, South Carolina, Florida, and Canada, also in France, Belgium, Norway, Spain, and North Africa. The present annual production of the world amounts to about three million tons, of which two million tons are produced in the United States, about 
one million for home consumption, and an equal amount for exportation, chiefly to Great Britain, Germany, and other parts of Europe.

It is estimated that the total phosphate deposits of the world thus far discovered will still furnish'somewhere from 200 million to 500 million tons of high-grade phosphate rock. Some phosphate deposits have recently been found in Wyoming, Idaho, and Utah, and doubtless still other extensive deposits will be discovered in various parts of the earth; but, nevertheless, the world's total supply of high-grade phosphate is apparently very limited when measured by crop requirements, as evidenced by the enormous shipment of phosphate from America to Europe, despite the extensive and long-continued search by geologists for any undiscovered European deposits. (See also Appendix.)

Facts worthy of careful consideration are that the Chilian government derives a large revenue from export duties on sodium nitrate, from the world's greatest natural deposits of combined nitrogen, an element which the Chilian landowners can always secure, however, from the inexhaustible atmospheric supply; whereas, from the United States we are exporting half of our total production of phosphates with no restrictions, although we are thus shipping away from our lands the only element we shall ever need to purchase in order to maintain the fertility of our own soils. The laws of Norway greatly restrict the exportation of phosphate from that country.

To restore to the soils of the United States the phosphorus removed by the corn crop alone, would require the annual application of our total annual production of phosphate rock, counting 23 pounds of phosphorus for a hundred-bushel crop of corn, and $2 \frac{1}{4}$ billion bushels as the average corn crop of the United States.

The Florida phosphates are classed chiefly as hard rock and soft rock, the South Carolina phosphates as land rock and river rock; and the Tennessee phosphates as brown rock and blue rock. The quality is usually expressed as percentage of purity; that is, percentage of tricalcium phosphate.

The South Carolina land rock is the lowest in phosphorus, averaging less than $5^{\circ}$ per cent calcium phosphate, or less than ro per cent of phosphorus. The South Carolina river rock and the Florida 
soft rock average 50 to 60 per cent pure; while the Florida hard rock and the Tennessee brown rock contain from 60 to 75 per cent of calcium phosphate. The Tennessee blue rock varies from less than 50 to more than 70 per cent, or from 200 to 300 pounds of phosphorus per ton of rock. The Florida soft rock contains chiefly phosphates of iron and aluminum, while in the other rocks the phosphorus is largely in the form of tricalcium phosphate.

Aside from the deposits of high-grade phosphate, containing 45 or 50 to 75 or 80 per cent of calcium phosphate, there are known to exist very much more extensive deposits of lower grade phosphates and phosphatic limestones containing from less than Io per cent to 40 per cent or more of calcium phosphate, corresponding to from 2 to 8 per cent of phosphorus, or from 40 to I 60 pounds of phosphorus per ton of rock. At present, these deposits have no market value, because, if the phosphate costs $\$ 4.00$ per ton fineground and on board cars at the mine, and if the freight charges are $\$ 3.00$ per ton, the freight on two tons of low-grade rock would amount to $\$ 6.00$; while the delivered cost of one ton of high-grade rock supplying the same amount of phosphorus would be only $\$ 7.00$, leaving but 50 cents a ton for the low-grade rock, which would barely pay for the expense of easy quarrying and grinding.

As the supplies of high-grade phosphate become exhausted and prices advance, the lower grades will no doubt be utilized in this country as they are in Europe, where 35 to 40 per cent Belgian phosphate is now one of the chief commercial grades.

About $62 \frac{1}{2}$ per cent calcium phosphate, or $12 \frac{1}{2}$ per cent of phosphorus, is the average grade of the fine-ground natural rock phosphate now used in Illinois, and to some extent in other states, for direct application to the soil in intimate connection with abundance of decaying organic matter, as farm manure, clover, or other green manures. In this form the element phosphorus costs the farmer about 3 cents a pound.

The information thus far secured amply justifies the adoption of a system of farming in which fine-ground natural phosphate rock should be applied at the rate of 1000 to 2000 pounds per acre every three to six years, for three or four successive crop rotations, after which the application may be reduced one half, or to 200 pounds per acre for each year in the rotation, which would still 
insure a small increase rather than a decrease in the future. years.

More specific data concerning the use of raw rock phosphate, the results of the most careful experiments, and the comparative value of different forms of phosphorus are more fully discussed in the following pages, after some consideration of organic matter.

Acid phosphate. Acid phosphate is the name of a manufactured product, not of a chemical compound.

Chemically, there are two acid phosphates of calcium, (I) the monocalcium phosphate, $\mathrm{CaH}_{4}\left(\mathrm{PO}_{4}\right)_{2}$, and (2) the dicalcium phosphate, $\mathrm{Ca}_{2} \mathrm{H}_{2}\left(\mathrm{PO}_{4}\right)_{2}$. These chemical compounds, together with tricalcium phosphate and tetracalcium phosphate, phosphoric acid, phosphorus pentoxid, and phosphorus, itself, form a very important and interesting series. For the sake of simplicity and uniformity, two atoms of phosphorus are given in each case, this being necessary in some cases:

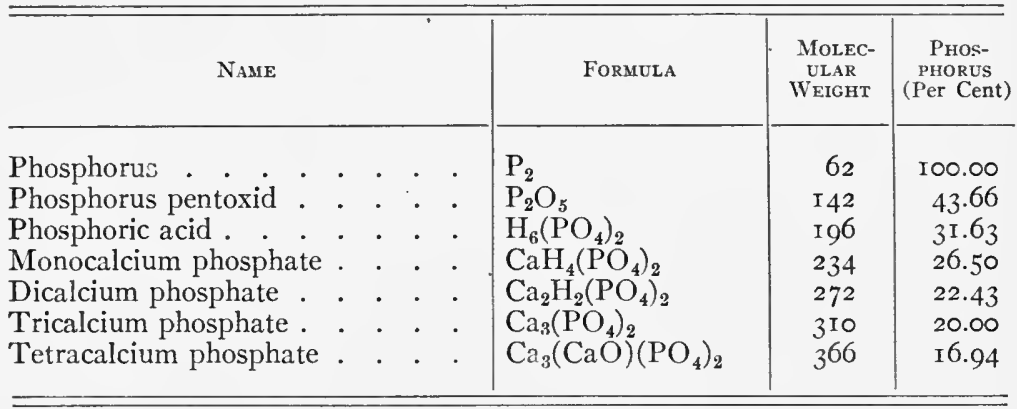

Of these substances, tricalcium phosphate is the only one that occurs in nature. The element phosphorus takes fire when exposed to the air, two atoms of phosphorus uniting with five atoms of oxygen to form phosphorus pentoxid, sometimes called phosphoric oxid. This compound is the most powerful dehydrating agent known in chemistry, having power to abstract water from many other substances. It unites with water to form true phosphoric acid, $\mathrm{H}_{3} \mathrm{PO}_{4}$, or $\mathrm{H}_{6}\left(\mathrm{PO}_{4}\right)_{2}$. This is one of the strong acids, and if it comes in contact with calcium carbonate, for example, it takes up one, two, and, finally, three bivalent atoms of calcium in place of the univalent hydrogen atoms, and thus forms acid monocalcium 
phosphate, acid dicalcium phosphate, or the neutral tricalcium phosphate, respectively, carbonic acid being liberated, which promptly decomposes into water and the gas, carbon dioxid.

Tetracalcium phosphate is thought by some to be the compound in which phosphorus exists in basic slag phosphate, being essentially tricalcium phosphate loosely united with the $\mathrm{CaO}$ group (see under basic slag phosphate).

In the manufacture of commercial acid phosphate, the phosphorus material most commonly used in mixed commercial fertilizers, one ton of ground raw rock phosphate is treated with about one ton of sulfuric acid, and the resulting material consists chiefly of monocalcium phosphate and calcium sulfate (land-plaster), together with all of the impurities contained in the original materials, and this mixture is the ordinary acid-phosphate fertilizer:

$$
\mathrm{Ca}_{3}\left(\mathrm{PO}_{4}\right)_{2}+2 \mathrm{H}_{2} \mathrm{SO}_{4}=\mathrm{CaH}_{4}\left(\mathrm{PO}_{4}\right)_{2}+2 \mathrm{CaSO}_{4} \text {. }
$$

This equation shows only the general reaction between the chemical compounds, tricalcium phosphate and sulfuric acid, but impurities are always present, and both the impurities and the calcium sulfate are included in acid phosphate, in which the phosphorus is held chicfly in the water-soluble compound, monocalcium phosphate. The reaction may be expressed in two equations, the two molecules of sulfuric acid being added separately, thus showing dicalcium phosphate as an intermediate product. Small amounts of both dicalcium phosphate and tricalcium phosphate usually remain in acid phosphate, and a considerable part of the sulfuric acid used reacts with impurities which consist chiefly of silicates of the abundant metals, aluminum, iron, calcium, magnesium, potassium, and sodium. Sometimes calcium carbonate is among the impurities. As a rule, about one fourth of acid phosphate consists of phosphates (chiefly monocalcium phosphate), while three fourths consist of calcium sulfate and impurities.

The readily available phosphorus in acid phosphate has a market value of about I 2 cents a pound. This includes the phosphorus soluble in water and also that dissolved by ammonium citrate solution, which is sometimes called the "citrate-soluble" or the " reverted." The term reverted is properly applied to dicalcium 
phosphate formed from monocalcium phosphate by reaction with tricalcium phosphate:

$$
\mathrm{CaH}_{4}\left(\mathrm{PO}_{4}\right)_{2}+\mathrm{Ca}_{3}\left(\mathrm{PO}_{4}\right)_{2}={ }_{2} \mathrm{Ca}_{2} \mathrm{H}_{2}\left(\mathrm{PO}_{4}\right)_{2} \text {. }
$$

On long standing, this sort of reaction evidently takes place if an excess of tricalcium phosphate was left in the original product, and consequently the percentage of water-soluble phosphorus may be greater in fresh acid phosphate than in that which has been stored for some time, the dicalcium phosphate, or " reverted," being soluble in citrate solution, but not in water.

If the raw phosphate rock contains I 2 per cent of phosphorus, the acid phosphate made from it will contain about 6 per cent of phosphorus. The most common grade is known as 14 per cent acid phosphate, which the fertilizer agent would say means that the acid phosphate contains I 4 per cent of " phosphoric acid," by which, however, is meant not 14 per cent of true phosphoric acid, $\mathrm{H}_{3} \mathrm{PO}_{4}$, but $\mathrm{x}_{4}$ per cent of phosphorus pentoxid, $\mathrm{P}_{2} \mathrm{O}_{5}$, which is equivalent to 6.I per cent of the element phosphorus, corresponding to $\mathrm{x} 22$ pounds of phosphorus per ton of acid phosphate, which sells at about $\$_{15}$ a ton.

Where $25^{\circ}$ pounds of phosphorus cost $\$ 7.50$ in fine-ground natural rock phosphate, the same amount of phosphorus will usually cost $\$ 30$ in the two tons of acid phosphate. ${ }^{1}$

Double superphosphate. Double superphosphate consists chiefly of monocalcium phosphate, $\mathrm{CaH}_{4}\left(\mathrm{PO}_{4}\right)_{2}$, and a moderate amount of impurities. It is richer in phosphorus than any other fertilizer material. It is made (I) by treating low-grade phosphate rock with an excess of sulfuric acid, by which true liquid phosphoric acid is liberated. This is leached out of the mass, and (2) this true phosphoric acid is applied to high-grade phosphate rock, thus:

$$
\begin{aligned}
& \text { (I) } \mathrm{Ca}_{3}\left(\mathrm{PO}_{4}\right)_{2}+3 \mathrm{H}_{2} \mathrm{SO}_{4}=\mathrm{H}_{6}\left(\mathrm{PO}_{4}\right)_{2}+{ }_{3} \mathrm{CaSO}_{4} \text {; } \\
& \text { (2) } \mathrm{Ca}_{3}\left(\mathrm{PO}_{4}\right)_{2}+2 \mathrm{H}_{6}\left(\mathrm{PO}_{4}\right)_{2}={ }_{3} \mathrm{CaH}_{4}\left(\mathrm{PO}_{4}\right)_{2} \text {. }
\end{aligned}
$$

${ }^{1}$ Both acidulated bone and acid phosphate are sometimes called superphosphate; and in England "super" (meaning literally over or higher) is the common term for acid phosphate, somewhat as photographers use the term "hypo" (meaning under or lower) for sodium thiosulfate, formerly incorrectly called hyposulfite of soda. 
By this means the impurities of the low-grade phosphate and the calcium sulfate formed in the first reaction are left behind, and the monocalcium phosphate is then formed as a condensation product, with only the impurities of the high-grade phosphate and a small amount of calcium sulfate made from the excess of sulfuric acid which is carried with the phosphoric acid. In practice, double superphosphate is made to contain about 20 per cent of the element phosphorus, corresponding to about 75 per cent of monocalcium phosphate, and to 400 pounds of phosphorus per ton of product. This material is not made in the United States, but is produced to a considerable extent in Germany. It has advantage over ordinary acid phosphate in long-distance shipping, and it also permits the use of phosphate rock containing more iron and aluminum than can be used for the manufacture of common acid phosphate on account of the deliquescent properties of the products.

Slag phosphate. Basic slag phosphate results as a by-product when pig iron, made from phosphatic iron ores and thus containing considerable phosphorus, is converted into steel by the basic process in which an excess of lime is used. By proper methods a slag is produced which may contain about 8 per cent of phosphorus, or 160 pounds per ton. It is commonly held that the phosphorus is in the form of tetracalcium phosphate, $\mathrm{Ca}_{4} \mathrm{O}\left(\mathrm{PO}_{4}\right)_{2}$, whose structural composition might be represented thus:

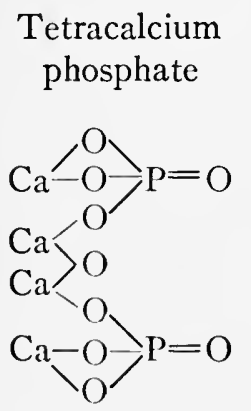

Tricalcium

phosphate

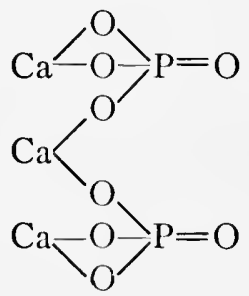

Phosphoric acid

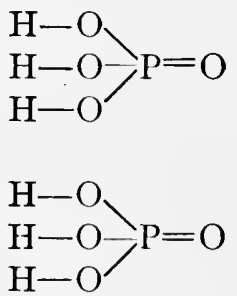

Whether these formulas express the relationship of tetracalcium phosphate to tricalcium phosphate and to phosphoric acid, is not fully known, and it is even questioned if the phosphorus in basic 
slag exists in the form of tetracalcium phosphate. However, an excess of calcium oxid is present, and the phosphorus in slag under suitable conditions can be made available. No doubt, the lime produces some benefit for its own sake on certain classes of soil. In value, the phosphorus is rated at ro cents a pound, the same as in bone meal.

The iron ores from the Lake Superior region, which are used in the Illinois Steel Works, contain too small an amount of phosphorus to give value to the slag produced, but some phosphorus-bearing ores are used in Pennsylvania, and slag phosphate has been produced and used in that state to a limited extent for several years.

In Europe very large quantities of slag phosphate are produced and sold under the name of Thomas slag, although Jacob Reese, who for many years controlled the production in Pennsylvania, claimed priority over the European discovery.

The conditions under which the different forms of phosphorus should be used are discussed in the following pages. 


\section{CHAPTER XIV}

\section{ORGANIC MATTER AND NITROGEN}

THE organic matter of the soil may be considered in two classes, active and inactive, although no very sharp line can be drawn between them.

The most active organic matter consists of such substances as decaying plant roots and crop residues, green manures and animal manures, incorporated with the soil. 'These products decay rapidly in the soil and in the process of decomposition liberate not only plant food which they contain, including nitrogen, phosphorus, and potassium, but they also set free other decomposition products, such as carbonic acid, nitric acid, and organic acids, which have power to dissolve more or less additional plant food from the mineral part of the soil.

The inactive, or less active, organic matter consists of the more resistant organic residue that remains after several years and that decomposes very slowly. If present in large quantity, its gradual decomposition may still supply sufficient nitrogen to meet the nceds of good crops, although its power to liberate mineral plant food from the soil may not provide adequate supplies of available phosphorus, potassium, etc.

Thus, we find that one soil may at the same time be richer in organic matter and less productive than another soil, even though the two soils are alike in other respects. Three tons per acre of fresh, actively decaying organic matter may be more effective for a year or two than thirty tons of old and less active humus.

The term humus is not synonymous with organic matter. Humus includes only that part of the organic matter that has passed the most active stage of decomposition and completely lost the physical structure of the materials from which it is made, and has thus become, as a rule, thoroughly incorporated with the soil mass. 
It is the decay of organic matter, and not the mere presence of it, that gives "life" to the soil. Partially decayed peat produces no such effect upon the productive power of the soil as follows the use of farm manure or clover residues.

\section{Decay of Organic Matter}

A matter that has led to much confusion and misunderstanding is the common talk of " available plant food," as distinct from the total supply, whereas there is no line of distinction. The question as to the amount of available plant food contained in the soil at any given time is very insignificant in comparison with the question how to make plant food available. The plant food removed from the soil by a crop is not a vailable when the crop is planted, but it must be made a vailable during the growing season.

Plant food is made available by chemical and biochemical processes, of which ammonification and nitrification are among those best understood.

For the exact information we now have regarding these processes, we are indebted to the researches of Pasteur and Schlösing and Müntz of France, Winogradsky of Russia, Warington of England, and others. The nitrogen in the soil is almost entirely in organic compounds; that is, the nitrogen is united or combined with other elements, notably carbon, hydrogen, and oxygen, with small amounts of phosphorus, and sulfur, in the form of partially decayed organic matter; but plants cannot use these insoluble organic compounds of nitrogen occurring in the soil.

There are at least three different kinds of microscopic organisms (called bacteria), and also three different steps, or stages, involved in the process of nitrification, the nitrogen being changed from the organic compounds, first into the ammonia ${ }^{1}$ form $\left(\mathrm{NH}_{3}\right)$, second into the nitrite form, as $\mathrm{Ca}\left(\mathrm{NO}_{2}\right)_{2}$, and third, into the nitrate form, as $\mathrm{Ca}\left(\mathrm{NO}_{3}\right)_{2}$. During the process the nitrogen is separated from the carbon and other elements composing the insoluble organic matter, and is united or combined with oxygen and some alkaline element to form the soluble nitrate, such as calcium nitrate,

${ }^{1}$ Technically this first step (ammonification) is preliminary to, and not a part of, nitrification proper. 
which is one of the most suitable compounds of nitrogen for plant food.

This, then, is the general process of nitrification (including ammonification and nitrification proper), in which the ammonifying and nitrifying bacteria transform or transfer the nitrogen from insoluble organic compounds into soluble nitrate compounds in which it may serve as available plant food. Each specific class of bacteria performs a distinct function. Thus, the ammonifying bacteria serve only to convert organic nitrogen into ammonia nitrogen; the nitrite bacteria (also called nitrous bacteria) serve only to convert ammonia nitrogen from ammonia or ammonium salts into nitrous acid $\left(\mathrm{HNO}_{2}\right)$ or nitrites; and the nitrate bacteria (also called nitric bacteria) serve only to convert nitrous acid or nitrites into nitric acid $\left(\mathrm{HNO}_{3}\right)$ or nitrates.

While we may assume that the nitrogen passes through the forms of nitrous and nitric acid, those acids are never present in detectable quantities, the presence of a salifiable base being essential for the progress of these biochemical reactions. The final product is always a nitrate, except under artificial conditions, when nitrites may be obtained in quantity in the absence of the nitrate bacteria. Under the natural conditions existing in normal soils, even nitrites can scarcely be detected, because of the quickness with which they are converted into nitrates.

The nitrate that is formed may be calcium nitrate, magnesium nitrate, potassium nitrate, sodium nitrate, or even ammonium nitrate, depending upon which base is present in the most suitable form. In the nitrification of ammonium carbonate, $\left(\mathrm{NH}_{4}\right)_{2} \mathrm{CO}_{3}$, the reaction will stop when only one half completed if no other base is present, the final product being ammonium nitrate, $\mathrm{NH}_{4} \mathrm{NO}_{3}$.

$$
\begin{aligned}
\left(\mathrm{NH}_{4}\right)_{2} \mathrm{CO}_{3}+3 \mathrm{O} & =\mathrm{NH}_{4} \mathrm{NO}_{2}+\mathrm{CO}_{2}+2 \mathrm{H}_{2} \mathrm{O} . \\
\mathrm{NH}_{4} \mathrm{NO}_{2}+\mathrm{O} & =\mathrm{NH}_{4} \mathrm{NO}_{3} .
\end{aligned}
$$

To continue the process beyond this point would require the formation of appreciable amounts of free nitric acid, of which the bacteria seem incapable. In the production of lactic acid in the souring of milk, the lactic bacteria are capable of continuing the 
process until the solution contains about .7 per cent of free lactic acid, beyond which they become inactive; but, if the free lactic acid is neutralized by the addition of some base, the bacteria again become active.

In the process of nitrification there is required, not only the presence of calcium or some other alkaline element or group, in suitable form (as in carbonates), but also a good supply of the element oxygen; for calcium nitrate contains but one atom of calcium (Ca) with two atoms of nitrogen $(\mathrm{N})_{2}$, and six atoms of oxygen $\left(\mathrm{O}_{3}\right)_{2}$, in each molecule, as indicated in the formula $\mathrm{Ca}\left(\mathrm{NO}_{3}\right)_{2}$. Magnesium nitrate, $\mathrm{Mg}\left(\mathrm{NO}_{3}\right)_{2}$, potassium nitrate, $\mathrm{KNO}_{3}$, and all other nitrates also contain oxygen. The supply of oxygen for the formation of nitrates in the process of nitrification comes from the air, and, aside from the killing of weeds, one of the most important effects of cultivation, or tillage, is that it permits the air more freely to enter the soil, and thus promotes nitrification.

Another absolute requirement for the process of nitrification is the presence of phosphorus and probably of other mineral food supplies necessary to the growth and multiplication of the bacteria themselves. It is known that without phosphorus there can be neither growth nor life. These minute forms of plant life do not utilize the carbon dioxid of the air by means of the sun's energy; but they derive energy from the oxidation of the nitrogen compounds, and by means of this energy they are able even to decompose carbonates, if necessary, and to derive their supply of carbon from this source for the formation of their own organic bodies; but for all of this the mineral plant food must be supplied. (As a rule, the carbohydrates furnish the necessary carbon for bacterial growth.)

An important consideration in this general connection is the fact that in the conversion of sufficient organic nitrogen into nitrate nitrogen for a hundred-bushel crop of corn, the nitric acid, if formed, would be alone sufficient to convert seven times as much insoluble tricalcium phosphate into soluble monocalcium phosphate as would be required to supply the phosphorus for the same crop. While this specific reaction could not occur in quantity, because the acid monocalcium phosphate would prevent nitrification, the suggestion is of interest in that it affords a quantitative comparison 
between one of the decomposition products of organic matter and the process of making insoluble plant food available, thus:

$$
\mathrm{Ca}_{3}\left(\mathrm{PO}_{4}\right)_{2}+{ }_{4} \mathrm{HNO}_{3}=\mathrm{CaH}_{4}\left(\mathrm{PO}_{4}\right)_{2}+{ }_{2} \mathrm{Ca}\left(\mathrm{NO}_{3}\right)_{2} .
$$

In accordance with this equation, $5^{6}$ parts of nitrogen are equivalent to 62 parts of phosphorus in the reaction; whereas, when measured by the requirements of the corn crop, $5^{6}$ parts of nitrogen are equivalent to less than 9 parts of phosphorus, or only one seventh of 62 .

Even though the nitric acid may be at once neutralized by reaction with calcium carbonate, it is known that the liberated carbonic acid exerts an influence in the conversion of insoluble phosphates and potassium salts into soluble compounds.

Of course, the quantity of organic acids and carbonic acid otherwise produced in the decay of organic matter is many times as great as that of nitric acid. (See also page 633.)

Recent investigations of Hall, Miller, and Gimingham (Proceedings Royal Society, I908) seem to prove that nitrification proper does not occur in acid soils, and that crops growing on such soils must take up their supplies of nitrogen in the form of ammonium salts, formed in the process of ammonification. It is shown, however, that there may be a small amount of nitrification in soils that are, on the whole, acid, but which contain here and there particles of calcium carbonate within whose limited sphere of influence the soil is alkaline and nitrification takes place.

Under certain abnormal conditions, as under a slime or scum from sewage which prevents access of air, some denitrification may occur. In this process the denitrifying bacteria may even decompose nitrates in order to secure oxygen, and the element nitrogen may be liberated as free gas. Such loss may readily occur in the decay of manure in piles, but in normal soils there is practically no denitrification.

\section{Methods of Supplying Organic Matter}

There are three general methods of supplying organic matter to the soil in practical agriculture: 
(I) By green manures and crop residues.

(2) By accumulations in pasturing.

(3) By applications of farm manure.

So much has been said and written regarding the value of farm manure that it is common talk that the manurial value of the food is almost wholly recovered in the manure; and there is even a vague notion in the minds of some that the manure is worth more for soil improvement than is the food from which the manure is made; while it is very generally believed that pasturing land increases the fertility of the soil.

The fact is that the most important and least appreciated method of maintaining or increasing the supply of organic matter in the soil is by the use of green manures and crop residues. This is best understood by considering the digestibility of common food stuffs and by applying mathematics to the data (see Table 29).

\section{Table 29. Average Digestibility of Some Common Food Stuffs}

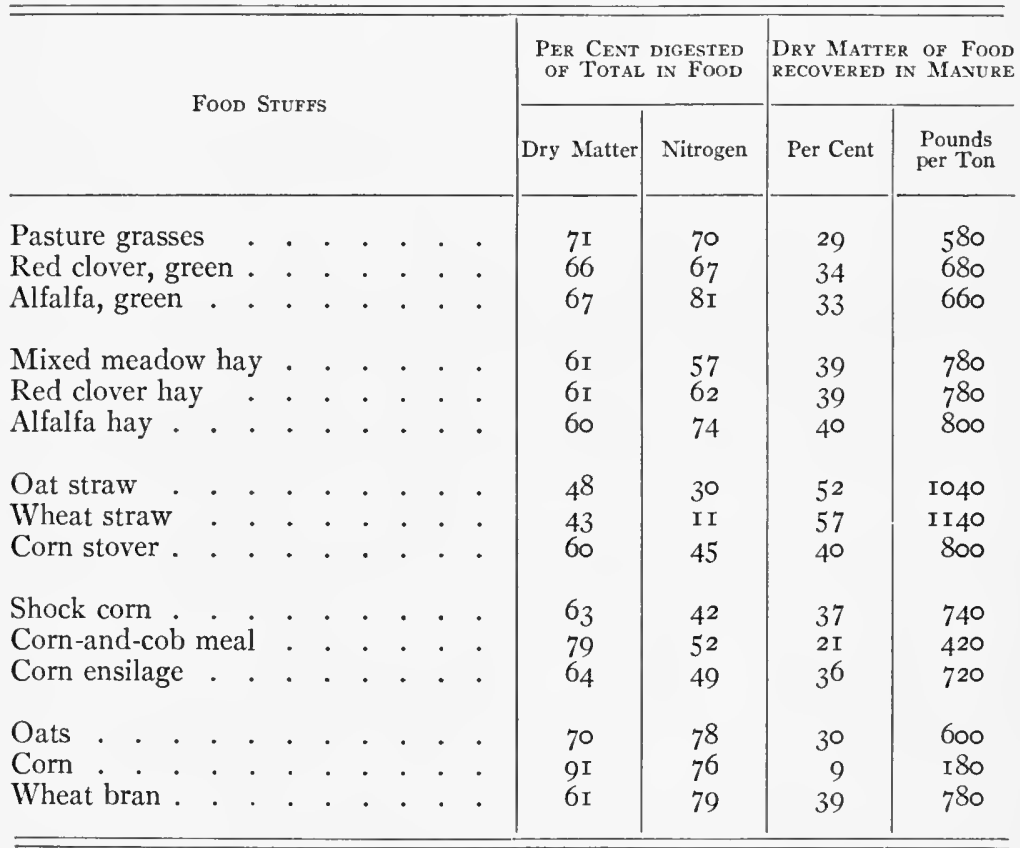


Thus, when pasture grasses containing one ton of dry matter are caten, only 580 pounds of the dry matter consumed will be returned to the land in the droppings; and the manure made from one ton of dry clover hay contains only 780 pounds of dry matter instead of the 2000 pounds taken from the field. In other words, a ton of clover plowed under will add nearly three times as much organic matter to the soil as can possibly be recovered in the manure if the clover is fed. In the case of oat straw, about one half is digested and one half recovered in the manure, while only one tenth of the dry matter of corn is found in the manure.

It must be kept in mind, furthermore, that to return even these proportions of organic matter to the land requires that the manure shall be applied to the soil before losses occur by fermentation and decay.

The Maryland Experiment Station allowed 8o tons of manure to lie in an uncovered pile exposed to the weather for one year, during which time the amount was reduced to 27 tons.

Professor Shutt, Chief Chemist for the Experiment Stations of the Dominion of Canada, exposed two tons of manure containing I 938 pounds of organic matter, from April 29 to August 29, four months, during which time the organic matter was reduced by fermentation and decay to 655 pounds. During the same time the nitrogen was reduced from 48 . x pounds to 27.7 pounds.

In ordinary farm practice more or less loss of organic matter is almost certain to occur unless the manure is applied to the soil within a day or two after it is produced.

Because the nitrogen of the soil is contained in the organic matter and must be applied in that form in general farming, and because the figures are available, the per cent of nitrogen digested is shown in Table 29 for the common food stuffs named. The fact that 62 per cent of the nitrogen in red clover hay is digested means that only $3^{8}$ per cent of the nitrogen in the food consumed will be recovered in the solid excrement. If the food ration consists of equal parts of corn and clover hay, the solid excrement will contain 3I per cent, or less than one third, of the nitrogen in the food. Of the remaining 69 per cent, about one third will be retained by the animal (or secreted in milk) and two thirds excreted in the liquid manure, as a general average in live-stock farming for animal 
products. Mature work animals excrete practically as much nitrogen as they consume. These facts certainly emphasize the importance of saving all liquid manure and the danger of loss of nitrogen in that form.

In a series of digestion experiments (not yet published) conducted by the Illinois Experiment Station, with six milk cows, during a period of 15 days, the a verage daily consumption of food per cow was 19.67 pounds of dry matter contained in a ration of clover hay, corn silage, and mixed concentrates, including corn, oats, wheat bran, gluten meal, and linseed meal. The total dry matter recovered in the dung and urine amounted to 8. I I pounds, or 4 I.23 per cent. (With heavy feeding the digestibility is appreciably less than with lighter feeding.)

Of the nitrogen consumed, $80.3^{2}$ per cent was recovered in the dung and urine, and $20 . \mathrm{I} 2$ per cent in the milk, indicating a slight loss from the animal bodies.

Of the phosphorus consumed, 73.34 per cent was recovered in the manures and 22.28 per cent in the milk, only 4.38 per cent being retained by the animals.

Of the potassium taken in the food, 76.02 per cent was recovered in the manures and I3.69 per cent in the milk, the balance, I0.29 per cent, probably having been largely excreted through the skin. The experiments were conducted the last half of June. (Considerable amounts of commercial potassium salts were once regularly obtained from the washing of sheep wool.) Table 30 shows these results in more detail for ready comparison:

Table 3o. Plant Food recovered from Food consumed by Milk Cows Illinois Experiments: Average of 90 Days

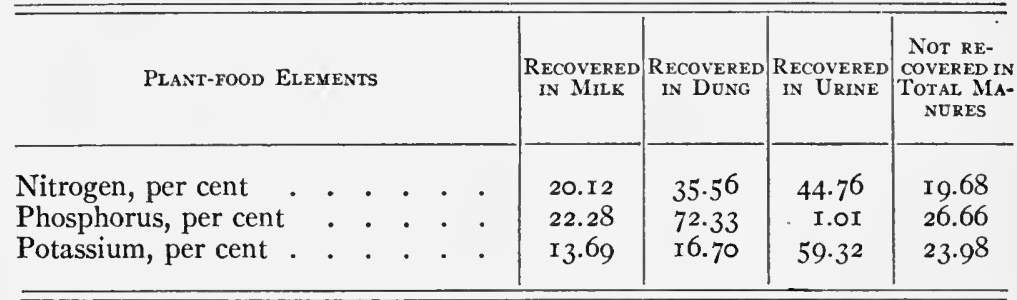

As an average of the best three cows, the plant food not recovered in the total solid and liquid manures was 25.03 per cent of the 
nitrogen, 28.07 per cent of the phosphorus, and 28.45 per cent of the potassium, of the food consumed, the differences being practically accounted for by the larger amounts of milk produced by the best cows. However, the poorest cow of the six, in milk production, digested, during the three successive 5-day periods, 47.18 per cent, 44.77 per cent, and 52.54 per cent, respectively, of the total phosphorus consumed in the food; or, as an average of the I 5 -day period, only 52.94 per cent of the phosphorus taken in the food was recovered in the dung and urine from this cow.

The Pennsylvania Experiment Station (Annual Report for I899I900, page 32I) reports digestion experiments with two milk cows during a period of 50 days, with the results shown in Table $3 \mathrm{I}$. The rations fed were three fifths mixed clover and timothy hay, and two fifths concentrates, including corn meal, buckwheat middlings, cotton-seed meal, and linseed meal.

Table 3i. Plant Food recovered from Food consumed by MIL.K Cows

Per Cow for 50 Days: Average for 2 Cows: Pennsylvania Experiments

\begin{tabular}{|c|c|c|c|c|c|}
\hline Plant-food Elements & $\begin{array}{l}\text { Consumed } \\
\text { IN } 50 \text { DaYS }\end{array}$ & $\begin{array}{l}\text { ReCovered } \\
\text { IN MILK }\end{array}$ & $\begin{array}{l}\text { ReCovered } \\
\text { IN DUNG }\end{array}$ & $\begin{array}{l}\text { RECOVERED } \\
\text { IN URINE }\end{array}$ & $\begin{array}{l}\text { NOT RECOV- } \\
\text { ERED IN } \\
\text { TOTAL } \\
\text { MANURES }\end{array}$ \\
\hline Nitrogen, pounds . & 67.96 & I I.39 & 21.46 & 36.07 & 10.43 \\
\hline Phosphorus, pounds & 9.73 & 2.06 & 6.75 & .13 & 2.85 \\
\hline Potassium, pounds & 37.68 & $3 \cdot 7^{6}$ & 5.93 & 28.38 & $3 \cdot 37$ \\
\hline Nitrogen, per cent . & 100 & I6. 76 & $31.5^{8}$ & 53.06 & $15 \cdot 3^{6}$ \\
\hline Phosphorus, per cent & 100 & 2 I.I 7 & 69.37 & I. 34 & 29.29 \\
\hline Potassium, per cent & 100 & $9 \cdot 98$ & 15.74 & $75 \cdot 3^{2}$ & 8.94 \\
\hline
\end{tabular}

In the Pennsylvania experiments both the nitrogen and potassium are slightly more than accounted for, but 8. I 2 per cent of the phosphorus in the food consumed was retained by the animals, probably in part for the formation of bones in unborn calves.

As an average of both the Pennsylvania and Illinois experiments, only one third (exactly 33.57 per cent) of the nitrogen consumed was recovered in the dung, and nearly one half (48.9I per cent) was excreted in the urine. These facts are worth remembering, and also that 28 per cent of the phosphorus consumed was not recovered in the total manurial excrements. 
Pennsylvania Bulletin 63 reports an experiment covering two months, with four steers, two fed on a cement floor with the manure kept tramped under their feet, and two on an earth floor from which the manure was piled into an adjoining stall and kept under cover. If we assume no loss from the litter used, the following percentages were recovered from the food consumed:

Percentages reconered of Plant Food in Feed

\begin{tabular}{c|c|c|c}
\hline \hline Method of keeping Manure & Nitroges & Phosphorus & Potassium \\
\hline On cement floor, tramped . . & 84.8 & $8 \mathrm{r} .3$ & $9 \mathrm{r} .5$ \\
On earth floor, piled . . . & 54.0 & 69.0 & $7 \mathrm{r} .0$ \\
\hline Average per cent recovered. & 69.40 & $75 . x_{5}$ & $8 \mathrm{r} .25$ \\
\hline
\end{tabular}

Of the total dry matter used for feed and bedding, 40.35 and 3 I.03, or, as an average, 35.69 per cent was recovered in the manure.

In Table 32 are given data (in part estimated) from an experiment by the Ohio Station (Bulletin $\mathrm{I}_{3}$ ) in which 28 steers were fed on a cement floor from December I, I904, to June I, I905, a period of six months, or 182 days, during which time the average weight of the steers increased from 872 to I 230 pounds.

At best, these results can be considered only as approximations, except as to the composition of the manure and the phosphorus added in the raw rock, but they are of interest and of some value as indicating what can be accomplished under the conditions.

The amounts of feed and bedding used were accurately weighed, but their plant-food content was computed from accepted a verages from each material. "The steers were turned out of the stable once a day to get water, and were allowed to run in the yards from one to two or three hours, consequently some manure was left in the yards." One would assume from this that one tenth or more of the excrements were voided in the yards.

An experiment with roo sheep (averaging 84 pounds each) for a feeding period of I 2 days was conducted by the Ohio Station, in which more definite data were secured. Of the feed, 26,936 pounds consisted of hays which were analyzed; while accepted averages were used only for the standard concentrates, including 20,057 pounds of corn, 905 pounds of cotton-seed meal; and 905 pounds 
Table 32. Record of Six Months' Feeding of 28 Steers on CEMENT Floor

Ohio Experiment Station

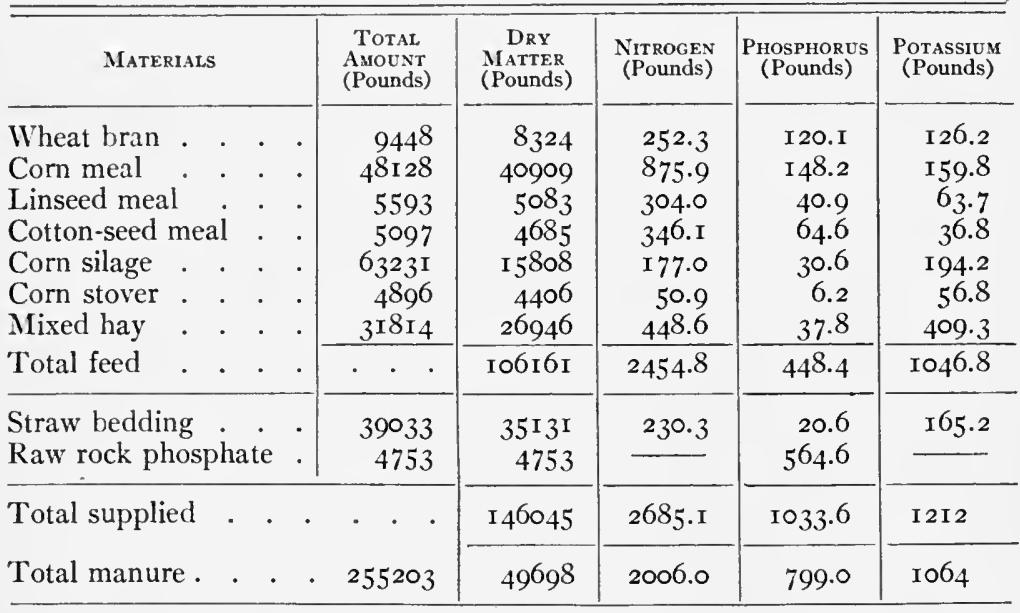

Percentages Recovered

From total supplied

With phosphate excluded Corrected for loss in yards
34.0

31.8

$35 \cdot 3$

74.7
74.7
83.0

87.8

87.8

97.6

of linseed meal; and for 3020 pounds of oat straw used for bedding. It is understood that the sheep were kept confined in the stables during the entire time.

Eight different analyses were made of the manure, and the Ohio Station computes that, of the total plant food contained in the feed and bedding, 64 per cent of the nitrogen, 79 per cent of the phosphorus, and 97 per cent of the potassium, were recovered in the manure.

Wood, of the University of Cambridge, England, reports an experiment with four heifers to determine losses in making and storing farm manure (Journal of Agricultural Science, April, I907).

The experimental feeding began on January 3 I, rgo6, and ended on April 25, 1906, a period of 84 days. During this time two of the animals consumed 13,720 pounds of mangels (containing $\mathrm{I} 784$ 
pounds of dry matter), II 76 pounds of hay, and used up r963 pounds of straw as food and litter. The other two animals in an adjoining stall consumed exactly the same amounts of mangels and hay, Ioo pounds less straw, and, in addition, 672 pounds of oil cake made from hulled cotton seed.

The stalls in which the animals were housed during the experiment were bricked up to the highest level reached by the accumulated manure. The floors were not cemented, but were made of clay which was well rammed, and through which, according to Wood's statement, " there could be little leakage of soluble constituents."

The manure was kept tramped under the feet of the animals, sampled for analysis at the end of the feeding period without disturbing the mass, then left in the compact condition for six months (till November 6, I906), when it was sampled and weighed (8075 pounds from lot I and 8106 from lot 2) and applied to the soil. Following are the essential results:

Lot I. (CAKe Not Fed)

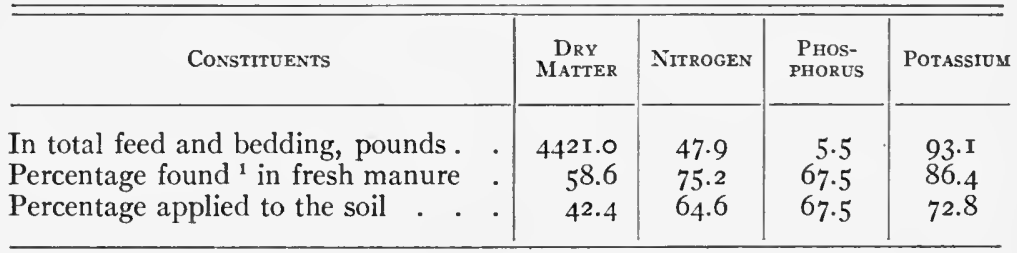

LOT 2. (CAKE FED)

\begin{tabular}{ll|r|r|r|r}
\hline In total feed and bedding, pounds . . & 4942.0 & 90.3 & I 4.8 & I05.0 \\
Percentage found 1 in fresh manure &. & 60.0 & 78.5 & 69.3 & - \\
Percentage applied to the soil . . . & $4 \mathrm{I} .6$ & $5 \mathrm{I} .6$ & 69.3 & $7 \mathrm{I.I}$ \\
\hline
\end{tabular}

${ }^{1}$ Assuming no loss of phosphorus during storage.

Wood computes that the following percentages from the oil cake fed were recovered and applied to the soil:

Dry matter . . . 29 per cent.

Nitrogen . . . . 37 per cent.

Phosphorus . . . 70 per cent.

Potassium . . . $5^{2}$ per cent. 
As a general average for dairy farming, cattle feeding, and sheep feeding, it is shown that practically one third of the organic matter, three fourths of the nitrogen, and three fourths of the phosphorus contained in the feed and bedding are recovered in the total manures. Nearly all of the potassium may be recovered except that sold in milk. (Some potassium may be excreted through the skin, especially in hot weather, but even this is washed off in the pastures by summer rains.)

Emmet and Grindley have reported the following suggestive data from digestion experiments with swine (Journal American Chemical Society (1909), 31, 577):

Coefficients of Digestibility of the Constituents in the Feeds Consumed

Per Cent Digested

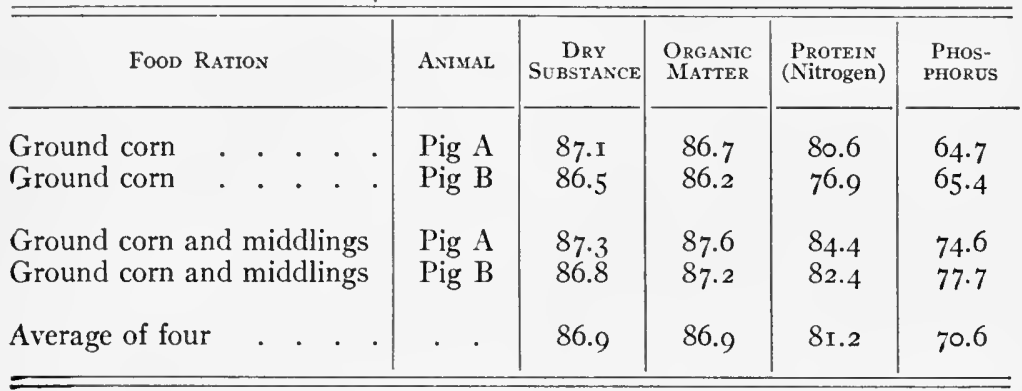

It is common knowledge among farmers that swine fed largely on grain produce but little solid manure; and in these experiments only about I 3 per cent of the organic matter, 20 per cent of the nitrogen, and 30 per cent of the phosphorus were recovered in the solid excrement. However, the existing data are not sufficient to justify the adoption of these determinations as representing the a verage digestibility by swine of the phosphorus contained in the grain rations. That the normal coefficient is high, is evidenced by the fact that, unlike most animals, swine normally excrete very appreciable amounts of phosphorus in the urine.

The production, composition, care, and value of farm manure are discussed in a later chapter. 


\section{The Fixation of Free Nitrogen}

As already stated, the nitrogen naturally in the soil is contained essentially in the organic matter. Any process which tends to decompose or destroy this organic matter, such as nitrification or other forms of oxidation, will also tend to reduce the total stock of nitrogen in the soil, whether removed by cropping or lost by leaching. Because of this fact, the matter of restoring nitrogen to the soil becomes of very great importance. Of course, a part of the nitrogen removed in crops may be returned in the manure produced on the farm; and nitrogen may also be bought in the markets in such forms as dried blood (I 4 per cent), sodium nitrate (I $5 \frac{1}{2}$ per cent), and ammonium sulfate ( 20 per cent); but when we bear in mind that such commercial nitrogen costs from ${ }_{5} 5$ to 20 cents a pound, and that one bushel of corn contains about one pound of nitrogen, it will be seen at once that the purchase of nitrogen cannot be considered practicable in general farming, although in market gardening, and in some other kinds of intensive agriculture, commercial nitrogen can often be used with very marked profit.

Considering all of these facts, and the additional facts that there are about seventy-five million pounds of atmospheric nitrogen resting upon every acre of land, and that it is possible to obtain unlimited quantities of nitrogen from the air for the use of farm crops, and at small cost, the inevitable conclusion is, that the inexhaustible supply of nitrogen in the air is the store from which we must draw to maintain a sufficient amount of this element in the soil for the most profitable crop yields.

It is often stated that legume plants, such as clover, have power to obtain free nitrogen from the air. This is not strictly true. Red clover, for example, has no power in itself to get nitrogen from the air. It is true, however, that certain microscopic organisms ${ }^{1}$ which commonly live in tubercles upon the roots of the clover plant do have the power to take up free nitrogen and cause it to unite with other elements to form compounds suitable for plant food.

${ }^{1}$ Among the scientists who were prominent in making these discoveries regarding the action of bacteria in the fixation of free nitrogen were Hellriegel, Willfarth, and Nobbe in Germany, Atwater in America, Lawes and Gilbert in England, and Boussingault and Ville in France. 
The clover plant then draws upon this combined nitrogen in the root tubercles, and makes use of it in its own growth, both in the tops and in the roots of the plant.

These nitrogen-fixing bacteria live in tubercles upon the roots of various legume plants, such as red clover, white clover, alfalfa, sweet clover, cowpeas, soy beans, retch, field peas, garden peas, field and garden beans, etc. The tubercles vary in size from smaller than a pinhead to larger than a pea, varying somewhat with the different kinds of plants, being especially small upon some of the clovers, and large upon cowpeas and soy beans. The tubercles are, of course, easily seen with the eye, but the tubercle is only the home of the bacteria, somewhat as the ball upon the willow twig is the home of the insects within. The bacteria themselves are far too small to be seen with the unaided eye, although they can be seen by means of the powerful microscope. Several million bacteria may inhabit a single tubercle. It is not necessary to see the bacteria, because if we find the tubercles upon the roots of the plant, we know that the bacteria are present within, otherwise the tubercle would not be formed. ${ }^{1}$

It has also been demonstrated that, as a rule, there are different modifications of nitrogen-fixing bacteria for markedly different species of legume plants. Thus, we have one kind of bacteria for red clover, another for cowpeas, another for soy beans, and still a different kind for alfalfa.

There are some noteworthy exceptions to this rule. Thus, the bacteria of alfalfa (Medicago satiz'a) and of common sweet clover (Mellilotus alba) are interchangeable, and apparently identical, as are also the bacteria of cowpeas (Vigna unguiculata) and the widely distributed native partridge pea (Cassia chamaecrista), relationships of much importance in connection with soil inoculation for alfalfa and cowpeas. There is evidence that, by a comparatively long process of breeding, or evolution, the bacteria which naturally live upon one kind of legume may gradually develop the power to live upon a distinctly different legume to which they were not at first adapted. This change which has been brought about

1 A few plants form starchy nonbacterial tubers, which may be of large size, like the potato and artichoke, or of smaller size, as on the rootstalks of nut grass (Cyperus rotunda). 
with some certainty in artificial cultures, and which very possibly occurs to some extent in farm manure from legume hay, may furnish bacteria with feeble action for a time, but ultimately, no doubt, with full power. Of course, this process of forcing bacteria to live upon a legume to which they are not naturally adapted has little or no practical value, because it is unnecessary, if there is a species of bacteria which naturally live upon the same legume. On the other hand, if, by any such process of breeding, or evolution, a species of nitrogen-fixing bacteria could be developed which could live on a nonleguminous plant, as corn, for example, it would be of incalculable value. As yet, the efforts of bacteriologists, working on this problem, have given only negative results, so far as known to the author.

Attention is called to the fact that there are numerous instances where two different kinds of plants live together in intimate partnership relation. If only one of the two plants receives benefit from this relationship or association, then the plant receiving the benefit is called a parasite. Thus the mistletoe is a parasite upon the elm or gum or other tree on which it lives. The mistletoe draws its nourishment from the tree. The tree is injured rather than benefited by the mistletoe. Dodder is also a parasitic plant, living upon other plants, except during the early part of its growth. Ticks and lice are common examples of animal parasites, living upon other animals.

In some cases a relationship exists which is not parasitic, but symbiotic. The term symbiosis, which is commonly used by biologists to define this relationship, means living together in mutual helpfulness. The association of bees and flowers may serve to illustrate this mutual helpfulness, although this is not an example of intimate symbiosis. Thus, the bees obtain their food from the flowers and, in turn, the flowers, many of them, are incapable of producing seed or fruit unless the pollen is carried from the male flower to the female flower by bees or other agencies. It is well known that plant lice and ants are mutually helpful.

Likewise, the association of nitrogen-fixing bacteria and legume plants is a relationship of mutual helpfulness, and this is one of the best illustrations of what is meant by symbiosis. The legume furnishes a home for the bacteria and also furnishes in its juice or 
sap most of the nourishment upon which the bacteria live. The bacteria, on the other hand, take nitrogen from the air, contained in the pores of the soil, and cause this nitrogen to combine with other elements in suitable form for plant food, which is afterward given up to the legume for its own nourishment.

Another illustration of remarkable parasitism, if not, indeed, one of true symbiosis, is found in the common lichens living upon rocks and trees. The lichen is not a single plant, but two plants, one an alga, which lives upon the wood or stone, and the other a fungus, which lives upon the alga. Algæ also live in the free state separate from fungi, and the present opinion of botanists seems to be that when the two are associated in the form of lichens, this association is not detrimental, but rather beneficial, to the alga, as well as to the parasitic fungus. If this is true, then it is another case of true symbiosis. (It is now known that some fungi have power to feed upon atmospheric nitrogen, and probably those in lichens furnish combined nitrogen to the algæ upon which they live.)

In the symbiosis of legume plants and nitrogen-fixing bacteria we have a partnership or relationship of immeasurable value to agriculture. Here is a class of plants (legumes) that are capable of consuming or utilizing nitrogen in quantities larger than could possibly be obtained from ordinary soils for any considerable length of time. They have no power in themselves of taking nitrogen from the atmosphere, and to them the symbiotic relation with this low order of plants (the nitrogen-fixing bacteria, Pseudomonas radicicola), is especially helpful, and for the best results it is absolutely necessary.

\section{InOCulation For Nitrogen Fixation}

While it is true that nitrogen-fixing bacteria are essential to the most successful growing of legumes, it is also true that, as a very general rule, the proper bacteria for the ordinary legumes are already present in the most common soil, especially where the particular legume has been grown in the vicinity for several years, or where manure made from the legume has been applied. This applies especially to alfalfa in the alfalfa country of the West, to 
cowpeas in the cowpea country of the South, and to the clovers throughout the Central and Eastern states. Where the special legume has not been grown successfully in the vicinity; or even on fields where the legume has not been grown for many years, and where neither manuring, overflow, nor dust storms have brought the bacteria from other fields, it is worth while to consider inoculation.

The bacteria for clover, cowpea, and vetch are now very widely distributed over the United States (in part because of the partridge pea and wild vetches); but for alfalfa (except in alfalfa regions) and for soy beans, the question of inoculation should always be considered. For inoculating alfalfa, either alfalfa soil or sweet-clover soil can be used, care being taken to use only wellinfected soil, collected where the plants have been growing for several years, well provided with root tubercles.

The accumulated practical experience of the past twenty years, and the data thus far reported from many comparative experiments, combine to prove that the simplest and surest and most economical method of inoculation is by means of well-infected natural soil, collected where the plants are thrifty and free from noxious weed seeds, although the danger of carrying weed seeds or plant diseases by overflow, by wind storms, and in purchased manures and farm seeds is probably a hundred times greater than by using infected soil for inoculation. The amount of soil used varies from roo pounds to a wagon load to the acre. It may be applied broadcast with some degree of uniformity, and it should be mixed with the surface soil without delay, as by harrowing or disking, because exposure to the sunlight tends to destroy the bacteria.

Successful seed inoculation can be performed with fresh, properly prepared artificial cultures, but, as a rule, this method has proved unsatisfactory. Some years ago German promoters undertook to establish the business of selling nitrogen bacteria for seed inoculation, and more recently American promoters have widely advertised similar products, but failure is the most common report from their use.

For large seeds, such as soy beans, a very satisfactory method of inoculation, suggested by the Illinois Experiment Station, is to thoroughly moisten the seed with a ro per cent solution of glue, 
immediately sift over them sufficient dry, pulverized, infected soil to absorb all of the moisture, thus furnishing a coating of infected soil for every seed. The seed should be shoveled over a few times, then screened, and planted within a day, or spread out to dry, after which they may be kept as long as though not covered with dust. The coat of thoroughly infected soil provides a much better inoculation than is common from the use of artificial cultures, and it does not interfere with drilling the seed immediately after treatment. If this method is used for inoculating small seeds, such as alfalfa, greater care must be taken to screen them afterward to prevent clusters of seeds from remaining glued together.

If seeds are moistened, they should either be planted very soon thereafter or spread out and thoroughly dried, otherwise they are likely to mold and lose vitality. Infected soil should never be long exposed to bright sunshine, which is very destructive to all forms of bacteria.

There has been much discussion during recent years concerning the development of unusually virile bacteria, but even if it were possible to develop and maintain in the soil bacteria of greater nitrogen-fixing power, it is a question whether the discovery would have great practical value (especially after the first year), for the simple reason that bacteria multiply with such tremendous rapidity that we may soon have many times the number of bacteria that are really needed to do the work. In other words, the increase in numbers may result in just as great efficiency as would result from any increased power of the individual bacteria. One who carefully studies the formation of root tubercles on plants growing on soils in varying conditions or degrees of infection will observe that on plants sparsely infected the individual tubercles or clusters develop to enormous size, comparatively speaking; while in well-infected soils the individual tubercles are much smaller, and clusters scarcely form. It is also observed that the marked effect on the growth, color, and composition of the plant is produced even though only a half-dozen large tubercles form on the roots. It is very evident that the relationship between the bacteria and the host plant is such that if the soil is sparsely infected, so that the roots come in contact with but few bacteria, and but few tubercles are started, those few tubercles will be so enlarged, either in individuals or as 
clusters, that the multiplication and activity of the bacteria are sufficient to meet the needs of the host plant so far as nitrogen is concerned. Of course, as soon as the soil becomes well infected, the plant roots come in contact with large numbers of bacteria, and many tubercles are formed, but most of them remain small, and no large clusters are formed, because the bacteria in the large number of small tubercles are apparently capable of furnishing all the nitrogen needed by the host plant. If the other elements were provided in greater abundance, the tubercles would undoubtedly become enlarged, as much as necessary to supply the nitrogen needed to balance the supply of the other plant-food elements utilized by the plant.

\section{Nitrogen from SoIL AND Air}

Experiments or demonstrations almost without number have been performed to determine the amounts of nitrogen taken from the air by various legume plants when grown in sand cultures essentially free of combined nitrogen, but there are much less data concerning the relative amounts of nitrogen taken from the soil and from the air by legume crops grown on normal cultivated land.

There are two methods by which such information can be secured with a fair degree of satisfaction. One of these is to determine the amounts of nitrogen in infected plants and in similar plants not infected, grown on the same type of soil; and the other is to compare the total nitrogen content of a nonleguminous crop with that of a crop of infected legume plants, grown at the same time on similar soil. Though not strictly exact, these methods furnish practically correct information.

In Table 33 are shown the results of a field experiment to determine the amount of nitrogen taken from the air by alfalfa when grown on the common corn-belt prairie land (Illinois Bulletin 76).

The difference between the amount of nitrogen contained in the crop from the inoculated soil, on the one hand, and in the crop from the uninoculated soil, on the other hand, represents the amount of nitrogen secured by the bacteria. In no case will this give too much credit to the bacteria; but, if any unavoidable cross inoculation 
Table 33. Fixation of Nitrogen by Alfalfa in Field Culture Illinois Experiments on Common Prairie Land

\begin{tabular}{|c|c|c|c|c|c|c|c|c|}
\hline $\begin{array}{l}\text { Plot } \\
\text { No. }\end{array}$ & \multicolumn{4}{|c|}{ Treataent Applied } & $\begin{array}{c}\text { DRY } \\
\text { MATTER } \\
\text { IN CROPS } \\
\text { (Pounds) }\end{array}$ & $\begin{array}{c}\text { Nitrogen } \\
\text { IN DRy } \\
\text { MatTER } \\
\text { (Per Cent) }\end{array}$ & $\begin{array}{l}\text { Nitrogen } \\
\text { IN Crofs } \\
\text { (Pounds) }\end{array}$ & $\begin{array}{l}\text { Nitrogen } \\
\text { Fixed BX } \\
\text { BACteria } \\
\text { (Pounds) }\end{array}$ \\
\hline I $a$ & None . . . & . & . & . & I I 80 & I. 85 & $2 \mathrm{I} .8 \mathrm{I}$ & - \\
\hline $\mathrm{I} b$ & Bacteria . . & - & $\cdot$ & . & 2300 & 2.70 & 62.04 & 40.23 \\
\hline $2 a$ & Lime . . . & . & . & . & I 300 & 2.02 & 26.20 & - \\
\hline $2 b$ & Lime, bacteria. & & $\cdot$ & - & 2570 & 2.65 & 68.02 & 41.82 \\
\hline $3^{a}$ & Lime, phosphoru & & . & . & I 740 & 2.03 & 35.40 & 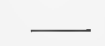 \\
\hline $3^{b}$ & Lime, phosphoru & $\mathrm{s}, \mathrm{l}$ & cteri & & 3290 & $2.7 I$ & 89.05 & 53.65 \\
\hline
\end{tabular}

occurred during the progress of the experiment, these amounts might understate the effect of the bacteria. It is very probable, however, that the increased root development, induced by removing the nitrogen limit in plant growth, would make it possible for the infected plants to secure somewhat more soil nitrogen than otherwise. (Note the effect of phosphorus in the record.) However, this, too, should perhaps be placed to the credit of the bacteria, even though it is not atmospheric nitrogen, because if such nitrogen existed in the soil solution, it would soon have been lost in drainage waters if not taken up by the enlarged root system of the growing crop.

Slightly more than one third of the total nitrogen contained in the crop from the inoculated unfertilized plot was secured from the soil, with larger proportions and larger actual amounts for the other plots.

It should be borne in mind that nitrogen is required for root growth as well as for growth above ground, and that three other crops of alfalfa were cut from these plots during the season, this cutting having been made on May 28. Evident cross inoculation occurred before a second cutting was obtained; but the data given in Table 33 indicate that plot $\mathrm{I} b$ secured about $\mathrm{I}^{2}$ pounds of nitrogen from the air during the season, the yield of air-dry hay having been $25^{6} 3$ pounds for the first cutting and 10,980 for the 
season. The value of this "gathered" nitrogen amounts to $\$ 25.80$ " per acre at $I_{5}$ cents a pound. Similarly, plot $3 b$, yielding 3625 pounds of air-dry hay in the first cutting and 17,060 per acre for the season, "gathered" 252 pounds of nitrogen from the air, worth $\$ 37.80$ at $I_{5}$ cents a pound.

The Illinois Station also conducted a series of pot cultures including I 2 inoculated pots and I 2 similar uninoculated pots, the results of which support very well the field experiments reported in Table 33. (See Illinois Bulletin 76.)

The Dominion of Canada Experiment Stations (Report for I905) as an average of twenty-one pot cultures increased the nitrogen content of the soil from .0392 per cent to .0457 by growing mammoth clover for two successive seasons, and turning it all back into the soil. 'This amounted to I 79 pounds' increase of nitrogen per acre to a depth of 9 inches, but it should be noted that the soil was extremely poor in nitrogen, containing only 784 pounds in 2 million at the beginning. In a similar plot experiment for two full seasons, two cuttings of mammoth clover and all residues being returned to the soil each season, the nitrogen content was increased from .0437 to .0580 per cent, making a gain of 175 pounds per acre to a depth of 4 inches; but only 874 pounds of nitrogen were contained in 2 million of soil at the beginning; so that in both of these experiments the results are not very different than would be secured in sand cultures. The clover was reseeded each year and grown without a nurse crop. The average annual fixation reported amounts to less than 90 pounds per acre.

In another experiment by the Illinois Station (Bulletin 94) six sets of immature cowpea plants (1o plants in each set) were carefully collected, tops and roots. Three sets were infected, the others not infected. The plants were taken from a catch crop grown after oats had been harvested, on land that had been heavily cropped with corn and oats until nitrogen had become a limiting element, especially for a catch crop grown after oats. As a general average, the infected plants contained 86 parts of nitrogen in the tops, 5 parts in the roots, and 9 parts in the tubercles, while in direct comparison the noninfected plants contained 25 parts of

1 " They not only work for nothing and board themselves, but they pay for the privilege." - DAVENPORT. 
nitrogen in the tops and 2 parts in the roots, thus indicating that 73 per cent of the nitrogen containcd in the infected plants was secured by the bacteria. The nitrogen in the dry matter of the infected plants varied from 4.09 to 4.33 per cent in the tops, from $\mathrm{I} .45$ to $\mathrm{I} .53$ per cent in the roots, and from 5.76 to 6.05 per cent in the tubcrcles; while the nitrogen in the dry matter of the noninfected plants varied from 2.32 to 2.69 per cent in the tops, and amounted to .88 per cent (in cach of three lots) in the roots. From an experiment with soy beans by the Wisconsin Station (Report for 1907), it is computed that only 14 per cent of the nitrogen contained in well-infected plants was secured from the air. The yield of dry matter was practically the same, but the infected plants were richer in nitrogen and protein, and thus of better quality. "The soy beans were grown on low, rich soil in these experiments."

The Michigan Station (Bulletin 224) reports data showing that 33 per cent of the nitrogen in soy beans was secured by the bacteria, on well-infected plants.

As an average of 20 untreated plots in one test, and of 16 plots treated with phosphorus and potassium in another test, both over a period of 25 years, in a four-year rotation of corn, oats, wheat, and hay (mixed clover and timothy), the Pennsylvania Experiment Station reports the following yields in pounds per acre per annum:

POUNDS PER ACRE

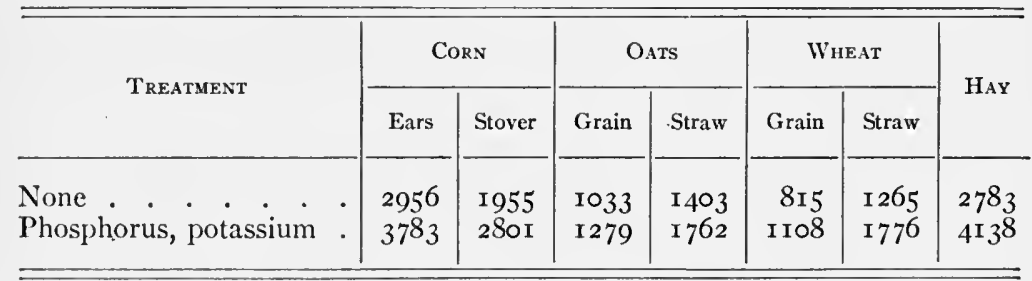

If we compute the nitrogen in the three uncultivated crops (sce Table 23), adopt the estimate that the hay was three fourths clover and one fourth timothy, and assume the soil nitrogen for the hay crops to be as indicated by a curve projected from the amounts furnished to the oats and wheat crops, then the clover must have secured from the air 66 per cent of its nitrogen when grown on 
untreated land, and 64 per cent on land treated with phosphorus and potassium, the average annual yields of nitrogen per acre being 29.I pounds for oats, 25.9 for wheat, and 50.1 for hay, on untreated land, and 36 . I 5 pounds for oats, 35.5 for wheat, and 75.5 pounds for hay, on treated land. While the calculation of 65 per cent is probably near the truth for the treated land, where the nitrogen is likely to be the limiting element in crop production, the marked reduction in yield of nitrogen between the oats and the wheat crops on the untreated land is probably not a true index of the change in available soil nitrogen, because on these plots phosphorus is certainly the limiting element for wheat, as will be seen from later discussion.

In any case, we are safe in concluding that soil which will furnish from 26 to 36 pounds of available nitrogen for a crop of oats or wheat will also furnish approximately as much for the hay crops, whether timothy or clover.

Clover and other legumes take available nitrogen from the soil in preference to the fixation of free nitrogen from the air, the latter being drawn upon only to supplement the soil's supply and thus balance the plant-food ration. In other words, the legumes have no nitrogen limit in yielding power when properly infected, but with abundance of available soil nitrogen constantly provided to fully balance other essential elements or factors, there is little or no development of root tubercles, and little or no fixation of free nitrogen occurs.

From the experimental data here presented or referred to, and from many other calculations approximating exactness, the conclusion may be drawn that on normally productive soils at least one third of the nitrogen contained in legume plants is taken from the soil, not more than two thirds being secured from the air. This proportion would apply to the nitrogen content of the roots as well as to the tops; so that, if one third of the nitrogen of the entire plant is in the roots and stubble, and two thirds in the crop harvested, the soil would neither gain nor lose in nitrogen because of the legume crop having been grown, the soil having furnished as much nitrogen to the plant as remains in the roots and stubble.

When grown on richer soils, such legume crops leave the soil poorer in nitrogen; but on poorer soils, furnishing less than the 
normal amount of available nitrogen, the growing of such legumes would enrich the soil in proportion to its poverty. In other words, to the soil that hath not, shall be given; but, from the soil that hath, shall be taken away.

When properly infected, legume plants have power to make normal growth and full development on soils absolutely devoid of nitrogen, if available mineral plant food, limestone, moisture, aëration, and all other essential factors are provided in abundance or perfection; and the statement sometimes made that the presence of soluble nitrogen is necessary, in order to give clover a start, is not correct, as witness the accompanying illustrations of clover growing in purified quartz sand void of nitrogen, with all plant food

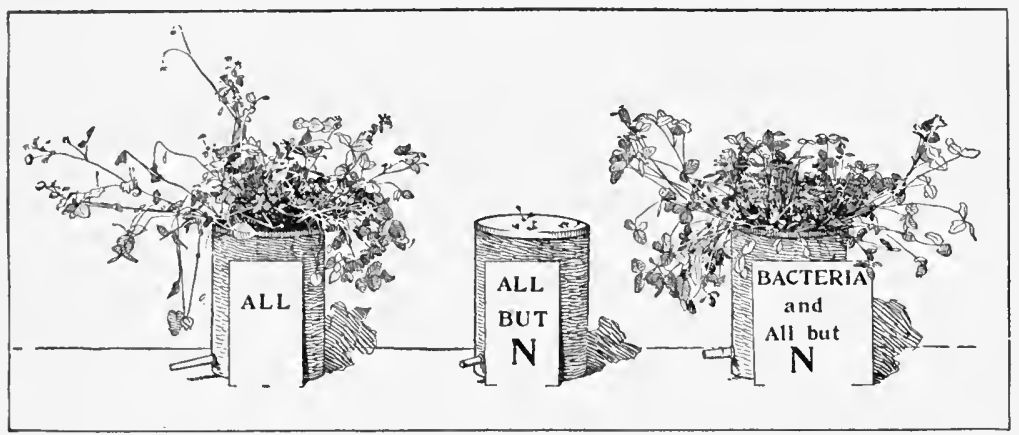

provided except nitrogen, the culture on the right marked "Bacteria" having been well inoculated with the clover bacteria; while the middle culture was started in exactly the same manner, except that it was not inoculated. In the culture on the left, all plant food was provided, including nitrogen.

\section{Nitrogen in Tops and Roots of Legumes}

From data already given it will be seen that in the study of immature cowpeas at the Illinois Station, the infected plants contained only I 4 per cent of their total nitrogen in the roots with more than half of this in the tubercles themselves, at that stage of growth. As the plants approach maturity, the tubercles decay, and only the shell, or outer coat, remains, the nitrogen being absorbed largely by the host plant, but in some part evidently by companion 
plants, as timothy or blue grass, whose roots may come in contact with the decomposing tubercles. In case of the noninfected cowpeas, only 7 per cent of the nitrogen was found in the roots at that stage of growth.

Pot-culture experiments by the Dominion of Canada Experiment Station, with plants planted May 20 and harvested August 4, showed that very poorly infected horse beans contained is per cent of their nitrogen and I8 per cent of their organic matter in the roots, while better infected plants made a larger yield and contained 25 per cent of their nitrogen and also 25 per cent of their organic matter in the roots; whereas well-infected mammoth red clover contained 40 per cent of its nitrogen and 35 per cent of its organic matter in the roots.

In a field experiment with mammoth clover, seeded with barley in the spring and harvested May 25 the following year, the Canadian Station found, per acre, I23.8 pounds of nitrogen in the tops and 48.5 pounds in the roots, to a depth of four feet, corresponding to 72 per cent in the tops and 28 per cent in the roots.

As an average of four determinations with red clover, the Connecticut Station found 28 per cent of its nitrogen, 35 per cent of its phosphorus, and $2 \mathrm{I}$ per cent of its potassium in the roots and stubble.

As an average of two determinations by the Illinois Station, the red-clover roots found in the surface soil (o to 7 inches) contained 25 per cent of the total nitrogen of the plants, while only one per cent of the total was contained in the roots in the subsurface stratum ( 7 to 20 inches). In the case of nearly mature cowpeas, I 2 per cent of the total nitrogen was found in the surface roots (o to 7 inches), and I per cent in the subsurface ( 7 to 20 inches); and the corresponding figures for nearly mature soy beans were 8 per cent and I per cent.

In Table 34 are recorded the data from an Illinois investigation of sweet clover, in which determinations were made of the total dry matter and nitrogen; (I) in the tops as they would ordinarily be cut with a mower, (2) in the surface residues, consisting of stubble and fallen leaves and old stems, (3) in the large roots in the plowed soil to a depth of seven inches, (4) in the smaller roots in the plowed soil, and (5) in the roots of the subsurface stratum from 7 
to 20 inches in depth. The investigation was made when the sweet clover was full grown and nearly mature. The crop was started the previous season, sweet clover being a biennial plant.

Table 34. Illinois Investigations of Sweet Clover (Mellilotus alba)

\begin{tabular}{|c|c|c|c|c|c|}
\hline \multirow{2}{*}{ Parts of Plant } & \multirow{2}{*}{$\underset{\text { (Inches) }}{\text { DEPTH }}$} & \multicolumn{2}{|c|}{ Dry Matter per Acre } & \multicolumn{2}{|c|}{ NTtrogen per ACre } \\
\hline & & Pounds & $\begin{array}{l}\text { Per Cent } \\
\text { of Total }\end{array}$ & Pounds & $\begin{array}{l}\text { Per Cent } \\
\text { of Total }\end{array}$ \\
\hline $\begin{array}{l}\text { Tops harvested } \\
\text { Surface residues }\end{array}$ & $\bar{L}$ & $\begin{array}{l}9029 \\
1338\end{array}$ & $\square$ & $\begin{array}{r}174 \\
23 \\
\end{array}$ & $\overline{ }$ \\
\hline Total tops & & 10367 & $8 \mathrm{I}$ & 197 & 86 \\
\hline $\begin{array}{l}\text { Large surface roots } \\
\text { Small surface roots }\end{array}$ & $\begin{array}{l}\circ \text { to } 7 \\
\circ \text { to } 7\end{array}$ & $\begin{array}{r}1568 \\
24 \mathrm{I}\end{array}$ & 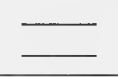 & $\begin{array}{r}17 \\
5\end{array}$ & $\square$ \\
\hline $\begin{array}{l}\text { Total surface roots } \\
\text { Subsurface roots }\end{array}$ & $\begin{array}{l}\text { o to } 7 \\
7 \text { to } 20\end{array}$ & $\begin{array}{r}1809 \\
601\end{array}$ & $\begin{array}{r}14 \\
5\end{array}$ & $\begin{array}{r}22 \\
9\end{array}$ & $\begin{array}{r}10 \\
4\end{array}$ \\
\hline Total roots . . . & $\circ$ to 20 & 2410 & I9 & $3^{I}$ & 14 \\
\hline Total tops and roots & . & I 2777 & 100 & 228 & 100 \\
\hline
\end{tabular}

It will be seen that the yield of sweet clover is very large, amounting to 6.4 tons of total dry matter, of which, however, the roots contain only I.2 tons per acre, or less than one fifth of the total. The tops of sweet clover are nearly as rich in nitrogen as fullgrown red clover ( 40 pounds per ton), but the roots contain only one seventh, or I 4 per cent, of the total nitrogen. Nearly 24 per cent of the total nitrogen was found in the roots, stubble, and surface residues (largely of the previous season's growth).

The sweet clover used in the investigation was well infected; but, in a previous experiment on the same soil (brown silt loam prairie of the early Wisconsin glaciation), it was found that the yield of sweet clover was almost exactly doubled by thorough inoculation, and the percentage of nitrogen in the infected plants was also about one half more than in the noninfected plants, showing that on this soil about two thirds of the nitrogen required for this large crop was secured from the air.

While sweet clover makes a fair quality of hay, if cut sufficiently early in its growth, and is also used for pasture with some success 
when nothing better can be had, it is not to be compared with red clover or alfalfa for either purpose, but it does give promise of great value as a green manure crop, and it seems appropriate to emphasize the fact that the 6.4 tons of dry matter furnish as much humus-forming material and as much nitrogen as would be furnished by 25 tons of average farm manure.

In the Wisconsin experiments above referred to, the infected soy beans contained in their roots about 4 per cent, 6 per cent, and 5 per cent, of their nitrogen, phosphorus, and potassium, respectively; and in the Michigan experiments the corresponding figures are about 4 per cent, 6 per cent, and 6 per cent, respectively.

From an exhaustive investigation of the crimson-clover plant (Trifolium incarnatum), Penny (Delaware Bulletin 67) reports the following average results ${ }^{*}$ for fall-seeded crops harvested about

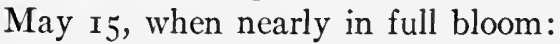

Table 35. Composition of Crimson Clover in Bloom

Delaware Experiments: Pounds per Acre

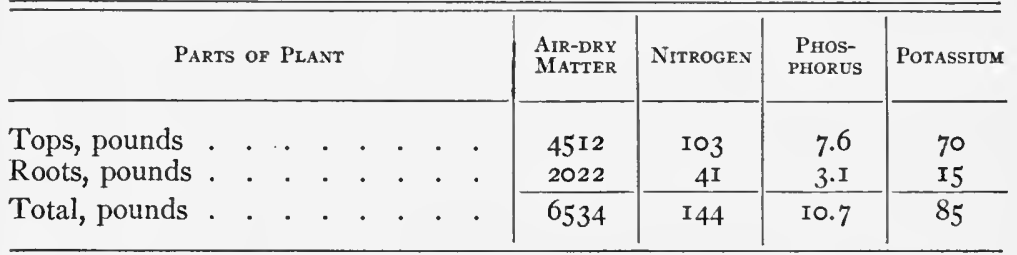

Percentage of Total

\begin{tabular}{|c|c|c|c|c|c|c|c|c|c|}
\hline Tops, per cent . & . & . & - & . & . & 69 & 72 & $7 \mathrm{I}$ & 82 \\
\hline Roots, per cent & . & . & . & . & . & $3 I$ & 28 & 29 & I8 \\
\hline
\end{tabular}

The proportions were found to vary considerably, but this general average shows the crimson-clover roots (to a depth of 24 inches) to contain less than one third of the organic matter, nitrogen, and phosphorus, and less than one fifth of the potassium of the entire plant. It was found that 77 per cent of the roots were in the first 6 inches of soil, and 13 per cent in the second 6 inches, 7 per cent in the third, and 3 per cent in the fourth 6 inches.

In Table 36 are recorded much additional information concern- 
Table 36. Composition of Plants (Tops and Roots)

Delaware Experiment Station: Crops seeded July 22

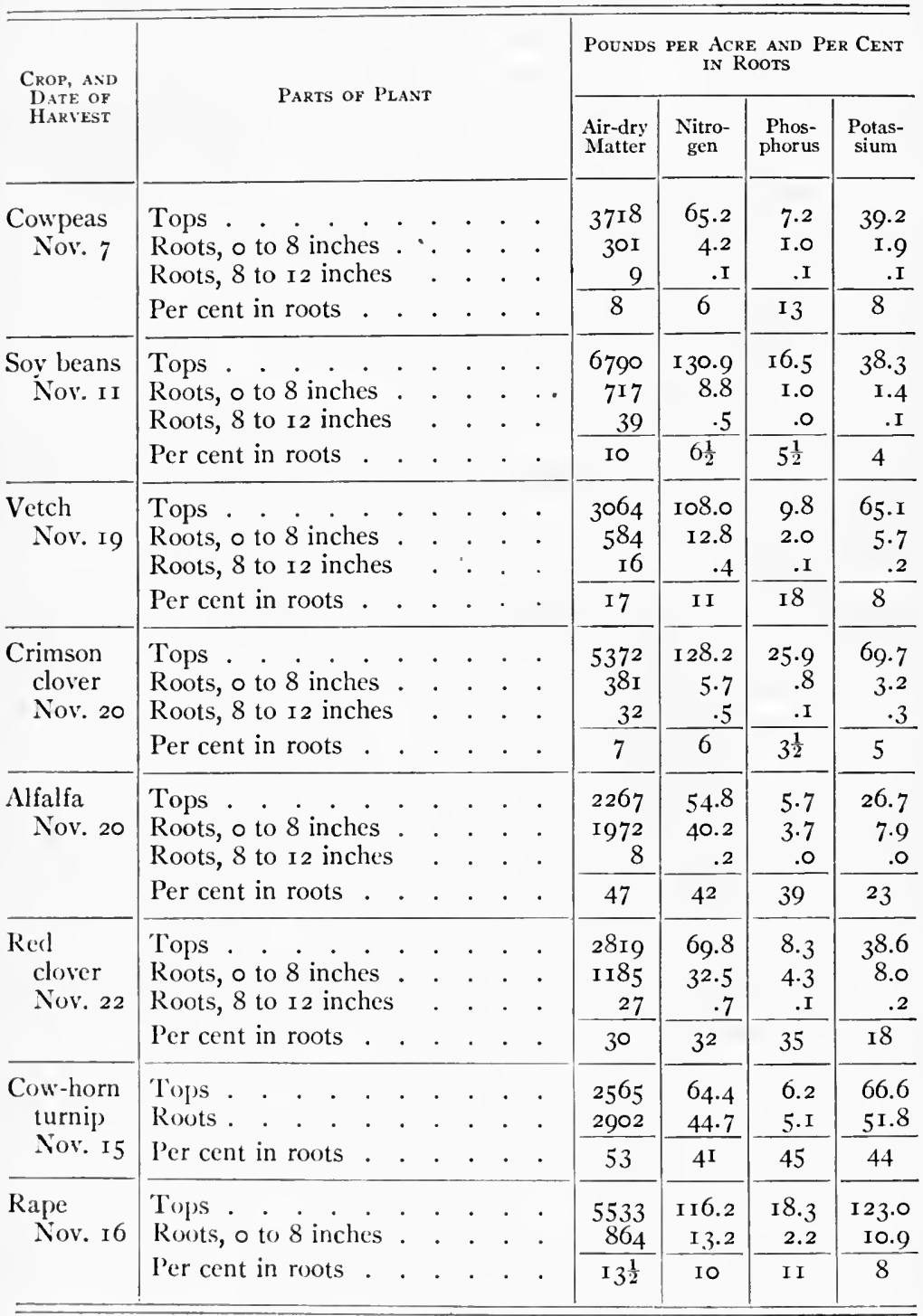


ing the composition of the tops and roots of the most important field legumes. It summarizes a series of investigations by Penny and Close, and confirms much other data relating to these crops and bearing directly upon the problems of supplying the soil with organic matter and nitrogen.

As an average of all determinations, it is safe to say that about one third of the nitrogen of the red-clover plant is contained in the roots and stubble, and that the growth of clover above ground contains, before rotting or leaching, about 40 pounds of nitrogen to the ton of air-dry substance.

Alfalfa contains a somewhat larger proportion of its nitrogen in the roots, at least during the first year of its growth; and possibly the total nitrogen of the alfalfa roots would average one half as much as the total removed in the crops, even when the plants are several years old, considering the entire root system, which commonly reaches a depth of 20 feet or more with old plants. Alfalfa hay contains 50 pounds of nitrogen per ton.

In the case of such annuals as cowpeas and soy beans, not more than one tenth of the nitrogen is found in the roots and stubble, as a rule. 'The crop above ground contains (when thoroughly air-dry) about 43 pounds of nitrogen per ton for cowpeas and about 53 pounds per ton for soy beans.

Extensive experiments are in progress in Illinois to determine, under actual field conditions, what systems of grain farming (with green manures and crop residues) and what systems of independent live-stock farming will increase or maintain the organic matter and nitrogen of the soil; but these are investigations that require time, and but few results have as yet been published.

A series of pot cultures has been reported (Illinois Bulletin II5) which illustrates the fact that legume green manures may take the place of commercial nitrogen.

The soil used in these experiments was the yellow silt loam from the unglaciated area of southern Illinois (Pulaski County), which, as will be seen from Table $\mathrm{r}_{5}$, is quite deficient in nitrogen. The field from which this soil was collected had been under cultivation for about 75 years, during which time the average yield of wheat had decreased from about 25 bushels to 5 bushels per acre.

In the pot-culture experiments, catch crops of cowpeas were 
planted on certain pots every year after the wheat was harvested, the legumes being turned under before sowing wheat for the next year.

From a study of Table 98 , it will be seen that practically no gain has been made except where nitrogen has been supplied, either directly in commercial form or indirectly by means of legume treatment. It should be borne in mind that no legume treatment preceded the I902 wheat crop. The catch crop of cowpeas which was planted after the 1902 wheat crop and turned under later in the fall, produced a marked effect upon the I903 wheat crop. This effect became more marked in 1904 and 1905, when every pot recciving legume treatment outyielded the pot receiving limenitrogen treatment. Previous to 1905 , the addition of phosphorus to nitrogen or legume treatment always increased the yield. The addition of potassium still further increased the yield more or less. The effect of both phosphorus and potassium has been less where decaying organic matter has been provided in the legume treatment than where the nitrogen has been supplied in commercial form (dried blood) carrying but little organic matter.

The last line in the table gives the yield from a pot of virgin soil collected from a piece of unbroken virgin sod land adjoining the cultivated field from which the soil in all the other pots was taken.

\section{Nitrogen Fixation by Nonsymbiotic Bacteria}

Aside from the fixation of free nitrogen by the bacteria living in symbiotic relationship with legume plants, there are at least three groups of bacteria that have nitrogen-fixing power without this relationship.

First, and possibly of greatest importance, are the legume bacteria themselves, which continue to fix nitrogen in pure cultures entirely separated from legume plants, and very probably also continue thus to fix some nitrogen in the soil, even after the legume plants have been destroyed, the bacteria drawing their nutriment from the decaying organic matter.

Second, is the anaërobic group of bacteria discovered by Winogradsky in I893, and called Clostridium; but these have little 
agricultural significance, because they develop only in the absence of free oxygen.

Third, is the azotobacter, an aërobic group described by Beijerinck in I90I, of which Lipman has recently found some additional species, one of which (Azotobacter vinelandii) appears to be quite active in the fixation of free nitrogen when the best artificial conditions are provided. (See Lipman's " Bacteria in Relation to Country Life," page I99.)

Beijerinck has found, " as a result of improved technique for the determination and study of the distribution of the organism, that azotobacter fixes nitrogen, and that there is a distinct relation between the distribution of this organism and leguminous plants." The author questions if there may not be a relationship between the legume bacteria and the azotobacter. (See Experiment Station Record, I909, Vol. 20, page 920.)

Whether any of these nonsymbiotic bacteria are of appreciable agricultural importance under practical conditions, is not fully established. It is known, however, that a supply of organic matter is essential for their development, and the organic matter of the soil which must be decomposed in order to furnish their necessary supplies of carbonaceous food may also furnish part or all of the nitrogen which they require. (See also pages 434-440.) 


\section{CHAPTER XV}

\section{ROTATION SYSTEMS FOR GRAIN FARMING}

АвоUт three fourths of the farmers of central United States are so-called grain farmers. There has always been a large proportion of grain farmers; and, furthermore, there always will be, and always must be, for the world does not live by meat alone, nor even upon meat and dairy products; bread is the staff of life.

Notwithstanding these well-known facts, whenever the grain farmer of central United States has asked for information as to how he could maintain the fertility of his soil, the reply has always been, "Become a live-stock farmer." While this may or may not be good advice for the individual farmer, it is certainly not good advice for all the farmers of the state or nation.

On the other hand, grain farming is not only profitable, - and often more profitable than live-stock farming, - but there are methods, and profitable, practical methods, by which the grain farmer can not only maintain the fertility of his soil, but even make it more productive than it ever was even in its virgin state.

Let us consider the simple three-year rotation: (I) corn, (2) oats, and (3) clover, which is becoming somewhat common in the Illinois corn belt; or (I) corn, (2) wheat, and (3) clover, the most common crop rotation of Ohio. Of course, as many fields should be provided as there are years in the rotation, so that every crop may be represented every year.

We may assume yields of 100 bushels per acre of corn and oats, 50 bushels of wheat, 4 tons of clover, and 4 bushels of clover seed; or these yields may be divided by two, the same proportions being maintained. With the smaller yields the corn, oats, and clover seed will remove $86_{2}^{1}$ pounds of nitrogen; while, in accordance with the average data thus far obtained, we may count that the clover secures 40 pounds of nitrogen from the air for each ton of hay it 
would produce, the nitrogen contained in the roots and stubble being no more than that furnished by the ordinary corn-belt soil. If the two regular cuttings would make two tons of clover hay; and if the growth of clover during the previous season (after wheat or oats harvest) and during the autumn (after the clover-seed harvest) and the following spring (before plowing for corn) would make another half-ton of clover hay, or two and one half tons in all, then roo pounds of nitrogen would be secured from the air to balance the $86 \frac{1}{2}$ or 89 pounds removed in the grain and seed. In other words, from I 3 to I 5 per cent more nitrogen is returned by the clover than is removed in the grain and seed.

On normal soils the only addition to this system that is necessary in order to establish a permanent agriculture is the application of 20 pounds of phosphorus for the lower yields, or 40 pounds for the larger yields, these amounts being ample to replace the phosphorus removed in the grain and seed and to cover all possible loss by leaching. For the smaller yields, 200 pounds per acre of steamed bone meal or 200 pounds of raw rock phosphate or 400 pounds of acid phosphate, every three years, will be more than sufficient to maintain the phosphorus content of the soil; and twice these quantities would be ample for the larger yields after the productive power of the soil has been raised to that point. To do this may require much heavier initial applications of phosphorus, or moderately heavy applications for the first four or five rotations. Thus, an application of one ton of good rock phosphate ( $12 \frac{1}{2}$ per cent phosphorus) every three years would add I250 pounds of phosphorus per acre in I 5 years, or more than Iooo pounds above the amount removed in the grain or seed for the larger yields in the rotation. In other words, the phosphorus content of the average Illinois surface soil should be doubled in 15 years under this system, and the annual cost of phosphorus $(\$ 2.50)$ would be no more than is commonly paid by farmers in the Eastern and Southern states for so-called "complete" fertilizers. If the phosphorus applied produced increased yields of 7 bushels of corn and equivalent values of other crops, the cost would be covered by the increased crops. (See actual results reported in later pages.)

This system requires that the ears of corn shall be husked and the stalks returned to the soil, that the oat straw and clover straw 
shall also be returned to the land after threshing out the grain or seed, and that the regular crop of clover shall be mowed and left lying on the land. If necessary, to prevent too rank a growth (which might smother the plants), the clover may be mowed twice before the seed crop is allowed to grow.

If the larger yields are considered, the same rotations hold, except that the richer soil would very possibly furnish a larger proportion of the nitrogen required by the clover plant.

With some modifications, these two three-year rotations may be combined in a six-year rotation of (1) corn, (2) corn, (3) oats, (4) clover, (5) wheat, and (6) clover, which avoids the necessity of seeding wheat on the corn ground, a task sometimes difficult to accomplish. If necessary, this may be reduced to a five-year rotation, either by omitting one corn crop, or by plowing under the clover in the spring of the fifth year as late as practicable for corn. With the former change it will be less difficult, and with the latter more difficult, to maintain the nitrogen, than with the six-year rotation.

A four-year rotation, which the author prefers for the general conditions in the North Central states, includes the four crops, wheat, corn, oats (or barley), and clover, in the order given. Clover should also be seeded on the young wheat in the early spring, and plowed under (after disking, if necessary to insure capillary connection) as late as practicable the next spring before planting corn. In grain farming only the seed crop of clover is removed from the land, and the phosphate is plowed under with the clover residues for the wheat. All of the threshed straw (from wheat, oats, and clover) is hauled from the threshing directly to the field, where it may be thrown off in windrows, and soon afterward spread over the land as uniformly as necessary. It may be used for a top dressing for wheat, or it may be applied in moderate amounts to the land from which wheat has been harvested, where the young clover is growing as a green manure for the following corn crop. Judgment must always be exercised in the matter of applying large amounts of straw, or of plowing under heavy crops, or applications of coarse material, which may do damage if turned under too late in the spring, especially if the season is dry or if the soil is deficient in lime. 
For southern Illinois and other Southern states, a four-year rotation of (I) corn, (2) cowpeas (or soy beans), (3) wheat (or oats), and (4) clover is very satisfactory; and a three-year rotation, in which it is more difficult to maintain the nitrogen, is (I) wheat, (2) corn, and (3) cowpeas; or (I) cotton, (2) corn and cowpeas, and (3) oats and cowpeas, in either of which soy beans may be substituted, and should be substituted in case of danger from cowpea wilt or other disease; and similarly, alsike or sweet clover may be sometimes substituted for red clover in case of clover sickness, which is more fully discussed later on. In these rotations considerable use can be made of legume catch crops. Thus red clover or sweet clover may be started with the wheat and plowed under the following spring as green manure for corn, or cowpeas can be grown after the wheat is harvested. Clover or vetch or cowpeas (or a mixture of legumes) can be seeded in the corn at the time of the last cultivation and plowed under late the following spring before seeding the regular cowpea crop; and, where cotton is to follow, some legume catch crop could be seeded after the regular cowpea crop is harvested, allowed to grow during the late fall, winter, and early spring, and plowed under for cotton.

If necessary, not only the cotton stalks, but also the cotton seed may be returned to the land, the lint of itself being of much greater value than any grain crop. (Two bales of cotton, or 1000 pounds of lint, worth \$100, is no larger crop, comparatively, than Ioo bushels of corn, worth $\$ 40$, as a ten-year average price in Illinois.)

Any one who is familiar with agricultural practice can estimate closely the probable or possible crop yields, and with the yields determined and with the disposition of the crops, catch crops, and crop residues decided upon, any one can compute very closely from the data given in Table 23 as to the probable maintenance of the nitrogen supply.

Two factors of opposite effect - (I) the loss of nitrogen, especially by leaching, and (2) the addition of nitrogen in rain and by fixation of free nitrogen independent of legume plants, especially by the azotobacter (factors which tend to counterbalance each other) - are discussed on another page.

From all of the facts it will be understood that there is just as much reason and as much satisfaction in computing that a 50- 
bushel crop of corn removes from the soil 74 pounds of nitrogen and that eight tons of average manure, or two tons of clover, plowed under will return 80 pounds of nitrogen to the soil, as there is in estimating the quantity of corn and hay that will be required to feed a car load of stecrs for eight months.

The avcrage American grain farmer "changes" his crops more or less by occasionally substituting oats or barley for corn or wheat. He rarely even plows under a catch crop of clover, often burns his straw and corn stalks, and makes almost no effort to restore to the soil the fertility removed in crops. The supply of active organic matter rapidly decreases., Consequently the land soon reaches a condition of low productiveness, and he is correctly termed a "soil robber." He knows his soil is running down, but he hopes it will last as long as he does.

The average live-stock farmer is forced to keep more or less of his land in meadow and pasture, and in the residues and grass and clover roots supplies some fresh organic matter, which, as it decays, hastens the decomposition of the old humus and also the liberation of mineral elements from the soil. By these means and by the better avoidance of insect injuries and plant diseases, he produces larger crops when corn or other grains are grown, which may reduce the fertility of his soil even more rapidly than the smaller crops of the grain farmer; but he does not know it, and, as he makes a good show on new, rich land for two generations or more, he is incorrectly held up as a "soil builder." In actual practice most of the farm rarely, if ever, receives an application of manure. "Farm manure is good enough, but there's not enough of it" is the common report of experienced live-stock farmers. 'This inadequacy of the manure supply is due not only to the large destruction of organic matter when fed to animals, but also in part to unavoidable losses of manure and in part to unnecessary waste.

In planning systems of permanent agriculture of wide application, a distinction should be kept in mind between the ordinary live-stock farmer, who markets his own farm produce in the form of meat, wool, or dairy products, and the stock breeder, who sells breeding animals at higher prices, or the stock feeder, who often buys both stock and feed and is to that extent not a farmer but a manufacturer. 


\section{CHAPTER XVI}

\section{LIVE-STOCK FARMING}

IF a four-year rotation is practiced, including two crops of corn, followed by oats, with clover seeded the third year, and clover for hay and pasture the fourth year, and all crops used for feed and bedding, the nitrogen balance can be determined by simple computations based upon facts established within narrow limits by such data as have been cited in the preceding pages. We may assume 5o-bushel crops of corn and oats, and $I_{2}^{\frac{1}{2}}$ tons of hay in the first cutting, with I ton additional for all previous and subsequent growth, the same as for the grain system; or here, too, we may double the assumed yields and maintain the same proportions. With the lower yields the three grain crops and the $\mathrm{I} \frac{1}{2}$ tons of clover hay would contain 256 pounds of nitrogen. Under the most careful system of saving manure, three fourths of this, or 192 pounds, can be returned directly to the land, and to this may be added 30 pounds of nitrogen added to the soil in the manure from the one ton of pastured clover, making 222 pounds added by pasturing and manuring. If we consider that the nitrogen contained in the clover hay was taken from the air, the real draft upon the soil is only 196 pounds. In this system about 13 per cent more nitrogen is returned in the manure and pasture than is removed from the soil by the three grain crops.

If the rotation is extended to five years by sowing clover and timothy and pasturing the fifth year, assuming the growth to be three fourths clover the fourth year and the pasture herbage to be only one fourth clover the fifth year, the outcome with respect to nitrogen would be $25^{6}$ pounds removed from the soil and 267 pounds returned in the manure and pasture droppings during the five years, if we disregard the strong probability that timothy, growing as a companion crop, secures some portion of its nitrogen from the decaying tubercles of the clover roots. 
If we assume that three fourths of the produce harvested is used for feed and one fourth for bedding, and that one third of the organic matter consumed by animals is recovered in the manure or droppings, then the four-year rotation under live-stock farming would add organic matter to the soil at the rate of $1 \frac{1}{4}$ tons a year, while the three-year rotation of corn, oats, and clover, under the grain system, would add organic matter at the rate of $I_{4}^{3}$ tons a year.

Thus, it will be seen that the grain system under a three-year rotation of corn, oats, and clover, or of corn, wheat, and clover, or under a four-year rotation of wheat (and clover), corn, oats (or barley), and clover; or under a six-year rotation of corn, corn, oats, clover, wheat, and clover, will maintain the nitrogen as well, and the humus, or organic matter, somewhat better, than the livestock system under the four-year rotation of corn, corn, oats, and clover, or under the five-year rotation of corn, corn, oats, clover, and timothy, with all produce either harvested or pastured.

Furthermore, the most uncertain feature in these methods is in regard to saving the manure. The computations here given provide for practically no loss of solid or liquid excrement, for no loss by fermentation or fire-fanging, which may occur even under cover, and for no loss by leaching of manure exposed to the weather in the open barnyard. It is common knowledge that a large part of the value of manure is frequently lost before it is applied to the land.

The author has diligently inquired at many farmers' meetings for several years for a man who had applied manure made from crops grown on his own farm to all of the cultivated land on a I6oacre farm, - not to all during one year or during one rotation, but even during all the time he had farmed the land. Very few men have been found who could answer that all of their cultivated land had been thus manured, - not more than one in a thousand.

In nearly all sections of the country a farmer can be found, here and there, - sometimes one in ten, and sometimes only one in a hundred, - who feeds all the crops he raises and also all that he can buy at reasonably low prices from his neighbors, who supplements all this with more or less purchased bran and shorts, oil meal, cotton-seed meal, etc., and who is thus able to produce suffi- 
cient manure of good quality to maintain or even to increase the fertility of his own farm.

In specially favored localities, a few farmers haul manure from town, or even ship it from the larger cities, especially for use in market gardening, and they, too, are thus enabled to enrich their lands at the expense of many other farms; but no extensive state or nation ever has or ever can maintain sufficient live stock; even in country and city combined, to furnish manure with which to maintain the productive power of all the farm lands.

Even under the best system of independent live-stock farming; that is, without dependence upon the purchase of supplementary food stuffs or the use of manure from town, it is necessary to purchase and apply some phosphorus in order to replace that sold in the animals and animal products, butter and cream being the only important farm products that do not contain appreciable amounts of phosphorus.

In order to increase the phosphorus content of normal soils, phosphorus should be applied in live-stock farming the same as in grain farming, but to merely replace that sold in animal products will require applications of only one half as much phosphorus as is required for grain farming, assuming that all of the grain and clover and part of the corn stover and oat straw are eaten by the live stock. Thus, for the larger yields, the loss of phosphorus would be about 20 pounds per acre in four years with live-stock farming, and 30 pounds in three years with grain farming, as can readily be determined by computation from the data given in Table 23 and the results of the digestion and feeding experiments with dairy cows by the Illinois Station, with dairy cows and steers at the Pennsylvania Station, and with sheep at the Ohio Station, from which we must conclude that as an average at least one fourth of the phosphorus contained in the feed is not recovered in the manure.

In comparison with these permanent systems of agriculture, it is worth while to compute the results of a four-year rotation of three crops of corn and one of oats, seeded with clover to be plowed under the next spring, assuming that the corn is husked and the stalks burned (except the third year, when the stalks are disked down for oats), that the oat crop is all removed, and that the total growth 
of clover would equal one ton of hay per acre. This will be recognized as the "best" common system of grain farming followed in past years in the heart of the corn belt. And not infrequently the live-stock farming has been like unto it, except that the corn stalks have been pastured before being burned or disked down, the clover has been pastured the first fall, cut for hay the next summer, and pastured again before plowing for corn, and ro loads per acre of rotted and leached manure have been applied occasionally to the high places, where the land is getting thin and where the clover fails to catch.

Another most significant fact should be considered in this comparative study of grain farming and live-stock farming; namely, that rooo bushels of grain has at least five times as much food value and will support five times as many people as will the meat or milk that can be made from it. (Not more than one fifth of the nitrogen consumed in the food of animals is retained, as a rule, in the milk or other edible animal products, and the proportion saved of carbonaceous food is usually still less.)

In his American lectures on the "Agricultural Investigations at Rothamsted, England, during a Period of Fifty Years," which were published as Bulletin 22, Office of Experiment Stations, United States Department of Agriculture, Sir Henry Gilbert "summarizes the results of very numerous experiments" conducted at Rothamsted with growing and fattening cattle, sheep, and swine. From this summary we obtain the following data:

Disposition of ioo Pounds of Dry Substance in Food Consumed

Summary of Rothamsted Feeding Experiments

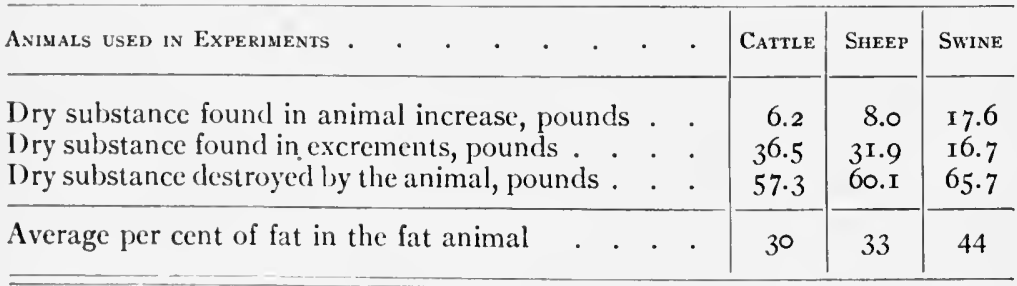

Thus, a large proportion of the food digested is destroyed by the animal and must be exhaled or thrown off as carbon dioxid, water, urea, etc. Of the small percentage of the food that is 
actually retained in the animal tissues, only one half to two thirds may serve as human food, after discarding the offal and nonedible parts. On the other hand, the carbohydrates of the food contribute largely to the formation of animal fat, the energy value of which is about $2 \frac{1}{4}$ times that of carbohydrates; so that, in case of fat swine, the edible food produced is equivalent to about 20 per cent of the dry substance in the ration consumed by the animal; while, in the production of fat cattle, less than ro per cent of the dry matter in the ration consumed is represented in the human food produced.

These data do not answer questions as to the comparative value of vegetable and animal food for human nutrition; but 50 cents for a piece of steak, with Io cents for potatoes, and no extra charge for bread, must roughly represent the relative cost of the materials; and perhaps the vegetarian would hold that the steak might as well be replaced by peas or beans costing 10 or 15 cents.

With all of these facts considered, it seems evident that livestock farming must and should continue to decrease, except on rough lands not suited to cultivation, in semiarid sections where the average produce is not worth harvesting otherwise, or in especially favored sections near the cities where dairy farming is profitable and may easily be made permanent because of the addition of manure hauled from town or made from purchased fecds.

It should be understood, however, that America still produces a large surplus of grain suitable for human food, and for some years to come more or less of this, especially of corn, will be most profitably marketed through the production of live stock. For the live-stock farmer, all must agree with the following statement from Mumford's "Beef Production" (page r3):

"When we remember that the production of manure of the rooo-pound steer for a six-months' feeding period varies from three to four tons, we can appreciate what a factor farmyard manure may become in increasing the revenues of the farm, and that profits and losses in cattle feeding should not stop with a consideration of the cost of cattle and feed and their selling price." 


\section{CHAPTER XVII}

\section{THE USE OF PHOSPHORUS IN DIFFERENT FORMS}

HAVING determined how to correct soil acidity (when necessary) and how to keep the soil sweet, by means of ground limestone; having detcrmined how to maintain or increase the supply of organic matter and nitrogen in the soil, by means of farm manure in live-stock farming, or by means of legume crops and catch crops and crop residues in grain farming, or by a combination of these in mixed or diversified farming, which is sometimes preferable and more profitable than either alone; and having determined the absolute necessity of maintaining or increasing the supply of phosphorus in the soil by direct applications exceeding the amounts removed in crops harvested, - the next most important question, and the only remaining exccedingly important question, is, What form or forms of phosphorus shall be used?

There are four general sources of phosphorus for use in soil improvement: (I) farm manure, (2) bone meal, (3) phosphate rock, and (4) basic slag phosphate.

The first two are themselves farm products, and at the best only provide that the phosphorus taken from the soil shall be returned to the soil, and if there is any loss whatever, the ultimate effect, applied to the state or country as a whole, must be a reduction in the general average fertility of the soil.

To supply to a 40-acre field rooo pounds of phosphorus (25 pounds per acre) in the form of manure made from purchased corn, would require an investment of more than $\$ 3000$ at 40 cents a bushel for corn. While the purchase of grain and other food stuffs provides a method by which soils can be positively enriched in phosphorus, and while there is usually more or less profit from feeding, so that the phosphorus thus obtained may really cost nothing in the end, nevertheless, it is worth while to keep in mind that this method requires large capital, special equipment, such as buildings, 
water supply, and fences, and some knowledge and skill in the livestock line, including business ability in the purchase and sale of stock and animal products, in addition to the requirements for the production of crops.

The addition of phosphorus in farm manures is undoubtedly one of the best methods for those who are able to practice it, and by use of liberal proportions of grain and other concentrates rich in phosphorus, especially bran from different grains, cake or meal from various seeds from which the oil has been expressed, very considerable amounts of phosphorus are added. It is important, however, to understand and to keep in mind that average farm manure is poor in phosphorus in comparison with its content of nitrogen and potassium, especially when made from the produce that remains after part of the grain has been sold from the farm, and more especially when used in connection with a rotation including legume crops and on soils abundantly supplied with potassium but poor in phosphorus. In other words, under such conditions average farm manure is a very poorly balanced fertilizer, and if used even in moderate quantities the production of stalks or straw is likely to be excessive in comparison with the yield of grain; and the small grains are also likely to lodge, because the unbalanced ration produces weakness even in straw of large growth.

Considering the more concentrated phosphorus products, there are four classes to be kept in mind: (1) natural bone, (2) natural rock phosphate, (3) basic slag phosphate, and (4) acid phosphate.

In the first group are raw bone meal, steamed bone meal, bone tankage, and phosphatic guanos. In the second group are the various natural mineral phosphates, as the hard and soft phosphates of Florida, the land rock and pebble phosphate of South Carolina, the brown and blue phosphates of Tennessee, and the apatite of Canada. The third group consists of basic slag only, sometimes called Thomas phosphate. The fourth group includes all acidulated phosphates, such as acidulated bone meal, acidulated bone black, acidulated bone ash, common acid phosphate, and double superphosphate. The term dissolved is often used for acidulated goods.

Non-acidulated bone black and bone ash are best considered as belonging to the second group with the natural mineral phosphates. In groups $\mathrm{r}$ and 2, the phosphorus is present chiefly in the same 
compound, tricalcium phosphate, $\mathrm{Ca}_{3}\left(\mathrm{PO}_{4}\right)_{2}$, the difference between these two groups being the presence of more or less organic matter within the pores of the bone, while the products in group 2 contain little or no organic matter. In group 3 the phosphorus is contained in a basic or alkaline compound or mixture, and in group 4 the phosphorus exists chicfly in monocalcium phosphate, an acid salt. This form of phosphorus is soluble in water, and even the dicalcium, or "reverted," phosphate is soluble in very weak solvents (as in neutral ammonium citrate solution); while all products in groups $\mathrm{I}, 2$, and 3 , are known as insoluble forms of phosphorus.

About seventy years ago Sir John Lawes, independent of a suggestion previously made by Licbig, treated bone meal with sulfuric acid and formed an acid phosphate that proved of greater benefit to the turnip crop grown on the Rothamsted soils than the crushed bone or coarse bone meal then in use; and in 1842 a patent was taken out by him for treating mineral phosphates with sulfuric acid in order to increase their availability in crop production.

Acidulated bone meal has been much used as a fertilizer, but gradually its use has given way, largely because the most successful and influential farmers in our Eastern states have insisted that in the long run fine-ground pure raw bone meal was more profitable than acidulated bone. It is always recognized that the acidulated bone gave the best results the first year, but, on the basis of equal cost, the raw bone proved much more durable, and hence, more profitable in the end, especially where good rotations were practiced and some effort made to keep the soil supplied with organic matter.

In more recent years steamed bone meal is replacing the raw bone, because, as a rule, it gives better results, due in part to its larger phosphorus content and in part to the fact that it is usually more finely ground than the raw bone. There are still to be found those who argue that "if one wishes to benefit himself, he should use acidulated phosphates, but if he wishes to benefit his grandchildren, he should use bone." However, the farmers' demand for "pure raw bone" and for "steamed bone meal " continues to increase, and this steady demand is based upon long-continued 
experience in the practice of agriculture. These products are everywhere looked upon as safe fertilizers. They never injure the soil, and where most used they are classed with farm manure in that regard. And this is a correct view, for farm manure and bone are two important products from the same source. In other words, from the fertility standpoint, animals separate crops roughly into manure and bone, and if we return the bone with the manure, we thus return practically all of the fertility removed by the crop, except a part of the nitrogen, which it is not necessary to return directly, because the legumes are able to secure it from the air.

Basic slag phosphate, a by-product in the manufacture of steel from pig iron containing considerable quantities of phosphorus, has been used as a phosphorus fertilizer since $\mathrm{I} 882$.

Recent investigation ${ }^{1}$ by Director Hall of Rothamsted have convinced him that the typical phosphorus compound in basic slag is a double phosphate and silicate of calcium of the composition $\mathrm{Ca}_{3}(\mathrm{CaO})\left(\mathrm{PO}_{4}\right)_{2} \mathrm{CaSiO}_{3}$, but the more common teaching has been that a tetracalcium phosphate, $\mathrm{Ca}_{3}(\mathrm{CaO})\left(\mathrm{PO}_{4}\right)_{2}$, exists in the slag. In any case the slag contains very considerable proportions of lime, which undoubtedly greatly assists in the disintegration of the product after being incorporated with the soil, thus bringing the phosphate into an extremely finely divided state. The presence of lime in the slag is of itself of some benefit on certain soils, although as a source of lime it is, of course, very expensive and very insignificant, compared to ground limestone.

The use of slag phosphate is quite likely to give disappointing results for the first year or two, resembling natural bone in this regard; but like bone, also, it gives very satisfactory results with continued use, and no prejudice has developed regarding its use on account of any supposed injury to the soil.

Herbert Ingle, in his "Manual of Agricultural Chemistry," makes the following significant statements (page I62):

"Many attempts to improve basic slag as a manure have been made, some directed to the removal of the iron, others the sulfur, while others have attempted

1 This statement is based upon the information given by Director Hall in connection with his course of lectures before the Graduate School of Agriculture of the Association of American Agricultural Colleges and Experiment Stations, held at Cornell University, July, I908. His final conclusions should not be assumed in advance of publication by him. 
to render the phosphorus ${ }^{2}$ more soluble, by treatment with sulfuric acid. Practically all these attempts have been abandoned, and the only process through which the slag is passed is that of grinding. This must be thoroughly done, for it is found that the availability of the phosphorus depends very largely upon the fineness of subdivision. A sample should contain at least 80 or $9 \circ$ per cent of powder which passes through a sieve of roo meshes to the linear inch, i.e. 10,000 to the square inch. Thomas phosphate has given excellent results, especially in soil somewhat deficient in lime and rich in organic matter."

The total quantity of basic slag phosphate now used in Europe as a phosphorus fertilizer amounts to several million tons a year.

Ground natural rock phosphate has not been put to direct use as a fertilizer to any large extent, but the subject merits and receives a thorough consideration in the following pages. Numerous trials both in Europe and Amcrica extending over only one or two years, without addition of organic matter, and in direct com. parison with acid phosphate or bone meal containing an amount of phosphorus cqual to the total amount in the raw phosphate used, have not, as a rulc, given satisfactory results, and in consequence the direct use of this material has been discouraged by some investigators, and the Association of German Agricultural Experiment Stations has even passed formal resolutions discouraging the general use of nonacidulated rock phosphate (Landwirtschaftlichen Versuchs-Stationen, 67, 329).

The mincral phosphates differ from bone, in that they lack the organic matter in porous structure; and they differ from slag in that they are not mixed or combined with caustic lime capable of slacking and disintegrating into extremely small particles. The fact is, however, that wherever fine-ground natural rock phosphate has been used libcrally; that is, somewhat in proportion to equivalent values in comparison with acid phosphate, and in connection with decaying mattcr, it has given satisfactory results, even during the first rotation, and, with continued use, it proves to be the most economical and profitable form of phosphorus to use in the adoption of systems of permanent agriculture.

In the study of this extremely important question it is well to keep in mind some broad fundamental facts. Thus, the phos-

'Substituted for "phosphoric acid," both here and in several other quotations from different writers. $-C . G . H$. 
phorus contained in the soil is not in the form of acid phosphate, but largely, at least, in the form of pulverized or disintegrated rock; and yet it is the common experience that this phosphorus can be made available by large use of clover and other green manures. It is an interesting and absolute fact, too, that phosphatic marls, containing phosphorus in the ordinary insoluble mineral form, have been much used for centuries for direct application to the land. It is recorded by writers that, when the Romans first invaded Britain, "the natives were found using phosphatic marls to obtain better crops."

The United States Bureau of Soils states that millions of tons of the greensand marl of New Jersey have been used "as a natural fertilizer"; and, according to the Bureau's analysis of a specimen " collected as a sample to show the amount of plant food in material actually used as a fertilizer," this marl contains less than I per cent (I 8 pounds per ton) of acid-soluble potassium, and but little more calcium and magnesium than could be combined in the phosphates present. Evidently, the fertilizing value of the marl is due very largely to its phosphorus content, which amounts to 28.6 pounds per ton. In comparison it may be noted that one ton of the most common corn-belt soil contains about I.2 pounds of phosphorus, 8 pounds of acid-soluble potassium, and 35 pounds of total potassium; and that 200 pounds (the a verage application) of the most common " complete" commercial fertilizer contain about $8 \frac{1}{2}$ pounds of total phosphorus and $3 \frac{1}{2}$ pounds of potassium.

An analysis by the Bureau of Soils of the greensand marl of Prince George County, Maryland, shows about $\frac{1}{2}$ pound of phosphorus and 42.6 pounds of acid-soluble potassium, in one ton. The following statements are quoted from the Report of the Bureau of Soils for I90I, pages I86-I87:

"It is probable that the New Jersey greensand marls would, on the average, have a phosphorus content fifty times as great as the corresponding marls from Maryland."

"In the Prince George area this greensand marl, which occurs along the numerous stream cuttings and natural cliffs, has only been used to a slight extent as a source of fertilizer. . . . In other areas, both in the United States and foreign countries, the greensand marl has long been utilized as an inexpensive though effective medium for restoring impoverished soils." 
There are several points especially favorable to the use of natural rock phosphate where proper conditions can be provided:

The first is the fact that phosphorus in fine-ground raw phosphate can be obtained, delivered to the heart of the corn belt, for about 3 cents a pound, or for $\$ 7.50$ for a ton of phosphate containing 250 pounds of phosphorus, or perhaps $\$ 9.00$ for a ton containing 300 pounds of phosphorus; while phosphorus will cost about Io cents a pound in steamed bone meal, I 2 cents a pound in acid phosphate, and about 30 cents a pound in ordinary so-called complete fertilizers. In the adoption of systems of permanent agriculture, one can easily afford to apply to the soil, in natural phosphate, larger quantities of phosphorus than are removed in the largest crops, and thus provide a truly permanent system with respect to phosphorus.

The second point is that lower grades of phosphate can be used for direct application to the soil than can be utilized in the manufacture of acid phosphate. For acid-phosphate manufacture the raw material must be not only high in phosphorus, but it must be low in certain forms of impurities, such as iron and aluminum compounds, which, if present, require much larger use of sulfuric acid and also make an unsatisfactory product; but phosphates of moderate phosphorus content and even with considerable iron and aluminum present, which have hitherto been left on the dump piles as worthless, are now being used for direct application to the land in connection with liberal amounts of farm manure or clover or other forms of decaying organic matter. Other low-grade phosphates are being mined and ground for direct use. If $12 \frac{1}{2}$ per cent phosphate ( $62 \frac{1}{2}$ per cent tricalcium phosphate) is worth $\$ 7.50$ per ton, then ro per cent phosphate ( 50 per cent pure) is worth $\$ 6.00$ a ton; and even 8 per cent phosphate (I60 pounds of phosphorus per ton) is worth $\$ 4.80$ a ton, which would allow $\$ 2.00$ a ton for the fine-ground phosphate on board cars in bulk at the mine, and $\$ 2.80$ for freight, the average rate from the Tennessee phosphate district to southern Illinois points. The possibility of using these low-grade phosphates, of which there are immense deposits, is of enormous importance in the general adoption of permanent systems of soil improvement.

A third point in favor of raw phosphate, in common with bone 
and slag, is that it is free from acidity and has no tendency to injure the soil. This is a minor advantage, because, if acidity develops from the continued use of acid phosphate (and it does), it can be corrected at small expense by the addition of any form of lime.

Another point, previously mentioned, of fundamental significance is the simple fact that a form of phosphorus originally present in all natural soil material is finely divided natural rock phosphate, and through all agricultural history the principal source of phosphorus in plant growth has been this same natural phosphate. On most normal soils one of the chief benefits of farm manure and green manures is undoubtedly due to their power to liberate phosphorus from these insoluble natural phosphates of the original soil.

In considering culture experiments, whether field cultures or pot cultures, three points should be kept in mind:

(I) What are the limiting factors of plant growth under the conditions of the experiment?

(2) Does the applied fertilizer increase the crop yield by direct or indirect action?

(3) In case of insoluble fertilizers, are the conditions such that the plant food applied will be made a vailable to the crop?

Thus, an experiment to determine the comparative agricultural value of different forms of phosphorus cannot be expected to furnish satisfactory evidence if conducted on a soil in which nitrogen is the element that limits the crop yield; or, even though phosphorus is the first limiting element, the results cannot be conclusive if the nitrogen limit is but little higher. For example, if the conditions are such that the soil will furnish phosphorus for only 40 bushels of corn per acre, and sufficient nitrogen for only 45 bushels per acre, the yield cannot be increased above 45 bushels by the addition of phosphorus alone, no matter what form is applied or how much becomes available. In other words, one phosphate fertilizer might supply phosphorus for only 5 bushels, and another sufficient for 25 bushels, increase, but the results of the culture experiment would show no such difference, because beyond the 45 bushels the yield is limited by a second entirely different factor.

The second point is important with every form of experiment. Thus, a student reported having found silver in an unknown solu- 
tion because the addition of hydrochloric acid produced.a white precipitate. The Professor asked: "How do you know that this precipitate is not due to lead or mercury?" and the student replied, "Because I was not testing for lead or mercury at all."

Similarly one may apply wood ashes to ascertain if the soil is deficient in potassium, or he may turn under a spring growth of clover to ascertain if the soil needs more nitrogen, and from the increased yield he may think both of these elements are deficient; but in the one case the increase may be due, not to the potassium as plant food, but to the basic or alkaline properties of the lime and other carbonates in correcting soil acidity, and in the other case not to the nitrogen supplied, but to the liberation of phosphorus from the meager supply in the soil by the action of decaying organic matter.

It is never safe to assume that the action of soluble fertilizers, such as sodium nitrate, acid phosphate, kainit, or other potassium salts, is due entirely to the respective plant-food elements for which those materials are valued, especially when heavy applications are made, as must be done with sodium nitrate and kainit if sufficient nitrogen and potassium are thus provided to meet the needs of good crops, more than 900 pounds of sodium nitrate and 700 pounds of kainit being required for a hundred-bushel crop of corn.

About 400 pounds of acid phosphate would be required for such a crop, and this would contain more manufactured land-plaster (calcium sulfate) than monocalcium phosphate, as will be seen by computation from the reaction expressed by the equation:

$$
\mathrm{Ca}_{3}\left(\mathrm{PO}_{4}\right)_{2}+{ }_{2} \mathrm{H}_{2} \mathrm{SO}_{4}=\mathrm{CaH}_{4}\left(\mathrm{PO}_{4}\right)_{2}+{ }_{2} \mathrm{CaSO}_{4} \text {. }
$$

Dried blood and steamed bone meal are among the most trustworthy materials for culture experiments to determine if the soil is in need of nitrogen or phosphorus, and potassium sulfate is probably the least objectionable form of potassium, although solutions of such soluble salts ha ve some power to liberate phosphorus contained in, or applied to, the soil, and by this indirect action to bring about more or less increase in crop yields not due to potassium as plant food. Steamed bone meal contains a small amount of organic nitrogen, but even if it were all made available, the 
amount in 200 pounds would be sufficient to increase the yield of corn by one bushel, while such an application would contain more phosphorus than a hundred-bushel crop of corn.

In Tables 37,38 , and 39 are recorded in detail the results of the world's most important and complete investigation thus far reported concerning the use and comparative value of raw rock phosphate. These experiments were begun by the Ohio Agricultural Experiment Station in 1897 , and through the kindness of Director Thorne the author is able to include twelve years' data in these tables.

In these experiments a three-year rotation of corn, wheat, and clover has been followed on three separate tracts of land, so that every crop may be represented every year. One plot in each series receives 8 tons per acre of manure "taken from the open barnyard, where it has been accumulating during the winter," and applied to the clover sod in the spring, to be plowed under for corn. Another plot receives at the correct time 8 tons per acre of manure " taken from box stalls, where it has accumulated under the feet of animals kept continuously in the stalls."

Two other plots in each series receive the same kind and quantity of manure with each ton of which 40 pounds of fine-ground raw rock phosphate have been mixed, and two other plots receive manure with each ton of which 40 pounds of acid phosphate have been mixed.

Every third plot in each tract or series receives no manure or other fertilizer.

In the tables are reported the yields of corn, wheat, and clover, the experiment having been started in 1897 on section $\mathrm{A}$, and in 1898 on sections B and C. Clover failed the first three years, and in its place soy beans were grown, and they were plowed under. The hay crop harvested in 1907 was soy beans, grown because of clover failure.

Chemical analysis and the results of other field experiments show that the Wooster soil is most deficient in phosphorus, with nitrogen as the second limiting element.

In considering the data given in Tables 37,38 , and 39 , it should be kept in mind that each table gives results that are complete and entircly independent. Thus, by using three different tracts 
of land, the experiment was conducted in triplicate; and even each of the triplicate tests was in a sense duplicated in that a double comparison is made between the two forms of phosphorus, the test with yard manure being entirely independent of the test with stall manure.

For convenience the average yield of each crop is given by plots for each series of plots separately. Thus, as an average of four corn crops in Series A, plot I 5 with yard manure alone produced $4 \mathrm{I} .5$ bushels, and plot 2 with yard manure and raw phosphate produced 54.9 bushels, showing by direct comparison a gain of I 3.5 bushels due to the raw phosphate. Further comparison shows average gains of 2. I bushels of wheat and $.5^{8}$ ton of clover hay by raw phosphate and yard manure above the yields made where untreated manure was used.

A similar comparison shows average gains of 5 bushels of corn, 3.9 bushels of wheat, and .37 ton of hay by raw phosphate and stall manure above the yields where stall manure alone was used. Acid phosphate also produced marked gains, the average gross increase being somewhat greater than with the raw phosphate, but the net profit being slightly less on Series A.

Attention is called to the fact that 8 tons of manure per acre have been applied every three years to all manured plots. This does not do full justice to the phosphate plots, because these plots have yielded as an average about one fourth more produce than the plots receiving manure alone, and from this increased produce about one fourth more manure can be made in regular farm practice. Consequently, after the first rotation, the applications of manure should be larger on the phosphate plots in proportion to the produce of the previous rotation; whereas, to apply equal amounts of manure to plot $\mathrm{I}_{5}$ and plot 2, for example, means essentially that some of the produce from plot 2 is used to make part of the manure that is applied to plot $\mathrm{I}_{5}$.

In the above comparison to determine the effect of the phosphorus used, the yields with manure alone are subtracted directly from the yields with manure and phosphorus. As an average of many tests, this rlirect method of comparison is perhaps as good as any indirect method, but where a small number of tests on only a few fields are to be considered, probably an indirect method of 


\begin{tabular}{|c|c|c|c|c|c|c|c|c|c|}
\hline & $\sum$ & $\begin{array}{l}\frac{\omega}{2} \\
\vdots \\
z \\
z\end{array}$ & 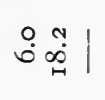 & जि & $\begin{array}{lrr}0 & \sim & m \\
0 & 0 & \ddot{i}\end{array}$ & 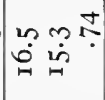 & مُّ & $\begin{array}{l}m \\
0 \\
0 \\
\tilde{N}\end{array}$ & \\
\hline & $\stackrel{0}{4}$ & 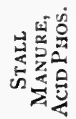 & 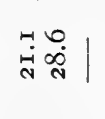 & 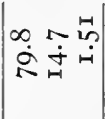 & 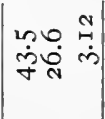 & $\mid \begin{array}{ccc}n & -1 & 0 \\
\infty & \infty & \sim \\
\infty & N\end{array}$ & 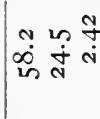 & 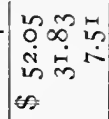 & 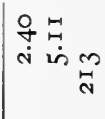 \\
\hline & ${ }_{4}^{n}$ & 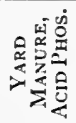 & 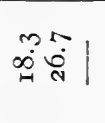 & 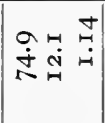 & نَّ & 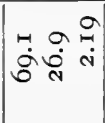 & $\begin{array}{l}\circ \stackrel{0}{0} \\
\dot{\dot{\omega}} \stackrel{\dot{N}}{\text { in }}\end{array}$ & 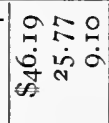 & 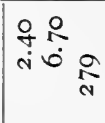 \\
\hline & 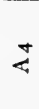 & 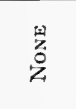 & $\ddot{a} \underset{\infty}{\infty} \mid$ & 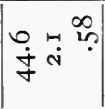 & 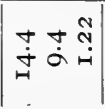 & 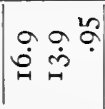 & 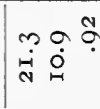 & 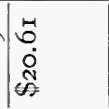 & \\
\hline 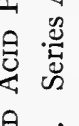 & $\stackrel{m}{4}$ & 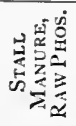 & 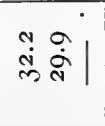 & 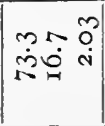 & 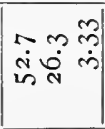 & 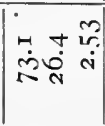 & $\begin{array}{lll}\infty & \infty & 0 \\
\dot{\sim} & \dot{+} \\
\text { in } & \text { i }\end{array}$ & 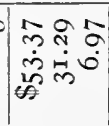 & 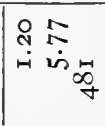 \\
\hline 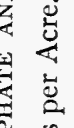 & $\stackrel{N}{\leftarrow}$ & 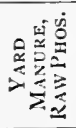 & 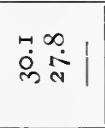 & $\therefore \dot{n}$ & 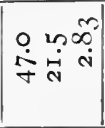 & 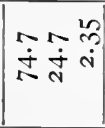 & 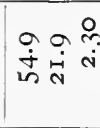 & $\left\{\begin{array}{l}m \infty \\
3 \infty \\
\infty \\
\dot{+}+\infty \\
\dot{+}\end{array}\right.$ & 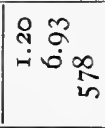 \\
\hline 总 & $\bar{z}$ & $\begin{array}{l}\text { 量 } \\
2 \\
2\end{array}$ & نேं & 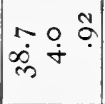 & تَ & $\underset{\sim}{\sim} \underset{\sim}{\sim}$ & 롫 & 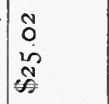 & \\
\hline 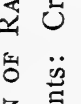 & ‡ & 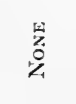 & $\begin{array}{ll}\ddot{0} & \mathfrak{n} \\
\dot{n}\end{array}$ & 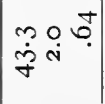 & 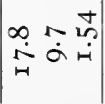 & 安 & 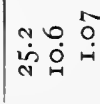 & $\begin{array}{l}8 \\
\dot{N} \\
\tilde{N}\end{array}$ & \\
\hline 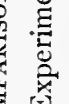 & $\stackrel{0}{4}$ & 造 & $\begin{array}{ll}0 & n \\
\infty & \dot{m} \\
\sim & \stackrel{\sim}{*}\end{array} \mid$ & 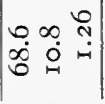 & $\left|\begin{array}{ccc}\infty & 0 & \infty \\
0 & 0 & \sim \\
\dot{q} & \stackrel{\sim}{*} & \dot{m}\end{array}\right|$ & 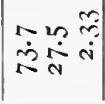 & 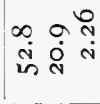 & 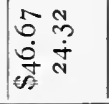 & \\
\hline$\frac{0}{0}$ & in & 至 & 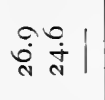 & $\therefore \stackrel{\infty}{6}$ & 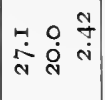 & 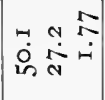 & 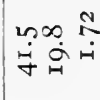 & $\begin{array}{l}N 5 \\
\infty \\
\infty \\
\infty \\
\infty\end{array}$ & \\
\hline & $\underset{4}{\sharp}$ & 里 & 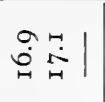 & ஸุ & 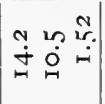 & $\begin{array}{lll}2 & 0 \\
\infty & 0 & 0\end{array}$ & 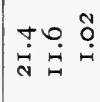 & $\begin{array}{l}\stackrel{2}{\mathfrak{N}} \\
\stackrel{N}{*}\end{array}$ & \\
\hline & $\begin{array}{l}\dot{0} \\
2 \\
5 \\
0 \\
0\end{array}$ & · & 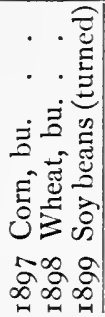 & 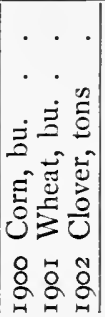 & 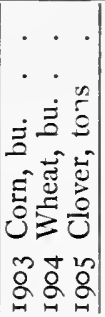 & 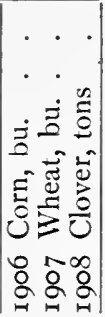 & 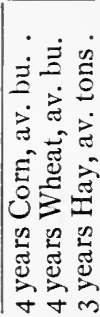 & 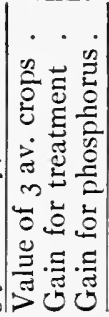 & 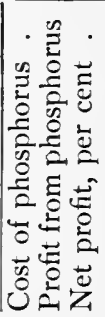 \\
\hline
\end{tabular}




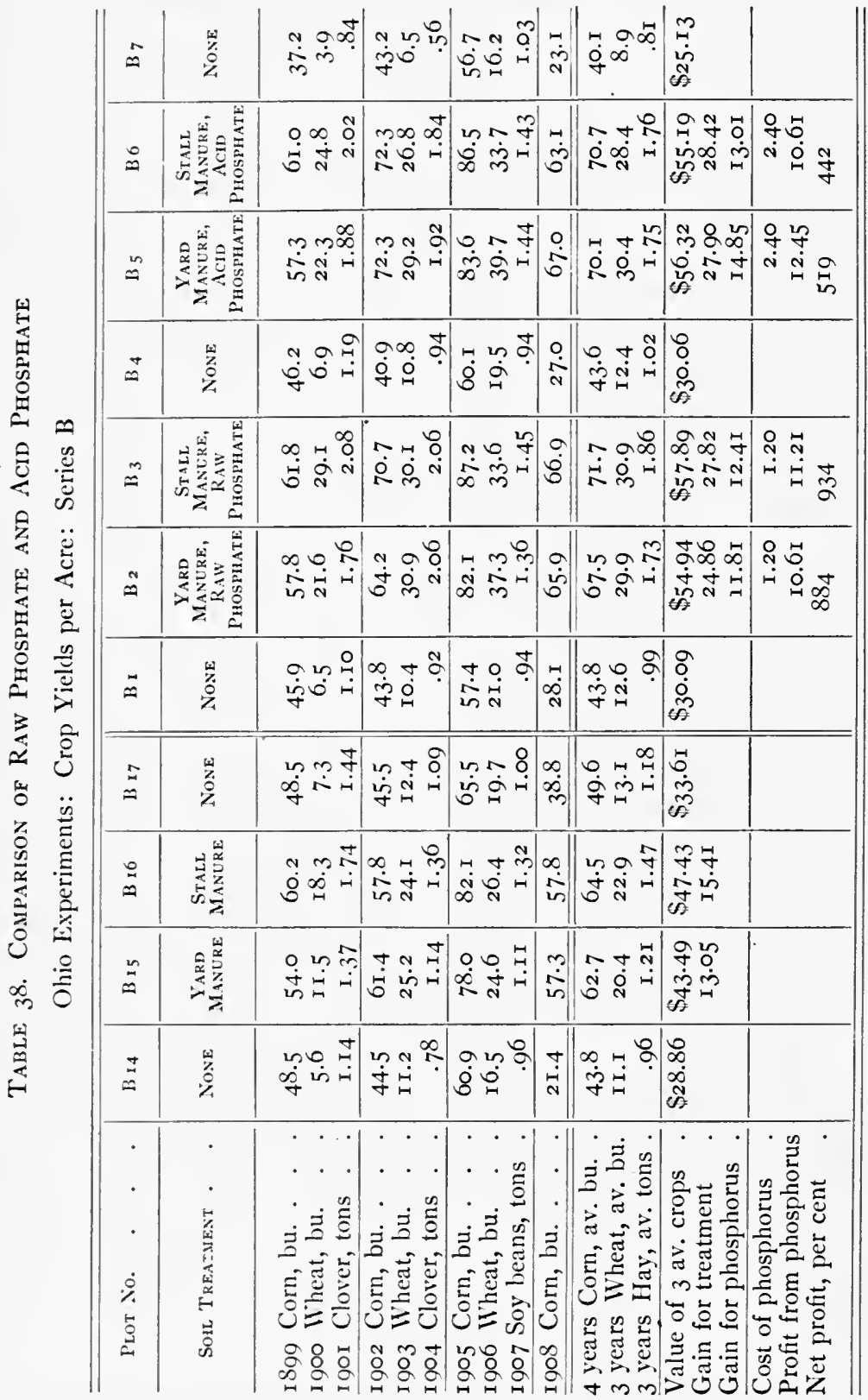




\begin{tabular}{|c|c|c|c|c|c|c|c|c|c|}
\hline & $\dot{v}$ & $\begin{array}{l}\text { 关 } \\
\text { 号 }\end{array}$ & 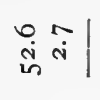 & 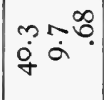 & 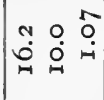 & 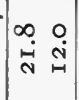 & $\begin{array}{l}\infty \infty \infty \\
\mathrm{m}^{\infty}\end{array}$ & $\begin{array}{l}\mathfrak{N} \\
\mathfrak{N} \\
\stackrel{N}{2}\end{array}$ & \\
\hline & $\dot{U}$ & 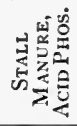 & 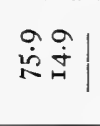 & 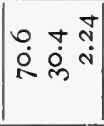 & 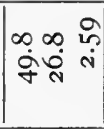 & $\mid \begin{array}{ll}n \\
0 & 2 \\
8 & 2\end{array}$ & 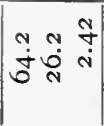 & 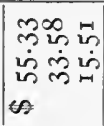 & 물 \\
\hline & $u^{n}$ & 包是 & $\begin{array}{l}\infty \\
\dot{n}\end{array}$ & 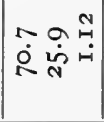 & $\underset{m}{\operatorname{m}}$ & in & 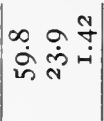 & 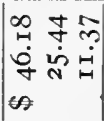 & 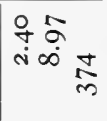 \\
\hline & $\dot{u}$ & 我 & in & 范。 & $\begin{array}{l}n \infty \\
\dot{N} \infty \\
\sim\end{array}$ & 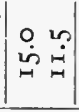 & $\underset{\sim}{m} \infty \overline{0}$ & 衣 & \\
\hline $\begin{array}{l}\mathscr{巳} \\
\ddot{n} \\
\ddot{0}\end{array}$ & $\dot{u}^{3}$ & 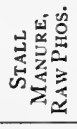 & 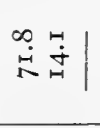 & 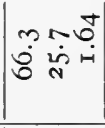 & 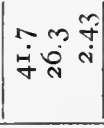 & $\begin{array}{ll}-1 & + \\
\text { N่ } & \stackrel{m}{~}\end{array}$ & 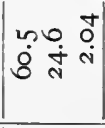 & 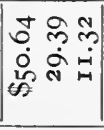 & 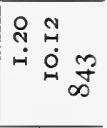 \\
\hline 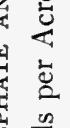 & $e^{N}$ & 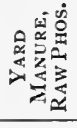 & $\begin{array}{l}\ddot{n} \\
\ddot{n}\end{array}$ & 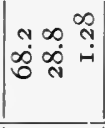 & $\begin{array}{l}\dot{m} \tilde{R} \\
\dot{m} \dot{n}\end{array}$ & 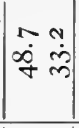 & $\begin{array}{l}9 \\
\text { in } \\
\text { in }\end{array}$ & 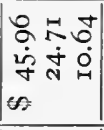 & 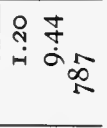 \\
\hline $\begin{array}{l}\stackrel{0}{0} \\
\vdots \\
0\end{array}$ & $\dot{U}$ & 㔯 & 또| & นُ & त̃ & 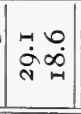 & $\begin{array}{lll}0 & 0 & 0 \\
0 & \dot{i} & \ddots \\
\dot{H} & \end{array}$ & 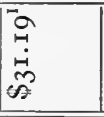 & \\
\hline $\begin{array}{l}\ddot{U} \\
\ddot{\ddot{z}}\end{array}$ & $\underset{U}{E}$ & $\begin{array}{l}\text { w } \\
\text { 号 }\end{array}$ & $\begin{array}{l}\stackrel{\infty}{\infty} \\
\dot{\sim}\end{array}$ & $\underset{⿱ 亠 乂}{+} \stackrel{\infty}{+}$ & 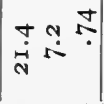 & 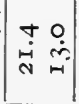 & $\begin{array}{ll}90 & 6 \\
\dot{d} & 1\end{array}$ & 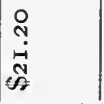 & \\
\hline 袁 & $\stackrel{\mathscr{Z}}{U}$ & 起总 & \begin{tabular}{ll|}
0 & 1 \\
0 & 0
\end{tabular} & 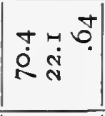 & 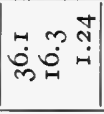 & 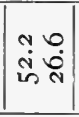 & 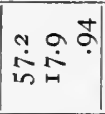 & $\begin{array}{ll}a & 1 \\
-1 & 0 \\
\infty & \infty \\
\tilde{N}^{2} & -1\end{array}$ & \\
\hline$\frac{0}{0}$ & ú & 紊 & $\begin{array}{ll}\dot{+} 0 & 0 \\
\mathbb{1}\end{array}$ & ำ & 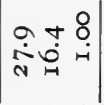 & $\begin{array}{ll}\infty & + \\
\dot{v} & \dot{v}\end{array}$ & 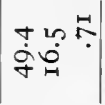 & 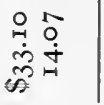 & \\
\hline & $U^{ \pm}$ & 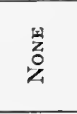 & 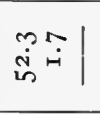 & $\begin{array}{ll}\infty & \infty \\
\operatorname{mb}^{\infty} & ?\end{array}$ & 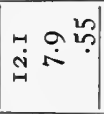 & 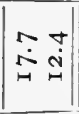 & 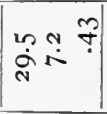 & 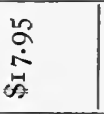 & \\
\hline & $\begin{array}{l}\dot{0} \\
z \\
5 \\
0 \\
0\end{array}$ & 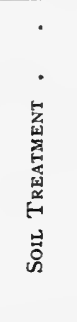 & 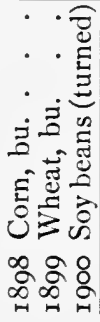 & 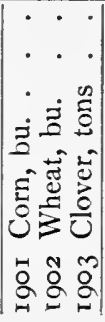 & 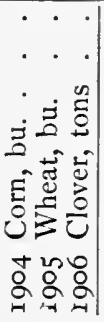 & 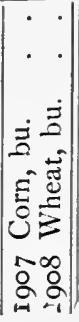 & 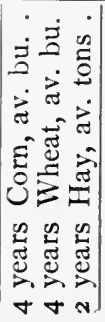 & 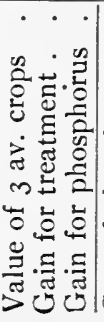 & 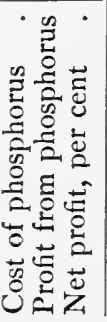 \\
\hline
\end{tabular}


comparison, will, as a rule, give more trustworthy results. Thus, we may subtract the average yields of the adjoining untreated plots, $\mathrm{I}_{4}$ and $\mathrm{I} 7$, from the yields of the manured plots, $\mathrm{I}_{5}$ and 16 , to determine the increase produced by manure alone. Then we may subtract the yield either of plot 4 or the average yield of the three untreated plots, I, 4, and 7, from the yields of the plots which receive both manure and phosphorus, to determine the increase produced by manure and phosphorus combined, subtracting from these figures the increases for manure alone, to determine the effect of phosphorus. Still another method would be to average all of the untreated plots whose results are in satisfactory agreement, and discard the results of those that differ so widely as to be clearly abnormal. By this method probably the results from plots $\mathrm{Ar}, \mathrm{B}_{7}$, and $\mathrm{Cr}$ would be discarded.

$\mathrm{By}$ any of these methods of comparison, direct or indirect, it will be found that, as a general average of all tests on all series, the raw phosphate has produced practically the same gross increase as the acid phosphate, although the acid phosphate applied cost twice as much as the raw phosphate.

Yet another indirect method of comparison can be made and this one is preferred by the Ohio Experiment Station. This method assumes that naturally the land varies somewhat uniformly from one untreated plot to the next untreated plot, so that plot I $_{5}$, for example, if it had remained unmanured, would have produced a yield equal to the sum of two thirds of the yield of plot I4 plus one third of the yield of plot I7, and that this computed yield for plot $5_{5}$ (untreated), subtracted from the actual yield of plot I $_{5}$, gives the increase produced by the manure. The effect of the manure and phosphate is computed in the same manner, and the difference gives the effect of the phosphorus.

'This method would be correct if the assumption upon which it is based were correct; but considering that the change in the direction of such a curve is just as likely to occur on any other plot as on the plots that happen to be numbered I, 3, 4, 7, etc., its application may be of questionable value. However, in Tables 37, 38 , and 39 , the actual yields are reported for the twelve years, and from these any one can make his own deductions.

The total value of the three crops, based upon the average yields, 
is given for each series, counting 35 cents a bushel for corn, 70 cents for wheat, and $\$ 6.00$ a ton for hay. These prices ${ }^{1}$ are based upon the ten-year a verage farm price for Illinois as reported by the United States Department of Agriculture for the years 1899 to I908, for which the reported averages are 40.I cents a bushel for corn, 76.5 cents for wheat, and $\$ 9.32$ a ton for marketable hay. The differences between these averages and the prices used in the tables will probably cover the cost of husking corn and threshing wheat, stacking and baling the hay, and marketing the increase. The value of the increase in corn stover and wheat straw may perhaps cover the extra cost of handling (binding twine, etc.) and occasional losses for poor quality of grain and hay. The prices used are intended to be sufficiently conservative to guard against financial exaggeration. Other prices should be used to suit local conditions.

The special purpose of reducing all results to the basis of value is to make possible a more simple comparison. From these total values of the three crops by plots, the gain for treatment is computed by the Ohio method, except that in Series C the results from plot I are discarded ${ }^{2}$ as being plainly abnormal and untrustworthy. A comparison of the value of crops grown on plots $\mathrm{A}_{2}, \mathrm{~A}_{3}$, and $\mathrm{A}_{5}$, on plots $\mathrm{B}_{2}, \mathrm{~B}_{3}$, and $\mathrm{B}_{5}$, and on plots $\mathrm{C}_{2}, \mathrm{C}_{3}$, and $\mathrm{C}_{5}$, plainly indicates that plot $\mathrm{C}_{2}$ is normal; and the effect of manure and phosphorus on plots $\mathrm{C}_{2}$ and $\mathrm{C}_{3}$ is determineed by subtracting the average results of plots $\mathrm{C}_{4}$ and $\mathrm{C}_{7}$.

It. will be noted that the cost of raw phosphate is reckoned at $\$ 7.50$ per ton and the cost of acid phosphate at $\$ 15$ per ton, or $\$$ I. 20 for 320 pounds of raw phosphate and $\$ 2.40$ for 320 pounds of acid phosphate, applied with the 8 tons of manure every three years.

Three important facts are clearly established by these data: (r) the value of manure, (2) the superiority of stall manure over

${ }^{1}$ Elsewhere the author uses 30 cents a bushel for oats, the ro-year average price for Illinois being 32.2 cents; 40 cents a bushel for barley, 44.7 cents being the Io-year average price for Minnesota and Wisconsin, leading barley states; and 50 cents a bushel for potatoes, the New York ro-year average farm price being 57.6 cents.

${ }^{2}$ A personal communication from Director Thorne states that this plot occupies a depression, running lengthwise of the plot, with higher land on each side. Evi- 
yard manure, and (3) the value of phosphorus when applied in connection with manure. The first two will be further discussed under the subject of farm manure.

As an average of the results from the three series of plots, the value of the increase from 320 pounds of raw phosphate was \$ro. I9 with yard manure and \$10.23 with stall manure; and the value of the increase from 320 pounds of acid phosphate was \$II.77 with yard manure and $\$$ I2.OI with stall manure, the value of the manure alone having been deducted in all cases. If we subtract from these gross gains the cost of the phosphorus, we have average net profits of \$9.0I for raw phosphate and \$9.49 for acid phosphate; or, on the basis of money invested, we have net profits of $75^{\mathrm{I}}$ per cent from raw phosphate and 395 per cent from acid phosphate.

With double the investment the profit per acre is slightly greater from acid phosphate; but, on the basis of money invested, the profit from raw phosphate is almost double that from acid phosphate.

dently more or less surface wash has accumulated in this depression in times past. (See the accompanying contour map of this Ohio field.)

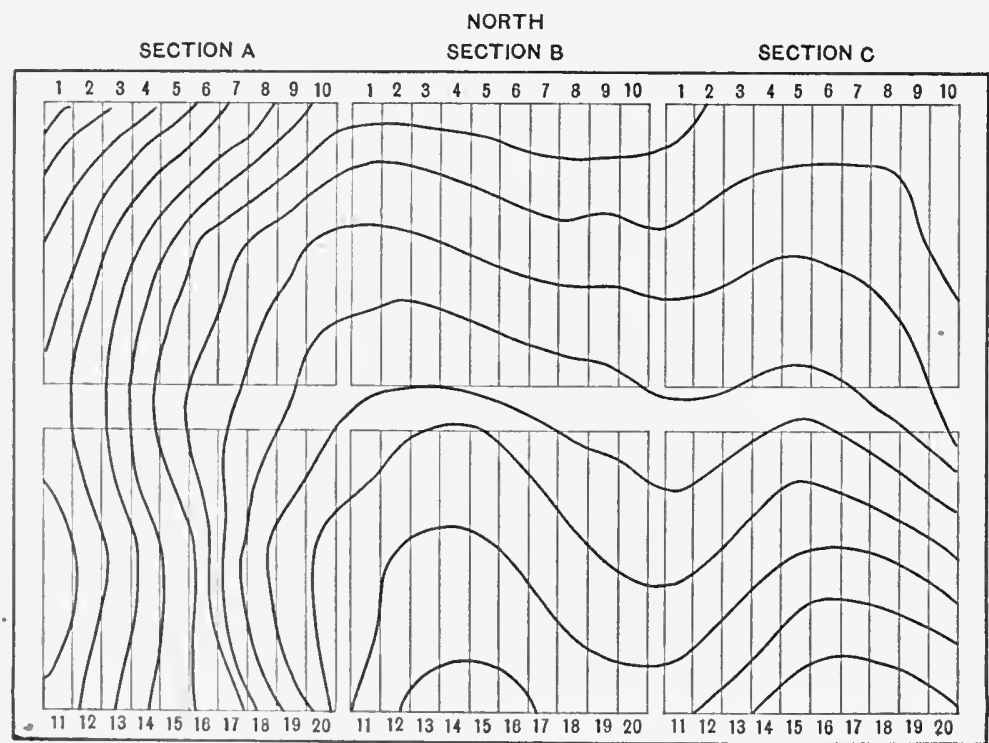

Topography of Land: Ohio Experiment Field

One-foot contour lines; highest land at south end of section C. 
The student or landowner must draw his own conclusions as to which is the better basis upon which to compute the profit. It should be kept in mind that 320 pounds of raw phosphate contains 40 pounds of phosphorus, while 320 pounds of acid phosphate contains about 20 pounds of that element, so that the raw phosphate is enriching the soil in phosphorus twice as much as the acid phosphate, while the removal in crops is practically equal.

An examination of the values of the three crops by plots suggests that the use of the data from plot AI (\$25.02) is unfavorable to the raw phosphate on that series, because of the lower uniform values from plot $\mathrm{A}_{4}\left(\mathbf{\$}_{20.6 \mathrm{I}}\right)$ and plot $\mathrm{A}_{7}(\$ 20.03)$. On the other hand, the use of the data from plot $\mathrm{B}_{7}$ is favorable to the acid phosphate, by the Ohio method of comparison.

By the method of direct comparison, by which the total values from plots 15 and 16 (manure alone) are subtracted from the total values from plots 2 and 3 and from plots 5 and 6, respectively, it will be seen that the average value of the increase is \$10.59 from 320 pounds of raw phosphate, and \$10.6I from 320 pounds of acid phosphate, the net profit per acre being $\$ 9.39$ for the raw phosphate and \$8.2I for the acid phosphate; or, on the basis of money invested, the net profit is 783 per cent for raw phosphate and 342 per cent for acid phosphate. For convenient reference, the average actual yields and values are summarized in the accompanying tabular statement.

Table $39 b$. Ohio Experiments with Manure, Raw Rock Phosphate, and Acid Phosphate

Average of Twelve Years, with Duplicate Tests on Each Field

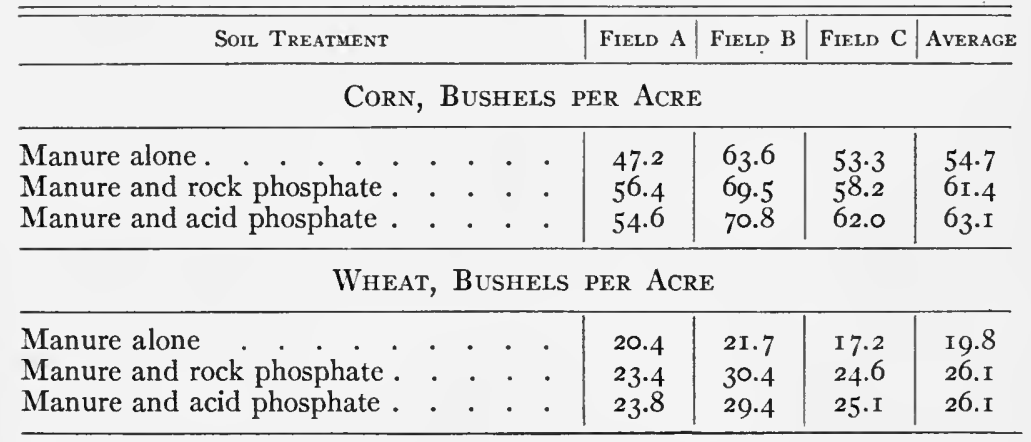


Table 39 . Ohio Experiments with Manure, Raw Rock Phosphate, And Acid Phosphate-Continued

\begin{tabular}{|c|c|c|c|c|c|c|}
\hline Soll Treatment & & & FIELD A & FIELD B & FIELD C & Average \\
\hline \multicolumn{7}{|c|}{ Clover Hay, ToNs per ACre } \\
\hline Manure alone . . . . . & . & & I.99 & I. 34 & .83 & I.39 \\
\hline Manure and rock phosphate. & . & . & 2.47 & I.90 & I. 79 & 2.05 \\
\hline Manure and acid phosphate. & - & . & 2.23 & I. 76 & 1.92 & I.97 \\
\hline
\end{tabular}

Total Value of the Three Crops per Acre

Manure alone

Manure and rock phosphate

Manure and acid phosphate .

\begin{tabular}{r|r|r|r}
$\$ 42.69$ & $\$ 45.47$ & $\$ 35.65$ & $\$ 41.27$ \\
50.86 & 56.42 & 48.30 & 51.86 \\
49.12 & 55.76 & 50.76 & 51.88
\end{tabular}

Cost of rock phosphate for the three crops . . . . . . . . . \$I.20 Cost of acid phosphate for the three crops . . . . . . . . . 2.40

It is worth while to note that the first corn crop on Series C (Table 39) was not benefited by raw phosphate, and the first corn crop on Series B (Table 38) was increased only 2.7 bushels, as an average, by raw phosphate, while other instances appear in which phosphorus produced no apparent benefit, as, for example, with stall manure for corn in I90I and I906, and with either manure for wheat in 1907 , all of which emphasizes the fact that one field trial with one crop for one year may have almost no value in determining the effect of additions of phosphorus to the soil.

Director 'Thorne has expressed some disappointment ${ }^{1}$ because

${ }^{1}$ Considering its source, the following statement by Director Thorne, taken by itself, probably constitutes the strongest "evidence" that can be quoted in favor of acid phosphate and against the use of raw rock phosphate. In referring to the general averages of all results secured in these manure-phosphate experiments from 1897 to 1907 , he says (Ohio Agricultural Experiment Station Circular 83 , page 23):

"While the treaiment of manure has in every case increased its effectiveness, the gain per acre produced by reënforcing the manure with acid phosphate has been so much greater than that from any other treatment that it has not been profitable to use anything else, even though the other materials had cost nothing."

Of course, in this statement, Director Thorne refers not to profit on investment, but to profit per acre regardless of the amount invested, and he includes the data 


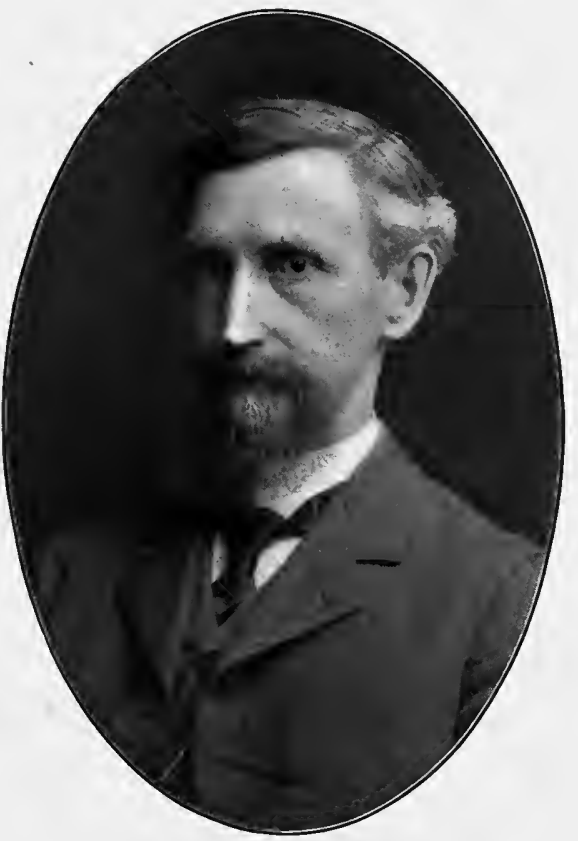

Charles E. Thorne, Director of Ohio Agricultural Experiment Station 


$$
\cdot
$$

.

. .

(1)

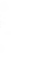
. 
the 40 pounds of phosphorus applied in raw phosphate has not produced markedly greater benefit than the 20 pounds in acid phosphate, these applications having been repeated in connection with manure every three years for twelve years. This is an important and interesting question. It may be best considered in connection with the general a verage yields recorded in Table 40, which, it may be observed, includes results from the use of kainit, gypsum, and "complete" fertilizers. The amounts of kainit and gypsum used are the same as raw phosphate and acid phosphate; namely, 320 pounds with 8 tons of manure per acre every three years. The kainit costs about $\$ 15$ per ton and the gypsum about $\$ 6$ per ton. The footnotes to Table 40 give further data, so that any one may make his own computations concerning the increase in yield or profit from every kind of treatment. (See also page 299.)

Attention is called to the fact that plot II is a continuation of plot $\mathrm{I}$, and on Series C it is so abnormal that its influence is seen in the general average of every crop.

By computations from Tables 23 and 40 it is a simple matter to construct most of Table 4I, in which a balance is shown for the elements nitrogen and phosphorus supplied and removed in these experiments with manure and phosphates.

The figures given in Table $4 \mathrm{I}$ may be considered as approximately correct, but the amounts of nitrogen furnished by the soil and by the clover residues are roughly estimated. This estimate is based upon the assumption that the total clover tops, aside from the clover hay harvested, will be equivalent to one half of the regular hay crop. These residues consist of (I) the first season's growth, chiefly after the wheat harvest; (2) the fall growth the second season; and (3) the following spring growth before plowing for corn. These estimates are added to Table $4 \mathbf{r}$, not as well-established facts, but rather as suggesting methods of study that deserve further investigation. To one familiar with field conditions it seems certain that the clover is given at least all credit due for

from plot $\mathrm{C}_{\mathrm{I}}$ in computing the increase produced by the raw phosphate by the Ohio method of comparison. As a suitable topic for a debating society, the author suggests the question:

Shall we use acid phosphate or raw rock phosphate in systems of permanent agriculture? (See page 299 for later average results.) 


\section{SYSTEMS OF PERMANENT AGRICULTURE}

Table 40. Crop Yields per Acre in Ohio Experiments With Manure, Phosphates, Kainit, Gypsum, and "Complete" Fertilizers

Average of Three Series

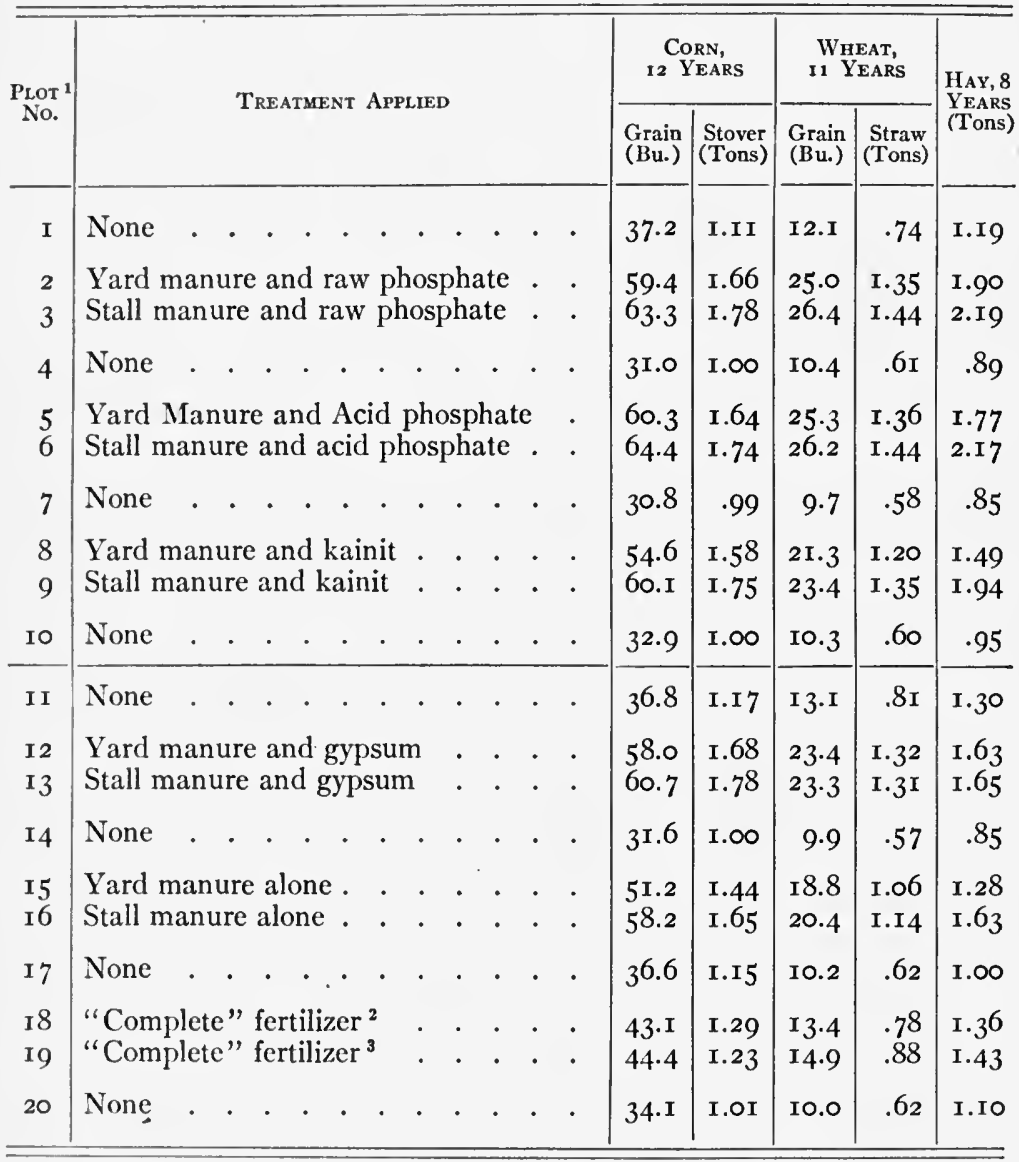

${ }^{1}$ In the field, plots I and I I, 2 and I 2 , etc., lie end-to-end, plot I I being essentially a continuation of plot $I$, etc.

${ }^{2}$ The "complete" fertilizer applied to plot I8, every three years, contains $\mathrm{I} 60$ pounds sodium nitrate, 80 pounds acid phosphate, and 80 pounds potassium chlorid.

2 The "complete" fertilizer applied to plot I9, every three years, consists of roo pounds of slaughter-house tankage (containing 6 pounds of nitrogen and 6 pounds of phosphorus), so pounds of acid phosphate, and Io pounds of potassium chlorid. 
Table 4I. Balance Sheet for Nitrogen and Phosphorus in ManurePhosphate Experiments

Totals for Three Years, Pounds per Acre: in Part roughly Estimated

\begin{tabular}{|c|c|c|c|c|}
\hline Plot No. . & 2 & 3 & 5 & 6 \\
\hline Treatment Applied & $\begin{array}{c}\text { YARD } \\
\text { MANURE, } \\
\text { RAW } \\
\text { PHOS- } \\
\text { PHATE }\end{array}$ & \begin{tabular}{|} 
STALL \\
MANURE, \\
RAW \\
PHOS- \\
PHATE
\end{tabular} & \begin{tabular}{|c} 
YaRD \\
MaNURE \\
ACID \\
PHOS- \\
PHATE
\end{tabular} & $\begin{array}{c}\text { Stall } \\
\text { MaNURE } \\
\text { ACID } \\
\text { PHOS- } \\
\text { PHATE }\end{array}$ \\
\hline 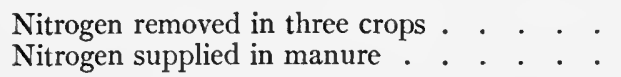 & $\begin{array}{r}211 \\
80\end{array}$ & $\begin{array}{r}232 \\
80\end{array}$ & $\begin{array}{r}207 \\
80\end{array}$ & $\begin{array}{r}231 \\
80\end{array}$ \\
\hline 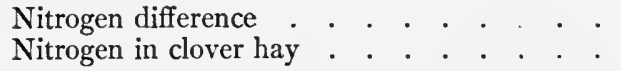 & $\begin{array}{r}131 \\
76\end{array}$ & $\begin{array}{r}152 \\
88\end{array}$ & $\begin{array}{r}127 \\
7 \mathrm{I}\end{array}$ & $\begin{array}{r}\mathbf{I} 5 \mathrm{I} \\
87 \\
\end{array}$ \\
\hline $\begin{array}{l}\text { Nitrogen from soil and clover residues } . \\
\text { Nitrogen from clover residues (estimated). }\end{array}$ & $\begin{array}{l}55 \\
38\end{array}$ & $\begin{array}{l}64 \\
44\end{array}$ & $\begin{array}{l}56 \\
36\end{array}$ & $\begin{array}{l}64 \\
44\end{array}$ \\
\hline Nitrogen furnished by soil (estimated) . . & I 7 & 20 & 20 & 20 \\
\hline 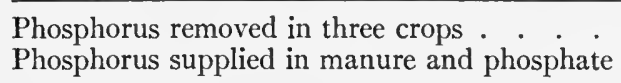 & $\begin{array}{l}3 \mathrm{I} \\
64\end{array}$ & $\begin{array}{l}34 \\
56 \\
\end{array}$ & $\begin{array}{l}3 \text { I } \\
44 \\
\end{array}$ & $\begin{array}{l}34 \\
36 \\
\end{array}$ \\
\hline Phosphorus added in excess . . . . . . . & 33 & 22 & 13 & 2 \\
\hline
\end{tabular}

nitrogen fixation. In other words, that the draft upon the soil by the crops grown is likely to be greater rather than less than 20 pounds above that supplied by the manure and clover, and, in addition to this, there are losses of nitrogen in drainage waters probably exceeding all other additions (as in rainwater, by azotobacter, etc.). The loss of nitrogen by drainage is no doubt much greater from the best-treated plots than from the untreated plots. Failing nitrogen may finally reduce the phosphorus effect.

On the whole, it seems clear that nitrogen must limit the crop yields on these four plots treated with manure and phosphate. On the other hand, in every case the phosphorus applied exceeds the amount removed in the crops, so that, instead of there being any draft upon the soil, there is a positive increase in the phosphorus content of the soil above the crop requirements. This increase varies from 2 and I 3 pounds with acid phosphate to 22 and 33 pounds with raw phosphate. If nitrogen is the limiting element on all of these manure-phosphate plots, it is plain to see why the raw phosphate gives practically no larger yields than the acid phos- 
phate, even though twice as much phosphorus is applied in the raw phosphate as in the acid phosphate. If more clover were plowed under or if more manure were returned, so as to remove the nitrogen limit, the comparative value of the two forms of phosphorus could, perhaps, be more definitely determined. Such additional supplics of decaying organic matter would tend to make available still larger supplies of potassium, magnesium, etc., and thus to avoid their becoming limiting factors. It is possible that the use of acid phosphate tends to prevent loss of ammonia from the manure during the few weeks that elapse between the mixing of the phosphate with manure and the application to the land.

Two important facts are well established by these Ohio experiments: First, that fine-ground natural rock phosphate is a material that can be employed with very large profit as a phosphorus fertilizer, when used in connection with liberal amounts of decaying organic matter; and, second, that, under the conditions of these experiments, the raw phosphate gave practically the same profit per acre, and twice as much profit for the money invested, as the acid phosphate. (For later averages, see page 299.)

In the Ohio Farmer for August 22, I908, Director Thorne reports some interesting and valuable results showing the effect of raw phosphate on clover grown in 1908 on the Strongsville Experiment Farm, located between Wooster and Cleveland, on a heavier type of soil of nearly level topography. The author has also been given the figures for the rgo8 oat crop.

Director Thorne states that lime and raw phosphate were applied across the plots in the five-year rotation, "dividing the section of plots into 4 divisions, using one ton of lime per acre on the first, two tons of lime on the second, one ton of floats on the third, and two tons of floats on the fourth, applying the lime and floats across all the plots, fertilized and unfertilized alike."

The crops grown in the five-ycar rotation experiments at Strongsville are corn, oats, wheat, clover, and timothy, and the fertilizers applied are similar to those in the older five-year rotation at Wooster as reported in Table 82 , with ten additional plots in each series. It is understood that during the course of five years all of the series have received (or will receive) the treatment with lime and raw phosphate, as above described. 
The data thus far reported concern only the clover and oats for I908, and they almost certainly show more marked differences than will appear from long-continued and more general experiments:

Ohio Experiments with Lime and Raw Phosphate

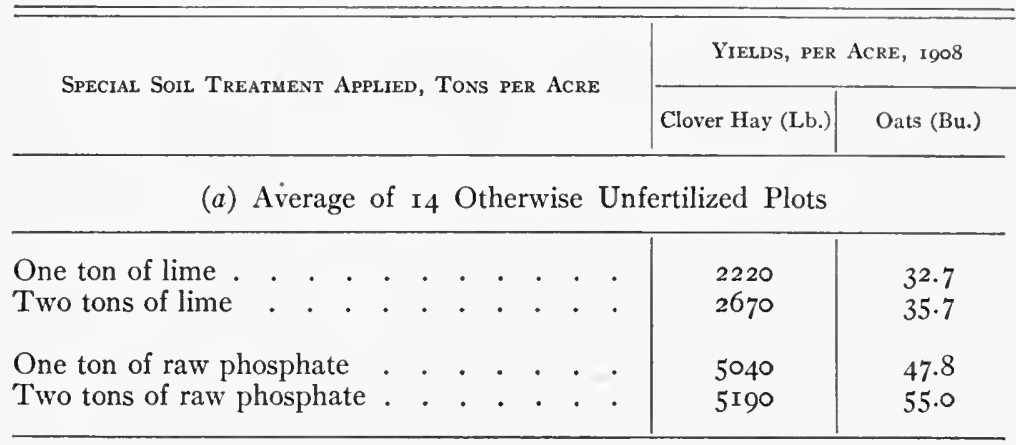

(b) Average of 26 Otherwise Fertilized Plots

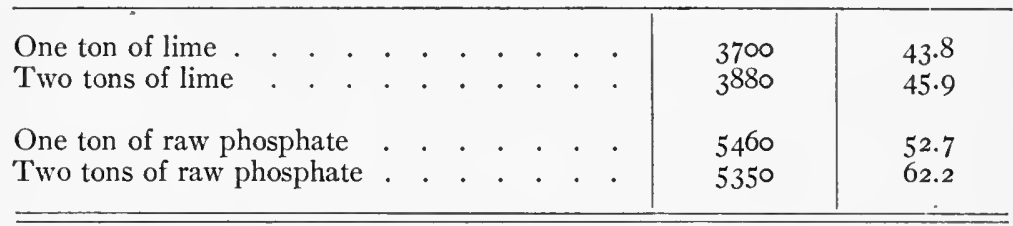

Even if we assume that the lime produced no increase, the effect of the raw phosphate is very marked. On the "otherwise unfertilized" land one ton of raw phosphate per acre produced I.4I tons more clover and I5. I bushels more oats, the value of which, at $\$ 6$ per ton and 30 cents a bushel, respectively, would amount to $\$_{12.99}$, or enough to pay for two tons of raw phosphate at $\$ 3.50$ per ton where the freight rate does not exceed $\$_{3}$ (as in southern Illinois).

The two-ton application produced markedly greater effect on the oats, but not on the clover. These results include two entirely separate series of plots, and each reported yield is the average from a large number of plots. The data must not be considered as exceedingly trustworthy, but we must agree with Director Thorne's statement that "it looks as though we were getting something worth while there." Knowing that the effect of lime where needed 
is usually marked on both clover and oats, the "increase" given for phosphate must be regarded as quite unusual. Not more than one tenth of the phosphorus applied would be removed in the two crops. These results point toward the possibility of adopting profitable systems of permanent agriculture; and yet the most common fertilizer practice among the farmers of Ohio is to apply about 7 pounds of soluble phosphorus per acre, with 3 or 4 pounds each of nitrogen and potassium, in 200 pounds of "complete" fertilizer about twice during a four-year or five-year rotation.

In the Rural New Yorker for June 5, I909, Director Thorne reports an average yield of 2440 pounds of clover hay with lime applied, and $5 \times 12$ pounds where rock phosphate is used, with no other fertilizers; and where nitrogen or potassium had been applied, the yield with lime was 2606 pounds and with rock phosphate, 5488 pounds, although where lime and a "complete" fertilizer, including nitrogen, potassium, and 480 pounds of acid phosphate, were used, the total yield of clover hay was only 4259 pounds. The following comment is made by Thorne:

"'This experiment thus indicates that floats (raw phosphate) may be very usefully employed for the combined purpose of carrying lime and phosphorus, the increase over the limed land being more than enough in this one crop to pay for one ton of floats per acre, which quantity has seemed to be as effective as the larger quantity, although the two tons of lime have produced a larger yield than the one ton, though not enough larger to pay the additional cost. This experiment, therefore, is confirming those of the Maryland and Illinois stations in showing that floats may be profitably used as a carrier of phosphorus on acid soils well stocked with organic matter, but the meager effect produced upon cereal crops preceding clover would call for caution in depending upon floats alone."

Of course, more clover means more humus and more nitrogen if the clover is plowed under either directly or in manure; and, while the cereal crops preceding clover are quite certain to be unsatisfactory, they are sure to be increased after plowing under the larger amount of clover or manure with phosphate. The data reported by $T$ horne in these experiments do not show what increase was produced by lime alone, all plots having been treated either with lime or with raw phosphate, and consequently there seems to be no support for the suggestion that the effect of the raw phosphate is in part due to the lime which it carries. In fact, the ordi- 
nary high-grade raw phosphate carries very little, if any, lime, about 7 per cent of calcium carbonate being the largest amount in any high-grade phosphate known to the author. Tricalcium phosphate is a neutral substance which has practically no power to correct soil acidity, except as the phosphorus is converted into the dicalcium or monocalcium compound and removed from the soil by the growing crop.

Furthermore, the most marked benefit from the use of raw rock phosphate in Illinois is not on markedly acid soils, but on the most common corn-belt prairie land, as on the Urbana and Galesburg experiment fields on brown silt loams, which are practically neutral soils valued at $\$$ I 50 to $\$ 200$ an acre.

The Ohio investigations with raw and acid phosphates are in a class by themselves. No others have been conducted anywhere in the world that can compare with these in agricultural value. Many experiments with various phosphates have been carried on for a single season, and some for several years, but, as a rule, no farm manure has been used, and no adequate provision made for a supply of decaying organic matter. Where nitrogen has been supplied, it has usually been in some commercial form, such as sodium nitrate. One exception to this is found in the Maryland experiments, which have been conducted on one field since 1895 , eleven years' results having been reported by Director Patterson (Maryland Bulletin II4). Aside from single plots treated with different acid phosphates and reverted phosphates in the Crimson Clover Series, there is a strictly comparable triplicate test with (I) raw bone meal, (2) slag phosphate, (3) no phosphate, (4) South Carolina raw rock phosphate, and (5) Florida soft rock phosphate (containing phosphates of iron and aluminum). Equal amounts of phosphorus were used in all tests, $65 \frac{1}{2}$ pounds of phosphorus per acre having been applied only at the beginning of the experiment. The surface soil contained 1300 pounds of phosphorus in 2 million pounds of the soil.

The following crops were grown:
Corn in 1895 .
Wheat in 1899 .
Corn in I9o3.
Corn in 1896.
Hay in 1900 .
Corn in 1897 .
Hay in I9or.
Crop failure in 1898 .
Corn in Igo2.
Wheat in I904.
Hay in 1905 .
Corn in 1906. 
In one series of tests, crimson clover was regularly seeded in the corn to be plowed under later as a green manure, and in another series rye was employed in a similar manner, the third test being made without special provision for organic matter. Table 42 gives a summary of these investigations for all forms of phosphorus that were used under the three different conditions:

\section{Table 42. Maryland Experiments with Different Forms OF PHOSPHORUS}

Twelve Years' Work: Yields per Acre: Average of Three Plots

\begin{tabular}{|c|c|c|c|c|c|c|c|c|}
\hline \multirow{2}{*}{ Plot Nos. } & \multirow{2}{*}{ Phosphorus APPLIED } & & \multicolumn{2}{|c|}{$\begin{array}{l}\text { SIx Corn } \\
\text { Crops, Av. }\end{array}$} & \multicolumn{2}{|c|}{$\begin{array}{l}\text { Two Wheat } \\
\text { Crops, Av. }\end{array}$} & \multirow{2}{*}{$\begin{array}{c}\text { THREE } \\
\text { HAY } \\
\text { CROPS, } \\
\text { Av. } \\
\text { (Tons) }\end{array}$} & \multirow{2}{*}{$\begin{array}{l}\text { Total } \\
\text { AVER- } \\
\text { AGE } \\
\text { YIELD } \\
\text { (Tons) }\end{array}$} \\
\hline & & & $\begin{array}{l}\text { Grain } \\
\text { (Bu.) }\end{array}$ & $\begin{array}{c}\text { Stover } \\
\text { (Tons) }\end{array}$ & $\begin{array}{c}\text { Grain } \\
(\text { Bu. })\end{array}$ & $\begin{array}{l}\text { Stoiver } \\
\text { (Tons) }\end{array}$ & & \\
\hline 8, I 3, I 8 & Raw bone meal & & $39 \cdot 6$ & 1.25 & 23.6 & I. 22 & I. 85 & $6.4 \mathrm{I}$ \\
\hline 9, I 4, I9 & Slag phosphate & & 39.1 & I. 22 & 22.6 & $\mathrm{r} .24$ & x.95 & 6.46 \\
\hline $10,15,20$ & No phosphorus . . & & 40.0 & I. 7 & I 2.I & .73 & I. 44 & 5.10 \\
\hline II, I6, 2 I & S. C. rock phosphate & $\cdot$ & 39.7 & I.25 & 20.I & 1.07 & I.95 & 6.26 \\
\hline $12,17,22$ & Florida soft rock. . & • & 42.5 & 1.27 & I9.9 & .94 & I.89 & 6.19 \\
\hline
\end{tabular}

Here are represented thirty-three separate tests (three plots for eleven years) for each form of phosphorus. As an average, the raw rock has given nearly the same results as the bone and slag. The average increase in yield is very marked with wheat, less marked with hay, and practically no effect is seen with corn. The value of the total increase in twelve years is about ten times the cost of the raw rock phosphate, at Illinois prices, and still more at Maryland prices, for farm produce. In commenting upon his experiments, Director Patterson says:

"The results obtained with the insoluble phosphates has cost usually less than one half as much as that with the soluble phosphates.

"The results show decidedly that plants are able to utilize insoluble rock phosphates.

"The use of an abundance of organic matter in the soil when insoluble phosphates are applied was evidently a necessity for their best effects.

"Soluble phosphates produced the best yield of wheat.

"Florida soft phosphate produced the best yield of corn.

"Reverted phosphates produced the best yield of hay. 
"Insoluble South Carolina phosphate rock produced a higher total average yield than dissolved South Carolina rock.

"Florida soft phosphate is chiefly an aluminum-iron phosphate which occurs in large quantities deposited in many parts of that state. It is not well adapted to treatment with acid for making soluble phosphates, as the aluminum and iron make a sticky mass which is hard to dry and keep in a good mechanical condition. The Florida soft rock has been largely used as a fertilizer in its natural condition in some parts of that state on the light, sandy land, giving good "results. When used in this way, there has been applied at the same time heavy dressings of the native mucks from the swamps and lakes. This muck furnishes nitrogen as well as the much-needed organic matter. In order to have a complete fertilizer, there is also applied some German potash ${ }^{1}$ salt."

The Pennsylvania Experiment Station has reported the results of an experiment extending over twelve years (I884 to I895), in which four different kinds of phosphorus were used in a four-year rotation of corn, oats, wheat, and hay (clover and timothy). Only one field was employed, so that each crop was grown only three times during the twelve years.

The four forms of phosphorus were (I) acid phosphate made from bone black, (2) "reverted" phosphate made by mixing equal weights of dissolved bone black and quicklime twelve hours before application, (3) fine-ground bone meal (containing 8 pounds of nitrogen and 35 pounds of phosphorus in 300 pounds of bone), and South Carolina ground raw rock phosphate. The amounts applied per acre in each four years were 28 pounds of soluble and " reverted" phosphorus, and 35 pounds in bone and raw rock.

No special provision was made for supplying decaying organic matter, but 94 pounds of nitrogen (102 pounds on the bone-meal plots) and 83 pounds of potassium (in potassium chlorid) were applied per acre, each four years, to all phosphorus plots and also to two comparison plots that received no phosphorus. In addition, there were two plots that received no application of plant food. The entire experiment was carried on in duplicate. One half of the fertilizer for the rotation was applied to the corn crop and the other half to the wheat crop.

Table $43^{a}$ gives the average yields of all products harvested dur-

1 Most peat soils and some sands are extremely deficient in potassium, and it is also difficult to liberate potassium that may exist locked up in coarse sand grains, as suggested, for example, by the Illinois experiments at Momence, p. 474. - C. G. H. 
ing the entire twelve years, and Table $43^{b}$ gives the average results for the last four years.

Table 43. Pennsylvania Experiments with Different Forms of Phos phorus: Yields per Acre: Average of Duplicate Plots

(a) Average of Twelve Years' Work

\begin{tabular}{|c|c|c|c|c|c|c|c|c|}
\hline \multirow{2}{*}{$\begin{array}{l}\text { Plot } \\
\text { Nos. }\end{array}$} & \multirow{2}{*}{ Plant Food Applied } & \multicolumn{2}{|c|}{$\begin{array}{c}\text { CORn, } \\
\text { 3-YEAR } \\
\text { AVERAGE }\end{array}$} & \multicolumn{2}{|c|}{$\begin{array}{c}\text { OATS, } \\
\text { 3-YEAR } \\
\text { AVERAGE }\end{array}$} & \multicolumn{2}{|c|}{$\begin{array}{c}\text { WHEAT, } \\
\text { 3-YEAR } \\
\text { AVERAGE }\end{array}$} & \multirow{2}{*}{ 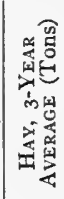 } \\
\hline & & $\begin{array}{l}\text { Grain } \\
(\mathrm{Bu} .)\end{array}$ & $\begin{array}{l}\text { Straw } \\
\text { (T.) }\end{array}$ & $\begin{array}{l}\text { Grain } \\
(\mathrm{Bu} .)\end{array}$ & $\begin{array}{l}\text { Straw } \\
\text { ('T.) }\end{array}$ & $\begin{array}{l}\text { Grain } \\
\text { (Bu.) }\end{array}$ & $\begin{array}{c}\text { Straw } \\
\text { (T.) }\end{array}$ & \\
\hline$A \& G$ & NK and dissolved bone black & 48.9 & .97 & 43.8 & .67 & 28.2 & $\mathrm{I} .5 \mathrm{I}$ & $1.5^{8}$ \\
\hline $\mathrm{B} \& \mathrm{H}$ & NK and "reverted" bone black & 49.6 & .97 & $47 \cdot 1$ & .66 & 29.9 & 1.60 & $-x_{0}$ \\
\hline$C \& I$ & NK and bone meal & 52.0 & 1.04 & $49 \cdot 4$ & .80 & 31.6 & 1.67 & 1.68 \\
\hline D $\& \mathrm{~J}$ & NK and raw rock phosphate. & 47.6 & .95 & 48.2 & .78 & $3^{1} .6$ & 1.67 & 1.57 \\
\hline $\mathrm{E} \& \mathrm{~K}$ & Nitrogen and potassium only . & 40.7 & .83 & $45 \cdot 5$ & $.6 \mathrm{r}$ & 30.6 & 1.40 & I.25 \\
\hline$F \& L$ & None . . . . . . . . . & 33. I & $.5 \mathrm{I}$ & $3^{8.8}$ & .55 & 22.5 & .98 & 1.02 \\
\hline
\end{tabular}

(b) Average of Last Four Years

\begin{tabular}{|c|c|c|c|c|c|c|c|c|}
\hline$A \& G$ & NK and dissolved bone black & 49.3 & $.9^{9}$ & 33.6 & .89 & 22.7 & I.6r & 2.05 \\
\hline $\mathrm{B} \& \mathrm{H}$ & NK and "reverted" bone black & $54 \cdot 3$ & I.O3 & $3^{8.3}$ & .87 & $25 \cdot 4$ & I. $5 \mathrm{I}$ & $2 \cdot 3^{6}$ \\
\hline$C \& I$ & NK and bone meal . . . . & 55.0 & 1.08 & 39. I & 1.00 & 25.9 & I. 75 & 2.40 \\
\hline D \& J & NK and raw rock phosphate . & 50.0 & .95 & 39.2 & $.9 \mathrm{I}$ & 26.3 & I.69 & 2.13 \\
\hline $\mathrm{E} \& \mathrm{~K}$ & Nitrogen and potassium only. & $4 I .4$ & .83 & 30.8 & .59 & 23.9 & $1.2 \mathrm{I}$ & 1.93 \\
\hline $\mathrm{F} \& \mathrm{~L}$ & None . . . . . . . . . & 32.9 & .47 & 22.2 & .69 & 21.4 & 1.03 & $\mathrm{I} .45$ \\
\hline
\end{tabular}

By computation it will be found that the cost of the nitrogen and the potassium for four years was $\$ 24.06$ per acre $(\$ 25.26$ on the bone-meal plots); while the phosphorus for four years cost $\$ 3.36$ in soluble or reverted form, $\$ 3.50$ in bone $(\$ 4.70$ including the cost of nitrogen), and $\$ \mathrm{I} .05$ in the raw rock phosphate, at the prices mentioned in Table 24.

At safe prices for increase in produce based upon ro-year averages for the corn belt: corn 35 cents a bushel, oats 30 cents, wheat 70 cents, and hay $\$ 6$ (about $\$ 3$ per ton being allowed for stacking, baling, marketing, and loss), the value of the increase produced in four years by $\$ 24$ worth of nitrogen and potassium is $\$$ II.72 per acre as an average of the twelve years, and \$IO.J9 per 
acre for the last four years; while the value of the increase produced by $\$ 1.05$ worth of raw phosphate (above the increase produced by the nitrogen and potassium) was $\$ 5.85$ per acre as an average of the twelve years, and $\$ 8.4 \mathrm{I}$ for the last four years.

As an average of all crops, the raw phosphate produced larger yields than the acid phosphate (dissolved bone black) and practically the same yields as the reverted phosphate (including lime); but the bone-meal plots gave slightly larger average yields, the increase from $\$ 4.70$ worth of bone meal being $\$ 8.4 \mathrm{r}$ per acre for four years as an average of the entire period, and \$II.47 per acre for the last four years, above the increase produced by nitrogen and potassium alone.

When used in addition to nitrogen and potassium, \$1.05 worth of raw phosphate produced net profits amounting to $\$ 4.80$ per acre every four years as an average of the twelve years, and $\$ 7.36$ for the last four years; while the corresponding net profits from $\$ 4.70$ worth of bone meal were $\$ 3.7 \mathrm{I}$ for the twelve years' average and $\$ 6.77$ for the last four years. Thus, the greatest total net profits were from the raw phosphate. On the basis of money invested in phosphorus, the net profits from raw phosphate were 457 and 700 per cent, and from bone meal they were 79 and 144 per cent, respectively.

In no case was the net profit from the use of phosphorus sufficient to cover the net loss from the use of nitrogen and potassium, so that the total result was a net loss in all cases. It must be kept in mind, too, that the effects produced by phosphorus when used in addition to nitrogen and potassium (over and above those produced by nitrogen and potassium alone) are usually greater than the effects produced by phosphorus when used alone, as is fully shown by other experiments hereinafter discussed.

On the other hand, these Pennsylvania investigations clearly indicate that if the nitrogen were secured from the inexhaustible supply in the air and turned under in the form of farm manure, legume crops, or other residues, and if the potassium can be liberated from the practically inexhaustible supply in the soil by the decay of this same organic matter, then the use of phosphorus would not only be profitable in itself, but the total result of the system should yield large net profits. 
The soil of the farm of the Pennsylvania State College is a residual clay loam from the disintegration, weathering, and leaching of impure limestone. The soil contains 85 to 90 per cent of fine earth and to to 15 per cent of small stones, quartz, silicates, etc. In 2 million pounds of the fine earth of this surface soil there are 1090 pounds of acid-soluble phosphorus and 50,700 pounds of total potassium, an amount equivalent to $\$ 3000$ worth of commercial potassium salts.

The following comments concerning these experiments are made by the Pennsylvania Station (Annual Report for I895, page 210), on the basis of prices prevailing at that time:

"The yearly average for the twelve years gives us a gain per year of $\$ 2.83$ from insoluble phosphorus ${ }^{1}$ (ground bone), $\$ 2.45$ from insoluble phosphorus (South Carolina rock), \$r.6I from reverted phosphorus, and 48 cents from soluble phosphorus, thus giving us considerably better results from the two forms of insoluble phosphorus than from the reverted or soluble forms, thus indicating that the insoluble phosphorus is of more value as a manure than is often supposed, and that it is worthy of more attention than has been given to it in the past."

In I894, the Rhode Island Experiment Station began an investigation to ascertain the relative value of eight different forms of phosphorus, and a ninth form (double superphosphate) was introduced in 1895 . The experiment included the common raw rock phosphate (containing tricalcium phosphate), raw and roasted aluminum phosphate (containing also some iron phosphate), basic slag phosphate, steamed bone meal, and three acid phosphates (one made from raw rock, one from bone meal, and one from bone black), besides the double superphosphate. The following statements from Rhode Island Bulletin II4 give further information:

"According to the original plan of Ex-Director Flagg, like money values of phosphate were to be compared, and the applications were made for several years upon that basis. Owing, however, to the widely varying market prices from year to year, it was decided in 1898 to change the plan of the experiment so as to make it a comparison of like amounts of phosphorus. ${ }^{2}$

"Substitutel for "phosphoric acicl" here and elsewhere.

2 Substituted for "phosphoric acid" here and elsewhere, with equivalent amounts. 
"The crops of 1894 and 1895 were Indian corn and oats, respectively. In the autumn of 1895 the land was replowed and seeded to clover and grass, as follows:

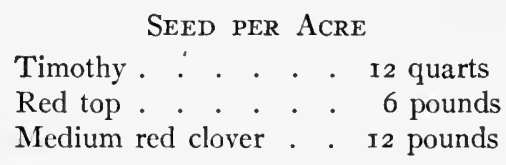

"Owing chiefly to the dryness of the soil, a stand of clover was not secured, and medium red clover was sown again, the next April, at the same rate.

"On account of the fact that some of the phosphates contained soluble phosphorus while others were pratically insoluble in water, all of the more insoluble phosphates were sown broadcast after plowing, and were then thoroughly harrowed into the soil before seeding. These applications were made sufficiently large to cover the crop requirements for three years that the land was expected to be left in grass. It was planned to divide the application of soluble phosphates into three parts, one third to be applied annually as a top dressing, in the spring, together with the nitrogenous and potassic manures which have been applied annually at like rates to all of the plots in both series. Owing to the change in the plan of the experiment in 1898 , the land was left for an additional year in grass. In the spring of 1899 such quantities of phosphates were applied as were supposed, based upon their composition, to equalize the amount of phosphorus upon all the plots. It was discovered, however, in 1902 , that the assistant to whom the calculations were intrusted in I899 omitted to take into account the applications of the insoluble phosphates which had been made in the autumn of 1896 , and owing to this oversight the complete equalization of the phosphorus was not finally accomplished until the spring of 1902. The total aniount of phosphorus which was applied per plot (two fifteenths acre) to all excepting the two check plots, from 1894 to 1902 inclusive, amounted to 43 pounds, or to $322 \frac{1}{2}$ pounds per acre."

Thus, from 1894 to 1898 , the experiments are a comparison of equal money values of different phosphates; from I 899 to I 90 I the common raw phosphate plots contained about one third more applied phosphorus than the soluble phosphorus plots, about one fifth more than the bone-meal and slag plots, and slightly more than the aluminum phosphate plots.

The entire experiment was carried on over two series of plots, one series having been given one ton of burned lime per acre in I894, while the other series remained unlimed.

In I90I, fourteen different kinds of plants were grown, from 3 to 8 rows of each having been planted across all of the plots in both series. In Tables 44 and 45 are given the number of pounds harvested of the different kinds of produce. 


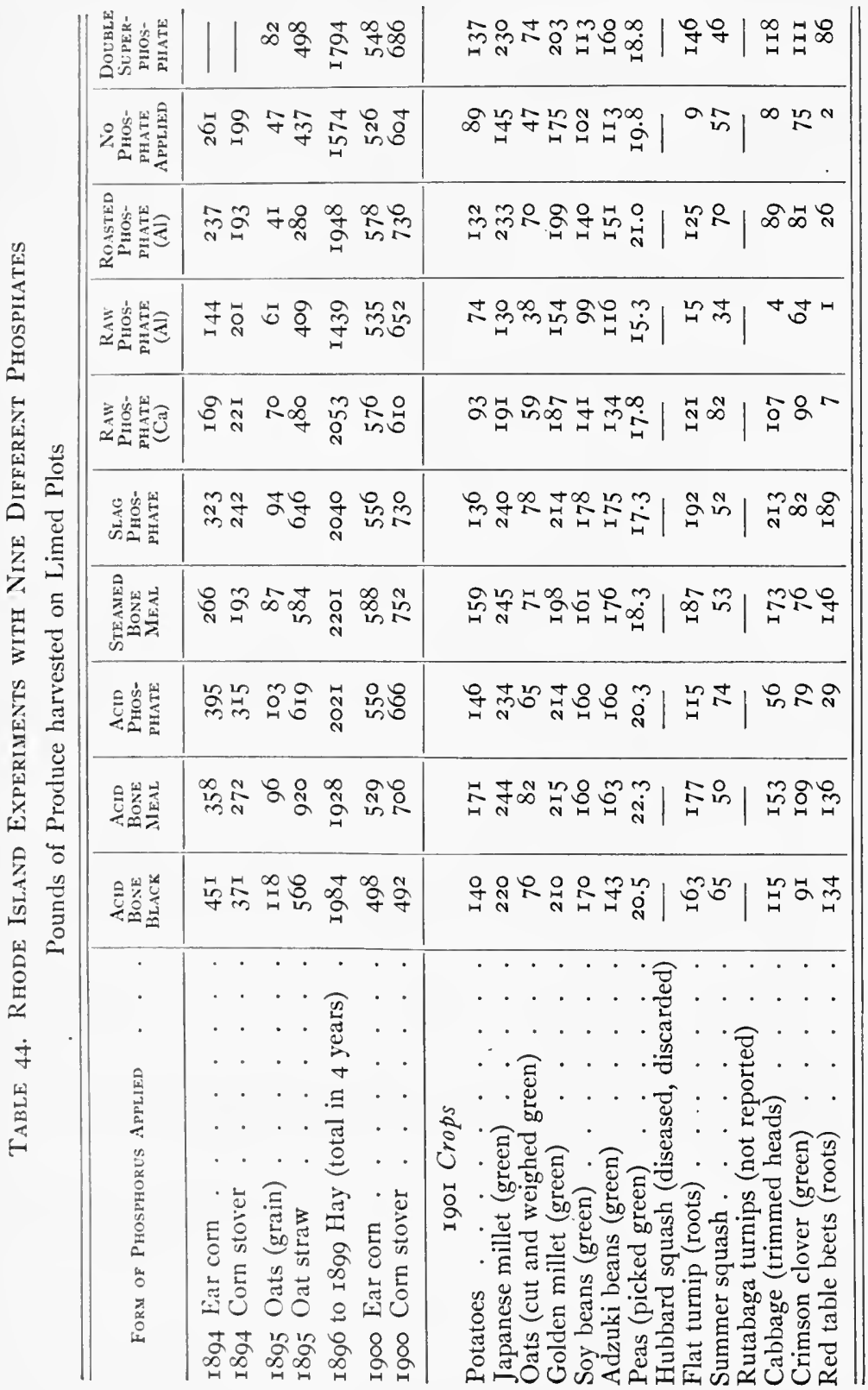


USE OF PHOSPHORUS IN DIFFERENT FORMS 269

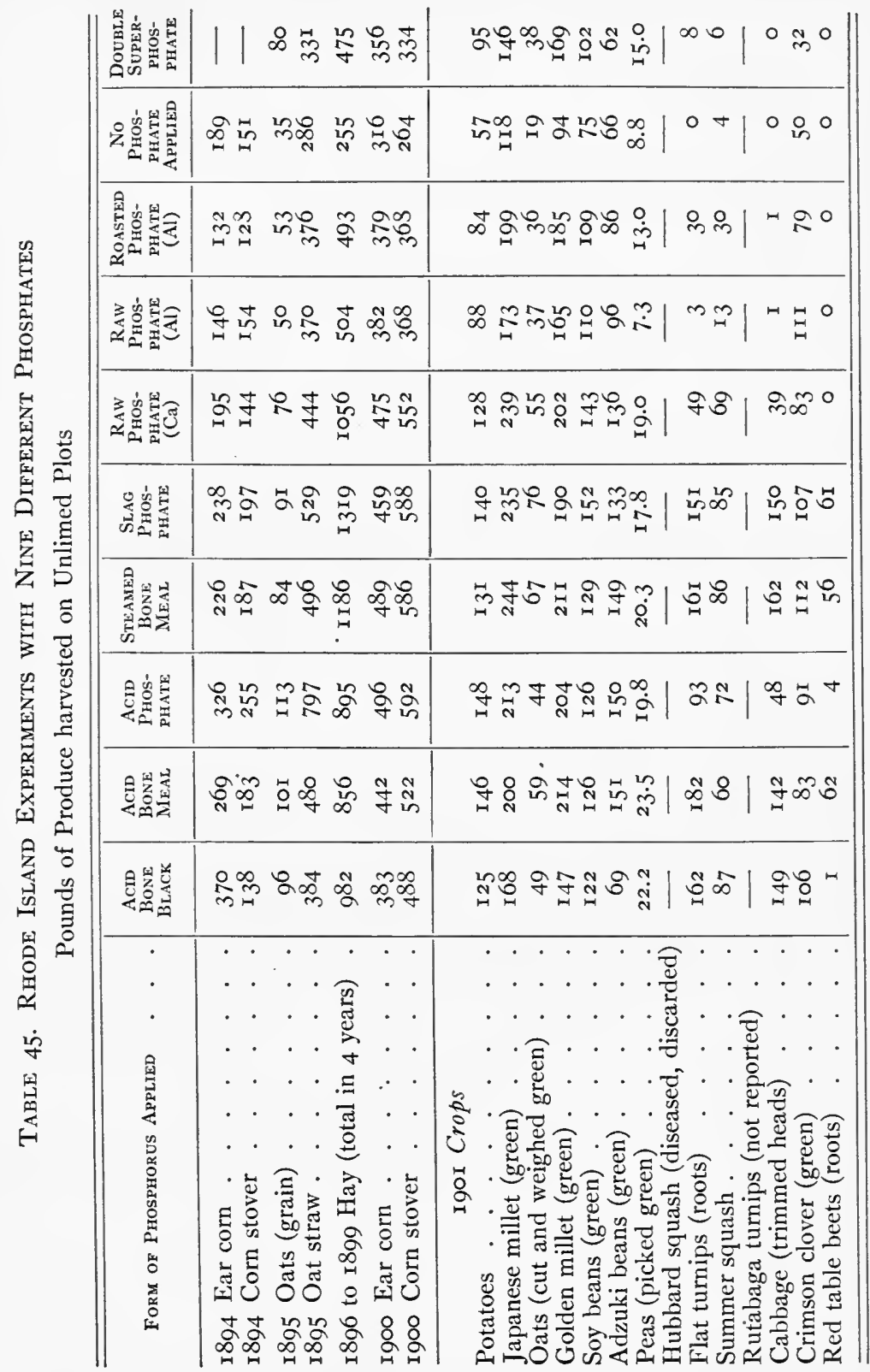


A study of Table 44 shows a decrease in ear corn and a small increase in corn stover from the use of raw calcium phosphate the first year, and some increase in both oats and oat straw the second year. During the next four years this raw rock phosphate produced a larger average increase in the yield of hay than any other form of phosphorus applied, except steamed bone meal. This suggests that the longer growing biennial and perennial plants, such as clover and timothy, may be better able to utilize the raw phosphate than the short-lived annuals.

It is important to keep in mind also that these four years constitute a considerable part of the entire time of the experiment, and that it was only during these four years that the investigations have the greatest practical significance, because the first two years would be required to get the phosphates thoroughly incorporated with the soil and get well under way the action of the various agencies that help to make the raw phosphates available, and it was only during the first six years that equal money values of the different phosphates were used. As stated by the Rhode Island Station, "Dehérain and other French writers recommend that, upon acid soils, such untreated phosphates should be applied several months or a year before liming is resorted to, so as to secure as great a decomposing action upon them by the soil as possible."

In I900, the three largest yields of ear corn were produced by steamed bone meal, raw calcium phosphate, and roasted aluminum phosphate, in the order named.

The results from the several crops grown in rgor are reported as the weight of the fresh or green crops. It will be seen that the raw calcium phosphate produced some increase in eleven of the twelve crops reported, and the average increase from this raw rock phosphate is more than three fourths as much as from the common acid phosphate costing two or three times as much for the applications made previous to rgor.

The relative effects of the different phosphates are about the same on the unlimed land as where some lime had been applied, except that the superiority of the slag phosphate, steamed bone mcal, and common raw rock phosphate (calcium phosphate) over the four acid phosphates (including superphosphate) was even more markerl in the four years' hay crops on the unlimed land. 
As an average, the raw calcium phosphate produced more than 90 per cent as much increase as the common acid phosphate in the various crops grown in rgor on the unlimed land.

The value of the increase produced by the raw calcium phosphate in the hay crops alone is twice the cost of all the phosphorus applied in this form during the eight years.

The value of the lime in the slag phosphate is indicated especially in the increase in hay on the unlimed land. The aluminum phosphates (which also contain some iron phosphate) gave much poorer results than the raw calcium phosphate; but no final conclusions should be drawn regarding this, because the aluminum phosphate may not have been as finely ground as the common rock phosphate, which in these experiments was applied as "floats," the dust that collects about phosphate mills. There is evidently no advantage from roasting the aluminum-iron phosphate (Redondite).

The somewhat poorer results obtained with the double superphosphate, as compared with the other three acidulated phosphates, is probably due to the manufactured land-plaster (calcium sulfate), which is a powerful soil stimulant, and which as already explained constitutes about 50 per cent of ordinary acid phosphate.

It will be noted that the lime itself more than doubled the yield of hay as an average of all plots, and also increased the yield of corn. This Rhode Island soil is acid, and for most crops is markedly improved by liming.

In commenting upon these experiments, Director Wheeler says (Rhode Island Bulletin Ir4):

"With the pea, oat, summer squash, crimson clover, Japanese millet (on the unlimed land), golden millet, white-podded Adzuki bean, soy bean, and potato (on the unlimed land), floats (raw calcium phosphates) gave very good results; but with the flat turnip, table beet, and cabbage they were relatively very inefficient."

"The use of fine-ground bone, basic slag meal, and floats has tended continually to make the unlimed land more favorable to clover, as is well shown by its appearance only upon those plots of the unlimed series where these phosphates had been used, while it was absolutely lacking where the raw and roasted Redondite and the soluble phosphates had been applied. Upon the limed land, clover has been uniformly common upon all the plots."

"Floats can probably be used to best advantage on moist soil, rich in decay. 
ing vegetable matter, and for such crops as certain legumes, Indian corn, millet, and possibly wheat and oats, which seem far better able to make use of them than certain vegetables."

In Tables $44 c$ and $45^{c}$ are recorded the results obtained in the continuation of thesc Rhode Island experiments, with soy beans in I902, with nineteen different kinds of plants in I903 (varying from I row of spinach and 2 rows of lettuce to Io rows of barley and I6 rows of oats), and with oats in 1904 .

The heavy applications made in the spring of 1902 , amounting to 1426 pounds of acid bone black, I 738 pounds of acid bone meal, and $I 77 I$ pounds per acre of acid phosphate, with no additional application of raw calcium phosphate, render the subsequent crop yields of less economic importance, in the author's opinion, but they are of interest because of the great variety of plants represented, although the data are not sufficient to justify very definite conclusions.

The following comments on the results of I902, I903, and I904, are given in Rhode Island Bulletin II8, page 84:

"Floats (raw calcium phosphate) gave very good results with the soy beans, peas, crimson clover, mangel-wurzel (on limed land), barley (on limed land), potato (on unlimed land), Japanese millet, oats, and golden millet; but they proved highly inefficient, especially for Hubbard squash, rutabaga, crookneck squash, flat turnip, cabbage, mangel-wurzel (on the acid unlimed land), tomato, lettuce, New Zealand spinach, and red valentine bean."

One of the oldest known facts concerning plant nutrition is the weak power of turnips and other plants of the cabbage family (Cruciferæ) to secure phosphorus from insoluble forms. Thus, almost the first important result of Sir John Lawes' agricultural experiments was the discovery, seventy years ago, that dissolved bone black was very much more efficient than the untreated material for the production of turnips.

In no case in the Rhode Island results for 1902, I903, or I904, with soy beans, crimson clover, millet, or oats (representing the farm grains, grasses, and legumes) was the increase from acid phosphate double the increase from raw calcium phosphate, and as an average of the results with these crops (on limed or on unlimed plots) the increase from acid phosphate was not more than $\mathbf{I} \frac{\mathbf{1}}{\mathbf{2}}$ times that from the raw calcium phosphate, although the cost of 
USE OF PHOSPHORUS IN DIFFERENT FORMS

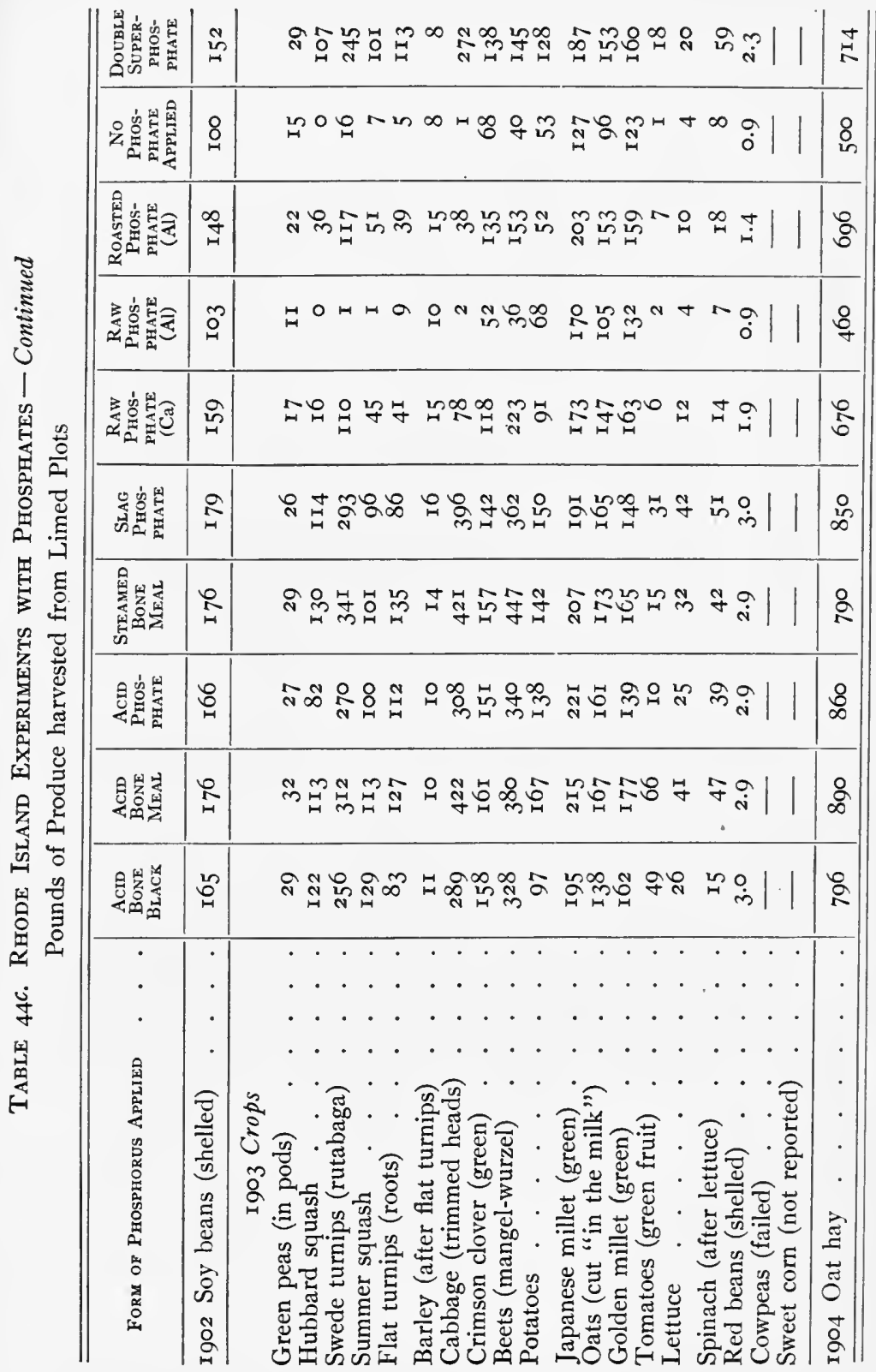




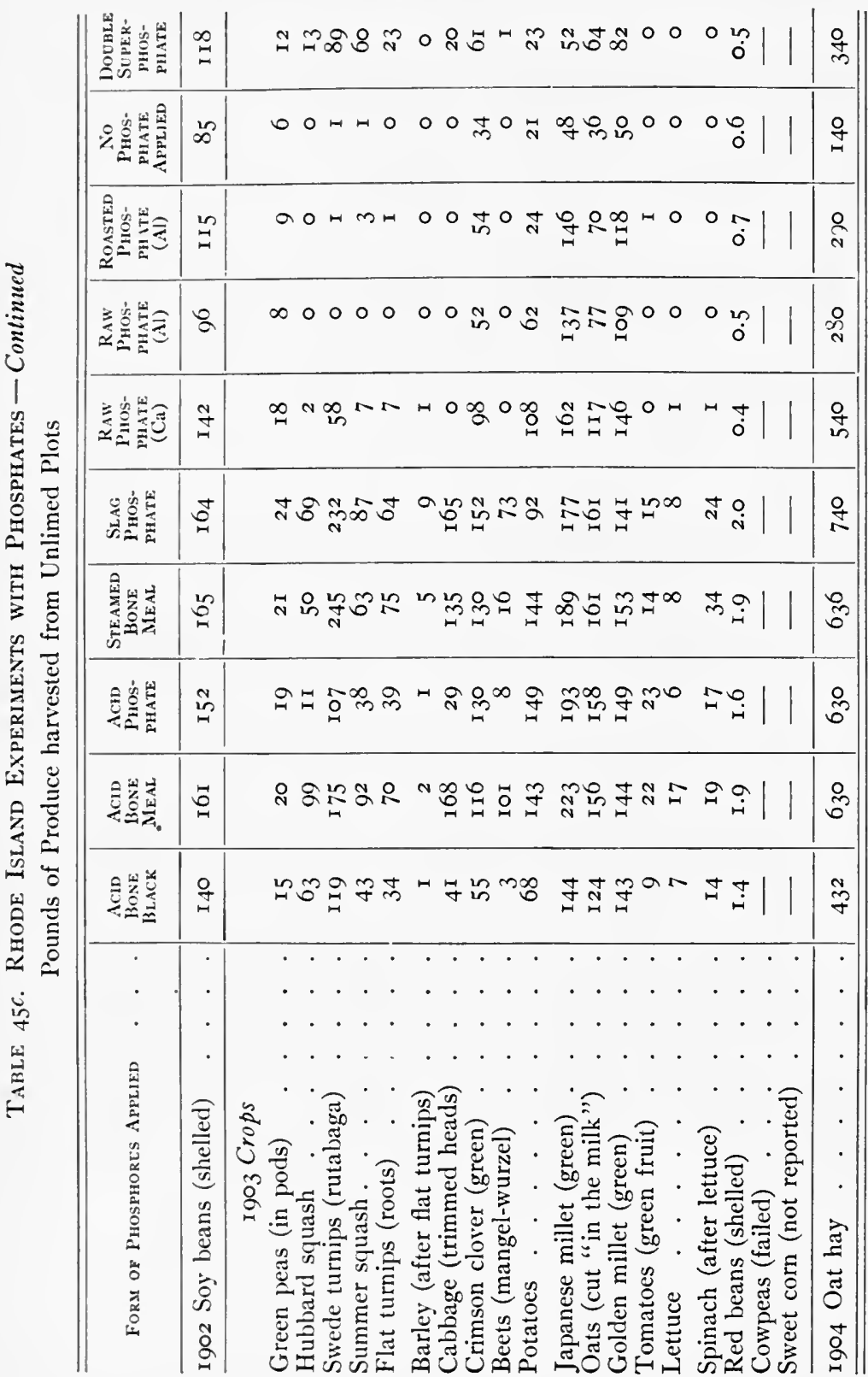


the acid phosphate applied is three times that of the raw rock; and it should be kept in mind that no provision was made to keep the soil supplied with decaying organic matter, although nitrogen and potassium, in commercial form, were applied to all plots alike.

If we add together all of the grain and hay produced during the decade following the first year of the experiment, including the oat grain in 1895 , the hay in $1896,1897,1898,1899$, and 1904 , the ear corn in 1900, and the soy beans in 1902 , we secure the following totals for the plots designated:

\begin{tabular}{|c|c|c|c|c|c|c|}
\hline \multirow{2}{*}{ Soll Treatment } & \multicolumn{2}{|c|}{ No Phosphate } & \multicolumn{2}{|c|}{ Rock Phosphate } & \multicolumn{2}{|c|}{ Acio Phosphate } \\
\hline & Unlimed & Limed & Unlimed & Limed & Unlimed & Limed \\
\hline $\begin{array}{l}\text { Pounds per acre . } \\
\text { Gain for phosphorus } \\
\text { Gain for lime. }\end{array}$ & 8310 & $\frac{27470}{19160}$ & $\begin{array}{l}22890 \\
14580 \\
\end{array}$ & $\begin{array}{r}35340 \\
7870 \\
I 2450\end{array}$ & $\begin{array}{l}22860 \\
I 455^{\circ}\end{array}$ & $\begin{array}{r}37000 \\
9530 \\
14140\end{array}$ \\
\hline
\end{tabular}

These figures present in very concise form an economic summary of the Rhode Island experiments with "floats" and acid phosphate, as applied to the more valuable produce of the general farm crops grown during the ten years. The acid phosphate gave slightly poorer results than the raw rock on the unlimed land and 20 per cent better results on the limed land. The value of lime is also strikingly shown. It should be kept in mind, however, that the more abundant growth of clover upon the limed land during the four years, 1896 to 1899 , would likely benefit succeeding crops, irrespective of the lime itself.

The Maine Experiment Station reports two series of experiments with different phosphates, one covering a period of nine years with all tests in triplicate on 2oth-acre plots where equal amounts of phosphorus were compared, and the other for five years (I 890 to I894) on $2 \frac{1}{2}$-acre plots where equal money values of phosphorus were compared.

In the nine-year experiments, fertilizers were applied five times in $1886,1887,1889,1893$, and 1894 . When applied, the amounts per acre were 200 pounds of ammonium sulfate, Ioo pounds of potassium chlorid, 360 pounds of fine-ground bone, 300 pounds of 


\section{SYSTEMS OF PERMANENT AGRICULTURE}

fine-ground South Carolina raw rock phosphate; and, for soluble phosphorus, 400 pounds of acidulated bone black were used for I886, I 887 , and I889, and 500 pounds of acid phosphate made from South Carolina rock for 1893 and 1894 . The stable manure was applied five times at the rate of 20 tons per acre. The results are reported in Table 46 for each of the eight crops harvested.

Table 46. Maine Experiments with Different Phosphates Pounds per Acre of Air-dry Produce: Average of Three Plots in Each Case

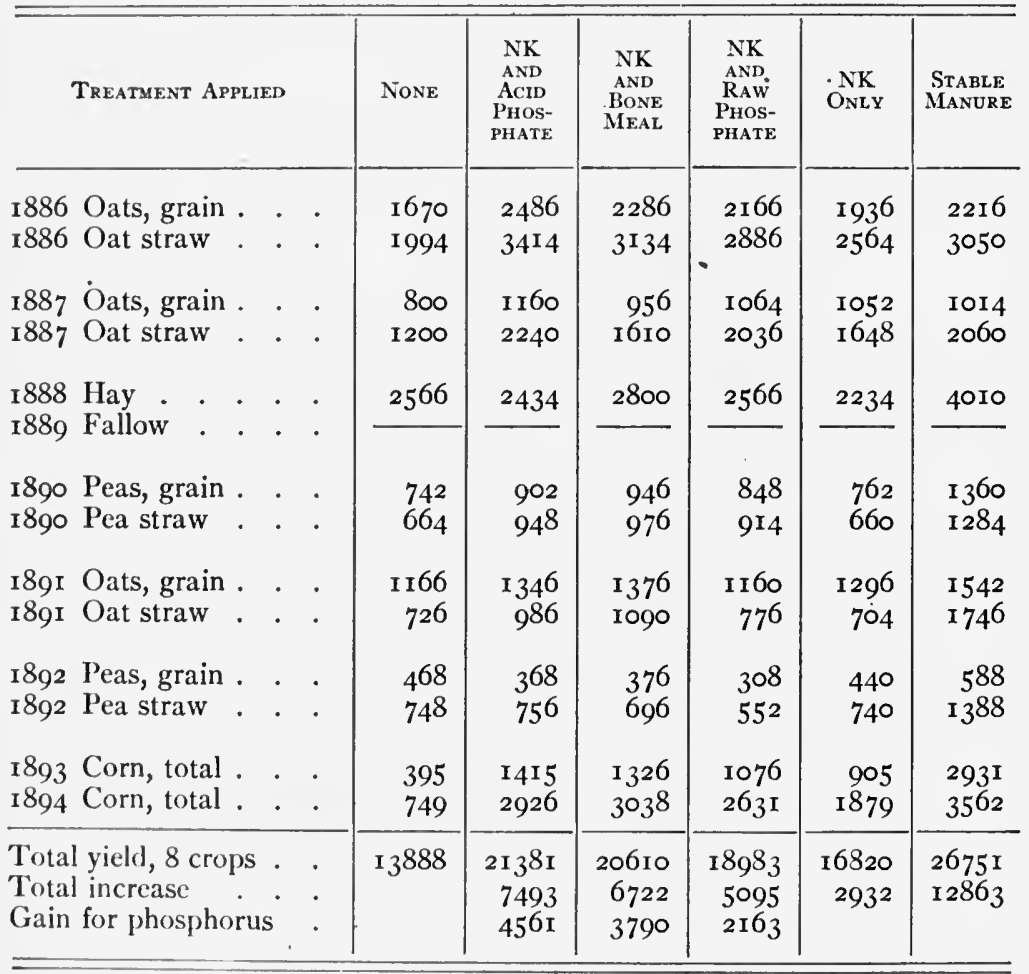

Of the different forms of phosphorus, the acid phosphate gave the best results for the first two years, especially in oat straw, but afterward the bone meal gave the best results. The raw phosphate produced only about one half as much increase as the other forms, but at less than one third the cost. 
In the other phosphate experiment by the Maine Station, covering five years on a ro-acre field divided into four $2 \frac{1}{2}$-acre plots, the fertilizer applications were made but once (in 1890 ). The amounts applied per acre were 20 loads of stable manure on plot I, and 66 pounds of sodium nitrate, I6 pounds of ammonium sulfate, and Ioo pounds of potassium chlorid (supplying only I4 pounds of nitrogen and 42 pounds of potassium) on plots 2 and 3 . In addition, plot 2 received Iooo pounds of raw rock phosphate (containing I07 pounds of phosphorus), and plot 3 received 500 pounds of acid phosphate (containing 35 pounds of phosphorus), per acre. Plot 4 received no fertilizer.

Table 47 gives the results obtained for the five years of the experiment, and also the average yields of hay for two years before the fertilizers were applied.

Table 47. Maine Experiments with Equal Money Values of Raw Phosphate and Acid Phosphate

Pounds per Acre of Air-dry Produce

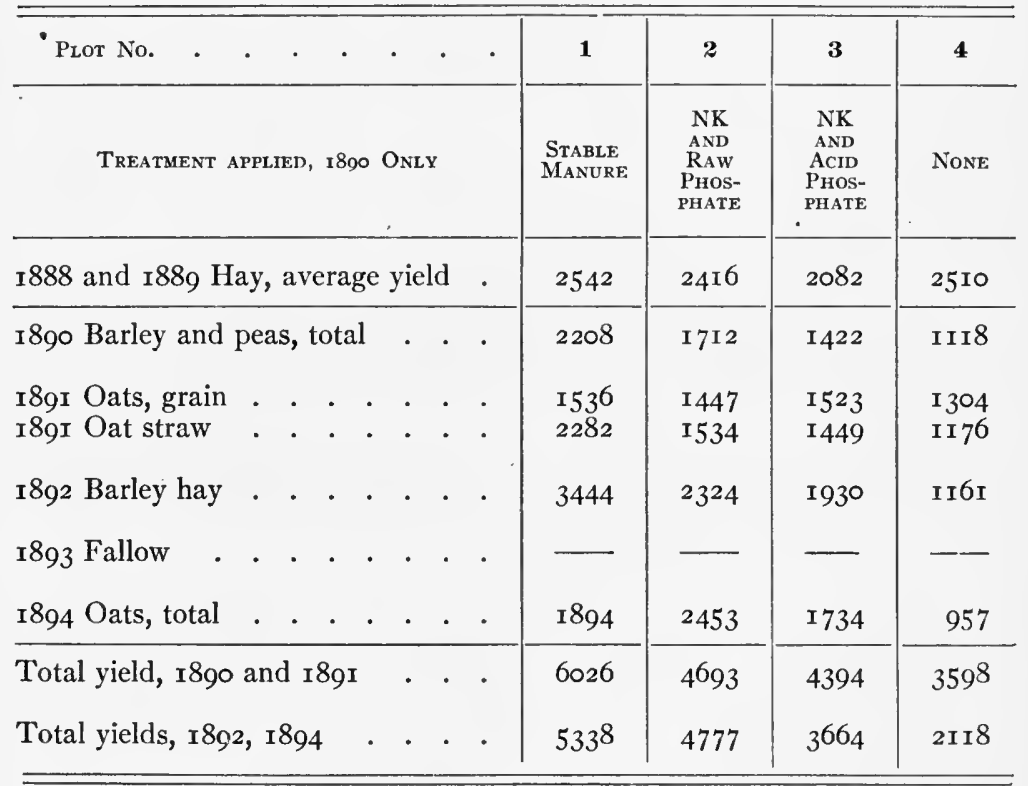


These data show that the first two years after application the acid phosphate gave about the same results as the raw phosphate, but the last two crops gave better results from the raw phosphate, even when compared with the original apparent difference in the productive power of the two plots, - a difference which may or may not hold for other crops in other years.

In commenting on these experiments, Director Jordan said (Maine Report, I894, page 3I):

"With the exception of the oat crop of I89 I the production of plot two has largely exceeded that of plot three. Especially is this true of the I894 crop after the exhausting effect of three years of cropping. . . . This is certainly one instance of the unmistakable persistent influence of a crude phosphate in increasing the growth of a field crop."

According to Doctor Jordan, the 20 loads of stable manure contained 172 pounds of nitrogen, 50 pounds of phosphorus, and 146 pounds of potassium.

The Massachusetts Experiment Station has reported, with the following explanations, an experiment with different kinds of phosphates, extending over I I years, I890 to I900 (see gth, roth, and I3th Annual Reports):

"This series of experiments was begun by Doctor Goessman in I890, with a view of determining whether it is not more profitable to employ one of the cheaper natural phosphates than to use the more costly acid phosphate."

"The field was first divided into five plots, containing about 6600 square feet each. These plots received equal money's worth (on the basis of prices in 1890 ) of the phosphates used, as follows:

Plot I. Phosphatic slag.

Plot 2. Mona guano.

Plot 3. Apatite at first; later Florida phosphate.

Plot 4. South Carolina phosphate.

Plot 5. Dissolved bone black.

"Plot 3, as above stated, received an application of ground apatite in 1890 . In I89J it was found impossible to obtain this material, and no phosphate of any kind was applied to the plot. In 1892 and 1893 ground hard Florida phosphate was applied to this plot. It is not believed, however, that it is fair to this phosphate to compare it with the others, since it has been used only two years, while the others have been applied for four years.

"From the beginning, each of these five plots has received the same applica tion of nitrate of soda and potash-magnesia sulfate. The quantities of thes: applied per plot during the first four years were about 44 pounds of the former and 66 pounds of the latter. 
"Since 1894 no phosphate of any kind has been applied to these plots, but the quantity of nitrate of soda and of potash-magnesia sulfate has been used in one half greater quantities.

"At first Doctor Goessman included no plot on which phosphate was not used for comparison with the others. Later such a plot was added, but it was left entirely unmanured until 1896 . During 1896 and 1897 it has received the nitrate of soda and potash-magnesia sulfate at the same rate as the other plots."

The data (excepting from plot 3 ) are recorded in Table 48.

Table 48. Massachusetts Experiments with Equal Money Values of Different Phosphates

Pounds per Plot (about 6600 Square Feet)

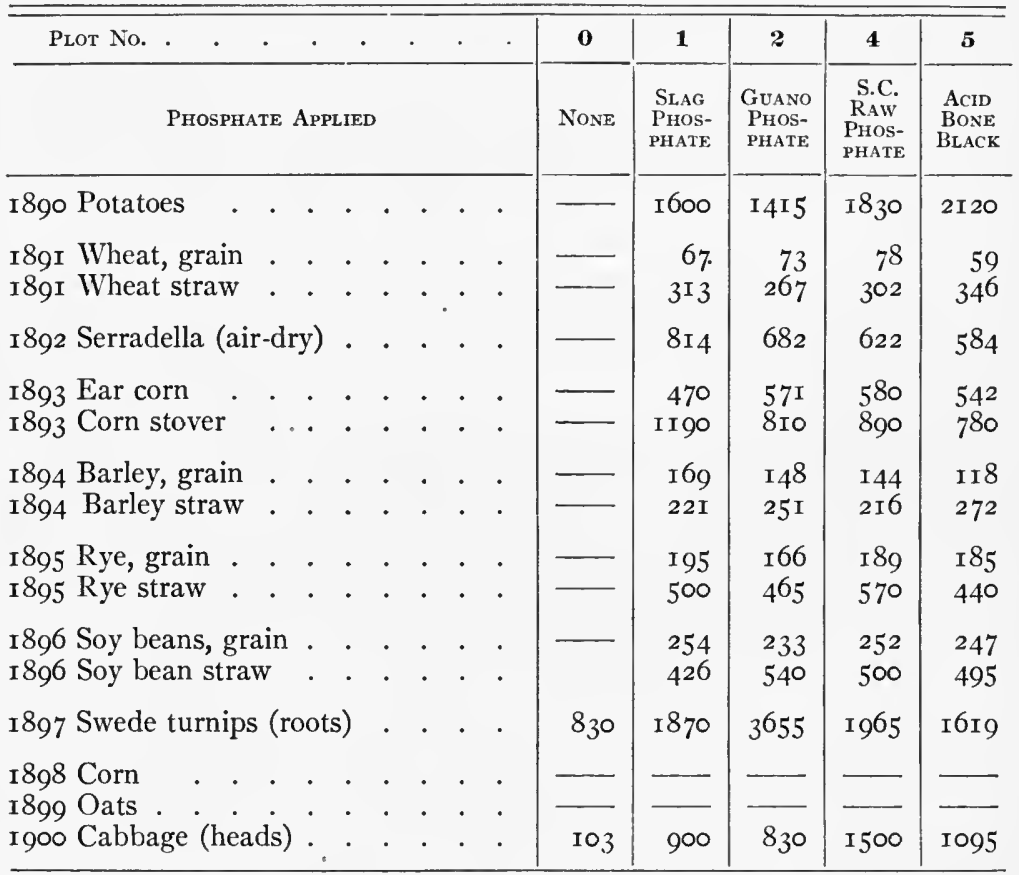

Pounds per Acre

\begin{tabular}{|c|c|c|c|c|c|c|}
\hline $\begin{array}{l}\text { I } 890-1893 \text { Phosphorus applied . } \\
\text { r } 890-1900 \text { Phosphorus removed }\end{array}$ & & None & $\begin{array}{l}278 \\
124\end{array}$ & $\begin{array}{l}207 \\
121\end{array}$ & $\begin{array}{l}416 \\
122\end{array}$ & $\begin{array}{l}\text { I } 42 \\
\text { I } 6\end{array}$ \\
\hline $\begin{array}{l}\text { Igoo Balance not removed } \\
\text { Phosphorus unused, per cent . }\end{array}$ & . & - & $\begin{array}{r}\text { I } 54 \\
55\end{array}$ & $\begin{array}{l}86 \\
43\end{array}$ & $\begin{array}{r}294 \\
71\end{array}$ & $\begin{array}{l}26 \\
18\end{array}$ \\
\hline
\end{tabular}


The record for yields for I 898 and I 899 appears not to have been published, but the report states that in 1898 the yield of corn was good upon all of these phosphate plots, and that there was but little difference between the yields of oats on the different plots in 1899 . In the Report for 1900 the following summaries are made by Professor Brooks:

"Taking into account all of the crops which have been grown upon this field, except the Swedish turnips (rutabaga), which were affected by disease not apparently due to the fertilizer which had been used on a portion of the plots, and the yields of which, therefore, as expressed in figures, would be misleading, and representing the aggregate yield which stands highest, by 100, the efficiency of the different phosphates is as follows:

\begin{tabular}{|c|c|}
\hline Phosphatic slag & 100.0 \\
\hline Ground South Carolina rock & 92.3 \\
\hline Dissolved bone black & 90. \\
\hline Mona guano . & 88.3 \\
\hline
\end{tabular}

"There was at first no no-phosphate plot used in the experiment, but we have had a no-phosphate plot since I895. Taking into account the yields of the several plots since 1895 , and excepting the Swedish turnips, which were grown in 1897 , for reasons above stated, the phosphates have the following relative rank:

\begin{tabular}{|c|c|c|}
\hline South Carolina rock & sphate & 100.0 \\
\hline Phosphatic slag . & & 99.0 \\
\hline Dissolved bone black & & 97. \\
\hline Mona guano . & . & 95. \\
\hline No phosphate & . & 55 . \\
\hline
\end{tabular}

"The following conclusions appear to be justified by the results which we have obtained:

"It is possible to produce profitable crops of most kinds by liberal use of natural phosphates, and in a long series of years there might be a considerable money saving in depending, at least in part, upon these rather than upon the higher priced dissolved phosphates."

"Between ground South Carolina rock, Mona guano, and the phosphatic slag there is no considerable difference in the economic result."

It will be seen that the South Carolina rock phosphate produced larger yields than the dissolved bone black with all of the fourteen different crop products reported, excepting potatoes the first year, wheat straw the second year, and barley straw the fifth year. It should be kept in mind, too, that no adequate provision was made for supplying decaying organic matter to this soil during the eleven 
years of the experiment, and we have the following statement from the Massachusetts Report for I896, page I9o, concerning the earlier history of this field:

"Previous to 1887 it was used as a meadow, which was well worn out at that time, yielding but a scanty crop of English hay. During the autumn of 1887 the sod was turned under and left in that state over winter. It was decided to prepare the field for special experiments with phosphates by systematic exhaustion of its inherent resources of plant food. For this reason no manurial matter of any description was applied during the years I887, I888, and I889.

"The soil, a fair sandy loam, was carefully prepared every year by plowing during the fall and in the spring, to improve its mechanical condition; during the same period a crop was raised every year."

A second series of experiments with different phosphates was begun by the Massachusetts Station in I897, upon thirteen plots of land that had all received 600 pounds of bone meal per acre in r896. In this series equal amounts of phosphorus are being applied in ten different phosphates. The results thus far reported are variable and inconclusive. In some cases soluble phosphates have produced the best yields, especially upon garden vegetables, while in some other cases the raw phosphates have given better results. Of course the 600 pounds of bone meal applied to the entire field in 1896 greatly reduced the need for phosphorus for some years. The published data are given in Table 49. (See Massachusetts Reports 1898 to 1907.)

In the report for 1903 , Professor Brooks makes the following comments concerning the cabbage crops:

"Apatite and soft Florida phosphate are the least effective among the phosphates employed.

"South Carolina rock gives a surprisingly good return, being exceeded in yield of hard heads by only one plot, - the one receiving dissolved bone, while in total yield it is materially exceeded by but few.

"The phosphatic slag ranks among the best of the phosphates."

Professor Brooks also makes the following general statements concerning these phosphate experiments:

"In estimating the significance of the results upon this field, it is important to keep in mind the facts as regards the character of the soil. It is what would be called a strong and moderately heavy loam, and has great capacity to retain moisture. The relatively insoluble phosphates are known to give better results on soils of this character than on those which are lighter and drier." 


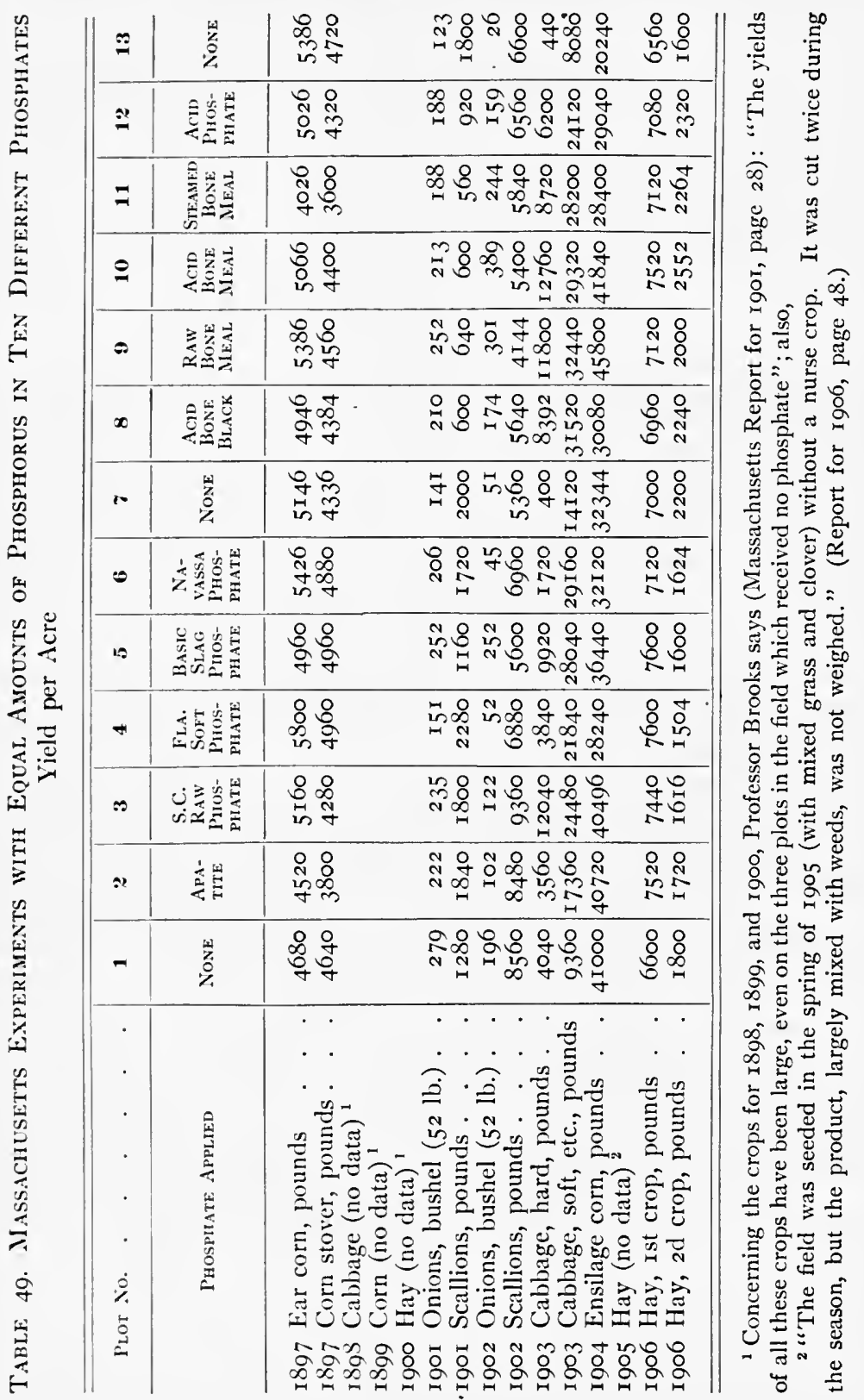


"It appears reasonable to believe that on soils of the character of this field the farmer may safely depend for a considerable portion at least of the phosphorus needed by his crops upon the cheaper natural phosphates, such as finely ground South Carolina rock and finely ground bone, while phosphatic slag also promises to give a most useful fertilizer upon soil of this character."

This entire field, including the no-phosphate plot, has received $5^{2}$ pounds of nitrogen and 126 pounds of potassium per acre per annum for the ten years. The phosphate plots have each received 42 pounds of phosphorus per acre each year; but no provision was made for maintaining organic matter in the soil. It should also be kept in mind that the raw phosphates that gave poor results may not have been ground to a sufficient degree of fineness.

The Illinois Experiment Station is conducting much more extensive experiments than any other state with the use of fineground natural rock phosphate, but these investigations were begun too recently to furnish information from which such final conclusions can be drawn as from the Ohio work, for example.

In Table 50 are reported results obtained from the University of Illinois soil experiment field near Galesburg, Knox County, on the ordinary brown silt loam prairie soil of the Upper Illinoisan glaciation, which, in 1903 , contained in 2 million pounds of the surface soil 5020 pounds of nitrogen, I 60 pounds of total phosphorus, and $3 \mathrm{I}, 700$ pounds of potassium.

A six-year rotation is under way on this field, including corn for two years, oats the third year, and wheat the fourth, followed by two years of clover and timothy. (After the first six years the rotation will be corn, corn, oats, clover, wheat, clover.) There are three independent series of plots, so that every year corn is growing on one series, oats or wheat on another serics, and clover and timothy on the other.

The land was timothy sod at the beginning, and Series 300 was not broken during the first two years, $\frac{1}{2}$ ton of phosphate per acre having been applied at the beginning as a top dressing, which, as was expected, produced practically no effect. A ton of phosphate per acre applied in the beginning to Series 200 produced no effect on the oats seeded on timothy sod in r9o4, and but little effect on the wheat which followed in I905. The regular plan is to apply $\mathbf{I} \frac{1}{2}$ tons of raw rock phosphate per acre to the clover and timothy 
sod before plowing for corn, and this application will probably be repeated every six years until the total phosphorus content of the plowed soil is about doubled, after which the amounts applied for each rotation will be reduced to supply only about as much phosphorus as is removed in the crops grown.

The heavy applications of phosphorus that will thus be made during the first three or four rotations cost about $\$ \mathrm{I} .88$ per acre per annum, which is less than is commonly expended for "complete" fertilizers in the older states, in a system that supplies less phosphorus than is removed in the crops grown and that thus leaves the land poorer year by year. (An application of 200 pounds of " $2-8-2$ " fertilizer " would furnish less than 9 pounds of total phosphorus and at an a verage cost of at least \$2.)

Different systems of supplying organic matter are followed upon the different plots numbered in Table 5o (legume catch crops, crop residues, and farm manure), so that the same yields are not to be expected upon plots 2, 3, 4, and 5, for example; but these four plots differ from the next four only by the application of phosphorus to plots $6,7,8$, and 9 . For the student of details, it may be said that, aside from the phosphorus applied, plot 5 is treated the same as plot 6 , while plots 2,3 , and 4 are treated the same as plots 7,8 , and 9 , respectively.

Of course, the benefits of the crop rotation, including the use of different methods of supplying organic matter and nitrogen, cannot be determined before even the first rotation is completed; and the results thus far secured from the phosphorus applied are to be considered very preliminary. They show but little of what it is reasonable to expect from the system when fully under way after the benefit of one or two full rotations is felt.

In the last column of Table 50 are given the values of the increases produced by the raw rock phosphate, including the yearly totals from the three crops; that is, from three acres. By keeping in mind that the annual cost of the phosphate for three acres is $\$ 5.63$ (while the heavy applications are being made), the financial progress of the experiment during the first five years is seen at a glance. In round numbers, the increase paid 50 per cent interest

1 This means 2 per cent of ammonia $\left(\mathrm{NH}_{3}\right), 8$ per cent of available "phosphoric acid" $\left(\mathrm{P}_{2} \mathrm{O}_{5}\right)$, and 2 per cent of potash $\left(\mathrm{K}_{2} \mathrm{O}\right)$. 
USE OF PHOSPHORUS IN DIFFERENT FORMS 285

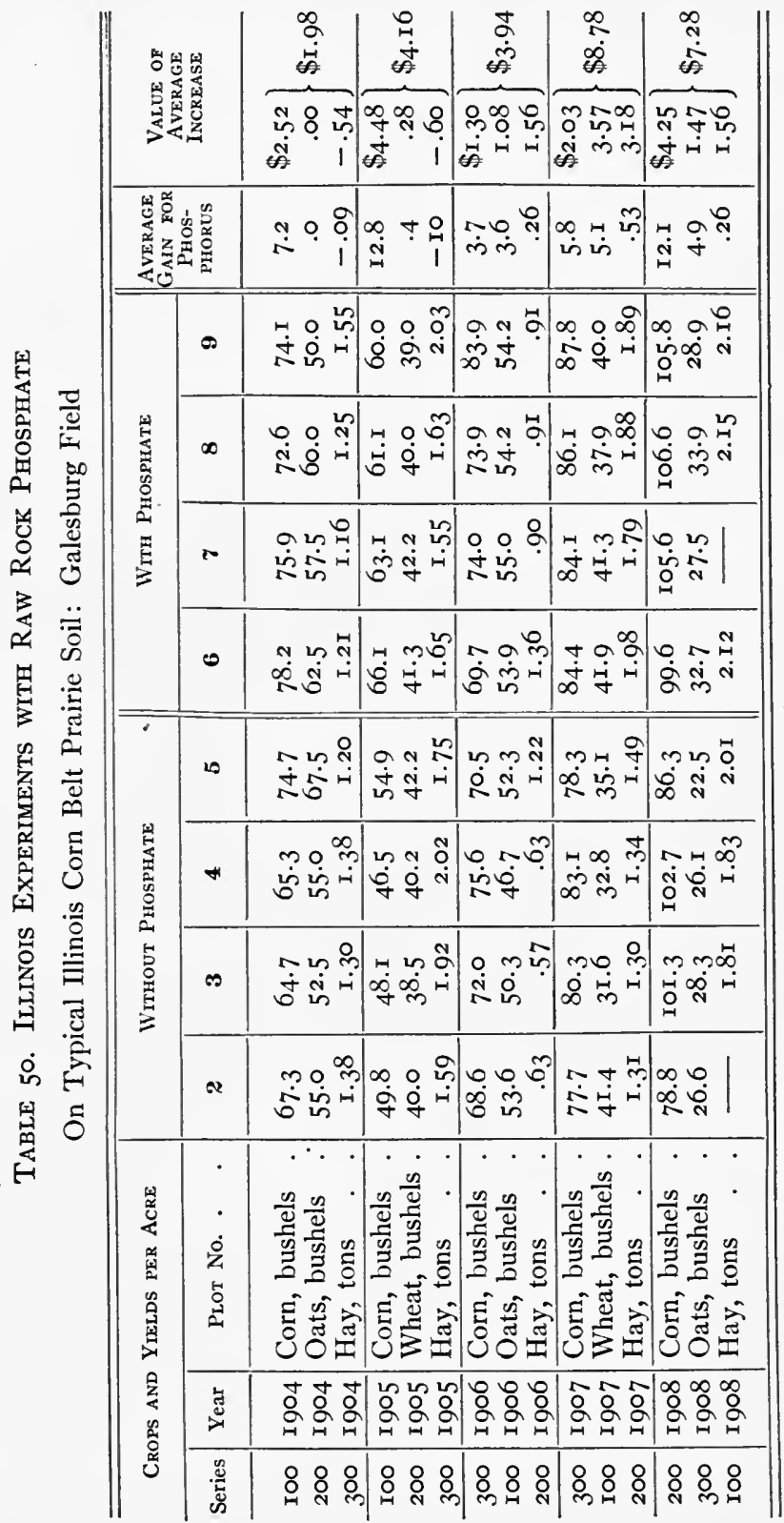


on the invesiment in the first three years, and during the next two years it paid the annual cost and 40 per cent net profit on the same.

The results of the Galesburg field are in harmony with those thus far secured from many other University of Illinois soil experiment fields in different parts of the state, and they are also in harmony with numerous practical tests by progressive Illinois farmers who make adequate provision for supplying the soil with decaying organic matter. Thus, as an average of four independent tests on each experiment field, Tennessee raw rock phosphate increased the yield of corn in 1908 by I2.I bushels per acre on the Galesburg field, by i I.9 bushels on the Myrtle field for first-year corn and 9.3 bushels for second-year corn, by 16.0 bushels on the Rockford field for first-year corn and 7.6 bushels for second-year corn, by 3.5 bushels on the Antioch field, by 9.I on the Auburn field, and by 8.4 bushels on the Urbana field.

These experiment fields are in six different counties, and they have been in operation from four to six years. The average yield of corn in I908 was 67.3 bushels where raw phosphate has been applied and 57.5 bushels without phosphorus. The phosphate applied thus far adds phosphorus to the soil at the rate of 60 pounds or more per year, while i 6 pounds are required for a 68-bushel crop and about 2 pounds for the Io-bushel increase. Thus, the value of the increase $\left(\$_{3.43}\right)$ will pay the cost of the phosphate (less than $\$ 2$ ) and leave 50 per cent net profit, and with 70 per cent of the phosphorus left in the soil.

The effect on wheat and clover is almost as marked as on corn. Of course, more clover means more nitrogen secured from the air, and it may also mean more manure to return to the soil. Meanwhile, the untreated land grows poorer year by year.

In Table 5I are given the results reported by the Illinois Experiment Station (Circular 97) from a series of pot cultures conducted for the purpose of comparing equal money values of raw rock phosphate and steamed bone meal. In the Illinois field experiments, the standard annual application of phosphorus is 25 pounds per acre in 200 pounds of steamed bone meal and nearly equal money values of other forms of phosphorus. The 25 pounds is based upon the requirements of a Ioo-bushel crop of corn, with I or 2 pounds for loss in drainage. In pot cultures very large crops are commonly 
produced, and to meet the needs of such crops the applications of plant food are made three times as large as in field experiments.

The soil used was from the gray silt loam prairie of the lower Illinoisan glaciation, and wheat was the crop grown in the pots. The phosphate used is known as the Tennessee blue rock. In certain pots the phosphorus was turned under with a good growth of clover; in other pots with farm manure, and in others with both clover and manure.

Table 5i. Comparative Effects of Steamed Bone Meal and Raw Rock Phosphate, in Connection with Clover and Manure

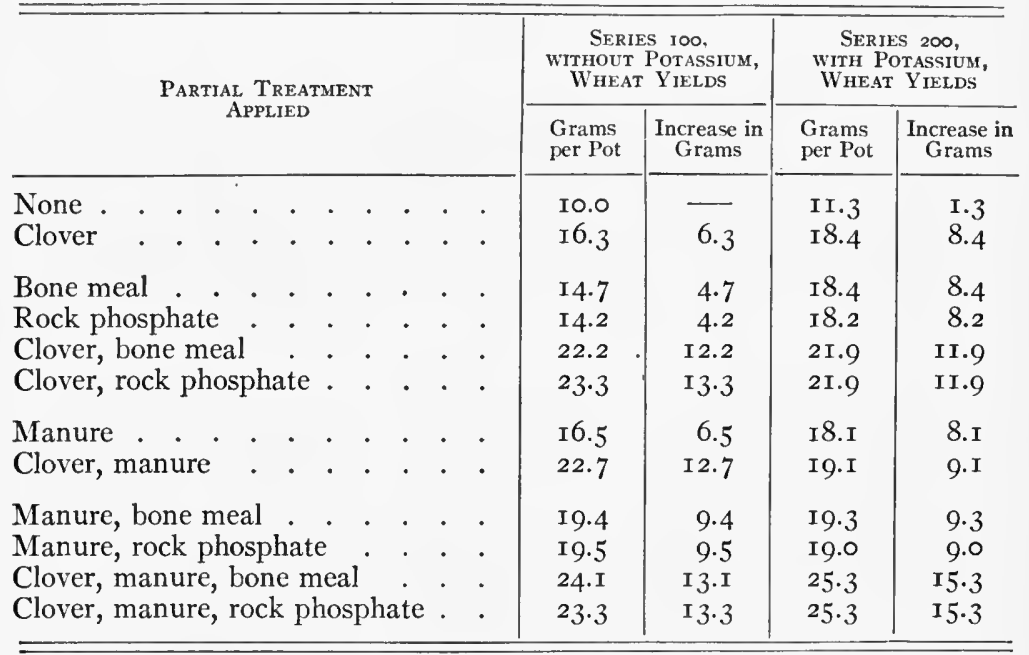

It will be seen that the untreated soil (pot Ior) yielded ro grams of wheat. Where clover was turned under (IO2), the yield was increased by 6.3 grams, and where bone meal was turned under with clover (105), the yield was 22.2 grams, the increase of 12.2 grams being nearly double that produced by clover without bone meal.

Where raw rock phosphate was turned under with clover (I06), the wheat yielded 23.3 grams, making a total increase of $\mathrm{I} 3.3$ grams over the yield of the untreated soil. Of this increase 6.3 grams should be credited to the clover and 7 grams to the rock phosphate, by one computation; or 4.2 to the phosphate and 9. I to the clover, by the other route. Thus, rock phosphate used alone produced an 
increase of only 4.2 grams, which, added to the increase of 6.3 grams due to clover alone, makes only 10.5 grams. "In other words, the sum of the gains which they make when used separately was 2.8 grams less than the increase produced when the rock phosphate and clover were turned under together. Somewhat similar results are produced with clover and bone meal when used separately and together; also with bone meal and potassium, and with rock phosphate and potassium. Such marked combined action does not appear, however, from other combinations, possibly because of other limiting factors. As a general average, the rock phosphate has made slightly better gains than the steamed bone meal.

The pots used in these investigations are $10 \frac{1}{2}$ inches in diameter, consequently I gram per pot corresponds to I pound per square rod, or to $\mathrm{I} 60$ pounds per acre. The actual yields in grams per pot are given, but the results may also be computed to bushels per acre. It should be remembered that pot cultures constitute an intensive form of agriculture. They are carried on under almost complete control, except in very warm weather, when too much shade may be required to avoid too high temperature. The yields obtained are usually two or three times as much as can be expected in the field under ordinary weather conditions. They are not, however, larger than could be obtained in the field under perfect weather conditions. The largest yield reported in Table $5 \mathrm{I}$ is 25.3 grams per pot, or 67 bushels of wheat per acre. Pot culture yields have been produced corresponding to $\mathrm{I}_{42}$ bushels of wheat, and to 230 bushels of oats, per acre.

Doctor Alfred M. Peter of the Kentucky Station has kindly furnished the author the following data secured by him with the coöperation of Mr. S. C. Jones of the Kentucky Geological Survey:

Kentucky Experiments: Pot Cultures

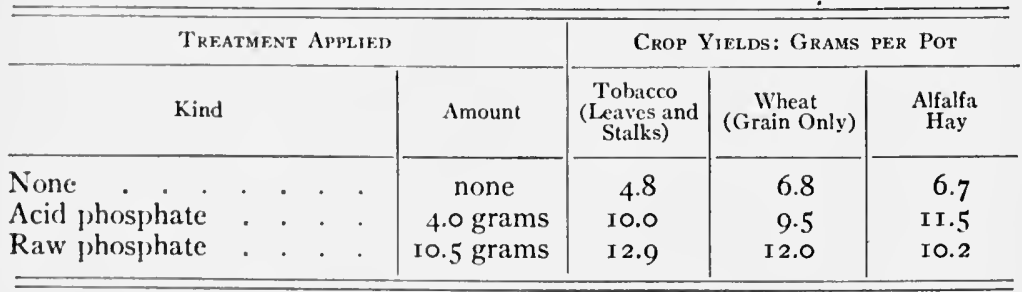


The soil used in these pot cultures (which were 2-gallon jars) was a residual limestone soil from Christian County, Kentucky, and contained 870 pounds of total phosphorus and $32, \mathrm{I} 20$ pounds of potassium in 2 million pounds of surface soil. The results are of interest; but, as Doctor Peter writes, " it must be understood that they are only single experiments carried out one season, and must be valued accordingly."

The Wisconsin Agricultural Experiment Station (Bulletin 174) also reports a single year's experiment with field cultures showing that manure and raw phosphate increased the yield of rutabagas by 27 per cent and the yield of potatoes by 47 per cent above the yield from manure alone, and the opinion is expressed that " these results leave no doubt that the use of phosphate supplementing manure is beneficial."

In describing Mr. J. F. Jack's Virginia farm, Joseph E. Wing, the well-known agricultural writer, makes the following statements (Breeders' Gazette, June 2, I909):

"Proud as we are of Woodland Farm, I find acre after acre of alfalfa on Mr. Jack's farm as good as our best. I find it as good as the best that I ever saw in California. Is it all good? No. There are acres that are thin, stunted. What cause? He is seeking that now. Doubtless there are areas that are too poorly drained, there are places yet sour, and some land needs more feeding. No doubt at all of that. He has not limed liberally at all times. Last year, for example, some men told him that they had a prepared lime that was two times as effective as ordinary lime. He had been using a ton to the acre; he bought this lime, at a higher price, and used but 1000 pounds. Then he learned to his sorrow that the lime was simply slacked at the kilns, was so-called 'agricultural lime' and had only about half the strength of fresh burned lime.' So it seems sure that much of his land has had too little lime. He finds that lime carbonate, that is, simply ground limestone, gives him as good results as anything, and that fortunately is cheap."

"What an interesting thing it is to find this old Eastern land being newly discovered. . . . But here the soil must be fed, do not forget that! The natives forgot it, hence their sorrow now."

"Business methods apply to farming as well as to anything else. Farming is a business, and, with present prices for things, a paying business. It pays to buy lime (Mr. Jack is getting his ground limestone delivered to him for \$2.90 this year) to make land sweet, to buy phosphorus, to sow legumes, to build soil. Alfalfa is as easily set in Virginia as in any other state, and it grows splendidly when the land is made sweet with lime, filled with decaying vegetable matter or humus, given inoculation and phosphorus." 
"Alfalfa will make land in Virginia yield good returns on a valuation of \$200 per acre, or more, and land that was worth $\$ 30$ per acre can be set in alfalfa at a cost of about $\$_{15} 5$ per acre, including lime, fertilizer, seed, and the growth of crimson clover. Enthusiasm and faith, with carbonate of lime, phosphorus, and clovers, can make a land beautiful to the eye, inspiring to the soul, and filling to the purse."

"One most valuable result seen here is apparently that untreated Tennessee phosphate rock is giving as good results as phosphorus in any other form, using not the same amounts, but the same cost equivalents. In fact, there seems decided gain from the use of the raw phosphate."

This temporary superiority of raw phosphate was doubtless due to some liberation by one green manuring. Later Mr. Wing says:

"The results as they now show are about like this, speaking roughly: Acid phosphate leads by far. Bone meal comes next. Whether slag phosphate or Tennessee rock follows I do not know, but both are far in the rear of either bone meal or acid phosphate." (Breeder's Gazette, Nov. 8, I9I I.)

Note. On the author's Poorland Farm, including about 320 acres in the prairie section of southern Illinois (gray silt loam on tight clay), limestone is applied at the rate of 2 to 3 tons per acre, and raw rock phosphate at the rate of $I$ ton per acre, every six years. After the phosphorus content of the plowed soil has been increased from 800 pounds per acre to about 2000 per acre, the application of that element will probably be reduced to an amount which will simply maintain the supply. Thus far the use of I I car loads of raw phosphate and i 7 car loads of ground limestone has given as satisfactory results as one could reasonably expect during the first crop rotation. For this special soil a six-year rotation is planned, as follows:

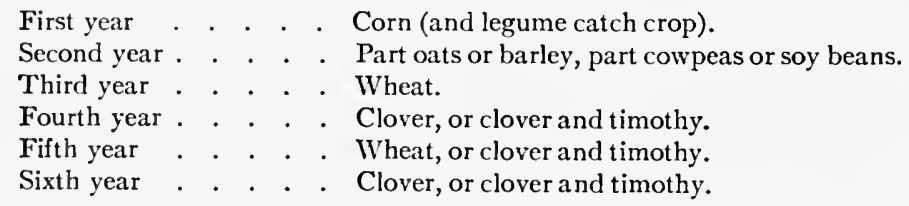

The plan may be a grain system where wheat is grown the fifth year, only clover seed being harvested the fourth and sixth years, or it may be changed to a live stock system by using a field for pasture and meadow the last three years, all manure produced being applied to the pasture land to be plowed under for corn. While the untreated land has produced about one third of a ton per acre of poor hay (part timothy and redtop, part foul grass, sorrel, and other weeds), the treated land has produced more than $x \frac{1}{2}$ tons per acre of clean clover and timothy hay. A car load of limestone or phosphate is purchased with less hesitation than a cow or a horse, and at about the same cost.

A careful study of the literature of agricultural science from European countries reveals no investigations with the use of raw rock phosphate that compare in value with those conducted by 
any one of the seven states, Ohio, Maryland, Pennsylvania, Rhode Island, Maine, Massachusetts, or Illinois.

There are three essential points to be kept in mind concerning the use of raw rock phosphate:

First, all rock is not phosphate rock, and the farmer should purchase only guaranteed material, and he should know how much phosphorus is contained in the ground rock he applies to the land, if necessary by taking roo teaspoonfuls from roo different parts of the car load (including different depths), thoroughly mixing, and sending half a pound of this to a reliable commercial chemist for analysis.

Second, the rock should be very finely ground, and it should be purchased upon a guarantee that at least 90 per cent of it will pass through a sieve with 100 meshes to the linear inch (10,000 meshes to the square inch), which is no finer than is required for slag phosphate.

Third, raw phosphate should not be expected to give marked benefits except when used in connection with adequate supplies of decaying organic matter. It has practically no value as a top dressing, but must be plowed under and thoroughly incorporated with the soil where the roots feed. Of course, it will supply only the element phosphorus, and will not take the place of any other deficient element, nor act as a soil stimulant to liberate other plant food from the soil, although it sometimes contains small amounts of carbonate, and then has some tendency to correct soil acidity, but in this it is insignificant compared to the effect of ground limestone.

The following interesting discussion concerning the use of raw rock phosphate, from the viewpoint of the fertilizer manufacturer, was published in pamphlet form and widely disseminated in I908, by the National Fertilizer Association. It was also published in full in the American Fertilizer, August, 1908, and in part in Armour's Farmer's Almanac for I909. It is reproduced in complete form in the following pages, because it deserves to be read by every careful student of soil fertility. Its cautions against the use of raw phosphate as a source of immediately a vailable plant food are commended. It also serves to emphasize the fact stated in the introduction, that, "if the independent farmer is to adopt and 
maintain permanent systems of profitable agriculture, he cannot accept "parrot' instruction," not even when offered by the fertilizer agent.

The fact that acid phosphate and " $2-8-2$ " fertilizers are still used in the Eastern and Southern states, largely as soil stimulants and for a single crop, or for one year's effect only, fairly raises the question whether agricultural practice in those states is not influenced more by the "arguments" of the fertilizer agent than by the established facts and principles from the experiment stations.

\section{Raw Rock Phosphate, "Floats" \\ PUBLISHED BY}

\section{The National Fertilizer Association}

For years the raw rock question has cropped out spasmodically, in different parts of the world, like the measles or some other affliction.

Sometimes it was the result of the recommendation of some impractical theorist who occupied a position that brought him before the farmer - oftener it was foisted on an unsuspecting farming community by some one who was either directly or indirectly interested in an offgrade phosphate mine, and who used his official position to further the interests of the rock mine at the expense of the farmer.

But no matter what started its use, the result has always been the same- no benefit derived from its use - a distrust of legitimate fertilizers, and a distinct set-back to agricultural interests which has taken several years to overcome.

In the following pages we give you the opinions of foreign experiment station men as well as those of our own country.

Both statistics and your good common sense tell you that the older the state or country, the more fertilizers are used and the greater the knowledge they have of their use.

The mere fact that in these older communities, both abroad and in this country, the use of legitimate fertilizers has increased rapidly from year to year for a hundred years conclusively shows their value.

The fact that wherever raw rock has been used, its use has been abandoned, shows its worthlessness.

Read what authorities who know have to say on this subject.

Resolution passed by the Association of German Agricultural Experiment Stations, in congress assembled, September 14, 1907, at Dresden, Germany:

"As a result of the extensive advertising which is done by certain parties advocating the use of RAW ROCK PHOSPHATE, the association passed the following resolution:

"ThE ASSOCIATION HAS CONCLUDED, FROM FERTILIZER EXPERIMENTS AT HAND WITH RAW PHOSPHATE FERTILIZER, THAT THERE IS SHOWN NO PROFIT- 
ABLE FERTILIZER EFFECT, APART FROM THOSE OF ACID SOIL. IN CONSEQUENCE THEREOF THE ASSOCIATION FEELS IT SHOULD DISCOURAGE THE USE OF RAW PHOSPHATE ON OTHER SOILS."

See. 67 th Volume (5-6), page 329, "LANDwirtschaftlicher Versuchs Station."

The Association of German Agricultural Experiment Stations represents the highest authority on agricultural matters in Germany, and undoubtedly the best in the world.

German investigators, particularly Dr. Von Liebig, were the authors of most of the fundamental principles underlying fertilization and agriculture, - and it is to them that we largely owe the progress made in this direction.

In view of the well-known thoroughness of German agricultural investigators, and the fact that the Association of German Agricultural Experiment Stations is universally regarded as the world's highest authority on such matters, their opinion on the use of RAW PHOSPHATE as a fertilizer is of great importance to the American farmer.

On account of the high price of land in Germany intensive farming is everywhere practiced. The farmers must, of necessity, use fertilizer containing plant food in available condition. Their selection of fertilizers is based on innumerable experiments covering over a hundred years.

The difference in crop yields per acre in Germany as compared with the United States is conclusive evidence of the soundness of their methods of fertilization. The average wheat yield per acre in Germany for the ten years r 895 to 1904 , inclusive, was 27.2 bushels, as compared with 13.4 bushels in the United States for the same period. On oats the yield per acre in Germany was 46.0 bushels, as compared with 29.2 bushels in the United States for the same period. (See pages 671 and 678, "Statistical Matter," reprint from Year Book of Department of Agriculture for 1905.) 1

The soils of Germany have been cropped for hundreds of years, while a large portion of those in this country are virgin or comparatively fresh. Proper fertilization is the secret of the higher yield per acre in Germany. If the United States is to maintain its supremacy in agriculture, farmers in this country will have to properly fertilize their crops, - and they can well take heed to the experience of their German brothers in this respect.

Before using raw rock, therefore, you would do well to ascertain its true fertilizing value - the availability of the plant food it is supposed to contain and especially to consider the decision of the German experimenters after years of careful testing.

From the standpoint of furnishing available plant food, RAW ROCK PHOSPHATE is not a fertilizer. The report of the twenty-fourth annual meeting of the Association of German Agricultural Experiment Stations, at which the

${ }^{1}$ The ten-year average yield of corn in the great state of Georgia, where more manufactured acidulated commercial fertilizers are used than in any other state, is II bushels per acre. - C. G. H. 
resolution quoted was passed, states that from "real exact experiments," conducted by such authorities as P. Wagner, Tacke, Bottcher, Lemmerman and others, "but little fertilizing effect was shown."

Further experiments made by Czerhati, L. Rey, Clausen, and others, led to similar results just stated.

The same report states that, "From the present experiments it can be concluded with certainty that the general use of earthly phosphates (RAw ROcK PHosphate) cannot be considered as phosphoric acid fertilization." Phosphoric acid is the only element this material contains, and if IT is Not available it is useless for fertilizing purposes.

The experiment station officials of Germany have gone on record against the use of RAW ROCK PHOSPHATE in no uncertain tone. Their opinion is shared, with but one or two exceptions, by all the experiment stations in this country. If THIS material cannot be recommended for German soils, where proper fertilization has been studied for so many years, is it not folly to attempt its use on the comparatively fresh soils of this country?

This report also refers to some recent experiments conducted by parties endeavoring to promote the sale of raw rock phosphate in Europe. In commenting on the so-called tests or experiments, the German report states - that they "were carried out with but very little exactness." They further class these experiments as "entirely unfounded, have been rejected by scientific agriculturists, and especially by Wagner, Tacke, and Bottcher, in a manner not to be misunderstood."

The said representations of these promoters are classed as "A very serious deception," and misleading to the farmers.

The efforts to promote the sale of RAW ROCK PHOSPHATE in this country in the light of world-wide failure to show any appreciable fertilizing effect can only be classed, in the language of the German experimenters, as "a very serious deception," and misleading to the farmers.

Not alone in Germany have experiments with RAW ROCK PHOSPHATE proven very unsatisfactory. Professor F. H. Storer, in Volume I of his book "Agriculture," in speaking of the value of raw phosphate USED IN CONNECTION WITH MANURE, as compared with superphosphate, says: "This question would seem to have been answered long ago, in so far as good land is concerned, by the common English practice of using superphosphates."

Again, later, in comparing the effects of the same materials for fertilizing purposes in European countries, he says: "For Europe at least, i.c., for fertile districts, the question has been decided fully long ago and most emphatically in favor of superphosphate. It has been decided by the long-continued experiments of a multitude of farmers, and their conclusion has been plainly expressed by the ever increasing demand for superphosphate." 1

${ }^{1}$ Director Hall of Rothamsted, in his "Fertilizers and Manures" (I909), page II 8, says: "The mineral phosphates have been but little employed directly as manures, though there is plenty of evidence that when they are really finely ground, they are effective enough on soils retaining plenty of water." - C. G. H. 
Coming down to our country, we find that experiments with RAw ROCK PHOSPHATE - with scarcely any exception - have proven unsatisfactory. Experiments conducted by the Maine Experiment Station, covering several years on various crops, designed to show the relative availability of phosphoric acid as supplied in acid phosphate, floats (raw rock phosphate), and redonda phosphate, were summarized as follows:

"In every case the acid rock (Acid Phosphate) gave the best returns. The gain was especially marked with the family Gramineæ, three members of which (barley, corn, and oats) yielded nearly double the amount produced by the Floats or Redonda. The effect upon sunflowers and buckwheat was equally marked. If we compare the amount of dry matter produced by the acid rock with that produced by the Floats for all crops grown, we find the balance in favor of the acid rock to be FIFTY-TWO PER CENT. In other words, the effect of the available phosphoric acid as compared with the insoluble phosphate was to increase the product MORE THAN ONE HALF." 1

The Georgia Experiment Station, commenting in Bulletin No. 2, concerning field experiments with phosphates and kainit applied to cotton, states: "Of phosphates, Acid Phosphate appears to lead, slag comes next, and the FLOATS ARE LAST." 2

A later Georgia Bulletin (No. $3^{\mathrm{I}}$ ), in reviewing a comparison of superphosphate with Tennessee soft phosphate, states: "Superphosphate in a complete fertilizer was compared with one, one and a half and two times the same amount of Tennessee soft phosphate. The latter ('Tennessee soft phosphate) was applied in each case at a loss." 2

In the Annual Massachusetts Experiment Station Report for 1902, concerning an experiment with various kinds of phosphates which were applied in equal amounts of phosphoric acid, there is the following regarding raw rock phosphate: "Tennessee phosphate and Florida soft phosphate gave results very much inferior to all the others." This was an experiment on onions.

In the Massachusetts Annual Report for the following year (I903), concerning the same experiment continued on cabbages, the previous year's results are confirmed: "That Tennessee phosphate and Florida soft phosphate proved very much inferior to all others." 3

${ }^{1}$ This quotation is taken from page 72 of the 1898 Report of the Maine Experiment Station; while on page 57 of the I 900 Report occur the following statements: "For the first year the largest increase of crop was produced by soluble phosphoric acid. For the second and third years, without further addition of fertilizers, better results were obtained from the plots where stable manure and insoluble phosphates were used."- C. G. H.

${ }^{2}$ These are single-year tests. The following quotation might also be made from page I6I of Georgia Bulletin No. 25: "Florida Soft Phosphate appears to be equally as valuable as Acid Phosphate, the difference, if any, being rather in its favor." C. G. H.

${ }^{3}$ On the other hand, the South Carolina raw rock phosphate produced a much larger yield than acid phosphate, especially of marketable cabbage, as shown in Table 49. - C. G. H. 
In Scott County, Indiana, an experiment to determine the relative value oi raw rock phosphate and acid phosphate was started in 1904 and continued for four years. Equal values of rock phosphate and acid phosphate were applied in ONE application the first year - corn and wheat alternating. The actual amount of plant food applied was 286 pounds of total phosphoric acid in the rock phosphate and roo pounds phosphoric acid in the acid phosphate. There were three plots in the experiment - one fertilized with rock phosphate, one with acid phosphate, one unfertilized. Notwithstanding the fact that the first year's corn crop was a total failure on all plots, the results on wheat showed a gain of fourteen bushels per acre with acid phosphate as against only nine bushels for the rock phosphate over the unfertilized plot. The profit per acre in four years from rock phosphate was $\$ 11.55 ;^{1}$ the profit in four years from acid phosphate was \$I 3.50 .

In Marion County, Indiana, another experiment for the same purpose was started, and crops harvested for two years. ${ }^{2}$ Only one application of fertilizer was made, the entire amount being applied the first season. As in Scott County, equal values of rock phosphate and acid phosphate were applied. The results speak for themselves, and they are given in the table below as taken from Circular No. Io of the Indiana Experiment Station. The yields are given in bushels per acre:

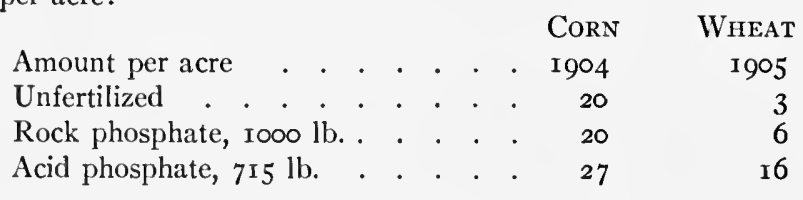

The value of the increase per acre, figuring corn at 35 cents and wheat at 80 cents per bushel, on the plot fertilized with acid phosphate, was .

$\$ 12.85$

Deducting cost of acid phosphate

Net return on the increase

Value of the increase with rock phosphate . . . . . . 2.40

Deducting cost of rock phosphate . . . . . . . . . 5.00

Or a net loss of . . . . . . . . . . . . $\$ 2.60$ per acre

On the total yields the results were as follows:

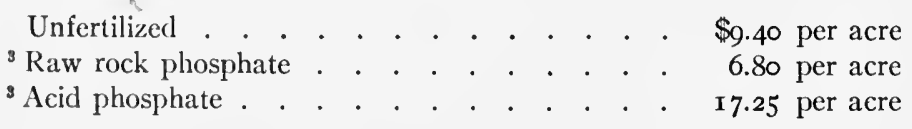

${ }^{1}$ This is a very fair profit considering that about two thirds of the raw rock phosphate will remain in the soil after the acid phosphate is completely exhausted. It should also be noted that the cost of the acid phosphate was figured at \$14 per ton, and the cost of the raw phosphate at $\$$ Io per ton.-C. G. H.

${ }^{2}$ Italics mine. - C. G. H.

Cost of rock phosphate and acid phosphate deducted. 
These figures show that the rock phosphate was applied at a dead loss of $\$ 2.60$ per acre - the unfertilized yield value being $\$ 2.60$ per acre more than the rock phosphate. The yield with acid phosphate was $\$ 7.85$ more than the UNFERTILIZED, and \$10.45 per acre more than the RAW ROCK PHOSPHATE. These results are from experiments primarily intended to show the value of raw rock as a fertilizer. They are self-explanatory, and show conclusively the FOLLY OF CONSIDERING THIS MATERIAI, AS A FERTILIZER. Further, these results were obtained from roo pounds of phosphoric acid in acid phosphate as compared with 286 pounds of raw rock phosphate.

The practical farmer, interested in the proper use of commercial fertilizers, can easily figure that where acid phosphate gave such remarkable returns on experiments covering a series of years, it will pay him a handsome profit to invest judiciously in fertilizers every year giving such good returns.

Tennessee has some of the largest phosphate deposits in the world. In this state where the value of phosphate is so well understood, Professor C. A. Mooers, chemist and agronomist of the Agricultural Experiment Station at Knoxville, in a recent letter to THE AMERICAN FERTILIZER has the following to say with regard to the use of this material in its crude state:

"A bill was introduced in the Legislature, just adjourned, to allow the sale of ground rock phosphate as a fertilizer. In presenting this matter to the Agricultural Committee, the Commissioner of Agriculture and myself took the position that it would not be desirable to tag this material, as that would, to a certain extent, stamp it with the State's approval. Our position is better understood when it is considered that a very large part of the fertilizers used in this State are for wheat, and, as is well known, RAW PHOSPHATE ROCK, as ordinarily used, GIVES NO RETURNS ON THIS CROP. Other large amounts are used, especially in West Tennessee, by the truckers, and for garden crops also RAw PHOSPHATE WOULD BE INADVISABLE. Fertilizers have been used in this State for many years, but our farmers have not studied the matter to any great extent, so that many of them would buy a fertilizer just BECAUSE IT WAS CHEAP, especially if it had the State's tag on it.

"Our results on leguminous crops, which are supposed to be better able to make use of the so-called insoluble forms of phosphoric acid than others, do not warrant the general use of RAW PHOSPHATE. I have recently corresponded with a number of station men who are interested in the use of fertilizers, and I find that the general opinion is AGAINST THE USE OF THIS MATERIAL, although under special conditions, such as are found on a decidedly acid soil, its use may be advisable."

The state of Alabama is one of the oldest of the states using commercial fertilizers. Bulletin No. 24, issued May 15, r9o8, contains an article on "Raw Phosphate Rock as a Fertilizer." Following are extracts from this article:

"Many parties have written to this office for information as to the relative fertilizing value of the raw phosphate, as compared with the acidulated phosphates, and the writer has invariably advised caution in the employment of this particular kind of phosphate. 


\section{SYSTEMS OF PERMANENT AGRICULTURE}

"The samples of this material which have reached this laboratory have almost invariably exhibited a poor mechanical condition, the particles being coarse and irregular in size. As the fineness of division of this phosphate has a most important influence upon its availability to the plant, purchasers of this material have been advised to only use the rock which has been pulverized to a state of practical impalpability, the material in this condition being commonly designated by the name of 'floats.'

"A typical analysis of the raw phosphate rock sent to this laboratory this season is given herewith:

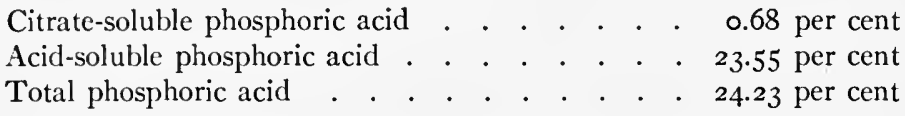

"It will be noted that nearly all of the phosphoric acid in this phosphate is in an insoluble or acid-soluble condition, and there Is SCARCELY A TRACE OF WATER SOLUBLE PHOSPHORIC ACID TO BE FOUND IN THIS RAW PHOSPHATE.

"With regard to the comparative availability of raw phosphate rock, it might be stated that the Experiment Station at Auburn has, during the past few years, carried out under its supervision more than one hundred coöperative soil and crop tests in a great many different localities in the State with a view to determining the comparative efficiency of raw phosphate and acid phosphate for fertilizing purposes. These tests have been carried out upon quite a variety of soils, and upon most soils the RAW PHOSPHATE HAS FAILED TO GIVE ANYTHING LIKE AS GOOD RESULTS AS THE ACID PHOSPHATE.

"In the case of acid phosphate, the ready solubility of most of the phosphoric acid contained therein promotes its rapid and thorough distribution through the top layer of the soil, and hence the plant food is so well disseminated that it is brought within easy reach of the root system of the plant, whereas in the case of the crude insoluble phosphate the diffusion and distribution of the phosphoric acid is necessarily slow, and much of the phosphate is left unutilized at the end of the season in which it is applied.

"For the above reasons IT IS DEEMED INADVISABLE TO EMPLOY THE CRUDE PHOSPIATE to any great extent upon any given soil until comparative tests of the crude rock and acid phosphate have been made upon that soil, and, even under these conditions, it will probably be found necessary to use much larger amounts of phosphate rock than are ordinarily employed to secure a satisfactory return from its application."

While the experience of the German Experiment Stations, combined with a majority in this country, show emphatically that raw rock phosphate has little or no fertilizing value, in addition the method of applying followed by users of this material in this country is MOST EXTRAVAGANT AND WASTEFUL. The method followed would soon exhaust the known or visible supply of phosphate rock. Further, the enormous quantities necessary to apply per acre, instead of being scattered over and benefiting millions of acres, would be wasted on comparatively few. 
On the other hand, this crude material, when properly treated with sulfuric acid and converted into acid phosphate, to be used either as straight acid phosphate or in mixed fertilizers, becomes a source of available plant food of greatest value. Raw rock phosphate, as mined and sold by certain operators; does not contain plant food immediately available to growing crops. It is only by proper handling and treatment with sulfuric acid that this material is converted into fertilizer furnishing plant food available to various crops and soils.

Reputable fertilizer manufacturers decry the use of raw rock phosphate as a fertilizer, knowing that it will NoT prove satisfactory, as borne out by extensive experiments of the world's best agriculturists. They have gone on record against its use, and any lack of results on the part of those using this material should not vitiate against the use of commercial fertilizers rightly prepared, furnishing available, nourishing plant food for all crops.

(Signed).'The National Fertilizer Association.

The author feels that no further comment is necessary regarding this statement from the National Fertilizer Association. The facts are presented in very complete form in the preceding pages, and the reader must draw his own conclusions. For other illustrations of the possibility of erroneous conclusions being drawn by such German investigators as advance theories or reach conclusions without sufficient facts, reference may be made to Chapter $3 \mathrm{I}$, and also to Sir Henry Gilbert's very interesting and complete discussion of the sources of fat in the animal body, based upon Rothamsted investigations in which 327 different animals were dissected, Io different selected carcasses having been subjected to chemical analysis, following the analysis of the foodstuffs provided during long feeding periods. (See Office of Expt. Stations Bul. 22.)

Ohio Experiments with Manure and Phosphates, i897-igi i

\begin{tabular}{|c|c|c|c|c|c|c|}
\hline \multirow{2}{*}{ Soil Treatment } & \multirow{2}{*}{$\begin{array}{c}\text { CORN, } 1 \\
\text { I5-YEAR } \\
\text { AvERAGE } \\
\text { (Bushels) }\end{array}$} & \multirow{2}{*}{$\begin{array}{c}\text { CORN, } \\
\text { I4-YEAR } \\
\text { AvERAGE } \\
\text { (Bushels) }\end{array}$} & \multirow{2}{*}{$\begin{array}{c}\text { WhEAT, } \\
\text { I4-YEAR } \\
\text { AVERAGE } \\
\text { (Bushels) }\end{array}$} & \multirow{2}{*}{$\begin{array}{c}\text { HAY, } \\
\text { II-YEAR } \\
\text { AVERAGE } \\
\text { (Tons) }\end{array}$} & \multicolumn{2}{|c|}{$\begin{array}{c}\text { VALUE of Three } \\
\text { Crops }\end{array}$} \\
\hline & & & & & $\begin{array}{l}\text { Igog Corn } \\
\text { Excluded }\end{array}$ & $\begin{array}{l}\text { rgog Corn } \\
\text { lncluded }\end{array}$ \\
\hline None . . . & 33.0 & 34.4 & I I .2 & I.30 & $\$_{27.68}$ & $\$_{27.19}$ \\
\hline Manure alone . . . & 54.6 & 56.0 & $2 \mathrm{I} . \mathrm{O}$ & I.80 & 45.10 & $44.6 \mathrm{I}$ \\
\hline Manure, rock phosphate & 62.4 & 62.5 & $25 \cdot 7$ & 2.28 & $53 \cdot 54$ & $53 \cdot 5^{I}$ \\
\hline Manure, acid phosphate & 62.0 & 63.8 & 26.1 & 2.25 & 54.10 & 53.47 \\
\hline
\end{tabular}

${ }^{1}$ Because of irregular insect injury, the Ohio Station prefers not to include the Igog corn crop in the general average. (For details, see pages $245^{\circ}$ to $25^{8}$.) 


\section{CHAPTER XVIII}

\section{THEORIES CONCERNING SOIL FERTILITY}

ABout three hundred years ago Van Helmont, a Flemish alchemist, planted a five-pound willow tree in 200 pounds of dry soil. He watered it with rain water for five years, and then found that the tree had gained 164 pounds and that the soil had lost only 2 ounces, in weight. Therefore, he concluded, water is the source of plant food. While it seemed to him that his evidence was strong and positive, all know now that his conclusion was wrong, and that the air, the water, and the soil are all essential sources of plant food.

It will be noted that 2 ounces removed from the 200 pounds of soil correspond to I 250 pounds from 2 million pounds of soil.

Later, Bradley, in his "General Treatise of Husbandry and Gardening," argued that water could be distilled or evaporated, which was not the case with willow trees; and, hence, that water is not the food of plants. He held that air must be the food of plants.

About two hundred years ago, Jethro Tull, the inventor of the first seed drill, taught that neither water nor air could be the food of plants because they were furnished alike to all plants; whereas, two adjoining fields produced very different yields because one was impoverished soil while the other had been enriched. Tull wrote as follows:

"It is agreed that all the following materials contribute in some manner to the increase of plants, but it is disputed which of them is that very increase of food: (1) Niter, (2) Water, (3) Air, (4) Fire, (5) Earth. . . .

"Niter is useful to divide and prepare the food, and may be said to nourish vegetables in much the same manner as my knife nourishes me, by cutting and dividing my meat; but when niter is applied to the root of a plant, it will kill it as certainly as a knife misapplied will kill a man; which proves that niter is, in respect of nourishment, just as much the food of plants, as white arsenic is the food of rats, and the same may be said of salts. 
"Water, from Van Helmont's experiment, was by some great philosophers thought to be it. But these were deceived, in not observing that water has always in its intervals a charge of earth, from which no art can free it.

"Air, because its spring, etc., is as necessary to the life of vegetables as the vehicle of water is, some modern virtuosi have affirmed, from the same and worse arguments than those of the water philosophers, that air is the food of plants. ... .

"Fire. No plant can live without heat, though different degrees of it be necessary to different sorts of plants. Some are almost capable of keeping company with the salamander, and do live in the hottest exposures of the hot countries. Others have their abode with fishes under water, in cold climates; for the sun has his influence, though weaker, upon the earth covered with water, at a considerable depth, which appears by the effect the vicissitudes of winter and summer have upon the subterraqueous vegetables.

"But that fire is the food of plants, I do not know any author has affirmed, except Mr. Lawrence, who says: 'They are true fire-eaters'; and even he does not seem to intend that this expression of his should be taken literally."

"Earth. That which nourishes and augments a plant, is the true food of it.

"Every plant is earth, and the growth and true increase of a plant is the addition of more earth."

"Too much earth, or too fine, can never possibly be given to roots . . . and earth is so surely the food of all plants, that with the proper share of the other elements, which each species of plants requires, I do not find but that any common earth will nourish any plant."

"The mouths, or lacteals, being situate, and opening in the convex superficies of roots, they take their pabulum, being fine particles of earth, from the superficies of the pores, or cavities, wherein the roots are included. . . . These particles, which are the pabulum of plants, are so very minute and light, as not to be singly attracted to the earth, if separated from those parts to which they adhere, or with which they are in contact (like dust to a looking glass, turn it upwards, or downwards, it will remain affixed to it), as these particles do to those parts, until from thence removed by some agent.

"A plant cannot separate these particles from the parts to which they adhere, without the assistance of water, which helps to loosen them.

"As to the fineness of the pabulum of plants, it is not unlikely that roots may insume no grosser particles than those on which the colors of bodies depend; but to discover the greatness of those corpuscles, Sir Isaac Newton thinks, will require a microscope that with sufficient distinctness can represent objects five or six hundred times bigger than at a foot distance they appear to the naked eye."

In general, Jethro Tull taught that the soil particles are the food (pabulum) of plants, and that, if the soil were made sufficiently fine by cultivation, the plants could then absorb these fine particles of earth and produce large crops continuously. In answer to the 
arguments of his critics that the agricultural practice of his time was the result of long experience and consequently must be correct, he expressed a fundamental truth in the following words:

"The experience of $\mathrm{I} 700$ years no more proves this practice to be right, than the long experience of cattle drawing by their tails proved that practice right, before drawing by traces was by experiment proved to be better: for nothing can be depended on as experience, which has not been tried by experiment."

$\mathrm{He}$ also classes himself with those who "cannot believe that a man will become bald by being shaved at the wrong time of the moon, without more experience than has been made for it these I 700 years past.') -

Another century passed, during which the humus theory advanced by Thaer and others gained some recognition. The humus of the soil was held to be the source of carbon and carbonaceous matter for the plant. Humus and water were considered the only sources of plant food, and the productive power of the soil was believed to depend solely upon its humus content.

In the "Georgical " Essays" (Edition of I777) by Doctor A. Hunter, which also includes many essays or reports by other " philosiophical farmers," we find the following interesting statements:

"The ancient writers gave us excellent comments upon the husbandry of their times. Hesiod wrote very early upon Agriculture. Mago, the Carthaginian general, composed twenty-eight books upon the same subject, which were translated by order of the Roman Senate. Upon these models Virgil formed his elegant precepts of husbandry.

"Cato, the Censor, wrote a volume upon Agriculture. Columella has left us twelve books upon rural matters. Varro's treatise will ever be esteemed. . . .

"The celebrated Sully calls Agriculture one of the breasts from which the State must draw its nourishment. That great man could not possibly have given us a more happy simile. . . ."

"Colbert entertained a different notion of policy. Esteeming manufacturers and commerce as the sinews of the State, he gave all possible encouragement to the Artisan and the Merchant, but forgot that the manufacturer must eat his bread at a moderate price. The farmer being discouraged, the necessaries of

' Georgical, like the proper name George (Latin Georgius), meaning husbandman or farmer, is derived from the Greek $\gamma \hat{\eta}$ ( $g e$-, as in geology), the earth, and $\check{\epsilon} \gamma \epsilon \epsilon \nu$ (ergein, as in energy), to work. The Georgics of Virgil are poems on agricultural affairs. 
life became dear; the public granaries became ill stored; manufactures languished; commerce drooped; a numerous army soon consumed the scanty harvest; and, in a short time, Industry fell a sacrifice to the ill-judged policy of the minister.

"From that period to the present, the French nation have constantly been availing themselves of their mistake. Under the genial influence of the King, Societies are erected in every province. Men of the first distinction do not disdain the cultivation of their own lands. M. de Chateauvieux and Duhamel are the greatest ornaments of their country. - Let us imitate the virtues of that fashionable nation. . . ."

"The art of husbandry boasts an origin coeval with the human race. Its age, however, seems to have contributed but little towards its advancement, being at present extended but a few degrees beyond its primitive institution. Until the philosopher condescends to direct the plow, Husbandry must remain in a torpid state. . . .

"I take it upon me to say, that, to be a good husbandman, it is necessary to be a good chymist. Chymistry will teach him the best way to prepare nourishment for his respective crops, and, in the most wonderful manner will expose the hidden things of nature to his view. The principles of Agriculture depend greatly upon chymistry; and without principles, what is art, and what is science?

"Directed by instinct, the animal seeks its own proper food; but the vegetable, not being possessed of the power of motion, must be satisfied with the nourishment we give it. To direct this upon rational principles, is the business of the philosopher. The practical farmer will suffer himself to be instructed as soon as he perceives the practice correspond with the theory laid down to him. Let us expect no more of him. Men of limited education commit great errors when they attempt to reason upon science. In husbandry, effects are constantly applied to improper causes. Hence proceed the errors of our common farmers. To overcome these is the peculiar province of the philosopher; who, in his turn, must support his reasoning by facts and experiments.

"I lay it down as a fundamental maxim, that all plants receive their principal nourishment from oily particles incorporated with water, by means of an alkaline salt or absorbent earth. . . . It may be asked, whence do natural soils receive their oily particles? I answer, the air supplies them. During the summer months, the atmosphere is full of putrid exhalations arising from the steam of dunghills, the perspiration of animals and smoke. Every shower brings down these oleaginous particles for the nourishment of plants."

"The ingenious Mr. Tull, and others, have contended for earth's being the food of plants. If so, all soils equally tilled would prove equally prolific. Water is thought, by some, to be the food of vegetables, when in reality it is only the vehicle of nourishment."

After pointing out the great value of oil meals, rape cake, etc. (and later of fish scrap), for soil improvement, and after noting 
that all seeds contain oil, and that hemp, rape, and flax (rich in oil) are very exhaustive crops, Doctor Hunter adds, much to his credit as a scientist:

"As I have not the vanity to think my experiments sufficiently conclusive, I embrace this opport unity to request assistance of the practical farmer, in order that the merits of the invention may be fully determined. Should my theory concerning the food of plants be thought erroneous, the compost (made in part of crude whale oil, 'train oil') will of course be disregarded. But, on the contrary, should it be agreed to that oil, made miscible with water, constitutes the chief nourishment of vegetables, then the invention will probably become the subject of future experiment.

"Though theory may direct our inquiries, yet experience must at last determine our opinions, for which reason I propose to enlarge my experiments; and as I have no other view but the investigation of the truth, I shall lay them faithfully before the public, whether they prove successful or not."

Among the "Georgical Essays," the two reports which follow are of special interest. The first bears upon the oil theory, and both show evidence of the search for truth, and indicate the approaching dawn of chemical science. The editor says that the I 777 edition is a reprint, and that " this volume contains several additional papers"; so it is not clear that Doctor Hunter knew of these experiments.

\section{"A Comparative View of Manures}

"By A. Young, Esq.

"In the year I 77I, I marked out a rood of land into divisions, and sowed them with oats. The variety of manures made use of in this experiment are marked as follows:

Produce PER ACre

No.

I. 40 cubical yards of farmyard compost, and dung . . . $40 \quad 2 \frac{1}{2}$

2. 20 ditto . . . . . . . . . . . . . . . . . 5 I I

3. 10 ditto . . . . . . . . . . . . . . . . . . . 45 o

4. Io ditto . . . . . . . . . . . . . . . . . . 46 . I

5. ro loads of bones, each 40 bushels. . . . . . . . . 63 I

6. 20 ditto . . . . . . . . . . . . . . . . . . 57 o

7. 200 bushels of lime . . . . . . . . . . . . . . . . $3^{8} \quad \mathrm{I}^{\frac{3}{4}}$

8. 40 yards of chalk . . . . . . . . . . . . . 3 I I

9. No manure . . . . . . . . . . . . . . . . 30 $2 \frac{1}{2}$

1. 80 yards of chalk . . . . . . . . . . . . . . $25 \quad 2 \frac{1}{2}$

II. 120 ditto 
12. 40 yards of chalk, earth mixed with train oil, six months ago, and often turned . . . . . . . . . . . . 33

I3. 40 ditto, earth mixed with urine, four months ago, and often turned.

I4. 40 ditto, earth alone

I5. 40 ditto, earth from the farmyard . . . . . . . 37

$37 \quad 2$

I6. I 20 ditto, red gravelly loam

I7. 160 ditto

$\begin{array}{cccccc}\cdot & \cdot & \cdot & \cdot & \cdot & 37 \\ \cdot & \cdot & \cdot & \cdot & \cdot & 33 \\ \cdot & \cdot & \cdot & \cdot & \cdot & 37 \\ \cdot & \cdot & \cdot & \cdot & \cdot & 29 \\ . & \cdot & \cdot & \cdot & \cdot & 31\end{array}$

"N.B. The season was remarkably dry, which circumstance certainly had a considerable effect upon the different crops."

\section{"On Bones used as a Manure \\ “By Anthony St. Leger, Esq.}

"During a long course of speculative and practical Agriculture, in which, with critical exactness, I employed myself in making experiments upon almost every kind of manure, I was fortunate enough to discover that bones are superior to all the manures made use of by the farmer.

"Eight years ago I laid down to grass a large piece of very indifferent limestone land with a crop of corn (Wheat, presumably); and, in order that the grass seeds might have a strong vegetation, I took care to see it well dressed. From this piece I selected three roods of equal quality with the rest, and dressed them with bones broken very small, at the rate of sixty bushels per acre. Upon lands thus managed, the crop of corn was infinitely superior to the rest. The next year the grass was also superior, and has continued to preserve the same superiority ever since, insomuch that in spring it is green three weeks before the rest of the field.

"This year I propose to plow up the field as the Festuca sylvatica (prye grass) has overpowered the grass seed originally sown. And here it will be proper to remark that, notwithstanding the species of grass is the natural produce of the soil, the three roods on which the bones were laid have hardly any of it, but, on the contrary, have all along produced the finest grasses.

"Last year I dressed two acres with bones, in two different fields prepared for turnips, sixty bushels to the acre, and had the pleasure to find the turnips greatly superior to the others managed in the common way. I have no doubt but these two acres will preserve their superiority for many years to come, if I may be allowed to prognosticate from former experiments most carefully conducted.

"I also dressed an acre of grass ground with bones last October (I 774) and rolled them in. The succeeding crop of hay was an exceeding good one. However, I found from repeated experience that, upon grass ground, this kind of manure exerts itself more powerfully the second year than the first.

"It must be obvious to every person, that the bones should be well broken 
before they can be equally spread upon the land. No pieces should exceed the size of marbles.) To perform this necessary operation, I would recommend the bones to be sufficiently bruised by putting them under a circular stone, which, being moved round upon its edge by means of a horse, in the manner that tanners grind their bark, will very expeditiously effect the purpose. At Sheffield it is now become a trade to grind bones for the use of the farmer. Some people break them small with hammers upon a piece of iron, but that method is inferior to grinding.(.To ascertain the comparative merit of ground and unground bones, I last year dressed two acres of turnips with large bones, in the same field where the ground ones were used; the result of this experiment was, that the unground material did not perform the least service; while those parts of the field on which the ground bones were laid were greatly benefited.

"I find that bones of all kinds will answer the purpose of a rich dressing, but those of fat cattle I apprehend are the best. The London bones, as I am informed, undergo the action of boiling water, for which reason they must be much inferior to such as retain their oily parts; and this is another of the many proofs given in these essays that oil is the food of plants. The farmers in this neighborhood are become so fond of this kind of manure, that the price is now advanced to one shilling and fourpence per bushel, and even at that price they send sixteen miles for it.

"I have found it a judicious practice to mix ashes with the bones; and this winter I have six acres of meadow land dressed with that compost. A cart load of ashes may be put to thirty or forty bushels of bones, and when they have heated for twenty-four hours (which may be known by the smoking of the heap) let the whole be turned. After laying ten days longer, this most excellent dressing will be fit for use."

In 1822 , William Corbett, in his compilation of the writings of Jethro Tull, made the following statements:

"Mr. Tull's main principle is this, that tillage will supply the place of manure; and his own experience shows that a good crop of wheat, for any number of years, may be grown every year upon the same land without any manure from first to last."

"Mr. Tull continued his wheat crops to the harvesting of the twelfth upon the same land without manure; and when he concluded his work, he had, as he informs us in a memorandum, the thirteenth crop coming on, likely to be very good."

It may be stated, however, that, after the time of Jethro Tull and before Corbett's republication of the 'Tullian methods and theories, some truly scientific facts had been discovered. In fact, chemistry had begun to assume the character of an exact science. Priestly had discovered oxygen and also identified as oxygen the gas which others had previously observed is given off from the 
leaves of plants under the influence of sunlight; ${ }^{1}$ Sénébier had shown that the carbon of the plant is derived from the carbon dioxid of the air; and De Saussure had analyzed the ash of many plants, had shown that these ash constituents were derived from the soil, and that, though small in quantity as compared with the amount of material furnished to the plant by the air and water, the ash constituents were also essential to plant growth.

De Saussure's publication in I804 of his " Reserches Chimique sur la Vegetation" gave to the world the first definite and approximately correct statement concerning the requirements and sources of plant food. While Davy's lectures on Agricultural Chemistry

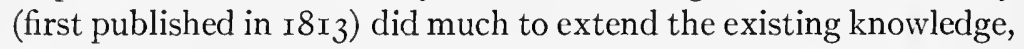
and the investigations of Bousingault and Lawes began to develop (about I835), it remained for Liebig to bring together the work of all and present it in a more comprehensive form in his "Organic Chemistry in its Application to Agriculture and Physiology," published in $\mathrm{x} 840$.

Thus, while Liebig is popularly known as the "Father of Agricultural Chemistry," the more fundamental contributions to knowledge concerning soil fertility and plant growth have been made by Sénébier (of Switzerland), De Saussure (of France), Lawes and Gilbert (of England), and Hellriegel (of Germany), the last being the discovery (in I886) of nitrogen fixation by the root-tubercle bacteria of legumes.

Liebig devoted much effort toward the proof of his theory that the ammonia of the air is the source of nitrogen for plants; but in this he failed, and Lawes and Gilbert's laboratory and field investigations at Rothamsted, which were in part planned for the purpose of disproving Liebig's nitrogen theory, clearly established the fact that in the main the soil must furnish nitrogen as well as the mineral elements of plant food.

The following quotations from Liebig's writings are interesting; and they are also instructive, in that they well illustrate the weakness of drawing quantitative deductions and specific conclusions from qualitative data and general observations. Thus wrote Liebig:

1 Any one may observe the bubbles of oxygen formed upon fresh leaves placed under water in the sunlight. 
"Let us picture to ourselves the condition of a well-cultured farm, so large as to be independent of assistance from other quarters. On this extent of land there is a certain quantity of nitrogen contained both in the corn and fruit which it produces, and in the men and animals which feed upon them, and also in their excrements. We shall suppose this quantity to be known. The land is cultivated without the importation of any foreign substance containing nitrogen. Now, the products of this farm must be exchanged every year for money, and other necessaries of life, for bodies, therefore, which contain no nitrogen. A certain proportion of nitrogen is exported with corn and cattle; and this exportation takes place every year, without the smallest compensation; yet after a number of years, the quantity of nitrogen will be found to have increased. Whence, we may ask, comes this increase of nitrogen? The nitrogen in the excrements cannot reproduce itself, and the earth cannot yield it. Plants, and consequently animals, must, therefore, derive their nitrogen from the atmosphere.

"The last products of the decay and putrefaction of animal bodies present themselves in two different forms. They are in the form of a combination of hydrogen and nitrogen, - ammonia, in the temperate and cold climates, and in that of a compound, containing oxygen, nitric acid, in the tropics and hot climates. The formation of the latter is preceded by the production of the first. Ammonia is the last product of the putrefaction of animal bodies; nitric acid is the product of the transformation of ammonia. A generation of a thousand million men is renewed every thirty years: thousands of millions of animals cease to live and are reproduced in a much shorter period. Where is the nitrogen which they contained during life? There is no question which can be answered with more positive certainty. All animal bodies, during their decay, yield the nitrogen, which they contain to the atmosphere, in the form of ammonia. Even in the bodies buried sixty feet underground in the churchyard of the Eglise des Innocens, at Paris, all the nitrogen contained in the adipocere was in the state of ammonia. Ammonia is the simplest of all the compounds of nitrogen; and hydrogen is the element for which nitrogen possesses the most powerful affinity.)

"The nitrogen of putrefted animals is contained in the atmosphere as ammonia in the form of a gas which is capable of entering into combination with carbonic acid, and of forming a volatile salt. Ammonia in its gaseous form as well as all its volatile compounds are of extreme solubility in water. Ammonia, therefore, cannot remain long in the atmosphere, as every shower of rain must condense it, and convey it to the surface of the earth. Hence, also, rain water must, at all times, contain ammonia, though not always in equal quantity. It must be greater in summer than in spring or in winter, because the intervals of time between the showers are in summer greater; and when several wet days occur, the rain of the first must contain more of it than that of the second. The rain of a thunderstorm, after a long-protracted drought, ought for this reason to contain the greatest quantity, which is conveyed to the earth at one time. ..."

"If a pound of rain water contain only one fourth of a grain of ammonia, 
then a field of 40,000 square feet must receive annually upwards of $80 \mathrm{lb}$. of ammonia, or $65 \mathrm{lb}$. of nitrogen; for, by the observations of Schiibler, which were formerly alluded to, about $700,000 \mathrm{lb}$. of rain fall over this surface in four months, and consequently the annual fall must be $2,500,000 \mathrm{lb}$. This is much more nitrogen than is contained in the form of vegetable albumen and gluten, in $2650 \mathrm{lb}$. of wood, $2800 \mathrm{lb}$. of hay, or $200 \mathrm{cwt}$. of beet root, which are the yearly produce of such a field, but it is less than the straw, roots, and grain of corn which might grow on the same surface, would contain.

"Experiments, made in this laboratory (Giessen) with the greatest care and exactness, have placed the presence of ammonia in rain water beyond all doubt. It has hitherto escaped observation, because no person thought of searching for it. ${ }^{1}$ All the rain water employed in this inquiry was collected 600 paces southwest of Giessen, whilst the wind was blowing in the direction of the town. When several hundred pounds of it were distilled in a copper still, and the first two or three pounds evaporated with the addition of a little muriatic acid, $\mathrm{HCl}$, a very distinct crystallization of sal-ammoniac $\left(\mathrm{NH}_{4} \mathrm{Cl}\right)$ was, obtained: the crystals had always a brown or yellow color.

"Ammonia may likewise be always detected in snow water. Crystals of sal-ammoniac were obtained by evaporating in a vessel with muriatic acid several pounds of snow, which were gathered from the surface of the ground in March, when the snow had a depth of 10 inches. Ammonia was set free from these crystals by the addition of hydrate of lime. The inferior layers of snow, which rested upon the ground, contained a quantity decidedly greater than the which formed the surface.

"It is worthy of observation, that the ammonia contained in rain and snow water possesses an offensive smell of perspiration and animal excrements, a fact which leaves no doubt respecting its origin. . . ."

"We find this nitrogen in the atmosphere, in rain water, and in all kinds of soils, in the form of ammonia, as a product of the decay and putrefaction of preceding generations of animals and vegetables. We find, likewise, that the proportion of azotized matters in plants is augmented by giving them a large: supply of ammonia conveyed in the form of animal manure.

"No conclusion can then have a better foundation than this, that it is the ammonia of the atmosphere which furnishes nitrogen to plants." )

As an average of I $_{5}$ years, the total amount of nitrogen brought to earth in rain and snow was found to be 3.97 pounds per acre per annum, at Rothamsted. Other records, varying from 3 to 7 years, have shown 3.45 pounds per acre per annum on the Barbados Islands, 3.54 pounds in British Guiana, 3.69 pounds in Kansas, 5.42 pounds in Utah, and 3.64 pounds in Mississippi; while the records from Paris show 8.93 pounds, and those from Grembloux,

1 "It has been discovered by Mr. Hayes in the rain water in Vermont." - W. 
Belgium, 9.20 pounds, both of which are doubtless influenced by the atmosphere from the cities with their numerous factories and other sources of pollution.

Professor Shutt reports 4.32 pounds of nitrogen per acre in one year's precipitation at Ottawa, Canada, in 37.35 inches, of which 3.24 pounds were found in 24.05 inches of rain and 1.08 pounds in I 3.3 inches of snow water (corresponding to about 133 inches of snow), the average composition being based upon analyses of 46 . samples of rain water and 32 samples of snow water. Of the nitrogen found in rain water, 6I per cent existed in free ammonia, 22 per cent in nitrate (and nitrite) form, and 17 per cent as organic nitrogen, the corresponding percentages for snow water being $5^{6}$, 34 , and Io.

Liebig also discussed very interestingly and, in the main, very erroneously, the reasons for the value of crop rotation. In 1840 he wrote as follows:

"Of all the views which have been adopted regarding the cause of the favorable effects of the alternations of crops, that proposed by $M$. Decandolle alone deserves to be mentioned as resting on a firm basis.

"Decandolle supposes that the roots of plants imbibe soluble matter of every kind from the soil, and thus necessarily absorb a number of substances which are not adapted to the purposes of nutrition, and must subsequently be expelled by the roots, and returned to the soil as excrements. Now as excrements cannot be assimilated by the plant which ejected them, the more of these matters which the soil contains, the more unfertile must it be for plants of the same species. These excrementitious matters may, however, still be capable of assimilation by another kind of plants, which would thus remove from the soil, and render it again fertile for the first. And if the plants last grown also expel substances from their roots, which can be appropriated as food by the former, they will improve the soil in two ways.

"Now a great number of facts appear at first sight to give a high degree of probability to this view. Every gardener knows that a fruit tree cannot be made to grow on the same spot where another of the same species has stood; at least not until after a lapse of several years. Before new vine stocks are planted in a vineyard from which the old have been rooted out, other plants are cultivated on the soil for several years. In connection with this it has been observed, that several plants thrive best when growing beside one another; and, on the contrary, that others mutually prevent each other's development. Whence it was concluded, that the beneficial influence in the former case depended on a mutual interchange of nutriment between the plants, and the injurious one in the latter on a poisonous action of the excrements of each on the other respectively. 
"A series of experiments by Macaire-Princep gave great weight to this theory. He proved beyond all doubt that many plants are capable of emitting extractive matter from their roots. He found that the excretions were greater during the night than by day, and that the water in which plants of the family of the Leguminosa grew, acquired a brown color. Plants of the same species, placed in water impregnated with these excrements, were impeded in their growth, and faded prematurely, whilst, on the contrary, corn plants grew vigorously in it, and the color of the water diminished sensibly; so that it appeared, as if $a$ certain quantity of he excrements of the Leguminose had really been absorbed by the corn plants. These experiments afforded as their main result, that the characters and properties of the excrements of different species of plants are different from one another, and that some plants expel excrementitious matter of an acrid and resinous character; others mild (douce) substances resembling gum. The former of these, according to Macaire-Princep, may be regarded as poisonous, the latter as nutritious.

"The experiments of Macaire-Princep are positive proof that the roots, probably of all plants, expel matters, which cannot be converted in their organism either into woody fiber, starch, vegetable albumen, or gluten, since their expulsion indicates that they are quite unfitted for this purpose. But they cannot be considered as a confirmation of the theory of Decandolle, for they leave it quite undecided whether the substances were extracted from the soil, or formed by the plant itself from food from another source. It is certain that the gummy and resinous excrements observed by Macaire-Princep could not have been contained in the soil; and as we know that the carbon of a soil is not diminished by culture, but, on the contrary, increased, we must conclude that all excrements which contain carbon must be formed from the food obtained by plants from the atmosphere. Now, these excrements are compounds, produced in consequence of the transformations of the food, and of the new forms which it assumes by entering into the composition of the various gegans.

"M. Decandolle's theory is properly a modification of an earlier hypothesis, which supposed that the roots of different plants extracted different nutritive substances from the soil, each plant selecting that which was exactly suited for its assimilation. According to this hypothesis, the matters incapable of assimilation are not extracted from the soil, whilst $M$. Decandolle considers that they are returned to it in the form of excrements. Both views explain how it happens that after corn, corn cannot be raised with advantage, nor after peas, peas; but they do not explain how a field is improved by lying fallow, and this in proportion to the care with which it is tilled and kept free from weeds; nor do they show how a soil gains carbonaceous matter by the cultivation of certain plants, such as lucern and esparsette.

"Theoretical considerations on the frocess of nutrition, as well as the experience of all agriculturists, so beautifully illustrated by the experiments of Macaire-Princep, leave no doubt that substances are excreted from the roots of plants. ..." 
"It is scarcely necessary to remark that this excrementitious matter must undergo a change before another season. During autumn and winter it begins to suffer a change from the influence of air and water; its putrefaction, and, at length, by continued contact with the air, which tillage is the means of procuring, its decay are effected; and at the commencement of spring it has become converted, either in whole or in part, into a substance which supplies the place of humus, by being a constant source of carbonic acid.

"The quickness with which this decay of the excrements of plants proceeds, depends on the composition of the soil, and on its greater or less porosity. It will take place very quickly in a calcareous soil; for the power of organic excrements to attract oxygen and to putrefy is increased by contact with the alkaline constituents, and by the general porous nature of such kinds of soil, which freely permit the access of air. But it requires a longer time in heavy soils consisting of loam or clay.

"The same plants can be cultivated with advantage on one soil after the second year, but in others not until the fifth or ninth, merely on account of the change and destruction of the excrements which have an injurious influence on the plants being completed in the one, in the second year; in the others, not until the ninth.

"In some neighborhoods, clover will not thrive until the sixth year; in others not till the twelfth; flax in the second or third year. All this depends on the chemical nature of the soil; for it has been found by experience that in those districts where the intervals at which the same plants can be cultivated with advantage, are very long, the time cannot be shortened even by the use of the most powerful manures. The destruction of the peculiar excrements of one crop must have taken place before a new crop can be produced.

"Flax, peas, clover, and even potatoes, are plants the excrements of which, in argillaceous soils, require the longest time for their conversion into humus; but it is evident, that the use of alkalies and burnt lime, or even small quantities of ashes which have been lixiviated, must enable a soil to permit the cultivation of the same plants in a much shorter time.

"A soil lying fallow owes its early fertility, in part, to the destruction or conversion into humus of the excrements contained in it, which is effected during the fallow season, at the same time that the land is exposed to a further disintegration."

In the first American edition of Liebig's book, published in I84I, Doctor John W. Webster, then Professor of Chemistry in Harvard University, inserted an appendix, in which he wrote as follows:

"It should be stated that the accuracy of the experiments of Macaire-Princep atduced by the author (Liebig) is not generally admitted. Other chemists have been unable to obtain similar results, or, if they do, are inclined to ascribe them to injury of the roots of the plants examined. Professor Lindley has in his notice of Liebig's work remarked that he has no fixed opinion on the subject, it being a question of facts and not of induction." 
Liebig so emphasized the importance of the mineral plant food, as established by De Saussure's careful work, that it has ever since been referred to as "Liebig's mineral theory of plant nutrition."

In recent years, Whitney and Cameron have revived Decandolle's theory of toxic excreta from plant roots, in support of another more radical theory announced by them, to the effect that soils do not wear out or become depleted by cultivation and cropping. While this theory is advanced with no adequate foundation and in direct opposition to practical experience and to so many known facts of mathematics, chemistry, and geology, that it is in itself quite unworthy of further consideration, the fact is that it has been promulgated by Professor Whitney as Chief of the United States Bureau of Soils, and by Doctor Cameron, as the chief chemist of the same Bureau; and, consequently, it cannot be ignored.

The author finds practically no support for these radical theories, either in the American Experiment Station bulletins or in the publications from the older scientific bureaus at Washington, such as the United States Geological Survey, the Bureau of Chemistry, and the Bureau of Plant Industry; while they are directly contrary to the teachings of all recognized European authorities. But even above any so-called authorities, we must recognize facts, if there are any, for an opinion contrary to the facts is of no permanent value by whomsoever it may be held.

The following statements from Whitney and Cameron will give a clear idea of the plain teachings of the Bureau of Soils, so far as represented by its leaders.

Thus, on page 64 of Bulletin 22 of the Bureau of Soils, published by Whitney and Cameron in 1903, we read:

"That practically all soils contain sufficient plant food for good crop yields, that this supply will be indefinitely maintained," etc.

Again, on pages 21 and 22, Farmers' Bulletin 257, published in I906, we have the following definite statements from Professor Whitney:

"There is another way in which the fertility of the soil can be maintained, viz., by arranging a system of rotation and growing each year a crop that is not injured by the excreta of the preceding crop; then when the time comes round for the first crop to be planted again, the soil has had ample time to dispose of the sewage resulting from the growth of the plant two or three years before. This, I 
think, is the basis or reason in many cases for our crop rotation, viz., that these excreted substances are not toxic alike for all plants, and the soil has time to recover its tone and cleanse itself. I have told you that barley will follow potatoes in the Rothamsted experiments after the potatoes have grown so long that the soil will not produce potatoes. The barley grows unaffected by the excreta of the potatoes, another crop follows the barley, and the soil is then in condition to grow potatoes again." )

Again in the report of the Hearings before the Committee on Agriculture of the United States House of Representatives, under date of January 28, I908, page 428, we find the following statements by Professor Whitney:

"The investigations of the Bureau of Soils, as to the cause of the deterioration of soils, and the causes that limit crop production, have changed the viewpoint of the entire world."

On pages 445-449 of the same publication, Doctor Cameron makes the following statements:

"All soils contain practically all the common rock-forming minerals. Now, it is a principle of chemistry that when a solvent is brought in contact with a substance, that substance will go into solution until there is a state of equilibrium between the quantity of the substance outside and inside; in other words, we get a saturated solution. If these rock-forming minerals were in all soils, we should have the same solution in every soil, and that has been shown to be the case. There are various variations, due to absorption, perhaps, of the soil. In the first place, I must ask you gentlemen to remember that the soil and the plant and the water in the soil is moving. The soil grains are constantly moving, and the solution in the soil is constantly moving, and the growing plant is constantly moving. If a plant stops for a moment, it dies. The soil solution cannot stop for a moment, because it has to be moving all the time. When water falls on the soil, part of it runs off the surface, and part of it runs through the surface by gravitation and comes out in the subsoil, and part of it starts and rises as soon as we get sunlight on the surface, and this part comes up in films over and through the finer spaces, and is bringing with it dissolved material from below.

"The water that falls and goes through down and out goes rapidly through larger openings, and gets very little of the soluble material, because it is not long in contact with the soil grains. It gets some by reason of the fact that, as we know, our springs and rivers and wells are all soil solutions, and carry mineral matter. Now, water rising by capillarity cannot get very concentrated because it gets saturated with the minerals, and any excess that is contained in it is thrown out, except in extreme conditions, as in the West, and then we get alkali conditions; but under ordinary humid conditions we cannot have an excess of it, and the soil solution is bringing materials from below which the 
plant gets, and, as a matter of fact, the most important discovery of the Bureau of Soils in recent years is that plants are feeding on material from the subsoils, far below where the roots go.")

Subsequent to this statement, the following dialogue is recorded:

The Chairman. "When you say that all soils contain all the elements of plant food, and there is in those soils at all times a saturated solution of which all these elements of plant food make a part, do you not practically say that all soils have all the plant food they need, and that it is at all times available for the plant; or is it not available for the plant if it is in a saturated solution?"

Mr. Cameron. "Certainly, if there is water enough; if the soil is moist."

The Chairman. "Is it not therefore a justifiable inference from what you have said, that there is all the time in all soils enough plant food available for plant life?"

Mr. Cameron. "True; perfectly true as regards mineral nutrients."

The Chairman. "Then I come back again to the question, why is it necessary, or is it in your judgment necessary, ever at any time to introduce fertilizing material into any soil for the purpose of increasing the amount of plant food in that soil."

Mr. Cameron. "Not in my judgment."

The Chairman. "Then in your judgment the only reason for the introduction of fertilizers is for the antitoxic effect or the mechanical effect they may have on the soil."

Mr. Cameron. "Mainly that, but there are other functions of fertilizers that we know comparatively little about. We know that certain kinds of life, bacteria, molds, can grow in certain solutions of salts, and cannot in others. It may be that fertilizers affect them. But all that is an unexplored field, and little is known about it. . . . If you will allow me to say one more word about fertilizers: What are fertilizers? What are the characteristics that a substance must have in order to be a fertilizer? It must be obtained in large quantities. It must also be cheap. Now, the substances which are used as fertilizing material are substances which can be obtained in large quantities. They are substances, and arethe only substances, which we can get hold of that we can get in large quantities, that we can get cheap, and with one exception - that is, sodium chlorid - common salt. It has not been much used as a fertilizer, because it has not any so-called plant food in it; and yet it has been used in quite a large number of experiments on quite a large scale, and wherever it has lieen used, it has generally been found to be quite a good fertilizer. In the investigations of the Bureau we have used pyrogallol. It contains no plant food, but carbon, hydrogen, and oxygen, yet, nevertheless, it is a powerful fertilizer ${ }^{1}{ }^{1}$ but

${ }^{1}$ Director Wheeler of the Rhode Island Agricultural Experiment Station reported to the Graduate School of Agriculture held at Cornell University, July, 1908, that a thorough investigation under field conditions at the Rhode Island Station showed practically no benefit from the use of pyrogallol as a fertilizer; whereas, very marked effects were produced by manures and commerical fertilizers. - C.G.H. 


\section{$3^{16}$ SYSTEMS OF PERMANENT AGRICULTURE}

cannot be obtained cheaply. It is worth over $\$ 2$ a pound, and nobody would think of recommending it as a fertilizer. . . ."

"There has not been a publication on the subject of soil fertility going out from the Bureau of Soils - and I think I can speak advisedly, for every one has gone through my hands - in which we did not have the experimental proof long before the publication went out, and that this is being recognized I think I can claim by the fact that a number of agricultural colleges in the country are using our bulletins as text-books. I have recently come from a lecture trip extending from Louisiana to Michigan, and I found everywhere that this is being taught, and, as I say, our publications are being used for text-books."

\section{On page 5 of Farmers' Bulletin 257, Professor Whitney makes.} the following statements:

"I shall be glad, however, to speak of certain general features of the essential and broadly applicable laws of soil fertility that the Bureau of Soils, with its large force of field men and its large force of chemists and soil physicists, has investigated in the last twelve years. We think that as a result of this work we understand far more of the principles of soil fertility now than we ever have before, and I wish to give the results in words as simple as possible. You need not necessarily believe everything I say (because I cannot say truly that I believe everything myself, but only that our opinions seem reasonable deductions)."

In general, the soil fertility theories of Whitney and Cameron may be briefly summarized in the following statements, all of which are direct quotations:

I. "It appears further that practically all soils contain sufficient plant food for good crop yields, that this supply will be indefinitely maintained, and that the actual yield of plants adapted to the soil depends mainly, under favorable climatic conditions, upon the cultural methods and suitable crop rotation."

- Whitney and Cameron, in Bureau of Soils Bulletin 22, page 64 .

2. "In all soils there are rock particles or minerals contajning phosphoric acid and potash, and in all the soil solutions that we have ever examined and we have examined hundreds of them from all parts of the country - you will be astonished to learn that the composition and concentration of the soil moisture, which is the nutrient solution spread throughout the surface soil of the earth for plants to grow in and to gather their food from, you will be astonished to learn that the concentration of this soil moisture is sensibly the same whether we examine your sandy truck soils on your river necks, your sandy clay wheat soils on the uplands, the Hagerstown clay in the valley of the Shenandoah, or the black prairie soils of the West. These minerals are contributing to the solution in which the plant feeds. As I have said, these minerals are difficultly soluble, but they are appreciably soluble. They are soluble enough to maintain a solution which is amply sufficient for the plants to 
gather their food from. All soils having, broadly speaking, all of these minerals in them, have approximately the same composition in their soil moisture.

"This is a very astonishing fact, but, looked upon in the light of our experiments, it is an actual fact that all soils contain sufficient plant food for the support of plants. Further, when the plant takes into its substance some of the mineral matter from the solution, the solid minerals in contact with the solution immediately dissolve, and the solution is restored to its former concentration. The exhaustion of the soil, therefore, is merely a relative phrase and resolves itself into the question of the rate at which the solution can recover itself. I may state to you that the rate is as fast on an acre planted in our ordinary crops as the demand made upon it by the plant."

- Whitney, in Farmers' Bulletin 257, pages Io, II.

3. "It is not to be denied that plants will not infrequently do better when they are growing in a soil, a nutrient solution, or a soil solution many times stronger than they actually need. . . .

"If we take a plant and grow it in a water culture, the plant does better if we have a solution containing several times more phosphorus and potash than it actually needs to feed on. Why it is we do not know, but granting that the plant does better in a solution stronger than it actually needs as a food, we still have a solution in the soil apparently strong enough for any need the plant may have.

"Now we come to a very interesting thing to the farmer. If soils have sufficient food for the needs of plants and if this supply is constantly maintained, as I say, by the solution of these minerals in the soil, then what is the function of fertilizers, and what do we mean by worn-out lands or exhausted lands ?... The chemical idea of the exhaustion of a soil is not logical in the light of the experience which all of us have seen, that when fertilizers are applied, the soils are not always made immediately productive. You can go into many of the regions of the worn-out soils of our Eastern states and reclaim those soils or make them productive, but not with any amount of fertilizers you can apply."

"I should say that the soil ought to take care of the excrement of plants. It is its business to do so. It is its proper function. Whether it does this through the agency of bacteria, whether it is due to the abnormal absorptive power of the soil or to direct oxidation, we do not know. It is probably due in part to each. Take a natural soil, a prairie sod; the sanitary conditions in that soil are almost perfect." 1

- Whitney, in Farmers' Bulletin 257, pages II, I2, and 15.

4. "Apparently these small amounts of fertilizers we add to the soil have their effect upon these toxic substances and render the soil sweet and more healthful for growing plants. We believe that it is through this means that our fertilizers act rather than through the supplying of plant food to the plant."

- Whitney, in Farmers' Bulletin 257, page 20.

${ }^{1}$ See Table 70 for effect of plant food on permanent grass park more than $25^{\circ}$ years old. - C. G. H. 
5. "I have attempted to show you the way I believe fertilizers act and the reason we use them. I think that this is the way stable manure and green manures act. I think that is the principal office of nitrate of soda, potash, and phosphoric acid; but they do not all act alike on the same soils. We are working now on a soil in Iowa which with stable manure every time produces a smaller crop than without. ...

6. "There is another way in which the fertility of the soil can be maintained, viz., by arranging a system of rotation and growing each year a crop that is not injured by the excreta of the preceding crop; then when the time comes round for the first crop to be planted again, the soil has had ample time to dispose of the sewage resulting from the growth of the plant two or three years before."

- Whitney, in Farmers' Bulletin 257, page 21.

7. "The soil solution is bringing materials from below which the plant gets, and as a matter of fact the most important discovery of the Bureau of Soils in recent years is that plants are feeding on materials from the subsoils, far below where the roots go."

- Cameron, in the Hearings before the Committee on Agriculture of the United States House of Representatives, page 446 (Igo8).

8. The Chairman. "Then I come back again to the question, Why is it necessary, or is it in your judgment necessary, ever at any time to introduce fertilizing material into any soil for the purpose of increasing the amount of plant food in that soil?"

Mr. Cameron. "Not in my judgment."

- Hearings before the Committee on Agriculture of the United States House of Representatives, page 446 (igo8).

9. "In the truck soils of the Atlantic coast, where Io or $I_{5}$ tons of stable manure are annually applied to the acre, in the tobacco lands of Florida, and of the Connecticut Valley, where 2000 or 3000 pounds of high-grade fertilizers carrying to per cent of potash are used, even when these applications have been continued year after year for a considerable period of time, the dissolved salt content of the soil as shown by this method is not essentially different from that in surrounding fields that have been under extensive cultivation.

"In England and in Scotland it is customary to make an allowance to tenants giving up their farms for the unused fertilizers applied in the previous seasons. The basis of this is usually taken from 30 to 50 per cent for the first year, and at ro to 20 per cent for the second year after application, but in the experience of this Bureau there is no such apparent.continuous effect of fertilizers on the chemical constitution of the soil."

- Whitney and Cameron, in Bureau of Soils Bulletin 22, page 59.

'The question may be asked if the plant food brought to the surface by capillary moisture in humid sections is greater than that lost by leaching. Compare, for example, the composition of the old prairic soil (gray silt loam) in the lower Illinoisan glaciation 
and the more recent prairie soil (brown silt loam) of the late Wisconsin glaciation. Compare also the amounts in the surface and subsoil (in 2 million pounds of each) of potassium or any other element which does not accumulate in plant residues. Note whether the calcium carbonate on Broadbalk and Hoos fields at Rothamsted is steadily accumulating at the surface. There are abundant supplies in the subsoil "far below where the roots go." Note the complete absence of calcium carbonate in very many Illinois soils. (See also Tables 4, 5, and $2 \mathrm{I}$ in the preceding pages.)

Attention is called to the fact that nitrification is a process of biochemical action and not one of mere solution. Director Hall of the Rothamsted Experiment Station makes the following statement in his "Fertilizers and Manures" (I909), page 288.

"When the Rothamsted soils, with their long-continued differences in fertilizer treatment, are extracted with water charged with carbon dioxide the nearest laboratory equivalent to the actual soil water - the amount of phosphoric acid going into solution is closely proportional to the previous fertilizer supply, and this proportionality is maintained if the extraction is repeated with fresh solvent, as must be the case in the soil."

It should be kept in mind, of course, that a one-crop system followed year after year upon the same land usually encourages the growth of certain weeds whose "habits" are similar to those of the crop grown, that it also tends toward the breeding of insect enemies and to the development of fungous diseases peculiar to that crop, such as "flax sickness," investigated by the North Dakota Experiment Station, and "clover sickness," which has long been thought to be an actual fact in practical agriculture, concerning which the Tennessee Station has recently reported some promising results. The legume plants appear to be especially susceptible to such fungous diseases, the cowpea wilt being well known, and "bean-sick" soil is a common expression. It seems probable that bacterial as weil as fungous diseases may develop under suitable conditions.

While it is possible that inanimate toxic substances may also be formed in the soil from possible plant excreta, or less improbably from the decomposition of the crop residues, there is no knowledge or evidence sufficient, in the author's opinion, to justify a theory that fertilizers act primarily as antitoxins. It should be 
remembered that well-fed plants are usually better able to resist or overcome the attacks of insects and discases. It is well known that there are some exudations from germinating seeds, and it seems evident that water used repeatedly for 20-day cultures with seedling plants becomes stagnant, putrid, or toxic, but can we correlate this with field conditions?

Alkaline slag phosphate, acidulated rock phosphate, neutral steamed bone meal, and insoluble raw rock phosphate are very different chemical substances, and the very complete data already presented show that any one of these forms of phosphorus may be used to increase crop yields. Sodium nitrate, ammonium sulfate, and dried blood are exceedingly different substances, but they. all contain nitrogen, and where nitrogen is deficient in the soil, any one of these materials will benefit the crop. Moreover, with legume plants, essentially the same results are secured whether nitrogen is supplied in dried blood or provided by the nitrogen-fixing bacteria without fertilizer application.

It may be noted that while Whitney and Cameron in Bulletin 22 (I903), of the Bureau of Soils, included nitrogen as distinctly as phosphorus, potassium, and calcium, as being contained in practically all soils in an ample supply which "will be indefinitely maintained," and while Professor Whitney also asserts, in Farmers' Bulletin 257 (1906), that the correction of toxic substances is " the principal office of nitrate of soda, potash, and phosphoric acid," and while Cameron admits in the Hearings before the Committee on Agriculture (I908) that it is never necessary at any time to introduce fertilizing material into any soil for the purpose of increasing the amount of plant food in that soil; nevertheless, Whitney and Cameron are beginning to qualify their theories by saying " mineral elements " or " mineral plant food," presumably because the mathematical opposition is too strong, considering that the soil contains but very small amounts of nitrogen "far below where the roots go."

On December 9, 1908, the National Conservation Commission presented its report (prepared for the President) to the Conference of Governors and State Conservation Commissioners assembled in Washington, in which great emphasis was laid upon the importance of conserving the supply of natural phosphates, as a result 
of which the President soon afterward withdrew from entry the remaining government lands that were known to contain phosphate deposits, acting upon the advice of the United States Geological Survey and the National Conservation Commission; while on December Io, I908, the daily press of the country very generally published a Washington dispatch headed "SoIL WON'T WEAR Out," in which Professor Whitney was credited with the following statements:

"There is a general impression among economists that soil fertility is declining through loss of mineral plant food, but the Bureau of Soils, through the extensive soil surveys and investigations made in the laboratories and from the study of world-wide records, has determined that this impression of the decline of soil fertility is erroneous.

"It is not unreasonable to expect that as this country becomes more thickly settled and our people are forced to cultivate smaller areas, with more intelligent and more intensive methods, the actual amount of crops obtained from the land now in crops can be increased two and one half times over what we are now producing.

"But the amount of land in crops is only about one fourth of the amount in farms. Applying this ratio to the whole amount in farms, it is apparent that the land in farms at present can be expected to produce in time something like ten or twelve times the amount of crops that are now produced on these farms.

"So far as the present outlook is concerned, the nation possesses ample resources in its soils for any conceivable increase in population for several centuries.

"The Bureau of Soils finds that the decline in yield is due generally to the accumulation of organic products in the soil which are not eliminated through proper cultural methods as fast as they have accumulated, and that the failures that are reported are, therefore, due to improper methods of cultivation and crop rotation.

"Our own government statistics show that during the last forty years the yields per acre of all our cereal crops have shown a tendency to increase. Statistics of all the European countries show that the yields in recent years have consistently increased."

Of course this press dispatch would not be quoted here except that it is in strict accord with the persistent teaching of Whitney and Cameron, which will be found of greatest interest for comparison with that of Jethro Tull or Doctor Hunter, and with Liebig's nitrogen theory.

Since the above was written, Bulletin 55 of the Bureau of Soils, "Soils of the United States," by Milton Whitney, has been pub- 


\section{lished (February, I909), from which the following statements are quoted:}

"The soil is the one indestructible, immutable asset that the nation possesses. It is the one resource that cannot be exhausted; that cannot be used up. The general conception of the exhaustion of soils is that the crop removes plant food, and that unless we return some considerable portion of plant food to the soil it eventually becomes incapable of longer producing adequate crops. We quote from a recent article in one of the agricultural journals:

" "We have warned our readers for the last ten years of what is coming if they continue to grow grain crops and sell them off the farm continuously from year to year. . . . Don't imagine for one minute that your soils are of inexhaustible fertility. No such soils were ever made in the Western Hemisphere, except, perhaps, such as are enriched by overflow every three or four years.'

"The impression prevails that our crops take out phosphoric acid, potash, and nitrates to such an extent that the soil becomes incapable of longer supplying these plant-food constituents for a satisfactory yield."

"As we see it now, the main cause of infertile soils or the deterioration of soils is the improper sanitary conditions originally present in the soil or arising from our injudicious culture and rotation of crops. It is, of course, exceedingly difficult to work out the principles which govern the proper rotation for any particular soil. ${ }^{1}$

"The important thing is that we now understand the nature of the soil; how it supplies the nutrient constituents for the crops and how it maintains the supply; how crops may affect each other when grown in succession on the soil; how cultivation affects the conditions resulting from the crop, and, lastly, we are beginning to understand how fertilizers come into this scheme and themselves act on or change toxic conditions in the soil, rendering the soil again sweet and healthy for the growing crop."

"It has been shown that in southern Maryland and in middle Virginia the cause of the recent depression in agriculture and of the low yield of crops is due to methods which have prevailed rather than to any exhaustion of the soil, and that with improved methods these areas are coming up and will again be made to produce satisfactory crops. The soils are not wearing out in the sense that they are unable longer to provide mineral nutrients, but the yields are low because through the prevailing methods the soils have not been maintained in proper condition. In these latter instances the yields have actually declined, but not from the cause which has been generally ascribed.

"It has been shown that from the modern conception of the nature and purpose of the soil it is evident that it cannot wear out, that so far as the mineral food is concerned, it will continue automatically to supply adequate quantities of the mineral plant foods for crops, but it has also been shown that the soil can be abused and its fertility temporarily impaired by improper methods of handling.

1 Italics mine. - C. G. H. 
"Lastly, it has been shown from the statistics of European countries that the soils of the world are not wearing out, but that, on the contrary, after a thousand years of cultivation, with the introduction of better methods, with the necessity of raising larger crops, these soils are responding with an increased yield even over what they produced at the beginning of the last century.

"As a national asset the soil is safe as a means of feeding mankind for untold ages to come. So far as our investigations show, the soil will not be exhausted of any one or all of its mineral plant-food constituents. If the coal and iron give out, as it is predicted that they will before long, the soil can be depended on to furnish food, light, heat, and habitation not only for the present population, but for an enormously larger population than the world has at present."

This general outline of soil-fertility theories has been introduced at this point in order that the reader may note their application in the following pages; and it is hoped that the preceding and succeeding data are sufficient to enable him to form his own opinion.

It is well to keep in mind a few general facts: e.g., that the total corn acreage of Rhode Island and Connecticut combined averages less than three townships (about one sixth of one average Illinois county, of which there are I02); that the total corn acreage of Maine, New Hampshire, Vermont, Massachusetts, Connecticut, Rhode Island, New York, New Jersey, Pennsylvania, Delaware, and Maryland, all combined, is less than the average com acreage of Georgia, whose ten-year average yield is I I bushels per acre, and less than one half the corn acreage of Illinois; that Illinois produces the same amount of corn per annum as the aggregate production of the six New England states, the six Middle Atlantic states, and the six South Atlantic and Gulf stateseighteen in all-extending from Maine to the mouth of the Mississippi, although Georgia, one of these states, is larger than Illinois; that during the last ten years the average corn acreage of Illinois has been increased from 7 million to Io million acres by putting under cultivation old blue-grass pastures and drained swamp areas representing the richest soil of the state; that in the Eastern states manure, made in part from food stuffs shipped from the newer states, is worth about $\$_{2}$ a ton; that level or gently undulating farm lands in Maryland and Virginia sell for less than $\$ 5$ an acre, while those of Illinois and Iowa are worth $\$ 100$ or $\$ 200$; that, while England produces 32 bushels of wheat per acre with a total production of $5^{\circ}$ million bushels, 
England imports 200 million bushels of wheat, 100 million bushels of corn, nearly a billion pounds of oil cake, and much phosphate and other fertilizing material; that Germany produces I25 million bushels of wheat, and in addition imports 75 million bushels of wheat, 40 million bushels of corn, a billion pounds of oil cake, and much phosphate, etc., and that Germany's chief export is 2 billion pounds of sugar $\left(\mathrm{C}_{12} \mathrm{H}_{22} \mathrm{O}_{11}\right)$; that Denmark produces 4 million bushels of wheat, imports 5 million bushels of wheat, $1_{5}$ million bushels of corn, 800 million pounds of oil cake, phosphates, etc., and exports 175 million pounds of butter; that Belgium produces 12 million bushels of wheat and imports 60 million bushels, etc.

It is interesting also to keep in mind the following statement ${ }^{1}$ by Doctor Bernard Dyer in his American lectures on "Results of Investigations on the Rothamsted Soils," in connection with his discussion of the Broadbalk wheat plot that has received an annual application of 15.7 tons of farm manure since I 844 :

"It is to be borne in mind, however, that the quantity of dung used in these continuous wheat-growing experiments is, on the yearly average, far less than would be used in practical agriculture on any of the rotation systems."

As early as 1855 , England was importing annually more than 200,000 tons of guano from the west coast of South America and from the islands of the sea. The guanos vary in composition from about 15 per cent of nitrogen and 5 per cent of phosphorus to less than I per cent of nitrogen and more than 15 per cent of phosphorus.

Aikman writes in "Manures and the Principles of Manuring" (I894) as follows concerning the use of bones in England:

"Employed first in $\mathbf{~ 7 7 4}$, their use has steadily increased ever since, and their popularity as a phosphatic manure is among farmers in this country quite unrivaled. ... . Soon their use became so popular that the home supply was found inadequate. . . . So largely were they used by English farmers that Baron Liebig considered it necessary to raise a warning protest against their lavish applicacation: 'England is robbing all other countries of the condition of their fertility. Already in her eagerness for bones she has turned up the battlefields of Leipzig, of Waterloo, and of the Crimea; already from the catacombs of Sicily has she carried away the skeletons of many successive generations. Annually she recovers from the shores of other countries to her own the manurial equivalent of three millions and a half of men.')"

'Page 50, Bulletin 106, Office of Experiment Stations, United States Department of Agriculture. 
Aikman states that at the present time about 100,000 tons of bones are used annually on English soils, and that bone ash is still imported from South America. The East Indians complain that England has robbed India of bones.

The importation of mineral phosphates into England exceeded 250,000 tons in 1885 , when more than a dozen countries were being drawn upon for this material, representing three continents and Australia; and as early as 1892 the United States was furnishing Great Britain more than 200,000 tons of phosphate a year.

Besides this, England has her own phosphate deposits in the form of coprolites or phosphatic nodules, which, according to Aikman, " have been found in great abundance in the greensand formation, in the crag of the eastern counties, and in the chalk formations of the southern counties." He adds:

"They are found in large quantities in Cambridgeshire. . . They were also found in enormous quantities in Suffolk, Norfolk, Bedfordshire, and Essex, and were for a long time largely used in the manufacture of superphosphate (acid phosphate), but of late years have not been used to anything like the same extent, owing to the fact that there are richer and cheaper sources of phosphate of lime available:"

In addition to all this, England produces and supplies to her soils large quantities of slag phosphate, the amount of which exceedied 100,000 tons a year before the close of the last century, and her annual production has since risen to 300,000 tons per annum.

France, Germany, and other small European countries are not far behind England in the matter of increasing the fertility of their soils. By I 890 France was using about 400,000 tons of phosphate annually, and this was supplemented by slag phosphate, the amount of which exceeded 200,000 tons in 1899, while Germany applied 800,000 tons of slag phosphate to her soils the same year. The application of phosphates to the soils of Europe has largely increased during the years of the present century. Thus, in 1907, Italy, with a total area of less than I I 5,000 square miles (about twice as large as Illinois), used 950,000 metric tons of phosphate (also 82,000 tons of nitrogen fertilizer, and 7000 tons of potassium salts; and during the five years, 1904 to 1908 , more than $I \frac{1}{4}$ million long tons of Florida phosphate were shipped to Germany. 
Since the promulgation of much definite knowledge during the first half of the last century, by such teachers as De Saussure, Davy, Bousingault, Liebig, and Lawes and Gilbert, the increasing applications of phosphates, manures made in part from imported food stuffs, and other fertilizing materials, including more or less potassium salts and nitrates, and in more recent years a larger use of legumes, are found to bear fruit in the corresponding increase in the crop yields of western Europe, as will be seen from the following crop statistics, compiled by Professor Wilhelm Kellerman (Landwirtschaftliches Jahrbuch, I906, page 289) and republished by the United States Bureau of Soils (Bulletin 55) for the purpose of showing that soils do not wear out.

The data from Schmatzfeld are of interest because of the old records, but they appear to represent in the main single years, and in part selected years. Even the tenth-year records from 1830 to 1870 may signify but little. Thus the rye and oats for 1870 average less than for 1830 . The late averages are, of course, very significant.

The Trebsen records have much value because they include several 10-year averages which show no advancement prior to the publication of De Saussure's work, which gave to the world the

Yields of Cereals in Schmatzfeld, Germany

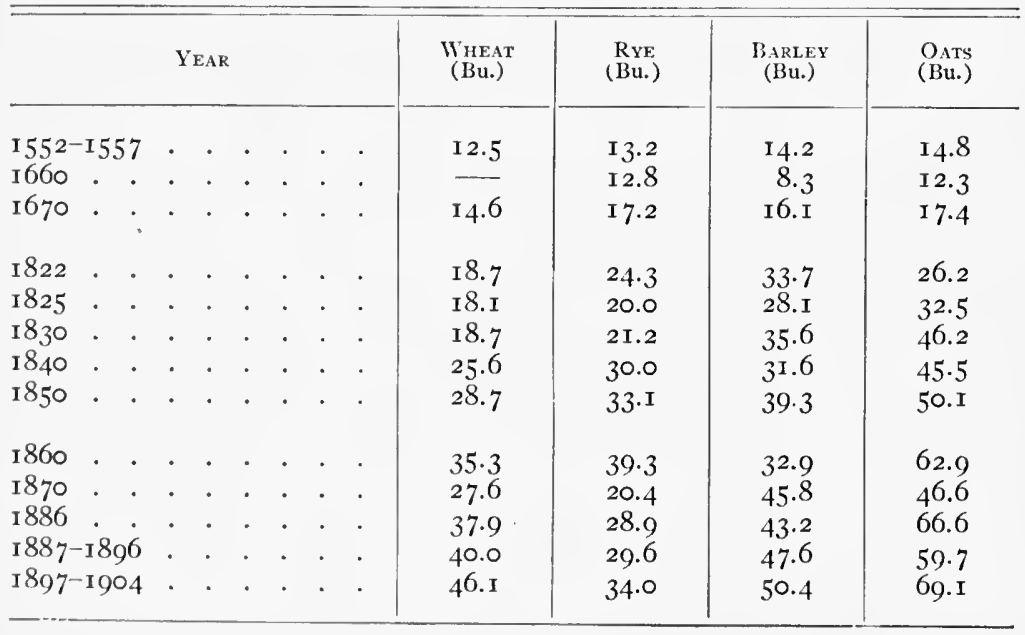


Yields of Cereals on Rittergut Trebsen, near Leipzig

\begin{tabular}{|c|c|c|c|c|c|c|c|c|c|c|}
\hline \multicolumn{7}{|c|}{ YEAR } & \multirow{2}{*}{$\begin{array}{c}\begin{array}{c}\text { WhEAT } \\
\text { (Bu.) }\end{array} \\
\text { I3.25 }\end{array}$} & \multirow{2}{*}{$\begin{array}{c}\begin{array}{c}\text { RyE } \\
(\text { Bu. })\end{array} \\
\text { I } 2.33\end{array}$} & \multirow{2}{*}{$\frac{\begin{array}{c}\text { BaRLEY } \\
\text { (Bu.) }\end{array}}{2 \mathrm{I} .7 \mathrm{I}}$} & \multirow{2}{*}{$\begin{array}{c}\begin{array}{c}\text { OATS } \\
(\text { Bu. }\end{array} \\
23.48\end{array}$} \\
\hline I $766-$ I 775 & - & . & . & . & . & . & & & & \\
\hline I 776 - 785 & . & . & . & . & . & . & 16.63 & 14.47 & 20.44 & 23.45 \\
\hline I 736 - I 795 & . & . & . & . & . & . & I 3.98 & 13.67 & I6.77 & I9.1 6 \\
\hline $1796-1800$ & . & . & . & . & . & . & I 3.89 & I $5 \cdot 3^{6}$ & 15.16 & 17.90 \\
\hline I8I4-I8I6 & . & . & . & . & . & . & I 5.28 & I5.68 & $25.4 \mathrm{I}$ & 25.72 \\
\hline I $820-1822$ & . & . & . & . & . & . & I6.90 & I9.1 4 & I 8.28 & 26.36 \\
\hline $1825^{-18} 34$ & . & . & . & . & . & . & 21.04 & 21.63 & 30.19 & $3^{1.8} 3$ \\
\hline I $835^{-I} 844$ & . & . & . & . & . & . & 33.40 & 27.92 & 36.66 & 46.54 \\
\hline I $845^{-1849}$ & . & & & . & . & . & $25 \cdot 5^{I}$ & 28.75 & & 56.25 \\
\hline $188_{3}-1892$ & . & • & . & . & . & . & 27.03 & 23.06 & 30.95 & 44.64 \\
\hline I893-I894 & . & . & . & . & . & . & 29.85 & $28.3^{6}$ & 30.95 & 54.74 \\
\hline I895-I899 & . & - & . & . & . & . & 35.85 & 30.45 & $35 \cdot 39$ & 51.15 \\
\hline I $900-I 904$ & . & . & . & . & . & . & $3^{6.1} 4$ & $3^{2.52}$ & 43.23 & 57.80 \\
\hline
\end{tabular}

Yields of Cereals on another German Estate

\begin{tabular}{|c|c|c|c|c|c|c|c|c|c|c|}
\hline I $800-1810$ & . & . & . & . & . & . & 2 I.I 5 & 14.64 & I9.80 & 17.22 \\
\hline I $810-I 820$ & . & . & . & . & . & . & 20.02 & I I. 76 & 20.92 & 13.44 \\
\hline $1820-1830$ & . & . & . & . & . & . & 23.25 & I $7.76^{\circ}$ & 21.29 & I 4.84 \\
\hline I $830-1840$ & . & . & . & . & . & . & I 8.82 & I5.04 & I6.37 & I 3.86 \\
\hline I $840-I 850$ & . & . & . & . & . & . & 23.10 & I 9.84 & $20.8_{3}$ & $27.5^{8}$ \\
\hline I $850-I 855$ & . & . & . & . & . & . & 26.40 & 23.12 & 32.75 & $33 \cdot 4^{6}$ \\
\hline I855-I860 & . & . & . & . & . & . & 25.27 & 24.16 & 27.71 & 34.44 \\
\hline I $860-1865$ & . & . & . & . & . & . & 29.77 & $30.4^{8}$ & 37.85 & $44 \cdot 5^{2}$ \\
\hline I $865-1870$ & . & . & . & . & . & . & 27.45 & 26.48 & 36.17 & 55.72 \\
\hline I $870-1875$ & . & . & . & . & . & . & 29.92 & $28.3^{2}$ & $35 \cdot 7 \mathrm{I}$ & $51 \cdot 38$ \\
\hline I $875^{-1} 880$ & . & . & - & . & . & - & 28.12 & $24 \cdot 3^{2}$ & $29 \cdot 3^{8}$ & $39 \cdot 4^{8}$ \\
\hline I $380-1885$ & . & . & . & . & . & . & 25.57 & 25.12 & 36.45 & 45.08 \\
\hline I $885-$ I 894 & . & . & . & . & . & . & $35 \cdot 70$ & $29.5^{2}$ & 41.06 & 4.3 .96 \\
\hline
\end{tabular}

Average Yields of Cereals in Germany

\begin{tabular}{lllllll|l|l|l|l}
\hline $\mathrm{I} 88 \mathrm{I}-\mathrm{I} 885$ & $\cdot$ & $\cdot$ &. &. &. & $\cdot$ & $2 \mathrm{I} .75$ & $\mathrm{I} 8.56$ & 29.07 & 36.96 \\
$\mathrm{I} 886-\mathrm{I} 890$ & $\cdot$ & $\cdot$ & $\cdot$ & $\cdot$ &. & $\cdot$ & 22.65 & $\mathrm{I} 9.04$ & 29.07 & 40.42 \\
$\mathrm{I} 89 \mathrm{I}-\mathrm{I} 895$ & $\cdot$ & $\cdot$ & $\cdot$ & $\cdot$ & $\cdot$ & $\cdot$ & 24.30 & $2 \mathrm{I} .28$ & $3 \mathrm{I} .54$ & 40.88 \\
$\mathrm{I} 896-\mathrm{I} 900$ & $\cdot$ & $\cdot$ & $\cdot$ & $\cdot$ & $\cdot$ & $\cdot$ & 26.55 & 23.04 & 32.49 & 45.08 \\
\hline
\end{tabular}

Average Yields of Cereals in France

\begin{tabular}{|c|c|c|c|c|c|c|c|c|c|c|}
\hline I 8 I $5-I 824$ & - & . & - & - & - & - & II. 86 & IO.10 & I 4.45 & 17.12 \\
\hline I $825-I 834$ & - & . & • & • & . & - & 13.44 & I 2.34 & I 4.64 & 17.78 \\
\hline I $835-x 844$ & . & . & . & . & . & . & 14.30 & 13.01 & 15.92 & 20.10 \\
\hline I $855-$ I 864 & . & . & . & . & - & . & I5.90 & I4.II & 19.90 & 24.93 \\
\hline I $865-1874$ & . & . & . & . & . & . & I $5.8 \mathrm{I}$ & I 4.65 & I 9.75 & 24.49 \\
\hline I $875-1876$ & . & : & . & . & . & . & I6.60 & 15.71 & 19.00 & $23.6 \mathrm{I}$ \\
\hline
\end{tabular}


first definite information which could serve as a scientific basis for systems of soil improvement. The few records from 1800 to I 825 are of little or no value, but the averages from I825 to I834 show very clearly the application of definite knowledge as compared with the averages previous to I 800 ; while the further marked increase for the ten years ending I 844 clearly shows that the teachings of Davy, Bousingault, and Liebig were being applied on the Trebsen estate as well as by Sir John Lawes at Rothamsted.

The most satisfactory data are from the third German estate, showing ro-year or 5-year averages for practically all of the last century, from which it is plain to see that the first distinct increases date from the publication of Liebig's teachings in 1840 .

While the larger private estates would perhaps be the first to adopt the teachings of science, the records show general increases for both Germany and France. The average yields of wheat of late years for England, Germany, and France are 32.2, 28.0, and I 9.8 bushels per acre, respectively, or, as a general average, about double the average of Ioo years ago. It is safe to credit this increase very largely to the use of plant food, including the more general use of atmospheric nitrogen by legume crops during the last quarter century. The average yield of wheat in the United States is 13.7 bushels for the ten years, 1899 to 1908 .

A second factor ${ }^{1}$ of much importance in crop improvement, though very subordinate to that of plant food, is the improvement in seed by selection and breeding. A German economist has estimated that, as an average, seed improvement has produced a gain of 25 per cent. In exceptional cases, as with the sugar beet, very remarkable progress has been made by breeding, the average sugar content of the beet having been raised from about 4 per cent to 12 per cent or more.

The following extracts from an address by President Creelman, of the Ontario Agricultural College, to the Ontario Agricultural and Experimental Union, December, I908, is well worthy of careful consideration (Report for I908, page 62):

1 Other factors of improvement are of doubtful consequence, including correction of toxic bodies. Tillage and crop-rotation have been the rule for centuries in old countries. Isolation of such bodies signifies little. The soil is earth's wastebasket, wherein we may find almost every substance, toxic or nontoxic. 


\section{"Some Observations of Farming in Southern Europe}

"Italy has been practicing the art of agriculture since the early, early days of the old, old civilization, hundreds of years before the Christian era began, and agriculture is still the most important industry in Italy, as 85 per cent of all the Italian soil is productive land. Dairying is not one of the leading lines, however, nor is any other kind of stock raising. Oxen and asses are still the principal beasts of burden, and wine the largest crop.

"And yet, the agricultural products of Italy are varied, and in the aggregate amount to a very large total. Remember that Italy is only twice the size of the State of New York, and you will realize that not much land is wasted when the following crops are produced annually:

Wheat

Corn .

Oats .

Rye and barley

Rice .

Other cereals

Total cereals

Potatoes

Hemp

Flax .

Cotton

Tobacco

Olive oil

Wine
I 43,400,000 bushels $85,600,000$ bushels I $9,360,000$ bushels I $8,400,000$ bushels $26,000,000$ bushels I $8,000,000$ bushels 310,760,000 bushels

I $9,360,000$ bushels I I I ,000,000 pounds $30,000,000$ pounds $22,000,000$ pounds $7,250,000$ pounds $74,500,000$ gallons $666,000,000$ gallons

"But, like the Swiss and the French, the peasant people are a frugal, thrifty race; and while the rich eat wheat bread, the work-people are content with bread made from corn or rye.

"Legumes everywhere. In looking about to find how the fertility of the soil was maintained, in districts where live stock was not common, and hence farm manure was far from plentiful, I noticed that everywhere leguminous crops (or pulse) were the rule. I also discovered that in some form it was eaten every. day by rich and poor alike. All the time I was in Italy I never once sat down to a dinner without being served with peas or beans or lentils, or some other variety of leguminous annual. I found also that the poorer classes consume large quantities of pulse, it being used to a large extent as a substitute for meat."

The increases in these European crop yields since about 1825 to I 840 should be a most effective object-lesson to the American farmer to "go and do likewise"; and if he will talk with any man who has had experience in western European agriculture during the last quarter century, he will promptly receive the positive assur- 
ance that no successful farmer in those countries thinks of trying to farm without liberal applications of plant food, especially of phosphate fertilizers, and, as a rule, either farm manure or green manure. Often commercial nitrogen and potassium are also used, in part because of the very high value of farm produce and also because of the low price of potassium salts, Germany's supply of which is estimated to be sufficient to meet the present consumption of the world for I90,000 years.

In comparison with these European records, marked contrast appears in the average crop yields of the state of Kansas during 48 years. Professor W. J. Spillman, of the United States Bureau of Plant Industry, has called attention to these statistics in the following words:

"The following table of figures is interesting:

"Yields Per Acre - Average for State of Kansas

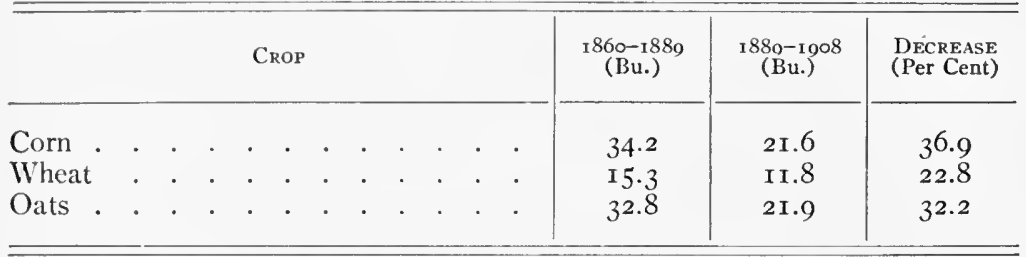

"These figures are in general agreement with data collected from other sections of this country. When rich virgin soil is brought into cultivation and farmed without any reference to the conservation of fertility, good yields are obtained for about forty years. Then begins a decline, and the yield ultimately sinks down to a point where there is no profit for the farmer. . . In the case of each of the three crops above mentioned the average yield for the past nine years is slightly greater than for the preceding ten years. This indicates that the - Kansas farmer is slowly but surely improving his system of farming. Dairying and the feeding of beef cattle, also hay raising are becoming more prevalent, and there is every reason to believe that before another generation has passed the Kansas farmer will have rehabilitated his soil and have developed suitable systems of farming that will keep Kansas near the forefront in agriculture." (Hoard's Dairyman, May I4, I909.)

While the average yields are probably approximately correct and the results are exceedingly striking, in the author's opinion these Kansas results have little significance, because of the enormous increase and westward extension of the area put under cul- 
tivation in Kansas during the fifty years, as briefly indicated by the following tenth-year records:

Acreage of Cereals in Kansas

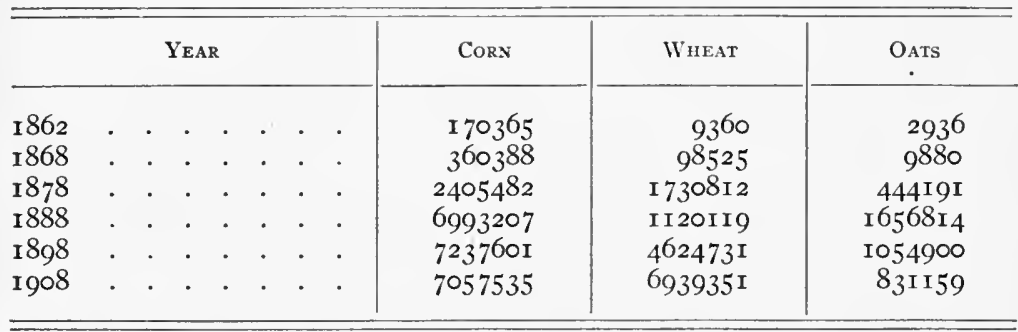

When we consider that eastern Kansas, the part first settled, is in the humid section of the United States, and that the later years include the records from the central and western parts of the state where semiarid conditions prevail, it will be seen that the average yields computed by Professor Spillman may serve best to illustrate the possibility of drawing erroneous conclusions from the use of general statistics unless full consideration is given to all important factors. The explanation for the slight increase in the average yields of the last nine years of the period, as compared with the preceding ten years, is very possibly to be found in the increased rainfall in the semiarid region, as is well illustrated by the very interesting and very instructive diagram (shown on another page) of the rainfall record at North Platte, Nebraska, for the thirty-four years, I 875 to I 908 (Nebraska Bulletin ro9, April, I909), from which it will be seen that the ten years, r89o to r 899 , included eight years below normal and averaged only 15.35 inches, while the following nine years, 1900 to 1908 , show but three years below normal, and average $21.2 \mathrm{I}$ inches.

It should be kept in mind that meat and dairy products bring much larger returns in Maryland than in Kansas, and until the well-situated, well-drained, and well-watered farm lands of Maryland and Virginia have been rehabilitated by these methods of live-stock farming (which farmers have been familiar with for centuries); until such soils as the Leonardtown loam, comprising 4I per cent of St. Mary County, Maryland, where, to quote the 
language of the Bureau of Soils, " it is worth from $\$$ I to $\$ 3$ an acre," which also covers 45,770 acres of land in Prince George County, adjoining the District of Columbia, where it " can be bought for $\$_{1} .50$ to $\$_{5}$ an acre, even within a few miles of the District line," - until this Leonardtown loam, which, according to Whitney's latest decision (Bureau of Soils Bulletin 55, page I I6, February, I909), " is a valuable upland soil of Maryland and Virginia; the surface is slightly rolling, the drainage in most areas good, and altogether the land is well suited to general farming "; until this land which, according to the analyses of the Bureau of Soils (Bulletin 54, page 19), contains in 2 million pounds of the surface soil only i6o pounds of total phosphorus and Iooo pounds of total calcium; that is, sufficient total phosphorus and total calcium in the plowed soil of an acre for about 8 crops of clover, with such yields as we can and do produce on our best-treated land in good seasons ( 4 tons in 2 cuttings), - until these impoverished lands surrounding the National Capital have been rehabilitated and changed in value from $\$_{I_{5}} \mathrm{~S}_{\mathrm{O}}$ to $\$_{\mathrm{I}_{5}} \mathrm{O}$ an acre, by crop rotation, or cven by live-stock farming without the purchase of plant food in feed or fertilizers, - until these results have actually been accomplished, the student of agriculture is earnestly warned against accepting any predictions that the farmers of Kansas or of any other states are actually enriching their soils because they are practicing live-stock farming to a greater or less extent. The student is urged to have faith in the exact data of scientific in vestigations, such, for example, as those conducted for more than 60 years at Rothamsted, England, and for about 30 years at Urbana, Illinois, and at State College, Pennsylvania, full records of which are given in the following pages.

Of course the small commercial countries of Europe which retain practically all of their own fertility and import much more in food stuffs and fertilizers can markedly enrich their soils, just as some of our small states can build up some small areas of cultivated lands; but as the average yield of corn in the great state of Georgia is only i i bushels per acre, so the average yield of wheat on the "black soils" of Russia, for the 20 years, I88 3 to 1902, is" $8 \frac{1}{4}$ bushels per acre, and as a rule this land lies fallow every third year. The following comment is recorded on page 27 of Bulletin 42 
of the Bureau of Statistics, United States Department of Agriculture:

"It may be claimed that this extremely low average yield in European Russia is caused by the total failure of crops in famine years, and that these should have been omitted in calculating the average for a series of years. But the extreme variability of the average yield is no less a characteristic feature of Russian agriculture than its very low yield; and the famine years have been so frequent as to become a permanent feature of Russian agriculture, each one of the five-year periods including at least one famine year, and some even two."

It may be added that in famine years the average yield of wheat in Russia is $6 \frac{1}{4}$ bushels, the lowest recorded average yield being $5 \frac{1}{5}$ bushels per acre.

In India the average yield of cotton on the "black cotton soils" is less than roo pounds of lint per acre. The following extract from an article written by Saint Nihal Singh of India (see Wallaces' Farmer, April 30, Igo9) is given as a faithful description of the present condition of our cousins in India, the Eastern Branch of our own Aryan ${ }^{1}$ race, " the sons of Japheth ":

"If the American farmer were to seek contrast to his life and labor, he would find it on the farm in India; and the contrast would be as clearly defined as that which exists between day and night."

"Almost all the farm land has to be irrigated. While the rainfall is heavy at seasons, it is uncertain, and prolonged drouths make irrigation positively necessary." (In the main the water for irrigation is collected in ponds or large shallow wells during the rainy season, and then drawn to the fields by oxen or carried by hand as needed. When the monsoons fail and the wells or reservoirs are not filled, at least partial crop failure results, and famine is likely to follow. C. G. H.)

"The farm in India is very small in area. It is very rarely larger than ten or twenty acres - often it is only two or three acres.

1 "The languages of all these branches or groups of people are akin; that is to say, they are descendant of one original tongue, once spoken in a limited locality, by a single community, but where or when it is impossible to say.

"Many words still live in India and England that have witnessed the first separation of the northern and southern Aryans, and these are witnesses not to be shaken by any cross examination. The terms for God, for house, for father, mother, son, daughter, for dog and cow, for heart and tears, for axe and tree, identical in all the Indo-European idioms, are like the watchwords of soldiers. We challenge the seeming stranger; and whether he answer with the lips of a Greek, a German, or an Indian, we recognize him as one of ourselves. There was a time when the ancestors of the Celts, the Germans, the Slavonians, the Greeks and Italians, the Persians and Hindus, were living together beneath the same roof, separate from the ancestors of the Semitic and Turanian races." - MAX Múller. 


\section{SYSTEMS OF PERMANENT AGRICULTURE}

"As to the nature of the crops grown in the country: wheat, corn, various kinds of peas and lentils, cotton, and sugar cane are grown exclusively in northern India, except such portions where the lands are low and the rainfall heavy where rice is grown. Rice is the principal crop in southern India."

"Considering the amount of hard drudging work that the Indian farmer puts into his work, the yield ${ }^{1}$ from the labor is pitifully disappointing."

"At harvest time extra hands are needed and they are employed by the farmer, who agrees to pay them a certain amount of grain to compensate them for their labor. If payment is made in coin, it seldom exceeds two and a half annas (five cents ${ }^{2}$ ) a day. The income of the average East Indian, according to governmental statistics, is only fifty cents a month, and farmers, as a community, live in the most miserable poverty.

"There are 450,000 square miles of waste land in Hindustan, or nearly one fourth of the country, that is to-day uncultivated, though capable of yielding rich harvests. The people of India do not know enough to bring these lands under cultivation. The soil that is in use is never allowed to lie fallow, even for a brief space of time. Crops follow one another in quick rotation. The farmer lacks the knowledge and resources to enrich his land by means of fertilizers. The only fertilizer that he knows about is cow dung and, unfor-

${ }^{1}$ Nitya Gopal Mukerji, Professor of Agriculture and Agricultural Chemistry in the Civil Engineering College at Sibpur, Bengal, India, in his "Handbook of Indian Agriculture" (1907), reports "the area under food grains in India at 164 million acres and the produce of grain per acre per annum at $840 \mathrm{lb}$., and the population at 350 millions."

There are about 70 million acres of rice and nearly 30 million acres of wheat. The average yields are estimated at 17 bushels of rice (of $60 \mathrm{lb}$. each), about 10 bushels of wheat, and 7 to 12 bushels of corn, per acre, and in the main the crops are grown under irrigation.

The following quotations from Mukerji are of interest:

"The farmer aims at doing without manures (the English term for commercial fertilizers) as much as possible, at keeping up the fertility of his land simply by feeding his cattle with nourishing oil cakes and utilizing all the cattle dung, urine, and litter in manuring his fields. By growing leguminous crops and by adopting a judicious system of rotation he also tries to avoid the purchase of manures (fertilizers)."

"The reported fertility of Indian, soils is more a myth than a reality. Where the soil has been in cultivation for many years, the virgin richness has disappeared, except where it is irrigated by canals (e.g., the Eden Canal) bringing rich desposits of silt, or annually flooded by rivers leaving such deposits (e.g., in eastern Bengal). As a rule, Indian soils yield poor crops.

"In the famine of $1_{770}$, in nine months, ten million people died in Bengal. The famine of 784 was of such a bad type that four seers $(8 \mathrm{lb}$.) of wheat were sold for a rupe $(48 \mathrm{ct}$.), and the deaths from starvation were innumerable. The most recent of all famines, viz., that prevailing in some part of India or other from 1897 to 1900 , has been severer than the famine of $1874-1878$."

${ }^{2}$ The anna is about 3 cents, but it sometimes depreciates to less than 2 cents. - C. G. H. 
tunately, he is able to spare little of this for enriching the field, for timber is scarce in most parts of India and the cow chips are used for fuel.

"When these old-fashioned methods are taken into consideration, it is easy to understand why agriculture does not pay in India. Since 95 per cent of the people of Hindustan are engaged in farming or allied industries, it is easy to realize why the people of India live in excruciating poverty. Famine rages in the country all the year round, and it will continue to do so until the East Indian agriculturist is taught to use better methods. As it is, only one out of I 47 women and only ten out of Ioo men farmers are capable of reading and writing, and only one out of every five villages in India has a schoolhouse.

"The home life of the farmer is so filled with desperate poverty that it lacks all picturesque details. . . . The house usually consists of but one room or, at best, two or three, and all of these are most rudely furnished. There are no carpets on the floor, which is of dirt, uncovered by boards or even by matting. The men and women usually squat on the floor, using small, narrow pieces of gunny sacks to sit on. The bedstead is home-made and may be described as a cot made in the most elementary manner of bamboo laced across with coarse twine. The same room is used for storing goods of all descriptions, preparing and eating food, and for sitting and sleeping purposes. Not unoften the cattle are given a corner in the room. Since the married sons of the father live at home, the shortage of space compels two or three families to herd together in the same apartment.

"Life for the woman is especially filled with drudgery. She gets up between three and four o'clock in the morning. While the husband is feeding the stock she milks the cows. Over night the milk has been boiled and allowed to curdle. The woman puts it into an earthen pot and churns it. Buttermilk forms an important item of the scanty breakfast. About the only thing that the farmer eats along with the whey is corn or wheat bread, which, unlike in this country, is made thin like a pancake and six or eight inches in diameter. Both men and women take a bite of this bread and pour down a quantity of buttermilk. In eating no knives, forks, spoons, are employed. The fingers are made to perform the various eating operations."

"The life of great hardship and excruciating poverty that farmers in India are obliged to lead makes them subnormal. They lack vim and vitality. In their waking moments they are only half awake. Through insufficient nutrition they are unable to do the hard physical work they would be able to do otherwise. Naturally the people in India are fatalists by religion. They look upon life as an adversity that has to be shouldered as best it can be. They are not afraid of death; in fact, they long for death, for they believe that on the other side of existence they would lead a happier and a better-fed life. Thus do the people of India live and labor."

In China, the fourth great agricultural country comparable with the United States in extent and necessary self-dependence, there are areas of arable upland plains, sometimes roo square miles or 
more in extent, that are not now populated, the reclamation of which has been called the "Problem of China."

The information available is not sufficient to determine to what extent the waste lands of India and China represent abandoned farms that were once cultivated, but it is fully known that to some extent this is the case. On the other hand, the Chinese have maintained well the fertility of much of the lands they are now cultivating. The explanation is found in the following quotations, taken largely from Sir Humphry Davy's "Agricultural Chemistry" (1827) and from Davis, Fortune, and other writers, through extracts published in the works of Baron Justus von Liebig (I 840 to I859):

"The Chinese, who have more practical knowledge of the use and application of manures than any other people existing, mix their night soil with one third of its weight of a fat marl, make it into cakes, and dry it by exposure to the sun. These cakes, we are informed by the French missionaries, have no disagreeable smell, and form a common article of commerce of the empire." - DAvY.

"Davis, in his 'History of China,' states that every substance convertible into manure is diligently husbanded. 'The cakes that remain after the expression of their vegetable oils, horns, and hoofs reduced to powder, together with soot and ashes, and the contents of common sewers are much used. The plaster of old kitchens, which in China have no chimneys, but an opening at the top, is much valued : so that they will sometimes put new plaster on a kitchen for the sake of the old. All sorts of hair are used as manure, and barber's shavings are carefully appropriated to that purpose. The annual produce must be considerable, in a country where some hundred millions of heads are kept constantly shaved. Dung of all animals, but more especially night soil, is esteemed above all others. Being sometimes formed into cakes, it is dried in the sun, and in this state becomes an object of sale to farmers, who dilute it previous to use. They construct large cisterns or pits lined with lime plaster, as well as earthen tubs sunk in the ground, with straw over them to prevent evaporation, in which all kinds of vegetable and animal refuse are collected. These, being diluted with a sufficient quantity of liquid, are left to undergo the putrefactive fermentation, and then applied to the land."

"Human urine is, if possible, more husbanded by the Chinese than night soil for manure; every farm, or patch of land for cultivation, has a tank where all substances convertible into manure are carefully deposited, the whole made liquid by adding urine in the proportion required, and invariably applied to the soil in that state. The business of collecting urine and night soil employs an immense number of persons, who deposit tubs in every house in the cities for the reception of the urine of the inmates, which vessels are removed daily with as much care as our farmers remove their honey from the hives. The night soil is collected in the same way, as well as on the roads and by-places, 
persons being always on the alert with baskets and rakes to avail of the least particle that appears. The Chinese get as much off their land as it is capable of producing, and this is done by the liberal use of manure and application of much more labor in working the soil than in other countries. The reason they do not use dung is that they have comparatively no animals."

"It is quite impossible for us in Europe to form an adequate conception of the great care which is bestowed in China upon the collection of human excrements. In the eyes of the Chinese, these constitute the true sustenance of the soil (so Davis, Fortune, Hedde, and others tell us), and it is principally to this most energetic agent that they ascribe the activity and fertility of the earth."

"Except the trade in grain, and in articles of food, generally there is none so extensively carried on in China as that in human excrements. Long, clumsy boats, which traverse the street canals, collect these matters every day, and distribute them over the country. Every coolie who has brought his produce to market in the morning carries home at night two pails full of this manure on a bamboo pole.

"The estimation in which it is held is so great that everybody knows the amount of excrements voided per man in a day, month, or year; and a Chinese would regard as a gross breach of manners the departure from his house of a guest who neglects to let him have that advantage to which he deems himself justly entitled in return for his hospitality. The value of the excrements of five people is estimated at two Teu per day, which makes 2000 Cash $^{1}$ per annum, or about twenty hectoliters ( 440 gals.), at a price of seven florins."

"Every substance derived from plants and animals is carefully collected by the Chinese and converted into manure. Oil cakes, horn, and bones are highly valued, and so is soot, and especially ash. To give some notion of the value set by them upon animal offal it will be sufficient to mention that the barbers most carefully collect, and sell as an article of trade, the somewhat considerable amount of hair of the beards and heads of the hundreds of millions of customers whom they daily shave. The Chinese know the action of gypsum and lime; and it often happens that they renew the plastering of the kitchens for the purpose of making use of the old matter for manure." - DAvIs.

"During the summer months all kinds of vegetable refuse are mixed with turf, straw, peat, weeds, and earth, collected into heaps, and when quite dry, set on fire; after several days of slow combustion the entire mass is converted into a kind of black earth. This compost is only employed for the manuring of seeds. When seedtime arrives, one man makes holes in the ground; another follows with the seed, which he places in the holes; and a third adds this black earth. The young seed planted in this manner grows with such extraordinary vigor that it is thereby enabled to push its rootlets through the hard solid soil, and to collect its mineral constituents." - FORTUNE.

"The Chinese farmer sows his wheat, after the grains have been soaked in

${ }^{1}$ The Chinese coin tsien (pronounced chen), called cash by foreigners, is valued at about one tenth of a cent.- C. G. H. 


\section{$33^{8}$ SYSTEMS OF PERMANENT AGRICULTURE}

liquid manure, quite close in seed beds and afterwards transplants it. Occasionally, also, the soaked grains are immediately sown in the field properly prepared for their reception, at an interval of four inches from each other. The time of transplanting is toward the month of December. In March the seed send up from seven to nine stalks with ears, but the straw is shorter than with us. I have been told that wheat yields 120 fold and more, which amply repays the care and labor bestowed upon it."

- Eckegerg, in Report to the Academy of Sciences at Stockholm, r765.

"In Chusan, and the entire rice districts of Chekiang, and Keangaoo, two plants are exclusively cultivated for the purpose of serving as green manure for the rice fields; the one is a species of Coronilla, clover is the other. Broad furrows, similar to those intended for celery, are made, and the seeds are planted on the ridges in patches, at a distance of five inches from each other. In the course of a few days germination begins, and long before the winter is gone the entire field is covered with a luxuriant vegetation. In April the plants are plowed in; and decomposition soon begins, attended with a most disagreeable odor. This method is adopted in all places where rice is grown." - ForTunE.

"These extracts," said Liebig, "which, from want of space, cannot be further extended, will probably suffice to convince the German agriculturist that his practice, when compared with that of the oldest agricultural nation in the world, stands somewhat in the position of the acts of a child to those of a full-grown and experienced man."

A communication dated Chengtu, Szechuan, China, July 4, I9०7, from Elrick Williams (formerly associated with the author, as student and teacher, at the University of Illinois) contains the following information:

"One of the first things which attract the attention of a foreigner on reaching China is the simple form of closets and 'outhouses' in vogue. Private ones consist of a square box in which is placed an earthenware vessel usually smaller than a bushel basket. A stranger will notice that it is empty every morning, even at an early hour. Greater still is one's astonishment to note along the streets convenient places for accommodating one's necessity in this regard. They are, of course, very simple. Along the river where there are multitucles of trackers (men who tow the boats), one finds earthenware vessels set in the ground behind a half circle of matting about three or four feet high. Enterprising farmers put these in to reap the passing reward. Last, but by no means least, is the man with the dung basket and fork. The man may be a woman or child but the majority are grown men. They haunt the streets, alleys, lanes, or loafing places of men, and the feeding places of beasts. I have seen a woman run down a steep hill with a basket in order to be nearest to a squatting tracker. Before he is twenty feet away, often the prize is gathered up. 
"Human manure is the most highly prized, although a friend told me that the manure from silk worms was even more valuable. Dog manure, pig manure, cow manure, and water buffalo manure are prized in about this order."

Thus do the people of China follow the products of the land to the place of consumption and return to the soil every possible recoverable residue, and to this are added a large use of legume crops and applications of muck, marl, lime, etc., and silt deposits on overflowed or irrigated lands. (See also page 594.)

The following quotations from circular letters from Doctor Alfred M. Peter, Head of the Division of Agricultural Chemistry of the Kentucky University Agricultural Experiment Station, will be of interest to the student (see also pages $263^{-267}$, Vol. I, Journal of Industrial and Engineering Chemistry, April, I909):

"DEAR Sir:

$$
\text { “Lexington, Ky., January 21, Ig09. }
$$

"In a 'Hearing before the Committee on Agriculture of the House of Representatives,' I 908 , Doctors Whitney and Cameron of the Bureau of Soils have made statements to the effect that the recent teachings of the Bureau in regard to soil fertility are generally accepted throughout this country and Europe, and that they are being widely taught in the Agricultural Colleges of this country. The teachings referred to, with which you are, no doubt, familiar, may be summarized in the following statements:

"I. That all soils contain enough mineral plant food in available form for maximum crops, and that this supply will be indefinitely maintained.

" 2 . That the real cause of infertility is the accumulation in the soil of poisonous excreta from plant roots.

"3. That it is not ever necessary to add fertilizers for the purpose of increasing the plant food in the soil, the good effect of fertilizers being due to their power of neutralizing or destroying these toxic substances or their activity.

" 4. That soil fertility can be maintained indefinitely by practicing a system of rotation by which a crop is grown each year that is not injured by the excreta of the preceding crop.

"In order to ascertain just how extensively these views are accepted and taught in our Agricultural Colleges and Experiment Stations, the writer is sending this letter to professors of agriculture, agronomists, and agricultural chemists in all such institutions on the "Organization Lists." It is proposed to publish a summary of the data obtained, without giving names of institutions or individuals. Will you kindly assist by telling me whether or not these views are accepted and taught by you or your institution, or by referring this letter to some one who will give me an authoritative answer? 
"Dear Sir:

“Lexington, Ky., February 18, I909.

"Replies to my letter of January $2 \mathrm{I}$ have now been received from $\mathrm{IO}_{4}$ in. dividuals in the United States and Canada, including 35 Agricultural Chemists, 25 Agronomists, 2I Professors of Agriculture, 9 Soil Specialists, both chemists and physicists, 8 Experiment Station Directors, not otherwise classified, 3 Directors of Farmers' Institutes, I Professor of Vegetable Pathology, I of Horticulture, and I of Natural Science. Out of these only two indorse the Bureau's views without qualification and say they are taught in their institutions as established facts. These two are from minor or branch institutions, however, not one of the Land-grant Colleges or State Experiment Stations being willing to accept or teach them in the sense in which they have been put forward by the Bureau. About half recognize more or less truth in the doctrines, and present and discuss them in advanced teaching. Most of them recognize the value of the Bureau's work on toxic substances and consider them a possible factor in soil fertility, though not the most important one. The rest either say they do not accept and teach the Bureau's views on these subjects, or oppose them. The Agricultural Colleges and Experiment Stations in 47 States and Territories of the United States are represented in these answers, showing a very general interest in the subject of the inquiry. It is apparent that while the Bureau's views on soil fertility are not being accepted and taught as established, in these institutions, they are being generally presented and discussed in advanced teaching of agriculture.

"In a letter to me dated January 28 , a copy of which has been sent to you, Doctor Cameron takes exception to my presentation of the Bureau's teachings and explains his position in this matter. Doctor Whitney in a letter to me approves Doctor Cameron's letter, so it may be taken as an authoritative expression of the Bureau's views. If, after reading it, you desire to modify your opinion already expressed to me, I will be glad to hear from you before making my final publication.

"Yours very truly,

(Signed) "Alfred M. Peter."

From the numerous exact quotations hereinbefore given the student will be able to determine for himself how fairly Doctor Peter has summarized the teachings of the Bureau of Soils. Under date of July 3, I909, Doctor Peter wrote the author as follows:

"About half of my correspondents wrote me again to say that Doctor Cameron's letter had made no change in their views. I did not hear from any one who desired to change his expression of opinion."

The persistent and long-continued teaching of the Federal Bureau of Soils, that the fertility of the soil can be indefinitely maintained without the restoration of plant food, is widely promulgated by inspired press reporters and other prolific writers and 
gladly accepted by land agents and by landowners inexperienced in the management of truly depleted soils.

And why not? No doctrine could be more pleasing, - an inexhaustible national asset! - a self-maintaining food supply ! - a dish from which we can eat and eat, to-day, to-morrow, and forever! - a bank account which requires for its maintenance only the rotation of the check book among the members of the family! - a "philosopher's stone" that creates an infinite supply of golden grain from finite quantities of baser materials!

The possible enormous and irreparable damage of such teaching lies in the fact that even our remaining supply of good land will ultimately be depleted by the present practices beyond the point of self-redemption, thus repeating the history of our abandoned Eastern lands, where the rotation of crops was the common rule of practice for more than a hundred years.

The following extracts are typical:

\section{"SoILS NOT WEARING OUT}

"A most comprehensive bulletin has recently been published by the National Department of Agriculture dealing with the question of soil composition."

"The facts and figures presented in this bulletin tend to show that there is not any immediate danger of the soils of the United States wearing out."

"Considering the fact that the farms of the United Kingdom have been under cultivation for a thousand years or more, it is held by Professor Whitney that continuous cropping does not necessarily tend to decrease production."

"We believe that Professor Whitney's statements will come as a surprise to a great majority of our readers, because the average man labors under the belief that soils are gradually wearing out; on the other hand, it is a fact that our leading farmers, in every state in the Union, are not only able to maintain their crop yield, but they are increasing it from year to year."

"It is true that there may be annually some loss.of mineral elements, but in ordinary good soils, such as our clays and loams, the supply of these minerals is so great that a five-hundred or even a thousand-year period will not reduce the supply to a point where production is materially affected." - The Homestead, October 28, 1909.

"Fertility of SoIl

"Artificial Fertilizers Said to be all Wrong

"Special Correspondence.

"Washington, Nov. I 7. - Artificial fertilizers - phosphates and nitrates, chiefly - act upon the soil as drugs act upon the human body, according to 
investigations just completed by the Bureau of Soils of the Department of Agriculture.

"Although there are some experiments and some tabulation of results yet to be made, the scientists have gone far enough to evolve a theory that may upset present-day methods of agriculture.

"The new theory is based on a series of experiments that have been con. ducted during the summer and for several years prior to this season. They intend to show that there are natural agencies at work in the soil that will replenish worn-out 'soil tissues' just as the worn-out tissues of the body in man are replaced by agencies inside. Only in the case of man there is usually a limit to this process, whereas, in soils, the scientists have observed some wonderful results from soils long ago abandoned as useless.

"Sensible rotation of crops will produce much better and more lasting results than the artificial fertilization of soils, say the experts." - Freeport (Illinois) Daily Bulletin, November I9, 1909.

\section{"Secretary Wilson on Eastern Farming}

"Secretary of Agriculture Wilson has been traveling through some of the Eastern States for the purpose of studying farming conditions, and is quoted as saying:

" 'It was a beautiful country that we passed through, but the farms generally did not show prosperity. Many of the districts looked depopulated. We saw plenty of children in the villages, but few in the rural regions. The country looked deserted. In fact, interest in agriculture appears to have declined.'

" "The soils in this state are not exhausted. In some cases they have become unproductive by failure to rotate crops, and again because there has been no change of seed. I am told that many farmers hereabout have planted seed from the same source for fifty years. In the West they know the value of changing seed. We have searched the world for seeds which would flourish in all climates and conditions, and we are going to increase our production by making use of them." " -Wallaces' Farmer, November 5, rgog.

In conclusion it may be stated that the four great fundamental facts of plant nutrition still stand against every test: thus, Sénébier's proof of the fixation of carbon, oxygen, and hydrogen by photosynthesis, De Saussure's discovery of the presence and absolute necessity of mineral plant food, Lawes and Gilbert's proof that the soil must furnish the nitrogen for most plants, and Hellriegel's discovery of the fixation of free nitrogen by the bacteria of legumes always lead to the same conclusion whenever, wherever, or by whomsoever they are repeated. They are fully recognized as absolutely established facts, at least as well established as the fact that the earth is round. 


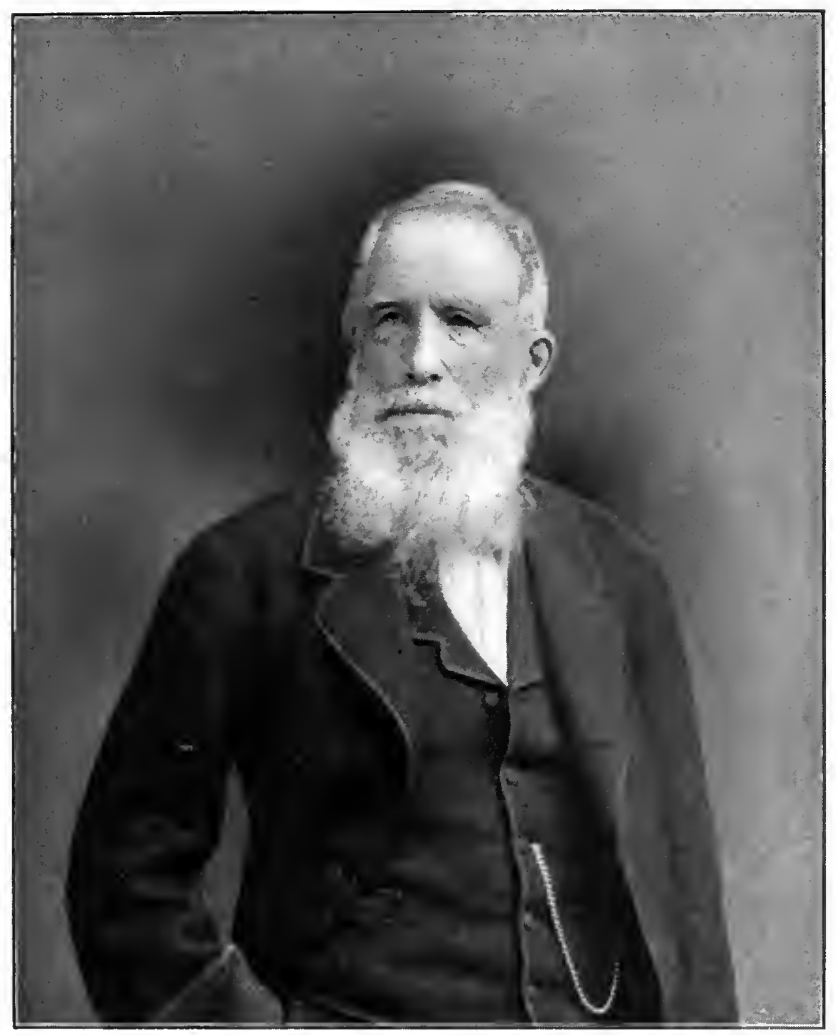

Sir JUHN BeNNET LAWES (ISI4-I900) 



\section{PART III}

\section{SOIL INVESTIGATION BY CULTURE EXPERIMENTS}

IN the preceding pages we have considered the subject of soil fertility in large part from the chemical and mathematical standpoint (the last chapter being disregarded). Thus, we have discussed briefly the chemical composition of earth, air, water, plants, and animals; the essential plant-food elements and their relative abundance in plants and in plant and animal products and residues, also in normal and abnormal soils; and the sources and forms of materials whose use is necessary for the adoption of systems of permanent agriculture on ordinary lands under general farming.

We have thus far referred to field or pot-culture experiments mainly to cite the existing evidence concerning the possibility and practicability of using methods or materials regarding which the scientific, agricultural, and commercial interests are not agreed.

Before taking up a study of various factors that influence crop production, including the use of special fertilizers for special soils and crops, it seems wise to consider in detail the results of some of the long-continued field experiments with general farm crops on ordinary normal soils; and, after wandering through the wilderness of the last chapter, the seeker after truth will welcome the positive data from thoroughly scientific cultural investigations, not from 20-day cultures in pound pots or water extracts or even from single-year tests, but the definite yields of mature crops year after year for twenty, thirty, and even for sixty years.

At the same time the author begs some consideration for the question if we need prepare to avoid in America a repetition of the Dark Ages that followed the high civilization of the Mediterranean countries, until relieved by the discovery of the New World, and that still exist for the masses in Russia, India, and China. 


\section{CHAPTER XIX}

\section{THE ROTHAMSTED EXPERIMENTS}

RothAMSTED is the oldest agricultural experiment station. It was formally established in I843, nine years before the first German experiment station was started at Möckern (Leipzig), although some experiments had been conducted at Rothamsted at least as early as 1837 , and more extensive field experiments were begun in 1840. The published records report all of the crops grown on Broadbalk field since 1839 , and the exact yields of produce are recorded since 1844 , so that the records now cover about two thirds of a century.

It was in 1843 that John Bennet Lawes, the proprietor of the Rothamsted estate and founder of the experiment station, secured the services of Doctor Joseph Henry Gilbert; and this association, which continued to the end of the century, made the names, Lawes and Gilber, almost synonymous with Rothamsted.

The earlier extensive investigations of De Saussure concerning the mineral constituents of plants, followed by the discussion and further investigations of Sir Humphry Davy and others, and the confident announcement of well-defined theories by Baron Justus von Liebig, were among the important factors that influenced the general plans that were adopted for the Rothamsted field experiments.

Lawes and Gilbert did not concur in Liebig's theory so far as concerns the element nitrogen, and the central plan in most of the Rothamsted field experiments is based upon this difference of opinion; and, while the accumulated information showing the correctness of Lawes and Gilbert's views is exceedingly full and complete, some other important facts find little proof in the Rothamsted data. 


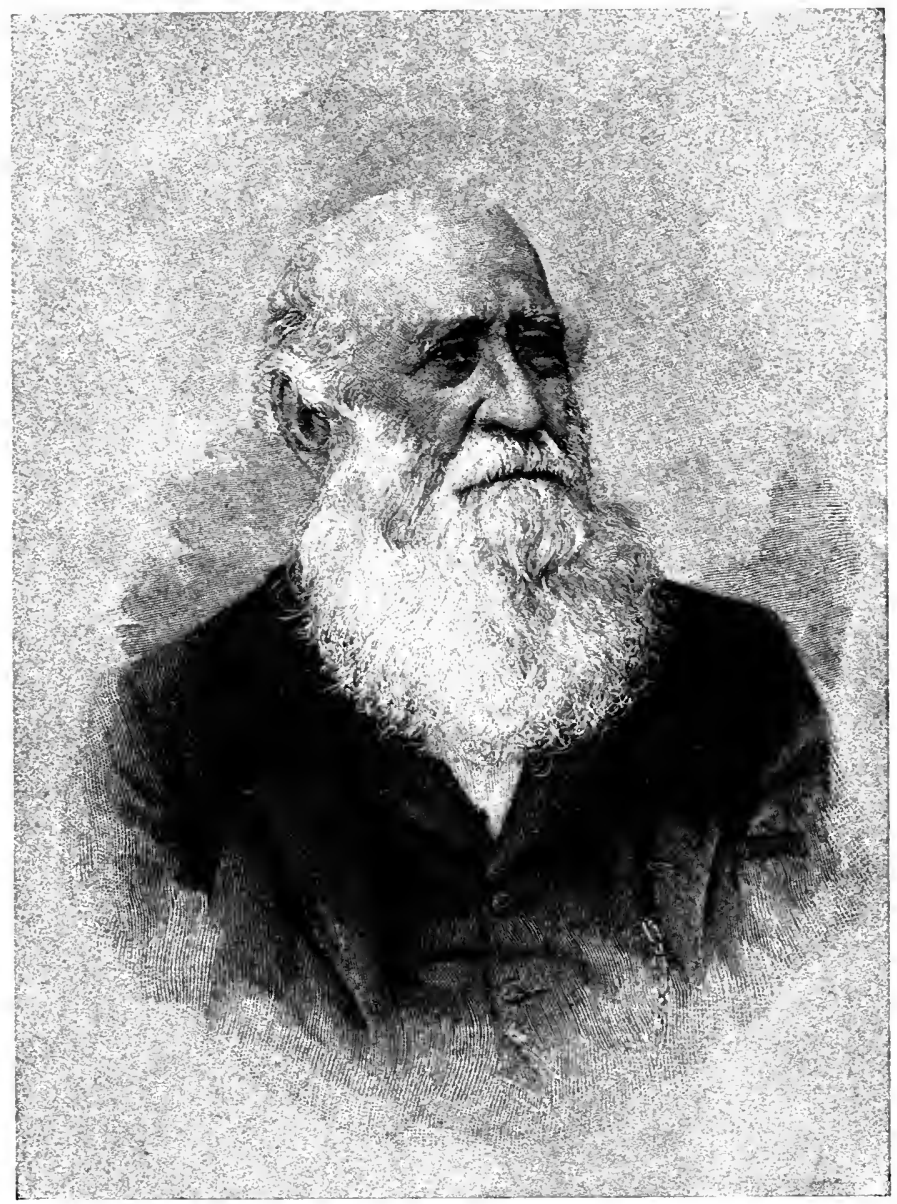

Sir JOSEPH HeNRY Gilbert (ISI7-I9OI) 


$$
1^{\prime}
$$


Notwithstanding this somewhat restricted character of the general plans, the records of Rothamsted are the greatest source of knowledge concerning many of the most fundamental problems of soil fertility; and in justice to the American farmer and student of permanent agriculture, the author cannot do less than to reproduce the following records of Rothamsted investigations that scem to bear most directly upon the maintenance of soil fertility as measured by crop yields:

I. Crops grown in rotation on Agdell field, with records since I848.

2. Wheat grown continuously on Broadbalk field, with records since 1844 .

3. Wheat alternating with fallow on Hoos field, with records since $185 \mathrm{I}$.

4. Barley grown continuously on Hoos field, with records since I85 I.

5. Potatoes grown continuously on Hoos field, twenty-six years' records (I876 to I9OI).

6. Hay grown continuously on the permanent Park, with records since 1856 .

7. Experiments with root crops on Barn field, with records since I845.

This mass of valuable data is given in order that one who so desires may study these results from any point of view and draw his own conclusions. Space is also taken for a brief discussion of the summaries of the Rothamsted laboratory investigations, and frequent reference to these data must be made for proof of established principles.

\section{Agdell Field Rotation Crops ،}

The Agdell field includes two series of six plots each. On one series a four-year rotation is practiced, as follows:

First year . . . Swede turnips (rutabagas).

Second year . . . barley.

Third year . . . clover (or beans).

Fourth year. . . wheat. 


\section{INVESTIGATION BY CULTURE EXPERIMENTS}

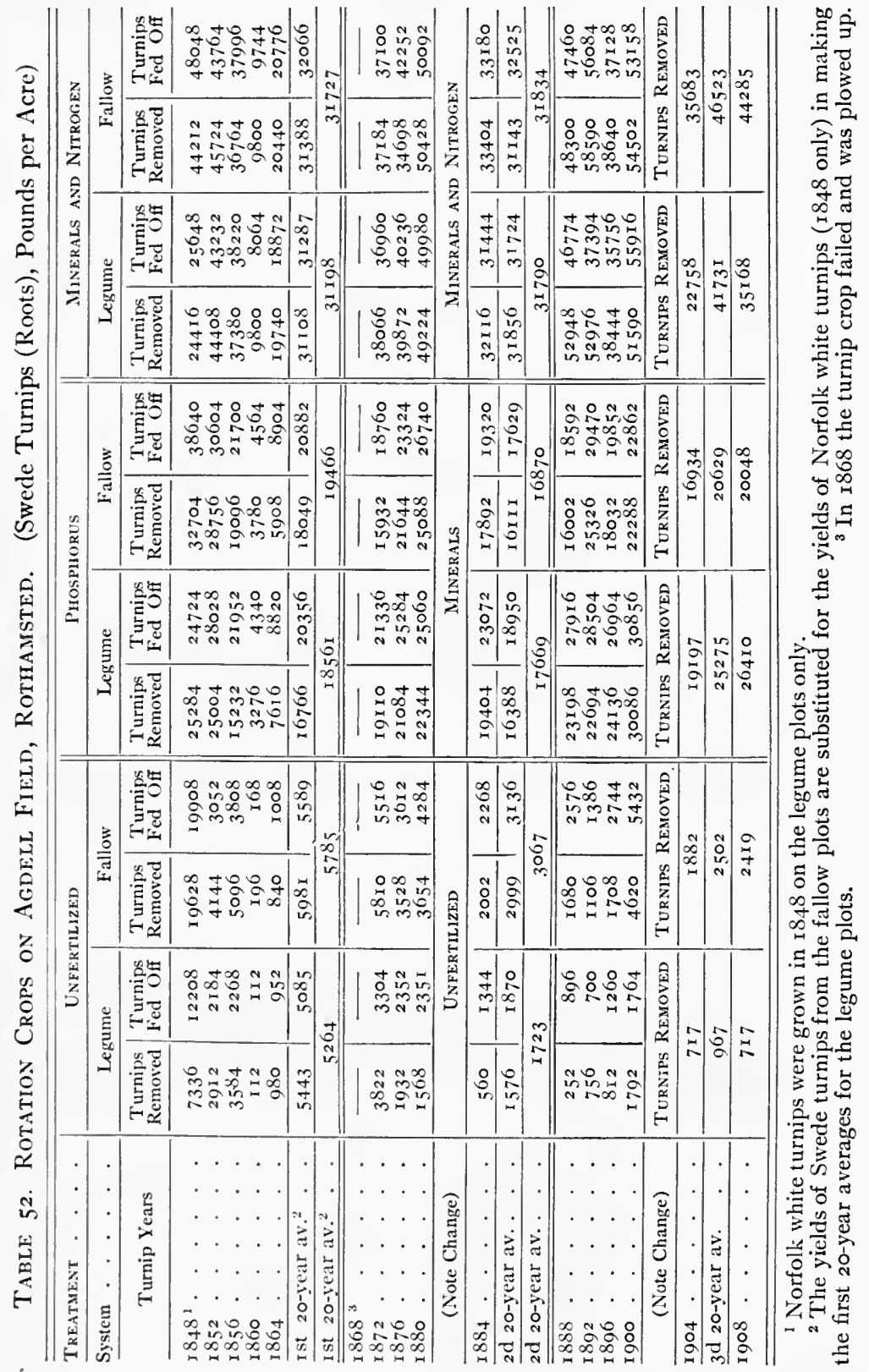




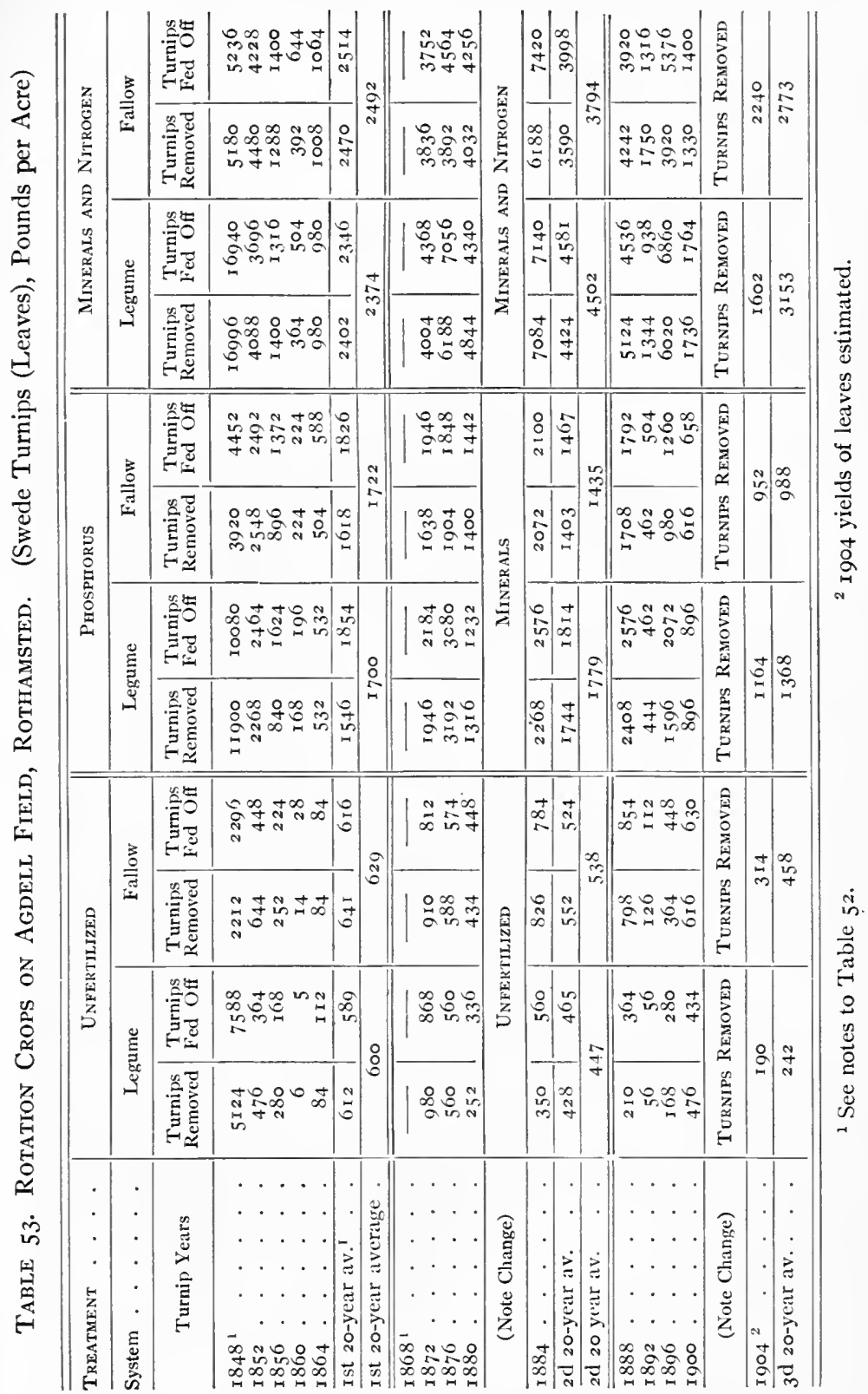




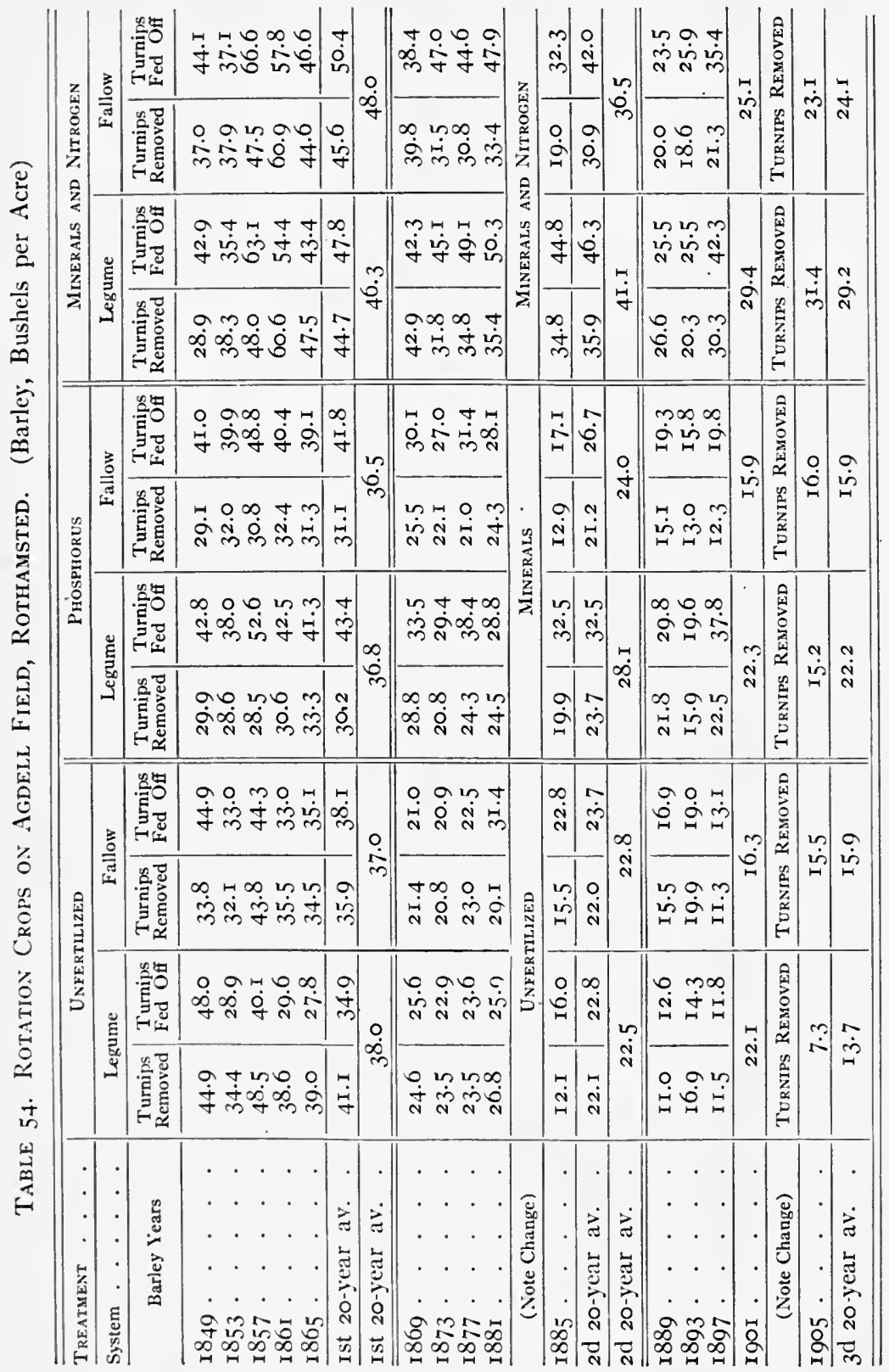




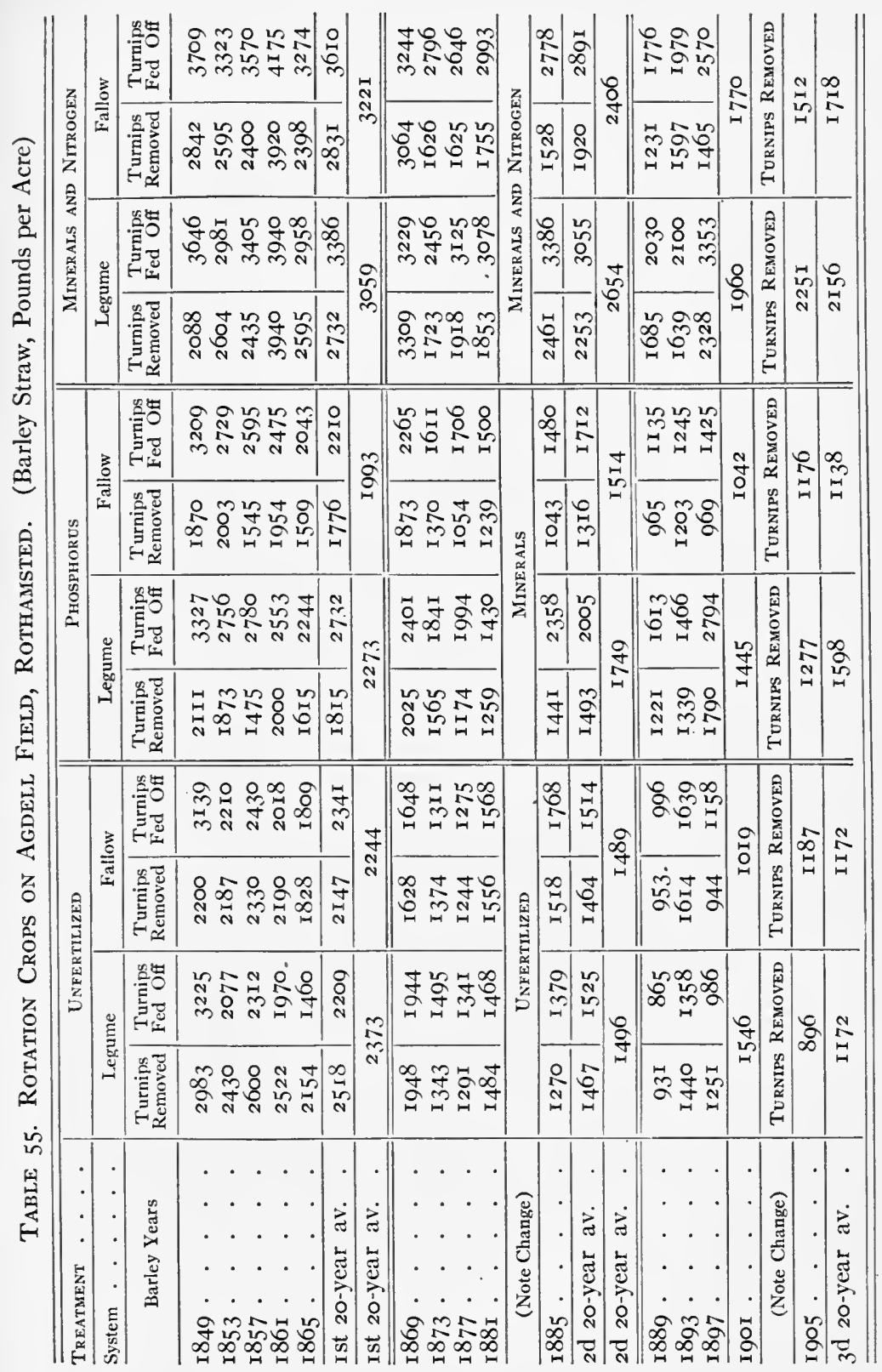




\section{$35^{\circ}$ INVESTIGATION BY CULTURE EXPERIMENTS}

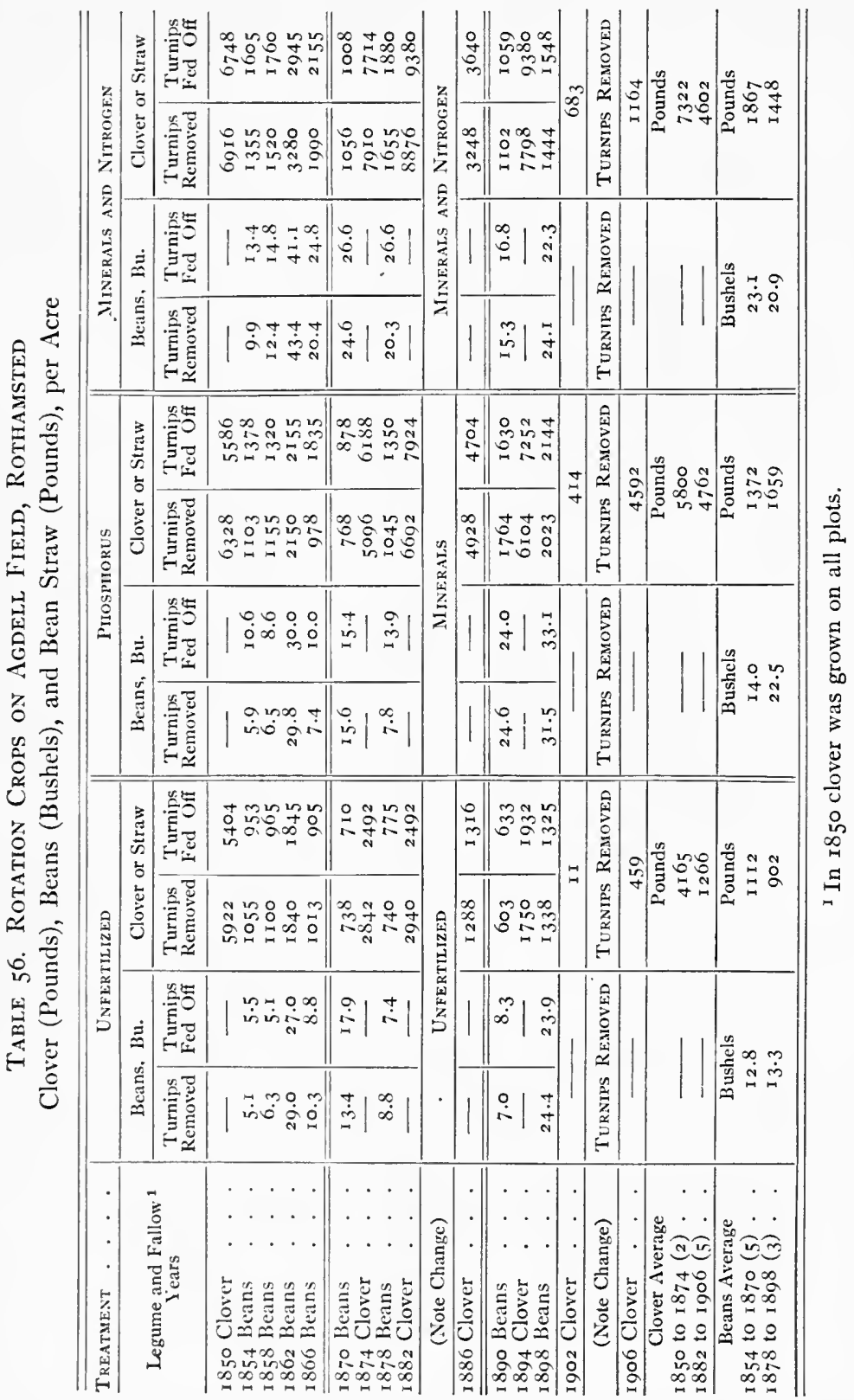




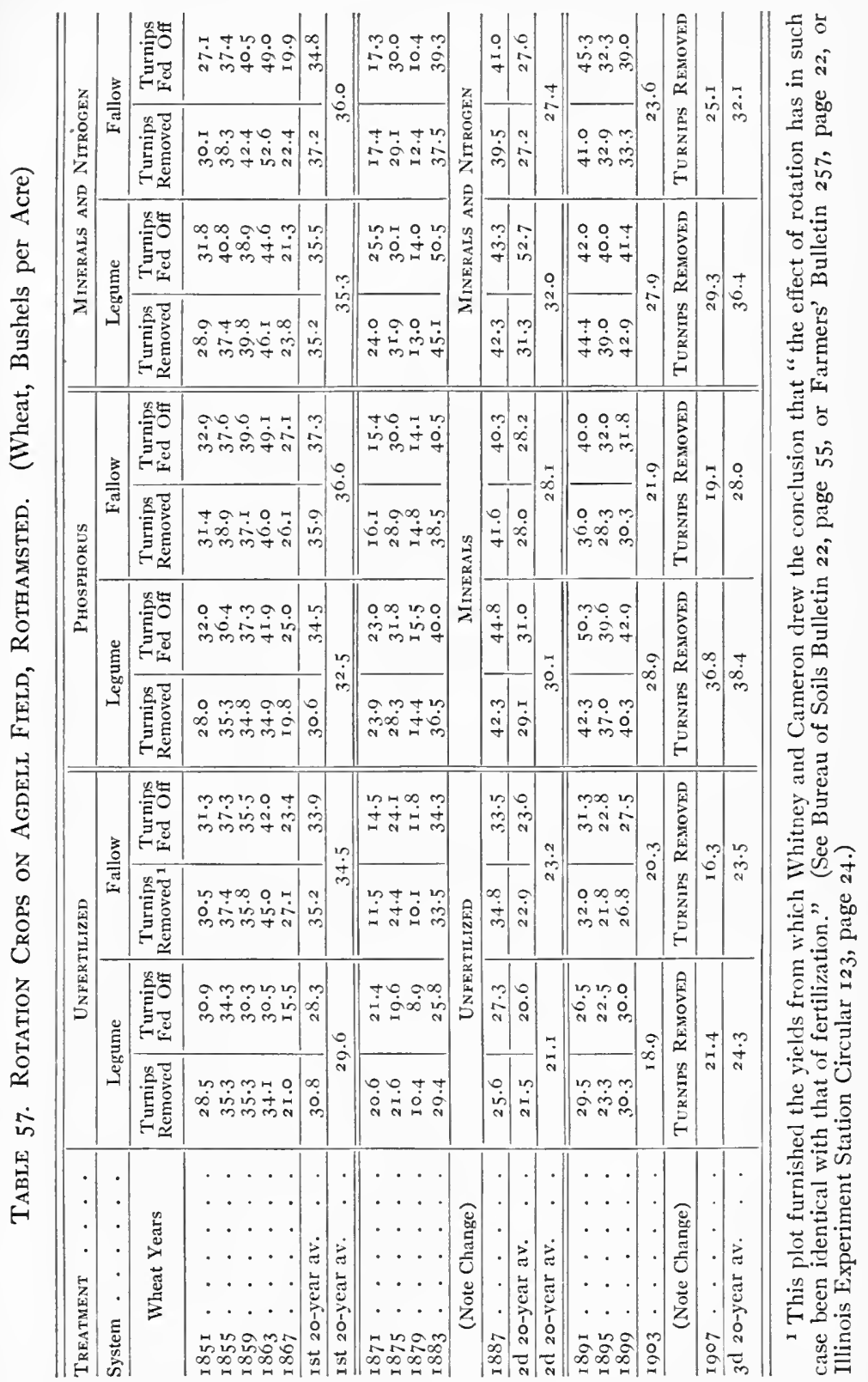




\section{$35^{2}$ INVESTIGATION BY CULTURE EXPERIMENTS}

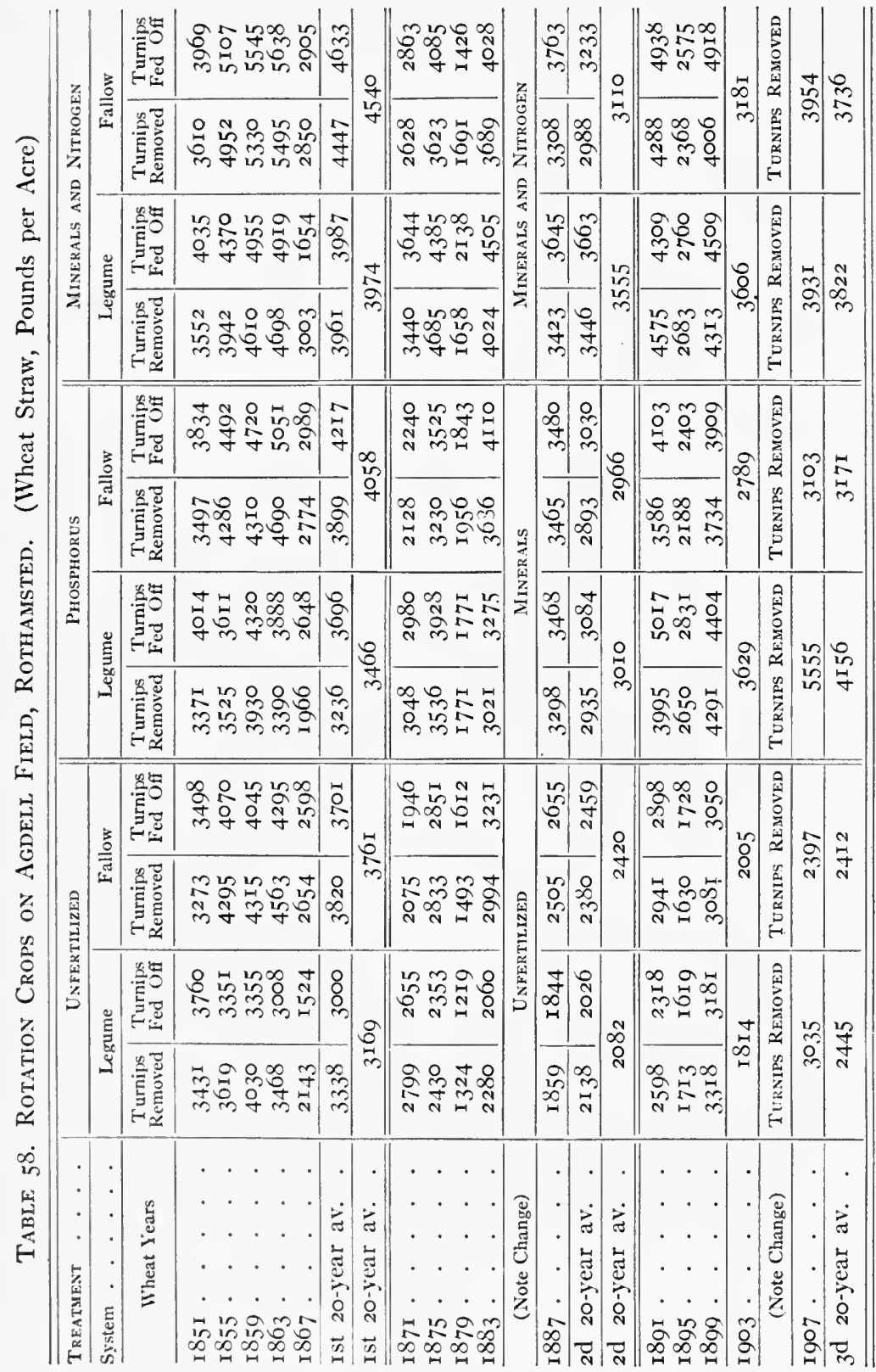


The cropping of the other series is the same, except that fallow cultivation is practiced instead of growing clover or beans the third year. In the tabular statements the one is termed the "legume" system, and the second the "fallow" system.

Crosswise, Agdell field is divided into three sections of four plots each. One section is unfertilized, the second or middle section received a phosphorus fertilizer for the first nine rotations $(36$ years) and a mixed mineral fertilizer, including phosphorus, potassium, magnesium, and sodium, during the last six rotations (24 years), while the third section of four plots has received both the mixed minerals and nitrogen during the entire sixty years. The fertilizers are all applied for the turnip crop, that is, only once every four years.

In each of the three sections two plots (one legume and one fallow) have had the turnip crops all removed (leaves and roots); while the other two plots (one legume and one fallow) have had the turnips all fed off by sheep, all other crops having been removed from all plots as regularly harvested. In I904 the plan was adopted of removing the turnips from all of the plots, thus simplifying the experiments as shown in the tables. In 1850, only, clover was grown on the entire field, including the series since in fallow every four years. The twelve individual plots were each one fifth acre in size and nearly square; so that, as conducted since 1904 (or evidently since r9or), the six individual plots are each two fifths acre in size and about twice as long as wide.

In 1848 Norfolk white turnips were grown on the "legume" series and Swede turnips on the "fallow" series. The exact yields are recorded in Tables $5^{2}$ and 53 ; but in computing the average yields for the first twenty years (5 rotations) the 1848 yields from the fallow series were used for both series, as otherwise the averages would not be comparable.

The clover was regularly cut twice during the season (three times in 1874). Undoubtedly the frequent failure of the clover ${ }^{1}$ crop has to a considerable extent been caused by clover "sickness."

${ }^{1}$ For many years the best farmers of England and Continental Europe have practiced the substitution of some other legume, as beans, yellow trefoil, etc., in alternate rotations, thus seeding clover on the same land only once in about eight years. 


\section{INVESTIGATION BY CULTURE EXPERIMENTS}

The fertilizers applied per acre every four years (for the turnip crop only) have been about as follows, where used:

(a) Fertilizers for Agdell Field, Pounds per ACre, I892 AND Previously

\begin{tabular}{|c|c|c|c|c|c|c|}
\hline ELEMENTS AND & Mate & ERIAL & & UNFERTILIZED & $\begin{array}{c}\text { Minerals } \\
\text { (Phosphate only } \\
\text { previous to } 1884 \text { ) }\end{array}$ & $\begin{array}{l}\text { Minerals and } \\
\text { Nitrogen }\end{array}$ \\
\hline $\begin{array}{l}\text { Nitrogen . } \\
\text { Phosphorus . } \\
\text { Potassium }\end{array}$ & $\begin{array}{ll}\cdot & . \\
\cdot & . \\
\cdot & .\end{array}$ & $\begin{array}{ll}\cdot & \cdot \\
\cdot & \cdot \\
\cdot & \cdot\end{array}$ & & $\begin{array}{l}\text { None } \\
\text { None } \\
\text { None }\end{array}$ & $\begin{array}{l}\text { None } \\
28 \\
\text { I } 25\end{array}$ & $\begin{array}{r}140 \\
45 \\
147\end{array}$ \\
\hline $\begin{array}{l}\text { Ammonium sulf: } \\
\text { Ammonium chlo } \\
\text { Rape cake } \\
\text { Acid phosphate } \\
\text { Potassium sulfat } \\
\text { Magnesium sulf } \\
\text { Sodium sulfate }\end{array}$ & $\begin{array}{l}\text { fate } \\
\text { orid } \\
. \quad \\
. \quad \\
\text { te } \\
\text { fate } \\
.\end{array}$ & $\begin{array}{l}\cdot \\
\cdot \\
\cdot \\
\cdot \\
\cdot \\
\cdot \\
. \\
.\end{array}$ & $\begin{array}{l}\dot{ } \\
\dot{ } \\
\dot{ } \\
\dot{ } \\
\dot{ }\end{array}$ & $\begin{array}{l}\text { None } \\
\text { None } \\
\text { None } \\
\text { None } \\
\text { None } \\
\text { None } \\
\text { None }\end{array}$ & $\begin{array}{l}\text { None } \\
\text { None } \\
\text { None } \\
350 \\
300 \\
100 \\
200\end{array}$ & $\begin{array}{r}100 \\
100 \\
2000 \\
350 \\
300 \\
100 \\
200\end{array}$ \\
\hline
\end{tabular}

(b) Fertilizers for Agdell Field, Pounds per Acre, i896 and Since

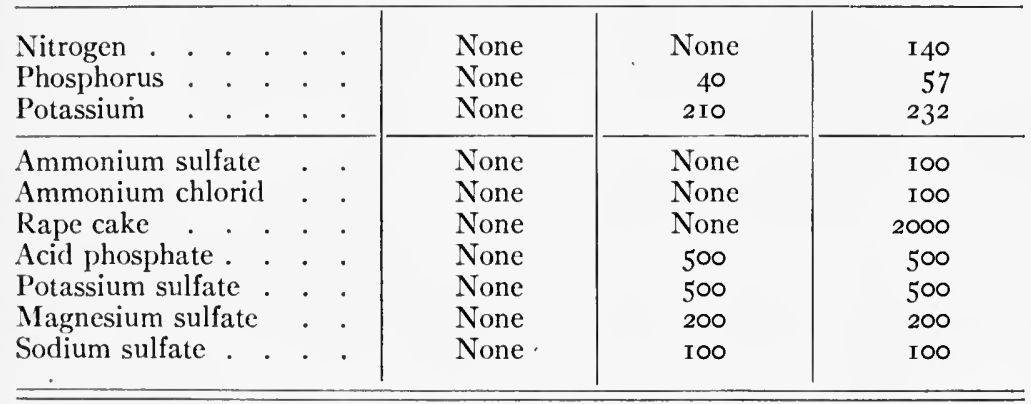

Exceptions to these tabular statements are as follows:

In 1848 , about 40 pounds of nitrogen, 20 pounds of phosphorus, and 60 pounds of potassium were applied, with no magnesium or sodium salts.

In 1852 , about 30 pounds of phosphorus and only ioo pounds of sodium sulfate were applied, otherwise the applications for $185^{2}$ were the same as shown in table, except as explained below.

In 1884 , the applications of alkali minerals were made for the first time to the middle section and for that year were double the 
regular amounts; that is, 600 pounds of potassium sulfate, 200 pounds of magnesium sulfate, and 400 pounds of sodium sulfate.

In 1896 and in 1900,600 pounds of basic slag phosphate were applied instead of 500 pounds of acid phosphate.

The sixty years' data from Agdell field are exceedingly valuable in the study of many important soil fertility problems. No exhaustive discussion can be given here, but these results will be referred to for many years at least as the greatest source of information concerning the effect of long-continued crop rotation. A ferw of the plainly indicated conclusions may be noted.

(I) On the unfertilized land the rotation of crops does not maintain the fertility of the soil, the yields of every crop having decreased with the possible exception of beans. The yield of Swede turnips dropped from about ro tons per acre in 1848 to less than 2 tons in 1852 , and never equaled 3 tons per acre afterward. That is to say, the turnips have always been grown at a loss since the first year, the best yields being scarcely worth harvesting. The barley yields have decreased from more than 40 bushels, I849, to I 5 bushels as an average of the last 20 years, but the decrease has been very gradual. The yield of legumes has been very irregular, but, with the exception of the beans in 1898 , has markedly decreased, the clover from 2.8 tons in 1850 to less than one half ton per acre as an average of the crops grown during the third 20-year period.

The yield of wheat has been greatly influenced by several conditions, but during the sixty years has decreased as an average by 8 bushels in the legume system and by 16.5 bushels in the fallow system, if we assume that the difference between the averages for the first 20 years and the last 20 years represents the decrease of 40 years. The lowest average yield is for the second 20 years, but this period includes the abnormally low yields of 1879 (when the best fertilized plots averaged only $\mathrm{r} 3.5$ bushels) and two other rather poor years.

It should be kept in mind, too, that the wheat crop comes in the next year after legumes or fallow, and thus has the most favored place in the rotation.

(2) The application of mineral plant food has as an average maintained the yields of legumes and of the following wheat crops. 


\section{INVESTIGATION BY CULTURE EXPERIMENTS}

Even the yield of turnips has been fairly good and practically maintained since $185^{2}$ in the legume system, but it should be noted that the yield of Swede turnips fell off nearly io tons from 1848 to $185^{2}$ (sec fallow series only for Swedes in 1848 ). In case of the barley the influence of the legumes grown three years before is less apparent, and the barley yields have decreased during the sixty years by 22 bushels in the legume system and by $3 \mathrm{I}$ bushels in the fallow system, if we consider that the averages for the first and third 20-year periods are 40 years apart.

(3) Where both minerals and nitrogen have been applied (always to the turnip crop only), the yield of turnips has been appreciably increased; and, if allowance be made for the failure of 1868 , the increase has been somewhat regular; while the barley crop, which follows the turnips, has apparently suffered approximately in proportion to the increasing drafts upon the soil by the turnips, and with as near approach to regularity. The fact that this marked decrease in yield appears in the barley straw as well as in the grain clearly indicates that the abundant supplies of minerals applied and liberated from the soil make it possible for the enormous turnip crop to appropriate so much of the available nitrogen supply that the quick-growing spring barley is limited in yield by lack of nitrogen. In the case of the legumes the average yields have distinctly decreased where commercial nitrogen has been supplied. This raises the question whether the larger crops of turnips and barley where nitrogen was supplied have not removed such large amounts of the mineral elements that the yield of the legumes (which have power to balance their own nitrogen ration) is thereby limited. In this connection it may be noted that, as an average, the yields of both clover and beans have been better where the full minerals alone are applied (middle section since r884) than where nitrogen also has been added. The yield of wheat following the legumes has been well maintained, not only where both minerals and nitrogen are applied, but also where minerals alone are used.

(4) On the unfertilized land the fallow system has given better average yields of turnips, of barlcy, and of wheat than the legume system, throughout the entire sixty years, except for the wheat in the last twenty. The fallow system also gave better results 
on the phosphorus plots with wheat and turnips, and practically the same yields of barley, as the legume system, clearly indicating that where the soil contains a fair supply of nitrogen in proportion to its phosphorus content the legume crops add little if any nitrogen to the soil in excess of what they take from the soil, when the regular legume crops are all removed. Ultimately, however, with the continued reduction of the absolute or relative supply of nitrogen, in comparison with other essential elements, a point is reached below which the legumes leave in the roots and stubble more nitrogen than they have taken from the soil. In soils practically devoid of available nitrogen only legumes can be grown, and their total content of nitrogen must, of course, be taken from the air.

It is evident that nitrogen has become so depleted in the unfertilized land that the legume residues are now furnishing the wheat crop with some nitrogen taken from the air, but this effect does not extend to the turnips or barley crop. On the other hand, where an abundant supply of minerals makes possible the production of large crops of legumes, the atmospheric nitrogen stored in the legume crop residues (or possibly gathered subsequently as suggested elsewhere) not only maintains the yield of wheat but markedly affects both the turnips and the barley, although the yield of barley is steadily decreasing.

As a general average on unfertilized land the wheat after clover or beans has yielded about to per cent less than after fallow; but the clover residues have increased the yield of wheat by i 8 per cent on the mineral plots and by 13 per cent on the plots receiving minerals and nitrogen, compared with the fallow system; whereas the wheat yields after beans have averaged less than after fallow on all plots. These results are in accord with the data already given, showing that the roots and stubble of annual legumes, such as cowpeas and soy beans, contain much less nitrogen and organic matter than the roots and residues of red clover, alfalfa, and sweet clover.

(5) The fallow system is unquestionably very exhaustive of the soil's supply of nitrogen. During the first twenty years the fallow system produced as an average larger crops than the legume system, but the decrease in yield under the fallow system has in most cases been more marked than under the legume system. 


\section{INVESTIGATION BY CULTURE EXPERIMENTS}

This is especially noticeable on the mineral section, where best provision is made for rapidly exhausting the nitrogen by removing other limits to crop production. With barley under the fallow system the yield for the last twenty years averages no more where minerals are supplied than where no fertilizer is used, thus indicating the same nitrogen limit for that crop, and emphasizing the fact that no amount of phosphorus or other elements can increase the yield of crops where nitrogen has become the limiting element. In the case of wheat, the yield is still greater where the minerals are supplied, because wheat is the first crop grown after the year of fallow cultivation, the principal effect of which is to liberate nitrogen from the residue still contained in the soil humus; and whatever weeds are allowed to grow, during the fallow year or other years, will help to save soluble nitrogen from loss in drainage water; and if the volunteer herbage includes any legume plants, some atmospheric nitrogen would thus be added. Of course if any growth of this character were larger on the mineral plots than on the unfertilized land, the effect would be greatest on those plots in the increased growth of the wheat, turnips, and barley.

It is pointed out by Dyer (Results of Investigations on the Rothamsted Soils, Bulletin 106 of the Office of Experiment Stations, United States Department of Agriculture) that where barley is grown every year on Hoos field the most common weed on the plot receiving minerals without nitrogen is yellow trefoil, which grows even while the barley crop is supposed to occupy the land; and that Sir Henry Gilbert had expressed the opinion that very appreciable quantities of nitrogen were added to the soil by that leguminous plant, which grows persistently as a weed on that plot despite the efforts to cradicate it.

Since the above was written, Director Hall, of Rothamsted, has kindly furnished the specific information that the fallow portion of Agdell fielil is kept plowed, and is therefore practically free from weeds during that year; but when wheat is grown, " there is a good deal of wild yellow trefoil, particularly in certain seasons, and on the plots receiving mineral manures only." He states that this trefoil was so abundant in 1907 that after the wheat harvest he had it cut and weighed separately, and found that the amounts per acre (including, presumably, the wheat stubble etc.) were 
I330 pounds on the unfertilized land, 2633 pounds where minerals alone are used, and 718 where both minerals and nitrogen are applied. These figures relate only to the fallow plots. On the legume plots there was very much less trefoil. Director Hall states that the amounts that grew on the fallow plots in 1907 are rather exceptional, but that in every crop of wheat or barley there is some of this wild legume, "which must have some influence upon the nitrogen content of the soil."

(6) The effect of feeding off the turnips by pasturing with sheep is a distinct benefit to succeeding crops wherever the yield of turnips amounts to much. This effect is most marked, of course, on the mineral plots, where nitrogen is very deficient, and it is also most marked on the barley crop, which follows immediately after the turnips, although the influence can usually be seen on the legumes and wheat, and even on the following turnip crop.

Before leaving Agdell field we may well try to view these results from the financial standpoint, particularly during the last twenty years, because the world affords no other data from crop-rotation experiments in which can be studied 20-year averages secured after a preliminary period of forty years. (See also page 4 I9.)

In Table 59 the turnips are valued at \$I.40 per ton, the clover hay at $\$ 6$ per ton, the barley at 50 cents a bushel, the beans at $\$$ I.25 a bushel, and the wheat at 70 cents a bushel. At these prices, the turnips and beans were more valuable per acre than the wheat. Nitrogen is figured at I 5 cents a pound, phosphorus at I 2 cents, and potassium at 6 cents; and it is assumed that the magnesium and sodium salts cost the same as the extra salts in kainit at $\mathrm{Sr}_{5}$ a ton. These various prices may be modified and the results recalculated to fit different local conditions.

No values are allowed for the straw of barley, beans, or wheat, or for turnip leaves; but in computing the value of increases it is assumed the increase in these by-products would be worth as much as the extra cost of harvesting, threshing, etc.

At the prices used in Table 59, the use of minerals in the legume system has more than doubled the value of the crops produced during the last 20 years, the a verage of which really represents the condition just fifty years from the beginning, in 1848 . While the effect upon turnips is to change a practical failure into a crop which 


\section{INVESTIGATION BY CULTURE EXPERIMENTS}

almost pays for the minerals the first year, the residual effect upon the other crops is to nearly double their total value.

Table 59. Rotation Crops on Agdeli field, Rothamsted Average per Acre of Third 20-year Period, I888 to 1907

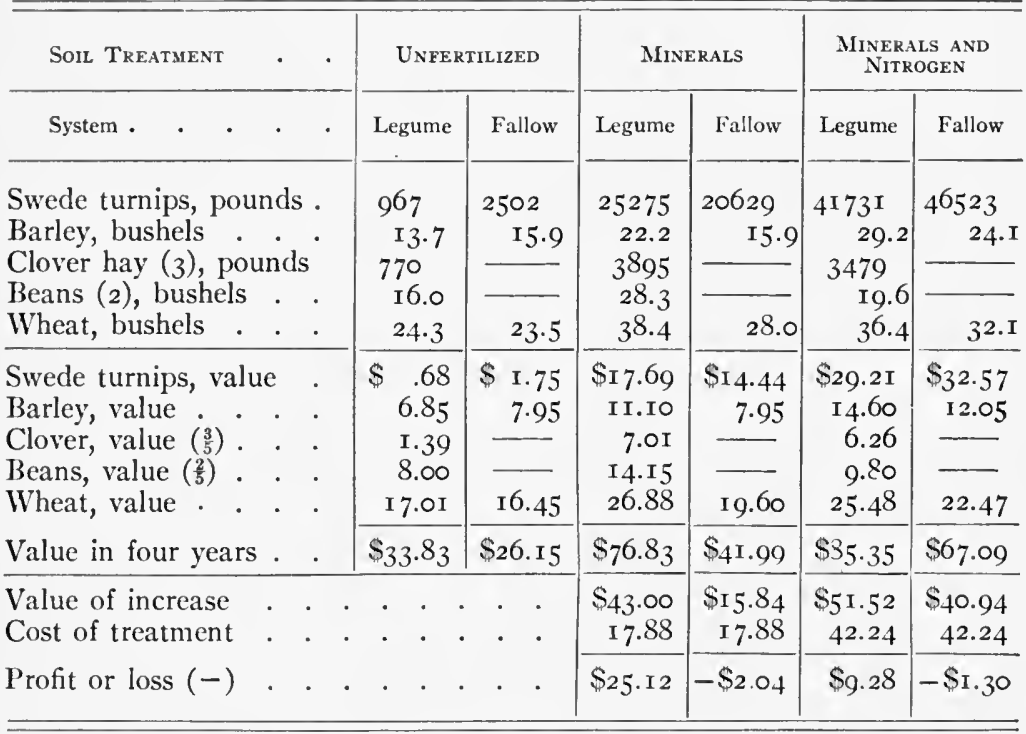

In this system the minerals have paid for themselves and made a net profit of 140 per cent on the investment. They have also fully maintained the average yield of legumes, wheat, and turnips since $185^{2}$, but the system fails to maintain the supply of nitrogen, and because of this the barley has markedly decreased in yield.

One may assume with reasonable confidence that if the turnip leaves, the wheat and barley straw, the bean straw, and perhaps part of the clover crop, had been returned to this land to furnish nitrogen and decaying organic matter, the barley yields might also have been maintained and the turnip crops kept equal to that of 1848 , thus providing a permanent system; whereas, under the system practiced, it seems certain that the yield of turnips must decrease in time; and in the opinion of the author the nitrogen supplied by the legume residues will ultimately be insufficient to 
maintain the yield of wheat, unless the azotobacter or some other nitrogen-fixing agency is more efficient than our present knowledge indicates; or unless the leguminous weeds are allowed to grow in sufficient quantity to furnish and maintain the nitrogen balance.

The application of commercial nitrogen does not solve the problem for present conditions of general farming in the United States, because at reasonable average prices the addition of $\$ 2 \mathrm{I}$ of nitrogen has increased the average crop values by only $\$ 8.52$ under the only profitable system, notwithstanding the additional phosphorus and potassium also supplied in the rape cake. As would be expected, the applied nitrogen produced a more marked effect in the fallow system, which is so very exhaustive of the soil nitrogen; and in this case the minerals and nitrogen produced slightly less loss than the minerals alone; so that, if produce from the mineral plots could be figured at prices which would show some profit, it would then be profitable to add the ammonium salts and rape cake.

The question remains whether a liberal supply of decaying organic matter in connection with the phosphorus fertilizer would not have rendered the use of potassium sulfate and other salts unnecessary or unprofitable, especially since much of the potassium removed in crops would be returned in the straw and leaves. Since there has been a recent change on Agdell field, by which the practice of pasturing off the turnips has been discontinued, Director Hall is considering the plan of applying to the "fed " plots, in addition to the regular fertilizers, amounts of farm manure equivalent to the root crops, straw, and clover hay produced on those respective plots, because that would more closely agree with ordinary farming practice in England.

In passing from the Agdell rotation field to the continuous wheat-growing on Broadbalk field, attention is called to the fact that as an average of the third 20-year period the unfertilized plot 3 on Broadbalk produced I2.2 bushels of wheat per acre (see Table 62), which at 70 cents a bushel would be worth $\$ 34.16$ in four years; whereas the average value of the rotation crops produced on unfertilized land during four years (as an average of the third 20-year period on Agdell field) was only $\$ 33.83$ in the 


\section{INVESTIGATION BY CULTURE EXPERIMENTS}

legume system, and \$26.I 5 in the fallow system, at the prices used in Table 59. (See also comparative statement of prices on page 359.)

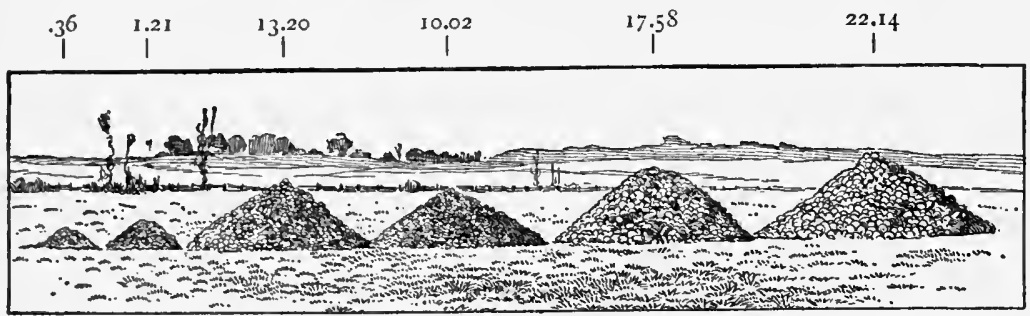

Turnip Crop of 1908 on Agdell Field, Rothamsted; 6ist Crop in 4-Year Rotation; TONS PER ACre

$\underbrace{\mathrm{I}}_{\text {Unfertilized }} \underbrace{3}_{\text {Mineral plant food }} \overbrace{\text { Minerals and nitrogen }}^{4}$

Counting from the left, lots $\mathrm{I}, 3$, and 5 were grown on land where the rotation is turnips, barley, clover, and wheat, while lots 2,4 , and 6 were grown on land where the rotation is turnips, barley, fallow, and wheat. The six lots were all produced on plots of ground of equal size. Plots $I$ and 2 have received no fertilizer. Plots 3 and 4 received only a phosphorus fertilizer for the 36 years, 1848 to 1883 , but since that time they have received mixed minerals, including phosphorus, potassium, magnesium, and sodium. (The average yield of turnips in 1880 was $1 \frac{1}{2}$ tons for plots $I$ and 2 , and the average yield of plots 3 and 4 for the same year was $12 \frac{1}{2}$ tons per acre.) Plots 5 and 6 have received mixed minerals and nitrogen since 1848 .

These are the rotation experiments referred to by Professor Whitney on page 22 of U. S. Farmers' Bulletin 257, as follows:

"In other experiments of Lawes and Gilbert they have maintained for fifty years a yield of about 30 bushels of wheat continuously on the same soil where a complete fertilizer has been used. They have seen their yield go down where wheat followed wheat without fertilizers for fifty years in succession from 30 bushels to 12 bushels, which is what they are now getting annually from their unfertilized wheat plot. With a rotation of crops without fertilizers they have also maintained their yield for fifty years at 30 bushels, so that the effect of rotation has in such case been identical with that of fertilization."

In commenting upon these statements, Director A. D. Hall, of the Rothamsted Experiment Station, says:

"I cannot agree with Professor Whitney's reading of the results on the Agdell field in the least. The figures he quotes for wheat are hardly justifiable as approximations, and are in spirit contrary to the general tenor of the particular experiment. In my opinion the results on the Adgell rotation field are directly contrary to Professor Whitney's idea that rotation can do the work of fertilizers." (See Report of the Committee of Seven, including Woll of Wisconsin, Van Slyke of New York, Lipman of New Jersey, Davidson of Virginia, 
Ross of Alabama, Peter of Kentucky, and Penny of Pennsylvania, appointed by the Association of Official Agricultural Chemists, "to consider in detail the questions raised"; published in full in Circular 123 of the University of Illinois Agricultural Experiment Station.)

\section{Broadbalk Field}

Undoubtedly Broadbalk is the best-known experiment field in the world, and plots 2 and 3 are the most often referred to. While the continuous growing of wheat on the same land is not to be considered the best practice, the records given in Table 60 show very clearly that it is possible. These plots are compared with most of the others for a period of 55 years. Perhaps the most interesting and instructive results are the average yields of 12.9 bushels on the unfertilized land, 35.5 bushels with farm manure, and 37.I bushels with the heaviest applications of commercial plant food.

Plots 5, 6, 7, and 8 differ only in the amount of nitrogen applied; and, with successive additions of 43 pounds of nitrogen per acre, the average yields increase from 14.9 bushels with no nitrogen applied, to 23.8 bushels with 43 pounds of nitrogen, to 32.8 bushels with 86 pounds of nitrogen, and to 37 .I bushels with I 29 pounds of nitrogen. The average yield of 55 crops is only 2 bushels more per acre where 792 pounds of mixed mineral fertilizers have been applied every year than where no fertilizer of any kind has been used. These data are in striking contrast with the results from Agdell field, where, as an average of the last 20 years, the increase with minerals alone is 83 per cent of the total increase with minerals and nitrogen, while on Broadbalk the minerals alone have produced an average increase which is only 8 per cent of the increase from minerals and nitrogen (plot 8).

With the fallow system on Agdell field the results are tending in the same direction as those from Broadbalk, and most markedly, of course, where all crops were removed.

This must emphasize a fact which it is exceedingly important to keep in mind while studying the results from Broadbalk field; and indeed, when studying the data from not only the Rothamsted fields but from nearly all of the oldest soil experiment fields in 


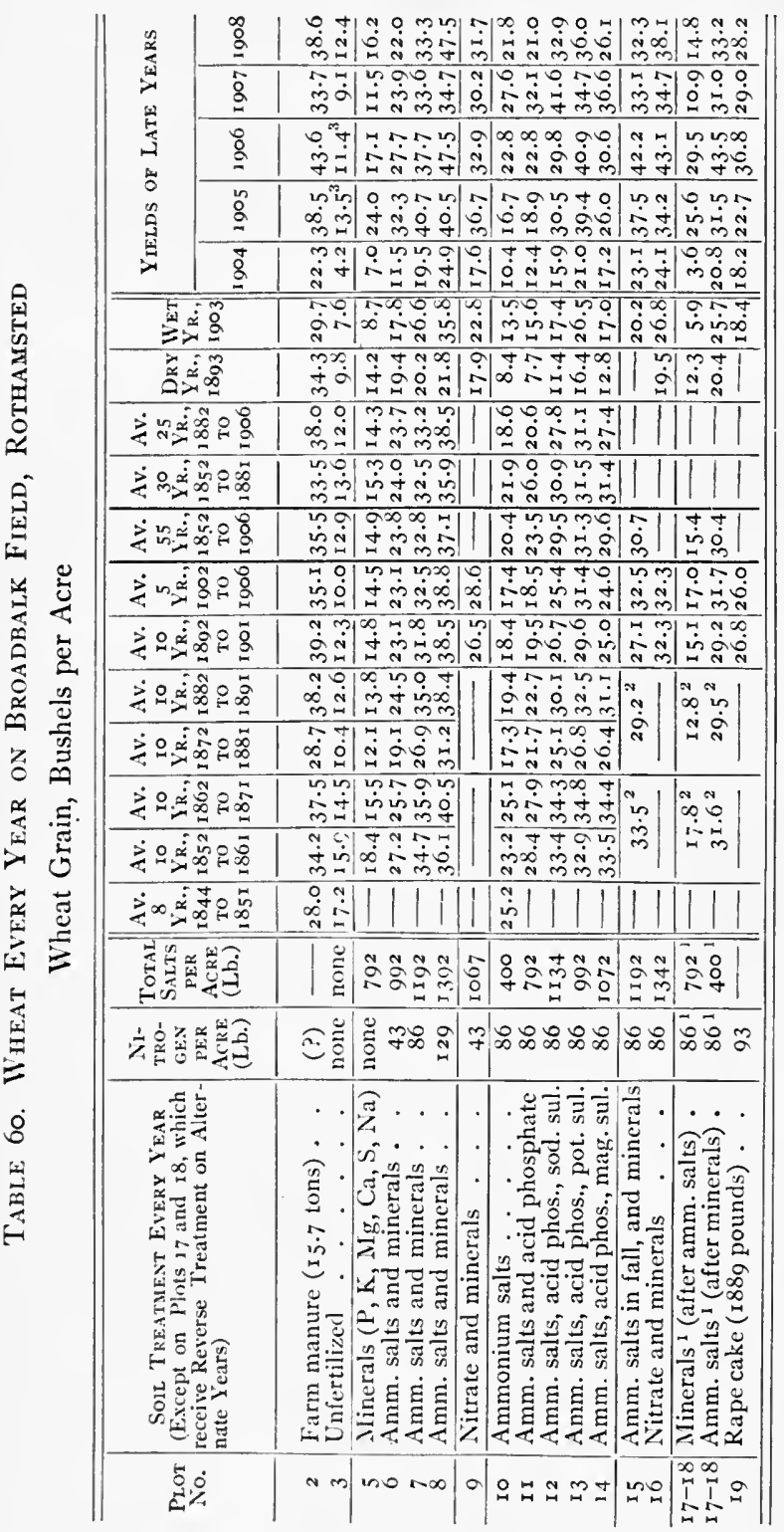

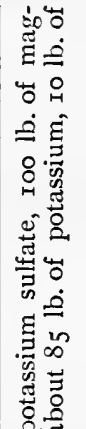

马्己 药

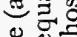
ग नु० 营苟出

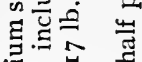
क्ष

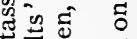

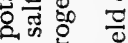
누욜 을 응 政 प्ते जी ف을 ิิ $0=$ 四号 유 เं. 莽号 등 है, 巳્ पै $\dot{0}$ 토 ชู. m. 츨 를 额艺 코 ○至 ज 究些 1) 엉

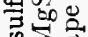
क्य 刍。 氜芯 윤 पै के : 局 엄. 월 능 胥 క in ํㅐㄴㅇㅠ

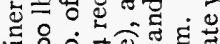

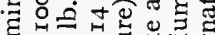

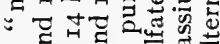
ข

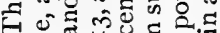

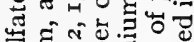

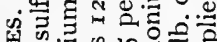
क.

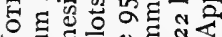
焉 


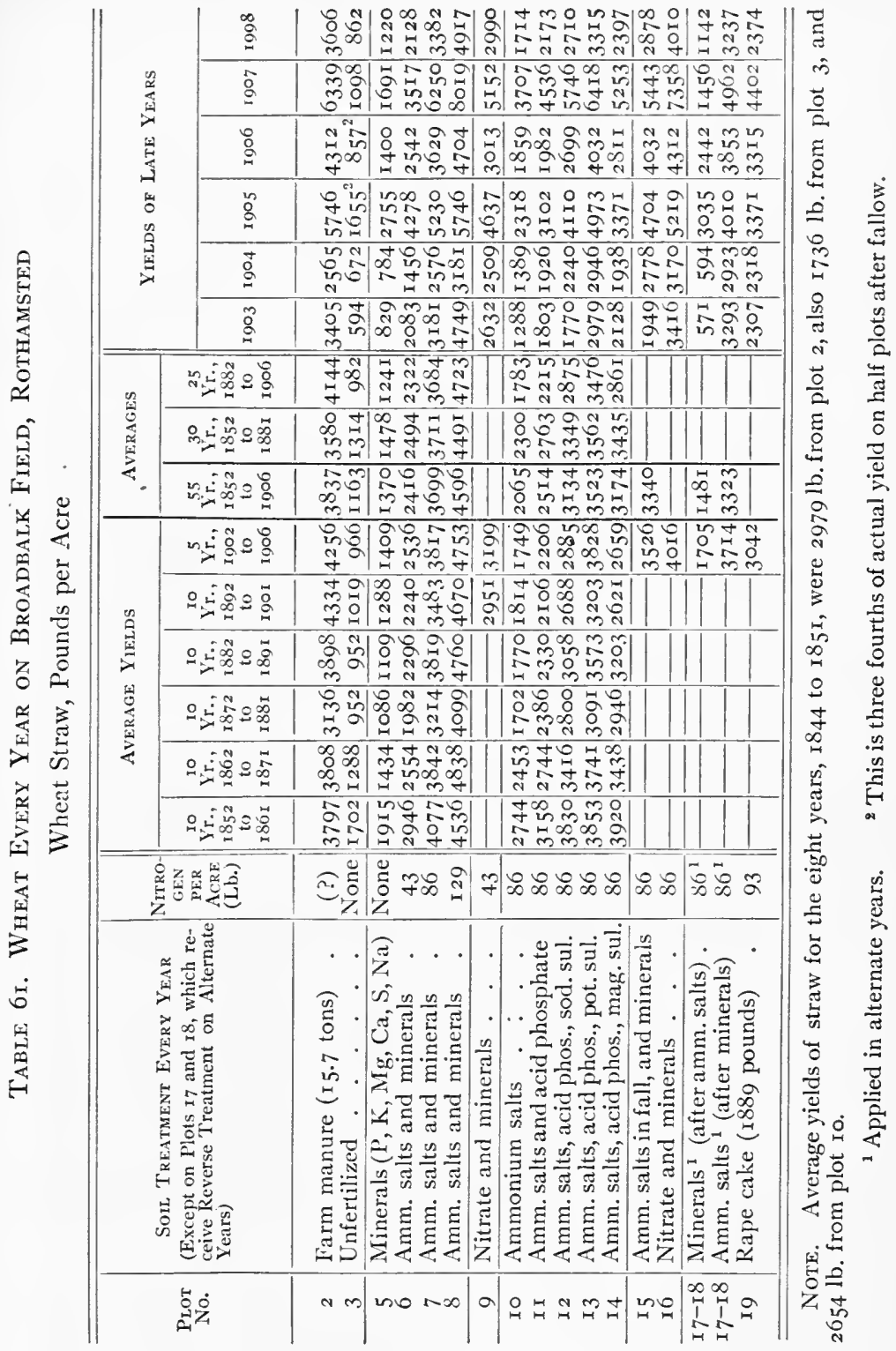


America as well; namely, that practically no provision has been made for maintaining any adequate supply of decaying organic matter in the soil, in consequence of which, in the author's opinion, the soil itself becomes practically inactive, and, if satisfactory crops are to be grown, every essential element of plant food must be supplied artificially in readily available form.

According to well-established and universally accepted physical laws, a solution is always saturated so long as there is contact and equilibrium between the solution and the undissolved substance; but, in the author's opinion, this law of solution does not apply to the soil mass as a whole, for equilibrium is never established in the soil mass as a whole. In the unlimited and unqualified application of this entirely correct solution theory, we might say that the peaty swamp lands of Illinois have direct capillary connection with the potassium mines of Germany; but the fact is, that, where 200 pounds of potassium sulfate per acre have been applied to that peaty swamp land with a resultant yield of more than 50 bushels of corn per acre, the crop on the untreated adjoining land, separated only by a half-rod division strip, receives absolutely no benefit because of any capillary connection, and yiclds less than 5 bushels of corn per acre, even where the experiment is continued year after year.

Even regarding the Rothamsted permanent grass plots, which are separated only by a line, which vary in soluble fertilizers received from none to a ton per acre per annum, in average yield from one to four tons of hay per acre, and in herbage from strictly nonleguminous to fifty per cent of legume plants, the statement is made by Director Hall that, "although the treatment has been repeated now for fifty-two years, the dividing line between the two plots remains perfectly sharp, and the rank herbage produced by the excess of nitrogenous fertilizer on one side does not stray six inches over the boundary."

Unquestionably the film of water surrounding a soil grain becomes a saturated solution of all the minerals exposed on the surface of that individual particle, but this solution may be of different composition from each of the other films surrounding the other billion or more soil grains which may exist in the same cubic inch of soil, of which, perhaps, only one in a thousand con- 
tains any phosphorus, for example. If the 87 pounds of acidsoluble phosphorus contained in 2 million pounds of the surface soil of an acre of the level upland "barrens" of the Highland Rim of Tennessee were all distributed in a coating of uniform thickness over the surfaces of all the soil grains in the stratum, it is very possible that, if all other essentials were provided in abundance or perfection, the abundant sunshine and rainfall of Tennessee would bring forth from that soil hundred-bushel crops of corn for three successive years, or possibly longer, because, according to the Tennessee Experiment Station (Bulletin 3, Volume X, I897), there are 6r pounds of acid-soluble phosphorus in each 2 million pounds of the subsoil.

Absolute science shows no necessary relation between the amount of potassium, for example, that may be dissolved from Io0 grams of soil by 500 grams of water, during twenty minutes of laboratory manipulation, and the amount of the same element that a corn plant may secure from a cubic yard of earth during the four months' period of growth.

Referring again to the Broadbalk field data, it will be seen that even where 86 pounds of nitrogen are applied (plot 10), the average yield is only 20.4 bushels, or I8.6 for the last 25 years; and the increase of 6.6 bushels by nitrogen alone is raised to $2 \mathrm{I} .2$ bushels (or to 33.2 bushels per acre) when both nitrogen and minerals are supplied. Under these conditions, nitrogen and phosphorus are powerless to maintain the yield (see plot II); for, although the soil contains abundance of potassium and other less important essential elements, there is evidently but little action in the soil by which they can be made available. One is inclined, for the land's sake, to wish that one or two good crops of clover might be plowed under on plots 5 and II, were it not for the fact that these plots are far too valuable for the lessons they are now teaching to justify any such change.

It is even questionable whether the effect of the potassium applied to plot $\mathrm{I}_{3}$ is wholly due to the use of that element as plant food, or perhaps due in part to its power to hold other elements, as phosphorus, in a vailable form. It will be observed that during the first 30 years sodium and magnesium salts (applied in molecular proportions) produced essentially the same increase (about 


\section{INVESTIGATION BY CULTURE EXPERIMENTS}

5 bushels) as potassium sulfate. It is commonly assumed that the effect of the sodium and magnesium salts is due to their reaction with insoluble potassium silicates with liberation of soluble potassium, and the results of the later years certainly strongly support that view. The regularity with which potassium is surpassing sodium and magnesium in its influence upon crop yields would even lead one to imagine that the 1907 yields of plots $I_{2}$ and $x_{3}$ might have been interchanged, except that the exceedingly careful methods of the Rothamsted Station makes such an error practically impossible, and that the more certain explanation lies in the enormous variation (which every experimenter is familiar with) in different seasons among field plots, subject to so many uncontrolled and uncontrollable influences. Compare, for example, plot II with plot I7 (minerals) in 1904 and 1906.

In studying plots $\mathrm{I} 7$ and $\mathrm{I} 8$, it should be understood that for the I907 crop (for example) the minerals only were applied to plot I 7 and the ammonium salts only to plot 18 , while for the 1908 crop the ammonium salts only were applied to plot I7 and the minerals only to plot 18 , this system of alternating having been followed since $185^{2}$, and the amounts recorded in Table 60 for these two plots are thus applied biennially and not annually.

The data prove conclusively that almost none of the applied nitrogen remains to benefit the second crop, while the minerals remain and exert marked benefit on the succeeding crop. Compare with plot 7 (for example), which receives twice as much minerals during the biennium.

It is of interest to note that in the dry season of 1893 (see rainfall record, Table 65) the farm manure plot produced I 2.5 bushels more wheat than the best fertilized plot (No. 8), while as an average the heaviest applications of commercial plant food have given slightly larger yields than the farm manure, and the difference in favor of the commercial materials seems to be greater in wet seasons. Thus, in I903, plot 8 produced 6. I bushels more than plot 2. Compare also the wet year of 1879 with the dry year of 1898 .

It must be understood, of course, that Broadbalk field is designed to secure knowledge and establish principles rather than to serve as a model for agricultural practice. Nevertheless, it is of interest to apply some financial measurements to the results. 
Thus, the average increase of 22.6 bushels resulting from the annual application of 15.7 tons of farm manure ( 14 tons of 2240 pounds) would be worth $\$_{15} .82$ at 70 cents a bushel. In other words, manure is worth \$I per ton for use at this rate in continuous wheat culture.

In no case has the total application of commercial plant food paid for its cost at standard prices; and rarely has any addition paid for itself in increase produced, even though the cost of other materials be disregarded. We may reckon $\$ 6.45$ as the cost of 43 pounds of nitrogen, $\$ 3.48$ for 29 pounds of phosphorus, $\$ 5.10$ for 85 pounds of potassium, and $\$ 8.98$ for the full minerals (assuming that the magnesium and sodium salts can be bought as cheaply as in kainit at \$ 5 a ton when used in connection with sufficient potassium).

Thus the minerals alone on plot 5 produced an average increase of 2 bushels, worth $\$$ I.40, at a cost of $\$ 8.98$, and of course any application made in addition to minerals must pay for this deficit of $\$ 7.58$ as well as for its own cost before there could be any profit. But if we disregard this deficit, we find that $\$ 6.45$ in nitrogen on plot 6 produced 8.9 bushels increase, worth only $\$ 6.23$; that a second $\$ 6.45$ in nitrogen on plot 7 produced a further increase of 9 bushels, worth $\$ 6.30$; and that the third $\$ 6.45$ invested in nitrogen on plot 8 produced 4.3 bushels of wheat, worth $\$ 3$. 0 .

We may also begin our computations with the 400 pounds of ammonium salts applied to plot Io, on which 86 pounds of nitrogen (only I 2 pounds more than would be contained in a 50-bushel crop), costing $\$$ I 2.90 , produced 7.5 bushels increase, worth $\$ 5.25$, thus placing a deficit of $\$ 7.65$ against any additional treatment. The increase from minerals alone was worth only \$1.40, but with nitrogen provided (on plot 7) the minerals costing $\$ 8.98$ produced $\$ 8.68$ increase in the value of the crop, thus adding only 30 cents to the deficit; while acid phosphate on plot I I added \$I.3I, making a total deficit of $\$ 8.96$ for nitrogen and phosphorus, which, however, was reduced to $\$ 8.60$ by the potassium on plot ${ }^{13}$. The plan of the Broadbalk experiment affords no answer to the question as to how much effect would be produced by potassium salt by itself, but some extensive American experiments hereinafter discussed indicate that by itself the potassium sulfate would have 
been much less effective than where liberal provision is also made for phosphorus and nitrogen.

The sodium sulfate and the magnesium sulfate produced more than three fourths as much increase as the potassium sulfate, and may have been profitable in themselves, but even if they cost nothing, they would not overcome one half of the deficit standing against the treatment with nitrogen and phosphorus.

In the last five-year average, potassium pays a profit of $\$ 3.93$, but meanwhile the deficit on plot II has increased to \$10.43, the soil having become so deficient in decaying organic matter that only half a crop can be produced with the amount of potassium liberated from the immense supply still remaining in the soil, even though phosphorus and nitrogen are supplied in available form. The other sulfates have become only half as effective as the potassium salt, and the fact that sodium produces the same effect as magnesium strengthens the common belief that their chief action is to liberate potassium from the insoluble silicates.

Under these conditions, it ought not to be expected that decaying organic matter of itself would liberate sufficient potassium from the soil for the production of maximum crops. However, any system under which the organic matter content of the soil can be maintained in optimum amount will necessarily return to the soil in the organic matter most of the potassium taken from the soil. On the other hand, all of the crops taken from plot 2 during the 55 years have removed in both grain and straw only 2330 pounds of potassium (based upon Rothamsted analyses), or only one fifteenth as much as was contained at the beginning in 2 million pounds of the fine surface soil. In other words, the total supply of potassium contained in 2 million pounds of the soil would be sufficient for such crops (grain and straw) for 800 years.

The 55 crops from plot 2 have removed about $65^{\circ}$ pounds of phosphorus, and 2 million pounds of the surface soil of plot 3 (unfertilized) now contain only 980 pounds of phosphorus soluble in strong nitric or hydrochloric acid, after ignition, and reported by Doctor Bernard Dyer ${ }^{1}$ as total phosphorus. Here we find that the phosphorus actually removed in 55 crops from plot 2 is two

${ }^{1}$ Bulletin 106, Office of Experiment Stations, United States Department of Agriculture. 
thirds as much as the total phosphorus now contained in the plowed soil of the adjoining plot. Furthermore, the surface soil of the farm manure plot to the same depth now contains I 700 pounds of total phosphorus. Plots 5, 7, II, I2, I3, and I4 now contain as much phosphorus as plot 2, while plots 4 , Io $a$, and 1o $b$, none of which has received any phosphorus fertilizer during the 55 years, now contain about the same amount as plot 3 .

Because of the extreme difficulty with some very persistent weeds on the unfertilized land, one half of plot 3 was fallowed in 1904 and the other half in 1905 , but this weed trouble is now being controlled by drilling the wheat in somewhat wider rows and hand hoeing when necessary. Manifestly, the actual yields from one half of plot 3 for 1905 and from the other half for 1906 ought not to be used in making averages for wheat after wheat every year; but it will be seen from Table 63 that the average yield of continuous wheat is about three fourths of the yield of wheat alternating with fallow, and consequently this factor has been employed as stated.

In Table 62 are given the actual annual yields of wheat harvested from certain Rothamsted plots since 1844 .

Space is taken for these complete records because the author feels that they will be of genuine interest to the more careful readers, and also because every reader is entitled to such records of these oldest and most valuable soil investigations, in order that he may make any comparisons that may be desired. Questions may occur to the reader that neither the author nor any other writer has even thought of; and, since these are the longest continuous records the world affords, they are likely to furnish the best data for helping to solve some very practical questions. For example, is it a true saying that, as a rule, poor crops are followed by good crops the next year? If so, then what kind of a crop should follow an exception to this rule; that is, should two poor crops in succession be followed by an exceptionally good crop? It is also said that an extra good crop is likely to be followed by another good crop.

One might eliminate the poorest yield or the best yield in every eight-year period, for example, and then determine if the average 


\section{$37^{2}$ INVESTIGATION BY CULTURE EXPERIMENTS}

\section{Table 62. Wheat Yields at Rothamsted \\ Wheat, Bushels per Acre}

\begin{tabular}{|c|c|c|c|c|c|c|c|c|}
\hline Field & $\begin{array}{c}\text { BROAD- } \\
\text { BALK }\end{array}$ & Hoos & AGDELL & AGDELL & AGDELL & $\begin{array}{l}\text { BROAD- } \\
\text { BALK }\end{array}$ & $\begin{array}{l}\text { BROAD- } \\
\text { BALK }\end{array}$ & $\begin{array}{c}\text { BROAD- } \\
\text { BALK }\end{array}$ \\
\hline $\begin{array}{c}\text { Crop } \\
\text { System }\end{array}$ & $\begin{array}{l}\text { Wheat } \\
\text { Every } \\
\text { Year: } \\
\text { Plot } 3\end{array}$ & $\begin{array}{c}\text { Wheat and } \\
\text { Fallow } \\
\text { Alterna- } \\
\text { ting }\end{array}$ & $\begin{array}{l}\text { Turnips, } \\
\text { Barley, } \\
\text { Fallow, } \\
\text { Wheat }\end{array}$ & $\begin{array}{l}\text { Turnips, } \\
\text { Barley, } \\
\text { Legume, } \\
\text { Wheat }\end{array}$ & $\begin{array}{l}\text { Turnips, } \\
\text { Bariey, } \\
\text { Legume, } \\
\text { Wheat }\end{array}$ & $\begin{array}{l}\text { Wheat } \\
\text { Every } \\
\text { Year: } \\
\text { Plot } 2\end{array}$ & $\begin{array}{l}\text { Wheat } \\
\text { Every } \\
\text { Year: } \\
\text { Plot } 8\end{array}$ & $\begin{array}{l}\text { Wheat } \\
\text { Every } \\
\text { Year: } \\
\text { Plot I6 }\end{array}$ \\
\hline $\begin{array}{c}\text { Soil } \\
\text { Treatment }\end{array}$ & None & None & None & None & $\begin{array}{l}\text { Phos- } \\
\text { phorus }\end{array}$ & $\begin{array}{c}\text { Farm } \\
\text { Manure }\end{array}$ & $\begin{array}{l}\text { Minerals } \\
\text { and } 129 \\
\text { lb. } N\end{array}$ & $\begin{array}{l}\text { Minerals } \\
\text { and i } 7^{2} \\
\text { lb. N }\end{array}$ \\
\hline $\begin{array}{l}\text { I } 844 \\
1845 \\
1846 \\
1847 \\
1848 \\
1849 \\
1850 \\
185^{1}\end{array}$ & $\begin{array}{l}15.0 \\
23.3 \\
18.0 \\
16.9 \\
14.8 \\
19.3 \\
15.9 \\
15.9\end{array}$ & (fallow) & $\begin{array}{c}\text { (clover) } \\
30.5\end{array}$ & $\begin{array}{c}\text { (clover) } \\
28.5\end{array}$ & $\begin{array}{c}\text { (clover) } \\
28.0\end{array}$ & $\begin{array}{l}20.5 \\
32.0 \\
27.3 \\
29.9 \\
25.6 \\
31.0 \\
28.5 \\
29.6\end{array}$ & & \\
\hline $\begin{array}{l}1852 \\
1853 \\
1854 \\
1855 \\
1856 \\
1857 \\
1858 \\
1859\end{array}$ & $\begin{array}{r}\mathrm{r} 3.9 \\
5.9 \\
21.1 \\
17.0 \\
14.5 \\
20.0 \\
18.0 \\
18.4\end{array}$ & $\begin{array}{c}37.0 \\
\text { (fallow) } \\
42.0 \\
17.4 \\
21.8 \\
38.0 \\
25.8 \\
34.0\end{array}$ & $\begin{array}{c}- \\
\text { (fallow) } \\
37.4 \\
\\
\text { (fallow) } \\
35.8\end{array}$ & $\begin{array}{c}-\overline{-} \\
\text { (beans) } \\
35 \cdot 3 \\
\\
\text { (beans) } \\
35 \cdot 3\end{array}$ & $\begin{array}{c}\text { (beans) } \\
\begin{array}{c}35 \cdot 3 \\
\\
\text { beans) } \\
34.8\end{array}\end{array}$ & $\begin{array}{l}27.6 \\
19.1 \\
41.1 \\
34.6 \\
36.3 \\
41.3 \\
38.8 \\
36.3\end{array}$ & $\begin{array}{l}27.5 \\
23.5 \\
48.6 \\
31.5 \\
39.1 \\
48.4 \\
41.9 \\
34.5\end{array}$ & $\begin{array}{l}28.5 \\
25 \cdot 1 \\
49.9 \\
32.9 \\
37.9 \\
49.4 \\
41.9 \\
34.6\end{array}$ \\
\hline $\begin{array}{l}1860 \\
1861 \\
1862 \\
1863 \\
1864\end{array}$ & $\begin{array}{l}12.9 \\
11.4 \\
16.0 \\
17.3 \\
16.5\end{array}$ & $\begin{array}{l}12.1 \\
17.9 \\
22.9 \\
32.9 \\
31.4\end{array}$ & $\begin{array}{c}- \\
\text { (fallow) } \\
45.0 \\
\end{array}$ & $\begin{array}{c}\overline{(b e a n s)} \\
34.1 \\
\end{array}$ & $\begin{array}{c}\overline{\text { (beans) }} \\
349 \\
\end{array}$ & $\begin{array}{l}32.3 \\
34.9 \\
38.4 \\
44.0 \\
40.0\end{array}$ & $\begin{array}{l}31 \cdot 3 \\
35 \cdot 1 \\
39 \cdot 5 \\
55 \cdot 8 \\
49 \cdot 9\end{array}$ & $\begin{array}{l}32.6 \\
37.0 \\
36.3 \\
55.9 \\
51.1\end{array}$ \\
\hline $\begin{array}{l}\text { (Note } \\
\text { Change) }\end{array}$ & & & & & & & & None \\
\hline $\begin{array}{l}1865 \\
1866 \\
1867\end{array}$ & $\begin{array}{r}13.4 \\
12.1 \\
8.9\end{array}$ & $\begin{array}{r}24.3 \\
10.8 \\
9.6\end{array}$ & $\begin{array}{c}(\text { fallow }) \\
27.1\end{array}$ & $\begin{array}{c}\text { (beans) } \\
21.0\end{array}$ & $\begin{array}{c}\text { (beans) } \\
19.8\end{array}$ & $\begin{array}{l}37.1 \\
32.6 \\
27.5\end{array}$ & $\begin{array}{l}43.6 \\
32.1 \\
30.5\end{array}$ & $\begin{array}{l}32.4 \\
17.4 \\
14.6\end{array}$ \\
\hline $\begin{array}{l}1868 \\
1869 \\
1870 \\
1871 \\
1872 \\
1873 \\
1874 \\
1875\end{array}$ & $\begin{array}{r}16.6 \\
14.3 \\
15.0 \\
9.4 \\
10.8 \\
11.8 \\
11.5 \\
8.6\end{array}$ & $\begin{array}{r}25.0 \\
10.3 \\
17.3 \\
9.3 \\
12.8 \\
2.8 \\
21.5 \\
16.1\end{array}$ & $\begin{array}{c}\text { (fallow) } \\
\text { I I.5 } \\
\\
\begin{array}{c}\text { (fallow) } \\
24.4\end{array}\end{array}$ & $\begin{array}{c}\bar{~} \\
\begin{array}{c}\text { (beans) } \\
20.6\end{array} \\
\\
\begin{array}{c}\text { (clover) } \\
21.6\end{array}\end{array}$ & $\begin{array}{c} \\
\text { (beans) } \\
23.9 \\
\\
\text { (clover) } \\
28.3\end{array}$ & $\begin{array}{l}41.8 \\
38.3 \\
36.5 \\
39.0 \\
32.4 \\
26.8 \\
39 \cdot 3 \\
28.9\end{array}$ & $\begin{array}{l}46.5 \\
34.8 \\
45 \cdot 3 \\
27.8 \\
35.6 \\
27.5 \\
40.5 \\
30.0\end{array}$ & $\begin{array}{l}22.8 \\
16.1 \\
18.3 \\
13.5 \\
13.1 \\
12.8 \\
11.9 \\
10.1\end{array}$ \\
\hline
\end{tabular}


Table 62. Wheat Yields at Rothamsted - (Continued).

Wheat, Bushels per Acre

\begin{tabular}{|c|c|c|c|c|c|c|c|c|}
\hline FIELD & $\begin{array}{l}\text { BROAD- } \\
\text { BALK }\end{array}$ & Hoos & AgDell & AGDELL & AgDell & $\begin{array}{l}\text { BROAD- } \\
\text { BALK }\end{array}$ & $\begin{array}{l}\text { BROAD- } \\
\text { BALK }\end{array}$ & $\begin{array}{c}\text { BroAD- } \\
\text { BALK }\end{array}$ \\
\hline $\begin{array}{l}\text { Crop } \\
\text { System }\end{array}$ & $\begin{array}{l}\text { Wheat } \\
\text { Every } \\
\text { Year: } \\
\text { Piot } 3\end{array}$ & $\begin{array}{l}\text { Wheat and } \\
\text { Fallow Ai- } \\
\text { ternating }\end{array}$ & $\begin{array}{l}\text { Turnips, } \\
\text { Barley, } \\
\text { Fallow, } \\
\text { Wheat }\end{array}$ & $\begin{array}{l}\text { Turnips, } \\
\text { Bariey, } \\
\text { Legume, } \\
\text { Wheat }\end{array}$ & $\begin{array}{l}\text { Turnips, } \\
\text { Barley, } \\
\text { Legume, } \\
\text { Wheat }\end{array}$ & $\begin{array}{l}\text { Wheat } \\
\text { Every } \\
\text { Year: } \\
\text { Plot } 2\end{array}$ & $\begin{array}{l}\text { Wheat } \\
\text { Every } \\
\text { Year: } \\
\text { Plot } 8\end{array}$ & $\begin{array}{l}\text { Wheat } \\
\text { Every } \\
\text { Year: } \\
\text { Plot 16 }\end{array}$ \\
\hline $\begin{array}{c}\text { Soil } \\
\text { Treatment }\end{array}$ & None & None & None & None & $\begin{array}{l}\text { Phos- } \\
\text { phorus }\end{array}$ & $\underset{\text { Manure }}{\text { Farm }}$ & $\begin{array}{l}\text { Minerals } \\
\text { and } \\
\text { I } 29 \mathrm{lb} \text {. N }\end{array}$ & None \\
\hline $\begin{array}{l}1876 \\
1877 \\
1878 \\
1879 \\
1880 \\
1881 \\
1882 \\
1883\end{array}$ & $\begin{array}{r}8.1 \\
8.9 \\
12.4 \\
4.8 \\
11.5 \\
13.8 \\
11.0 \\
13.9\end{array}$ & $\begin{array}{r}10.3 \\
10.5 \\
19.8 \\
6.0 \\
15.3 \\
12.3 \\
11.8 \\
18.1\end{array}$ & 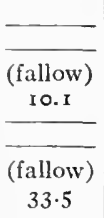 & 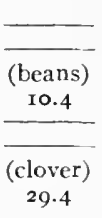 & $\begin{array}{c} \\
\text { (beans) } \\
\text { I } 4.4 \\
\\
\text { (clover) } \\
3^{6.5}\end{array}$ & $\begin{array}{l}23.9 \\
24.1 \\
28.3 \\
16.0 \\
38.4 \\
30.3 \\
32.8 \\
35 \cdot 3\end{array}$ & $\begin{array}{l}29.6 \\
24.8 \\
38.1 \\
20.6 \\
35.4 \\
30.8 \\
37.0 \\
41.9\end{array}$ & $\begin{array}{r}\text { I } 1.0 \\
9.9 \\
\text { I } 3.6 \\
4.9 \\
\text { I } 4.6 \\
\text { I } 3.5 \\
\text { I } 0.8 \\
\text { I } 5.9\end{array}$ \\
\hline $\begin{array}{l}\text { (Note } \\
\text { Changes) }\end{array}$ & & & & & Minera!s & & & $\begin{array}{l}\text { Minerals } \\
\text { \& } 86 \text { bb. N }\end{array}$ \\
\hline $\begin{array}{l}1884 \\
1885 \\
1886 \\
1887 \\
1888 \\
1889 \\
1890 \\
1891\end{array}$ & $\begin{array}{r}13.0 \\
15.3 \\
9.0 \\
14.9 \\
10.0 \\
12.3 \\
14.0 \\
13.8\end{array}$ & $\begin{array}{r}20.3 \\
23.0 \\
9.3 \\
19.0 \\
12.8 \\
13.0 \\
17.8 \\
23.1\end{array}$ & $\begin{array}{c}\overline{ } \\
\text { (fallow) } \\
34.8 \\
\\
\text { (fallow) } \\
32.0\end{array}$ & $\begin{array}{c} \\
\begin{array}{c}\text { (clover) } \\
25.6\end{array} \\
\\
\text { (beans) } \\
29.5\end{array}$ & $\begin{array}{c} \\
\begin{array}{c}\text { (clover) } \\
42.3\end{array} \\
\\
\text { (beans) } \\
42.3\end{array}$ & $\begin{array}{l}32.5 \\
40.1 \\
36.5 \\
34.8 \\
38.0 \\
40.5 \\
43.0 \\
48.5\end{array}$ & $\begin{array}{l}43 \cdot 5 \\
36.8 \\
42.4 \\
34 \cdot 5 \\
35 \cdot 3 \\
35 \cdot 5 \\
37 \cdot 6 \\
40.0\end{array}$ & $\begin{array}{l}35.0 \\
37.9 \\
44.6 \\
39.6 \\
33.9 \\
29.0 \\
37.3 \\
42.1\end{array}$ \\
\hline $\begin{array}{l}1892 \\
1893 \\
1894 \\
1895 \\
1896 \\
1897 \\
1898 \\
1899\end{array}$ & $\begin{array}{r}9.4 \\
9.8 \\
18.0 \\
10.0 \\
16.8 \\
8.9 \\
12.0 \\
12.0\end{array}$ & $\begin{array}{r}11.8 \\
13.5 \\
15.5 \\
15.5 \\
16.1 \\
7.0 \\
20.3 \\
15.8\end{array}$ & $\begin{array}{c}\overline{(\text { fallow) }} \\
2 \mathrm{I} .8 \\
\end{array}$ & $\begin{array}{c}\overline{ } \\
\text { (clover) } \\
23 \cdot 3 \\
\\
\text { (beans) } \\
30.3\end{array}$ & $\begin{array}{c}\overline{ } \\
\text { (clover) } \\
37.0 \\
\\
\text { (beans) } \\
40.3\end{array}$ & $\begin{array}{l}33 \cdot 4 \\
34 \cdot 3 \\
45 \cdot 5 \\
43 \cdot 9 \\
44.0 \\
37 \cdot 3 \\
38.0 \\
42 \cdot 5\end{array}$ & $\begin{array}{l}38.1 \\
21.8 \\
49.0 \\
40.0 \\
44.1 \\
37.0 \\
29.4 \\
39.1\end{array}$ & $\begin{array}{l}31.8 \\
19.5 \\
47.0 \\
32.6 \\
37.8 \\
27.5 \\
23.8 \\
37.5\end{array}$ \\
\hline $\begin{array}{l}1900 \\
1901 \\
1902 \\
1903 \\
1904 \\
1905 \\
1906 \\
1907\end{array}$ & $\begin{array}{c}12.3 \\
\text { I1 } .8 \\
\text { I } 3.3 \\
7.6 \\
4.2 \\
\text { I } 8.0^{1} \\
15.21 \\
9.1\end{array}$ & $\begin{array}{r}11.9 \\
14.7 \\
22.4 \\
14.0 \\
8.2 \\
12.9 \\
13.4 \\
14.3\end{array}$ & $\begin{array}{c}\ldots \\
\begin{array}{c}\text { fallow) } \\
20.3\end{array} \\
\\
\begin{array}{c}\text { fallow) } \\
16.3\end{array}\end{array}$ & $\begin{array}{c} \\
\begin{array}{c}\text { (clover) } \\
\text { 1 } 8.9\end{array} \\
\\
\text { (clover) } \\
2 \mathrm{I} .4\end{array}$ & 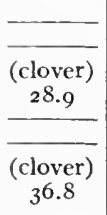 & $\begin{array}{l}33.3 \\
39.6 \\
41.5 \\
29.7 \\
22.3 \\
38.5 \\
43.6 \\
33.7\end{array}$ & $\begin{array}{l}44.0 \\
42.4 \\
45.2 \\
35.8 \\
24.9 \\
40.5 \\
47.5 \\
34.7\end{array}$ & $\begin{array}{l}34.9 \\
30.5 \\
33.5 \\
26.8 \\
24.1 \\
34.2 \\
43 \cdot 1 \\
34.7\end{array}$ \\
\hline 1908 & I 2.4 & 7.2 & & $-\ldots$ & $\ldots$ & $3^{8.6}$ & $47 \cdot 5$ & $3^{8.1}$ \\
\hline
\end{tabular}

${ }^{I}$ Actual yield on half-plot after fallow (in making average, only $\frac{3}{4}$ of these yields are used). 
yield for the succeeding years is greater than the average of all, excluding, of course, the yields eliminated.

The data recorded will be especially useful for working out assigned problems, and it has been brought together from several different publications, and the complete records are made possible only through the kindness of Director Hall of Rothamsted, who has furnished the author with some unpublished data.

The last column in Table 62 shows in greater detail about the same fact as is well illustrated in the data from the twin plots, I 7 and 18 , in Table 6o; namely, that commercial nitrogen must be utilized by the crop for which it is applied, or it will be largely lost in drainage water.

While plot $\mathrm{I} 6$ received $\mathrm{I} 72$ pounds of nitrogen in 800 pounds of ammonium salts per annum for 13 years ( $185^{2}$ to 1864 ), and produced 39.5 bushels of wheat per acre as an average for those years, there is apparently but little residual effect except for one year after the application was discontinued, the average yields of the I9 years without fertilizers being 14.6 bushels of wheat and 1400 pounds of straw per acre.

The following statement will be of some interest in this connection:

Table 63. Wheat Yields on Broadbalk Field, Rothamsted Thirteen Years' Average, I852-1864

\begin{tabular}{|c|c|c|c|c|c|c|}
\hline \multirow{2}{*}{$\begin{array}{l}\text { Plot } \\
\text { No. }\end{array}$} & \multirow{2}{*}{\multicolumn{2}{|c|}{ SoIl Treatment applied Every Year }} & \multirow{2}{*}{$\begin{array}{c}\text { Nitrogen } \\
\text { PER } \\
\text { Acre } \\
\text { (Lb.) }\end{array}$} & \multirow{2}{*}{$\begin{array}{l}\text { Total } \\
\text { SALTS } \\
\text { PER } \\
\text { ACRE } \\
\text { (Lb.) }\end{array}$} & \multicolumn{2}{|c|}{ Yields PER ACRE } \\
\hline & & & & & $\begin{array}{l}\text { Wheat } \\
\text { (Bu.) }\end{array}$ & $\begin{array}{l}\text { Straw } \\
\text { (Lb.) }\end{array}$ \\
\hline 5 & Minerals (P, K, Mg, Na, S) & . & None & 792 & I8.3 & I 862 \\
\hline 6 & Minerals and ammonium salts & . & 43 & 992 & 28.6 & 3038 \\
\hline 7 & Minerals and ammonium salts & . & 86 & I I 92 & $37 . \mathrm{I}$ & 4270 \\
\hline 8 & Minerals and ammonium salts & - & I 29 & I 392 & 39.0 & 4788 \\
\hline 16 & Minerals and ammonium salts & . & 172 & I 592 & $39 \cdot 5$ & $\dot{5} 222$ \\
\hline
\end{tabular}

While the second addition of nitrogen produced almost as large an increase as the first, the third addition gave but little increase of grain, and the fourth still less, although the yield of straw was very appreciably increased, even by the fourth increment of nitrogen.

For convenience a general summary of some of the more impor- 
tant data relating to wheat yields at Rothamsted is given in Table 64:

TABLE 64. Wheat Yields at RothaMsted

Wheat, Bushels per Acre, Averages

\begin{tabular}{|c|c|c|c|c|c|c|c|c|}
\hline F1ELD. $\cdot \cdot \cdot \cdot$ & $\begin{array}{c}\text { BROAD- } \\
\text { BALK }\end{array}$ & Hoos & AgDell & AgDeLl & AGDELL & $\underset{\text { BALK }}{\text { BROAD- }}$ & $\begin{array}{c}\text { BROAD- } \\
\text { BALK }\end{array}$ & $\begin{array}{l}\text { BROAD- } \\
\text { BALK }\end{array}$ \\
\hline Crop System . . & $\begin{array}{l}\text { Wheat } \\
\text { Every } \\
\text { Year: } \\
\text { Plot } 3\end{array}$ & $\begin{array}{l}\text { Wheat and } \\
\text { Fallow } \\
\text { Alternating }\end{array}$ & $\begin{array}{c}\text { Turnips, } \\
\text { Barley, } \\
\text { Fallow, } \\
\text { Wheat }\end{array}$ & $\begin{array}{l}\text { Turnips, } \\
\text { Barley, } \\
\text { Legume, } \\
\text { Wheat }\end{array}$ & $\begin{array}{l}\text { Turnips, } \\
\text { Barley, } \\
\text { Legume, } \\
\text { Wheat }\end{array}$ & $\begin{array}{l}\text { Wheat } \\
\text { Every } \\
\text { Year: } \\
\text { Plot } 2\end{array}$ & $\begin{array}{l}\text { Wheat } \\
\text { Every } \\
\text { Year: } \\
\text { Plot } 8\end{array}$ & $\begin{array}{l}\text { Wheat } \\
\text { Every } \\
\text { Year: } \\
\text { Plot I6 }\end{array}$ \\
\hline Soil Treatment & None & None & None & None & $\begin{array}{l}\text { Phos- } \\
\text { phorus }\end{array}$ & $\underset{\text { Manure }}{\text { Farm }}$ & $\begin{array}{c}\text { Minerals } \\
\text { and } \\
129 \mathrm{lb} . \mathrm{N}\end{array}$ & $\begin{array}{l}\text { Minerals } \\
\text { and } \\
7_{2} \text { lb. } \mathrm{N}\end{array}$ \\
\hline I844-I85I . & I 7.4 & & & & & 28.0 & & 30.8 \\
\hline I85I & I 5.9 & (fallow) & 30.5 & 28.5 & 28.0 & 29.6 & & \\
\hline I852-I867 & I 4.8 & $25.2^{1}$ & & - & - & 35.0 & $3^{8} \cdot 3$ & $39 \cdot 5^{2}$ \\
\hline I855,' $59,6_{3},{ }^{\prime} 67$ & I 5.4 & $23 \cdot 5$ & $3^{6.3}$ & $3 I .4$ & 31.2 & 35.6 & 38.1 & $4 I^{3}$ \\
\hline (Note Change) & & & & & & & & None \\
\hline $\begin{array}{l}\text { I868-I88, } \\
\text { I871, '75, '79, '83 }\end{array}$ & $\begin{array}{r}\text { I I. } 4 \\
9.2\end{array}$ & $\begin{array}{l}13.7 \\
12.4\end{array}$ & I9.9 & 20.5 & $\overline{25.8}$ & $\begin{array}{l}32.0 \\
29.8\end{array}$ & $\begin{array}{l}34.1 \\
30.1\end{array}$ & $\begin{array}{l}\text { I } 3.3 \\
\text { II.I }\end{array}$ \\
\hline (Note Changes) & & & & & Minerals & & & $\begin{array}{l}\text { Minerals } \\
\text { and } \\
86 \mathrm{lb} . \mathrm{N}\end{array}$ \\
\hline $\begin{array}{l}\text { г884-г } 899 \\
\text { г887,'9г,'95, ;99 }\end{array}$ & $\begin{array}{l}\text { I } 2.5 \\
\text { I } 2.7\end{array}$ & $\begin{array}{l}\text { I } 5.9 \\
\text { I } 8.4\end{array}$ & 28.9 & 27.2 & 40.5 & $\begin{array}{l}39.6 \\
42.4\end{array}$ & $\begin{array}{l}37.8 \\
38.4\end{array}$ & $\begin{array}{l}34.9 \\
3^{8} .0\end{array}$ \\
\hline I900-I907 & 10.4 & 14.0 & $\ldots$ & - & 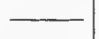 & $35 \cdot 3$ & $39 \cdot 4$ & 32.7 \\
\hline I903-1907 & 8.4 & I 4.2 & I8. 3 & 20.2 & 32.9 & $3 \mathrm{I} \cdot 7$ & $35 \cdot 3$ & 30.8 \\
\hline $\begin{array}{l}\text { I } 844-1875 \\
\text { I } 876-\text { I907 }\end{array}$ & $\begin{array}{l}\text { I } 4.8 \\
\text { II. } 5\end{array}$ & $\begin{array}{l}2 I .4 \\
\text { I } 4.7\end{array}$ & $\begin{array}{l}30.2 \\
24.5\end{array}$ & $\begin{array}{l}28.1 \\
23.6\end{array}$ & $\begin{array}{l}29 \cdot 3 \\
34.8\end{array}$ & $\begin{array}{l}33 \cdot 4 \\
35.8\end{array}$ & $\begin{array}{l}37.5 \\
36.8\end{array}$ & \\
\hline I844-I907 & I $3 . I$ & I 7.5 & 27.2 & $25 \cdot 7$ & 32.2 & 34.6 & $37 \cdot 1$ & \\
\hline
\end{tabular}

${ }^{1}$ Average of ${ }_{15}$ crops. ${ }^{2}$ Average of ${ }_{13}$ crops (18 $52-1864$ ).

${ }^{3}$ Average of 3 crops ( 1855 , '59, '63).

In Table 64 , the average wheat yields from the plots indicated are grouped in two ways. 'First are given the averages of all years for those plots or twin plots (on Hoos field) which furnish a continuous record; and, second, the averages are given only for those years when wheat was grown on Agdell field. 


\section{INVESTIGATION BY CULTURE EXPERIMENTS}

There are a preliminary and a final period of 8 years each, and three 16 -year periods intervening. These figures show that the middle I6-year period (I868-I883) gives averages clearly below the normal, and that the average of the four years within that period are still lower, thus proving that even two I6-year periods may not positively establish by crop yields whether land is growing better or poorer. A comparison of the first and second i6-year periods indicates that all plots are growing poorer; while a comparison of the second and third i6-year periods indicates that all plots are growing better.

In the lower part of Table 64 are recorded the average yields for all wheat crops grown in two 32 -year periods, and these figures are the best that can be secured. They show decreases of 6.7 bushels with the wheat and fallow plot (Hoos field), 5.7 bushels with the fallow system, and 4.5 bushels with the legume system, on Agdell field, and 3.3 bushels decrease with unfertilized continuous wheat, which, however, is a greater percentage decrease than on either of the Agdell plots. It should be kept in mind, however, that wheat is the only profitable crop now grown on the unfertilized Agdell plots. The yields increased slightly on the farm manure plot and very considerably where minerals and legumes were used on Agdell field.

Finally, in the last line, are recorded the general average of all wheat crops grown on these plots since the experiments were begun, with extremes differing by 24 bushels, a difference which in 64 years amounts to 1500 bushels more wheat from the application of plant food than could be obtained without it, in the same system of cropping.

Table 65 gives, in brief, some of the very interesting and valuable weather records of Rothamsted, and for comparison is given the very trustworthy average rainfall records for northern, central, and southern Illinois, and Tennessee, as representing a wide range of latitude in central United States, with the average precipitation (including snow measured as water) varying from 33.48 inches in northern Illinois to 53.69 in Tennessee. (See also map showing average annual precipitation in the various parts of the United States.)

The 50-year record gives practically 28 inches as the average 


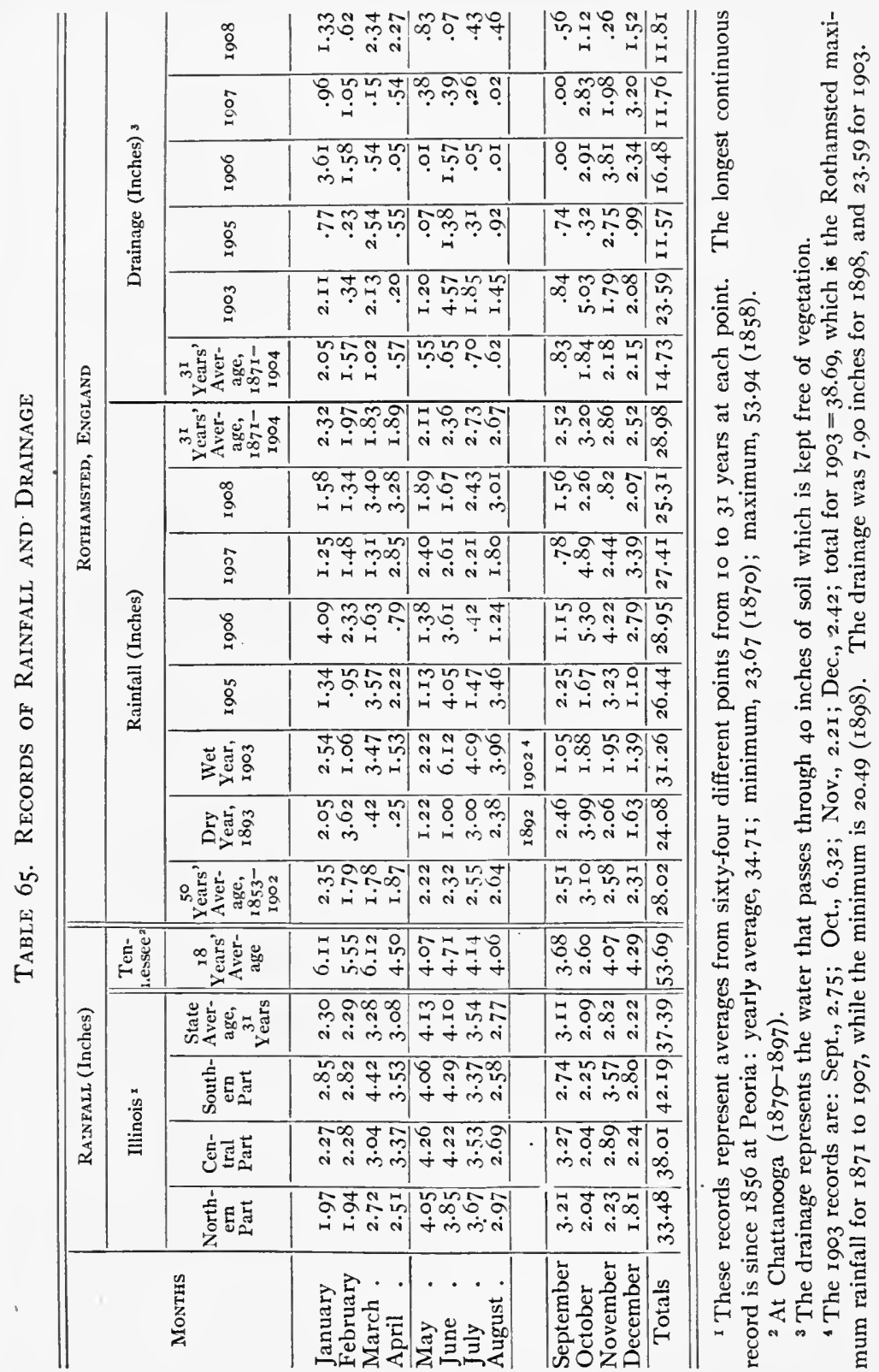




\section{INVESTIGATION BY CULTURE EXPERIMENTS}

annual rainfall at Rothamsted, and of this amount 5 opercent passes off in drains, at a depth of 40 inches, and 50 per cent is evaporated, from a soil kept free of vegetation. Roughly, the evaporation from a bare soil may be regarded as a constant, to be subtracted from the rainfall to find the drainage (and run-off, if any). Thus, if we regard 14.25 inches as the constant for evaporation at Rothamsted, the drainage should be 6.24 inches for 1898 and 24.44 inches for I $90_{3}$, while the actual records show 7.90 and 23.59 inches, respectively.

Of course the evaporation can be markedly reduced by cultivating the surface as soon as practicable after each rain, in order to destroy the capillary connection and to maintain a dust mulch, and thus largely preventing the rise of moisture to the surface. On the other hand, evaporation is greatly increased by growing crops, so that during the growing season the drainage would be less on the ordinary field than from the bare soil. ${ }^{1}$

\section{Barley Every Year on Hoos Field, Rothamsted}

Table 66 presents in summarized form the data secured from Hoos field, where barley has been grown every year since $185^{2}$. These experiments help to answer some important questions concerning which neither Agdell nor Broadbalk give any information. The yields, as an average of 55 years, vary from 14.8 bushels on the unfertilized land, and I $5.7_{\text {bushels where only the sulfates }}$ of potassium, magnesium, and sodium were used, to 43.9 bushels with sodium nitrate and acid phosphate, and 47.7 bushels with farm manure ( 5.7 tons a year).

As an average of the 30-year and 25-year periods, the yields have decreased nearly io bushels per acre on all plots receiving nitrogen, undoubtedly because the 43 pounds of nitrogen was not sufficient for larger crops, after deducting losses by leaching. It will be remembered that the second addition of 43 pounds of nitro-

"Ingle reports some computations in his "Manual of Agricultural Chemistry," page 76 , in which the drainage is reckoned at about 86 inches; but probably the intention was to use 8.6 inches, which would reduce his estimated "enormous loss of phosphoric acid" to a very insignificant amount quite in harmony with other data, such as he gives on page 77 . 
gen on Broadbalk produced 9.0 bushels of wheat per acre. A 40bushel crop of barley would remove in the grain and straw about 56 pounds of nitrogen, in accordance with the average of many analyses; so that, where 40-bushel crops are produced with only 43 pounds of nitrogen supplied, the soil is now being exhausted of its nitrogen content about as rapidly as on the unfertilized land: According to the analyses reported by Dyer, the nitrogen content of the soil to a depth of 27 inches decreased by 528 pounds per acre on plot $\mathrm{A}_{4}$ and by $84 \mathrm{I}$ pounds on plot $\mathrm{N}_{4}$ during the $\mathrm{I} 4$ years from I868 to $\mathrm{I} 882$, while the nitrogen content of plot $\mathrm{O}_{4}$ actually increased by 8 I pounds per acre.

This problem is complicated by the fact that there is often considerable growth of leguminous weeds (especially of yellow trefoil) on plot $\mathrm{O}_{4}$. The decrease in yield from 24.2 to ${ }_{5} 5.5$ bushels certainly does not harmonize with any actual increase in the nitrogen content of plot $\mathrm{O}_{4}$, but it seems very certain that the nitrogen content of plots $\mathrm{A}_{4}$ and $\mathrm{N}_{4}$ was drawn upon during the $\mathrm{I}_{4}$ years at the rate of 40 to 50 pounds a year, of which probably one half is lost in drainage, as an average.

In the lower part of Table 66 are recorded some computed effects for different elements under different conditions. Of course, many other similar computations could be made from the data. In computations of this sort, the first effect should be determined for the most limiting element, the next effect for the second limiting element, etc. While it is of interest to compute the effect of applying the most limiting element where all others have been applied, the result has no practical significance, because every application should pay for itself.

It is evident that nitrogen is the most limiting element for barley on Hoos field, because the ammonium salts produce a greater increase alone than either acid phosphate or alkali salts. Phosphorus is as clearly the second limiting element.

While the alkali salts alone had some power to increase the yields during the earlier years (probably due to their power to liberate phosphorus or encourage nitrification), their stimulating action during those years is indicated by reduced yields during the later 25-year period when plot $\mathrm{O}_{3}$ produced less than $\mathrm{O}$. Exactly the same conditions appear where alkali salts have been added to acid 


\section{INVESTIGATION BY CULTURE EXPERIMENTS}

年

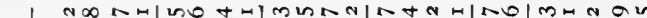

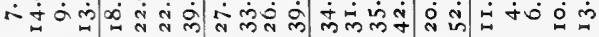

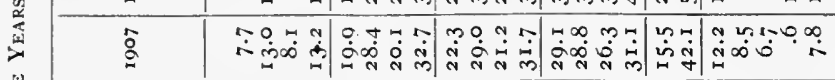
点

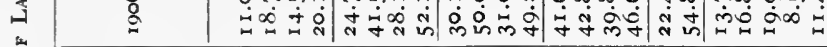
n 2 \%

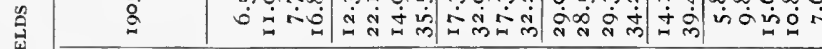

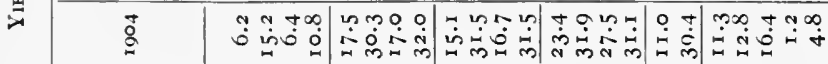

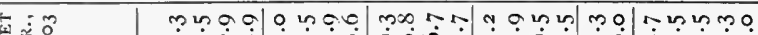
Z $\approx=m \quad$ \%๐ a $=-\infty$

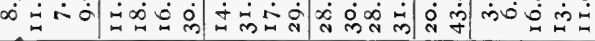

$\mid$ mon

䑸

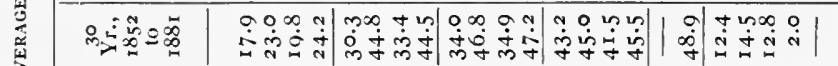

भूँ

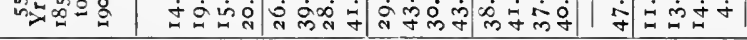

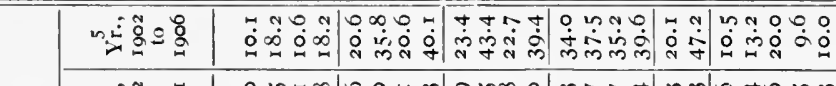

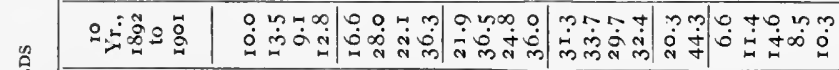
o 㐾

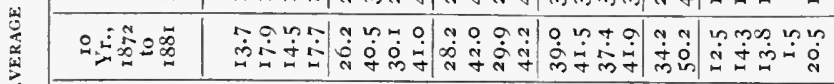

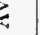

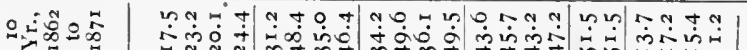

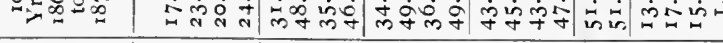

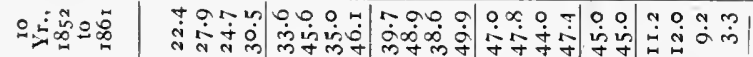

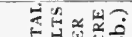

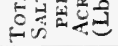

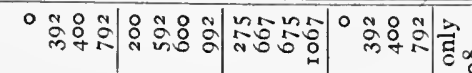

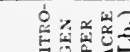

党

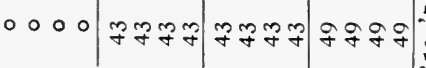
$\%$

管

\begin{tabular}{|c|c|c|c|}
\hline$\circ \circ \circ \circ$ & 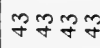 & 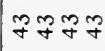 & gq $q g$ \\
\hline
\end{tabular}




\begin{tabular}{|c|c|c|c|c|c|c|c|c|}
\hline \multirow{6}{*}{ 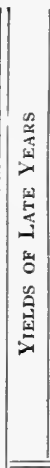 } & $\begin{array}{l}\infty \\
\stackrel{2}{\circ} \\
2\end{array}$ & 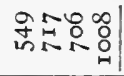 & 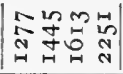 & 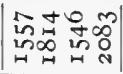 & 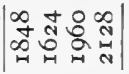 & 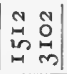 & $\mid \begin{array}{c}\infty \\
N \\
N\end{array}$ & \\
\hline & s. & $\left|\begin{array}{ccc}0 & \infty & N \\
0 & 1 & N \\
0 & 0 & N \\
1 & N\end{array}\right|$ & 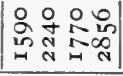 & 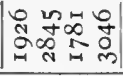 & 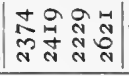 & $\left|\begin{array}{cc}n & 0 \\
0 & 1 \\
0 & 9 \\
7 & 4\end{array}\right|$ & & \&్ \\
\hline & $:$ & $\left|\begin{array}{cc}n & 1 \\
\infty & N \\
\infty & N \\
n-1\end{array}\right|$ & 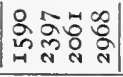 & 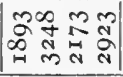 & 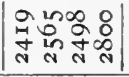 & $\left|\begin{array}{ll} \pm & m \\
m & 0 \\
7 & m\end{array}\right|$ & in & 늠 \\
\hline & $\check{0}$ & $\begin{array}{ll}0 & m \\
\infty & m \\
m & m\end{array}$ & 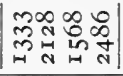 & 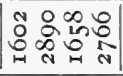 & 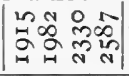 & $\left.\mid \begin{array}{ll}2 & 0 \\
8 & 0 \\
0\end{array}\right]$ & 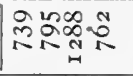 & ᄋे \\
\hline & & O & 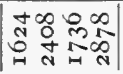 & 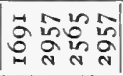 & 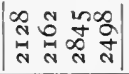 & 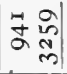 & 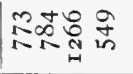 & 음 \\
\hline & & $\begin{array}{c}a \\
1 \\
10 \\
-1\end{array}$ & 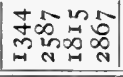 & 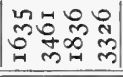 & 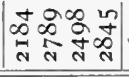 & \begin{tabular}{ll}
$+\infty$ \\
\multirow{3}{*}{} & $\infty$ \\
0 & 0 \\
\end{tabular} & 渋 & 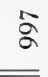 \\
\hline \multirow{3}{*}{ 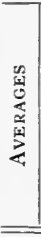 } & 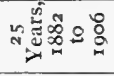 & & 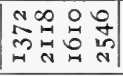 & 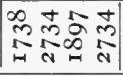 & 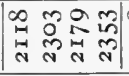 & 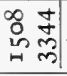 & & \\
\hline & 일 & $\begin{array}{ll}0 & 0 \\
0 & \infty \\
-1 & 0\end{array}$ & 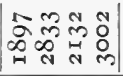 & 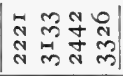 & 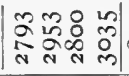 & 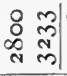 & $\operatorname{loc}$ & 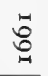 \\
\hline & น & 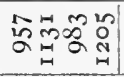 & 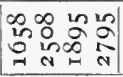 & 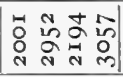 & 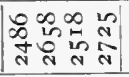 & $\begin{array}{ll}m & m \\
& \infty \\
N & m\end{array} \mid$ & 궁요 & \\
\hline \multirow{6}{*}{ 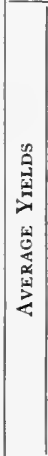 } & 的曾 & 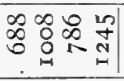 & 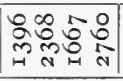 & 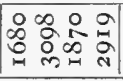 & 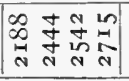 & 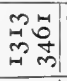 & 里蛋学 & \\
\hline & & 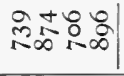 & 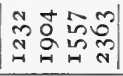 & 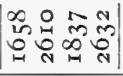 & 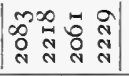 & 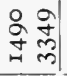 & $2 N$ & \\
\hline & $\circ$ & 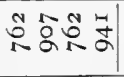 & 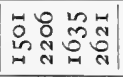 & 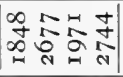 & 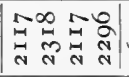 & 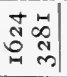 & 능츄 & $\stackrel{\infty}{\infty}$ \\
\hline & 일 & ミ゙ュำ & 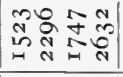 & 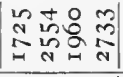 & 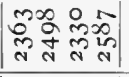 & 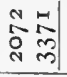 & 웅 & §ิ \\
\hline & 点 & $\begin{array}{ll}\infty & \Xi \\
g & \Xi \\
z & \Xi\end{array}$ & 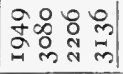 & 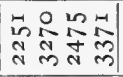 & 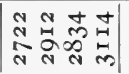 & $\begin{array}{l}\stackrel{q}{q} \\
\stackrel{+}{m} \\
m \\
m\end{array}$ & $\stackrel{-1}{=}$ & کָ \\
\hline & ᄋ & 0 & 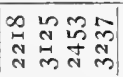 & $\infty$ & 0 & 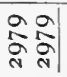 & 송 & \\
\hline
\end{tabular}

告 总完 | 


\section{$3^{82}$ INVESTIGATION BY CULTURE EXPERIMENTS}

phosphate (compare $\mathrm{O}_{2}$ and $\mathrm{O}_{4}$ for the 30-ycar and 25-year periods).

Where nitrogen has been applied without phosphorus, the stimulating effects of the alkali salts is still apparent, probably because they continue to liberate some phosphorus from the soil. Where both nitrogen and phosphorus are provided, the effect of the alkali salts is most marked, and here it is increasing, very possibly because all of the potassium needed by the larger crops is not liberated from the soil on account of lack of decaying organic matter. Here it will be scen, however, that the sodium in sodium nitrate without potassium (plot $\mathrm{N}_{2}$ ) produces even better results than the alkali salts, including potassium (plots $\mathrm{A}_{4}$ and $\mathrm{N}_{4}$ ), but this comparison is complicated by the fact that ammonia nitrogen and nitrate nitrogen may have different effects, and the chlorin and sulfate radicle may also produce some effect.

It is of special interest to compare the marked residual effect of farm manure on plot $7-\mathrm{I}$, Hoos field, with the absence of such an effect from the heavy applications of commercial fertilizers (including $I_{72}$ pounds of nitrogen) on plot 16 of Broadbalk field. (See Table 62.) However, it should be kept in mind that plot $7-1$ received $3 \mathrm{I} 4$ tons of manure during the 20 years ( $185_{2}$ to $\mathrm{I} 87 \mathrm{I}$ ), which is equivalent to almost 6 tons per acre a year for the entire 55 years.

At 40 cents a bushel for barley, the manure applied to plot $7^{-2}$ has been worth about 85 cents a ton, while that applied to plot $7^{-I}$ has already paid $\$$ I.36 a ton for itself, not deducting interest on investment or counting the remaining residual effect, plot $\mathrm{O}_{\overline{\mathbf{i}}}$ bcing used as the basis for comparison.

A comparison of plots $\mathrm{N}_{2}$ and $7^{-2}$ shows the marked superiority of the farm manure in a dry season (I893), while the commercial fertilizers give nearly as good results in normal or wet seasons, and probably would surpass the farm manure if the nitrogen were increased sufficiently.

If the 43 pounds of nitrogen cost $\$ 6.45$ and the 29 pounds of phosphorus $\$ 3.48$, and if barley is worth 40 cents a bushel, the ammonia nitrogen has left a deficit of \$1.97 a year for the 55 years, while phosphorus, in addition to nitrogen, has overcome $\$ 1.92$ of the deficit, leaving a net loss of 5 cents per acre per annum. 
The nitrate nitrogen practically paid for itself as an average of the first 30 years, but left a deficit of about \$I a year for the subsequent 25-year period, of which, moreover, the last is years show an annual loss of \$I.49.

Phosphorus added to nitrate has paid for itself and 60 per cent net profit as an a verage of the 55 years, and the effect of phosphorus is apparently increasing where applied in this connection, which practically amounts to using it in addition to both nitrogen and potassium, assuming that the sodium has power to liberate potassium from the soil. If the nitrogen were secured from the air by clover, and if the potassium were liberated from the soil also by clover, plowed under directly or in manure, it is easy to see that applied phosphorus would be still more profitable, especially if the 29 pounds were applied in raw natural phosphate at a cost of 87 cents instead of in acid phosphate costing $\$ 3.48$.

It should be remembered always that computations based upon increases compared with the yields from unfertilized land may indicate profits that would not be wholly realized if the total yield of the unfertilized land is not sufficient to pay for its own cost. In other words, if it costs more than the value of I 4.8 bushels of barley to secure that yield, then the financial deficit from the unfertilized land must also be overcome before any profit can be had from the use of fertilizers.

Furthermore, in planning systems of permanent agriculture, we must also consider whether the apparent increasing gains are due solely to improvement resulting from soil treatment, or in part to the general depletion of the unfertilized land. Probably nothing is more difficult for the average landowner to realize than that what appears to be profit is in part at least taken from his own capital. This is very clearly illustrated in the Hoos barley experiments. Thus, with nitrogen on plot AI, during the I 5 years (I892 to I906), there appears to be an average increase in yield of nearly 8 bushels per acre above the unfertilized yield; but, by referring to the average for the first Io years ( $185^{2}$ to 1861 ), it will be seen that the unfertilized yield has decreased by more than 12 bushels. On this basis, as an average of the last 25 years, the apparent increase from nitrogen is wholly represented in the decrease in productive power, and consequently in the decrease in value, of the unfertilized land. 


\section{Potatoes Every Year on Hoos Field, Rothamsted}

On another part of Hoos field potatoes were grown every year for 26 years (I876-I90I). There were several changes in the varieties grown, so that but little importance, at most, should be attached to the yields in successive periods as indicating decreasing or increasing fertility, except in those cases where the change is so regular and so marked as to leave no room for doubt. It is especially to be kept in mind that the variety "White Beauty of Hebron" was grown only during the last five years (I897-I90I). During the previous $2 \mathrm{I}$ years the varieties grown were "Rock" for 4 years, "Champion" for II years, "Sutton's Abundance" for 5 years, and "Bruce" for one year, and, in this order, from I 876 to I 896 . Thus, the two five-year periods from 1882 to I89I should be comparable, but, of course, seasonal variation renders even that possible comparison of doubtful value.

The special object of the experiment was to ascertain the effect upon the yield of potatoes of different fertilizing materials, as indicated in Table 68, which shows the general plan, the treatment applied, and the yields obtained each year.

One of the points most clearly indicated by the data in Table 68 is that "White Beauty of Hebron," grown from I897 to I90I, was a very poor yielding variety.

It may be said that 1879 was an exceedingly wet year at Rothamsted, the rainfall being $2.79,3.48,5.55,4.24$, and 6.56 inches for the respective months April to August.

In any consideration of these potato experiments, it should be kept in mind that potatoes are a market-garden crop, and constitute one form of intensive agriculture. An annual investment of $\$ 25$ to $\$ 40$ an acre for fertilizing materials is not beyond consideration for a crop that may yield 300 bushels, that may be worth $\$_{150}$ an acre.

In the last lines of Table 68 are given the average yields for the first 6-year period and for the four successive 5 -year periods, and, finally, the average for the 26 -year period, followed by the several averages for the value of the increase and the cost of treatment.

Since New York leads in the production of potatoes, the price 
used in these computations is 50 cents a bushel $(57.6$ cents being the Io-year average farm price for New York State, and also for Ohio), and the cost of manure is figured at \$2 a ton; but these figures should always be modified to meet average local conditions. They only help to summarize the results so as to bring to mind their economic importance.

Thus, at the prices named, the treatment applied to plot 4 has cost $\$ 35.32$ a year, and the increase produced has been worth $\$ 70$ a year, or sufficient to pay the cost and leave practically roo per cent net profit.

The ammonium salts on plot 5 have paid but half their cost, and the sodium nitrate alone has but slightly more than paid for itself. By far the largest returns for money invested has been from acid phosphate on plot 9, which has paid for itself and added more than 600 per cent net profit as an average of the 26 years. Indeed, the acid phosphate alone exactly doubled the average yield of 26 years.

The alkali minerals, including 300 pounds of potassium sulfate, Ioo pounds of magnesium sulfate (Epsom salt), and roo pounds of sodium sulfate (Glauber salt), have not paid their cost when used in addition to acid phosphate, the average annual increase of plot Io over plot 9 being only 7 bushels, and the annual cost $\$ 7.90$.

The largest average yield and the largest net profit per acre is from plot 8 , which produces as much on one acre as were grown on four acres of untreated land. It should be noticed, however, that, during the last io years of the experiment, the farm manure plots, 3 and 4 , have forged ahead of the complete chemical fertilizers on plots 7 and 8 .

Director Hall makes the following statements in his book on "Rothamsted Experiments" (I905):

"In the Hoos field, experiments upon potatoes were begun in 1876 , and continued for twenty-six years; they were then discontinued, because the crop on the plots receiving no organic manures had fallen to a very low ebb in consequence of the deterioration of the texture of the soil. But on the plots receiving farmyard manure, and even on those receiving only a complete artificial manure (plots 7 and 8), the crop was maintained in favorable seasons. No falling off was observed which could be attributed to the land having become 'sick' through the continuous growth of the same crop, or through the accumulation of disease in the soil." 


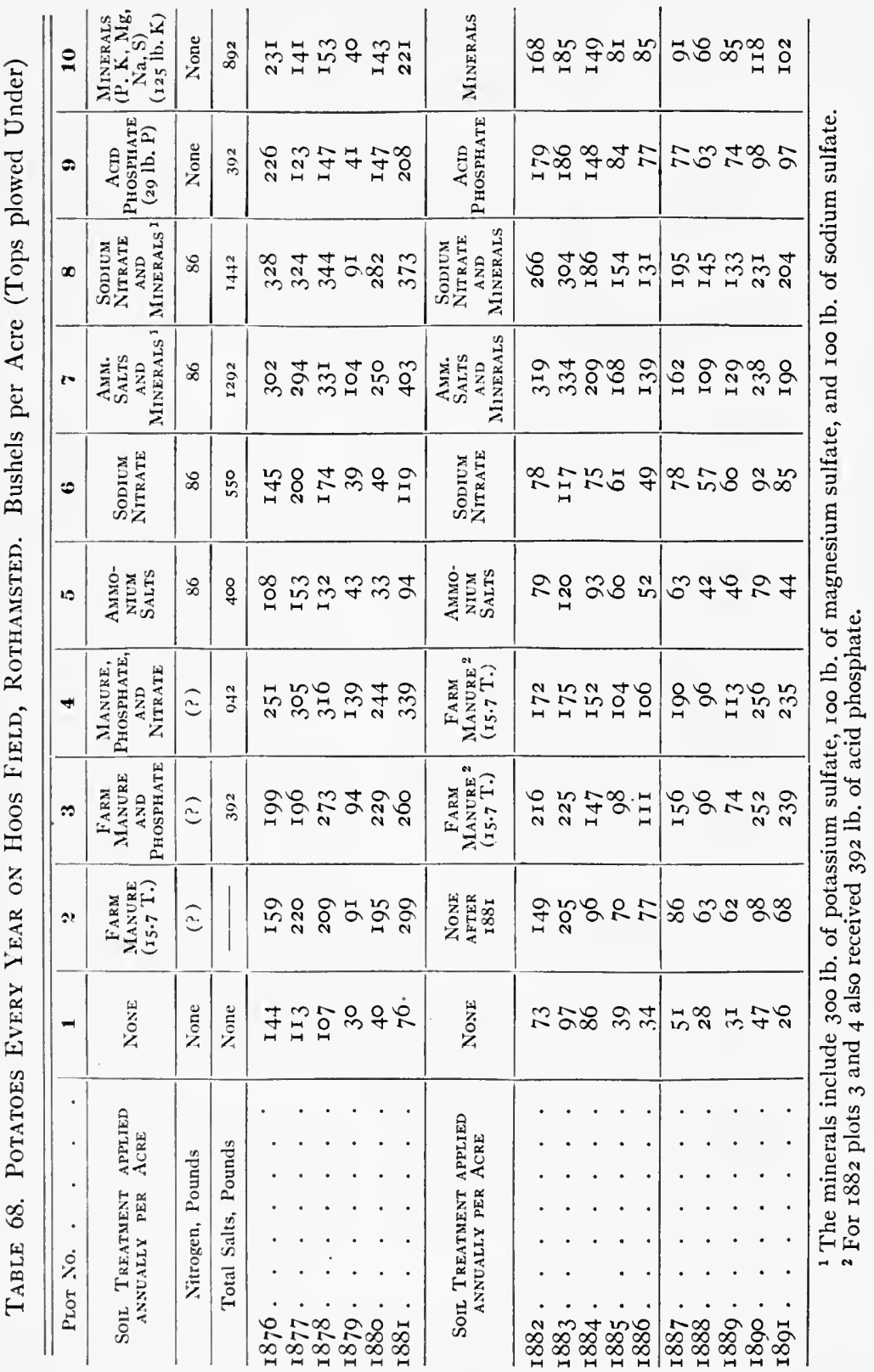




\begin{tabular}{|c|c|c|c|c|c|c|c|}
\hline$\varrho$ & 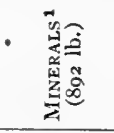 & 毕 & 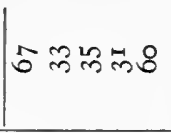 & $\stackrel{20}{n \rightarrow 1}$ & $\underset{\sim}{m} \alpha 2 \infty$ & 尺. & 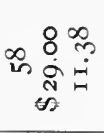 \\
\hline 0 & 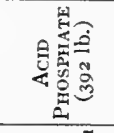 & రం & 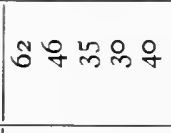 & $\stackrel{g}{q}$ & 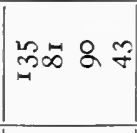 & Õ & 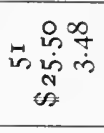 \\
\hline$\infty$ & 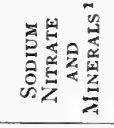 & 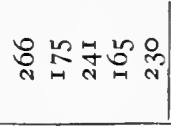 & 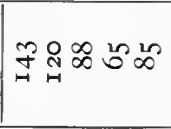 & ฉ) & 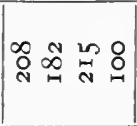 & \%) & 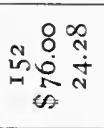 \\
\hline$x$ & 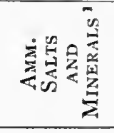 & ¿̊ำ & 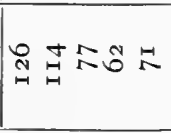 & $\underset{\sim}{\infty}$ & స్రా & a & 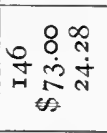 \\
\hline 0 & 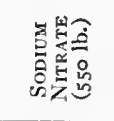 & ${ }_{N}^{\infty} g \underset{H}{\infty} \sin$ & 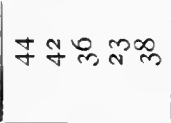 & $\underset{\sim}{\stackrel{O}{N}}$ & $0+\infty \approx$ & 9 & 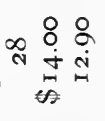 \\
\hline to & 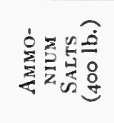 & 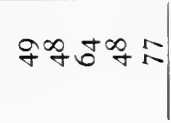 & 유요 9 in & ప & $\rightarrow$ 는 & రా & $m$ in \\
\hline+ & 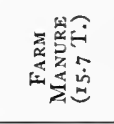 & 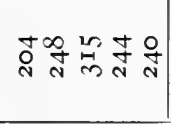 & 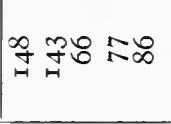 & రి & 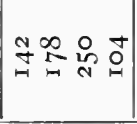 & a & 욤요 \\
\hline$\infty$ & 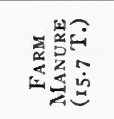 & ज્ञ & テ & ฉ్ & 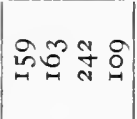 & $\stackrel{\infty}{N}$ & 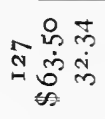 \\
\hline 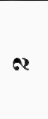 & 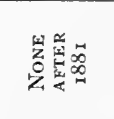 & ลูธี กษ์ & 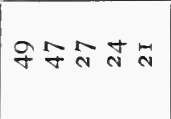 & $\stackrel{8}{0}$ & 음용. & סิ & 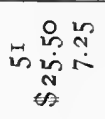 \\
\hline-1 & 㣺 & m & กั กัน & $\infty$ & $\because \approx$ 움 & जิ & 11 \\
\hline $\begin{array}{l}\cdot \\
\cdot \\
\dot{0} \\
\dot{2} \\
\dot{0} \\
\dot{0}\end{array}$ & 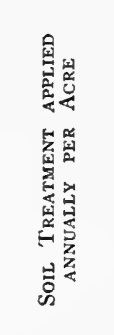 & 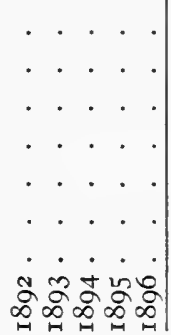 & 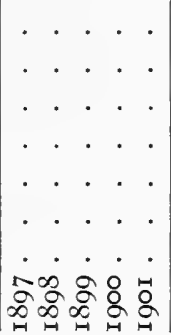 & 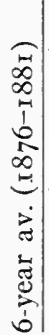 & 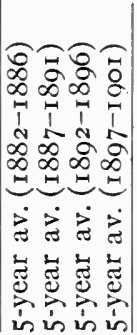 & 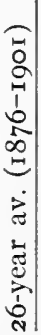 & 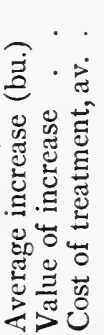 \\
\hline
\end{tabular}




\section{INVESTIGATION BY CULTURE EXPERIMENTS}

It should be noted that the average yields on plots 3,4 , and 8 increased during the fifteen years previous to the last five, when the "Beauty of Hebron" variety was introduced; and, as an average, the farm-manure plots yielded higher during the five years ending 1896, than during the six years beginning 1876 , notwithstanding the addition of acid phosphate during the earlier period.

During the first six years the use of $\$ 150$ worth of plant food on plot 8 produced $\$ 61_{5}$ worth of potatoes, above the 85 -bushel yield on the untreated land, which is also the ro-year average yield of potatoes for New York State. Even when used in addition to manure, during the first six years, acid phosphate, as well as phosphate and nitrate, paid roo per cent net profit on the investment; but no test was made with manure and nitrate without phosphate.

These Rothamsted data furnish no information concerning the effect of potassium, except that it failed to pay its cost on plot Io. It might be said that all but 9 bushels of the I96-bushel increase on plot 7 should be credited to the minerals (compare plot 5 ), but how much of this increase would have been produced by acid phosphate and ammonium salts is not revealed; on the other hand, nitrogen must be credited with the increase from plot 7 above plot Io; all of which means that phosphorus is the first limiting element and nitrogen the second, for the growth of potatoes on this normal soil.

To maintain satisfactory soil texture and to provide for the liberation of potassium, magnesium, etc., from the immense supply in the soil, liberal applications of manure should be made, and for the improvement of the subsoil the growing of clover in rotation will produce benefits that manure cannot produce. On the other hand, in such intensive agriculture, there is large profit in a moderate use of commercial nitrogen, especially in such form as sodium nitrate, which also furnishes sodium as a soil stimulant.

Whether one should use raw phosphate or acid phosphate, in connection with the manure, clover, and sodium nitrate, is not established, but the Rhode Island and Wisconsin data indicate that potatoes are able to utilize the raw phosphate to some extent, and (in Rhode Island) even without adequate provision for decaying organic matter. It would seem advisable, however, to use the acid phosphate until the raw rock has been more thoroughly tested for potatoes, especially considering that the expense for phosphorus, 
even in acid phosphate, is one of the smallest items in the production of this expensive and valuable crop.

\section{Residual Effect of Fertilizers on Hoos Field}

Any one who has made himself acquainted with the 26-year potato experiments on Hoos field will naturally be interested in the further history of those plots. The data reported since IgOI are given in Table 69, following a summary of the soil treatment and potato yields.

The barley yields for I902 are in harmony with the common experience that potatoes leave an excellent seed bed for a succeeding crop of barley or wheat; and the residual effect for one year is also very marked where nitrogen has been applied, as was the case with continuous wheat on plot I6 of Broadbalk field. Even the first barley crop on plots 9 and Io are no better than on plots I and 2, clearly showing that nitrogen was the limiting element for the quickgrowing barley crop. Aside from the farm-manure plots, much less residual effect is apparent after 1902; and, in all cases where the treatment is comparable, the barley yields of these plots in I 903 were less than on corresponding plots in the same field (Hoos) where barley had been grown every year for more than half a century.

If we keep in mind that nine of the eighteen plots of continuous barley produced more than $3^{6}$ bushels per acre in 1902, also that four of the ten plots where potatoes had been grown for 26 years produced less than $3^{6}$ bushels of barley in I902, and that the largest average yield of potatoes from the farm-manure plots (3 and 4 ), either for one year or for five years, was secured after potatoes had been grown on the same land every year for more than fifteen years, then the following statement by Whitney seems clearly inapplicable:

"One of the most interesting instances going to show that toxic substances are formed and that what is poisonous to one crop is not necessarily poisonous or injurious to another is a series of experiments of Lawes and Gilbert - the growing of potates for about fifteen years on the same field. At the end of this period they got the soil into a condition in which it would not grow potatoes at all. The soil was exhausted, and under the older ideas it was necessarily deficient in some plant food. It seems strange that, under our old ideas 
390 INVESTIGATION BY CULTURE EXPERIMENTS

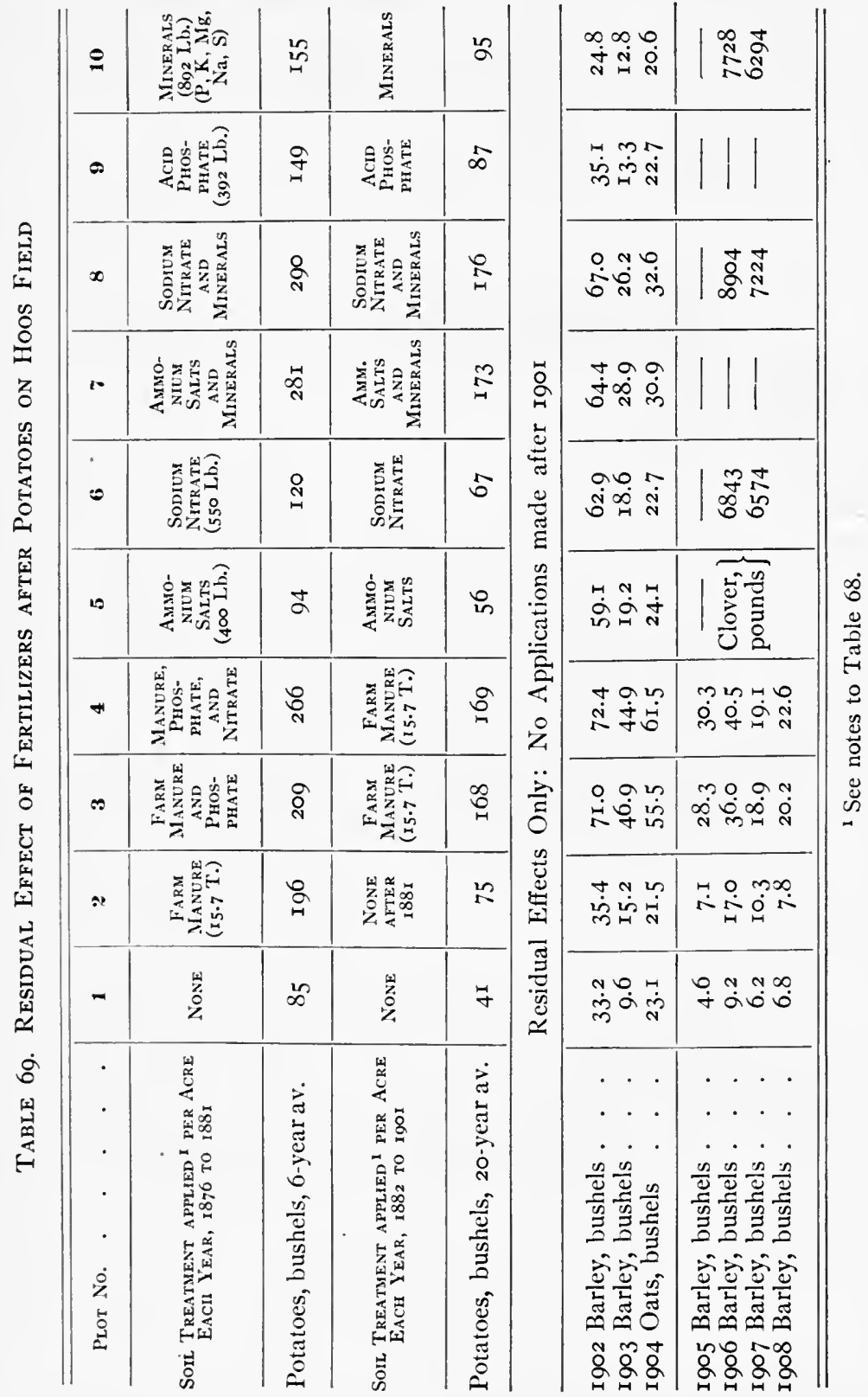


of soil fertility, if the soil became exhausted for potatoes, it should grow any other crop, because the usual analysis shows the same constituents present in all of our plants, not in the same proportion, but all are present and all necessary, so far as we know. This field was planted in barley, and on this experimental plot that had ceased to grow potatoes they got 75 bushels of barley." 1

While the avoidance of possible injury to plants from the possible toxic substances that may possibly be excreted from the roots of the same kind of plants is by no means precluded from among the possible benefits of crop rotation, the Rothamsted data furnish little evidence in favor of such a theory, and even less in support of the Whitney theory, that crop rotation alone will maintain the fertility of the soil. On the other hand, the residual effect of the farm manure applied to plot 3 (Table 69), previous to I882, is still apparent after the removal of twenty-five crops, in comparison with the unfertilized land.

Clover was seeded in 1905 on plots 6,8 , and ro, and cowpeas on plots 5,7 , and 9. The cowpeas failed, and in 1906 clover was seeded on 5,7 , and 9 . The clover yields thus far reported are recorded in Table 69. They are of some interest for comparison with the I906 clover on Agdell field (Table 56), where clover " sickness" has been recognized by the Rothamsted Station as the probable cause of frequent failure during more than half a century. There is much evidence to show that soils frequently become " sick" from the continuous growing of flax and of certain legume crops. "Clover sick" land and "bean sick" land are expressions common to nearly all countries. Cowpea wilt and flax wilt are well understood fungous diseases, and the evidence thus far secured indicates that clover "sickness" is also due to a fungus rather than to any possible toxic excreta. (See below.)

\section{Hay Every Year from Permanent Meadow at Rothamsted}

In 1856 , experiments were begun at Rothamsted in top-dressing meadow land with various fertilizing materials, as indicated in

${ }^{1}$ From page I4 of Farmers' Bulletin 257, U. S. Department of Agriculture. The careful student is advised to secure a copy of this interesting bulletin and also Bulletins 22 and 55 of the U. S. Bureau of Soils in which are set forth in greater detail the unique theories of Whitney and Cameron concerning soil fertility. They should be read in connection with Circulars 72, I05, I23, I24, and I29, of the University of Illinois Agricultural Experiment Station. 
Table 7o. The land was known to have been used for meadow and pasture for at least two centuries previous to the beginning of these experiments.

The field was known as The Park, and consisted of normal, nearly level upland soil, very similar to Agdell, Broadbalk, Hoos, and other Rothamsted fields, except that The Park had not been heavily chalked in the earlier years, while the other Rothamsted fields (with the exception of Geescroft at least) had received chalk dressings probably amounting to roo tons or more of calcium carbonate per acre.

The Rothamsted Station has no knowledge of any grass seed ever having been sown on The Park, either before or since the beginning of the experiments. From I 856 to 1874 only the first crops were harvested and weighed as hay, the second crops having been fed off by sheep, as a rule, and the sheep having been confined upon the plots so that the droppings were returned to the respective plots. Since 1874 , the second crops, when sufficient in amount to justify it, have also been harvested and removed as hay.

On a few plots the treatment was not fully decided upon until a few years after the beginning of the experiments. Thus, plot II was divided in 1862 , when the addition of sodium silicate was begun on $\mathrm{II}-2$. At the same time the application of potassium was discontinued on plots 8 and to and the sodium sulfate changed from 200 pounds to 500 pounds for $\mathrm{I} 862$ and $I 863$ and then to $25^{\circ}$ pounds. The periods represented in the first column of averages vary from 7 to ro years.

In studying the results from Table 70 , it should be kept in mind that all applications have been made only as top-dressings; and, consequently, that benefit could be expected only from those materials which were sufficiently soluble to permit of their being carried into the soil to the depth where the plant roots secure considerable amounts of their food supplies. It should be kept in

Notes to Table 70. The "minerals" regularly included $392 \mathrm{lb}$. of acid phosphate ( $400 \mathrm{Ib}$. of basic slag, I 897 to $\mathrm{r} 902$ ), $500 \mathrm{lb}$. of potassium sulfate ( $300 \mathrm{lb}$. for 1878 and previously), roo lb. of magnesium sulfate, and roo lb. of sodium sulfate ( 200 lb., 1856 to 1863 ), but where potassium was omitted (plots 8 and ro), the sodium sulfate was increased to $250 \mathrm{lb}$. from 1864 to 1904 . The farm manure applied to plots I and 2 was at the rate of 15.7 tons per acre for the eight years, I 856 to 1863 . 


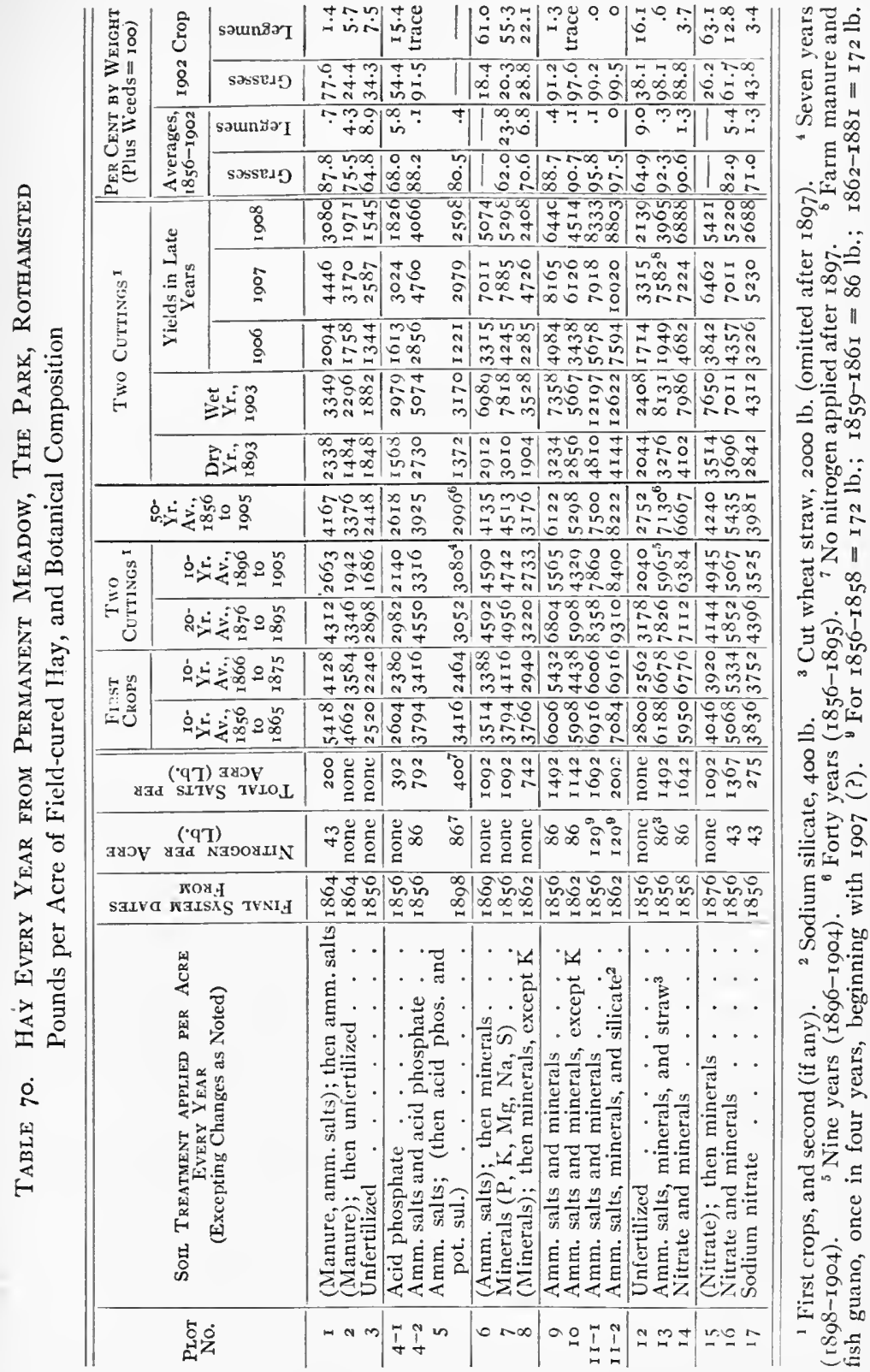


mind, also, that soluble acid phosphate is almost immediately converted into an insoluble form when brought in contact with ordinary soil, and that alkali salts have more or less power to make phosphates soluble.

The yields harvested for the first and second Io-year periods are comparable for most plots, and this is also true for the following 20-year and Io-year periods; although the yields of first crops only ( 1856 to 1875 ) cannot be compared with the yields of two cuttings ( 1876 to 1905 ). The double comparisons plainly indicate that the yield of hay is decreasing on all plots except those to which minerals are applied without nitrogen (plots 5, 6, 7, and I 5) or with organic matter (plot I3). The largest percentage decrease during the last thirty years has occurred on the unfertilized land (plots 2, 3, and I2) and on plot I, where ammonium salts and heavy applications of farm manure were used during the eight years, I 856 to I863, and ammonium salts alone thereafter. Marked decreases have also followed the use of acid phosphate and ammonium salts, either separately or together; while the addition of alkali salts with both nitrogen and phosphorus has lessened the decrease, but not entirely prevented it.

Plots 6 and 7 appear to have reached an equilibrium, having produced about the same yield during the last ro-year period as during the previous 20-year period, and plot $\mathrm{I}_{5}$ appears to be in the same class during the last io-year period.

A most striking fact is the controlling influence of the alkali salts; but there is no plot receiving alkali salts alone, and the question again arises whether the effect of the alkali salts is more largely direct or indirect. Here, as on the Broadbalk field, the magnesium and sodium salts have produced a marked effect, as will be seen from plots 8 and Io in comparison with plots $4^{-1}$ and $4^{-2}$. Thus, as an average of the thirty years, 1876 to 1905 , the addition of 250 pounds of sodium sulfate and roo pounds of magnesium sulfate increased the yield of plot Io over that of plot $4^{-2}$ by 1243 pounds of hay per acre per annum; but increasing the application of alkali salts from $35^{\circ}$ pounds to 700 pounds, by substituting 500 pounds of potassium sulfate for I 50 pounds of the sodium sulfate, produced a further increase of only roog pounds of hay on plot 9; while the further addition of 400 pounds of sodium silicate on plot 
I I-2 produced an increase of 845 pounds of hay over plot II-I, as a 30 -year a verage. When we remember that the sulfates of magnesium and sodium contain large amounts of water of crystallization, and that potassium sulfate is an anhydrous salt, the value of potassium for its own sake is still more questionable.

Attention is called to the fact that the total weight of salts applied to the best-yielding plot (II-2) is greater than the total weight of field-cured hay produced on the unfertilized land, as an average of the last Io-year period.

It seems very probable that the benefit of the alkali salts is due in part at least to their power to increase or maintain the solubility of the phosphorus, and thus provide a means by which that element is carried deeper into the soil, where it may be taken up by the plant roots. Even then it is probable that a very considerable part of the phosphorus applied to The Park plots during the past half-century still remains within an inch or two of the surface.

The botanical composition of the herbage (first crops only) is given in the last four columns of Table 70; first for the average of nearly fifty years, and second for the season of I902. It is especially interesting to note the large percentages of legumes on plots 6,7 , and $I_{5}$, which receive the minerals alone and consequently must depend upon legumes for a supply of nitrogen. Plot 8 (minerals, except potassium) shows the next highest percentage of legumes in 1902; and, in proportion to the actual application of anhydrous alkali salts, this is relatively higher than the figures indicate.

Plot 16 , which receives the minerals and the smaller application of nitrate, shows about the same percentage of legumes as the unfertilized plots and the acid-phosphate plot. Where heavy applications of nitrogen are used, the legumes are almost lacking, and entirely so in a few cases.

On some plots the herbage is largely weeds. Thus, the I902 crop of plot 2. (unfertilized since 1864) consisted of 30 per cent of grasses and legumes and 70 per cent of weeds, so that the produce is deteriorating in quality as well as in yield. The following statement by Lawes and Gilbert was published in I900:

"The total number of species that have been observed on the plots is 89 , comprised in $6_{3}$ genera, and 22 orders; whilst, to take some of the more important 


\section{INVESTIGATION BY CULTURE EXPERIMENTS}

orders, there have been found - of Gramineæ (grasses) zo species, of 5 genera; of Leguminosæ ro species, of 5 genera; of Compositæ I 3 species, of 12 genera; of Umbelliferæ 5 species, of 5 genera; of Polygonaceæ 3 species, of $\mathbf{I}$ genus; of Ranunculacer 5 species, of I genus; and of Plantaginaceæ 2 species, of I genus. The majority of the 22 orders are, however, represented by only one, two, or three species, and only one genus each. To take an example, it may be stated that the herbage of the unmanured plot comprises about 50 species, and that any kind of manure - that is, anything that increases the growth of any species - induces a struggle, greater or less in degree, causing a greater or less diminution, or a disappearance, of some other species; until on some plots, and in some seasons, not more than 15 species have been observable; indeed, on some, after a number of years, no more than this are ever traceable."

Director Hall reports that in 1903 about 97 per cent of the produce from plot II-I (ammonium salts and minerals) consisted of three species: false oat grass (Arrhenatherum avenaceum), meadow foxtail (Alopecurus pratensis), and meadow soft grass (Holcus lanatus). On plot $\mathrm{I} 4$, which receives nitrate and minerals, the herbage is quite similar except that about 45 per cent of meadow soft grass is replaced by 23 per cent of soft brome grass (Bromus mollis), 9 per cent of blue grass (Poa pratensis), 3 per cent of meadow pea (Lathyrus pratensis), and Io per cent of wild beaked parsley (Anthriscus sylvestris), a weed practically never found on any other plot.

The herbage of plot 7 (minerals) in 1903 included 4.27 per cent of white clover, 6.4I per cent of red clover, .43 per cent of bird-foot trefoil (Lotus corniculatus), and 22.04 per cent of meadow pea; while plot 8 (minerals except potassium) showed I.25 per cent of white clover, I.38 per cent of red clover, I 2.24 per cent of bird-foot trefoil, and 3.70 per cent of meadow pea. Yarrow (Achillea millefolium) is a common weed (I to Io per cent) on plots $6,7,8$, and I 5 .

The produce of plot 6 (changed from ammonium salts to minerals in I869) contained sorrel (Rumex acetosa) to the extent of I2.I I per cent in 1862 and 24.27 per cent in 1867 , which dropped to $7.5 \mathrm{I}$ per cent in $\mathrm{I} 872$ and to 5.24 per cent in 1903 . Plot 5 showed I 4.84 per cent of sorrel in I903. Lance-leaf plantain was found to the extent of 1.98 per cent on plot 3 (unfertilized), 2.49 per cent on plot $4^{- \text {I }}$ (acid phosphate), 5.85 per cent on plot 8 (minerals except potassium), and 10.70 per cent on plot I 7 (sodium nitrate), in 1903 . 
The number of species found in I 903 varied from Io on plot I I-I to 47 on the unfertilized plot 3 . On plot 3 there were I 6 species varying in amount from .59 per cent to 5.98 per cent, while 3 species were present in large quantity; namely, 2O. I 5 per cent of quaking grass (Briza media), I 7.45 per cent of sheep's fescue grass (Festuca ovina), and 13.8I per cent of the burnet weed (Poterium sanquisorbia). For a more complete discussion of the produce from 'The Park, see pages I 50 to I 89 of Director A. D. Hall's book, "The Rothamsted Experiments."

In considering the financial aspect of these experiments, probably we cannot do better than to take 2600 pounds of hay, the average of plots 3 and I 2 for the fifty years, as a general basis of comparison, and then figure the increase in the yield of mixed hay at $\$ 3$ per Iooo pounds, or $\$ 6$ per ton, which allows more than $\$ 3$ per ton for the extra expense of harvesting, stacking, baling, and marketing, and for loss, based upon the ro-year average price for central United States.

On this basis the top-dressing with $\$ 3.48$ worth of acid phosphate produced practically no effect, the average increase of 18 pounds of hay per acre being worth about 5 cents. The use of $\$ 12.90$ worth of ammonium salts on plot 5 produced \$I. I9 worth of hay; but with both ammonium salts and acid phosphate (plot $4^{-2}$ ) the increase was worth $\$ 3.98$ (cost $\$$ 工 6.38$)$. The addition of alkali salts on plot 7 has increased the yield over plot $4^{-2}$ by 2 I 97 pounds of field-cured hay, worth $\$ 6.59$, but the average cost of the potassium itself is more than \$Io.

The total increase on plot II-I over the unfertilized land is 4900 pounds, or $\$ 14.70$, while the total cost amounts to more than $\$ 33$. As an average the minerals on plot 7 paid less than half their cost, but as an average of 40 years the wheat straw was worth about $\$ 2.60$ a ton as a fertilizer for the increase it produced on plot I3 above plot 9; or as a substitute for nitrogen, at I5 cents a pound, the straw was worth $\$ 4.85$ a ton. (See plot I I-I.)

An investment of $\$ 6.45$ in sodium nitrate, applied alone to plot $I_{7}$, returned $\$ 4$. I 4 ; but, if the hay were figured at $\$$ Io a ton net, it would have been worth $\$ 6.90$, thus showing an average profit of 45 cents per acre per annum, if we disregard the gradual decrease in yield of the unfertilized plots, which, however, cannot be ig- 
nored in planning systems of permanent agriculture. With hay at $\$_{15}$ to $\$_{25}$ a ton, which are common prices near the large Eastern markets, very satisfactory profits may be made by top-dressing timothy meadows with 200 pounds or more of sodium nitrate, or with perhaps 300 pounds each of sodium nitrate, acid phosphate, and kainit. As a rule, smaller applications will give the greater profit for the money invested in fertilizers, but larger amounts may yield still greater profit per acre, especially when the price of hay is $\$ 20$ or more.

On the other hand, at the average prices that can be counted on for the Central states, the data from the Rothamsted investigations afford no evidence of profit from the use of commercial nitrogen or potassium salts or acid phosphate or any combination of these materials, for top-dressing permanent meadows.

\section{Root Crops on Barn Field, Rothamsted}

While some important experiments with turnips were made by Sir John Lawes, even before 1840 , the principal individual plot records date from 1845 ; and, with the exception of three years when barley was grown without the annual fertilizing (1853I 855), root crops have been grown every year on this part of Barn field.

These experiments were made more extensive in 1856 , as will be seen from Table $7 \mathrm{I}$, which gives certain average yields in four periods, from 1845 to 1870 , and the detailed records of sugar beets grown on these plots from 187 I to 1875 , the last two years without the full yearly application of fertilizers. The last column shows the percentage of sugar in the beets in 1873 , which was apparently a normal season and the last in which the fertilizers were applied in full for the sugar beets. From these data, the sugar per acre can be computed, but it should be kept in mind that the yield of beets is given in tons of 2240 pounds and for roots with only the leaves removed. The fertilizers applied were in general the same as those specified in Table $7 \mathrm{I} b$.

It will be seen that the first year sugar beets were ever grown on this field the yield varied from 5.05 tons to 28.90 tons, - a fact which 


\section{Table 7I. Root Crops on Barn Field, Rothamsted Yield per Acre of Roots, in Long Tons (2240 lb.)}

\begin{tabular}{|c|c|c|c|c|c|c|c|c|c|c|c|}
\hline \multirow[b]{2}{*}{$\begin{array}{l}\text { PLOT } \\
\text { No. }\end{array}$} & \multirow[b]{2}{*}{$\begin{array}{l}\text { SoIL TREATMENT Every YEAR } \\
\text { (About } 43 \mathrm{lb} \text {. N till r } 860 \text {; then } 86 \\
\text { h. Nothing applicd for the Bar- } \\
\text { ley, and no Manure, Rape Cake, or } \\
\text { Nitrogen applied for is74 or } 8775 \text {. } \\
\text { About } 300 \text { lb. Potassium Suifate } \\
\text { till } 1871 \text {; afterward } 5001 \mathrm{~b} \text {.) }\end{array}$} & \multirow{2}{*}{ 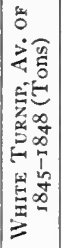 } & \multirow{2}{*}{ 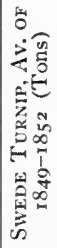 } & \multirow{2}{*}{ 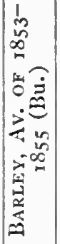 } & \multirow{2}{*}{ 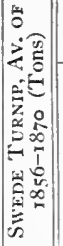 } & \multicolumn{6}{|c|}{ Sugar BeEts (Vilmorin's) } \\
\hline & & & & & & $\mid \begin{array}{c}0 \\
0 \\
5 \\
5 \\
5 \\
5 \\
0 \\
1 \\
0\end{array}$ & 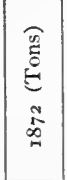 & 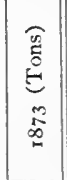 & 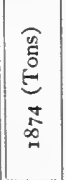 & 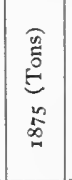 & 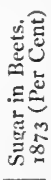 \\
\hline $\begin{array}{l}\mathrm{O}_{1} \\
\mathrm{O}_{2} \\
\mathrm{O}_{3} \\
\mathrm{O}_{4} \\
\mathrm{O}_{5} \\
\mathrm{O}_{6} \\
\mathrm{O}_{7} \\
\mathrm{O}_{8}\end{array}$ & 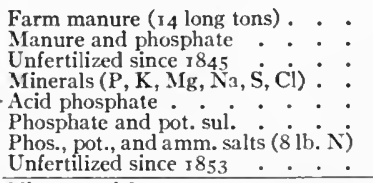 & \begin{tabular}{l|}
- \\
-1.20 \\
8.05 \\
8.80 \\
8.00 \\
- \\
\end{tabular} & $\begin{array}{l}- \\
- \\
2.30 \\
7.85 \\
7.45 \\
6.80 \\
= \\
-\end{array}$ & \begin{tabular}{|l|}
- \\
18.8 \\
20.8 \\
21.0 \\
18.8 \\
- \\
\end{tabular} & \begin{tabular}{|l|}
6.20 \\
6.35 \\
.55 \\
2.80 \\
2.60 \\
2.35 \\
2.60 \\
1.15 \\
\end{tabular} & $\begin{array}{r}18.15 \\
14.65 \\
7.55 \\
7.55 \\
5.60 \\
5.05 \\
5.90 \\
7.50\end{array}$ & $\begin{array}{r}15.65 \\
16.00 \\
7.85 \\
6.70 \\
6.85 \\
6.30 \\
6.75 \\
5.20 \\
\end{array}$ & $\begin{array}{r}15.10 \\
14.30 \\
5.05 \\
5.10 \\
5.25 \\
4.60 \\
5.95 \\
4.55 \\
\end{array}$ & $\begin{array}{r}10.80 \\
13.15 \\
5.10 \\
6.50 \\
5.95 \\
5.55 \\
6.70 \\
5.00 \\
\end{array}$ & $\begin{array}{r}17.25 \\
15 \cdot 55 \\
5 \cdot 45 \\
5 \cdot 45 \\
5 \cdot 55 \\
5 \cdot 20 \\
5 \cdot 55 \\
4 \cdot 75 \\
\end{array}$ & $\begin{array}{l}12.1 \\
12.3 \\
13.1 \\
13.1 \\
13.5 \\
13.6 \\
13.7 \\
13.9 \\
\end{array}$ \\
\hline $\begin{array}{l}N_{1} \\
N_{2} \\
N_{3} \\
N_{4} \\
N_{5} \\
N_{6} \\
N 7 \\
\text { N } 8\end{array}$ & $\begin{array}{l}\text { Nitrate and farm manure } \\
\text { Nitrate, manure, and phosphate : } \\
\text { Sodium nitrate . } \\
\text { Nitrate and minerals : : : : } \\
\text { Nitrate and phosphate } \\
\text { Nitrate, phosphate, and pot. sul. } \\
\text { Nitrate, phos, pot., amm. } \\
\text { Sodium nitrate : }\end{array}$ & $\begin{array}{l}\bar{z} \\
\bar{z} \\
\bar{z}\end{array}$ & $\begin{array}{l}= \\
\bar{z} \\
= \\
=\end{array}$ & $\begin{array}{l}= \\
= \\
= \\
=\end{array}$ & \begin{tabular}{l|}
7.45 \\
7.65 \\
.95 \\
5.10 \\
4.65 \\
4.55 \\
4.65 \\
1.65 \\
\end{tabular} & $\begin{array}{l}27.65 \\
25.80 \\
22.15 \\
22.75 \\
20.95 \\
21.25 \\
20.05 \\
21.65 \\
\end{array}$ & \begin{tabular}{|l|}
23.45 \\
24.30 \\
21.35 \\
20.10 \\
19.30 \\
16.80 \\
17.00 \\
15.30 \\
\end{tabular} & \begin{tabular}{|l|}
20.25 \\
21.50 \\
14.25 \\
16.45 \\
18.40 \\
15.85 \\
16.70 \\
12.45 \\
1
\end{tabular} & $\begin{array}{r}11.70 \\
7.45 \\
3.10 \\
8.80 \\
7.50 \\
8.05 \\
9.25 \\
7.65 \\
\end{array}$ & $\begin{array}{r}10.90 \\
19.90 \\
9.25 \\
0.40 \\
9.95 \\
8.20 \\
8.10 \\
7.20 \\
\end{array}$ & $\begin{array}{l}10.6 \\
10.2 \\
11.3 \\
11.4 \\
10.9 \\
11.8 \\
11.5 \\
10.3 \\
\end{array}$ \\
\hline $\begin{array}{l}A_{1} \\
A_{2} \\
A_{3} \\
A_{4} \\
A_{5} \\
\text { A } 6 \\
\text { A } 7 \\
\text { A } 8\end{array}$ & 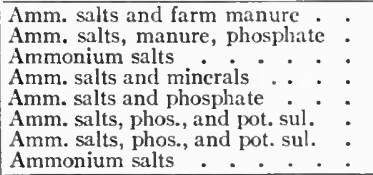 & $\begin{array}{l}= \\
- \\
\text { r.35 } \\
9.75 \\
0.00 \\
0.80 \\
=\end{array}$ & $\begin{array}{l}\bar{Z} \\
3.85 \\
9.45 \\
8.70 \\
8.70 \\
=\end{array}$ & $\begin{array}{l}-\bar{Z} \\
\overline{20.5} \\
22.5 \\
23.0 \\
20.5 \\
= \\
\end{array}$ & \begin{tabular}{|l|}
8.40 \\
8.25 \\
.65 \\
4.60 \\
3.80 \\
4.25 \\
4.60 \\
1.10
\end{tabular} & $\begin{array}{l}22.05 \\
21.75 \\
15.30 \\
17.50 \\
15.20 \\
17.20 \\
18.40 \\
16.10\end{array}$ & \begin{tabular}{|l|}
22.70 \\
22.00 \\
15.15 \\
1.50 \\
14.25 \\
14.35 \\
15.45 \\
13.50 \\
\end{tabular} & $\begin{aligned} 22.10 \\
19.20 \\
9.15 \\
12.50 \\
10.95 \\
12.90 \\
13.00 \\
8.40 \\
\end{aligned}$ & \begin{tabular}{|l|}
11.35 \\
9.25 \\
3.35 \\
7.50 \\
7.30 \\
8.05 \\
8.75 \\
6.50 \\
\end{tabular} & $\begin{array}{r}21.00 \\
18.85 \\
8.00 \\
7.80 \\
7.80 \\
7.05 \\
7.30 \\
6.05 \\
\end{array}$ & $\begin{array}{l}10.7 \\
11.0 \\
12.4 \\
12.4 \\
12.5 \\
12.5 \\
13.0 \\
12.5\end{array}$ \\
\hline $\begin{array}{l}\mathrm{AC} \text { I } \\
\mathrm{AC} 2 \\
\mathrm{AC} 3 \\
\mathrm{AC} 4 \\
\mathrm{AC} 5 \\
\mathrm{AC} 6 \\
\mathrm{AC} 7 \\
\mathrm{AC} 8\end{array}$ & $\begin{array}{l}\text { Amm. salts, rape cake, and manure } \\
\text { Amm. salts, cake, manure, phos. } \\
\text { Amm. salts and rape cake . } \\
\text { Amm. salts, cake, and minerals. } \\
\text { Amm. salts, cake, and phospliate } \\
\text { Amm. salts, cake, phos., and pot. } \\
\text { Amm. salts, cake, phos., and pot. } \\
\text { Amm. salts and rape cake }\end{array}$ & \begin{tabular}{|c|} 
\\
-50 \\
5.50 \\
10.25 \\
10.05 \\
10.35 \\
$=$ \\
\end{tabular} & $\begin{array}{r}-\bar{Z} \\
7.00 \\
13.05 \\
11.20 \\
12.40 \\
- \\
\end{array}$ & $\begin{array}{l}\bar{Z} \\
24 \cdot 5 \\
25.0 \\
26.8 \\
25.0 \\
= \\
\end{array}$ & $\begin{array}{l}8.80 \\
8.70 \\
3.30 \\
6.60 \\
5.80 \\
6.30 \\
6.75 \\
3.05 \\
\end{array}$ & \begin{tabular}{|l|}
20.20 \\
25.10 \\
19.50 \\
2.75 \\
19.00 \\
23.55 \\
21.00 \\
17.05 \\
\end{tabular} & $\begin{array}{l}26.40 \\
25.45 \\
20.40 \\
23.40 \\
18.55 \\
22.80 \\
23.45 \\
10.60 \\
\end{array}$ & \begin{tabular}{|l|}
22.75 \\
23.35 \\
15.60 \\
20.15 \\
14.75 \\
20.10 \\
10.80 \\
19.80 \\
15.10 \\
\end{tabular} & $\begin{array}{r}13.35 \\
12.25 \\
2.55 \\
10.60 \\
7.75 \\
9.50 \\
1.70 \\
7.30 \\
\end{array}$ & $\begin{array}{l}22.35 \\
2.45 \\
14.05 \\
12.70 \\
13.85 \\
12.40 \\
11.85 \\
12.10\end{array}$ & $\begin{aligned} 9.7 \\
9.8 \\
10.7 \\
10.6 \\
11.0 \\
11.3 \\
11.5 \\
10.3 \\
\end{aligned}$ \\
\hline $\begin{array}{l}C_{1} \\
C_{2} \\
C_{3} \\
C_{4} \\
C_{5} \\
C_{6} 6 \\
C_{7} \\
C_{8}\end{array}$ & 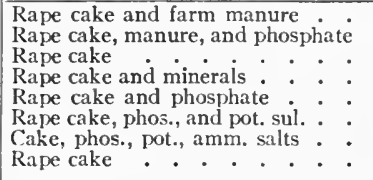 & $\begin{array}{l}= \\
6.55 \\
11.10 \\
10.90 \\
10.85 \\
=\end{array}$ & $\begin{array}{l}- \\
7.70 \\
12.35 \\
10.50 \\
11.70 \\
-\end{array}$ & $\begin{array}{l}\bar{Z} \\
25.9 \\
25.2 \\
27.0 \\
25.0 \\
-\end{array}$ & $\begin{array}{l}8.00 \\
7.80 \\
3.40 \\
5.40 \\
5.00 \\
5.15 \\
5.45 \\
3.70\end{array}$ & $\begin{array}{l}28.90 \\
25.20 \\
2.80 \\
21.35 \\
18.95 \\
21.00 \\
2 \mathrm{2} .35 \\
20.35\end{array}$ & $\begin{array}{l}22.25 \\
20.75 \\
16.15 \\
17.00 \\
15.00 \\
15.85 \\
15.50 \\
15.00\end{array}$ & $\begin{array}{l}23.50 \\
21.00 \\
14.65 \\
16.05 \\
13.95 \\
14.70 \\
1.78 \\
12.10 \\
12.10\end{array}$ & \begin{tabular}{|r|}
14.50 \\
13.05 \\
3.95 \\
8.10 \\
5.85 \\
7.65 \\
8.20 \\
3.60 \\
\end{tabular} & \begin{tabular}{|l|}
10.65 \\
18.50 \\
11.85 \\
10.15 \\
11.10 \\
10.10 \\
10.30 \\
11.60
\end{tabular} & $\begin{array}{l}11.0 \\
10.9 \\
13.5 \\
12.5 \\
12.8 \\
12.3 \\
12.4 \\
12.4\end{array}$ \\
\hline
\end{tabular}

does not suggest that the principal office of farm manure and rape cake is to destroy toxic excreta from the roots of sugar beets.

In Table $7 \mathrm{~s} b$ are recorded the yields of mangel roots since 1876 , in averages of 5-year periods for 30 years, and for single years subsequently. (Swede turnips were grown in I908, after the mangels failed, the yield of turnips varying from $\mathrm{I} .34$ to I3.OI tons.) 


\section{Table 7ib. Mangel-wurzel on Barn Field, Rothaysted Yield per Acre of Roots, in Long Tons (2240 lb.)}

\begin{tabular}{|c|c|c|c|c|c|c|c|c|c|c|c|c|}
\hline \multirow{2}{*}{$\begin{array}{l}\text { Plot } \\
\text { No. }\end{array}$} & \multirow{2}{*}{$\begin{array}{l}\text { SoIL TrEatment EvEry } \\
\text { YEaR } \\
\text { (Except no Nitrogen Salts } \\
\text { in } 1885 \text { and roor; 500 Po- } \\
\text { tassium Sulfate app ied to } \\
\text { Plots } 2 \text { for 1895 and since, } \\
\text { and Ninera's with No Potas- } \\
\text { sium or Extra Nitrogen ap- } \\
\text { plied to Plots } 7 \text { for r } 903 \text { and } \\
\text { Since) }\end{array}$} & \multirow{2}{*}{ 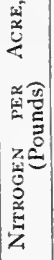 } & \multirow{2}{*}{ 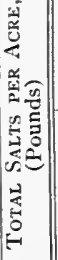 } & \multicolumn{6}{|c|}{ Average Yields } & \multicolumn{3}{|c|}{ LATE Yield } \\
\hline & & & & $\begin{array}{c}1876 \\
\text { to } \\
1880\end{array}$ & $\begin{array}{c}1881 \\
\text { to } \\
1884\end{array}$ & $\begin{array}{l}1886 \\
\text { to } \\
1890\end{array}$ & $\begin{array}{l}1801 \\
\text { to } \\
1895\end{array}$ & $\begin{array}{c}1806 \\
\text { to } \\
1900\end{array}$ & $\begin{array}{c}1002 \\
\text { to } \\
1905\end{array}$ & 1906 & 1907 & $\begin{array}{l}\text { Tur- } \\
\text { nips, } \\
\text { I908 }\end{array}$ \\
\hline & arm manure ( 14 long tons) & (?) & & 14.60 & 16.75 & 15.75 & 22.20 & 17.40 & 18.68 & 20.39 & $5 . \infty$ & I 1.69 \\
\hline & & (?) & 392 & I 5.05 & 16.60 & 16.35 & 21.80 & 18.95 & & 20.94 & 26.52 & 13.01 \\
\hline & I 845 & none & nonc & $4 \cdot 30$ & 4.8 .5 & $4 \cdot 15$ & 6.35 & 6.35 & & & & \\
\hline & $(\mathrm{P}, \mathrm{K}, \mathrm{Mg}, \mathrm{Na}, \mathrm{S}, \mathrm{Cl})$ & none & 1292 & 5.70 & 5.80 & $4 \cdot 75$ & 5.10 & 5.45 & 4.06 & $5.5 \mathrm{I}$ & 5.95 & 4.07 \\
\hline & & none & 392 & 5.05 & $5 \cdot 35$ & 4.70 & 5.60 & 5.00 & 4.66 & 5.91 & 6.21 & 3.91 \\
\hline & d pot. sul. . $\dot{0}$ & none & 892 & $4 \cdot 50$ & 4.75 & 4.20 & 4.85 & $4 \cdot 40$ & 3.63 & $5 \cdot 31$ & 5.78 & 3.53 \\
\hline & and amm. salts & & 929 & $6 . \infty$ & 6.60 & 5.05 & 6.00 & 5.85 & & 5.44 & 6.59 & 8.76 \\
\hline 08 & Unfertilized since 1853 . & none & none & 3.45 & 4.25 & $3 \cdot 50$ & 4.40 & 4.05 & 3.13 & 3.67 & 5.15 & $\mathbf{1 . 3 4}$ \\
\hline $\begin{array}{l}\mathrm{Ni} \\
\mathrm{Ni}\end{array}$ & $\begin{array}{l}\text { te and farm manure } \\
\text { te, manure, and phos- }\end{array}$ & (?) & 550 & 20.85 & 23.45 & 20.95 & 29.65 & 26.90 & 30.32 & 30.31 & $4 \mathrm{I} \cdot 42$ & 12.73 \\
\hline &. & $\begin{array}{l}\text { (?) } \\
86\end{array}$ & $\begin{array}{l}942 \\
550\end{array}$ & $\begin{array}{l}22.90 \\
13.30\end{array}$ & \begin{tabular}{|l|}
25.05 \\
12.90
\end{tabular} & $\begin{array}{l}22.55 \\
13.65\end{array}$ & $\begin{array}{l}25.80 \\
12.80\end{array}$ & $\begin{array}{l}28.05 \\
18.25\end{array}$ & 31.24 & 30.24 & 42.13 & 12.49 \\
\hline & and minerals & 86 & 1842 & 19.40 & 17.70 & 18.40 & 14.20 & & 22.51 & I 3.98 & 0.46 & I r. I0 \\
\hline & and phosphate & 86 & 942 & 16.45 & 14.65 & 15.60 & 12.90 & 16.15 & 18.57 & $14 \cdot 30$ & 24.62 & $9 \cdot 30$ \\
\hline & $\begin{array}{l}\text { Nitrate, phosphate, and pot. } \\
\text { sul. }\end{array}$ & 86 & 1442 & 17.30 & 14.55 & 15.20 & 12.05 & 16.45 & & & 5.05 & 8.03 \\
\hline$N_{7}$ & $\begin{array}{l}\text { Nitrate, phos., pot., amm. } \\
\text { salts }\end{array}$ & 94 & 1479 & I 7.65 & 14.80 & I 5.80 & 12.20 & $\left.16.05\right|^{2}-1-2$ & $\mid 21.03$ & 21.92 & 54 & \\
\hline N8 & Sodium nitrate $. \quad . \quad . \quad$. & 86 & 5.50 & I 1.00 & 10.15 & 10.00 & 6.00 & 11.4 .5 & 11.06 & 10.25 & & 2.70 \\
\hline$A_{1}$ & Amm. salts and farm manure & (?) & 400 & 23.00 & $2 \mathrm{I} .35$ & 20.10 & .00 & .70 & 4.34 & 25.69 & .52 & 1.05 \\
\hline & Irc, phospliate & (?) & 792 & 22.70 & $2 \mathrm{I} .45$ & 10.75 & 22.60 & & 30.15 & 30.95 & I.68 & II.9. \\
\hline & $\therefore \quad \cdot \cdot$ & 86 & 400 & 8.15 & 6.00 & 6.35 & $4 \cdot 95$ & 6.95 & & & & \\
\hline & incrals. • & 86 & 1692 & 15.55 & I6.10 & 14. & 12.80 & & 16.08 & 12.29 & .68 & II 4 \\
\hline & 1 phosphate . & 86 & 792 & 9.70 & 8.00 & & 5.70 & & 6.93 & & .88 & 6.4 \\
\hline & os., and pot. sul. & 86 & 1292 & 14.00 & 14.40 & 13.65 & 12.80 & 14.65 & 5.46 & 16.38 & .22 & 0.07 \\
\hline & , phos., and pot. sul. & $r 4$ & 1329 & 14.65 & 14.65 & 14.70 & 13.25 & 14.85 & $6.5 \mathrm{I}$ & 16.95 & 26.52 & 10.84 \\
\hline & Ammonium salts $\cdot \cdot \cdot \cdot$ & $\varepsilon 6$ & 400 & 7.05 & 5.45 & 6.1 .5 & $4 \cdot 30$ & 6.20 & 6.01 & $6.3^{6}$ & 9.87 & 2.53 \\
\hline & $\begin{array}{l}\text { Amm. salts, rape cake, and } \\
\text { manure }\end{array}$ & (?) & 400 & 24.95 & 25.15 & 21.45 & 28.55 & 20.50 & 26.54 & 26.82 & 34.29 & 10.98 \\
\hline AC. 2 & $\begin{array}{l}\text { Amm. salts, cake, manure, } \\
\text { phos. }\end{array}$ & (?) & & 24.10 & 24.90 & 21.55 & 26.25 & 25.80 & 34.15 & 32.06 & 3.52 & $11 . x$ \\
\hline & Cane & 183 & 400 & I 1.80 & 0.95 & 10.40 & 0.85 & 7.85 & & & & \\
\hline & Amm. salts, cake. and minerals & $18_{3}$ & 1692 & $24 \cdot 40$ & 26.00 & 22.35 & 28.65 & 24.25 & 31.52 & $26.3 I$ & .97 & II.5 \\
\hline & $\begin{array}{l}\text { Amm. salts, cakc, and phos. } \\
\text { Amm. salts, cake, phos., and }\end{array}$ & 183 & 792 & 12.50 & 11.25 & 10.50 & 10.35 & 7.60 & 8.44 & 6.57 & I 11.26 & $5 \cdot 4$ \\
\hline & ialis cale & 183 & 1292 & 21.05 & 24.10 & 19.65 & 25.80 & 20.70 & 27.77 & 25.28 & 35.88 & $9 \cdot 5^{2}$ \\
\hline & salts, cake, phos., and & & & & 23.60 & & & & & & & \\
\hline $\mathrm{AC} 8$ & Amm. salts and rape cake. & $1 i_{3}$ & 400 & 12.00 & $0.7 \div$ & 0.50 & $\begin{array}{r}0.7= \\
\end{array}$ & 8.70 & $\begin{array}{r}28.25 \\
\end{array}$ & $\begin{aligned} 20.19 \\
8.05 \\
\end{aligned}$ & $\begin{array}{l}1.30 \\
\end{array}$ & $\begin{array}{l}9 \cdot 5 \\
4.6 \\
\end{array}$ \\
\hline $\mathrm{C}_{\mathrm{I}}$ & Rape cake and firm manute & (?) & & & 25.15 & 21.55 & 20.80 & 22.25 & 25.13 & $\mid 25.26$ & 5.02 & 9.7 \\
\hline & nd phos. & (?) & 392 & 22.15 & 24.40 & 21.40 & 28.25 & 24.75 & 30.57 & 30.10 & 40.74 & 10.3 \\
\hline & unds) & 97 & & II.20 & II.15 & 10.75 & 11.05 & 8.05 & & & & \\
\hline & & 97 & 1292 & 18.90 & 20.45 & 19.35 & 26.15 & 20.85 & 24.08 & 23.18 & 33.09 & 13.0 \\
\hline & c . & 97 & 392 & 12.40 & 12.50 & & I 1.80 & 8.00 & & & & 5.1 \\
\hline & ot. sul. & 97 & 892 & & & & & & & $2 \pi .66$ & & 9.2 \\
\hline & & 105 & 920 & 16.00 & 20.75 & 17.15 & 22.65 & I8. I 5 & 26.83 & 24.68 & 30.59 & 9.4 \\
\hline & Rape cake ( 2000 pounds). & 97 & & 10.10 & 10.35 & 9.75 & I 1.45 & 8.30 & 8.84 & 9.93 & 13.24 & 4.2 \\
\hline
\end{tabular}

'These data are presented for examination by the reader, and only a few special points will be referred to here. The records of 1885 and IgOI are not included in the averages because, owing to un- 
favorable conditions, no nitrogen salts were applied for those years. For the same reason the records for plots $\mathrm{N}_{3}$ to $\mathrm{N} 8$ and $\mathrm{A}_{3}$ to $\mathrm{A} 8$ are not used for 1903 . The Rothamsted Station reports that, owing to very heavy rains in November, I894, flooding the lower parts of the experimental mangel field, and washing soil from the farm-manure plots, especially on to plot $\mathrm{O}_{3}$, and to a less degree on to plot $\mathrm{N}_{3}$, there is no doubt that the results from those plots are too high for 1895 and each year since. Of late years no data are reported from plot 3 , but the No. 8 plots are sufficient.

As explained in the table, 500 pounds of potassium sulfate has been applied since 1895 , in addition to the other regular treatments, to plots $\mathrm{O}_{2}, \mathrm{~N}_{2}, \mathrm{~A}_{2}, \mathrm{AC}_{2}$, and $\mathrm{C}_{2}$; and for $\mathrm{I}_{90}$ and since the application of potassium and the extra nitrogen (8 pounds per acre) has been discontinued on plots $\mathrm{O}_{7}, \mathrm{~N}_{7}, \mathrm{~A}_{7}, \mathrm{AC}_{7}$, and $\mathrm{C}_{7}$, but instead those plots have received the full minerals, except potassium.

The " minerals " regularly include 392 pounds of acid phosphate, 500 pounds of potassium sulfate, 200 pounds of magnesium sulfate, and 200 pounds of common salt (sodium chlorid); but from I896 to I902 the acid phosphate was replaced throughout by slag phosphate.

The mangel leaves are each year spread over the respective plot, and thus returned to the soil.

It had been suggested that plants with large leaf surface, like the mangel, could probably secure sufficient nitrogen from the air, in the form of ammonia or possibly as free nitrogen, for their full requirement, provided a small amount of available nitrogen was furnished to give the plants a good start; and because of this the special 8 pounds of nitrogen were applied to plots $\mathrm{O}_{7}, \mathrm{~N}_{7}, \mathrm{~A}_{7}$, and $\mathrm{C}_{7}$ until I902, after which the treatment for those plots was changed as stated.

Where no other nitrogen was supplied (plot $\mathrm{O}_{7}$ ), the 8 pounds increased the yield of mangel-wurzel by 1.36 tons as an average of 25 years. At $\$ 1.50$ per long ton this increase would be worth $\$ 2.04$ per acre, while the nitrogen would cost only $\${ }_{1.20}$ at I $_{5}$ cents a pound. Two points must be kept in mind, however; first, that the total crop on plot 08 was produced at a loss; second, that the increase from the phosphorus and potassium applied to plot O6 was worth less than ro per cent of the cost of those elements. 
Where organic nitrogen was applied in rape cake, the additional 8 pounds of soluble nitrogen produced only two thirds of a ton increase, which would be worth less than the cost of the nitrogen, at the price used.

It may be stated that the first crop of mangel-wurzel (1876) on plot 08 was 5.45 tons, while the same plot produced 6.95 tons in I 898 and 7.75 tons in I900. Plot $\mathrm{N}_{4}$ produced 25.05 tons in 1876 , and several plots produced still higher yields, the highest being $3 \mathrm{I} .45$ tons on plot ACI.

Since I904, the 200 pounds of sodium chlorid has been omitted from one half of plot $\mathrm{N}_{4}$, which receives sodium in the nitrate. The subsequent yields for this half have been 24.69 , I6.69, and 35 . I 5 tons per acre for the years $1905-1907$, or distinctly more than where the common salt was included, as will be seen from Table $7 \mathrm{r} b$.

Of special interest is the evident effect of the potassium applied to plots 2 for 1895 and since. The previous records indicate that the heavy applications of manure had furnished sufficient phosphorus for the crops grown, and the yields since I 895 plainly show that potassium was the limiting element wherever nitrogen had been applied in addition to the farm manure. Since phosphorus is also applied to plots 2 , it is impossible to determine what increase would have been made by potassium without the added phosphorus; but on plots $\mathrm{A}_{2}, \mathrm{AC}_{2}$, and $\mathrm{C}_{2}$ the yields since 1895 have averaged about 5 tons more than on the No. I plots. The sodium applied in the sodium nitrate on plot Ni appears to produce almost the same effect as the potassium applied (since r895) to plot A2. It will be observed that phosphorus produced an appreciable effect on $\mathrm{N}_{2}$ from 1876 to i 890 .

As an average, one ton (2000 pounds) of mangel-wurzel contains about 3.6 pounds of nitrogen, .5 pound of phosphorus, and 6.6 pounds of potassium, and the average requirements for such an enormous crop as grew on plot $\mathrm{AC}_{2}$ in 1907 would be about 175 pounds of nitrogen, 24 pounds of phosphorus, and 330 pounds of potassium, for the roots only. If we assume the farm manure to have ro pounds of nitrogen, 2 pounds of phosphorus, and 8 pounds of potassium per ton of 2000 pounds, the annual applications now being made to plot $\mathrm{AC}_{2}$ contain about 340 pounds of nitrogen, 60 pounds of phosphorus, and 360 pounds of potassium. On this 
basis, the crop of 1907 required for the roots alone, I80 pounds more potassium than was supplied in the manure and rape cake; and it seems remarkable that the I4I pounds of sodium on plot Ni produced almost as great an effect as the 2 Io pounds of potassium on plot $\mathrm{AC}_{2}$.

It is of interest to note that the total supply of potassium contained in the surface soil ( $6 \frac{2}{3}$ inches deep) of the peat lands of New York or Illinois, for example, would be sufficient for less than Io such crops as were grown on plots $\mathrm{N}_{1}, \mathrm{~N}_{2}, \mathrm{~A}_{2}, \mathrm{AC}_{2}, \mathrm{AC}_{4}$, and $\mathrm{C}_{2}$, of Barn field, Rothamsted, in I907; and that even the total potassium in 2 million pounds of the most common type of soil in the Illinois wheat belt (gray silt loam prairie, lower Illinoisan glaciation) would be sufficient for only 75 such crops, although it would be sufficient for 50 bushels of wheat per acre every year for I9 centuries, if the straw is returned to the land.

\section{Abandoned Lands at Rothamsted}

Since 1882 , a piece of Broadbalk field, which had been cropped with wheat every year since 1844 , has been abandoned to nature, except that trees and shrubs have been kept out. Likewise, a piece of Geescroft field, which had been used for beans from 1847 to I88I (only four crops grown during the last I I years), and for clover from $\mathrm{r} 882$ to $\mathrm{I}_{8} 8_{5}$, has been abandoned to volunteer vegetation since $r 885$.

Nothing has been harvested from these pieces of land, not even by pasturing, since they have been left to "lie out," or " run wild."

The most marked difference that has developed between the herbage of the two fields is the absence of legumes on Geescroft and the abundance of legume plants on Broadbalk, although Broadbalk was abandoned with a wheat crop standing on it (of which some volunteer plants continued to appear for three or four years), while Geescroft was in clover when abandoned. Observers (including Sir John Lawes ${ }^{1}$ ) commonly attributed the absence of

${ }^{1}$ In I900, when I had the deeply appreciated privilege of being shown over the Rothamsted fields by Sir John Lawes (about a month before his sudden death), he climbed the fence like a boy, to take me into Geescroft field and point out a few legume plants (of a single species) the development of which he had been watching for two or three years. - C. G. H. 
legumes on Geescroft to the fact that the land was legume "sick" from the effort to grow beans for more than 30 years, although some good crops of clover were grown from I 882 to 1885 .

Some interesting data concerning these two abandoned fields are given in Table 72 .

Table 72. Rothamsted Fields, abandoned to Naturf, for 20 Years

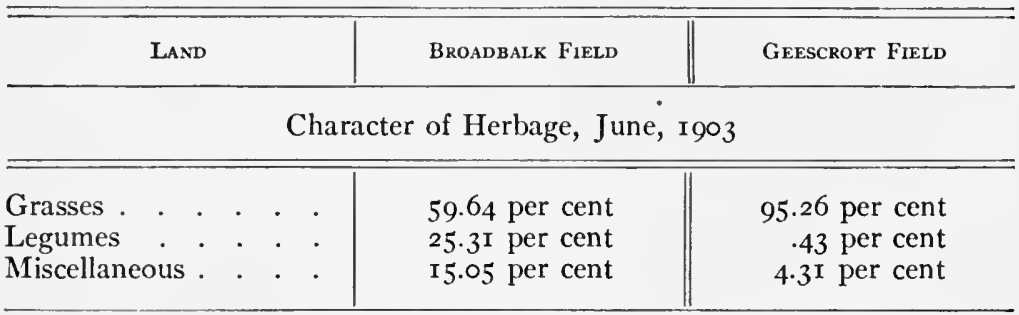

Percentages in Soils from Broadbalk (I 88r) and Geescroft (1883)

\begin{tabular}{|c|c|c|c|c|c|c|c|c|}
\hline \multicolumn{3}{|c|}{ DEPTH (Inches) } & \multirow{2}{*}{$\frac{0-9}{.108}$} & \multirow{2}{*}{$\begin{array}{l}9-18 \\
.070\end{array}$} & \multirow{2}{*}{$\begin{array}{r}.8-27 \\
.058\end{array}$} & \multirow{2}{*}{$\frac{0-9}{. \operatorname{to8}^{1}}$} & \multirow{2}{*}{$\frac{.9-18}{.074}$} & \multirow{2}{*}{$\begin{array}{r}.8-27 \\
.060\end{array}$} \\
\hline Total nitrogen & . & . & & & & & & \\
\hline Organic carbon & . & . & I. I 43 & .624 & $.46 \mathrm{I}$ & I. I I I & .600 & .447 \\
\hline
\end{tabular}

Percentages in Soils in 1904

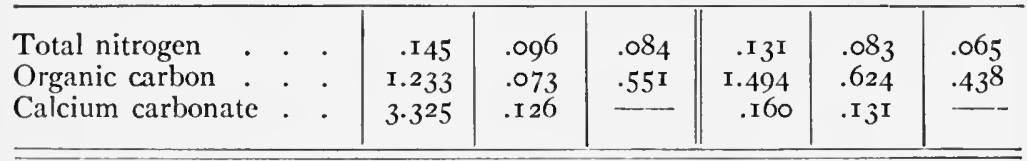

1 This percentage was .108 in $188_{3}$ and.$I_{5}$ in $I_{188}$, the clover crops having been harvested and removed during the two years.

It seems that the practice of chalking the land, which prevailed at Rothamsted a century or more ago, had not extended to Geescroft field, and without much doubt this has been the chief factor in determining the character of the herbage, in part because of the chemical reaction of the soil and in part because of the physical difference, the Geescroft land being close-textured, poorly drained, wet, and cold, while the Broadbalk soil, because of the lime present, flocculates or granulates and drains well. (The adjoining regular plots are tile-drained on Broadbalk.)

Hall states that " where nitrate of soda had been used (on Gees- 
croft field), the land became specially difficult to manage, remaining persistently wet, and then drying out with an excessively hard crust."

From any estimates that can be based upon the percentages of nitrogen found in samples of soil from these fields, very large increase is shown; in fact, much larger than can be accounted for by any existing knowledge concerning nitrogen fixation. It is questioned if the samples collected in 1904 are strictly comparable with those taken 20 years before, because of the increasing porosity and looseness of the soil. Thus, the 9-inch stratum of I88I might occupy Io inches or more in I904.

Director Hall estimates that Geescroft field (even without legume plants) has gained a quantity of nitrogen "which at the lowest reckoning amounts to about 25 pounds per acre per year," and adds:

"The nitrogen brought down in the rain would account for perhaps 5 lbs. per acre per annum, a little more will come in the form of dust, bird-droppings, and other casual increments, while some may be due to fixation of atmospheric nitrogen by bacteria in the soil not associated with leguminous plants, like the Azotobacter chroococcum of Beijerinck and Winogradsky's Clostridium pastorianum. Two other causes may be at work, the absorption of atmospheric ammonia by soil and plant, and the rise of nitrates from the subsoil."

In the author's opinion, the two most important factors involved are the difficulty of securing comparable samples and the mechanical addition of foreign substances, especially the dust of summer, and the dirty, drifting snow of winter, light trash (leaves, weeds, etc.), which blow about until they find a lodging place in such a small "wilderness" as the abandoned portions of these fields furnish. An extreme illustration of this is found in a Rothamsted note concerning the potato tops on Hoos field in 1877 :

"Tops withered, not weighed, each lot spread on its own plot, but high wind (October I4) blew all off before plowing."

One experienced in farm practice will easily recall conditions under which field dust is drifted by the wind. The extent varies from the cloud which follows the harrow to the dust storm, during which a field, even of clay loam, in certain mechanical condition, may lose very appreciable amounts of its best soil, which requires 
for its deposition and accumulation only an undisturbed lodging place, and dirty snowbanks form in such places near open fields.

\section{Notes on the Rothamsted Field Experiments}

The records herein given must be considered at best as summaries of the Rothamsted field experiments. Aside from the experiments already mentioned, beans were grown every year from I849 to I859, and oats every year (except I 877 , fallow) from I869 to I878, under different systems of fertilizing, on Geescroft field. The average yicld of oats for the five years (I869 to 1873) range, in bushels per acre, from 19.9 (unfertilized) and 24.5 (minerals) to 47 (ammonium salts) and 59 (ammonium salts and minerals); and for the other four years from I3.I (minerals) and I3.8 (unfertilized) to 28.9 (ammonium salts) and 38 (ammonium salts and minerals).

No oats were grown on this field from I 847 to 1868 , and the first crop of oats (1869) varied, in bushels per acre, from 36.6 (unfertilized) and 45 (minerals) to 56.1 (ammonium salts) and 75.2 (ammonium salts and mincrals). The records for the 9 years, I860 to I868, are: fallow, wheat, wheat, fallow, beans, wheat, beans, wheat, wheat; with no fertilizers applied during those years except farm manure for the beans in 1864 .

Experiments with legume crops, especially with beans and clover, have been in progress on Geescroft or Hoos fields (or both) most of the time since 1847 . In summarizing their experimental results after more than fifty years, Lawes and Gilbert recorded the following statements (Rothamsted Memoranda, published in I90I) :

"When the same description of leguminous crop is grown too frequently on the same land, it seems to be peculiarly subject to disease, which no conditions of manuring that we have hitherto tried seem to obviate."

"The general results of the experiments on ordinary arable land in the field has been that neither organic matter rich in carbon as well as other constituents, nor ammonium salts, nor nitrate of soda, nor mineral constituents, nor a complex mixture, supplied with manure, availed to restore the clover-yielding capabilities of the land; though, where some of these were applied in large quantity, and at considerable depths, the result was better than when they were used in only moderate quantities, and applied only on the surface. 
"On the other hand, it is clear that the soil in the garden, which at the commencement contained in its upper layers about four times as much nitrogen as the arable land, and would doubtless be correspondingly rich in other constituents, has supplied the conditions under which clover can be grown year after year on the same land for many years in succession.

"The results obtained on the soil in the garden seem to show that what is called 'clover sickness,' cannot be due to the injurious influence of excreted matters upon the immediately succeeding crop.

"That clover frequently fails coincidently with injury from parasitic plants or insects cannot be disputed; but it may be doubted whether such injury should be reckoned as the cause, or merely the concomitant, and an aggravation, of the failing condition."

"When land is not what is called 'clover-sick,' the crop of clover may frequently be increased by top dressings of manure containing potash and superphosphate of lime; but the high price of salts of potash, and the uncertainty of the action of manures upon the crop, render the application of artificial manures (as top dressings) for clover a practice of doubtful economy.

"When the land is what is called 'clover-sick,' none of the ordinary manures, whether 'artificial' or natural, can be relied upon to secure a crop.

"So far as our present knowledge goes, the only means of securing a good crop of red clover is to allow some years to elapse before repeating the crop upon the same land."

In his book on the "Rothamsted Experiments" (page I46), Director Hall gives the complete data and the following summary of the clover grown year after year on a small plot of rich garden soil at Rothamsted:

Red Clover on Rich Garden Soil, Rothamsted

Pounds per Acre

\begin{tabular}{|c|c|c|c|}
\hline YEARS & AIR-DRY HAY & Dry Matter & $\begin{array}{c}\text { Nitrogen in } \\
\text { Crops }\end{array}$ \\
\hline Average of 25 years $(1854-1878)$ & 7664 & $63^{87}$ & I 79 \\
\hline Average of 25 years ( $879-$ - 903 ) & 3924 & 3270 & IOI \\
\hline
\end{tabular}

During the fifty years there have been only two crop failures ( 1895 and I900); but the plot required seeding only five times during the first twenty years (I854, I860, I865, I868, and I87I), whereas since 1874 it has been seeded or reseeded almost every year, and sometimes two or three seedings in one year have been required to secure a stand. Late yields of dry matter are: 2887 
pounds in I90I, II69 pounds in I902, and 1589 pounds in 1903 ; and Hall's book contains the following:

"In March, I897, and in July, 1899, all the plants were removed by hand, burnt and their ashes returned, and the soil was carefully picked over by hand for the Sclerotia of the fungus, Sclerotinia trifoliorum, many of which were found. The soil was also dressed with carbon bisulfid as a fungicide, before fresh seed was sown. In 1903 , which was a favorable year for the growth of clover, a fair plant was obtained by reseeding, and in the spring of 1904 the best crop for many years was cut from this plot."

Director Hall expresses the opinion that the fungus named is not the only cause of "clover sickness."

Finally, it should be understood that, while the Rothamsted field experiments have been conducted with extreme care, there are some possible sources of error, and the Rothamsted Station has been very careful to point these out where they are of probable consequence. Warrington, in his Rothamsted lectures (Bulletin No. 8, Office of Experiment Stations, United States Department of Agriculture), delivered before the Association of American Agricultural Colleges and Experiment Stations, in $180 \mathrm{I}$, under the provisions of the Lawes Agricultural Trust, makes the following statements:

"The earlier experimental fields at Rothamsted were not arranged as skillfully as the later ones; thus, Broadbalk wheat field has long, narrow plots, and the influence of the manure of neighboring plots is in some cases distinctly felt. The barley experiments in Hoos field are the best laid out; here the plots are nearly square; they have each an area of one fifth of an acre."

(In the author's opinion, tenth-acre plots, 2 by 8 rods or I by I 6 rods, or fifth-acre plots, 4 by 8 rods or 2 by 16 rods, are more satisfactory than square plots for field experiments, because greater uniformity between plots is thus secured; but in all cases a protecting border of at least one fourth rod should completely surround every plot, the same crops being grown upon the border as upon the plot proper. This requires a half-rod division strip between plots, and wherever needed, an additional uncultivated strip of grass sod should be left between the plots.)

On the Grass Park at Rothamsted an imaginary line is the only division between the plots, but the ground is never broken, and the fertilizers are applied as top dressings with exactness (a cloth screen 


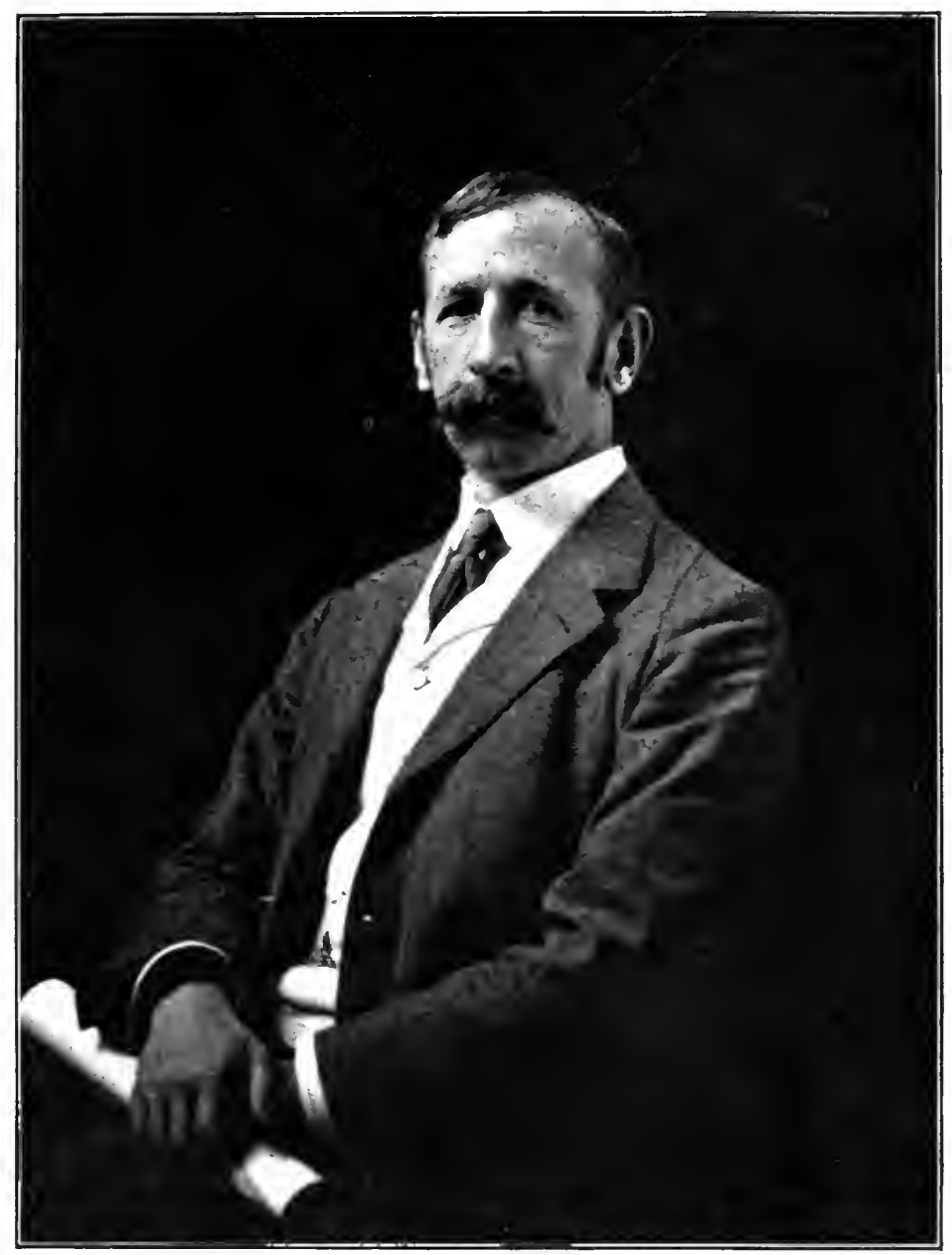

A. D. HALL, DIRECTOR OF ROTHAMSTED EXPERIMENT STATION Author of "The Soil," "Fertilizers and Mlanures" 

being placed on the line), and Director Hall states that the influence of the fertilizers can scarcely be detected six inches over the line, either in the yield or in the character of the herbage, despite the exceedingly marked differences that have developed between the plots.

\section{The Chemistry of Rothamsted Field Experiments}

While much chemical work has been carried on from the beginning by the Rothamsted Experiment Station in connection with the field experimentation, it has been directed more largely to investigations concerning the composition of the crops produced than to soil analyses. From most of the fields few soil analyses have been reported; but in the case of Broadbalk field some very complete and thorough investigations have been made of several plots. The results are briefly summarized in Table 73 .

The soil samples upon whose analysis the data in Table 73 are chiefly based were collected in 1893 , fifty years from the beginning of definite plot experiments on Broadbalk field, although on several plots the final systems of treatment were not fully settled until 1852. For this reason the average yields are given for the fortytwo years, $185_{2}$ to 1893 , but the plant food removed and applied is computed for the fifty years; and, in the main, estimation of plant food removed is based upon the analysis of the actual crops harvested.

In computing from percentages found by analysis to pounds per acre, Doctor Dyer has used as the weight of fine dry soil per acre $2,590,000$ pounds for the first 9 inches, $2,670,000$ pounds for the second, and 2,790,000 pounds for the third 9 inches. The corresponding weights, including stones, are $3,120,000,3,040,000$, and $3,000,000$ in round numbers. (For the common silt loam soils of Illinois, we have found 300,000 pounds per acre-inch to be practically correct. This would correspond to $2,700,000$ pounds per acre for a 9 -inch stratum, or 2 million pounds for a $6 \frac{2}{3}$-inch stratum.)

In considering the composition of the soils represented in Table 73 , it should be kept in mind that the nitrogen reported is total, while the phosphorus and potassium are the portions soluble in strong acid. In the case of phosphorus, this usually represents 
nearly the total, but in different soils it may vary from the total to as low as 75 per cent of the total; while only from I 5 per cent to 30 per cent of the total potassium is acid soluble, although in some abnormal soils, as certain peaty soils, it may reach 60 per cent or more of the total. Potassium varies greatly in this respect at different depths in the same field. Thus, on the gray silt loam prairic of the lower Illinoisan glaciation the percentage of the total potassium that is soluble in hydrochloric acid (specific gravity I. I I5), during ten hours' digesțion at the temperature of boiling water, varies from as low as 14 per cent in the surface soil to as high as 38 per cent in the subsoil of the same field.

Because of these facts the determinations of potassium reported in Table 73 must not be considered as the basis for any final conclusions, but the phosphorus data must be approximately correct, and the results for nitrogen are practically exact, except for possible variation (from the field a verage) of the samples of soil collected. The data are all reported for 9-inch strata of soil, corresponding to the depths to which the samples were taken.

Table 73 contains much information, but it is self-explanatory. Thus, plot 7 , which has received both ammonia and the regular minerals (as more fully explained in the previous pages), produced an average yield of 32.8 bushels of wheat and 3668 pounds of straw, and $245^{\circ}$ pounds of nitrogen, 482 pounds of phosphorus, and 2 I I 7 pounds of potassium were removed in the crops during the fifty years; while there were applied 4300 pounds of nitrogen, 1336 pounds of phosphorus, and $4 \mathrm{I} 8 \mathrm{I}$ pounds of potassium. The applications have been nearly double or more than double the amounts removed.

If we compare plots 7 and 3 , we find in the first 9 inches about 23 per cent more nitrogen, 7I per cent more phosphorus, and I9 per cent more potassium in plot 7 than in the unfertilized plot 3 . On the other hand, in the lower strata, plot 7 contains distinctly less phosphorus than plot 3 or 4 , but this difference is much less marked if plots I2, I3, and I4 be considered. The variations in the lower strata are too great to draw conclusions from any one plot, and this is more especially true as regards potassium.

In the lower part of Table 73 are recorded some average results that should be more significant, at least for nitrogen and phos- 


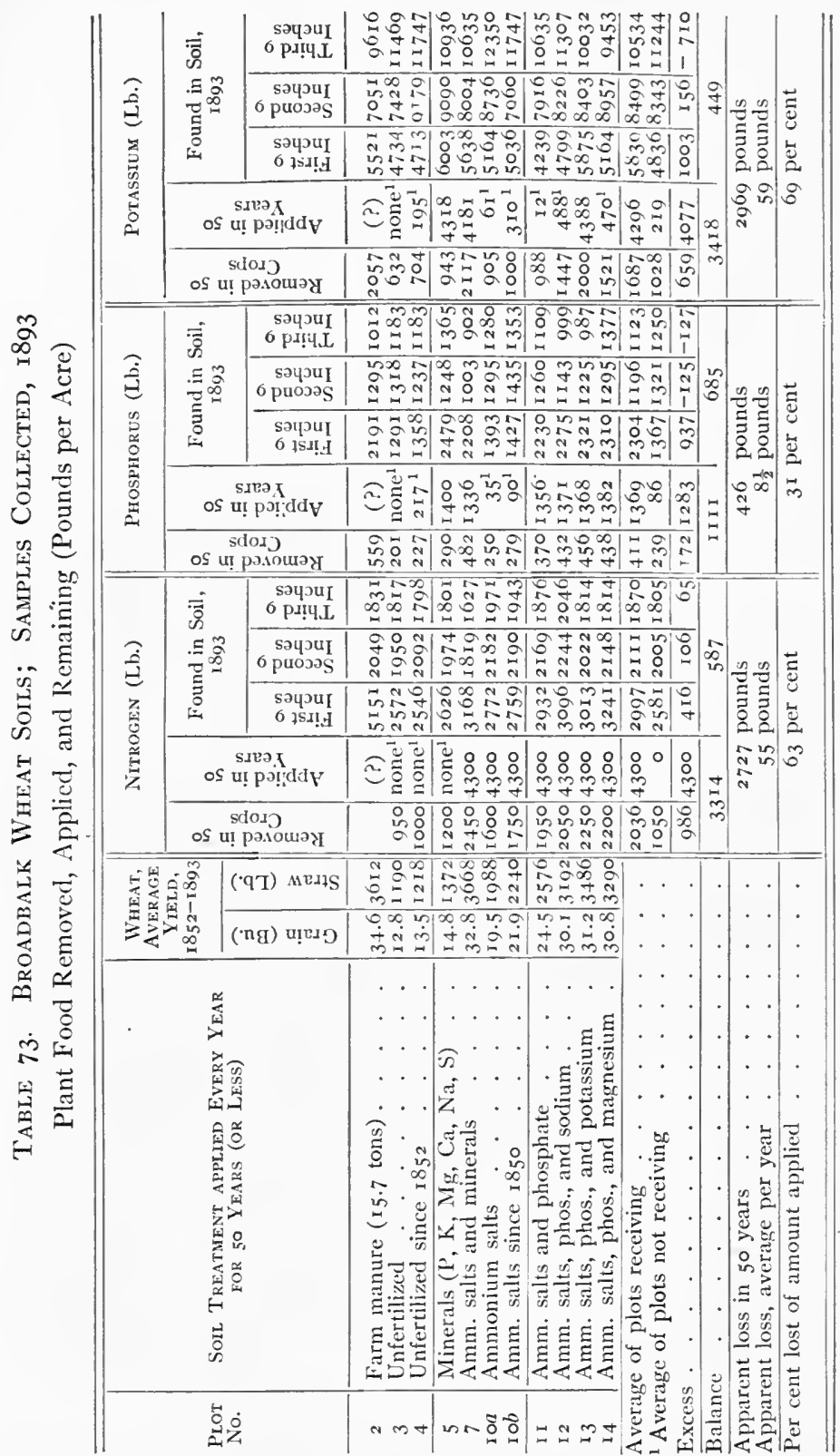




\section{I 2 INVESTIGATION BY CULTURE EXPERIMENTS}

phorus. The line marked " average of plots receiving" includes the average of plots 7 to 14 for nitrogen, of plots 5,7 , and I I to I 4 for phosphorus, and of plots 5, 7, and I3 for potassium; while in the next line are given the averages for the plots as indicated (1) for the respective elements. By subtraction we find the excess or deficiency $(-)$. The difference between the sum of the excesses found in the three soil strata and the balance with respect to applications and removal in crops gives us the apparent loss in 50 years of the respective elements, and indicates an annual loss per acre of 55 pounds of nitrogen, $8 \frac{1}{2}$ pounds of phosphorus, and 59 pounds of potassium, - losses besides those which are accounted for in the crops removed. In terms of plant food applied, these losses amount to 63 per cent of the nitrogen, to $3 \mathbf{I}$ per cent of the phosphorus, and to 69 per cent of the potassium.

There are two principal ways in which plant food may be lost from the surface soil, aside from removal in crops; namely, by leaching and by erosion (including erosion by wind action as well as by water). In addition, some mechanical mixing of surface and subsoil may occur, because of burrowing animals and insects, soil cracking, etc., and losses of nitrogen by dentrification are possible, though not probable to any important extent under normal conditions.

In Table 74 is recorded the average composition of waters collected from the tile drains of Broadbalk field during the years I866, I867, I868, and I869. These averages represent the mean of a large number of analyses made by Doctor Augustus Voelcker. The results are given in Table 74 on the basis of 3 million pounds of water, which corresponds to a drainage of $13 \frac{1}{3}$ inches per acre, which is less than the average annual drainage (I4.73 inches) from the uncropped bare soil of the Rothamsted drain gauge (see Table 65), and more than Dyer's estimate (Io inches) for the ordinary cropped soils at Rothamsted, but probably not more than the average for the cropped soils of central United States. The actual amounts found in pounds per million of drainage water will be secured by dividing these data by three.

Some apparent relationships may be noted between the applications and losses of certain elements, and also between certain elements in the drainage water, such as calcium and sulfur, but 


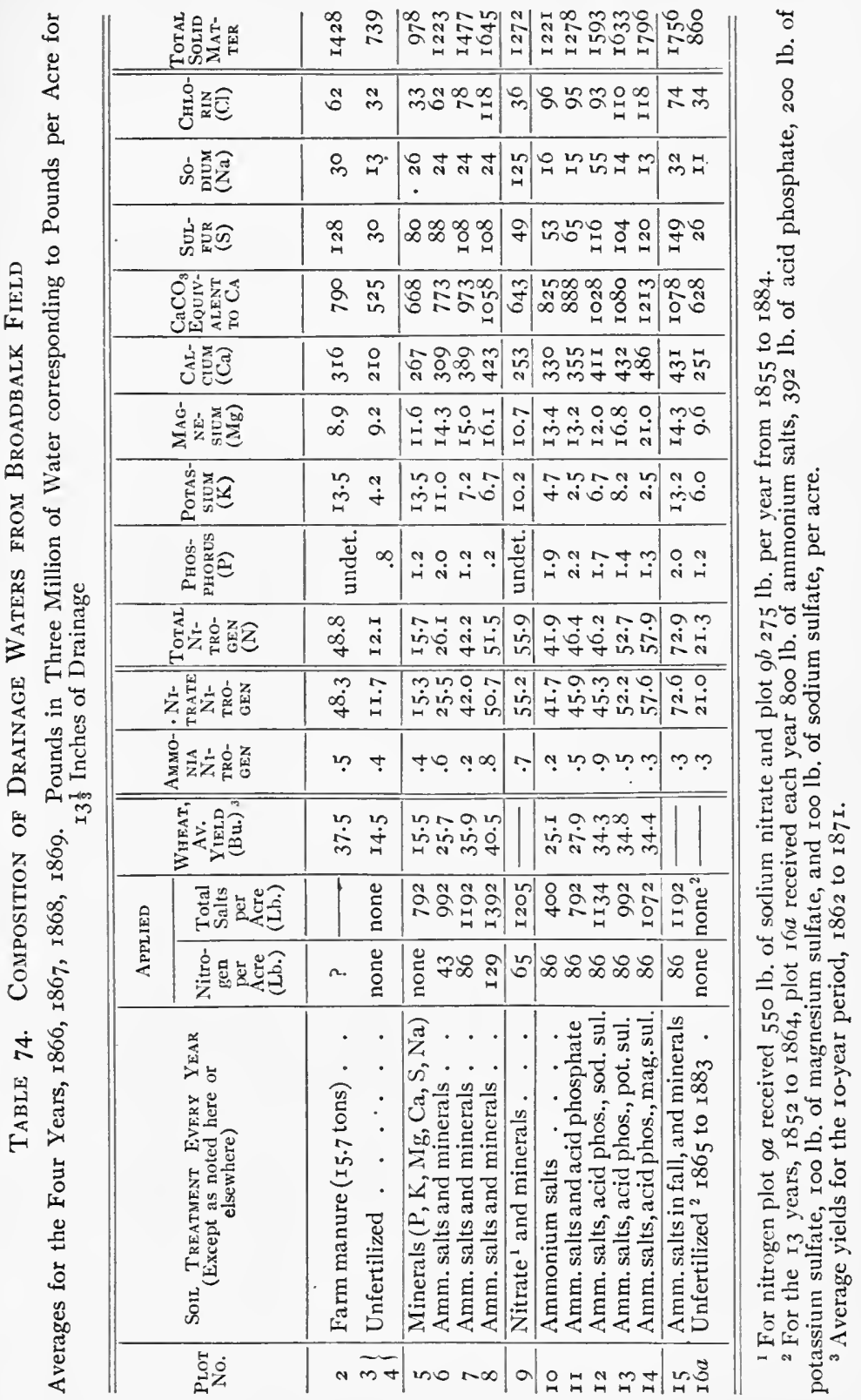




\section{I4 INVESTIGATION BY CULTURE EXPERIMENTS}

the points of chief interest are that from the four or five best yiclding plots the annual losses per acre are probably not more than 50 pounds of nitrogen, $I_{2} \frac{1}{2}$ pounds of phosphorus, and 7 pounds of potassium. Dyer assumes an average drainage of to inches per annum for Rothamsted, which would reduce these figures by one fourth, but he also suggests that the losses in drainage are probably greater now than they were in I866-I869.

While the drainage ccrtainly accounts for most of the loss of nitrogen, there remains not accounted for an annual loss of about 7 pounds of phosphorus and 50 pounds of potassium per acre. Dyer suggests that these losses are to be accounted for by descent into the subsoil. The data for potassium, representing the "acidsoluble" only, are too uncertain to warrant any conclusion. In the author's opinion it is not improbable that some of the potassium, applied as soluble potassium sulfate, may have reacted with silicates and formed compounds that are not dissolved by strong acid. This seems less doubtful when we consider the properties of cement, and the changes that occur even in a short time in the "setting" of that material.

The data afford practically no evidence for the descent into the subsoil of cither phosphorus or potassium. The phosphcrus determinations so nearly represent the total amounts that they serve satisfactorily for general computations, and as an average they show less phosphorus in the subsoil of the plots where phosphorus has been applied, although plots 5 and $\mathrm{I} 4$ are exceptions.

At least most of the unused phosphorus remains in the plowed soil. Thus plots 4 and 5 have produced almost the same average yiclds, and plot 5 contains I I I pounds more phosphorus in the first 9 inches, but only i pounds more in the second depth, than plot 4. The third depth shows a different relation, but this is reversed in the case of plots $10 b$ and $\mathrm{I}$, whose average yields are not markedly different.

With $225^{\circ}$ pounds of phosphorus in the surface 9 inches, it would require about one inch of crosion in 35 ycars to account for an annual loss of 7 pounds of phosphorus. 'This would also account for ro pounds additional loss in nitrogen, and it seems the most probable explanation. Land that has sufficient slope to provide any surface drainage will suffer some erosion if such drain- 
age occurs when the land is not covered with vegetation. Whenever roily water leaves a field, some soil goes with it; and the loss of a tenth of an inch in three or four years is not improbable, even for nearly level land, if annually cultivated, especially if torrential rains sometimes occur (see record of Barn field)

Whether one assumes Io inches or $13 \frac{1}{3}$ inches of drainage, there is some degree of correlation between the computed calcium carbonate equivalent to the calcium found in the drainage water, as shown in Table 74, and the loss of calcium carbonate from the surface soil of Broadbalk field, as recorded in Table 27. While there are marked discrepancies, both methods agree that, as an average, more calcium is removed from the plots receiving ammonium salts.

Analyses made of surface soil from the barley plots on Hoos field in 1889 show in 2 million pounds of soil 960 pounds of phosphorus as an average in the 8 plots receiving no phosphorus, 1560 pounds as an average in the 8 plots receiving acid phosphate without rape cake, Igoo pounds as an average in the 2 plots receiving acid phosphate and rape cake, and 1540 pounds in the farm manure plot $(7-2)$.

Table 75 shows the nitrogen content of the surface 9 inches of the different plots on the Agdell rotation field.

From the data thus far reported, the nitrogen content of the soil on Agdell field appears to be decreasing about ro pounds a year, except on the legume plots which receive rape cake and ammonium salts, where an increase is shown on the "fed " plot amounting to 2 I 2 pounds in 16 years. While the individual variations are great, the results indicate a slightly larger loss of nitrogen in the legume rotation than with fallow, but where nitrogen is applied, the opposite is shown.

The factors of erosion and deposition and of difficulty in securing samples (by the method used) which fairly represent the average of the plot are sufficient to account for any of the changes indicated by these analytical data; and it may be stated that the topography of Agdell field suggests the possible influence of such factors. On the other hand, the indicated gain of 180 pounds of nitrogen per acre during seven years with the legume rotation on the unfertilized land, with all crops removed, has actually been 
Table 75. Agdell Rotation Field, Rothamsted Nitrogen in Surface 9 inches; Pounds per Acre

\begin{tabular}{|c|c|c|c|}
\hline Systems and Soll Treatment & $\begin{array}{l}\text { Nov., } 1867 \\
\text { (After } \\
\text { Wheat) }\end{array}$ & $\begin{array}{c}\text { Oct., I } 874 \\
\text { (After Clover } \\
\text { or Fallow) }\end{array}$ & $\begin{array}{l}\text { Nov. }- \text { J AN., } \\
\text { I } 888_{3} \text { - } 884 \\
\text { (After Wheat) }\end{array}$ \\
\hline $\begin{array}{l}\text { Legume, unfertilized, turnips removed } \\
\text { Legume, unfertilized, turnips fed off } \\
\text { Legume, phosphorus, turnips removed } \\
\text { Legume, phosphorus, turnips fed off . }\end{array}$ & $\begin{array}{l}3 \text { I } 27 \\
3 \text { I I } 3 \\
3 \text { I } 85 \\
3.3 \text { I } 2\end{array}$ & $\begin{array}{l}3307 \\
2349 \\
2978 \\
3170\end{array}$ & $\begin{array}{l}3139 \\
2892 \\
2897 \\
3110\end{array}$ \\
\hline 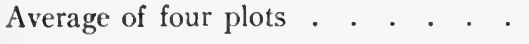 & $3^{I 85}$ & 3076 & 3010 \\
\hline Loss in 16 years . . . . . . . . & $\cdot$ & - & I 75 \\
\hline $\begin{array}{l}\text { Fallow, unfertilized, turnips removed } \\
\text { Fallow, unfertilized, turnips fed off } \\
\text { Fallow, phosphorus, turnips removed } \\
\text { Fallow, phosphorus, turnips fed off }\end{array}$ & $\begin{array}{l}3127 \\
2959 \\
2938 \\
2976\end{array}$ & $\begin{array}{l}3113 \\
2976 \\
2753 \\
2702\end{array}$ & $\begin{array}{l}2952 \\
2724 \\
2786 \\
2947\end{array}$ \\
\hline 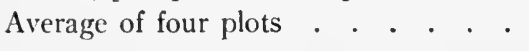 & 3000 & 2842 & 2853 \\
\hline Loss in 16 years & - & . & 147 \\
\hline
\end{tabular}

Plots receiving Minerals, Rape Cake, and Ammonium Salts

\begin{tabular}{|c|c|c|c|c|c|c|c|c|}
\hline $\begin{array}{l}\text { Legume, turnips removed } \\
\text { Legume, turnips fed off }\end{array}$ & & & & . & & $\begin{array}{l}30.38 \\
.3194 \\
\end{array}$ & $\begin{array}{l}3096 \\
329.3 \\
\end{array}$ & $\begin{array}{l}3012 \\
3408 \\
\end{array}$ \\
\hline Average of two plots & & & . & . & $\cdot$ & 3 II 6 & 3195 & 3210 \\
\hline Gain in 16 years & & & . & . & & 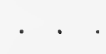 & . & (94) \\
\hline $\begin{array}{l}\text { Fallow, turnips removed } \\
\text { Fallow, turnips fed off }\end{array}$ & . & & . & . & & $\begin{array}{l}3010 \\
3197\end{array}$ & $\begin{array}{l}2887 \\
2940\end{array}$ & $\begin{array}{l}2918 \\
2986\end{array}$ \\
\hline Average of two plots . & - & & . & . & - & $3^{104}$ & 2914 & $295^{2}$ \\
\hline Loss in 16 years & & & . & . & & . & . & $15^{2}$ \\
\hline
\end{tabular}

cited by a writer for the agricultural press in support of the teaching that crop rotation will maintain the fertility of the soil.

Probably no information could now be furnished by the Rothamsted Station that would be of greater interest to the agricultural world than the changes that have occurred in the nitrogen content of the Agdell plots since 1883 .

In Tables 76 and 77 are recorded the average composition of the Agdell crops (except barley not reported) and the Park hay, re- 
spectively. The data are given in pounds per acre removed in the actual crops grown, - on the plots receiving both minerals and nitrogen in case of the Agdell field.

Table 76. Average Composition of Crops grown on Agdell Field Pounds per Acre actually removed in the Crops Harvested.

\begin{tabular}{|c|c|c|c|c|c|c|c|c|c|c|}
\hline \multicolumn{2}{|c|}{ Crops Analyzed } & \multirow{3}{*}{$\begin{array}{c}\text { CRop } \\
\text { YIELDS } \\
\text { (Approx.) }\end{array}$} & \multirow{2}{*}{$\begin{array}{c}\text { NITRO- } \\
\text { GEN } \\
(\mathrm{N})\end{array}$} & \multirow{2}{*}{$\begin{array}{c}\text { PHOS- } \\
\text { PHO- } \\
\text { RUS } \\
\text { (P) } \\
\\
6.8\end{array}$} & \multirow{2}{*}{$\begin{array}{c}\begin{array}{c}\text { Po- } \\
\text { TAS- } \\
\text { SIUM } \\
(\mathrm{K})\end{array} \\
8.5\end{array}$} & \multirow{2}{*}{$\begin{array}{c}\mathrm{MAG}- \\
\mathrm{NE}- \\
\mathrm{SIUM} \\
(\mathrm{Mg}) \\
\\
\\
2 . \mathrm{I}\end{array}$} & \multirow{2}{*}{$\begin{array}{r}\text { CaL- } \\
\begin{array}{l}\text { ClUM } \\
(\mathrm{Ca})\end{array} \\
.7\end{array}$} & \multirow{2}{*}{$\begin{array}{c}\text { SuL- } \\
\text { FUR } \\
\text { (S) }\end{array}$} & \multirow{2}{*}{$\begin{array}{c}\begin{array}{c}\text { SodI- } \\
\text { UM } \\
(\mathrm{Na})\end{array} \\
. \mathrm{C}_{4}\end{array}$} & \multirow{2}{*}{$\begin{array}{r}\text { Chlo- } \\
\text { RIN } \\
\text { (Cl) } \\
.01\end{array}$} \\
\hline Wheat, grain & . & & & & & & & & & \\
\hline Wheat, straw & & & I3.4 & $2 . I$ & 21.8 & 2.0 & 6.4 & $2 . I$ & .62 & 3.28 \\
\hline Wheat crop & & $\longrightarrow$ & $4^{\text {I. }} 7$ & 8.9 & 30.3 & $4 \cdot I$ & $7 \cdot 1$ & 2.3 & .66 & 3.2 \\
\hline wede turnips & & I6 T. & $75 \cdot 5$ & 8.6 & $65 \cdot 7$ & $3 \cdot 7$ & I 5.6 & 10.4 & $7 \cdot 5$ & 5.2 \\
\hline Turnip leaves & & & 8.5 & 1.9 & II.9 & .5 & 9.I & 2.3 & .7 & $5 \cdot 5$ \\
\hline Turnip crop & . & & 94.0 & 10.5 & 77.6 & 4.2 & $24 \cdot 7$ & I 2.7 & 8.2 & $10: 7$ \\
\hline s, grain & - & $23 \mathrm{bu}$. & 49.6 & 5.0 & I 2.6 & I. 5 & 1.5 & 1.0 & .6 & .9 \\
\hline Bean straw & - & $.9 \mathrm{~T}$ & I 4.0 & .9 & 5.8 & I.6 & I $7 \cdot 5$ & I.I & 0.3 & 2.2 \\
\hline Bean crop . & • & & 63.6 & $5 \cdot 9$ & 18.4 & $3 . I$ & 19.0 & 2.I & 9.9 & 3.1 \\
\hline Clover, first $\mathrm{c}$ & & 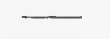 & 103.3 & 7.8 & 58.6 & I 1.6 & 92.5 & 3.7 & I. 9 & II 7 \\
\hline Clov & l crop & & & 4.5 & 26.5 & 5.0 & 36.8 & $2 . I$ & .8 & 6.I \\
\hline Clover, both $\mathrm{c}$ & rops & $3.0 \mathrm{~T}$. & I 59.3 & I 2.3 & 85.1 & I 7.5 & $129 \cdot 3$ & 5.8 & 2.7 & I 7.8 \\
\hline
\end{tabular}

The results for wheat are the average of the eight crops grown from 1850 to 1879 ; for turnips, the average is for three crops (1864, I872, and 1876 ); for beans, six crops (I854 to 1870 and $1878)$; and the clover data are averages of 1850 and 1874 for the first and second crops.

In Table 77 the data represent, as a rule, in pounds removed per acre per annum, the averages for the 18 years, 1856 to 1873 (first crops only).

This mass of data concerning actual results with mixed grasses is especially valuable for the use of the analytical mind. A cursory examination will show that, within the groups, the total yield of organic matter correlates better with the nitrogen and phosphorus removed than with most other constituents, while the amount of potassium removed seems to be controlled by the 
4I8 INVESTIGATION BY CULTURE EXPERIMENTS

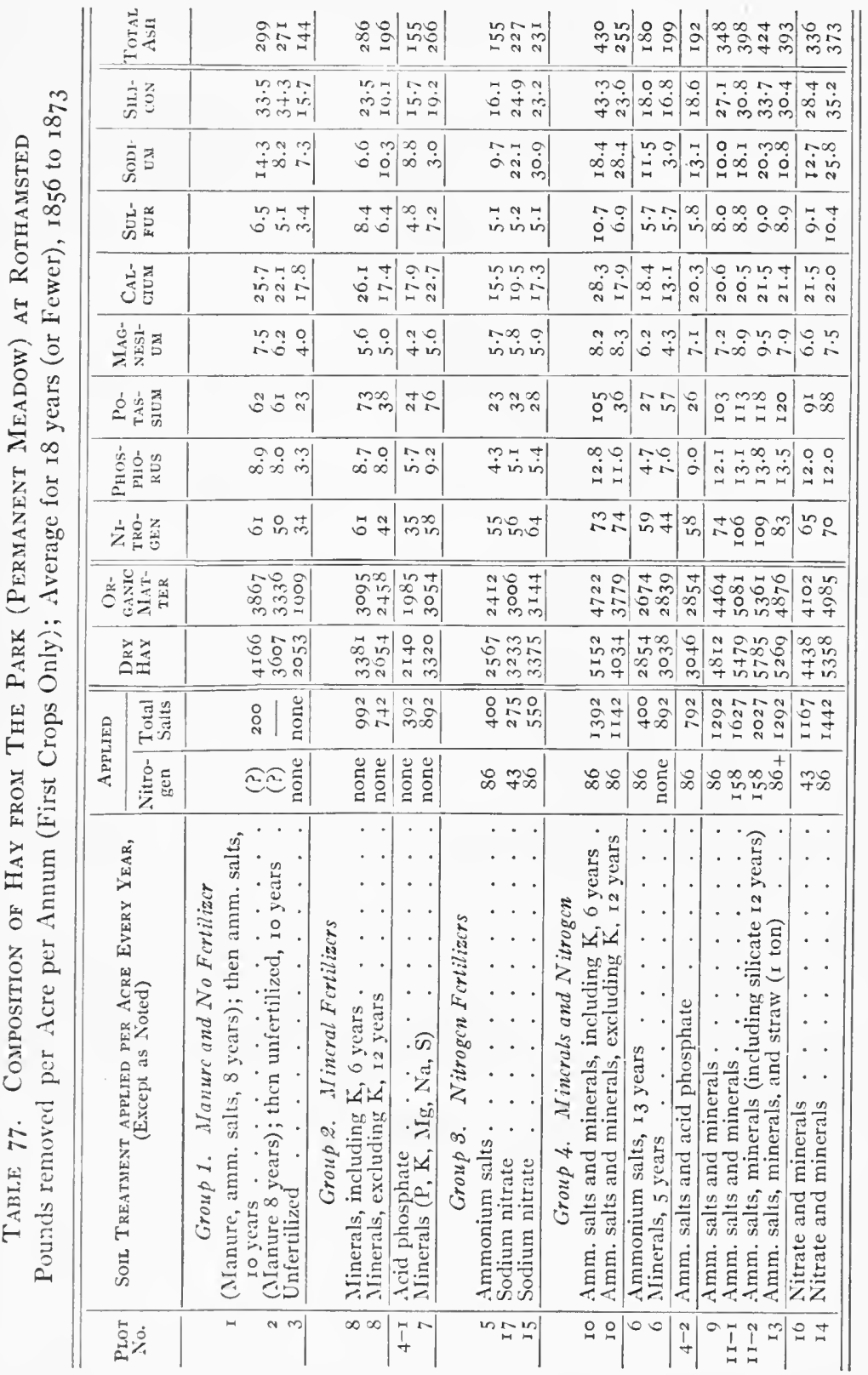


amount applied as much or more than by the amount of crop harvested. Thus the organic matter from plot 7 is 1.54 times that from plot $4-\mathrm{I}$; while the corresponding ratios are $\mathrm{I} .62$ for phosphorus and 1.66 for nitrogen, but 3.19 for potassium. Quite similar results are secured by comparing plots $4^{-2}$ and 9 , the ratios being 1.56 for organic matter, I. 28 for nitrogen, I. 34 for phosphorus, and 3.96 for potassium.

These facts seem to harmonize with the suggestion previously made that some of the apparent effect on the yield of hay, of the potassium and other alkali salts, is associated with their power to take phosphorus (in part from the surface, where applied in top dressings) and deliver it to the root system of the plant. Another influence of possible importance is the tendency of the alkali salts to reduce or prevent soil acidity. Of course, potassium has some value for its own sake under certain conditions, as clearly shown in the previous and subsequent pages (see especially the mangelwurzel data).

With the great differences that have developed in the character of the herbage on the different plots, especially in different groups, direct comparisons must involve several factors; and coincidence or indirect correlation may easily be mistaken for direct causal relationship. Thus, compared with plot I4, we would assume that potassium must be the limiting element on plot 4-2; and possibly such is the case, but reference to plots 7 and ro show that other factors are also involved.

Late Crop Yields per Acre on Agdell Field, Rothamsted

\begin{tabular}{|c|c|c|c|c|c|c|c|}
\hline \multirow{2}{*}{\multicolumn{2}{|c|}{$\frac{\text { Soll Treatment . . }}{\text { System . . . . . }}$}} & \multicolumn{2}{|c|}{ UNFERTILized } & \multicolumn{2}{|c|}{ Minerals } & \multicolumn{2}{|c|}{ Minerals and Nitrogen } \\
\hline & & Legume & Fallow & Legume & Fallow & Legume & Fallow \\
\hline Igo8 & $\begin{array}{c}\text { Turnips, roots, lb. } \\
\text { Leaves, lb. . }\end{array}$ & $\begin{array}{l}717 \\
470\end{array}$ & $\begin{array}{l}2419 \\
1747\end{array}$ & $\begin{array}{r}26410 \\
4838\end{array}$ & $\begin{array}{r}20048 \\
3315\end{array}$ & $\begin{array}{l}35 \mathrm{I} 68 \\
\mathrm{~J} 55^{68}\end{array}$ & $\begin{array}{l}44285 \\
14314\end{array}$ \\
\hline I909 & $\begin{array}{l}\text { Barley, grain, bu. } \\
\text { Straw, lb. . . }\end{array}$ & $\begin{array}{l}10.0 \\
1263\end{array}$ & $\begin{array}{l}\text { Ir.4 } \\
\text { II } 34\end{array}$ & $\begin{array}{l}22.1 \\
1892\end{array}$ & $\begin{array}{r}17.4 \\
1426\end{array}$ & 2661 & 20.8 \\
\hline Jgro & Clover, hay, lb. . & 1949 & & 7590 & & 8590 & \\
\hline 1911 & $\begin{array}{l}\text { Wheat, grain, bu. } \\
\text { Straw, lb. . }\end{array}$ & $\begin{array}{l}24.5 \\
2400\end{array}$ & $\begin{array}{c}23.9 \\
2290\end{array}$ & 3753 & $\begin{array}{l}31.9 \\
3205\end{array}$ & ${ }_{363^{3}}^{38.0}$ & 3280 \\
\hline
\end{tabular}




\section{CHAPTER XX \\ PENNSYLVANIA FIELD EXPERIMENTS}

IN 1882 the Pennsylvania Agricultural Experiment Station began, at State College, the oldest extensive field experiments now in progress in America. They include four separate fields, each of which contains 36 eighth-acre plots, or 144 different plots in all. A 4-year rotation is practiced, consisting of corn, oats, wheat, and hay (mixed clover and timothy seeded on the wheat land in the early spring), every crop being represented every year (excepting the hay crop in 1882 ). The land is quite undulating, but the individual plots are separated by a permanent strip of grass sod or turf about two or three feet wide, which practically prevents surface washing from one plot to another, and in but few cases is there evidence of soil washing on the fields. The plots are about $\mathrm{I} \frac{1}{4}$ rods wide by $\mathrm{I} 6$ rods long.

The soil consists largely of a silty clay loam, and contains perhaps Io per cent of small angular rock fragments, chiefly of chert. While this field had been treated with lime some years before the beginning of these experiments, recent examination has shown that the soil is more or less acid. Even where sodium nitrate has been applied, acidity is found as a rule, notwithstanding the tendency of sodium nitrate to neutralize soil acidity, much of the sodium being left in the soil when the nitrogen is taken up by plants. Where ammonium sulfate has becn used, especially where heavy applications are made, the soil is very much more acid; and on such plots the red sorrel (Rumex acetocella) is becoming a pest, and a good stand of clover is not secured as a rulc. As hereinbefore stated, the average soil of this ficld contains 2320 pounds of nitrogen, ro8o pounds of acid-soluble phosphorus, and 50,700 pounds of total potassium, in 2 million pounds of the surface soil. 
The following statements are made in the Pennsylvania Report for I90I-1902, pages 195-I97:

"It should be stated that this soil has been formed in place on the underlying rock. The rock is in some instances but a few feet below the surface of the ground. While the surface soil is fairly uniform in fertility and in depth, the subsoil varies greatly as to depth. This soil has good natural underdrainage, and contains a fair supply of humus. While the soil is a somewhat stiff clay loam, the natural drainage is entirely sufficient to carry off excessive moisture, even in time of heavy rainfall."

"The cultivation given this series of plots has been similar to that given to ordinary field crops under good cultural conditions."

"The operations of harvesting have been performed as uniformly as possible for all plots, in order that any variation of the yield might not be due in any way to the difference in the manner of handling the crops when matured.

"Corn. The corn was cut by hand and placed in medium-sized shocks to cure. From the shocks it was husked in the field, and the ears of corn weighed and the yield of stalks weighed when sufficiently cured to store in the barn without danger from heating.

"Oats and Wheat. The oats and wheat have been cut with a twine binder, and the bundles placed in shocks on the plots, where they remained until sufficiently dry for threshing. They were then drawn to the barn, weighed, threshed, and the weight of the grain deducted from the total weight to ascertain the weight of straw and chaff, the difference being the credited weight of straw.

"Hay. The grass (clover and timothy mixed) has been cut with a mowing machine and given the same treatment as found practical to give grass and hay on the College and Experiment Station farms. When the forage was sufficiently cured to store in the barns without danger from fermentation, the hay was drawn to the barn and weighed."

While the three grain crops werc grown in 1882 and all crops in I883, the full fertilizer treatment for the four years was not received by some plots until ${ }^{8} 88_{5}$, and consequently the results for the first three years must be considered as preliminary. The fertilizer applications are made only in alternate years, for corn and wheat (excepting the caustic lime, which is applied but once in four years, for corn).

The application for nitrogen is at three different rates, 24, 48, and 72 pounds per acre in alternate years, or 48,96 , and 144 for each rotation; and three different forms of nitrogen are used, dried blood, sodium nitrate, and ammonium sulfate. For the four years the potassium applied amounts to I66 pounds (always in potassium chlorid, so-called "muriate" of potash), and the phos- 
phorus amounts to 42 pounds (usually in dissolved bone black). On two plots ( 12 and 35 ) the phosphorus ( 42 pounds) is applied in the form of ground bone, which also supplies ro pounds additional nitrogen.

Farm manure (commonly called " yard manure," but sometimes "barn manure," in the Pennsylvania Reports) was applied at three different rates, I $2, \mathrm{I} 6$, and 20 tons per acre (one half for corn and the other half for wheat), and in addition 12 tons were applied on one of the caustic lime plots (No. 22). No analysis seems to have been made of the manure, but the Pennsylvania Station has at times adopted an average published by the United States Department of Agriculture, representing one ton to contain 9.8 pounds of nitrogen, 2.8 pounds of phosphorus, and 7.I pounds of potassium, - figures that are not far from the general average of yard manure (10, 3, 8). Probably the 20 tons of manure carry a third more nitrogen and phosphorus, and nearly the same amount of potassium, as the heaviest fertilizer application ( $144 \mathrm{lb} . \mathrm{N}, 42 \mathrm{lb} . \mathrm{P}$, and $\mathrm{I} 66 \mathrm{lb} . \mathrm{K}$ ).

The other applications for each four years include 640 pounds of land-plaster (gypsum), 4 tons of ground limestone, and 2 tons of caustic lime, weighed as calcium oxid and applied after being waterslacked.

In addition there are five plots in each series that have received no fertilizer since 1882 , but one of these (No. 8) is reported to have received annual applications of farm manure during the ro years previous to $\mathrm{I} 882$.

The numbering of plots and the treatment applied for one series of 36 plots is the same as for every other series. By using four different series, four times as much data are secured during a given number of years as could be secured from one series. Thus, during the 24 years ( 1885 to I908), there have been 24 crops of corn, 24 of oats, 24 of wheat, and 24 of hay, with every different kind of treatment; whereas, during 6I years, on Agdell field at Rothamsted there have been harvested only I $_{5}$ crops of turnips, I 5 of barley, I $_{5}$ of legumes, and I $_{5}$ of wheat (the turnips having failed one year). Of course the effect of 60 years' cropping cannot be secured in 27 years, but the Pennsylvania system must give more trustworthy results for the like number of years. 


\section{Table 78. Pennsylvania Experiments: Four-year Rotation}

Records per Acre for Six Complete Rotations, I885 to I 908

\begin{tabular}{|c|c|c|c|c|c|c|c|c|c|c|c|c|}
\hline \multicolumn{4}{|c|}{$\begin{array}{c}\text { TREATMENT FOR EACH } \\
\text { FOUR YEARS }\end{array}$} & \multicolumn{4}{|c|}{$\begin{array}{l}\text { AVERAGE OF } \\
24 \text { YEARS }\end{array}$} & \multicolumn{5}{|c|}{ From Four Acres } \\
\hline $\begin{array}{l}0 \\
7 \\
\frac{0}{0}\end{array}$ & $\begin{array}{l}\text { Important } \\
\text { Elements } \\
\text { App'ied }\end{array}$ & $\begin{array}{l}\text { Ni- } \\
\text { tro- } \\
\text { gen } \\
\text { per } \\
\text { Acre } \\
\text { (Lb.) }\end{array}$ & $\begin{array}{l}\text { Form of Nitro- } \\
\text { gen Applied }\end{array}$ & $\begin{array}{l}\text { Corn } \\
\text { Av. } \\
\text { Bu. } \\
\text { per } \\
\text { Acre }\end{array}$ & $\begin{array}{l}\text { Oats } \\
\text { Av. } \\
\text { Bu. } \\
\text { per } \\
\text { Acre }\end{array}$ & $\begin{array}{c}\text { Wheat } \\
\text { Av. } \\
\text { Bu. } \\
\text { per } \\
\text { Acre }\end{array}$ & $\begin{array}{c}\text { Hay } \\
\text { Av. } \\
\text { Lb. } \\
\text { per } \\
\text { Acre }\end{array}$ & $\begin{array}{l}\text { Value } \\
\text { of the } \\
\text { Four } \\
\text { Crops }\end{array}$ & $\begin{array}{l}\text { Va'ue } \\
\text { if Un- } \\
\text { fertil- } \\
\text { ized }\end{array}$ & $\begin{array}{l}\text { Va!ue } \\
\text { of In- } \\
\text { crease }\end{array}$ & $\begin{array}{c}\text { Cost } \\
\text { of } \\
\text { Treat- } \\
\text { ment }\end{array}$ & $\begin{array}{c}\text { Profit } \\
\text { or } \\
\text { (- Loss) }\end{array}$ \\
\hline $\begin{array}{l}I \\
2 \\
3 \\
4 \\
\end{array}$ & 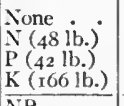 & $\begin{array}{r}48 \\
- \\
\end{array}$ & Dried blood & $\begin{array}{l}29.2 \\
3.3 .2 \\
40.4 \\
33.1 \\
\end{array}$ & $\begin{array}{l}27.8 \\
29.4 \\
34.9 \\
3 \mathrm{I} .2 \\
\end{array}$ & $\begin{array}{l}10.1 \\
11.7 \\
15.1 \\
10.0\end{array}$ & 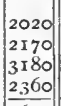 & $\begin{array}{r}331.69 \\
35.14 \\
44.72 \\
35.66 \\
\end{array}$ & $\begin{array}{r}831.69 \\
32.12 \\
32.55 \\
32.08 \\
\end{array}$ & $\begin{array}{r}\$- \\
3.02 \\
12.17 \\
2.68 \\
\end{array}$ & $\begin{array}{l}\$-\text { - } \\
7.20 \\
5.04 \\
0.96 \\
\end{array}$ & $\begin{array}{l}(-4.18) \\
7.13 \\
(-7.28) \\
\end{array}$ \\
\hline $\begin{array}{l}5 \\
6 \\
7 \\
\end{array}$ & $\begin{array}{lll}\mathrm{NP} & \cdot & \cdot \\
\mathrm{NK} & \cdot & \cdot \\
\mathrm{PK} & \cdot & \cdot\end{array}$ & $\begin{array}{r}48 \\
48 \\
\end{array}$ & $\begin{array}{l}\text { Dried blood : } \\
\text { Dried blood : }\end{array}$ & $\begin{array}{l}42.8 \\
34.7 \\
48.4\end{array}$ & $\begin{array}{l}38.9 \\
3.3 \cdot 5 \\
40.8\end{array}$ & $\begin{array}{l}\text { I } 8.9 \\
12.8 \\
17.7\end{array}$ & $\begin{array}{l}3610 \\
2690 \\
4340\end{array}$ & & $\begin{array}{l}33.41 \\
33.84 \\
34.27\end{array}$ & $\begin{array}{r}17 \cdot 30 \\
5 \cdot 39 \\
20.32\end{array}$ & $\begin{array}{l}12.24 \\
17.16 \\
15.00\end{array}$ & $\begin{array}{r}5.06 \\
(-11.77) \\
5.32\end{array}$ \\
\hline 8 & Manure for & Io vear & irs prior to 1882 & 45.0 & 3.5 .4 & I 5.1 & 3560 & 47.62 & $34 \cdot 70$ & 12.92 & (?) & I 2.02 \\
\hline $\begin{array}{r}9 \\
10 \\
11 \\
12 \\
\end{array}$ & 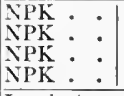 & $\begin{array}{r}48 \\
96 \\
144 \\
60 \\
\end{array}$ & $\begin{array}{l}\text { Dried blood : } \\
\text { Dried blood : } \\
\text { Dried blood : } \\
\text { Blood and bone }\end{array}$ & $\begin{array}{l}47.6 \\
47.4 \\
48.5 \\
4 \sim .6 \\
\end{array}$ & $\begin{array}{l}4 \mathrm{I} .9 \\
42.9 \\
42 . \mathrm{I} \\
4 \mathrm{II.I} \\
\end{array}$ & & $\begin{array}{l}4380 \\
4140 \\
4220 \\
4220 \\
\end{array}$ & & & & $\begin{array}{l}22.20 \\
29.40 \\
36.60 \\
23.16 \\
\end{array}$ & $\begin{array}{r}(-.33) \\
(-6.98) \\
(-13.10) \\
(-2.88) \\
\end{array}$ \\
\hline$\underline{13}$ & Land-plaster & r (Ĺas & $\left.\mathrm{SO}_{4}\right), 640 \mathrm{lb}$. & 36.2 & 30.6 & 12.0 & 2480 & 38.32 & 36.84 & 1.48 & 1.60 & $(-.12)$ \\
\hline $\begin{array}{l}14 \\
15 \\
\end{array}$ & $\begin{array}{l}\text { None } \cdot \cdot 1 \\
\mathrm{PK} \\
\end{array}$ & -1 & & $\begin{array}{l}35.5 \\
47.8\end{array}$ & $\begin{array}{l}29.4 \\
37.8\end{array}$ & & $\begin{array}{l}2400 \\
4290\end{array}$ & & $\begin{array}{l}37.27 \\
37.20\end{array}$ & 16.20 & $\overline{15.00}$ & $\overline{1.20}$ \\
\hline$\frac{\overline{16}}{17}$ & Yard manur & $\begin{array}{r}\text { re, } 12 \\
48 \mid \\
\end{array}$ & tons $\cdot$ Dried biood & $\begin{array}{l}49 \cdot 5 \\
4 \mathrm{I} . \mathrm{I} \\
\end{array}$ & $\begin{array}{l}39.0 \\
37.8 \\
\end{array}$ & $\begin{array}{l}22.5 \\
20.3 \\
\end{array}$ & $\begin{array}{l}4030 \\
3660 \\
\end{array}$ & $\begin{array}{l}56.87 \\
50.02 \\
\end{array}$ & $\begin{array}{l}37.12 \\
37.05 \\
\end{array}$ & $\begin{array}{l}19.75 \\
13.87 \\
\end{array}$ & $\begin{array}{r}3.60 \\
22.20 \\
\end{array}$ & $\begin{array}{r}16.15 \\
(-8.33) \\
\end{array}$ \\
\hline I8 & Yard manur & e, $16 \mathrm{t}$ & tons : . & 46.5 & 41.0 & 23.7 & $42 \mathrm{co}$ & 58.04 & 36.97 & 21.07 & 4.80 & \\
\hline I0 & NPK . . I & 961 & Dried blood & 47.8 & 40.1 & 22.9 & 4120 & 57.15 & 36.90 & 20.25 & 29.40 & $(-9.15)$ \\
\hline 20 & Yard manur & $\mathrm{re}, 20$ & tons . . . & 50.1 & 40.8 & 24. I & 4.300 & 59.55 & 36.82 & 22.73 & 6.00 & I6.73 \\
\hline $2 \mathrm{I}$ & NPK . . I & $144 !$ & Dried blood . & 48.8 & 40.4 & 24.8 & 4000 & & 36.75 & $21.8 \mathrm{I}$ & 36.60 & $(-14.79)$ \\
\hline 23 & $\begin{array}{l}\text { Lime }(\mathrm{CaO} \\
\text { nure, I2 } \\
\text { Lime (CaO) }\end{array}$ & $\begin{array}{l}\text {, } 2 \text { to } \\
\text { ons } \\
12 \text { ton }\end{array}$ & 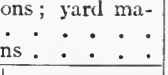 & $\begin{array}{l}51.4 \\
27.4 \\
\end{array}$ & $\begin{array}{l}40.6 \\
27.2 \\
\end{array}$ & $\begin{array}{l}22.5 \\
14.4 \\
\end{array}$ & $\begin{array}{l}4330 \\
2440 \\
\end{array}$ & $\begin{array}{l}58.0 \mathrm{I} \\
35 . \mathrm{I} 5 \\
\end{array}$ & $\begin{array}{l}36.67 \\
36.60 \\
\end{array}$ & $\left(\begin{array}{r}22.24 \\
-1.45) \\
\end{array}\right.$ & $\begin{array}{r}12.60 \\
0.00 \\
\end{array}$ & $\begin{array}{r}9.64 \\
(-10.45) \\
\end{array}$ \\
\hline $\begin{array}{l}24 \\
25 \\
26 \\
27 \\
28 \\
\end{array}$ & 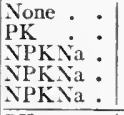 & $\begin{array}{r}- \\
48 \\
96 \\
144\end{array}$ & $\begin{array}{l} \\
\text { Sodium nitrate } \\
\text { Sodium nitrate } \\
\text { Sodium nitrite }\end{array}$ & $\begin{array}{l}30.4 \\
47 \cdot 5 \\
49 \cdot 3 \\
49 \cdot 5 \\
4 ? .6 \\
\end{array}$ & $\begin{array}{l}30.9 \\
40.2 \\
40.3 \\
4 \mathrm{I} . \mathrm{I} \\
4 \mathrm{I} .3 \\
\end{array}$ & $\begin{array}{l}13.4 \\
18.5 \\
21.9 \\
23.7 \\
24.5 \\
\end{array}$ & \begin{tabular}{|l|}
2410 \\
4230 \\
4330 \\
4370 \\
4370 \\
\end{tabular} & & $\begin{array}{l}36.52 \\
36.74 \\
36.96 \\
37.18 \\
37.40 \\
\end{array}$ & & $\begin{array}{l}15.00 \\
22.20 \\
29.40 \\
36.60 \\
\end{array}$ & $\begin{array}{r}2.59 \\
(-1.49) \\
(-7.22) \\
(-13.99) \\
\end{array}$ \\
\hline $\begin{array}{r}29 \\
30 \\
31 \\
32 \\
\end{array}$ & $\begin{array}{l}\mathrm{PK} \\
\mathrm{NPK}: \\
\mathrm{NPK}: \\
\mathrm{NPK}: \\
\end{array}$ & \begin{tabular}{r|}
48 \\
96 \\
$\mathrm{r} 44$
\end{tabular} & $\begin{array}{l}\text { Amm. su'fate : } \\
\text { Amm. su'fate : } \\
\text { Amm. sulfate : }\end{array}$ & $\begin{array}{l}42.7 \\
46.4 \\
46.9 \\
40.1 \\
\end{array}$ & $\begin{array}{l}38.6 \\
39.8 \\
41.1 \\
40.3 \\
\end{array}$ & $\begin{array}{l}17.4 \\
21.6 \\
23.5 \\
22.5 \\
\end{array}$ & $\begin{array}{l}4040 \\
4020 \\
3630 \\
3280 \\
\end{array}$ & $\begin{array}{l}50.83 \\
55 \cdot 36 \\
56.09 \\
51.72 \\
\end{array}$ & $\begin{array}{l}37.62 \\
37.84 \\
38.06 \\
38.28 \\
\end{array}$ & $\begin{array}{l}\text { I } 3.2 \text { I } \\
\text { I } 7.52 \\
\text { I } 8.03 \\
\text { I } 3.44 \\
\end{array}$ & $\begin{array}{l}5.00 \\
22.20 \\
29.40 \\
36.60 \\
\end{array}$ & $\begin{array}{l}(-1.79) \\
(-4.68) \\
(-11.37) \\
(-23.16) \\
\end{array}$ \\
\hline $\begin{array}{r}33 \\
34 \\
\end{array}$ & $\begin{array}{l}\text { Land-plaster } \\
\text { Ground lime }\end{array}$ & $\begin{array}{l}r \text { (CaS } \\
\text { esione }\end{array}$ & $\begin{array}{l}\left.\mathrm{SO}_{4}\right), 640 \text { lb. } \\
\left(\mathrm{CaCO}_{3}\right), 4 \text { ton }\end{array}$ & $\begin{array}{l}31.5 \\
34.9\end{array}$ & $\begin{array}{l}31.2 \\
32.4\end{array}$ & $\begin{array}{l}13.1 \\
15.5\end{array}$ & $\begin{array}{l}2570 \\
2880\end{array}$ & $\begin{array}{l}37.27 \\
41.43\end{array}$ & $\begin{array}{l}38.50 \\
38.72\end{array}$ & 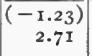 & $\begin{array}{l}1.60 \\
6.00\end{array}$ & $\begin{array}{l}(-2.83) \\
(-3.29)\end{array}$ \\
\hline $\begin{array}{l}35 \\
36\end{array}$ & $\begin{array}{l}\text { N'K * : } \\
\text { None : }\end{array}$ & 60 & Blood and bone & $\begin{array}{l}48.5 \\
33.6\end{array}$ & $\begin{array}{l}40.4 \\
31.1\end{array}$ & $\begin{array}{l}21.7 \\
14.1\end{array}$ & $\begin{array}{l}4690 \\
2730\end{array}$ & $\begin{array}{l}58.36 \\
39.15\end{array}$ & $\begin{array}{l}38.94 \\
39.15\end{array}$ & 19.42 & 23.16 & $(-3 \cdot 74)$ \\
\hline
\end{tabular}

${ }^{1}$ Where used, potassium is always applied at the rate of $\mathrm{I} 66 \mathrm{lb}$. per acre in potassium chlorid, and phosphorus always at the rate of $42 \mathrm{lb}$. per acre in acid bone black except on plots 12 and 35, where ground bone is used. One half of the application is made for corn and the other half for wheat, except the burnt lime, which is all applied for corn.

In Table 78 are recorded the average results in actual yields of corn, oats, wheat, and hay, for the 24 years, 1885 to 1908 . In order 
to eliminate so far as possible the influence of seasonal variation in individual crops and to simplify comparison, the aggregate value of the four crops has been computed, so that in all cases the financial statement refers to values for four acres. No value is allowed for the corn stover or straw, and the prices used are 35 cents a bushel for corn, 30 cents for oats, 70 cents a bushel for wheat, and $\$ 3$ per I000 pounds for hay. While these prices should be modified to suit local conditions, they are as high as can safely be used as a basis for planning profitable systems in the center of the principal graingrowing section of the United States, especially if we must allow for some shrinkage (particularly in the yield of hay) and for occasional unavoidable losses from damaging storms.

In the column headed "Value of the four crops," it will be seen that the figures range from $\$ 3$ I.69 (plot $\mathrm{x}$, untreated) to $\$ 60.0 \mathrm{r}$ (plot 28, receiving phosphorus, potassium, and the heaviest application of sodium nitrate). The four untreated plots show \$31.69, $\$_{37.27}, \$_{36.52}$, and $\$_{39.15}$, making a very considerable variation; and the problem presents itself, How shall we determine the increase produced by the different kinds of treatment? Manifestly, we must adopt some method of estimating what would have been the yield of the fertilized plots if they had not been fertilized. The average of the four untreated plots would be the most satisfactory under some conditions, but plainly this is not correct for these conditions, because this would show an injurious effect from the nitrogen alone, whereas positive and very appreciable gains are produced in every crop on plot 2 in comparison with the immediately adjoining unfertilized plot (No. I). In the absence of specific objections it seems best to assume that the productive power of the land, if unfertilized, would vary in uniform graduation from one check plot to the next, and the figures given in the column headed "Value if unfertilized" are computed on this basis. While this seems fair to plots near No. I, a comparison of duplicate plots shows some marked differences in "Value of increase," especially be-

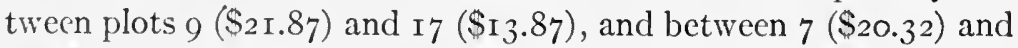
29 ( $\$ 3.21$ ), although in the main the duplication is sufficiently harmonious to justify full confidence in important average results. Thus, the four plots receiving phosphorus and potassium show "Value of increase" amounting to \$20.32, \$I6.20, \$I7.59, and 
\$I3.2I (average $\$$ I6.83); and with 48 pounds of nitrogen in addition, the increase is $\$_{12.87}, \$_{13} .87, \$_{20.7}$, and $\$_{17.52}$ (average \$I 8.49). Here we have an average increase of \$I.66 resulting from the application of $\$ 7.20$ in 48 pounds of nitrogen. Further addition of nitrogen produces some additional increases, but always far below the cost of the nitrogen applied.

After subtracting the cost of treatment (counting nitrogen at I 5 cents a pound, phosphorus at 2 cents in acid bone black and at ro cents in ground bone, and potassium at 6 cents a pound), we find the greatest net profit from commercial plant food is in the use of phosphorus alone.

While $\$ 5.04$ worth of phosphorus used alone produced \$1 2.I 7 increase (plot 3 ), when applied in addition to other treatment, the same amount of phosphorus produced $\$$ I 4.28 over nitrogen (plot 5 over plot 2), \$I 7.64 over potassium (plot 7 over plot 4 ), and \$I6.48 over nitrogen and potassium (plot 9 over plot 6 ). Plots 12 and 35 also show marked increases from the use of ground bone. Plot I7 appears to give too low results compared with the general averages or with plot I 5 , although the increase from plot I 7 (NPK) is $\$ 8.48$ more than that from plot 6 (NK). Thus, under every condition phosphorus has much more than paid its cost, the average effect being a net profit of about 200 per cent for phosphorus if we disregard the cost of the other elements. While phosphorus and nitrogen together more than paid the combined cost and produced distinctly better crops, this system yields less net profit than the phosphorus alone. Similarly, phosphorus and potassium gave larger increases, but less profit than phosphorus alone. In no case has either nitrogen or potassium paid their cost.

It is noted that $\$ 9.96$ worth of potassium alone produced only $\$ 2.68$ increase, but when applied with phosphorus the average increase (\$16.83) was $\$ 4.66$ more than that from phosphorus alone (\$I2.I7). Surely we should try to secure this increase by some means. If kainit at one third the cost would produce the same increase, it could be used with profit, and if farm manure or clover as green manure would produce still greater increase at still less cost, we should plan accordingly.

Where manure was applied at the rate of 12 tons per acre in four years ( 6 tons for corn and 6 for wheat), the value of the increase is 
$\$ 19.75$, as an average of the 24 years. With 16 tons the increase was $\$ 21.07$, and with 20 tons it was $\$ 22.73$. Thus, the 12 tons were worth $\$ r .65$ a ton, 16 tons were worth $\$ 1.32$ a ton, and 20 tons were worth \$r.I4 a ton. Thus, we may say that the first 12 tons were worth $\$ 1.65$ a ton, the next 4 tons were worth 33 cents each, and the last 4 tons were worth 42 cents each, or, as an average, the 8 tons of manure applied after the first I 2 tons were worth 37 cents a ton.

The "cost of treatment" for the manure applied may be determined in at least three different ways:

First, we may consider the manure as a by-product of the farm and only allow for the cost of hauling and spreading, for which 30 cents a ton is sufficient, as a rule. This is the figure used in the tables under discussion.

Second, we may estimate the cost of shipping manure from some fairly large source of supply, such as the stock yards of Chicago or other cities. This cost would probably amount to $\$ \mathrm{r}$ to $\$ 2$ per ton, including the hauling from the railway station and spreading on the land.

Third, we may purchase feed and thus produce manure on the farm and allow for the manure whatever is necessary:

Table 78 shows the average value of the manure applied at different rates, and also the profit from using the manure that is regularly produced on the farm.

There is no record of the amounts of manure applied to plot 8 (on the four series) previous to the beginning of these experiments; but its residual effect is very apparent, the average increase amounting to $\$ 3.23$ per acre per annum for the 24 -year period, in comparison with the unfertilized plots.

Caustic lime alone decreased the crop yields as an average, but when used with manure it produced an average increase of $\$ 2.49$, or about 25 per cent of its cost at $\$ 4.50$ per ton. As an average of the two tests, the light application of land-plaster produced practically no effect. The heavy applications of ground limestone produce an average increase of $\$ 2.7 \mathrm{I}$, or not quite half its cost at $\$ 1.50$ per ton. In the last four or five years the effect of ground limestone alone is apparently decreasing, - a result to be expected sooner or later where no manure or plant food is returned to the 
land. It should be kept in mind, too, that this soil is not very acid, and, consequently, neither burned lime nor ground limestone would be expected to produce marked effects.

Since phosphorus and manure were both used separately with marked effect and profit, it seems probable that phosphorus and manure together would have produced still more satisfactory results; and, if the action of the ground limestone were modified by being used with manure as much as was that of caustic lime, then it, too, would have produced increases above its cost. At least, the facts suggest that manure, phosphorus, and limestone would make a very profitable combination; and green manures and other crop residues could of course be used in place of animal manures.

In Tables 79 and 80 are recorded the 24 years' data arranged in two periods of I 2 years each. While 24 years is too short a period to furnish very trustworthy data concerning the tendency of a system of farming toward increase or decrease in crop yields on one piece of land or with one crop, probably the average results from all crops on the four series of plots in these Pennsylvania Experiments furnish almost, if not quite, as satisfactory information along this line as any of the Rothamsted fields. Such results are recorded in the columns headed "Value of the four crops." It should be remembered that a poor year for oats may be a very good year for winter wheat, corn, or hay, and that four crops every year for 27 years furnish almost twice as much data as the single system on Agdell field, even though continued for 60 years.

As an average of the 20 plots that have received no treatment since 1882 (including the No. 8 plots), the yields have decreased as shown below:

Average Yields per Acre on 20 Unfertilized Plots

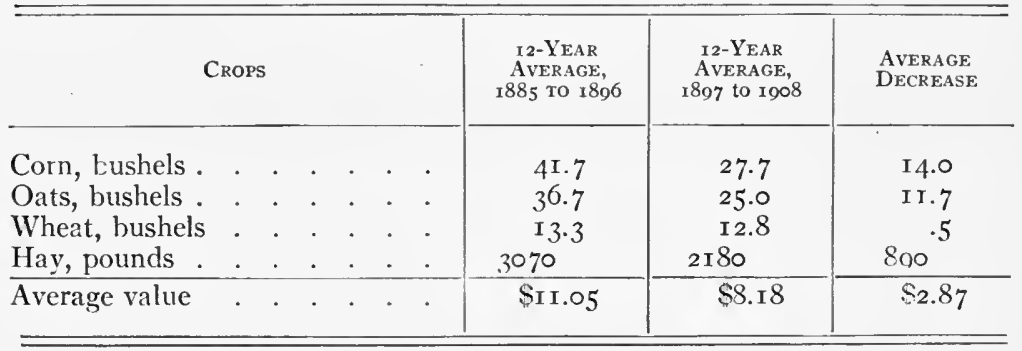




\section{Table 79. Pennsylvania Experiments: Four-year Rotation}

Records per Acre for Three Complete Rotations, I 885 to I 896

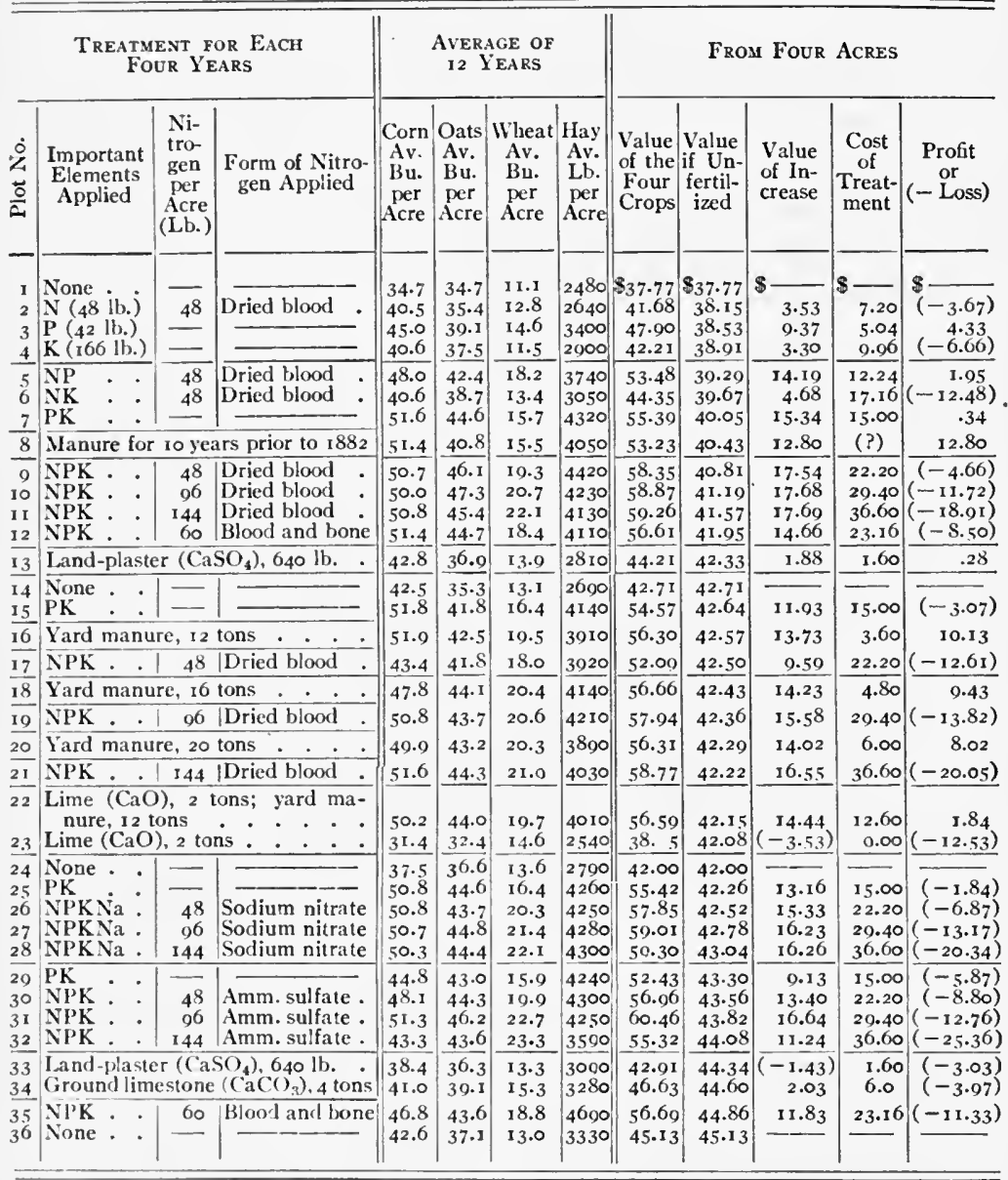

With every crop there has been a decrease in yield, varying from $\frac{1}{2}$ bushel of wheat, or 4 per cent of the crop, to 14 bushels of corn, or 33 per cent of that crop. The average yearly value of produce from one acre has decreased from $\$_{11.05}$ to $\$ 8$. I 8 ; and this $\$ 2.87$ represents the total decrease, not for a 24 -year period, but for a 
Table 80. Pennsyluania Experiments: Four-year Rotation Records per Acre for Three Complete Rotations, I897 to I ģo8

\begin{tabular}{|c|c|c|c|c|c|c|c|c|c|c|c|c|}
\hline \multicolumn{4}{|c|}{$\begin{array}{c}\text { TrEatMent FOR EACH } \\
\text { FoUR Years }\end{array}$} & \multicolumn{4}{|c|}{$\begin{array}{l}\text { AVERAGE OF } \\
\text { I } 2 \text { YEARS }\end{array}$} & \multicolumn{5}{|c|}{ FroM Four ACrEs } \\
\hline $\begin{array}{l}\dot{0} \\
\bar{z} \\
\stackrel{0}{a}\end{array}$ & $\begin{array}{l}\text { Important } \\
\text { Elements } \\
\text { Applied }\end{array}$ & $\begin{array}{l}\text { Ni- } \\
\text { tro- } \\
\text { gen } \\
\text { per } \\
\text { Acre } \\
\text { (Lb.) }\end{array}$ & $\begin{array}{c}\text { Form of Nitro- } \\
\text { gen Applied }\end{array}$ & $\begin{array}{l}\text { Corn } \\
\text { Av. } \\
\text { Bu. } \\
\text { per } \\
\text { Acre }\end{array}$ & $\begin{array}{l}\text { Oats } \\
\text { Av. } \\
\text { Bu. } \\
\text { per } \\
\text { Acre }\end{array}$ & $\begin{array}{l}\text { Wheat } \\
\text { Av. } \\
\text { Bu. } \\
\text { per } \\
\text { Acre }\end{array}$ & $\begin{array}{c}\text { Hay } \\
\text { Av. } \\
\text { Lb. } \\
\text { per } \\
\text { Acre }\end{array}$ & $\begin{array}{l}\text { Value } \\
\text { of the } \\
\text { Four } \\
\text { Crops }\end{array}$ & $\begin{array}{l}\text { Value } \\
\text { if Un-- } \\
\text { fertil- } \\
\text { ized }\end{array}$ & $\begin{array}{l}\text { Value } \\
\text { of ln- } \\
\text { crease }\end{array}$ & $\begin{array}{c}\text { Cost } \\
\text { of } \\
\text { Treat- } \\
\text { ment }\end{array}$ & $\begin{array}{c}\text { Profit } \\
\text { or } \\
\text { (- Loss) }\end{array}$ \\
\hline $\begin{array}{l}1 \\
2 \\
3 \\
4 \\
\end{array}$ & $\begin{array}{l}\text { None } \\
N \text { (48 lib.) } \\
\mathrm{P}(42 \text { lb.) } \\
\mathrm{K} \text { (r66 lb.) }\end{array}$ & $\stackrel{-\overline{48}}{\square}$ & Dried blood . & $\begin{array}{l}23.6 \\
25.8 \\
35.8 \\
25.5 \\
\end{array}$ & $\begin{array}{l}21.0 \\
23.5 \\
30.8 \\
24.9 \\
\end{array}$ & $\begin{array}{r}9.1 \\
10.7 \\
15.5 \\
10.4 \\
\end{array}$ & $\begin{array}{l}1550 \\
1650 \\
2950 \\
1820 \\
\end{array}$ & $\begin{array}{r}\$ 25.58 \\
28.64 \\
41.47 \\
29.14\end{array}$ & $\begin{array}{r}\$ 25.58 \\
26.06 \\
26.54 \\
27.03 \\
\end{array}$ & $\begin{array}{r}\$ 2.58 \\
14.93 \\
2.11 \\
\end{array}$ & $\begin{array}{r}\$-1.20 \\
5.04 \\
0.06 \\
\end{array}$ & $\begin{array}{c}\$-4.62) \\
(-80 \\
(-7.85) \\
\end{array}$ \\
\hline $\begin{array}{l}5 \\
6 \\
7 \\
\end{array}$ & $\begin{array}{lll}\mathrm{NP} & \cdot & \cdot \\
\mathrm{NK} & \cdot & \cdot \\
\mathrm{PK} & \cdot & \cdot \\
\end{array}$ & $\begin{array}{r}48 \\
48 \\
\end{array}$ & $\begin{array}{l}\text { Dried blood } \\
\text { Dried blood }\end{array}$ & $\begin{array}{l}37.6 \\
28.8 \\
45.1\end{array}$ & $\begin{array}{l}35 \cdot 5 \\
28.3 \\
37 \cdot 2\end{array}$ & $\begin{array}{l}10.6 \\
12.3 \\
19.7\end{array}$ & $\begin{array}{l}3470 \\
2340 \\
4360\end{array}$ & & $\begin{array}{l}27.51 \\
27.99 \\
28.48\end{array}$ & & $\begin{array}{l}12.24 \\
17.16 \\
15.00\end{array}$ & $\begin{array}{r}8.19 \\
(-10.95) \\
10.34\end{array}$ \\
\hline 8 & Manure for & Io year & iss prior to I 882 & 38.6 & 29.9 & $\mathrm{I} 4.5$ & 3070 & $4 \mathrm{I} .84$ & 28.96 & & $(!)$ & \\
\hline $\begin{array}{r}9 \\
10 \\
11 \\
12 \\
\end{array}$ & 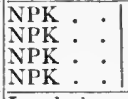 & $\begin{array}{r}48 \\
96 \\
144 \\
60 \\
\end{array}$ & $\begin{array}{l}\text { Dried blood } \\
\text { Dried blood } \\
\text { Dried blood } \\
\text { Blood and bone }\end{array}$ & $\begin{array}{l}44.5 \\
44.8 \\
46.5 \\
47.9 \\
\end{array}$ & $\begin{array}{l}37.7 \\
38.5 \\
38.7 \\
37.5 \\
\end{array}$ & $\begin{array}{l}22.6 \\
25.3 \\
27.2 \\
22.7 \\
\end{array}$ & $\begin{array}{l}4340 \\
4060 \\
4320 \\
4330 \\
\end{array}$ & & & & $\begin{array}{l}22.20 \\
20.40 \\
36.60 \\
23.16 \\
\end{array}$ & $\begin{array}{r}4.09 \\
(-2.21) \\
(-7.12) \\
2.85 \\
\end{array}$ \\
\hline 13 & Land-piaste & ( $(\mathrm{CaS}$ & $\left.\mathrm{SO}_{4}\right), 640 \mathrm{lb}$. & 29.6 & 24.4 & 12.0 & 2140 & 32.50 & $3 \mathrm{I.38}$ & 1.12 & $\mathrm{r} .60$ & $(-.48)$ \\
\hline $\begin{array}{l}14 \\
15 \\
\end{array}$ & $\begin{array}{l}\text { None } \cdot \cdot \cdot \\
\text { PK }:\end{array}$ & $=$ & & $\begin{array}{l}28.5 \\
43.9\end{array}$ & $\begin{array}{l}23.6 \\
33.9\end{array}$ & $\begin{array}{l}\text { I } 2.1 \\
\text { I } 9.3\end{array}$ & $\begin{array}{l}2110 \\
4440\end{array}$ & $\begin{array}{l}31.86 \\
52.37\end{array}$ & $\begin{array}{l}31.86 \\
31.77\end{array}$ & $\overline{20.60}$ & I 5.00 & $\overline{5.60}$ \\
\hline 16 & Yard manur & re, I 2 tc & tons . . . & 47.2 & $35 \cdot 5$ & $25 \cdot 4$ & 4150 & $57 \cdot 40$ & 31.68 & $25 \cdot 72$ & 3.60 & 22.12 \\
\hline 17 & $\mathrm{NPK} \cdot .1$ & $48 \mid 1$ & Dried blood . & 38.7 & $\underline{33.8}$ & 22.6 & 3390 & 40.68 & 31.50 & I 8.00 & 22.20 & $(-4.1 \mathrm{I})$ \\
\hline$\overline{18}$ & Yard manur & re, 16 to & tons $\cdot \cdot$ & $\overline{45 . I}$ & 37.9 & 27.0 & 4440 & $59 \cdot 38$ & 31.50 & 27.88 & 4.80 & 23.08 \\
\hline 19 & NPK.-1 & $96 \mid 1$ & Dried blood & 44.7 & 36.5 & $25 \cdot 3$ & 4020 & 56.37 & 31.42 & & 29.40 & $(-4.45)$ \\
\hline 20 & Yard manur & re, 20 tc & tons : : : & 50.2 & 38.5 & $27 \cdot 9$ & 4710 & 62.78 & $31 \cdot 33$ & & 6.00 & $25 \cdot 45$ \\
\hline $2 \mathrm{I}$ & NPK . . I & 144 & Dried blood & 46.1 & 36.5 & 27.7 & 3980 & 58.42 & 31.24 & 7.18 & 36.60 & $\left(-9.4^{2}\right)$ \\
\hline 23 & $\begin{array}{l}\text { Lime }(\mathrm{CaO}) \\
\text { nure, I } 2 \mathrm{t} \\
\text { Lime }(\mathrm{CaO})\end{array}$ & $\begin{array}{l}\text { ), } 2 \text { to } \\
\text { tons } \\
, 2 \text { ton }\end{array}$ & 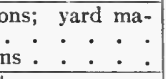 & $\begin{array}{l}52.6 \\
23 \cdot 3 \\
\end{array}$ & $\begin{array}{l}37 \cdot 3 \\
21.9 \\
\end{array}$ & & $\begin{array}{l}4650 \\
2340 \\
\end{array}$ & $\begin{array}{l}61.26 \\
31.62 \\
\end{array}$ & $\begin{array}{l}31.15 \\
31.06 \\
\end{array}$ & $\begin{array}{r}30.11 \\
.56 \\
\end{array}$ & $\begin{array}{r}12.60 \\
9.00 \\
\end{array}$ & $\begin{array}{r}17.51 \\
(-8.44) \\
\end{array}$ \\
\hline $\begin{array}{l}24 \\
25 \\
26 \\
27 \\
28 \\
\end{array}$ & 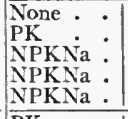 & \begin{tabular}{|r|}
- \\
48 \\
96 \\
144
\end{tabular} \mid & $\begin{array}{l}\text { Sodium nitrate } \\
\text { Sodium nitrate } \\
\text { Sodium nitrate }\end{array}$ & $\begin{array}{l}23 \cdot 3 \\
44 \cdot 1 \\
47 \cdot 7 \\
48.2 \\
49.0 \\
\end{array}$ & $\begin{array}{l}25.2 \\
35 \cdot 7 \\
36.8 \\
37 \cdot 4 \\
38.2 \\
\end{array}$ & $\begin{array}{l}13.1 \\
20.5 \\
23.6 \\
26.2 \\
27.1 \\
\end{array}$ & $\begin{array}{l}2030 \\
4200 \\
4410 \\
4460 \\
4450 \\
\end{array}$ & $\begin{array}{l}30.08 \\
53.10 \\
57 \cdot 49 \\
59.81 \\
60.93\end{array}$ & & $\begin{array}{l}\overline{21.03} \\
26.13 \\
28.26 \\
20.19 \\
\end{array}$ & $\begin{array}{l}\overline{15.00} \\
22.20 \\
29.40 \\
36.60 \\
\end{array}$ & $\begin{array}{r}6.93 \\
3.93 \\
(-1.14) \\
(-7.41) \\
\end{array}$ \\
\hline $\begin{array}{l}29 \\
30 \\
31 \\
32 \\
\end{array}$ & 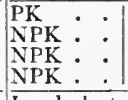 & \begin{tabular}{|r|}
48 \\
96 \\
$\mathrm{r} 44$
\end{tabular} \mid & $\begin{array}{l}\text { Amm. sulfate } \\
\text { Amm. sulfate } \\
\text { Amm. sulfate }\end{array}$ & $\begin{array}{l}40.5 \\
44.6 \\
42.6 \\
36.8 \\
\end{array}$ & $\begin{array}{l}34 \cdot 2 \\
35 \cdot 3 \\
36.0 \\
37.0 \\
\end{array}$ & $\begin{array}{l}18.7 \\
23.3 \\
24.3 \\
21.6 \\
\end{array}$ & $\begin{array}{l}3850 \\
3740 \\
3010 \\
2060 \\
\end{array}$ & $\begin{array}{l}49.08 \\
53.73 \\
51.75 \\
47.98 \\
\end{array}$ & $\begin{array}{l}31.93 \\
32.12 \\
32.31 \\
32.50 \\
\end{array}$ & $\begin{array}{l}17.15 \\
21.61 \\
19.44 \\
15.48 \\
\end{array}$ & $\begin{array}{l}15.00 \\
22.20 \\
29.40 \\
36.60 \\
\end{array}$ & $\begin{array}{r}2.15 \\
(-.59) \\
(-0.96) \\
(-21.12) \\
\end{array}$ \\
\hline $\begin{array}{l}33 \\
34 \\
\end{array}$ & $\begin{array}{l}\text { Land-plaste } \\
\text { Ground lime }\end{array}$ & $\begin{array}{l}\text { er (CaS } \\
\text { estone ( }\end{array}$ & $\begin{array}{l}\left.\mathrm{SO}_{4}\right), 640 \mathrm{lb} . \\
\left(\mathrm{CaCO}_{3}\right), 4 \text { tons }\end{array}$ & $\begin{array}{l}24.7 \\
28.8\end{array}$ & $\begin{array}{l}26.1 \\
25.7\end{array}$ & $\begin{array}{l}\text { I } 2.9 \\
\text { I } 5.8\end{array}$ & $\begin{array}{l}2050 \\
2470\end{array}$ & $\begin{array}{l}31.66 \\
36.26\end{array}$ & $\begin{array}{l}32.69 \\
32.88\end{array}$ & 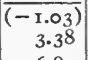 & $\begin{array}{l}1.60 \\
6.00\end{array}$ & $\left(\begin{array}{l}(-2.63) \\
(-2.62)\end{array}\right.$ \\
\hline $\begin{array}{l}35 \\
36\end{array}$ & $\begin{array}{l}\mathrm{NPK} \cdot \\
\text { None } \cdot\end{array}$ & 60 & Blood and bone & $\begin{array}{l}50.1 \\
24.6\end{array}$ & $\begin{array}{l}37.1 \\
25.2\end{array}$ & $\begin{array}{l}24.6 \\
15.3\end{array}$ & $\begin{array}{l}4690 \\
2130\end{array}$ & $\begin{array}{l}50.96 \\
33.27\end{array}$ & $\begin{array}{l}33.07 \\
33.27\end{array}$ & 26.89 & 23.16 & 3.73 \\
\hline
\end{tabular}

I2-year period. Of course, the actual decrease will grow less and less as soil depletion continues, even though the per cent of decrease remain constant, for, as already stated, it is as impossible to completely exhaust a soil as it would be to exhaust a bank account under a contract that only 2 per cent of the remaining deposit 


\section{INVESTIGATION BY CULTURE EXPERIMENTS}

could be withdrawn at any one time. (Two per cent per annum is approximately the rate of decrease in crop values from the 20 unfertilized plots in these experiments.)

There are only four combinations of commercial plant food that have maintained the productive power of the soil, and these are all combinations of the three elements; plot I I (with dried blood, I $44 \mathrm{lb} . \mathrm{N}$ ), plots 27 and 28 (with sodium nitrate, 96 and $444 \mathrm{lb} . \mathrm{N}$ ), and plots 12 and 35 (with bone and blood, $60 \mathrm{lb} . \mathrm{N}$ ). However, as an average of the 24 years, the increase was not sufficient to pay for the cost of treatment on any of these plots. It appears, however, that during the second I 2 -year period plots I 2 and 35 have, as an average, paid the cost of the plant food and left a net profit of $\$ 3.29$ from the four acres. Thus it will be noted that the only plots receiving commercial plant food that has paid its cost even for the second I 2 -year period and that has also fully maintained the crop yields are those treated with ground bone. The difference in favor of ground bone is not sufficient to show that it is distinctly better than acid phosphate, but we may surely conclude that the insoluble bone is at least as good as the acidulated form.

During the first I2-year period the net profit from the use of manure decreased as the amount of manure increased above I 2 tons, but during the second I2-year period the value of the I2-ton application is more than twice as much as during the previous I2 years, and the greatest net profit per acre is where the heaviest applications are made (counting 30 cents a ton for manure), but the value per ton is still greatly in favor of the lighter application, the first I 2 tons being worth $\$ 2$. I 4 a ton and the next 8 tons only 72 cents, compared with \$r.I4 and 4 cents, respectively, for the first I 2 years. While the larger amounts of manure show a distinct cumulative effect $(\$ 56.3$ I to $\$ 62.78$, or $\$ 6.47$ a year from the four crops), the lightest application has but little more than maintained the earlier crop yields, the markedly greater apparent profit during the second I 2 years being due to the decreased yields of the unfertilized land.

In Table $8 \mathrm{I}$ is given a summary of the effect of treatment over the 24-year period, and also a concise statement showing the actual or absolute profit or loss from every system, based upon the average yields secured during the second 12 -year period in comparison 
Table 8i. Pennsylvania Experiments: Four-year Rotation Summary of Financial Results from Soil Treatment in Four-year Rotation

\begin{tabular}{|c|c|c|c|c|c|c|c|c|c|c|c|}
\hline \multicolumn{4}{|c|}{ Treatment for Each Four Years } & \multicolumn{8}{|c|}{$\begin{array}{l}\text { From Four ACREs, ONe EaCh of Corn, OAts, Wheat, } \\
\text { AND HaY }\end{array}$} \\
\hline \multirow{2}{*}{$\begin{array}{l}\dot{0} \\
z \\
\stackrel{0}{c}\end{array}$} & \multirow{2}{*}{$\begin{array}{l}\text { Important } \\
\text { Elements } \\
\text { Applied }\end{array}$} & \multirow{2}{*}{\begin{tabular}{|c|}
$\mathrm{Ni}-$ \\
tro- \\
gen \\
per \\
Acre \\
(L b. $)$
\end{tabular}} & \multirow{2}{*}{$\begin{array}{c}\text { Form of Nitrogen } \\
\text { Applied }\end{array}$} & \multicolumn{2}{|c|}{\begin{tabular}{|c} 
Effect of \\
Treatment \\
(Av. of 24 \\
Years, \\
1885 to 1908 )
\end{tabular}} & \multirow{2}{*}{$\begin{array}{l}\text { Value } \\
\text { of the } \\
\text { Four } \\
\text { Crops } \\
\text { Av. of } \\
2 d^{\prime} \text { I } \\
\text { Yrr. }^{\prime}\end{array}$} & \multirow{2}{*}{$\begin{array}{l}\text { Value } \\
\text { if Un- } \\
\text { fertil- } \\
\text { ized } \\
\text { Av. of } \\
\text { rst I } \\
\text { Yr. }\end{array}$} & \multirow{2}{*}{$\begin{array}{l}\text { Value of } \\
\text { Increase } \\
\text { of } 2 \mathrm{~d} \\
\text { over Ist } \\
\text { I } 2 \text { Yr. }\end{array}$} & \multirow{2}{*}{$\begin{array}{l}\text { Cost } \\
\text { of } \\
\text { Treat } \\
\text { ment }\end{array}$} & \multicolumn{2}{|c|}{$\begin{array}{l}\text { For } \\
\text { Permanent } \\
\text { Systems }\end{array}$} \\
\hline & & & & Profit & Loss & & & & & Profit & Loss \\
\hline $\begin{array}{l}1 \\
2 \\
3 \\
4 \\
\end{array}$ & $\begin{array}{l}\text { None } \\
N(48 \text { lib. }) \\
P(42 \text { lb.) } \\
\text { K ( } 166 \quad \text { lb. })\end{array}$ & $\underline{\underline{48}}$ & $\begin{array}{l}\text { Dried blood }: \\
\end{array}$ & $\frac{3-}{7.13}$ & $\frac{8-18}{7.28}$ & $\begin{array}{r}\$ 25.58 \\
28.64 \\
41.47 \\
29.14 \\
\end{array}$ & $\begin{array}{r}\$ 37.77 \\
38.15 \\
38.53 \\
38.01 \\
\end{array}$ & $\left(\begin{array}{r}-\$ 12.19) \\
(-0.5 \mathrm{I}) \\
2.94 \\
(-0.77)\end{array}\right.$ & $\begin{array}{l}\$-20 \\
7.04 \\
9.06\end{array}$ & 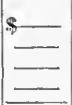 & $\begin{array}{r}\$ 12.10 \\
16.71 \\
2.10 \\
19.73 \\
\end{array}$ \\
\hline $\begin{array}{l}4 \\
5 \\
6 \\
7 \\
\end{array}$ & $\begin{array}{l}\mathrm{NP}: \\
\mathrm{NK}: \\
\mathrm{PK}:\end{array}$ & $\begin{array}{r}48 \\
48 \\
\end{array}$ & $\begin{array}{l}\text { Dried blood } \\
\text { Dried blood : : } \\
\end{array}$ & $\frac{5.06}{5 \cdot 32}$ & $\overline{\mathrm{Ir} .77}$ & $\begin{array}{l}47.94 \\
34.20 \\
53.82\end{array}$ & $\begin{array}{l}39.29 \\
39.67 \\
40.05\end{array}$ & $\begin{array}{r}8.65 \\
(-5.47) \\
13.77\end{array}$ & $\begin{array}{l}12.24 \\
17.16 \\
15.00\end{array}$ & $\bar{E}$ & $\begin{array}{r}3.50 \\
22.63 \\
1.23\end{array}$ \\
\hline 8 & Manure for & r 10 ye & ars prior to 1882 . & 12.02 & - & 41.84 & 53.23 & $(-11.30)$ & $=$ & 二 & 11.30 \\
\hline $\begin{array}{r}9 \\
10 \\
\text { II } \\
12\end{array}$ & $\begin{array}{l}\text { NPK }: \\
\text { NPK }: \\
\text { NPK }: \\
\text { NPK }:\end{array}$ & \begin{tabular}{|r|}
48 \\
96 \\
144 \\
60 \\
\end{tabular} & $\mid \begin{array}{l}\text { Dried blood : } \\
\text { Dried blood : } \\
\text { Dried blood : } \\
\text { Blood and bone: }\end{array}$ & $\bar{E}$ & $\begin{array}{r}.33 \\
6.98 \\
13.10 \\
2.88 \\
\end{array}$ & $\begin{array}{l}55.73 \\
57.12 \\
50.89 \\
56.90 \\
\end{array}$ & $\begin{array}{l}40.81 \\
41.19 \\
41.57 \\
41.95 \\
\end{array}$ & & $\begin{array}{l}22.20 \\
29.40 \\
36.60 \\
23.16 \\
\end{array}$ & $\bar{E}$ & $\begin{array}{r}7.28 \\
13.47 \\
18.28 \\
8.21 \\
\end{array}$ \\
\hline I3 & Land-plast & $\operatorname{ter}(\mathrm{Ca}$ & $\left.\mathrm{SO}_{4}\right), 640 \mathrm{lb}$. & $=$ & .12 & 32.50 & 42.33 & $(-0.8 .3)$ & $\mathrm{I.60}$ & $=$ & $1 \mathrm{I} .43$ \\
\hline $\begin{array}{r}14 \\
15 \\
\end{array}$ & $\begin{array}{l}\text { None : } \\
\text { PK }\end{array}$ & - & $=: \therefore:$ & $\overline{\overline{1.20}}$ & $=$ & $\begin{array}{l}31.86 \\
52.37\end{array}$ & $\begin{array}{l}42.71 \\
42.64\end{array}$ & $\begin{array}{c}(-10.85) \\
9.73\end{array}$ & $\overline{15.00}$ & $\overline{-}$ & $\begin{array}{r}10.85 \\
5.27\end{array}$ \\
\hline$\frac{16}{17}$ & $\frac{\text { Yard mant }}{\text { NPK }}$ & $\frac{\text { ure, I } 2}{148}$ & tons $\cdot$. $\cdot$. & $\underline{16.15}$ & -18.33 & $\begin{array}{l}57.40 \\
49.68\end{array}$ & $\begin{array}{l}42.57 \\
42.50\end{array}$ & $\begin{array}{r}14.83 \\
7.18\end{array}$ & $\begin{array}{r}3.60 \\
22.20\end{array}$ & 11.23 & 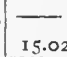 \\
\hline $\mathbf{I} 8$ & Yard man & ure, 16 & tons . . . . . . & 16.27 & - & $59 \cdot 38$ & 42.43 & 16.95 & 4.80 & 12.15 & \\
\hline$\overline{\text { Io }}$ & NPK & 96 & Dried blood . . & $\ldots$ & 0.15 & 56.37 & 42.36 & 14.01 & 29.40 & - & 15.30 \\
\hline$\frac{20}{21}$ & $\frac{\text { Yard manı }}{\text { NPK }}$ & $\begin{array}{l}\text { ure. } 20 \\
\mid 144\end{array}$ & tons $\cdot$ Dried blood $\cdot \cdot$ & $\begin{array}{r}\mathrm{I} .73 \\
\end{array}$ & $=$ & $\begin{array}{l}62.78 \\
58.42 \\
\end{array}$ & $\begin{array}{r}42.29 \\
42.22 \\
\end{array}$ & $\begin{array}{l}20.49 \\
16.20\end{array}$ & $\begin{array}{r}6.00 \\
36.60 \\
\end{array}$ & $\mathbf{1 4 . 4 9}$ & $\overline{20.40}$ \\
\hline$\overline{22}$ & $\begin{array}{l}\text { Lime }(\mathrm{CaC} \\
\text { I2 tons } \\
\text { Lime (CaC }\end{array}$ & $\begin{array}{l}0), 2 \mathrm{t} \\
0), 2 \mathrm{t}\end{array}$ & 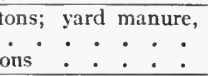 & 9.64 & 10.45 & $\begin{array}{l}61.26 \\
31.62 \\
\end{array}$ & $\begin{array}{l}42.15 \\
42.08 \\
\end{array}$ & $\begin{array}{c}10.1 x \\
(-10.46) \\
\end{array}$ & $\begin{array}{r}12.60 \\
9.00 \\
\end{array}$ & $6.5 \mathrm{I}$ & $\overline{10.46}$ \\
\hline $\begin{array}{l}24 \\
25 \\
26 \\
27 \\
28 \\
\end{array}$ & $\begin{array}{l}\text { None } \\
\text { PK } \\
\text { NPKNa } \\
\text { NPKNa } \\
\text { NPK Na } \\
\end{array}$ & $\begin{array}{r}- \\
48 \\
96 \\
144 \\
\end{array}$ & $\begin{array}{l} \\
\text { Sodium nitrate } \\
\text { Sodium nitrate } \\
\text { Sodium nitrate }\end{array}$ & $\overline{2.59}$ & \begin{tabular}{r|}
$=$ \\
1.49 \\
7.22 \\
13.99
\end{tabular} & \begin{tabular}{|l|}
30.08 \\
53.10 \\
57.49 \\
50.81 \\
60.93 \\
\end{tabular} & $\begin{array}{l}42.00 \\
42.26 \\
42.52 \\
42.78 \\
43.04 \\
\end{array}$ & $\begin{array}{r}(-11.02) \\
10.84 \\
14.97 \\
17.03 \\
17.80 \\
\end{array}$ & \begin{tabular}{l|}
15.00 \\
22.20 \\
2.40 \\
36.60
\end{tabular} & $\bar{z}$ & $\begin{array}{r}11.02 \\
4.16 \\
7.23 \\
12.37 \\
18.71 \\
\end{array}$ \\
\hline $\begin{array}{l}29 \\
30 \\
31 \\
32\end{array}$ & $\begin{array}{l}\mathrm{PK} \\
\mathrm{NPK}: \\
\mathrm{NPK} \\
\mathrm{NPK}:\end{array}$ & $\begin{array}{r}\overline{48} \\
96 \\
\mathbf{4} 44\end{array}$ & $\begin{array}{l}\text { Ammonium sulfate } \\
\text { Ammonium sulfate } \\
\text { Ammonium sulfate }\end{array}$ & E & \begin{tabular}{r|}
1.79 \\
4.68 \\
1.37 \\
23.16
\end{tabular} & $\begin{array}{l}49.08 \\
53.73 \\
51.75 \\
47.98 \\
\end{array}$ & $\begin{array}{l}43.30 \\
43.56 \\
43.82 \\
44.08 \\
\end{array}$ & $\begin{array}{r}5.78 \\
10.17 \\
7.93 \\
3.00 \\
\end{array}$ & $\begin{array}{l}15.00 \\
22.20 \\
29.40 \\
36.60 \\
\end{array}$ & E & $\begin{array}{r}9.22 \\
12.03 \\
21.47 \\
32.70 \\
\end{array}$ \\
\hline $\begin{array}{r}33 \\
34 \\
\end{array}$ & $\begin{array}{l}\text { Land-plast } \\
\text { Ground lin }\end{array}$ & $\begin{array}{l}\text { er }(\mathrm{Ca} \\
\text { nestone }\end{array}$ & $\begin{array}{l}\left.\mathrm{SO}_{4}\right), 640 \mathrm{lb} . \\
\mathrm{e}\left(\mathrm{CaCO}_{3}\right), 4 \text { tons }\end{array}$ & $=$ & \begin{tabular}{r|}
2.83 \\
3.29
\end{tabular} & $\begin{array}{l}31.66 \\
36.26\end{array}$ & $\begin{array}{l}44.34 \\
44.60\end{array}$ & $\begin{array}{r}(-\mathrm{I} 2.68) \\
(-8.34)\end{array}$ & $\begin{array}{l}1.60 \\
6.00\end{array}$ & $=$ & $\begin{array}{l}14.28 \\
14.34\end{array}$ \\
\hline $\begin{array}{l}35 \\
36\end{array}$ & $\begin{array}{l}\text { NPK } \\
\text { None : }\end{array}$ & 60 & Blood and bone : & 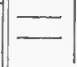 & 3.74 & $\begin{array}{l}59.96 \\
33.27\end{array}$ & $\begin{array}{l}44.86 \\
45 \cdot 13\end{array}$ & $\begin{array}{r}15.10 \\
(-\mathrm{I} 1.86)\end{array}$ & 23.16 & 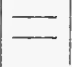 & $\begin{array}{r}8.06 \\
11.86\end{array}$ \\
\hline
\end{tabular}

with yields of the unfertilized land during the previous i2 years. By this means only are we able to avoid the exaggerated influence which is always credited to the soil treatment when comparison is made with the decreasing productiveness of unfertilized check plots. 
For this purpose these Pennsylvania data are probably the most valuable the world affords; and, in the author's opinion, this volume presents no more significant facts than are contained in Table 8I.

The decrease in productive value of the unfertilized plot is markedly uniform, notwithstanding the variation among those plots, the average decrease in value per acre per annum being $\$ 2.87$ and the widest variation from that average being 18 cents. Plot 8 , which had received manure during the Io years previous to $\mathrm{I} 882$, shows the same decrease as the other four unfertilized plots, the average for the four others being $\$$ I I.46, while plot 8 shows \$I I.39. The average yield of the No. 8 plots during the second I2-year period is slightly less than the average yield of the four other unfertilized plots during the first period.

From Table 8I, it will be seen that, for permanent systems of farming, no form or combination of commercial plant food has been used with profit, the annual loss from four acres varying from $\$ 2.46$ with phosphorus alone, $\$ 3.59$ with phosphorus and nitrogen, and $\$ 5$ (as an average) with phosphorus and potassium, to $\$ 20.40$ and $\$ 32.70$ with the complete fertilizer carrying the largest amounts of dried blood and ammonium sulfate, respectively.

Manure costing 30 cents a ton shows net profit in all cases, but the profit is greatly reduced by the addition of caustic lime at $\$ 4.50$ a ton; although the lime produced sufficient increase to pay \$2.I4 a ton for it for use with manure, and the effect of the limemanure treatment is distinctly cumulative, especially upon the clover and timothy, the yield of hay from the lime-manure plots being 640 pounds higher during the second I 2 years than during the earlier period, and 500 pounds more than from the manure alone during the second period.

Would ground limestone at less cost produce a greater benefit, and would the use of phosphorus also with farm manure or green manure produce still greater net profit? The Ohio investigations answer the latter question with a most emphatic affirmative. (See Tables 37, 38, 39, and 39b.)

Thus it will be noted that, as an average of the same I 2 years ( 1897 to I908), the value of the produce per acre per annum is $\$ 14.35$ where 12 tons of manure are used in the Pennsylvania 
four-year rotation, $\$ 13.76$ where 8 tons of manure are used in the Ohio three-year rotation (corn, wheat, and clover, - see Table $39 b$ ), and 17.29 where 40 cents worth of raw phosphate, or 80 cents' worth of acid phosphate, was used in connection with 8 tons of manure in the Ohio rotation.

From Table 8I it can easily be determined that the absolute value per ton of manure for permanent systems is $\$_{1.24}$ for the smallest amount used, \$1.06 for the medium amount, and \$1.02 for the heaviest application. For the additional 8 tons (I2 to 20) the manure was worth $7 \mathrm{r}$ cents a ton.

Based upon comparison with the yields from the untreated land during the last I 2 years, the I 2 tons of manure for the Pennsylvania four-year rotation were worth $\$ 2.14$ a ton; while, for the same I2 years, the 8 tons of manure, in the Ohio three-year rotation, were worth $\$ \mathrm{I} .82$ a ton for the yard manure and \$2.4I a ton for the stall manure. (See Tables 37, 38, and 39.)

Director Thorne has emphasized the fact that the Ohio experiments at Wooster were started on fields that had for many years been under exhaustive tenant husbandry, and the unfertilized plots at Wooster during the last I 2 years are more nearly comparable with those at State College during the same i2 years than during the first $\mathrm{I} 2$ years. Thus the a verage annual produce per acre for the same three crops, corn, wheat, and clover, was \$10.35 for the first I2-year period and $\$ 7.77$ for the second 12-year period, in Pennsylvania; while for the last $\mathrm{I} 2$ years the average value in Ohio has been $\$ 8.06$, these values being based upon the normal unfertilized plots, the No. 8 plots at State College, and the No. I and No. II plots at Wooster (see Table 40) not being included. If the oats are included, the Pennsylvania figures would be \$10.47 for the first 12 years and \$7.61 for the second period.

In Pennsylvania Bulletin 90 (1909), Director Hunt summarizes the results of the first 25 years covered by these experiments. The following tabular statement, containing figures based upon Pennsylvania values, may be of special interest to the student of Eastern conditions.

The upper part of this table shows the total weights of the seven products harvested, including ear corn, corn stover, oats, oat straw, wheat, wheat straw, and hay; and the lower part shows the total 


\section{INVESTIGATION BY CULTURE EXPERIMENTS}

values at 75 cents per 100 pounds of ear corn, 32 cents a bushel for oats, $\$$ I.33 per 100 pounds of wheat, $\$ 2.50$ a ton for corn stover and straw, and \$ro a ton for hay.

\section{Table 8ip. Pennsylvania Field Experiments}

\begin{tabular}{|c|c|c|c|c|c|c|c|c|c|c|}
\hline $\begin{array}{l}\text { Plant } \\
\text { FoOd } \\
\text { APPLIED }\end{array}$ & $\begin{array}{l}\text { UN- } \\
\text { IERTIL- } \\
\text { IZED }\end{array}$ & $\begin{array}{c}\text { Nitro- } \\
\text { GEN } \\
(48 \text { Lb. })\end{array}$ & $\begin{array}{l}\text { Phos- } \\
\text { PHORUS } \\
\text { (42 Lb.) }\end{array}$ & \begin{tabular}{|c|} 
Potas- \\
SIUM \\
(166 \\
Lb.)
\end{tabular} & $\begin{array}{c}\text { Nitro- } \\
\text { GEN } \\
\text { AND } \\
\text { PHOS- } \\
\text { PHORUS }\end{array}$ & $\begin{array}{l}\text { NitRo- } \\
\text { GEN } \\
\text { AND } \\
\text { POTAS- } \\
\text { SIUM }\end{array}$ & $\begin{array}{c}\text { PHOS- } \\
\text { PHORUS } \\
\text { AND } \\
\text { POTAS- } \\
\text { SIUM }\end{array}$ & $\begin{array}{c}\text { BLOOD } \\
\text { (48 Lb. } \\
\text { N), } \\
\text { PHOS- } \\
\text { PHORUS, } \\
\text { POTAS- } \\
\text { SIUM }\end{array}$ & $\begin{array}{l}\text { BLOOD } \\
\text { (96 Lb. } \\
\text { N), } \\
\text { PHOS- } \\
\text { PHORUS, } \\
\text { POTAS- } \\
\text { SIUM }\end{array}$ & $\begin{array}{l}\text { BLOOD } \\
\text { (144 } \\
\text { Lb. N), } \\
\text { PHOS- } \\
\text { PHORUS, } \\
\text { POTAS- } \\
\text { SIUM }\end{array}$ \\
\hline YEARS & \multicolumn{10}{|c|}{ Pounds of Total Products from Four Acres. (Averages) } \\
\hline I $882-86$ & I 4679 & I 4479 & I 4628 & I 4598 & I6I 76 & 15031 & I6577 & I6889 & I 7994 & I 7933 \\
\hline I $887-9$ I & I 4339 & 14060 & I5204 & 14476 & I6469 & I 5959 & I 7000 & I 7492 & I 8706 & I 92 IO \\
\hline $\mathbf{I} 89 \mathbf{I}-96$ & I 26 I I & I I $46 \mathrm{I}$ & I 4647 & I 2404 & I6622 & I 2840 & I 7764 & I 8352 & I94I 5 & I9786 \\
\hline I $897-0$ I & 9562 & 8326 & I 2229 & 8780 & 14038 & 10450 & I 5440 & I. 5867 & I $698 \mathrm{I}$ & I 7221 \\
\hline $1902-06$ & 9848 & 89.55 & I 2907 & $9.58 \mathrm{I}$ & $\mathbf{I} 4.358$ & I I 778 & I6.368 & I6.3.3. & I 7780 & I 8908 \\
\hline $1882-06$ & 12210 & I I 457 & $\mid \mathbf{I} 3922$ & I I967 & I 5534 & I 28I 4 & I 6647 & I6986 & 18137 & I8653 \\
\hline Years & \multicolumn{10}{|c|}{ Values of Total Products from Four Acres. (Averages) } \\
\hline $\mathbf{r} 882-86$ & $\$_{75.35}$ & $\$ 73.61$ & $\$ 74.76$ & $\$ 73.90$ & $\$ 83.35$ & $\$ 74.82$ & $\$ 85.34$ & $\$ 85.20$ & $\$ 89.2 \mathrm{I}$ & $\$ 9 r .53$ \\
\hline I $887^{-9}$ I & 75.46 & 74.I 3 & 79.66 & $74.6 \mathrm{I}$ & 86. I 5 & 77.85 & 87.56 & $87.8 \mathrm{I}$ & 93.49 & 94.70 \\
\hline I $892-96$ & 64.29 & 58.57 & $75 \cdot 5^{8}$ & $6 \mathrm{I} \cdot 34$ & 85.75 & 62.88 & 89.08 & 90.75 & 95.59 & 96.56 \\
\hline I $897^{-0}$ - I & 49.16 & $4^{2} \cdot 3^{6}$ & 61.80 & 43.63 & 71.91 & $5 \mathrm{I} .85$ & $76.8 \mathrm{I}$ & 77.92 & 83.07 & 85.25 \\
\hline $1902-06$ & 50.88 & 45.50 & 67.28 & 47.30 & $74.8_{3}$ & 54.13 & $83 \cdot 73$ & 8.3 .87 & 90.92 & 95.87 \\
\hline I $882-06$ & $\$ 63.03$ & $\$ 58.84$ & $\$ 71.79$ & \$60.16 & $\$ 80.40$ & $\$ 64.3 I$ & $\$ 84.51$ & $\$ 85.10$ & \$90.47 & $\$ 02.79$ \\
\hline I $887-96$ & $\$ 69.88$ & $\$ 66.35$ & $\$ 77.62$ & $\$ 67.98$ & $\$ 85.95$ & $\$ \$ 70.37$ & $\$ 88.3^{2}$ & $\$ 39.28$ & $\$ 94.54$ & $\$_{95.63}$ \\
\hline I $897-06$ & 50.02 & 43.93 & 65.54 & $45 \cdot 47$ & 73.37 & 52.99 & 80.27 & 80.90 & 87.00 & $90.5^{6}$ \\
\hline
\end{tabular}

The last two lines in the table are Io-year averages computed by the author, all other figures being copied from Pennsylvania Bulletin 90.

In his discussion of these experiments, Doctor Hunt makes the following comments (Bulletin 90, page I4):

"The most striking fact brought out by this table is that the application of 48 pounds of phosphoric acid and Ioo pounds of potash in alternate years to a rotation consisting of corn, oats, wheat, and mixed hay (timothy and clover), namely, to the corn and wheat, has, during twenty-five years, maintained the crop-producing power of the soil. There is no evidence thus far to show but what the supply of nitrogen can be indefinitely maintained on this limestone soil by means of a rotation containing clover, provided the mineral fertilizers are abundantly supplied." 
These statements, if true, are of tremendous significance to American agriculture, for they refer to the oldest experiments of the kind in the United States; furthermore, the phosphoruspotassium plot is repeated four times in every series, so that the average results are from 16 different plots of normal soil every year for twenty-five years, and they must be considered highly trustworthy. The small amount of limestone contained in this Pennsylvania soil can very easily be supplied to any other soil by the direct application of ground limestone.

It will doubtless be agreed by all that the results of the first few years at the beginning of a rotation and fertilizer experiment are not to be considered as comparable with the subsequent results. There are several reasons for this; but, for the present purpose, it is sufficient to consider that nitrogen may not have been a limiting element for all crops at the beginning. The data given in Table 8I P are not satisfactory for making any study of this special point, because the averages for the unfertilized land include the results from plot 8 which is represented to have received annual applications of manure during the ten years previous to I882, because of which the addition of nitrogen alone appears (from Table $8 \mathrm{rP}$ ) to have actually decreased the crop yields, which is not the case if we accept the system of comparison adopted for Tables 78 to $8 \mathrm{r}$.

It must be evident from every point of view that nitrogen was not the limiting element for all crops at the beginning of these experiments. It is evident, however, that phosphorus was the principal limiting element at the beginning.

Now, for the sake of simplicity, let us assume that from a given type of very uniform soil (see Table 87) sufficient phosphorus will become available during the season (1903) to meet the needs of a 54 -bushcl crop of corn (plot I02), while sufficient nitrogen will be liberated for a 62-bushel crop. The application of nitrogen without phosphorus could not be expected to appreciably increase the yield (plot 103), while the addition of sufficient phosphorus without nitrogen should increase the yield from 54 to 62 bushels, but unless nitrogen was also supplied, the yield could not be expected to go above 62 bushels. However, by applying nitrogen in addition to phosphorus, the yield might be still further increased (as to 69 


\section{INVESTIGATION BY CULTURE EXPERIMENTS}

bushels on plot 106) to a point where perhaps the supply of available phosphorus again becomes the limiting factor. In other seasons or in later years, these conditions may become reversed, with nitrogen as the most limiting element, and phosphorus with little or no effect except in addition to nitrogen. (Note the results for 1907 and 1908 , in Table 87.)

We can conceive of conditions under which the supply of nitrogen naturally liberated from the soil, when supplemented by that secured from the air by clover grown in the rotation, will meet the needs of the crops grown for several years, during which the nitrogen does not become the limiting element to any marked degree, and it must be plain that in such case the crop yields give little or no information concerning the maintenance of nitrogen in the soil. Thus, it is only after nitrogen becomes the limiting element, in any given system, that the crop yields become an index as to the possible permanency of the nitrogen supply.

In soils that are markedly deficient in phosphorus, that element may still remain the limiting element after the first small application has been made, provided the increased supply of available phosphorus is not sufficient to raise the crop yields to the point where nitrogen, for example, becomes the limiting factor; and it is easily conceivable that the increase produced by supplying potassium in addition to phosphorus, in the Pennsylvania experiments, was due, in part at least, to the power of potassium salts to hold the phosphorus in available form. Even where heavy applications of potassium were made, the sodium nitrate was more effective than dried blood, and, if only sodium nitrate had been added with phosphorus, the sodium would very probably have produced nearly as marked results as were produced by potassium.

There are too marked variations among duplicate plots on the Pennsylvania field to justify fine distinctions, and even on more uniform land there are many factors involved with different crops and different seasons; but we dare not ignore the fact (Table $8 \mathrm{I} P$ ) that the average value of the crops from four acres receiving phosphorus-potassium treatment decreased from $\$ 88.32$ to $\$ 80.27$ during ten years, from $1891-1892$ to $1901-1902$, which are the midldle points of the two ro-year periods. Whether we consider the values or the pounds of products, the apparent decrease is 
approximately Io per cent in Io years, and if this rate of decrease continues, we may expect the average values to drop during successive Io-year periods from $\$ 80$ to $\$ 72$, to $\$ 65$, to $\$ 59$, to $\$ 53$, and to $\$ 48$, in the next 70 years.

It will be noted that the dividing point between the two ro-year periods in Table $8 \mathrm{IP}$ is exactly the same as between the two I 2year periods referred to in Tables 79 and 80; and it may also be noted that, as an average of the four phosphorus-potassium plots, the average yields during the second I2-year period show 6.4 bushels less corn, 8.3 bushels less oats, and 25 pounds less hay, but with 3.5 bushels more wheat, than during the first I2 years. These figures mean that for each rotation (four years) the yields have decreased by 2.I bushels of corn, 2.8 bushels of oats, and 8 pounds of hay, while the yield of wheat shows an increase of $\mathbf{I . 2}$ bushels. The algebraic sum shows, as an average, that each recurring rotation produces $\$ 2.36$ lower crop values from an acre of land than during the preceding four years.

All this must remind us of the mineral plot on Agdell field, where the yields of turnips and legumes are still well maintained, and the wheat yield has appreciably increased, while only the barley has very markedly decreased.

Mathematically, it is not possible for the roots and stubble of the clover crop to furnish sufficient nitrogen for the other four crops, - timothy (associated with the clover), corn, oats, and wheat; but the question again arises, whether important amounts of atmospheric nitrogen may not be fixed that are not thus accounted for. It is fully established that the azotobacter (and possibly other similar bacteria) fixes measurable quantities of free nitrogen under favorable conditions; and it is also fully established that the bacteria which commonly live in symbiotic relationship with legume plants can fix appreciable amounts of free nitrogen, under suitable artificial conditions, and entirely independent of legume plants. It is thus conceivable that these may fix nitrogen to a greater or less extent while they continue to live, not in the tubercles of growing clover, but upon the dead and decaying residues; and, if such is the case, it is exceedingly probable that the presence of carbohydrate matter (as in plant residues) and a liberal supply of available mineral plant food in a 


\section{$43^{8}$ INVESTIGATION BY CULTURE EXPERIMENTS}

limestone soil, will furnish the very favorable conditions, although the data thus far reported from Agdell field (Table 75) show a greater average loss of nitrogen (245 pounds from the surface 9 inches only) from the phosphorus plots than from the untreated plots (I05 pounds) in the legume rotation; while, as an average of the four plots, the fallow rotation lost less nitrogen than the legume system.

It should be kept in mind, also, that the organic matter of the soil contains nitrogen as well as carbon, and that the amount of combined nitrogen liberated from this organic matter may be nearly or quite sufficient to meet the needs of the bacteria that can be supported by the carbonaceous food. In laboratory cultures the fixation of nitrogen amounts to about io milligrams for each gram of sugar (mannite) consumed by the "frec-living" bacteria. ${ }^{1}$ Thus the amount of nitrogen fixed is equal to about I per cent of the carbonaceous food consumed; whereas the organic matter of the soil contains, as a rule, more than 2 per cent of nitrogen.

On Broadbalk field the nitrogen ${ }^{2}$ content of the surface 9 inches decreased during 28 ycars ( 1865 to $\mathrm{I} 893$ ) by 285 pounds (from 2722 to 2437 ) on plot 3 (unfertilized), by 265 pounds (from 2782 to 25 I 7 ) on plot 5 (minerals), and by 63 pounds (from 3034 to $297 \mathrm{I}$ ) on plot 7 (minerals and 86 pounds of nitrogen); while the only increases shown are 633 pounds (from 4343 to 4976 ) on plot 2 (farm manure), and $\mathrm{I}_{3} \mathrm{I}$ pounds (from $299 \mathrm{I}$ in 1865 to 3015 in $188 \mathrm{I}$ and to 3 I 22 in I893) on plot 14 , which receives ammonium salts (86 lb. N), acid phosphate, and magnesium sulfate. (The possibility of erosion or deposit from surface washing should not be overlooked. Compare the nitrogen content of plots II, I2, I3, and I4 with respect to each stratum, as shown in Table 73.)

${ }^{1}$ In this connection attention is called to the point that if increased growth of plants is caused by the use of pyrogallol, as reported from the unverified experiments of Whitney and Cameron, it may be due to the fixation of free nitrogen by the nonsymbiotic bucterit that find in pyrogallol a suitable carbonaceous food supply. It is known that the addition of sugar to ordinary soil deficient in nitrogen will increase the growth of nonleguminous plants because of the increased nitrogen fixation by the "free-living" bacteri?.

${ }^{2}$ All of these determinations were made by the older soda-lime method and are considered trustworthy for comparison, but the 1893 analyses reported in Table 73 were made by the newer Kjeldahl method, which gives somewhat higher and more nearly correct results. 
As already stated, a study of the present nitrogen content of the soil of Agdell field will probably furnish more satisfactory information than can be secured from any other source at this time.

It is very evident that the loss of nitrogen in drainage water usually exceeds the addition in rainfall; and, unless there are sources of nitrogen other than can be found by the analysis of the legume plants (tops, roots, and tubercles), we must make provision to supply a sufficient excess of nitrogen in farm manure, crop residues, or otherwise, to meet the needs of large crops and to overcome the loss in drainage from rich land.

In Bulletin 22I of the New Jersey Agricultural Experiment Station, issued July, r9o9, Voorhees and Lipman report in detail the results of ten years' investigations with twenty culture experiments (in triplicate) in which corn, oats, wheat, and timothy were grown in rotations in 60 cylinders, each 4 feet long and $23 \frac{1}{2}$ inches in diameter, set in the earth and open at both ends, so as to approach natural conditions for drainage. Cow manure, fresh and leached, and cow dung (solid excrement), fresh and leached, were used with and without sodium nitrate, ammonium sulfate, and dried blood, in various combinations.

At the beginning of the experiment, in 1898 , the surface soil (8 inches deep) contained 155.47 grams of nitrogen in each cylinder. The amounts of nitrogen applied during the ten years varied from 38.25 grams in the leached dung to $58.3 \mathrm{I}$ grams in the fresh manure and sodium nitrate combined. The total amounts of nitrogen removed in the sixteen crops harvested during the ten ycars varied from 2 r.88 to 36.70 grams; and the total loss of nitrogen, other than that contained in the crops removed, varied from 25 . I 2 to 39.38 grams. Thus, in these long-continued and very carefully conducted experiments the absolute chemical control shows loss of nitrogen by leaching far in excess of possible additions by rainfall, azotobacter, etc.

After a full consideration of the data accumulated in these experiments with respect to their bearing upon the question of denitrification, the authors make the following statements:

"We must conclude, therefore, that at least with cow manure, used at the rate of sixteen tons per annum for a period of ten years, no destruction of nitrates takes place. In view of the long duration of the experiment, and of the 


\section{INVESTIGATION BY CULTURE EXPERIMENTS}

comparatively large amounts of manure used in the course of the ten seasons, we must assume that denitrification is not a phenomenon of economic importance, in general farming and under average field conditions. . . . We have no hesitation in emphasizing again the view expressed above that under the wide range of field conditions, denitrification is not a phenomenon of economic significance to the general farmer."

With our present knowledge we should not do less than to base our practice upon the known mathematical and chemical facts concerning the nitrogen requirements of crops and the nitrogen content of manures, legume crops, and crop residues, keeping in mind, of course, that there are some soils, such as peaty lands and others excessively rich in organic matter, which should be cropped for years with little or no return of nitrogen. 


\section{CHAPTER XXI}

\section{OHIO FIELD EXPERIMENTS}

AsIde from the experiments outlined in Table 40, which deal especially with manure, alone and reënforced with different materials, the Ohio Experiment Station has conducted, for 15 years, two very extensive and valuable investigations by means of plot experiments, relating to the maintenance of soil fertility. In one of these a five-year rotation is practiced on five separate fields or series, each of which contains 30 tenth-acre plots about I by 16 rods, each of the five crops, corn, oats, wheat, clover, and timothy, being represented evcry ycar (excepting the clover and timothy for the first two years). In the other investigation, potatoes, wheat, and clover are grown in a three-year rotation on three separate series, each of which contains 34 tenth-acre plots of the same shape. Each of the crops is represented every year (except wheat the first year and clover the first two years). The detail plan of these experiments and the average results secured for the I5 years (I894 to I908) are shown in Tables 82 and 83 .

Seasonal variations are too great to justify an attempt to determine from the data secured in fifteen years (only $\mathrm{z} 3$ years with clover and timothy) whether the productive power of the soil is increasing or decreasing. It will be recalled that Jethro Tull grew I3 crops of wheat in succession on the same land without the use of manure or fertilizers, and from the data secured the conclusion was drawn, "that a good crop of wheat, for any number of years, may be grown every year upon the same land without any manure from first to last." A more recent similar illustration is furnished by the Minnesota Experiment Station, showing average yields of I 4.7 bushels of wheat from 1893 to 1898 , and i 7.2 bushels from 1899 to I904, where wheat was grown every year without manure or fertilizer. 


\title{
442 INVESTIGATION BY CULTURE EXPERIMENTS
}

\author{
Table 82. Ohio Experiments: Five-year Rotation
}

Average Records per Acre for Three Rotations, I894 to I908

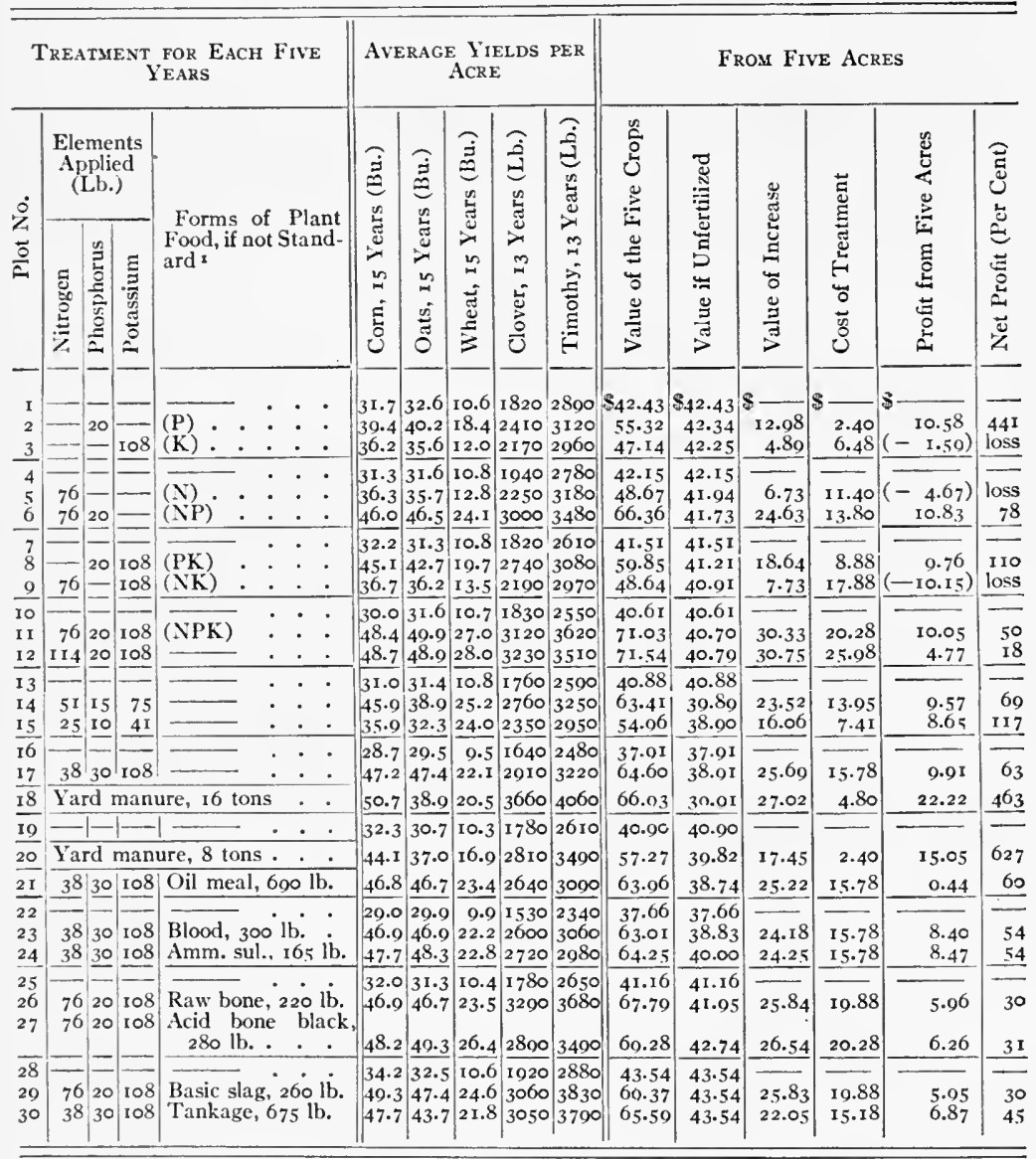

1 The standard forms of plant food are $50 \mathrm{lb}$. of dried blood $(25 \mathrm{lb}$. on plots 17 and 24 , and $20 \mathrm{lb}$. on plot 26 ) and the balance of the nitrogen in sodium nitrate (70 lb. $\mathrm{N}$ in $440 \mathrm{lb}$. of nitrate), acid phosphate $(20 \mathrm{lb} . \mathrm{P}$ in $320 \mathrm{lb}$. of phosphate), and potassium chlorid ( $108 \mathrm{lb}$. $\mathrm{K}$ in $260 \mathrm{lb}$. of potassium chlorid, "muriate" of potash). Where some other material is used for any element, as linseed-oil meal for nitrogen, less acid phosphate and potassium chlorid are applied, so as to correct for the phosphorus and potassium carried in the oil meal.

The possible influence of abnormal years upon the average of a few years is well illustrated in the wheat yields of these experi- 
ments at Wooster, Ohio, which are summarized in Table 82. The average yield of wheat on the ten unfertilized plots was 19.3 bushels per acre in 1894 and I9.5 bushels in I908, while I.I bushels was the average yield for 1896 , and I.I bushels was also the average yield for I900. The average was 3.0 bushels in 1895 and 13.9 bushels in 1907 .

As a rule, land that has been heavily cropped with almost continuous grain-growing, and with little or no manure, will produce markedly better crops for several years after a good rotation system is well established, and this fact often leads to a most scrious error on the part of the farmer; namely, to the conclusion that crop rotation will maintain the productive power of the land. The rotation helps to a void the breeding of insects that would prey upon a single crop, and it is beneficial in various other ways, especially when clover or other biennial or perennial crops are introduced which increase somewhat the amount of active organic matter in the soil, the decomposition of which will furnish succeeding grain crops with some plant food contained in such crop residues and with additional and often more important amounts liberated from the soil by the decaying organic matter.

Of course this benefit upon the grain crops cannot be sccured until after the clover or grass crops have been seeded and grown, and the land again plowed up and used for the grain crops; and, furthermore, on land which has not grown clover for many years, the infection with the clover bacteria is sometimes so imperfect that the first clover crop serves chiefly to increase the bacteria, and thus furnish a perfect infection for the second seeding, which very commonly produces a larger yield than the first seeding; and, if so, it may be followed by correspondingly larger yields of corn or other grains.

In consequence of these different influences the crop yields may be better the second or third rotation than during the first. With the Pennsylvania experiments we can pass over a preliminary period of three years, and then consider the results of three complete rotations followed by three other complete rotations; and, by including in our comparison the four crops grown every year, the results are significant; but as yet no such comparisons are possible with the Ohio investigations. We can, however, note the 
effect of the plant food applied by comparing the yields of the treated and the untreated plots, but we must not assume that all systems of treatment that appear profitable from this comparison will prove to be absolutely profitable in continued practice.

The common soil at Wooster contains about I880 pounds of total nitrogen, 960 pounds of acid-soluble phosphorus (perhaps I I 00 pounds of total), and 31,000 pounds of total potassium, in 2 million pounds of the surface soil. Thus it is markedly deficient in both nitrogen and phosphorus, and it may also be stated that this soil is distinctly acid. During the last six or eight years liberal applications of lime have been made to half or all of each of the five series, the unfertilized plots having been limed the same as the others; and in practically all cases distinct benefit has resulted for all crops, the most marked effect being upon clover, and then naturally upon the crops following clover.

Table 82 illustrates very well the fact that the farmer cannot always afford to raise the largest possible crops that can be produced by applications of commercial plant food. The largest gross return from the five acres is from the No. I2 plots (\$71.54), but the amount of net profit and the per cent of net profit from that plot are less than from any other profitable treatment.

It is plain that, as an average, for this rotation, phosphorus is the most limiting element, but, after phosphorus, the nitrogen limit is also very distinct. Thus phosphorus alone increases the returns from five acres from $\$_{42.34}$ to $\$_{55.32}$, with a net profit of $\$ 10.5^{8}$, or $44 \mathrm{I}$ per cent on the money invested in the 20 . pounds of the phosphorus applied. The addition of $\$ I I .40$ worth of nitrogen (with sodium) with phosphorus produces an increase of $\$ 11.65$ more than with phosphorus alone; thus showing a net profit for nitrogen of 25 cents, or 5 cents an acre, or 2 per cent on the money invested. In all other cases nitrogen, as well as potassium, has been applied at a loss, and in every other case wherever the use of commercial plant food has been profitable the entire profit has been made by the phosphorus, and after the phosphorus had paid for some net loss caused by the other elements.

Both the invoice (soil analysis) and the crop yields agree in the deficiency of nitrogen and phosphorus; but these two sources of information appear to disagree as to the need of potassium. There 
is some evidence which indicates that more or less of the effect of the potassium salt is due to indirect action rather than as plant food. Thus the sodium nitrate on plot I7. produces distinctly better results than the oil meal or dried blood on plots $2 \mathrm{I}$ and 23 . (About twice as much potassium was applied in the Pennsylvania Experiments, but the sodium nitrate shows superiority over dried blood during the second I 2 -year period, after the supply of humus has probably become somewhat depleted. If the blood nitrogen failed to become available with sufficient rapidity, one would expect it to produce cumulative benefits like the manure, to some extent, but such is not the case.)

In the Ohio experiments the average effect of potassium has been nearly the same, whether applied alone $(\$ 4.89$ on plot 3 ), in addition to phosphorus $(\$ 5.66$ on plot 8$)$, or in addition to both nitrogen and phosphorus $(\$ 5.70$ on plot II), although nitrogen and phosphorus without potassium (plot 6) produced an increase of $\$ 24.63$, or 59 per cent above the unfertilized land $(\$ 41.73)$. More than half of this increase must be credited to phosphorus alone, and less than half to nitrogen after phosphorus; while, in reverse order, nitrogen gets one fourth and phosphorus three fourths of the credit. Nitrogen alone produced an increase of only $\$ 6.73$ (plot 5), and it is questionable if this increase is not in part due to indirect action, such as increasing the availability of the soil phosphorus, the effect on the clover crop being as marked as on the other crops. As an average the effect of nitrogen and potassium together is only $\$ 7.73$, leaving a net loss of \$ro.r 5 ; but the addition of 20 pounds of phosphorus, under this most favorable condition, pays back this loss and adds a net profit of \$10.05, making a gross increase of $\$ 22.60$, or almost ten times the cost of the phosphorus, which certainly establishes well the fact that, if the farmer can supply the nitrogen in clover or in manure, and liberate the potassium etc. by means of the decaying organic matter, there must be large profit from the use of purchased phosphorus. (In fine-ground rock phosphate the 20 pounds of phosphorus will cost about 60 cents, at present prices.)

Phosphorus is evidently the limiting element on all plots where 76 pounds of nitrogen have been supplied, practically no increase being produced by the extra nitrogen on plot $\mathrm{r} 2$, and twice as much 


\section{INVESTIGATION BY CULTURE EXPERIMENTS}

phosphorus being removed from plot I I in the crops produced as is applied during the five years, as is easily determined by computation. It is impossible that the crop yields will be permanently maintained under this system, unless the partially depleted surface soil is removed by erosion at least in corresponding rapidity as the phosphorus is removed in crops.

On the other hand, nitrogen must be the limiting element where 30 pounds of phosphorus were used; but, wherever the amount of phosphorus was increased, the nitrogen was also reduced, so that it is impossible to determine what effect is produced either by increasing the phosphorus or by reducing the nitrogen.

The experiments on plots $I_{4}$ and $I_{5}$ are essentially variations in amount used of a complete fertilizer; but on $\mathbf{I}_{5}$ the fertilizer is applied for wheat, and on $\mathrm{I}_{4}$ for corn and wheat, while on all other plots the fertilizers are applied in three portions, for corn, oats, and wheat. (The manure is applied in two equal portions, for corn and wheat.)

The comparison of the different forms of nitrogen is valuable, because nitrogen is the limiting element on those plots; while the comparison of different phosphates is likewise so planned that phosphorus is the limiting element.

The insoluble phosphorus in raw bone, basic slag, and tankage is reckoned at ro cents a pound.

In the main the Ohio experiments reported in Table 82 were designed to supply about the same quantities of nitrogen, phosphorus, and potassium, as were removed in the average crops produced by farmers on the ordinary land in that section of the state.

Where complete fertilizers are used by farmers in a rotation of this kind, about 200 pounds per acre may be applied for corn and again for wheat, making 400 pounds for the rotation. The most common composition is the 2-8-2 goods, containing 2 per cent of ammonia $\left(\mathrm{NH}_{3}\right), 8$ per cent of "available phosphoric acid" $\left(\mathrm{P}_{2} \mathrm{O}_{5}\right)$, and 2 per cent of potash $\left(\mathrm{K}_{2} \mathrm{O}\right)$; or, in the 400 pounds, about 7 pounds of nitrogen, I 4 pounds of soluble (and 3 pounds of insoluble) phosphorus, and 7 pounds of potassium. In other words, the total amounts applied in four or five years would furnish enough nitrogen for one 5-bushel crop of corn, enough phosphorus for one 70-bushel crop, and enough potassium for one ro-bushel 
crop; and yet such use of plant food is the most common practice in the Eastern and Southern states.

In this connection the following quotation from Director Thorne of the Ohio Station is of interest (Ohio Farmer, January 2, 1904):

"For seven years raw bone meal and steamed bone meal have been used in comparison on the Strongsville test farm, side by side with four brands of factory-mixed, acidulated, complete fertilizers, these brands representing some of the most reputable manufacturers in the state, and ranging from 4 per cent of ammonia, Io per cent phosphoric acid and 4 per cent potash, to I per cent ammonia, 6 per cent phosphoric acid, and I per cent potash. The fertilizers are all applied at the rate of 200 pounds per acre to corn and wheat, grown in rotation and followed by one year in clover. Following is the average increase obtained from each crop:

\section{Plot Fertilizer}

2 Factory brand "A

5 Factory brand " $B$ "

8 Factory brand " $\mathrm{C}$ " Factory brand " $D$ "

Raw bone meal

Steamed bone meal

\begin{tabular}{|c|c|c|}
\hline Corn & Wheat & Hay \\
\hline Bus. & Bus. & Lbs. \\
\hline 7.62 & 10.62 & 675 \\
\hline 4.88 & II. 39 & 658 \\
\hline 3.79 & 8.13 & $45^{8}$ \\
\hline 5.87 & $8.5^{\circ}$ & $35^{\circ}$ \\
\hline 6.40 & 13.22 & 1309 \\
\hline XI.02 & 14.24 & 1300 \\
\hline
\end{tabular}

"At present, steamed bone meal furnishes available phosphorus in probably the cheapest and most effective form in which it can be bought."

In Table $8_{3}$ are recorded the average results secured from the potatoes-wheat-clover rotation during the fifteen years, I894 to Igo8.

It should be stated that plots 32,33 , and 34 were started one year later for the potatoes and clover, and two years later for the wheat, than the other plots, and that assumed yields for those plots for the one or two years are introduced (based upon the yields of other plots subsequently producing about the same as these three), in order that the comparison of the averages may be fair. This is essential, because the yield of potatoes the first year and the yields of wheat the first two years were markedly smaller than the average of all subsequent years.

The yield of wheat straw is shown because the data are available, and they complete the record for all crops, and especially because comparison is thus afforded of the yields of grain and straw. As an average for good yields for each bushel of wheat there are about roo pounds of straw.

The financial statement is based upon the following prices. potatoes, 30 cents (and 50 cents) a bushel; wheat, 70 cents; clover 


\section{INVESTIGATION BY CULTURE EXPERIMENTS}

\section{Table 83. Ohio Experiments: Three-year Rotation}

Average Records per Acre for Five Rotations, 1894 to 1908

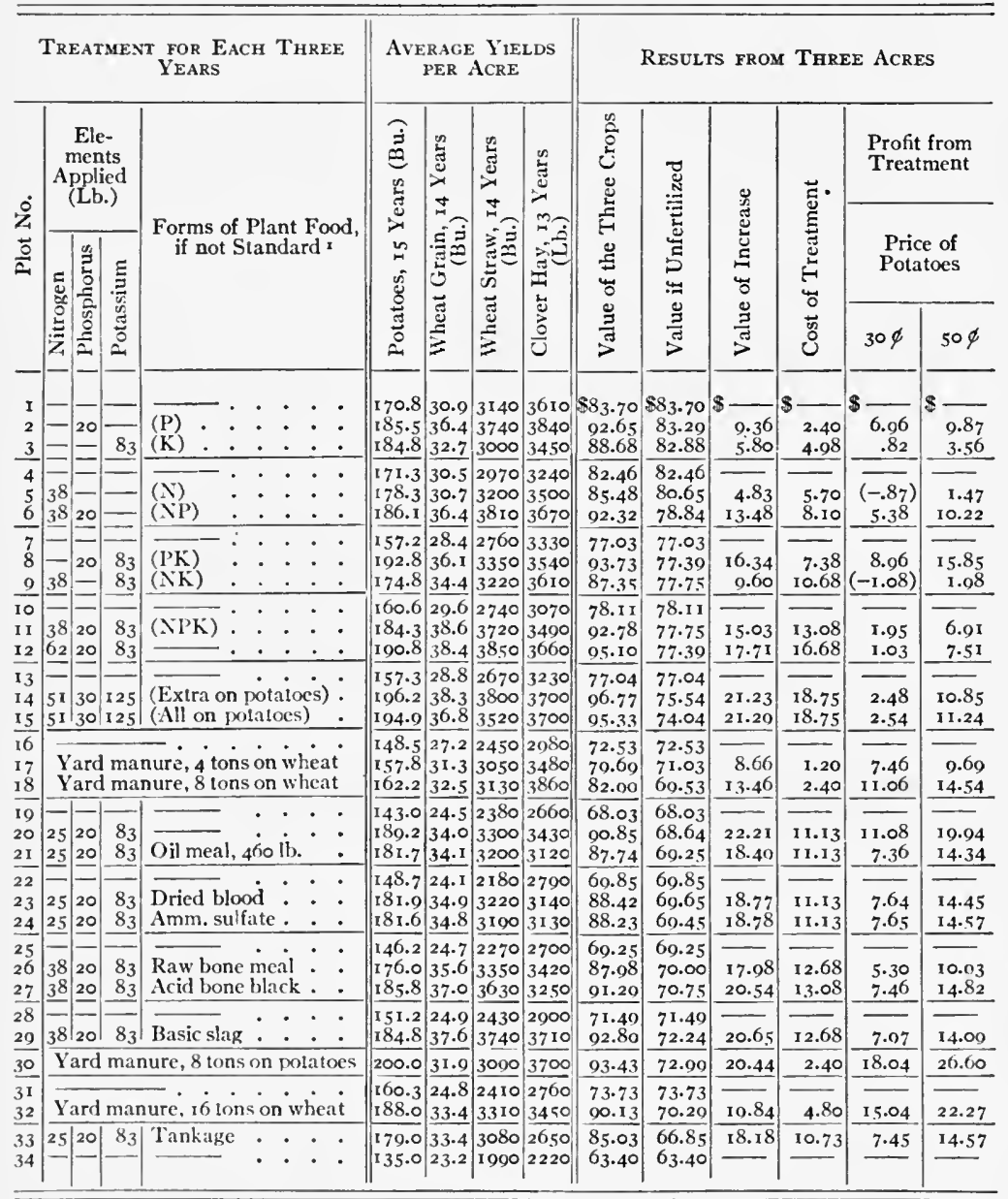

${ }^{1}$ The standard forms include both dried blood (usually $50 \mathrm{lb}$.) and sodium nitrate (usually $200 \mathrm{lb}$.), acid phosphate, and potassium chlorid, the applications being divided, in most cases, between the potatoes and wheat.

hay, $\$ 6.00$ a ton; nitrogen, I 5 cents a pound; phosphorus, 12 cents (ro cents in raw bone, slag, and tankage); and potassium, 6 cents. The price of potatoes varies greatly, and for that reason the figures 
given in the last column of Table $8_{3}$ are based upon the price of 50 cents a bushel for potatoes, while 30 cents a bushel is the price used in the other computations. Of course the increase in crop values resulting from treatment is not computed at the delivered price for marketable potatoes, but sometimes this would be justified, because the treatment may largely increase the percentage of marketable potatoes, and even with other crops the improvement in quality, as well as in quantity, may be a factor of some importance. In any case, potatoes belong to the crops of intensive agriculture, the largest average yield (200 bushels) amounting to $\$ 60$ an acre at 30 cents, and to \$roo an acre at 50 cents a bushel.

Part of the field upon which these experiments have been conducted was virgin soil, cleared from forest for the purpose, and all of the land was fairly rich at the beginning.

The average of 16 analyses of soil from the " East Farm," where the five-year rotation (Table 82) and reënforced manure expcriments (Table 40) are conducted, and 5 analyses of soil from the "South Farm," where the potato-wheat-clover rotation experiments are under way, show that the South Farm soil contains about one half more acid-soluble phosphorus than the East Farm soil. It is also somewhat richer in acid-soluble potassium, while in total nitrogen the East Farm soil is slightly richer. By referring to the column headed "Value if unfertilized " (Table 83), it will be seen that the natural productiveness of the land varies markedly from plot I $(\$ 83.70)$ to plot I9 $(\$ 68.03)$ and plot $34(\$ 63.40)$; but the oft-repeated check plot (unfertilized) makes possible a comparison that could not be made without it. On the other hand, we can never be sure that the treatment applied to one plot (as phosphorus to plot 2, for example) has produced the same total increase as it would have produced if applied to some other plot (as to plot 20, for example). Thus the actual total yield from plot 2 $\left(\$ 92.6_{5}\right)$ is greater than that from plot $20(\$ 90.85)$, but the computed increase from plot 20 is more than twice as great $(\$ 22.2 \mathrm{I})$ as that from plot $2(\$ 9.36)$. The fact is that more plant food is removed from plot 2 than from plot 20 , but this is also true, of course, with respect to the adjoining unfertilized control plots. These difficulties are emphasized, however, by comparing plots II and 20, both of which receive the three elements, nitrogen, phosphorus, and po- 
tassium, in the standard forms (the nitrogen chiefly in sodium nitrate).

The treatment for these two plots differs only by the addition of I 3 pounds more nitrogen to plot i I (plot i r receives 50 pounds of dried blood for wheat, and plot 20 only 25 pounds). The total yields (except potatoes) are greater from plot $\mathrm{I} x$, and the total value of the three crops is greater from plot II $(\$ 92.78)$ than from plot $20(\$ 90.85)$; but the increase from plot $20(\$ 22.2 \mathrm{I})$ is much greater than from plot I I (\$ I $_{5} .03$ ), and the net profit from

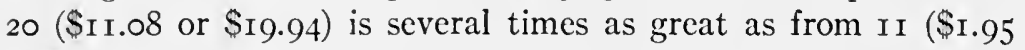
or $\$ 6.9 \mathrm{I})$. In comparison with such plots as 14 and 27 , it seems evident that plot 20 gives results above normal; while it is likewise evident that plot I I shows increases below normal, in comparison with such plots as 8 and 24. These opposite abnormalities develop the striking discrepancy between $x \mathrm{I}$ and 20. A study of the yearly details shows that for the first five years (r895 to 1899 ) the increase from treatment was greater every year in the wheat crops from plot II, the average difference being 3.6 bushels, whereas during the next five years (I900 to I904) the increase in wheat was greater every year on plot 20 , the average difference being 2.6 bushels. As an average of the four years, I 905 to I908, the increase from plot 20 averaged 2.5 bushels more wheat than from II, although in two of these years the treatment gave about equal results on those plots. As an average of the first six years (I896 to I90I) plot I I produced 79 pounds less clover than the unfertilized control plots, while on plot 20 the treatment produced an average increase of 630 pounds.

These results and discrepancies serve to emphasize the uncertainty of drawing correct conclusions from a single field experiment, even when continued for several years. On the other hand, most of the results from this potato-wheat-clover rotation are concordant, and justify confidence. Indeed, there is marked agreement in most cases where direct comparison is possible. Thus the increases from like amounts of plant-food elements on plots 2 I, 23, 24, and 33 vary only from $\$$ I 8 . I 8 to $\$$ I 8.78 .

In harmony with the results from all other sources, the use of phosphorus on normal soils proves highly profitable, the increase produced by phosphorus, both alone and in addition to other 
elements, being sufficient to pay for the phosphorus (even in acidphosphate) and leave a net profit of 200 to 300 per cent. The use of commercial nitrogen or potassium, alone or in combination, is of doubtful advantage with potatoes at 30 cents, but at 50 cents for potatoes the potassium has been a good investment, although, with sufficient manure or clover plowed under to supply the nitrogen, it is very probable that abundance of potassium would have been liberated from the soil.

Potatoes draw heavily upon potassium, and ultimately, on level land which neither receives deposits from overflow nor loses partially exhausted soil by erosion, potassium must become so deficient as to limit the crop yield, even with the best efforts to maintain adequate supplies of active organic matter; but the total supply of potassium in 2 million pounds of this Ohio soil is sufficient for 200 bushels of potatoes every year for more than 500 years, and the land has sufficient surface drainage to insure some soil erosion.

Another series of long-continued and very valuable experiments have been conducted by the Ohio Station on the Strongsville experiment farm, on a quite different type of soil, of nearly level topography, higher clay content, and less perfect physical condition. The surface acre-foot of Wooster soil contains, as a general average, about 2770 pounds of nitrogen, I 700 pounds of acid-soluble phosphorus, and 73 Io pounds of acid-soluble potassium, while the corresponding figures for the Strongsville soil are 6520 , I 700 , and 6300 . Thus the Strongsville soil averages more than twice as rich in nitrogen, but somewhat poorer in acid-soluble potassium, while the phosphorus content is practically equal in the two soils.

Table 84 gives the average results obtained from a series of 5year rotation experiments ( $1896-1897-1898$ to 1907$)$. The plantfood materials are 440 pounds of sodium nitrate (and 50 pounds of dried blood), 320 pounds of acid phosphate, and 260 pounds of potassium chlorid. (One plot (No. I2) receives 680 pounds of sodium nitrate.)

The more marked effect of phosphorus on the Strongsville soil is doubtless due to the larger supply of organic matter, the decomposition of which tends to furnish nitrogen and liberate potassium. As an average, the crops from the best-yielding plots have removed 
30 pounds of phosphorus during the five years, or 50 per cent more than was applied.

Table 84. Experiments at Strongsville, Ohio Data per Acre for Five-year Rotation: Increase Only, except as Noted

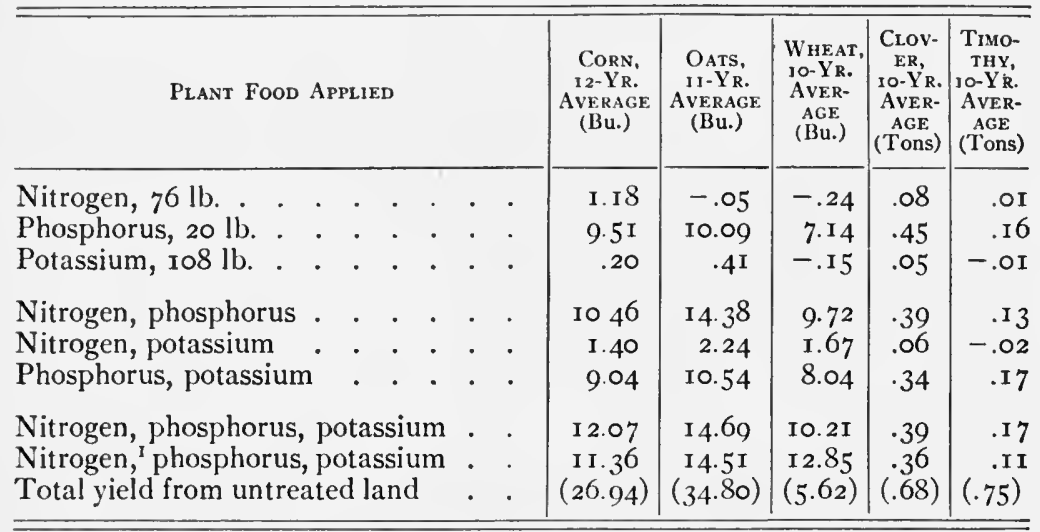

${ }^{1}$ On this plot $\mathrm{Ir}_{4} \mathrm{lb}$. of nitrogen; otherwise the applications were: nitrogen, $76 \mathrm{lb}$.; phosphorus, $20 \mathrm{lb}$; ; and potassium, $108 \mathrm{lb}$. ; per acre, in five years.

In general, it may be stated that the plant food applied in the Ohio experiments produced small effects the first few years. Thus, in the 5-year rotation at Wooster the largest increase in corn in I 904 was 3.5 bushels per acre, on plot 21 , and in 8 cases out of 20 the treated plots produced lower yields than the untreated control plots. As an average of the first five years, phosphorus (on the No. 2 plots) produced increases per acre as follows: corn, 4 bushels; oats, 3.5 bushels; wheat, 3. I bushels; clover, 390 pounds ; timothy, I 86 pounds. These are about one half the effect for the I5-year average, as will be seen from Table 82 .

From a consideration of the Rothamsted and Pennsylvania data, it seems probable that more or less of this apparent average increase is due to a comparative decrease on the unfertilized plots, although the time is too short since the Ohio rotations and soil treatment have been fully under way to make trustworthy averages, because of seasonal variations; for, while land may be decreasing in normal productive power, a few favorable seasons following unfavorable years may furnish data that indicate increasing yields, as in the Minnesota experiments referred to on a former page. 


\section{CHAPTER XXII}

\section{ILLINOIS FIELD EXPERIMENTS}

Aside from the old experiments on the University Farm, the Illinois field experiments have been in progress only for a few years, but they are of special interest and value because they are conducted in widely separated places and on different definite soil types of great extent and importance.

Brown silt loam constitutes the most common prairie soil in the middle and upper Illinoisan, pre-Iowan, and early Wisconsin glaciations, and is found also in the Iowan and late Wisconsin. It is called "the ordinary prairie land" by farmers throughout the corn belt, extending from Mattoon, Illinois, into Wisconsin, and from north-central Indiana into Nebraska and South Dakota.

While the different brown silt loams are similar in many respects, they differ somewhat in chemical composition, varying with age or formation of the different areas, and it is noteworthy that in the older soil areas the brown silt loam is either no longer represented (as in the lower Illinoisan glaciation), or it is replaced to some extent by a type of soil intermediate in character and value between brown silt loam and gray silt loam on tight clay. This intermediate type is well developed in places in the southern part of the middle Illinoisan glaciation and in the western part of the upper Illinoisan, but it is only one of many minor types whose exact location requires a detail soil survey.

The top soil of the brown silt loam consists of a friable darkcolored and fairly uniform soil to a depth of 16 to 20 inches, with appreciably less organic matter at the lower depth. Below the top soil, from 16 or 20 inches to 40 inches and more, is the yellow, silty subsoil, somewhat less porous or friable than the top soil, but not very compact.

This soil and subsoil have great capacity to absorb and retain water from heavy rains, and later to deliver the moisture to grow- 
ing crops as needed. In other words, the crops growing on brown silt loam soils are enabled to withstand drouths that would produce very severe damage on such a soil as the lower Illinoisan gray silt loam on tight clay. Of course even the brown silt loam becomes much less absorbent and less retentive of moisture where the surface soil is allowed to become deficient in humus.

As a general average (the late Wisconsin being disregarded) the brown silt loams contain in the surface soil of an acre (2 million pounds) about 4800 pounds of nitrogen, I 200 pounds of phosphorus, and 34,000 pounds of potassium, amounts which, if they could be drawn upon at will, would furnish the nitrogen for roo bushels of corn (grain only) every year for 48 years, the phosphorus for 70 years, or the potassium for 1790 years. For four tons per acre of clover hay each year, the nitrogen, if drawn only from the surface soil, would be sufficient for 30 years, the phosphorus for 60 years, and the potassium for 280 years.

These data are for very large crops, and take into account only the plant food in the surface soil to a depth of $6 \frac{2}{3}$ inches, but these crops are not loo large to try to raise, and the fertility of the surface soil must be maintained if we are to maintain a permanent, profitable agriculture. We may reduce the crop yields to the lowest limit of profit on land valued at $\$_{1} 50$ to $\$ 200$ an acre, but still the absolute limit in years is short for the nitrogen and the phosphorus in this most common prairie soil of the corn belt; and, if such crops of corn and clover as are mentioned above had been removed from this land from the time Columbus discovered America until now, every pound of phosphorus contained in the soil to a depth of four feet would have been required for the crops grown.

So far as the author has been able to learn, the oldest soil experiment field in the United States with an authentic record of its origin and with a present continuation of the experiments originally inaugurated is on the campus of the University of Illinois, or rather it is surrounded by the University campus. In the biennial report for 1879 and 1880 , on page 232 , and under date of March ro, I880, is the following:

"The Farm Committee then submitted the following report:

"To the Hon. Board of Trustees of the Illinois Industrial University: 
"Your committee beg leave to submit the following recommendations from the Professor of Agriculture in regard to experiments for the coming season : . . .

"Fifth. The formal commencement of what is designed to be a long-continued experiment to show the effect of rotation of crops, contrasted with continuous corn-growing, with and without manuring, and also the effect of clover and grass in a rotation. A commencement was made last year, and we are fortunate in having a piece of land more than usually well adapted for such a test.

"The report was approved, and its recommendation concurred in."

Thus, these oldest rotation experiments, begun, according to the official records, by Professor George E. Morrow, in I879, completed a record of thirty-one years in I909. Fortunately, these plots are located on the typical brown silt loam soil of the corn-belt prairie land.

In Bulletin I $_{3}$ of the Illinois Agricultural Experiment Station, published in I89 a and signed by Professor Morrow, the statement is made that from the beginning of these experiments plot No. 3 had "been in corn continuously," that plot No. 4 had been " in corn and oats alternately," and that plot No. 5 had " had this rotation: corn, 2 years; oats, I year; meadow (clover, timothy, or both), 3 years." 'The records also state that these plots had received "no manure or commercial fertilizers of any kind."

The series originally contained seven other plots, and included a limited use of commercial fertilizers and farm manure, and other rotation systems. All but three of the original plots have been taken for campus or buildings.

The Experiment Station was established in 1888 , and in the reports made by Professor Morrow and his assistants relating to these experiments and published in 1888 to 1894 there is no record of crop yields previous to 1888 . The most important thing, perhaps, is the record that the crop systems were followed during those early years.

Since 1888 these crop systems for the three plots mentioned have been essentially maintained, with the modification on plot No. 5 during the later years of adopting the more simple rotation of corn, oats, and clover, one each year. From the recorded statements and the existing knowledge it is safe to say that all crops 


\section{INVESTIGATION BY CULTURE EXPERIMENTS}

have been removed, including the grain, hay, straw, and corn fodder, from 1879 to the present time, but records of yields are lacking in some cases.

Originally, these plots were one half acre each in size, being 5 rods wide (north and south) by 16 rods long (east and west), but in I904, because of the enlargement of the University campus, it became necessary to reduce the length to 9 rods in the central part of the original plots. At the same time one-half rod division strips were established between the plots, also a one-fourth rod cultivated or cropped protecting border around the plotted area, and each of the three plots was also divided in four quarters by half-rod division strips through the center in both directions. Thus, from each of the original plots four plots of one-twentieth acre each have been formed, with half-rod protecting strips. In each case the two plots on the north are continued as a duplicate test of the original system, without the use of manure or commercial fertilizers, while the two plots on the south are cropped the same, but they are now being improved by such applications of farm manure as can well be made from the crops grown, by the use of legume catch crops, applications of ground limestone to correct possible soil acidity, and by the use of phosphorus, applied for each year in the rotation in 200 pounds of steamed bone meal (on the east plot), or in 600 pounds of rock phosphate (on the west plot), per acre.

The original plot numbers are retained, the untreated north part being known as $3 \mathrm{~N}, 4 \mathrm{~N}$, and ${ }_{5} \mathrm{~N}$; and the treated south part as ${ }_{3} \mathrm{~S},{ }_{4} \mathrm{~S}$, and ${ }_{5} \mathrm{~S}$, respectively; and to each of these may be added $\mathrm{W}$ or $\mathrm{E}$ to designate the west or east half.

In Table 85 are recorded the yields of these old plots for the last twenty-two years, from I 888 to I909, including, since I904, for each rotation system, the average of the untreated duplicates and of the treated parts.

Seasonal influences are so great that no very satisfactory comparison can be made between different years for the sake of determining the effect of the different systems upon the productive power of the soil, and the thorough underdrainage provided for in 1904 must be expected to markedly increase the crop yields in subsequent seasons of excessive rainfall, such as 1907 , for example, 
Table 85. Crop Yields per Acre from the Oldest Illinois Experiment Plots: Urbana Soll Experiment Field

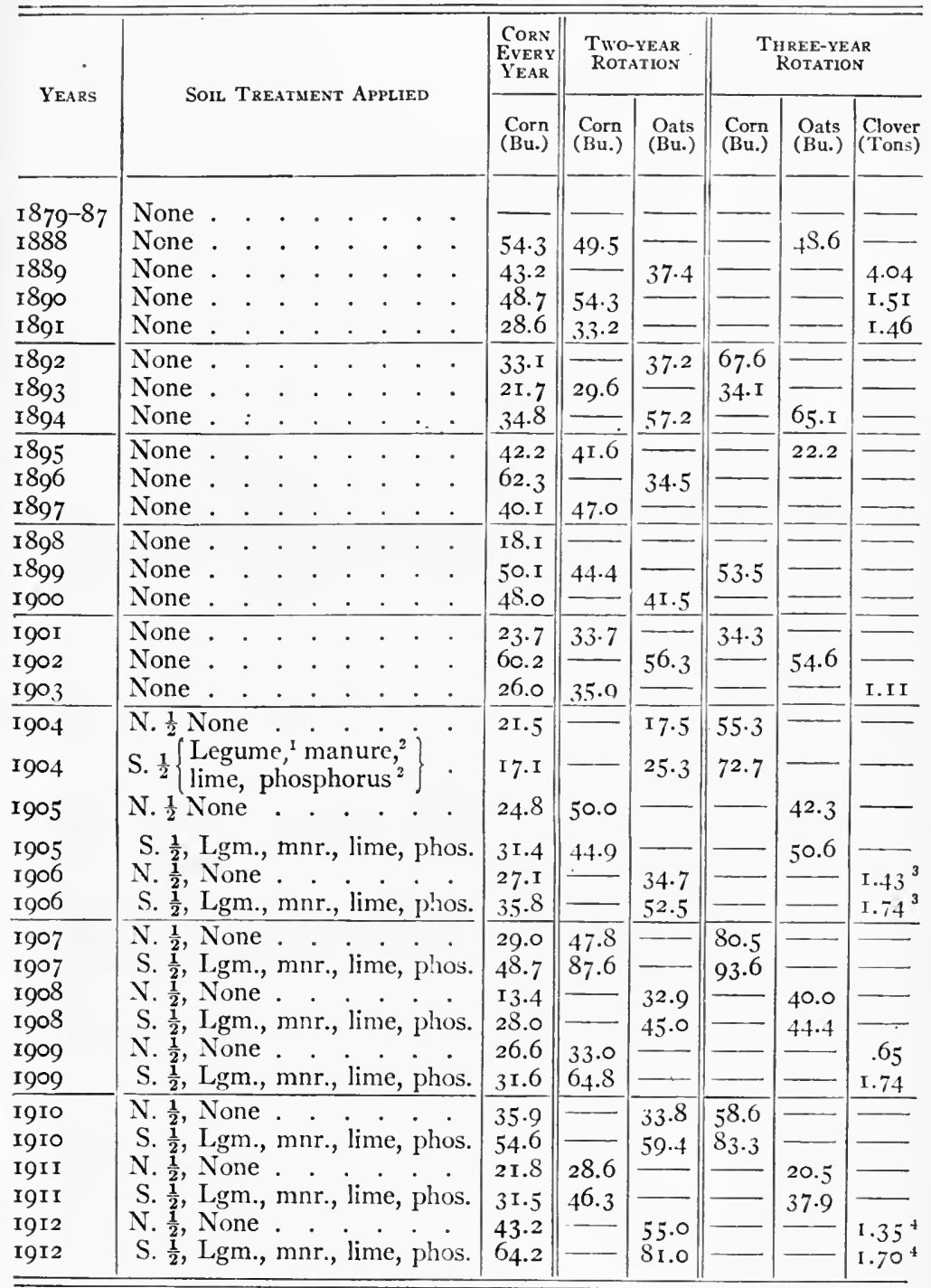

1 Legume catch crops first grown in 1904 to benefit 1905 crops.

${ }_{2}^{2}$ Manure and phosphorus first applied to plot ${ }_{5} \mathrm{~S}$ for 1904 crop, but to plots ${ }_{3} \mathrm{~S}$ and $4 \mathrm{~S}$ for 1905 crop. $\quad{ }^{3}$ Cow pea hay; the clover failed. ${ }_{4}^{4}$ Soy-bean hay. 


\section{$45^{8}$ INVESTIGATION BY CULTURE EXPERIMENTS}

as compared with previous years. Thus, on the continuous corn plot the yield was I8. I bushels in 1898 and 60.2 bushels four years later, and the largest recorded corn yield in the corn-oats-clover rotation was 80.5 bushels in the wet season of 1907 .

A fair comparison between different systems can usually be made in the same years, and the change in productive power under any system can best be ascertained by comparing the results from these old experiments with those from newer experiments, as shown in Table 86, when the effect of sixteen years' cropping can be noted. Every plot in the newer experiments produced more than 75 bushels of corn per acre in 1896 , and the average in 1897 was about 70 bushels. Upon these facts is based the assumption that all of the older plots originally produced 70 bushels or more per acre.

It is apparent that the legume catch crops (chiefly cowpeas) seeded in the corn decrease the yield for the first year at least, as shown in 1904 on plot 3 and, even in spite of the light manuring, on plot 4 in 1905 .

The general effect of the system of soil improvement adopted for the south half of each of these old plots is already very marked, an increase of 40 bushels of corn per acre being secured in 1907 from the treatment on plot 4 , where the most marked effect is to be expected because no clover or other legumes had been grown previous to I 904 in this rotation, and the frequent change from corn to oats has helped to avoid the development of corn insects.

Table 86 gives, for comparison, three-year averages for corn, including the IgOI -7 corn crops grown in the three-year rotation on the old field.

As an average of the three years where corn has been grown every year, the yield has been 27 bushels in the 29 -year experiments and 35 bushels in the 13 -year experiments. The lesson of these experiments is that 12 years of cropping where corn follows corn every year reduces the yield from more than 70 bushels to 35 bushels per acre, after which the decrease is much less rapid, amounting to only 8 bushels' reduction during the next i 6 years. Undoubtedly the rapid reduction during the first I 2 years of continuous corngrowing is due in large part to the destruction of the more active decaying organic matter, resulting ultimately in insufficient liberation of plant food within the feeding range of the corn roots. 
Table 86. Comparable Corn Yieldo from the University of Illinois Experiment Field at Urbana: Typical Brown Silt loam Prairie

Three-year Averages: Bushels per Acre

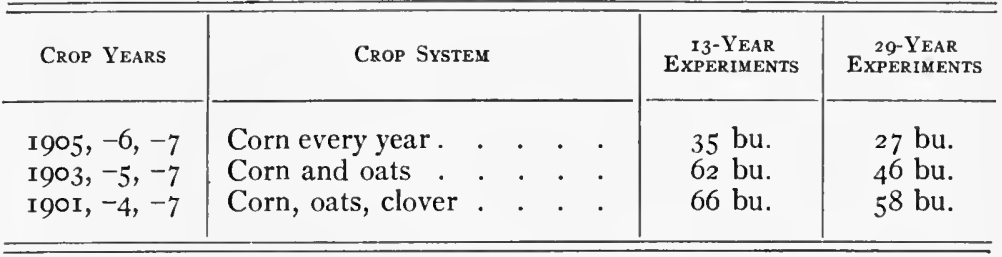

Average of Three Corn Crops in Corn-Oats-Clover Rotation

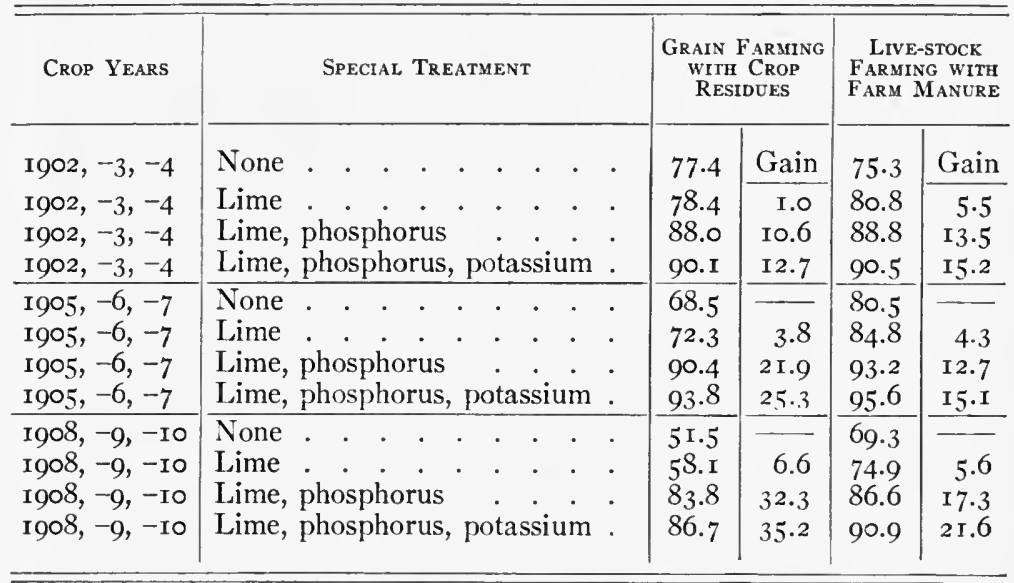

Where corn is followed by oats in a 2 -year rotation the average yield of the three crops of corn is $4^{6}$ bushels in the 29-year experiments, whereas in the 13 -year experiments the average yield for the same three years is 62 bushels of corn per acre. In this case the destruction of humus is less rapid, and the development of the corn insects is discouraged by changing to oats every other year, so that the decrease in yield is less marked during the early years, although the reduction continues persistently with passing years. During the first I I years the yield decreased from more than 70 bushels to 62 , and the next I 6 years show a further reduction of 16 bushels. 
With the 3-year rotation corn is grown for one year, followed by oats with clover seeding the second year, and clover alone the third year. During the first ten years under this system the yield of corn has decreased from more than 70 bushels to 66 , and during the next 16 years the yield has further decreased to 58 bushels, the average reduction being only one-half bushel a year. In this system the most marked reduction in crop yields has not yet appeared, although it must be expected in the future because the clover crop is already beginning to fail on the oldest field, even in seasons when clover succeeds well on newer land under the same crop rotation. When clover fails, cowpeas are substituted for that year on that field, which thus provides a legume crop and preserves the 3-year rotation.

In the lower part of Table 86 (third column) are included the average yields of corn for the last three years in a system of grain farming, in a 3 -year rotation of corn, oats, and clover. This system, when fully under way, provides that the corn shall be husked and the stalks disked down in preparation for the seeding of oats and clover the second year. In harvesting the oats, as much straw as possible is left in the stubble, which may be mowed later in the summer to prevent the seeding of the clover or weeds. In the spring of the third year the clover is mowed once or twice before the usual haying time and left lying on the land. The seed crop, if successful, is harvested with a hay buncher attached to the mower, or in any other way to avoid raking, and afterward the threshed clover straw and oat straw (or at least as much as is practicable) are returned to the land, all of this accumulated organic matter to be plowed under for the following corn crop, which begins the next rotation. In addition to this, catch crops of annual legumes, such as cowpeas, may be seeded in the corn at the time of the last cultivation and disked in the next spring with the corn stalks. If biennial or perennial legumes are used as catch crops, the corn ground may be plowed for oats. (This is a practice of doubtful advantage where the corn is rank.)

The corn yields reported for this system in Table 86 were secured where the system was not fully under way, the legume-catch crops being the only organic matter returned to the soil, aside from the residues necessarily left, except for the last crop rotation. By 
using three different fields for this rotation, every crop may be grown every year, and the yields of corn reported are true threeyear averages.

With no special soil treatment aside from crop residues and catch crops, the yield of corn for I908, I909, and I9ro averaged 52 bushels. Where the equivalent of $\frac{1}{2}$ ton per acre of ground limestone was applied (five years before) the corn has yielded $5^{8}$ bushels per acre; and, with the phosphorus added for six years at the rate per annum of 25 pounds per acre of the element phosphorus (in 200 pounds of steamed bone meal) the average yield of corn has been 84 bushels per acre for the last three years. The yearly addition of 42 pounds of potassium in 100 pounds of potassium sulfate has further increased the yield to 87 bushels.

Under the heading "Live-stock Farming," in Table 86, are recorded the average yields of corn secured during the same three years where farm manure has been applied to the clover ground to be plowed under for corn. The plan of this system is to remove all crops from thic land as usually harvested, including the corn and stover, oats and straw, and both first and second crops of clover. The amounts of manure applied to the different plots are determined by the crop yields secured during the previous rotation. While the system of cropping followed during the 6 years on these plots, and on those just described under "Grain Farming," has been approximately equivalent to a three-year rotation of corn, oats, and clover, the applications of manure have been made only for the last 6 years, from 1905 to I9Io. If the average yields are decreasing on plots that receive only the amounts of manure that can be produced in practice from the crops grown, then the applications of manure must also be reduced on such land; whereas if the crop yields are increasing where both manure and phosphorus are applied, then the applications of manure for such plots may be increased in direct proportion.

Where manure alone has been used in this rotation, the corn has averaged 69 bushels per acre for the three years; with lime added, the average is 75 bushels; with lime and phosphorus, the manured land has averaged 87 bushels of corn, and this was increased to $9 \mathrm{I}$ bushels by adding potassium.

While potassium has usually made some increase in crop yields 


\section{2}

on these fields, it has not nearly paid its cost. The most profitable yields are the 88 bushels in grain farming or the 90 bushels in the live-stock system (9-year averages). The effect of limestone has already been sufficiently uniform to recommend its use on this soil, and marked profit has resulted from the addition of phosphorus, which is applied in sufficient amount actually to enrich the land, and not as a stimulant. Phosphorus has been applied since 1902 .

Table 87 gives results obtained during seven years (I902 to I908) from the Sibley soil experiment field, located in Ford County, on typical brown silt loam prairie of the Illinois corn belt.

Table 87. Crop Yields in Illinois Soll Experinents: Sibley Field

\begin{tabular}{|c|c|c|c|c|c|c|c|c|}
\hline \multicolumn{2}{|r|}{$\begin{array}{c}\text { Brown Silt Loam Prairie, Eariy } \\
\text { Wisconsin Glaciation }\end{array}$} & $\begin{array}{l}\text { CORN, } \\
1902\end{array}$ & $\begin{array}{l}\text { CoRN, } \\
1903\end{array}$ & $\begin{array}{l}\text { OATS, } \\
1904\end{array}$ & $\begin{array}{c}\text { WHEAT, } \\
\text { I905 }\end{array}$ & $\begin{array}{l}\text { CoRn, } \\
1906\end{array}$ & $\begin{array}{l}\text { CORN, } \\
1907\end{array}$ & $\begin{array}{l}\text { OATS, } \\
\text { I908 }\end{array}$ \\
\hline Plot & Soil Treatment Applied & \multicolumn{7}{|c|}{ Bushels per Acre } \\
\hline IOI & None . . . . . & $57 \cdot 3$ & 50.4 & 74.4 & 29.5 & 36.7 & 33.9 & 25.9 \\
\hline IO2 & Lime . . . . . . & 60.0 & 54.0 & $74 \cdot 7$ & 31.7 & 39.2 & 38.9 & 24.7 \\
\hline 103 & Lime, nitrogen . . & $60 . c$ & $54 \cdot 3$ & 77.5 & 32.8 & $4 I .7$ & 48.1 & $3^{6.3}$ \\
\hline IO4 & Lime, phosphorus . & $6 \mathrm{I} \cdot 3$ & 62.3 & 92.5 & 36.3 & 44.8 & $43 \cdot 5$ & 25.6 \\
\hline 105 & Lime, potassium . & 56.0 & 49.9 & 74.4 & 30.2 & $37 \cdot 5$ & 34.9 & 22.2 \\
\hline \multirow{4}{*}{$\begin{array}{l}106 \\
107 \\
108\end{array}$} & Lime, nitrogen, phosphorus & $57 \cdot 3$ & 69.1 & 88.4 & 45.2 & 68.5 & 72.3 & 45.6 \\
\hline & Lime, nitrogen, potassium & $53 \cdot 3$ & $5 \mathrm{I} .4$ & $75 \cdot 9$ & $37 \cdot 7$ & $39 \cdot 7$ & 5 I.I & 42.2 \\
\hline & Lime, phosphorus, potas- & & & & & & & \\
\hline & sium $\cdot \cdot \cdot \cdot \cdot \cdot \cdot \cdot$ & 58.7 & 60.9 & 80.0 & 39.8 & $4^{\mathrm{I}} \cdot 5$ & 39.8 & 27.2 \\
\hline \multirow[t]{3}{*}{109} & Lime, nitrogen, phosphorus, & & & & & & & \\
\hline & $\begin{array}{l}\text { potassium } \cdot \text {. } \cdot \dot{\cdot} \cdot \overrightarrow{\text { po- }} \\
\text { Nitrogen, phosphorus, }\end{array}$ & 58.7 & & & $4^{8.0}$ & $69 \cdot 5$ & 80.I & 52.8 \\
\hline & tassium $\quad$. & 60.0 & 60.1 & 85.0 & 49.5 & $63 \cdot 3$ & 72.3 & $44 \cdot 1$ \\
\hline
\end{tabular}

The standard applications for this and other Illinois soil experiments are 100 pounds of nitrogen (in dried blood), 25 pounds of phosphorus (in steamed bone meal), and 42 pounds of potassium (in potassium sulfate), per acre per annum, but the phosphorus and potassium are usually applied in correspondingly heavier applications once for the rotation.

It is not necessary to take space here for a complete discussion of the data in Table 87 .

Previous to 1902 this land had been cropped with corn and oats 
for many years under a system of tenant farming, and the soil had become somewhat deficient in active humus. While phosphorus was the limiting element of plant food, the supply of nitrogen becoming available annually was but little in excess of the phosphorus, as is well shown by the corn yields for 1903 when phosphorus produced an increase of 8 bushels, nitrogen without phosphorus produced no increase, but nitrogen and phosphorus increased the yield by 15 bushels.

After six years of additional cropping, however, nitrogen appeared to become the limiting element, the increase in 1907 being 9 bushels from nitrogen and only 5 bushels from phosphorus, while both together produced an increase of 33 bushels of corn. By comparing the corn yields for the four years, 1902, 1903, 1906, and 1907, it will be seen that the untreated land has apparently grown less productive, whereas on land receiving both phosphorus and nitrogen the yield has appreciably increased, so that in 1907, when the untreated rotated land produced only 34 bushels of corn per acre, a yield of 72 bushels, or more than twice as much, was produced where lime, nitrogen, and phosphorus had been applied, although . these two plots produced exactly the same yield ( 57 bushels) in I902. While the actual yields might be quite different under different seasonal conditions, the relative and increasing differences between the plots must be considered as representative and due to the difference in soil treatment.

By comparing plots IOI and I02, and also IO9 and IIO, will be seen the increase by lime, suggesting that the time is near when lime also must be applied to these brown silt loam soils.

Because of the tremendous importance of this most common cornbelt soil to American agriculture and to the prosperity of the nation, space is taken to insert Table 88, giving all of the results thus far obtained from the Bloomington soil experiment field, which is also located on the brown silt loam prairie of the Illinois corn belt. (Additional data are inserted on page 475.)

The general results of the seven years' work on the Bloomington field tell the same story as those from the Sibley field. The rotations differ by the use of clover and cowpeas in 1906, and in discontinuing the use of commercial nitrogen after I905, on the Bloomington field, in consequence of which phosphorus without 
Table 88. Crop Yields in Illinois Soll Experiments: Bloomington FIELD

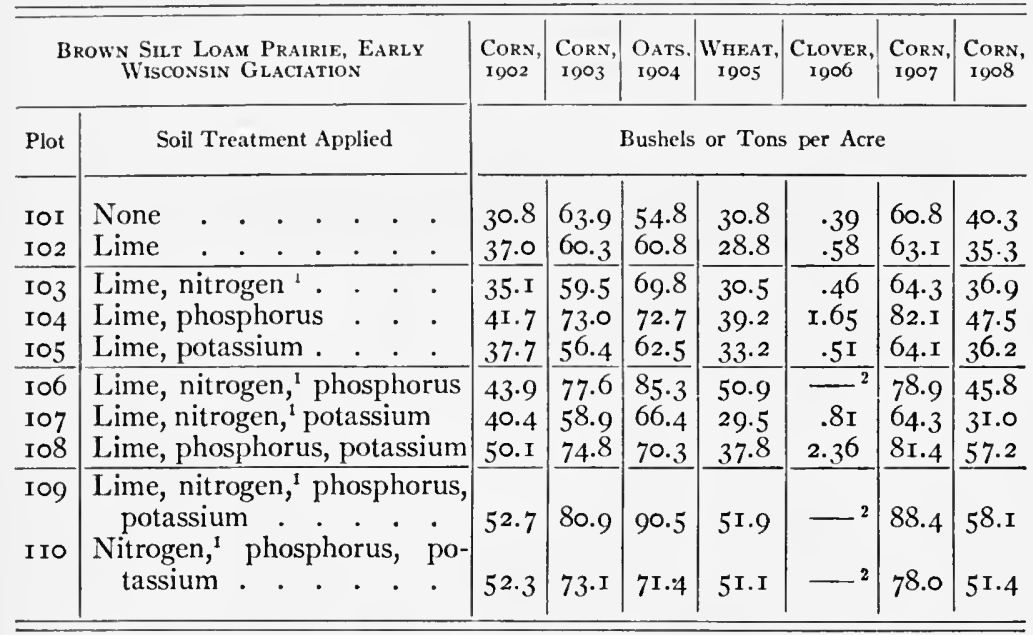

1 No commercial nitrogen applied after $19 \circ 5$.

${ }^{2}$ Clover smothered out by previous very heavy wheat crop. After the clover hay was harvested, all ten of the plots were seeded to cowpeas, and the crop was plowed under later on all plots as green manure for the 1907 corn crop.

nitrogen (plot I04) produced nearly as large an increase as the increase by phosphorus with nitrogen (plot Io6); whereas on the Sibley field phosphorus with nitrogen (plot I06) produced more than twice as large an increase as the increase by phosphorus without nitrogen.

It should be stated that a draw runs near plot i io on the Bloomington field, and the crops on that plot are sometimes damaged by overflow or imperfect drainage. Otherwise, all results reported in - Tables 87 and 88, including more than ${ }_{50}$ tests, are considered trustworthy, and they furnish much information and afford many interesting and instructive comparisons, as, for example, between plots 104 and 106 and between 108 and 109 on the Sibley field where no legumes are grown in the rotation; also, between plots 103 and I06 and between 107 and ro9 on both fields.

Wherever nitrogen was provided either by direct application or by the use of legume crops, the addition of the element phosphorus 
produced very marked increases, the average value being, as a rule, more than double its cost in steamed bone meal, the form in which it was applied to these fields. On the other hand, the use of phosphorus without nitrogen will not maintain the fertility of the soil (see plots 104 and I06, Sibley field), and a liberal use of clover or other legumes is suggested as the only practical and profitable method of supplying the nitrogen, the clover to be plowed under, either directly or as manure, preferably in connection with the phosphorus applied, especially if raw rock phosphate is used.

From the best treated plots, Ioo pounds per acre of phosphorus have been removed from the soil in the seven crops. This is equal to Io per cent of the total phosphorus contained in the surface soil of an acre. In other words, if such crops could be grown for 84 years, they would require as much phosphorus as the total supply in the surface $6 \frac{2}{3}$ inches of soil. The results plainly show, however, that without the addition of phosphorus such crops cannot be grown year after year. Where no phosphorus was applied, the crops removed only 75 pounds of phosphorus in seven years, or nearly i I pounds a year, equivalent to almost I per cent of the total amount (I 200 pounds) in the surface soil. (See also Table 5o, giving results of raw rock phosphate on brown silt loam.) The yellow-gray silt loams are found on the undulating upland areas that are, or were originally, timbered. The topography varies from nearly level to gently rolling, corresponding to the topography of the brown silt loam prairies. The yellow-gray silt loam varies from yellow to gray in the surface, and, as a rule, there is more or less "gray layer" in the subsurface (especially in the older formations). On the late Wisconsin glaciation, the loess covering being shallow, glacial material containing more or less gravel is frequently found in the subsoil within 40 inches of the surface.

As shown in Table ${ }_{5}$, the late Wisconsin yellow-gray silt loam (I034) contains in the surface $6 \frac{2}{3}$ inches about 2900 pounds of nitrogen, 800 pounds of phosphorus, and 47,600 pounds of potassium. Compared with the more productive, more durable, and more valuable soils (as the early Wisconsin black clay loam), this soil is very poor in phosphorus and quite low in humus as 
measured by the nitrogen or organic carbon, while it is extremely rich in potassium. ${ }^{1}$

The total supply of phosphorus in the plowed soil $\left(6 \frac{2}{3}\right.$ inches deep) is less than would be required for 35 crops of corn yielding I00 bushels of grain and 3 tons of stover, while the total nitrogen content even to a depth of 40 inches is less than would be required for 60 such crops, or for less than 90 if only the grain were removed, although the total potassium to a depth of 40 inches is sufficient to meet the requirements of roo-bushel crops of corn every year for more than 4 thousand years, or for more than 16 thousand years if only the grain is removed. Notwithstanding these positive facts, based upon absolute chemical analysis, showing such an enormous supply of potassium and a relatively small supply of nitrogen, the addition of soluble potassium salts, while not yielding profitable results, has actually produced a larger average increase than has been produced by nitrogen applied in dried blood on the Antioch soil experiment field about five miles from the Wisconsin line, in Lake County, Illinois, on the late Wisconsin yellow-gray silt loam, thus affording a good illustration of the fact that systems of soil treatment for permanent agriculture should not be based solely upon previous culture experiments.

This soil is deficient in active humus, and the soluble potassium

${ }^{1}$ It is appropriate to mention in this connection that Doctor A. S. Cushman of the United States Department of Agriculture has recently emphasized (Science (I 905), 22, 838; and U. S. Dept. of Agr. Bureau of Plant Industry Bulletin ro4) the possibility of using powdered granite and felspar as a source of potassium for fertilizing purposes, although some previous experiments with felspar (Svenska Mosskulturför. Tidskr. (I903), I7, 360; (ig04), I8, 33, 73) have not given encouraging results. While it is by no means certain that granite averaging 4 per cent of potassium or felspar with 8 or Io per cent of potassium may not be used with profit under some conditions, as where it can be secured as waste or by-product at very low cost near lands actually deficient in potassium, it is worth while to know that at $\$ 3$ per ton for powdered granite the surface 20 inches of the principal types of soil in the late Wisconsin glaciation already contains about $\$ 6000$ worth of potassium per acre in the form of finely powdered granitic rock. In other words, two tons of this soil (or three tons of any silt loam soil in the Illinois corn belt) spread over an acre of land would supply as much potassium, and in the same form, as would be supplied by a ton of average powdered granite.

While the phosphorus content of the surface soil of most \$150 Illinois land can be doubled by investing $\$ 25$ to $\$ 40$ per acre in raw rock phosphate at $\$ 7.50$ per ton, to double the potassium content by applying powdered granite at a cost of only $\$ 3$ a ton would cost from $\$$ I 200 to $\$ 1800$ per acre. 
salt acts in large part at least, if not entirely, as a soil stimulant rather than as plant food. As already shown by the results from Rothamsted, other soluble salts may produce the same effect.

In Table 89 are given the results of seven years' work on the Antioch soil experiment field.

Table 89. Crop Yields in Soil Experiments: Antioch Field

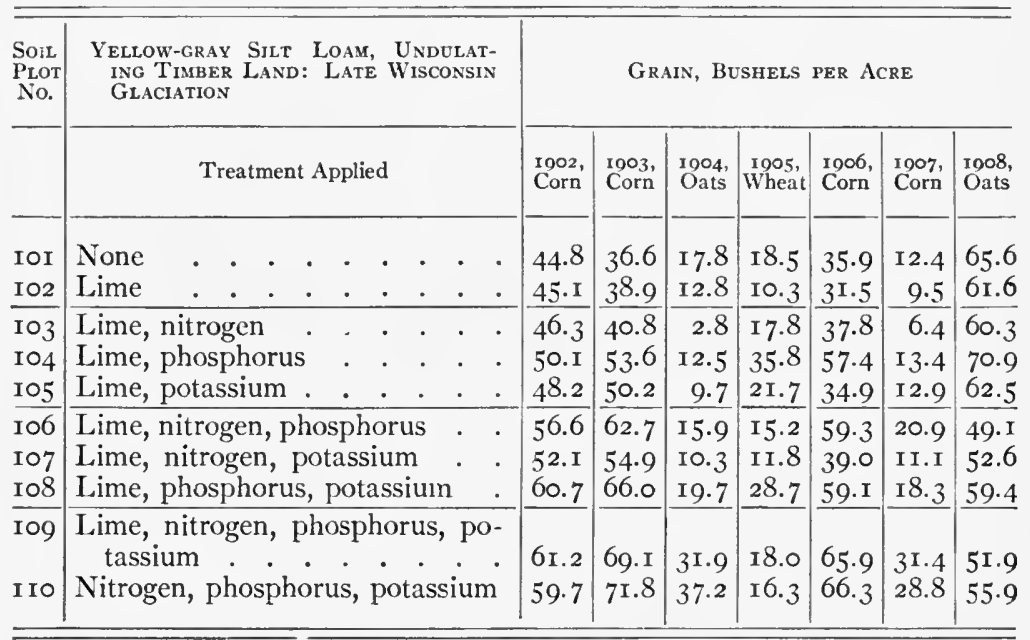

Plot No. I is naturally better land than the others, and both I and to serve only as checks against the lime treatment. They are not used in studying the effects of plant food applied.

The oats crop in 1904 and the I907 corn crop were almost failures. The low yields of wheat from plots 3, 6, 7, and 9, in 1905, were due to the fact that the wheat on these nitrogen plots grew very rank and lodged badly before it ripened. The straw on these plots also rusted badly, resulting in shriveled and light grain. The oats also lodged badly on the nitrogen plots in I9o8.

The total gains for seven years show very markedly the effects of soil treatment. After the first year the best treated plots produced about twice as much as plot 2, which serves properly as a check plot, to which no nitrogen, phosphorus, or potassium is applied.

Sand soil is found in considerable areas in Wisconsin and Michi- 
gan and in northern Illinois, Indiana, and Ohio, sometimes on sand plains and also in sand dunes where the sand has been blown into ridges varying from narrow drifts to extensive sand-hill areas, often covering many square miles, as in Tazewell, Mason, and Kankakee counties, in Illinois.

In composition this soil averages about I 400 pounds of nitrogen, 800 of phosphorus, and 31,000 pounds of potassium in the surface $6 \frac{2}{3}$ inches ( $2 \frac{1}{2}$ million pounds). The high percentage of potassium shows that this soil is not a pure quartz sand, but is, to a considerable extent, of granitic origin.

In composition this soil is extremely poor in nitrogen, rich in potassium, and fairly well supplied with phosphorus, if we consider its very porous character and the very deep feeding range afforded to plant roots.

The Green Valley soil experiment field is located on sand-ridge soil in Tazewell County, Illinois. The soil varies from a very sandy loam to a slightly loamy sand that is easily drifted by the wind when not protected by vegetation. This field was broken out of pasture in 1902 . In Table 90 are reported results secured in six years from contiguous and comparable plots in that part of the Green Valley field where nitrogen as well as other elements is supplied in commercial form.

Table 90. Crop Yields in Illinois Soll Experiments: Green Valley FIELD

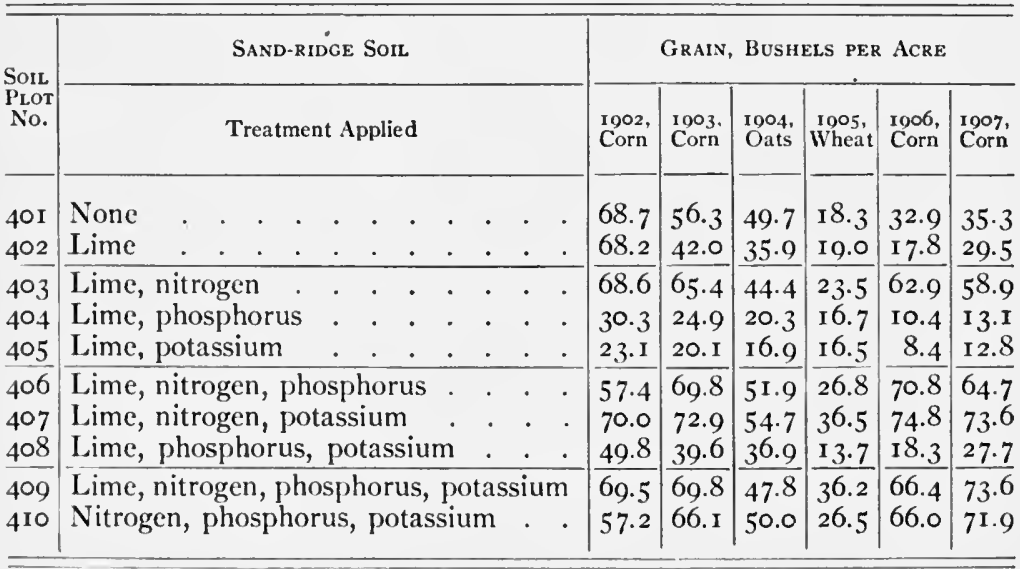


Plots I (especially) and 2 in this series were naturally more productive than the other plots, it being the regular custom of the Illinois Station to use the most productive land for the untreated check plots if any such differences are apparent when the field is established, as was the case in this instance. Plot I serves only as a check against the lime treatment, and the average of plots 2, 4, 5, and 8 gives a more reliable basis of comparison for ascertaining the effect of nitrogen.

Potassium is evidently the second limiting element in this soil where decaying organic matter is not provided, but the limit of potassium is very far above the nitrogen limit.

During the six years plot 7 , receiving nitrogen and potassium, produced 291.3 bushels of corn (averaging 72.5 bushels a year), 54.7 bushels of oats, and 36.5 bushels of wheat, per acre. To produce the increase of plot 7 over plot 5 would require about 75 per cent of the total nitrogen applied. Thus, there has been a loss of 25 per cent of the nitrogen applied, which is a smaller loss than usually occurs where commercial nitrogen is used. Without doubt, larger yields would have been produced, especially of corn, if I 50 or 200 pounds of nitrogen per acre per annum had been used, which would have increased the cost of nitrogen to $\$ 22.50$ or $\$ 30$, respectively, per acre each year.

It need scarcely be mentioned that commercial nitrogen is used in these and other experiments in Illinois only to help discover what elements are limiting the crop yields. It should never be purchased for use in general farming, but, if needed, secured from the atmosphere by legume crops to be returned to the soil directly or in manure.

On three other series of plots on the Green Valley soil experiment field, a three-year rotation of corn, oats, and cowpeas is practiced, every crop being represented every year. On plots receiving lime and phosphorus and legume crops, as green manure, the yield of corn was 45.6 bushels in 1906 and 67.8 bushels in 1907 , compared with 70.8 bushels and 64.7 bushels with lime, phosphorus, and nitrogen on plot 6 (see Table 90) and with 10.4 bushels and I3. I bushels with no nitrogen on plot 4, for the respective years. On other plots receiving comparable treatment, where lime, phosphorus, and potassium were used with nitrogen-gathering legume 


\section{INVESTIGATION BY CULTURE EXPERIMENTS}

crops as green manure, the corn yields in the three-year rotation were 54.6 bushels in 1906 and $5^{1.5}$ bushels in 1907 , compared with 66.4 bushels and 73.6 bushels on plot 9 with nitrogen applied, and compared with 18.3 bushels and 27.7 bushels on plot 8 with no nitrogen for the same years.

The growing of legume crops and the use of farm manure (and possibly limestone) are the only recommendations made for the improvement of these well-drained sand soils, although further tests may show profit from potassium until more organic matter is supplied. As a rule, clover cannot be grown successfully on this land, but cowpeas and soy beans are well adapted to such soil, and they produce very large yields of excellent hay or of grain very valuable for feed and also for seed.

Under the best conditions, with good preparation and heavy manuring, alfalfa can be grown on this sand soil, more than five tons of alfalfa hay per acre in one year having been grown on part of the Green Valley field. Both soy beans and alfalfa should be inoculated with the proper nitrogen-fixing bacteria.

Heavy applications of ground limestone also may be especially beneficial in getting alfalfa started.

(It should be kept in mind that residual sand soils, such as are found in the Coastal Plains soil province in the South Atlantic and Gulf States, are, as a rule, very deficient in mineral plant food, as well as in nitrogen.)

Peaty swamp lands. Peat is chiefly of two kinds, one being known as moss peat and the other as grass peat. Moss peat consists largely of dead and decaying sphagnum moss, and grass peat of the residues of coarse swamp grass, sedge, flags, etc. Probably most of the beds in Ohio, Indiana, Illinois, and Iowa are grass peat, although there is some moss peat in northern Illinois. Indeed, in the detail soil survey of Lake County, Illinois, one swamp of several acres was found where the sphagnum moss is still growing luxuriantly over a bed of moss peat.

Where the soil consists very largely of decaying peat to a depth of 30 inches or more, it is called deep peat.

As shown in Table ${ }_{5}$, deep peat contains in one million pounds of surface soil about 35,000 pounds of nitrogen, 2000 pounds of phosphorus, and 2900 pounds of potassium. This shows in the 
surface $6 \frac{2}{3}$ inches of an acre about five times as much nitrogen as the early Wisconsin black clay loam prairie. In phosphorus content these two soil types are about equal, but the peat contains less than one tenth as much potassium as the black clay loam. Thus, the total supply of potassium in the peat to a depth of $6 \frac{2}{3}$ inches (2930 pounds) would be equivalent to the full potassium requirement (75 pounds) of a hundred-bushel crop of corn for only 39 years, or if the equivalent of only one fourth of I per cent of this is annually available in accordance with the rough estimate previously suggested, about 7 pounds of potassium would be liberated annually, or sufficient for about ro bushels of corn per acre.

In Table $9 \mathrm{I}$ are given all results obtained from the Manito (Mason County, Illinois) experiment field on deep peat, which was begun in 1902 and discontinued after 1905. The plots in this field were one acre ${ }^{1}$ each in size, being 2 rods wide and 80 rods long, and untreated half-rod division strips were left between the plots, which, however, were cropped the same as the plots.

Table 9i. Corn Yields per Acre in Illinois Soll Experiments: Manito* Field: Typical Deep Peat Soll

\begin{tabular}{|c|c|c|c|c|c|c|c|}
\hline $\begin{array}{l}\text { PLot } \\
\text { No. }\end{array}$ & $\begin{array}{l}\text { SoIL TREATMFNT FOR } \\
\text { I902 (Per Acre) }\end{array}$ & $\begin{array}{l}\text { CoRN, } \\
1902 \\
(\mathrm{Bu} .)\end{array}$ & $\begin{array}{l}\text { CorN, } \\
\text { I9०3 } \\
(\mathrm{Bu} .)\end{array}$ & $\begin{array}{c}\text { SoIL TREATMENT FOR } \\
\text { 1904 (Per Acre) }\end{array}$ & $\begin{array}{c}\text { Cor N } \\
\text { I904 } \\
(\mathrm{Bu} .)\end{array}$ & $\begin{array}{l}\text { CoRN, } \\
\text { 1905 } \\
(\mathrm{Bu} .)\end{array}$ & $\begin{array}{l}\text { Four } \\
\text { C ROPS } \\
\text { (Bu.) }\end{array}$ \\
\hline I & . . . . . & 10.9 & 8.I & None . . . . . & I 7.0 & I 2.0 & 48.0 \\
\hline 2 & None . . . . . & 10.4 & 10.4 & Limestone, $4000 \mathrm{lb}$. & I 2.0 & IO. I & 42.9 \\
\hline 3 & Kainit, 600 lb. & 30.4 & 32.4 & $\begin{array}{c}\text { Limestone, } 4000 \text { lb. ; } \\
\text { kainit, I } 200 \text { lb. }\end{array}$ & 49.6 & 47.3 & I59.7 \\
\hline 4 & $\begin{array}{l}\text { Kainit, } 600 \text { lb. ; acid- } \\
\text { ulated bone, } 35^{\circ}\end{array}$ & & & $\begin{array}{l}\text { Kainit, I } 200 \text { lb. ; } \\
\text { steamed bone, } 395\end{array}$ & & & \\
\hline 5 & Potassium chlorid, & 30.3 & $33 \cdot 3$ & Potassium chlorid, & $53 \cdot 5$ & 47.6 & I6 $4 \cdot 7$ \\
\hline & $200 \mathrm{lb} . \quad . \quad . \quad$. & 31.2 & 33.9 & $400 \mathrm{lb} . \quad . \quad . \quad$. & 48.5 & 52.7 & I66.3 \\
\hline 6 & $\begin{array}{l}\text { Sodium chlorid, } 700 \\
\text { lb. }\end{array}$ & I I.I & I.3.I & None . . . . & 24.0 & $\overline{22 . I}$ & 70.3 \\
\hline 7 & $\begin{array}{l}\text { Sodium chlorid, } 700 \\
\text { lb. }\end{array}$ & I 3.3 & I 4.5 & Kainit, I 200 lb. . & $44 \cdot 5$ & $47 \cdot 3$ & \\
\hline 8 & Kainit, 600 lb. . & 36.8 & 37.7 & Kainit, 600 lb. & 44.0 & 46.0 & 164.5 \\
\hline 9 & Kainit, 300 lb. & 26.4 & $25 . \mathrm{I}$ & Kainit, 300 lb. . & $4 \mathrm{I} .5$ & 32.9 & I25.9 \\
\hline Io & None . . . & $\overline{14.9^{2}}$ & I 4.9 & None . . . & $\overline{26.0}$ & I3.6 & 69.4 \\
\hline
\end{tabular}

${ }^{1}$ In 1904 the yields were taken from quarter-acre plots because of severe insect injury on the other part of the field.

${ }^{2}$ Estimated from 1903 ; no yield was taken in I902 because of misunderstanding. 
The results of four years' tests as given in Table 9r are in complete harmony with the information furnished by the chemical composition of peat soil as compared with that of ordinary normal soils. Where potassium was applied, the yield was from three to four times as large as where nothing was applied. Where approximately equal money values of kainit and potassium chlorid were applied, slightly greater yields were obtained with the potassium chlorid, which, however, supplied about one third more potassium than the kainit: On the other hand, either material furnished more potassium than was required by the crops produced.

The use of 700 pounds of sodium chlorid (common salt) produced no appreciable increase over the best untreated plots, indicating that where potassium is itself actually deficient, salts of other elements cannot take its place.

Applications of two tons per acre of ground limestone produced no increase in the corn crops, neither when applied alone nor in combination with kainit, neither the first year nor the second.

Reducing the application of kainit from 600 pounds to 300 pounds, for each two-year period, reduced the yield of corn from I64.5 to I25.9 bushels. The two applications of 300 pounds of kainit furnished 60 pounds of potassium for the four years, or sufficient for 84 bushels of corn (grain and stalks). The difference between this and the 125.9 bushels obtained is 42 bushels, about what was obtained from the poorest untreated plot.

The underdrainage provided for this experiment field was not sufficient for the best results, probably because of insufficient nitrification. In other experiments on peaty soil with imperfect drainage, the addition of $\$_{I_{5}}$ worth of nitrogen with potassium produced about 15 bushels more corn than where potassium alone was used.

Peaty alkali soils. Aside from deep peat, there are many other types of peaty soil, as will be seen from the classification of Illinois soil types given in a previous chapter. Thus we find shallow peat and medium peat, underlain with clay, sand, rock, etc., and also sandy peat and peaty loam; and in some instances peaty soils also contain alkali, consisting chiefly of harmless calcium carbonate with smaller amounts of injurious magnesium carbonate.

In some cases these peaty soils actually contain a good percentage 
of total potassium, more commonly in the subsurface or subsoil, but sometimes in the surface soil, also; and yet the untreated soil is unproductive, while the addition of potassium salts produces large and very profitable increases in the yield of corn, oats, etc.

In pot-culture experiments the author has even been able by the addition of potassium sulfate to correct to a considerable extent the injurious property of magnesium carbonate that has been purposely applied to ordinary brown silt loam prairie soil which is known to contain abundance of available potassium. These facts are mentioned here because he recommends, in humid sections, trial applications of potassium salt to all classes of peaty and alkali soils that are unproductive after being well drained, whenever the supply of farm manure is insufficient. It should be understood that plenty of farm manure, preferably quick-acting, or readily decomposable, manure, such as horse manure, will supply potassium and thus accomplish everything that potassium salts can accomplish, and on some swamp soils manure produces good results where potassium is without effect.

In pot-culture experiments soils containing injurious amounts of magnesium carbonate have been treated with calcjum sulfate (land-plaster) which brings about a double decomposition, or interchange, forming the harmless insoluble calcium carbonate (limestone) and the very soluble magnesium sulfate, which is subsequently leached out, leaving the soil productive. (See page I7I.)

The new Manito experiment field is on alkali soil consisting of peaty, clayey sand with some gravel, and containing sufficient total potassium for normal crop yields. In Table 92 are recorded the treatment applied and results obtained in 1907 .

Table 92. Corn Yields in Illinois Soll Experiments: New Manito Field: Peaty Alkali Soll

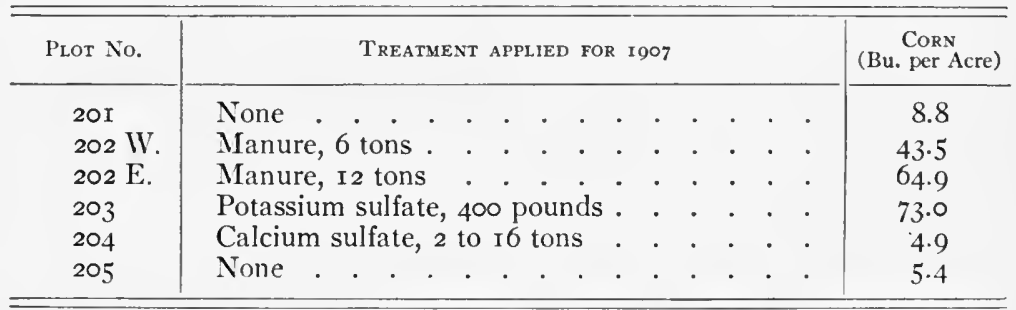




\section{INVESTIGATION BY CULTURE EXPERIMENTS}

Plot 204 is divided into four equal parts and the calcium sulfate applied at the rate of 2 tons, 4 tons, 8 tons, and 16 tons per acre, at a cost of $\$ 6$ per ton. It produced no benefit in 1907 . Whether it will assist in the removal of the magnesium carbonate by double decomposition and leaching and thus improve the soil in time, time alone will tell. (The Igo8-I9I I crops show no benefit.)

The 400 pounds of potassium sulfate are applied for a threeyear rotation at an initial cost of \$Io. The increase of 66 bushels of corn produced the first year, at 35 cents a bushel, amounts to more than twice the total cost of the potassium. The manure also gave very excellent results.

In Table 93 are given all results obtained during six years' experiments on part of the Momence soil experiment field, located in Kankakee County, Illinois, near the Indiana line, on peaty swamp land which contains much decaying peat and coarse sand in the surface and subsurface, with a clayey sand subsoil resting on impure limestone, while the surface, subsurface, and subsoil contain more than half of the normal amounts of total potassium (I9,000, 47,000, and 73,000 pounds, respectively, per acre). The soil contains but little alkali.

After I902 (when the corn was damaged by water) the land was tile-drained sufficiently well for ordinary years, but in the extremely wet season of I 907 the corn was planted very late, and with the continued wet weather resulted in almost a complete failure.

Potassium was not applied to plot 102 for 1902 and I903, and was not applied to plot i io for I904. The untreated check plot IOI is naturally somewhat more productive than the other plots.

These results from the new Manito field and from the Momence field, on abnormal swamp lands, emphasize the fact that, although some principles are well established and can be applied with normal results on normal soils and on some abnormal soils (as the deep peat and sand ridge soils), there are complex problems still unsolved relating to soils and soil fertility.

These problems may be chemical, physical, or biological, and their solution may require the application of science yet unknown. Thus, some essential eiement of plant food may be present in abundance but held in unavailable form by physical combination, as in grains of sanci: or there may exist some still undiscovered 
Table 93. Crop Yields in Illinois Soll Experiments: Momence Field

\begin{tabular}{|c|c|c|c|c|c|c|c|c|c|}
\hline \multirow{2}{*}{$\begin{array}{c}\text { PLOT } \\
\text { No. }\end{array}$} & \multirow{2}{*}{$\begin{array}{c}\text { Peaty Swamp Land: Soll Treat- } \\
\text { MENT Applied }\end{array}$} & \multicolumn{6}{|c|}{ CoRn (Bushels per Acre) } & \multicolumn{2}{|c|}{6 CRops } \\
\hline & & 1902 & 1903 & 1904 & 1905 & 1906 & 1907 & Bu. & Value \\
\hline $\begin{array}{l}\text { IOI } \\
\text { IO2 }\end{array}$ & 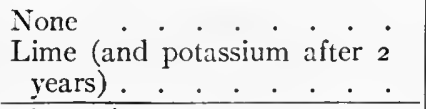 & $5 \cdot 5$ & $\begin{array}{c}14.9 \\
7.1 \\
\end{array}$ & $\begin{array}{r}4.8 \\
20 . \mathrm{I} \\
\end{array}$ & $\begin{array}{r}6.8 \\
33 \cdot 9 \\
\end{array}$ & $\begin{array}{r}6.8 \\
52.6 \\
\end{array}$ & I 4.9 & 40.5 & SI 4.I8 \\
\hline $\begin{array}{l}103 \\
104 \\
105\end{array}$ & $\begin{array}{llllll}\text { Lime, nitrogen } & \cdot & \cdot & \cdot & \cdot & \cdot \\
\text { Lime, phosphorus } & \cdot & \cdot & \cdot & \cdot \\
\text { Lime, potassium } & \cdot & \cdot & \cdot & \cdot & \cdot \\
\end{array}$ & $\begin{array}{r}0.0 \\
1.3 \\
23.7 \\
\end{array}$ & $\begin{array}{r}3.6 \\
4.6 \\
72.2 \\
\end{array}$ & $\begin{array}{r}\mathrm{I} \cdot 3 \\
.4 \\
34.6 \\
\end{array}$ & \begin{tabular}{r|}
$4 . I$ \\
$\mathrm{I} .8$ \\
$4 \mathrm{I} .4$ \\
\end{tabular} & $\begin{array}{r}5 \cdot 3 \\
1.9 \\
50.0 \\
\end{array}$ & $\begin{array}{r}.4 \\
.2 \\
16.2 \\
\end{array}$ & $\begin{array}{r}14.7 \\
10.2 \\
238.1 \\
\end{array}$ & $\begin{array}{r}\$ 5.15 \\
3.57 \\
83.34 \\
\end{array}$ \\
\hline $\begin{array}{l}106 \\
107 \\
108\end{array}$ & $\begin{array}{l}\text { Lime, nitrogen, phosphorus } \\
\text { Lime, nitrogen, potassium . } \\
\text { Lime, phosphorus, potassium. }\end{array}$ & $\begin{array}{r}0.0 \\
19.7 \\
32.0 \\
\end{array}$ & $\begin{array}{r}3 \cdot 9 \\
7 \mathrm{I} \cdot \mathrm{I} \\
73 \cdot \mathrm{I} \\
\end{array}$ & $\begin{array}{r}.6 \\
33 \cdot 5 \\
42.0 \\
\end{array}$ & $\begin{array}{r}1.6 \\
38.5 \\
36.3 \\
\end{array}$ & $\begin{array}{r}4 \cdot 5 \\
53 \cdot I \\
59 \cdot 4\end{array}$ & $\begin{array}{r}.4 \\
\mathrm{I} 6.5 \\
\mathrm{I} 9.9 \\
\end{array}$ & $\begin{array}{r}11.0 \\
232.4 \\
262.7\end{array}$ & $\begin{array}{r}3.85 \\
8 \mathrm{r} .34 \\
9 \mathrm{r} .95 \\
\end{array}$ \\
\hline IO9 & $\begin{array}{l}\text { Lime, nitrogen, phosphorus, po- } \\
\text { tassium }{ }_{\text {Nitrogen, phosphorus, potassium }}\end{array}$ & $\mid \begin{array}{l}25 \cdot 2 \\
24 \cdot \mathrm{I}\end{array}$ & $\begin{array}{l}66.8 \\
70.4\end{array}$ & $\begin{array}{l}39.2 \\
19.0\end{array}$ & $\begin{array}{l}42.9 \\
24.8\end{array}$ & & $\begin{array}{l}25 \cdot 1 \\
23 \cdot 4\end{array} \mid$ & 264.8 & $S_{92.68}$ \\
\hline
\end{tabular}

chemical substances injurious to agricultural plants or to necessary bacterial life, which may be corrected or destroyed by potassium salts or other materials; and the recent very extensive investigations by the United States Bureau of Soils indicate that conditions may be brought about, artificially at least, in which organic toxic substances develop that are injurious to plant growth.

Table 88, continued. Late Crop Yields: Bloonington Field

\begin{tabular}{|c|c|c|c|c|c|c|}
\hline $\begin{array}{l}\text { Plot } \\
\text { No. }\end{array}$ & Soll Treatment Applied & $\begin{array}{l}\text { OATS, } \\
\text { I } 909\end{array}$ & $\begin{array}{l}\text { Clover, } \\
\text { IgIO' }\end{array}$ & $\begin{array}{c}\text { WhEAT, } \\
\text { IgII }\end{array}$ & $\begin{array}{l}\text { VALUE OF } \\
\text { IO CROPS }\end{array}$ & $\begin{array}{l}\text { VALUE OE } \\
\text { INCREASE }\end{array}$ \\
\hline IOI & . . . . . . . & 46.4 & I. 56 & 22.5 & $\$ 147.90$ & \\
\hline 102 & Lime $\cdot$..$\quad \cdot \quad \cdot \quad \cdot \quad \cdot$ & 3.6 & I.09 & 22.5 & $\mathrm{I} 48.75$ & $\$ \quad .85$ \\
\hline IO3 & Lime and crop residues. & $49 \cdot 4$ & $(.83)$ & 25.6 & $\widehat{\text { SI } 5 \mathrm{I} .30}$ & $\$ 3.40$ \\
\hline 104 & Lime and phosphorus . & $6_{3}$ & 4.2 & 57.6 & .37 & $8 \mathrm{r} .47$ \\
\hline 105 & Lime and potassium . & $45 \cdot 3$ & $\mathrm{r} .26$ & $2 \mathrm{I} .7$ & I 49.43 & $\mathrm{I} .53$ \\
\hline 106 & Lime, residues, phosphorus & 72.5 & $(1.67)$ & 60.2 & $\$ 221.30$ & $\$ 73.40$ \\
\hline 107 & Lime, residues, potassium & $5 \mathrm{I}$ & & 27 & & 2.06 \\
\hline 108 & Lime, phosphorus, potassium & 50.5 & & & .20 & 8 I. 30 \\
\hline \multirow{3}{*}{$\begin{array}{l}\text { IO9 } \\
\text { I IO }\end{array}$} & Lime, crop residues, phos- & & & & & \\
\hline & $\begin{array}{l}\text { phorus, potassum } \\
\text { Crop residues, phosphorus, }\end{array}$ & & & 60.4 & & \\
\hline & & $55 \cdot 3$ & $(.60)$ & $6 \mathrm{r. \circ}$ & 209.26 & 61.36 \\
\hline
\end{tabular}

${ }^{1}$ Figures in parentheses for bushels of seed; the others for tons of hay. 


\section{CHAPTER XXIII}

\section{FIELD EXPERIMENTS IN THE SOUTH, INCLUDING SOUTHERN ILLINOIS}

THE gray silt loam on tight clay is one of the common types of prairie land in the Kansan and lower Illinoisan glaciations. This or very similar prairie soil is found in many places, as in southern Illinois, northern Missouri, southern Iowa, and southeastern Kansas. In Illinois this soil type is found chiefly between the Kaskaskia and Wabash rivers in an area bounded on the south by the Ozark Hills and on the north by the terminal moraine of the Wisconsin glaciation, which passes through Shelby, southern Coles, and Edgar counties.

This type of soil is well known and everywhere recognized by the farmers themselves as "hardpan land." It consists of a friable gray silt loam which commonly varies in depth from 6 to 12 inches, and below which is a light gray or nearly white layer, or stratum, of slightly loamy silt varying from less than one inch to more than ro inches in thickness, and commonly referred to as " the gray layer." At a depth of 16 to 20 inches the soil is underlain by a tight clay subsoil, frequently termed " hardpan." It should be understood, howcver, that this subsoil is not true hardpan, which consists of sand or gravel cemented together with clay to form a substance which is practically impervious to water.

The subsoil of this gray silt loam prairie is a tight clay, inclined to be gummy. Water passes through it, although quite slowly, and when wet it can be spaded without special difficulty, but when dry it becomes stiff and hard. Closely related to this prairie soil are level upland timbered soils underlain with tight clay, found in the southern part of Indiana, Illinois, and Iowa, and also in northern Missouri and western Kentucky.

Where this soil is enriched by proper treatment, excellent crops are grown in seasons of normal rainfall, but they are likely to suffer in times of drouth more than would be the case with a better sub- 
soil. As a rule, the rainfall in southern Illinois is abundant and well distributed during the growing season, and where the top soil is kept fertile, severe injury from drouth is not common.

From Table $\mathrm{I}_{5}$ it will be seen that the average surface soil of this type contains per acre 2880 pounds of nitrogen, 840 pounds of phosphorus, and 24,940 pounds of potassium, and it requires an application of 2 to 5 tons of ground limestone. Compared with the requirements for a practical crop rotation, this soil is very poor in phosphorus and very deficient in lime. Compared with the composition of fertile soils, it is also deficient in humus as indicated by the total nitrogen.

If by the best systems of crop rotations, with proper use of green manures, we can liberate, in favorable seasons, the equivalent of I per cent of the phosphorus contained in the surface soil, it would amount to about 8 pounds per acre for the first year ior the type of soil under consideration. This would be sufficient for a 25bushel crop of wheat. If with less perfect systems only half of I per cent is liberated, it would amount to 4 pounds, or enough for a I 2 -bushel crop of wheat, which is about the average yield for this soil.

On the Illinois soil experiment field near Odin, Marion County, on this ordinary prairie land of the lower Illinoisan glaciation, wheat is grown in a four-year crop rotation with clover, corn, and cowpeas. By having four different series of plots, every crop may be grown every year.

As an average of four years (1904, 1905, 1906, and 1907), wheat grown in this rotation produced $\mathrm{I} \mathrm{I}_{\mathbf{2}}^{\mathbf{1}}$ bushels per acre with no special soil treatment, all crops having been removed.

Where one cowpea crop and some catch crops (as cowpeas seeded in the corn) had been plowed under during the rotation, the average yield of wheat was increased to 14 bushels.

Where lime or ground limestone had been applied and the cowpeas also plowed under, the average yield of wheat was $18 \frac{1}{2}$ bushels per acre. On this set of plots better cowpea crops and catch crops were produced and turned under as green manure, because the soil acidity had been corrected by the lime, applied for the special benefit of the legume crops.

Where phosphorus was applied in addition to the use of lime and 


\section{INVESTIGATION BY CULTURE EXPERIMENTS}

green inanure, the average yield of wheat during the four years was 27 bushels; and where potassium also was included, the average yicld was $29 \frac{1}{2}$ bushels of wheat per acre.

These results are quite in harmony with what might be expected from the chemical composition of the soil. If, however, we consider the corn crops in the same rotation, we have a somewhat different set of results.

The average yield of corn for the four years on the untreated rotated land was 38 bushels per acre; with legume treatment (cowpeas turned under), 4I bushels; with legume and lime treatment, 45 bushels; with legume, lime, and phosphorus, 46 bushels; and with legume-lime phosphorus-potassium treatment the average yield of corn for four years was 6r bushels per acre.

For more convenient comparison, these results are shown in Table 94 .

Table 94. Crop Yields in Illinois Soll Experiments: Odin Field

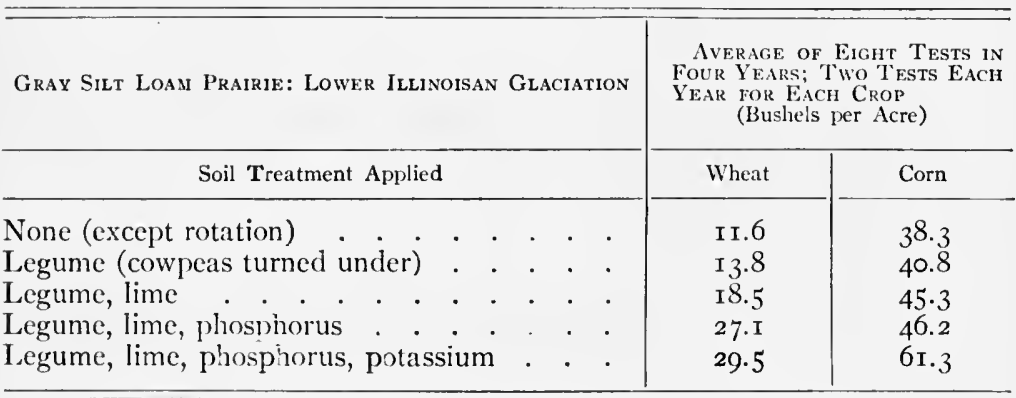

These results are four-year averages. They were made in duplicate each year. They are representative and trustworthy. They have also been confirmed by results from other experiment fields on the same type of soil.

The effects upon corn of the green manure alone and with lime are about the same as upon wheat, but the effects produced by phosphorus and potassium are very different with the two crops, phosphorus producing the largest increase in wheat, while potassium is much more effective with corn, although potassium without phosphorus (in other experiments) produces less increase in corn than when applied in addition to phosphorus. 
A study of Table 23 will show that a 6 I-bushel crop of corn requires more potassium than a 30 -bushel crop of wheat, which fact may account in part for the greater effect of potassium on corn, although about the same relation holds for phosphorus. A more important difference probably exists in the relative feeding powers of the two crops, influenced (I) by the difference in root system, including the different depths of feeding, (2) by the difference in seasonal conditions and consequent difference in decay of humus, in decomposition of other soil materials, and in activity of soil organisms during the principal period of growth, (3) by the solvent action of the carbon dioxid excreted by the bacteria and from the plant roots, and (4) possibly by different requirements as to the forms or combinations in which the plant-food elements can be absorbed and assimilated or utilized by corn and wheat.

The Rothamsted data contribute much toward the solution of this practical problem, but the very important question recurs, whether more or less of the effect attributed to potassium may not be due to the stimulating action of the soluble potassium salt in liberating other substances from the soil instead of serving directly as plant food; and, if so, would it be advisable and more profitable to substitute some other less expensive material, such as kainit, for the concentrated potassium sulfate used in these experiments?

It can also be stated that as an average of 56 tests (including the use of twenty-five different varieties of corn) conducted in I907 and I908 on the Illinois experiment field near Fairfield in Wayne County, on the same type of soil, an application of 200 pounds per acre of potassium sulfate, containing 85 pounds of the element potassium and costing $\$ 5$, increased the yield of corn by 5.4 bushels per acre; while 600 pounds of kainit containing only 60 pounds of potassium and costing $\$ 4$, gave 9.9 bushels' increase. These applications are made but once for a four-year rotation. The kainit with 25 pounds less potassium produced 4.5 bushels more corn than the sulfate. At 40 cents a bushel for corn, the kainit has paid for itself. Kainit contains about 25 per cent of potassium sulfate together with some I6 per cent of magnesium sulfate, I2 per cent of magnesium chlorid, and 33 per cent of sodium chlorid, all of which are soluble salts; and the results plainly indicate that the effects produced are due not solely to the element potassium, 
but in part at least, and probably in large part, to the stimulating action of the soluble salt.

The soluble salts were applied in addition to phosphorus and the yields compared with the results obtained where the same amounts of phosphorus were applied without the soluble salts mentioned. Limestone was also provided in all cases. The soil is not well supplied with decaying organic matter, the action of which will largely, or, if provided in abundance, entirely take the place of the action of the soluble salts as such. Additional experiments on the Fairfield field include an equally complete test with kainit and potassium sulfate on land to which 8 tons per acre of farm manure had been applied. As an average of $5^{6}$ tests with each material, 200 pounds of potassium sulfate increased the yicld of corn by r.6 bushels, while the 600 pounds of kainit gave I.4 bushels' increase, as compared with 5.4 bushels' and 9.9 bushels' increase, respectively, where these soluble salts were applied in the absence of manure, all other conditions being the same.

Thus, where farm manure is supplied, the soluble salts produced but little effect and are not used with profit. On the other hand, phosphorus usually produces its greatest effect when used in connection with organic matter.

In Table 95 are given the results obtained during seven years on the Du Bois experiment field, in Washington County, Illinois, on the same soil type (gray silt loam on tight clay). In this field there are two independent series of ten plots each, and the crop yields reported in the table are in all cases the average from two plots with like treatment.

For convenient comparison it may be stated that at conservative prices the value of the seven crops on the untreated land is $\$ 34.30$, while \$99. I r represents the corresponding value from an acre treated with lime, bone meal, and potassium sulphate, costing $\$ 46.25$.

The yellow silt loam is found in all glaciations, and much more abundantly (relatively) in the unglaciated areas in the South Central states. Like most of the soils of the Central states, it consists of a loessial deposit. It occupies much of the sloping lands or hillsides, not only in the original hilly sections (as in the unglaciated, or driftless, areas from southern Illinois to northern Mississippi), but also in the broken land regions along most of the 
Table 95. Crop Yields in Illinois Soll Experiments: Du Bois Field

Gray Silt loam Prairie: Lower Illinoisan Graciation

Soil Treatment Applied
Average of Two Series Each Year (Bushels or Tons per Acre)

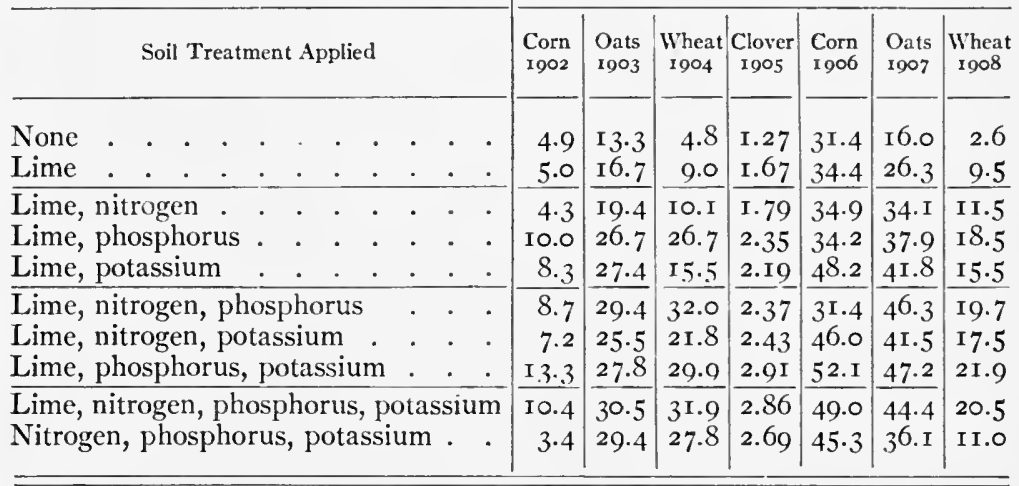

interior streams in glaciated areas. Under ordinary methods of cultivation these lands are subject to serious loss from surface washing, and even when not under cultivation there is and has been more or less rapid erosion taking place. Where this soil has been under ordinary cultivation for several years, it is almost in variably poor in humus and nitrogen, and the dominant problem is to maintain or increase the organic matter in the soil, which will also increase the nitrogen.

Of course the organic matter must in large part at least be grown upon the land, and legume crops are most suitable for this purpose because their growth is not limited by the small nitrogen content of the soil, and they also furnish green manures or animal manures rich in nitrogen.

While these soils are not rich in phosphorus, that element is not the chief limit to the yield of crops because the nitrogen limit is so much lower as measured by crop requirements and by culture experiments. Furthermore, by surface washing, the nitrogen, which is contained only in the humus, is rapidly depleted, while the phosphorus is constantly renewed because of the supplies in the underlying materials. It is certain that for the highest crop yields phosphorus must be applied, and very probably it can ultimately be applied with profit in the best systems of soil improve- 
ment and preservation, but, as stated above, the first requisite is an increase in humus and nitrogen.

There is, however, a serious difficulty to the growing of legume crops, especially for clover and alfalfa. This type of soil, where it has been long under cultivation, is markedly sour or acid. This applies to the Kansan glaciation in Missouri and to the lower Illinoisan glaciation, and especially to the unglaciated yellow silt loam in the southern parts of Illinois and Indiana, and in the loesscovered areas of Missouri, Kentucky, Tennessee, and Mississippi.

In the northern glaciations this type of soil is less acid than in the Kansan and lower Illinoisan, but it is usually more or less acid in the middle and upper Illinoisan, in the pre-Iowan and Iowan, and even in the early Wisconsin glaciation, - and not only in the Central states, but also in New York and other Eastern states.

In the unglaciated areas and in the lower Illinoisan and Kansan glaciations initial applications of at least two tons per acre of ground limestone are recommended for the yellow silt loam; and for the other glaciations two tons or more may well be applied where acidity is shown in the surface and subsoil and where difficulty is encountered in the growing of red clover or alfalfa.

One of the very best crops, and probably the most satisfactory and profitable crop, to be grown on these yellow silt loam soils is alfalfa. Its power to secure nitrogen from the air, to root deeply, and to live for many years are all very great advantages for this soil. Furthermore, experiments have shown that where the land is properly treated with heavy applications of lime or ground limestone (five tons per acre) and thoroughly inoculated with the alfalfa bacteria and the alfalfa seeded on well-prepared and wellmanured land at the proper time and given proper care, it grows luxuriantly and yields large and profitable crops on this soil, as in Illinois, Ohio, and New York. On the other hand, to sow 20 to 25 pounds of good alfalfa seed on this soil without special and proper treatment is much like throwing away about $\$ 4$ an acre.

Of course, if alfalfa is grown on this land, it should be fed on the farm, in part at least, and the manure returned to the soil, not only to help the alfalfa but also for other crops to be grown, such as corn and potatoes, which are a very profitable crop for this soil when properly enriched. 
Table 96 gives the yields of corn, wheat, and clover obtained in 1907 on the Vienna soil experiment field in Johnson County, Illinois, located on the less rolling phase of yellow silt loam in the unglaciated area, and typical of more extensive areas of this type in other Southern states. (It should be remembered that geographically and agriculturally one third of Illinois belongs with the South Central states. A straight line from the north point of Kentucky to the northeast corner of Missouri divides Illinois into two practically equal parts.)

The land on which the Vienna field is located has been cropped for about seventy-five years. It had never had any soil treatment, so far as can be determined, and was badly run down when the Experiment Station came into possession of it in 1902.

The field is divided into three series of five fifth-acre plots. A three-year rotation of corn, cowpeas, and wheat was followed for four years, then changed to corn, wheat, and clover, but, excepting the 1907 crop, the clover has failed. Cowpeas have been substituted and the crop harvested or plowed under, as seemed practical, according to the yield and weather conditions. In I902, oats were grown in the place of whea'.

The soil treatment has been as follows:

Plot I of each series, no treatment except as the cowpea stubble or the second growth of clover has been plowed under in the regular course of the rotation.

Plot 2, legume crops and catch crops plowed under, except in 1905-1 906-1907.

Plot 3 , legumes plowed under and lime applied.

Plot 4, legume, lime, and phosphorus.

Plot 5, legume, lime, phosphorus, and potassium.

Table 96. Crop Yields in Illinois Sole Experiments: Vienna Field

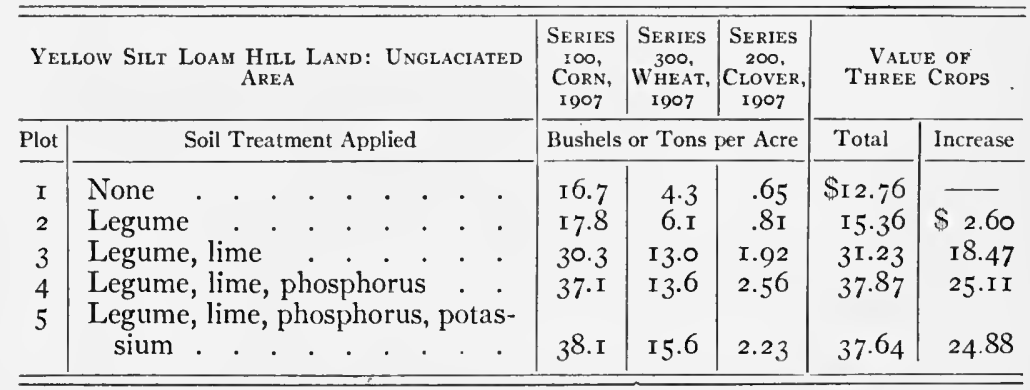


The primary object in applying lime is to correct soil acidity. In the spring of 1902 one ton per acre of slacked lime was applied; but, a method having been worked out by which it can be determined by chemical analysis how much lime is equivalent to the soil acidity to any depth, it was found that the soil on this field was acid in the surface, more acid in the subsurface, and still more acid in the subsoil; and in order to provide ample lime to correct this acidity, an additional application of eight tons per acre of ground limestone was made in the fall of I902. From all information now available, it is believed that two to five tons per acre of ground limestone as an initial application will give very satisfactory results. Heavier applications may give more profit per acre, but less profit per ton of limestone used.

Phosphorus has been applied at the rate of 25 pounds, and potassium at the rate of 42 pounds, per acre per annum, the present regular practice being to apply once in three years 600 pounds of steamed bone meal, containing I $2 \frac{1}{2}$ per cent phosphorus, and 300 pounds of potassium sulfate, containing 42 per cent of potassium.

Seven crops of corn, six of wheat, one crop of oats, and six of cowpeas and one of clover have been grown on the field since the work was begun in I902. The yields of corn, oats, and wheat are given in Table 97.

Counting only the crops removed, the limestone, at \$1.50 per ton, has paid for itself and left a net profit of 34 per cent; and, assuming rooo pounds' loss per acre per annum, more than half of the application still remains in the soil. Neither phosphorus nor potassium has been used with profit, but it is interesting to note that plot 5 has produced six times as much wheat as No. I.

Seasonal conditions have very markedly influenced the yields of crops. Larger use of crop residues to increase the organic matter of the soil promises further improvement.

Some very instructive results have been obtained from a series of pot-culture experiments which have been in progress since 1902 in the pot-culture greenhouse of the Illinois Experiment Station, and in which this yellow silt loam of the unglaciated hill land has been used. The soil was collected in the fall of rgor, and represents the old worn hill soil of Pulaski County, Illinois, only a few miles from Kentucky. It is much poorer in nitrogen and humus than the 
Table 97. Crop Yields in Illinois Soll Experiments: Vienna Field Corn, Bushels per Acre

\begin{tabular}{|c|c|c|c|c|c|c|c|c|c|}
\hline \multirow{2}{*}{$\begin{array}{l}\text { SoIL } \\
\text { PLOT } \\
\text { No. }\end{array}$} & \multirow{2}{*}{ Treatment Applied } & 1902 & 1903 & I 904 & I905 & 1906 & 1907 & 1908 & Total. \\
\hline & & $\begin{array}{c}\text { Series } \\
100\end{array}$ & $\begin{array}{c}\text { Series } \\
\text { 100 }\end{array}$ & $\begin{array}{c}\text { Series } \\
300\end{array}$ & $\begin{array}{c}\text { Series } \\
200\end{array}$ & $\begin{array}{c}\text { Series } \\
300\end{array}$ & $\begin{array}{c}\text { Series } \\
100\end{array}$ & $\begin{array}{c}\text { Series } \\
200\end{array}$ & $\begin{array}{l}\text { Seven } \\
\text { Years }\end{array}$ \\
\hline I & None . . . . . . & I 5.5 & $9 \cdot 3$ & 30.5 & $37 \cdot 5$ & $4 \mathrm{I} .2$ & I6.7 & 35.2 & I 85.9 \\
\hline 2 & Legume . . . . & I $3 \cdot 3$ & 5.0 & $35 \cdot 5$ & 42.9 & 40.6 & I 7.8 & 35.6 & I 90.7 \\
\hline 3 & Legume, lime . . & I 4.9 & 8.3 & $49 . \mathrm{I}$ & 61.9 & 48.9 & 30.3 & $43 \cdot 9$ & $257 \cdot 3$ \\
\hline 4 & $\begin{array}{l}\text { Legume, lime, phos- } \\
\text { phorus . } \\
\text { pegume lime phos- }\end{array}$ & 12.5 & $7 \cdot 4$ & $49 \cdot 4$ & 57.2 & 40.9 & 37.1 & 42.9 & $247 \cdot 4$ \\
\hline & phorus, potassium & I9.9 & II.6 & $44 \cdot 7$ & 56.5 & 40.9 & $3^{8 .} \mathrm{I}$ & 50.6 & $262 \cdot 3$ \\
\hline
\end{tabular}

Oats or Wheat, Bushels per Acre

\begin{tabular}{|c|c|c|c|c|c|c|c|c|c|}
\hline & & $\begin{array}{c}\text { Oats } \\
\text { Series } \\
200\end{array}$ & $\begin{array}{l}\text { Wheat } \\
\text { Series } \\
300\end{array}$ & $\begin{array}{l}\text { Wheat } \\
\text { Series } \\
200\end{array}$ & $\begin{array}{l}\text { Wheat } \\
\text { Series } \\
\text { too }\end{array}$ & $\begin{array}{l}\text { Wheat } \\
\text { Series } \\
200\end{array}$ & $\begin{array}{c}\text { Wheat } \\
\text { Series } \\
300\end{array}$ & $\begin{array}{l}\text { Wheat } \\
\text { Series } \\
\text { too }\end{array}$ & $\begin{array}{l}\text { Wheat } \\
\text { in } \\
6 \text { Years }\end{array}$ \\
\hline I & None & I9. I & .4 & 6.7 & I. 3 & 3.8 & $4 \cdot 3$ & none & 16.5 \\
\hline 2 & Legume . . & I 8.8 & .6 & 7.1 & I0.8 & $5 \cdot 4$ & 6.I & none & 30.0 \\
\hline 3 & Legume, lime . & 19.8 & .7 & 10.0 & I 8.2 & I 7.9 & 13.0 & 4.5 & $64 \cdot 3$ \\
\hline 4 & $\begin{array}{l}\text { Legume, lime, phos- } \\
\text { phorus. }\end{array}$ & 20.0 & 8.0 & I 4.8 & 25.6 & II. 3 & I 3.6 & 8.3 & 81.6 \\
\hline 5 & Legume, lime, phos- & & & & & & & & \\
\hline & phorus, potassium . & $3 \mathbf{I} \cdot 7$ & II.O & 17.5 & 30.0 & 15.0 & I5.6 & 9.8 & 98.9 \\
\hline
\end{tabular}

average of the type, although large areas are to be found as badly worn as the field from which this soil was collected. This field has been under cultivation for about seventy-five years, and was still cropped when the soil was collected. During the earlier period of its cultivation the soil frequently produced 25 bushels of wheat an acre, but during the later years about 5 bushels has been the average crop in normal seasons.

Table 98 gives the results from six years' experiments with pot cultures on this type of soil. It is seen that practically no gain has been made except where nitrogen was supplied, either directly in commercial form or indirectly by means of legume treatment. It should be borne in mind that no legume treatment preceded the I902 wheat crop. The catch crop of cowpeas, which was planted 
after the I902 wheat crop and turned under later in the fall, produced a marked effect upon the I903 wheat crop. This effect became more marked in 1904 and 1905 , when every pot receiving legume treatment outyielded the pot receiving lime-nitrogen treatment.

The last line in the table gives the yields from a pot of virgin soil collected from a piece of unbroken virgin sod land adjoining the cultivated field from which the soil in all the other pots was taken. It is seen that the yields from this pot are gradually decreasing, doubtless due to the exhaustion of the more active organic matter in the soil.

Table 98. Crop Yields from Pulaski County (Illinois) Soll

Pot-culture Experiments

\begin{tabular}{|c|c|c|c|c|c|c|}
\hline $\begin{array}{c}\text { Yellow Silt Loam Hill Land of the } \\
\text { Unglaciated Area }\end{array}$ & \multirow{2}{*}{$\begin{array}{c}\text { I9O2 } \\
\text { WHEAT } \\
\text { (Grams) }\end{array}$} & \multirow{2}{*}{$\begin{array}{c}\text { I903 } \\
\text { WHEAT } \\
\text { (Grams) }\end{array}$} & \multirow{2}{*}{$\begin{array}{c}\text { I904 } \\
\text { WHEAT } \\
\text { (Grams) }\end{array}$} & \multirow{2}{*}{$\begin{array}{c}\text { I905 } \\
\text { WHEAT } \\
\text { (Grams) }\end{array}$} & \multirow{2}{*}{$\begin{array}{c}\text { I906 } \\
\text { WHEAT } \\
\text { (Grams) }\end{array}$} & \multirow{2}{*}{$\begin{array}{c}\text { 1907 } \\
\text { OATS } \\
\text { (Grams) }\end{array}$} \\
\hline Soil Treatment Applied & & & & & & \\
\hline None & 3 & 5 & 4 & 4 & 4 & 6 \\
\hline Legume, lime . . . . & 4 & ro & 17 & 26 & 19 & 37 \\
\hline Legume, lime, phosphorus . . & 3 & I 4 & I9 & 20 & I8 & 27 \\
\hline 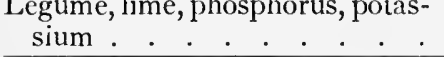 & 3 & I6 & 20 & $2 \mathrm{I}$ & 19 & 30 \\
\hline 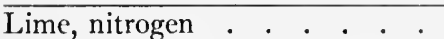 & 26 & I 7 & I 4 & I 5 & 9 & 28 \\
\hline Lime, phosphorus . . . . & 3 & 6 & 4 & 6 & 4 & 8 \\
\hline Lime, potassium . . . . . & 3 & 3 & 3 & 5 & 5 & Io \\
\hline Lime, nitrogen, phosphorus . & 34 & 26 & 20 & I 8 & I8 & 30 \\
\hline Lime, nitrogen, potassium . & .33 & I 4 & $2 I$ & $2 \mathrm{I}$ & I 6 & 23 \\
\hline Lime, phosphorus, potassium . & 2 & 3 & 3 & 5 & 3 & 7 \\
\hline 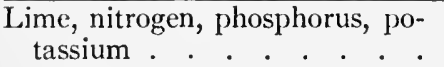 & 34 & $3 \mathbf{I}$ & 34 & $2 \mathrm{I}$ & 20 & 26 \\
\hline Virgin soil (no treatment) . . & 24 & I 7 & I 5 & I 7 & 13 & 6 \\
\hline
\end{tabular}

The results from the pot cultures bear out very conclusively the results obtained from the field tests; namely, that marked improvement can be made on this soil by turning under legume crops where lime has been applied. Very striking results appear in the oat crop in 1907 .

Of interest in this connection is another series of pot-culture experiments, with soil from the worn hill lands of Henry County, 
in northwestern Illinois, which furnish additional information concerning the general need of nitrogen for these hill lands.

The plan of these experiments, the soil treatment applied, and the results obtained are all shown in Table 98. I, and they require no further comment.

Table 98.I. Oat Yields from Henry County (Illinois) Soll Pot-culture Experiments

Yellow Silt loam Hill Land: Upper Ilinoisan Glaciation

None

Lime

Lime, nitrogen

Lime, phosphorus

Lime, potassium

Lime, nitrogen, phosphorus

Lime, nitrogen, potassium

Lime, phosphorus, potassium

Lime, nitrogen, phosphorus, potassium

Nitrogen, phosphorus, potassium

None

The Mississippi Experiment Station has reported in Bulletin ro8 one year's experiments (I906) at Holly Springs in the northwest part of that state, on similar worn hill land where fertilizers were used for cotton, corn, and cowpeas. The following comments are made:

"Phosphates hastened the maturity of cotton. On land with some decaying organic matter in it, phosphate alone gave good results, good enough to make it profitable. Potash alone, or in combination with nitrogen and phosphates, gave no apparent results. Nitrogen (cotton-seed meal) alone gave good results. Cotton-seed meal and phosphates mixed gave good results."

Similarly, in referring to the corn and cowpeas, the following statements are made:

"The land was thin upland. A drought of seven weeks obtained when the corn was young. Where the soil contained organic matter, phosphates alone gave good results. Potash alone, or in combination, failed to show any appre- 


\section{INVESTIGATION BY CULTURE EXPERIMENTS}

ciable benefit. Nitrogen (cotton-seed meal) alone gave good results. A mix. ture of cotton-seed meal and phosphates gave good results."

"The fertilizer test with peas was interfered with somewhat by the October storm, but it was apparent that both acid phosphate and crude, finely ground rock increased the growth of peas in a marked manner - apparently doubling the crop."

In Iowa Bulletin 98, r908, are reported the following yields of clover hay from the Leon experiment field on the loess and till soils of southern Iowa.

\section{Table 99. Southern Iowa Field Experiments}

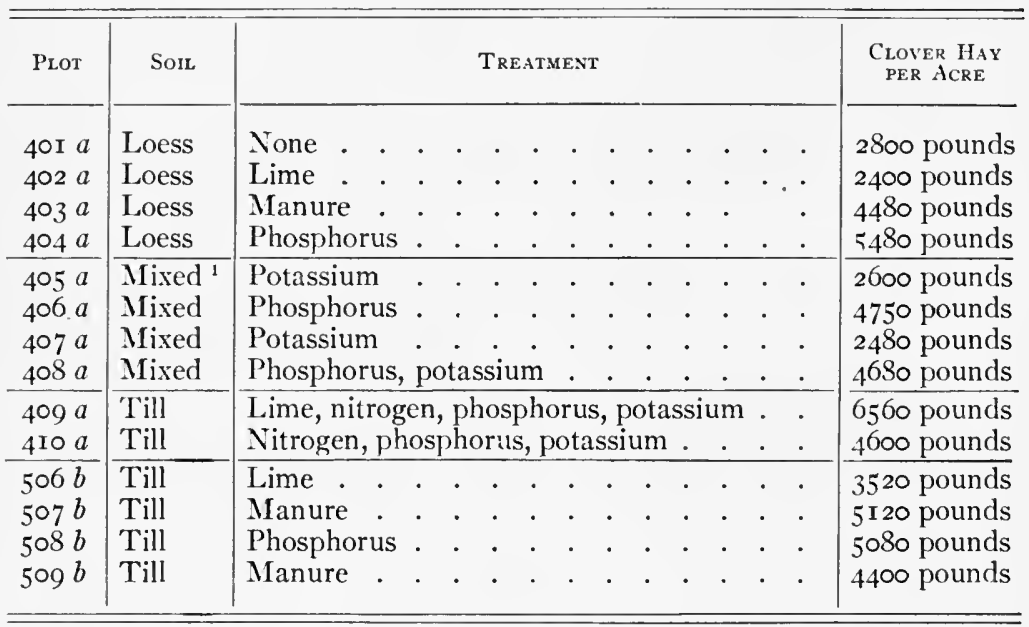

${ }^{1}$ Mixed loess and till.

The following comments are made in the summary of Iowa Bulletin 98:

"Manure applied to the soil at the rate of eight tons per acre was decidedly beneficial to the growth of clover."

"Phosphorus applied to the soil as steamed bone meal nearly doubled the yield of clover. The steamed bone meal was applied at the rate of 200 pounds per acre."

"Potassium, applied to the soil as potassium sulfate, did not increase the clover crop. Neither did this element of plant food prove beneficial when used in combination with phosphorus." 
"Nitrogen, applied to the soil as dried blood in combination with phosphorus and potassium, produced an increase of 1800 pounds of clover hay per acre over that grown with the minerals without dried blood."

"Clover should be grown extensively in southern Iowa for the following reasons:

" $a$. The soils of this section of the state are deficient in nitrogen and organic matter.

" $b$. These soils tend to wash because they lack humus."

Georgia field experiments. The Georgia Agricultural Experiment Station has reported a large number of fertilizer experiments, especially with cotton and corn; and the "Gcorgia rotation" has also won distinction for that station. 'This is a three-year rotation, as follows:

First ycar. Cotton.

Second year. Corn, with cowpeas seeded at the last cultivation and harvested for seed only, the rines being left on the land for soil improvement.

Third year. Winter oats, followed by a regular crop of cowpeas to be harvested for hay.

For this rotation, on worn uplands, Director Redding recommended the following applications per acre (Georgia Bulletin 72 , I906) :

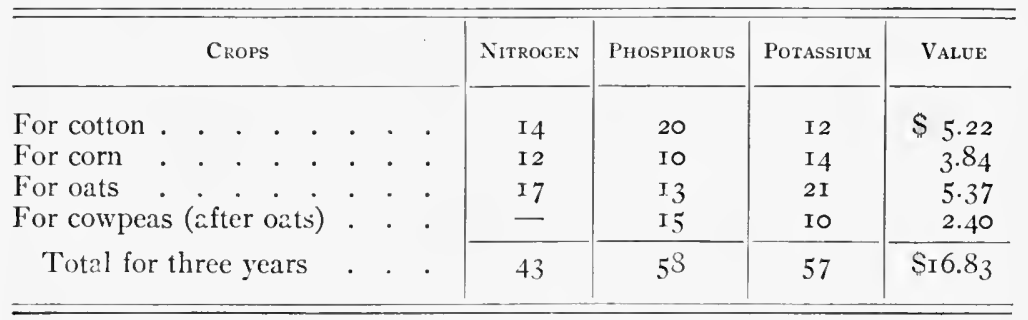

The fertilizer materials used are usually cotton-seed meal, acid phosphate, and potassium chlorid, although some use may be made of sodium nitrate, and kainit may replace the concentrated salt.

In the main this system is designed to apply for each crop the plant food which it needs, without much reference to the improvement of the soil, although farmers are urged to make and use farm manure so far as possible, and the statement is also made that 
"there are no fertilizers that will give better results on cotton than well-preserved and thoroughly rotted farmyard manures, applied very early in the season of preparation; but it will add very much to the effectiveness of such manures to mix with them a liberal dose of acid phosphate, say roo to 200 pounds to each ton."

It should be kept in mind that the upland soils of Georgia are as a rule much worn and extremely deficient in active organic matter. Thus, the average yield of corn on the $4 \frac{1}{2}$ million acres annually produced is II bushels per acre, for the Io years, I899 to I908.

The following statements regarding distances for planting corn occur on page I26 of Georgia Bulletin 72 :

"On soils of still less capacity, say from to to $\mathbf{I}_{5}$ bushels per acre, the distance should be still greater, say I $\overline{8}$ to 24 square feet to the stalk, or 2420 to 18 I 5 hills to the acre. Eighteen square feet to the stalk would be secured by spacing 6 feet by 36 inches, or 5 feet by 43 inches; or 4 feet 3 inches by 4 feet 3 inches. A soil that would produce less than Io bushels, with good seasons and very light manuring, is not fit to plant in corn."

Many of the Georgia experiments relate to a study of the effect of varying the proportions of the different fertilizers, as illustrated in Table 100 (Georgia Bulletin 62, page 93, year 1903):

Table ioo. Georgia Fertilizer Experiments with Corn

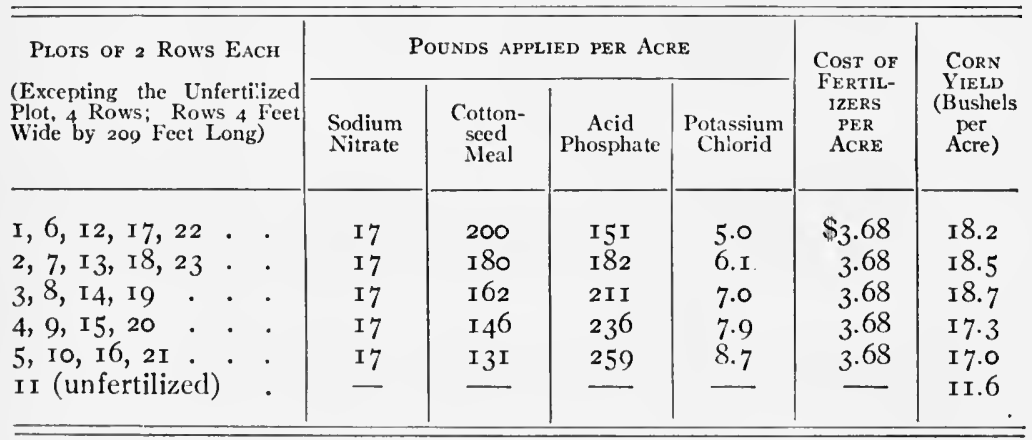

"The plan of the experiment was to make up five different formulas and apply the same cost value of each different formula to corresponding successive plots."

The same section of land (Div. B, Sect. I - East) was used for corn in I900, and the report for that year states that "no plots were left unfertilized." The fertilizer (including 53 pounds 
cotton-seed meal, 45 pounds of acid phosphate, and 2 pounds of potassium chlorid, in 100 pounds) was applied at the rate of 200 , 400 , and 600 pounds per acre, and the respective yields of corn were $35.8,37.0$, and 38.4 bushels per acre, from which the conclusion is drawn that " the results only confirm conclusions repeatedly reached in previous years that large doses of commercial fertilizers ' do not pay,' as a rule, when applied to corn on upland."

In this connection the following rainfall records are of interest:

Table iói. Rainfall Records at Experiment, Georgia

\begin{tabular}{|c|c|c|c|c|c|c|c|c|c|c|c|c|c|}
\hline \multicolumn{9}{|c|}{ YEARS } & \multirow{2}{*}{$\begin{array}{c}\begin{array}{c}\mathrm{M} \text { Ay } \\
\text { (Inches) }\end{array} \\
2.6 \mathrm{I}\end{array}$} & \multirow{2}{*}{$\frac{\begin{array}{c}\text { JunE } \\
\text { (Inches) }\end{array}}{\mathrm{I} 2.02}$} & \multirow{2}{*}{$\frac{\begin{array}{c}\text { JuLY } \\
\text { (Inches) }\end{array}}{6.84}$} & \multirow{2}{*}{$\begin{array}{c}\begin{array}{c}\text { August } \\
\text { (Inches) }\end{array} \\
4.45\end{array}$} & \multirow{2}{*}{$\begin{array}{c}\begin{array}{c}\text { TOTAL FOR } \\
\text { THE YEAR }\end{array} \\
62.33\end{array}$} \\
\hline I9OO & & - & - & - & - & - & - & . & & & & & \\
\hline I9OI & & - & - & - & - & . & - & . & 6.09 & 5.14 & 3.22 & 6.27 & 53.40 \\
\hline I 902 & . & - & - & - & . & - & - & . & .79 & I. 90 & I.54 & 4.99 & 47.05 \\
\hline I903 & • & - & - & - & - & - & - & • & 6.47 & 2.27 & 2.28 & 5.46 & 48.78 \\
\hline 1904 & & - & - & . & . & . & - & - & 2.43 & .83 & 3.64 & 6.91 & 29.96 \\
\hline I905. & • & - & - & - & - & - & - & - & $3 \cdot 3^{8}$ & 4.97 & 3.01 & 2.92 & 42.37 \\
\hline Işo6. & . & . & . & . & . & - & . & . & $2.2 \mathrm{I}$ & 5.03 & 4.17 & 6.48 & $44 \cdot 74$ \\
\hline Avera & , & & to $I$ & 906 & & ${ }^{\circ}$ & $\cdot$ & & 3.08 & 4. I I & 5.00 & 5.93 & 46.47 \\
\hline
\end{tabular}

The yearly records for I 900 and I904 are the extremes for the seventeen years.

In Table 102 are recorded the results of a series of fertilizer experiments with cotton, as reported in Georgia Bulletin $6_{3}$.

For the I904 corn crop fertilizers were applied uniformly to all plots (except No. I I) as follows, in pounds per acre:

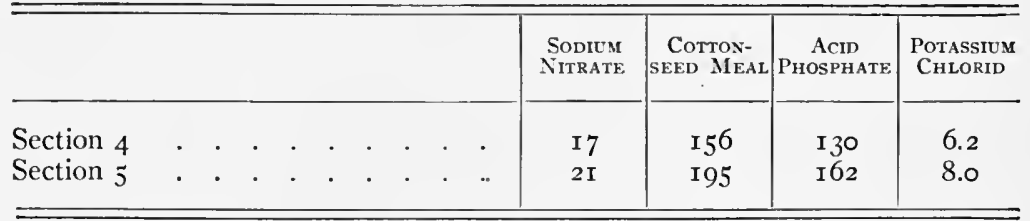

In I 906 cotton was grown on at least part of the same land as in I903, with the plan of experiment and results reported in Table 103. It is not clear whether these results may have been influenced 
Table io2. Georgia Fertilizer Experiments with Cotton

\begin{tabular}{|c|c|c|c|c|c|c|c|c|}
\hline \multirow{2}{*}{$\begin{array}{l}\text { PLOT Nos., } 2 \text { Rows IN } \\
\text { EACH PLOT } \\
\text { (4 Rows for Plot II?) }\end{array}$} & \multicolumn{4}{|c|}{ Pounds applied PER ACRE } & \multirow{2}{*}{$\begin{array}{l}\text { Cost of } \\
\text { FERTIL- } \\
\text { IZERS } \\
\text { (Except } \\
\text { Nitrate } \\
\text { per } \\
\text { Acre) }\end{array}$} & \multirow{2}{*}{$\begin{array}{l}\text { YIELD } \\
\text { OF SEED } \\
\text { CotTON } \\
\text { (Pounds } \\
\text { per } \\
\text { Acre) }\end{array}$} & \multirow{2}{*}{$\begin{array}{l}\text { VALUE } \\
\text { OF IN- } \\
\text { CREASE } \\
\text { AT 4\% } \\
\text { PER } \\
\text { POUND }\end{array}$} & \multirow{2}{*}{$\begin{array}{c}\text { I904, } \\
\text { ConN } \\
\text { (Bushels } \\
\text { per } \\
\text { Acre) }\end{array}$} \\
\hline & $\begin{array}{l}\text { Sodium } \\
\text { Nitrate } \\
\text { (With } \\
\text { Seed) }\end{array}$ & $\begin{array}{l}\text { Cotton- } \\
\text { seed } \\
\text { Meal }\end{array}$ & $\begin{array}{l}\text { Acid } \\
\text { Phos- } \\
\text { phate }\end{array}$ & $\begin{array}{l}\text { Potas- } \\
\text { sium } \\
\text { Chlorid }\end{array}$ & & & & \\
\hline
\end{tabular}

Nitrogen Test: Division B, Section 4. East, igo3

1904

\begin{tabular}{|c|c|c|c|c|c|c|c|c|}
\hline I, 6, I 2, I 7,22 . & I 5.6 & 200 & 250 & 25.0 & $\$ 4.15$ & I I 46 & $S_{15} 5.04$ & 20.3 \\
\hline $2,7,13,18,23$. & I 5.6 & 160 & 306 & 30.6 & 4.15 & I I 20 & 14.00 & 20.1 \\
\hline 3,8, I 4, I9. & I 5.6 & I 20 & $3^{62}$ & $3^{6.2}$ & 4.15 & 1072 & I 2.08 & I 8.5 \\
\hline 4,9, I 5,20 . & I 5.6 & 80 & 418 & 41.8 & 4.15 & 1057 & I I. 48 & I9.5 \\
\hline $5, \mathrm{IO}, \mathrm{I} 6,2 \mathrm{I}$. & I 5.6 & 40 & 474 & 47.4 & 4.15 & 1042 & I0.88 & 19.6 \\
\hline I I (unfertilized) & I 5.6 & & & & & 770 & & 20. I \\
\hline
\end{tabular}

Potassium Test: Division B, Section 4, West, I903

\begin{tabular}{|c|c|c|c|c|c|c|c|}
\hline I, 6, I 2, I 7, 22 . & I9.5 & I 95 & 520 & 65 & $\$ 6.50$ & 1503 & $\$ 22.13$ \\
\hline $2,7,13,18,23$. & I 9.5 & 205 & 547 & 52 & 6.50 & I $43^{8}$ & 19.71 \\
\hline 3,8 , I 4, I9. & 19.5 & 2 I 5 & 574 & 39 & 6.50 & I 448 & 20.16 \\
\hline 4,9, I $5,20$. & 19.5 & 225 & 601 & 26 & 6.50 & I 488 & 21.96 \\
\hline ; 10, I6, $2 \mathrm{I}$ & I9.5 & 235 & 628 & I3 & 6.50 & I $45^{\mathrm{I}}$ & 20.29 \\
\hline I (unfertilized) & I 9.5 & - & & & - & 1000 & \\
\hline
\end{tabular}

Potassium Test: Division B, Section 5, West, 1903

\begin{tabular}{l|r|r|r|r|r|r|r}
\hline I, 6, I2, I 7, 22. & I9.5 & I95 & 520 & 65 & $\$ 6.50$ & I556 & $\$ 24.93$ \\
2, 7, I3, I8, 23. & I9.5 & 205 & 547 & 52 & 6.50 & I639 & 28.66 \\
3, 8, I4, I9 . . & I9.5 & 2 I5 & 574 & 39 & 6.50 & I635 & 28.48 \\
4, 9, I5, 20 . . & I9.5 & 225 & 601 & 26 & 6.50 & I667 & 29.92 \\
5, I0, I6, 2 I . . & I9.5 & 235 & 628 & I3 & 6.50 & I693 & 31.09 \\
I I (unfertilized) & 19.5 & - & - & - & - & I002 & \\
\hline
\end{tabular}

\begin{tabular}{|c|c|c|c|c|c|c|c|c|}
\hline \multicolumn{8}{|c|}{ Potassium Test: Aver.lge, $19{ }^{2} 3$} & \multirow{2}{*}{$\begin{array}{r}1904 \\
25 \cdot 3\end{array}$} \\
\hline $1,6,12,17,22$. & I9.5 & I95 & 520 & 65 & $\$ 6.50$ & 1529 & $\$ 23.7^{6}$ & \\
\hline $2,7,13,18,23$. & I 9.5 & 205 & 547 & $5^{2}$ & 6.50 & I 538 & 24.16 & $25 \cdot 5$ \\
\hline 3,8, I4, I9. & 19.5 & 215 & 574 & 39 & 6.50 & I $54 \mathrm{I}$ & $24 \cdot 30$ & $25 \cdot 3$ \\
\hline $4,9,15,20$. & I9.5 & 225 & 601 & 26 & 6.50 & I 578 & 25.96 & $2 \mathrm{I} \cdot 7$ \\
\hline $5, \mathrm{IO}, \mathrm{I} 6,2 \mathrm{I}$. & I9.5 & 235 & 628 & I3 & 6.50 & I 572 & 25.96 & 24.0 \\
\hline I I (unfertilized) & 19.5 & & - & - & & IOOI & & 22.2 \\
\hline
\end{tabular}

by the residual effect of previous applications made in the " $\mathrm{ni}$ trogen test," for example (Table I02).

The use of fertilizers on corn in Georgia, if profitable at all, is evidently made possible only because the farm price of corn is very high (69 cents as a ten-year average), and the profit from the 
Table i03. Georgia Fertilizer Experiments with Cotton

(Division B, Sections 4 and 5, East, 1906)

\begin{tabular}{|c|c|c|c|c|c|c|}
\hline \multirow{3}{*}{ 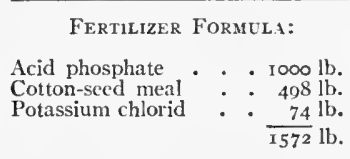 } & \multicolumn{3}{|c|}{ APPLIED PER ACRE } & \multicolumn{3}{|c|}{ RESUlts PER ACRE } \\
\hline & \multicolumn{2}{|c|}{ Mixed Fertilizer } & \multirow{2}{*}{$\begin{array}{l}\text { Nitrate } \\
\text { (With } \\
\text { Seed) } \\
\text { (Lb.) }\end{array}$} & \multirow{2}{*}{$\begin{array}{l}\text { Yield of } \\
\text { Seed } \\
\text { Cotton } \\
\text { (Lb.) }\end{array}$} & \multirow{2}{*}{$\begin{array}{c}\text { Increase } \\
\text { Due to } \\
\text { Fertilizer } \\
\text { (Lb.) }\end{array}$} & \multirow{2}{*}{$\begin{array}{l}\text { Value } \\
\text { of In- } \\
\text { crease }{ }^{1}\end{array}$} \\
\hline & $\underset{(\mathrm{Lb} .)}{\text { Amount }}$ & Cost & & & & \\
\hline I 2 plots of 3 rows each & 400 & $\$ 4.00$ & 22 & I 735 & $28 \mathrm{I}$ & \$IO.II \\
\hline I 2 plots of 3 rows each. & 800 & 8.00 & 22 & I 890 & $43^{6}$ & I 5.69 \\
\hline I 2 plots of 3 rows each. & I 200 & I 2.00 & 22 & 2042 & 588 & 21.17 \\
\hline 2 plots of 4 rows each & & & 22 & I 454 & & \\
\hline
\end{tabular}

1 At ro cents a pound for lint and 70 cents a hundred for seed.

use of fertilizers is found in the cotton crop, which it should be remembered is the most valuable per acre of all the general field crops grown in the United States (potatoes and tobacco being considered as truck or garden crops).

As an average seed cotton is about one third lint and two thirds seed, and a hundred-bushel crop of corn is more difficult to produce than 3000 pounds per acre of seed cotton, which would yield rooo pounds (or 2 bales) of cotton lint. At ten cents a pound for cotton lint and 70 cents per roo pounds for cotton seed, such a crop would be worth II $4_{4}$ an acre, or about three times as much as roo bushels . of corn at the ten-ycar average price in the corn belt. Georgia produces less than 200 pounds of cotton lint per acre, on about $4 \frac{1}{2}$ million acres, the annual acreage being second only to that of Texas.

Judging from the composition of the residual soils of Maryland, Tennessee, and Georgia, and from the statement by Director Redding concerning the value of farm manure reënforced with acid phosphate, it seems evident that large use of ground limestone and legume crops, the latter to be plowed under either directly or in farm manure, and liberal applications of phosphate, constitute the most essential factors for the permanent improvement of such land; although, under the present condition of most of the upland soils of Georgia and other Southern states, profitable use can no doubt be made of potassium, at least until the supply of active organic matter is greatly increased, and especially for the cotton crop, which pays such large returns for a comparatively small increase in yield per acre. 


\section{INVESTIGATION BY CULTURE EXPERIMENTS}

Table io4. Alabama Field Experiments, i 905-igo8

Averages per Acre per Annum

\begin{tabular}{|c|c|c|c|c|c|c|c|c|c|}
\hline $\begin{array}{l}\dot{0} \\
z \\
0 \\
0 \\
0\end{array}$ & Plant Food Applied & $\operatorname{Cos} r$ & $\begin{array}{l}\text { LAU- } \\
\text { DER- } \\
\text { DALE } \\
\text { Co., } \\
\text { GRAY } \\
\text { SLIT } \\
\text { LOAM } \\
\text { SoIL }\end{array}$ & $\begin{array}{c}\text { CULL- } \\
\text { MAN } \\
\text { CO., } \\
\text { GRAY } \\
\text { SANDY } \\
\text { UP- } \\
\text { LAND }\end{array}$ & $\begin{array}{c}\text { CHIL- } \\
\text { TON } \\
\text { Co., } \\
\text { GRAY } \\
\text { SANDY } \\
\text { SoIL }\end{array}$ & $\begin{array}{c}\text { AU- } \\
\text { TAU- } \\
\text { GA } \\
\text { CO., } \\
\text { RED- } \\
\text { DISH } \\
\text { SANDY } \\
\text { SOIL }\end{array}$ & $\begin{array}{c}\text { MONT- } \\
\text { GOM- } \\
\text { ERY } \\
\text { CO., } \\
\text { BLACK } \\
\text { OR RED } \\
\text { PRAI- } \\
\text { RIE }\end{array}$ & $\begin{array}{c}\text { TALLA- } \\
\text { POOSA } \\
\text { CO., } \\
\text { GRAY } \\
\text { SANDY } \\
\text { UP- } \\
\text { LAND }\end{array}$ & $\begin{array}{l}\text { MACON } \\
\text { Co., } \\
\text { DARK } \\
\text { GRAY } \\
\text { SANDY } \\
\text { LOAM }\end{array}$ \\
\hline \multicolumn{3}{|c|}{ No. of Years in Trial } & 4 & 3 & 4 & 3 & 3 & 4 & $\mathbf{3}$ \\
\hline
\end{tabular}

Seed Cotton per Acre, Ponnds

\begin{tabular}{|c|c|c|c|c|c|c|c|c|c|}
\hline I & Nitrogen ( ${ }_{4}$ lb. $)^{\mathrm{I}}$. & $\$ 2.50$ & 649 & $44^{2}$ & 647 & 888 & 464 & 635 & 468 \\
\hline 2 & Phosphorus (I6 lb.) & I.68 & 678 & $57 \mathrm{I}$ & 578 & 789 & 484 & $5^{87}$ & 625 \\
\hline 3 & Unfertilized . . & & 374 & $3^{20}$ & 483 & 676 & $40 \mathrm{I}$ & 433 & $48 \mathrm{I}$ \\
\hline 4 & Potassium (20 lb.). & I.5० & 796 & $45^{2}$ & 646 & 700 & 576 & 6ro & $6_{34}$ \\
\hline 5 & Nitrogen, phosphorus . & 4.18 & I 295 & $72 \mathrm{I}$ & 657 & 829 & $5 \circ 3$ & $65 \mathrm{I}$ & 728 \\
\hline 6 & Nitrogen, potassium . & 4.00 & 886 & 576 & 618 & $80 \mathrm{I}$ & 628 & 663 & 595 \\
\hline 7 & Phosphorus, potassium & 3.18 & 695 & 614 & 570 & 716 & 644 & 626 & 610 \\
\hline 8 & Unfertilized . & - & 387 & $29 I$ & 437 & 679 & 382 & $35^{8}$ & $5^{22}$ \\
\hline 9 & NPK $\cdot$. & 5.68 & 917 & $68_{3}$ & $77^{8}$ & 880 & 740 & 742 & 925 \\
\hline Io & NPK $\left(\frac{1}{2}\right)$ & 4.93 & $80 \mathrm{I}$ & 710 & 718 & 808 & 689 & 790 & 893 \\
\hline
\end{tabular}

Increase of Seed Cotton per Acre, Pounds

\begin{tabular}{|c|c|c|c|c|c|c|c|c|c|c|c|c|}
\hline I & $\mathrm{N}$ & . & - & & $\$ 2.50$ & 275 & I 22 & $16_{3}$ & 2 I 2 & 62 & 202 & $-I 3$ \\
\hline 2 & $\mathrm{P}$ & . & & . & I.68 & 304 & $25 \mathrm{I}$ & 94 & I 3 & 82 & I 54 & I 45 \\
\hline 4 & $\mathrm{~K}$ & - & & - & 1.50 & 419 & I 38 & I 72 & 23 & I 78 & I 92 & I 45 \\
\hline 5 & NP & • & & . & 4.18 & 916 & $4^{\mathrm{I}} 3$ & 192 & 152 & 109 & 2.48 & 231 \\
\hline 6 & NK & . & . & . & $4 . \infty$ & 504 & 274 & I6 3 & I 24 & $23^{8}$ & 275 & 90 \\
\hline 7 & PK & - & . & . & 3.18 & 3 I I & $3^{1} 7$ & I 24 & $3^{8}$ & $25^{8}$ & 253 & 96 \\
\hline 9 & NPK & . & . & . & 5.68 & $53^{\circ}$ & 393 & $34 \mathrm{I}$ & $20 \mathrm{I}$ & 357 & $3^{84}$ & 403 \\
\hline IO & NPK $\left(\frac{1}{2}\right)$ & . & . & . & 4.93 & $4 \mathrm{I} 4$ & 419 & 280 & I 29 & 307 & $43^{2}$ & $37^{\mathrm{I}}$ \\
\hline
\end{tabular}

VAlue OF INCREASE PER ACRE (AT 3.2 C. PER Lb.)

\begin{tabular}{|c|c|c|c|c|c|c|c|c|c|c|c|c|}
\hline I & $\mathrm{N}$ & . & • & & $\$ 2.50$ & $8.8 \mathrm{c}$ & 3.90 & 5.23 & 6.78 & I.99 & 6.46 & $-.4 \mathrm{I}$ \\
\hline 2 & $\mathrm{P}$ & . & . & & I.68 & 9.73 & 8.04 & 3.02 & 3.63 & 2.63 & 4.94 & .03 \\
\hline 4 & K & - & - & & I.50 & I $3.4 \mathrm{I}$ & $4.4 \mathrm{~T}$ & 5.49 & .75 & $5 \cdot 7 \mathrm{I}$ & 6.13 & 4.64 \\
\hline 5 & NP & . & . & & 4.18 & $29 \cdot 3 \mathrm{I}$ & 13.22 & 6.16 & 4.87 & 3.49 & 7.95 & $7 \cdot 39$ \\
\hline 6 & NK & . & . & . & 4.00 & I6.14 & 8.76 & 5.20 & 3.96 & $7.6_{3}$ & 8.80 & 2.88 \\
\hline 7 & PK & & - & & 3.18 & 9.95 & I0.I6 & $3.9^{6}$ & $1.2 \mathrm{I}$ & 8.24 & 8.09 & 3.08 \\
\hline 9 & NPK & . & . & & 5.68 & ז6.96 & I 2.57 & $10.9 \mathrm{I}$ & 6.44 & II.43 & I $2.3^{\circ}$ & I 2.80 \\
\hline IO & NPK $\left(\frac{1}{2}\right)$ & . & - & & 4.93 & I 3.25 & I 3.42 & 8.99 & 4.14 & $9.8 \mathrm{I}$ & I 3.84 & II.86 \\
\hline
\end{tabular}

I The nitrogen is regularly applied in $200 \mathrm{lb}$. of cotton-seed meal (at $\$ 25$ a ton), which also contains about $2 \mathrm{lb}$. of phosphorus and $3 \mathrm{lb}$. of potassium. The phosphorus is applied in $240 \mathrm{lb}$. of acid phosphate (at $\$ 14 \mathrm{a}$ ton) and the potassium in $200 \mathrm{lb}$. of kainit (only $100 \mathrm{lb}$. on plot 10 ), costing $\$ 15 \mathrm{a}$ ton. These are the prices reported in Alabama Bulletin 1.45, February, 1909. 
Alabama field experiments. The Alabama Agricultural Experiment Station has reported the results of fertilizer experiments with cotton on the common soils in several different counties. In Table 104 are given three-year or four-year averages from seven different counties. In computing the value of the increase, Director Duggar allows \$ 44 a ton for cotton seed and Io cents a pound for lint, the average price for the five years, 1904-1908. He also assumes that the seed cotton is one third lint, and thus counts the cotton seed at 3.8 cents a pound, or at 3.2 cents a pound for the increase, after allowing .6 cent a pound for picking and ginning.

These results especially emphasize two facts: first, that the soils are very poor, and second, that the cotton crop is so valuable that even small increases in yield justify large expenditures for fertilizers. As an average of the 48 different tests, the yield of the unfertilized land is less than 150 pounds of cotton lint per acre.

With few exceptions, every kind of fertilizer has more than paid its cost, and as a rule every addition has increased the profit per acre, the largest profit being secured from the most heavily fertilized land. It should be kept in mind, however, that as an average a pound of Alabama seed cotton is worth five times as much as a pound of Illinois corn. Very probably the 200 pounds of kainit have been more effective than 50 pounds of potassium chlorid would have been, because these soils are as a rule very deficient in active organic matter, and under such conditions the larger quantity of soluble salt is likely to become more effective.

The average annual rainfall of Alabama is given as $5 \mathrm{I}$ inches. The monthly rainfall from May to September averages more than 4 inches. Of the 20 records for these months during the four years, 1905-1908, the lowest was 2.42 inches, and only three others were below 3.44 inches. The highest was 8.50 inches, with only two others above 5.5 I inches.

Louisiana field experiments. The Louisiana Agricultural Experiment Station has conducted a series of field experiments since I889, on the experiment farm at Calhoun, in the northern part of the state, on hill land originally covered with pine trees. The soil had become much exhausted from 70 or 80 years of previous cotton culture.

The field consists essentially of six one-acre plots arranged in 
three series of two plots each, one unfertilized and the other fertilized chiefly with compost made as described below. A threeyear rotation has been practiced as follows:

First year . . . . Cotton.

Second year . . . . Corn and cowpeas.

Third year . . . . . Oats followed by cowpeas.

By having three series, each crop may be represented every year.

For cotton, 30 bushels per acre are applied of a compost made by mixing 2 tons of acid phosphate with roo bushels each of stable manure and cotton seed. For corn, 30 bushels per acre are used of a compost made with one ton of acid phosphate mixed with roo bushels of stable manure and roo bushels of cotton seed. After preparing the compost, it is allowed to ferment for two or three weeks, then thoroughly mixed, and after standing a few days longer is ready for use.

The oats are fertilized with 200 pounds of cotton-seed meal and Ioo pounds of acid phosphate per acre, and the cowpeas are also fertilized by applying 50 pounds of acid phosphate and 50 pounds of kainit per acre.

The following average results are reported by Director Dodson in Louisiana Bulletin I I , September, I908:

Table io4.I. Louisiana Field Experiments at Calhoun: Yields per ACRE: FroN I9 YEARS' RECORDS

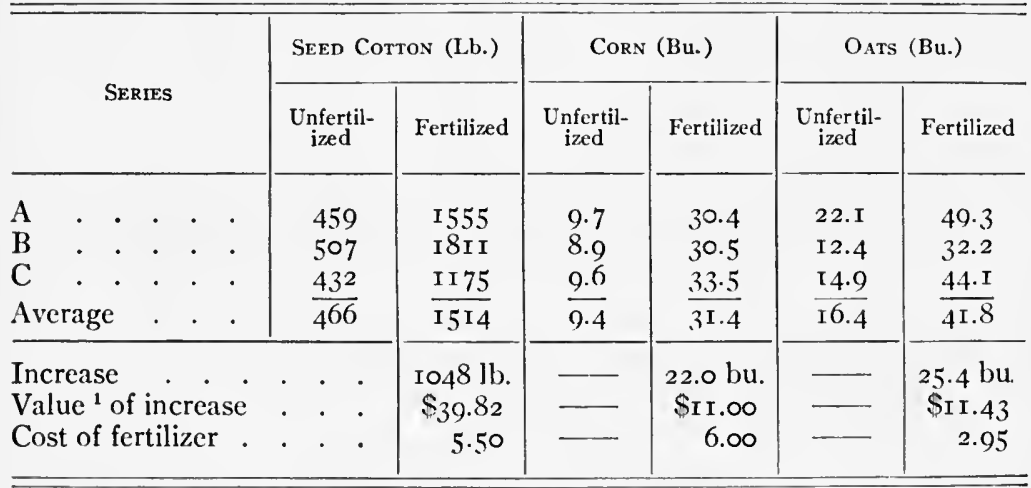

${ }^{1}$ Computed at Louisiana prices, 3.8 cents a pound for seed-cotton, $5^{\circ}$ cents a bushel for corn, and 45 cents a bushel for oats. 
The cost of fertilizer is given as estimated by Director Dodson. No report is made of the yield of cowpeas.

In 1889 the increases produced by the fertilizing were only 301 pounds of seed cotton, 4.7 bushels of corn, and 4.8 bushels of oats; but in the second year the increases were I 227 pounds of sced cotton, I9.7 bushels of corn, and 25.3 bushels of oats, which are practically as great as the averages for the entire period.

The I 5 I 4 pounds of seed cotton would yield about rooo pounds of cotton seed, or about 30 bushels, which would not be sufficient to make the compost for one acre of cotton and one acre of corn, counting the shrinkage in volume during the three or four weeks allowed for fermentation; and, besides the whole seed used in the compost, 200 pounds of cotton-seed meal are used for the oats. On the other hand, the corn, oats, and cowpea crops produced on the fertilized land would certainly make much more manure than was used in these experiments, so that, with little modification, this system could be made independent and permanent as well as more profitable.

The following significant statements are made by Professor Dodson:

"When we sell cotton lint, we sell cellulose, composed of hydrogen, oxygen, and carbon $\left(\mathrm{C}_{6} \mathrm{H}_{10} \mathrm{O}_{5}\right)$, which was derived from the air and water. When we sell our seed, we sell the fertility of the land, as the Northern and Western farmer does when he sells his grain. The oil, however, has no fertilizing value, being, like the lint, composed of elements taken from the air and water, and cannot be used again by the cotton plant; so if we sell only the lint and the oil, returning the hulls and the meal to the land, we have not reduced the fertility appreciably."

With liberal applications of ground limestone where needed, and large use of the most suitable legume crops turned under, either in farm manure or in green manures, including not only cowpeas, but also red clover, alsike clover, crimson clover, Japan clover (Lespedeza), vetch, velvet beans, and even alfalfa under proper conditions, and with plenty of phosphorus, either as acid phosphate, steamed bone meal, or fine-ground raw rock phosphate, it seems very certain that the cotton and grain crops of the South could be increased even much above the yields maintained for 20 years in these valuable experiments by the Louisiana Station. 


\section{INVESTIGATION BY CULTURE EXPERIMENTS}

It is highly probable that a liberal use of kainit would also be profitable for a time in getting such systems under way on the more depleted soils. It must be kept in mind that crops must be grown before either farm manure or green manure can be plowed under.

Notes. On the Coastal Plains, especially from North Carolina to Florida, are some extensive areas of very sandy soils. For truck farming these become very productive where heavily fertilized, but they are commonly too poor to be used profitably for general farming. Thus, Bulletin 68 of the Florida Agricultural Experiment Station contains 40 chemical analyses of the ordinary very sandy loams upon which nearly all of the pineapples produced in that state are grown, and in commenting upon these soils the authors say, "Few of the soils would be able to produce more than two or three crops of pineapples if all the plant food present were available."

This statement is well supported by analyses of samples of soil, representative of large areas in Southern Florida, which were collected by Professor F. H. King in I9Io and analyzed with the following results:

Average Pounds in 2 Mili.ion of Soll

\begin{tabular}{|c|c|c|c|c|c|c|}
\hline \multicolumn{3}{|c|}{ County } & Soll Stratum & Total Nitrogen & $\begin{array}{c}\text { Total } \\
\text { PhOSPHORUS }\end{array}$ & $\begin{array}{c}\text { Total } \\
\text { Potassium }\end{array}$ \\
\hline $\begin{array}{l}\text { De Sota } \\
\text { De Sota }\end{array}$ & . &. & $\begin{array}{l}\text { Ist Foot } \\
2 \text { d Foot }\end{array}$ & $\begin{array}{l}970 \\
340\end{array}$ & $\begin{array}{l}\text { trace } \\
\text { trace }\end{array}$ & $\begin{array}{l}2320 \\
1830\end{array}$ \\
\hline $\begin{array}{l}\text { Lee . . } \\
\text { Lee . }\end{array}$ & . &. & $\begin{array}{l}\text { Ist Foot } \\
2 \mathrm{~d} \text { Foot }\end{array}$ & $\begin{array}{r}2560 \\
840\end{array}$ & $\begin{array}{l}390 \\
160\end{array}$ & $\begin{array}{r}320 \\
\text { I } 160\end{array}$ \\
\hline
\end{tabular}

Two analyses of the peat or "muck" soil from the Everglades swamps of Florida show the following amounts per million:

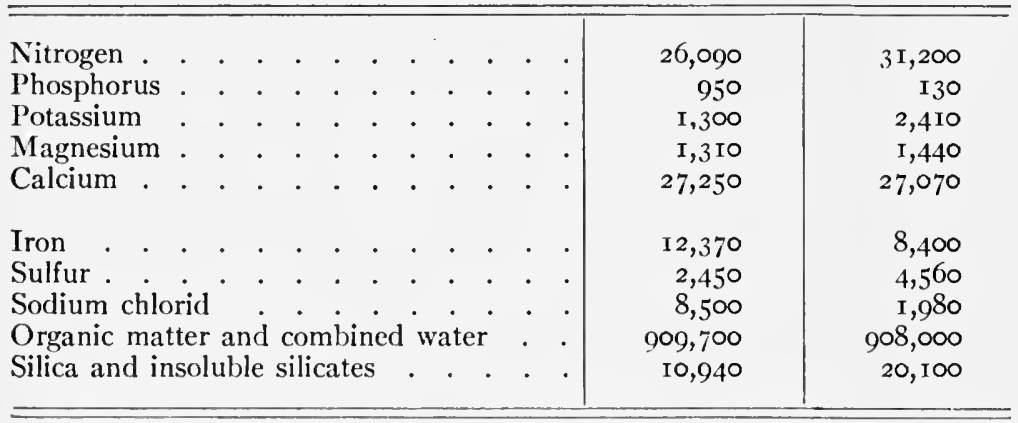

While these "muck" or peat soils are rich in nitrogen and calcium, they are either poor or extremely poor in phosphorus, potassium, and magnesium. 


\section{CHAPTER XXIV}

\section{MINNESOTA SOIL INVESTIGATIONS}

BECAUSE they have been so widely quoted in the agricultural press of the central West, and even in text-books on soils and fertilizers, it seems especially important to give in some detail the results of field and laboratory experiments conducted by the Minnesota Agricultural Experiment Station since I892.

Table i05. Minnesota Soll Investigations

(a) Crop Yields per Acre in Bushels or Tons

\begin{tabular}{|c|c|c|c|c|c|c|c|}
\hline$\frac{\text { YEAR }}{\text { I893 }}$ & \multicolumn{2}{|c|}{$\begin{array}{l}\text { PLOT NO! I } \\
\text { WITHOUT MANURE, } \\
\text { WHEAT GROWN CON-, } \\
\text { TINUOUSLY }\end{array}$} & \multicolumn{2}{|c|}{$\begin{array}{l}\text { PlOT No. }{ }^{2} \\
8 \text { LoAdS }{ }^{1} \text { OF MIANURE } \\
\text { IN FIVE-YEAR ROTATION }\end{array}$} & \multicolumn{3}{|c|}{$\begin{array}{l}\text { PLOT No. } 3 \\
8 \text { LOADS }{ }^{3} \text { OF MANURE } \\
\text { IN FOUR-YEAR ROTATION }\end{array}$} \\
\hline $\begin{array}{l}1893 \\
1894 \\
1895 \\
1896 \\
1897 \\
1898 \\
\end{array}$ & $\begin{array}{r}12.3 \\
8.9 \\
17.3 \\
14.1 \\
10.2 \\
25.2\end{array}$ & Av. 14.7 & $\begin{array}{l}\text { Wheat . } \\
\text { Clover . } \\
\text { Wheat . } \\
\text { Oats } \\
\text { Wheat . } \\
\text { Clover. }\end{array}$ & $\begin{array}{l}\text { I3.7 bu. } \\
2.16 \text { tons } \\
22.0 \text { bu. } \\
3 \mathrm{I} .4 \text { bu. } \\
\text { I } 4.2 \text { bu. } \\
\text { I.4 tons }\end{array}$ & $\begin{array}{l}\text { Oats } \\
\text { Clover } \\
\text { Barley } \\
\text { Corn . } \\
\text { Corn. } \\
\text { Oats. }\end{array}$ & $\begin{array}{l}\cdot \\
\cdot \\
\cdot \\
\dot{\cdot} \\
\cdot \\
\end{array}$ & $\begin{array}{cl}41.6 & \text { bu. } \\
\text { 1.1 } 8 & \text { tons } \\
42.5 & \text { bu. } \\
66.7 & \text { bu. } \\
33.7 & \text { bu. } \\
76.4 & \text { bu. } \\
\end{array}$ \\
\hline $\begin{array}{l}\text { I } 899 \\
\text { I } 900 \\
\text { I9OI } \\
\text { I902 } \\
\text { I903 } \\
\text { I904 }\end{array}$ & $\left.\begin{array}{l}\text { I } 7.6 \\
\text { I } 8.8 \\
\text { I6.2 } \\
\text { I } 8.3 \\
\text { I } 8.6 \\
\text { I.3.7 }\end{array}\right\}$ & Av. I7.2 & $\begin{array}{l}\text { Wheat } \\
\text { Wheat } \\
\text { Oats } \\
\text { Corn } \\
\text { Wheat. } \\
\text { Clover. }\end{array}$ & $\begin{array}{l}\text { I9.5 bu. } \\
24.4 \text { bu. } \\
58.7 \text { bu. } \\
(?) \\
30.0 \text { bu. } \\
3.98 \text { tons }\end{array}$ & $\begin{array}{l}\text { Clover } \\
\text { Barley } \\
\text { Corn . } \\
\text { Oats . } \\
\text { Clover } \\
\text { Barley }\end{array}$ & $\begin{array}{l}\cdot \\
\cdot \\
\cdot \\
\cdot \\
\cdot \\
\dot{\cdot}\end{array}$ & $\begin{array}{l}\text { ז.86 tons } \\
28.3 \text { bu. } \\
40.6 \text { bu. } \\
80.0 \text { bu. } \\
4.70 \text { tons } \\
40.0 \text { bu. }\end{array}$ \\
\hline Total c & over in & I 2 years & Clover & 7.55 tons & Clover & . & $7 \cdot 74$ tons \\
\hline
\end{tabular}

(b) Nitrogen ${ }^{2}$ in Soil per Acre 9 Inches Deep

\begin{tabular}{c|c|c|c|c|c|c}
\hline Years & Total (Lb.) & Loss (Lb.) & Total (Lb.) & Loss (Lb.) & Total (Lb.) & Loss (Lb.) \\
\cline { 1 - 4 } I892 & 5400 & - & 5400 & - & 5200 & \\
I896 & 47 I 5 & 685 & 5645 & 245 (gain) & 5360 & I60 (gain) \\
I900 & 4230 & 485 & 4840 & 805 (loss) & 4870 & 490 (loss) \\
I904 & 3955 & 275 & 4690 & I50 (loss) & 5480 & 6 I5 (gain) \\
\hline Total loss in 8 & & & & & & \\
years, I896 to & & & & & \\
I904 . . . & 760 & & 955 (loss) & & I 25 (gain) \\
\hline
\end{tabular}

${ }^{1}$ Evidently these loads of manure weighed $\mathrm{r} 200 \mathrm{lb}$. each, making $9600 \mathrm{lb}$., or less than 5 tons, per acre. - C. G. H.

${ }^{2}$ Based upon the statement that .22I per cent of nitrogen is equivalent to $5+00$ lb. of nitrogen per acre. 
Probably no agricultural investigations have ever been reported which have brought forth more error and confusion in the public mind than these experiments.

While they are carried on in part to determine the effect upon wheat yields of continuous wheat culture upon the same land, the information secured only shows that some factor or factors, other than the continuous growing of wheat, have thus far exerted predominating influence upon the production of wheat.

The figures for nitrogen given in Table ro5 are based upon the percentages reported from time to time by Professor Harry Snyder in Minnesota Bulletins 53, 70, and 89, and upon his later statement that all samples have been taken to a depth of 9 inches.

Thus, in Minnesota Bulletin 53, June, I897, we read:

"Plots I, 2, and 3 were 4 rods by 5 rods."

"On plot No. I, wheat was grown continuously. On plot No. 2, wheat was grown in 1893 , and clover was sown with the wheat; a crop of clover was harvested in 1894 . In the fall of 1894 the clover sod was plowed under, and the next year a crop of wheat was grown, and in 1896 a crop of oats. It is the plan to apply manure at this point and produce a crop of corn, and to follow the corn with wheat and clover, the complete rotation being: (I) wheat and clover, (2) clover, (3), wheat, (4) oats, (5) corn and manure.

"Plot No. 3. After the wheat crop in 1892 , oats were grown, and clover was seeded with the oats, and in 1894 a crop of clover was harvested. The clover sod was fall-plowed and the next year barley was grown. After the barley crop the plot received $\mathrm{r} 200$ pounds of manure, and the next year was seeded to corn, the complete rotation being: (I) oats and clover, (2) clover, (3) barley, (4) corn and manure."

"In plots Nos. I and 2 the re was originally present in the soil .22I per cent of nitrogen, equivalent to 5400 pounds of nitrogen per acre to a depth of 9 inches. After four years' continuous cropping of wheat, plot No. I yielded .I93 per cent of nitrogen, a loss of .028 per cent, equivalent to an annual loss of I 7 I pounds of nitrogen per acre."

"In plot No. 2, where clover has been grown in a rotation, there has been a gain of nitrogen. At the end of the rotation there was .23I per cent nitrogen present in the soil. On this plot clover was grown, and the second growth of clover was plowed under for green manure. The total nitrogen removed in the crops amounted to 178 pounds. Notwithstanding the fact that larger crops have been grown on this plot than on No. I, there has been a gain of 245 pounds of nitrogen in the four years' rotation, in addition to the nitrogen removed in the crops."

"The soil (of plot 3) originally contained .2 I I per cent of nitrogen. At the close of the rotation it contained .21 8 per cent of nitrogen. The amount of 
nitrogen removed in the crops during the four years amounted to 204 pounds. The gain in nitrogen has been at the rate of about 40 pounds per acre."

Four years later, in Minnesota Bulletin 7o, May, r9or, we find the following statements:

"Plots Nos. I and 2 contained, at the beginning of the experiments in 1892 , .22 I per cent of nitrogen, while plots Nos. 3, 4, 5, and 6 contained .2 I I per cent. It is estimated that an acre of the soil of plots Nos. I and 2, to a depth of 9 inches, would contain approximately 7700 pounds of nitrogen, while the remaining plots would contain approximately 7400 pounds. At the end of the first four years of continuous wheat cultivation, plot No. I contained .ro3 per cent of nitrogen; a loss of .028 per cent, equivalent to an annual loss of I $7 \mathbf{I}$ pounds of nitrogen per acre. At the end of the second period of four years, the soil contained .I 73 per cent of nitrogen.

"At the beginning of the experiment in 1892 , plot No. 2 contained .22 I per cent of nitrogen. At the end of eight years, after the removal of five crops of wheat, two of clover and one of oats, or six grain crops and two clover crops, the soil contained .198 per cent of nitrogen."

"On plot No. 3, oats, clover, barley, and corn have been grown. The soil of this plot originally contained .2 I I per cent of nitrogen. At the end of eight years the soil contained .198 per cent of nitrogen." (See pages $254^{-256}$ in Minnesota Bulletin 70.)

In Minnesota Bulletin 89 (January, 1905) we find the following statements:

"While 2I.7 per cent of the soil nitrogen was lost during the first eight years of continuous wheat culture, only 5.7I per cent was lost during the four years following."

"On plot No. 2 a rotation consisting of wheat, clover, wheat, oats, and corn and manure has been followed, with some modifications because of climatic conditions. The soil of this plot contained originally about the same amount of nitrogen as plot No. I, namely, 7700 pounds per acre to a depth of one foot. ${ }^{1}$ At the end of twelve years the soil contained 6725 pounds."

"The soil of plot number three originally contained about 7400 pounds per acre of nitrogen. At the close of the first period of four years, the soil showed a slight gain in nitrogen, and at the end of eight years, a slight loss. During

${ }^{1}$ On page 38 of Minnesota Bulletin 102 (September, 1907) a correction note states that this should read: "to the depth of three fourths of one foot," and consequently it must be assumed that the " 7700 pounds" should read " 5400 pounds" (less than 75 per cent), and that corresponding corrections should be made throughout. According to the data (5400 pounds for .22 I per cent) the soil of an acre to a depth of 9 inches would amount to about 2,450,000 pounds, which agrees with Professor Snyder's statement that the soil weighed about 75 pounds per cubic foot (page 9, Minnesota Bulletin 53). - C. G. H. 
the third four-year period also there was a slight gain of nitrogen, and at the end of twelve years, the soil contained about 7800 pounds per acre, showing that where clover was grown once in four years in a rotation with grains, and one dressing of farm manure was applied to the corn at the rate of eight loads per acre, the nitrogen content of the soil has been maintained unimpaired." (See pages 193 to 195 in Minnesota Bulletin 89.)

In his excellent and widely used text and reference book on "Fertilizers," Doctor Voorhees, Director of the New Jersey Agricultural Experiment Station, makes the following statements:

"Another source of natural loss of nitrogen is its escape from the soil as gas into the atmosphere. This is due to the oxidation of the vegetable matter, or to 'denitrification,' which takes place very rapidly where soils rich in vegetable matter are improperly managed. The possibilities of loss in this direction are strongly shown by investigations carried out at the Minnesota Experiment Station on ' the loss of nitrogen by continuous wheat raising' (Minnesota Bulletin 53). The results of these studies show that the total loss of nitrogen annually was far greater than the loss due to cropping. In other words, by the system of continuous cropping, which is universally observed in the great wheat fields in the Northwest, there was but 24.5 pounds of nitrogen removed in the crop harvested, while the total loss per acre was $\mathbf{I} 7 \mathbf{I}$ pounds, or an excess of 146 pounds, a large part of which loss was certainly due to the rapid using up of the vegetable matter by this improvident method of practice. Whereas, on the other hand, when wheat was grown in a rotation with clover, the gain in soil nitrogen far exceeded that lost or carried away by the crop."

These statements faithfully represent the teaching of Minnesota Bulletin 53, except as to the manner in which the nitrogen escapes. With the more recent accumulated information concerning soil bacteria, to which Doctors Voorhees and Lipman of the New Jersey Station have largely contributed, a revision of Voorhees' "Fertilizers" probably will not ascribe any large part of the loss to denitrification.

In his own text-book on "Soils and Fertilizers," published in June, 1905, Professor Snyder makes the following statements (page II2):

"A rotation of wheat, clover, wheat, oats, and corn with manure will leave the soil at the end of the period of rotation in better condition as regards nitrogen than at the beginning. These facts are illustrated in the following table: ${ }^{1}$

${ }^{1}$ Minnesota Agricultural Experiment Station Bulletin No. 53. 


\section{"Continuous Wheat Culture}

Nitrogen in soil at beginning of experiment . . . . $0.22 \mathrm{I}$ per cent Nitrogen at end of 5 years' continuous wheat cultivation . . 0.193 per cent Loss per annum per acre (in crop 24.5, soil 146.5). . . . I 7 I pounds

\section{"Rotation OF CROPS}

Nitrogen in soil at beginning of rotation . . . . . . $0.22 \mathrm{I}$ per cent Nitrogen at close of rotation . . . . . . . . . 0.231 per cent Gain to soil per annum per acre . . . . . . . . 6I pounds Nitrogen removed in crops per annum . . . . . . . . 44 pounds

"It is to be regretted that in the cultivation of large areas of land to staple crops, as wheat, corn, and cotton, the methods of cultivation followed are such as to decrease the nitrogen content and crop-producing power of the soil when this could be prevented."

Unquestionably the greatest practical problem that confronts the average American farmer is to maintain the humus and nitrogen content of the soil, ${ }^{1}$ and the author cannot be true to the student and neglect to present the determined facts in a matter of so vital consequence to American agriculture. It will be noted that the data just quoted relate only to the first four years (not five years or twelve years) of these Minnesota experiments, where no manure had been used. As a matter of fact, the published bulletins show that wheat (not corn) was grown on plot 2 the fifth year. The subsequent data show, however, that during the second four years (presumably with manure added) there was a loss of nitrogen from plot 2 amounting to .033 per cent (.23I-.I98), or about 800 pounds per acre (counting only 2,450,000 pounds of soil for a depth of 9 inches), and during the same four years the data for the other rotation, with manure applied, show a loss of 490 pounds of nitrogen per acre from plot 3 .

The only point the author would emphasize is that these Minnesota investigations have not yet furnished sufficient data to

${ }^{1}$ It is a very simple matter to maintain or materially increase the phosphorus content. One ton of raw rock phosphate, costing from $\$ 7$ to $\$$ Io (depending on distance of shipping), and containing, say, 250 pounds of phosphorus, will supply more of that element to an acre of land than would be removed in 12 years if the average crops were 100 bushels of corn (grain only removed), Ioo bushels of oats, 50 bushels of wheat, and 4 tons of clover. 


\section{INVESTIGATION BY CULTURE EXPERIMENTS}

determine the conditions under which the supply of nitrogen will be maintained. Of course it requires no new investigations to show that sufficiently large applications of manure will maintain the supply of nitrogen, whether the crops are rotated or grown continuously, as at Rothamsted, with wheat, barley, or mangels.

Note. In passing from this extended consideration of the field experiments conducted in various parts of the United States, the reader will perhaps be interested to note the following correspondence in relation to the application of science to practical farming:

\section{"Gilman, Illinois, November 23, rgog.}

"Dear Doctor Hopkins:- Am sending you a few comparative figures, which I trust may interest you. I have no doubt you can see more in them than I can, but I see much that gives encouragement for the future:

"Comparative Yields of Corn from Treated and Untreated LAND: 1909 CROP (Bushels per Acre)

Corn on clover sod; land cultivated 30 years, with no manure and no pasture: Untreated .. $\cdot$. $\cdot$. . . Same kind of land: Treated with $\frac{1}{2}$ ton raw rock phosphate. . . . . Same: Treated with $\frac{1}{2}$ ton phosphate and 3 tons limestone $. . \quad . \quad . \quad$

Second-year corn after clover: Untreated . . . . . . . . . 70.0 bushels Same: Treated with $\frac{1}{2}$ ton per acre of phosphate . . . . . . . . . 77.6 bushels

"On the clover sod there seems to be about a normal difference in yield. Much of the last field, including the check strip, has had two Io-ton applications of manure in 6 years.

"Kind regards,

$$
\text { (Signed) "F. I. MaNn." }
$$

"University of Illinois, Urbana, December r, r9o9.

"Mr. F. I. ManN, Gilman, Illinois.

"DEAR Sir:- I thank you for your letter of November 23, giving the I 909 results on your 200 acres of corn from the methods of soil improvement which you have been practicing for several years. I note that the cumulative effect of the system is apparently becoming evident. Where phosphorus produces a ton more clover per acre (as you reported last year), the increased clover and added phosphorus must increase the following corn crop.

"Two of our old plots here at the University yielded exactly the same (64 bushels) as an average of three corn crops (I895-I897) before we began applying limestone and phosphorus to one of them. This year the untreated clover sod produced 32.8 bushels, and the treated land yielded 77.6 bushels, per acre. Where limestone without phosphorus was applied, the yield was 38 bushels, and, with limestone, phosphorus, and potassium, 83.7 bushels.

"Very truly yours,

(Signed) "Cyril G. Hopkins." 


\section{CHAP'TER XXV}

\section{CANADIAN FIELD EXPERIMENTS}

THE government of Canada established an agricultural experiment station (Dominion Experimental Farms) in I886, and a series of field experiments were begun by Director Saunders in I887, which have been continued under his direction for more than 20 years.

The following quotations taken from the Annual Report for I897 give general information concerning these experiments:

"A piece of sandy loam, more or less mixed with clay, which was originally covered with heavy timber, chiefly white pine, was chosen for these tests. The timber was cut many years ago, and among the stumps still remaining when the land was purchased there had sprung up a thick second growth of trees, chiefly poplar, birch, and maple, few of which exceeded six inches in diameter at the base. Early in 1887 this land was cleared by rooting up the young trees and stumps and burning them in piles on the ground from which they were taken, the ashes being afterwards distributed over the soil as evenly as possible, and the land plowed and thoroughly harrowed. Later in the season it was again plowed and harrowed, and most of it got into fair condition for cropping."

"The plots laid out for the experimental work with fertilizers were one tenth of an acre each, 2I of which were devoted to experiments with wheat, 2I to barley, 2I to oats, 2I to Indian corn or maize, and 21 to experiments with turnips and mangels. Owing to the difficulty and unavoidable delay attending the draining of some wet places, it was not practicable to undertake work on all the plots the first season. The tests were begun in 1888 with 20 plots of wheat and 16 of Indian corn; and in 1889 all the series were completed excepting six plots of roots, Nos. I6 to $2 \mathrm{I}$ inclusive, which were available for the work in 1890 . In all cases the plots in each series have been sown on the same day."

"In I89o it was found that all the grain plots had become so weedy that the growth of the crops was much interfered with, and with the view of cleaning the land, one half of each of the wheat and oat plots was sown with carrots in I89I, and one half of each of the barley plots with sugar beets. In I 892 the other half of each plot in each of these series was sown with carrots. In 1893 it was thought desirable to continue this cleaning process, and carrots were again sown, on the half of the wheat and oat plots occupied with this crop in I89I, and also on the half of the barley plots cropped with sugar beets that year. In 


\section{INVESTIGATION BY CULTURE EXPERIMENTS}

I $894, \mathrm{I} 895, \mathrm{I} 896$, and 1897 the one half of the oat plots were sown again with carrots and the half of the plots devoted to wheat and barley were planted with potatoes."

Other changes from the original plans, and also some general conclusions drawn by Doctor Saunders at the end of 20 years, are given in the following statements quoted from the Report for the year ending March 3I, I908.

"These trials have shown that barnyard manure can be most economically used in the fresh or unrotted condition; that fresh manure is equal, ton for ton, in crop-producing power to rotted manure, which, other experiments have shown, loses during the process of rotting about 60 per cent of its weight. In view of the vast importance of making the best possible use of barnyard manure, it is difficult to estimate the value of this one item of information.

"When these experiments were planned, the opinion was very generally held that untreated mineral phosphate, if very finely ground, was a valuable fertilizer, which gradually gave up its phosphoric acid for the promotion of plant growth. Ten years' experience have shown that mineral phosphate, untreated, is practically of no value as a fertilizer.

"Sulfate of iron, which, at the time these tests were begun, was highly recommended as a means of producing increased crops, has also proven to be of very little value for this purpose.

"Common salt, which has long had a reputation with many farmers for its value as a fertilizer for barley, while others disbelieved in its efficacy, has been shown to be a valuable agent for producing an increased crop of that grain, while it is of much less use when applied to crops of spring wheat or oats. Land-plaster or gypsum has also proved to be of some value as a fertilizer for barley, while of very little service for wheat or oats. Some light has also been thrown on the relative usefulness of single and combined fertilizers.

"After ten years' experience had demonstrated that finely ground, untreated mineral phosphate was of no value as a fertilizer, its use was discontinued in 1898. Prior to this it had been used in each set of plots in Nos. 4, 5, 6, 7, and 8, in all the different series of plots, excepting roots. In 1898 and 1899 , similar weights of the Thomas phosphate were used in place of the mineral phosphate, excepting in plot 6 in each series. In this plot the Thomas phosphate was used in 1898 only.

"After constant cropping for ten or eleven years, it was found that the soil on these plots to which no barnyard manure had been applied was much depleted of humus, and hence its power for holding moisture had been lessened, and the conditions for plant growth, apart from the question of plant food, had on this account become less favorable. In 1899 the experiments were modified and an effort made to restore some proportion of the humus and at the same time gain further information as to the value of clover as a collector of plant food. In the spring of that year ten pounds of red clover seed per acre was sown with the 
grain on all the plots of wheat, barley, and oats. The young clover plants made rapid growth, and by the middle of October there was a thick mat of foliage varying in height and density on the different plots, which was plowed under. No barnyard manure was applied on plots $I$ and 2 in each series from 1898 to 1905 .

"In I 900 all the fertilizers on all the plots were discontinued, and from then to I 905 the same crops were grown on all these plots from year to year without fertilizers, sowing clover with the grain each season. In this way some information has been gained as to the value of clover as a collector of plant food, and also as to the unexhausted values of the different fertilizers which had been used on these plots since the experiments were begun. In I905-6-7 all the fertilizers were again used as in $1898 . "$

The corn plots and root plots were fertilized somewhat differently from the others, and the corn was cut green and weighed in the fresh condition. The results with wheat, oats, and barley are of more general interest, and the most significant data from these crops are recorded in Table Io6, in which all dated intervals are inclusive.

In the author's opinion, we must question the conclusion of Doctor Saunders that nonacidulated mineral phosphate is of no value as a fertilizer. There are at least two important points to be considered before drawing any final conclusion: First, does the land need phosphorus? Or, in other words, is phosphorus the limiting factor? Sandy loam soils are more likely to be deficient in either nitrogen or potassium than in phosphorus. ${ }^{1}$ Second, was any adequate means provided in the system of farming for liberating the phosphorus from the raw phosphate?

From Table ro6 we see that the raw phosphate used alone produced practically no increase on wheat, oats, or barley, but this is also true as regards fine-ground bone during the first ten years,

${ }^{1}$ Since the above was written, Professor Frank T. Shutt, Chief Chemist of the Dominion Experimental Farms, has kindly furnished the author unpublished analytical data from samples of soil collected in 1898 , which show that 2 million pounds of surface soil contained, for plot 3 in the oats series, 2130 pounds of nitrogen, I95० pounds of acid-soluble phosphorus, and 3160 pounds of acid-soluble potassium; while the corresponding figures for plot 3 of the barley series were 2600 , 1850, and 2990, and for the wheat series, 2120,1470 , and 3240 pounds. Compare the following significant figures:

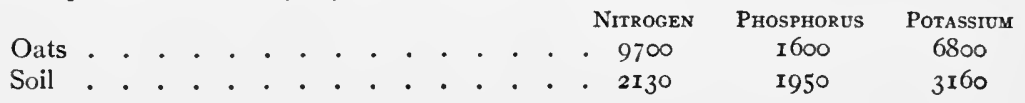




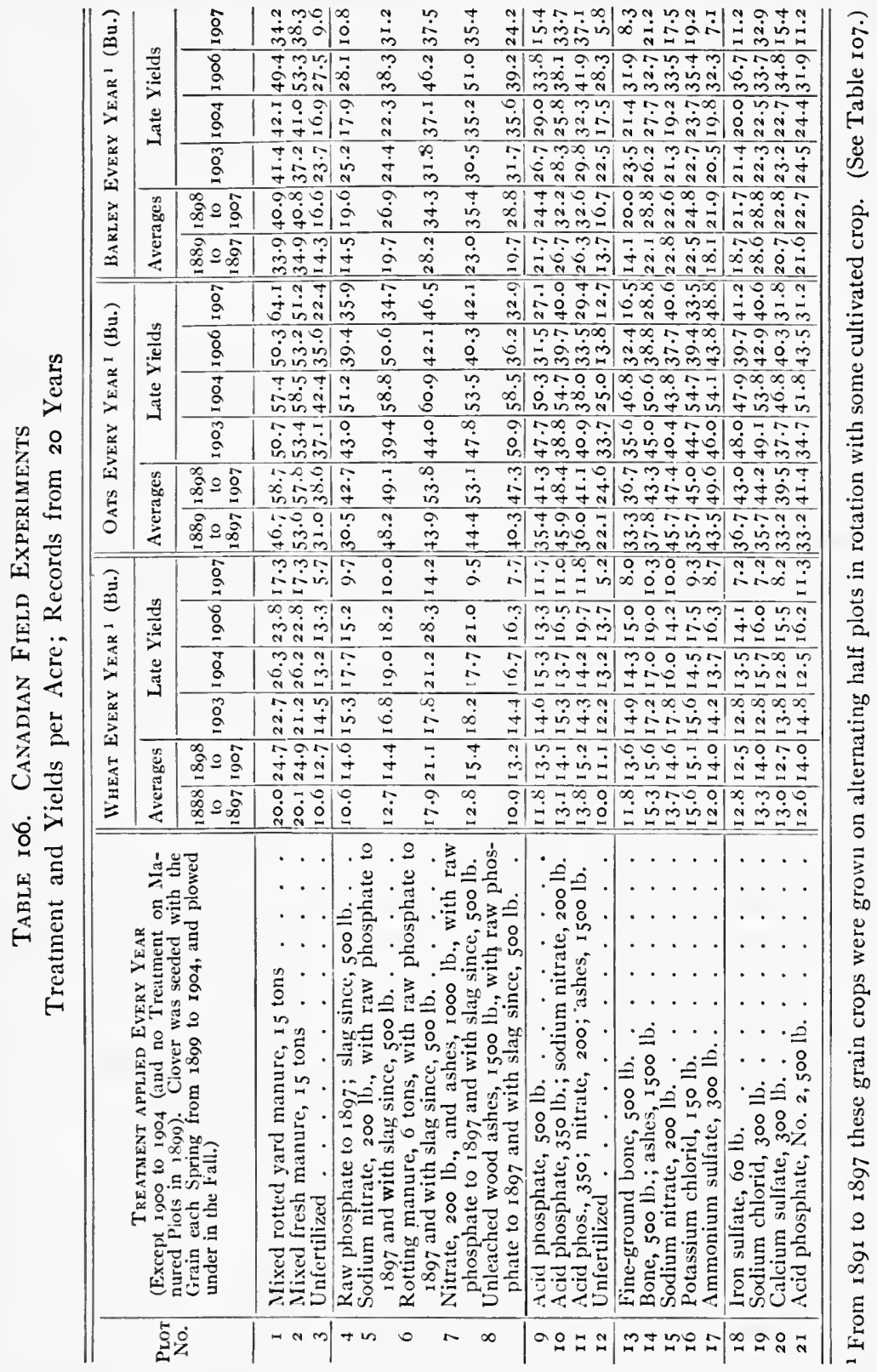


plot I3 yielding only I.2 bushels more wheat, 2.3 bushels more oats, and .4 bushel less barley than plot 4 . The 300 pounds of calcium sulfate on plot 20 produced .4 bushel more wheat, the same yield of oats, and .9 bushel less barley than the 500 pounds of acid phosphate on plot $2 \mathrm{r}$. By referring to Table 78 , we find that as an average of six 4-year periods, 640 pounds of calcium sulfate produced practically no effect ( $12 \frac{1}{2}$ cents per acre in four years), while dissolved bone black carrying 42 pounds of phosphorus produced an average increase of $\$$ I 2.I 7. These results certainly indicate that phosphorus is not the limiting factor in crop yields on the Ottawa soil.

The effect produced on oats by the fine-ground bone is probably due to the nitrogen contained in the bone. It is a common observation that oats respond to nitrogen more rapidly than most other crops on the same soil, and it will be observed that sodium nitrate alone (plot $\mathrm{r}_{5}$ ) produced practically the same effect on oats as the nitrate and acid phosphate combined. Where nitrogen was provided, the raw phosphate (plots 5 and 7 ) produced a larger average increase on oats than did the acid phosphate (plots ro and $\mathrm{r}$ ), during the first nine years.

A study of the results with wheat and barley indicate that potassium is the first limiting element for those crops. As an a verage of the first ten years, the largest yield of wheat was produced by potassium chlorid, aside from the farm-manure plots; and the second largest yield was with ashes (plot $\mathrm{I}_{4}$; compare with $\mathrm{I}_{3}$ ). Sodium chlorid also produced some increase in the yield of wheat, and with barley the 300 pounds of sodium chlorid produced the largest yield, aside from the two heavily manured plots. Even acid phosphate, containing much calcium sulfate and an acid salt of phosphorus, may liberate some potassium. It may be questioned whether potassium or nitrogen is most limiting for the barley crop, but it is plain that phosphorus is not the limiting element. Even during the second ten years, the $5_{50}$ pounds of potassium chlorid or the 300 pounds of sodium chlorid rank higher than 500 pounds of bone or 500 pounds of acid phosphate, in either trial (plots 9 and $2 \mathrm{r}$ ), and also far above the slag phosphate (plot 4).

On plot 6 the raw phosphate was applied in connection with " actively fermenting" manure, and it may have produced some 
effect, but this cannot be known, because there is no comparison plot on which the same amount of untreated manure was used. If we average plots $I$ and 2, we find that 6 tons of phosphated manure on plot 6 produced more than 70 per cent as much increase as 15 tons on plots I and 2. Comparison with the Pennsylvania and Ohio experiments does not help much in trying to decide if the raw phosphate was effective when mixed with the manure at Ottawa, in part because the applications are proportionately different, and in part because the manure itself produces different effects on different soils. With the data presented, any possible comparisons can be made by the student.

Except for the oat crops which, as stated, usually respond readily to nitrogen, ammonium sulfate with the $\epsilon_{0}$ pounds of nitrogen produced a smaller average effect than the sodium nitrate with 30 pounds of nitrogen, thus indicating that the sodium in the nitrate exerted appreciable influence.

Apparently, iron sulfate produced some small effect, but it is doubtful if it is greater than would have been produced by 60 pounds of sodium chlorid. For this and other comparisons involving few plots, the author calls attention to the fact that there are some marked natural variations among the individual plots in these series; and in such cases no final conclusions can be drawn. In the oat series, plot 3 produced 9 bushels more oats per acre than plot $\mathrm{I} 2$ as an average for the first nine years, and I4 bushels more for the next ten years. Plot II in the oat series is evidently a plot which yields below normal.

The quotations from Doctor Saunders show that some parts of the field were naturally wetter than others, and on page $5^{I}$ of the Annual Report for I 897 the statement is made that "plots I2, I3, and I4 were on a piece of rising ground on light soil."

The records for 1903 and 1904 give the yields for the last two years of green manuring with catch crops of clover, while 1906 and 1907 furnish later records after the fertilizer applications were renewed, beginning with 1905 .

In Table I07 are given probably the most significant data from the root crops (and potatoes) that were grown on alternating half plots in these scries during the seven years, I89I to I897. 


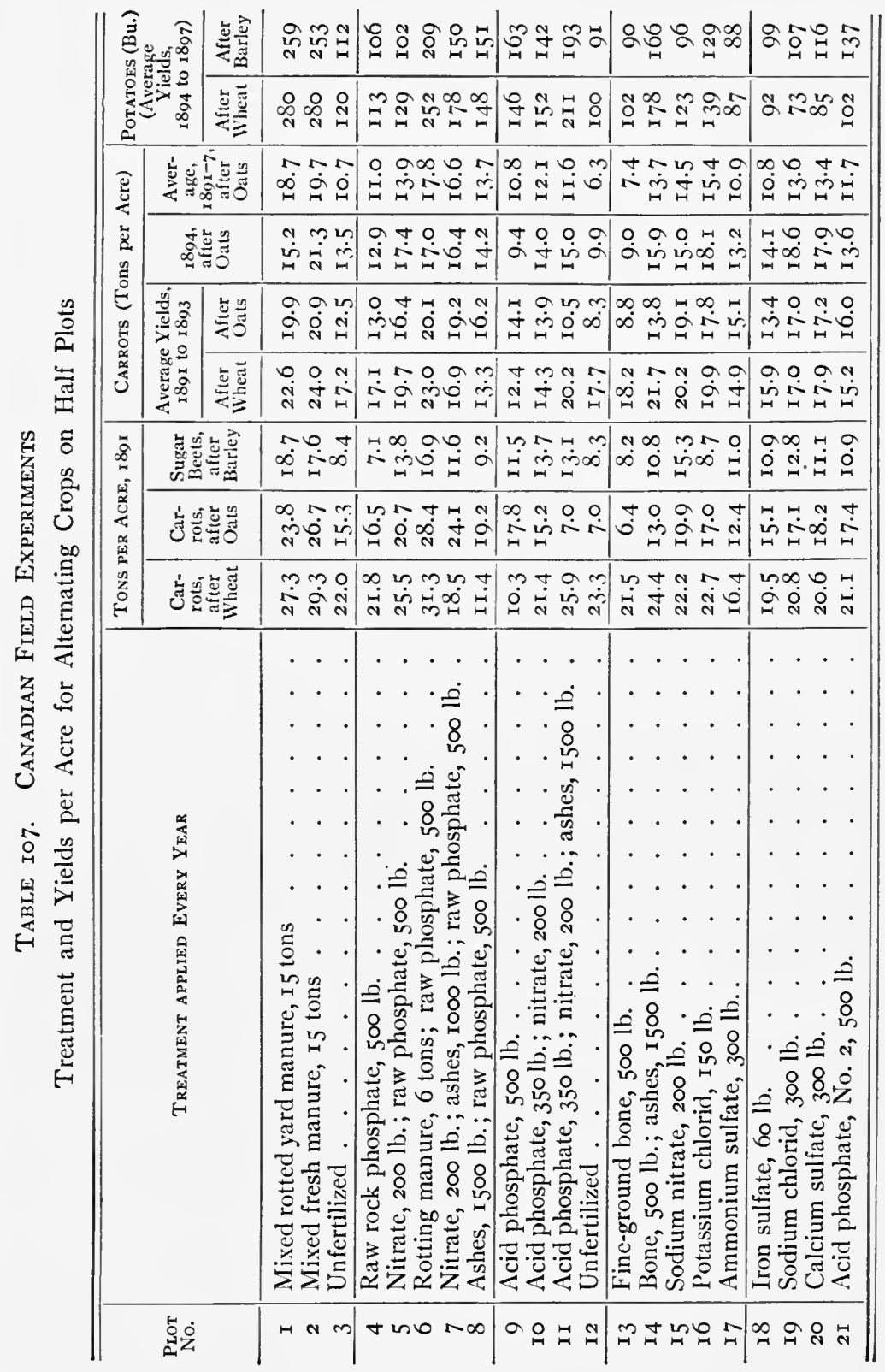




\section{I2 INVESTIGATION BY CULTURE EXPERIMENTS}

These results may serve as a control or check when comparisons are needed. ${ }^{1}$

Thus, from Table I06, we note that iron sulfate produced a more marked effect upon oats and barley than upon wheat; but in Table 107 we observe that, as a three-year average, iron sulfate decreased the yield of carrots on the wheat series, and increased markedly the carrot crop when grown on the oat series. Likewise, with potatoes, iron sulfate decreased the yield by 8 or 28 bushels on the wheat land, and produced an increase of 8 bushels or a decrease of $r_{3}$ bushels on the barley series. All of this means that apparent results from treatment not controlled by some sort of repetition are not to be given great confidence, especially when the apparent effect of the treatment is no greater than the difference between the untreated plots, or between any two plots which are fairly comparable, as plots 5 and Io, wherever plot 5 shows the larger yield.

${ }^{1}$ Evidently through a clerical error, the three-year average yield of carrots from the wheat series was credited to the oats series in the 1894 Report of the Dominion Experimental Farms, and this error was continued in the subsequent reports; consequently the above corrected seven-year average does not agree with the data given in the 1897 Report. 


\section{CHAPTER XXVI}

\section{SHORT-TIME POT-CULTURE AND WATER-CULTURE EXPERI- MENTS IN COMPARISON WITH FIELD RESULTS}

The United States Bureau of Soils has developed methods of making culture experiments in paraffined wire pots and in water extracts of soils, which it was hoped would furnish information from two or three weeks' growth of seedling plants that would serve as a useful guide in determining the fertilizer requirements of the soil.

Table io8. Experiments on Wooster (OHio) Soll

Comparison of Ohio Field Experiments with Bureau of Soils' Pot Cultures for determining Needed Elements of Plant Food

(a) Ohio Station's Nine Years' Test in Field

Average Increase in Yield per Acre

\begin{tabular}{|c|c|c|c|c|c|c|}
\hline Effect Produced By: & & & $\begin{array}{l}\text { CoRN } \\
\text { (Bu.) }\end{array}$ & $\begin{array}{l}\text { OATS } \\
(\mathrm{Bu} .)\end{array}$ & $\underset{(\text { Bu. })}{\text { WHeat }}$ & $\underset{(\mathrm{Lb} .)}{\mathrm{H}_{\mathrm{AY}}{ }^{1}}$ \\
\hline Nitrogen (NP over P) . . & - & & 6.53 & 6.52 & 4.17 & $88 \mathrm{I}$ \\
\hline Phosphorus (alone) . . & 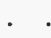 & - & 6.59 & $7 \cdot 46$ & 6.96 & 490 \\
\hline Potassium (KP over $\mathrm{P})$. . & - & - & 4.11 & 2.34 & 2.02 & 333 \\
\hline Nitrogen (NPK over $\mathrm{PK}$ ) . & . & . & $4 \cdot 4^{8}$ & 8. IS & $5 \cdot 44$ & 737 \\
\hline Phosphorus (PNK over NK) & & . & I I.05 & I 4.52 & I 2.45 & 1077 \\
\hline Potassium (KNP over NP) & . & . & 2.06 & 400 & 3.29 & 289 \\
\hline
\end{tabular}

(b) Bureau of Solls' Twenty-day Test in Pots Weight of Green Tops (Increase only, in Grams)

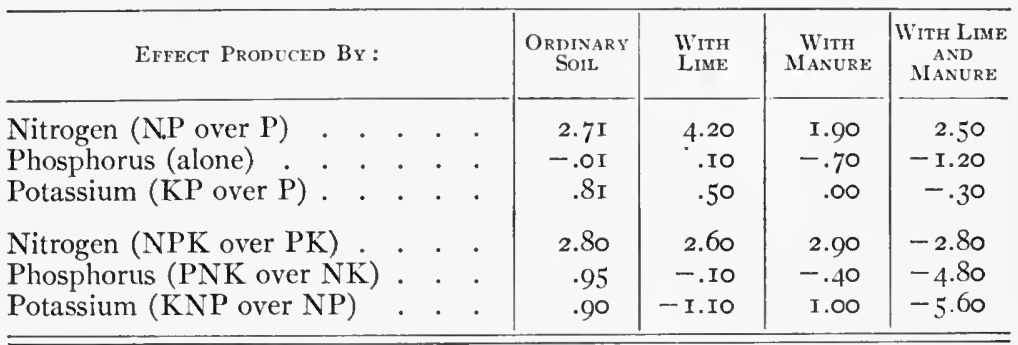

$\mathrm{N}=$ nitrogen; $\mathrm{P}=$ phosphorus $; \mathrm{K}=$ potassium.

${ }^{I}$ Increase in clover and timothy hay. 


\section{I4 INVESTIGATION BY CULTURE EXPERIMENTS}

Table iog. Experiments on Wooster (Ohio) Soll

(a) Statement showing Actunl Increase and Order of Effectiveness

\begin{tabular}{|c|c|c|c|c|c|c|c|}
\hline \multirow[t]{2}{*}{$\begin{array}{l}\text { PLOT } \\
\text { No. }\end{array}$} & \multirow{2}{*}{\multicolumn{3}{|c|}{ TrEATMENT }} & \multicolumn{2}{|c|}{$\begin{array}{l}\text { OHIO STATION'S 9 } \\
\text { YEARS' FIELD TEST } \\
\text { WITH WHEAT; AV. } \\
\text { BU. PER ACRE } \\
\text { (Increase Only) }\end{array}$} & \multicolumn{2}{|c|}{\begin{tabular}{|c} 
BUREAU OF SOILS' \\
SOIL EXTRACT CUL- \\
TURES; WATER TRANS- \\
PIRED BY WHEAT \\
SEEDLINGS \\
(Increase Only)
\end{tabular}} \\
\hline & & & & Bushels & Order & Grams & Order \\
\hline 5 & Nitrogen . & $\therefore$ & . $\quad$. & I.4I & I & 216 & 4 \\
\hline 3 & Potassium . . . . & · & $\therefore$ & I. $4^{8}$ & 2 & -4 & I \\
\hline 9 & Nitrogen, potassium & - & - & I.97 & 3 & $24 \mathrm{I}$ & 5 \\
\hline 2 & Phosphorus . . . & . & . & 6.96 & 4 & 78 & 2 \\
\hline 8 & Phosphorus, potassium & & . & 8.98 & 5 & $\mathrm{I} 2 \mathrm{I}$ & 3 \\
\hline 6 & Nitrogen, phosphorus & . & . . . & II. I 3 & 6 & 263 & 6 \\
\hline I I & Nitrogen, phosphorus, & po & tassium & 14.42 & 7 & 279 & 7 \\
\hline
\end{tabular}

(b) Comparison of Ohio Field Experiments with Bureau of Solls, Water Cultures for determining NeEded Elements of Plant Food

\begin{tabular}{|c|c|c|c|c|c|c|c|}
\hline \multicolumn{6}{|c|}{ Effect Produced By: } & $\begin{array}{l}\text { OHIO WHEAT YIELD } \\
\text { IN FIELD TESTS, AV- } \\
\text { ERAGE OF 9 YEARS, } \\
\text { BUSHELS PER ACRE } \\
\text { (lncrease Only) }\end{array}$ & $\begin{array}{l}\text { BUREAU OF SOILS' } \\
\text { EXTRACT CULTURES, } \\
\text { WATER TRANSPIRED } \\
\text { BY WHEAT SEEDLINGS } \\
\text { (Increase, Grams) }\end{array}$ \\
\hline Nitrogen (NK over K) & . & & & . & & .49 & 245 \\
\hline Nitrogen (alone) . & . & & & & & I. $4 \mathrm{I}$ & 216 \\
\hline Nitrogen (NP over P) & - & $\bullet$ & & . & & 4.17 & I90 \\
\hline Nitrogen (NPK over PK) & . & & & & & 5.44 & I 58 \\
\hline Phosphorus (PK over $\mathrm{K}$ ) & & & & & & $7 \cdot 5^{\circ}$ & 125 \\
\hline Phosphorus (alone) . & & & & & & 6.96 & 78 \\
\hline Phosphorus (PN over N) & & • & & & & $9 \cdot 72$ & $5^{2}$ \\
\hline Phosphorus (PNK over NK & & - & & & & I. 2.45 & $3^{8}$ \\
\hline Potassium (KP over $\mathrm{P}$ ). & . & & & & & 2.02 & 43 \\
\hline Potassium (KN over $\mathrm{N}$ ) & . & & & & & .56 & 25 \\
\hline Potassium (KNP over NP) & & & & & & 3.29 & II \\
\hline Potassium (alone) . . . & - & & & . & • & 1.48 & -4 \\
\hline
\end{tabular}

Tables I08 and rog show the results of such culture experiments in direct comparison with the average results of nine years' field experiments by the Ohio Agricultural Experiment Station on the 
same type of soil at Wooster. In one experiment the Bureau's results are reported in terms of "weight of green tops" of the wheat seedlings, and in the other in terms of water transpired by the young plants, which Whitney and Cameron have held to be a satisfactory measure of plant growth.

It will be noted that the disagreement between the 20-day tests of the Bureau and the nine years' field results of the Ohio Station is so nearly perfect as to render the short-time culture experiments of no value. (See Ohio Experiment Station Bulletin I67 and Illinois Experiment Station Circulars 105 and I23.)

The author has repeatedly emphasized the fact that the student of soil fertility should study the data secured in soil investigations, and thus be prepared to draw his own conclusions. The importance of this is well illustrated by the following statement from the Bureau of Soils concerning the data under discussion:

"The general conclusions from the field experiments, both in the beginning in 1894 and in their more advanced stages, are in agreement with those carried on by the methods of basket cultures and cultures in soil extract." (See page I16, Ohio Bulletin I67, written by the Bureau of Soils.)

In his introduction to Ohio Bulletin I68 (page I22), Professor Milton Whitney, as Chief of the United States Bureau of Soils, makes the following statement:

"The results of the two investigations at Wooster and Strongsville leave no reasonable doubt that the paraffin pot method does give results in harmony with the average results obtained by the much longer timed experiments in the field. It thus has an unquestionable value as a practical method for investigating the manurial requirements of the soil."

Attention is called to the fact that the form of statement used in Table Iog is not only entirely fair and trustworthy, but it is the only method by which the effect produced by each element can be ascertained for the different conditions. Suppose, for example, that a farmer is using potassium alone upon his land for increasing his crop yields (which, as a matter of fact, hundreds of Illinois farmers are doing on peaty swamp lands). The question may naturally arise, Will it pay to apply nitrogen also to the soil? According to the Bureau's results, such an addition to this Ohio soil would produce a greater increase than any other addition of a single element; while, according to nine years' actual field 


\section{I6 INVESTIGATION BY CULTURE EXPERIMENTS}

trials by the Ohio Station, such an addition produces a smaller increase than any other.

Again, suppose the farmer is adding nitrogen to his soil, as most farmers are doing by growing legumes, if not in commercial form. There is no more sensible or appropriate question than, Will it pay to add phosphorus also? The Ohio Station reports that such an addition of phosphorus will increase the yield of wheat 9.72 bushels per acre annually, which is almost seven times the increase produced by nitrogen alone; but according to the tests by the Bureau of Soils the increase of phosphorus added in this way would be less than one fourth of that produced by the nitrogen.

So far as nitrogen and phosphorus are concerned, the perfect disagreement between the water-culture method and the actual field results is indeed remarkable.

The addition of potassium produces some increases in the field experiments, but they are not in accordance with the results obtained with the soil-extract cultures, the lowest positive increase by potassium in the water cultures being produced where its effect should have been greatest, as, indeed, was the case in the field trials; namely, when applied in addition to both phosphorus and nitrogen. 



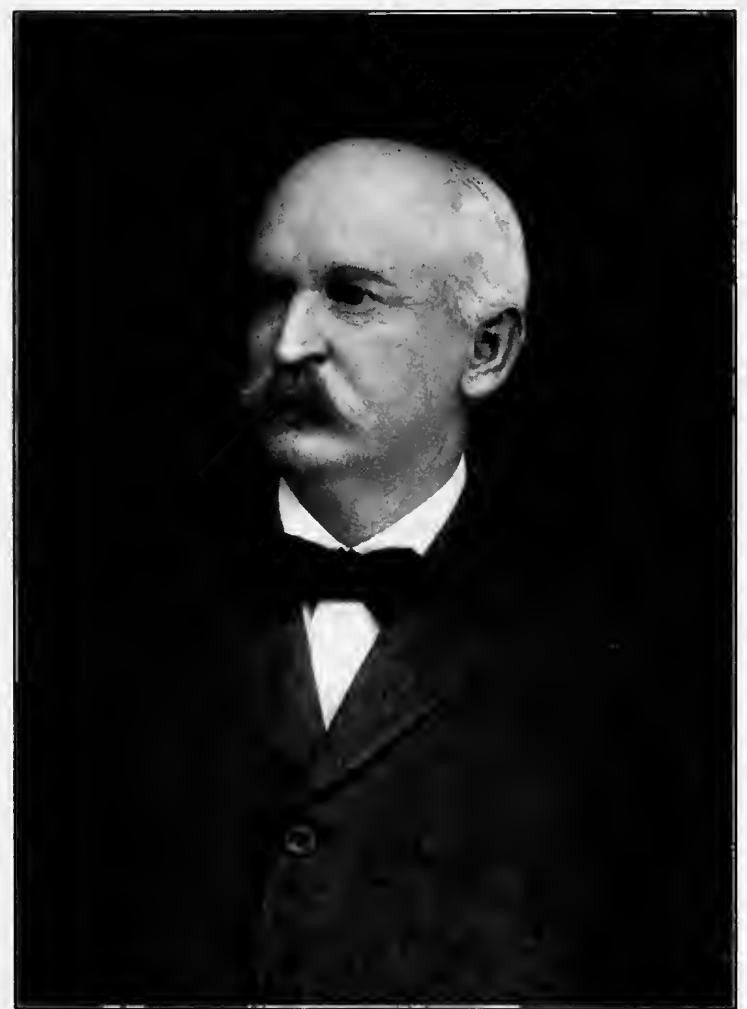

Enward b. Vourhees, Director of New Jersey Agricultural Experiment Station Author of "Fertilizers" 


\section{PART IV}

\section{VARIOUS FERTILITY FACTORS}

\section{CHAPTER XXVII}

\section{MANUFACTURED COMMERCIAL FERTILIZERS}

THE three elements, nitrogen, phosphorus, and potassium, in so-called available forms, have become important articles of commerce. In Europe they are usually purchased singly and applied with reference to the deficiencies of the soil and the needs of the crop; but in America the commercial fertilizer business has been developed largely in the line of mixed goods, or so-called complete fertilizers, which are, in fact, known and purchased by name much more generally than upon any clear understanding of their composition with respect to the needs of the soil and crop. This is very largely the fault of the American statesman, who, as Hunter said of the French Minister, Colbcrt, "gave all possible encouragement to the artisan and the merchant, but forgot that the manufacturer must eat his bread at a moderate price." Thus for a hundred years after most of the agricultural lands between Washington and Richmond had been abandoned for agricultural purposes, the American statesman gave no apparent thought to the development of permanent systems of agriculture.

No wiser use could be made of public money than for the Representatives in Congress to secure for the agricultural experiment stations of each state federal ${ }^{1}$ appropriations of say $\$ 5000$ for each congressional district in the state, to be used solely for

1 In this connection it is well to remember that even relatively the state revenues are very meager compared with those of the federal government. Thus, Illinois" "share" of the federal revenues is approximately ten times the total revenue of the Illinois state government. The soil is the principal source of all revenue, either direct or indirect. 
the investigation of the soils of the state with a view to the ultimate adoption of permanent systems of profitable agriculture on every type of soil in every state.

The first important movement tending in this direction by the national government is represented in "AN ACT donating Public Lands to the several States and Territories which may provide Colleges for the benefit of Agriculture and the Mechanic Arts," which was signed by President Lincoln on July 2, I862. This, the first "Morrill Bill," was an endowment for instruction only; and it was not until March 2, I887, that the "Hatch Act " became a law, "AN Act to establish Agricultural Experiment Stations in connection with the Colleges established in the several States under the provisions of an act approved July 2, I862."

Thus, the experiment station, which is the chief source of correct agricultural information, was established twenty-five years later than the agricultural college, with the result that for twenty-five years and more the state agricultural college was required to teach, without facts or knowledge concerning the agriculture of the state. ${ }^{1}$ Under these conditions it is not so strange that the practice of the American farmer with respect to the use of commerical fertilizers has been essentially a continuation of his previous system of soil depletion, the fertilizer being used almost invariably as a soil and crop stimulant, which leaves the soil poorer and poorer with continued use.

The following bona fide examples are fair illustrations of the "complete" commercial fertilizers now being used in the United States to the extent of more than $\$ 100,000,000$ annually.

\section{“Homestead Tobacco Grower \\ "Guaranteed Analysis}

Available phosphoric acid

I0.00 to $11.00 \%$ Equal to available bone phosphate . . . . . 21.00 to $24.00 \%$ Soluble phosphoric acid . . . . . . . . . . . 8.00 to $9.00 \%$ Equal to soluble bone phosphate . . . . . . . . 17.00 to $19.00 \%$ Insoluble phosphoric acid . . . . . . . . . . . $\quad .50$ to $1.50 \%$

\footnotetext{
${ }^{1}$ In 1900, when it became the author's duty to teach the subject of soil fertility to Illinois students, there was no source of knowledge concerning the composition of Illinois soils.
} 
Equal to insoluble bone phosphate Nitrogen, total available

Equal to total available ammonia Potash $\left(\mathrm{K}_{2} \mathrm{O}\right)$

As potash sulfate

I. 00 to $3.25 \%$ 3.00 to $4.00 \%$ 3.50 to $4.75 \%$ 3.50 to $4.00 \%$ 6.50 to $7.50 \%$

"Our Homestead Tobacco Grower is well known, especially in the tobacco-growing districts of Kentucky, Tennessee, and southern Ohio, and the excellent results given make it needless for us to add our own recommendation of it. For producing the best quality of tobacco it is unexcelled."

\section{“Complete Manure1. \\ "Guaranteed Analysis}

Total phosphoric acid

Available phosphoric acid

Equal to available bone phosphate

Nitrogen

Ammonia

Potash $\left(\mathrm{K}_{2} \mathrm{O}\right)$

Per Cent
8.00 to II .00
7.00 to 10.00
$\mathrm{I} 5.25$ to 21.85
.82 to 1.65
$\mathrm{I} .00$ to 200
$\mathrm{I} .00$ to 2.00

"This brand is what its name implies - a complete manure for general use, in good mechanical condition, containing all the different elements in proportions. In fact, it is a well-balanced fertilizer, and the demand for it has been large and is growing each year."

\section{"Western Brand \\ "Guaranteed Analysis}

\section{Nitrogen}

Ammonia

Available phosphoric acid

Equal bone phosphate

Total phosphoric acid

Potash sulfate

Potash $\left(\mathrm{K}_{2} \mathrm{O}\right)$

\begin{tabular}{|c|c|c|}
\hline \multicolumn{3}{|c|}{ Per Cent } \\
\hline $.4 \mathrm{I}$ & to & .82 \\
\hline$\frac{1}{2}$ & to & I \\
\hline 7 & to & 9 \\
\hline I 5 & to & I9 \\
\hline 9 & to & I0 \\
\hline .9 & to & I $\frac{3}{4}$ \\
\hline$\frac{1}{2}$ & & I \\
\hline
\end{tabular}

"We put this brand on the market to satisfy a call for a low-priced fertilizer. By looking up the matter you will find that most low-priced goods give you no ammonia at all, and some no potash, while we give you quite a liberal amount of both, which makes this brand worth more to you than any low-priced article on the market."

\footnotetext{
1 This was retailed at country stations at $\$ 26$ a ton. - C. G. H.
} 


\section{"York State Special \\ "Guaranteed Analysis}

Nitrogen

Per Cent

Ammonia

Available phosphoric acid

Total phosphoric acid .

Potash, actual $\mathrm{K}_{2} \mathrm{O}$

"A high-grade complete fertilizer especially prepared for general farm and garden purposes. A good sugar-beet fertilizer. Can be used under fruits, tobacco, grain, truck, and all agricultural products."

\section{"Wheat, Corn, and OAt Special" \\ "Guaranteed Analysis}

Per Cent

Nitrogen

Ammonia

Total phosphoric acid

Available phosphoric acid

Potash, actual $\mathrm{K}_{2} \mathrm{O}$.

"For wheat and cereals generally. Apply from 200 to 400 pounds per acre.".
.82 to 1.65

to 2

to II

to 9

to 2

"Eagle Wheat and Corn Grower ${ }^{2}$

Ammonia .

Potash, actual

Available phosphoric acid

Total phosphoric acid

Per Cent

"This goods meets the wants for a high-grade fertilizer for all grain crops, and is especially recommended for grass and clover, on account of the bone tankage used to make up the formula. Take no substitute for this well-known brand, but insist on GLobe Eagle."

The above quotations are from various fertilizer companies in different parts of the United States. The guaranteed analyses are almost invariably correct, but, of course, the guarantee applies only to the minimum percentage specified. The statement of composition is sometimes so complicated that it requires a chemist to understand it. For example, the author has received a com-

${ }^{1}$ Sold locally for $\$ 22$ and at $\$ 22.50$ per ton, at different points. - C. G. H.

2 Sold locally for $\$ 25$ per ton. - C. G. H. 
munication from a landowner of classical education, calling attention to the fact that a certain "guaranteed analysis" showed more than roo per cent by adding together the percentages of all ingredients. This would be true of the "Homestead tobacco grower" if the statement included "Total phosphoric acid " and "Equal to total bone phosphate," which are often reported.

The simplified statement would be as follows:

Homestead Tobacco Grower

Guaranteed Analysis

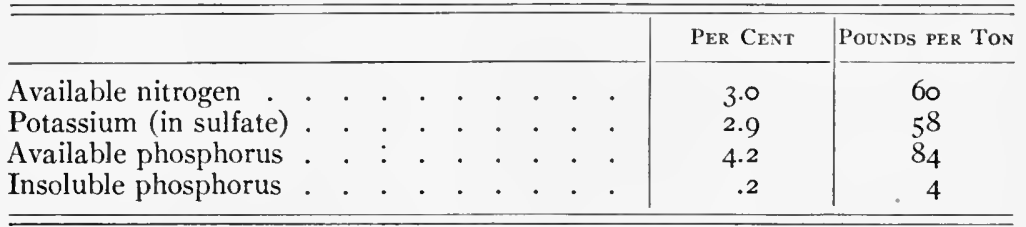

The following statement shows the complete line of fertilizers sold by one of the large packing-house companies of Chicago, and the quotations also show a hopeful tendency toward educational effort on the part of some manufacturers.

is 's Fertilizers

Brands and Analyses

"Maximum guaranteed analyses are misleading - our guaranteed analyses in table below are minimum.

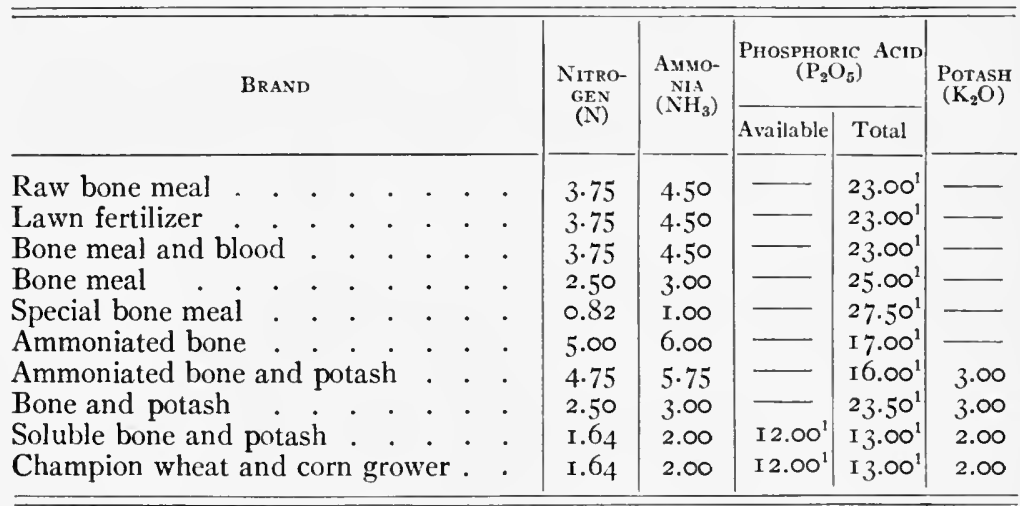

${ }^{1}$ Phosphoric acid derived entirely from bone. 
"_-'s Ferthlzers-Continued

Brands and Analyses

"Maximum guaranteed analyses are misleading - our guaranteed analyses in table below are minimum.

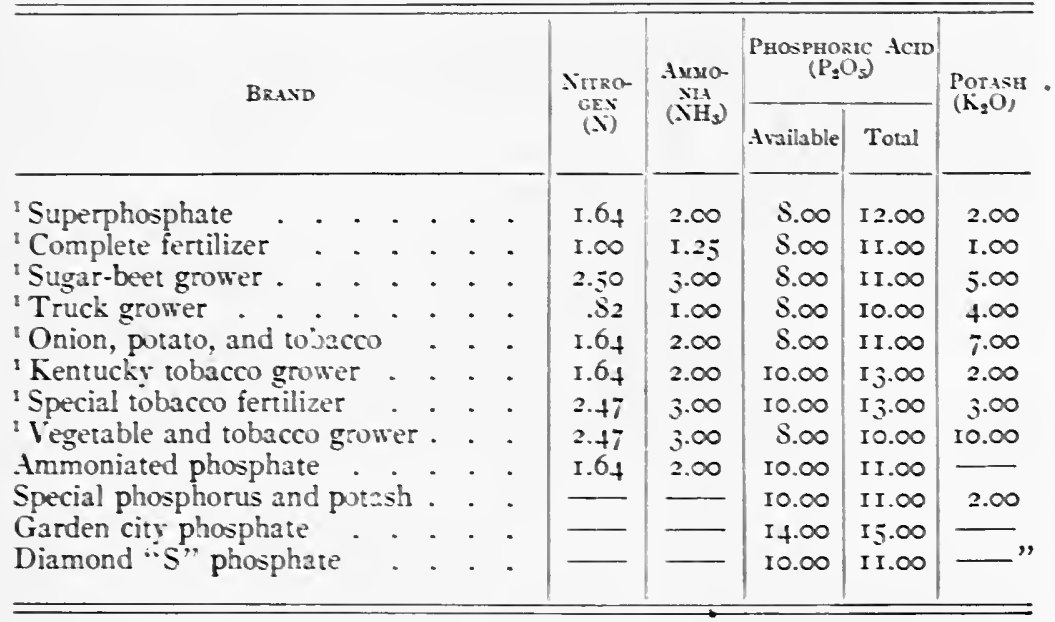

Insoluble phosphoric acid derived from animal bone.

"Nitrogen (ammonia) in all the above brands derived from Blood and Bone.

"Purchasers of fertilizers should profit by" the fact that the higher the guaranteed fertilizer analysis, the less the cost of the plant food obtained, allowing for equal distances of shipment. It pays, therefore, to buy fertilizers on the basis of analyses and not simply by the price per ton for some certain brand. By making a careful comparison of our analyses when buying fertilizers, _- 's will lead.

"For the convenience of our customers in making comparisons of values of different fertilizers, we suggest the following as being approximate values:

"( $(\mathrm{r})$ Pure Bone Fertilizers. If any one of these grades is desired, the values for the essential compound ingredients may be limited as follows:

Ammonia at I $_{5} \mathrm{c}$. per lb. .

Phosphoric acid at $5 \mathrm{c}$. per !b.

Potash, actual, at $6 \mathrm{c}$. per lb.

Ammonia at i5 c. per lb.

$\$ 3 . \infty$ per unit

I. $\infty$ per unit

I. 20 per unit

$3 . \infty$ per unit

"(2) Acidulated Fertilizers, which are more complex in their nature and mamiacture, may be judged comparatively by the following: 
Phosphoric acid, available, at $7 \mathrm{c}$. per Ib. .

Sr.40 per unit

Phosphoric acid, insoluble from bone, at $5 \mathrm{c}$. per lb.

I.00 per unit

Phosphoric acid, insoluble from rock, at I c. per lb.

.20 per unit

Potash, actual, at $6 \mathrm{c}$. per lb.

I. 20 per unit

"Multiplying the minimum guarantees with the above valuations per unit, the total is the relative value per ton of 2000 pounds."

Of these fertilizers, the "Special Bone Meal," containing I 2 per cent of phosphorus, is a fair grade of steamed bone meal, and the "Garden City Phosphate" containing 6.I per cent of available phosphorus and less than $\frac{1}{2}$ per cent of insoluble phosphorus represents the most common grade of acid phosphate on the market. At the prices given, a pound of phosphorus would cost about I I cents in steamed bone meal and about I6 cents in acid phosphate.

In some cases different brands have the same composition, even where sold by the same company. In fact, some of the larger fertilizer companies sell a dozen different brands of the same composition, so that the total number of brands sold by all companies is very large, amounting to about 900 in the state of Indiana and to more than 1800 in Georgia, which only emphasizes the fact that most farmers purchase fertilizers by name rather than on the basis of plant food. Probably half of all the fertilizers bought by American farmers have as an average the "2-8-2 formula," as in the "Superphosphate" and "Eagle Wheat and Corn Grower."

In some states, as in Illinois, a deficiency of I per cent below the miminum guarantee is "not considered evidence of fraudulent intent," but greater deficiencies subject the dealer to a severe penalty if prosecuted. (See Model Fertilizer Law, in the Appendix.) In most states the burden of "fertilizer inspection and control" is placed upon the agricultural experiment station, and sometimes this burden has almost prevented the stations from conducting investigations concerning the soils of the state or in other important lines where exact information is needed. In other states, as in Pennsylvania, Ohio, and Illinois, the enforcement of fertilizer laws is placed with the State Board of Agriculture, and the experiment station is left free to conduct agricultural experiments and investigations. It may be added that there is graye doubt if the agricultural investigator should be compelled to depend, either in large part or in small part, upon the income from tonnage tax 
or brand tax of commercial fertilizers sold in his state, as a source of revenue for the support of his department of investigation.

\section{Forms and Sources of Commercial Nitrogen}

Aside from the free nitrogen of the air, there are four distinct "forms" of nitrogen: (I) organic nitrogen, (2) ammonia nitrogen, (3) nitrate nitrogen, and (4) cyanamid nitrogen.

Aside from farm manure and crop residues, the chief sources of organic nitrogen are (I) dried blood and tankage from the slaughter houses or stock yards, (2) cotton-seed meal from the oil refineries in the South, and (3) fish-scrap in the Eastern and extreme Western states. (Near the coast seaweed often becomes the staple manure. It contains about as much nitrogen and phosphorus as farm manure, and nearly five times as much potassium.)

Dried blood. A good grade of dried blood contains I4 per cent of nitrogen, while tankage is of various grades, ranging almost from blood to bone. It contains much of the offal, and may include the undigested contents of the stomach and intestinal tract. One common grade is " 7 and 30 " tankage, meaning 7 per cent of ammonia $\left(\mathrm{NH}_{3}\right)$ and 30 per cent of "bone phosphate," $\mathrm{Ca}_{3}\left(\mathrm{PO}_{4}\right)_{2}$, corresponding to 6 per cent each of nitrogen and phosphorus. A mixture containing about 2 parts of tankage, 3 or 4 parts of acid phosphate, I part of kainit, and I or 2 parts of filler will produce the " $2-S-2$ formula," with about 2 per cent of "insoluble phosphoric acid derived from animal bone." The annual production of tankage and blood amounts to about I million tons.

Dried peat. Train loads of dried peat are shipped from the peat beds of Illinois and elsewhere to the fertilizer factories for use as a filler; and as a filler it is said to be superior to all other materials, because it is a very effective absorbent and thus keeps the acidulated fertilizers in excellent mechanical condition. Dried peat contains from 3 to 4 per cent of nitrogen which may be "found" by analysis, although the nitrogen in peat is at best no more active than that in the ordinary organic matter of the soil, which usually amounts to 3000 to 5000 pounds per acre in the plowed soil, so that 50 pounds of peat in 200 pounds of "complete" fertilizer would not appreciably affect the crop. 
Cotton seed. Cotton-seed meal contains about $\mathrm{I}_{2}^{\frac{1}{2}}$ per cent each of phosphorus and potassium. Sometimes the whole cotton seed, containing about 3 per cent of nitrogen, is used directly as a fertilizer, but as practically all of the plant food remains in the hulls and cake (after the oil is expressed), the meal is now largely used, and more profitably, of course, unless the farmer pays more for his nitrogen than he received for the same amount in seed, which is likely to be the case if he buys ready mixed "complete" fertilizer. The annual production of cotton seed in the United States amounts to about 6 million tons.

Fish scrap. Fish-scrap meal contains about 8 per cent of nitrogen and 6 per cent of phosphorus. There are various other sources of organic nitrogen, some of which, like hoof meal, furnish available nitrogen, while others, like hair, wool waste, and horn meal, are very slowly nitrified.

Ammonium sulfate. Commercial ammonium sulfate is usually about 95 per cent pure, containing 20 per cent or more of nitrogen. It is obtained by washing coal gas through dilute sulfuric acid and concentrating the liquid until the ammonium sulfate crystallizes out. About 100,000 tons of ammonium sulfate is the present annual production from the gas plants and coke ovens in the United States, and the production is likely to largely increase, because most of the American coke ovens are still wasting the ammonia produced.

Sodium nitrate. Sodium nitrate of commercial grade is about 95 per cent pure, and contains I 5 per cent or more of nitrogen. It is obtained from the extensive nitrate beds of Chile, where it is found in very extensive deposits, thought to have resulted from the decomposition of seaweed in connection with sea salt. The impure material is leached and the nitrate secured by crystallization. The exportation began about ${ }^{8} 80$ and has quite steadily increased from 8000 tons in 1840 to about 2 million tons in 1908 , the total exportation from 1830 to 1909 amounting to about 40 million tons, which is about one sixth of the estimated ${ }^{1}$ amount remaining in the Chilian and Peruvian beds. The export duty

1 The estimates of ten years ago placed the total supply at $8 \mathrm{r}$ million tons, but a so-called official report made in 1909 (American Fertilizer) estimates 246 million tons. 
yields an annual revenue of more than $\$ 20,000,000$, or about three fourths of the total income of the Chilian government. Most of the sodium nitrate imported into the United States is used for the manufacture of explosives.

Calcium nitrate. The artificial fixation of atmospheric nitrogen by an economic and practical method is a problem whose solution has been given much attention for many ycars; in fact, it has been the dream of many a chemist and a dream which has only recently been realized.

Calcium nitrate is now produced to a limited extent (chiefly at Notodden, Norway, by the aid of cheap water power) by the Birkeland-Eyde process, in which a current of air is subjected to powerful electric action, which results in the formation of nitrogen tetroxid (as observed by Priestly as early as I775), which by somewhat complex reaction with water and oxygen yiclds nitric acid. This is treated with lime to form calcium nitrate, which is obtained in crystallized form, $\mathrm{Ca}\left(\mathrm{NO}_{3}\right)_{2}{ }_{4} \mathrm{H}_{2} \mathrm{O}$, containing about I 2 per cent of nitrogen. Calcium nitrate is a highly deliquescent substance, and must be shipped in air-tight containers. In an experiment at Rothamsted io grams of calcium nitrate (produced at Notodden in 1906) absorbed 20 per cent of water and became liquid in 3 days, and in to days about 50 per cent of water had been absorbed.

Calcium cyanamid. Calcium cyanamid is also a product resulting from the artificial fixation of atmospheric nitrogen, by a process recently developed by Frank and Caro of Germany. The primary materials used in the process are limestone, cokc, and nitrogen gas. Calcium carbid is first produced by heating a mixture of burned lime and coke to a very high temperature produced by an electric furnace:

$$
\mathrm{CaO}+{ }_{3} \mathrm{C}=\mathrm{CaC}_{2}+\mathrm{CO} \text {. }
$$

The calcium carbid is fincly ground and then placed in closed retorts and heated to the requisite temperature in an atmosphere of nitrogen, which reacts with the calcium carbid with the formation of calcium cyanamid and separation of carbon:

$$
\mathrm{CaC}_{2}+2 \mathrm{~N}=\mathrm{CaCN}_{2}+\mathrm{C} \text {. }
$$


The nitrogen gas is obtained from the air, either by passing air through a hot tube containing copper turnings, which remove the oxygen by forming copper oxid (the oxid being again reduced by substituting coal gas for air), or by the Linde liquid-air process, in which advantage is taken of the difference between the boiling points of nitrogen $\left(-194^{\circ} \mathrm{C}\right.$.) and oxygen $\left(-184^{\circ} \mathrm{C}\right.$.), the nitrogen being evaporated at the lower temperature.

Potassium cyanid is a well-known substance with the formula $\mathrm{KCN}$, or $\mathrm{N} \equiv \mathrm{C}-\mathrm{K}$, and the group or radicle, $\mathrm{N} \equiv \mathrm{C}-$, is called cyanogen, somewhat as the group $-\mathrm{NH}_{4}$ is called ammonium, and the group $-\mathrm{NH}_{2}$ is called the amido group. Cyanamid contains the two groups, thus $\mathrm{N} \equiv \mathrm{C}-\mathrm{N}=\mathrm{H}_{2}$, and by replacing the two hydrogen atoms by one bivalent calcium atom, calcium cyanamid $(\mathrm{N} \equiv \mathrm{C}-\mathrm{N}=\mathrm{Ca})$ is produced. Calcium cyanamid itself contains 35 per cent of nitrogen; and, if the product could be made with the one atom of free carbon as the only impurity, the nitrogen would still reach 30 per cent, but about one third of the commercial article consists of other impurities (coal ash, lime, calcium carbid, sulfid, phosphid, etc.), the nitrogen being thus reduced to about 20 per cent. An analysis of a commercial sample gave the following results:

Calcium cyanamid $\left(\mathrm{CaCN}_{2}\right)$. . . . . . 57.0 per cent Carbon . . . . . . . . . . . I4.0 per cent Lime $(\mathrm{CaO})$. . . . . . . . . 21.0 per cent Silicon dioxid . . . . . . . . . . 2.5 per cent Iron oxid . . . . . . . . . . . . 4.0 per cent Calcium sulfid, phosphid, and carbonate . . . 1.5 per cent

When first added to the soil the commercial calcium cyanamid with its impurities produces an injurious effect upon young plants, and to avoid this it is applied a week or two before seeding. For the same reason it cannot safely be used as a top-dressing. It has a tendency, because of its lime content, to absorb moisture and carbon dioxid from the air, and for protection is usually treated with a small amount of heavy petroleum. A ten-gram sample of calcium cyanamid exposed for 12 days at Rothamsted increased 30 per cent in weight, and some loss of ammonia occurred. 
Many pot-culture and field experiments have been made with calcium cyanamid which show that when properly used the nitrogen in this form has about the same value as in ammonium sulfate.

When heated with water under pressure, calcium cyanamid decomposes with the formation of calcium carbonate and ammonia, as indicated by the following equation:

$$
\mathrm{CaCN}_{2}+3 \mathrm{H}_{2} \mathrm{O}=\mathrm{CaCO}_{3}+2 \mathrm{NH}_{3} \text {. }
$$

For long-distance shipping the final product from the artificial fixation of atmospheric nitrogen is, in the opinion of the author, to be ammonium nitrate, made by using the ammonia thus produced as a base for neutralizing the nitric acid obtained in the Birkeland-Eyde process.

$$
\mathrm{NH}_{3}+\mathrm{HNO}_{3}=\mathrm{NH}_{4} \mathrm{NO}_{3} .
$$

The ammonium nitrate thus formed, free from mineral impurities, would contain 35 per cent of nitrogen. To produce this compound would require five plants: (I) for nitrogen gas, (2) for calcium carbid, (3) for calcium cyanamid, (4) for ammonia, and (5) for nitric acid.

A publication issued June I, 1907, by the American Cyanamid Company, estimates that the original cost of a complete plant for the production of 10,000 tons per annum of calcium cyanamid would amount to $\$ 444,000$, including:

$$
\begin{aligned}
& \text { \$1 55,000 for the calcium carbid plant, } \\
& 70,000 \text { for the Linde nitrogen plant, } \\
& \text { 145,000 for the calcium cyanamid plant, } \\
& 74,000 \text { for expense not itemized. }
\end{aligned}
$$

This estimate of $\$ 444,000$ does not include the cost of the power plant, it being assumed that a separate company will be organized to furnish the power by utilizing a natural waterfall.

In connection with elaborated estimates as to the actual cost of producing cyanamid nitrogen in such a plant, the following statements are made in this publication:

"Throughout all estimates of costs of operating it is assumed that power costs the Cyanamid Company $\$ 15$ per 24 -hour horse power per annum, measured on the switchboard of the power company supplying the power. It is 
assumed also that the power company and the works of the Cyanamid Company are so close together that there will be no appreciable loss in electric transmission."

"Thus the total estimated cost, including interest upon the estimated investment of $\$ 444,000$, is $\$ 45$ per metric ton; equivalent to $22 \frac{1}{2}$ cents per kilogram of nitrogen, or to cents per pound."

It should be noted that this Io cents per pound for cyanamid nitrogen is the estimated cost to the manufacturers, and that it includes no allowance for transportation of the finished product from the factory to the farmer, no allowance for the cost of advertising and selling, and no allowance for any profit to anybody.

It should be noted, too, that the 4 million pounds of combined nitrogen which such a plant could produce in one year would be sufficient, if none were lost in drainage waters, to meet the "growing demands" of the average corn crop of the United States for less than 200 minutes.

A calcium cyanamid factory is located at Niagara Falls.

\section{Sources of Commercial Potassium}

There are three important sources of commercial potassium: (I) the German mines, (2) the salts recovered from the evaporation of sea water, and (3) wood ashes.

Potassium salts of Germany. The very extensive salt deposits in the region of the Harz Mountains in northern Germany constitute at present by far the most important source of commercial potassium. These deposits were discovered by borings made near Stassfurt in 1857 , and the potassium salts are found chiefly in strata overlying the much thicker stratum of common rock salt. It is estimated that these German salt deposits cover an area of a million acres, and that the supply of potassium which they contain is sufficient to supply the present rate of mining for 190,000 years.

It is thought that these salt and potash beds were formed in ancient geologic time by the evaporation of sea water confined in lakes somewhat like the Dead Sea, or Great Salt Lake, except that there.was at times connection with the ocean which supplied the salt water. Evaporation carries off water vapor and leaves the salts in solution, but if the evaporation proceeds far enough, the 
less soluble salts, such as (I) calcium sulfate (gypsum) and (2) sodium chlorid (common salt), begin to separate in crystals which settle to the bottom; and with further evaporation of water the more soluble salts of potassium and magnesium finally separate in crystals which are deposited in strata above the principal salt deposits.

After vast amounts of water had been evaporated and immense quantities of salts deposited, these accumulations sometimes became covered with drift material (clay etc.) several feet in thickness, and at a later period the sea water again.came in and by evaporation left a second stratum of calcium sulfate, and above it another immense salt deposit.

The total thickness of these various strata is about 5000 feet at Stassfurt. There are many variations and irregularities, but in the main the lower stratum consists largely of calcium sulfate; next above is the sodium chlorid deposit of great depth; then a layer of the mineral polyhalite, composed of the sulfates of potassium, calcium, and magnesium, kieserite (magnesium sulfate), and finally a stratum varying from 50 to 130 feet in thickness, which consists largely of carnallite, a double salt of potassium and magnesium chlorid.

In some places the overlying clay or earth became cracked, and water entered from the surface, so that more or less of the various salts were dissolved and redeposited in veins or pockets in compounds or forms not commonly found in the more general strata. Thus were formed comparatively small beds of kainit, sylvanite, and hartsalz. More than thirty different compounds or minerals are found in these Stassfurt deposits, and at least a dozen of these contain more or less potassium.

By far the most abundant source of potassium is the carnallite stratum, but even the pockets or beds of kainit, sylvanite, and hartsalz are of great importance. The following are commonly accepted as the formulas which represent these minerals:

Carnallite, $\mathrm{KCl} \mathrm{MgCl}_{2} 6 \mathrm{H}_{2} \mathrm{O}$.

Kainit, $\mathrm{K}_{2} \mathrm{SO}_{4} \mathrm{MgSO}_{4} \mathrm{MgCl}_{2} 6 \mathrm{H}_{2} \mathrm{O}$.

Sylvanite, $\mathrm{K}_{2} \mathrm{SO}_{4} \mathrm{MgSO}_{4} \mathrm{KCl} \mathrm{MgCl}_{2} \mathrm{NaCl}_{6} \mathrm{H}_{2} \mathrm{O}$.

Hartsalz, $\mathrm{KCl} \mathrm{MgSO}{ }_{4} \mathrm{NaCl} \mathrm{H}_{2} \mathrm{O}$. 
There are three principal potassium fertilizers brought to America from Germany: potassium chlorid, kainit, and potassium sulfate. 'The commerical kainit usually consists of two thirds of the mineral and one third sodium chlorid, and contains about Io per cent of potassium. It is ground and used very generally for direct application.

Potassium chlorid is obtained from carnallite, and potassium sulfate from kainit, by dissolving the minerals and allowing these salts to crystallize out at suitable temperatures. Commercial potassium chlorid is usually at least 80 per cent pure, while the sulfate has a purity of nearly 95 per cent. Each contains about 42 to 43 per cent of potassium. Potassium sulfate is-also produced from potassium chlorid and sulfuric acid in the manufacture of hydrochloric acid, for which sodium chlorid was formerly used.

Sylvanite and hartsalz (hard salt) are sometimes ground and applied in the crude state, but the concentrated salts may also be derived from them by solution and recrystallization.

Potassium-magnesium sulfate, or "double manure salt," is another Stassfurt preparation which is used to some extent. It contains, as found in the market, about 20 per cent of potassium. Its special value, like that of potassium sulfate, is for use in fertilizing those crops whose "quality" is injured by salts containing chlorin, particularly the tobacco crop.

Wood ashes. Unleached wood ashes commonly contain 5 per cent of the element potassium (as carbonate), 50 per cent of calcium carbonate, and .5 per cent of phosphorus. On most soils they are likely to be more valuable for the lime than for their potassium content; and, when applied at the rate of a ton or more per acre, even the phosphorus added is more than that contained in 200 or 300 pounds of the common " complete " commercial fertilizer.

Potassium from sea water. Where common salt is obtained from the evaporation of sea water, as has been done to some extent on the southern coast of France, potassium is secured as a byproduct from the concentration of the "mother liquor," and one may conceive of unlimited supplies being produced in this manner where the climatic conditions and other natural advantages can be utilized, as on an arid coast and under a tropical sun, especially 
where tidal power could fill extensive reservoirs and where a mountain stream could serve to dissolve and remove the salt deposit after the "mother liquor" is drawn off for further concentration.

It is sometimes claimed that potassium salts, especially kainit, have some power to prevent damage from fungous diseases and injurious insects, but it may be questioned whether the effect is direct or indirect; data already given show very conclusively that not only potassium salts, but also the salts of magnesium and sodium (usually to a smaller extent), produce marked benefit in many instances. In most cases, however, any influence which aids directly or indirectly in the proper nourishment of the plant will thus enable the plant itself better to resist attacks of insects or disease. The author has frequently observed that insect injuries are much more apparent on corn grown on poor land than on adjoining plots treated with phosphorus in connection with farm manure or crop residues.

Where the soil is markedly deficient in potassium, as compared with normal soils, as is the case with certain peaty swamp soils, and where the application of potassium salts on such soils produces marked benefit, while sodium salts produce practically no benefit (see Table 9I), there can be no question regarding the need and value of potassium for its own sake; and even where the soil contains normal amounts of potassium, if enormous crops are to be grown that draw very heavily on potassium, as the 40 to 50 tons per acre of mangels on Barn field at Rothamsted (see Table $7 \mathrm{I} b$ ), the time will come when potassium must be returned. (This, however, is also the case with magnesium and calcium.)

On the other hand, where the plowed soil contains sufficient total potassium to meet the draft upon it for, say, two thousand years, and where sodium or magnesium salts produce about the same effect as potassium salts, and where potassium produces little or no effect if applied in connection with liberal amounts of decaying organic matter, the conclusion may be safely drawn that the addition of commercial potassium is not essential in adopting systems of permanent agriculture, for even the slight erosion that occurs on nearly level lands will possibly provide an absolutely permanent supply. 


\section{CHAPTER XXVIII}

\section{CROP STIMULANTS AND PROTECTIVE AGENTS}

A CLEAR distinction should be made between the use of plant food in systems of permanent agriculture and the use of crop stimulants or crop "protectors." Unquestionably there are conditions under which the use of some particular substance, other than plant food, will produce a sufficient increase in the yield of the crop for which it is applied to more than pay the cost; and, furthermore, the use of such material may in some cases be advisable, but it should be used with intelligence and full understanding of its effect.

Land-plaster. Land-plaster (native calcium sulfate) is a wellknown crop stimulant, but it contains neither nitrogen, phosphorus, potassium, nor lime, supplies no plant food of commercial value and has no power to correct soil acidity, and its physical effect on the soil is probably injurious rather than beneficial. In fact, it is the common report that the soil tends to become hard and more compact with the long-continued use of land-plaster; but whether this effect is wholly due to the wearing out of the organic matter, or in some part due to the cementing properties of the calcium sulfate, cannot be stated with certainty. When dehydrated, calcium sulfate becomes plaster of Paris, and it is a constituent of different cementing materials.

The temporary beneficial effect of land-plaster is probably due to its chemical action in the soil. It may convert more or less of the supposedly difficultly available iron phosphate into the more readily a vailable tricalcium phosphate, as indicated by the following equation:

$$
2 \mathrm{FePO}_{4}+{ }_{3} \mathrm{CaSO}_{4}=\mathrm{Ca}_{3}\left(\mathrm{PO}_{4}\right)_{2}+\mathrm{Fe}_{2}\left(\mathrm{SO}_{4}\right)_{3} \text {. }
$$

Very possibly this or some similar reaction occurs to a limited extent when calcium sulfate is applied to a soil containing iron 
phosphate. Another possible reaction may result in the liberation of potassium or magnesium from polysilicates, as roughly indicated by the following equation:

$$
\begin{aligned}
\mathrm{AlFeMgNaK} & \\
\mathrm{x}+2 & \left(\mathrm{SiO}_{3}\right)_{\mathbf{y}}\left(\mathrm{H}_{2} \mathrm{O}\right)_{z}+\mathrm{CaSO}_{4} \\
& =\mathrm{AlFeMgNaK}_{\mathrm{x}} \mathrm{Ca}\left(\mathrm{SiO}_{3}\right)_{\mathbf{y}}\left(\mathrm{H}_{2} \mathrm{O}\right)_{\mathbf{z}}+\mathrm{K}_{2} \mathrm{SO}_{4} .
\end{aligned}
$$

With large supplies of potassium present in polysilicates, heavy applications of calcium sulfate would doubtless liberatc some potassium sulfate, although under the opposite conditions mass action would force the reverse reaction; that is, heavy applications of potassium sulfate to a soil containing much calcium in polysilicates would liberate some calcium sulfate.

The potassium sulfate liberated from the insoluble silicate, as indicated above, may serve directly as plant food, or it may react to increase the availability of phosphorus, thus:

$$
\mathrm{Ca}_{3}\left(\mathrm{PO}_{4}\right)_{2}+{ }_{2} \mathrm{~K}_{2} \mathrm{SO}_{4}=\mathrm{CaK}_{4}\left(\mathrm{PO}_{4}\right)_{2}+{ }_{2} \mathrm{CaSO}_{4} \text {. }
$$

These equations are given to show some of the possible reactions that may occur when a soluble salt is added to the soil. A dozen different reactions may be taking place at the same time within the same cubic inch of soil, and it is easily possible that, while one reaction is taking place in one part of the cubic inch, the reaction is running in reverse order in another part, depending upon the mass, composition, and concentration of the insoluble and soluble salts.

If a solution of ammonium sulfate or potassium chlorid is percolated through a stratum of soil, an examination will usually show that, while ammonium or potassium passed into the soil, calcium and magnesium have passed out in the percolate. If tricalcium phosphate be shaken with pure water, practically no phosphorus will be found in the filtrate; but if a solution of some neutral salt, such as sodium chlorid or potassium nitrate, be substituted for the pure water, very appreciable amounts of phosphorus are dissolved.

Land-plaster has been much used in some parts of the North Central and Eastern states, and for a time it usually gives quite profitable results; but finally, the element of real value that has been liberated by the action of the land-plaster becomes so depleted 
that even heavy applications of plaster fail to liberate sufficient for profitable crops, and thus the plastered land is made poorer than the untreated land.

A common method of advertising has been to write the word PIASTER with a heavy application of the material in large letters on a cultivated field in view of the public road. In the larger, greener grow th of grain crops or grass, the word PLASTER can be read by the passers-by; and thus the landowner is induced to plaster his whole field. If, however, he would only apply plaster year after year where the word was first written, the time would come when the word could not be read; and, if he still continued the applications, ultimately he would again be able to read Plaster, if we may judge from the testimony of common experience.

Common salt. Common salt (sodium chlorid) is sometimes used as a crop stimulant, but its beneficial effect is likely to be cven less durable than that of land-plaster. However, where common salt or other soluble salts, such as sodium sulfate or magnesium sulfate, or mixtures like kainit, are applied in connection with sufficient supplies of phosphorus, nitrogen, and lime, the effect of the stimulant must be confined chiefly to holding the phosphorus or other necessary elements in available form and to liberating potassium from the soil; and where the natural supply of potassium is extremely large, the beneficial effect of the applied salt may continue for many years, as is well shown in the results from Rothamsted.

Kainit. Kainit, of course, also supplies some potassium, and is thus in some part a fertilizer, though in large part a stimulant. To some extent this is also true of the common acid phosphate, which contains phosphorus mainly in the form of a soluble acid salt, and twice as many molecules of manufactured land-plaster:

$$
\mathrm{Ca}_{3}\left(\mathrm{PO}_{4}\right)_{2}+2 \mathrm{H}_{2} \mathrm{SO}_{4}=\mathrm{CaH}_{4}\left(\mathrm{PO}_{4}\right)_{2}+{ }_{2} \mathrm{CaSO}_{4} \text {. }
$$

It is difficult to conceive of a more effective combination than about 200 pounds per acre of a mixture of acid phosphate and kainit applied twice for each five-year rotation of corn, oats, wheat, clover, and timothy. With all crops removed, such a system would doubtless as thoroughly deplete the soil as any that could be devised, clover itself, used in this way, being a very powerful soil stimulant. If anything could be added to hasten the action, an application 
of five tons of farm manure about once in ten years (spread very uniformly, and an occasional dressing of burned lime, would make this system of ultimate land ruin very complete.

A mixture of 300 pounds of acid phosphate and roo pounds of kainit in five years would, with the manure system, furnish about 5 pounds of nitrogen, 5 pounds of phosphorus, and 6 pounds of potassium per acre per annum; whereas, crops as large as we ought to try to produce would remove from the soil as a yearly average about roo pounds of nitrogen, 20 pounds of phosphorus, and 80 pounds of potassium (see Table $\mathrm{I}_{3}$ ). When crops one half as large are produced under such a system of fertilization, the soil under the action of these stimulants must furnish about nine tenths of the nitrogen, half of the phosphorus, and six sevenths of the potassium required for the crops. An invoice of his stock of fertility will help the landowner to plan wisely for the future, because he can thus know in advance what the ultimate effect must be of such systems.

Protective agents. As protective agents we may include materials which tend to ward off disease or insect enemies; and the effect may be produced by substances destructive to fungi or repellent to insects. Kainit is thought to act sometimes as a fungicide, and tankage is held by some to prevent attack from certain insects.

Any treatment which hastens the normal growth of the plant usually helps the plant to resist or overcome the attack of insects or disease; and it is apparently true that imperfect or abnormal plants are more likely to suffer from such attacks than normal, healthy plants. It has been suggested that sucking insects prefer the concentrated sap of weak or somewhat withered plants to that of vigorous succulent plants. Doctor Forbes has suggested that the very dilute juice of a rapidly growing plant may constitute a starvation diet for healthy insects; in other words, that the capacity of the insect for such juice is not sufficient to furnish it with the amount of nutrition necessary for maintenance and reproduction.

It is common observation that chinch bugs may attack and destroy wheat that would otherwise yield Io or I 5 bushels per acre, while wheat growing in the same field on land capable of producing 30 bushels or more per acre is not attacked. The author has noted in several different seasons that corn growing on land that will 
yield 40 to 60 bushels per acre has been very severely injured by the colaspis root worm, while no apparent damage was done on adjoining well-fertilized plots which produced 80 to 100 bushels per acre, although the insects were found in both parts of the field. In any or all of these ways small applications of fertilizers or stimulants may produce results in crop yields far beyond the direct nutrient value of the plant food applied.

The practice is somewhat common in places of coating seed corn by stirring with a paddle dipped in warm tar, and to some extent castor oil has been used for the same purpose, the application being made two or three weeks before planting so that the oil coating may have time to "dry on." Turpentine has also been used, and some have advised putting powdered sulfur with the seed in the planter boxes. These of course are solely protective agents, if they have any value. Their use is based upon experience, however, and not upon experiment, and thus far the practice seems to rest upon no better foundation than that of planting potatoes "by the moon," or "witching" for water, an "art" which fails to find water twice in the same place if the operator is blindfolded. 


\section{CHAPTER XXIX}

\section{CRITICAL PERIODS IN PLANT LIFE}

IN this connection we may well consider another cause of differences in crop yields quite out of proportion to the difference in soil treatment. There may be, and often are, critical periods in the life of plants, when some small measure of assistance may change prospective failure into marked success. Thus, it is not infrequently a question of life or death with the clover plant when the nurse crop is removed; and, while most of the plants may die at that time on untreated land, a good stand of clover may be saved where a very light application had been made of manure, fertilizer, or soil stimulant. The nutrient value of the application may not be sufficient for half a ton of clover, but the difference in yield may amount to one or two tons; and from the larger crop larger residues are left on and in the soil, resulting in a larger crop of grain the following year. Thus, enormous credit may be given, which is not at all deserved, on the basis of total plant food concerned.

One of the most critical periods in the life of the corn plant is at the time the ears are forming, and an ample supply of moisture appears to be especially necessary at that time. If a severe summer drouth is coincident with this critical period, the yield of grain is likely to be small; and any soil treatment which has the effect either of hastening or retarding the development of the plant, and thus of bringing the earing time either before or after the drouth, may very markedly affect the crop yield.

The farmer is usually most anxious for conditions under which his wheat will " fill " well, and since this is influenced very appreciably by the temperature during this critical period, it follows that very marked effects upon both yield and quality may sometimes result from any soil treatment that causes the wheat to "fill" either a few days earlier or a few days later than on the untreated land. On the other hand, the treatment, whether applied as a crop 
stimulant or in a system of permanent soil improvement, may sometimes be the means of bringing this critical period at the time when the weather conditions are most unfavorable, while the untreated land may mature a larger crop at the more favorable time.

An instance has been reported of a field treated with half a ton per acre of raw phosphate having produced a crop of 45 bushels of oats free of rust, whereas only 20 bushels of badly rusted oats were produced from similar seed on adjoining untreated land. Two influences may help to produce this difference: the added phosphorus tends to balance the food ration and thus to strengthen the oats against the fungous disease (and against lodging, as well), and also to hasten the maturity by which the crop escapes the rust which might attack the plants maturing later and perhaps under weather conditions more favorable for the development of the disease. As was stated by the author to the farmer who reported this experience, the marked difference in yield is not to be credited even largely to the phosphorus because of the plant food for its own sake, but rather to a combination of influences to which the added phosphorus proved to be the key.

While such examples may serve temporarily as good advertisements for the treatment applied, they are just as misleading for wide application as are the occasional reports of damage to crops produced by applying manure. All of this serves to emphasize the importance of having some fundamental knowledge upon which to base definite systems of permanent agriculture. For this purpose we must rely primarily upon the absolute facts furnished by chemistry and mathematics and be guided only by the results of carefully conducted and long-continued experiments. Single examples can be found in support of almost any practice or theory that can be advanced; but a mere experience, though it be repeated, invariably with the same result, for fourscore times, furnishes no proof whatever that the octogenarian will live to celebrate another birthday.

A small amount of readily available plant food, such as 50 pounds of sodium nitrate per acre as a top dressing for wheat on poor land in a cold spring, may produce a sufficient increase in yield to more than pay the cost of the nitrate. Likewise, roo pounds of " ammoniated bone and potash," carrying perhaps 2 pounds of nitro- 
gen, 4 pounds of phosphorus, and 2 of potassium may be dropped in or near the hill of corn with a "fertilizer attachment" to the planter, and, under adverse conditions of soil and season, the crop increase may show some profit. It should be clearly understood, however, that all such systems of fertilizing are of themselves only an aid to soil depletion, because the "good start" thus given to the crop enables it to draw upon the soil itself for larger supplies of one or more elements of plant food than would be furnished by the untreated soil and the fertilizer applied.

Quite independent of any such practices, the landowner should make ample provision for maintaining the fertility of the soil, on normal soil, by large use of phosphorus and farm manure or legume crops and crop residues, sufficient limestone being applied when necessary to prevent or correct soil acidity. Where this is done, however, the use of "starters" is usually unnecessary and unprofitable. Indeed, the dropping of a small quantity of fertilizer in the hill of corn (or near it) is sometimes a source of damage, not so much because it may injure the seed or young plant, but because it does not encourage the normal development of the root system in proportion to the early growth of the plant, and as a consequence the crop may suffer from drouth later in the season much more than the unfertilized corn. 


\section{CHAPTER XXX}

\section{FARM MANURE}

THE value of farm manure is governed largely by four modifying and somewhat related factors.

First, the composition of the materials used for feed and bedding.

Second, the dryness, or dry-matter content, of the manure.

Third, the preservation or stage of decomposition or waste of the manure.

Fourth, the kind of animals producing the manure.

As a general average a ton of fresh-mixed cattle and horse manure contains about 500 pounds of dry matter, to pounds of nitrogen, 2 pounds of phosphorus, and 8 pounds of potassium. It would be produced from about 8IO pounds of air-dry feed (yielding 270 pounds of "dry excrement) and 270 pounds of air-dry bedding (containing 230 pounds of dry matter). On this basis, four tons of air-dry feed and bedding (used in the proportion of 3 to I) would produce about $7 \frac{1}{2}$ tons of a verage fresh manure containing 25 per cent of dry matter and 75 per cent of water.

Roughly, this represents the theoretically possible production of manure on the farm, if all crops grown are used for feed and bedding. If the crops sold from the farm amount to one third of the total produced, and if one fifth of the manure made is lost before it is applied to the land, then for every ton of air-dry produce harvested and removed from the land one ton of manure could be returned.

If we count 85 per cent of dry matter in the air-dry feed and bedding, and $66 \frac{2}{3}$ as the average digestion coefficient for the dry matter in the food consumed (see Table 29), and 75 per cent of the nitrogen and phosphorus and 90 per cent of the potassium returned in the manurial excrements, then a ration of 500 pounds of clover hay and 310 pounds of corn, with 270 pounds of wheat 
straw for bedding, would make a ton of manure containing 500 pounds of dry matter, about I $2 \frac{1}{2}$ pounds of nitrogen, 2 pounds of phosphorus, and $9 \frac{1}{2}$ pounds of potassium. Or a ration containing 500 pounds of timothy hay and 3 Io pounds of oats, with 270 pounds of oat straw for bedding, would make a ton of manure containing 500 pounds of dry matter, about I I pounds of nitrogen, I.7 pounds of phosphorus, and 9 pounds of potassium. Some loss of nitrogen is likely to occur by volatilization, and both nitrogen and potassium are very likely to be lost in the liquid excrement.

For the most common rations used in live-stock farming, 10, 2, 8 represent very approximately the average pounds of the three elements, nitrogen, phosphorus, and potassium, in a ton of "average fresh manure." By leaching and fermentation the dry matter, nitrogen, and potassium are lost in approximately the same proportion, but the phosphorus is lost only about half as rapidly, so that one ton of average yard manure, resulting from perhaps two tons of fresh manure, contains about 500 pounds of dry matter, Io pounds of nitrogen, 3 pounds of phosphorus, and 8 pounds of potassium, one half of the dry matter, nitrogen, and potassium, and one fourth of the phosphorus having been lost.

Wheat bran contains about 24 pounds of phosphorus per ton, so that, for every Ioo pounds of bran used in the ration, nearly one pound of additional phosphorus will be found in the manure. This illustration and reference to the average composition of food stuffs will show how important the factor of food is in affecting the quality of manure.

Most analyses of manure represent the product in a more or less decomposed state, in which case the phosphorus content is likely to be appreciably higher than in strictly fresh manure, and even manure commonly called fresh is likely to have lost some nitrogen and potassium in the liquid excrement. The following analyses include some accepted averages from the best authorities.

While these general averages may be satisfactorily applied to large quantities of mixed manure, or in estimating the amounts of plant food in repeated applications of fresh or yard manure, respectively, they cannot safely be used for small single lots, unless the per cent of dry matter is determined and the character of the feed and bedding used is known. 
Table ilo. Composition of Fresh Manure

Pounds per Ton

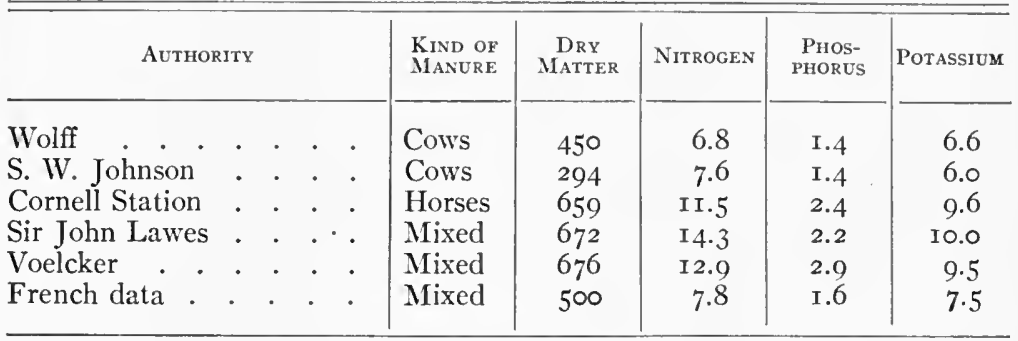

UNIFORM BASIS

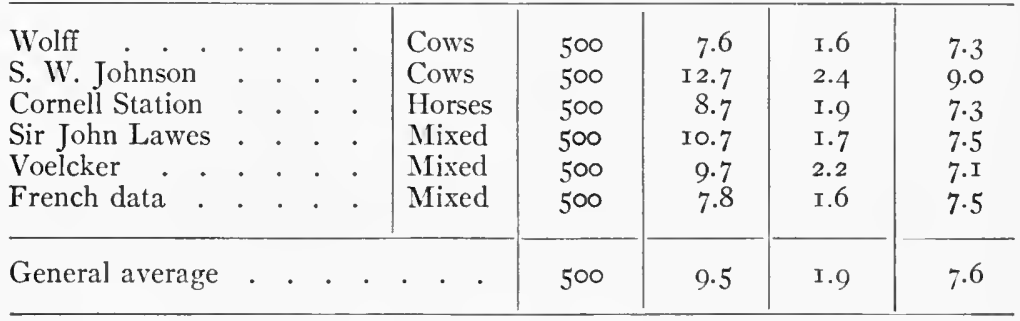

Composition of Exposed Yard Manure

Pounds per Ton

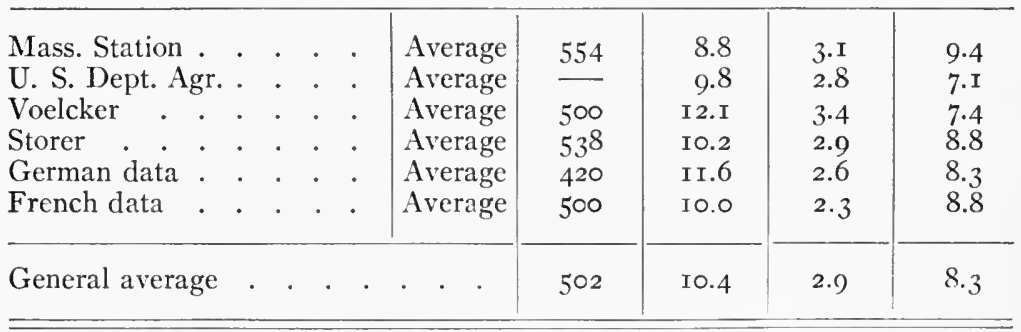

A ton of manure carrying 60 per cent of water contains twice as much plant food as the same manure carrying 80 per cent of water. This means that, with manure carrying 80 per cent of water, by allowing sufficient of the water to evaporate, the content of dry matter and plant food is doubled. Or, in case of manure containing 85 per cent of water, it is only necessary to reduce the water to 70 per cent in order to double its percentage composition in every valuable constituent. 
Sheep manure is commonly regarded as a rich manure, but this is largely due to the fact that sheep manure is usually much dryer than that from other kinds of stock. Thus, the Massachusetts Experiment Station reports the average of four analyses of sheep manure, showing 28.4 pounds of nitrogen, 8 pounds of phosphorus, and 19.4 pounds of potassium, per ton; but this manure contained only 29.22 per cent of water. If the water content were increased to 75 per cent, which is about the average for mixed manures, then this sheep manure would contain only Io pounds of nitrogen, 2.8 pounds of phosphorus, and 7 pounds of potassium, per ton.

By referring to the Pennsylvania experiments recorded in Table $3 \mathrm{I}$, it will be seen that of the 37.68 pounds of potassium in the food consumed, only 5.93 pounds were recovered in the dung, and 28.38 pounds in the urine. If these mixed excrements were exposed, and the urine quickly replaced by rain water, the potassium contained in one ton would decrease from about 8 pounds to 2 or 3 pounds. (See Table i r.)

The results of 79 analyses of various farm manures, made from different kinds of feed and bedding, containing varying amounts of water, and in different conditions of preservation or exposure, showed a range per ton of manure as follows: Nitrogen from 4.2 to 27.2 pounds, phosphorus from .9 to 6.5 pounds, and potassium from 2.2 to 23.2 pounds.

At different places in the central West sheep are shipped in from the Western range and kept upon full feed for a few months. Several plants have been installed for drying and pulverizing the sheep manure thus accumulated. Because of the large proportion of grain and other concentrates in the rations, the manure produced is about twice as rich in phosphorus as ordinary manure; but otherwise the dried sheep manure has about the same composition as average fresh manure reduced to the dry basis, as will be seen from Tables i io and III.

The value of dried sheep manure is best determined by direct comparison with ordinary manure, one ton of the former being worth about as much as four or five tons of average fresh manure. Probably the Pennsylvania data reported in Table 78 furnish the best information the world affords as to the agricultural value of ordinary manure when used on ordinary soils for the production 
Table ii . Composition of Pulverized. Dried Manures

Pounds per Ton

\begin{tabular}{|c|c|c|c|c|c|}
\hline Kind of Manure & & Place & $\begin{array}{l}\text { Total } \\
\text { NitRo- } \\
\text { GEN }\end{array}$ & $\begin{array}{l}\text { TOTAL } \\
\text { PHOS- } \\
\text { PHORUS }\end{array}$ & $\begin{array}{l}\text { Soluble } \\
\text { Potas- } \\
\text { SIUM }\end{array}$ \\
\hline Dried sheep manure & . & Elgin, Illinois (1906) & 43 & I6 & 20 \\
\hline Dried sheep manure & & Aurora, Illinois (1906) & $5 \mathrm{I}$ & I 8 & $3^{I}$ \\
\hline Dried sheep manure & . & Aurora, Illinois (rgo8) & 50 & I 8 & 23 \\
\hline Dried sheep manure & & Chicago, Illinois (I9o6) & 47 & I5 & 37 \\
\hline Dried sheep manure & . & Chicago, Illinois (I9o7) & 44 & 8 & 24 \\
\hline Dried cattle manure & & Chicago, Illinois (I907) & 40 & 6 & I9 \\
\hline Dried manure . . & & Chicago, Illinois (I908) & 35 & I6 & $3^{I}$ \\
\hline
\end{tabular}

of ordinary crops grown in a good rotation, and figured at average prices for the corn belt. These data give the manure a value of $\$$ I.65 per ton where I 2 tons per acre are used, \$I.32 where I6 tons are applied, and \$I.I 4 where 20 tons are applied, for each four-year rotation, corresponding to annual applications of 3,4 , and 5 tons per acre, respectively. Since the lightest application appears to maintain the (moderate) productive power of the land for the second i2-year period as compared with the average of the first I2 years, it seems that $\$ 1.65$ per ton may be regarded as the full agricultural value of the manure for use in permanent systems.

Of course the manure might be worth less on better land and more on poorer land; and with different crops (as cotton, fruit, potatoes, etc.). or with different prices, its value would be different.

If we refer our comparison to the unfertilized land during the I 2 year periods, the $\mathrm{I} 2$ tons of manure were worth $\mathrm{S}_{\mathrm{I}}$. I 4 a ton during the first I 2 years and $\$ 2.14$ a ton as an average of the second period, and during a third I2-year period the value will no doubt be still greater, measured against the still further depleted, untreated land. In the Ohio experiments, with the five-year rotation (Table 82) 8 tons of manure were worth $\$ 2.18$ a ton and I6 tons were worth $\$ 1.69$ a ton; while in the three-year rotation the 8 tons of manure applied for potatoes were worth $\$ 3.63$ per ton, with potatoes at 50 cents a bushel.

In the potato experiments on Hoos field at Rothamsted, 94.2 
tons of manure, applied at the annual rate of 15.7 tons per acre for six years ( 1876 to I88I), produced I 326 bushels' increase in the potatoes during the 26 years ( 1876 to I90I), which at 50 cents a bushel would give the manure a value of $\$ 7.04$ per ton. Here the plant food applied in the 94.2 tons of manure was from two to four times that removed from the soil in the 1326 bushels' increase in potatoes, and the subsequent yields of barley show that the manure still produces some residual effect. However, the large amount applied during the six years is equivalent to 3 tons of manure per acre per annum for more than 30 years.

When measured by crop yields, the value of a ton of manure increases with the size of the area over which it is spread, but the yield and profit per acre usually increases with the amount of manure applied. Hence, with much land and little manure, light applications are most profitable; while with less land and much manure available, heavy applications bring the greatest profit. It should be remembered, too, that manure may act as a powerful soil stimulant, when light, infrequent applications are made on good land, from which more plant food is removed in crops than is applied in the manure.

In an experiment conducted at Cornell University, 4000 pounds of ordinary manure from the horse stable, worth $\$ 2.74$ per ton for the plant food content (at commercial prices) were exposed in a pile out of doors from April 25 to September 22, but at the end of that time the total weight had decreased to 1770 pounds, worth only $\$ 2.34$ per ton. In other words, the value of this pile of manure was reduced from $\$ 5.48$ to $\$ 2.03$ during five months' exposure. In another Cornell experiment, manure exposed for six months lost $5^{6}$ per cent of its dry matter and 43 per cent of its plant-food value. In this case the fresh manure was worth $\$ 2.27$ a ton, while the rotted manure was worth $\$ 3.0$ I a ton (at commercial prices for plant food), but the total loss in weight and plant food was such that for each ton originally worth $\$ 2.27$ there remained only $\$$ I.3O worth after six months' exposure.

The Ohio Agricultural Experiment Station placed five lots of manure, of tooo pounds each, in flat piles in the barnyard. Four of these lots of manure had been treated with materials, as indicated in Table II2, at the rate of 40 pounds per ton of manure. The 
manure was sampled for analysis when put out in January and again when taken up in April:

Table ir 2. Composition of Steer Manure before and after Exposure for Three Months (Pounds per Ton of Fresh Manure)

\begin{tabular}{|c|c|c|c|c|c|c|c|c|}
\hline \multirow{2}{*}{ Treatment } & \multirow{2}{*}{ TIME } & \multirow{2}{*}{$\begin{array}{c}\text { OR- } \\
\text { GANIC } \\
\text { MATTER }\end{array}$} & \multicolumn{2}{|c|}{ Nitrogen } & \multicolumn{2}{|c|}{ Phosphorus } & \multicolumn{2}{|c|}{ Potassium } \\
\hline & & & Total & $\begin{array}{l}\text { Water- } \\
\text { soluble }\end{array}$ & Total & $\begin{array}{l}\text { Water- } \\
\text { soluble }\end{array}$ & Total & $\begin{array}{l}\text { Water- } \\
\text { soluble }\end{array}$ \\
\hline Raw phosphate & $\begin{array}{l}\text { January } \\
\text { April } \\
\text { \% loss }\end{array}$ & $\begin{array}{r}349.00 \\
310.74 \\
10.96\end{array}$ & $\begin{array}{r}10.70 \\
7.46 \\
30.28 \\
\end{array}$ & $\begin{array}{r}4.28 \\
1.06 \\
75.23 \\
\end{array}$ & $\begin{array}{r}8.60 \\
7.57 \\
11.97 \\
\end{array}$ & $\begin{array}{r}1.52 \\
1.32 \\
13.16 \\
\end{array}$ & $\begin{array}{r}7 \cdot 3^{8} \\
3 \cdot 5^{2} \\
52 \cdot 30 \\
\end{array}$ & $\begin{array}{r}6.58 \\
3.47 \\
47.26\end{array}$ \\
\hline Acid phosphate & $\begin{array}{l}\text { January } \\
\text { April } \\
\% \text { loss }\end{array}$ & $\begin{array}{r}357.80 \\
269.89 \\
24.57\end{array}$ & $\begin{array}{r}9.86 \\
7.18 \\
27.18 \\
\end{array}$ & $\begin{array}{r}3.04 \\
.84 \\
72.36 \\
\end{array}$ & $\begin{array}{r}5.70 \\
4.79 \\
15.96 \\
\end{array}$ & $\begin{array}{r}2.28 \\
\mathrm{I} .5 \mathrm{I} \\
3.3 .77 \\
\end{array}$ & $\begin{array}{r}6.88 \\
2.99 \\
56.54 \\
\end{array}$ & $\begin{array}{r}6.85 \\
2.5 \mathrm{I} \\
63.5 \mathrm{I}\end{array}$ \\
\hline Kainit . & $\begin{array}{l}\text { January } \\
\text { April } \\
\% \text { loss } \\
\end{array}$ & $\begin{array}{r}369.00 \\
291.50 \\
21.00 \\
\end{array}$ & $\begin{array}{r}9.76 \\
6.68 \\
3 \text { I.56 } \\
\end{array}$ & $\begin{array}{r}3.14 \\
.31 \\
90.12 \\
\end{array}$ & $\begin{array}{r}2.88 \\
2.48 \\
13.89 \\
\end{array}$ & $\begin{array}{l}\text { I. } 36 \\
\text { I. } 31 \\
3.68 \\
\end{array}$ & $\begin{array}{r}10.70 \\
4.98 \\
5.3 .46 \\
\end{array}$ & $\begin{array}{r}10.66 \\
4.96 \\
5.3 .47 \\
\end{array}$ \\
\hline Gypsum & $\begin{array}{l}\text { January } \\
\text { April } \\
\% \text { loss } \\
\end{array}$ & $\begin{array}{r}375.40 \\
267.35 \\
28.78 \\
\end{array}$ & $\begin{array}{r}9.68 \\
7.94 \\
17.97 \\
\end{array}$ & $\begin{array}{r}2.12 \\
1.46 \\
31.13 \\
\end{array}$ & $\begin{array}{l}2.76 \\
2.66 \\
3.63 \\
\end{array}$ & $\begin{array}{r}.78 \\
.75 \\
3.85 \\
\end{array}$ & $\begin{array}{r}7.86 \\
2.56 \\
67.42 \\
\end{array}$ & $\begin{array}{r}7.86 \\
2.49 \\
68.3^{2} \\
\end{array}$ \\
\hline None & $\begin{array}{l}\text { January } \\
\text { April } \\
\% \text { loss } \\
\end{array}$ & $\begin{array}{r}416.00 \\
254.79 \\
38.75 \\
\end{array}$ & $\begin{array}{r}\text { I0.30 } \\
7.18 \\
30.29 \\
\end{array}$ & $\begin{array}{r}3.3^{6} \\
1.14 \\
66.07 \\
\end{array}$ & $\begin{array}{r}3.24 \\
2.47 \\
23.76 \\
\end{array}$ & $\begin{array}{r}1.66 \\
1.26 \\
24.10 \\
\end{array}$ & $\begin{array}{r}8.14 \\
3.35 \\
58.84 \\
\end{array}$ & $\begin{array}{r}8.14 \\
2.84 \\
65.11 \\
\end{array}$ \\
\hline Average per cent & loss & $24.8 \mathrm{I}$ & 27.46 & 66.98 & I 3.84 & 15.70 & $57.7 \mathrm{I}$ & 59.53 \\
\hline
\end{tabular}

The results show that practically all of the potassium is watersoluble, and that more than half of this and two thirds of the watersoluble nitrogen was lost during three months' exposure to the weather of winter and early spring at Wooster, Ohio. Gypsum markedly reduced the solubility of both nitrogen and phosphorus.

Manure should either be hauled to the field and spread as soon as possible after it is produced, or it should be allowed to accumulate in the stalls or covered sheds in compact and moist condition, sufficient bedding being used to keep the animals clean (and this is a more sanitary practice for a well-ventilated dairy barn than to stir up the manure daily to clean the stable), and then hauled and applied at convenient intervals. In no case should it be allowed to heat and ferment before being spread on the land, if its full value is to be secured. 
Manure may be applied on pastures at almost any time of year with marked benefit to the grass and with additional benefit after being plowed under for succeeding crops. It may be applied for corn either before or after the ground is plowed, although very coarse manure applied after plowing may interfere with cultivation. Used as a top dressing for winter wheat, even very coarse manure gives good results if uniformly distributed.

Coarse manure or heavy applications of fresh manure plowed under late in the spring are likely to give unsatisfactory results in a dry season, in part because the layer of manure tends to interfere with the capiliary connection of the soil and subsoil and retards upward movement of the soil moisture in dry weather. Thorough disking just before plowing will help to aroid this trouble, whether farm manure or green manure (as a heary growth of clover) is to be plowed under.

In the author's opinion, the crop rotation in live-stock farming should be so planned that there is always a place to haul and spread manure, and so that every cultivated field is covered with manure at least once during each rotation, the manure being spread lightly or heavily in accordance with the annual supply and the size of the field to be covered; and, if necessary, in order to maintain the humus and nitrogen content of the soil, the farm manure should be supplemented by plowing under clover or other legumes, keeping in mind that one ton of clover hay plowed under is equivalent to four tons of average fresh manure, and that many can grow clover who cannot produce sufficient manure. 


\section{CHAPTER XXXI}

\section{LOSSES OF PLANT FOOD FROM PLANTS}

To determine the amounts of the different elements required for the production of crops, analyses have commonly been made of the mature plants, but there is much evidence that the results thus secured may not always represent the full amounts positively required for the growth of the crop produced. The ultimate purpose of every plant (if we may so speak) is reproduction; and in the main it is the function of the leaves and stem to contribute toward the formation of seed. The fixation of carbon, oxygen, and hydrogen occurs only in the leaves or other green parts of the plants, and the carbohydrates thus formed by photosynthesis, as well as the proteids, are in considerable part transported to, and stored in, the seed. The leaf is well called the laboratory of the plant, but in the workshop or factory certain tools are necessary, including potassium, magnesium, calcium, and iron, besides the nitrogen, phosphorus, and sulfur which are formed into living tissue in connection with the carbon, oxygen, and hydrogen. But these four elements (potassium, magnesium, calcium, and iron), which we may perhaps call work tools rather than structural materials, are in large part discarded after some use, and they are found deposited to some extent in the old leaves which may become dead or inactive before the growth of the plant is complete and while growth is still very active in the newer leaves and other younger parts of the plant.

As the older leaves become inactive, more or less of the plant food which they contained and required for their own growth is translocated to the newer leaves, but very considerable amounts may be removed by leaching and thus returned to the soil by an external route. As the plant approaches maturity, appreciable amounts of plant food are thus removed by being washed or leached 
from the leaves by rain water. It is not only possible, but even probable, that under some conditions the same plant food may be used twice by the same plant; that is, it may serve an essential need in the growth of the first leaves, then be leached out and carried back into the soil, and finally be reabsorbed through the roots and serve the plant again in the newer leaves. While this double use is probably insignificant, the point of special importance is that the analysis of the mature plant may not find all of the plant food which has been absolutely essential for the growth of the plant, as will be seen from the tabular statements.

Many years ago the Rothamsted Experiment Station harvested a bean crop from different parts of a uniform field at six different stages of growth or development, from May 26 to September 8, and for each period the crop harvested was weighed and analyzed, with the results indicated:

Table riz. Composition of the Bean Crop at Different Perions of Growth (RothaMsted Investigations)

Pounds per Acre

\begin{tabular}{|c|c|c|c|c|c|c|c|c|c|c|}
\hline Date of HaRves & . & . & - & . & May 26 & JUNE I7 & JULY 8 & JULY 27 & AcG. 30 & SEPT. 8 \\
\hline Condition of Plan & & . & - & . & $\begin{array}{c}\text { Before } \\
\text { Blooming }\end{array}$ & In Bloom & $\begin{array}{l}\text { Bloom off } \\
\text { at Bottom } \\
\text { but still } \\
\text { on at Top }\end{array}$ & In Pod & $\begin{array}{l}\text { Green } \\
\text { Pod be- } \\
\text { ginning } \\
\text { to Turn }\end{array}$ & $\begin{array}{l}\text { Seed } \\
\text { fairly } \\
\text { Ripe }\end{array}$ \\
\hline Dry matter & - & - & . & - & 294.0 & 960.0 & 2481.0 & 4245.0 & 4192.0 & 4500.0 \\
\hline Nitrogen . & - & - & . & . & I3.I & $3 \mathrm{I} .2$ & 72.2 & $I I 4.2$ & I 19.9 & I 29.6 \\
\hline Phosphorus & . & . & . & . & 1.2 & 3.1 & 6.9 & 9.5 & 11.2 & I I. 7 \\
\hline Potassium . & . & . & . & . & $9 \cdot 3$ & 24.2 & 50.7 & 66.4 & 57.1 & 56.0 \\
\hline Magnesium & . & • & . & . & .6 & I.6 & 3.8 & $5 \cdot 5$ & 4.8 & 5.2 \\
\hline Calcium . & . & . & . & . & 4.1 & 10.9 & 27.6 & 45.9 & 35.6 & 3I.I \\
\hline Sulfur . & . & - & . & . & $\cdot 3$ & I.I & 2.I & $3 \cdot 3$ & $3 \cdot \mathrm{I}$ & $3 \cdot 4$ \\
\hline Sodium . & - & & . & . & I.I & 3.4 & 6.5 & 6.4 & 5.2 & 7.4 \\
\hline Chlorin . & 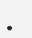 & • & - & . & I. 6 & 3.2 & 6.I & 7.6 & 6.I & 6.5 \\
\hline Total ash & . & . & . & . & 33.0 & 88.4 & r96.3 & $28 I .9$ & 230.2 & 223.1 \\
\hline
\end{tabular}

It will be noted that the dry matter, nitrogen, phosphorus, and sulfur all continue to increase until the full maturity of the plant, the slight apparent decrease for dry matter and sulfur in the crop 
of August 30 probably being due to variation in yield of the plots harvested. Concerning this investigation, Lawes and Gilbert made the following statements:

"It might be supposed that there was some error in these estimates of the amounts of the crop and of its constituents over a given area, and they admittedly involve some difficulty and uncertainty; as, for example, the possibility of loss by fallen leaves, etc. But the fact that the phosphoric acid, which would probably for the most part exist in a less soluble and less migratory condition, is shown by the figures to increase gradually in amount per acre from the first period to the last, tends to confirm the contrary results relating to the lime and potash; and, assuming them to be correct, the supposition is that a quantity of surplus lime and potash had been accumulated in, or excreted by, the roots."

There is no evidence to substantiate the "supposition" that potassium and calcium are excreted by the roots or that they tend to leave the tops and accumulate in the roots, but there is now complete proof of loss by leaching.

While these results obtained by Lawes and Gilbert many years ago show losses only of elements which are not constituent parts of the living tissue or structure of the plant, it should be kept in mind that phosphorus may have been the limiting element, and that the bean plant probably took up through its symbiotic relationship with the nitrogen-fixing bacteria no more nitrogen than was needed for the normal growth of the plant; also that where an excess of available nitrogen or phosphorus is furnished by the soil, any growing plant may take up and tolerate more than it can use in tissue building (because of some other limiting factor) and that such excess of any element beyond the needs of the plant may perhaps be removed in the process of leaching by rains.

An investigation by Wilfarth, Römer, and Wimmer was reported in 1905 (Landwirtschaftlichen Versuchs-Stationen), in which barley, wheat, and potatoes were harvested at different periods of growth and both the tops and roots were analyzed. The results for barley are shown in Table I 4 .

From these experiments it will be seen that the dry matter and phosphorus reached their maxima in the third harvest and declined but slightly thereafter; whereas the largest amounts of nitrogen and potassium were found at the time of the second harvest (June I 7) 
Table i 4 . Composition of Barley at Different Periods of Growth: Kilograms per Hectar ${ }^{1}$ (roughly, Pounds per Acre)

(Wilfarth, Römer, and Wimmer)

\begin{tabular}{|c|c|c|c|c|c|c|c|c|c|}
\hline \multicolumn{2}{|c|}{ HARVEST } & \multirow{2}{*}{ Straw } & \multirow{2}{*}{ GraIN } & \multirow{2}{*}{$\begin{array}{l}\text { Total. } \\
\text { Crop }\end{array}$} & \multirow{2}{*}{ Roots } & \multirow{2}{*}{$\begin{array}{c}\text { RoOTS } \\
\text { AND } \\
\text { STUBBLE }\end{array}$} & \multirow{2}{*}{$\begin{array}{l}\text { Total } \\
\text { PlaAt }\end{array}$} & \multicolumn{2}{|c|}{$\begin{array}{l}\text { Relative } \\
\text { AMOUNTS }\end{array}$} \\
\hline No. & Date & & & & & & & $\begin{array}{l}\text { Total } \\
\text { Crop }\end{array}$ & $\begin{array}{l}\text { Total } \\
\text { Plant }\end{array}$ \\
\hline
\end{tabular}

Dry Matter

\begin{tabular}{l|r|r|r|r|r|r|r|r|r}
\hline I & May 29 & 2025 & - & 2025 & 450 & 799 & 2824 & 23 & 29 \\
2 & June I7 & 5 I67 & 337 & 55 I0 & 322 & I 367 & 6871 & 63 & 72 \\
3 & July 3 & 6986 & I 773 & 8760 & 250 & 759 & 95 I8 & 99 & I00 \\
4 & July 27 & 5695 & 3108 & 8810 & I I I & 476 & 9279 & I00 & 97 \\
\hline
\end{tabular}

Nitrogen

\begin{tabular}{l|r|r|r|r|r|r|r|r|r}
\hline I & May 29 & 4 S.I & - & 48.1 & 5.9 & 9.2 & 57.3 & $7 \mathrm{I}$ & 66 \\
2 & June I 7 & $60 . \mathrm{I}$ & 7.4 & 67.5 & 3.6 & I9.0 & 86.5 & I00 & I00 \\
3 & July 3 & 40.0 & 26.6 & 66.6 & 2.2 & 4.6 & 71.2 & 99 & 82 \\
4 & July 27 & I 7.I & $44 . I$ & 6 I.2 & I.I & 3.2 & 64.4 & $9 \mathrm{I}$ & 75 \\
\hline
\end{tabular}

Phosphorus

\begin{tabular}{r|r|r|r|r|r|r|r|r|r}
\hline I & May 29 & 7.5 & - & 7.5 & .8 & I.8 & 9.3 & 42 & 49 \\
2 & June I 7 & I 2.7 & I.5 & I 4.2 & .7 & 3.7 & I 7.9 & 8 I & 94 \\
3 & July 3 & I0.8 & 7.0 & I 7.8 & .4 & I.4 & I9.2 & I00 & 100 \\
4 & July 27 & 4.2 & I 3.0 & I 7.2 & .1 & .6 & I 7.8 & 97 & 93 \\
\hline
\end{tabular}

Potassium

\begin{tabular}{l|l|r|r|r|r|r|r|r|r}
\hline I & May 29 & 58.9 & - & $59 . I$ & 2.3 & 9.6 & 20.7 & 6 I & 58 \\
2 & June I 7 & 92.0 & 4.9 & 96.9 & 2.3 & 2 I.8 & I I8.7 & I00 & I00 \\
3 & July 3 & 79.3 & I4.I & 93.4 & I.3 & 6.6 & I00.0 & 96 & 84 \\
4 & July 27 & 54.9 & I9.I & 74.0 & .4 & $3 . I$ & $77 . I$ & 76 & 65 \\
\hline
\end{tabular}

${ }^{1}$ The hectar contains I0,000 square meters (the meter being 39.37 inches), or $2.47 \mathrm{I}$ acres, and the kilogram contains 2.2046 pounds; so that I pound per acre is equivalent to I.I 2 kilograms per hectar. Thus, for practical accuracy, deduct one tenth to convert kilograms per hectar to pounds per acre.

and afterward decreased to 75 and 65 per cent, respectively, of the maxima. It is noteworthy that the barley crop, which 
finally yielded four tons of dry matter per acre, contained 87 pounds of potassium on June $\mathrm{I} 7$, but only 66.6 pounds at maturity. The total plant, including the roots and stubble, contained ro6.8 pounds per acre of potassium on June I 7 , but only 69.4 pounds at maturity (July 27).

Wilfarth, Römer and Wimmer's investigations with spring wheat showed the following results:

\section{Relative Amounts of Plant Food in Wheat Crops}

\begin{tabular}{|c|c|c|c|c|c|c|c|c|c|}
\hline \multicolumn{2}{|c|}{ HaRvest } & \multicolumn{2}{|c|}{ Dry Matter } & \multicolumn{2}{|c|}{ Nitrogen } & \multicolumn{2}{|c|}{ Phosphorus } & \multicolumn{2}{|c|}{ Potassium } \\
\hline No. & Date & $\begin{array}{l}\text { Total } \\
\text { Crop }\end{array}$ & $\begin{array}{l}\text { Total } \\
\text { Plant }\end{array}$ & $\begin{array}{l}\text { Total } \\
\text { Crop }\end{array}$ & $\begin{array}{l}\text { Total } \\
\text { Plant }\end{array}$ & $\begin{array}{l}\text { Total } \\
\text { Crop }\end{array}$ & $\begin{array}{l}\text { Total } \\
\text { Plant }\end{array}$ & $\begin{array}{l}\text { Total } \\
\text { Crop }\end{array}$ & $\begin{array}{l}\text { Total } \\
\text { Plant }\end{array}$ \\
\hline I & June 22 & 25 & 28 & 70 & 70 & 43 & 46 & 70 & 72 \\
\hline 2 & July I4 & 69 & 74 & 75 & 76 & 72 & 75 & 100 & $1 \infty$ \\
\hline 3 & Aug. 5 & 95 & 97 & 100 & IOO & 98 & 100 & 99 & 99 \\
\hline 4 & Aug 28 & 100 & 100 & 82 & $8 I$ & 100 & 99 & 59 & 59 \\
\hline
\end{tabular}

In the case of potatoes, the tops at maturity contained only 24 per cent of the maximum dry matter, the corresponding percentages being 43 for nitrogen, 39 for phosphorus, and 13 for potassium; but in the tubers the maxima for all constituents were found at maturity.

After discussing different suggestions, Wilfarth, Römer, and Wimmer state that the only possible assumption for the loss of potassium from the barley plants is that it returns to the soil through the roots ("durch die Wurzeln in den Boden zurückzuwandern").

In a letter dated March I3, I908, the author expressed the following opinion to his colleague, Professor J. H. Pettit, then at the University of Göttingen:

"I do not believe the return is by the internal route through the stem and root, but by leaching, even before the plants are sufficiently mature to harvest." I

${ }^{1}$ This opinion was based largely upon experience in the preparation of pharmaceutical infusions and upon field observations, as where corn on peaty swamp land shows markedly the effect of potassium leached from an oat shock which stood through one or two heavy rains the previous season. In the letter to Professor Pettit mentioned above, a complete outline was given for a laboratory and potculture experiment to secure more exact data upon the problem, but subsequentiy reported investigations render this unnecessary. 
In October, I908, Max Wagner reported ${ }^{1}$ a similar very extended investigation with barley, oats, mustard, and buckwheat, with various systems of fertilizing. With the barley and oats more or less loss of plant food occurred before the crops reached maturity, but in most cases phosphorus proved an exception to the rule wherever the crops were grown without the addition of a phosphorus fertilizer.

After suggesting and rejecting the possibility of explaining the loss of plant food $(a)$ by loss of leaves or roots in harvesting the plants, $(b)$ by the decay of root parts, and $(c)$ by volatilization (except for nitrogen), Wagner concludes that the only possible explanation is " that during the ripening processes of the plant, a part of the nutrient materials passes into the roots and from the roots out into the soil." ("Für Kali und Phosphorsäure, die ja durch Veratmung nicht verloren gehen können bleibt nur die Möglichkeit übrig, dass ein Teil dieser Nährstoffe während des Reifeprozesses der Pflanzen in die Wurzel zurückgewandert und aus den Wurzeln zurück in den Kulturboden getreten ist.")

In studying the composition of solutions used for spraying, Le Clerc and Breazeale of the United States Bureau of Plant Industry found material in the liquid other than that put in the prepared solution, and upon further investigation they determined with certainty that relatively large quantities of essential plant-food elements may be removed from growing plants by spraying with pure water, by a process similar to the action of falling rain.

On November 18, I908, a summary of these experiments was presented to the Washington meeting of the American Society of Agronomy, by Doctor Le Clerc. By collecting and analyzing the water used for spraying the plants and analyzing the fully mature plants, it was found that of the total amounts contained in the plants, the following percentages were leached out by pure water (according to the author's unverified notes, taken during Doctor Le Clerc's lecture) :

In these experiments nitrogen appears to have been the limiting element in plant growth, since practically all that was taken up of that element was evidently required in the plant structure,

${ }^{2}$ Die Landwirtschafllichen Versuchs-Stationen (1908) 69, 16I-233. 
Table i 15. Plant Food removed from Plants by leaching with Water Percentage of Total

\begin{tabular}{ll} 
Plants Leached & \\
\hline
\end{tabular}

and could not be removed by leaching, except in the case of the dead-ripe wheat; while phosphorus as well as the other elements was apparently taken up in excess of the absolute needs of the plants and in part tolerated until removed by leaching. This is the most probable explanation for the difference in results from these experiments and those reported by Wilfarth, Römer, and Wimmer; and the author has taken the liberty of suggesting to Le Clerc and Breazeale that by extending these investigations in connection with fertilizer experiments, results of great scientific value and of far-reaching practical importance will probably be secured in relation to the absolute requirements of plants for the different elements essential to plant growth. It has long been recognized that the analysis of the plant or of the plant ash was not a sufficient guide for use in planning systems of fertilization; but, for certain of the elements, the analysis of the thoroughly leached plant at the proper stage of growth may give more satisfactory information; and, because of its very general character, it seems especially appropriate that it should be continued by the federal government, while-local problems, such as county soil surveys, are perhaps better managed by the state institutions.

The fact that phosphorus is most frequently the limiting element in plant growth or crop yield on most normal soils, especially for legume crops, suggests that the averages commonly accepted for the composition of crops probably represent the minimum amounts of phosphorus, as a rule. 


\section{CHAPTER XXXII}

\section{LOSSES OF PLANT FOOD FROM SOILS}

There are four ways in which plant food may be lost or removed from the soil: (I) by removal in crops as already explained, (2) by leaching after solution in the rain water or soil water, (3) by mechanical erosion, either by surface washing or by wind action, and (4) by volatilization, a factor of minor importance, represented chiefly by the slight loss of nitrogen in ammonia or by denitrification, a process which may occur to a limited extent under somewhat abnormal conditions.

Loss of plant food from soils by the process of leaching is a matter of very great consequence, chiefly because large amounts of nitrogen may thus be lost every year in humid sections. Even under the best systems of farming more or less nitrogen is likely to pass off in drainage waters. The annual loss of lime by leaching is large (see Tables 27 and 28), and when long periods of time are considered, the amounts of magnesium, potassium, and other elements removed from the soil by leaching (see Table 74) become very significant.

The only practical method of preventing or reducing the loss by leaching is by the use of growing plants, the roots of which may absorb the plant food about as rapidly as it is made soluble. If desired, it may be then returned to the soil in the form of organic matter, afterward to become available when required to meet the needs of regular crops. The use of rye or rape as a grcen manure, by seeding in the fall and plowing under the next spring on land that would otherwise lie bare during the fall, winter, and early spring, is often profitable, in part because of the conservation of plant food that would otherwise be lost by leaching. This fact and principle is well illustrated by the following data from that great source of positive agricultural information, the Rothamsted Experiment Station. 
Table i 6 6. Nitrogen in Drainage Waters: Rothamsted Experiments Average of I2 Years (or More)

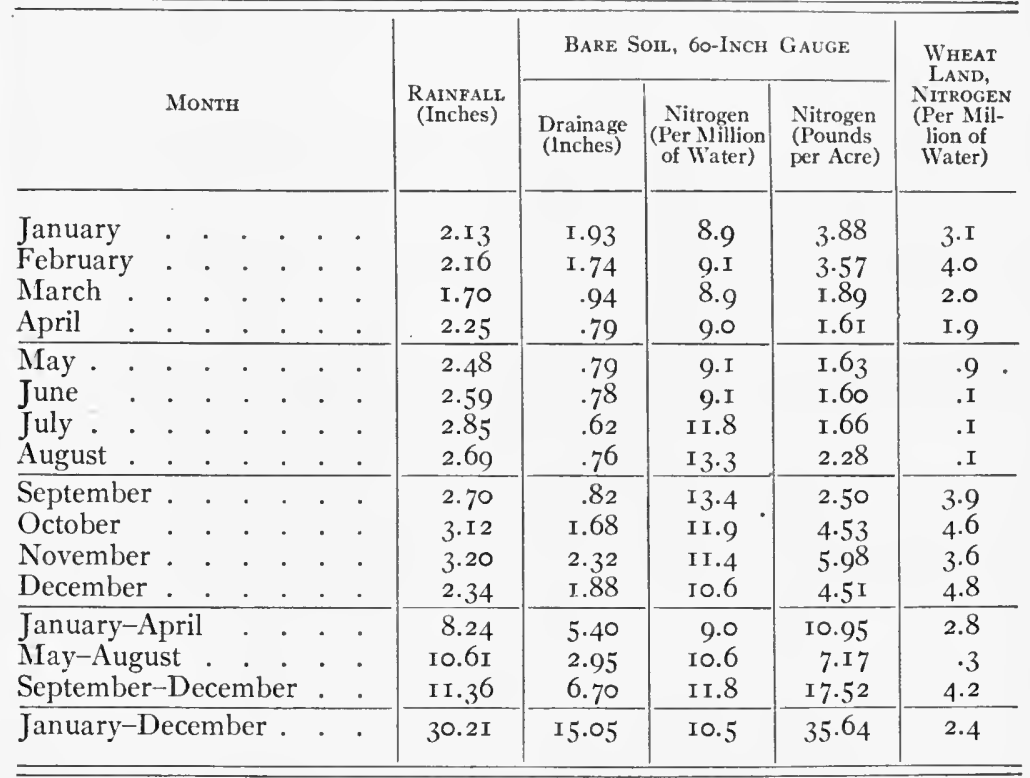

While the drainage water from the bare uncropped soil of the drain gauge contained I I. 4 parts of nitrogen per million during the summer months (June to August), the drainage water from the land on which wheat was growing (Broadbalk plots 3 and 4) contained only .I pound of nitrogen per million pounds of water, as an average of the three months. After the wheat harvest, the loss of nitrogen in the field drains quickly rises to about 4 pounds per million. In loss per acre the differences are much greater, because during the growing season the quantity of drainage from the field is probably even less than that from the drainage gauge, and the data from the gauge show two to three times as much drainage during the other months.

In Table I 7 are recorded the amounts of water-soluble nitrogen found in the soil and subsoil of Hoos field, where the shallow-rooting white clover (Trifolium repens) had been grown for seven years and where the vetch and the deep-rooting alfalfa had been grown for 
six years, also of Agdell field after the wheat crop had been harvested, in the legume system and the fallow system, for which the yields are recorded in Table 57.

Table I17. Soluble Nitrogen in Cropped Soils receiving no Nitrogen Fertilizer since 1849 (Pounds per Acre)

\begin{tabular}{|c|c|c|c|c|c|c|c|c|}
\hline \multirow{3}{*}{\multicolumn{2}{|c|}{ Depth }} & & & \multicolumn{3}{|c|}{ Hoos FiELD } & \multirow{2}{*}{\multicolumn{2}{|c|}{$\begin{array}{l}\text { Agdeli. Field } \\
\text { Wheat Land }\end{array}$}} \\
\hline & & & & \multirow{2}{*}{$\begin{array}{l}\text { White } \\
\text { Clover } \\
\text { Land, } \\
\text { July, } \\
\text { I } 885\end{array}$} & \multirow{2}{*}{$\begin{array}{c}\text { Alfalfa } \\
\text { Land, } \\
\text { July, } \\
\text { I } 885\end{array}$} & \multirow{2}{*}{$\begin{array}{l}\text { Vetch } \\
\text { Land, } \\
\text { July, } \\
\text { I } 883\end{array}$} & & \\
\hline & & & & & & & $\begin{array}{c}\text { After } \\
\text { Clover, } \\
\text { Fall, 1883 }\end{array}$ & $\begin{array}{c}\text { After } \\
\text { Fallow, } \\
\text { Fall, } 188_{3}\end{array}$ \\
\hline First 9 inches . & - & . & - & I I. 5 & 8.9 & IO. 2 & 6.1 & $3 \cdot 4$ \\
\hline Second 9 inches & . & . & .. & I.4 & I.I & 2.7 & $4 \cdot 4$ & 2.1 \\
\hline Third 9 inches & . & . & . . & .9 & .8 & I.I & I. 6 & .8 \\
\hline Fourth 9 inches & $\cdot$ & . & . $\cdot$ & 1.9 & .8 & 1.5 & I. 3 & 1.0 \\
\hline Fifth 9 inches. & . & . & . & $7 \cdot I$ & I.O & 2.5 & I. 5 & .8 \\
\hline Sixth 9 inches. & . & . . & .. & II.3 & .9 & $4 \cdot 4$ & .8 & .6 \\
\hline Seventh 9 inches & - & - & . . & I3.I & .6 & $4 \cdot 5$ & 2.2 & .8 \\
\hline Eighth 9 inches & . & . $\cdot$ & .. & I 2.6 & .8 & $4 \cdot 9$ & I. 7 & .9 \\
\hline Ninth 9 inches & . & . & - & I I.2 & .7 & 4.8 & 2.4 & .7 \\
\hline Tenth 9 inches & . & . & . & 10.7 & .6 & 5.1 & $2 . \mathrm{I}$ & 2.0 \\
\hline Eleventh 9 inches & & . & . & II.I & .4 & 6.4 & $2 . \mathrm{I}$ & 1.5 \\
\hline Twelfth 9 inches. & . & . & . & 10.0 & .4 & 6.5 & 2.8 & 3.8 \\
\hline o-9 inches . & & . & . & II.5 & 8.9 & 10.2 & 6.1 & 3.4 \\
\hline $9^{-36}$ inches & - & - & - & 4.2 & 2.7 & $5 \cdot 3$ & $7 \cdot 3$ & 3.9 \\
\hline $3^{-9}$ feet & . & . . & .. & $87 \cdot I$ & $5 \cdot 4$ & 39.1 & I 5.6 & I I.I \\
\hline
\end{tabular}

The crops of white clover were too small to cut in 1880,1883 , and I884, and in other years only a single cutting was harvested. Thus most of the rather small amount of produce was left to decay upon the white clover plot. Evidently 87.I pounds of nitrate nitrogen has escaped beyond the reach of the white clover roots, while almost no soluble nitrogen ( 5.4 pounds) was found in the same stratum ( 3 to 9 feet) under alfalfa. The root system of vetch is perhaps even less extensive than that of white clover (see Table $3^{6)}$, but the annual decay of the roots possibly gives it the intermediate position in loss of nitrogen as indicated, although a different season may perhaps have given quite different results. The data 
from Agdell field indicate that only small amounts of nitrogen escape from the wheat plant under the conditions, these results being in harmony with those reported in Table i 6 .

On the University of Illinois experiment field at Urbana are two adjoining plots, one of which (No. 3) grew corn for i6 years, while the other (No. 105) was kept in pasture. In I90I plot 3 contained 4000 pounds of nitrogen and plot I05 contained 49I4 pounds in 2 million of surface soil, a loss of about one fifth of the total being thus indicated.

Professor Shutt reports the nitrogen content of virgin soil and adjoining cultivated soil from the Northwest Territory of Canada. He says:

"Regarding the cultivated soil, we possess a complete and authentic record of the cropping and fallowing since the prairie was first broken, 22 years ago. It has borne 6 crops of wheat, 4 of barley, and 3 of oats, with fallows ( 9 in all) between each.

"Both samples were of a composite character and every precaution taken to have them thoroughly representative. It may, further, be added that there is every reason to suppose that the soil over the whole area examined was originally of an extremely uniform nature; in other words, that at the outset the nitrogen content was practically the same for the soils now designated as virgin and cultivated, respectively:"

\section{Nitrogen, Pounds PER ACre}

Virgin soil, to depth of 8 inches . . . . . . . . . . 6936

Cultivated soil, to depth of 8 inches . . . . . . . . . 44736

Difference or loss due to cropping and cultural operation. . $\frac{4736}{2200}$

"The results show that the cultivated soil is to-day still very rich, yet compared with the untouched prairie it is seen to have lost one third, practically, of its nitrogen. This is highly significant. Humus and nitrogen must be returned, either as manure or by the occasional growth of certain enriching crops, or fertility will inevitably decline." (Dominion Experiment Farms, Report for 1905, page I28.)

Shutt reports 3780 and 3240 pounds of nitrogen in the virgin and cultivated soils, respectively, of Grindstone Island, Magdalen Islands, Quebec; also 3160 and 2260 pounds of nitrogen from virgin and cultivated soils from Kent County, New Brunswick. The corresponding figures for acid-soluble phosphorus are 2160 and 1970 for the Quebec soils, and 2180 and 1070 for the New Bruns- 
wick soils. The New Brunswick soils are said to be representative of the district. In commenting upon the analytical data, Professor Shutt says:

"Since we must suppose, from the information furnished, that the cultivated soil was originally identical, or practically so, with the virgin soil, it is evident that great exhaustion of fertility has taken place, due, no doubt, to successive cropping without any adequate return of plant food." (Report for 1899, page I33.)

It is certain that on sloping lands a very considerable part of the total loss of humus, nitrogen, and phosphorus is due to soil erosion, although this is the minor factor on nearly level lands. It should be kept in mind that in respect to loss of humus, and of the plant food contained in humus, sheet washing on uniform slopes may be even more effective than gullying, and that it is extremely important and necessary to prevent or at least to reduce to the minimum both forms of erosion, the sheet washing by means of cover crops, deep contour plowing, contour ridging, or terracing, if necessary, and the gullying by frequent dams and by keeping the draws in permanent meadow.

President Van Hise makes the following statements regarding the loss of phosphorus from Wisconsin soils, as determined by "quantitative studies":

"Whitson finds as the result of an average of nine typical tests that 'the surface 8 inches of virgin soil contains 1256 pounds of phosphorus per acre, while that of the cropped fields contains but 792 pounds, an average loss per acre on these cropped fields of 464 pounds, or 36 per cent of its original content. The average of cropping for these fields has been 54.7 years.' In other words, during the past half century in Wisconsin one third of the original phosphorus of the soil has been lost in the cropped fields. What has been proved for Ohio, Illinois, and Wisconsin and other states where tests have been made is unquestionably true for the other states in the country which have been settled for some time.

"In what conditions will the soil of the United States be as to phosphorus content fifty years hence if this process of depletion be allowed to continue unchecked?" (See page 221 of "Conservation of Natural Resources," published by the American Academy of Political and Social Science, Philadelphia, 1909.)

It may be noted that a loss of 464 pounds of phosphorus in 55 years is only $8 \frac{1}{2}$ pounds per annum; and, if we deduct $I_{2} \frac{1}{2}$ pounds for loss in drainage (see Table 74), the loss by cropping does not 
exceed 7 pounds per acre, an amount sufficient only for a 30 bushel crop of corn, or $\mathbf{I}_{\mathbf{2}}^{\frac{1}{2}}$ tons of clover hay. It may be kept in mind that, so long as the surface soil contains more phosphorus than the subsurface, erosion helps to deplete the soil of phosphorus; but when the phosphorus content of the surface becomes reduced by cropping to a point below that of the subsurface, then erosion tends to increase the phosphorus in the surface soil.

In regard to erosion, President Van Hise says:

"It is plain that we must not permit soil erosion to take place more rapidly than the soil is manufactured by the process of nature. To do this will be ultimately to destroy our soils. If nature manufactures the soil at the rate of one inch in a century, then the erosion must not exceed one inch in one century."

Of course, this statement refers especially to residual upland soils and to the making of soils from the slow disintegration of the underlying rock. Most of the corn-belt subsoils include from 20 to 200 feet of loess and glacial drift above the bed rock.

The loss of plant food by cropping and leaching is the most serious matter on most of the valuable agricultural soils.

Lyon and Bizzell (Jour. Ind. and Eng. Chem., Oct., I9II) report a loss of II pounds of potassium, 76 of magnesium, and 407 of calcium, from uncropped soil; and 8 pounds of potassium, $3^{\mathrm{I}}$ of magnesium, and 166 of calcium, from cropped soil (average for corn and oats), in drainage water per acre from a four-foot stratum of clay loam soil, from May 23, I9ro, to May I, I9I I ; and Bartow (Illinois State Water Survey Bulletin) reports 90 analyses of Illinois well waters drawn chiefly from glacial sands, gravels, and till, showing, as an average, I I pounds of potassium, I 30 of magnesium, and 330 of calcium, in 3 million pounds of water (see Table 74). These data confirm the results of the Rothamsted investigations (pages I 74, I75, 4I3), showing an excessive availability of magnesium and especially of calcium; and they clearly indicate that in many cases those elements may be of much greater importance for soil improvement than potassium, even from the standpoint of plant food maintenance, and in addition to their value for correcting soil acidity. (See also pages 105 and 633.) 


\section{CHAPTER XXXIII}

\section{FIXATION OF PLANT FOOD BY SOILS}

WHEN soluble plant food is applied to the soil, it is as a very general rule changed into insoluble forms by reaction with the soil. Nitrogen in the form of nitrate is an exception to this rule, the only method of changing nitrate nitrogen to the insoluble form being by the growth of some plant which converts it into organic nitrogen, as already explained. ${ }^{\mathbf{1}}$

The fixation of bases includes not only the metals, but also the ammonium group, the soluble base taking the place of some other element in an insoluble polysilicate, as illustrated in the following general equation:

$$
\begin{aligned}
\mathrm{Al}_{\mathrm{x}} \mathrm{Fe}_{\mathrm{x}} \mathrm{Mg}_{\mathrm{x}} \mathrm{Na}_{\mathrm{x}} \mathrm{Ca}\left(\mathrm{SiO}_{3}\right)_{\mathrm{x}}\left(\mathrm{H}_{2} \mathrm{O}\right)_{\mathrm{x}}+2 \mathrm{KCl} & \\
& =\mathrm{Al}_{\mathrm{x}} \mathrm{Fe}_{\mathrm{x}} \mathrm{Mg}_{\mathrm{x}} \mathrm{Na}_{\mathrm{x}} \mathrm{K}_{2}\left(\mathrm{SiO}_{3}\right)_{\mathrm{x}}\left(\mathrm{H}_{2} \mathrm{O}\right)_{\mathrm{x}}+\mathrm{CaCl}_{2} .
\end{aligned}
$$

This equation typifies the reaction of soluble potassium chlorid with a zeolitic compound, resulting in the fixation of potassium and the liberation of calcium, which passes off in the drainage waters in combination with the acid radicle which formerly carried the potassium.

Other mineral bases and even ammonium may be fixed in a similar manner, but the ammonium fixation is very temporary, because under usual conditions nitrification proceeds rapidly and the ammonia nitrogen passes into soluble nitrate nitrogen, a fact which is well illustrated by the following data from Rothamsted.

The ammonium salts consisted of equal parts of the sulfate and chlorid. Warington makes the following comments:

"At the first running of the drain pipe (after October 25) sufficient time had not elapsed for the complete decomposition of the ammonium salt and the fixation of the ammonia. Some undecomposed salt of ammonium is thus

${ }^{1}$ Even low forms of plant life, as fungi and bacteria, may aid in this process. 
Table i i8. Nitrogen and Chlorin in Drainage Water before and after the Application of Ammonium Salts on October 25, i880:

Plot 15, Broadbalk Field

Pounds per Million of Water

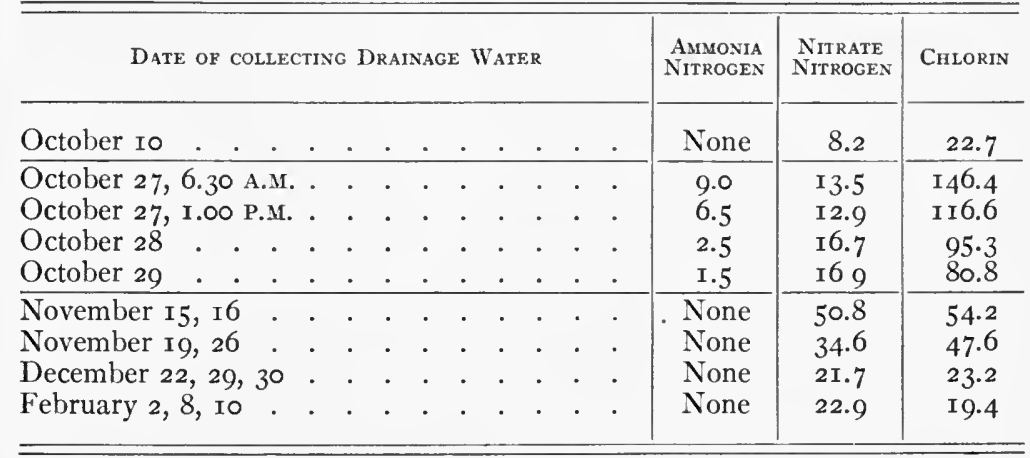

found in the early drainage waters, - a circumstance which is very unusual. That decomposition of the salt had already taken place to a very large extent, is shown, however, by the enormous amount of chlorin in the first runnings, an amount far exceeding that of the ammonia.

"Even at this early stage of the reaction, only forty-eight hours after the application of the ammonia, nitrification has made a distinct commencement."

While the ammonia fixation was probably completed soon after October 29, the process of nitrification was evidently not entirely completed on February 2-ro.

Schlösing reports experiments with II4 parts of ammonium chlorid per million of soil in which 88. I per cent of the ammonia was nitrified in 18 days, and in another experiment, with $5^{26}$ parts of ammonium carbonate per million of soil, 97.7 per cent of the ammonium was nitrified in 28 days.

The reactions involved in these fixation processes are usually incomplete, mass action being one of the controlling factors. Thus with soil silicates containing much calcium, magnesium, and sodium, and but little potassium, applied potassium would doubtless be largely fixed, with liberation of calcium or other bases; whereas, heavy applications of calcium sulfate will liberate more or less potassium from soils rich in insoluble potassium compounds. 
The fixation of soluble phosphates involves a very different reaction, which may be illustrated as follows:

$$
\begin{aligned}
\mathrm{CaH}_{4}\left(\mathrm{PO}_{4}\right)_{2}+\mathrm{CaCO}_{3} & =\mathrm{Ca}_{2} \mathrm{H}_{2}\left(\mathrm{PO}_{4}\right)_{2}+\mathrm{CO}_{2}+\mathrm{H}_{2} \mathrm{O} . \\
\mathrm{Ca}_{2} \mathrm{H}_{2}\left(\mathrm{PO}_{4}\right)_{2}+\mathrm{CaCO}_{3} & =\mathrm{Ca}_{3}\left(\mathrm{PO}_{4}\right)_{2}+\mathrm{CO}_{2}+\mathrm{H}_{2} \mathrm{O} .
\end{aligned}
$$

Compounds of iron or aluminum may take the place of the calcium carbonate in the fixation of phosphates.

Thus, we may apply to ordinary soil a solution containing soluble salts of potassium, ammonium, or phosphorus, but the liquid which passes through a soil stratum three inches or more in thickness will be found to contain very little of the salts applied. The chief value attached to soluble fertilizers is due to their thorough distribution in the soil before passing into insoluble forms. If every soil grain touched by the soluble fertilizer becomes coated with the insoluble product, it presents to the plant roots a very much greater surface than if the fertilizer is applied in small solid particles, as in ground rock phosphate. 


\section{CHAPTER XXXIV}

\section{ANALYZING AND TESTING SOILS}

WHILE the chemical analysis of soils requires knowledge, training, and skill, and while farmers and other students of agriculture cannot all be analytical chemists, they should all be able to understand the meaning of a chemical analysis if it is reported without unnecessary complications. The author's experience in practical agriculture and close contact with progressive farmers desiring to make practical application of scientific information revealed to him the fact that some of the common methods of reporting analyses of soils and fertilizers are extremely confusing, if not positively misleading. Thus, it is common to report the analysis of potassium chlorid $(\mathrm{KCl})$ in terms of potash $\left(\mathrm{K}_{2} \mathrm{O}\right)$, notwithstanding the fact that the material analyzed contains no oxygen. Sulfur in soils is usually reported as sulfur trioxid $\left(\mathrm{SO}_{3}\right)$, although the sulfur may exist in the form of sulfid or as organic sulfur. Still more confusing, very misleading, in fact, is to report in terms of calcium oxid $(\mathrm{CaO})$, or quicklime, all calcium found in the soil, even though it may exist only in acid silicates, and, instead of the soil containing any lime in any form, it may require an application of some form of lime to correct the existing acidity.

The only kind of lime which exists in the soil in the agricultural sense, that is, lime which has power to prevent or correct soil acidity, is limestone, either ordinary or magnesian; and this is sufficient reason why limestone present should be reported as limestone; and for the same reason soil acidity is reported in terms of limestone required. Instead of reporting in terms of percentage and leaving the computations to be made by every individual who desires to use the data, the analytical results may be reported in the more simple and usable form of pounds per acre or pounds per ton, which are the common farm units of weight and measure. Manures and fertilizers are applied in tons or pounds per acre, and they are 
mixed with the plowed soil. Hence, we should know what the plowed soil of an acre contains of the different important constituents and the relations between the amounts contained in the soil and the amounts applied in fertilizers and removed in crops.

This book is not a text on chemistry, but space is taken in the Appendix for a description of the details of soil analysis, such as are given in the "Soil Fertility Laboratory Manual," which is designed to accompany this text for use in schools and "colleges. Every student of soil fertility, even though not a chemist, should understand how to make a few simple and very important tests.

Soil Acidity. To test for soil acidity, make a ball of the fresh, moist soil, break it in two, place a piece of blue litmus ${ }^{1}$ paper between, and press the soil firmly together again. After a few minutes examine the paper. If it has turned pink or red, soil acidity is indicated. It is especially important to test the subsoil for acidity for reasons already mentioned.

To examine the soil thoroughly, samples should be tested from the surface and subsoil at several different places in the field; and the tests should be made by the landowner in the field rather than by the chemist in the laboratory. The amount of acidity is indicated to some extent by the intensity of color and the rapidity with which it develops. The litmus-paper test ${ }^{2}$ for soil acidity is a long-established, trustworthy, and very useful test. It can also be used as a test for acidity in other materials, as in acid phosphate or in mixed fertilizers which contain acid phosphate. Place two or three spoonfuls of the fertilizer in a glass, add half a glass of water, stir well, let settle, and then insert a strip of blue litmus paper, which will be quickly reddened by the acid solution.

A positive test for carbonates in the soil precludes the presence of soil acidity, because the carbonates are easily decomposed by

${ }^{1}$ Litmus is an organic coloring matter which turns red in acid solutions and blue in alkaline. Litmus paper is made by moistening paper with a solution of litmus, the paper then being dried. The prepared litmus paper ready for use can be obtained at most drug stores put up in packages of 20 or $3 \circ$ pieces for 5 cents a package.

${ }^{2}$ Cameron has reported experiments intended to show that the litmus-paper test has little or no value, because he was able to change blue litmus red by contact with absorbent cotton, the change being attributed by him to absorption; but it develops that bleached cotton may retain sufficient acid used in the bleaching process to produce the change of color in litmus. 
acids with the liberation of carbonic acid, which breaks down into water and gas, carbon dioxid. Consequently the carbonates, such as calcium carbonate and magnesium carbonate, serve as mild alkalis, in the presence of which soil acidity cannot exist.

Carbonates. To test for carbonates in the soil, make a shallow cup of a ball of soil and pour in a few drops of concentrated hydrochloric acid. If carbonates are present, a reaction occurs with the liberation of carbon dioxid which appears as gas bubbles, producing foaming, or effervescence:

$$
\mathrm{CaCO}_{3}+{ }_{2} \mathrm{HCl}=\mathrm{CaCl}_{2}+\mathrm{H}_{2} \mathrm{O}+\mathrm{CO}_{2} \text {. }
$$

With much carbonate present the action is rapid and abundant, but with mere traces of carbonate in the soil only few bubbles will appear.

The same test may be applied to limestone, marl, etc., to ascertain if carbonates are contained in the material. Most limestones and marls will show some effervescence with cold concentrated acid, but some nearly pure dolomitic limestones require the application of heat to properly develop the reaction.

Five cents' worth of concentrated hydrochloric acid in a small glass-stoppered bottle is sufficient for many tests for carbonates. Of course, care must be taken not to get the acid on the clothing or skin. In case the acid gets on the fingers, it should be washed off, or rubbed off with soil, as soon as possible. It is not especially dangerous to handle, but will soon "eat" or "burn" through the skin if not removed or neutralized, which could be easily done by rubbing with soil containing carbonates.

As in the case of acidity, it is especially important to test the subsoil for carbonates; for an abundance of carbonates only i to 3 feet beneath the surface serves as a store and protection, especially in critical periods in the growth of such plants as clover and alfalfa, which may die during a few weeks of summer drouth if the rising capillary moisture carries acidity, but would be kept alive if this moisture brought traces of calcium bicarbonate.

If the landowner has no other source of information concerning the composition of his soil, it is altogether advisable to collect a composite sample of the plowed soil (made by mixing together 
about 20 borings taken from as many different places where the soil appears to be uniform and truly representative of the soil type) and employ a skilled chemist to determine the total phosphorus and total nitrogen, and in case of naturally poor or abnormal soils it is well, also, to have determinations made of the total potassium, total magnesium, and total calcium.

The chief value of a chemical analysis is not to serve as a guide in the application of some certain plant-food element in readily available form for the special benefit of the next crop, but rather to serve as an absolute foundation upon which methods of soil treatment can be safely based for the adoption of systems of permanent soil improvement.

Thus, if the plowed soil of an acre is found to contain 8ro pounds of totai phosphorus and 47,600 pounds of total potassium, as is the case with the yellow-gray silt loam of the late Wisconsin glaciation, the most common upland soil in Lake County, Illinois, then a system of farming which will increase the phosphorus content of the soil and which will liberate potassium from the practically inexhaustible supply will certainly rest upon a practical and truly scientific foundation, notwithstanding the fact that in actual trials the application of soluble potassium salts in the absence of sufficient decaying organic matter might produce a marked effect on crop yields, as in the case of wheat in the Rothamsted experiments.

In practical agriculture the first soil test should be that for acidity, and if acidity is found in the surface and more marked acidity in the subsoil, the first treatment should be the application of 2 to 5 tons per acre of ground limestone. Following this, clover or some other legume should be grown, inoculation being provided, if necessary, and liberal supplies of decaying organic matter should then be provided by plowing under the clover either directly or in the form of manure. Next, some form of phosphorus should be added with the organic matter, more especially to note its effect on the yield of succeeding crops of legumes. Finally, if necessary or desirable, some soluble salts may be applied, such as potassium chlorid, sodium chlorid (common salt), kainit, or calcium sulfate (gypsum or land plaster), to note whether such addition would produce at least temporary profit until the supply of decaying 
organic matter becomes adequate to liberate sufficient plant food from the abundant supplies contained in the soil. Of course, if the absolute invoice of the soil shows that the total potassium is low, as in most pcaty swamp soils, then that element should be regularly provided in systems of permanent agriculture; and likewise, if the total magnesium is low, it is certainly advisable to apply liberal amounts of magnesian limestone. Even calcium as an element of plant food (especially for clover, which requires 29 pounds of calcium per ton) may become deficient, as is plainly the case with the extensive Leonardtown loam of southern Maryland.

Plot Experiments. The following outline is one of the simplest and most practical series of plot experiments:

Plan for Plot Experiments in Soll Improvement

\begin{tabular}{|c|c|}
\hline PL’T No. & Soll Treatment \\
\hline IOI & None, except crop rotation \\
\hline 102 & Manure \\
\hline 103 & Manure and limestone \\
\hline 104 & Manure, limestone, and phosphorus \\
\hline 105 & None, except crop rotation \\
\hline 106 & Residues turned under \\
\hline 107 & Residues and limestone \\
\hline I08 & Residues, limestone, and phosphorus \\
\hline IO9 & Residues, limestone, phosphorus, and kainit \\
\hline I IO & None, except crop rotation \\
\hline
\end{tabular}

For a four-year rotation, such as wheat, corn, oats, and clover, there should be four different series similar to the Ioo series, in order that every crop may be represented every year. The use of manure should be in amounts such as could easily be produced in independent systems of live-stock farming not involving the purchase of feed in excess of the crops sold. The use of crop residues should include all products except the grain or seed to be sold in grain farming. Thus, the clover should be clipped once or twice in May or June and left on the land, the cornstalks should be cut and plowed under, and the threshed straw (from wheat, oats, and clover) should be returned to the land either immediately or subsequently. 
In case the soil contains limestone, that application could be omitted, and perhaps two forms of phosphorus tried, such as steamed bone meal and an equal value of raw rock phosphate. The use of acid phosphate is not advised for such experiments because of its indirect effect, due in part to its marked acidity, and in part to its soluble salt content, including much calcium sulfate.

As a rule, the applications are made but once for the rotation, 2 tons of limestone, 2000 pounds of raw phosphate, 800 pounds of steamed bone meal, and rooo pounds of kainit, per acre, being recommended for a four-year rotation. 'For each ton of produce hauled off from any plot during the rotation, one ton of manure can be returned, even though the wheat and some part of the other grain should be sold, and by exercising great care and making large use of bedding, it is possible to return $\mathrm{I}_{2} \frac{1}{2}$ tons of average fresh manure for each ton of produce used for feed and bedding. Of course, the crop residues in the grain system will be returned in accordance with the amounts produced on the respective plots, excepting on plots I, 5, and Io, from which all crops are removed and nothing returned.

Another system which is especially designed to furnish information concerning the needs of the soil, rather than to demonstrate how those needs should be supplied, is as follows:

Plan for Plot Experiments with Fertilizers

\begin{tabular}{c|l}
\hline Plot No. & \multicolumn{1}{c}{ Plant Food Applied } \\
\hline I & None \\
2 & Dried blood \\
3 & Steamed bone meal \\
4 & Potassium sulfate \\
\hline 5 & None \\
6 & Blood and bone \\
7 & Blood and potassium sulfate \\
\hline 9 & Bone and potassium sulfate \\
ro & Blood, bone, and potassium sulfate \\
\hline \hline
\end{tabular}

The applications should be at the rate of rooo pounds of dried blood, 200 pounds of steamed bone meal, and 200 pounds of potas- 
sium sulfate, for each year. One half of each plot may be treated with limestone, applied at the rate of rooo pounds per acre, and for some soils magnesian limestone is undoubtedly preferable to the more common limestone, which contains only calcium carbonate.

Some rotation of crops should be practiced, such as corn, oats, wheat, and timothy. To introduce legumes in this system, largely destroys the value of the test with nitrogen, and the plan is designed to discover as quickly as possible what the soil fails to furnish to the crop.

When definite information has been secured, the materials which need to be added should as a rule be applied in larger amounts at longer intervals. Thus initial applications of to tons of ground limestone and even 3 or 4 tons per acre of fine ground rock phosphate are not unreasonable for land valued at \$10 to $\$ 50$ per acre which the owner desires to improve until it shall yield as much as is produced on $\$ 5_{5}{ }^{\circ}$ or $\$ 200$ land. 


\section{CHAPTER XXXV}

\section{RELATION OF FERTILITY TO APPEARANCE OF SOILS OR CROPS}

IT is probably not too much to say that the average man is ever on the alert to "discover" the cause for every effect. This is well, but not infrequently two or three examples are readily accepted as proof sufficient sometimes to become a tradition. Thus do some people still plant potatoes in the dark of the moon, although, as T. B. Terry says, it were better to plant in the light of the moon, when one can see to work late at night.

To find a "Shakespere" plant of wheat from which a new variety may be established is perhaps a laudable search, but, as a rule, hauling manure is a more remunerative employment. It is well that some men have the "gold fever," but those of large experience and observation tell us that more money is buried in gold mines than is ever dug out.

Success in agriculture depends largely upon knowledge and work. Fortunate is the man who knows what to do and does it. Not much knowledge or skill is required to secure temporary success where rich, virgin land is accepted as a gift or at a very low price, and where the unearned increment amounts to $\$$ Ioo or more per acre for the man who does little else than to draw upon his capital stock for support.

Permanent success requires knowledge, thought, investment, and work, and success for the many lies within reach along these lines; whereas, sudden riches from gold mines, oil wells, inventions, or discoveries are rare misfortunes; and there is no more free land in the humid section of the United States.

Directions are often given by which it is held that one can tell from the appearance of the crop what plant food is lacking in the soil. Thus we are told that nitrogen produces a rank growth of straw or 
stalk, and retards maturity, and that small growth and a pale color show lack of nitrogen; that phosphorus produces the seed and hastens maturity, and that poorly filled ears and heads show lack of phosphorus; that weakness of straw shows lack of potassium. However, these and other "rules" have commonly been evolved from experience on soils of one class, and they may have little or no value on other soil types.

Any kind of malnutrition produces imperfect growth. On sand land and other soils deficient in nitrogen, the addition of nitrogen does not retard, but positively hastens, maturity, sometimes by one or two weeks, and markedly increases the development of the seed or grain. On peaty swamp lands, which are well supplied with nitrogen, the plants are small and pale or yellowish in color, and under the rule appear to suffer "nitrogen hunger," but rank growth, dark color, and well-filled heads or ears result from the addition of potassium. On soils rich in nitrogen and potassium and deficient in phosphorus, the growth and strength of straw or stalk, as well as yield of grain, are markedly increased by addition of phosphorus; and roo bushels of good sound corn will often mature where the soil is properly balanced two weeks in advance of a $20-$ bushel crop grown from the same kind of seed planted at the same time on the same type of soil, where not properly balanced.

Nitrogen is an important constituent of the organic matter of the soil; consequently, soils rich in organic matter are also rich in nitrogen; and, conversely, soils markedly deficient in organic matter, such, especially, as worn hill lands and sand soils, are also deficient in nitrogen. Potassium is not a fixed constituent of organic matter, is easily leached from plant residues, and is usually deficient in peat soils, as well as in soils derived largely from quartz, as from some residual sandstones. Carbonates and phosphates derived from shells and skeletons may have some relation, ${ }^{1}$ and

\footnotetext{
${ }^{1}$ Whitson has suggested (Wisconsin Agricultural Experiment Station Bulletins I 39 and I 74) a vice versa relationship; namely, that there is correlation between soil acidity and lack of phosphorus. He says: "So far no case has been found in which acid soils have not shown a need of phosphate." While it is true that many acid soils are deficient in phosphorus, there is no necessary correlation between these two facts. The highly phosphatic soils of Tennessee and Kentucky are sometimes acid, and some of the peat soils of Illinois, which are as rich in phosphorus as any soil in the state, are distinctly acid. This is the case, for example, with the deep
} 
limestone soils are often well supplied with phosphorus, phosphatic limestones being especially rich in phosphate. Phosphorus is also a fixed constituent in most organic matter, and soils rich in humus usually have at least a fair supply of phosphorus. Silicate minerals contain much potassium, and clay soils or silt soils derived from silicates usually contain sufficient undecomposed minerals to insure a high content of potassium. These facts serve to indicate to some extent correlation between the physical appearance of the soil and its chemical composition; but these indications have no such value as the chemical invoice of the total plant food contained in the soil.

peat on the Manito experiment field, but both the soil analysis and the field experiments show that the soil is not deficient in phosphorus. (See Tables $15,16,17$, and gi.) 


\section{CHAPTER XXXVI}

\section{FACTORS IN CROP PRODUCTION}

THERE are six essential positive factors in the production of agricultural crops, which may be designated by the single words:
I. Seed.
2. Home.
3. Heat.
4. Light.
5. Moisture.
6. Food.

There are many negative factors against which the plant should be protected, such as injury from insects, birds, or other animals, fungous or other diseases or parasites, weeds, and even against an excess of some positive factors, such as moisture. To ignore any important essential factor is certainly to be one-sided or shortsighted.

Seed. The seed is a factor of much importance. The Illinois Station has produced, as an average yield of three years, I5.6 bushels per acre of one variety of wheat and 6. I bushels of another variety, in careful comparable tests on the same type of soil. The fact that the soil was poor helps to show the character of the wheat, because it requires a good variety to make a fair yield on poor soil. Aside from varietal differences, the vitality or vigor of the special lot of seed is important, and the selection of the best seed from a given lot is certainly good practice. Large seed are, as a rule, better than small seed, even though they may be of the same variety and all of good vitality. Thus, as an average of 7 years, the Ontario Agricultural College produced 62 bushels of oats per acre from large seed and only 47 bushels from small seed, both selected from the same stock each year. The selection and breeding of plants is at least as successful as the breeding of animals. Thus may plants be developed for power to yield or for special purposes. The Illinois Station has in ten years' breeding developed two strains of corn one of which now contains 6 per cent more protein than the other, and two other strains one of which contains about three times as much oil as the other, all four strains having been bred 
from a single variety of corn. Likewise, the sugar beet has been developed by breeding under the most exact scientific control until its sugar content has been changed from 4 per cent to more than I 2 per cent, and until about one half of the world's supply of sugar is now made from beets. But shall we practically ignore other equally essential factors because of the importance of seed?

Home of the plant. The home of the plant may vary from a stiff, compact, almost impervious clay, offering a very shallow feeding range for plant roots, to a porous, friable, easily penetrated, fine sandy loam, affording a very deep feeding range. To markedly modify the physical character of the soil is, as a rule, a difficult and expensive problem. Thorough underdrainage and large use of organic matter, including deep-rooting plants, which are the best subsoilers, and sometimes heavy applications of marl or ground limestone (Io tons or more per acre) will do much to improve the clay soils, and heavy applications of "clay" (say one wagon load to the square rod) will greatly improve some very light sand soils. An old English saying runs:

\footnotetext{
"Clay on sand is money in the hand; Sand on clay is money thrown away."
}

Temperature. A proper temperature is important in crop production, although some plants grow well in cool weather, while others do best under tropical conditions. Dark soils are warmer than light-colored soils, a difference of several degrees being noted during the forenoon in the early summer, and this difference extends to a depth of several inches; but the largest control of soil temperature lies in the control of soil moisture. Improperly drained soils are cold soils, because enormous quantities of heat are required to remove surplus water from the soil by the process of evaporation. Thus, to melt ice requires only 79 heat units, and to raise water from the freezing point to the boiling point requires only Ioo heat units, but to evaporate water requires 536.4 heat units. If the surplus soil water can be removed by underdrainage, the sun's energy may then be expended in warming the soil.

Light. Light is an absolute essential in the most fundamental process of plant growth, photosynthesis. One of the most damag- 
ing effects of weeds is that they shut off the light to a greater or less extent from the agricultural plant. Nurse crops drilled north and south permit the strong midday light to reach the young clover, and thus insure a hardier clover plant than when the nurse crop is sown broadcast or drilled in an east and west direction. In greenhouse cultures light is very commonly the limiting factor in plant growth. However, under ordinary field conditions, the light is probably adequate for crop yields at least ten times the present averages.

Moisture. Moisture is perhaps the most variable factor in crop production; and, in consequence, many seem to think that if we have timely rains, we should always have good crops; although on almost every farm, there are some patches of ground which produce twice as much as others, even though the rainfall, seed, preparation, cultivation, etc., are alike on both areas.

It may safely be stated that when corn or other crops begin to "fire" in time of partial drouth the real cause of the "firing" is more commonly due to a lack of plant food than to a lack of moisture for its own sake. To be sure, a more ideal rainfall, which we cannot control, would help to render available a more nearly adequate supply of plant food, even from a poor soil; but, on the other hand, a liberal enrichment of the soil, which we can control, will often render unnecessary additional rainfall. Almost every season in some part of Illinois, we observe the "firing" of corn on unfertilized land where the soil is incapable of producing more than 25 to 50 bushels per acre, while at the same time on adjoining properly fertilized plots which yield 75 to roo bushels, and where the crops are actually drawing much more moisture from the soil, there is little or no evidence of "firing." Even in the pot-culture laboratory, where water is daily supplied in sufficient abundance, plants "fire" with inadequate food supplies. In other words, the lower leaves die, and much of the plant food which they contain is translocated to the new, growing parts, in order that reproduction may ensue if possible.

The conservation of moisture in humid sections is a matter whose importance is commonly greatly exaggerated. If the expense so much advised for extra cultivation were devoted to a more liberal use of manure, clover, limestone, and phosphorus, greater and 
more lasting profits would result. As an average of six years' experiments at the Illinois Station, Professor George E. Morrow produced 70.3 bushels of corn per acre with ordinary cultivation (four times, or twice each way), while eight extra cultivations increased the yield to only 72.8 bushels. Furthermore, where no cultivation whatever was practiced, the land having been well prepared and, subsequent to planting, kept clean by clipping the weeds off at the surface of the ground, the average yield for the same six years was 68.3 bushels per acre. About one half of all the increase from the extra cultivation during the six years was produced during one especially dry season. For the other five years the extra cultivation was wasted energy; and as an average the increase produced was far below the cost of the extra work.

Table I 9 shows the results of more recent experiments at the Illinois Station, which include the effect of plowing, preparation of seed bed, cultivation, irrigation, and fertilization.

Table i ig. Effect of Soil Preparation, Cultivation, Irrigation, and Fertilization: Illinois Experiments

Corn, Bushels per Acre

\begin{tabular}{|c|c|c|c|c|}
\hline $\begin{array}{l}\text { Plot } \\
\text { No. }\end{array}$ & Soll Treatment & I906 & 1907 & I908 \\
\hline $\mathbf{I}$ & $\begin{array}{l}\text { Land not plowed; not cultivated; weeds clipped } \\
\text { off at surface . } . .5 \\
\end{array}$ & & 38.3 & 32.3 \\
\hline 2 & $\begin{array}{l}\text { Land plowed and well prepared, but not culti- } \\
\text { vated; weeds clipped off at surface . } \quad . \quad . \quad \text {. }\end{array}$ & & 44.0 & 39.6 \\
\hline 3 & $\begin{array}{l}\text { Land plowed and well prepared, but nothing done } \\
\text { after planting; weeds allowed to grow . } . .\end{array}$ & None & None & 4.4 \\
\hline 4 & Land plowed, well prepared, well cultivated . . & $44 \cdot 7$ & 49.6 & 29.4 \\
\hline 5 & $\begin{array}{l}\text { Land plowed, well prepared, well cultivated, and } \\
\text { irrigated in dry weather } . .5\end{array}$ & $4^{6.2}$ & 49.8 & 3.3 .8 \\
\hline 6 & $\begin{array}{l}\text { Land plowed, well prepared, well cultivated, irri- } \\
\text { gated, and heavily fertilized } . . \quad . \quad . \quad . \quad .\end{array}$ & $69 \cdot 7$ & 102.2 & $5^{2.8}$ \\
\hline
\end{tabular}

In I 908 a rainfall of 10.28 inches in 30 days during the usual time for corn planting necessitated very late preparation of the land, and with very light rainfall during the remainder of the season (only 8.93 inches between May 23 and November 22) the 
weeds on the uncultivated plot failed to smother the crop so completely as to entirely prevent the formation of ears, which in normal seasons is the common result of the unrestricted growth of weeds.

It is a matter of surprise to many people that a good crop of corn can be produced with no cultivation after the crop is planted; but they forget that 40 bushels of wheat, 80 of oats, 3 tons of clover, etc., are produced on good soil with no cultivation after planting. On good land in humid sections the greatest benefit of cultivation is due to the killing of weeds. For soils deficient in plant food, especially in nitrogen, frequent cultivation will hasten the decay of organic matter, encourage nitrification, and often markedly increase the crop yield. Thus, on the worn hill lands at Ithaca, New York, the Cornell Station has shown very beneficial results from long-continued cultivation of potatoes; but the question still remains if more clover plowed under would not have given better yields at less expense and have left the land in better condition for subsequent crops.

In the semiarid region, fallow cultivation is practiced during one season, the soil being stirred after every rain, in order to prevent evaporation and thus store up sufficient moisture in the soil to give the crop a good start, especially a fall-sown crop like winter wheat, which with moderate rainfall the next spring will usually produce a good yield. On the other hand, the much-talked-of "dry farming" is a great misnomer. Above everything else, every success in "dry farming" is coincident with a fair amount of rainfall in a semiarid region; and the prospective investor is warned not to be misled by the numerous exaggerated reports of successful "dry farming"; and the author speaks, not only from scientific data, but also from fourteen years' practical experience in a semiarid state. 'He has seen 20 to 30 bushels of wheat and corresponding yields of other crops produced for several years with a moderate rainfall well distributed, and he has also seen this period followed by four years in succession with so little rainfall that no sort of dry farming could produce a profitable crop.

Certainly it is possible and practicable to conserve and accumulate moisture with very moderate rainfall, so that one crop can be grown every two years, and much can be done to advantage where 
crops are grown every year; but the fact remains that at least 75 per cent of the talk of "dry farming " is falacious. It is to be credited largely to land agents, farmers of short experience, and to one-sided enthusiasts. When it is found impossible to win confidence in the "dry farming" theory, the advocate insists that the seasons in the semiarid region have changed, that more abundant rainfall follows the plow, and that the semiarid region has become humid.

It is true, as stated above, that a series of wet years may follow a dry series, but it is not true that seasons change measurably in any permanent way during human experience.

The accompanying chart showing the total annual rainfall at North Platte, Nebraska, for the 34 years, I875 to I908, presents some interesting, instructive, and valuable data.

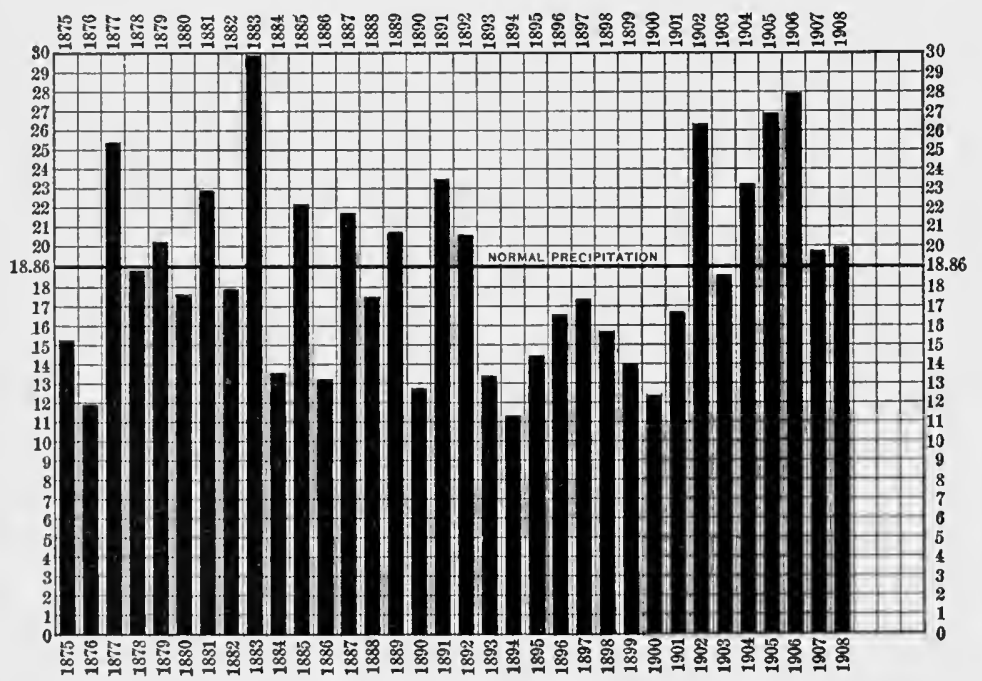

I'recipitation (inches) at North Platte, Nebraska, for Thirty-four YEARS - 1875 TO 1908

It will be observed that the average rainfall for the seven years, I902 to I908, is 23.17 inches, and it will also be noted that every year has been above normal, with the exception of I903, which was slightly below. Previous to I902 was a remarkable period of nine years when every year was distinctly below normal, the rainfall 
ranging from II.2I to I7.09. It is not surprising, perhaps, that "dry farming" should succeed fairly well in recent years with a rainfall ranging from $\mathrm{I} 8$ to 28 inches, and there is reason cnough to convince many ${ }^{1}$ that rainfall follows the plow. However, the heaviest rainfall on record is for $\mathrm{I}^{8} 83$ (29.88 inches), and the average for the ten years, 1877 to 1886 , is only .38 of an inch below the average for the last ten years, while the average for the first I7 years is .64 of an inch greater than the average for the last I 7 years, according to the records of the 34 years.

A matter worthy of important consideration is the distribution of rainfall. A rainfall of 15 to 20 inches is sufficient for very fair crops if it comes at the rate of 3 inches a month from April to September; but, if two or three torrential showers of 4 or 5 inches each all within a month or six weeks are parts of the total, the rainfall may be very inadequate.

The author is firmly of the opinion that most of the cultivable semiarid lands in the United States where the average annual rainfall exceeds I $_{5}$ inches should be and will be occupied, and also that a very satisfactory measure of prosperity can be attained by those who farm those lands under the best methods; but it should not be forgotten that there are certain to be periods of severe drouth sometimes for several years in succession; and, unless adequate provision is made against such times, there will be suffering for

${ }^{1}$ An experience reported to the author by Mr. N. S. Spencer, a resident of Champaign County, Illinois, cannot fail to be of interest, and may be of some value, to students of semiarid agriculture. Mr. Spencer stated that he went into central Nebraska some years ago and saw growing in the fields wheat crops that yielded 35 bushels per acre on very low-priced land, and he had positive assurance that excellent crops had been grown the year before and also in previous years. He bought a large farm, and broke up 400 acres the same season, on which wheat was seeded in the fall. The following year crop failure was common, and he threshed no wheat. However, there were some good summer rains and he prepared the land well and again seeded 400 acres of wheat, but again the rain failed and he threshed no wheat. Once more the summer rains were sufficient to enable him to put the land in good condition, and he sowed 300 acres of wheat, which, however, also resulted in complete failure. He then gave up the land upon which he had made two payments, disposed of his stock and tools as well as he could, and found that his total loss for the three years' experience amounted to about $\$ 10,000$.

Soon after hearing this story, the author looked up the rainfall record as reported above for North Platte, and then stated to Mr. Spencer that he must have bought his land in 1892 , which was found to be correct. 
animals and possibly for the people, unless relieved by food supplies from other sections.

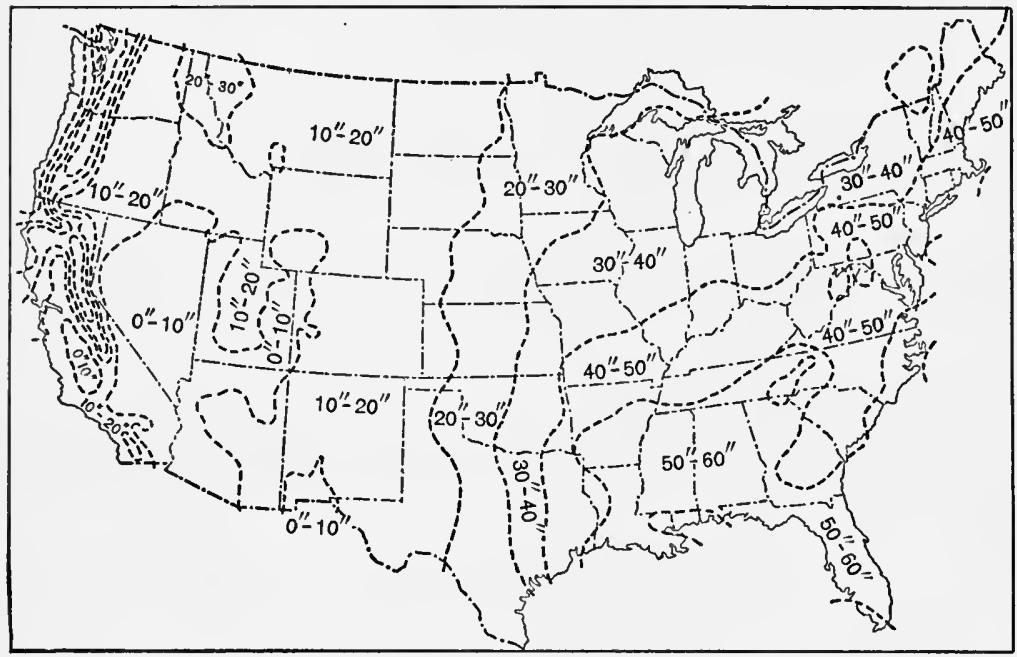

Average Annual Precipitation in different Parts of the United StaTes (in inches)

The accompanying map of the United States showing the average annual rainfall is based upon the record of the United States Weather Bureau, and furnishes some exceedingly valuable information. It will be noted that the average rainfall is about 35 inches for eastern Kansas and southeast Nebraska, about 25 inches for central Kansas and east-central Nebraska, and about I 5 inches for the western parts of those states. The average annual rainfall of the United States varies from less than Io inches in the Great Basin to more than 60 inches over small areas on the coast.

Some portion of the arid region will be reclaimed by irrigation; but while this subject is receiving much attention, with extensive advertising of both private and public enterprises, it can never be a very large factor in American agriculture. Director Frederick H. Newell, of the United States Reclamation Service, makes the following statements concerning the arid region ("Conservation of 
Natural Resources" published by the American Academy of Political and Social Science, Philadelphia, 1909):

"If all the run-off waters of this region could be conserved and employed in irrigation, the total area reclaimed might, perhaps, be brought to nearly $60,000,000$ acres. . . . Large portions of the water of the arid region cannot be used in irrigation, as no irrigable land exists upon which it can be brought at feasible cost."

"With present data, the closest statement is probably under $60,000,000$ acres and between 40,000,000 and 50,000,000 acres, including the lands now under ditch." (About $13,000,000$ acres are now under irrigation.)

For comparison it may be noted that the state of South Dakota contains $48,000,000$ acres, and the estimated total area of arid land that can still be brought under irrigation in the United States is equal to only one state like Illinois. Director Newell estimates that the total land areas that may possibly be brought under irrigation might support, directly and indirectly, Io million people, or about ro per cent of our present population.

It should be kept in mind that the fertility even of irrigated lands must be maintained if they are to continue productive. With large use of turbid water there is always soil enrichment, but reservoir water adds little or no fertility to the soil, as witness the low yields of irrigated lands in India. In his Handbook of Indian Agriculture, Mukerji makes the following statements:

"The best crops of wheat are grown on lands newly brought under canal irrigation. Where canal water is used for irrigation for a number of years, the outturn is found to fall off even below the original level. . . . No manure is required for dearh land which is annually renovated with silt."

In this connection it is of interest to know that the estimated area of reclaimable swamp land in the United States is less than 80 million acres, which would provide about two million 40-acre farms, thus furnishing homes for another ro million people corresponding to the normal increase in our population for five or six years. 


\section{CHAPTER XXXVII}

\section{ESSENTIAL FACTORS OF SUCCESS IN FARMING}

THERE are three factors which govern success in such an enterprise as farming: (I) knowledge, (2) executive ability, and (3) business ability.

First, we must have the necessary knowledge to make definite plans under which permanent success will be possible. Merely because one has considered that he was making money while he has been wearing out a rich soil, which may have cost him but little to begin with, is no assurance that he will be able to succeed when he has to deal with high-priced, partially exhausted land.

Second, one may have sufficient knowledge to plan well, but, if he lacks the executive ability to properly carry out his plans, he will surely fail. 'It is at this point that landowners frequently misjudge the young graduate from the agricultural college. They fail to distinguish between the knowledge of important fundamental facts, which the young man possesses, and the necessary executive ability to handle men and to get work done, which, as a rule, the young man does not possess.

Third, one must have judgment and ability in financial matters, for purchases must be made with economy and the farm products must be disposed of to advantage, if profit is to result. Business dealing is an essential part of the farm enterprise; and it matters not how well the farm system is planned or how well the plans are executed in the production of crops, the poor business man, who pays too much for the things he buys, buys things which he need not buy, or fails to buy the things he needs, who sells his produce in poor condition, holds produce when he ought to sell it, or sells when he ought to hold it, will certainly not attain a high degree of success in farming.

The manufacturer cmploys an expert for a definite purpose and the expert renders the required service to the great advantage of his employer; but what manufacturer would think of turning over 
the complete management of a complex business to an inexperienced young man, even though he were able to analyze the raw materials and point out some absolute essentials for the highest grade of finished products?

Let the landowner of executive and business ability take the graduate from the agricultural college as a junior partner, until he has had the opportunity to acquire those essentials in the school of experience under the wiser guidance of the older man, who should not forget, however, that land which has been running down for half a century cannot be built up in a year so as to pay both cost and profit on the improvement.

An investment of $\$ 2$ per acre per annum which always produces an increase above the preceding year of 2 bushels of corn per acre (and equivalent amounts of other crops in the rotation) furnishes corn as follows:

Cost of Corn per Bushel

First year.

Second year $\$ 1.00$

Third year

Fourth year

Fifth year

Sixth year

Eighth year

Tenth year

.20

$.16 \frac{2}{3}$

$.12 \frac{1}{2}$

.10

These figures mean that land which increases in productiveness at the rate of 2 bushels per annum would rise from 50 bushels to 70 bushels per acre in ten years' time, and if this change can be brought about at a cost of $\$ 2$ per acre per annum, it will be an extremely profitable investment, although there may be an apparent loss for the first few years. And this does not take into account the certain fact that if the land is not properly treated, it will sooner or later decrease in productive power below the 50-bushel yield.

Even large annual expense will ultimately prove profitable if it provides for a system of farming under which the land steadily increases in productiveness; whereas, if a system is followed which allows the soil to become depleted of any essential constituent, failure must finally result, whether we grow one grain crop year after year, rotate the grain crops, or use inadequatc amounts of manure, clover, or commercial fertilizers. 


\section{CHAPTER XXXVIII}

\section{THE VALUE OF LAND}

TABLE I 20 is presented in order to emphasize to some degree the very great importance of producing and maintaining large crop yields. It will be understood, of course, that these data, at most, represent only approximately average conditions. Thus the prices for produce ( 75 cents for wheat, 40 cents for corn, 30 cents for oats, and $\$ 6$ a bushel for clover seed) represent approximately the ro-year average prices for those products in the states where such a crop rotation is most practicable.

It is not suggested that the student accept these data, but only that he accept or consider the principle of measuring land values by crop returns.

In the expense for soil treatment, allowance is made for the purchase of 2 tons of limestone per acre (charged to the clover crop); for at least as much phosphorus as will be contained in the grain and seed produced; for an extra seeding of clover on the wheat ground, to be plowed under the next spring for corn; for the return of all straw and stalks to the land including extra work of hauling, and spreading straw, cutting and disking stalks, etc.; and even for returning the potassium sold in the grain. The regular clover crop is mowed once or twice and left lying on the land, only the seed crop being harvested.

The expense for growing the crops includes only the preparation of the seed bed, the seed, and seeding, and, in the case of corn, the cultivation. Under "harvest and market" is included the cost of binding twine, thresh bills, etc. For taxes is allowed the uniform rate of $\frac{1}{2}$ per cent of the actual valuation of the land, which is fixed by its interest-earning capacity, 5 per cent interest being used as the standard rate.

The minimal grain yields assumed for Table I 20 are above the minimal averages for the United States, and the maximal yields in 
Table i 20. Value of Land Measured by Crop Yields

\begin{tabular}{|c|c|c|c|c|c|c|c|c|}
\hline \multirow{2}{*}{$\begin{array}{l}\text { Crop Yields } \\
\text { PER ACRE }\end{array}$} & \multirow{2}{*}{$\begin{array}{l}\text { GROSS } \\
\text { VALUE OF } \\
\text { CROP }\end{array}$} & \multicolumn{5}{|c|}{ AnNual Expense, per ACre } & \multirow{2}{*}{$\begin{array}{c}\text { NET } \\
\text { VALUE OF } \\
\text { CROP }\end{array}$} & \multirow{2}{*}{$\begin{array}{c}\text { NET } \\
\text { VALEE OF } \\
\text { LAND PER } \\
\text { ACRE }\end{array}$} \\
\hline & & $\begin{array}{c}\text { Soil } \\
\text { Treat- } \\
\text { ment }\end{array}$ & $\begin{array}{c}\text { To } \\
\text { grow } \\
\text { Crops }\end{array}$ & $\begin{array}{c}\text { Harvest } \\
\text { and } \\
\text { Market }\end{array}$ & $\begin{array}{c}\text { Taxes on } \\
\text { Land }\end{array}$ & $\begin{array}{c}\text { Total } \\
\text { Annual } \\
\text { Expense }\end{array}$ & & \\
\hline
\end{tabular}

An Acre of Wheat at 75 Cents a Bushel

\begin{tabular}{l|r|r|r|r|r|r|r|r}
\hline 10 bushels & $\$ 7.50$ & $\$ 1.00$ & $\$ 3.00$ & $\$ 1.00$ & $\$ 0.23$ & $\$ 5.23$ & $\$ 2.27$ & $\$ 45.45$ \\
20 bushels & 15.00 & 2.00 & 3.00 & 2.00 & .73 & 7.73 & 7.27 & 145.45 \\
30 bushels & 22.50 & 3.00 & 3.00 & 3.00 & I.23 & 10.23 & I 2.27 & 245.45 \\
40 bushels & 30.00 & 4.00 & 3.00 & 4.00 & I.73 & I2.73 & I 7.27 & 345.45 \\
50 bushels & 37.50 & 5.00 & 3.00 & 5.00 & 2.23 & I5.23 & 22.27 & 445.45 \\
\hline
\end{tabular}

An Acre of Corn at 40 Cents a Bushel

\begin{tabular}{|c|c|c|c|c|c|c|c|c|}
\hline $\begin{array}{l}20 \text { bushels } \\
40 \text { bushels }\end{array}$ & $\begin{array}{r}\$ 8.00 \\
16.00\end{array}$ & $\begin{array}{r}\text { \$1.80 } \\
3.60\end{array}$ & $\begin{array}{r}\$ 4.00 \\
4.00\end{array}$ & $\begin{array}{r}\$ 1.00 \\
2.00\end{array}$ & $\begin{array}{r}\text { So. II } \\
.5^{8}\end{array}$ & $\begin{array}{r}\$ 6.9 I \\
10.18\end{array}$ & $\begin{array}{r}\$ 1.09 \\
5.82\end{array}$ & $\begin{array}{r}\text { S } 21.8 \mathrm{I} \\
\text { II } 6.36\end{array}$ \\
\hline 60 bushels & 24.00 & 5.40 & 4.00 & 3.00 & 1.05 & I 3.45 & I0. 55 & $210.9 \mathrm{I}$ \\
\hline 80 bushels & 32.00 & 7.20 & 4.00 & 4.00 & I. 53 & I6.73 & 15.27 & 305.45 \\
\hline Ioo bushels & 40.00 & 9.00 & 4.00 & 5.00 & 2.00 & 20.00 & 20.00 & 400. \\
\hline
\end{tabular}

An Acre of Oats at 30 Cents a Bushel

\begin{tabular}{|c|c|c|c|c|c|c|c|c|}
\hline 20 bushels & $\$ 6.00$ & So. 50 & $\$_{3.00}$ & $\$ 1.00$ & So. 14 & $\$ 4.64$ & \$ I. 36 & $\$ 27.27$ \\
\hline 40 bushels & I 2.00 & 1.00 & 3.00 & 2.00 & .55 & 6.55 & 5.45 & 109.09 \\
\hline 60 bushels & I8.00 & 1.50 & 3.00 & 3.00 & .95 & 8.45 & 9.55 & I90.9I \\
\hline 80 bushels & 24.00 & 2.00 & 3.00 & 4.00 & I. $3^{6}$ & 10.36 & I 3.64 & 272.72 \\
\hline I 00 bushels & 30.00 & 2.50 & 3.00 & 5.00 & х. 77 & I 2.27 & I 7.73 & 354.54 \\
\hline
\end{tabular}

An Acre of Clover at \$6 a Bushel for Seed

\begin{tabular}{|c|c|c|c|c|c|c|c|c|}
\hline I bushel & $\$ 6.00$ & $\$ 3.00$ & $\$ 1.00$ & \$. 50 & So.05 & $\$ 5.55$ & $\$ 0.45$ & 9.09 \\
\hline 2 bushels & 12.00 & 3.00 & 1.00 & 3.00 & .45 & 7.45 & 4.55 & $90.9 \mathrm{I}$ \\
\hline 3 bushels & 18.00 & 3.00 & 1.00 & $4.5^{\circ}$ & .86 & $9 \cdot 3^{6}$ & 8.64 & I 72.72 \\
\hline 4 bushels & 24.00 & 3.00 & 1.00 & 6.00 & I. 27 & II. 27 & I 2.73 & $254 \cdot 54$ \\
\hline 5 bushels & 30.00 & 3.00 & 1.00 & 7.50 & I. 68 & 13.18 & 16.82 & $33^{6} .3^{6}$ \\
\hline
\end{tabular}

Average for the 4-Year Rotation

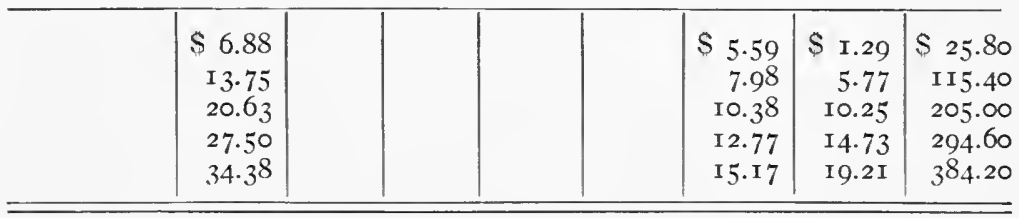


the table are less than have been produced on good soil in good seasons. They are not likely to be secured as an average even on the best treated land, but they are not too high to serve as an ideal toward which we may well strive and which we may expect to reach under favorable conditions.

If in the general equalization, or balance, between live-stock farming and grain the value of clover seed markedly decreases, beans, peas, and other edible legumes will to some extent be substituted for clover in the rotation of crops.

Perhaps the most valuable fact brought out in Table $\mathrm{r} 2 \mathrm{O}$ is the very rapid increase that occurs in net-earning power, and consequently in land value, after fixed expenses are covered. Thus, land which produces a 20 -bushel crop of corn is valued at $\$ 2 \mathrm{I} .8 \mathrm{I}$ an acre; while, if the crop yield is doubled, the land value is multiplied more than five times.

With 60 bushels of corn and yields of equivalent rank for other crops, the land becomes worth more than $\$ 200$ an acre, and with 50 bushels of wheat, roo of corn and oats, and 5 bushels of clover seed, the average value of the land approaches $\$ 400$ an acre.

A careful consideration of the figures given in Table I 20 will show that the expenses allowed for the large yields are relatively much more ample than those allowed for the small yields. Thus, 5 cents a bushel is allowed for husking and marketing corn; and, while this is ample for corn yielding 80 bushels per acre, it is probably inadequate for a 20 -bushel crop. Likewise, the taxes on poor land are, as a very general rule, relatively higher than on good land. This is due to the fact that most of the taxes are for local purposes (schools, roads, bridges, etc.), and the actual expense in a poor land section is about the same as where the lands are rich. Thus, land which produces only 20 bushels of corn may pay 30 cents an acre tax, while land producing 80 bushels (in another section of the state) may not be taxed more than 50 cents an acre. To be sure, the state tax might be properly equalized, but the county and local taxes are often more than ten times the state tax. ${ }^{1}$

It will easily be noted that when crop yields sink slightly below

\footnotetext{
${ }^{1}$ Likewise the federal tax, though indirect, is usually about ten times the state $\operatorname{tax}$.
} 
the minimal figures given in Table $\mathrm{I} 20$, the land becomes practically valueless for business or investment purposes.

Agriculture is often referred to as the most independent occupation; and in the struggle against poverty, in countries with increasing population and failing resources, it is certainly true that, after men in most other lines of occupation have literally starved out, the farmer will continue to eke out an existence. In fact, he may still have bread and potatoes, milk and butter, eggs and poultry, and even vegetables, fruits, sirup, and honey, for the support of his own family, long after he has practically ceased to buy or sell in support of a dependent urban population. Thus, the city is the first to feel the country's poverty; and for their own preservation the men of the town or. city must contribute their influence toward the development of systems of permanent agriculture.

Bankers, merchants, grain dealers, physicians, editors, teachers, and ministers, as well as educated landowners, because they have trained minds and are able with moderate study to acquire a correct and adequate understanding of the fundamental principles of soil improvement, must exert their influence over those who are less able to secure such positive knowledge but who may own or control much of the land, lest the lands generally become so impoverished that they will support only the agricultural people, who, of course, have the first right to the food they produce.

Under such conditions, land may have no value as a source of profit, and still be invaluable as a means of existence. Because a given amount of grain will support about five times as many people as will the meat or milk that can be made from it, grain-fed animals are not maintained in the poorest countries; and, when human labor becomes worth little more than the cost of existence, it is substituted for the labor of beasts of burden; and whatever domestic animals are kept must be supported upon uncultivated lands or upon refuse products not usable as human food or more valuable for direct use as fertilizer. 


\section{CHAPTER XXXIX}

\section{TWO PERIODS IN AGRICULTURAL HISTORY}

THE following quotations, separated by a lapse of twenty centuries, cannot fail to interest the student of American agriculture:

"The land must rest every second year, or be sown with lighter kinds of seeds, which prove less exhausting to the soil." — VARRO (B.C. I I6 to 28).

"A field is not sown entirely for the crop which is to be obtained the same year, but partly for the effect to be produced in the following; because there are many plants which, when cut down and left on the land, improve the soil. Thus lupines, for instance, are plowed into a poor soil in lieu of manure."

- VARRo.

"Horse dung is about the best suited for meadow land, and so in general is that of beasts of burden fed on barley; for manure produced from this cereal makes the grass grow luxuriantly." - VARRo.

"Plowing the land simply means rendering the earth porous and friable, which must tend to increase its productiveness." - CAто (B.C. 95 to 46 ).

"Wherein does a good system of agriculture consist? In the first place, in thorough plowing; in the second place, in thorough plowing; and, in the third place, in manuring." - CATo.

"Take care to have your wheat weeded twice - with the hoe, and also by hand." - Cato.

"A soil to be fertile must, above all things, be light and friable, and this condition we seek to bring about by the operation of plowing." - Virgil (B.C. 7o to I9).

"Linseed, poppy, and oats exhaust the soil." - VIRGIL.

"Still will the seeds, tho chosen with toilsome pains

Degenerate, if man's industrious hand

Cull not each year the largest and the best.

'Tis thus by destiny, all things decay

And retrograde, with motion unperceived."

- VirgiL's Georgics.

"On the other side of the Po, the use of ash is viewed so favorably by farmers, that they actually prefer it to the manure furnished by their cattle."

"On large estates ficlds are alternately allowed to lie fallow in order to save manure." - PLINY. 
"No one gifted with common sense will ever permit himself to be persuaded that our earth has grown old, as man grows old. The sterility of our fields is to be imputed to our doings, because we hand over the cultivation of them to the unreasoning management of ignorant and unskillful slaves."

- Columella (first century, A.D.).

"Some of the leguminous plants manure the soil, according to Saserna, and make it fruitful, whilst other crops exhaust it, and make it barren. Lupines, beans, peas, lentils, and vetches are reported to manure the land. Where no kind of manure is to be had, I think the cultivation of lupines will be found the readiest and best substitute. If they are sown about the middle of September in a poor soil, and then plowed in (when well grown), they will answer as well as the best manure." - Columella.

"The best forage plants are lucerne (alfalfa), fenugreek, and vetches. Lucerne may be placed in the foremost rank of such plants; for when once sown it lasts ten years, fattens lean cattle, and has a salutary action on sick cattle. It must be carefully weeded at first, lest the weeds choke the tender lucerne."

- Columella.

It was in 1859 that Baron von Licbig wrote as follows, regarding these and similar ancient teachings:

"All these rules had, as history tells us, only a temporary effect; they hastened the decay of Roman agriculture; and the farmer ultimately found that he had exhausted all his expedients to keep his fields fruitful and reap remunerative crops from them. Even in Columella's time, the produce of the land was only fourfold."

"It is not the land itself that constitutes the farmer's wealth, but it is in the constituents of the soil, which serve for the nutrition of plants, that this wealth truly consists."

"The deplorable effects of the spoliation system of farming are nowhere more strikingly evident than in America, where the early colonists in Canada, in the state of New York, in Pennsylvania, Virginia, Maryland, etc., found tracts of land, which for many years, by simply plowing and sowing, yielded a succession of abundant wheat and tobacco harvests."

"We all know what has become of those fields. In less than two generations, though originally teeming with fertility, they were turned into deserts, and in many districts brought to a state of such absolute exhaustion, that even now, after having been fallow for more than a hundred years, they will not yield a remunerative crop of a cereal plant."

"The American farmer despoils his farm without the least attempt at method in the process. When it ceases to yield him sufficiently abundant crops, he simply quits it, and with his seed and plants, betakes himself to a fresh farm; 
for there is plenty of good land to be had in America; and it would not be worth his while to work the same farm to absolute exhaustion."

"Agriculture is, of all industrial pursuits, the richest in facts, and the poorest in their comprehension. Facts are like grains of sand which are moved by the wind, but principles are these same grains cemented into rocks."

"Science is conservative in her nature, not destructive. She does not reject the truths discovered by practice, but receives them; they are never disputed by her, but are examined and receive from her their proper import and further application."

"Modern agriculture has, up to this time, no connection with the history of the development of man. That history is the mirror which reflects not only his errors and failures, but also his onward progress. But modern agriculture rejects the idea of ever being in error, and therefore she knows nothing of progress."

\section{It was also in 1859 that Abraham Lincoln spoke as follows:}

"To speak entirely within bounds, it is known that 50 bushels of wheat, or roo bushels of Indian corn, can be produced from an acre. . . Take 50 of wheat, and 100 of corn, to be the possibility, and compare it with the actual crops of the country. Many years ago I saw it stated, in a patent-office report, that 18 bushels was the average crop of wheat throughout the United States. . . . As to Indian corn, and, indeed, most other crops, the case has not been much better."

"What would be the effect upon the farming interest to push the soil up to something near its full capacity? Unquestionably it will take more labor to produce fifty bushels from an acre than it will to produce ten bushels from the same acre; but will it take more labor to produce fifty bushels from one acre than from five? Unquestionably, more thorough cultivation will require more labor to the acre; but will it require more to the bushel? If it should require just as much to the bushel, there are some probable, and several certain, advantages in favor of the thorough practice. It is probable it would develop those unknown causes which of late years have cut down our crops below their former average. It is almost certain, $I$ think, that, by deeper plowing, analysis of the soils, experiments with manures and varieties of seeds, observance of reasons, and the like, these causes would be discovered and remedied. It is certain that thorough cultivation would spare half, or more than half, the quantity of land. This proposition is self-evident, and can be made no plainer by repetitions or illustrations. The cost of land is a great item, even in new countries, and it constantly grows greater and greater, in comparison with other items, as the country grows older."

"No other human occupation opens so wide a field for the profitable and agreeable combination of labor with cultivated thought, as agriculture. I know nothing so pleasant to the mind as the discovery of anything that is at 
once new and valuable - nothing that so lightens and sweetens toil as the hopeful pursuit of such discovery. And how vast and how varied a field is agriculture for such discovery! The mind, already trained to thought in the country school, or higher school, cannot fail to find there an exhaustless source of enjoyment. Every blade of grass is a study; and to produce two where there was but one is both a profit and a pleasure. And not grass alone, but soils, seeds, and seasons - hedges, ditches, and fences - draining, droughts, and irrigation - plowing, hoeing, and harrowing - reaping, mowing, and threshing - saving crops, pests of crops, diseases of crops, and what will prevent or cure them - implements, utensils, and machines; their relative merits, and how to improve them - hogs, horses, and cattle - sheep, goats, and poultry - trees, shrubs, fruits, plants, and flowers - the thousand things of which these are specimens - each a world of study within itself.

"In all this, book learning is available. A capacity and taste for reading gives access to whatever has already been discovered by others. It is the key, or one of the keys, to the already solved problems. And not only so: it gives a relish and facility for successfully pursuing the unsolved ones. The rudiments of science are available, and highly available. Some knowledge of botany assists in dealing with the vegetable world - with all growing crops. Chemistry assists in the analysis of soils, selection and application of manures, and in numerous other ways. The mechanical branches of natural philosophy are ready help in almost everything, but especially in reference to implements and machinery.

"The thought recurs that education - cultivated thought - can best be combined with agricultural labor, or any labor, on the principle of thorough work; that careless, half-performed, slovenly work makes no place for such combination; and thorough work, again, renders sufficient the smallest quantity of ground to each man; and this, again, conforms to what must occur in a world less inclined to wars and more devoted to the arts of peace than heretofore. Population must increase rapidly, more rapidly than in former times, and erelong the most valuable of all arts will be the art of deriving a comfortable subsistence from the smallest area of soil. No community whose every member posesses this art, can ever be the victim of oppression in any of its forms. Such community will be alike independent of crowned kings, money kings, and land kings.

"It is said an Eastern monarch once charged his wise men to invent him a sentence to be ever in view, and which should be true and appropriate in all times and situations. They presented him the words, 'And this, too, shall pass away.' How much it expresses! How chastening in the hour of pride! How consoling in the depths of aftliction! 'And this, too, shall pass away.' And yet, let us hope, it is not quite true. Let us hope, rather, that by the best cultivation of the physical world beneath and around us, and the intellectual and moral world within us, we shall secure an individual, social, and political prosperity and happiness, whose course shall be onward and upward, and which, while the earth endures, shall not pass away." 
"Public prosperity is like a tree : agriculture is its roots; industry and commerce are its branches and leaves. If the root suffers, the leaves fall, the branches break, and the tree dies." - Chinese Philosophy.

"Let us never forget that the cultivation of the earth is the most important labor of man. Unstable is the future of a country which has lost its taste for agriculture. If there is one lesson of history that is unmistakable, it is that national strength lies very near the soil." - DANiEL Webster.

"The farm is the basis of all industry, but for many years this country has made the mistake of unduly assisting manufacture, commerce, and other activities that center in cities, at the expense of the farm." - JAMEs J. Hill.

Note. In the Orange Judd Farmer (January 22, I910), Professor F. H. King, who has recently visited the Orient, reports estimates based upon Japanese statistics as follows (Japan's population is nearly 53 millions):

Japan cultivates less than 14 million acres of land, to which are applied annually about 24 million tons of human manure; 23 million tons of compost made from animal manures and waste materials mixed with much grass, straw, sods, and mud (from canals and ditches); 5 million tons of green weeds, gathered from "weed lands" on uncultivated hills; and 776,000 tons of ashes. These materials make an average annual application of 3.8 tons per acre, containing, according to the accepted analyses of official Japanese chemists, 54 pounds of nitrogen, 14.8 pounds of phosphorus, and 29.2 pounds of potassium. In 1908 Japan imported 753,074 tons of commercial fertilizers (phosphates, etc.), which would probably raise to 20 pounds per acre per annum the amount of phosphorus applied. Besides this, large use is made of legume crops as green manures, and, where rice is grown, grass, straw, and chaff are used extensively for direct application to the land as organic manures.

From the data given here and in Table I 2 I, it will be seen that the total excrements per individual per year amount to about 900 pounds, and contain about 6 pounds of nitrogen, 1 pound of phosphorus, and $\mathrm{I} \frac{1}{2}$ pounds of potassium.

In comparison it may be stated that data gathered from digestion experiments with 24 men during a period of 220 days, by Dr. H. S. Grindley, University of Illinois, showed the average total excrements per year as 1032 pounds, containing 9.6 pounds of nitrogen and $\mathrm{I} .03$ pounds of phosphorus; while Wolff reports a total of 1035 pounds, containing 10.5 pounds of nitrogen, $\mathrm{I} .3$ of phosphorus, $\mathrm{r} .8$ of potassium, and 6.9 pounds of salt $(\mathrm{NaCl})$.

When we consider that nitrogen can be secured by legumes from the inexhaustible atmospheric supply, that potassium is exceedingly abundant in most soils, measured by the amount necessarily sold in either grain farming or livestock farming, and that the United States is exporting each year, for about 2 cents a pound, twice as much phosphorus as leaves our farms in the total wheat crop of the country, then the "argument" in favor of discarding our present system of city sewage disposal for that of China does not appear to be financially sound, with the present cost of labor in the United States. 


\section{APPENDIX}

\section{SECTION I}

\section{THE PRODUCTION OF PHOSPHATE ROCK ${ }^{1}$}

THE occurrence of rock phosphate in the United States has a very important bearing upon the agricultural industry, since certain classes of plant life cannot exist without the presence of phosphoric acid in the soil. Growing crops deplete the soil of its phosphoric acid, and if no steps are taken to restore this substance, the soil must eventually become nonproductive.

Florida, South Carolina, and Tennessee have for several years been the main soutces of phosphate in the United States. North Carolina, Alabama, and Pennsylvania have produced phosphate rock, but never on a large scale, and there is at present no production from these states. In I900 Arkansas entered the field as a producer, and in 1906 a new field was discovered in Wyoming, Idaho, and Utah.

Phosphate mining began in the United States in I868, in South Carolina. The existence of the rock had been known since 1837 , but the possibilities of its commercial use were not recognized until 1859 .

Until I 888 South Carolina enjoyed a monopoly of the phosphate industry of the United States. In that year Florida came forward as a phosphate state, with a production of 3000 long tons. In I 904 the production surpassed that of South Carolina, and Florida has maintained its lead up to the present time.

In 1892 phosphate was discovered in Tennessee, and two years later the production from that state was 19,188 long tons. In I899 Tennessee went ahead of South Carolina, the production from the latter state having decreased steadily since 1893 .

The production of phosphate from South Carolina from the beginning of the industry in 1867 to the year 1888 , during which period that state was the only producer, was $4,442,945$ long tons, valued at $\$ 23,697$, or 9 .

${ }^{1}$ Extracts from "Advance Chapter from Mineral Resources of the United States, Calendar Year 1908," by F. B. Van Horn of the United States Geological Survey. 
The following table shows the total production in the United States from I867 to 1908 :

Marketed Production of Phosphate Rock in the United States, I867-IgO8, AND EXPORTATION FOR 1899-I908

\begin{tabular}{|c|c|c|c|c|c|c|c|}
\hline YEAR & $\begin{array}{c}\text { QUANTITY } \\
\text { (Long Tons) }\end{array}$ & VALUE & YEAR & & $\begin{array}{l}\text { QUANTITY } \\
\text { (Long Tons) }\end{array}$ & Value & $\begin{array}{l}\text { EXPORTED } \\
\text { (Long Tons) }\end{array}$ \\
\hline $1867-1887$ & 4,442945 & $\$ 23,697019$ & I899. & & $\mathrm{I}, 5 \mathrm{I} 5702$ & $\$_{5}, 084 \circ 76$ & 867790 \\
\hline I888. & 448567 & 2,018552 & I900. & & 1,491216 & 5,359248 & 6I9995 \\
\hline I889. & 550245 & $2,93777^{6}$ & I9OI. & & $I, 483723$ & 5,3 I64०3 & 729539 \\
\hline I89o. & 510499 & 3,213795 & I9O2 & & $\mathrm{I}, 4903 \mathrm{I} 4$ & 4,693444 & 802086 \\
\hline I89I. & 587988 & 3,65 I I 50 & 1903. & & I, $5^{8} \mathrm{I} 57^{6}$ & 5,319294 & 785259 \\
\hline 1892 & 68 I $57 \mathrm{I}$ & 3,296227 & 1904 . & & $\mathrm{I}, 874428$ & 6,580875 & 842484 \\
\hline 1893 & 941368 & 4,136070 & I905. & & I,947I 90 & $6,76_{34} 0_{3}$ & 934940 \\
\hline I894. & 996949 & 3,479547 & I906. & & 2,080957 & 8,579437 & 904214 \\
\hline I895. & $\mathrm{I}, 03855^{\mathrm{I}}$ & 3,606094 & 1907 & & 2,265343 & 10,653558 & 1,018212 \\
\hline 1896. & $93 \circ 779$ & $2,80337^{2}$ & I908. & & $2,3^{86}$ I $3^{8}$ & I I ,399I 24 & I,I 884 I I \\
\hline 1897 . & I ,०39345 & 2,673202 & & & & & \\
\hline I 898 . & I, 308885 & 3,453460 & & & & . & \\
\hline
\end{tabular}

Of the total quantity (3I,594,279 tons) South Carolina has furnished I 2,1 38,454 tons; Florida, I4,087,833 tons; Tennessee, 5,315,422 tons; and other states, 53,570 tons. In twenty-one years Florida has produced more phosphate than has South Carolina in thirty-two years.

The phosphate deposits range in age from the Ordovician in Tennessee to the Tertiary in Florida, occurring also in the Devonian in Tennessee and Arkansas, and in the Carboniferous in the Wyoming-Idaho-Utah field.

Within the last few years a large area of phosphate-bearing rock has been discovered in the western United States. This discovery is of much importance, since it opens a new field in an area which is tributary to the great agricultural region of the Middle West. The phosphate occurs over a considerable area in southeastern Idaho, southwestern Wyoming, and northeastern Utah. It is found in rocks of "Upper Carboniferous" age in a series of shales and limestones, roo feet thick, within which are several beds of phosphate rock ranging in thickness from a few inches to ro feet. At the base of the series is a limestone, and 6 to 8 inches of soft brown shale separates this from the principal phosphate bed, which is 5 to 6 feet thick. This phosphate bed is oolitic in character and high in phosphoric acid. There are in the series several other beds ranging from a few inches to ro feet in thickness, and sepa- 
rated by thin beds of limestone or shale. Usually one and sometimes two of these beds at a given section are workable, and probably some of the others will eventually be mined. The lime phosphate content in the workable beds varies from $6_{5}$ to 80 per cent, with an average of 72 per cent.

\section{Development and Production}

The newness of the field, the lack of transportation facilities, and the high freight rates have prevented the development of this phosphate territory to any great extent, although there has been some shipment from Montpelier, Idaho, in the last three years.

The world's production of phosphate rock, 1905 to 1907 , inclusive, is given in the following table:

World's Production of Phosphate Rock, ig05-1907, By·Countries, in METRic Tons

\begin{tabular}{|c|c|c|c|c|c|c|}
\hline \multirow{2}{*}{ Country } & \multicolumn{2}{|c|}{1905} & \multicolumn{2}{|c|}{1906} & \multicolumn{2}{|c|}{1907} \\
\hline & QuAntity & Value & QUANTITY & Value & QUANTITY & Valee \\
\hline Algeria & 334784 & $\$_{1,225 \text { I } 26}$ & $33353 \mathrm{I}$ & $\$ 965600$ & 373763 & $\$ 2, I_{42} 352$ \\
\hline Aruba . . & 23307 & 42188 & 26 工 38 & (a) & $(b)$ & \\
\hline Belgium . . & 193305 & $33^{2292}$ & I 52140 & 2826 I 2 & (b) & \\
\hline Canada . . & I 338 & 8876 & $52 \mathrm{I}$ & 4024 & 748 & 6018 \\
\hline Christmas Island & 995 I9 & (a) & 92010 & (a) & $(b)$ & \\
\hline France . . . & 476720 & 2,093 I 8 & 469408 & $\mathrm{I}, 872000$ & 43 I 237 & I,8767.36 \\
\hline Norway . . . & 2522 & 33768 & 3482 & 46524 & $(b)$ & \\
\hline Spain . . . & I 370 & 7295 & I 300 & 7592 & & \\
\hline Tunis . . & $52173 \mathrm{I}$ & I, 8 I 2493 & 796000 & 2,304400 & 1,069000 & $(a)$ \\
\hline United Kingdom & & & & & & 224 \\
\hline United States . & $\mathrm{I}, 97^{8} 345$ & 6,763403 & $2, \operatorname{II} 4252$ & 8,579437 & 2,301588 & $10,65355^{8}$ \\
\hline
\end{tabular}

(a) Value not reported.

(b) Statistics not yet available.

\section{Available Phosphate Deposits}

The known phosphate deposits of the United States are distributed principally among four localities: (I) along the west coast of Florida, running back 20 to 25 miles inland; (2) along the coast of South Carolina, extending 6 to 20 miles inland; (3) in central Tennessee; and (4) in an area comprising southeastern Idaho, southwestern Wyoming, and northeastern Utah. In addition to these areas, some deposits occur in north-central Arkansas, along the Georgia-Florida state line, and in 
North Carolina, Alabama, Mississippi, and Nevada, but these are merely of low grade and not utilized at the present time. The three important deposits first mentioned have been worked from ten to thirty years; the fourth is a new field which has as yet had but a small output.

\section{Estimated Life of United States Phosphate Deposits}

The rate of increase in production for the last twenty years has been I 7 per cent for each decade. Assuming that this rate of increase will continue, it will require but a comparatively short time to exhaust the available supply of phosphate rock in the United States. The annual production, at the stated rate of increase, will be approximately I 7,000,000 tons in 1932 .

It is hardly probable that the rate of increase in production will be so great as for the last decade, since the agricultural lands of the Middle West do not at present need artificial assistance. But increasing population, with its accompanying intensive farming, will eventually force these states to the use of fertilizing materials. The reclamation of arid lands in the West will probably postpone the day, but even those lands will early need some assistance to grow the large crops which will be required of them.

Of course, the vast amount of low-grade rock which is not now available will be in reserve, and some time before the exhaustion of the highgrade phosphates we shall doubtless have begun to use this rock. The increasing price of the 60 to 80 per cent phosphate will have a hastening effect on the utilization of the present low-grade material. The deposits of Arkansas, Georgia, North Carolina, Alabama, Tennessee, and the West, which run from 30 to 50 per cent in lime phosphate, will be available to draw upon after the high-grade rock is exhausted. This class of deposits, especially in Tennessee and the Western States, will afford an enormous tonnage, but, based upon present available deposits, the life of the phosphates must at best be a short one.

\section{Foreign Deposits}

Deposits of phosphate rock exist in Algeria, France, New Zealand, Canada, Russia, Spain, Tunis, Belgium, French Guiana, and some of the South Sea Islands. The deposits of France and Belgium are practically exhausted, only those of low grade remaining. Concerning the other countries no information as to reserve tonnage is at hand except for the three South Sea Islands - Ocean, Pleasant, and Makatea. These 
three islands have deposits which are estimated to aggregate $60,000, \infty 00$ tons of high-grade phosphate rock.

It would appear certain that the phosphate deposits of the United States are to be drained for the benefit of the worn-out farm lands of foreign countries. So far as the deposits of Florida, Tennessee, and South Carolina are concerned, this cannot be easily prevented, but it has been suggested that "the production of the newly opened Western fields may be preserved for the United States by retaining, in the government, title to all the phosphate rock in the lands now belonging to the United States, and by leasing these deposits under appropriate terms. In the lease could be included a clause providing that the lessee shall agree to mine phosphate rock only for domestic consumption."

\section{SECTION II}

\section{MODEL FERTILIZER LAW}

The following is offered as a model law for governing the sale of commercial fertilizers, conforming to a report. adopted by the Association of American Agricultural Colleges and Experiment Stations. (See Proceedings ${ }^{1}$ Twelfth Annual Convention (1906), page I 28 , Bulletin I 84 , of the Office of Experiment Stations, United States Department of Agriculture; also Proceedings ${ }^{2}$ 24th Annual Convention of the Association

1 "Providing concurrent action is taken by the Association of Official Agricultural Chemists and the American Chemical Society, your committee favors the adoption of the element system for reporting analytical results in the analysis of soils, ashes, and fertilizers, and recommends that the association urge those responsible for fertilizer legislation to have the laws changed, if necessary, and as soon as practicable, to meet with these recommendations, if concurred in."

"The committee also recommends that in case of the adoption of the foregoing there be required to be printed on the bag or on the tag to be attached to the bag or to accompany fertilizers sold in bulk an explanatory statement naming the materials in which the plant food is carried."

2 "That the association vote upon the advisability of permitting the use of a dual system of nomenclature, where desirable, with a view to the ultimate adoption of the element system for reporting the analysis of fertilizers, soils, ash, etc."

"That the suggestion of the committee looking toward the ultimate adoption of the element system be approved, but that no state should discontinue the use of the terms now in use until such discontinuation is also approved by this association, and that meanwhile the subject should be brought before the International Congress of Applied Chemistry in an effort to secure international agreement."

NoTE. - In the author's opinion, international agreement will never be secured, judging from the systems in vogue for money, weights and measures, etc. If secured, 
of Official Agricultural Chemists (1907), page roo, Bulletin I 6, of the Bureau of Chemistry, United States Department of Agriculture.)

\section{AN ACT to prevent fraud in the manufacture and sale of commercial fertilizers.}

Section r. Be it enacted by the people of the State of - represented in the General Assembly: That any person or company who shall offer, sell, or expose for sale, in this State any commercial fertilizer, the price of which exceeds. five dollars a ton, shall affix to every package in a conspicuous place on the outside thereof, or furnish to the purchasers of goods sold in bulk, a plainly printed certificate, naming the materials, including the filler (if any), of which the fertilizer is made, stating the name or trade-mark under which the article is sold, the name of the manufacturer and the place of manufacture, and a chemical analysis, stating only the minimum percentages of nitrogen in available form, of potassium soluble in water, of phosphorus in available form (soluble or reverted), and of insoluble phosphorus, the analyses to be made in accordance with the methods adopted by the Association of Official Agricultural Chemists of the United States.

Section 2. Before any commercial fertilizer is sold, or offered for sale, the manufacturer, importer, or party who causes it to be sold, or offered for sale, within the State of —— shall file in the office of the State Board of Agriculture, a certified copy of the certificate referred to in Section $\mathrm{r}$ of this ACT, and shall deposit with the secretary of the said Board of Agriculture a sealed glass jar, containing not less than one pound of the fertilizer, accompanied with an affidavit that it is a fair average sample.

SECTION 3. The manufacturer, importer, or agent of any commercial fertilizer exceeding five dollars per ton in price, shall pay, annually, a license fee of twenty-five dollars for each one thousand tons (or fraction thereof) of said fertilizer, for the privilege of selling or offering for sale,

it would be a matter of some convenience to scientists, but of little or no practical value to American agriculture. The fertilizer laws of some states (at least of Kansas and Illinois) already require fertilizer guarantees to be made on the basis of the actual plant-food elements; and the agricultural experiment stations of some other states (at least of Ohio, Iowa, Nebraska, and South Dakota) now report the results of soil investigations in terms of the elements.

The use of the simple element system is of great value to any state, even though all adjoining states continue to use the complex systems, which require, for example, that the potassium in potassium chlorid $(\mathrm{KCl})$ shall be reported in terms of potash $\left(\mathrm{K}_{2} \mathrm{O}\right)$ and that the calcium, even in acid soils, shall be reported in terms of quicklime $(\mathrm{CaO})$. 
within the State, during the calendar year, said fee to be paid to the treasurer of the - State Board of Agriculture: Provided, that whenever the manufacturer or importer shall have paid the license fee herein required, any person previously certified to the Office of the State Board of Agriculture to be an authorized agent for such manufacturer or importer shall not be required to pay the fee named in this section.

Section 4. All analyses of commercial fertilizers sold within the State, shall be under the direction of the State Board of Agriculture, and paid for out of funds arising from license fees, as provided for in Section 3 . At least one analysis of each fertilizer shall be made annually, from a sample collected in the open market.

SEction 5. Any person or party who shall offer or expose for sale any commercial fertilizer without complying with the provisions of Sections I, 2, and 3 of this Act; or shall permit an analysis of such fertilizer to be furnished, stating that it contains a larger percentage of any one or more of the constituents named in Section I of this Act, than it really does contain, shall be fined not less than two hundred dollars for the first offense, and not less than five hundred dollars for every subsequent offense; and the offender, in all cases, shall also be liable for damages sustained by the purchaser of such fertilizer: Provided, however, that a deficiency of one half per cent of the nitrogen, potassium, or phosphorus claimed to be contained, shall not be considered as evidence of fraudulent intent.

Section 6. Suit may be brought for the recovery of fines or damages under the provisions of this ACT, in the county where the fertilizer was offered for sale, or where it was manufactured; and all fines so recovered, shall be paid into the treasury of the State Board of Agriculture by the court collecting the same. The treasurer of the State Board of Agriculture, after payment of expenses for collecting and analysis, and the publication of the annual report relating to the analysis, use, and results obtained from fertilizers, shall on or before the first day of July pay into the treasury of the State any surplus remaining in his hands, on account of license fees and fines, received during the previous calendar year through the provisions of this Act.

SEction 7. The - State Board of Agriculture shall publish, annually, a correct report of all analyses made and certificates filed, together with a statement of moneys received on account of license fees and fines, and expended for analyses and publication of the report relating to fertilizers.

Section 8. The officers and members of the State Board of Agriculture or any person authorized by said board is hereby empowered 
to select from any lot or package of commercial fertilizers exposed for sale in any county of - , a quantity not exceeding two pounds, which quantity shall be for analysis to compare with the sample deposited with the secretary of said Board of Agriculture, as provided for in Section 2 of this Act, and with the printed certificate described in Section $\mathrm{r}$.

SEction 9. All suits for the recovery of fines, under provisions of this Act, shall be brought by the Attorney-general of the State in the name of the people of the State of -

In some states fertilizers can be sold only with tags or certificates purchased in advance from the State Board of Agriculture or other official control. The certificates may be issued in different denominations, as Io-ton tags, I-ton tags, and o.I-ton tags, at a fixed tax per ton, which may amount to as much as 25 cents per ton (in South Carolina, for example),

\section{SECTION III}

TABLE 121a. COMPOSITION OF ANIMAL PRODUCTS, WASTE, LITTER, AND ASHES

(Pounds in 1000 of the Material)

\begin{tabular}{|c|c|c|c|c|c|}
\hline MATERIAL & $\underset{\text { MATTER }}{\text { DRY }}$ & Nitrogen & PHOSPHORUS & РотAssium & $\begin{array}{c}\text { Calciem } \\
\text { CARBoNate }\end{array}$ \\
\hline 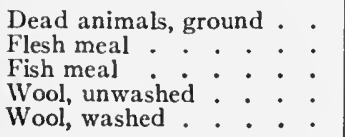 & $\begin{array}{l}950 \\
720 \\
880 \\
850 \\
850\end{array}$ & $\begin{array}{l}65.0 \\
97.0 \\
81.0 \\
54.0 \\
92.0\end{array}$ & $\begin{array}{r}61.6 \\
27.5 \\
56.8 \\
.3 \\
.8\end{array}$ & $\begin{array}{r}2.5 \\
5.8 \\
2.0 \\
46.5 \\
1.6\end{array}$ & \\
\hline $\begin{array}{l}\text { Buttermilk } \\
\text { Human manure (mixed), fresh } \\
\text { Human solid excrement, fresh } \\
\text { Human urine, fresh } \\
\text { Chicken manure, fresh }: .\end{array}$ & $\begin{array}{r}100 \\
65 \\
228 \\
37 \\
420\end{array}$ & $\begin{array}{r}6.5 \\
7.0 \\
10.0 \\
6.0 \\
13.6\end{array}$ & $\begin{array}{r}1.0 \\
1.1 \\
4.8 \\
.7 \\
-5 \cdot 3\end{array}$ & $\begin{array}{l}1.7 \\
1.7 \\
2.1 \\
1.7 \\
5.8\end{array}$ & \\
\hline $\begin{array}{l}\text { Red clover straw } \\
\text { Soy bean straw }\end{array}$ & $\begin{array}{l}850 \\
850 \\
900 \\
900\end{array}$ & $\begin{array}{r}14.7 \\
17.5 \\
10.4 \\
5.8\end{array}$ & $\begin{array}{r}1.8 \\
1.7 \\
.6 \\
.6\end{array}$ & $\begin{array}{r}10.4 \\
11.0 \\
6.6 \\
1.1\end{array}$ & \\
\hline 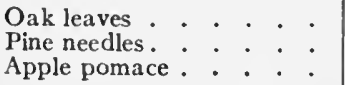 & $\begin{array}{l}850 \\
850 \\
200\end{array}$ & $\begin{array}{r}10.0 \\
8.8 \\
2.3\end{array}$ & $\begin{array}{l}.9 \\
.8 \\
.1\end{array}$ & $\begin{array}{r}2.8 \\
.6 \\
1.1\end{array}$ & \\
\hline $\begin{array}{l}\text { Wood ashes, unleached } \\
\text { Wood ashes, leached } \\
\text { Coal ashes (soft) } \\
\text { Coal ashes (hard) }\end{array}$ & $\begin{array}{l}87 \stackrel{0}{5} \\
700\end{array}$ & $\bar{\square}$ & $\begin{array}{r}5.0 \\
5.0 \\
1.5 \\
.5\end{array}$ & $\begin{array}{r}50.0 \\
10.0 \\
3.0 \\
1.0\end{array}$ & $\begin{array}{l}500 \\
400\end{array}$ \\
\hline
\end{tabular}


TABLE x $2 x$. COMPOSITION OF PLANTS AND PLANT PRODUCTS (CHIEFLY AFTER VON WOLFF, 1889)

(Pounds in rooo of Produce)

\begin{tabular}{|c|c|c|c|c|c|c|c|c|c|c|c|}
\hline Produce & 蛋 & 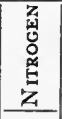 & 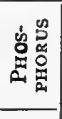 & 楁忽 & 离离 & 䓛 & 点 & 总 & $\begin{array}{l}\text { हैं } \\
\text { 今. }\end{array}$ & 宽 & 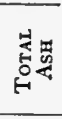 \\
\hline 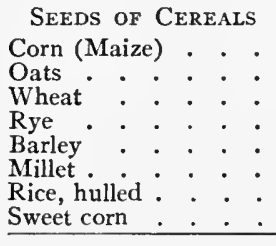 & $\begin{array}{l}850 \\
850 \\
850 \\
850 \\
850 \\
850 \\
850 \\
180 \\
\end{array}$ & $\begin{array}{r}16.0 \\
17.6 \\
20.8 \\
17.6 \\
16.0 \\
20.3 \\
10.5 \\
4.6 \\
\end{array}$ & $\begin{array}{l}2.5 \\
3.0 \\
3.4 \\
3 \cdot 7 \\
3 \cdot 4 \\
2.8 \\
0.8 \\
0.3 \\
\end{array}$ & $\begin{array}{l}3 \cdot 1 \\
4.0 \\
4 \cdot 3 \\
4.8 \\
3.9 \\
2.7 \\
0.7 \\
2.0 \\
\end{array}$ & $\begin{array}{l}\text { I.I } \\
1.1 \\
1.2 \\
1.2 \\
1.2 \\
1.7\end{array}$ & $\begin{array}{l}0.2 \\
0.7 \\
0.4 \\
0.4 \\
0.4 \\
0.1\end{array}$ & $\begin{array}{l}0.04 \\
0.2 \\
0.04 \\
0.08 \\
0.2 \\
0.04\end{array}$ & $\begin{array}{l}0.1 \\
4.9 \\
0.1 \\
0.1 \\
2.7 \\
7.3\end{array}$ & $\begin{array}{l}0.07 \\
0.3 \\
0.2 \\
0.2 \\
0.4 \\
0.3\end{array}$ & $\begin{array}{l}0.2 \\
0.3 \\
0.1 \\
0.1 \\
0.2 \\
0.1\end{array}$ & $\begin{array}{l}12.4 \\
26.7 \\
16.8 \\
17.9 \\
22.3 \\
29.5\end{array}$ \\
\hline 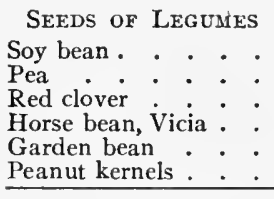 & $\begin{array}{l}85^{\circ} \\
85^{\circ} \\
85^{\circ} \\
85^{\circ} \\
85^{\circ} \\
85^{\circ} \\
\end{array}$ & \begin{tabular}{|l|}
53.4 \\
35.8 \\
30.5 \\
40.8 \\
39.0 \\
38.0 \\
\end{tabular} & $\begin{array}{l}4.3 \\
3.6 \\
6.3 \\
5 \cdot 3 \\
4.2 \\
3.3 \\
\end{array}$ & $\begin{array}{r}9.9 \\
8.4 \\
11.3 \\
10.7 \\
10.1 \\
7.0 \\
\end{array}$ & $\begin{array}{l}1.4 \\
1.1 \\
3.0 \\
1.3 \\
1.3\end{array}$ & $\begin{array}{l}1.1 \\
0.8 \\
1.8 \\
1.1 \\
1.1\end{array}$ & $\begin{array}{l}0.3 \\
0.3 \\
0.4 \\
0.4 \\
0.4\end{array}$ & $\begin{array}{l}0.09 \\
0.2 \\
0.09 \\
0.09\end{array}$ & $\begin{array}{l}0.2 \\
0.1 \\
0.3 \\
0.2 \\
0.3\end{array}$ & $\begin{array}{l}0.1 \\
0.4 \\
0.5 \\
0.5 \\
0.3\end{array}$ & $\begin{array}{l}28 . \\
23 . \\
38 . \\
31 . \\
27 .\end{array}$ \\
\hline 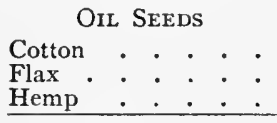 & $\begin{array}{l}850 \\
850 \\
850 \\
\end{array}$ & $\begin{array}{l}36.5 \\
32.8 \\
26.1 \\
\end{array}$ & $\begin{array}{l}4.2 \\
5 \cdot 7 \\
7.1 \\
\end{array}$ & $\begin{array}{l}8.4 \\
8.0 \\
7.6 \\
\end{array}$ & $\begin{array}{l}3.1 \\
2.7 \\
1.5 \\
\end{array}$ & $\begin{array}{l}1.2 \\
1.8 \\
7.5 \\
\end{array}$ & $\begin{array}{l}0.3 \\
0.3 \\
0.04 \\
\end{array}$ & $\begin{array}{l}0.04 \\
0.2 \\
2.5 \\
\end{array}$ & $\begin{array}{l}1.6 \\
0.5 \\
0.3 \\
\end{array}$ & 0.5 & $\begin{array}{l}33 . \\
32 . \\
46 . \\
\end{array}$ \\
\hline 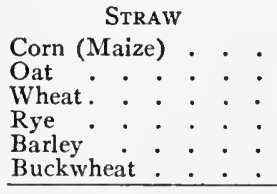 & $\begin{array}{l}850 \\
850 \\
850 \\
850 \\
850 \\
850 \\
\end{array}$ & $\begin{array}{r}4.8 \\
5.6 \\
4.8 \\
4.0 \\
6.4 \\
13.0 \\
\end{array}$ & $\begin{array}{l}1.7 \\
1.2 \\
1.0 \\
1.1 \\
0.8 \\
2.7 \\
\end{array}$ & $\begin{array}{r}13.7 \\
13.5 \\
5.2 \\
7.1 \\
8.8 \\
20.4 \\
\end{array}$ & $\begin{array}{l}1.6 \\
1.4 \\
0.7 \\
0.7 \\
0.7 \\
1.2 \\
\end{array}$ & $\begin{array}{l}3.5 \\
3.0 \\
1.9 \\
2.2 \\
2.3 \\
6.9 \\
\end{array}$ & $\begin{array}{l}1.0 \\
0.6 \\
0.4 \\
0.6 \\
0.7 \\
1.1 \\
\end{array}$ & $\begin{array}{r}6.2 \\
13.4 \\
14.4 \\
8.8 \\
10.90 \\
1.4 \\
\end{array}$ & $\begin{array}{l}0.4 \\
1.5 \\
0.4 \\
0.5 \\
1.2 \\
0.8 \\
\end{array}$ & $\begin{array}{l}0.6 \\
2.7 \\
0.8 \\
0.8 \\
1.5 \\
4.1 \\
\end{array}$ & $\begin{array}{l}45 . \\
61 . \\
46 . \\
38.2 \\
45.9 \\
51.7\end{array}$ \\
\hline 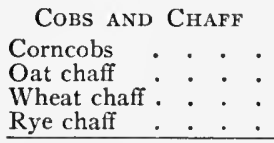 & $\begin{array}{l}85^{\circ} \\
85^{\circ} \\
850 \\
850 \\
\end{array}$ & $\begin{array}{l}2.3 \\
6.4 \\
7.2 \\
5.8 \\
\end{array}$ & $\begin{array}{l}0.09 \\
0.6 \\
1.7 \\
2.4 \\
\end{array}$ & $\begin{array}{l}1.9 \\
3.7 \\
6.9 \\
4 \cdot 3 \\
\end{array}$ & $\begin{array}{l}0.1 \\
0.9 \\
0.7 \\
0.7 \\
\end{array}$ & $\begin{array}{l}0.1 \\
2.8 \\
1.2 \\
2.5 \\
\end{array}$ & $\begin{array}{l}0.04 \\
1.4 \\
0.04 \\
\end{array}$ & $\begin{array}{r}0.6 \\
23.5 \\
34.8 \\
30.9 \\
\end{array}$ & $\begin{array}{l}0.07 \\
2.1 \\
1.3 \\
0.2 \\
\end{array}$ & $\begin{array}{l}0.2 \\
0.8 \\
0.4 \\
\end{array}$ & $\begin{array}{r}4.5 \\
71.2 \\
92.0 \\
82.7 \\
\end{array}$ \\
\hline $\begin{array}{l}\quad \text { HAY } \\
\text { Redtop. } \\
\text { Red clover in flower : } \\
\text { Alsike clover } \\
\text { Alfalfa, early bloom } \\
\text { Red clover, ripe } \\
\text { Red clover, in bud } \\
\text { Red clover, young. } \\
\text { White clover in flower } \\
\text { From very young grass }\end{array}$ & $\begin{array}{l}850 \\
850 \\
850 \\
850 \\
850 \\
850 \\
850 \\
850 \\
850 \\
\end{array}$ & $\begin{array}{l}10.5 \\
19.7 \\
24.0 \\
23.0 \\
12.5 \\
24.5 \\
35.5 \\
23.2 \\
25.5 \\
\end{array}$ & $\begin{array}{l}1.5 \\
2.5 \\
1.8 \\
2.3 \\
1.9 \\
3 \cdot 1 \\
4.5 \\
3 \cdot 5 \\
3.2 \\
\end{array}$ & $\begin{array}{r}8.0 \\
15.7 \\
9.4 \\
12.3 \\
8.3 \\
21.5 \\
25.3 \\
11.1 \\
26.3 \\
\end{array}$ & $\begin{array}{l}3 \cdot 9 \\
3.1 \\
1.9 \\
4.2 \\
4.7 \\
4.7 \\
3.6 \\
2.8 \\
\end{array}$ & $\begin{array}{r}14.6 \\
9.8 \\
18.2 \\
\text { I } 1.3 \\
\text { r } 5.1 \\
\text { r } 7.1 \\
\text { r } 3.3 \\
7.2 \\
\end{array}$ & $\begin{array}{l}0.8 \\
0.6 \\
1.5 \\
0.6 \\
0.7 \\
0.7 \\
1.8 \\
1.1\end{array}$ & $\begin{array}{l}0.8 \\
0.8 \\
0.8 \\
2.8 \\
1.4 \\
0.9 \\
1.2 \\
1.3 \\
7.5\end{array}$ & $\begin{array}{l}0.8 \\
0.9 \\
0.8 \\
1.0 \\
1.1 \\
1.4 \\
3 \cdot 3 \\
1.0\end{array}$ & $\begin{array}{l}2.2 \\
2.2 \\
1.9 \\
1.3 \\
2.4 \\
3 \cdot 3 \\
2.6 \\
8.4 \\
\end{array}$ & $\begin{array}{l}57.6 \\
40.0 \\
62.0 \\
44.7 \\
68.4 \\
82.3 \\
61.1 \\
82.4\end{array}$ \\
\hline $\begin{array}{l}\text { GRASSES } \\
\text { Timothy . } .: \\
\text { Rye grass : } \\
\text { Orchard grass : } \\
\text { Rich pasture grass }\end{array}$ & $\begin{array}{l}300 \\
300 \\
300 \\
218\end{array}$ & $\begin{array}{l}5 \cdot 4 \\
5 \cdot 7 \\
7 \cdot 2\end{array}$ & $\begin{array}{l}1.0 \\
1.0 \\
0.6 \\
0.8\end{array}$ & $\begin{array}{l}5 \cdot 9 \\
5 \cdot 9 \\
4 \cdot 9 \\
6.8\end{array}$ & $\begin{array}{l}0.4 \\
0.2 \\
0.3 \\
0.7\end{array}$ & $\begin{array}{l}\text { I. } 2 \\
1.1 \\
0.8 \\
1.9\end{array}$ & $\begin{array}{l}0.2 \\
0.3 \\
0.2 \\
0.3\end{array}$ & $\begin{array}{l}3.1 \\
3.1 \\
2.8 \\
1.9\end{array}$ & $\begin{array}{l}0.3 \\
0.5 \\
0.6 \\
0.2\end{array}$ & $\begin{array}{l}1.1 \\
2.1 \\
1.3 \\
2.1\end{array}$ & $\begin{array}{l}20.5 \\
20.4 \\
17.8 \\
21.1\end{array}$ \\
\hline
\end{tabular}


TABLE 12I $b$. COMPOSITION OF PLANTS AND PLANT PRODUCTS (CHIEFLY AFTER VON WOLFF, I889)-Continued

(Pounds in 1000 of Produce)

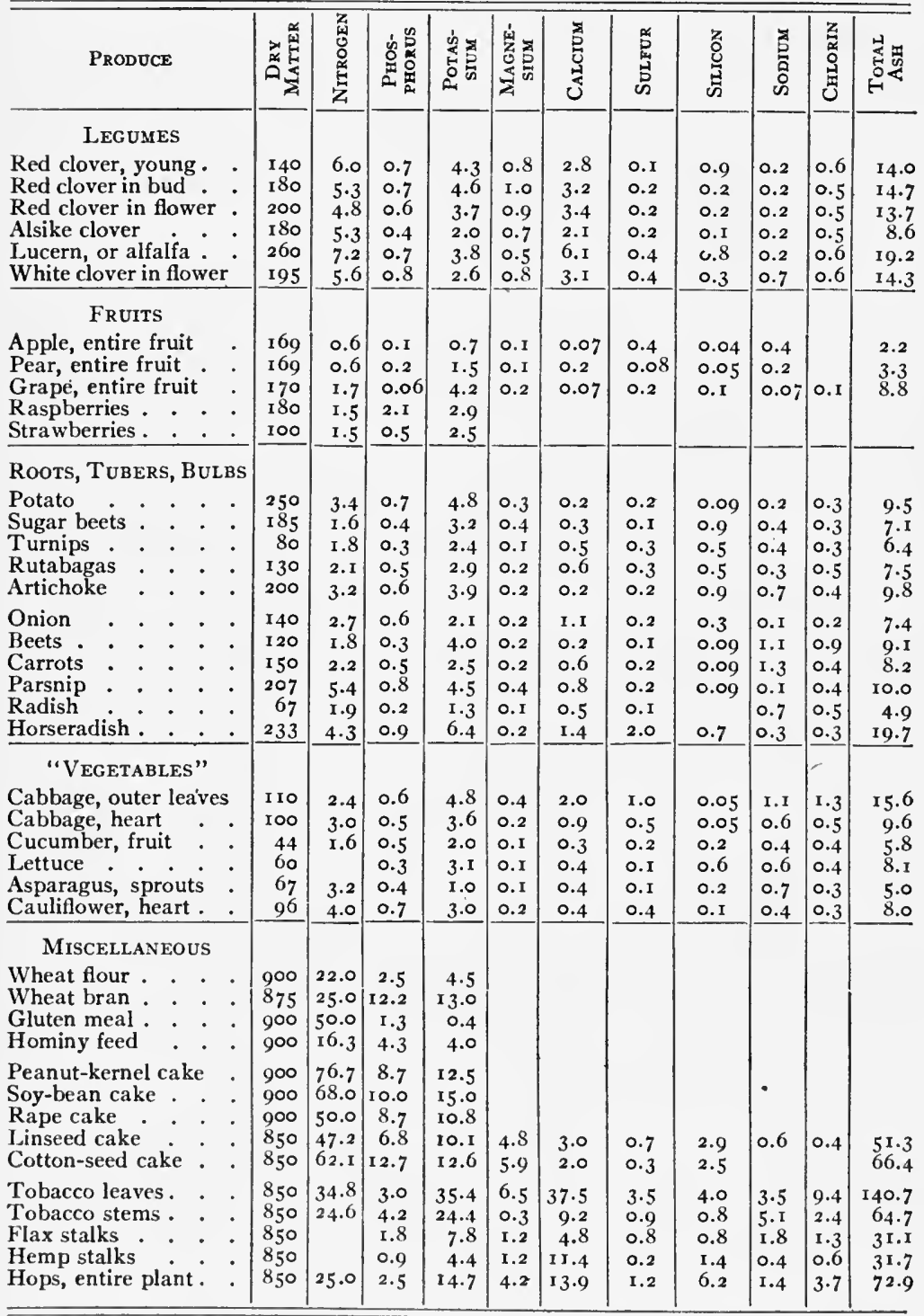




\section{SECTION IV}

\section{STATISTICS OF AGRICULTURAL PRODUCTS ${ }^{1}$}

\section{Crop Areas, Yields, and Values, 1908}

The final revised estimates of the Crop Reporting Board of the Bureau of Statistics, United States Department of Agriculture, based on the reports of the correspondents and agents of the Bureau, supplemented by information derived from other sources, indicate the acreage, production, and value, in 1908 and 1907 , of important farm crops of the United States to have been as follows:

\begin{tabular}{|c|c|c|c|c|c|c|c|c|}
\hline & & & & & & DDUCTION & FARM & ALUUE, DEC. I \\
\hline $\mathrm{C}_{\mathrm{ROP}}$ & & & & $\begin{array}{l}\text { ACREAGE } \\
\text { (Acres) }\end{array}$ & $\begin{array}{c}\text { Per } \\
\text { Acre } \\
\text { (Bu.) }\end{array}$ & $\begin{array}{l}\text { Total } \\
\text { (Bu.) }\end{array}$ & $\begin{array}{c}\text { Per } \\
\text { Bushel }\end{array}$ & Total \\
\hline 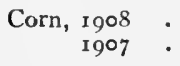 & . & & . & $\begin{array}{r}101,788000 \\
99,931000\end{array}$ & $\begin{array}{l}26.2 \\
25.9\end{array}$ & $\begin{array}{l}2,668,651000 \\
2,59^{2}, 320000\end{array}$ & $\begin{array}{r}\text { \$o.606 } \\
.516\end{array}$ & $\begin{array}{r}\$ 1,616,145000 \\
1,336,901000\end{array}$ \\
\hline Winter wheat, & $\begin{array}{l}90 \\
90\end{array}$ & & : & $\begin{array}{l}30,349000 \\
28,132000\end{array}$ & $\begin{array}{l}14.4 \\
14.6\end{array}$ & $\begin{array}{l}437,908000 \\
409,442000\end{array}$ & $\begin{array}{l}.937 \\
.882\end{array}$ & $\begin{array}{l}410,330000 \\
361,217000\end{array}$ \\
\hline Spring wheat, & $\begin{array}{l}908 \\
90 \%\end{array}$ & & : & $\begin{array}{l}17,208000 \\
17,079000\end{array}$ & $\begin{array}{l}\text { I } 3.2 \\
13.2\end{array}$ & $\begin{array}{l}226,694000 \\
224,645000\end{array}$ & $\begin{array}{l}.911 \\
.860\end{array}$ & $\begin{array}{l}206,496000 \\
193,220000\end{array}$ \\
\hline $\begin{array}{r}\text { Oats, } 1908 \text {. } \\
1907\end{array}$ & $\dot{.}$ & . & : & $\begin{array}{l}32,344000 \\
31,837000\end{array}$ & $\begin{array}{l}25.0 \\
23.7\end{array}$ & $\begin{array}{l}807,156000 \\
754,443000\end{array}$ & $\begin{array}{l}.472 \\
.443\end{array}$ & $\begin{array}{l}3^{8} \mathrm{I}, \mathrm{I} 7 \mathrm{1} 1000 \\
334,568000\end{array}$ \\
\hline $\begin{array}{r}\text { Barley, } 1908 \text {. } \\
\text { I907. }\end{array}$ & : & & . & $\begin{array}{l}6,646000 \\
6,448000\end{array}$ & $\begin{array}{l}25.1 \\
23.8\end{array}$ & & $\begin{array}{l}.554 \\
.666\end{array}$ & $\begin{array}{r}92,442000 \\
102,290000\end{array}$ \\
\hline $\begin{array}{r}\text { Rye, } \\
1908 . \\
1907 .\end{array}$ & : & & : & $\begin{array}{l}1,948000 \\
1,926000\end{array}$ & $\begin{array}{l}16.4 \\
16.4\end{array}$ & & $\begin{array}{l}.73^{6} \\
.731\end{array}$ & $\begin{array}{l}23,455000 \\
23,068000\end{array}$ \\
\hline Buckwheat, 19 & & & : & $\begin{array}{l}803000 \\
800000\end{array}$ & $\begin{array}{l}19.8 \\
\times 7.9\end{array}$ & & $\begin{array}{l}.756 \\
.698\end{array}$ & $\begin{array}{r}\text { I } 2,004000 \\
9,975000\end{array}$ \\
\hline $\begin{array}{r}\text { Flaxseed, } 1908 \\
1907\end{array}$ & . & . & : & $\begin{array}{l}2,679000 \\
2,864000\end{array}$ & $\begin{array}{l}9.6 \\
9.0\end{array}$ & $\begin{array}{l}25,805000 \\
25,851000\end{array}$ & $\begin{array}{r}\text { I. } 184 \\
.956\end{array}$ & $\begin{array}{l}30,577000 \\
24,713000\end{array}$ \\
\hline${ }_{1907}^{\text {Rice, }}$ & : & • & . & $\begin{array}{l}655000 \\
627300\end{array}$ & $\begin{array}{l}33.4 \\
29.9\end{array}$ & $\begin{array}{l}21,890000 \\
18,73^{8000}\end{array}$ & $\begin{array}{l}.812 \\
.858\end{array}$ & $\begin{array}{l}17,771000 \\
16,081000\end{array}$ \\
\hline $\begin{array}{r}\text { Potatoes, } 1908 \\
1907\end{array}$ & . & & . & $\begin{array}{l}3,257000 \\
3,124000\end{array}$ & $\begin{array}{l}85 \cdot 7 \\
95 \cdot 4\end{array}$ & $\begin{array}{l}278,985000 \\
297,942000\end{array}$ & $\begin{array}{l}.706 \\
.617\end{array}$ & $\begin{array}{l}197,039000 \\
183,880000\end{array}$ \\
\hline 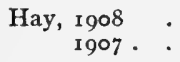 & : & $\cdot$ & . & $\begin{array}{l}46,486000 \\
44,028000\end{array}$ & $\begin{array}{l}21.52 \\
21.45\end{array}$ & $\begin{array}{l}270,798000 \\
263,677000\end{array}$ & $\begin{array}{r}38.98 \\
{ }^{3} 8.68\end{array}$ & $\begin{array}{l}635,423000 \\
743,507000\end{array}$ \\
\hline $\begin{array}{r}\text { Tobacco, } 1908 \\
1907\end{array}$ & . & : & : & $\begin{array}{l}875000 \\
820000\end{array}$ & $\begin{array}{l}4820.2 \\
4850.5\end{array}$ & $\begin{array}{l}4718,061000 \\
4698,126000\end{array}$ & $\begin{array}{l}5.103 \\
5.102\end{array}$ & $\begin{array}{l}74,130000 \\
71,411000\end{array}$ \\
\hline
\end{tabular}

${ }^{1}$ Figures furnished by the Bureau of Statistics, United States Department of Agriculture, except where otherwise credited.
2 Tons.
3 Per ton.
1 Pounds.
s Per pound. 


\section{CORN}

\section{Average Yield per Acre of Corn in the United States (with} TOTALS FOR I9O9)

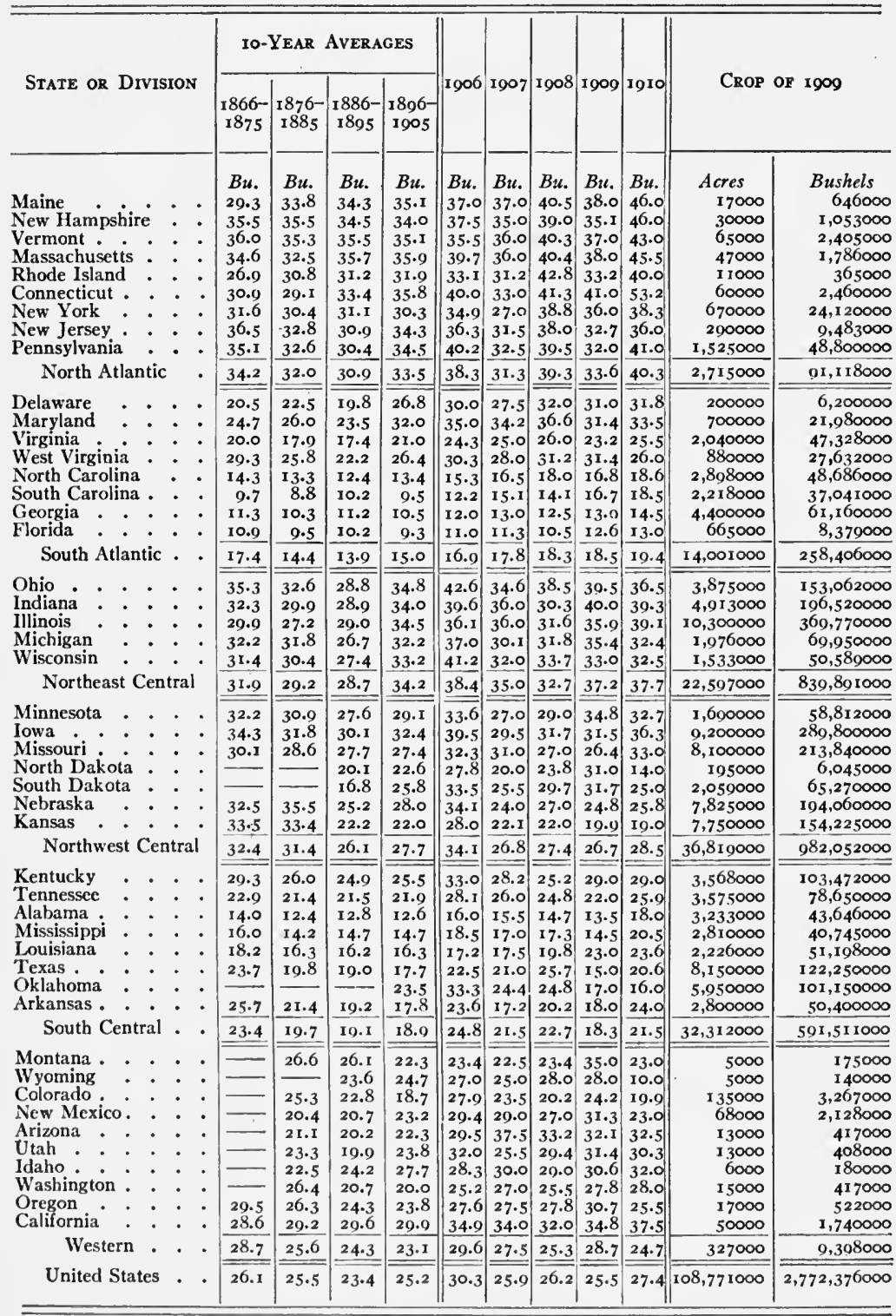




\section{CORN-Continued}

Acreage, Production, Value, Price, and Exports of Corn in the United StATES, I849-I909

\begin{tabular}{|c|c|c|c|c|c|c|c|c|c|c|c|c|}
\hline & & Year & & & & Acreage & $\begin{array}{l}\text { Aver- } \\
\text { age } \\
\text { yield } \\
\text { per } \\
\text { acre }\end{array}$ & Production & $\begin{array}{l}\text { Aver- } \\
\text { age } \\
\text { farm } \\
\text { price } \\
\text { per } \\
\text { bushel, } \\
\text { Dec. I }\end{array}$ & $\begin{array}{c}\text { Farm value } \\
\text { Dec. } 1 .\end{array}$ & $\begin{array}{l}\text { Domestic } \\
\text { exports, } \\
\text { including } \\
\text { corn meal, } \\
\text { fiscal year } \\
\text { beginning } \\
\text { July I }\end{array}$ & $\begin{array}{l}\text { Per } \\
\text { Cent } \\
\text { of } \\
\text { Crop } \\
\text { ex- } \\
\text { port- } \\
\text { ed }\end{array}$ \\
\hline & & & & & & Acres & $B u$. & Bushels & Cenis & Dollars & Bushels & P.ct. \\
\hline $1840^{x}$ & & - & - & - & - & & - & 592,071104 & - & & 7,632860 & I. 3 \\
\hline $1859^{x}$ & & - & - & - & - & & & 838,792742 & $\overline{ }$ & & 4,24899 I & .5 \\
\hline 1866 & - & - & - & - & - & 34,306538 & $25 \cdot 3$ & 867,946295 & $47 \cdot 4$ & 4 I I ,450830 & 16,026947 & \\
\hline 1867 & - & - & - & - & - & 32,520249 & 23.6 & 768,320000 & 57.0 & 437,769763 & 12,493522 & 1.6 \\
\hline I 868 & - & - & - & - & - & 34,887246 & 26.0 & 906,527000 & 46.8 & 424,056649 & 8,286665 & .9 \\
\hline 1869 & - & - & - & - & - & 37,103245 & 23.6 & 874,320000 & 59.8 & 522,550509 & 2,140487 & .2 \\
\hline 1870 & . & . & . & - & - & 38,646977 & 28.3 & $1,094,255000$ & 49.4 & $540,52045^{6}$ & $10,673.553$ & 1.0 \\
\hline $187 \mathrm{I}$ & . & . & . & - & - & 34,091137 & 20.1 & 99 r, 898000 & 43.4 & 430,355910 & 35,727010 & 3.6 \\
\hline 1872 & - & - & - & - & - & 35,526836 & 30.8 & $1,092,719000$ & $3.5 \cdot 3$ & 385,7362 工o & 40,154374 & 3.7 \\
\hline 1873 & • & - & - & - & - & 39,197148 & 23.8 & 932,274000 & 44.2 & 4 I I, 96 I I 5 I & 35,985834 & 3.9 \\
\hline I 874 & - & - & - & - & - & 41,036918 & 20.7 & 850,148500 & 58.4 & 496,271255 & 30,025036 & $3 \cdot 5$ \\
\hline 1875 & - & - & - & - & - & 44,84 I 371 & 29.5 & I,321,060000 & 36.7 & 484.674804 & 10532 & $3 \cdot 9$ \\
\hline 1876 & . & - & - & - & - & 49,033364 & 26.2 & $\mathrm{I}, 28_{3}, 827500$ & 34.0 & 436,108521 & 611 & 5.7 \\
\hline 1877 & - & - & - & - & - & 50.369 I 3 & 26.7 & $1,342,558000$ & 34.8 & 467,635230 & 87, & 6.5 \\
\hline 1878 & - & - & - & - & - & 51,585000 & 26.9 & I, 388,2 I 8750 & 31.7 & 440,280517 & 87,884892 & 6.3 \\
\hline 1879 & - & - & - & - & - & 53,085450 & 29.2 & $1,547,901790$ & 37.5 & 580,486217 & 99,572329 & 6.4 \\
\hline 1880 & . & . & . & - & - & 62,3 I 7842 & 27.6 & $1,717,434543$ & 39.6 & 679,714499 & 93,648147 & 5.5 \\
\hline I 88I & - & . & . & . & . & 64,262025 & 18.6 & I, I 94,916000 & 63.6 & 2170 & 0683 & 3.7 \\
\hline 1882 & - & - & - & - & - & 65,659545 & 24.6 & $1,617,025100$ & 48.5 & $783,867 \times 75$ & 41,655653 & 2.6 \\
\hline 1883 & - & • & - & - & - & 68,301889 & 22.7 & I,55 I ,066805 & 42.4 & 658,051485 & 46,258606 & 3.0 \\
\hline 1884 & - & - & . & - & - & 69,683780 & 25.8 & $1,795,528432$ & 35.7 & 640,735859 & 52,876456 & 2.9 \\
\hline 1885 & . & - & . & . & . & 73,130150 & 26.5 & $1,936,176000$ & 32.8 & 635,674630 & 64,829617 & $3 \cdot 3$ \\
\hline 1886 & - & . & . & . & . & 75,694208 & 22.0 & $1,665,441000$ & 36.6 & 610,311000 & 41,368584 & 2.5 \\
\hline 1887 & . & . & . & . & . & 72,392720 & 20.1 & $1,456,161000$ & 44.4 & 646,106770 & 25,360860 & 1.7 \\
\hline 1888 & - & - & - & - & - & 75,672763 & 26.3 & $1,987,7,90000$ & 34.1 & 677,561580 & 70,841673 & 3.6 \\
\hline 1889 & • & • & - & - & - & 78,3 I065 I & 27.0 & $2,112,892000$ & 28.3 & 597,918829 & 103,418700 & 4.9 \\
\hline 1890 & - & - & - & - & - & 71,070763 & 20.7 & $1,489,970000$ & 50.6 & 754,43345 I & 32,04 I 529 & 2.2 \\
\hline I 89 I & - & - & - & & - & $76,2045 \times 5$ & 27.0 & $2,060,1_{54000}$ & 40.6 & 836,439228 & 76,602285 & $3 \cdot 7$ \\
\hline 1892 & . & - & - & - & - & 70,626658 & 23.1 & $1,628,464000$ & 30.4 & 642,146630 & 1894 & 2.9 \\
\hline I 893 & . & . & . & - & . & 72,036465 & 22.5 & $1,619,406131$ & 36.5 & 591,625627 & $66.4895^{29}$ & 4.1 \\
\hline I 894 & - & - & - & - & - & 62,582269 & 19.4 & $1,212,770052$ & $45 \cdot 7$ & $554,7 \times 9162$ & 28,585405 & 2.4 \\
\hline 1895 & - & - & - & - & - & $82,075^{8} 30$ & 26.2 & $2,151,3^{8} 580$ & $25 \cdot 3$ & 544,985534 & IOI, 100375 & 4.7 \\
\hline I 896 & - & - & . & - & - & 81,027156 & 28.2 & $2,283,875165$ & $2 \mathrm{I} \cdot 5$ & 491,006967 & 178,817417 & 7.8 \\
\hline 3897 & . & . & . & . & . & 80,005051 & 23.7 & $\mathbf{I}, 902,967933$ & 26.3 & 501,0 & 212,055543 & II.I \\
\hline 1808 & - & - & - & - & & 77,721781 & 24.8 & $1,924,184660$ & 28.7 & 552,023428 & I 77,255046 & 9.2 \\
\hline 1899 & - & - & - & - & & 82,108587 & $25 \cdot 3$ & $2,078,143933$ & 30.3 & 629,210110 & 2 I 3,1234 I 2 & 10.3 \\
\hline 1900 & . & . & - & . & - & 83,320872 & 25.3 & $2,105,102516$ & 35.7 & & $\mathbf{I} 8 \mathbf{I}$ & 8.6 \\
\hline 1901 & - & . & . & . & 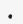 & 01,349928 & 16.7 & $1,522,519891$ & 60.5 & 768 & 28,028688 & I. 8 \\
\hline 1902 & - & $\bullet^{\circ}$ & . & . & . & 94,043613 & 26.8 & $2,523,648312$ & 40.3 & $1,017,017349$ & 76,639261 & 3.0 \\
\hline 1903 & - & 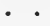 & . & . & - & 88,091993 & 25.5 & $2,244,176925$ & 425 & 952,868801 & 58,222061 & 2.6 \\
\hline 1904 & • & - & - & - & - & 92,23 I $58 \mathrm{I}$ & 26.8 & $2,467,480934$ & $44 \cdot I$ & $1,087,461440$ & 90,293483 & 3.7 \\
\hline 1905 & - & - & - & - & - & 94,011360 & 28.8 & $2,707,993540$ & 41.2 & $\mathbf{1}, \mathbf{1} 16,6967.38$ & I 19,893833 & 4.4 \\
\hline 1906 & - & 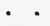 & - & - & - & 96,737581 & 30.3 & $2,927,416091$ & 39.0 & $1,166,626479$ & 86,368228 & 3.0 \\
\hline 1907 & - & - & 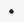 & - & 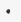 & 99,931000 & 25.9 & $2,592,320000$ & 51.6 & $1,336,901000$ & 55,063860 & 2.1 \\
\hline 1908 & . & . & . & & & 101,788000 & 26.2 & $2,668,651000$ & 60.6 & $1,616,145000$ & 37,665040 & I. 4 \\
\hline 1909 & - & - & - & - & - & 108,771000 & $25 \cdot 5$ & $2,772,376000$ & 59.6 & $1,652,822000$ & 38,128498 & 1.4 \\
\hline
\end{tabular}

1 Census figures of production. 


\section{CORN-Continued}

Corn Crop of Countries Named, r902-rgo6

\begin{tabular}{|c|c|c|c|c|c|}
\hline Country & $\begin{array}{l}1902 \\
(\mathrm{Bu} .)\end{array}$ & $\begin{array}{l}1903 \\
\text { (Bu.) }\end{array}$ & $\begin{array}{l}\mathbf{1 9 0 4} \\
(\mathrm{Bu} .)\end{array}$ & $\begin{array}{l}1905 \\
\text { (Bu.) }\end{array}$ & $\begin{array}{l}1906 \\
(\mathrm{Bu} .)\end{array}$ \\
\hline \multirow{2}{*}{$\begin{array}{l}\text { United States } \\
\text { Canada (Ontario): } \\
\text { Mexico : } \cdot \text {. } \\
\text { Total No.America }\end{array}$} & $\begin{array}{r}2,523,648000 \\
21,159000 \\
78,099000 \\
\end{array}$ & $\begin{array}{r}2,244,177000 \\
30,211000 \\
90,879000 \\
\end{array}$ & $\begin{array}{r}2,467,481000 \\
20,880000 \\
88,131000 \\
\end{array}$ & $\begin{array}{r}2,707,994000 \\
21,582000 \\
85,000000 \\
\end{array}$ & $\begin{array}{r}2,927,416000 \\
24,745000 \\
70,000000 \\
\end{array}$ \\
\hline & $2,622,906000$ & $2,365,267000$ & $2,576,492000$ & 2814,576000 & $3,022,161000$ \\
\hline \multirow{3}{*}{$\begin{array}{l}\text { Argentina } \\
\text { Total So. America } \\
\text { Austria-Hungary }\end{array}$} & 84,018000 & I 48,948000 & 175, I 89000 & 140,708000 & 194,912000 \\
\hline & 89,944000 & 155,355000 & 179,701000 & 146,369000 & 198,984000 \\
\hline & 139,126000 & I 83,994000 & 89,757000 & I 39,307000 & 215,636000 \\
\hline \multirow{3}{*}{ 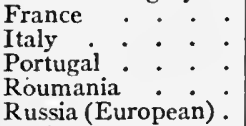 } & 8000 & $\infty$ & 000 & 2000 & 000 \\
\hline & $\begin{array}{l}71,028000 \\
16,000000\end{array}$ & $\begin{array}{r}88,990000 \\
14,000000\end{array}$ & & $\begin{array}{r}97,265000 \\
16,000000\end{array}$ & \\
\hline & 68,447000 & 80,272000 & I 9,598000 & 59,275000 & I 30,546000 \\
\hline $\begin{array}{l}\text { Russia (European). } \\
\text { Spain }\end{array}$ & $\begin{array}{l}48,419000 \\
25,272000\end{array}$ & $\begin{array}{l}50,464000 \\
18,759000\end{array}$ & & & $\begin{array}{l}70,501000 \\
30,000000\end{array}$ \\
\hline$\underset{\text { Total Europe }}{\text { Tpain }}$ & 429.716000 & 504,154000 & 303,858000 & 442,168000 & 618,057000 \\
\hline \multirow{4}{*}{$\begin{array}{l}\text { Africa } \\
\text { Australia : }: \\
\text { New Zealand } \\
\text { Total Australasia } \\
\text { Grand total }\end{array}$} & $\begin{array}{r}36,899000 \\
7,256000 \\
\end{array}$ & $\begin{array}{r}36, \text { I I } 8000 \\
4,987000 \\
\end{array}$ & $\begin{array}{r}38,862000 \\
9,972000 \\
\end{array}$ & $\begin{array}{r}37,655000 \\
8,374000 \\
\end{array}$ & $\begin{array}{r}37,700000 \\
8,608000 \\
\end{array}$ \\
\hline & 590000 & 627000 & 547000 & 506000 & 653000 \\
\hline & 7,846000 & 5.614000 & 10,519000 & 8,880000 & 9,261000 \\
\hline & 318,7311000 & $3,066,508000$ & $3,109,432000$ & $3,449,648000$ & $3,886,16,3000$ \\
\hline
\end{tabular}

Corn, Average Yields per ACre, Bushels

\begin{tabular}{|c|c|c|c|c|c|}
\hline YEARS & $\begin{array}{c}\text { South } \\
\text { Carolixa }\end{array}$ & GEORGIA & IowA & ILLINOIS & United States \\
\hline I 866-1 875 (ro years) & $9 \cdot 7$ & I I.3 & $34 \cdot 3$ & 29.9 & 26.1 \\
\hline I $876-1885$ ( 10 years) & 8.8 & 10.3 & 31.8 & 27.2 & $25 \cdot 5$ \\
\hline I 886-1 895 (10 years) & 10.2 & I 1.2 & 30.1 & 29.0 & 23.4 \\
\hline 1896-1905 (10 years) & $9 \cdot 5$ & 10.5 & 32.4 & $34 \cdot 5$ & 25.2 \\
\hline I $866-1885$ (20 years) & $9 \cdot 3$ & I0.8 & 33.0 & 28.6 & 25.8 \\
\hline $1886-1905$ (20 years) & $9 \cdot 9$ & 10.8 & $3 \mathrm{I} .2$ & 31.7 & $24 \cdot 3$ \\
\hline I 866-I905 (40 years) & 9.6 & 10.8 & 32.1 & 30.1 & 25.0 \\
\hline
\end{tabular}

Corn, Single-year Records

I 899 , bu. per acre r9o9, bu. per acre I 899 , acres of corn I 909 , acres of corn I 899 , bu. of corn r 909 , bu. of corn 1899 , price per bu. r go9, price per bu. I 899 , value of crop roog, value of crop

\begin{tabular}{|r|r|r|r|r}
9.0 & 10.0 & 31.0 & 36.0 & $25 \cdot 3$ \\
16.7 & 13.9 & 31.5 & 35.9 & $25 \cdot 5$ \\
1,857000 & 3,249000 & 7,815000 & 6,865000 & 82,109000 \\
2,218000 & 4,400000 & 9,200000 & 10,300000 & 108,771000 \\
16,713000 & 32,495000 & 242,250000 & 247,150000 & $2,078,000000$ \\
37,041000 & 61,160000 & 289,800000 & 369,770000 & $2,772,360000$ \\
$45 \%$ & $49 \%$ & $35 \%$ & $36 \%$ & $37.2 \%$ \\
$90 \%$ & $86 \%$ & $49 \%$ & $52 \%$ & $59.6 \%$ \\
$\$ 8,357000$ & $\$ 16,247000$ & $\$ 55,717000$ & $\$ 64,259000$ & $\$$ \\
33,337000 & 52,598000 & 142,062000 & 192,280000 & $1,652,822000$ \\
\hline
\end{tabular}




\section{INTERNATIONAL TRADE IN CORN, INCLUDING CORN MEAL, I902-I906}

General Note. Substantially the international trade of the world.

The exports given are domestic exports and the imports given are imports for consumption, as far as it is feasible and consistent so to express the facts. While there are some inevitable omissions from such a table as this, on the other hand, there are some duplications because of reshipments that do not appear as such in official reports. For the United Kingdom import figures refer to imports for consumption.

EXPORTS

\begin{tabular}{|c|c|c|c|c|c|c|c|}
\hline COUNTRY & & $\begin{array}{c}\text { YEAR } \\
\text { BEGIN- } \\
\text { NING }\end{array}$ & $\begin{array}{c}1902 \\
\text { (Bu.) }\end{array}$ & $\begin{array}{l}1903 \\
\text { (Bu.) }\end{array}$ & $\begin{array}{c}1904 \\
\text { (Bu.) }\end{array}$ & $\begin{array}{c}1905 \\
\text { (Bu.) }\end{array}$ & $\begin{array}{c}1906 \\
\text { (Bu.) }\end{array}$ \\
\hline Argentina & & Jan. I & 46,959590 & 82,8459 I 5 & 97,221783 & 87,487629 & 106,047790 \\
\hline Austria-Hungary & & Jan. I & 3,010624 & 310804 & I 74342 & 63218 & 322361 \\
\hline Belgium . . & & Jan. I & 4,346609 & $6,579^{6} 55$ & 6,287688 & 8,078215 & 6,588557 \\
\hline Bulgaria ; . & & Jan. I & 7,883279 & 5,089 I 14 & 9,762657 & 3,870090 & 5,658500 \\
\hline Netherlands . & & Jan. I & 4,726324 & 5,373194 & 4,449009 & 4,2785 I5 & $6,0 \operatorname{101} 76$ \\
\hline Roumania & & Jan. I & 43,013192 & 31,080198 & 18,042377 & I, 44 I 437 & 23,3943 OI \\
\hline Russia & & Jan. I & 44,1 & ${ }^{2} 5,349683$ & I 8,633663 & 7,372386 & ${ }^{2} 9,878$ I 4 I \\
\hline Servia $\cdot$ & & Jan. I & $\mathbf{1}, 091588$ & 171767 & 130225 & 806115 & I,755446 \\
\hline United States & & July I & $76,63926 \mathrm{I}$ & $5^{8,222061}$ & $90,2934^{8} 3$ & II 9,893833 & $86,3^{6} 79^{88}$ \\
\hline Uruguay · • & & July I & 703770 & $1,00406_{3}$ & 2,002431 & 28519 & ${ }^{2} 034696$ \\
\hline Other countries & & & $\mathrm{I}, 528000$ & $I, 086000$ & 1,009000 & 4,100325 & ${ }^{2} 3,547299$ \\
\hline Total . . & & $\longrightarrow$ & 234,050827 & 217,112454 & 248,006658 & 237,420282 & $250,205^{2} 55$ \\
\hline
\end{tabular}

IMPORTS

\begin{tabular}{|c|c|c|c|c|c|c|c|c|}
\hline & & Jan. I & \multirow{2}{*}{$\begin{array}{r}5,874971 \\
14,583008\end{array}$} & \multirow{2}{*}{$\begin{array}{l}\mathrm{II}, \mathrm{I} 30274 \\
20,323863\end{array}$} & \multirow{2}{*}{$\begin{array}{l}14,090377 \\
10,47+3,30\end{array}$} & \multirow{2}{*}{$\begin{array}{l}\text { I } 8,5 \text { I I } 368 \\
24, \text { I } 60780\end{array}$} & \multirow{2}{*}{$\begin{array}{r}7,118221 \\
20,1255^{\circ} 7\end{array}$} \\
\hline \multicolumn{3}{|c|}{ Belgium . } & \multirow{4}{*}{$\begin{array}{l}\text { Jan. I } \\
\text { Jan. I } \\
\text { July I } \\
\text { Jan. I } \\
\text { Jan. I }\end{array}$} & & & & & \\
\hline \multirow{2}{*}{\multicolumn{3}{|c|}{$\begin{array}{l}\text { Canada } \\
\text { Cape of Good Hope }\end{array}$}} & & $7,1545^{22}$ & I I, $33353^{\circ}$ & I 2,003574 & I1,779679 & \multirow{3}{*}{\begin{tabular}{r|r}
9 & $\begin{array}{r}2 \\
1\end{array}, 233894$ \\
215007 \\
8 & 2,489087
\end{tabular}} \\
\hline & & & & 1,943896 & $3.47128 \mathrm{I}$ & 1,236927 & 2,171601 & \\
\hline \multicolumn{3}{|c|}{ Cuba . . . } & & 1,150176 & 619326 & 696517 & I, 843348 & \\
\hline \multirow{5}{*}{\multicolumn{3}{|c|}{ 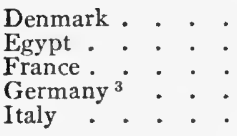 }} & \multirow{5}{*}{$\begin{array}{l}\text { Jan. I } \\
\text { Jan. I } \\
\text { Jan. I } \\
\text { Jan. I } \\
\text { Jan. I }\end{array}$} & I $2,355^{\circ} 5^{\circ}$ & 8,772022 & 9,284777 & IO 859257 & \multirow{5}{*}{$\begin{array}{r}18,855752 \\
1,43^{8} 435 \\
14,5 \circ 9103 \\
44,883053 \\
8,666763\end{array}$} \\
\hline & & & & $55^{266}$ & 537 & 3017 & 79749 & \\
\hline & & & & 8,67493 I & II, 347 II 44 & 10,124353 & 22512 & \\
\hline & & & & 35,454243 & 37,527343 & 30,450853 & 36,538366 & \\
\hline & & & & & & & 5,902875 & \\
\hline \multirow{5}{*}{\multicolumn{3}{|c|}{$\begin{array}{l}\text { Mexico } \\
\text { Netherlands: }:\end{array}$}} & \multirow{5}{*}{$\begin{array}{l}\text { Jan. I } \\
\text { Jan. I } \\
\text { Jan. I } \\
\text { Jan. I } \\
\text { Jan. I }\end{array}$} & 142102 & 496028 & 476182 & & \multirow{5}{*}{\begin{tabular}{r|r}
7 & 22,079553 \\
5 & 25,305233 \\
6 & 718277 \\
0 & 2,724050 \\
9 & 2437868
\end{tabular}} \\
\hline & & & & 15,817237 & 20,160078 & 16,547198 & 16,234785 & \\
\hline & & & & 387 & 5246 & $999 \mathrm{I}$ & 544596 & \\
\hline & & & & & & & 2,724 & \\
\hline & & & & 135822 & $4577 \times 5$ & 625526 & I63979 & \\
\hline \multirow{5}{*}{\multicolumn{3}{|c|}{$\begin{array}{l}\text { Spain : : } \\
\text { Sweden : } \\
\text { Switzerland : } \\
\text { Transvaal : } \\
\text { United Kingdom }\end{array}$}} & \multirow{5}{*}{$\begin{array}{l}\text { Jan. I } \\
\text { Jan. I } \\
\text { Jan. I } \\
\text { Jan. I } \\
\text { Jan. I }\end{array}$} & & $\mathrm{I}, 48$ & 2,761426 & 1,904186 & \multirow{6}{*}{\begin{tabular}{r|r}
6 & 2,647975 \\
5 & 56494 \\
0 & 2,887291 \\
3 & 1,27735 \\
0 & 97,73685 \\
$\mathrm{I}$ & 27,09099 \\
\end{tabular}} \\
\hline & & & & & & & & \\
\hline & & & & 2,404644 & 2,611202 & 2,704457 & 2,498380 & \\
\hline & & & & 1,306038 & 2,197476 & & 1,277353 & \\
\hline & & & & $89,37 \mathbf{1} 445$ & 101,284919 & 86,076697 & 84, I 56490 & \\
\hline \multirow{2}{*}{\multicolumn{3}{|c|}{$\begin{array}{c}\text { Other countries. } \\
\text { Total. . }\end{array}$}} & & 3,260478 & 7,318470 & 3,309436 & $7,42935 \mathrm{I}$ & \\
\hline & & & & 210,4833 I 5 & 257,091403 & 221,026621 & 243,057067 & $7 \longdiv { 2 7 7 , 0 0 5 2 1 1 }$ \\
\hline
\end{tabular}

1 Average, I902-I905.

${ }^{2}$ Preliminary.
${ }^{3}$ Not including free ports prior to March $\mathbf{I}, \mathbf{1} 906$. Year preceding. 


\section{WHEAT}

Wheat Crop of Countries Named, 1903-I907

\begin{tabular}{|c|c|c|c|c|c|}
\hline COUNTRY & $\begin{array}{l}1903 \\
(\mathrm{Bu} .)\end{array}$ & $\begin{array}{l}\mathbf{1 9 0 4} \\
\text { (Bu.) }\end{array}$ & - $\begin{array}{r}\mathbf{1 9 0 5} \\
(\mathrm{Bu} .)\end{array}$ & $\begin{array}{c}1906 \\
(\mathrm{Bu} .)\end{array}$ & $\begin{array}{l}1907 \\
(\mathrm{Bu} .)\end{array}$ \\
\hline \multirow{4}{*}{ 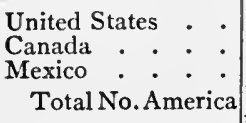 } & 000 & $55^{2}, 400000$ & 692,979000 & 735,261000 & 634, \\
\hline & & & & & \\
\hline & & & & & 10,000000 \\
\hline & 733,586000 & 637,006000 & 813,420000 & 874,066000 & 740,693000 \\
\hline \multirow{2}{*}{$\begin{array}{l}\text { Argentina } \\
\text { Total So. America }\end{array}$} & 103, & 129,672000 & I 50,745000 & 134,931000 & 155,993000 \\
\hline & IIO. & 155.185000 & 160,834000 & 151,604000 & 178,636000 \\
\hline \multirow{6}{*}{ 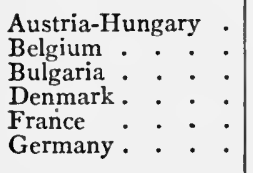 } & 226 & 406000 & 8000 & 268 & 9000 \\
\hline & I 2 & 000 & $\infty$ & & \\
\hline & 35,5 & 000 & 000 & & \\
\hline & & & & & \\
\hline & 364,4 & 298, & 000 & 324 & $3^{69}$, \\
\hline & & I 39 & 1000 & & 127,843000 \\
\hline \multirow{5}{*}{ 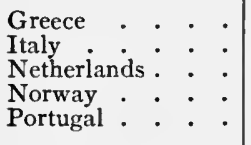 } & & & & & 0000 \\
\hline & 184,4 & 167, & 160 & 176 & 177 \\
\hline & & & Doo & & \\
\hline & & & & & 0000 \\
\hline & & & 000 & & 00000 \\
\hline \multirow{2}{*}{ Roumania $\cdot$. } & & & 103 & I I 3 & \\
\hline & $55 \mathrm{I}$, & & 568 & $45^{\circ}$ & \\
\hline Servia . . . & & & .000 & & \\
\hline & 128 & & & 140 & 100, \\
\hline Sweden $\cdot \cdot \cdot$ & & & & & 5,953000 \\
\hline \multirow[t]{2}{*}{ Turkey (European) } & & & & & \\
\hline & & & & & \\
\hline $\begin{array}{c}\text { Total Un it ed } \\
\text { Kingdom }\end{array}$ & 50, & 39,082000 & 62,188000 & 62,481000 & 5000 \\
\hline Total Europe & $1,830,526000$ & $1,747,262000$ & $1,803,132000$ & $1,826,42$ & $1,616,086000$ \\
\hline $\begin{array}{l}\text { British India, includ- } \\
\text { ing such native } \\
\text { states as report . }\end{array}$ & & & 3000 & & \\
\hline \multirow{2}{*}{ 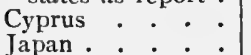 } & boo & 000 & $\infty$ & 00 & 2000 \\
\hline & poo & 000 & 000 & 20 & 2000 \\
\hline Russia (Asiatic) & 69,6 & & & & \\
\hline \multirow{2}{*}{$\begin{array}{c}\text { Turkey (Asiatic) } \\
\text { Total Asia }\end{array}$} & & & 35 & & \\
\hline & 430,516000 & 477.550000 & 423,152000 & 451,586000 & $447,5 \mathrm{I} 8000$ \\
\hline \multirow{3}{*}{$\begin{array}{l}\text { Algeria } \\
\text { Cape of Good Hope } \\
\text { Egypt } \cdot: \cdot \dot{-} \\
\text { Natal }: \\
\text { Sudan (Anglo-Egyp- } \\
\quad \text { tian) }\end{array}$} & $\begin{array}{r}34,035000 \\
1,755000\end{array}$ & $\begin{array}{r}25,484000 \\
2,000000\end{array}$ & $\begin{array}{r}25,579000 \\
2,000000\end{array}$ & $\begin{array}{r}34,080000 \\
2,000000\end{array}$ & $\begin{array}{r}31,120000 \\
2,000000\end{array}$ \\
\hline & 12,000000 & 12,000000 & 12,000000 & 12,000000 & 12,000000 \\
\hline & $\begin{array}{r}4000 \\
294000\end{array}$ & $\begin{array}{r}7000 \\
486000\end{array}$ & $\begin{array}{r}4000 \\
483000\end{array}$ & $\begin{array}{r}8000 \\
542000\end{array}$ & $\begin{array}{r}6000 \\
500000\end{array}$ \\
\hline \multirow{2}{*}{ Total Africa } & 7,523000 & 10,519000 & 5,729000 & 4,409000 & 6,000000 \\
\hline & 55.611000 & .50 .406000 & $45.70,5000$ & $5.3 .0,30000$ & 51,626000 \\
\hline \multirow{4}{*}{$\begin{array}{l}\text { Australia } \\
\text { New Zealand } \\
\text { Total Australasia } \\
\text { Grand total }\end{array}$} & & & & & \\
\hline & & & & & \\
\hline & 20,461000 & 84,628000 & 65,626000 & 77,604000 & 73,967000 \\
\hline & $\overline{3,189,813000}$ & 3,152, I 27000 & $3,320,959000$ & $\overline{3,435,401000}$ & $3,108,526000$ \\
\hline
\end{tabular}




\section{WHEAT - Continued}

\section{Acreage, Production, Value, Price, and Exports of Wheat in the United} States, r849-rgo9

\begin{tabular}{|c|c|c|c|c|c|c|c|c|c|c|c|c|}
\hline & & Year & & & & Acreage & $\begin{array}{l}\text { Aver- } \\
\text { age } \\
\text { yield } \\
\text { per } \\
\text { acre }\end{array}$ & Production & $\begin{array}{c}\text { Aver- } \\
\text { age } \\
\text { farm } \\
\text { price } \\
\text { per } \\
\text { bushel, } \\
\text { Dec. I }\end{array}$ & $\begin{array}{c}\text { Farm value } \\
\text { Dec. } 1\end{array}$ & $\begin{array}{l}\text { Domestic } \\
\text { exports, } \\
\text { including } \\
\text { flour, fiscal } \\
\text { year } \\
\text { beginning } \\
\text { July I }\end{array}$ & $\begin{array}{l}\text { Per } \\
\text { cent } \\
\text { of } \\
\text { crop } \\
\text { ex- } \\
\text { ported }\end{array}$ \\
\hline $\begin{array}{l}1849^{x} \\
1859^{x} \\
1866 \\
1867 \\
1868\end{array}$ & . & 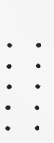 & $\dot{:}$ & $\dot{:}$ & $: \dot{:}$ & $\begin{array}{c}\text { Acres } \\
\begin{array}{l}15,424496 \\
18,321561 \\
18,460132\end{array}\end{array}$ & 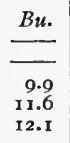 & $\begin{array}{c}\text { Bushels } \\
100,485944 \\
173,104924 \\
151,999906 \\
212,441400 \\
224,036600\end{array}$ & $\begin{array}{l}\text { Cents } \\
\\
152.7 \\
145.2 \\
108.5\end{array}$ & $\begin{array}{l}\text { Dollars } \\
232,109630 \\
308,387146 \\
243,032746\end{array}$ & $\begin{array}{c}\text { Bushels } \\
7,535901 \\
17,213133 \\
12,646941 \\
26,323014 \\
29,717201\end{array}$ & $\begin{array}{r}P . c t . \\
7.5 \\
9.9 \\
8.3 \\
12.4 \\
13.3\end{array}$ \\
\hline $\begin{array}{l}1869 \\
1870 \\
1871 \\
1872 \\
1873\end{array}$ & $\dot{.}$ & $\dot{0}: \dot{:}$ & $\begin{array}{l}\dot{\bullet} \\
\dot{.} \\
\dot{\bullet}\end{array}$ & $:$ & 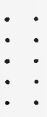 & $\begin{array}{l}19,181004 \\
18,992591 \\
19,943893 \\
20,858359 \\
22,171676\end{array}$ & $\begin{array}{ll}1 & 3.6 \\
1 & 2.4 \\
1 & 1.6 \\
1 & 1.9 \\
1 & 2.7\end{array}$ & $\begin{array}{l}260,146900 \\
235,884700 \\
230,722400 \\
249,997100 \\
281,254700\end{array}$ & $\begin{array}{r}76.5 \\
94.4 \\
\text { I } 14.5 \\
\text { I I } 1.4 \\
\text { I06.9 }\end{array}$ & $\begin{array}{l}199,024906 \\
222,766969 \\
264,075851 \\
278,522068 \\
300,669528\end{array}$ & $\begin{array}{l}53,900780 \\
52,5741111 \\
38,995755 \\
52,014715 \\
91,510398\end{array}$ & $\begin{array}{l}20.7 \\
22.3 \\
16.9 \\
20.8 \\
32.5\end{array}$ \\
\hline $\begin{array}{l}1874 \\
1875 \\
1876 \\
1877 \\
1878\end{array}$ & : & : : & $\dot{:}$ & $\dot{:}$ & 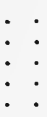 & $\begin{array}{l}24,967027 \\
26,381512 \\
27,627021 \\
26,277546 \\
32,108560\end{array}$ & $\begin{array}{l}12.3 \\
11.1 \\
10.5 \\
13.9 \\
13.1\end{array}$ & $\begin{array}{l}308,102700 \\
292,136000 \\
289,356500 \\
364,194146 \\
420,2112400\end{array}$ & $\begin{array}{r}86.3 \\
89.5 \\
96.3 \\
105.7 \\
77.6\end{array}$ & $\begin{array}{l}265,881167 \\
261,396926 \\
278,697238 \\
385,094844 \\
325,814119\end{array}$ & $\begin{array}{r}72,012817 \\
74,750682 \\
57,043936 \\
92,141626 \\
150,502506\end{array}$ & $\begin{array}{l}23.7 \\
25.6 \\
19.7 \\
25.3 \\
35.8\end{array}$ \\
\hline $\begin{array}{l}1879 \\
1880 \\
1881 \\
1882 \\
1883\end{array}$ & : & $: \dot{:}$ & : & $:$ & $: \dot{:}$ & $\begin{array}{l}32,545950 \\
37,986717 \\
37,709020 \\
37,067194 \\
36,455593\end{array}$ & $\begin{array}{l}13.8 \\
13.1 \\
10.2 \\
13.6 \\
11.6\end{array}$ & $\begin{array}{l}448,756630 \\
498,549868 \\
383,280090 \\
504,185470 \\
421,086160\end{array}$ & $\begin{array}{r}110.8 \\
95.1 \\
119.2 \\
88.4 \\
91.1\end{array}$ & $\begin{array}{l}497,030142 \\
474,201850 \\
456,880427 \\
445,602125 \\
383,649272\end{array}$ & $\begin{array}{l}180,304180 \\
186,321514 \\
121,892389 \\
147,811316 \\
\text { I I } 1,534182\end{array}$ & $\begin{array}{l}40.2 \\
37.4 \\
31.8 \\
29.3 \\
26.5\end{array}$ \\
\hline $\begin{array}{l}1884 \\
1885 \\
1886 \\
1887 \\
1888\end{array}$ & $\dot{:}$ & $: \dot{:}:$ & $\dot{:}$ & $\dot{:}$ & 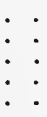 & $\begin{array}{l}39,475885 \\
34,180246 \\
36,806184 \\
37,641783 \\
37,336138\end{array}$ & $\begin{array}{l}13.0 \\
10.4 \\
12.4 \\
12.1 \\
11.1\end{array}$ & $\begin{array}{l}512,765000 \\
357,112000 \\
457,218000 \\
456,329000 \\
415,868000\end{array}$ & $\begin{array}{l}64 \cdot 5 \\
77.1 \\
68.7 \\
68.1 \\
92.6\end{array}$ & $\begin{array}{l}330,862260 \\
275,320390 \\
314,226020 \\
310,612960 \\
385,248030\end{array}$ & $\begin{array}{r}132,570366 \\
94,565793 \\
\text { I } 53,804969 \\
119,625344 \\
88,600743\end{array}$ & $\begin{array}{l}25.9 \\
26.5 \\
33.6 \\
26.2 \\
21.3\end{array}$ \\
\hline $\begin{array}{l}1889 \\
1890 \\
1891 \\
1892 \\
1893\end{array}$ & . & 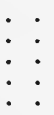 & $\dot{\dot{:}} \dot{.}$ & $\dot{:}$ & 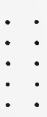 & $\begin{array}{l}38,123859 \\
36,087154 \\
39,916897 \\
38,554430 \\
34,629418\end{array}$ & $\begin{array}{l}12.9 \\
11.1 \\
15.3 \\
13.4 \\
11.4\end{array}$ & $\begin{array}{l}490,560000 \\
399,262000 \\
6 \text { I I } 780000 \\
5 \text { I } 5,949000 \\
396,13 \text { I } 725\end{array}$ & $\begin{array}{l}60.8 \\
83.8 \\
83.9 \\
62.4 \\
53.8\end{array}$ & $\begin{array}{l}342,491707 \\
334,773678 \\
513,472711 \\
322,111881 \\
213,171381\end{array}$ & $\begin{array}{l}109,430467 \\
106,181316 \\
225,665811 \\
101,912635 \\
164,283129\end{array}$ & $\begin{array}{l}22.3 \\
26.6 \\
36.9 \\
37.2 \\
41.5\end{array}$ \\
\hline $\begin{array}{l}1894 \\
1895 \\
1896 \\
1897 \\
1898\end{array}$ & : & $: \dot{:}$ & $\dot{:}$ & $\dot{:}$ & 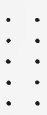 & $\begin{array}{l}34,882436 \\
34,047332 \\
34,618646 \\
39,465066 \\
44,055278\end{array}$ & $\begin{array}{l}13.2 \\
13.7 \\
12.4 \\
13.4 \\
15.3\end{array}$ & $\begin{array}{l}460,267416 \\
467,102947 \\
427,684346 \\
530,149168 \\
675,148705\end{array}$ & $\begin{array}{l}49.1 \\
50.9 \\
72.6 \\
80.8 \\
58.2\end{array}$ & $\begin{array}{l}225,902025 \\
237,938998 \\
310,602539 \\
428,547121 \\
392,770320\end{array}$ & $\begin{array}{l}144,812718 \\
126,443968 \\
145,124972 \\
217,306005 \\
222,618420\end{array}$ & $\begin{array}{l}31.5 \\
27.1 \\
33.9 \\
41.0 \\
33.0\end{array}$ \\
\hline $\begin{array}{l}1899 \\
1900 \\
1901 \\
1902 \\
1903\end{array}$ & : & $: \dot{:}$ & $\dot{:}$ & : & $::$ & $\begin{array}{l}44,592516 \\
42,495385 \\
49,895514 \\
46,202424 \\
49,464967\end{array}$ & $\begin{array}{l}12.3 \\
12.3 \\
15.0 \\
14.5 \\
12.9\end{array}$ & $\begin{array}{l}547,303846 \\
522,229505 \\
748,460218 \\
670,063008 \\
637,821835\end{array}$ & $\begin{array}{l}58.4 \\
61.9 \\
62.4 \\
63.0 \\
69.5\end{array}$ & $\begin{array}{l}319,545259 \\
323,5 \text { I5 } 77 \\
467,350156 \\
422,224117 \\
443,024826\end{array}$ & 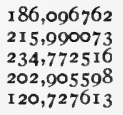 & $\begin{array}{l}34.0 \\
41.4 \\
31.4 \\
30.3 \\
18.9\end{array}$ \\
\hline $\begin{array}{l}1904 \\
1905 \\
1906 \\
1907 \\
1908 \\
1909\end{array}$ & : & $\begin{array}{l}\dot{:}: \\
\dot{0} \\
\dot{0}\end{array}$ & $\begin{array}{l}\dot{.} \\
\dot{.} \\
\dot{.}\end{array}$ & $\begin{array}{l}\dot{.} \\
\dot{.} \\
\dot{.}\end{array}$ & 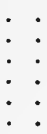 & $\begin{array}{l}44,074875 \\
47,354079 \\
47,305829 \\
45.211000 \\
47.557000 \\
46,723000\end{array}$ & $\begin{array}{l}12.5 \\
14.5 \\
15.5 \\
14.0 \\
14.0 \\
15.8\end{array}$ & $\begin{array}{l}552,399517 \\
692,979489 \\
735,260970 \\
634,087000 \\
664,602000 \\
737,189000\end{array}$ & $\begin{array}{l}92.4 \\
74.8 \\
66.7 \\
87.4 \\
92.8 \\
99.0\end{array}$ & $\begin{array}{l}510,489874 \\
518,372727 \\
490,332760 \\
554,437000 \\
616,826000 \\
730,046000\end{array}$ & $\begin{array}{r}44,112910 \\
97,609007 \\
146,700425 \\
163,043569 \\
114,268468 \\
87,364318\end{array}$ & $\begin{array}{r}8.0 \\
14.1 \\
20.0 \\
25.7 \\
17.2 \\
11.9\end{array}$ \\
\hline
\end{tabular}

1 Census figures of production. 


\section{WHEAT - Continued}

Average Yield per Acre of Wheat in the United States (with TOTALS FOR 1909)

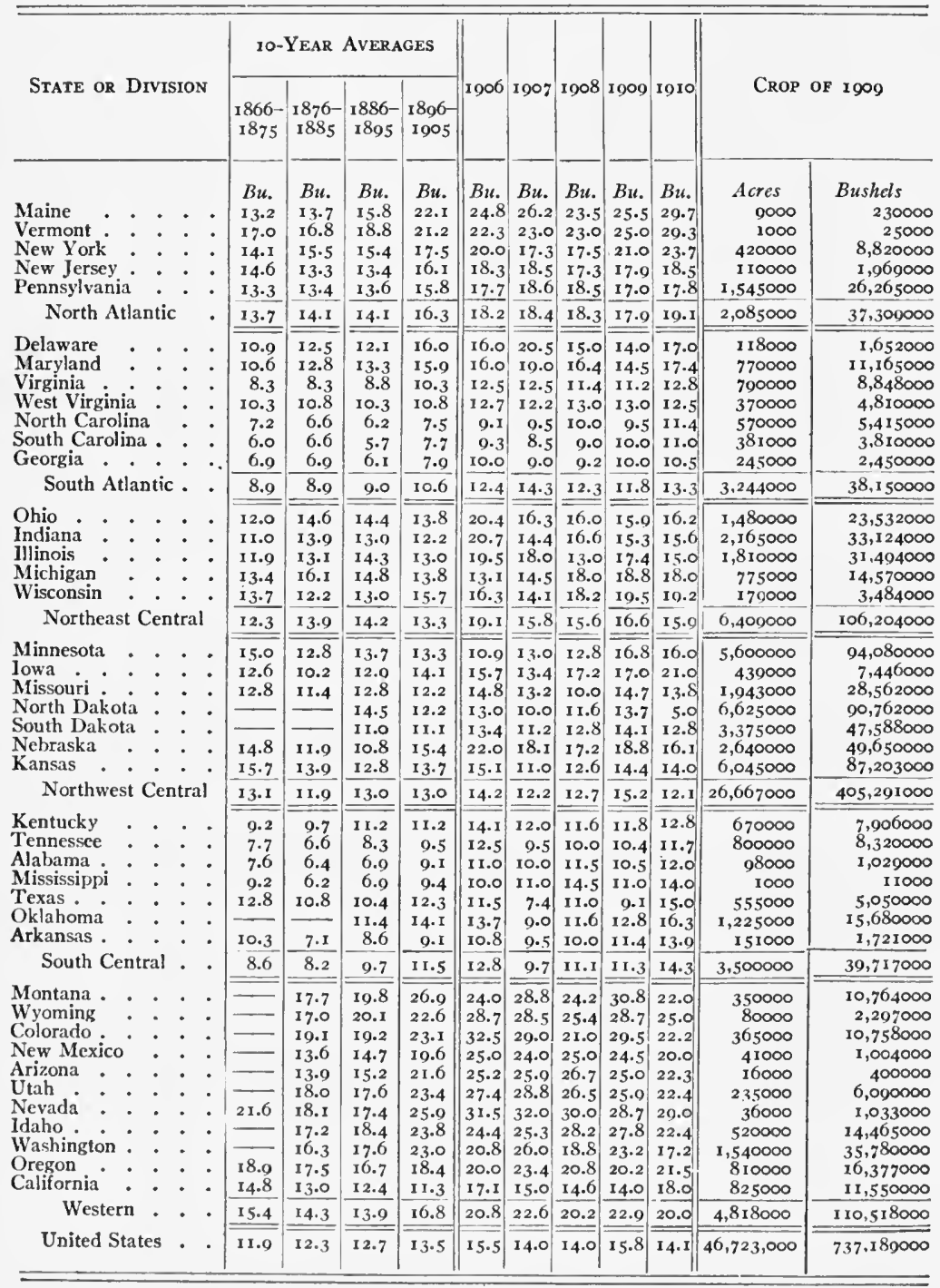


INTERNATIONAL TRADE IN WHEAT, INCLUDING WHEAT FLOUR, 1902-1906

EXPORTS

\begin{tabular}{|c|c|c|c|c|c|c|c|}
\hline Country & & $\begin{array}{l}\text { YEAR } \\
\text { BEGIN- } \\
\text { NING }\end{array}$ & $\begin{array}{l}1902 \\
\text { (Bu.) }\end{array}$ & $\begin{array}{l}1903 \\
\text { (Bu.) }\end{array}$ & $\begin{array}{c}\mathbf{1 9 0 4} \\
\text { (Bu.) }\end{array}$ & $\begin{array}{l}\mathbf{1 9 0 5} \\
\text { (Bu.) }\end{array}$ & $\begin{array}{l}1906 \\
\text { (Bu.) }\end{array}$ \\
\hline $\begin{array}{l}\text { Argentina } \\
\text { Australia } \\
\text { Austria-Hungar } \\
\text { Belgium } \\
\text { British India }\end{array}$ & $\dot{.}$ & $\begin{array}{l}\text { Jan. I } \\
\text { Jan. I } \\
\text { Jan. I } \\
\text { Jan. I } \\
\text { Apr. I }\end{array}$ & $\begin{array}{r}25,672368 \\
10,799165 \\
5,534270 \\
13,890599 \\
21,389010\end{array}$ & $\begin{array}{r}65,421537 \\
1,489763 \\
5,532485 \\
13,362799 \\
50,684276\end{array}$ & $\begin{array}{r}90, \text { I I } 5 \text { 工 I I } 9 \\
38,850 \text { 工 } 66 \\
3,984789 \\
\text { 18, } 2 \text { I } 7597 \\
83, \text { I } 28272\end{array}$ & $\begin{array}{r}\text { I I } 2,7 \text { I } 8476 \\
32,506453 \\
3,630659 \\
18,496029 \\
37,483073\end{array}$ & $\begin{array}{r}89,128802 \\
38,878679 \\
4,059153 \\
18,030378 \\
32,213417\end{array}$ \\
\hline $\begin{array}{l}\text { Bulgaria : } \\
\text { Canada : } \\
\text { Chile : } \\
\text { Germany }{ }^{2}: \\
\text { Netherlands }\end{array}$ & $:$ & $\begin{array}{l}\text { Jan. I } \\
\text { Jan. I } \\
\text { Jan. I } \\
\text { Jan. I } \\
\text { Jan. I }\end{array}$ & $\begin{array}{r}9,320644 \\
39,820238 \\
1,043883 \\
4,044662 \\
37,349804\end{array}$ & $\begin{array}{r}13,1857 \text { 10 } \\
24,452019 \\
2,270728 \\
7,956750 \\
40,218462\end{array}$ & $\begin{array}{r}20,286368 \\
2 \mathrm{I}, 110205 \\
3,146416 \\
8,640465 \\
4 \mathrm{I}, 268227\end{array}$ & $\begin{array}{r}17,508259 \\
48,566652 \\
706932 \\
10,512765 \\
53,951447\end{array}$ & $\begin{array}{r}11,037613 \\
42,224469 \\
1706932 \\
10,350641 \\
33,626290\end{array}$ \\
\hline $\begin{array}{l}\text { Roumania } \\
\text { Russia } \\
\text { Servia } \\
\text { United States } \\
\text { Other countries }\end{array}$ & : & $\begin{array}{l}\text { Jan. I } \\
\text { Jan. I } \\
\text { Jan. I } \\
\text { July I }\end{array}$ & $\begin{array}{r}34,7 \text { I } 5888 \\
\text { I I } 4,872260 \\
1,8755^{80} \\
202,905598 \\
\text { I } 4,499026\end{array}$ & $\begin{array}{r}31,860939 \\
158,064833 \\
2,016358 \\
120,727613 \\
9,311 \text { I } 307\end{array}$ & $\begin{array}{r}26,718698 \\
174,334 \text { I } 82 \\
3,098326 \\
44,112910 \\
10,955^{2} 45\end{array}$ & $\begin{array}{r}65,246599 \\
181,759796 \\
3,520627 \\
97,609007 \\
13,116253\end{array}$ & $\begin{array}{r}{ }^{1} 65,246599 \\
{ }^{3}{ }^{3} 37,130392 \\
3,365644 \\
146,700424 \\
1460424 \\
{ }^{3} 14,227728\end{array}$ \\
\hline Total & & - & $537,73^{2} 995$ & $54^{6}, 555579$ & $5^{87}, 966975$ & 697,333027 & $646,927 \times 6 I$ \\
\hline
\end{tabular}

IMPORTS

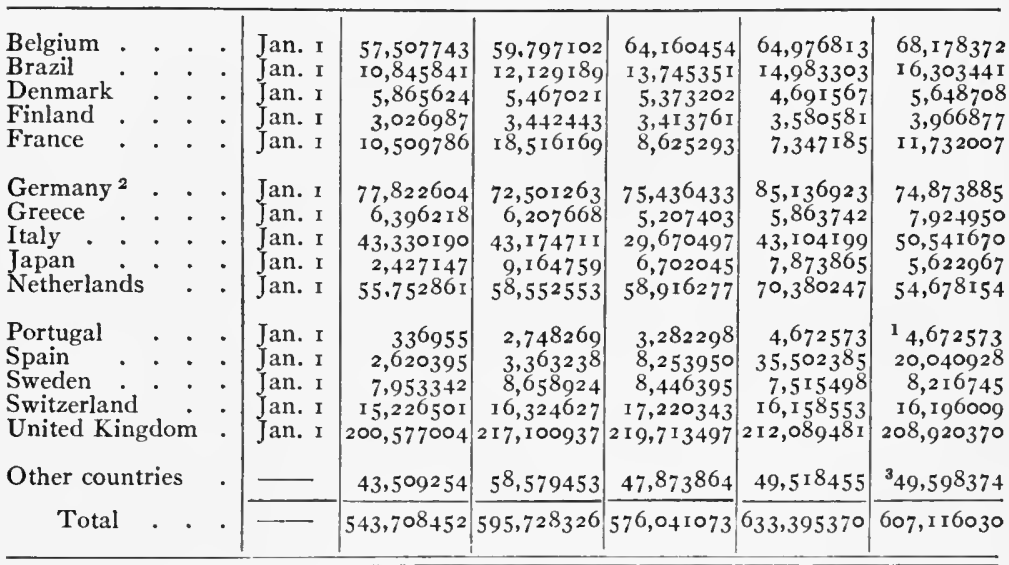

1 Year preceding.

${ }^{2}$ Not including free ports prior to March I, 1906.

${ }^{8}$ Preliminary. 


\section{WHEAT - Continued}

Quantity and Percentage of Exports of Domestic Wheat, 1907 AND 1908, By LEADINg PoRTS

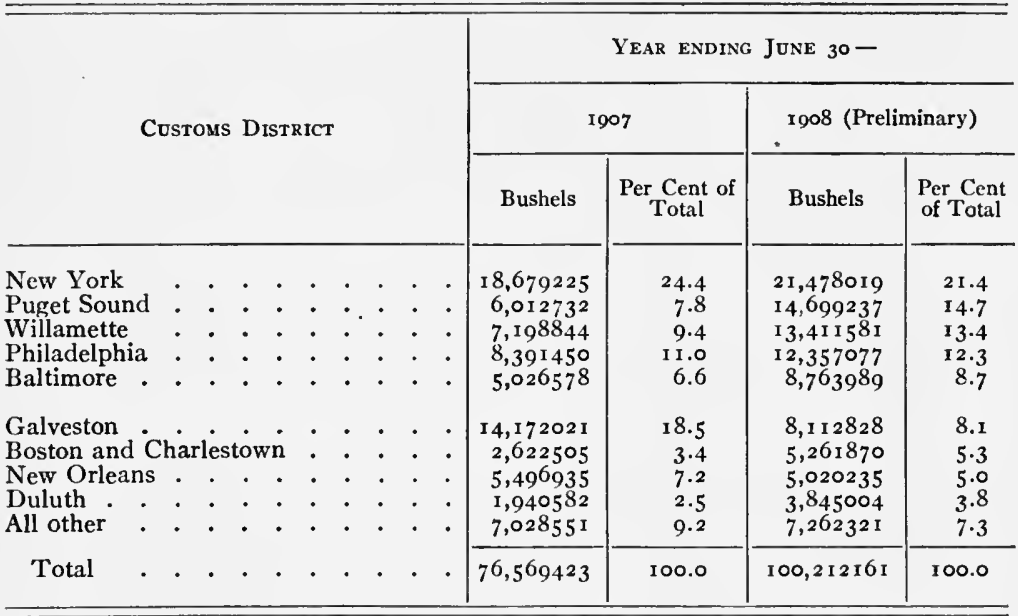

Average Yield of Wheat in Countries Named, ${ }^{3}$ Bushels per Acre, r898-igo7

\begin{tabular}{|c|c|c|c|c|c|c|c|c|c|c|c|}
\hline \multicolumn{5}{|c|}{ YEAR } & $\begin{array}{c}\text { UNITED } \\
\text { STATES I }\end{array}$ & $\begin{array}{l}\text { RUSSIA, } \\
\text { EURO- } \\
\text { PEAN } 2\end{array}$ & $\begin{array}{c}\text { GER- } \\
\text { MANY } 2\end{array}$ & ACsTRIA ${ }^{2}$ & $\begin{array}{c}\text { HUNGARY } \\
\text { PROPER } 2\end{array}$ & FRANCE ${ }^{1}$ & $\begin{array}{l}\text { UNITED } \\
\text { KING- } \\
\text { DOM }^{1}\end{array}$ \\
\hline \multicolumn{5}{|c|}{ Average ( 1888 to 1897 ) } & I 2.8 & 8.4 & 22.7 & 15.6 & 17.9 & 17.6 & 30.1 \\
\hline $\begin{array}{l}1898 \\
1899\end{array}$ & : & . & : & & $\begin{array}{l}15 \cdot 3 \\
\text { I } 2.3\end{array}$ & $\begin{array}{l}9.6 \\
8.7\end{array}$ & $\begin{array}{l}27.2 \\
28.4\end{array}$ & $\begin{array}{l}18.0 \\
10.0\end{array}$ & $\begin{array}{l}17.1 \\
17.8\end{array}$ & $\begin{array}{l}2 \mathrm{I} . \mathrm{I} \\
2 \mathrm{I} .2\end{array}$ & $\begin{array}{l}35.8 \\
32.8\end{array}$ \\
\hline 1900 & $\dot{8}$ & : & : & & $\begin{array}{l}12.5 \\
12.3\end{array}$ & 8.3 & 20.4 & 15.5 & $\begin{array}{l}1.0 \\
16.9\end{array}$ & 19.2 & $\begin{array}{l}33.0 \\
29 \cdot 5\end{array}$ \\
\hline 1901 & . & . & . & . & 15.0 & 8.I & 23.5 & 16.7 & 15.1 & 18.5 & 31.9 \\
\hline 1902 & - & - & - & . & 14.5 & II.I & 30.3 & 19.0 & 20.7 & 20.2 & $33 \cdot 9$ \\
\hline $19 \circ 3$ & - & . & - & - & I 2.9 & 10.6 & 29.2 & 17.8 & I 9.0 & 22.8 & $3^{\text {I.I }}$ \\
\hline 1904 & - & . & - & - & 12.5 & I 1.5 & $29 \cdot 5$ & I 9.5 & I 6.3 & I 9.3 & 27.8 \\
\hline 1905 & . & . & - & - & 14.5 & 10.0 & 28.5 & 19.6 & I 8.7 & 20.8 & 33.9 \\
\hline 1906 & • & - & • & - & $15 \cdot 5$ & $7 \cdot 7$ & 30.3 & 20.2 & 22.5 & 20.2 & 34.7 \\
\hline 1907 & • & - & . & . & 14.0 & 7.9 & 29.6 & I 8.0 & 15.1 & 23.2 & 35.0 \\
\hline \multicolumn{5}{|c|}{ Average ( 1898 to 1907 ) } & I 3.9 & $9 \cdot 3$ & 28.4 & 18.3 & 17.9 & 20.8 & 32.6 \\
\hline
\end{tabular}

1 Winchester bushels.

${ }^{2}$ Bushel of 60 pounds.

${ }^{3}$ For the ten years, 1886 to 1895 , the average yield of wheat was 27.7 bushels per acre in Holland, and 37.3 in Denmark; and for the succeeding ten-year period, 1896 to 1905 , the average yield in Holland was 31.2 bushels, and in Denmark 40.6 bushels per acre, with only two years below a 40 -bushel average ( 35.2 bushels in 1898 , and 29.2 in r9or). - C.G.H. 


\section{OATS}

Oat Crop of Countries NaMed, 1903-1907

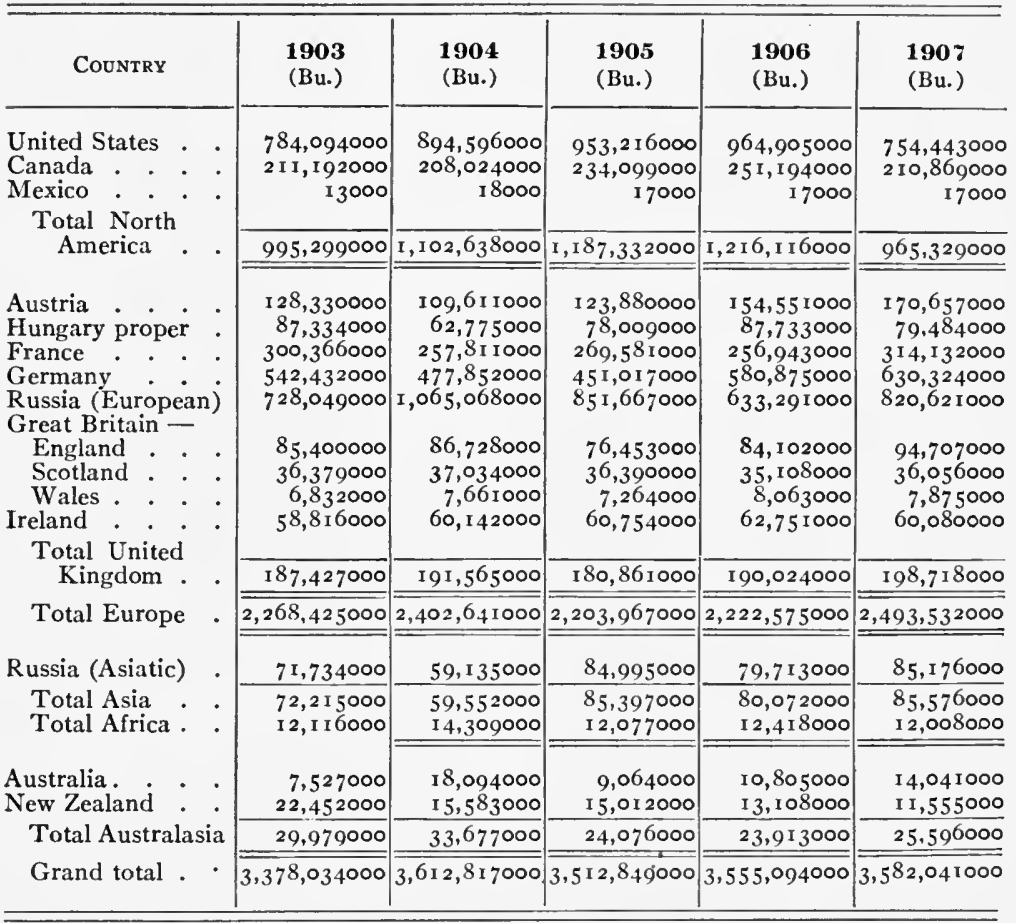

Average Yield of Oats in Countries Named, i898-igo7 Bushels per Acre

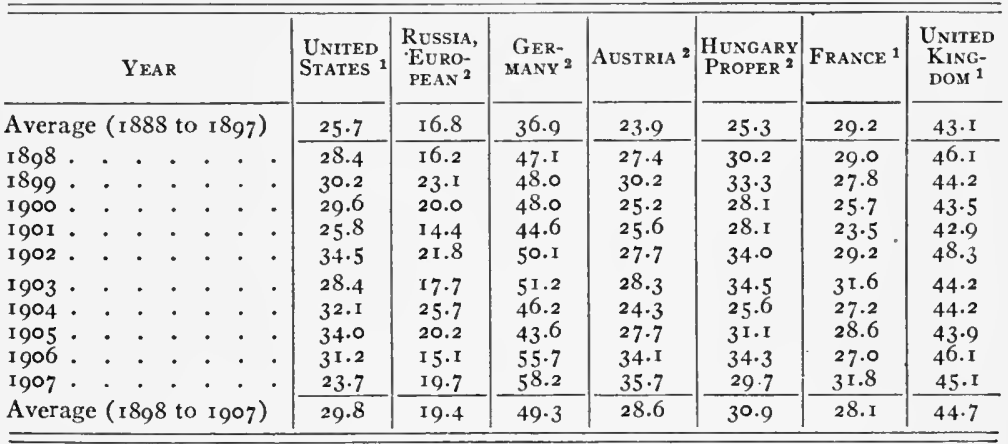

1 Winchester bushels.

${ }^{2}$ Bushels of 32 pounds. 


\section{BARLEY}

Barley Crop of Countries NaMed, I903-I907

\begin{tabular}{|c|c|c|c|c|c|}
\hline Country & $\begin{array}{l}1903 \\
\text { (Bu.) }\end{array}$ & $\begin{array}{l}1904 \\
\text { (Bu.) }\end{array}$ & $\begin{array}{l}1905 \\
\text { (Bu.) }\end{array}$ & $\begin{array}{l}1906 \\
\text { (Bu.) }\end{array}$ & $\begin{array}{l}1907 \\
\text { (Bu.) }\end{array}$ \\
\hline $\begin{array}{l}\text { United States : } \\
\text { Canada : } \\
\text { Mexico : } \\
\text { Total North }\end{array}$ & $\begin{array}{r}131,861000 \\
39,035000 \\
9,061000\end{array}$ & $\begin{array}{r}139,749000 \\
42,244000 \\
7,355000\end{array}$ & $\begin{array}{r}\text { I } 36,651000 \\
45,389000 \\
7,000000\end{array}$ & $\begin{array}{r}178,916000 \\
50,820000 \\
7,000000\end{array}$ & $\begin{array}{r}153,597000 \\
45,235000 \\
7,000000\end{array}$ \\
\hline America . & 179,957000 & 189,348000 & 189,040000 & $23^{6,736000}$ & 205,832000 \\
\hline $\begin{array}{l}\text { Austria } \\
\text { Hungary proper : } \\
\text { France }: . \\
\text { Germany } \\
\text { Russia (European) }\end{array}$ & $\begin{array}{r}73,873000 \\
64,577000 \\
43,345000 \\
152,653000 \\
350,486000\end{array}$ & $\begin{array}{r}66,8 \text { I } 5000 \\
49,9 \text { I } 5000 \\
38,338000 \\
\text { I } 35,409000 \\
339,7 \text { I } 7000\end{array}$ & $\begin{array}{r}70,469000 \\
62,453000 \\
40,841000 \\
134,204000 \\
338,836000\end{array}$ & $\begin{array}{r}76,024000 \\
69,747000 \\
36,538000 \\
142,901000 \\
304,276000\end{array}$ & $\begin{array}{r}78,548000 \\
63,078000 \\
45,095000 \\
160,650000 \\
344,104000\end{array}$ \\
\hline $\begin{array}{l}\text { England : : } \\
\text { Scotland : } \\
\text { Wales : } \\
\text { Ireland : }\end{array}$ & $\begin{array}{r}50,628000 \\
7,739000 \\
2,981000 \\
6,076000\end{array}$ & $\begin{array}{r}48,511000 \\
7,408000 \\
3,077000 \\
5,478000\end{array}$ & $\begin{array}{r}48,778000 \\
8,257000 \\
2,906000 \\
7,181000\end{array}$ & $\begin{array}{r}51,543000 \\
7,803000 \\
3,116000 \\
7,211000\end{array}$ & $\begin{array}{r}51,912000 \\
7,466000 \\
2,88_{5000} \\
6,995000\end{array}$ \\
\hline $\begin{array}{l}\text { Total United } \\
\text { Kingdom }\end{array}$ & 67,424000 & 64,474000 & 67,122000 & 69,673000 & 69,258000 \\
\hline Total Europe & 931,758000 & 841,070000 & 867,392000 & 907,895000 & $911,45^{1000}$ \\
\hline $\begin{array}{l}\text { Cyprus }: \\
\text { Japan } \\
\text { Russia (Asiatic) }\end{array}$ & $\begin{array}{r}3,969000 \\
59,737000 \\
6,084000 \\
\end{array}$ & $\begin{array}{r}3,122000 \\
80,794000 \\
6.538000\end{array}$ & $\begin{array}{r}2,980000 \\
77,436000 \\
8,130000\end{array}$ & $\begin{array}{r}2,778000 \\
83,968000 \\
7,763000\end{array}$ & $\begin{array}{r}3,000000 \\
90,544000 \\
9.345000\end{array}$ \\
\hline Total Asia . & 70,728000 & 90,512000 & 88,596000 & 94,558000 & 102,039000 \\
\hline Africa $\cdot . \cdot$. & 50,987000 & 52,097000 & 35,703000 & 44,102000 & 44,205000 \\
\hline $\begin{array}{l}\text { Australia. } \\
\text { New Zealand : }\end{array}$ & $\begin{array}{l}\mathrm{I}, 184000 \\
\mathrm{I}, \mathrm{I} 72000\end{array}$ & $\begin{array}{l}2,740000 \\
1,197000\end{array}$ & $\begin{array}{l}2,084000 \\
1,164000\end{array}$ & $\begin{array}{l}1,945000 \\
1,056000\end{array}$ & $\begin{array}{l}2,319000 \\
1,068000 \\
\end{array}$ \\
\hline Total Australasia & 2,356000 & 3.937000 & 3,248000 & 3,001000 & 3,387000 \\
\hline Grand total . & $1,235,786000$ & $1,176,964000$ & $1,183,979000$ & $1,286,292000$ & $\overline{1,267,814000}$ \\
\hline
\end{tabular}

Average Yield of Barley in Countries Named, Bushels per Acre, i 898-igo7

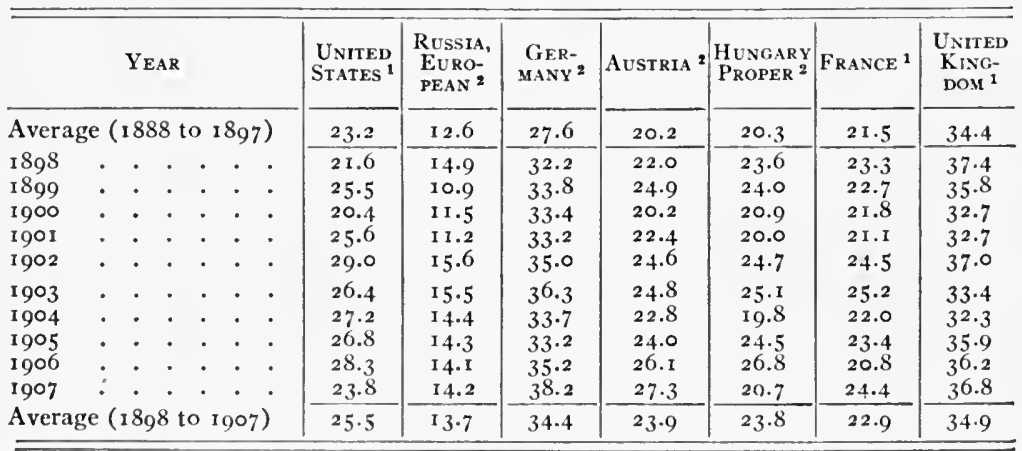

${ }^{1}$ Winchester bushels.

${ }^{2}$ Bushels of $4^{8}$ pounds. 
RYE

Rye Crop of Countries Named, 1903-igo7

\begin{tabular}{|c|c|c|c|c|c|}
\hline Country & & & & & \\
\hline \multirow{2}{*}{ 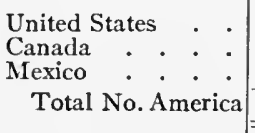 } & $\begin{array}{r}29,3^{6} 3000 \\
3,915000 \\
136000 \\
\end{array}$ & $\begin{array}{r}27,242000 \\
2,995000 \\
67000 \\
\end{array}$ & $\begin{array}{r}28,486000 \\
2,748000 \\
70000 \\
\end{array}$ & $\begin{array}{r}33,375000 \\
2,273000 \\
70000 \\
\end{array}$ & $\begin{array}{r}31,566000 \\
2,002000 \\
70000 \\
\end{array}$ \\
\hline & 33,414000 & 30,304000 & $3^{1,304000}$ & $35,7 \times 8000$ & 33,638000 \\
\hline \multirow{2}{*}{$\begin{array}{l}\text { Austria-Hungary } \\
\text { France } \\
\text { Germany }: \\
\text { Russia (European) } \\
\text { United Kingdom } \\
\text { Total Europe. }\end{array}$} & $\begin{array}{r}132,2 \\
57,9 \\
389,9 \\
879,8 \\
2,0 \\
\end{array}$ & $\begin{array}{r}\mathbf{1} 37,9 \\
52, \mathbf{1} \\
396,0 \\
977,9 \\
2,0 \\
\end{array}$ & $\begin{array}{r}151,641000 \\
58,116000 \\
378,204000 \\
708,692000 \\
2,000000 \\
\end{array}$ & $\begin{array}{r}153,515000 \\
50,429000 \\
378,948000 \\
638,675000 \\
2,000000 \\
\end{array}$ & $\begin{array}{r}\text { I } 29,234000 \\
58,578000 \\
384,150000 \\
776,000000 \\
2,000000 \\
\end{array}$ \\
\hline & $\mathrm{I}, 594,370000$ & $\mathrm{I}, 68 \mathrm{I}, 280000$ & $\mathrm{I}, 436,406000$ & $\mathrm{I}, 37 \mathrm{I}, 881000$ & $1,479,851000$ \\
\hline $\begin{array}{l}\text { Russia (Asiatic) } \\
\text { Total Asia }\end{array}$ & 32,059000 & 30,457000 & 28,750000 & 28,169000 & 000000 \\
\hline \multirow{3}{*}{$\begin{array}{l}\text { Australia } \\
\text { New Zealand } \\
\text { Total Australasia } \\
\text { Grand total }\end{array}$} & $\begin{array}{l}78000 \\
40000 \\
\end{array}$ & & & $\begin{array}{r}94000 \\
65000 \\
\end{array}$ & $\begin{array}{l}8900 \\
4300 \\
\end{array}$ \\
\hline & 118000 & 152000 & 118000 & I 59000 & 132000 \\
\hline & $1,659,961000$ & $1,742,193000$ & $1,496,578000$ & $\mathrm{I}, 435,9^{2} 7000$ & $\mathrm{r}, 545,62 \mathrm{I000}$ \\
\hline
\end{tabular}

Average Yield of Rye in Countries Named, i 898-igo7

(Bushels per Acre)

\begin{tabular}{|c|c|c|c|c|c|c|c|c|c|c|c|c|}
\hline \multicolumn{5}{|c|}{ YEAR $_{\text {EAR }}$} & & $\begin{array}{l}\text { United } \\
\text { States }\end{array}$ & $\begin{array}{c}\text { RUSSIA, } \\
\text { EURO- } \\
\text { PEAN }\end{array}$ & $\begin{array}{l}\text { GER- } \\
\text { MANY }\end{array}$ & $\begin{array}{l}\text { AUS- } \\
\text { TRIA }\end{array}$ & $\begin{array}{l}\text { HUN- } \\
\text { GARY } \\
\text { PROPER }\end{array}$ & France & $\begin{array}{l}\text { IRF- } \\
\text { LAND }\end{array}$ \\
\hline \multicolumn{5}{|c|}{ Average ( 1888 to 1897 ) } & & I 3.5 & 10.0 & I9.० & I 5.5 & 16.3 & $17 \cdot 1$ & 25.4 \\
\hline I 898 & . . & . & . & . . & . & 15.6 & 10.6 & 24.2 & $17 \cdot 7$ & I6.9 & I 8.3 & $25 \cdot 5$ \\
\hline I 899 & . & . & . & . & . & 14.4 & I 2.8 & 23.5 & 18.7 & 17.7 & I 8.2 & 25.8 \\
\hline 1900 & - & . & . & - & . & I 5.1 & 12.7 & 22.9 & I 3.0 & 15.1 & I 6.9 & 25.7 \\
\hline I 901 & . & . & . & . & & 15.3 & I0. 3 & 22.4 & 16.9 & $\times 5.8$ & 16.7 & $27 \cdot 3$ \\
\hline 1902 & - & - & - & - & & 17.0 & I 2.5 & 24.6 & I 8.2 & 19.1 & 14.3 & 28.1 \\
\hline $19 \circ 3$ & . & . & . & . & & I 5.4 & 12.2 & 26.2 & I 8.2 & 18.2 & I 8. I & 26.9 \\
\hline 1904 & . & . & . & . & . & & & 26.3 & I 9. & I 7 & I 6.6 & 26.0 \\
\hline 1905 & . & . & . & . & & 16.5 & IO.I & 24.9 & 20.2 & 19.4 & I 8.5 & 27.0 \\
\hline 1906 & . & & . & . & & 16.7 & 8.8 & $25 \cdot I$ & & 19.8 & 16.3 & 27.6 \\
\hline 1907 & . & . & . & . & & 16.4 & I0.8 & 25.7 & I 8.8 & 16.2 & 18.2 & 27.0 \\
\hline \multicolumn{6}{|c|}{ Average ( 1898 to 1907 ) } & I 5.8 & II.5 & 24.6 & I8.I & 17.5 & 17.2 & 26.7 \\
\hline
\end{tabular}

Note. The student may well remember that the reported crop yields, acreage, and production are based upon estimates, while the statistics for imports and exports are based upon definite data. In census years the estimates are made with greater care and detail, but even these are largely estimates.

In some cases the annual estimates are undoubtedly far from the facts, as is strongly suggested by comparing the federal "statistics" with the "statistics" 
POTATOES

Potato Crop of Countries Named, ig02-igo6

\begin{tabular}{|c|c|c|c|c|c|}
\hline COUntry & $\begin{array}{l}1902 \\
\text { (Bu.) }\end{array}$ & $\begin{array}{l}1903 \\
\text { (Bu.) }\end{array}$ & $\begin{array}{l}\mathbf{1 9 0 4} \\
\text { (Bu.) }\end{array}$ & $\begin{array}{l}1905 \\
\text { (Bu.) }\end{array}$ & $\begin{array}{l}1906 \\
\text { (Bu.) }\end{array}$ \\
\hline $\begin{array}{l}\text { United States : } \\
\text { Canada : } \\
\text { Mexico : } \\
\text { Newfoundland }\end{array}$ & $\begin{array}{r}284,633000 \\
51,206000 \\
347000 \\
1350000 \\
\end{array}$ & $\begin{array}{r}247, \text { I } 28000 \\
56,944000 \\
539000 \\
1,350000 \\
\end{array}$ & $\begin{array}{r}332,830000 \\
55,436000 \\
527000 \\
1,350000 \\
\end{array}$ & $\begin{array}{r}260,741000 \\
55,257000 \\
400000 \\
1,350000 \\
\end{array}$ & $\begin{array}{r}308,038000 \\
59,804000 \\
400000 \\
1,350000 \\
\end{array}$ \\
\hline $\begin{array}{l}\text { Total North } \\
\text { America . . }\end{array}$ & 337,536000 & 305,961000 & 390,143000 & 317,748000 & 369,592000 \\
\hline Chile. . . . & $1 \mathrm{I}, 6 \mathrm{r} 6000$ & 10,349000 & 6,131000 & 6,532000 & 6,532000 \\
\hline $\begin{array}{l}\text { Austria-Hungary : } \\
\text { France : }: \cdot \\
\text { Germany }: \cdot \\
\text { Russia (European) }\end{array}$ & $\begin{array}{r}584,619000 \\
441,055000 \\
1,596,969000 \\
1,028,036000 \\
\end{array}$ & $\begin{array}{r}544,166000 \\
426,422000 \\
1,576,361000 \\
887,600000 \\
\end{array}$ & $\begin{array}{r}520,461000 \\
451,039000 \\
\mathrm{I}, 333,326000 \\
893,908000 \\
\end{array}$ & $\begin{array}{r}765,117000 \\
523,876000 \\
1,775,579000 \\
1,032,888000 \\
\end{array}$ & $\begin{array}{r}709,237000 \\
372,076000 \\
1,577,653000 \\
939,717000 \\
\end{array}$ \\
\hline $\begin{array}{l}\text { United Kingdom: } \\
\text { Great Britain : } \\
\text { Ireland . . }\end{array}$ & $\begin{array}{l}\text { I1 } 9,250000 \\
101,761000\end{array}$ & $\begin{array}{r}108,779000 \\
88,227000 \\
\end{array}$ & $\begin{array}{r}133,961000 \\
98,635000 \\
\end{array}$ & $\begin{array}{r}140,474000 \\
127,793000 \\
\end{array}$ & $\begin{array}{r}\text { I } 28,005000 \\
99,328000 \\
\end{array}$ \\
\hline $\begin{array}{c}\text { Total United } \\
\text { Kingdom }\end{array}$ & 221,011000 & I97,006000 & $23^{2}, 596000$ & 268,267000 & 227,333000 \\
\hline Total Europe . & $4,280,644000$ & $4,038,566000$ & $3,8+3,08 \mathrm{r} 000$ & $4,779,590000$ & $4,305,3 \mathrm{I} 3000$ \\
\hline Russia (Asiatic) : & $\begin{array}{r}7,418000 \\
13,142000 \\
\end{array}$ & $\begin{array}{r}9,824000 \\
19,364000 \\
\end{array}$ & $\begin{array}{l}\text { I I }, 274000 \\
\text { I } 8,800000 \\
\end{array}$ & $\begin{array}{r}16,255000 \\
\mathrm{I} 8,865000 \\
\end{array}$ & $\begin{array}{r}16,255000 \\
16,481000 \\
\end{array}$ \\
\hline Total Asia & 20,560000 & 29,188000 & 30,074000 & 35,120000 & $3^{2,736000}$ \\
\hline Total Africa & 3,884000 & 3,541000 & 4,048000 & 4,071000 & 4,138000 \\
\hline $\begin{array}{l}\text { Australia } \\
\text { New Zealand: }\end{array}$ & $\begin{array}{r}12,039000 \\
7,721000 \\
\end{array}$ & $\begin{array}{r}\mathrm{r} 4,973000 \\
7,215000 \\
\end{array}$ & $\begin{array}{r}16,777000 \\
7,795000 \\
\end{array}$ & $\begin{array}{r}\text { I I }, 071000 \\
5,025000 \\
\end{array}$ & $\begin{array}{r}10,0 \text { I } 6000 \\
4,607000 \\
\end{array}$ \\
\hline 'Total Australasia & 19,760000 & 22,188000 & 24,572000 & 16,006000 & 14,623000 \\
\hline Grand total. & $4,674,000000$ & $4,409,793000$ & $4,298,049000$ & $5,159,157000$ & $4,73^{2,934000}$ \\
\hline
\end{tabular}

from some of the states which have crop-reporting boards, such as the Illinois State Board of Agriculture and the Iowa Weather and Crop Service. Thus in I 907 , Illinois produced, according to the federal report, more than 40 million bushels of wheat, but less than 25 million bushels by the state report. In I 908 the federal estimate gave Illinois $9,450,000$ acres of corn, while the state report was $6,780,000$ acres. The same year the state of Iowa claimed to produce only $4,968,250$ bushels of wheat, but in the federal report Iowa receives credit for $8,068,000$ bushels. These are extreme variations, but they should serve to emphasize the fact that crop "statistics" should not weigh heavily as against actual data, such, for example, as the records of the long-continued field experiments of Rothamsted, Pennsylvania, etc.

On the other hand, the United States crop statistics are probably as good as those from any nation; and, while gross errors may appear in specific instances, 
RICE

\section{Rice Crop of Countries Named, ig02-1906}

[Mostly cleaned rice. China, which is omitted, has a roughly estimated crop of 50,000,000,000 to $60,000, \infty 00, \infty 00$ pounds. Other omitted countries are Afghanistan, Algeria, Brazil, Colombia, Federated Malay States, Madagascar, Persia, Russia (Asiatic), Trinidad and Tobago, Turkey (Asiatic and European), Venezuela, and a few other countries of small production.]

\begin{tabular}{|c|c|c|c|c|c|}
\hline COUNTRY & $\begin{array}{c}1902 \\
\text { (Lb.) }\end{array}$ & $\begin{array}{l}1903 \\
\text { (Lb.) }\end{array}$ & $\begin{array}{r}1904 \\
\text { (Lb.) }\end{array}$ & $\begin{array}{l}1905 \\
\text { (Lb.) }\end{array}$ & $\begin{array}{l}1906 \\
\text { (Lb.) }\end{array}$ \\
\hline $\begin{array}{l}\text { United States: } \\
\text { Contiguous : : } \\
\text { Hawaii : : : } \\
\text { Mexico . : : }\end{array}$ & $\begin{array}{r}319,400000 \\
33,400000 \\
40,000000 \\
\end{array}$ & $\begin{array}{r}560,800000 \\
33,400000 \\
48,700000 \\
\end{array}$ & $\begin{array}{r}586,000000 \\
33,400000 \\
62,000000 \\
\end{array}$ & $\begin{array}{r}378,000000 \\
33,400000 \\
62,000000 \\
\end{array}$ & $\begin{array}{r}496,000000 \\
33,400000 \\
62,000000 \\
\end{array}$ \\
\hline Total No. America & 401,600000 & 652,000000 & 690,800000 & 482,800000 & 600,800000 \\
\hline TotalSouth America & 85,600000 & 87,500000 & 95,100000 & $97,300000^{\circ}$ & 120,500000 \\
\hline${ }_{\text {Spain }}^{\text {Italy }}: \vdots:$ & $\begin{array}{l}668,400000 \\
359.800000 \\
\end{array}$ & $\begin{array}{l}761,400000 \\
417,100000 \\
\end{array}$ & $\begin{array}{l}760,500000 \\
394,600000\end{array}$ & $\begin{array}{l}676,600000 \\
478,800000 \\
\end{array}$ & $\begin{array}{l}728,600000 \\
475,400000\end{array}$ \\
\hline Total Europe & $1,038,300000$ & $\mathrm{I}, \mathrm{I} 88,500000$ & $1,167,500000$ & $\mathrm{I}, \mathrm{I} 66,500000$ & $1,215,000000$ \\
\hline $\begin{array}{l}\text { British India: } \\
\text { British Provinces : } \\
\text { Native States : } \\
\text { Japanese Empire : } \\
\text { Total Asia : : } \\
\text { Total Africa : }\end{array}$ & $\begin{array}{r}72,688,000000 \\
799,000000 \\
13,295,300000 \\
105,075,200000 \\
22,200000 \\
\end{array}$ & $\begin{array}{r}68,580,000000 \\
838,000000 \\
16,809,200000 \\
104,887,800000 \\
22,200000 \\
\end{array}$ & $\begin{array}{r}71,561,000000 \\
764,000000 \\
18,658,700000 \\
110,212,200000 \\
22,200000 \\
\end{array}$ & \begin{tabular}{|r|}
$67,916,000000$ \\
640,000000 \\
$14,639,200000$ \\
$102,147,000000$ \\
21,800000 \\
\end{tabular} & $\begin{array}{r}67,464,000000 \\
640,000000 \\
17,185,900000 \\
104,974,000000 \\
21,800000 \\
\end{array}$ \\
\hline Grand total & $106,626,400000$ & $106,84 \mathrm{I}, 000000$ & I 2, I 90,800000 & $103,919,100000$ & $106,943,900000$ \\
\hline
\end{tabular}

they doubtless approximate the truth as a general rule, and are more trustworthy, especially for purposes of comparison, than some state estimates.

It should be kept in mind that certain crops, such as wheat, are now quite regularly fertilized in some of the Eastern and East Central states.

Comparison of crop yields in different states is most significant when the acreage is also comparable. In 1907 the average yield of wheat per acre was 23 bushels in Vermont and only in bushels in Kansas; but Vermont raised one thousand acres and Kansas raised six million acres, and on many thousand acres the Kansas yield may have exceeded 30 bushels per acre. In 1905 the average yield of corn per acre was 42.7 bushels in Connecticut and only 39.8 bushels in Illinois; but Connecticut raised only 55,595 acres of corn, while Champaign County, Illinois, raised some 200,000 acres of corn, which made an average yield of 65 bushels per acre.

South Carolina is authentically credited with having produced 239 bushels of air-dry corn on one acre of land in one season, but the average yield for the state for the 44 years, I866 to 1909, is 1o bushels per acre. Even the average yield of corn for the United States has varied from 30.8 bushels per acre, in 1872 , to 16.7 bushels, in I90I; and if these records were interchanged the average yield would become the same for two successive 20-year periods, 25.0 bushels per acre. 


\section{SUGAR}

\section{Sugar Production of Countries Named, 1903-1904 to 1907-1908}

[European beet sugar, as estimated by Licht; United States beet sugar, from reports of Department of Agriculture on the Progress of the Beet-sugar Industry in the United States; production of British India (except 1907-1908) and of Formosa and Natal prior to 1905 - 1906 from official statistics; other data, from Willett \& Gray. The estimates of Willett \& Gray do not include the production of China, and some other less important sugar-producing countries.]

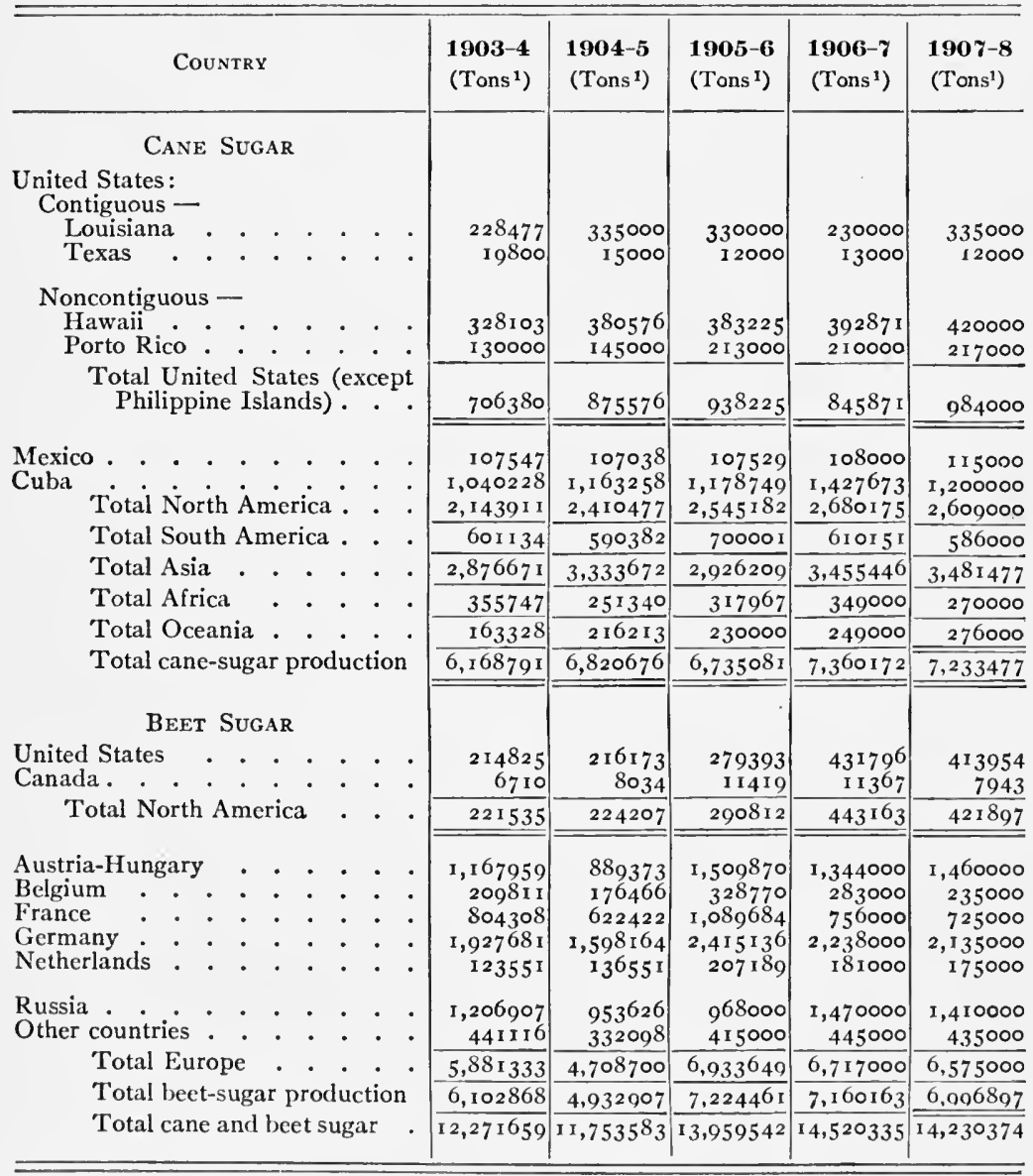

1 Tons of 2240 pounds, except beet sugar in Europe, which is shown in metric tons of 2204.622 pounds. 


\section{SUGAR - Continued}

Production of Sugar in the United States and its Possessions, 1874-75 to $1907-8$

\begin{tabular}{|c|c|c|c|c|c|c|c|c|c|}
\hline \multirow[b]{2}{*}{ YEAR } & & & \multirow[b]{2}{*}{$\begin{array}{l}\text { BEET } \\
\text { SugaR } \\
\text { (Long } \\
\text { Tons) }\end{array}$} & \multicolumn{5}{|c|}{ Cane Sugar } & \multirow[b]{2}{*}{$\begin{array}{l}\text { TotaL } \\
\text { (Long } \\
\text { Tons) }\end{array}$} \\
\hline & & & & $\begin{array}{c}\text { Louisiana } \\
\text { (I Long } \\
\text { Tons) }\end{array}$ & $\begin{array}{l}\text { Other } \\
\text { Southern } \\
\text { States } \\
\text { (Long } \\
\text { Tons) }\end{array}$ & $\begin{array}{l}\text { Porto } \\
\text { Rico } \\
\text { (Long } \\
\text { Tons) }\end{array}$ & $\begin{array}{l}\text { Hawaii } \\
\text { (Long } \\
\text { Tons) }\end{array}$ & $\begin{array}{c}\text { Philippine } \\
\text { Islands } \\
\text { (Long } \\
\text { Tons) }\end{array}$ & \\
\hline $\begin{array}{l}1874-1875 . \\
1875-1876 . \\
1876-1877 . \\
1877-1878 . \\
1878-1879 .\end{array}$ & $\dot{\text { : }}$ & $\dot{:}$ & $\begin{array}{l}100^{\prime} \\
200\end{array}$ & $\left\{\begin{array}{r}60047 \\
72954 \\
85122 \\
65671 \\
106908\end{array} \mid\right.$ & $\begin{array}{l}3454 \\
40.46 \\
3879 \\
533 \circ \\
5090\end{array}$ & $\begin{array}{l}72128 \\
70016 \\
62340 \\
84347 \\
76411\end{array}$ & $\begin{array}{l}\text { I I } 1997 \\
\text { I } 1639 \\
\text { I } 1418 \\
\text { I } 7157 \\
2 \text { I } 884\end{array}$ & $\begin{array}{l}126089 \\
128485 \\
121052 \\
120096 \\
129777\end{array}$ & $\begin{array}{l}273015 \\
287240 \\
283911 \\
292701 \\
340270\end{array}$ \\
\hline $\begin{array}{l}1879-1880 . \\
1880-1881 \\
1881-1882 \\
1882-1883 \\
1883-1884\end{array}$ & : & : & \} $\begin{array}{r}1200 \\
500 \\
500^{1} \\
535\end{array}$ & $\left\{\begin{array}{r}88822 \\
121867 \\
71373 \\
135297 \\
128443\end{array}\right.$ & $\begin{array}{l}3980 \\
5500 \\
5000 \\
7000 \\
6800\end{array}$ & $\begin{array}{l}57057 \\
61715 \\
80066 \\
77632 \\
98665\end{array}$ & $\begin{array}{l}28386 \\
41870 \\
50972 \\
51705 \\
63948\end{array}$ & $\begin{array}{l}178329 \\
205508 \\
148047 \\
193726 \\
120199\end{array}$ & $\begin{array}{l}357774 \\
436960 \\
35595^{8} \\
465860 \\
418590\end{array}$ \\
\hline $\begin{array}{l}1884-1885 \\
1885-1886 . \\
1886-1887 \\
1887-1888 \text {. } \\
1888-1889 .\end{array}$ & $\dot{.}$ & : & $\begin{array}{r}953 \\
600 \\
800 \\
255 \\
1861\end{array}$ & $\begin{array}{r}94376 \\
\mathbf{1} 27958 \\
80859 \\
\times 57971 \\
\mathbf{1} 44878\end{array}$ & $\begin{array}{l}6500 \\
7200 \\
4535 \\
9843 \\
9031\end{array}$ & $\begin{array}{l}70000 \\
64000 \\
86000 \\
60000 \\
62000\end{array}$ & $\begin{array}{r}76496 \\
96500 \\
95000 \\
100000 \\
120000\end{array}$ & $\begin{array}{l}200997 \\
182019 \\
169040 \\
158445 \\
224861\end{array}$ & $\begin{array}{l}449322 \\
478277 \\
43^{62334} \\
486514 \\
562631\end{array}$ \\
\hline $\begin{array}{l}\text { I } 889-1890 . \\
1890-1891 . \\
1891-1892 . \\
1892-1893 . \\
1893-1894 .\end{array}$ & $\dot{:}$ & : & $\begin{array}{r}2203 \\
3459 \\
5356 \\
12018 \\
1995^{\circ}\end{array}$ & $\begin{array}{l}124772 \\
215^{8} 44 \\
160937 \\
2175^{25} \\
265^{8} 3\end{array}$ & $\begin{array}{l}8159 \\
6107 \\
4500 \\
5000 \\
6854\end{array}$ & $\begin{array}{l}55000 \\
50000 \\
70000 \\
50000 \\
60000\end{array}$ & $\begin{array}{l}\text { I } 200000 \\
\text { I } 25000 \\
\text { I } 5598 \\
\text { I } 40000 \\
\text { I36689 }\end{array}$ & $\begin{array}{l}142554 \\
136035 \\
248806 \\
257392 \\
207319\end{array}$ & $\begin{array}{l}452688 \\
536445 \\
605197 \\
681935 \\
696648\end{array}$ \\
\hline $\begin{array}{l}\text { I894-1 } 895 . \\
\text { r895-1896. } \\
1896-1897 . \\
1897-1898 . \\
\text { 1898-1 } 899 \text {. }\end{array}$ & $\dot{:}$ & : & $\begin{array}{l}20092 \\
29220 \\
37536 \\
4039^{8} \\
32471\end{array}$ & $\begin{array}{l}317334 \\
237721 \\
282009 \\
310447 \\
245512\end{array}$ & $\begin{array}{l}8288 \\
4973 \\
5570 \\
5737 \\
3442\end{array}$ & $\begin{array}{l}52500 \\
50000 \\
58000 \\
54000 \\
53826\end{array}$ & $\begin{array}{l}131698 \\
201632 \\
224218 \\
204833 \\
252507\end{array}$ & $\begin{array}{r}336076 \\
230000 \\
202000 \\
178000 \\
93000\end{array}$ & $\begin{array}{l}865988 \\
753546 \\
809333 \\
793415 \\
68075^{8}\end{array}$ \\
\hline $\begin{array}{l}1899-1900 . \\
1900-1901 . \\
1901-1902 . \\
1902-1903 . \\
1903-1904 .\end{array}$ & : & $:$ & $\begin{array}{r}72944 \\
76859 \\
164827 \\
194782 \\
214825\end{array}$ & $\begin{array}{l}\mathbf{1} 47164 \\
270338 \\
321676 \\
329226 \\
228477\end{array}$ & $\begin{array}{r}2027 \\
2891 \\
3614 \\
3722 \\
29800\end{array}$ & $\begin{array}{r}\mathbf{3 5 0 0 0} \\
80000 \\
85000 \\
85000 \\
130000\end{array}$ & $\begin{array}{l}25^{8} 521 \\
321461 \\
317509 \\
391062 \\
328103\end{array}$ & $\begin{array}{l}62785 \\
55400 \\
78637 \\
90000 \\
84000\end{array}$ & $\begin{array}{r}578441 \\
806949 \\
971263 \\
\mathrm{I}, 093792 \\
\mathrm{I}, 005205\end{array}$ \\
\hline $\begin{array}{l}1904-1905 . \\
1905-1906 . \\
1906-1907 . \\
1907-1908 .\end{array}$ & $\dot{\dot{.}}$ & $\dot{.}$ & $\begin{array}{l}216173 \\
279393 \\
431796 \\
413954\end{array}$ & $\begin{array}{l}335000 \\
330000 \\
230000 \\
335000\end{array}$ & $\begin{array}{l}2 \text { I } 5000 \\
\text { I } 2000 \\
2 \text { I } 3000 \\
2 \text { I } 2000\end{array}$ & $\begin{array}{l}145000 \\
213000 \\
210000 \\
217000\end{array}$ & $\begin{array}{l}380576 \\
383225 \\
392871 \\
420000\end{array}$ & $\begin{array}{l}\text { I } 06875 \\
\text { I } 455^{25} \\
\text { 1 } 45000 \\
\text { I } 35000\end{array}$ & $\begin{array}{l}\mathrm{I}, \mathrm{I} 98624 \\
\mathrm{I}, 3^{6} 3^{1} 43 \\
\mathrm{~J}, 4^{2} 3 \mathrm{I} 67 \\
\mathrm{I}, 53^{2} 954\end{array}$ \\
\hline
\end{tabular}

I Production uncertain; not exceeding quantity stated.

2 Texas. 
INTERNATIONAL TRADE IN SUGAR, I902-1906

EXPORTS

\begin{tabular}{|c|c|c|c|c|c|c|}
\hline COUntry & $\begin{array}{c}\text { YEAR } \\
\text { BEGIN- } \\
\text { NING }\end{array}$ & $\begin{array}{l}1902 \\
\text { (Lb.) }\end{array}$ & $\begin{array}{l}\mathbf{1 9 0 3} \\
\text { (Lb.) }\end{array}$ & $\begin{array}{l}\mathbf{1 9 0 4} \\
\text { (Lb.) }\end{array}$ & $\begin{array}{l}1905 \\
\text { (Lb.) }\end{array}$ & $\begin{array}{l}1906 \\
\text { (Lb.) }\end{array}$ \\
\hline Austria-Hungary . & Jan. $I$ & I, 500,882186 & $\mathrm{I}, 564,43769 \mathrm{I}$ & $1,125,102823$ & $1,265,791878$ & $\mathrm{I}, 631,529629$ \\
\hline Argentina . . & Jan. I & 91,919510 & $66,88823 \mathrm{I}$ & 40,368833 & 4,847964 & 233690 \\
\hline Belgium . & Jan. $\mathbf{I}$ & $296,28777 \mathrm{I}$ & 80695 & 406,944665 & 304,103682 & 462,076753 \\
\hline Brazil $\therefore . \cdot$ & Jan. I & 301,498062 & 48,256067 & 17,331526 & 83,216786 & 187,278902 \\
\hline British Guiana & Apr. I & 280,284480 & 282,125760 & $239,043^{8} 40$ & 261,072000 & 257,400912 \\
\hline British India . & Apr. I & 55,645520 & 502 & I I 504 & 64,546044 & 58.660806 \\
\hline China & Jan. $I$ & & & 48,787467 & 8800 & 06000 \\
\hline Cuba. & Jan. I & $1,781,561643$ & $2,118,279^{6} 4^{6}$ & $2,450,166945$ & $2,412,01539 \mathrm{r}$ & $2,643,700075$ \\
\hline Dutch East Indies & Jan. I & $\mathbf{1}, 9 \circ 4,3$ & $\mathrm{I}, 907,867045$ & $2,318,243282$ & $2,314,655085$ & $2,197,208868$ \\
\hline Egypt . . . & Jan. I & 98,521149 & 86,469803 & 50,620531 & 67,82 I 106 & I0, 495854 \\
\hline Formosa & Jan. I & 100,873254 & $54,128,545$ & $79,5188 \div 6$ & 93,930689 & 93,930689 \\
\hline & Jan. I & & & & & \\
\hline ay & Jan. I & 2,367, & $2,249,141034$ & $1,720,574001$ & $1,636,803746$ & $2,671,8$ \\
\hline Mauritius & Jan. I & 72713 & 375,505049 & 435,923559 & 361,987596 & 4 I0,91 78 I 7 \\
\hline Netherlands & Jan. I & 310,694069 & 287,238939 & 403,476558 & 215,001603 & 356,157015 \\
\hline Peru & Jan. I & 258,738790 & $281,48288 \circ$ & 290,916853 & $295,935^{80} 5$ & 295,935805 \\
\hline ine Islands & & & 188, I I 4307 & 7567 & 239 & 4747 \\
\hline Reunion & Jan. & 50 & 107,862584 & 80,432029 & 41,433135 & 41,433135 \\
\hline Russia $\dot{0}^{\circ} \cdot$ & Jan. I & 288 & 540,418988 & 398,854898 & $220,925 \circ 74$ & 206,854 I I 8 \\
\hline $\begin{array}{l}1 \text { rindaa and } \\
\text { Tobago } .\end{array}$ & Apr. I & $105,86 \pm 392$ & 90,460944 & 106,573936 & 81,179056 & 100,809856 \\
\hline Other countries & - & 617,792000 & 609,680000 & 560,646000 & 901,932 I & $95^{2}, 5477^{23}$ \\
\hline Total . . & & I I $, 854,814706$ & II $, 682,0344$ I & $11,677,016184$ & I I $, 594,676863$ & I $3,506,338012$ \\
\hline
\end{tabular}

IMPORTS

\begin{tabular}{|c|c|c|c|c|c|c|c|c|}
\hline Australia . & & & Jan. I & 208,55 1056 & 205,026640 & 85,108624 & 55,023056 & 94,137680 \\
\hline British India & - & & Apr. I & 549,868704 & 672,147168 & 724,262224 & 862,453200 & $\mathbf{I}, 000,152784$ \\
\hline Canada & & & July I & 388,370832 & 390,544660 & 346,75 & 448,962523 & 423,6896 I 4 \\
\hline Cape of Good & Hop & & Jan. I & 120,365406 & 104,629048 & IOI, $4 \mathrm{C}$ & 82,805094 & 87,165626 \\
\hline Chile • • & - & & Jan. I & 97,002936 & I 15,467959 & 124,139619 & 75,610563 & 75,61 \\
\hline China & - & & Jan. I & 607,880000 & $435,7 \times 1467$ & 509,959200 & 626,433333 & 806, \\
\hline tark & - & & Jan. $I$ & 621 & & & & \\
\hline ( & - & & Jan. 1 & $144 \mathrm{I}$ & & 45 , & 395 & 099 \\
\hline linland. & - & & Jan. $I$ & 745 & 55 & $533 \mathrm{I}$ & 207 & 2752 \\
\hline lirance. & - & & Jan. $I$ & 220,187363 & 288,073883 & 179,849557 & I 79,460755 & $222,56232 \mathrm{I}$ \\
\hline & & & Jan. I & & & & & \\
\hline Japa & - & & Jan. I & & 67 & 547 & 733 & 933 \\
\hline ands & • & - & Jan. & 655 & 602 & 129 & $\infty$ & I 18 , \\
\hline ealand & - & - & Jan. & 074 & 686 & 944 & 230 & 93 \\
\hline Norway . & 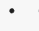 & & Jan. & 82,791956 & 83,5 & $76,7 \circ 3 \circ 54$ & 77,9 & \\
\hline & & & Mar.2 r & 167,1 & $I_{79,4} 1_{22} 8$ & 154,81 & 154 & I 54 \\
\hline & 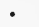 & & Jan. I & 016 & & & & 380 \\
\hline ore & . & & Jan. & & 9867 & 107600 & 3267 & I I 7 \\
\hline Itic & . & & Jan. & 180 & 5742 & I $75,44470 \mathrm{I}$ & 9994 & 187 \\
\hline 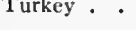 & & & Jan. I & 273,612826 & 273,612826 & 273,6 工 2826 & 273,612826 & 273,612826 \\
\hline Unite & & & Jan. I & 2768 & $3,009,0$ & $3,400,501648$ & & \\
\hline & & & July I & 4,216 & $3,700,623613$ & $3,680,0$ & $3,979,331430$ & $4,391,83$ \\
\hline ay & $\dot{0}$ & - & July I & & & & & 33,8 \\
\hline & & & & 3 I 2,617000 & 361,562533 & $383,86 \times 800$ & $587,12259 \mathrm{I}$ & 552,306790 \\
\hline Total . & . & & & I I $, 924,544723$ & I I , 300, 2606,35 & I I, 5 I 5,5 & I I , 7 I I , 64049 I & I $2,725,444045$ \\
\hline
\end{tabular}


BUTTER

INTERNATIONAL TRADE IN BUTter, I9O2-1906

EXPORTS

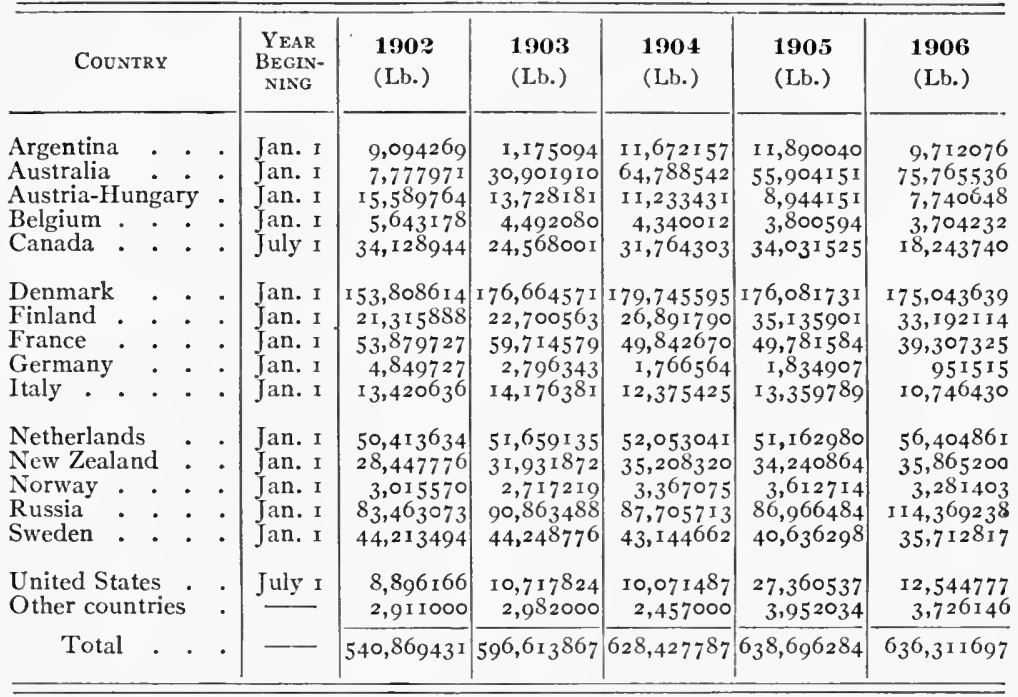

IMPORTS

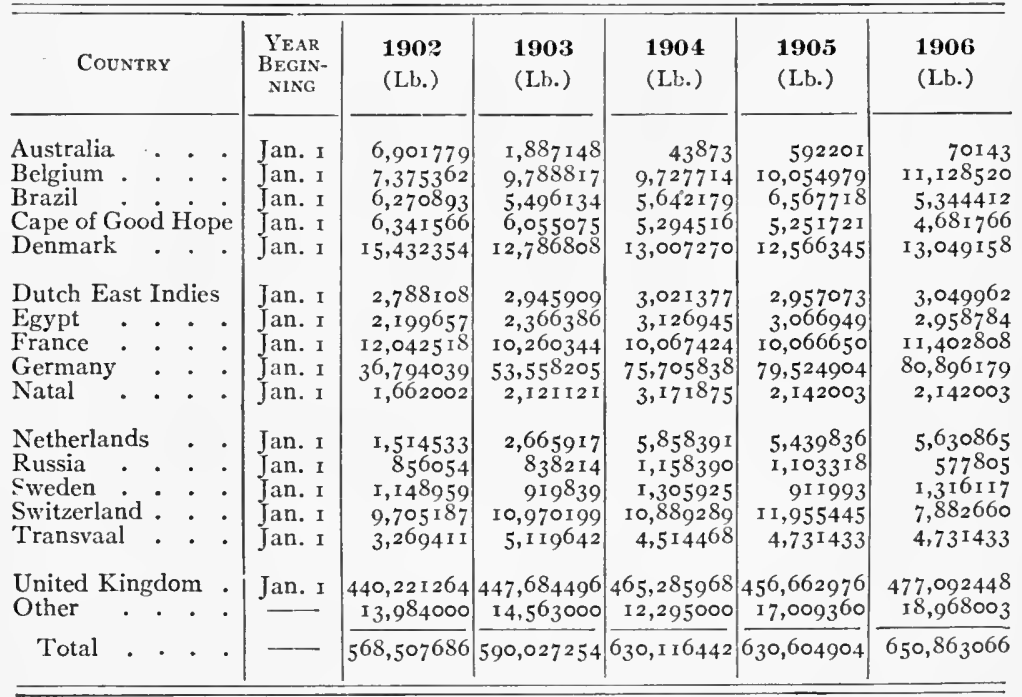




\section{COTTON}

\section{Cotton Crop of Countries Named, 1902-1906}

[No statistics for Siam and some other less important cotton-growing countries. Bales of 500 pounds, gross weight, or 478 pounds of lint, net]

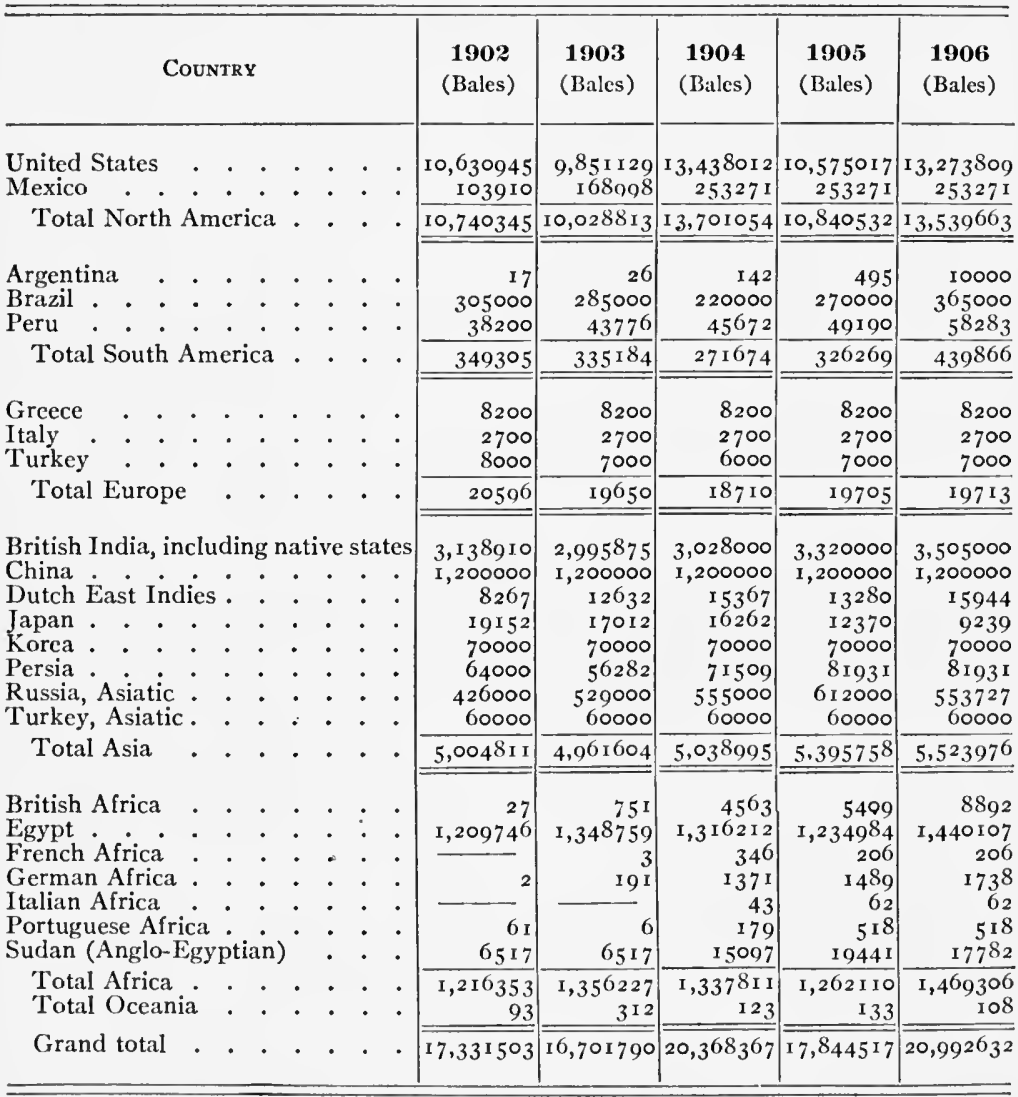

Note. The total area of hay grown in the United States varies from 40 to 50 million acres, the production varies from 50 to 70 million tons, the average value varies from 500 to 700 million dollars, and as a ten-year average ( 1900 to 1909 ) the yield is 1.44 tons per acre and the farm price $\$ 9.59$ per ton. 


\section{COTTON-Continued}

Cotton ACReage, by States, 1902-1907

Iо6

[As reported by Bureau of Statistics, Department of Agriculture]

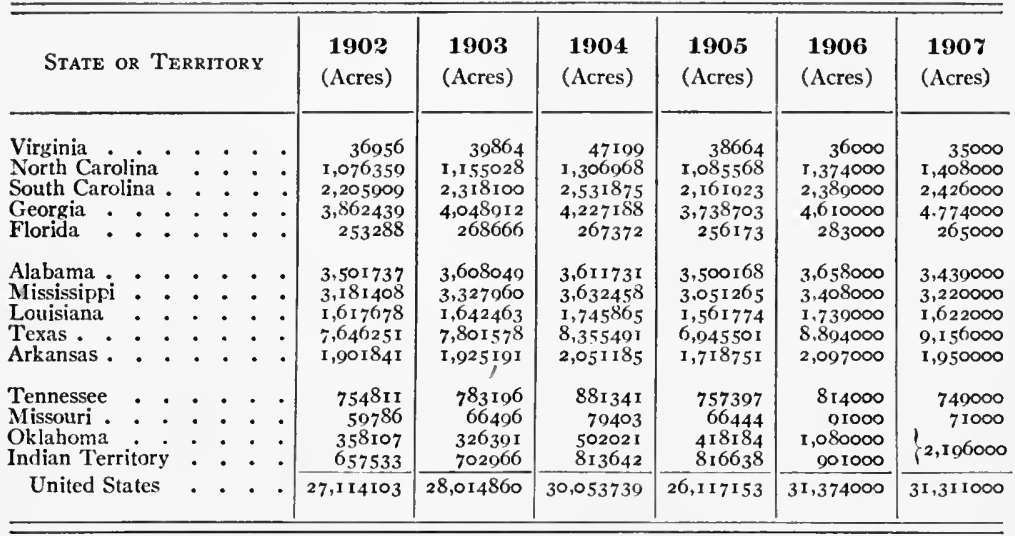

Production of Cotton, in 5oo-Pound Gross Weight Bales, by States, and Total. VALUE OF CROP, 1902-1903 TO $1907-1908$

[As finally reported by U.S. Census Bureau]

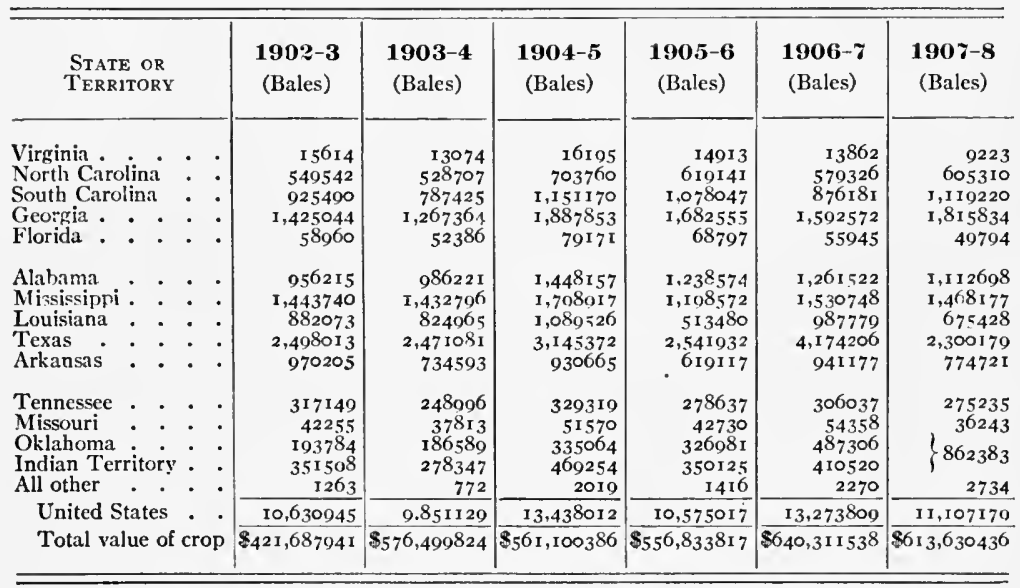


INTERNATIONAL TRADE IN OIL CAKE AND OIL-CAKE MEAL, I902-I906 EXPORTS

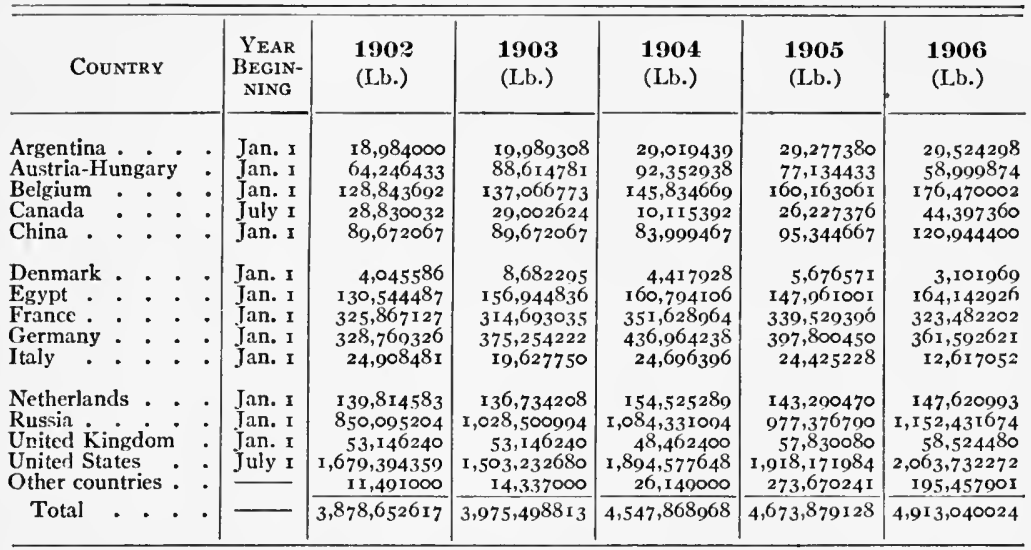

IMPORTS

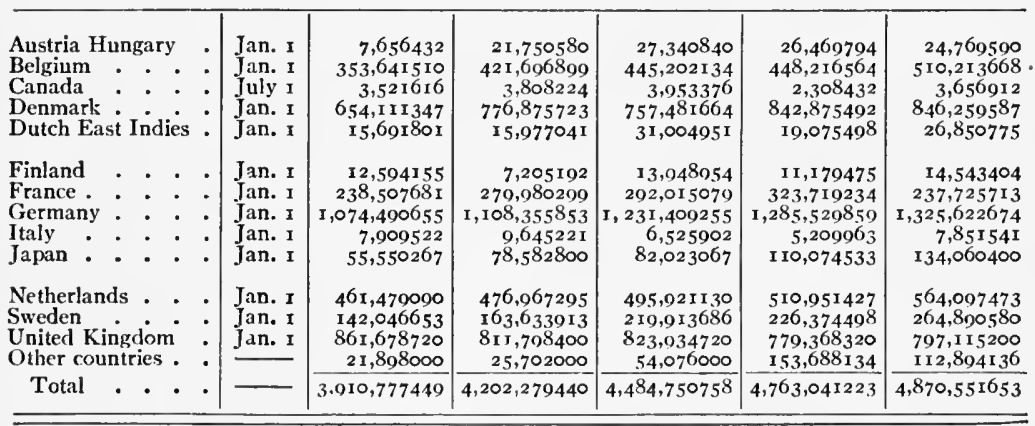

\section{SECTION V}

\section{METHODS OF SOIL ANALYSIS}

Collecting soil samples. After one has become familiar with the typical boring of the soil type to be studied, the sample is collected by taking borings from to to 20 different places, each of which should appear to be truly representative of the soil type. These borings, thoroughly mixed, should make a trustworthy sample for analysis. An auger about $\mathbf{1} \frac{1}{4}$ inches in diameter, with the screw point and the vertical lips filed off, 
is the most satisfactory implement to use. The stem may be cut in two and $x$ steel rod of good quality welded in to make the auger about 40 inches long.

Ordinarily, samples may well be taken in sets of three: the surface, or average plowed soil (o to $6 \frac{2}{3}$ inches), the subsurface, or that which can possibly be moved with a subsoil plow ( $6 \frac{2}{3}$ to 20 inches), and the subsoil (20 to 40 inches), corresponding to about 2 million, 4 million, and 6 million pounds, respectively, of ordinary soil. The surface boring is made and the hole enlarged about $\frac{1}{2}$ inch in diameter, the soil all being saved. The subsurface boring is then taken and the hole again enlarged, but the extra soil is not saved. Finally the subsoil boring is taken and the soil saved from only one half (one groove) of the auger. This provides about equal quantities of soil from each stratum.

Preparation of sample. The sample of soil after air-drying is pulverized to pass through a sieve with round holes $\mathrm{I} \mathrm{mm}$. in diameter. Any gravel which does not pulverize as easily as the dried lumps of clay is weighed and its percentage determined, after which it is discarded. For all determinations except reaction and acidity the soil is further pulverized to pass through a roo-mesh sieve.

Dry matter. Five grams of soil are placed in a glass weighing tube fitted with glass stopper, heated for eight hours at a temperature of $105^{\circ}$ to $107^{\circ} \mathrm{C}$. in a current of air dried by passing through $\mathrm{H}_{2} \mathrm{SO}_{4}$ and $\mathrm{CaCl}_{2}$, the stopper replaced, and the tube allowed to cool in a desiccator. On weighing, duplicate samples should check within $5 \mathrm{mg}$. The results of all analyses are calculated to the dry basis as found by this determination.

Reaction. The reaction of the soil is determined by the test suggested by Veitch (Bulletin 73, page 136 , Bureau of Chemistry, United States Department of Agriculture). About ro g. of soil are placed in a Jena flask with $150 \mathrm{cc}$. water, thoroughly shaken, and allowed to settle until the water is practically clear. The supernatant liquid is carefully drawn off and boiled down with a few drops of phenolphthalein in a Jena beaker (covered with a watch-glass) to about $25 \mathrm{cc}$. A pink color indicates alkalinity. If no color appears, the soil is either acid or neutral. In case the soil is acid, its acidity, calculated to calcium carbonate required to neutralize, is determined; and in case it is alkaline, the carbonate carbon present is determined and calculated to calcium carbonate.

Acidity. Place roo g. of soil in a $400 \mathrm{cc}$. wide-mouthed bottle, add $250 \mathrm{cc}$. normal potassium nitrate solution, stopper, and shake continuously for three hours in a shaking machine or every five minutes by hand. Let stand over night. Draw off I25 cc. of the clear supernatant liquid, 
boil ten minutes to expel carbon dioxid, cool, and titrate with standard sodium hydroxid solution (of which I cc. is equivalent to $4 \mathrm{mg}$. of calcium carbonate), using phenolphthalein as indicator.

The acids and acid salts of the soil are difficultly soluble in water, but by treating with a salt solution, as potassium nitrate, a double decomposition takes place, carrying acidity into solution. An equilibrium is reached, however, before this reaction runs to an end, and if, after having drawn off $125 \mathrm{cc}$. to titrate, $125 \mathrm{cc}$. of fresh potassium nitrate are added to the bottle and the bottle again shaken for three hours, $125 \mathrm{cc}$. drawn off will give a titration which is more than one half of the first. By continuing this process until the last $\mathrm{I} 25 \mathrm{cc}$. shows practically no acidity, we have a series of titrations the sum of which represents the total acidity of the $100 \mathrm{~g}$. of soil. It has been found by working with a number of different soils, that as an average the sum of such a series is $2 \frac{1}{2}$ times the first titration. Consequently, when the sodium hydroxid is made up so that I cc. is equivalent to $4 \mathrm{mg}$. of calcium carbonate, and I $25 \mathrm{cc}$. (which represents $50 \mathrm{~g}$. of soil) are titrated, each $0.1 \mathrm{cc}$. required to neutralize corresponds to I $\mathrm{mg}$. of calcium carbonate required by the $100 \mathrm{~g}$. of soil, or to 0.001 per cent of calcium carbonate required by the soil tested.

The titrations of duplicate samples should not differ more than $0.8 \mathrm{cc}$. for soil samples requiring less than Ioo cc. $\mathrm{NaOH}$.

Carbonate carbon. Carbonate carbon, when present, is determined volumetrically in the apparatus used for total carbon, described and illustrated in the Journal of the American Chemical Society, Vol. 26, pages 294 and 1640 , by treating the air-dried soil with dilute ( $\mathrm{I}: \mathrm{I})$ hydrochloric acid and measuring the gas evolved both before and after absorption of carbon dioxid in an alkali pipette containing a 33 per cent solution of potassium hydroxid. The size of sample used for this test varies (according to the amount of calcium carbonate present) between two and ten grams. Duplicate tests of ordinary soils not very high in inorganic carbon should check within 0.2 to $0.4 \mathrm{cc}$. These results are calculated to and reported as calcium carbonate present.

Corrections must be made for pressure and temperature, and absorption of carbon dioxid should be repeated to a constant reading; also the gas should be allowed to stand for three minutes before the initial and the final readings.

Organic carbon. The total carbon of the soil is determined by means of Parr's apparatus ${ }^{1}$ as modified by Pettit ${ }^{2}$ to contain an absorption pipette of potassium hydroxid. 
Two grams of ordinary soil (or $\frac{1}{2}$ to I g. of peaty soil) are placed together with $10 \mathrm{~g}$. of sodium peroxid in the Parr explosion bomb, 0.7 to I g. (ordinarily about $0.8 \mathrm{~g}$.) powdered magnesium added to start combustion, the whole thoroughly mixed by shaking, and the charge exploded by means of a hot iron plug or an electric current. (.7 g. magnesium is used with soils high in organic matter.) The contents of the bomb are then washed into a beaker by means of a fine stream of hot water and brought to a boil to break up the coarse particles and expel as much oxygen as possible. It is then run from a separatory funnel into a flask containing dilute sulfuric acid $\left(\mathrm{I}_{2} \mathrm{SO}_{4}\right.$ to $\left.2 \mathrm{H}_{2} \mathrm{O}\right)$ and the gas collected in a measuring pipette. When all of the sample has been added to the sulfuric acid and boiled until it is decomposed, the flask is filled with water through the separatory funnel to force the last of the gas into the measuring pipette. After noting the volume, the carbon dioxid is absorbed in the potassium hydroxid pipette and the volume again read. In taking the initial and the final readings, the same precaution should be taken as for carbonate carbon. Duplicate samples should check within I cc. for every roo cc. gas obtained, and corrections must be made for pressure and temperature.

A blank determination must be run on the sodium peroxid, and this is best done by using first a 2-gram, then a I-gram sample of the same soil, calculating the amount of carbon in the reagents from the difference in results, e.g.

Let $\quad x=$ carbon in reagents;

then, if

2 g. soil $+x=45 \mathrm{mg}$. C,

and

I g. soil $+x=25 \mathrm{mg}$. C,

we get by multiplying the last equation by 2

$$
2 \text { g. soil }+2 x=50 \mathrm{mg} \text {. C, }
$$

and, subtracting the first equation from this, we get

$$
x=5 \mathrm{mg} \text {. C }
$$

Much better results can be obtained by determining the blank in this way than where no soil is used.

The total carbon thus found minus the carbonate carbon is reported as organic carbon and is taken as a measure of the organic matter present in the soil.

Nitrogen. Nitrogen is determined by the regular Kjeldahl method. Ten grams of soil ( $5 \mathrm{~g}$. if high in nitrogen) are weighed into a Kjeldahl flask, $20 \mathrm{cc}$. sulfuric acid (more if necessary) and approximately $.65 \mathrm{~g}$. 
metallic mercury added and the contents of the flask digested until colorless. Oxidation is completed by adding, while still boiling hot, powdered potassium permanganate until the solution is green. It is then allowed to cool and transferred with $250 \mathrm{cc}$. of nitrogen-free water to a copper flask of about $700 \mathrm{cc}$. capacity and enough strong alkali solution ${ }^{1}$ added to more than neutralize the acid. The flask is then immediately connected with a still, the ammonia distilled off and collected in a flask containing a measured amount of standard hydrochloric acid. The excess of hydrochloric acid is then titrated back with standard ammonium hydroxid, using lacmoid as indicator, and the amount of nitrogen in the soil calculated. A convenient strength of ammonia solution is one in which I cc. is equivalent to $.0032 \mathrm{~g}$. nitrogen.

Duplicates should check within $0.2 \mathrm{cc}$. A blank determination must be run, by using approximately $.5 \mathrm{~g}$. pure sugar instead of the soil sample, and a correction made for the nitrogen in the reagents used.

Phosphorus. For the phosphorus determination the soil is decomposed by heating with sodium peroxid as given on page $\mathrm{r} 45$, Bulletin ro5, Bureau of Chemistry, U. S. Department of Agriculture.

Five grams of ordinary soil are thoroughly mixed with Io g. of sodium peroxid in an iron crucible of about r ro cc. capacity, the flame applied directly to the surface just long enough to start the action, the crucible covered, and the heating continued over a low flame for twenty-five minutes. The tip of the flame should just touch the bottom of the crucible and the heat be kept low enough so the peroxid will not fuse. In decomposing a soil very low in organic matter, such as some subsoils, 0.1 to $0.5 \mathrm{~g}$. of powdered sugar should be added to favor the reaction.

Peat soils are usually high in phosphorus, and $2 \frac{1}{2} \mathrm{~g}$. are sufficient for the determination. Such soils, high in organic matter, will not fuse slowly when heated with peroxid, but by moistening the sample with $5 \mathrm{cc}$. of calcium acetate of sufficient strength to fix the phosphorus, the organic matter can be safely burned off, and after cooling, enough sugar added to effect decomposition with sodium peroxid in the usual way.

After decomposition, the sample is washed into a beaker, the coarser particles broken up, then transferred to a $500 \mathrm{cc}$. flask acicunied with hydrochloric acid and boiled for five minutes. A little strong nitric acid is added to insure complete oxidation of the iron to the ferric condition. It is then allowed to cool and made up to volume. There should be no undecomposed soil in the bottom of the flask. The silica is allowed to

${ }^{1}$ Containing $60 \mathrm{lb}$. Greenbank's alkali and $800 \mathrm{~g}$. potassium sulfid for each 30 litres of water. 
settle over night, $200 \mathrm{cc}$. of the clear supernatant solution drawn off, and the iron, aluminum, and phosphorus precipitated by adding ammonium hydroxid to the boiling solution. If there is not enough iron present to give a very decided brown color to the precipitate, a little ferric chlorid should be added before precipitation to insure complete removal of the phosphorus from solution. The precipitate is filtered off, washed 5 times, dissolved with warm dilute nitric acid, evaporated, and heated on the steam bath to dehydrate the silica, taken up with strong nitric acid, heated, then diluted, and the silica filtered off. The filtrate is evaporated to about 5-10 cc., care being taken that it does not go to dryness, as alumina and some silica are almost sure to separate out and cause trouble. It is then completely neutralized with ammonia, cleared up with nitric acid, approximately I g. of crystalline ammonium nitrate added, and the phosphorus precipitated at $40^{\circ}-50^{\circ}$ with $I_{5} \mathrm{cc}$. ammonium molybdate solution, allowing it to stand on the water bath at this temperature for one to two hours, stirring occasionally for the first I 5 or 20 minutes. It is then allowed to stand at room temperature over night, the precipitate filtered off through a double filter and washed with a tenth-normal solution of ammonium nitrate until free from molybdic acid and finally twice with cold distilled water. ${ }^{1}$ It is then removed together with the filter paper to a beaker, dissolved with a measured excess of standard potassium hydroxid solution, and the excess titrated back with standard nitric acid.

A very convenient strength of potassium hydroxid solution is $.83236 \mathrm{~g}$. $\mathrm{KOH}$ per $100 \mathrm{cc}$. One cubic centimeter is then equivalent to $0.2 \mathrm{mg}$. of phosphorus.

The nitric acid should be made equivalent in strength to the potassium hydroxid, and with these strengths of solutions, duplicates should check within $0.2 \mathrm{cc}$.

A blank determination must be run, using no soil, and a correction made for the phosphorus found in the reagents.

(Ammonium molybdate solution is made by dissolving Ioo g. molybdic acid in $400 \mathrm{cc}$. $\mathrm{NH}_{4} \mathrm{OH}$ (sp. gr. .96) and adding very slowly to I250 cc. $\mathrm{HNO}_{3}$ (sp. gr. I.20), kecping the solution cool and well stirred.)

Total potassium. This test is carried out as given on page I47, Bulletin 105, Bureau of Chemistry, Department of Agriculture. One gram of soil, one gram of ammonium chlorid, and eight grams of calcium

${ }^{1}$ Molybdic oxid is of ten precipitated if the first few washings, while iron is still present, are done with either water or ammonium nitrate solution. This may be prevented by washing two or three times, until free of iron, with ammonium nitrate containing a little of the ammonium molybdate solution. 
carbonate are fused as directed in Fresenius' "Quantitative Analysis," page 426 , and by Hillebrand in Bulletin 305 of the United States Geological Survey, where an illustration of the apparatus is given. The fused mass is transferred to a porcelain dish, slacked with hot water, finely ground with an agate pestle and transferred to a filter. After washing with about $600 \mathrm{cc}$. hot water, the filtrate and washings are run to dryness in a Jena beaker, taken up with hot water and again filtered, acidified with hydrochloric acid, concentrated to about ro cc., and $\mathrm{I} \frac{1}{2} \mathrm{cc}$. of a platinum chlorid solution (ro cc. containing I g. platinum) added. This is then evaporated to a sirupy consistency, taken up and washed about fifteen times with 80 per cent alcohol, three times with ammonium chlorid solution, and again fifteen times with alcohol. The precipitate is then washed through the filter with hot water into a platinum dish, evaporated on the steam bath to dryness and heated in an air .oven at $110^{\circ} \mathrm{C}$. for an hour, cooled in a desiccator, and weighed. Duplicate samples should not differ more than $\mathrm{I} .5 \mathrm{mg}$. in the final weight.

A correction must be made for the amount of potassium in the reagents which is found by making a blank determination, using no soil.

(Ammonium chlorid solution is made by dissolving $200 \mathrm{~g} . \mathrm{NH}_{4} \mathrm{Cl}$ in rooo cc. water and saturating with $\mathrm{K}_{2} \mathrm{PtCl}_{6}$.)

Calcium. Decompose $2 \mathrm{~g}$. of soil (less if high in calcium) by heating with 6 to $8 \mathrm{~g}$. of sodium peroxid in an iron crucible; transfer with water, acidify with hydrochloric acid, evaporate to dryness; and continue heating for about an hour, on the steam bath, to dehydrate the silica. Digest the residue with hydrochloric acid on the steam bath until all that will has gone into solution (about ten minutes will usually suffice); filter, and wash free from chlorids with hot water. Bring the filtrate and washings to about $150 \mathrm{cc}$; add $.5 \mathrm{~g}$. ammonium persulfate, heat to boiling; and add ammonia in excess to precipitate iron, aluminum, phosphorus, and manganese. After boiling about five minutes, filter while still boiling hot, and wash with hot water till practically free from chlorids; acidify with hydrochloric acid, evaporate to about Ioo cc., add I cc. of a 6 per cent solution of ferric chlorid and about $.5 \mathrm{~g}$. of ammonium persulfate; heat to boiling, precipitate with ammonia in decided excess, boil for several minutes; then filter and wash as before. Bring the filtrate and washings to a volume of about $150 \mathrm{cc}$; ; boil, and to the boiling solution add slowly, and with constant stirring, enough concentrated ammonium oxalate ( 5 to ro $\mathrm{cc}$.) to precipitate the calcium and to change the magnesium to the oxalate. Digest for an hour or more on the steam bath, care being taken that the volume does not go below $75 \mathrm{cc}$; filter, and wash free from chlorids with hot water. (As a rule, one precipitation of calcium is 
sufficient.) Burn the filter and ignite the precipitate in the blast to constant weight. Weigh as calcium oxid and compute to calcium.

Magnesium. Evaporate to dryness the filtrate and washings from the calcium determination; wash the residue with hot water into a longneck Jena flask; remove ammonium salts by boiling to a small volume with nitric and hydrochloric acids (about $25 \mathrm{cc}$. of each), adding more of the acids ( 10 to $5 \mathrm{cc}$. of each) two or three times, and finally evaporating nearly or quite to dryness. Transfer the remaining salts to a beaker with hot water; add enough ammonium chlorid to prevent the precipitation of magnesium hydroxid, make alkaline with ammonia, and then add $.5 \mathrm{~g}$. ammonium persulfate; digest on the steam bath for 30 minutes, taking care that there is always an excess of ammonia present; filter, and wash free from chlorids with hot water. Concentrate the filtrate and washings to about 50 or $75 \mathrm{cc}$., acidify with hydrochloric acid, and add 5 to ro cc. of a normal solution of $\mathrm{NH}_{4} \mathrm{NaHPO}_{4}$ to insure the precipitation of all magnesium. While stirring vigorously and taking care not to strike or rub the sides of the beaker, slowly add enough ammonia to make the solution distinctly alkaline. After 30 minutes, add ro cc. of strong ammonia, slowly and with vigorous stirring; cover closely to reduce the escape of ammonia, and let stand for I2 hours. Then filter, and wash the precipitate free from chlorids, using $2 \frac{1}{2}$ per cent ammonia water. Dry the filter, burn at a moderate heat, and then ignite intensely to constant weight, using the blast. Weigh as magnesium pyrophosphate and compute to magnesium.

Note. In all cases the above determinations relate to the total amounts present in the soil. If much alkali or other soluble salts are present, the amount may be determined by extracting with water, evaporating, and weighing the residue, which may be analyzed subsequently if desired. The author does not advise the analysis of soils by determining only the "acid-soluble" portion of the constituents, - a method which involves five arbitrary conditions: (I) the choice of solvent, (2) the strength of solvent, (3) the relative amounts of soil and solvent, (4) the time of digestion, and (5) the temperature of digestion. To change any one of these arbitrarily fixed conditions may change the amount of soil constituents dissolved. Such analyses furnish little information, and they tend to discredit the very exact and highly serviceable science of chemistry.

Pot-culture experiments by the Illinois Experiment Station have shown that crops can be grown in the "insoluble residue," from ordinary acid digestion of soils, without addition of potassium; and they markedly improve by green manuring. 


\section{SECTION VI}

\section{COMPOSITION OF SOME EUROPEAN SOILS}

THE data relating to the composition of European soils are very incomplete, and the analytical methods used have been far from uniform. A good compilation of these data from Germany, France, and the United Kingdom is contained in Bulletin 57 (1909) of the United States Bureau of Soils, giving principally the results secured by digesting the soils with strong acids. This compilation includes no nitrogen determinations, but the phosphorus, potassium, and calcium are usually given, and sometimes the magnesium, chiefly in terms of the oxids.

In the Rothamsted laboratories, after previous ignition of the soil, very strong hot hydrochloric and nitric acids are employed in soil analysis, and probably this method is used quite generally in Great Britain. If so, the data for phosphorus will closely approach the total. In Germany cold hydrochloric acid is the common solvent used, and the results thus secured are not comparable with those of England.

Four analyses by Burguy (Inaug.-Diss. Berlin, 1899) show as an average $4 \mathrm{I}, 330$ pounds of potassium (evidently total) in two million of the loess soil of North Germany. (The phosphorus content of this soil is not given.) About $45^{\circ}$ analyses of German soils are reported in this compilation, but for the reason given above they signify but little to the student of permanent agriculture. Wohltmann, as Director of the Institute for Soil and Crop Investigations, Bonn-Poppelsdorf, in a report (I $9 \circ \mathrm{I}$ ) on "The Fertility-Invoice of West-German Soils" ("Das Nährstoff-Kapital West-Deutscher Böden"), shows that the cold acid which he used generally dissolved about one fourth as much potassium from soils as hot acid (which he also used for additional potassium determinations), but the proportion varied with different soils from about one seventh to one half. A trial with a single soil showed that digestion with hot acid for 12 hours, dissolved one third more phosphorus than digestion with cold acid for 48 hours; and numerous other experiments have shown that as an average the ordinary io hours' digestion with hot hydrochloric acid will dissolve only 85 per cent of the total phosphorus, and with some soils less than one half of the total is thus dissolved.

Wohltmann concludes from extended chemical and cultural investigations that in West Germany soils which contain less than I 200 pounds 
(in two million) of phosphorus soluble in cold hydrochloric acid are in need of phosphorus fertilizer ("ersatzbedürftig in Phosphorsäure").

The compiled data from France include about $155^{\circ}$ soil analyses, but here also only the plant food dissolved by the acid used is reported, and no information is given concerning the strength of acid, time, or temperature. While these results may have some value for purposes of comparison among themselves, they are of little or no value for comparison with the total amounts of plant food contained in other soils. Furthermore this great mass of data relates to the soil of only a few provinces. There are in all eighty-seven different provinces, or counties, in France, and 705 of the soil samples reported upon were collected in the one province of Aisne, while 674 others were collected in Pas-de-Calais and Loire-Inferieure, and I 29 more in three other provinces. The remaining 42 samples represent six additional provinces, leaving seventyfive provinces from which no soil analyses are reported. Practically all of the $155^{\circ}$ soil samples were evidently collected about I890 or before, and no information is given in the compiler's report to show whether they are supposed to represent good land or poor land, although in one case a single field is represented by analyses of 73 samples of soil.

In considering the analyses of European soils, it may well be kept in mind that there are still to be found areas of "abandoned" land even in western Europe, and chemical analyses of these soils are often made before attempting to bring them back into agricultural use by means of fertilizers and manures. Thus the marked differences in the plantfood content of different soils in England may serve best as an index of the agricultural history of the farms with respect to the past use of bones, guanos, phosphates, etc., while in America such differences apply not so much to individual farms, fields, or plots (see Table 73, page 4II), but rather to types of soil more or less modified in the older States by the general and almost invariable practice of gradual soil depletion.

The data showing the phosphorus content of soils from Great Britain make a contribution of probable value, (I) because approximately the total amount is reported, and (2) because the soil formation is frequently recorded. In the case of Dorset County, the samples appear to have been collected in connection with some sort of systematic survey or classification, as indicated by the records and also the reference: "Fifth Annual Report on the Soils of Dorset, University College, Reading, I9०3."

The compiler has combined the calcium found in limestone (calcium carbonate) with that reported in other forms, so that the calcium data have too little value to justify their reproduction here. It may be 
stated, however, that, of the 286 samples of soil reported below, I 29 contained an amount of acid-soluble calcium which if present as carbonate would represent ro tons or more of limestone per acre in the plowed soil, and of these about 60 apparently contained more than 50 tons per acre of calcium carbonate, thus suggesting the British farmer's common appreciation of the importance of having limestone in the soil.

The following table shows the phosphorus reported for each of these 286 samples of soil, and the data certainly indicate that Liebig's account of the tendency (even then apparent) toward the accumulation of phosphorus in British soil was well founded. As a general average of all analyses, it will be seen that the soil of England now contains about twice as much phosphorus as the most common Illinois corn-belt land (brown silt loam), three times as much as the ordinary wheat-belt soil of southern Illinois (gray silt loam on tight clay), and from four to fifteen times as much as the depleted or abandoned lands of the Atlantic Coastal Plain (such as the Leonardtown loam and Norfolk loam, the latter belonging to a series of thirteen soil types already represented by surveyed areas aggregating about to million acres, of which, however, soil analyses have been reported for only two types, as shown in Table 22, page $\left.{ }^{3} 3^{8}\right)$.

The amount of phosphorus in 2 million pounds of surface soil varies in the Gault soils of Kent County from 330 to 22 ro pounds; in the chalk soils from 820 (Kent County) to 6800 pounds (Dorset County); in the Kimmeridge clay from 8 Io pounds (Cambridgeshire) to 7760 pounds (Dorset County); and in the London clay from 460 pounds (Surrey County) to 4100 pounds (Dorset County). Contrasted with these variations, the records ${ }^{1}$ of analysis of 555 samples of Illinois soils, including surface, subsurface, and subsoil, show an extreme variation from 540 to 2780 pounds of phosphorus in 2 million pounds of soil, the late Wisconsin yellow-gray silt loam varying from 540 pounds in 2 million of the subsurface to 900 pounds in the surface, and the early Wisconsin black clay loam varying from 980 pounds in 2 million of the subsoil to 2780 in the surface.

${ }^{1}$ University of Illinois Agricultural Experiment Station Bulletin 123 (I908), pp. 262-294. 
Phosphorus in Solls in the United Kingdom

Pounds per Acre in 2 Million of Soil (about $6 \frac{2}{3}$ Inches Deep)

\begin{tabular}{c|c||c|c}
\hline $\begin{array}{c}\text { Description AND Locality } \\
\text { (Original Sample Nos.) }\end{array}$ & $\begin{array}{c}\text { Phos- } \\
\text { PHORUS } \\
\text { (Lb.) }\end{array}$ & $\begin{array}{c}\text { Description and LoCALITY } \\
\text { (Original Sample Nos.) }\end{array}$ & $\begin{array}{c}\text { Phos- } \\
\text { Phorus } \\
\text { (Lb.) }\end{array}$ \\
ENGLAND
\end{tabular}

Berkshire
Sutton's seed trial grounds,
Reading .. . .

\section{Cambridge}

Hatley plot (3) Joint rotation (9) .

Fields I I-I 3

Fields $14-15$

Fields $16-17$

Fields I8-I9

Bowlder clay:

Above gault (I4)

Above green sand (19)

Above gault (20)

Above gray chalk (2I)

Gault soils (3). . .

$$
\text { (7) . }
$$$$
\text { (8) }
$$

Kimmeridge clay soils (12)

$$
\begin{array}{r}
(\mathrm{I} 5) \\
(\mathrm{I} 7)
\end{array}
$$

Ampthill clay soils (6) . . .

Oxford clay soils (Io) . . . I030

$$
\text { (II) } \cdot \cdot \cdot \cdot
$$

Lower greensand soils (5) . $\quad$ I 780

\begin{tabular}{rr|r}
$(5)$ & $\cdot$ & 1780 \\
$(18)$ & $\cdot$ & 2260 \\
$(9)$ & $\cdot$ & 1720 \\
$(4470$
\end{tabular}

$$
\text { (6) } \cdot 1720
$$

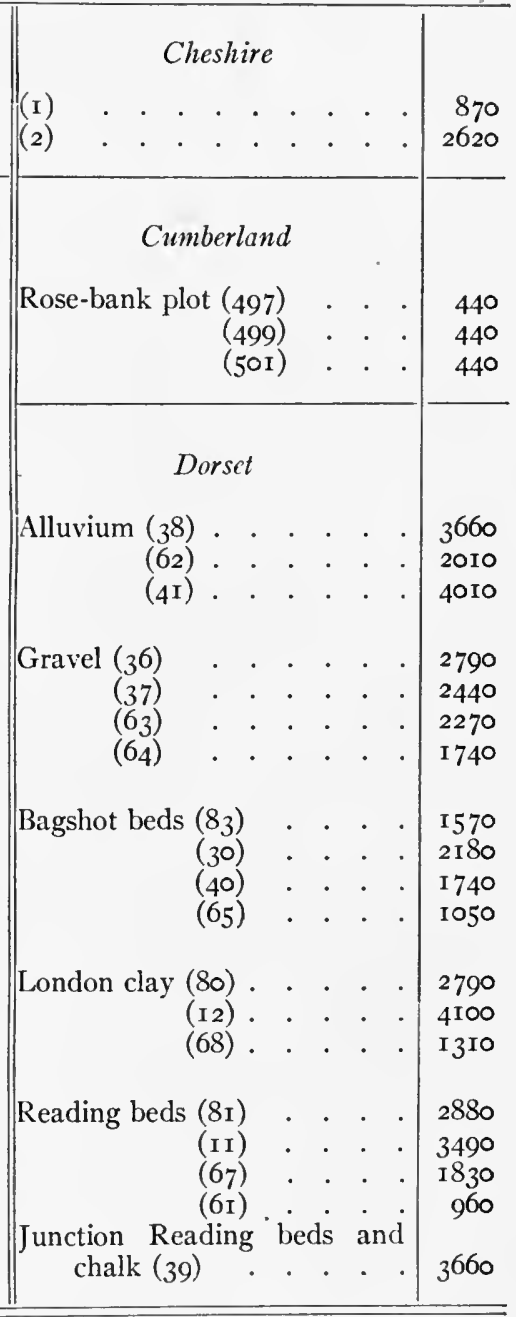


Phosphorus in Solls in the United Kingdom (Continued)

(Pounds per Acre in 2 Million of Soil (about $6 \frac{2}{3}$ Inches Deep)

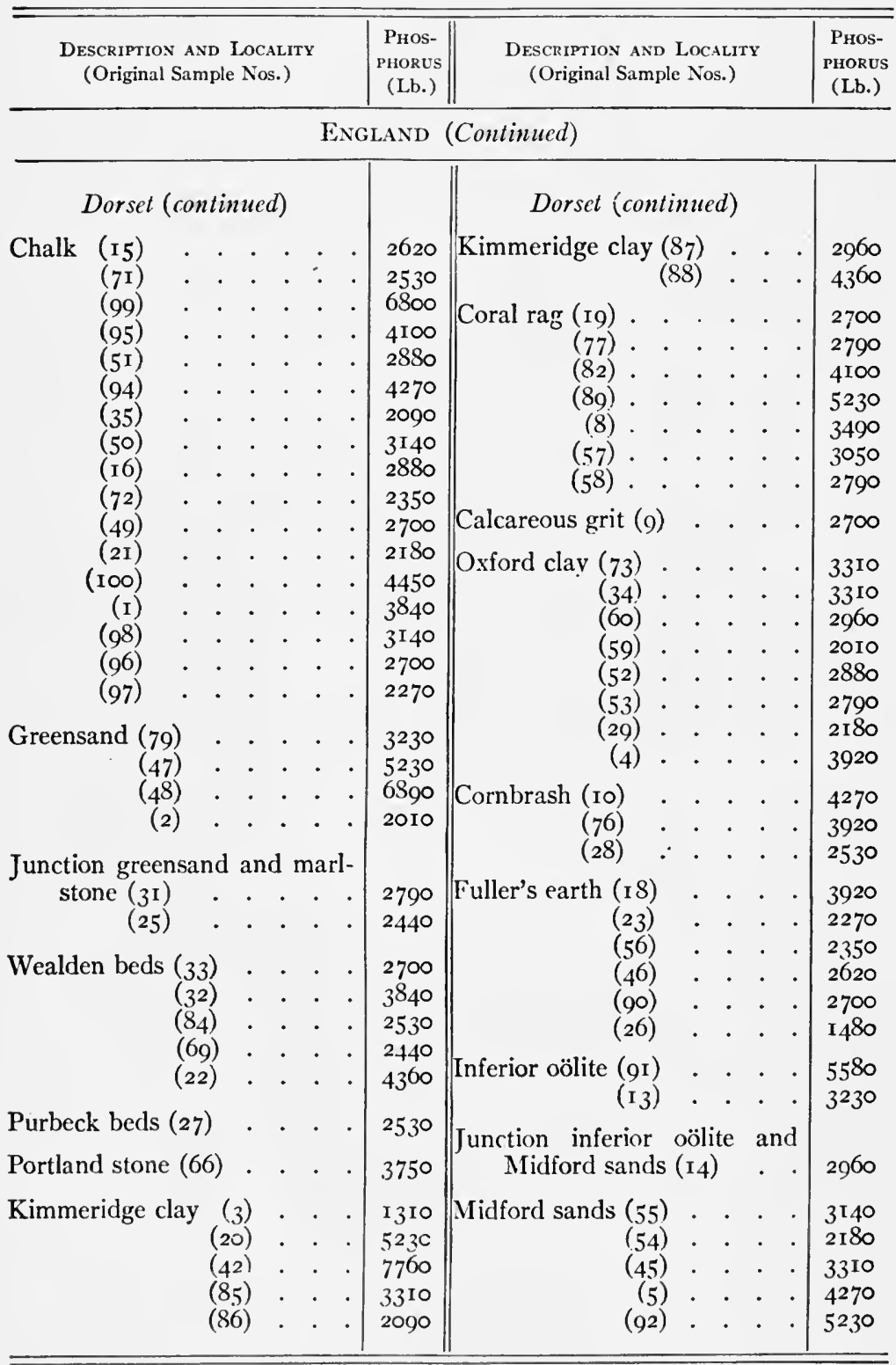


Phosphorus in Soils in the United Kingdom (Continued)

Pounds per Acre in 2 Million of Soil (about $6 \frac{2}{3}$ Inches Deep)

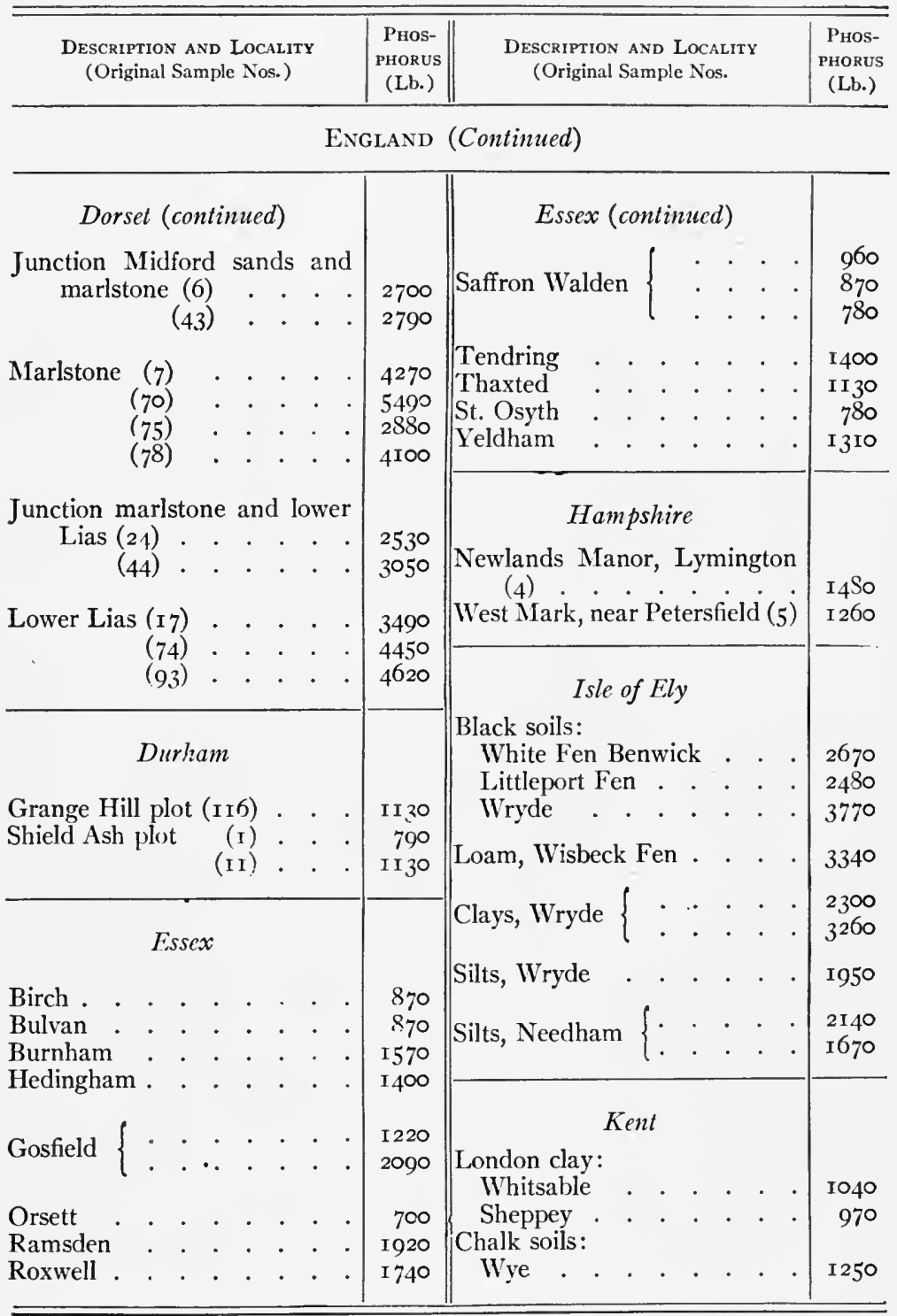


Phosphorus in Solls in the United Kingdom (Continued)

Pounds per Acre in 2 Million of Soil (about $6_{3}^{2}$ Inches Deep)

\begin{tabular}{c|c|c|c|c}
\hline $\begin{array}{c}\text { Description and Locality } \\
\text { (Original Sample Nos.) }\end{array}$ & $\begin{array}{c}\text { Phos- } \\
\text { Phorus } \\
\text { (Lb.) }\end{array}$ & $\begin{array}{c}\text { Description and LocaltTy } \\
\text { (Original Sample Nos.) }\end{array}$ & $\begin{array}{c}\text { Phos- } \\
\text { PHoRus } \\
\text { (Lb.) }\end{array}$ \\
\hline
\end{tabular}

England (Continued)

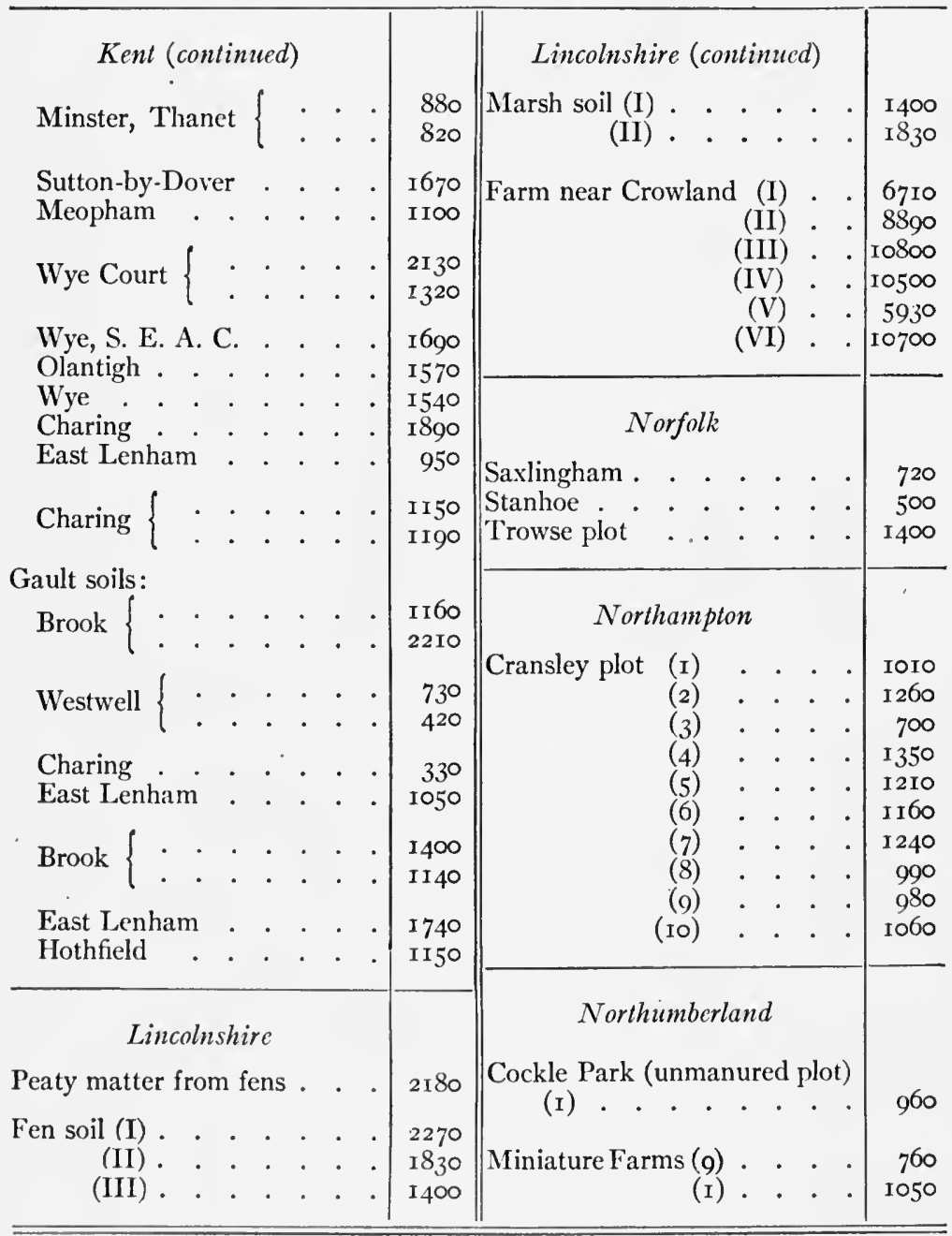


Phosphorus in Solls in the United Kingdom (Continued)

Pounds per Acre in 2 Million of Soil (about $6 \frac{2}{3}$ Inches Deep)

\begin{tabular}{c|c||c|c}
\hline $\begin{array}{c}\text { Description and Locality } \\
\text { (Original Sample Nos.) }\end{array}$ & $\begin{array}{c}\text { Phos- } \\
\text { Phorus } \\
\text { (Lb.) }\end{array}$ & $\begin{array}{c}\text { Description ANd Locality } \\
\text { (Original Sample Nos.) }\end{array}$ & $\begin{array}{c}\text { Phos- } \\
\text { Phorus } \\
\text { (Lb.) }\end{array}$ \\
\hline
\end{tabular}

ENGLand (Continued)

\section{Northumberland (continued)}

Miniature Farms(2) .

$(3) \cdot \cdot \cdot$
$(4) \cdot \cdot \cdot$
$(5): \cdot \cdot$
$(6) \cdot \cdot$

Hanging Leaves (265)

Castle Steads (267)

Davy Houses (266)

East Tower Hill

Peepy

Whitefield

Kimblesworth (355).

Cockle Park:

Tower Hill

Back House

Tree Field

Pallace Leas Field-plot

(I) . 870

(2) . 700

(6) . 520

(8) . 520

(I2) . 520

(13) $\cdot 440$

Oxford

Wick. Farm:

Headington (I)

430 1050

\section{Suffolk}

Bramford

Saxmundham

\begin{tabular}{|c|c|c|}
\hline Surrey & & \\
\hline London clay: & & \\
\hline Wanborough Station & & \\
\hline $\begin{array}{l}\text { Ashtead Common } \\
\text { Wyke . }\end{array}$ & & $53.3>3$ \\
\hline Flexford : : & & \\
\hline Stoughton . & & \\
\hline ough & & 6 \\
\hline Ray & & \\
\hline Horsley & & \\
\hline Chalk soils: & & \\
\hline Seale & & \\
\hline Fetcl & & \\
\hline & & \\
\hline ugh - . & & \\
\hline Sutton & & $8 c$ \\
\hline Gault soils, Alder Holt & & \\
\hline & & \\
\hline Christchurch Allotment S & & \\
\hline $\begin{array}{c}\text { Christchurch Allotment } \\
\text { tion, Warminster }\end{array}$ & $\begin{array}{l}\text { Sta- } \\
.\end{array}$ & \\
\hline Boreham Road & & \\
\hline Horningsham . & & \\
\hline Heytes & & \\
\hline $\begin{array}{l}\text { Codford allotment soil } \\
\text { Chitterne allotment soils }\end{array}$ & & \\
\hline Imber allotment (I). & & \\
\hline (2). & & \\
\hline Corsley plot & & \\
\hline Clay soil, Warminster & & \\
\hline York warp soil & & \\
\hline
\end{tabular}


Phosphorus in Soils in the United Kingdom (Contmued) Pounds per Acre in 2 Million of Soil (about $6 \frac{2}{3}$ Inches Deep)

\begin{tabular}{|c|c|c|c|}
\hline DESCRIPTION AND LOCALITY & $\begin{array}{l}\text { PHOS- } \\
\text { PHORUS } \\
\text { (Lb.) }\end{array}$ & DESCRIPTION AND LOCALITY & $\begin{array}{l}\text { PHOS- } \\
\text { PHORUS } \\
\text { (Lb.) }\end{array}$ \\
\hline
\end{tabular}

\section{SCOTLAND}

\section{Lanark}

Cleghorn, near Lanark:

Plot I .

Plot 2

\section{Dumbarton}

Drumfork, Helensburgh . .

3920

Nairn

Easterboard, Croy

B

I 20

Birgidale Knock, Rothesay

2130

IIOO Aberdeen

Tarves

\section{Wester Fin}

-

Kin

.

(Lb.)

Fedderate, Maud . . 3200

Nairn
Easterboard, Croy $\quad . \quad \cdot \quad . \quad$.
Tulloch, Lumphanan . . . 990

Kincardine

\section{IRELAND}

\section{Cork}

Limestone soils, Shanagany Old red sandstone, Killeigh

\section{Tipperary}

Limestone soils:

Rockford

St. Kieran's

\section{Wexford}

Silurian clay slate soils:

Bally-Carney . . . . . I360

Clonroche . . . . . 1460

Garden soil . . . . . 2670

Garden soil . . . . . 2670

WALES

1400

I 130

Averages of all Samples

England (269 samples)

2230

Scotland (Io samples)

Ireland (6 samples)

Wales (I sample) 


\section{SECTION VII}

Agricultural Colleges and Experiment Stations in the United States AND Canada

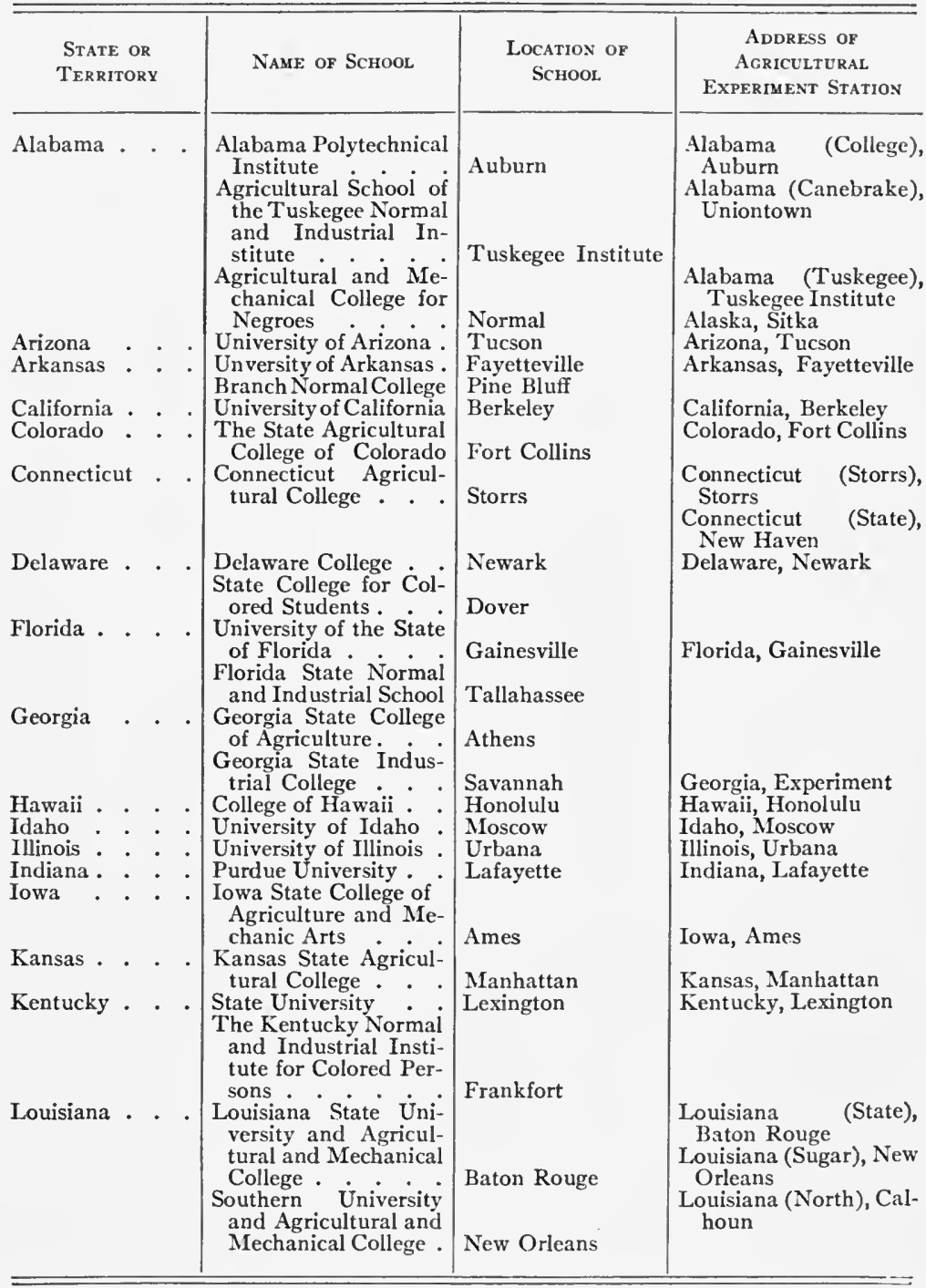


Agricultural College and Experiment Stations in the United States and Canada (Continued)

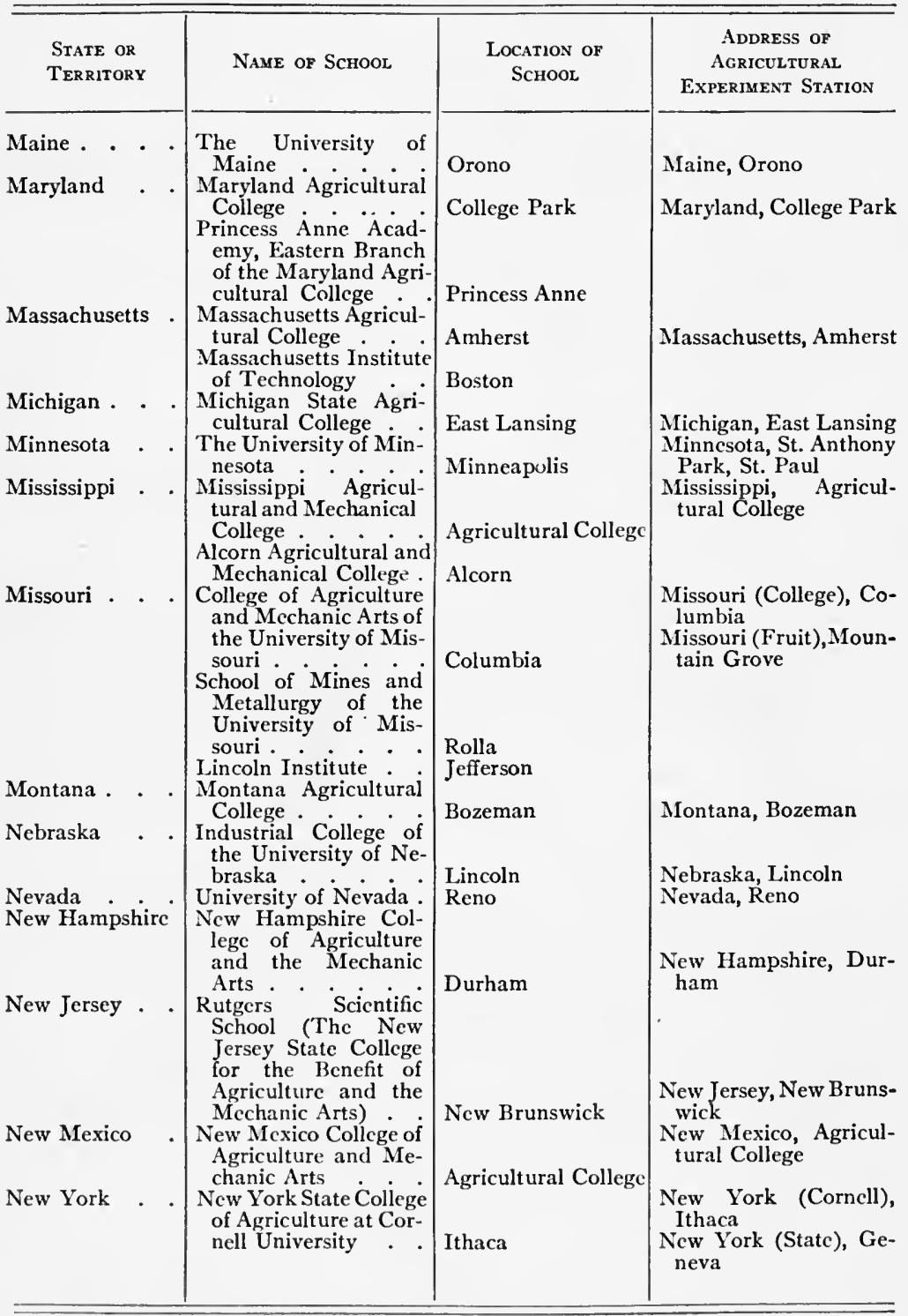


Agricultural Colleges and Experinent Stations in the United States and Canada (Continued)

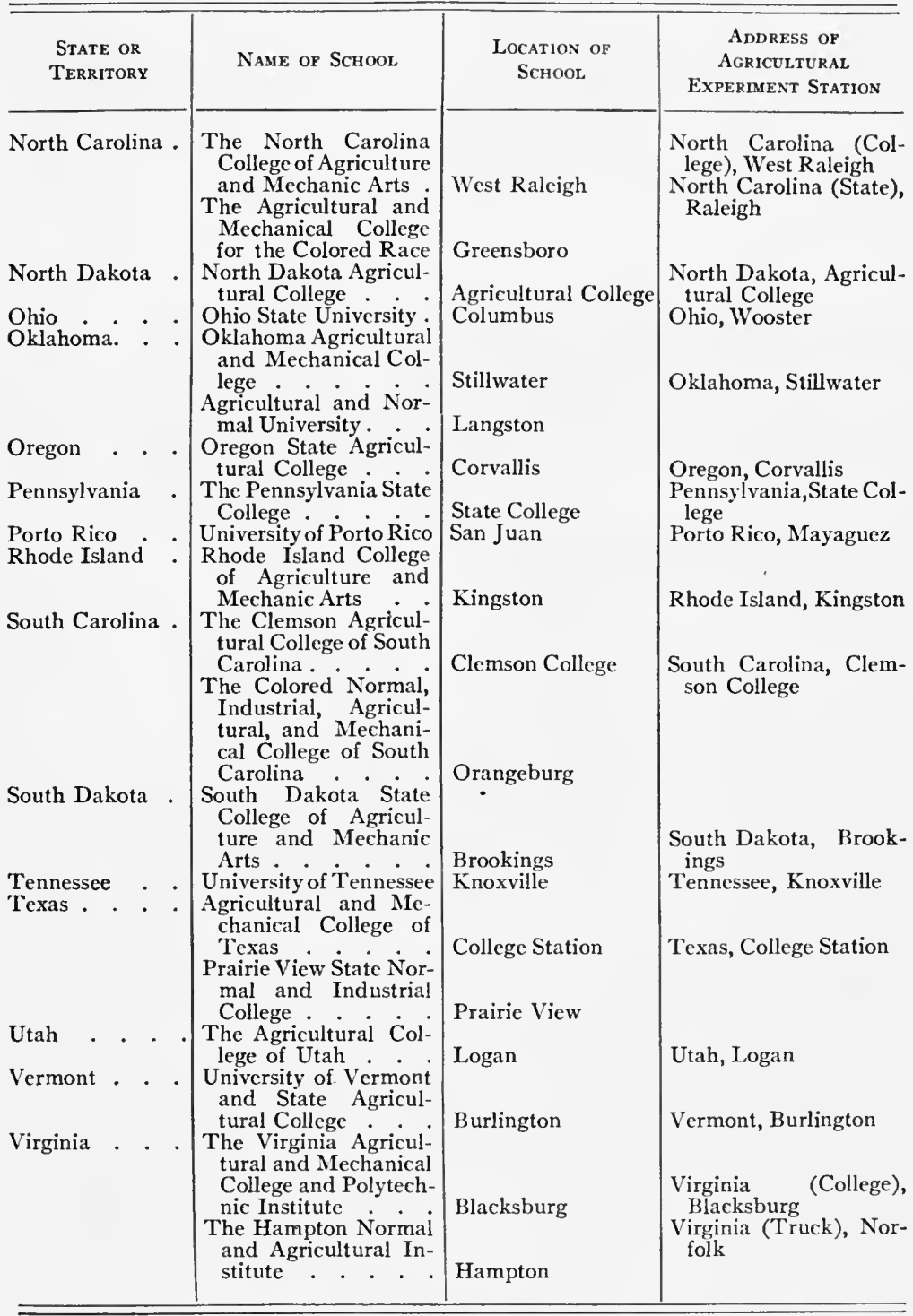


Agricultural Colleges and Experiment Stations in the United States and Canada (Continued)

\begin{tabular}{|c|c|c|c|c|}
\hline $\begin{array}{l}\text { State or } \\
\text { Provincess }\end{array}$ & & Name of School & $\begin{array}{l}\text { Location of } \\
\text { SchOOL }\end{array}$ & $\begin{array}{c}\text { ADDRESS OF } \\
\text { AGRICULTURAL } \\
\text { EXPERIMENT Station }\end{array}$ \\
\hline $\begin{array}{l}\text { Washington . } \\
\text { West Virginia }\end{array}$ & . $\cdot$ & $\begin{array}{l}\text { State College of Wash- } \\
\text { 1ngton } \\
\text { West Virginia Univer- } \\
\text { sity } \dot{\text { Un }} \text { - } \\
\text { The West Virginia Col- } \\
\text { ored Institute. - }\end{array}$ & $\begin{array}{l}\text { Pullman } \\
\text { Morgantown } \\
\text { Institute }\end{array}$ & $\begin{array}{l}\text { Washington, Pullman } \\
\text { West Virginia, Morgan- } \\
\text { town }\end{array}$ \\
\hline $\begin{array}{l}\text { Wisconsin : } \\
\text { Wyoming : } \\
\text { Alberta. : }\end{array}$ & $\dot{:}:$ & $\begin{array}{l}\text { University of Wisconsin } \\
\text { University of Wyoming } \\
\text { University of Alberta }\end{array}$ & $\begin{array}{l}\text { Madison } \\
\text { Laramie } \\
\text { Edmonton }\end{array}$ & $\begin{array}{l}\text { Wisconsin, Madison } \\
\text { Wyoming, Laramie } \\
\text { Alberta (Provincial), } \\
\text { Edmonton } \\
\text { (Dominion), Lacombe } \\
\text { (Dominion), Leth- } \\
\text { bridge } \\
\text { British Columbia } \\
\text { (Dominion), Agassiz }\end{array}$ \\
\hline Manitoba . & $\cdot$ & $\begin{array}{c}\text { Manitoba Agricultural } \\
\text { College . } . .\end{array}$ & Winnipeg & $\begin{array}{l}\text { Manitoba } \\
\text { (Dominion), Brandon } \\
\text { (Provincial), Winne- } \\
\quad \text { peg }\end{array}$ \\
\hline Nova Scotia & - . & $\begin{array}{c}\text { Nova Scotia Agricul- } \\
\text { tural College. }\end{array}$ & Truro & $\begin{array}{l}\text { Nova Scotia } \\
\text { (Dominion), Nappan } \\
\text { (Provincial), Truro }\end{array}$ \\
\hline Ontario. & - $\cdot$ & $\begin{array}{l}\text { Ontario Agricultu- } \\
\text { ral College } .\end{array}$ & Guelph & $\begin{array}{l}\text { Ontario } \\
\text { (Provincial), Guelph } \\
\text { (Dominion central), } \\
\text { Ottawa } \\
\text { Prince Edward Island } \\
\text { (Dominion), Char- } \\
\text { lottetown }\end{array}$ \\
\hline Quebec . . & - $\cdot$ & $\begin{array}{l}\text { MacDonald Agricul- } \\
\text { tural College }\end{array}$ & St. Anne & $\begin{array}{l}\text { Quebec } \\
\text { (College), St. Anne }\end{array}$ \\
\hline Saskatchewan & n & $\begin{array}{c}\text { University of } \\
\text { katchewan }\end{array}$ & Saskatoon & $\begin{array}{l}\text { Saskatchewan } \\
\text { (Dominion), Indian } \\
\text { Head } \\
\text { (Dominion), Rosthern } \\
\text { (Provincial), Saska- } \\
\text { toon }\end{array}$ \\
\hline
\end{tabular}




\section{INDEX}

Abandoned lands : eastern United States, 342, $59 \mathrm{I}$

Maryland, I40

Rothamsted, 403

Acid, defined, 20

Acid phosphate, r89

Acid salts, 23

Acidity of soils, I63, 566

determination, 627

test, 566

Acids, common, 24

Adobe soil, 65

African soils, 66

Agdell field, Rothamsted, 345

Agricultural colleges in the United States and Canada, 643 established by law, 5 I 8

Agricultural experiment stations in the United States and Canada, 643 established by law, 505, 518

Agricultural history, two periods, 590

Agriculture, permanent systems, 159

Aikman, early use of bones, 324

Air, composition, 13

Alabama, field experiments, 494 soils, 138

Albite, 47

Aldehydes, 30

Alkali, defined, 20

Alkali salt, fertilizer or stimulant, 364 ,

Allyl, 40 $393,402,479,533$

Aluminum, 44

American agricultural colleges and experiment stations, 643

Amids and amido group, 37

Ammonification, 195

Ammonium sulfate, 525

Analysis of animal and plant products, I 57,602

Analysis of soils, 626

Analyzing, and testing soils, 565,626

Animal and plant products, composition, 157,602

Animal fats, 35
Animals destroy organic matter, 199

Anorthite, 47

Appearance of soils and crops in relation to fertility, $57^{2}$

Arid and semiarid sections, rainfall records, $580,5^{82}$

Arid soils, 126, 129, 139

Arkansas soils, 97

Asbestos, 49

Ashes, composition, 602

fertility experiments, 508,5 I I

Asiatic soils, 66,67

Association, National Fertilizer, report on raw phosphate, 292

Atom, defined, 3

Atomic bond, 4

Atomic weight, defined, 3

Atomic weights, table, ro

Available plant food, 107, 314, 366

Bacteria :

denitrifying, 439

nitrifying, 195

nitrogen-fixing, 207

nonsymbiotic, or "free-living," 225,437

Barley:

Canadian experiments, 505

composition, 603

Rothamsted experiments, 378

statistics, 6 I 6

Barn field, Rothamsted, 398

Barren soils, 63,367

Base, defined, 20

Basic slag phosphate, 192

Beans, composition, 417,603

- fertility loss, $55^{\circ}$

Bond, atomic, 4

Bone meal, $1_{57}, 185$

Bones and other phosphates used in Eu. rope, 324

Bottom land soils, 62, I20, 138

Bradley's soil fertility theories, 300

Bran, wheat, composition, 4I, 604

Breathing pores, 29

Broadbalk field, Rothamsted, 363 
Bulbs, composition, 604

Bureau of Soils, United States Department of Agriculture:

pot cultures, $5^{I} 3$

soil analyses, 136

soil fertility theories, $3^{1} 3,3^{62}, 3^{67}$

soil surveys, II4

Butter, composition, 154

statistics, $6 \mathbf{2} 3$

Cabbagc, composition, 604 experiments, 266,278

Cake, oil, composition, 604

fertility loss, 205

statistics, 626

Calcium, 43

Calcium cyanamid, 526

Calcium detcrmination, 632

Calcium nitrate, 526

California soils, I02, 138

Canadian colleges of agriculture, 646 experiment stations, 505,646

field experiments, $5^{\circ} 5$

soils, 103, 507, 559

Carbohydrates, 30

Carbon, 26

Carbon cycle, 32 determination, 628

fixation, 29 , supply as plant food, 33

Carbonates, 50 determination, 628

loss by leaching, 5 I, 174

test, 567

Carrots, composition, 604

field experiments, 5 II

Casein, 4 I

Central states soils, 77, I 38

Cereal seeds, composition, I 54, 603

Chaff, composition, 603

Chemical action, 3, 107, 194, 562

Chemical clements, io

Chemistry, defined, I organic, 30

China, agricultural conditions and practices, 335

Chinese philosophy, 594

Chlorin, 44

Chlorophyll, 43

Clarke, on composition of earth's crust, 13

Clay, 50, 55

Clover, composition, 75, 154, 417, 603

Clover sickness, 312, 406

Coal ashes, composition, 602

Coastal plains soils, $117,138,139$

Cobs, corn, composition, 603

Colleges of agriculture, 518, 643

Colorado soils, I0 I
Combining weights of elements, 3

Commercial fertilizers, 517

Commercial plant food materials, 157

Common elements, I3

Common functions of elements, 45

Composition of animal and plant products, 157,602

Compound, defined, 2

Connecticut, investigations with legumes, 219 soil, 138

Corn, composition, $13,75,1_{54}, 603$

cost per bushel, $5^{8} 5$

record yield, 6r9

statistics, 606

Corn cobs, composition, $6 \circ 3$

Cotton, composition, 154, 497, 603

statistics, 624

Cotton seed, 154, 525, 603

Cotton-seed meal, 525,604

Condition of soil, 576

Conservation of soil moisture, 577

Coral limestone soil, 65

Creelman, on farming in Southern Europe, 329

Crimson clover tops and roots, composition, $22 \mathrm{I}$

Critical periods in plant life, $53^{8}$

Crop residues, 199

statistics, 605

stimulants, 533

yields (sce also statistics):

Asia, 334

Europe, 326

Kansas, 330

Crops, composition, botanical, 393

chemical, I 54, 4I7, 4I8, 602

Crysolite, 47

Curie and Gleditsch, on transmutation of elcments, II

Cyanamid, 526

Czapek, on availability of plant food, 109

Decandolle's soil-fertility theories, 310

Decay of organic matter, 195

Delaware investigations with legume plants, 221,222

Denmark, wheat yicld, 614

Dentrification, 439, 502

De Saussure's discovery of mineral plant food, 307

Digestion coefficients for organic matter: I99, 206

Dolomitic limestone, 169

Drainage reclamation possible in the United States, $5^{8} 3$

Dry farming, 579,581

Dyer, on manure used in England, 324 
Earth's crust, r 3,46

Eastern states soils, 72, 75, ${ }^{3} 8$

Element system for reporting analyses, 565,599

Elements in air, ocean, and earth's crust, r 3

of plant growth, $x_{2}$

the more common, $x_{3}$

transmutation, $\mathrm{II}$

English soils, 637

Equilibrium in nature, 62

Essential elements of plant food, I2

European crop yields (see also statistics), 326

European soils, 634

Experiment stations in the United States and Canada, 643

established by law, 505, 5 r8

Factors in crop production, 435, 575

Famines, Indian, 334

Russian, 333

Farm manure, composition, 542

Cambridge University investigation, 205

Canadian experiments, 508, 5 I I

dried, 545

English practice, 324

Illinois experiments, $20 \mathrm{r}, 206,459,473$, 480

Japan, human and compost, 594

Ohio experiments, 204, 256, 442, 448, 547

Pennsylvania experiments, 202, 423, 43 I

Rothamsted experiments, $364,380,390$,

Fats, 34 $393,399,400,407,41 \mathrm{I}$

Felspars, 47

Fertility theories, $300,362,366,385,389$

Fertilizer Association's report on raw phosphate, 292

Fertilizer law, 599

Fertilizers, commercial, $157,5^{1} 7$

Fish-scrap fertilizer, 525

Fixation of plant food by soils, 562 of carbon, oxygen, and hydrogen, 29 of free nitrogen, $207,225,437$

Flax, composition, 603, 604

sickness, 3 r9

statistics, 605

Florida phosphates, 187, 188, 595 sand and peat soils, 498

Formula, chemical, defined, 7

France, crop yields (see also statistics), 327

soils, 635

Fruits, composition, 604

Functions that are common to different elements, 45
Gas law, 7

Georgia, field experiments, 489 soils, 94

Germany, crop yields (see also statistics), 326

soils, 634

Glacial material, 54

Glacial soils, r23, r38, 144

Glycerin, 40

Gneiss, 48

Grain farming, 226, 329, 345, 434, 459, 478,483

Granite, 48

Graphite, 26

Grass, composition, 603

digestibility, 199

Green manuring, 199, 2 r 8

Ground limestone and burned lime, r 65

Growth of plants, 32

Hall, on soil-fertility theories, 319,362 , $3^{66}, 3^{8} 5$

Hay, composition, 75, r54, 4r 7, 4r8, 603

Hay grown every year, Rothamsted, 39r

Hay statistics, 605, 624

Heat factor in crop production, 576

Hellriegel's discovery of nitrogen-fixing bacteria, 307

Hill's view of agriculture, 594

History of agriculture, 590

Holland, soil, 63

wheat yield, 614

Home of plants, 576

Hoos field, Rothamsted, 378

Hops, composition, 604

Hornblende, 49

Hunter's soil-fertility theories, 302

Hydrate, defined, 28

Hydrogen, 28

Hydroxid, defined, 17

Idaho, phosphates, 595

soils, 102

Illinois, field experiments, $283,453,476$

pot-culture experiments, $x 7 \mathrm{r}, 287,486$, 487

soils, $82, x_{3} 8$

India, agricultural conditions, 333 soils, 66

Indiana soils, 88

Inoculation for nitrogen fixation, 2 II

Intermountain soils, 127

Iowa, field experiments, 488

soils, 89

Ireland, soils, 642

Iron, $43,69,73,75,106,603$

Iron sulfate as a fertilizer, $r 58,505$

Italian agriculture, 329 
Irrigation, in India, 333,583 possible in the United States, $5^{8} 3$

Japan, agricultural practices, 594

Jethro Tull's soil-fertility theories, 300

\section{Kainit, 530, 535}

Kansas, crop yields (see also statistics), $33^{\circ}$ soils, ${ }_{1} 8$

Kentucky, pot-culture experiments, 288 soils, $64,65,92,{ }_{13} 8$

King, on Japanese agriculture, 594 on water-soluble plant food, 142

Kossowitsch, availability of raw phosphate, 109

Land-plaster, 256, 420, 505, 533

Land reclamation possible in United States, $5^{8} 3$

Land values, 586

Law, constant proportions, 8

diminishing returns, 374

gas, 7

governing sale of fertilizers, 599

periodic, 9

solution, 314, 316, 366

Lawes and Gilbert, source of nitrogen for plants, 307

Leaching, rocks, soils, 49, 5 I, 1 74, 4I 3, 556 plants, 549

Lecithin, 40

Legume plants, composition, 154, 218, 604 inoculation, 210,218 nitrogen fixation, 207 tops and roots, 2 I 8

Legume seeds, composition, 1 54, 603

Liberation of plant food, 109

Liebig's soil-fertility theories, 308

Liebig's view of agriculture, $59 \mathrm{I}$

Life, 29

Life of soil, I95

Light factor in crop production, 576

Lime and ground limestone, 165

Lime burning, 27

Limestone, amount to apply, 172 how to apply, 179

loss by leaching, $51,174,561$ magnesian, or dolomitic, 169 soils, I 23, 147

spreader, 179

time to apply, 178

use in soil improvement, 160

Limiting factors in crop production, 435, 575

Lincoln's view of agriculture, 592

Lipman, on dentrification, 439

Live stock destroy food values, 234 organic matter, 199

Live-stock farming, 23 I, 459
Loess, characteristics, 54 composition, 69

in United States, 68

Loessial soils, I 23, I44, 634

Losses of plant food, from manure, 200, 546,547

from plants, 549

from soils, 4 I I, 4 I 3,556

Louisiana, field experiments, 495 soils, $96,{ }^{3} 8$

Machine for spreading limestone and phosphate, 179

Magnesian limestone, 169

Magnesium, 42

Magnesium determination, 633 in fertilizer experiments, 171,364

Maine field experiments, 275

Maintenance rations, 33

Manganese, 44

Manganese separation, 633

Mangel-wurzel, composition, 402 field experiments, 400

Mann, on the use of raw phosphate, 504

Manure, losses from exposure, 200, 256, $508,546,547$

preservatives and reënforcing materials, 256,547

recovered in live-stock farming, $20 \mathrm{I}$

Manure in culture experiments, 256, 343

Manures (see farm manure and green manuring)

Marl carbonates, 167

Marl phosphates, 24 I

Maryland, field experiments, 26I soils, 138 , 141 subsoils, 73

Massachusetts field experiments, 278

Mellilotus for green manuring, 220

Mica, 49

Michigan, investigations with legume plants, $216,22 \mathrm{I}$

soils, 97

Minnesota, soil experiments, 499 soils, 100, 138

Mississippi soils, 93

Missouri soils, $89,{ }_{3} 8$

Moisture factor in crop production, 577

Molecule, defined, 4

Montana soils, IO2

Mountain soils, I 22, 128

Nascent, defined, 4

National Fertilizer Association report on raw phosphate, 292

Nebraska rainfall, $33^{1}, 5^{80}, 5^{82}$ soils, 89

Nevada soils, 102 
New Jersey, pot-culture experiments, 439 soil, 138

New York, investigation of phosphorus in wheat bran, 4 I

soils, 75

Nitrate of calcium, 526

Nitrate of sodium, $\mathbf{5 2 5}$

Nitrification, I95

Nitrogen, 36

Nitrogen and organic matter, 194

Nitrogen determination, 629

fixation by legumes, 207

by nonsymbiotic bacteria, 224, 405, 437

from air and soil, 213

gain or loss difficult to determine, 499

in animal and plant products, I 54, 602

in drainage waters, $557,5^{6} 3$

in fertilizers, 157,517

in rain, 309

in roots and tops of legumes, 218

in sweet clover, 220

recovered in live-stock farming, zor

retained by animals, 201

used in different amounts, 374,423

used to give crops a start, $218,401,533$

Nitrogenous compounds, 38

Nomenclature, $19,565,599$

North Carolina soils, I 38 , 142

North Dakota investigations of flax sickness, 319

North Platte, Nebraska, rainfall, 33I, 580

Northern states soils, $97,1_{3} 8$

Nuclein, 40

Oats, composition, 75, 154,603 statistics, 615

Ocean, composition, $\mathrm{I} 3$

Ohio, field experiments, 245, 299, 44I investigations with manure, 547 soils, $88, \mathrm{r}_{3} 8$ in pot-culture experiments, $5^{1} 3$

Oil cakes, composition, 604

fertility loss, 205

statistics, 626

Oil seeds, composition, 603

Oils and fats, 34

Oregon soils, 102

Organic chemistry, 30

Organic matter, defined, 30

decomposition, 195

loss in digestion, I99

methods of supplying, 198

Organic matter and nitrogen, 194

Orthoclase, 47

Oxids, defined, 17

occurrence, 53

Oxygen, 26
Pacific coast soils, 102, I $30, \mathbf{I}_{3} 8$

Park field, Rothamsted, 39 I

"Parrot" instruction, 292

Pasturing land, I99

Peat, dried, 524

Peat soils, $75,83,98,100,470$

Pennsylvania, field experiments, 263,420 investigations with manure, 202, 203 soils, 76,142

Pentosans, 31

Periodic law of chemical elements, 9

Permanent systems of agriculture, 159

Peter, on soil fertility theories, 339

Phosphate deposits, 597

Phosphate experiments:

Canada, 505

Illinois, 283,504

Indiana, 296

Kentucky, 288

Maine, 275

Maryland, 26I

Massachusetts, 278

Ohio, 245, 442, 448, $45^{2}$

Pennsylvania, 263

Rhode Island, 266

Phosphate production, 595

raw rock and slag must be fine-ground, 239

in practical agriculture, 289, 504

Phosphate report by National Fertilizer Association, 292

spreader, I 79

supply, 597

Phosphates, 52, 186

low-grade, $188,242,598$

natural, 52, 186

used in Europe, 324

Phosphatic limestone, $5^{2}$

marl, 2.4 I

slag, I92

Phosphorus, 40, 52, 183, 236

Phosphorus compounds, I 89

determination, 630

' in fertilizers, 157,517

in plant and animal products, 154,602

in wheat bran, $4 \mathrm{I}$

production, 595

retained by animals, 20I

supply, 597

use in different forms, 237

used in Europe, 324

Photosynthesis, 29

Physical condition of soil, 576

Piedmont soils, I 21, r 38

Plant and animal products, composition, 157,602

Plant food, 26

available, 107, 314, 366 
Plant food, essential, I 2

in crops, $75, \mathrm{I}_{54}, 602$

in culture experiments, 236,343

in sea weed, 524

lost from manure, $200,546,547$

from plants, 549

from soils, 4 I I, 4r 3,4 r 8,556

Plant food, recovered in live-stock farming, 199

retained by animals, $20 \mathrm{I}$

sources and cost, commercially, $157,5^{17}$

value, 154

water-soluble, I $4 \mathbf{I}$

Plot experiments for testing soils, 569,570

Potassium, 42

Potassium chlorid and sulfate, $53 \mathrm{r}$

Potassium determination, 631

Potassium, from sea water, $53 \mathrm{I}$

in fertilizers, 157,517

in plant and animal products, I54, 602

Potassium salts of Germany, 529

Potato experiments, $384,447,511$

Potatoes, composition, 154, 604 statistics, 605, 6I 8

Prairie soils, $78,82,132,{ }_{3} 8$

Prefixes in chemical names, I9

Proportions, law of constant, 8

Protective agents, 536

Protein and proteids, 37

Quartz, 49

Radicle, defined, I7

Rain, composition, 309

Rainfall and drainage records, 309, 377, 4 I 3,49 I $, 557,580,5^{82}$

Rainfall averages for the United States, 582

Rainfall in dry farming sections, 580,582

Ramsay, on composition of air, 13

Ramsay and Cameron, on transmutation of elements, II

Rate of growth, 32

Residual soils, 54, 126, 146, I 49

Residues of crops used in soil improvement, 199

Rhode Island field experiments, 266

Rice, composition, 603

statistics, 6I9

Rock weathering, 49

Roman agriculture, 590

Root crops, composition, 417, 604

in Canadian experiments, $5 \mathrm{rI}$

in Rothamsted experiments, 398

Roots and tops of legumes, composition, $2 \times 8$

Root tubercles, composition, 2 I 5

size, 212
Rotation crops grown in experiments:

Agdell field, Rothamsted, 345

Illinois, 453

Louisiana, 495

Minnesota, 499

Ohio, 245, 256, 44 I

Pennsylvania, $42 \mathrm{I}$

Rotation crops, plant food required, 75

Rotation of crops and soil fertility, $3 \times 8$ : $339,362,389,435,443$

Rotation systems, 226, 23 I

Russia, agricultural conditions, 332 soils, 66

Rye, composition, 603 statistics, 6r 7

Sachs, on availability of plant food, ros

Salt, common, 535 defined, 20

Salt deposits, 53,529

Sand soils, 80, 98, 100, 138, 468, 498

Science, defined, I

Scotland, soils, 63,642

Seed factor in crop production, 575

Semiarid section, rainfall records, $33 \mathrm{I}, 580$, 582

Sénébier's discovery of carbon fixation, 307

Shale, 50

Shutt, on loss of organic matter and nitrogen, 200, 559

Silicates in earth's crust, 47,48

Silicon, 44,46

Slag phosphate, 192

Snow, composition, 3 ro

Soaps, 36

Sodium, 44

Sodium in fertilizer experiments, 364,380 , 402, 508

Soil analysis, methods, 626

classification, 54, 116

composition, $5^{8}, \mathrm{I}_{3} 8$

depletion, 556

by natural agencies, $6 \mathrm{r}$

Soil fertility theories, $300,362,366,3^{8} 5$

formation, 54

materials, 55

provinces of the United States, I 6

samples, method of collecting, 626

series, II $6, \mathrm{I}^{2}$

stimulants, $45, \mathrm{r}^{8}, 533$

structure, i 16

surveys, 57,77, I 4,5 r 7,555

texture, I 16

types, 55

Soils of Africa, 66, 67

Canada, Io3

central states, $77,1_{3} 8$ 
Soils of eastern states, 72, 75, 106, 138

Europe, 63, 634

India, 66

Northern states, 97, 138

Rothamsted, 63, 4II, 4 I 6

Russia, 66

South America, 67

southern states, $92,13^{8}$

Transvaal, 67

Turkey, 67

western states, Ior, I38

Solution law, 314, 316, 366

South American soil, 67

South Carolina, phosphates, I87, 595

record yield of corn per acre, 619

Southern states soils, 92, 138

Spencer, on farming in semiarid region, $58 \mathrm{I}$

Spillman, on Kansas crop yields, $33^{\circ}$

Spreader for limestone and phosphate, 179

Starches, $3 \mathbf{I}$

Statistics of agricultural products, 605

Steatite, 48

Sterile soils, 63,367

Stimulants, 368, 394, 402, 479, 508, 533

Straw, composition, 157,603

Structure of soils, I 6

Success in farming, $5^{84}$

Sugar beets, 155, 399, 604

Sugar statistics, 620

Sugars, 3 I

Sulfates and sulfids, 52

Sulfur, $39,57,106,15^{8}$

in rain, 106

Superphosphate, I9I

Supply and demand of plant food, 59

Swamp soils, 80,583

Sweet clover, content of nitrogen and organic matter, 220

Symbol, defined, 7

Systems of permanent agriculture, I 59

Temperature factor in crop production, $57^{6}$

Tennessee, phosphates, $187,188,595$

soils, $64,93,138,3^{67}$

Terminations in chemical names, Io

Terrace soils, 124

Testing soils, $5_{65}, 626$

Texas soils, 95,138

Texture of soils, I 6

Thaer's soil-fertility theories, 302

Theories concerning soil fertility, 300,362 , $3^{66}, 3^{8} 5$

Timber soils, 79, 133

'Tobacco, composition, 604

experiments, 288

statistics, 605
Transmutation of elemenis, II

Transported soils, 54

Transvaal soils, 67

Tubercles on roots of legumes, 2 I 2, 2 I 5

Tubers, composition, $60_{4}$

Tull's soil-fertility theories, 300

Turkish soil, 67

Turnips, composition, 417, 604

experiments, 346,399

Utah, phosphates, 596

soils, IOI

Valence, defined, 4

Value of land, 586

Van Helmont's soil-fertility theories, 300

Van Hise, on phosphates, 560

Vegetable fats and oils, 34

Vegetables, composition, 604

Vesuvius lava, composition, 67

Virginia, field results with raw phosphate, 289 soil, 138

Vital processes in plant growth, 33

Volcanic ash, 67,138

Wales soil, ${ }^{4} 42$

Washington soils, 102

Water (see moisture)

Water-soluble plant food, I4I, 5 I 3

Weathering of rocks and soils, 49, 6I, I74

Webster's view of agriculture, 594

Western states soils, Ior, I38

Wheat, composition, 75, 154, 417, 603

Wheat bran, composition, 4I, 604

Wheat grown every year:

Canada, 505

Jethro Tull, 306

Minnesota, 499

Rothamsted, 363

Whitney, on potatoes at Rothamsted, 389

Whitney and Cameron's soil-fertility theories, $313,362,367,385$

Whitson, on loss of phosphorus from Wisconsin soils, 560

Widtsoe, on arid soils and vegetation, Ior

Williams, on value of manure in China, 338

Wilson, on abandoned lands, 342

Wing, on use of limestone and raw phosphate, 289

Wisconsin experiments, $216,221,289,560$ soils, $99,{ }_{1} 8$

Wood ashes, 531, 602

Wyoming phosphates, 595 soils, I02

Zein, 39

Zeolites, $5^{\circ}$ 


\section{-}


This book is DUE on the last date stamped below

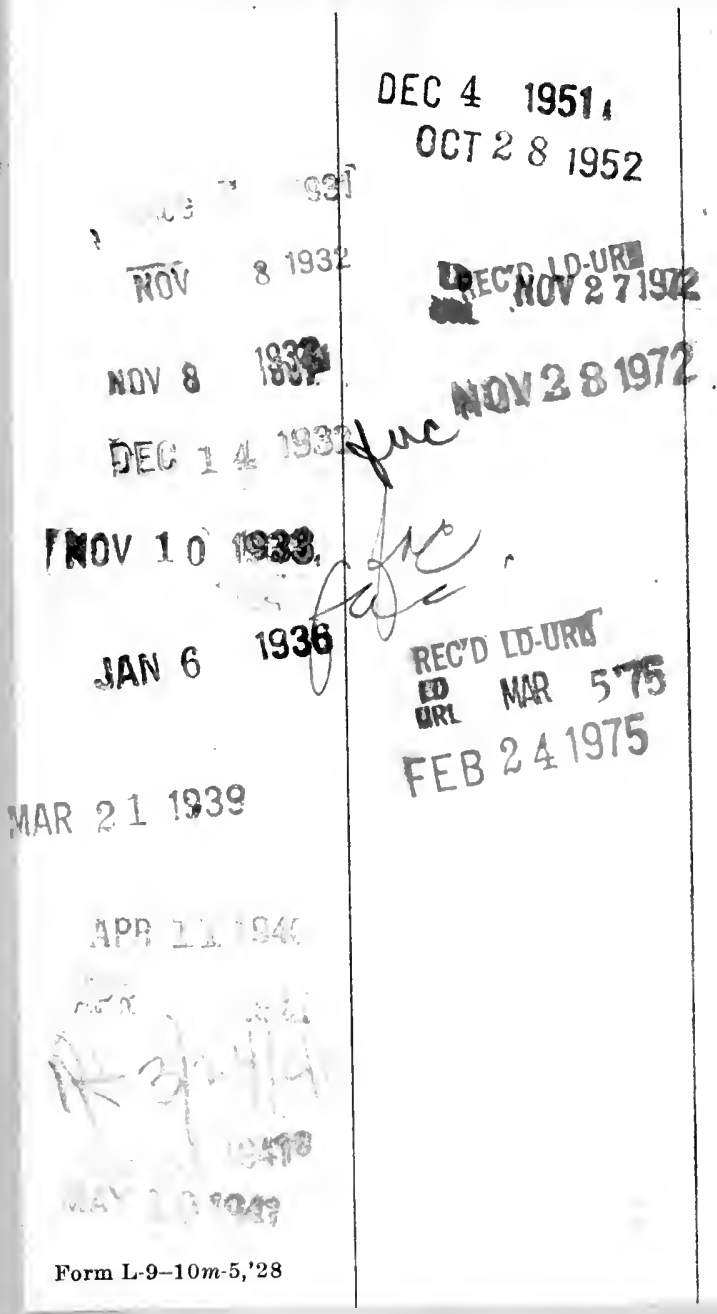


